University of Nebraska - Lincoln

DigitalCommons@University of Nebraska - Lincoln

$6-8-2020$

\title{
PreColumbian Textile Conference VIII / Jornadas de Textiles PreColombinos VIII
}

Lena Bjerregaard

University of Copenhagen, bjerregaardlena@aol.com

Ann H. Peters

University of Pennsylvania, ann.h.peters@gmail.com

Follow this and additional works at: https://digitalcommons.unl.edu/zeabook

Part of the Fiber, Textile, and Weaving Arts Commons, Indigenous Studies Commons, Latin American Languages and Societies Commons, Museum Studies Commons, and the Other History of Art, Architecture, and Archaeology Commons

\section{Recommended Citation}

Bjerregaard, Lena and Peters, Ann H., "PreColumbian Textile Conference VIII / Jornadas de Textiles PreColombinos VIII" (2020). Zea E-Books. 91.

https://digitalcommons.unl.edu/zeabook/91

This Book is brought to you for free and open access by the Zea E-Books at DigitalCommons@University of Nebraska - Lincoln. It has been accepted for inclusion in Zea E-Books by an authorized administrator of DigitalCommons@University of Nebraska - Lincoln. 
Contents:

Preface - Lena Bjerregaard \& Ann Hudson Peters

\section{Archaeological textiles - Textiles arqueológicos - Textiles archéologiques:}

- 1, Recontextualizando el patrimonio arqueológico: los textiles paracas descubiertos por Engel en Cabezas Largas - Jessica Lévy Contreras • 2, Two-headed serpents and rayed heads: Precedents and reinterpretations in Paracas Necropolis imagery - Ann H. Peters • 3, Representaciones textiles en los iconos de la litoescultura Tiwanaku: significado y distribución - Carolina Agüero \& Arturo Martínez $\bullet 4$, Middle Horizon textiles from Chimu Capac, Supe Valley, Peru - Amy Oakland • 5, Una prenda triangular con plumas en la colección del museo de sitio de Pachacámac - Lourdes Chocano Mena • 6, Las relaciones interculturales vistas a través de los textiles del Cerro la Horca, durante el periodo intermedio tardío y horizonte tardío, valle de Fortaleza - Perú - Arabel Fernández L. \& Luis Valle A. • 7 , La momia de Marburg: su recontextualización a través del ajuar y ofrenda textil - Isabel Martínez Armijo, AnnaMaria Begerock \& Mercedes González • 8, A highland textile tradition from the far south of Peru during the period of Inka domination - Penelope Dransart • 9, Los tocapus de Llullaillaco - Beatriz Carbonell • 10, El tapiz con tocapus del Museo Nacional de Arqueología, Antropología e Historia del Perú - Mónica Solórzano Gonzales • 11, La cestería de los cazadores-recolectores, procedente de la cueva de la Candelaria, Torreón, Coahuila, México - Gloria Martha Sánchez Valenzuela, Alejandra Quintanar Isaías \& Ana Jaramillo Pérez • 12, Signos comunes en los textiles Andinos y los Mesoamericanos - Victoria Solanilla Demestre

\section{Museum collections history - Historia de colecciones - Histoire des collections:}

- 13, The pre-Columbian textile collection of the German Textile Museum Krefeld - Katalin Nagy • 14, Ancient Peruvian textiles in the Vatican Museums and their link to the Musée du Trocadéro collections - Jean-François Genotte • 15, Hidden in plain sight. How 'disturbing' features found within two Peruvian textile fragments have turned into a 'significant guide' for conservation - Griet Kockelkoren \& Emma Damen • 16, Life of a Peruvian art collector: Guillermo Schmidt Pizarro and the fostering of public collections of pre-Hispanic art in the first half of the $20^{\text {th }}$ century - Carolina Orsini \& Anna Antonini

\section{Ethnographic textiles - Textiles etnográficos - Textiles ethnographiques:}

- 17, Colorantes presentes en mochilas ika de la colección etnográfica del Världskulturmuseet (Antiguo Museo Etnografico) en Gotemburgo, Suecia, realizada por Gustav Bolinder Beatriz Devia \& Marianne Cardale de Schrimpff - 18, Colecciones textiles etnográficas del Gran Chaco Sudamericano del Museo Etnográfico "J. B. Ambrosetti” y el estudio de su materialidad: un desafío a la mirada occidental sobre los otros no-occidentales - Mariana Alfonsina Elías - 19, Documentando y conservando las colecciones plumarias del Museo Etnográfico Juan B. Ambrosetti; Facultad de Filosofía y Letras, Universidad de Buenos Aires - Silvana Di Lorenzo \& Silvia Manuale • 20, Textil y territorio: sobre los tejidos intrincados de Poroma, Norte de Chuquisaca, Bolivia - Verónica Auza Aramayo • 21, Un fundamento de la textualidad textil: los colores Tarabuco - Ricardo Cavalcanti-Schiel • 22, Los “diseños verdaderos" en los tejidos de las mujeres cashinahuá del Alto Purús - María Elena del Solar

Sponsored by The Royal Museums of Art and History (RMAH), Bruxelles.

ISBN 978-1-60962-174-2

DOI: $10.32873 /$ unl.dc.zea.120o

Zea Books

Lincoln, Nebraska

\section{Nebraska




\section{PreColumbian Textile}

Conference VIII

Jornadas de Textiles

PreColombinos VIII

The Royal Museums of Art and History (RMAH), Cinquantenaire Museum, Bruxelles

Lena Bjerregaard and Ann Peters, editors

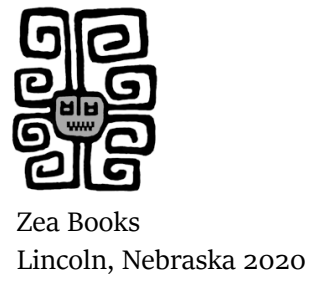


All articles are copyright (C) 2020 by their authors.

Compilation copyright (C) 2020 Centre for Textile Research, University of Copenhagen.

ISBN 978-1-60962-174-2

DOI: $10.32873 /$ unl.dc.zea.1200

Cover image: Wari Kayan 89 sp. 6, llautu, slit tapestry headband, Museo Nacional de Antropología, Arqueología e Historia del Perú, RT 183, photo by Anne Peters (page 44).

Composed in Sitka types, with Matura numerals.

Zea Books are published by the University of Nebraska-Lincoln Libraries.

Electronic (pdf) edition available online at http://digitalcommons.unl.edu/zeabook/

Print edition available from http://www.lulu.com/spotlight/unlib

UNL does not discriminate based upon any protected status.

Please go to unl.edu/nondiscrimination

\section{Nebraska




\section{Contents}

Preface

Lena Bjerregaard \& Ann Hudson Peters 5

Archaeological textiles - Textiles arqueológicos - Textiles archéologiques:

1, Recontextualizando el patrimonio arqueológico: los textiles paracas descubiertos por Engel en Cabezas Largas Jessica Lévy Contreras . . . . . . . . . . . . . . . . . . . . . . . . . . . . . . 7

2, Two-headed serpents and rayed heads: Precedents and reinterpretations in Paracas Necropolis imagery

Ann H. Peters . . . . . . . . . . . . . . . . . . . . . . . . . . . . . . . . 23

3, Representaciones textiles en los iconos de la litoescultura Tiwanaku: significado y distribución Carolina Agüero \& Arturo Martínez . . . . . . . . . . . . . . . . . . . . . . . 50

4, Middle Horizon textiles from Chimu Capac, Supe Valley, Peru Amy Oakland. . . . . . . . . . . . . . . . . . . . . . . . . . . . . . . . . 65

5, Una prenda triangular con plumas en la colección del museo de sitio de Pachacámac Lourdes Chocano Mena . . . . . . . . . . . . . . . . . . . . . . . . . . . . 86

6, Las relaciones interculturales vistas a través de los textiles del Cerro la Horca, durante el periodo intermedio tardío y horizonte tardío, valle de Fortaleza - Perú Arabel Fernández L. \& Luis Valle A. . . . . . . . . . . . . . . . . . . . . . . . . 99

7, La momia de Marburg: su recontextualización a través del ajuar y ofrenda textil Isabel Martínez Armijo, Anna-Maria Begerock \& Mercedes González ． . . . . . . . . . 121

8, A highland textile tradition from the far south of Peru during the period of Inka domination Penelope Dransart . . . . . . . . . . . . . . . . . . . . . . . . . . . . . . 137

9, Los tocapus de Llullaillaco Beatriz Carbonell . . . . . . . . . . . . . . . . . . . . . . . . . . . . . . . 157

10, El tapiz con tocapus del Museo Nacional de Arqueología, Antropología e Historia del Perú Mónica Solórzano Gonzales . . . . . . . . . . . . . . . . . . . . . . . . . . . 175

11, La cestería de los cazadores-recolectores, procedente de la cueva de la Candelaria, Torreón, Coahuila, México Gloria Martha Sánchez Valenzuela, Alejandra Quintanar Isaías \& Ana Jaramillo Pérez 191

12, Signos comunes en los textiles Andinos y los Mesoamericanos Victoria Solanilla Demestre . . . . . . . . . . . . . . . . . . . . . . . . . 202 
Museum collections history - Historia de colecciones - Histoire des collections:

13. The pre-Columbian textile collection of the German Textile Museum Krefeld Katalin Nagy . . . . . . . . . . . . . . . . . . . . . . . . . . . . . . . . . 215

14, Ancient Peruvian textiles in the Vatican Museums and their link to the Musée du Trocadéro collections Jean-François Genotte . . . . . . . . . . . . . . . . . . . . . . . . . . . . . 232

15, Hidden in plain sight. How 'disturbing' features found within two Peruvian textile fragments have turned into a 'significant guide' for conservation Griet Kockelkoren \& Emma Damen. . . . . . . . . . . . . . . . . . . . . . . . 247

16, Life of a Peruvian art collector: Guillermo Schmidt Pizarro and the fostering of public collections of pre-Hispanic art in the first half of the $2 \mathrm{O}^{\text {th }}$ century Carolina Orsini \& Anna Antonini . . . . . . . . . . . . . . . . . . . . . . . . . 258

\section{Ethnographic textiles - Textiles etnográficos - Textiles ethnographiques}

17, Colorantes presentes en mochilas ika de la colección etnográfica del Världskulturmuseet (Antiguo Museo Etnografico) en Gotemburgo, Suecia, realizada por Gustav Bolinder Beatriz Devia \& Marianne Cardale de Schrimpff . . . . . . . . . . . . . . . . . . 279

18, Colecciones textiles etnográficas del Gran Chaco Sudamericano del Museo Etnográfico “J. B. Ambrosetti" y el estudio de su materialidad: un desafío a la mirada occidental sobre los otros no-occidentales Mariana Alfonsina Elías . . . . . . . . . . . . . . . . . . . . . . . . . . . . 295

19, Documentando y conservando las colecciones plumarias del Museo Etnográfico Juan B. Ambrosetti; Facultad de Filosofía y Letras, Universidad de Buenos Aires Silvana Di Lorenzo \& Silvia Manuale . . . . . . . . . . . . . . . . . . . . . . . 311

20, Textil y territorio: sobre los tejidos intrincados de Poroma, Norte de Chuquisaca, Bolivia Verónica Auza Aramayo . . . . . . . . . . . . . . . . . . . . . . . . . . . . 326

21, Un fundamento de la textualidad textil: los colores Tarabuco Ricardo Cavalcanti-Schiel. . . . . . . . . . . . . . . . . . . . . . . . . . . . 345

22, Los “diseños verdaderos" en los tejidos de las mujeres cashinahuá del Alto Purús María Elena del Solar . . . . . . . . . . . . . . . . . . . . . . . . . . . 357 


\section{Preface}

We are delighted to present the collected papers from the Conference on Pre-Columbian Textiles VIII, which was organized by Serge LeMaitre and held at the Museum of Art and History in Brussels on March $18^{\text {th }}$ to $22^{\text {nd }}, 2019$. These papers represent a considerable number of those presented orally in Brussels. Subsequently, a new version of each text and its images has been submitted for publication, sent for peer review and then revised by the author(s). As text editors and coordinators of this publication, our goal has been to facilitate each author's project and the recognition due to all persons and institutions involved.

The 22 articles in this volume represent a large variety of themes. While a majority analyzes archaeological textiles, a significant group addresses ethnographical textiles. The essays cover areas of the Andean highlands, the Peruvian desert coast, the Gran Chaco in Argentina and also Mesoamerica, up to northern Mexico. A number of the articles describe museum collections - either to characterize textiles from a particular site or region, or to review a collection's history. Some present excavation data, analysis of colorants or conservation processes, while others explore the worldview of historic or Pre-Columbian peoples through textile analysis.

We thank all those who offered their time and expertise in the peer review process and thank Jessica Lévy Contreras and Sophie Desrosiers, who have translated many of the abstracts. We applaud our colleagues who have previously organized this international meeting of textile specialists, particularly its founder, Victòria Solanilla Demestre. Special thanks to our technical editor at the University of Nebraska, Paul Royster.

Lena Bjerregaard Ann Hudson Peters

\section{Prefacio}

Nos alegramos presentar esta colección de ensayos procedentes de las Jornadas de Textiles Precolombinos VIII, organizado por Serge LeMaitre, que se llevó a cabo en el Museo de Arte e Historia en Bruselas, del 18 al 22 de marzo de 2019. Estos artículos representan un número considerable de las presentaciones orales en Bruselas. Subsecuentemente, una nueva versión de cada texto y de sus imágenes ha sido entregada para su publicación, se pasó por una revisión por pares y luego ha sido pulido por su(s) autor(es). Como editoras y coordinadoras de esta publicación, nuestra meta ha sido facilitar el proyecto de cada autor y el reconocimiento debido a cada persona e institución involucrada.

Los 22 artículos en este volumen representan una gran variedad de temas. Mientras una mayoría analiza textiles arqueológicos, un grupo significativo trata de textiles etnográficos. Se cubren áreas de la cordillera Andina, la costa desértica del Perú, el Gran Chaco en Argentina y también Mesoamérica, hasta el norte de México. Varios de los artículos describen colecciones museográficas - o para caracterizar los textiles procedentes de un sitio o una región, o para revisar la historia de una colección. Varios presentan datos de excavación, análisis de colorantes o procesos de conservación, mientras otros exploran el pensamiento de pueblos históricos o sus antecesores a través del análisis textil.

Se agradece a todos los que han ofrecido de su tiempo y sus conocimientos en el proceso de revisión por pares, y se agradece a Jessica Lévy Contreras y a Sophie Desrosiers, quienes han traducido muchos de los resúmenes. Un aplauso para nuestros colegas que en años anteriores han organizado esta reunión internacional de especialistas en textiles, y en particular para su fundadora, Victòria Solanilla Demestre. Un agradecimiento especial a nuestro editor técnico en la Universidad de Nebraska, Paul Royster.

\section{Préface}

Nous sommes très heureuses de vous présenter les articles réunis suite à la VIII ${ }^{\mathrm{e}}$ Conférence sur les Textiles Précolombiens qui a été organisée par Serge Lemaitre au Musée d'Art et d'Histoire de Bruxelles du 18 au 22 mars 2019. Ces articles reprennent un grand nombre de ceux qui ont été présentés oralement à Bruxelles. Une nouvelle version de chaque texte et de leurs illustrations a été soumise pour publication, envoyée pour évaluation à des pairs, puis revue par son ou ses auteur(e) s. En tant qu'éditrices et coordinatrices de cette publication, notre objectif a été de respecter le projet de chaque auteur(e) et de reconnaître l'implication de toutes les personnes et institutions impliquées.

Les 22 articles de ce volume représentent un large éventail de thèmes. Alors qu'une majorité analyse des textiles archéologiques, un groupe non négligeable s'intéresse aux textiles ethnographiques. L'ensemble s'étend géographiquement sur les hautes terres andines, la côte désertique du Pérou, le Grand Chaco d'Argentine et aussi la Mésoamérique, jusqu'au nord du Mexique. Certains articles décrivent des collections de musée - soit pour définir les caractéristiques des textiles d'un site ou d'une région, soit pour retracer l'histoire d'une collection. Certains présentent des données de fouilles, des analyses de colorants, ou des procédés de conservation, tandis que d'autres explorent à travers l'analyse des textiles les formes de pensée des populations précolombiennes ou postérieures à la conquête européenne.

Nous remercions tous ceux qui ont offert leur temps et leur expertise pour mener à bien les processus d'évaluation, et Jessica Lévy Contreras et Sophie Desrosiers pour la traduction de beaucoup de résumés. Nous félicitons nos collègues qui ont organisé les conférences précédentes réunissant de nombreux spécialistes internationaux , en particulier la fondatrice, Victòria Solanilla Demestre. Enfin des remerciements particuliers vont à notre éditeur technique à l'université du Nebraska, Paul Royster.
Lena Bjerregaard Ann Hudson Peters

DOI: 10.32873/unl.dc.zea.1201 


\section{Archaeological textiles}

Textiles arqueológicos

\section{Textiles archéologiques}
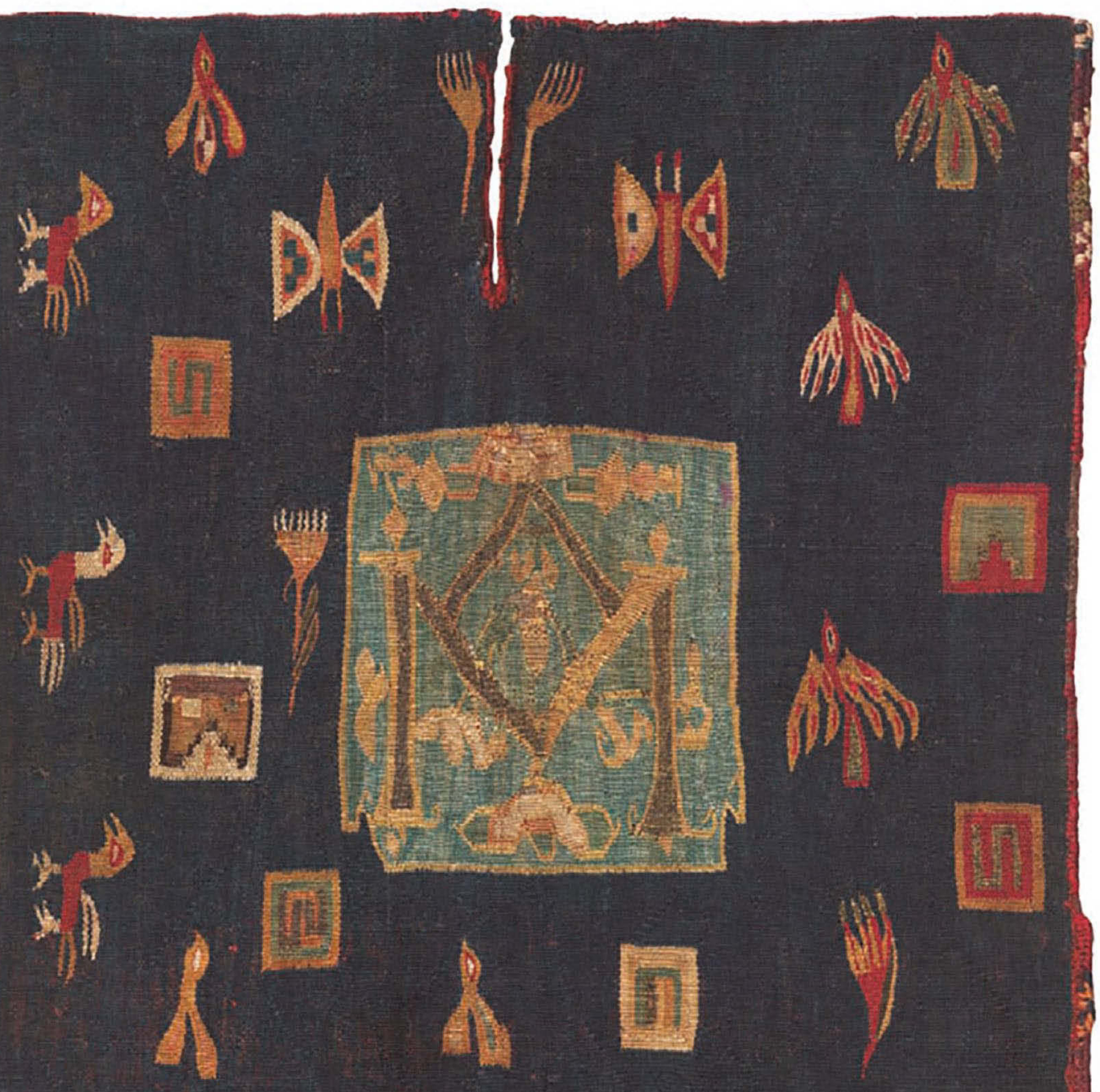


\title{
Recontextualizando el patrimonio arqueológico: los textiles paracas descubiertos por Engel en Cabezas Largas
}

\author{
Jessica Lévy Contreras
}

Investigadora independiente

jessica.levy@pucp.pe

\section{Resumen}

El archivo de Frédéric Engel, arqueólogo suizo quien trabajó en la costa sur del Perú entre los años 1950 y 1960, representa un patrimonio documental importante conservado en el Museo Nacional de Antropología, Biodiversidad, Agricultura y Alimentación (MUNABA) de la Universidad Nacional Agraria La Molina en Lima. Gracias a la revisión de los registros gráficos y fotográficos de las excavaciones realizadas en Cabezas Largas, sitio ubicado en la Península de Paracas, y particularmente de los materiales hallados en la tumba T.27, este artículo presenta los principales textiles asociados a la parafernalia ritual de siete fardos funerarios para tratar de entender mejor las técnicas de manufactura y las prácticas mortuorias del final del Horizonte Temprano en la región (fases Ocucaje 8, 9 y 10). Esta investigación pretende demostrar la relevancia de los datos recopilados en vista de la recontextualización y del análisis de los textiles de la tumba T.27.

Palabras claves: Textiles paracas, Frédéric Engel, tumba T.27, Cabezas Largas, recontextualización del patrimonio arqueológico, análisis de contexto mortuorio.

\begin{abstract}
The archive of Frédéric Engel, Swiss archaeologist who worked in the South coast of Peru between the years 1950 and 196o, represents an important documentary heritage conserved in the Museo Nacional de Antropología, Biodiversidad, Agricultura y Alimentación (MUNABA) of the Universidad Nacional Agraria La Molina in Lima. Based on the review of the graphic and photographic records of the excavations conducted in Cabezas Largas, site located in the Paracas Peninsula, and particularly the materials found in the tomb T.27, this paper presents the principal textiles associated with the ritual paraphernalia of seven funerary bundles to try to better understand manufacturing techniques and mortuary practices from the end of the Early Horizon in the region (phases Ocucaje 8, 9 and 10). This research intends to demonstrate the relevance of the data reassembled for the recontextualization and analysis of the textiles of tomb T.27.
\end{abstract}

Keywords: Paracas textiles, Frédéric Engel, tomb T.27, Cabezas Largas, recontextualization of archaeological heritage, mortuary analysis.

\section{Résumé}

Les documents d'archives de Frédéric Engel, archéologue suisse qui a travaillé sur la côte sud du Pérou entre les années 1950 et 196o, représentent un patrimoine documentaire important conservé au Museo Nacional de Antropología, Biodiversidad, Agricultura y Alimentación (MUNABA) de l'Universidad Nacional Agraria La Molina à Lima. Grâce à la révision des registres graphiques et photographiques des fouilles réalisées à Cabezas Largas, site localisé dans la Péninsule de Paracas, et particulièrement des objets découverts dans la tombe T.27, cet article présente les principaux tissus associés à l'attirail rituel de sept fardos funéraires pour essayer de mieux comprendre les techniques de manufacture et les pratiques mortuaires de la fin de l'Horizon Ancien dans la région (phases Ocucaje 8, 9 et 10). Cette étude prétend démontrer la pertinence des données recueillies pour recontextualiser et analyser les textiles de la tombe T.27.

Mots clés: Textiles paracas, Frédéric Engel, tombe T.27, Cabezas Largas, recontextualisation du patrimoine archéologique, analyse de contexte mortuaire.

DOI: 10.32873/unl.dc.zea.1202

Published in PreColumbian Textile Conference VIII / Jornadas de Textiles PreColombinos VIII, ed. Lena Bjerregaard and Ann Peters

(Lincoln, NE: Zea Books, 2020). https://digitalcommons.unl.edu/zeabook/ 


\section{Introducción}

Esta investigación empezó de manera indirecta entre febrero y mayo de 2016, cuando se realizó la conservación y el montaje de un conjunto de materiales paracas para el nuevo $\mathrm{Mu}-$ seo de Sitio "Julio C. Tello" de Paracas (en adelante, MSP) inaugurado en julio del mismo año. Los materiales intervenidos con Luis Alberto Peña Callirgos, en particular los textiles, despertaron nuestro interés por sus características técnicas y tratamiento decorativo y curiosidad por su contexto arqueológico. Hallados en diferentes sitios de la Península de Paracas por el arqueólogo suizo Frédéric Engel, quien trabajó en la costa sur del Perú entre los años 1950 y 196o, estos artefactos ofrecen datos inéditos para estudiar la cultura Paracas, del cual sabemos que existen registros gráficos y fotográficos conservados en el Museo Nacional de Antropología, Biodiversidad, Agricultura y Alimentación (en adelante, MUNABA) de la Universidad Agraria La Molina en Lima, institución que apoyó los trabajos de Engel en todo el Perú y su difusión a través del Centro de Investigaciones de Zonas Áridas (CIZA).

En el marco del I Coloquio de Arqueología del Museo "Julio C. Tello" de Paracas, organizado en abril de 2018, se presentó en colaboración con Katherine Román Aquino la recontextualización y el análisis de una de las piezas más emblemáticas de esta colección, el manto pintado MSP0043-02. Se descubrió que el material formaba parte del ajuar funerario asociado al Fardo VII de la tumba T.27 de Cabezas Largas, contexto excavado por Engel y su equipo entre julio y agosto de 1959 (Lévy Contreras y Román Aquino 2018). Los resultados obtenidos a partir de la recopilación de los datos arqueológicos procedentes del archivo de Engel en el MUNABA abrieron paso para desarrollar la presente investigación, la misma que tiene como la finalidad de recontextualizar y analizar todos los materiales encontrados en la tumba.

En efecto, la mayoría de los artefactos hallados en la tumba T.27 no fueron publicados ni analizados desde una perspectiva formal, decorativa o comparativa, salvo algunos ejemplares, probablemente elegidos por su carácter excepcional, mostrando el detalle de una pieza sin su rótulo y/o datos de contexto completos (Engel 1966: 177 Fig. 49 A, 180 Figs. 49 C y D, 182 Fig. 49 H, 183 Figs. 49 I y J, 216 Fig. 61; 1991: 97 Figs. 6o, 61 y 62, 98 Fig. 64, 102 Figs. 70 y 71, 113 Figs. 84 y 87, 114 Fig. 89). Dato aún más curioso cuando el dibujo de perfil de la tumba T.27 fue publicado y descrito por Engel (1966: 189 Fig. 53, 203-204). Estos materiales, que son familiares para los investigadores que traten de la cultura Paracas, siguen generando preguntas acerca de su descubrimiento puesto que se encuentran hoy descontextualizados y dispersos en diferentes museos del Perú.
Desde setiembre de 2018 se viene realizando un estudio pluridisciplinar exhaustivo sobre la tumba T.27 de Cabezas Largas a partir del análisis del archivo de Engel y de los materiales asociados al contexto en el MUNABA. Si bien faltan examinar algunas piezas en exposición en el MSP y otras en custodia en el Museo Regional de Ica "Adolfo Bermúdez Jenkins” (en adelante, MRI), esta investigación pretende demostrar la relevancia de los datos recuperados para estudiar el ajuar de cada fardo funerario y de la tumba en su conjunto y tratar de entender mejor las tradiciones estilísticas, las prácticas de producción y las costumbres funerarias de las últimas fases del Horizonte Temprano (fases Ocucaje 8, 9 y 10, aproximadamente entre 400 y 100 a.C.) en la región. Este artículo muestra por primera vez los resultados preliminares obtenidos sobre los textiles del contexto. Se eligió una selección de los artefactos más importantes que combinan diferentes elementos en formas y técnicas antes desconocidas para esta época y cultura. Tras haber explicado nuestra metodología para realizar los trabajos archivísticos en el MUNABA, se presenta la recontextualización y el análisis de los principales textiles de la tumba T.27 para abrir una discusión sobre los rituales mortuorios paracas comparando los datos de Engel a los obtenidos por otros estudiosos en la región.

\section{El análisis del archivo de Engel en el MUNABA}

El archivo de Engel se compone de varios documentos gráficos y fotográficos escritos en castellano, francés y/o inglés sobre la tumba T.27 de Cabezas Largas en el MUNABA. Se conservaron notas de campo manuscritas o escritas a máquina, varios catálogos de materiales, un registro de las fotografías realizadas con su número de negativo y descripción de los sitios o artefactos reproducidos, fotografías en blanco y negro de diversos tamaños, negativos, diapositivas en blanco y negro o en color, dibujos, mapas, informes, así como textos cortos, a veces corregidos e ilustrados, a manera de pruebas para futuras publicaciones. La riqueza de esta documentación se centra en las notas de campo y los inventarios de los materiales redactados por Engel, quien dirigió las investigaciones en Cabezas Largas y designó a Henning Bischof para supervisar la excavación de la tumba. Las notas de campo de Bischof, en particular sus descripciones, dibujos y análisis bioantropológico, realizados cuando asistió al desenfardelamiento de los individuos de la tumba T.27, resaltan por sus detalles puntuales y calidad científica dentro de los datos mencionados (Figura 1). La pluralidad de la información conservada se convierte en una fuente de información primordial para esta investigación.

Tras haber leído y traducido al castellano los registros gráficos de Engel y Bishof para gestionar la información con 


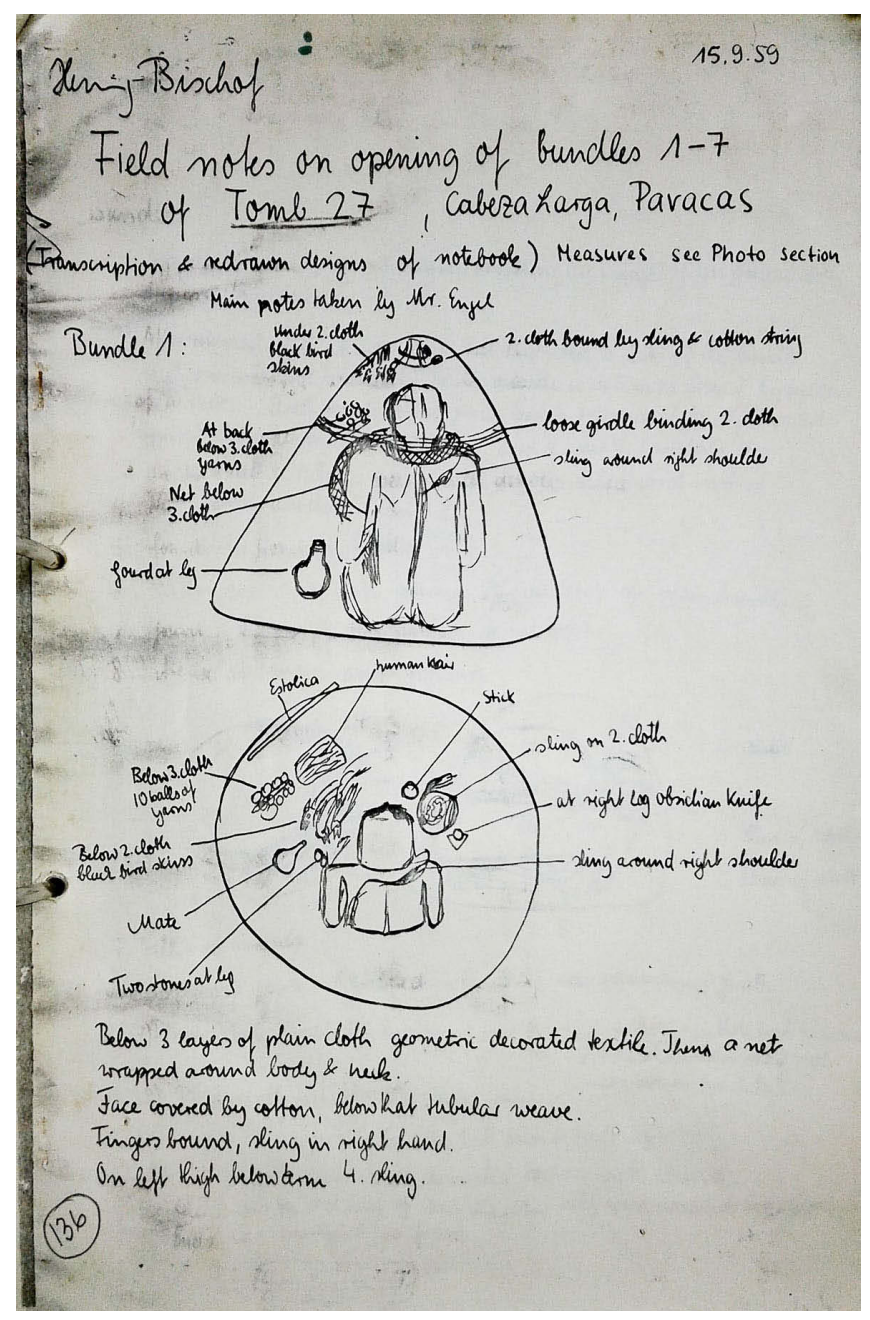

Figura 1: Primera página de las notas de campo tomadas por Bischof el 15 de setiembre de 1959 (Archivo de Engel, Lima [MUNABA] 14a-VI-3 Tumbas (B) f. 91: 136).

mayor facilidad, se cotejaron los datos obtenidos con los inventarios de los materiales de la tumba para identificar todos los objetos asociados al contexto y buscar las fotografías y los negativos originales de cada pieza. Aunque existen contradicciones entre ambos autores (Archivo de Engel, Lima [MUNABA] 14a-VI-3 Tumbas (B) f. 91: 111-161), esta etapa fue determinante para nuestro estudio porque permitió al mismo tiempo identificar y comprobar la validez de los rótulos de cada artefacto ${ }^{1}$. Por otra parte, gracias a la revisión de los catálogos elaborados para cada tipo de material descubierto en excavación, divididos según la tipología de Engel en Textiles (incluyendo fibra vegetal), Óseo (animal), Cerámica, Piedra [Lítico], Concha [Malacológico], Varios (entre otros hallazgos, óseo humano, metales y restos botánicos) y Madera, se buscaron las fichas de inventario de cada pieza procedente de la tumba. En esta labor aparecieron más documentos fotográficos y dibujos de los materiales. Se registraron en total más de 1200 documentos relacionados con el descubrimiento de la tumba T.27 de Cabezas Largas. Estos últimos fueron digitalizados e inventariados para acceder más fácilmente a su contenido y determinar su ubicación exacta en el archivo. Luego se comparó dichos resultados con las publicaciones de Engel $(1966,1991)$ para verificar la presencia de datos e ilustraciones sobre el contexto y el ajuar de la tumba.

Finalmente, se procedió al nuevo registro fotográfico y al análisis de los materiales de la tumba conservados en el MUNABA. La mayoría de las piezas se encuentran hoy en los depósitos del museo salvo unas excepciones que pertenecen a la muestra de la exposición permanente. La otra parte de la colección fue trasladada al antiguo Museo de Paracas para su inauguración en 1964 (Archivo de Engel, Lima [MUNABA] Catálogo Paracas). Si bien algunos de estos materiales siguen siendo parte de la exposición permanente del MSP, los otros fueron dados en custodia al MRI para ser almacenados. Cuando el estado de conservación de las piezas lo permitía, se efectuó la limpieza mecánica y el cambio de embalaje de los materiales del MUNABA. Lamentablemente, la mayoría de los textiles presentan daños irreparables, principalmente por su carbonización avanzada, su consolidación con pegamento y/o hilos en soportes de papel acartonado y su apolillamiento. Es posible que los artefactos no recibieron tratamientos de conservación preventiva después de su hallazgo, incluso si estos fueron fijados en bastidores para su exposición. Algunos montajes, que permanecen hasta la fecha, fueron registrados en las fotografías y las diapositivas de Engel y su equipo.

Resumiendo la información obtenida del archivo de Engel, se estima que cerca de 215 piezas conformaban la parafernalia ritual de la tumba T.27 de Cabezas Largas. Este número toma en cuenta los materiales recontextualizados tanto como los materiales indeterminados, es decir, las piezas cuyos números de inventario y/o datos de contexto no permiten saber con certeza a qué fardo funerario pertenece (Tabla 1). Los textiles representan $45 \%$ de la muestra total (Figura 2). Sin embargo, por problemas inherentes a la práctica arqueológica de la época y a la falta de sistematización de los datos recuperados, es muy probable que el número total de materiales hallados en la tumba sea más significativo. De facto, algunas piezas descritas en las notas de campo no aparecen en los inventarios generales y tampoco fueron dibujadas o fotografiadas. Además, las fotografías tomadas durante el desenfardelamiento de los individuos muestran a veces artefactos que no aparecen en otros registros gráficos o fotográficos asociados a la tumba.

1. Salvo algunas excepciones, se pudo corregir los rótulos de los materiales comparando sus números de inventario, sus descripciones y/o su imagen en cada documentación. 


\begin{tabular}{|c|c|c|c|c|c|c|c|c|c|c|}
\hline & \multicolumn{9}{|c|}{ Recontextualizados } & \multirow{2}{*}{ Indeterminados } \\
\hline Materiales & "Casa" & Tumba & Fardo I & Fardo II & Fardo III & Fardo IV & Fardo V & Fardo VI & Fardo VII & \\
\hline Textiles & 2 & 8 & 3 & 9 & 8 & 15 & 9 & 6 & 29 & 7 \\
\hline Óseo & - & 6 & - & 1 & 5 & 3 & - & 5 & 3 & - \\
\hline Cerámica & 3 & 2 & - & - & - & - & - & 1 & - & 1 \\
\hline Piedra [Lítico] & - & - & 4 & 1 & - & - & - & - & 1 & - \\
\hline Concha [Malacológico] & - & - & - & 4 & 3 & - & - & - & - & - \\
\hline Varios & - & 5 & 6 & 4 & 3 & 5 & 2 & 2 & 6 & 8 \\
\hline Madera & - & 16 & 6 & 2 & 1 & - & - & 2 & 3 & 5 \\
\hline
\end{tabular}

Tabla 1: Cuadro-resumen presentando los materiales recontextualizados e indeterminados de la tumba T.27 de Cabezas Largas (Jessica Lévy Contreras, elaborado a partir del Archivo de Engel, Lima [MUNABA]).

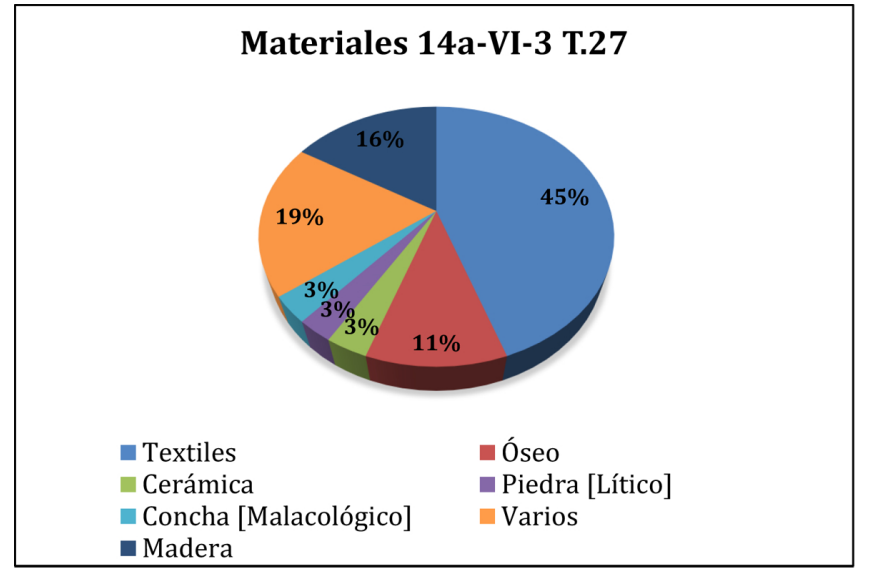

Figura 2: Proporción de materiales hallados en el contexto estudiado (Jessica Lévy Contreras, elaborado a partir del Archivo de Engel, Lima [MUNABA]).

\section{Hacia la recontextualización de la Tumba T.27 de Cabezas Largas}

La tumba T.27, con código de sitio 104 AG o 14a-VI-32 , se localiza en el sitio de Cabezas Largas - denominado también Arena Blanca - a unos metros de la Bahía de Paracas, entre los valles de Pisco e Ica en la costa sur del Perú. Ubicada en una de las terrazas de la Unidad III Corte Estratigráfico $\mathrm{V}$ del sitio ${ }^{3}$, la tumba fue descubierta de manera fortuita debido a que el relleno de esta cedió por el peso de un camión que pasó encima del sitio (Archivo de Engel, Lima [MUNABA], 14a-VI-3 (2) f. 89: 25). Al remover el relleno se encontró una capa de caliche y debajo de ella diversos materiales asociados a la tumba. Comparando el registro gráfico con los dibujos de campo de Engel y Bischof (Archivo de Engel, Lima [MUNABA], 14a-VI-3 (2) f. 89: 26-28; 14aVI-3 Tumbas (B) f. 91: 116-118 y 120), la estratigrafía de la tumba es discutible y parece aludir a la ampliación al oeste de las excavaciones. Engel comenta incluso en una de sus notas que se mantienen "incertidumbres" en los datos recolectados (Archivo de Engel, Lima [MUNABA], 14a-VI-3 Tumbas (B) f. 91: 147), posiblemente debido a la metodología empleada.

De forma rectangular, la tumba T.27 medía $3.15 \mathrm{~m}$ de largo por $0.70 \mathrm{~m}$ de ancho y parece corresponder a una antigua estructura habitacional elaborada con piedras cementadas con algas, como se suele observar en la estratigrafía de los sitios atribuidos a Paracas Necrópolis (Engel 1966: 160; Tello y Mejía Xesspe 1979: 254). Entre otros artefactos, los fardos estaban cubiertos por dos costillas de ballena, cinco esteras de fibra vegetal y una piel de lobo marino curtida ${ }^{4}$ (Archivo de Engel, Lima [MUNABA], 14a-VI-3 Tumbas (B) f. 91: 113-114). Estas ofrendas son comunes en los sitios de Cabezas Largas y de Wari Kayan - llamado también Cerro Colorado por el color rojizo de sus lomas - localizado a poca distancia hacia el sur (Tello 1929: 680, 1959: 56; Tello y Mejía Xesspe 1979: 78 y 297).

La tumba T.27 contenía siete fardos funerarios (Figura 3), seis adultos - confirmada la presencia de tres hombres y dos mujeres - y dos niños. De acuerdo con las interpretaciones de Bischof (Archivo de Engel, Lima [MUNABA] 14a-VI-3 Tumbas (B) f. 91: 136-145), los Fardos I, II, III y VII contenían un adulto, los Fardos V y VI llevaban cada uno un niño y un adulto enfardelados separadamente ${ }^{5}$, y ningún individuo fue registrado al interior del Fardo IV. Por lo mencionado, una de las publicaciones de Engel hace referencia a la tumba con el número equivocado de individuos (Engel 1966:

2. El primer código representa una versión antigua del segundo, siendo la segunda versión el único código publicado por Engel.

3. Según la información recopilada en el archivo de Engel, el código completo de la tumba sería 104 AG/14a-VI-3 U.III SC.V T.27.

4. Cuatro esteras se encuentran en las colecciones del MUNABA y la otra en custodia en el MRI. Una de las costillas de ballena fue traslada al antiguo Museo de Paracas (Archivo de Engel, Lima [MUNABA] Catálogo Paracas: 1) pero no fue ubicada hasta la fecha, tal vez por un problema de rótulo en la pieza. Por otro lado, es probable que la piel de lobo marino curtida fuese desechada por su estado de conservación.

5. Los niños fueron encontrados en bultos superiores, reforzando la idea de Bischof de que podría tratarse de entierros segundarios (Archivo de Engel, Lima [MUNABA] 14a-VI-3 Tumbas (B) f. 91: 139). 


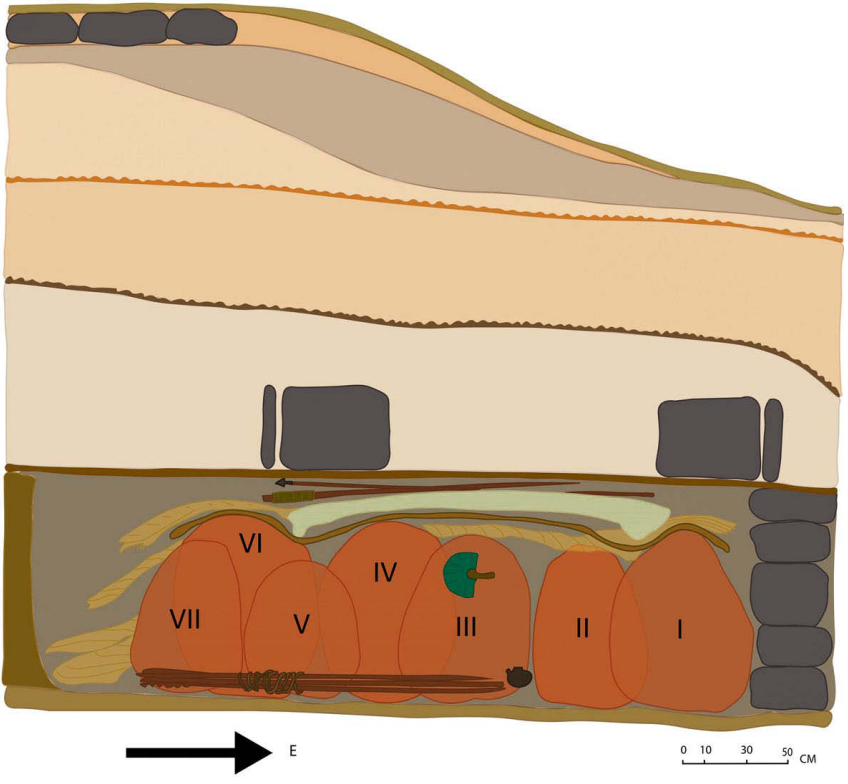

Figura 3: Dibujo de perfil de la tumba T.27 de Cabezas Largas (Lévy Contreras y Román Aquino 2018: 42, Img. 03).

175) y describe más adelante el mismo contexto con el número de individuos correcto (Engel 1966: 204). Como lo explica Paul (1991: 26), aunque los trabajos de Engel son importantes para la región estudiada, estos descuidos o errores revelan que la presentación de los datos recuperados es imprecisa. Es tal vez por este motivo que los aportes científicos de Engel son criticados en la arqueología peruana (Velarde 2002-2003).

Los entierros descubiertos en la tumba T.27 de Cabezas Largas presentan materiales atribuidos al estilo Paracas Necrópolis-Topará (fases Ocucaje 8, 9 y 10) relacionados con el final del Horizonte Temprano en la región. Un fechado radiocarbónico tomado en muestras de carbón y restos botánicos $^{6}$, con fecha $2060 \pm 170$ A.P. (Engel 1991: 56), confirma esta filiación estilística que coincide con el Periodo II de Engel (1966: 171; 1991: 94-96). Por ende, los textiles del contexto estudiado pueden ser comparados con los materiales hallados por Tello y Mejía Xesspe en los sitios de Cabezas Largas y de Wari Kayan (Tello 1929, 1959; Tello y Mejía Xesspe 1979, Archivo Tello 2009, 2012; MNAAHP 2013).

\section{Los textiles paracas analizados en la muestra}

En la muestra estudiada, 96 textiles fueron registrados por Engel y su equipo: 53 textiles pertenecen a la colección del MUNABA, tres de ellos siguen en exposición en el MSP, 22 se encuentran en los depósitos del MRI y una pieza fue robada $^{7}$. Por ende, 17 materiales no fueron localizados hasta la fecha. Resumiendo los datos obtenidos en esta investigación, se registraron hasta la fecha:

- Elementos de tocado en fibra de algodón o de camélido elaborados en sprang o torsal doble.

- Bandas anudadas con flecos de urdimbre en fibra de camélido (llautos).

- Cordones anillados de forma tubular en fibra de camélido decorados con plumas.

- Mantos y paños de tela llana en fibra de algodón con decoración bordada en fibra de camélido.

- Mantos de tela llana en fibra de algodón con decoración pintada o recamados con plumas.

- Túnicas de tela llana en fibra de algodón decoradas con flecos.

- Mantos de tela llana en fibra de algodón o de camélido decorados con zonas de urdimbres cruzadas creando ojales

- Mantos y túnicas en fibra de algodón decorados con bandas tejidas con urdimbres suplementarias en fibra de camélido.

- Bolsas de tejido abierto en fibra de algodón.

- Hondas en fibra vegetal trenzada decoradas con borlas en fibra de algodón.

Para demostrar la importancia de la tumba T.27 de Cabezas Largas, se presentará a continuación una selección de los principales hallazgos textiles del contexto haciendo énfasis en el tipo de material o vestimenta elaborado, su ubicación, como ofrendas exteriores o asociadas a los fardos funerarios, sus características técnicas y, si posible, su contenido iconográfico. Se identificarán las piezas por su código completo ${ }^{8}$.

\section{Los plumarios:}

Dos abanicos de plumas fueron colocados encima del Fardo III (Archivo de Engel, Lima [MUNABA] 14aVI-3 Tumbas (B) f. 91: 114). Uno de ellos se ubica en los

6. El fechado NZ-1127/2 (no cal.) fue realizado en 1961 a partir de una muestra tomada por Engel y Bischof en el Fardo V (Archivo de Engel, Lima (MUNABA), Fechados RC. 14 por Sitio: Cuaderno 7). Su resultado fue publicado como una referencia para discutir el inicio del Horizonte Temprano en la costa sur del Perú (Ravines 1982: 170-171; Burger 1988: 109, Tabla 1).

7. Gracias a la ayuda de Rubén García Soto (comunicación personal, 2018), se pudo confirmar el robo del material en el antiguo Museo de Paracas en 1992.

8. Para el MUNABA, estos códigos corresponden a los números de inventario dados por Engel. Para el MSP, aparecen los códigos de propietario seguidos entre corchetes de los números de inventarios originales de las piezas. Se precisará por escrito si los materiales están en custodia en el MRI. 

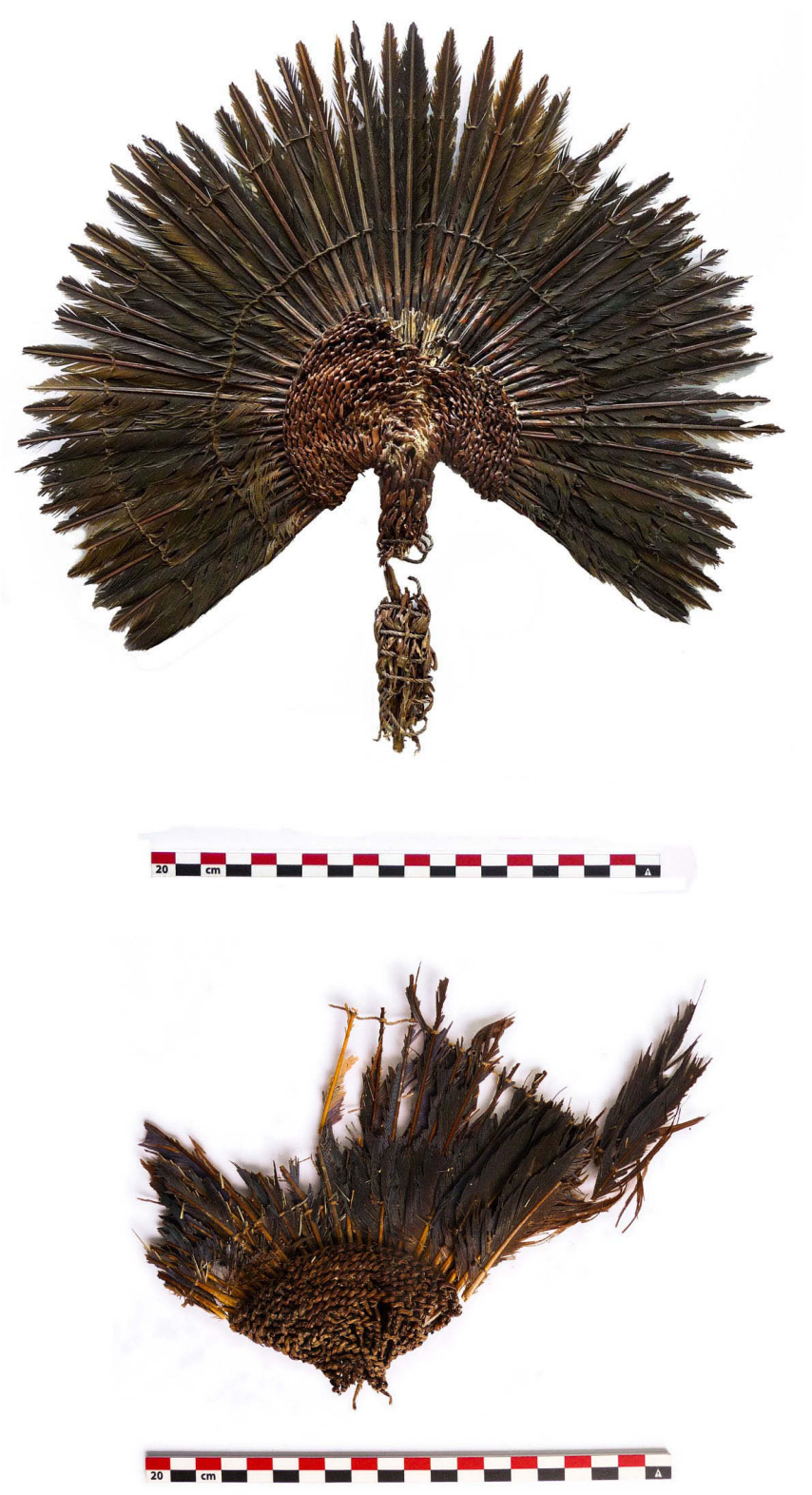

Figuras 4 A y B: Los abanicos MSP-0114-09 [0.2293-V.244] y V.245 en su vista posterior (Fotografías: Jessica Lévy Contreras, cortesía MRI).

depósitos del MRI (MSP-0114-o9 [0.2293-V.244]) y el otro ejemplar en el MUNABA (V.245). Por lo tanto, sólo la primera pieza se encuentra en estado de conservación regular. Se trata de un abanico de fibra vegetal decorado con plumas de color marrón oscuro de dimensiones generales $27.3 \mathrm{~cm}$ de alto por $29 \mathrm{~cm}$ de ancho (Figura $4 \mathrm{~A}$ ). El cálamo de las plumas está entrelazado a la estructura de fibra vegetal compuesta por cabos de junco de 2 a $2.5 \mathrm{~mm}$ de grosor. En la parte central de la estructura, de forma semicircular y de diámetro $9.2 \mathrm{~cm}$, se observa residuos de pegamento de color beige indicando una conservación o un montaje anterior del material. La estructura de fibra vegetal termina por dos fragmentos de mango amarrados hasta su base con un cordón de algodón beige de estructura $\mathrm{Z}(2 \mathrm{~s}(4 \mathrm{z}))^{9}, 5 \mathrm{O}^{\circ}$ de torsión y $2 \mathrm{~mm}$ de grosor para dar más solidez a la pieza. Las dimensiones del mango son de $17.2 \mathrm{~cm}$ de alto por $2.5 \mathrm{~cm}$ de ancho y tiene un grosor de $1.4 \mathrm{~cm}$. Las plumas, con dimensiones aproximadas de 14.5 $\mathrm{cm}$ de largo por $1.5 \mathrm{~cm}$ de ancho, fueron atadas de manera regular en dos partes de su raquis con un hilo en fibra de algodón de estructura $Z(2 \mathrm{~s}), 40^{\circ}$ de torsión y $1 \mathrm{~mm}$ de grosor. Por sus dimensiones, las plumas parecen provenir de las alas de un ave costeña. Un fragmento del segundo abanico fue conservado y presenta las mismas características técnicas. De dimensiones $21 \mathrm{~cm}$ de alto por $21.5 \mathrm{~cm}$ de ancho y $1.7 \mathrm{~cm}$ de grosor, sus plumas de color azul pertenecen a la especie de guacamayo Ara ararauna (Figura 4 B). Por lo visto, los abanicos MSP-0114-09 [0.2293-V.244]) y V.245 se asemejan a los ejemplares encontrados en Wari Kayan (Tello y Mejía Xesspe 1979: 478).

Relacionados con las ofrendas del Fardo VII, dos adornos de plumas conservados en el MUNABA destacan por su confección (V.292 A y B). De forma circular, las piezas fueron elaboradas con plumas de color beige amarillento y negro atadas en su raquis con un hilo en fibra algodón de estructura $\mathrm{S}(2 \mathrm{z}), 50^{\circ}$ de torsión y $0.5 \mathrm{~mm}$ de grosor de manera regular. Las plumas, con dimensiones aproximadas de 8 a $3 \mathrm{~cm}$ de largo por 3 a $1.5 \mathrm{~cm}$ de ancho, fueron colocadas en alternancia de color y sus puntas cortadas para acentuar su decoración en círculos concéntricos. Gracias a las imágenes obtenidas con microscopio digital portátil Dino-Lite, se pudo observar en el material V.292 A que los cálamos de las plumas fueron doblados en dos y amarrados con un hilo en fibra de algodón de estructura $\mathrm{S}(2 \mathrm{z}), 6 \mathrm{o}^{\circ}$ de torsión y $1 \mathrm{~mm}$ de grosor a un elemento de madera tallado en punta y pulido de aproximadamente $9 \mathrm{~cm}$ de largo por $3 \mathrm{~mm}$ de grosor. La punta de madera, semejante a la forma de un tupu, sugiere que el adorno fuese un elemento de tocado. Las dimensiones generales de la pieza son de $21.5 \mathrm{~cm}$ de alto por $20.2 \mathrm{~cm}$ de ancho y $1.8 \mathrm{~cm}$ de grosor (Figura $5 \mathrm{~A}$ ). El adorno V.292 B, en estado fragmentario y con manchas de carbonización, tiene rasgos técnicos y decorativos similares. Sin embargo, este se diferencia del otro adorno por estar asociado a dos borlas de plumas de color beige amarillento y negro atadas a un cabo de junco de estructura $\mathrm{Z}(2 \mathrm{~s}), 6 \mathrm{o}^{\circ}$ de torsión y $4 \mathrm{~mm}$ de grosor con un hilo de algodón de estructura $\mathrm{S}(2 \mathrm{z}), 50^{\circ}$ de torsión y $0.5 \mathrm{~mm}$ de grosor. Se puede pensar que las borlas decoraban originalmente el contorno 

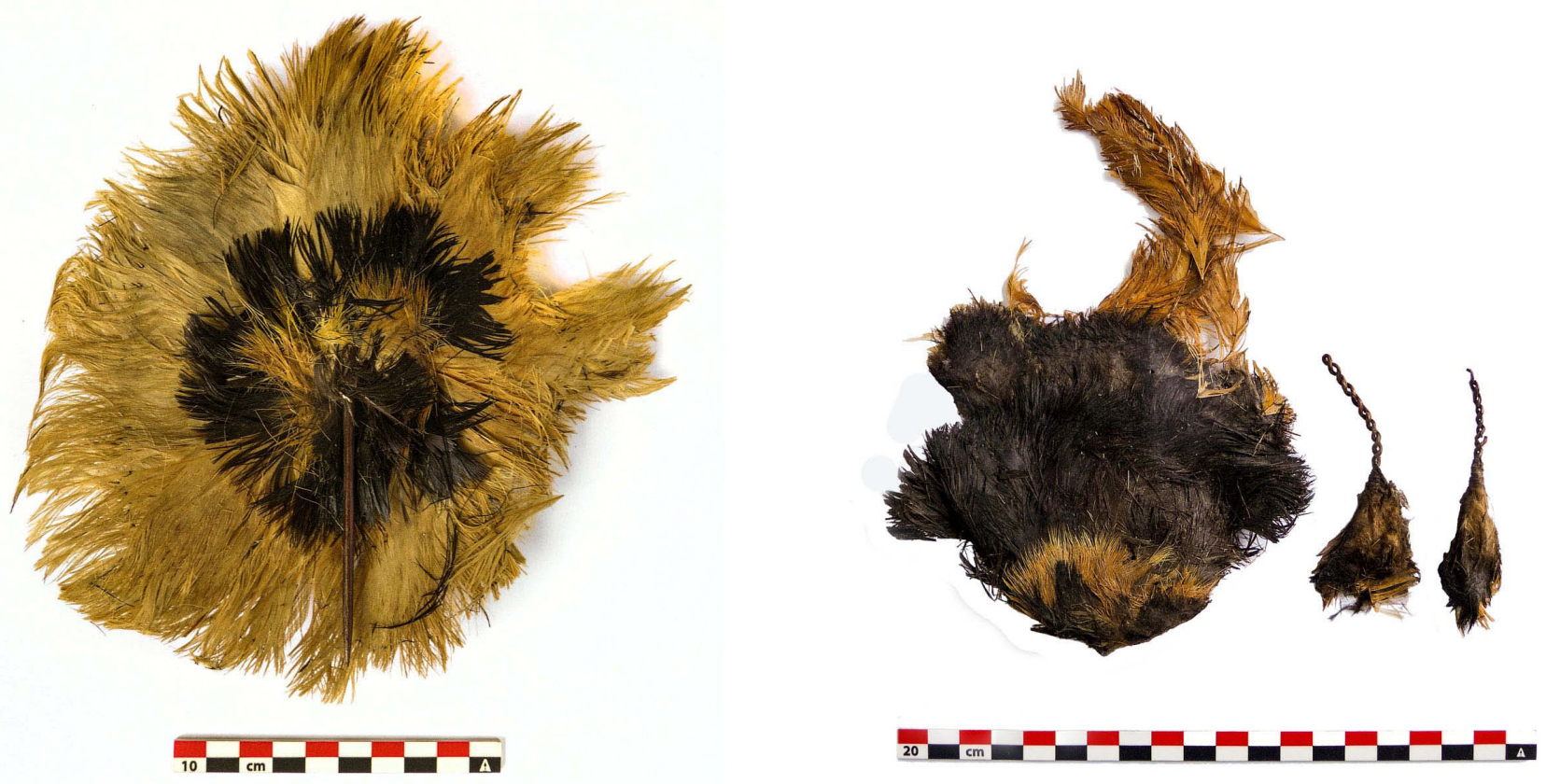

Figuras 5 A y B: Los adornos de plumas V.292 A y V.292 B (Fotografía: Jessica Lévy Contreras).

de la pieza. Las dimensiones generales del artefacto son de $18 \mathrm{~cm}$ de alto por $14 \mathrm{~cm}$ de ancho y tiene un grosor de 2 $\mathrm{cm}$. Sus borlas miden $9 \mathrm{~cm}$ de alto por $3.5 \mathrm{~cm}$ de ancho y $8.2 \mathrm{~cm}$ por $2.3 \mathrm{~cm}$ de ancho. Ambas tienen $8 \mathrm{~mm}$ de grosor (Figura 5 B). El tamaño de las plumas varía entre 7 y $3 \mathrm{~cm}$ de alto por 2 a $3 \mathrm{~cm}$ de ancho y parecen provenir de diferentes aves costeñas ${ }^{10}$. Al parecer, los adornos V.292 A y B son únicos por su forma y su técnica.

Asimismo, se mencionan en los registros gráficos de Engel y Bischof el hallazgo de mantos recamados con plumas en los Fardos IV, V Individuo B y VII (Archivo de Engel, Lima [MUNABA] 14a-VI-3 Tumbas (B) f. 91: 133, 138, 142, 156, 158 y 160). Aunque dichos materiales no fueron ubicados hasta la fecha, a excepción de un fragmento conservado en los depósitos del MRI asociado al Fardo VII (MSP-0391-02 [V.309] $)^{11}$, algunas fotografías en blanco y negro permiten observar sus características. Por ejemplo, existe una toma fotográfica del manto plumario encontrado durante el desenfardelamiento del Fardo V Individuo B (Figura 6). Cruzando los datos de la documentación recopilada, podemos afirmar que se trataba de un manto en fibra de algodón recamado con plumas de color amarillo y negro, las últimas decorando los bordes de la tela a manera de banda ancha. La pieza corresponde a la primera capa de envoltorio del individuo, tras haber retirado un manto de tela llana al exterior

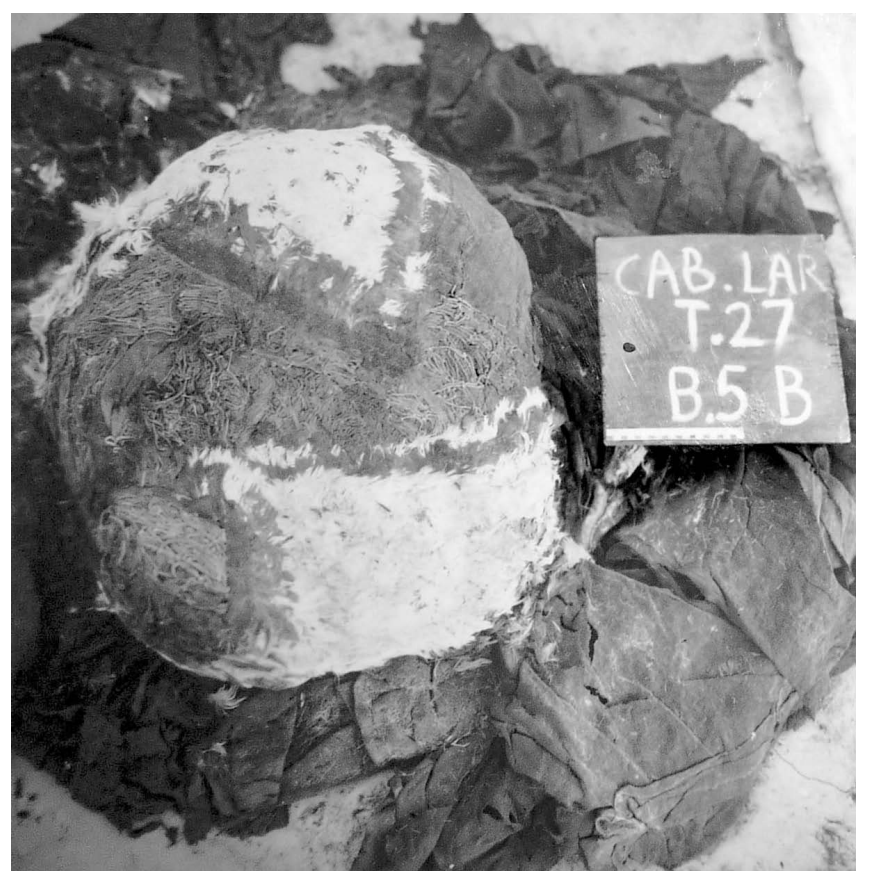

Figura 6: El manto plumario MSP-0391-02 [V.309] durante el desenfardelamiento del Fardo V Individuo B (Archivo de Engel, Lima [MUNABA] 14a-VI-3 Tumbas (B) f. 91: 85).

del fardo (Archivo de Engel, Lima [MUNABA] 14a-VI-3 Tumbas (B): f. 91: 138 y 158). 

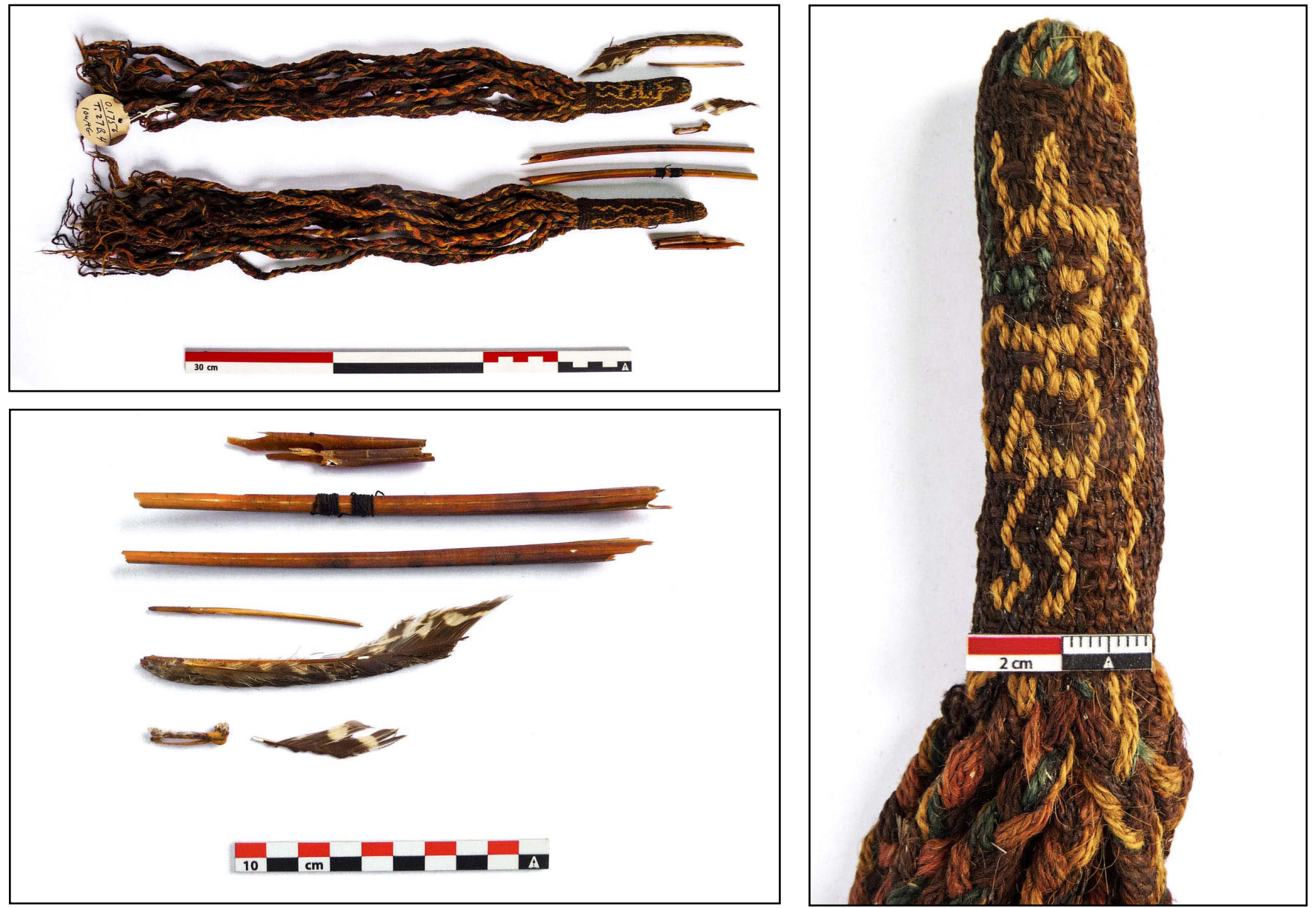

Figuras 7 A, B y C: Las borlas o.1756, detalle de su decoración bordada y plumas de halcón (Fotografías: Jessica Lévy Contreras).

Los materiales compuestos:

Varios materiales compuestos por elementos de diferente naturaleza fueron descubiertos en la tumba T.27. Relacionada con las ofrendas del Fardo IV, la pieza 0.1756 representa a dos borlas en fibra de camélido crudo y teñido en diversos colores que combinan diferentes elementos. Se trata de uno de los materiales del contexto mejores conservados en el MUNABA. Confeccionadas a partir de 15 y 14 cordones trenzados de color marrón, beige ocre, rojo y azul verdoso, las borlas fueron envueltas de forma tubular en su parte superior por una tela llana de color marrón con decoración bordada de color beige ocre y azul verdoso y cosida en su borde de urdimbre con puntadas diagonales de color marrón (Figura 7 A). Las trenzas, de $8 \mathrm{~mm}$ de ancho, fueron realizadas con hilos de estructura $\mathrm{S}(2 \mathrm{z}), 45^{\circ}$ de torsión y $1 \mathrm{~mm}$ de grosor. La tela, con 5 elementos de urdimbre por 4 elementos de trama en un centímetro cuadrado, tiene hilos de estructura $\mathrm{S}(2 \mathrm{z}), 50^{\circ}$ de torsión y $1 \mathrm{~mm}$ de grosor. Los hilos de la decoración bordada, que muestra a dos personajes antropomorfos representados de perfil sosteniendo en una de sus manos un atributo y de cuya cabeza sale una línea en zigzag a manera de serpiente, poseen las mismas características que los hilos de los cordones trenzados (Figura $7 \mathbf{B}$ ). La parte tubular mide para cada borla $8.8 \mathrm{~cm}$ de largo por $2.2 \mathrm{~cm}$ de ancho y $7.2 \mathrm{~cm}$ de largo por $2.3 \mathrm{~cm}$ de ancho. Por último, la puntada diagonal tiene rasgos similares a los elementos de la tela llana. Varios fragmentos de plumas de halcón, atadas en su raquis con un hilo en fibra de algodón ${ }^{12}$ de estructura $\mathrm{S}(2 \mathrm{z}), 60^{\circ}$ de torsión y $0.5 \mathrm{~mm}$ de grosor, fueron recuperados junto con las borlas (Figura 7 C). Gracias al registro fotográfico original de la pieza (Archivo de Engel, Lima [MUNABA] Cuaderno $\mathrm{N}^{\circ}$ 5, Negativo: F.3570), se supone que dichos elementos estaban amarrados a la extremidad superior de las borlas. Las dimensiones generales para cada artefacto son de $45.2 \mathrm{~cm}$ de largo por $6.5 \mathrm{~cm}$ de ancho y $43.8 \mathrm{~cm}$ de largo por $6.3 \mathrm{~cm}$ de ancho. 

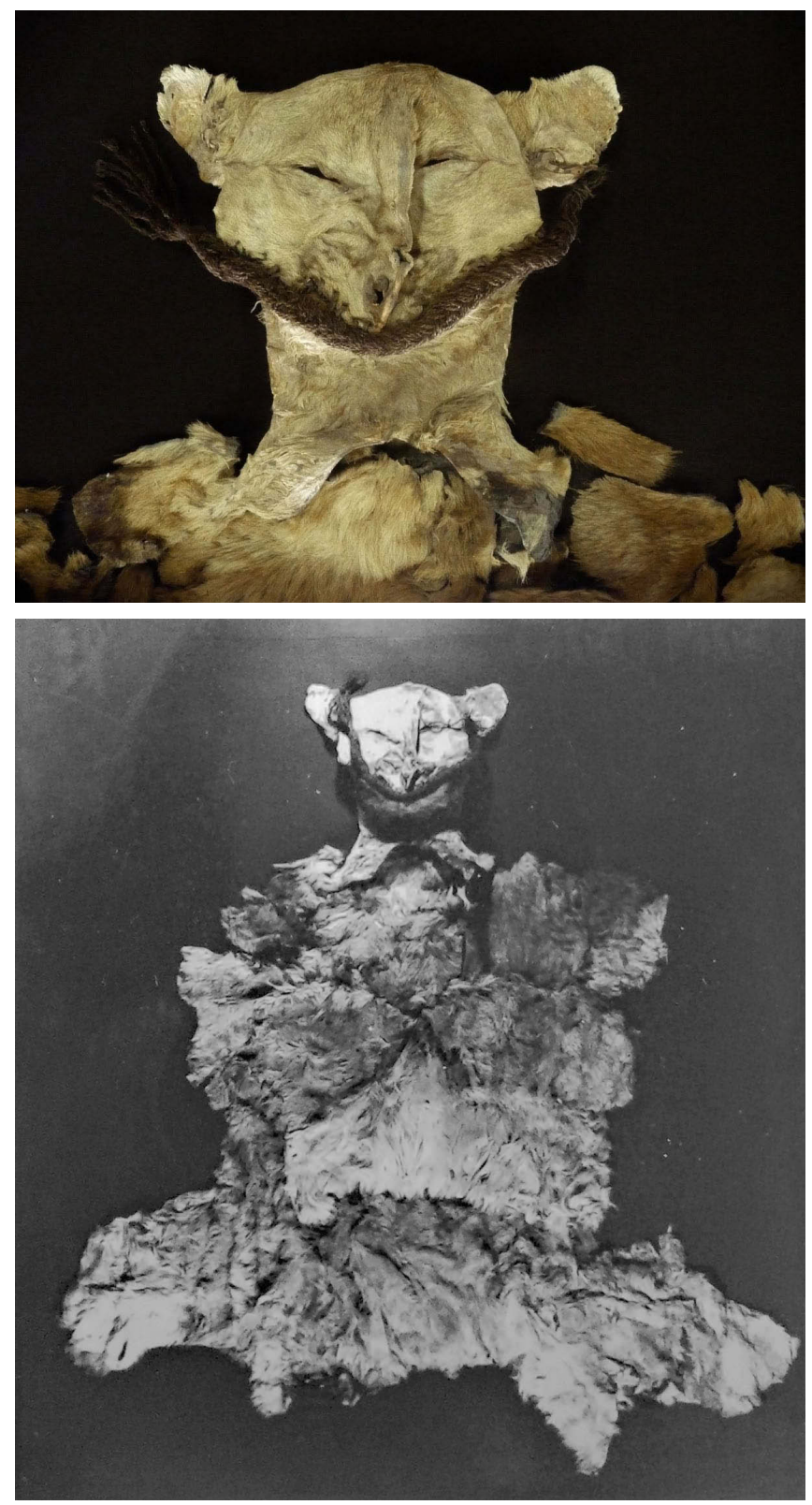

Figuras 8 A y B: Detalle de la piel de puma MSP-oo93-16 [V.269] en su estado de conservación actual y fotografía original de la pieza (Fotografía: Jessica Lévy Contreras; Archivo de Engel, Lima [MUNABA] Caja No 1 , Tipología Varios: Ficha V.269).

La piel de puma MSP-oo93-16 [V.269], hallada entre dos capas de envoltorio del Fardo VII (Archivo de Engel, Lima [MUNABA] 14a-VI-3 Tumbas (B) f. 91: 160), fue intervenida en 2016 para su exposición en el MSP. Si bien la pieza tiene hoy un aspecto muy fragmentario, esta fue curtida, perforada y cosida antes de ser depositada como ofrenda. La cabeza del puma (Puma concolor), puesta en vista frontal, conserva cartílagos en las orejas y la nariz.
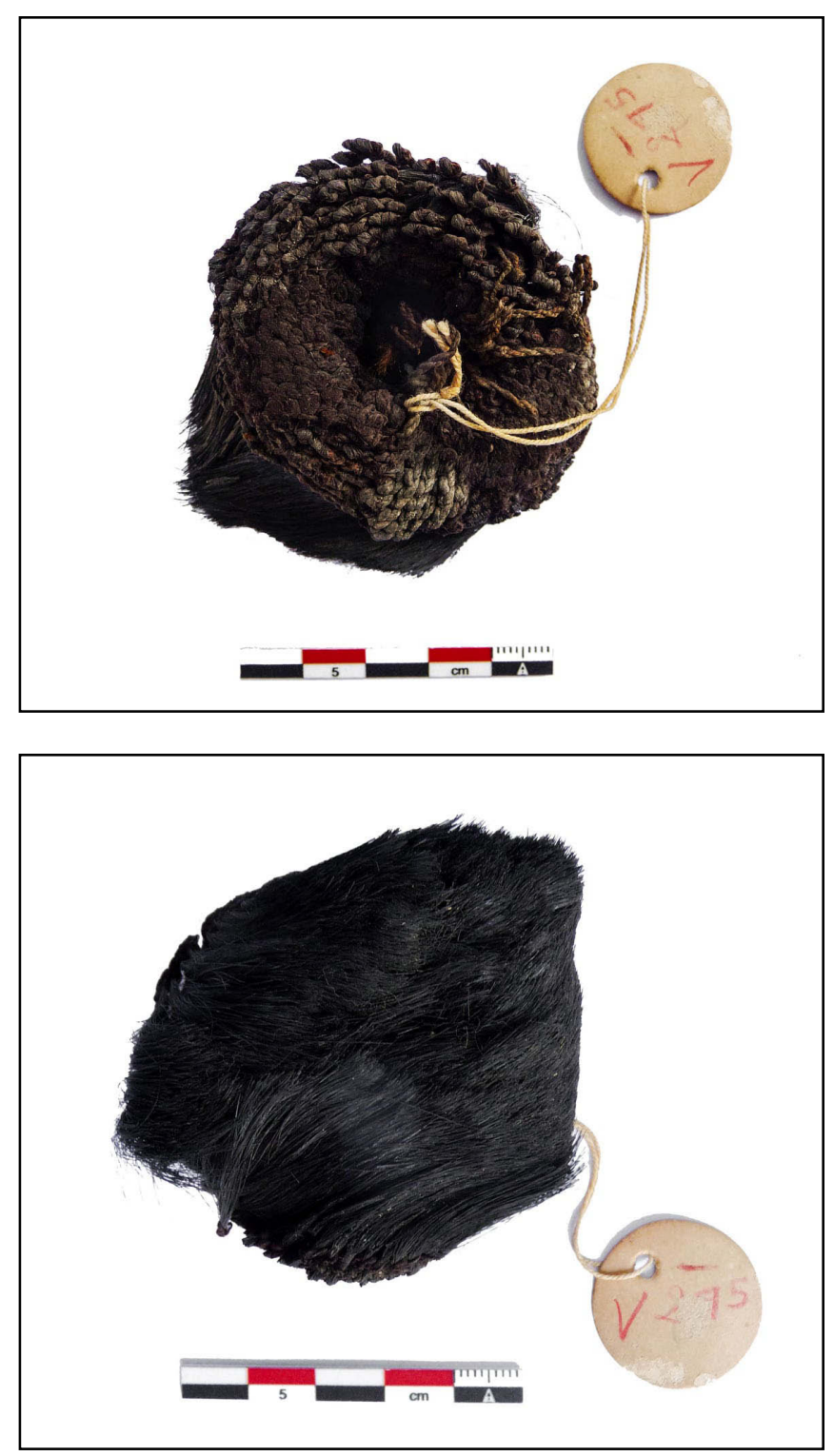

Figuras 9 A y B: Artefacto V.275-W.275 A en su vista anterior y posterior (Fotografías: Jessica Lévy Contreras).

Su boca fue cosida con un hilo en fibra de camélido de color marrón de estructura $\mathrm{S}(2 \mathrm{z})$ a una trenza en fibra de camélido de color marrón con elementos similares ${ }^{13}$. La trenza, que termina con nudo y flecos largos en sus extremidades, parece representar el bigote que el felino tenía en vida (Figura 8 A). Se observa también puntadas irregulares con restos de hilo en fibra de camélido de color marrón de estructura $\mathrm{S}(2 \mathrm{z})$ en la parte inferior del material. No obstante, es importante mencionar que el estado de conservación actual de la pieza no coincide con el registro fotográfico de Engel. Una flecadura independiente, 
probablemente cosida a la trenza, cubría originalmente la parte inferior de la boca hasta el cuello del animal (Figura 8 B). Este elemento pudo servir para resaltar los rasgos faciales del felino y/o su aspecto simbólico. Por ende, la piel de puma de la tumba T.27 de Cabezas Largas no parece tener equivalentes en los Andes centrales para este periodo ${ }^{14}$. Sus medidas aproximadas son de $92 \mathrm{~cm}$ de alto por $82 \mathrm{~cm}$ de ancho.

Un curioso artefacto compuesto por cabello, fibra vegetal y fibra de algodón fue encontrado en el ajuar del Fardo I (Archivo de Engel, Lima [MUNABA] 14a-VI-3 Tumbas (B) f. 91: 92). Conservada en el MUNABA, la pieza V.275-W.275 A fue elaborada con mechas de cabello de $3 \mathrm{~cm}$ de alto anudadas entre sí a un cordón de junco de estructura $\mathrm{S}(2 \mathrm{z})$, $45^{\circ}$ de torsión y $1 \mathrm{~mm}$ de grosor. Las mechas fueron atadas de forma concéntrica para formar la estructura del adorno. Asimismo, la parte superior del material presenta un cordón en fibra de algodón de color beige ocre de estructura $\mathrm{S}(2 \mathrm{z}), 50^{\circ}$ de torsión y $0.5 \mathrm{~mm}$ de grosor con nudos. Dicho elemento pudo servir para dar más solidez a la estructura y/o decorarla (Figuras 9 A y B). De dimensiones $6.8 \mathrm{~cm}$ de largo por $5.2 \mathrm{~cm}$ de ancho, el artefacto fue descrito como "escobilla" (Archivo de Engel, Lima [MUNABA] Caja $\mathrm{N}^{\circ}$, Número Varios: Ficha V.275 A; Caja ${ }^{\circ}$ 3, Tipología Madera: Ficha W.275 A) mientras que otro ejemplar similar, encontrado en las ofrendas del Fardo VII ${ }^{15}$, fue interpretado como "brocha" (Archivo de Engel, Lima [MUNABA] Caja Nº 1 , Número Varios: Ficha V.295) o "peine" (Archivo de Engel Caja $\mathrm{N}^{\circ} 3$, Tipología Madera: Ficha W.295). En todo caso, no cabe duda de que se trata de una pieza particular.

Los textiles y los elementos de tocado:

El manto 0.1862 fue descubierto entre las capas 6 y 8 del Fardo VII, como lo demuestra una fotografía del individuo en proceso de desenfardelamiento (Figura 10 A). Aunque sólo se conservaron fragmentos carbonizados de la pieza en el MUNABA, consolidados con pegamento e hilos en un soporte de papel acartonado, se observa restos de tela llana en fibra de algodón con decoración bordada en fibra de camélido crudo y teñido en diversos colores. Los hilos de la tela tienen una estructura $\mathrm{S}(2 \mathrm{z}), 6 \mathrm{o}^{\circ}$ de torsión y $0.5 \mathrm{~mm}$ de grosor, mientras que los hilos de la decoración bordada tienen una estructura $\mathrm{S}(2 \mathrm{z}), 50^{\circ}$ de torsión y $1 \mathrm{~mm}$ de grosor. La decoración bordada, de color beige ocre, marrón, gris y rojo, muestra personajes antropomorfos representados de frente con lagrimales de halcón en su rostro, un felino visto de perfil al interior de su cuerpo y apéndices que
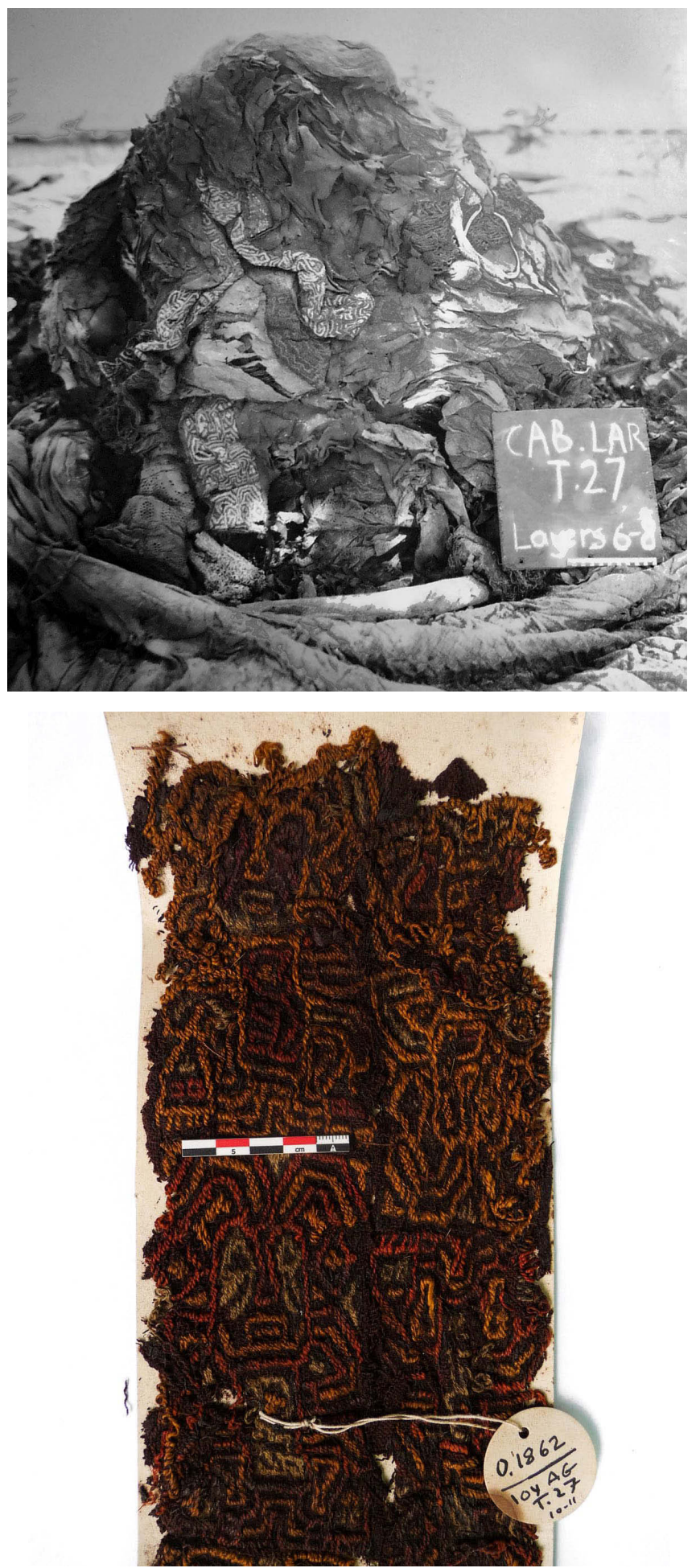

Figuras 10 A y B: Vista del manto 0.1862 entre las capas 6 y 8 del Fardo VII, detalle de su decoración bordada conservada en el MUNABA (Archivo de Engel, Lima [MUNABA] 14a-VI-3 Tumbas (B) f. 91: 88; Fotografía: Jessica Lévy Contreras).

14. A manera de comparación, una máscara de puma procedente del valle de Azapa y asociada con el Periodo Medio (500-10oo d.C.) fue encontrada en Arica, Chile. Dicha pieza pertenece a la colección del Museo Arqueológico San Miguel de Azapa de la Universidad de Tarapacá (Cf. Portada de Chungara: Revista de Antropología Chilena, Vol. 50 (1) 2018).

15. Solamente se conserva un dibujo de la pieza en su ficha de inventario. 

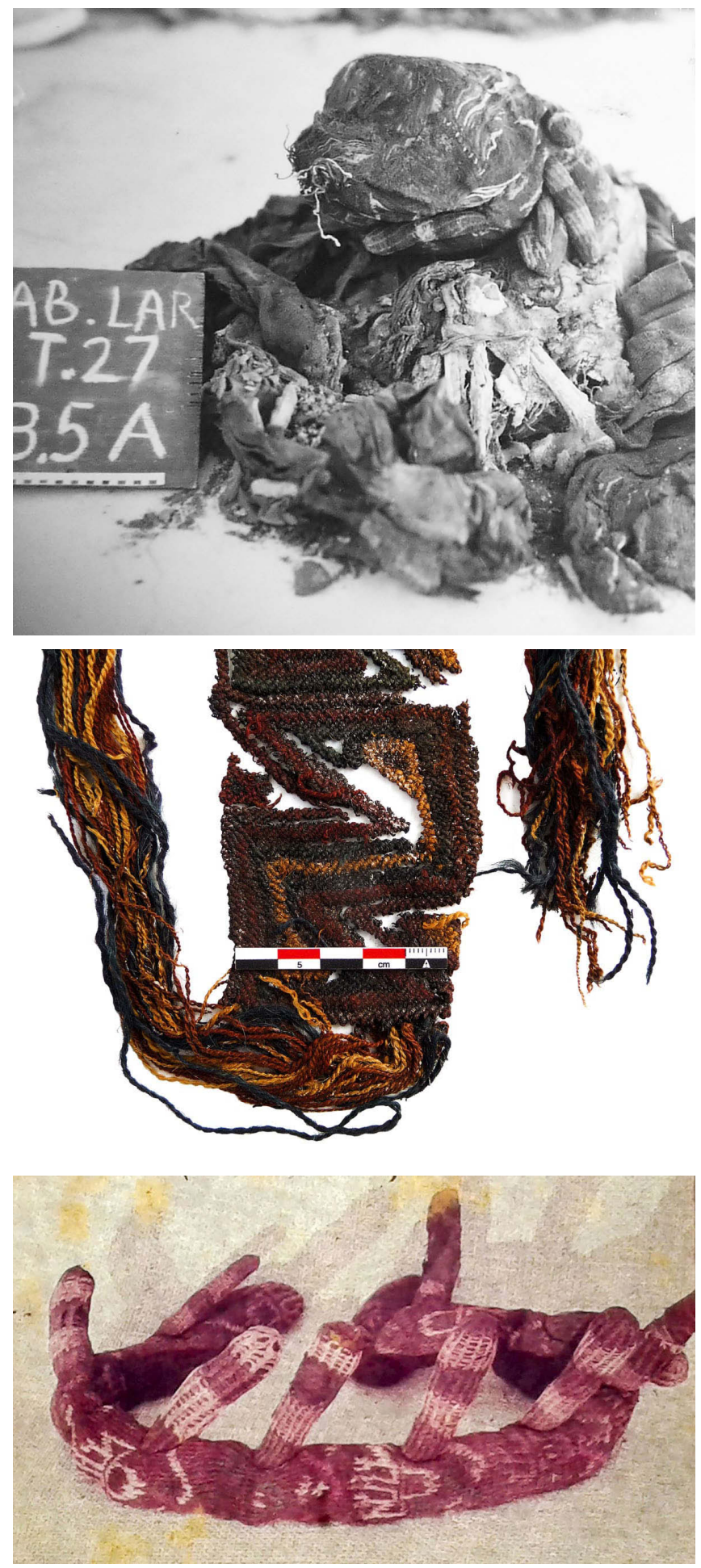

Figuras 11 A, B y C: Registro fotográfico de los materiales 0.1706 y 0.2015 en la cabeza del Fardo V Individuo A, detalle de la banda anudada 0.1706 y diapositiva a color del tocado 0.2015 (Archivo de Engel, Lima [MUNABA 14a-VI-3 Tumbas (B) f. 91: 85; Fotografía, Jessica Lévy Contreras; Caja $\mathrm{N}^{\circ} 3$, Tipología Tejidos: Ficha 0.2015). brotan de su cabeza y cintura de cuyas terminaciones nacen cabezas-trofeo (Figura 10 B). Por el estado de conservación actual del manto, se estima que la decoración bordada corresponde al borde de urdimbre y mide $7 \mathrm{~cm}$ de ancho. Las dimensiones originales de la pieza no fueron registradas en las fichas de inventario del material (Archivo de Engel, Lima [MUNABA] Caja Nº3, Tipología Tejidos: Ficha o.1862; Caja $\mathrm{N}^{\circ} 2$, Colección Básica Tejidos: Ficha 0.1862; Caja 14a-VI-3 T.27 Paracas, Análisis Textil Sitios: Ficha 0.1862). Se trata del fragmento de manto bordado en mejor estado de conservación estudiado en la muestra hasta la fecha.

De acuerdo con el registro fotográfico del Fardo V Individuo A (Archivo de Engel, Lima [MUNABA] 14a-VI-3 Tumba (B) f. 91: 85 y 92; Cuaderno $\mathrm{N}^{\circ} 1$, Negativos: F.686 y 688), la cabeza de un niño estaba originalmente decorada por dos tocados (Figura 11 A). Si bien la pieza 0.1706 se encuentra muy deteriorada por su carbonización, esta fue analizada con microscopio digital portátil para determinar su estructura y colores originales en el MUNABA. Realizada con hilos de camélido crudo y teñido en diversos colores de estructura $\mathrm{S}(2 \mathrm{z}), 50^{\circ}$ de torsión y $1 \mathrm{~mm}$ de grosor, se trata de una banda anudada con flecos de urdimbres decorada con diseños geométricos de color beige ocre, marrón, negro, rojo y azul oscuro (Figura 11 B). El material tiene dimensiones aproximadas de $1.05 \mathrm{~m}$ de largo por $6.3 \mathrm{~cm}$ de ancho (Archivo de Engel, Lima [MUNABA] Caja $\mathrm{N}^{\circ} 3$, Tipología Tejidos: Ficha 0.1706; Caja $\mathrm{N}^{\circ}$ 1, Colección Básica Tejidos: Ficha 0.1706; Caja 14a-VI-3 T.27 Paracas, Análisis Textil Sitios: Ficha 0.1706). Por otro lado, el tocado 0.2015 no fue ubicado hasta la fecha. Gracias al registro gráfico y fotográfico de la pieza (Archivo de Engel, Lima [MUNABA] Caja $\mathrm{N}^{\circ} 3$, Tipología Tejidos: Ficha 0.2015; Caja $\mathrm{N}^{\circ} 2$, Colección Básica Tejidos: Ficha 0.2015; Caja 14a-VI-3 T.27 Paracas, Análisis Textil Sitios: Ficha 0.2015), podemos observar que el material se compone de un cordón anillado de forma tubular decorado con nueve puntas en anillado cruzado $^{16}$, probablemente rellenadas con fibra de algodón y cosidas de forma radiante en la parte superior del cordón. La pieza muestra además una decoración compleja con aves bicéfalas y diseños geométricos creada con hilos en fibra de camélido crudo y teñido en diversos colores (Figura 11 C). Es la primera vez que se registra este tipo de tocado en la cultura Paracas.

\section{El manto pintado MSP-0043-02 [0.1316]:}

El Fardo VII, sin duda uno de los individuos más importantes de la tumba por su ajuar funerario, contenía por lo menos 13 capas de envoltorio y cerca de 80 ofrendas (Archivo de Engel, Lima [MUNABA] Tumbas (B) f. 91: 142-145,

16. Se encontraron fragmentos de un tocado similar decorado con borlas de plumas amarillas asociado al Fardo II (V. 290). Por lo tanto, el registro gráfico de Engel y Bischof no permite confirmar si la pieza pertenece al ajuar del individuo. 


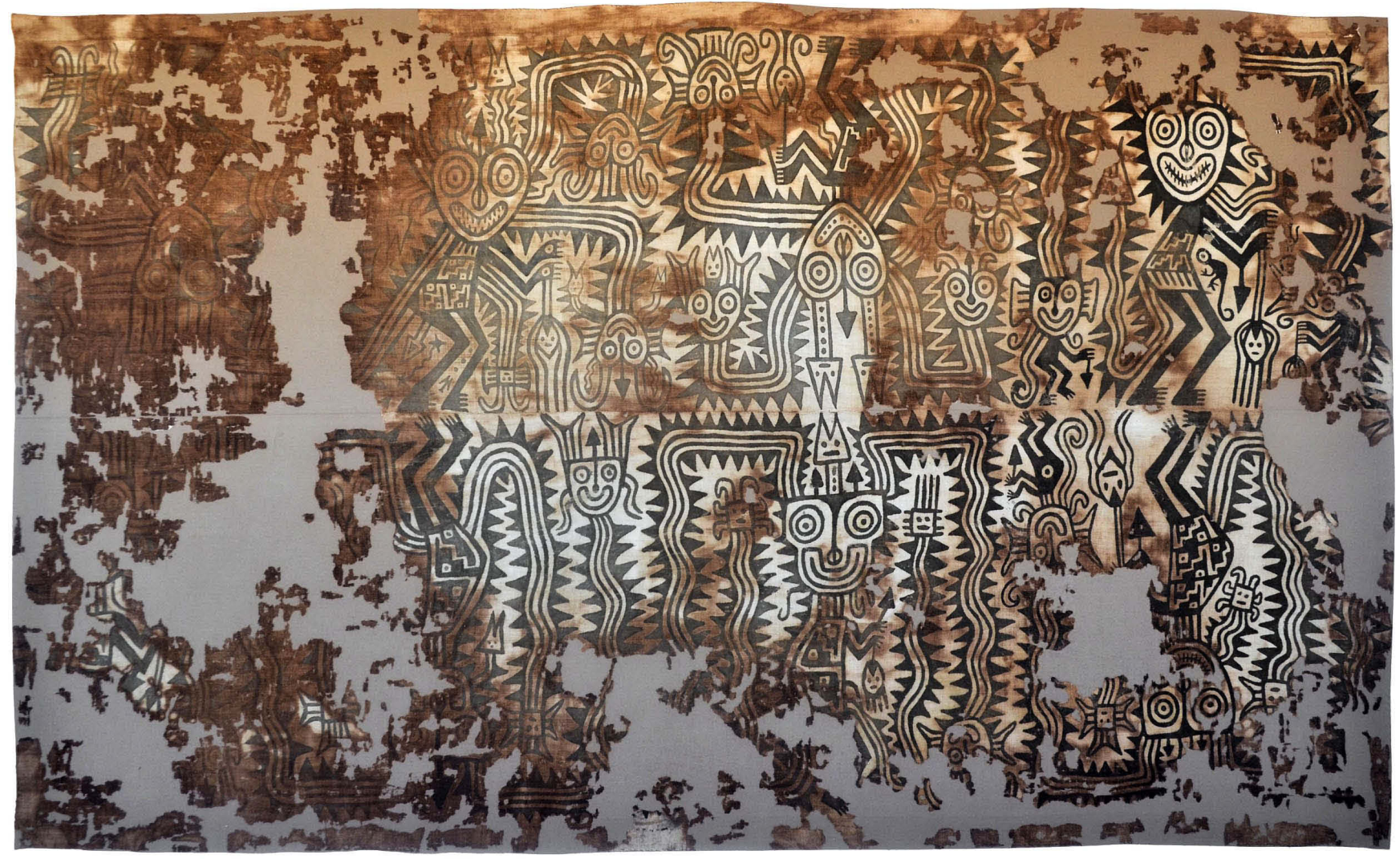

Figura 12: El manto pintado MSP-0043-02 [0.1316] (Fotografía: cortesía, Luis Alberto Peña Callirgos).

159-161). Aunque solamente 42 artefactos fueron identificados y ubicados entre las colecciones del MUNABA y del MSP-MRI, sabemos que el manto pintado MSP-0043-02 [0.1306] fue descubierto en los primeras capas de envoltorio del fardo, posiblemente en la capa 5 . Por su carácter excepcional, se trata del material más documentado ${ }^{17}$ de la tumba T.27 del cual sólo un detalle fue publicado por Engel (1991: 102, Fig. 71). De dimensiones $2.60 \mathrm{~m}$ de largo por 1.56 $m$ de ancho, el manto se compone de dos paños de tela llana en fibra de algodón beige unidos en su borde de urdimbre con puntada diagonal. La tela tiene 13 elementos de urdimbre por 10 elementos de trama en un centímetro cuadro y fue elaborada con hilos de estructura $\mathrm{S}(2 \mathrm{z})$ cuya torsión varía entre $40^{\circ}$ y $45^{\circ}$ y grosor entre 0.5 y $1 \mathrm{~mm}$. La puntada fue realizada con un hilo en fibra de algodón beige de estructura $\mathrm{S}(2 \mathrm{z}), 45^{\circ}$ de torsión y $1.5 \mathrm{~mm}$ de grosor. Pintado con pigmentos naturales de color negro, el manto está decorado con ocho personajes antropo-zoomorfos representados de pie con la cara de frente y el cuerpo de perfil que alternan en sus posiciones (Figura 12). Estos se diferencian por su vestimenta, sus atributos de poder (cabezas-trofeo y flechas) y el número de sus apéndices serpentiformes, extraños brotes que sirven para transformar a un humano en un ser sobrenatural (Makowski 2000, 2017; Lévy Contreras 2017). Por sus características iconográficas, en particular por su rostro cordiforme con ojos redondos y boca sonriente, los personajes se relacionan con la figura del "Ser Oculado” cuya representación se vincula con la cerámica del valle de Ocucaje entre el final del Horizonte Temprano y el inicio del Periodo Intermedio Temprano (Menzel, Rowe y Dawson 1964; Dywer y Dwyer 1975; Massey 1986; Bachir Bacha y Llanos 2012; Carmichael 2016). El estado de conservación de la pieza sufrió por el montaje que esta recibió para su exposición en el antiguo Museo de Paracas, lo cual fue confirmado por la comparación de los documentos fotográficos de Engel con el estado actual del material (Lévy Contreras y Román Aquino 2018).

\section{Las “muñecas” de la tumba T.27:}

Denominadas como "muñecas" y asociadas a los Fardos III (0.2766), IV (0.2765) y V (0.2767), tres estructuras elaboradas con fibra de totora y decoradas con telas bordadas

17. Existe más de 6o documentos fotográficos del manto pintado (Archivo de Engel, Lima [MUNABA] 14a-VI-3 Tumbas (B) f. 91: 87, 88, 90, 93, 96 y 162; Cuaderno $\mathrm{N}^{\circ}$ 1, Negativos: F.703, 704 y 717-730; Cuaderno $\mathrm{N}^{\circ}$ 5, Negativos: F.3571, 3751, 3892 y 3895; Cuaderno $\mathrm{N}^{\circ} 8$, Negativos: F.639o-6393; Caja Nº2, Tipología Tejidos: Ficha 0.1316; Caja Nº 1, Colección Básica Tejidos: Ficha 0.1316; Caja 14a-VI-3 T.27 Paracas, Análisis Textil Sitios: Ficha 0.1316; Caja Fotos Tejidos: 0.1316; Caja Fotos Tejidos Textiles: 0.1316; Caja Tejidos Colecciones de Slides: o.1316). 

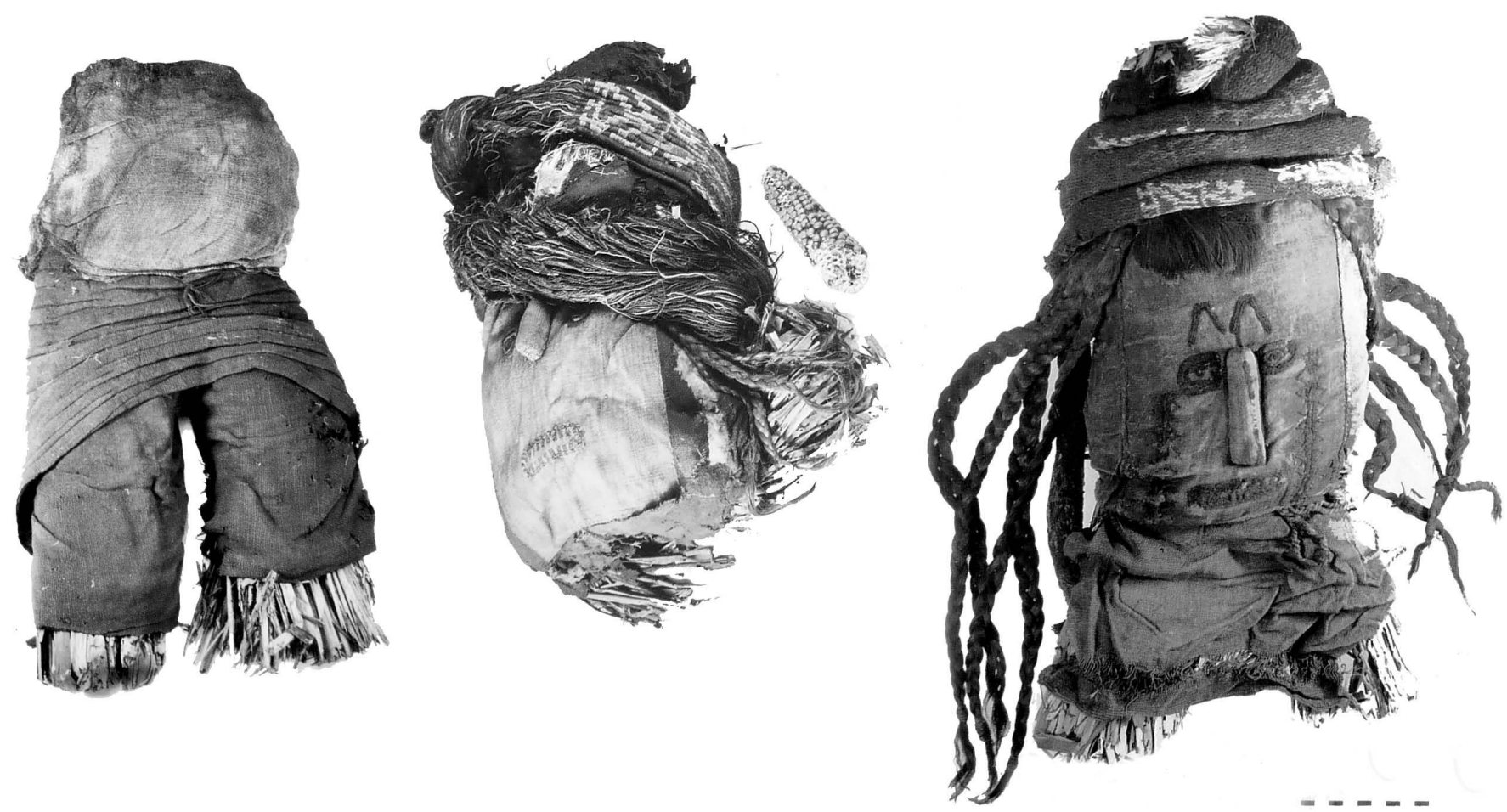

Figuras 13 A, B y C: Las "muñecas" 0.2766, 0.2765 y 0.2767 de la tumba T.27 de Cabezas Largas elaboradas con totora, tela bordada, cabello y decoradas con tocados (Archivo de Engel, Lima [MUNABA] Caja ${ }^{\circ}{ }^{\circ}$, Tipología Tejidos: Ficha o.2766; Análisis Textil Sitios: Ficha 0.2765; Caja $\mathrm{N}^{\circ}$ 5, Tipología Tejidos: Ficha 0.2767).

para simbolizar su rostro fueron colocadas como ofrendas al interior de cada fardo funerario (Archivo de Engel, Lima [MUNABA] 14a-VI-3 Tumbas (B) f. 91: 129, 137, 154, 156 y 157). Si bien se conservaron únicamente las fotografías originales de las piezas, puesto que una de ellas fue hurtada del antiguo Museo de Paracas y que las dos otras no fueron localizadas hasta la fecha, se puede observar sus detalles técnicos y decorativos para explicar la importancia de dichos materiales dentro del contexto estudiado. La "muñeca" 0.2766 , de $58 \mathrm{~cm}$ de alto, parece estar en proceso de elaboración (Figura 13 A). Su estructura de totora muestra una cabeza sin rostro y piernas largas arropadas con diferentes telas (Archivo de Engel, Lima [MUNABA] Caja $\mathrm{N}^{\circ} 5$, Tipología Tejidos: Ficha 0.2766; Caja $\mathrm{N}^{\circ}$, Colección Básica Tejidos: Ficha 0.2766; Caja 14a-VI-3 T.27 Paracas, Análisis Textil Sitios: Ficha 0.2766). La segunda "muñeca" 0.2765, de $20 \mathrm{~cm}$ de alto por $18 \mathrm{~cm}$ de ancho, representa una cabeza humana con trenzas de cabello llevando una banda anudada con flecos de urdimbre y cordones enrollados de forma tubular decorados con aves bicéfalas y plumas de color amarillo. Los elementos de su rostro, en particular sus ojos y su boca sonriente con dientes, fueron bordados con hilos en fibra de camélido sobre una tela llana en fibra de algodón (Archivo de Engel, Lima [MUNABA] Caja $\mathrm{N}^{\circ} 5$, Tipología Tejidos: Ficha 0.2765; Caja $\mathrm{N}^{\circ} 3$, Colección Básica Tejidos: Ficha 0.2765; Caja 14a-VI-3 T.27 Paracas, Análisis Textil Sitios: Ficha 0.2765 ). Su nariz, de forma tridimensional, pudo haber sido rellenada con fibra de algodón (Figura 13 B). Finalmente, la "muñeca" 0.2767 , de $45 \mathrm{~cm}$ de alto, es la más compleja de la muestra. Su estructura de totora, similar a la de la pieza 0.2766 , se conforma de una cabeza con dos piernas cortas. Estás últimas fueron recubiertas por una tela decorada con flecos a manera de prenda corta. Su cabeza, con cerquillo y trenzas de cabello, tiene como tocado un cordón anillado de forma tubular ${ }^{18}$ decorado con aves bicéfalas y plumas de color amarillo (Archivo de Engel, Lima [MUNABA] Caja ${ }^{\circ}$ 5, Tipología Tejidos: Ficha 0.2767; Caja $\mathrm{N}^{\circ} 3$, Colección Básica Tejidos: Ficha 0.2767). El rostro de la "muñeca" está figurado con diferentes elementos bordados con fibra de camélido crudo y teñido en diversos colores $^{19}$ : cejas de forma geométrica, ojos redondos con pupilas, dos bandas decoradas con bordes dentados a manera de

18. No se menciona el tipo de fibra utilizada en los cordones anillados de forma tubular, pero se supone, por la técnica empleada, que dichos elementos fueron confeccionados con fibra de camélido.

19. Los elementos de la pieza eran de color marrón, rojo y verde oscuro (Rubén García Soto, comunicación personal 2018). 
pinturas faciales o tatuajes y una boca sonriente con dientes. De forma tridimensional, su nariz está decorada además con una línea bordada (Figura 13 C). Debemos resaltar que la "muñeca" 0.2767 estaba originalmente atada con un cordón al cuerpo del individuo (Archivos de Engel, Lima [MUNABA] 14a-VI-3 Tumbas (B) f. 91: 156). De acuerdo con las descripciones de Bischof (Archivo de Engel, Lima [MUNABA] 14a-VI-3 Tumbas (B) f. 91: 137-138), el adulto relacionado con el Fardo V (Individuo B) puede ser de sexo femenino por su parafernalia ritual. El peinado de la "muñeca" podría respaldar este argumento. De esta manera, aunque las "muñecas" recuerden las falsas cabezas paracas del valle de Ocucaje (Dawson 1979), estos materiales podrían ser interpretados como réplicas o miniaturas de las personas enterradas dado que presentan los mismos peinados y/o elementos de tocado. Si bien este planteamiento sólo es factible para el Fardo V, ya que la "muñeca” del Fardo III está incompleta y que el Fardo IV no contiene cuerpo, no cabe duda que los peinados y los elementos de tocado que decoran sus cabezas son idénticos a los utilizados en la parafernalia ritual de los individuos de la tumba.

\section{Conclusiones}

Depositados como ofrendas rituales, los textiles paracas muestran patrones diacrónicos y diferencias en el estatus social de los individuos por su técnica de manufactura, su decoración y la distribución del tipo de prendas hallado en cada fardo funerario (Yacovleff y Muelle 1934; O’Neale 1942; Carrión Cachot 1949; King 1965; Tello y Mejía Xesspe 1979; Frame 1986; Paul 1990; Peters 1997). Por lo mencionado, los textiles fueron utilizados como soportes ideológicos para enfatizar relaciones de poder, el género y posiblemente la edad de los individuos (Peters 2000, 2011; Frame 2008; Peters y Tomasto-Cagigao 2017). Este argumento puede ser explicado por la construcción del fardo funerario que legitima el poder de varios grupos o linajes (Dwyer y Dwyer 1975). De esta manera, los textiles de la tumba T.27 de Cabezas Largas podrían indicar el alto estatus de los individuos, su parentesco y/o procedencia. La recurrencia de los tipos de vestimenta encontrados en cada fardo funerario, tanto como el acceso a diferentes materias primas y su preparación, muestran rituales mortuorios y elementos culturales comunes a la región.

Si bien faltan analizar aún algunos materiales descubiertos por Engel y su equipo en la tumba, los resultados preliminares obtenidos sobre los textiles del contexto ofrecen elementos inéditos para entender mejor la parafernalia ritual paracas en su fase tardía. En efecto, la mayoría de los artefactos presentan una iconografía cuyas características estilísticas difieren de las fases Ocucaje 9-10, salvo algunas excepciones como el manto pintado MSP-0043-02 [0.1316]. Es interesante notar que las figuras complejas relacionadas con la transición Paracas-Nasca, a saber la representación de seres antropo-zoomorfos que varían por su postura, sus atributos de poder y sus apéndices serpentiformes, generalmente figurados en las decoraciones bordadas de mantos importantes, son ausentes en la muestra estudiada.

Asimismo, varios textiles de la tumba T. 27 de Cabezas Largas no parecen tener equivalentes por su forma, técnica y/o tratamiento decorativo. Analizados en este ensayo (V.292 A-B, MSP-0093-16 [V.269], V.275-W.275 A, 0.2015, $0.2765,0.2766$ y 0.2767 ), estos materiales parecen ser propios del ajuar de la tumba reforzando la idea de que los individuos tuvieran lazos de parentesco y/o convivieran en la misma comunidad. A contrario, los otros textiles del contexto estudiado muestran técnicas, decoraciones y colores similares a los materiales "Cavernas" excavados por Tello y Mejía Xesppe en Wari Kayan, reforzando la idea de que dichos artefactos pudieran ser relacionados con una fase anterior (Ocucaje 8). Finalmente, sólo futuros aportes permitirán confirmar las hipótesis presentadas en esta investigación para resaltar los datos obtenidos por Engel y Bischof hace medio siglo en la región.

\section{Agradecimientos}

Quisiera agradecer al director del MUNABA, Julio César Alfaro Moreno, y los trabajadores de dicha institución, Paolo Zaragastúa López y Lucio Laura Aguirre, por su constante apoyo y ayuda durante esta investigación; Katherine Román Aquino sin la cual no hubiera empezando esta labor; Susana Arce Torres, directora del MRI, por haberme permitido revisar algunos materiales de la tumba en vista de la preparación de la segunda parte del proyecto; Ann $\mathrm{H}$. Peters por prestarme su microscopio digital portátil y ayudarme en la identificación de las estructuras textiles más complejas; Luis Alberto Peña Callirgos por su fotografía del manto pintado conservado en 2016; Rubén García Soto por las informaciones brindadas acerca de las colecciones del antiguo Museo de Paracas; y José Ochatoma Cabrera por editar las imágenes de la presente publicación.

\section{Referencias citadas}

Archivo Tello

2009 Paracas Cavernas. Cuaderno del Archivo Tello 7. Museo de Arqueología y Antropología, Universidad Nacional Mayor de San Marcos, Lima.

2012 Paracas Wari Kayan. Cuaderno del Archivo Tello 9. Museo de Arqueología y Antropología, Universidad Nacional Mayor de San Marcos, Lima. 
Bachir Bacha, Aïcha y Oscar Daniel Llanos Jacinto

2012 Arqueología e iconografía de los textiles Paracas descubiertos en Ánimas Altas, Ica, Perú. En Actas de las $V$ Jornadas Internacionales sobre Textiles Precolombinos, 29 noviembre - 1 diciembre 2010, pp. 211-230, Universidad Autónoma de Barcelona, Barcelona.

Burger, Richard L.

1988 Unity and Heterogeneity within the Chavín Horizon. En Peruvian Prehistory: An Overview of Pre-Inca and Inca Society, editado por Richard W. Keatinge, pp. 99144, Cambridge University Press, Cambridge.

Carmichael, Patrick H.

2016 Nasca Origins and Paracas Progenitors. Nawpa Pacha: Journal of Andean Archaeology 36(2): 53-94.

Carrión Cachot, Rebeca

1949 Paracas Cultural Elements. Corporación Nacional de Turismo, Lima.

Dawson, Lawrence E.

1979 Painted Cloth Mummy Masks of Ica. En The Junius B. Bird Pre-Columbian Textile Conference, May $19^{\text {th }}$ and $20^{\text {th }}$, 1973, editado por Ann P. Rowe, Elizabeth P. Benson and Anne-Louise Schaffer, pp. 83-104, The Textile Museum and Dumbarton Oaks Research Library and Collections, Trustees for Harvard University, Washington, DC.

Dwyer, Edward y Jane P. Dwyer

1975 Mortuary Patterns in a Peruvian South Coastal Tradition. En Death and Afterlife in Pre-Columbian America: A Conference at Dumbarton Oaks, October $27^{\text {th }}, 1973$, editado por Elizabeth P. Benson, pp. 145-161, Dumbarton Oaks Research Library and Collections, Washington, D.C.

Engel, Frédéric

1966 Paracas: cien siglos de cultura peruana. Editorial Juan Mejía Baca, Lima.

1991 Un desierto en tiempos prehispánicos: Río Pisco, Paracas, Río Ica. Centro de Investigaciones de Zonas Áridas, Lima.

Frame, Mary

1986 The Visual Images of Fabric Structures in Ancient Peruvian Art. En The Junius B. Bird Conference on Andean Textiles, April $7^{\text {th }}$ and $8^{\text {th }}$, 1994, editado por Ann P. Rowe, pp. 47-8o, The Textile Museum, Washington, DC.

2008 Representaciones de género, jerarquía y otras relaciones en los bordados Paracas Necrópolis. Arqueología y Sociedad 19: 241-264.

King, Mary E.

1965 Textiles and Basketry of the Paracas Period, Ica Valley, Peru. PhD dissertation, Department of Anthropology, University of Arizona. University Microfilms, Tucson.
Lévy Contreras, Jessica

2017 Los apéndices serpentiformes en la iconografía Nasca: repertorio y significado. Tesis de Maestría, Arqueología, Programa de Estudios Andinos, Pontificia Universidad Católica del Perú, Lima.

Lévy Contreras, Jessica y Katherine Román Aquino

2018 El manto pintado Paracas: el legado olvidado de Engel a la arqueología peruana. En Ponencias desarrolladas del I Coloquio de Arqueología del Museo Julio C. Tello de Paracas, 13 y 14 de abril 2018, editado por Katherine Román Aquino, pp. 38-54, Repositorio digital del Ministerio de Cultura del Perú. http://repositorio.cultura.gob.pe/handle/ CULTURA/652

Makowski, Krzysztof

2000 Los seres sobrenaturales en la iconografía Paracas y Nasca. En Los dioses del antiguo Perú, editado por Krzysztof Makowski, Vol, 1, pp. 277-311, Banco de Crédito del Perú, Lima.

2017 Lo real y lo sobrenatural en las iconografías Paracas y Nasca. En Nasca, editado por Cecilia Prado y Peter Fux, pp. 144-153, Museo de Arte de Lima, Lima, Rietberg Museum, Zurich.

Massey, Sarah A.

1986 Sociopolitical Change in the Upper Ica Valley, BC 400 to 400 AD: Regional States on the South Coast of Peru. PhD Dissertation, Department of Archaeology, University of California, Los Angeles.

Menzel, Dorothy, John H. Rowe y Lawrence E. Dawson 1964 The Paracas Pottery of Ica: a Study in Style and Time, University of California Press in American Archaeology and Ethnology, vol. 50, Berkeley, Los Angeles.

Museo Nacional de Antropología, Arqueología e Historia del Perú (MNAAHP)

2013 Paracas. Ministerio de Cultura del Perú, Lima.

O’Neale, Lila M.

1942 Textile Periods in Ancient Peru: II Cavernas and the Grand Necropolis. University of California Publications in American Archaeology and Ethnology 39(2): 143-202.

Paul, Anne

1990 Paracas Ritual Attire: Symbols of Authority in Ancient Peru. University of Oklahoma Press, Norman, London.

Peters, Ann H.

1997 Paracas, Topara and Early Nasca: Ethnicity and Society on the South Central Andean Coast. PhD Dissertation, Department of Anthropology, Cornell University, Ithaca.

2000 Funerary Regalia and Institutions of Leadership in Paracas and Topará. Chungara: Revista de Antropología Chilena 32(2): 245-252. 
2011 Diversidad en el componente textil y modelos de las relaciones sociales: un ejemplo de Paracas Necrópolis. En Actas de las V Jornadas Internacionales sobre Textiles Precolombinos, 29 noviembre - 1 diciembre 2010, pp. 231-256, Universidad Autónoma de Barcelona, Barcelona.

Peters, Ann H. y Elsa Tomasto-Cagigao

2017 Masculities and Feminities: Forms and Expressions of Power in the Paracas Necropolis. En Dressing the Part: Power, Dress, Gender and Representation in the Pre-Columbian Americas, editado por Sarah E. Scher and Billie J. Follensbee, pp. 371-449, University Press of Florida, Gainesville.

Ravines, Roger

1982 Panorama de la arqueología andina. Instituto de Estudios Peruanos, Lima.

Splitstoser, Jeffrey C.

2012 The Parenthetical Notation Method for Recording Yarn Structures. Proceedings of the $13^{\text {th }}$ Biennial Symposium of the Textile Society of America, September 19-22, Paper 745, Washington, D.C. http://digitalcommons.unl.edu/tsaconf/745
Tello, Julio C.

1929 Los descubrimientos del Museo de Arqueología Peruana en la Península de Paracas. Atti del XXII Congresso Internazionale degli Americanisti, Vol. 1: 679-69o, Roma.

1959 Paracas: primera parte. Empresa Gráfica T. Scheuch S.A., Lima.

Tello, Julio C. y Toribio Mejía Xesspe

1979 Paracas: segunda parte: Cavernas y Necrópolis. Universidad Nacional Mayor de San Marcos, Institute of Andean Research of New York, Lima.

Velarde, Leonid

2002-2003 Frederic Engel y la arqueología de la costa sur del Perú. Bulletin de la Société Suisse des Américanistes / Schweizerische AmerikanistenGesellschaft, No. 66-67: 95-98.

Yacovleff, Eugenio y Jorge C. Muelle

1934 Un fardo funerario de Paracas. Revista del Museo Nacional 3(1-2): 63-153.1. 


\title{
Two-headed serpents and rayed heads: Precedents and reinterpretations in Paracas Necropolis imagery
}

\author{
Ann H. Peters \\ Independent Researcher \\ Consulting scholar, American Section, Penn Museum, University of Pennsylvania
}

\begin{abstract}
The Necropolis of Wari Kayan and other tombs of the Paracas Necropolis mortuary tradition present an astonishing diversity of textile styles, and an even greater diversity of imagery. More than 100 different motifs can be distinguished and tracked among the documented mortuary contexts. While is it not likely that our sample of 45 mummy bundles includes all important variants of any particular motif, in many cases it is possible to propose a sequence of reinterpretations of a key icon.

By documenting the known assemblage of images and artifacts we can perceive what icons and styles are predominant, recurrent or unusual. The images have been created with variable techniques, representational conventions, details present and color schemes, on an array of garment types and other artifacts with distinctions in their production and finishes. An icon often presents ambiguous or hybrid references to animal and plant species, types of artifacts and categories of persons, which can be explored by examining variations in its form. Comparing the patterns of combination of elements can permit evaluation of relationships among icons, as well as shifts in their significance over time. By tracing their sequence among the mortuary contexts, it will be possible to propose social connections among the deceased, ritual officiants and producer communities.

As an example, we consider here the incidence and interaction of two icons with Paracas Tradition antecedents: the twoheaded serpent and the rayed head.
\end{abstract}

Keywords: Paracas Necropolis, Wari Kayan, embroidery, iconography, style analysis

\section{Resumen}

La Necrópolis de Wari Kayan y otras tumbas de la tradición mortuoria Paracas Necrópolis presentan una tremenda diversidad de estilos textiles, y una diversidad aún mayor de iconografía. Más de 100 motivos diferentes se distinguen y se trazan entre los contextos documentados. Es poco probable que nuestra muestra de 45 fardos mortuorios incluya todas las variantes importantes de un motivo particular, pero en muchos casos es posible proponer una secuencia de reinterpretaciones de un ícono clave.

$\mathrm{Al}$ documentar el conjunto conocido de las imágenes y sus artefactos se perciban cuales íconos y estilos son predominantes, recurrentes o escasos. Las imágenes han sido creadas con diversas técnicas, convenciones representativas, detalles presentes y esquemas de color, en distintos tipos de vestimenta y otros artefactos con prácticas productivas y acabados variables. Un ícono suele presentar referencias ambiguas o híbridas a especies de animales y plantas, tipos de artefactos y categorías de personas, las que se exploran al examinar variaciones en su forma. Comparar los patrones en la combinación de elementos permite evaluar la relación entre íconos y cambios en su significado a través de tiempo. Al trazar su secuencia entre los contextos mortuorios, se podrá proponer conexiones sociales entre los fallecidos, los que oficiaban en los ritos y las comunidades de producción.

Como ejemplo, aquí se considera la incidencia y la interacción de dos íconos con antecedentes en la Tradición Paracas: la serpiente bicéfala y la cabeza radiada.

Palabras clave: Paracas Necrópolis, Wari Kayan, bordados, iconografía, análisis de estilo

DOI: $10.32873 /$ unl.dc.zea.1203

Published in PreColumbian Textile Conference VIII / Jornadas de Textiles PreColombinos VIII, ed. Lena Bjerregaard and Ann Peters

(Lincoln, NE: Zea Books, 2020). https://digitalcommons.unl.edu/zeabook/ 


\section{Résumé}

La Nécropole de Wari Kayan et d'autres tombes de la tradition mortuaire Paracas Necropolis présentent une incroyable diversité de styles textiles, et une diversité iconographique encore plus vaste. Plus de 100 motifs différents ont été distingués et répertoriés parmi les contextes documentés. Il est peu probable que notre corpus de 45 paquets funéraires inclut la totalité des variantes les plus importantes d'un motif particulier, mais dans la plupart des cas il est possible de proposer une séquence des réinterprétations d'une icône clé.

Les icônes et les styles prédominants, récurrents ou rares ont pu être mis en avant. Les images ont été créées selon diverses techniques, conventions représentatives, détails et schémas en couleur, dans divers types de vêtements et autres artefacts aux pratiques productives et finitions variées. Une icône fait habituellement référence de façon ambiguë ou hybride à des espèces animales et végétales, à des types d'artefacts et des catégories de personnes, qui sont explorés en analysant les variations de leurs formes. Comparer les modèles dans la combinaison des éléments permet d'évaluer la relation entre les icônes et leurs changements de sens à travers le temps. En traçant leur séquence entre les contextes mortuaires, nous pouvons proposer les connexions sociales entre les défunts, ceux qui célébraient les rites et les communautés de production.

Par exemple, nous considérons ici l'incidence et l'interaction de deux icônes avec des antécédents dans la Tradition Paracas : le serpent bicéphale et la tête rayonnante.

Mots-clés: Paracas Necropolis, Wari Kayan, broderies, iconographie, analyse textile

\section{Theory and method}

Studies of imagery in both the history of art and archaeology generally part from the compilation of all known variants of a hypothetical motif (pre-iconographic analysis) and then describe the consistencies that form the basis of an argument that these variants constitute an icon linked to a conventional meaning (iconography). An authoritative conventional meaning may be ascribed in the cases where texts from the period refer to such motifs (Panofsky, 1960). However, such significance is always indeterminate, because at the time it was created, and subsequently, it was associated by individual viewers and interpretive communities with different sets of concepts and connotations (iconology). Therefore, the study of 'Pre-Columbian' imagery without textual references is not unlike the study of textually documented images: both can only access a tiny percentage of the meanings attached to an object.

In the case of traditions of material culture not linked to translated, deciphered or legible texts, a group of motifs with formal consistencies can be hypothesized as an icon. Aspects of the field of reference of an icon can be hypothesized based on their visual resemblance to persons, animals, plants, artifacts, objects etc. that arguably formed part of the observable universe of the persons who created and interpreted this imagery (Peters, 1991). Conventional meanings cannot be accessed, nor can the full range of concepts and connotations associated with each motif or icon for a particular observer, but it is possible to posit thematic spheres of reference by examining consistent or recurrent features of an interrelated group of images, such as species and gender references, body positions and associated artifacts (Proulx,
1989). Such observations underlie assertions made by archaeologists, for example that we are looking at a maritime theme, warrior imagery, or scenes describing a particular ritual, although the strengths and limitations of the background analysis are not always specified.

The assertion of any relationship between iconography and a social group should be grounded in practice theory and semiotic analysis (Roberts, 2011). Iconography is a form of conventional communication, in semiotic terms symbolic and representational - aspects of its form motivated by resemblance to its linguistic and conceptual referent. However, motifs very similar in form may express quite different meanings in different places, times and contexts. An image also carries indexical meaning, linked to its production process and the social and ritual contexts in which it has been created, discussed, manipulated and displayed (Gell, 1998). None of these types of meaning, perceived by the original makers and users, are accessible to a modern observer. Imagery is also imbued with the particular style of its makers. Like other aspects of artifact style - materials, technical practices, proportions, design principles and color schemes - image style reflects the practices, skills and concepts of an artist, workshop and production community. The iconographic analysis discussed here examines groups of motifs that demonstrate similarities in image style, as well as groups of motifs with formal dissimilarities that nonetheless are proposed to represent a common icon.

Here I propose a particular approach to the analysis of iconography based on uniting a corpus of all imagery associated by research to date with a particular archaeological site produced by specialized ritual practices, in this case the Paracas Necropolis mortuary tradition (Tello and Mejía, 
1979; Peters, 2016a, 2019). Rather than trying to track a hypothetical group of related motifs among many contemporary sites, or through time, I have created a data set of all recorded motifs depicted in all artifact types recovered in mortuary contexts from a single site. These come from the Necrópolis of Wari Kayan and other burials at the Paracas site characterized by similar mortuary practices and artifact assemblages, dated between 350 BCE and 250 CE (Paul, 1991; León, 2007).

This period can be characterized as the Paracas-Nasca transition, during which communities linked to the Paracas, Topará and Nasca artifact traditions interacted and were transformed. While this process postdates the Early Horizon, I refer here to Berkeley School phases 9 and 10 (Menzel et al. 1964) as well as phases 1, 2 and 3 of the Nasca sequence. While these style-based phases appear to overlap in time (Carmichael, 2016; Peters and Tomasto, 2018), they are still temporally significant and provide an excellent basis for style comparisons. Based on arguments for a sequence of embroidery styles (Dwyer, 1979; Paul, 1982; 1990; Rowe, 2015) and their interrelationships (Paul, 1986), as well as the social and temporal distribution of emblematic color schemes (Peters, 2016b), garment forms (Peters, 2017a, $2018 \mathrm{~b}$ ) and other types of artifacts (Peters and Tomasto, 2017), we can trace the associations between particular motifs and gendered tomb assemblages, artifact styles, and the Paracas Necropolis timeline. In some cases, I propose a sequence for the reinterpretations of a particular icon.

In analysis of late Paracas, Topará and early Nasca imagery, I find it useful to employ the concept of representational conventions applied to related imagery by Makowski (2000, and elsewhere). I also adopt Makowski's 'hybridity', the term he employs for the combination of referents to multiple types of beings and objects in a single image. This Paracas and Nasca convention appears to express the concept of mythological being or person endowed with supernatural power. Building on a previous exploration of this topic (Peters, 1991), I discuss features that appear to be emblematic of particular types of persons, animals, plants and artifacts and the ways they are combined, linked or juxtaposed in an image. A complex image includes one or several figures that each may be a variant of a motif present in other images, and a figure may have features that appear as motifs in other images. Makowski, Lévy (2017) and I have used the term 'appendage' to describe the convention of a serpentine band that emits from a figure and links to another figure, or ends in a head. These appendages may appear in the place of a tongue, tail, garment tie or headband - a form of hybridity termed "kenning" by Rowe (1967) in an analogy to Norse linguistic conventions.
More than 99 percent of the imagery in the Paracas Necropolis assemblage is on textiles, although incised, burnished, modelled and painted ceramics, carved wood, bone and ivory, pyro-engraved canes, and painted leather contribute to the sample. The most prevalent representational technique is embroidery (back stitch, running stitch, weft wrapping, needle weaving, binding and crossed looping) on a balanced to somewhat warp-predominant plain weave. Other textile techniques include close simple looping and knotting, complex flat braiding and oblique twining, plain weave with supplementary warp patterning, discontinuous weft patterning (tapestry), plain weave with discontinuous (scaffolded) warps and wefts, openwork 'gauze weave' with crossed warps and/or weft slits, weft twining and warp linking in sprang technique (O’Neale, 1942). Dye resist by wrapping (planghi) and painting with mineral and vegetal pigments on a textile surface are unusual, but occur in several mortuary contexts.

In the full Paracas Necropolis assemblage I distinguish more than 100 different motif categories, far too many to present here. To demonstrate the complexity and advantages of including all documented imagery in a single analytic process, I focus on two recurrent motifs: a frontal face surrounded by recurved rays (Rayed Head, Cabeza Radiada), and a serpentine figure, often depicted with a head at each end (Two-Headed Serpent, Serpiente Bicéfala). Each of these motifs occur alone and as an element in complex figures. Both are combined in a single recurrent icon. Each may reference elements of regalia worn by deceased individuals or placed on the mortuary bundles built around them. Both appear to be referenced in depictions of clothing and regalia, faunal imagery and mythic imagery.

This essay seeks to define relationships between each motif and the styles in which it is represented. As I group motifs to define recurrent icons, I note changes in representational conventions that may be linked to differences among producers and over time, and changes in the manner and degree that multiple motifs are linked within a single image. A well-defined icon or a less consistent group of related motifs can be traced from one mortuary context to another, evidence that certain images may be precedents for, or influenced by, others. These arguments are based on a model of mortuary practice in which ritual specialists and the families and allies of a deceased person gather for events in which artifacts are offered, displayed, rearranged and added to the mortuary bundle and tomb (Peters, 2019). Close observation of objects worn and carried by participants, living and dead, could become an inspiration for the design of a next generation of artifacts. 


\section{The Rayed Head and the Two-Headed Serpent}

The Rayed head is an icon prominent in imagery of the late Paracas tradition, appearing in the Animas Altas modelled clay frieze (Massey, 1991; Bachir Bacha, 2017) and on triplecloth bands sewn as borders on mantles and tunics in Ocucaje phase 9 (Peters, 2018). Rayed heads are imaged as two-headed serpents crossing the face and extending to form the margin of several Chongos ceramic masks and Ocucaje 9 painted mummy bundle 'false head' panels (Dawson 1979). Large-scale rayed head images are depicted on looped tunics from Ocucaje (Peters 2018a). Rayed heads depicted in crossed-warp gauze weave and double-cloth from both the lower Ica Valley and the Cerro Colorado sector of the Paracas site resemble those in our sample below. Rayed heads carved on the ivory handles of wood or bone spear throwers from early Wari Kayan and other Paracas sectors have an oval face with punctate eyes and mouth, surrounded by short, straight rays.

The curved rays differ in their orientation in later textiles, such as the warp-wrapped central panel of the Brooklyn Museum's "Paracas Textile", a headcloth in an early Nasca style allegedly excavated in the "Cabezas Largas" cemetery of the Paracas site, and the embroidered central panel of an early Nasca style mantle (Peters 2018a).

\section{The Rayed Head (alone): (Figure 1)}

A frontal face with large ring-like eyes and smiling mouth, surrounded by curved rays arranged in pairs with bilateral symmetry on both axes.

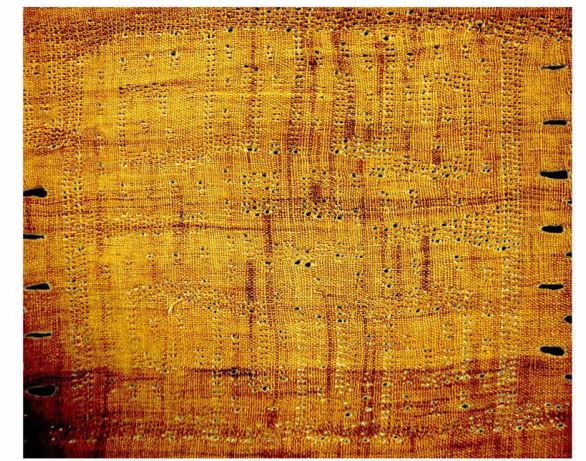

a
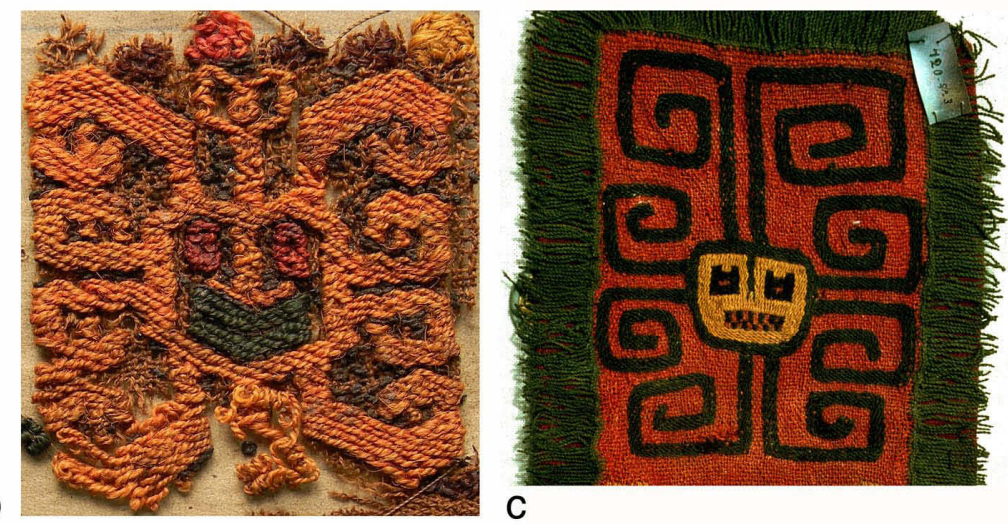

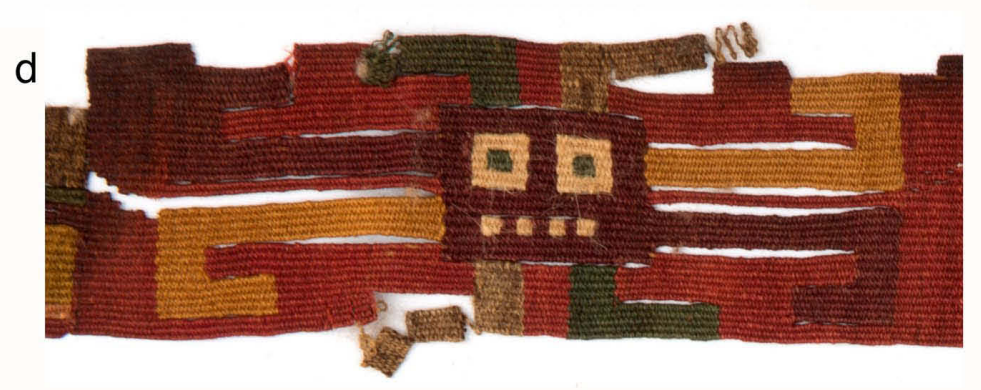

Figure 1. a. Wari Kayan 114 sp. 17, open-sided tunic (casulla, tabard), AMNH 41.2/8753, photo AHP; b. Wari Kayan 352 sp. 115, probable headcloth, MRI DB 7, photo AHP; c. Wari Kayan 420 sp. 3, unkuña, open tunic with tab (Tunic 5 variant), MNAAHP RT 2999, photo AP; d. Wari Kayan 89 sp. 7, llautu, tapestry headband, MNAAHP RT 183, photo M. Jhong/MNAAHP.

Distribution:

\begin{tabular}{llllll} 
Paracas sector & Context & Sp. & Object type & Form $^{1}$ & Technique \\
\hline (1) Wari Kayan & 114 & 17 & tunic, open-sided, 1 panel & atypical at WK & Embroidery \\
(2) Wari Kayan & 352 & 115 & probable ñañaka, headcloth & fragmentary & Embroidery \\
(3) Wari Kayan & 420 & 3 & unkuña, tunic, dorsal tab & Tunic 5 & Embroidery \\
(4) Wari Kayan & 89 & 7 & llautu headband, tapestry & multifigure & Slit tapestry
\end{tabular}

1. This column is used for garment form classification or other explanatory remarks. 
Media: Textile², plain weave cotton with (1) warp-crossed gauze weave and sets of short discontinuous-weft slits, (2) camelid embroidery, back-stitch in the Broad Line mode, (3) camelid embroidery, back-stitch in a style combining Linear and early Block Color conventions, with plied camelid hair fringe; (4) camelid hair, slit tapestry band.

Color: (1) yellow-beige cotton; (2) red, yellow, green and dark purple-blue outlined figures, no background embroidery; (3) dark blue, green, yellow-gold figures on bright red background, medium green fringe; (4) red background, figures in red-purple, cream-white, yellow-gold, medium green and natural gray.

Commentary: A highly consistent group of motifs defining a recurrent icon, while diverse in production techniques and image style. The gauze-weave tunic (1) is a Paracas Tradition textile, in excellent condition but doubtless a 'trade piece' and 'heritage piece', a product of gift exchange or obtained by less amicable means from the neighbors, folded and placed atop the second outermost layer of this early $10 B$ bundle. Found among fragmentary objects at the disturbed core of this early $10 \mathrm{~B}$ bundle, this possible headcloth (2) has somewhat dissimilar (S(2z)) warp and weft yarns which, like the Broad Line embroidery style, suggests late Paracas Tradition producers. The small tabbed 'unkuña' (3) from atop bundle WK 420 is a garment form recurrent during the Paracas-Nasca transition, also characterized by very early Block Color embroidery. However, it has unusual layout, imagery and production techniques: its fully embroidered surface is covered with diverse 'standing' figures with long serpentine appendages, sharing the same vertical alignment, and it has a directly attached fringe in a contrasting color. Tapestry headdress bands (4) are unusual in the Paracas Necropolis assemblage, with five documented to date, and all three multi-figure bands each include a rayed head, a figure with a rayed head, or a double-headed serpent.

In short, all four textiles appear to come from outside the core textile-producing communities associated with the Paracas Necropolis mortuary tradition, hypothetically from the lower Ica valley or Nasca drainage.

\section{Interlinked bands with rayed heads and felines: (Figure 2)}

A highly consistent group of motifs define an icon that is always represented in Linear mode embroidery and has been termed the 'twisted strands' (Frame 1986). Bands designed in rotational symmetry have an intermediate section with zigzag margins angled to form an $\mathrm{S}$ or $\mathrm{Z}$ motif and identical ends that lock together in the form of a fret. They may end in a tiny fringe or set of 'fingers', similar to the llautu
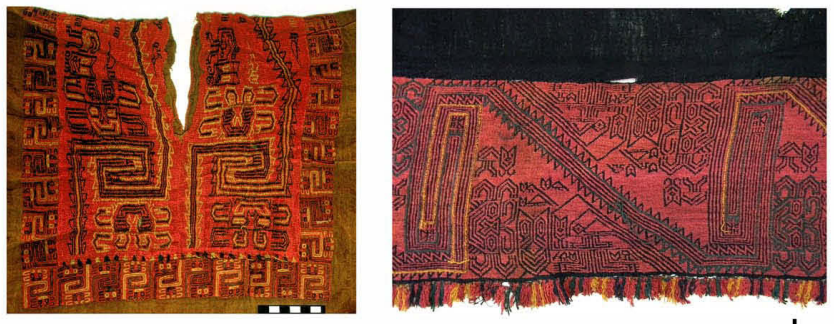

a b

C
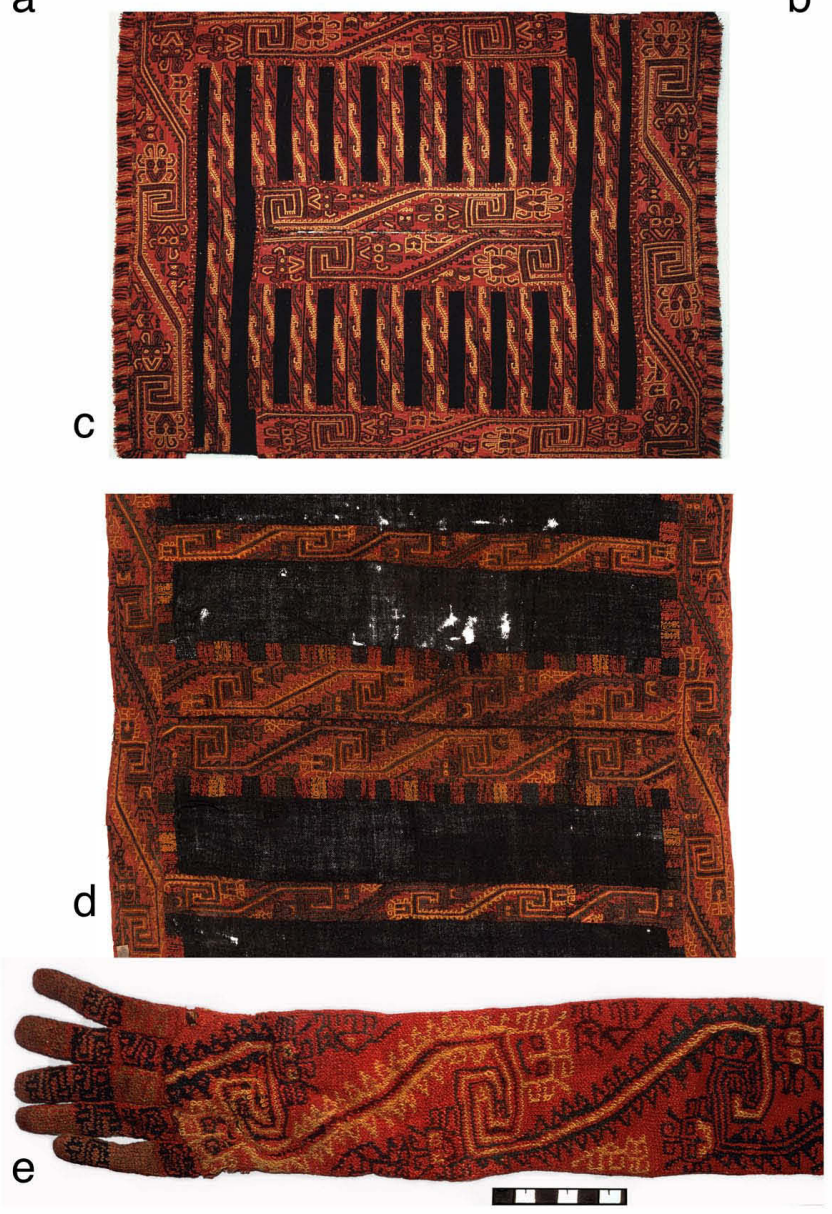

Figure 2. a. Wari Kayan 49 sp. 39 unku (Tunic 2), MNAAHP RT 1215, photo AP; b. Wari Kayan 26 sp. 6, Mantle 1, incomplete, MNAAHP RT 27151, photo AHP; c. Wari Kayan 421 sp. 44 unkuña tunic (Tunic 5), MNAAHP RT 205, photo AP; d. Wari Kayan 28 sp. 21, woman's mantle (Mantle 5), MNAAHP RT 3070, photo M. Jhong/MNAAHP; e. Wari Kayan 12 (382) sp. 12, llautu, looped headband, MNAAHP RT 1265, photo AP.

headband in this group. A rayed head motif in matching color is attached to the fret at each end. Adjacent to the top of each head is a feline figure in horizontal position (head perpendicular to body), its tail parallel to the band. Other

2. The numbers here refer to objects listed in the table above. 
Distribution:

\begin{tabular}{llllll} 
Paracas sector & Context $^{3}$ & Sp. & Object type & Form & Technique \\
\hline (1) Wari Kayan & 49 & 27 & open-sided fringed tunic with woven borders & Tunic 2 & Supplementary warps, Embroidery \\
(2) Wari Kayan & 49 & 39 & open-sided fringed tunic with woven borders & Tunic 2 & Supplementary warps, Embroidery \\
(3) Wari Kayan & 49 & 4 & large mantle & Mantle 1 & Embroidery \\
(4) Wari Kayan & 28 & 21 & woman's small mantle & Mantle 5 & Embroidery \\
(5) Wari Kayan & $28 ?(421)$ & 4 & woman's small mantle & Mantle 5 & Embroidery \\
(6) Wari Kayan & 1 & 4 & woman's small mantle & Mantle 5 & Embroidery \\
(7) Wari Kayan & 401 & s/n & llautu, looped headband & tubular & Looping \\
(8) Wari Kayan & $12(382)$ & 12 & llautu, looped headband & tubular & Looping \\
(9) Wari Kayan & $12(382)$ & 40 & man's skirt & Skirt 2 & Embroidery \\
(10) Wari Kayan & 421 & 49 & man's skirt & Skirt 2 & Embroidery \\
(11) Wari Kayan & 421 & 44 & unkuña open tunic & Tunic 5 & Embroidery \\
(12) Wari Kayan & 421 & 4 & Mantle & Mantle 1 & Embroidery \\
(13) Wari Kayan & 26 & 6 & mantle, unfinished & Mantle 1 & Embroidery \\
(14) Wari Kayan & $292(190)$ & 27 & unkuña, open tunic & Tunic 5 & Embroidery \\
(15) Wari Kayan & $292(190)$ & {$[6$ ?] } & mantle, unfinished & Mantle 1 & Embroidery \\
(16) Wari Kayan & 352 & 95 & mantle? & fragment & Embroidery
\end{tabular}

smaller feline figures may be present. Tiny figures that line the inner margins of embroidered borders are usually present, and may take the form of a small version of the fret and rayed heads, facing pairs of rayed heads or double-headed serpents.

Media: Textile, plain weave natural ochre cotton or dark blue dyed camelid hair with back-stitch and whipping-stitch used to create Linear mode imagery. On two tunics the imagery is worked on a separately woven band with supplementary warps in the three figure colors substituting in the plain weave, running along the back of the band where not engaged.

Color: (1) dark blue cloth, red woven background and embroidered outlines, figures in yellow-gold, dark blue and green, dark blue woven basal fringe, polychrome plied shoulder fringe; $(2,3)$ golden-brown (ochre) cotton cloth, red embroidered and woven background and outlines, figures in yellow-gold, dark blue and green; (9) ochre cotton cloth and yarn fringe, red embroidered background and outlines, figures in yellow-gold, dark blue and green, triangles in all embroidery colors along the inner border margin; (4, $5,6,10,11,12,13,14,15)$ dark blue cloth, red embroidered background and outlines, figures in yellow-gold, dark blue and green, and except for the women's mantles, polychrome plied yarn fringe; $(7,8)$ looped with red background, figures in yellow-gold, dark blue and green.

Commentary: The recurrence of a single icon in garments sets or individual mantles placed in a large number of mortuary bundles is characteristic of Linear mode design, particularly among garments with the bright red background predominant in the Topara-associated Wari Kayan assemblage. There are Paracas tradition precedents for the double-headed serpent group, including close-knotted llautu headdress bands and a yellow and brown doublecloth mantle from Ocucaje (King 1965). However, this particular icon recurs in the Wari Kayan tombs: certain male contexts that span the Paracas-Nasca transition and some men's and women's contexts of phase 1 . The mantle and tunic from WK 292 (190) have only the red background embroidery, a characteristic of several Linear mode embroideries in this tomb. Note that one woman's mantle (5) has lost its original contextual data. The presence of a fragment among materials in the disturbed base of phase 10 context WK 352 is interesting, though it very likely intruded from the bundle exterior (Peters and Tomasto 2017). Many other phase 10 and transitional bundles that include Linear Mode textiles do not include any object with this icon, so its prominent presence in certain bundles indicates a relationship in their social identity or ritual role.

The women's mantles and the large mantle in WK 421 have the border imagery depicted on a reduced scale in paired bands that cross the central cloth panel(s), perpendicular to the main lateral borders. The unkuña tunic in WK 421 has narrower paired transverse bands depicting a simplified double-headed serpent icon with an interlocking limb and a pair of hooked rays from the top of the head, and tiny figures with curved rays line the inner border margin. Images created using structural media and on narrower

3. Where mortuary contexts have two numbers, it is because the textile bundle was opened under a different number (in parentheses) than that assigned to the whole context during excavation. Restoration of the original tomb designation is important both for mapping style and time across the cemetery and to reunite data on the human remains, textiles, other objects placed within the bundle and objects placed adjacent during its final burial. 
embroidered borders and transverse bands demonstrate the basic components of the icon. The large mantles add more felines and other figures in the background areas and a tiny two-headed bird at the end of each band.

Tiny figures that line the inner margins of embroidered borders are usually present, and may take the form of a small version of the fret and rayed heads $(1,2,3)$ or facing pairs of rayed heads (11). Reduced scale representations take the form of a double-headed serpent in $\mathrm{S}$ or $\mathrm{Z}$ position on the inner border margins of the women's mantles $(4,5,6)$ and the fingers of the looped llautus $(7,8)$, but as an angled double-headed serpent on the transverse bands of the unkuña tunic (11). The two mantles that lack inner borders (13, 15) have near-identical imagery and share other elements of technique and image style. The various types of reducedscale motifs seem to be indicators of style groups with social significance, and are related to other icons discussed below.

\section{Figure wearing a large headdress with recurved 'rays' or textile bands: (Figure 3)}

Standing 'warrior-ritual' figure (Peters 2000) with human head-body orientation. Arms are extended and from one hand hangs a cord ending in a small object. The early version (1) has a trapezoidal headdress flanked by two large down-curving loops, and on one side a third larger loop resembling later headcloths. Small cords from the sides of the head end in fringe. The later versions (2-3) lack the long loop and instead have three more curved loops from each side of the headdress and a diadem, fringed bands set with metal plaques at each side of the face and two serpents matching in color, one larger and curved, hang below the upper arms. The later figures wear a fringed tunic and skirt, and ankle bands, and a knife-like object hangs below one hand, a head with fringe-like hair below the other.

\begin{tabular}{llllll}
$\begin{array}{l}\text { Distribution: } \\
\text { Paracas sector }\end{array}$ & Context & Sp. & Object type & Form & Technique \\
\hline (1) Wari Kayan & 94 & 61 & unkuña open-sided tunic & Tunic 5 & Embroidery \\
(2) Wari Kayan & 243 & 7 & mantle & Mantle 3 & Embroidery \\
(3) Wari Kayan & 243 & 34 & unkuña open-sided tunic & Tunic 5 & Embroidery
\end{tabular}
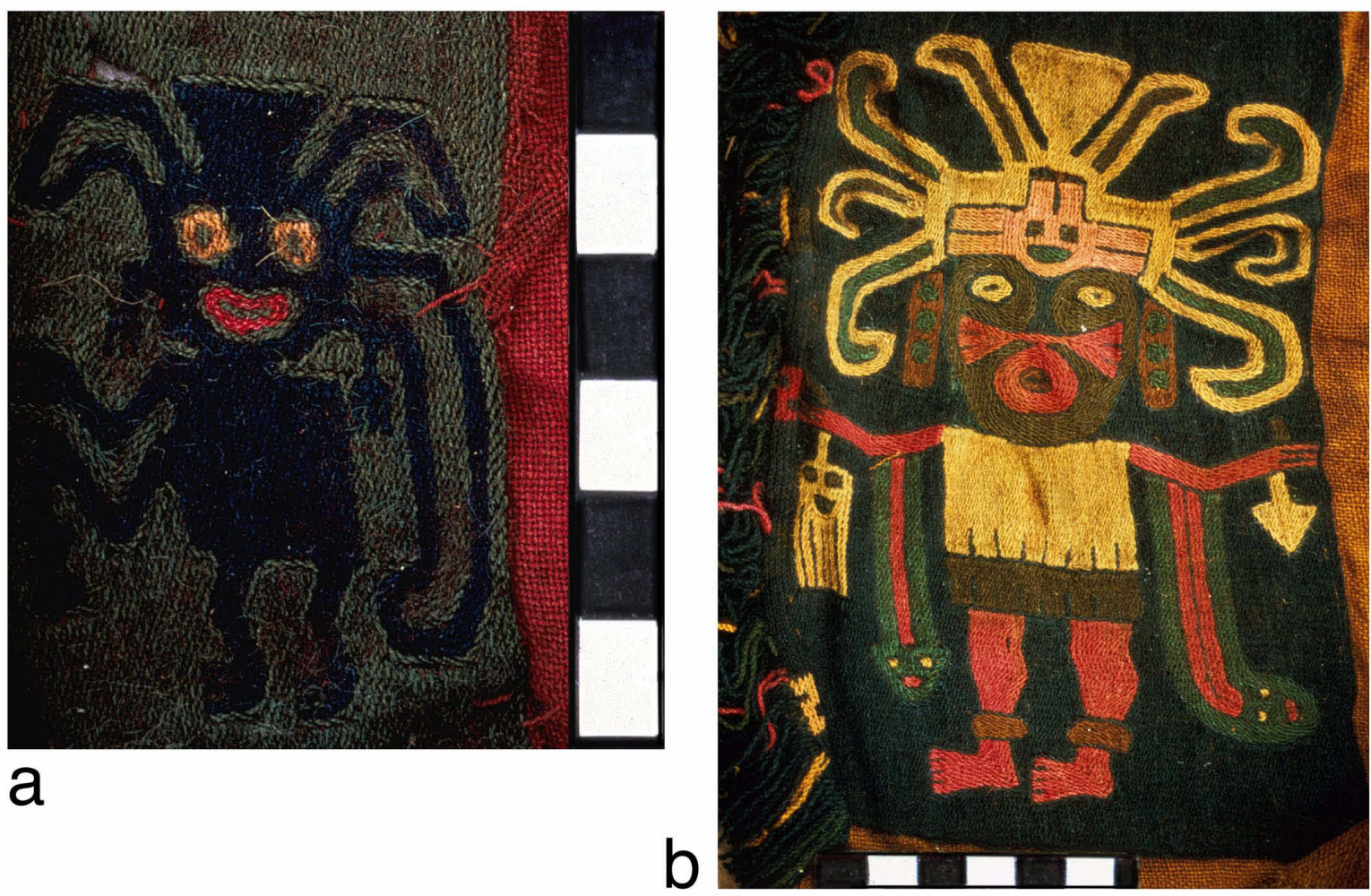

Figure 3. a. Wari Kayan 94 sp. 61, unkuña (Tunic 5), MNAAHP RT 2639, photo AP; b. Wari Kayan 243 sp. 7, Mantle 3 with cross-looped binding on central seam, MNAAHP RT 3173, photo AP. 
Media: Textile, plain weave cotton with camelid backstitch embroidery: (1) figures in an early style transitional from the Broad Line to the Block Color mode (2-3) figures in an early Block Color style.

Color: (1) green background, figures in red, yellow-gold and dark blue; $(2,3)$ dark green background, figures in red, yellow-gold, dark blue, medium green and brown, looped edging with S/Z motifs, polychrome plied fringe of the embroidery yarns.

Commentary: A small, well-defined group, including a simple, very early representation and a garment set with the more fully developed image. No subsequent examples of this icon have been defined, although it appears to be related to later 'standing' figures with rayed heads (below). The outlines of this headdress link this icon to representations of dorsal insect-like creatures, and all of them to sheet metal ornaments with repoussée decoration that echoes these forms.

The relationship between these two variants of one icon demonstrates the development of the representational conventions of the Block Color mode. In the Broad Line and Block Color modes, it is common to be able to trace recurrence of an icon among only two or three mortuary bundles, as is seen below.

\section{'Warrior-ritual' figures with rayed heads: (Figure 4)}

Frontal or semi-frontal 'standing' figures with rayed heads have a human head-body orientation and limbs and carry objects in their hands typical of the 'warrior-ritual complex' (Peters, 2000) such as a sling, knife, banded staff, spear, or severed head (Paul 1990, Makowski, 2000, fig. 34; Peters, 2018a). This figure type sometimes has a net bag at its back with a human head protruding.

Media: Textile, $(1,2)$ cotton plain weave, camelid embroidery, back-stitch in the Block Color mode $(3,4,5,6)$ camelid plain weave, camelid embroidery, back-stitch in the Block Color mode

Color: $(1,2)$ Brown or dyed (carbonized) cloth, purple borders with polychrome figures, plied fringe $(1) ;(3,4,5,6)$ yellow cloth with dark purple borders, polychrome figures, edging and fringe of looped triangular tabs (5) or plied yarn $(4,6)$.

Commentary: These motifs define an icon within the more general Warrior-ritual theme, but are not combined with other figures of this genre on the 'Warrior figures' mantles of phase 1 . Note their consistent placement on a purple background. Within the icon, there are variants in the object held and carried and in the facial details, which include very short whiskers or a crustacean-like

\begin{tabular}{llllll}
$\begin{array}{c}\text { Distribution: } \\
\text { Paracas sector }\end{array}$ & Context & Sp. & Object type & Form & Technique \\
\hline (1) Wari Kayan & 378 & 7 & large mantle & Mantle 2 & Embroidery \\
(2) Wari Kayan & 378 & 25 & ñañaka, unfinished & Headcloth 3 & Embroidery \\
(3) Wari Kayan & 310 & 44 & unkuña, open tunic & Tunic 5 & Embroidery \\
(4) Wari Kayan & 310 & 43 & wara, loincloth & Loincloth 3 & Embroidery \\
(5) Wari Kayan & 310 & 39 & ñañaka, headcloth & Headcloth 3 & Embroidery \\
(6) Wari Kayan & 310 & 27 & mantle, center panels & Mantle 1 & Embroidery
\end{tabular}

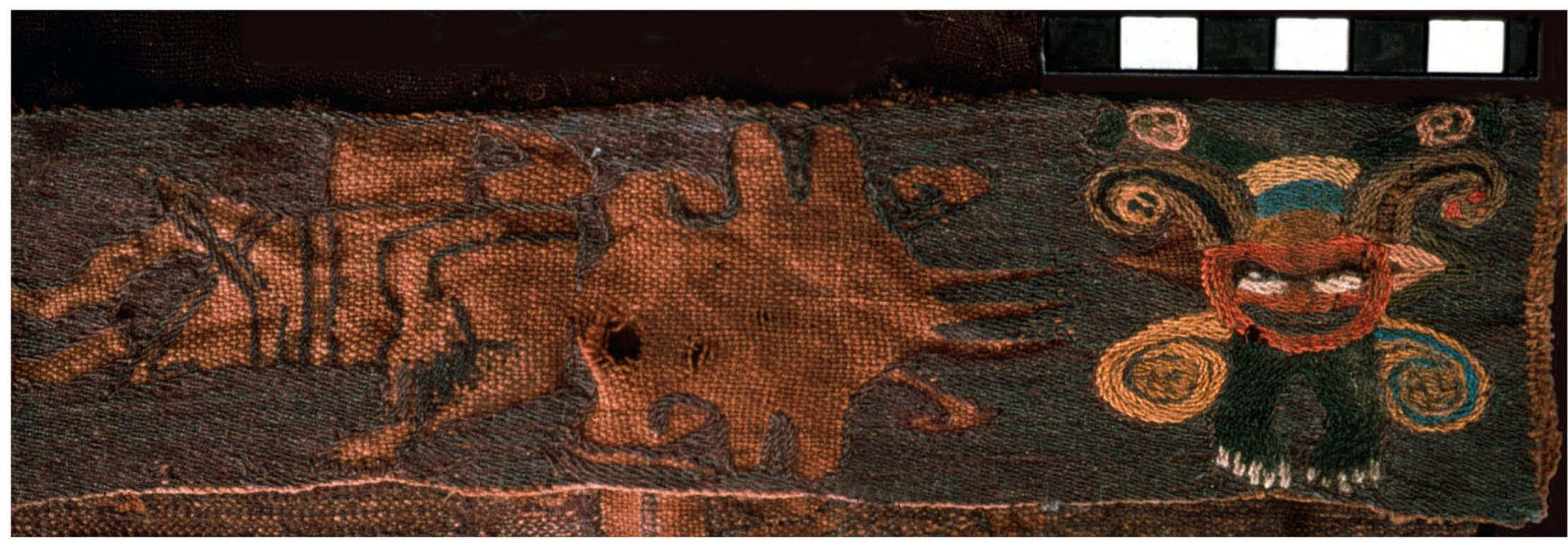

Figure 4. a. Wari Kayan 378 sp. 25 ñañaka (Headcloth 3), MNAAHP RT 2732, photo AP. 
mouth-mask. Most share an unusual form of skirt depicted as lateral triangles, over another loincloth. This garment form is depicted in early Nasca imagery, appearing on a painted mantle in a unique Nasca 2 style at the Cleveland Museum of Art and on others (Sawyer 1979, fig. 13). Early Nasca lower garments are large rectangles with ties at the four corners (O’Neale, 1937; Frame 2007; Peters 2017, 2018b) and this imagery may indicate how they were worn by mythic beings.

From a later time period than the depictions of the Rayed Head alone, these figures combine straight and curved rays, so their antecedents may lie in the ceramic or textile mummy bundle heads of Chongos or Ocucaje - or other representations of figures with straight vertical and lateral rays - rather than in the embroidered versions of the Rayed Head icon. They are embroidered with purple, green and yellow backgrounds, colors associated with Nasca style textiles found in lower Ica and the Nasca watershed. The garment forms in WK 310 also show 'outside' influence, adopting an unusual loincloth design, Wara 3 (Peters, 2018b), and a short headcloth with fringe.

Related motifs on earlier and contemporary textiles include 'warrior figures' with a headdress incorporating sets of straight radiant bands (possibly feathers), often combined with a long headcloth (a variant on the mantle 292(190) Sp. 17 has six tiny heads), as well as two examples of a 'warrior figure' icon wearing an animal skin headdress, with a net bag at their backs.

\section{Dorsal insect-like figures with bilaterally symmetrical recurved rays: (Figure 5 )}

Two distinct groups of motifs are proposed as variants of a single icon that differ in both style and the connotations made explicit in the imagery. Two others are proposed as a possible antecedent and probable descendent. Variant A $(2,3,4)$ resembles the head ornaments discussed above, small motifs of a face flanked by a straight prongs and symmetrically curved rays, with a curved trapezoidal or tail-like element above and two simple bands extending from the mouth below. Variant B $(5,6)$ is a more detailed image, in which the lateral triangles resemble ears, the rays curve towards the base of the face and end in small heads, two arms extend below, and the tail-like upper feature is banded, its corners ending in small heads: a dorsal figure resembling a mythic insect (see Figure 4).

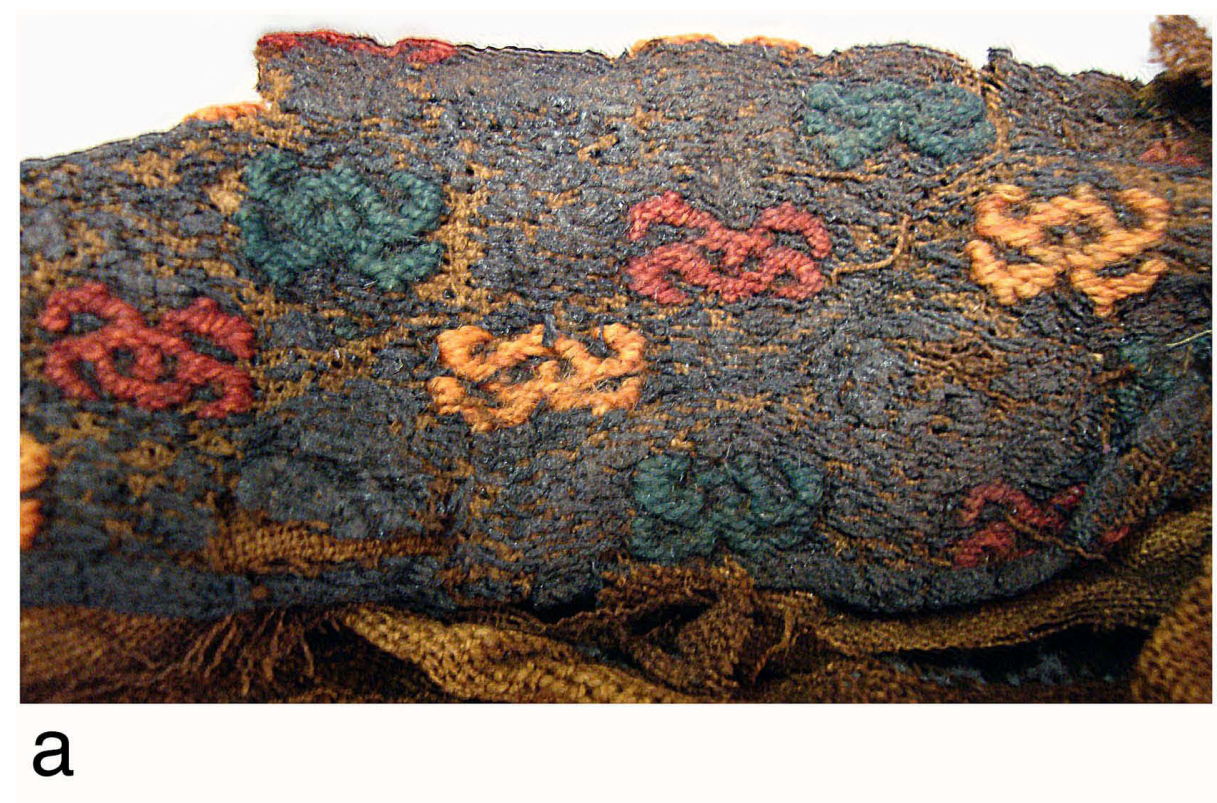

Figure 5. a. Wari Kayan 113, headcloth, AMNH 41.2/8839b, photo AHP; b. Wari Kayan 89 sp. 33, anako (probable loincloth), MNAAHP RT 2924, photo M. Jhong/MNAAHP.

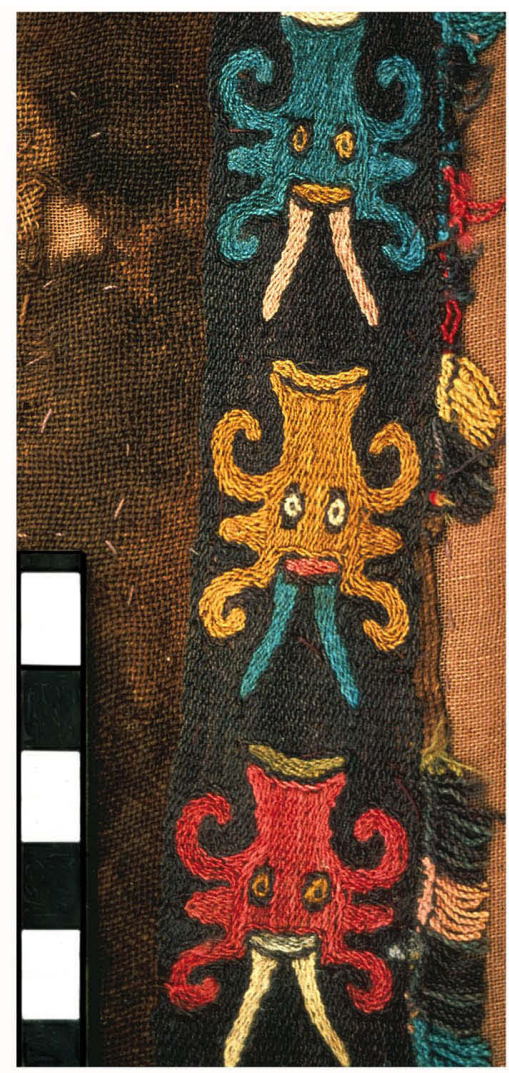


Distribution:

\begin{tabular}{llllll} 
Paracas sector & Context & Sp. & Object type & Form & Technique \\
\hline (1) Wari Kayan & 113 & s/n & Headcloth & atypical at WK & Embroidery \\
(2) Wari Kayan & 89 & 30 & headcloth, wide & Anako type & Embroidery \\
(3) Wari Kayan & 89 & 33 & loincloth, fragments, ties & Anako type & Embroidery \\
(4) Arena Blanca & 157 & 19 & Headcloth & atypical at WK & Embroidery \\
(5) Wari Kayan & $190(290)$ & 54 & unkuña open tunic & Tunic 5 & Embroidery \\
(6) Wari Kayan & 378 & 25 & ñañaka, unfinished & Headcloth 3 & Embroidery \\
(7) Wari Kayan & 318 & 9 & mantle, center panels & Mantle 1 & Embroidery
\end{tabular}

A possible prototype (1) is found in tiny monochrome images in the Mosaic style on a woman's headcloth from phase 10. A later variant (7) is a large scale Nasca 2 representation in which a figure similar in its position and core elements appears with diadem, mouthmask and flanking disks, arms and legs, serpentine appendages and patterned beans. This version is repeated on square 'chessboard' panels on the central ground of a mantle; larger versions on the lateral borders have been damaged by loss of the underlying cotton plain weave band.

Media: Textile, plain weave $(1,2)$ natural cotton, $(3,5,6)$ natural or dyed (carbonized, absent) cotton, (4) dyed cotton, or (7) dyed camelid hair, with camelid embroidery, figures in Block Color styles.

Color: (1) brown cotton, dark (carbonized) border background with monochrome figures in red, yellow-gold, greenblue and blue-purple; $(2,3)$ beige or brown cotton ground, purple border background, red, yellow, brown-gold and medium blue figures with white used in details; (4) dark red cotton, bright red figures and a green and polychrome cross-looped edging and short plied fringe; (5) dyed cotton ground, red border background, polychrome figures; (6) brown cotton border band, purple background, polychrome figure; (7) dark red camelid ground, dark purple background on borders and square panels, polychrome figures, cross-looped edging and plied polychrome fringe.

Commentary: The 'mosaic' style embroidered cloth on the head of the woman in phase 10 bundle WK 113 is an unusual early style that is also present as monochrome outlined figures that line the inner borders of many phase 10 and early phase 1 mantles and a few other garments. The mosaic style is one of several distinctive inner border styles.

Among new garment forms introduced in phases $1 \mathrm{~A}$ and 1B are those originally called ‘anako' by Tello's research team, which are related to contemporary garment forms from the Nasca valley (Peters 2017b, 2018b). With them come a swarm of insect motifs, or more explicit representations of themes already present in Linear mode imagery. These images bear an obvious relationship to the Rayed Head, clear in an unfinished border representing standing figures with rayed heads (Figure 4) in which a related motif has been inserted to fill the end - a recurrent practice in the anako garment system. This may be a precedent for the red-bordered unkuña tunic (4), which incorporates this novel image into a tunic form and color scheme more typical of the Wari Kayan assemblage. The other rayed-head images of this group are associated with color schemes and other aspects of garment design characteristic of the lower Ica valley and Nasca watershed. The large mantles in the late phase 2 bundle WK 318 display images sharing aspects of iconography and image style with Nasca 3 painted ceramics.

\section{Two bands connected to a rayed head, above a figure's head: (Figure 6)}

This group consist of two examples of a recurrent icon and several more loosely related figures, all of which incorporate a rayed motif attached to a figure by two bands.

Variant A $(1,2)$ in horizonal position (head perpendicular to body) has small lateral curved ears, a prominent mouthmask with long, curling, backswept upper whiskers (sea otter features), and a diadem before a domed head and short headcloth. The large tunic extends over his shoulders, above a fringed skirt. One hand grasps a pair of short, crossed sticks. From the mouth extends a serpentine appendage with spiked margins, ending in a human/bird figure (which appears elsewhere as a principal icon), who holds a diadem

4. Grouped tombs known as "Cabezas Largas" were located in the Arena Blanca residential sector, as well as other isolated tombs and small groups that correspond to the Paracas Necropolis mortuary tradition. 

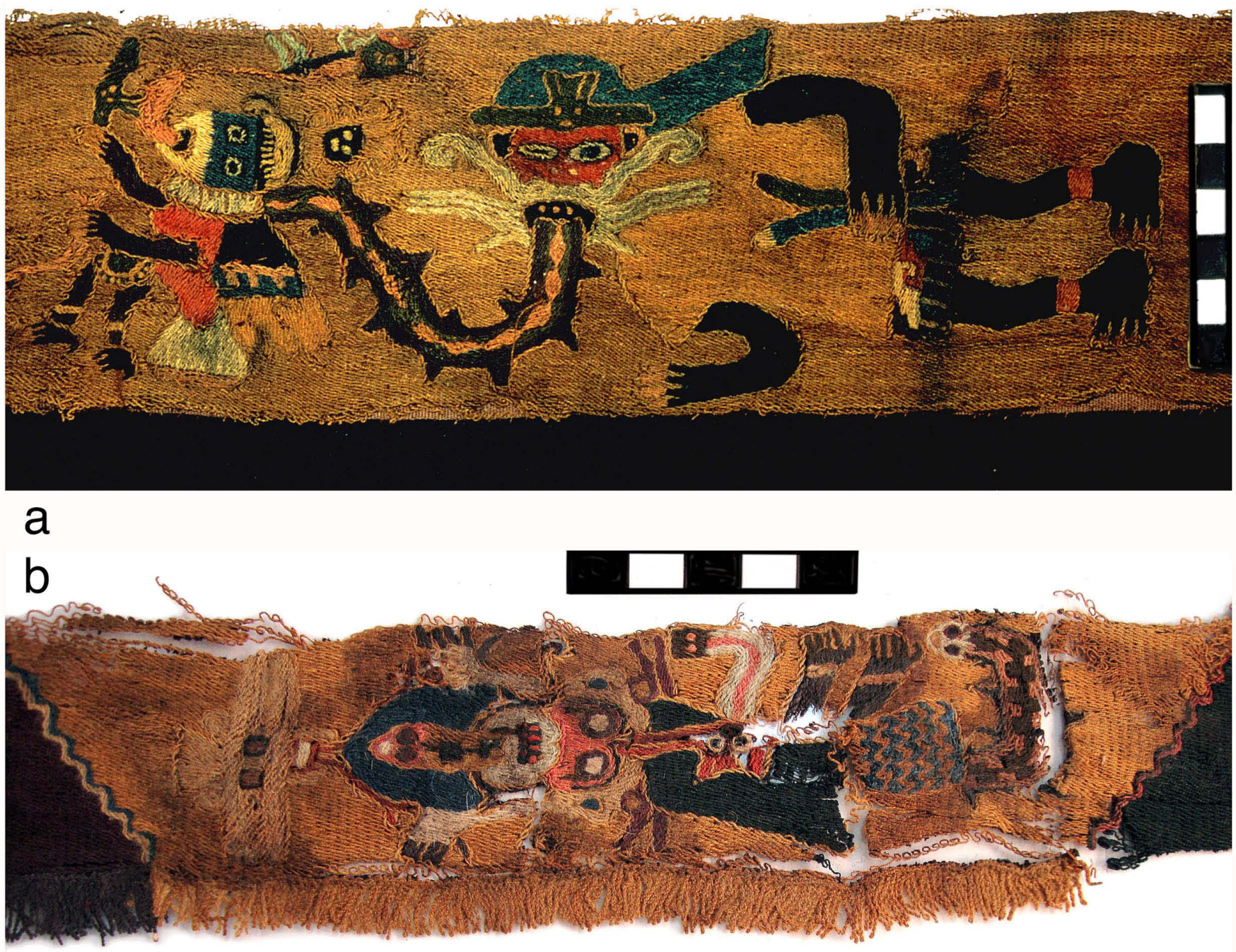

Figure 6. a. Wari Kayan 420 sp. 2, atypical mantle, MNAAHP RT 5907, photo AP; b. Wari Kayan 27 sp. 11, anako (mantle, headcloth or loincloth), MI-UNSAAC 3561, photo AHP.

and has a tongue appendage ending in a small catlike figure. Above this figure's head is the small rayed head. The later version has simian feet, holds a severed head, and a second head ornaments a panel at his back, from which extends a serpentine appendage ending in a feline head.

Variant B (3) has human and bird attributes and wears a large mouth-mask, from which emits a serpentine appendage, while another extends from the tail. He grasps a diadem and wears a double diadem, and a lobed headdress with a rayed look, above which extends the cords leading to an ornament with lateral curved rays. Variant $\mathrm{C}$ is semidorsal figure (4) with the head of a sea otter, who trails a vertical diadem before a short headcloth and an avian or marine tail that emits a serpentine appendage. Another appendage extends from the mouth, flanked by two cords from his hands that lead to a large diadem. Flanking his nostrils, his thick whiskers have faces, and his large cat-skin headdress has two cords from its mouth. One leads to a human/bird figure grasping a cord, whose mouth appendage leads to a flower. The other leads to a human/bird figure grasping a pod of patterned beans. In the middle of it all is the rayed head, its cords emerging from the head of the catskin headdress. Variant D is a standing figure (5) with human and simian attributes who wears a shell pendant before a large tunic with borders of patterned beans and fringe at shoulders and base and grasps a fan and a tuber. From his back, a large serpentine appendage leads to a dorsal catlike figure with extended tongue and forearms. 
Distribution:

\begin{tabular}{llllll} 
Paracas sector & Context & Sp. & Object type & Form & Technique \\
\hline (1) Wari Kayan & 420 & 2 & Mantle & Mantle 1 & Embroidery \\
(2) Wari Kayan & 38 & 5 & mantle & Mantle 1 & Embroidery \\
(3) Wari Kayan & 89 & 15 & Mantle & Mantle 2 & Embroidery \\
(4) Wari Kayan & 27 & 11 & anako, mantle?, fragments & Anako type & Embroidery \\
(5) Wari Kayan & 253 & 26 & Mantle & Mantle 3 & Embroidery
\end{tabular}

Media: Textile, plain weave $(1,2)$ dark green camelid hair or $(3,4,5)$ probably dyed cotton with camelid embroidery: $(1,2)$ figures in a phase $1 A-B$ Block Color style (3) figure in a different phase $1 \mathrm{~B}$ Block Color style; $(4,5)$ figures in two different Nasca 2 Block Color styles.

Color: (1) dark (carbonized) dyed cotton ground, yellow-gold border background, polychrome figures; (2) green background, red borders and outlines, polychrome figures; (3) ochre cotton ground, red border background, polychrome figures; (4) dark (carbonized) dyed cotton, segmented polychrome border and figures, red fringe and dark purple-black flat-braided ties at each corner; (5) black camelid ground, red border background, polychrome figures, rectangular tabbed fringe in close looping.

Commentary: A well-distinguished icon in $(1,2)$, despite added elements in the later representation, demonstrates a surprisingly direct connection between these mortuary bundles. The crossed sticks and the combination of other elements are unique to date.

The other three images show recombination of elements referencing sea otters and human/birds, a variability characteristic of Block Color mode imagery, as well as the introduction of cat-skin headdresses and explicit vegetal motifs, prominent in the phase 2 assemblages. The rayed head motif depicted as a headdress ornament and the prominent use of yellows link it to sheet metal ornaments, which were particularly large, abundant and decorative in late Paracas contexts and the contemporary Wari Kayan mortuary bundles. The Nasca region must have controlled the gold sources, as metal ornaments become scarcer and simpler in the Wari Kayan bundles, while they are well-developed and abundant at the Cahuachi site. These Rayed Head ornaments are reminiscent of early Nasca ornaments found at Cahuachi (Orefici 2012, p. 202, fig. 7-16).

\section{Diagonal two-headed serpents: (Figure 7)}

A diagonal serrated band has a triangular serpent head at each end, flanked by simple lines that also mark the opposite diagonal, with a tiny double-headed serpent or another figure fitted into the triangular spaces on each margin. Variant A, depicted in the Linear mode, has a straight body. Variant $\mathrm{B}$, depicted in the Block Color mode, has a zigzag body.

Media: Textile, plain weave cotton or dyed camelid hair (9) with back-stitch and whipping-stitch used to create Linear mode imagery (1-9) or Block Color mode imagery $(10,11)$

Color: (1) yellow cloth, dark (carbonized) background, figures in blue-green, red, yellowgold, plied cord edging; $(2,3,4)$ probably dyed (carbonized) cloth, red background, polychrome figures; $(5,7)$ natural beige cloth, red background, figures in dark blue, green, yellow-gold; $(6,8)$ dyed (carbonized) cloth, dark purple background, figures in dark

\section{Distribution:}

\begin{tabular}{llllll} 
Paracas sector & Context & Sp. & Object type & Form & Technique \\
\hline (1) Wari Kayan & 352 & $28 / 73$ & probable man's skirt & fragments & Embroidery \\
(2) Wari Kayan & 438 & 15 & Mantle & fragmentary & Embroidery \\
(3) Wari Kayan & 438 & 18 & Possible ñañaka headcloth & fragmentary & Embroidery \\
(4) Wari Kayan & 438 & 25 & unkuña, open tunic & Tunic 5 & Embroidery \\
(5) Wari Kayan & 91 & 94 & wara, loincloth & Wara 2 & Embroidery \\
(6) Wari Kayan & 243 & 28 & ñañaka, headcloth & Headcloth 1 & Embroidery \\
(7) Wari Kayan & $190(290)$ & 64 & ñañaka, headcloth & Headcloth 1 & Embroidery \\
(8) Wari Kayan & $190(290)$ & 56 & ñañaka, headcloth & Headcloth 1 & Embroidery \\
(9) Wari Kayan & 310 & 40 & ñañaka, headcloth & Headcloth 1 & Embroidery \\
(10) Wari Kayan & 319 & 49 & unkuña, open tunic & Tunic 5 & Embroidery \\
(11) Wari Kayan & 319 & 106 & ñañaka, headcloth & Headcloth 3 & Embroidery
\end{tabular}



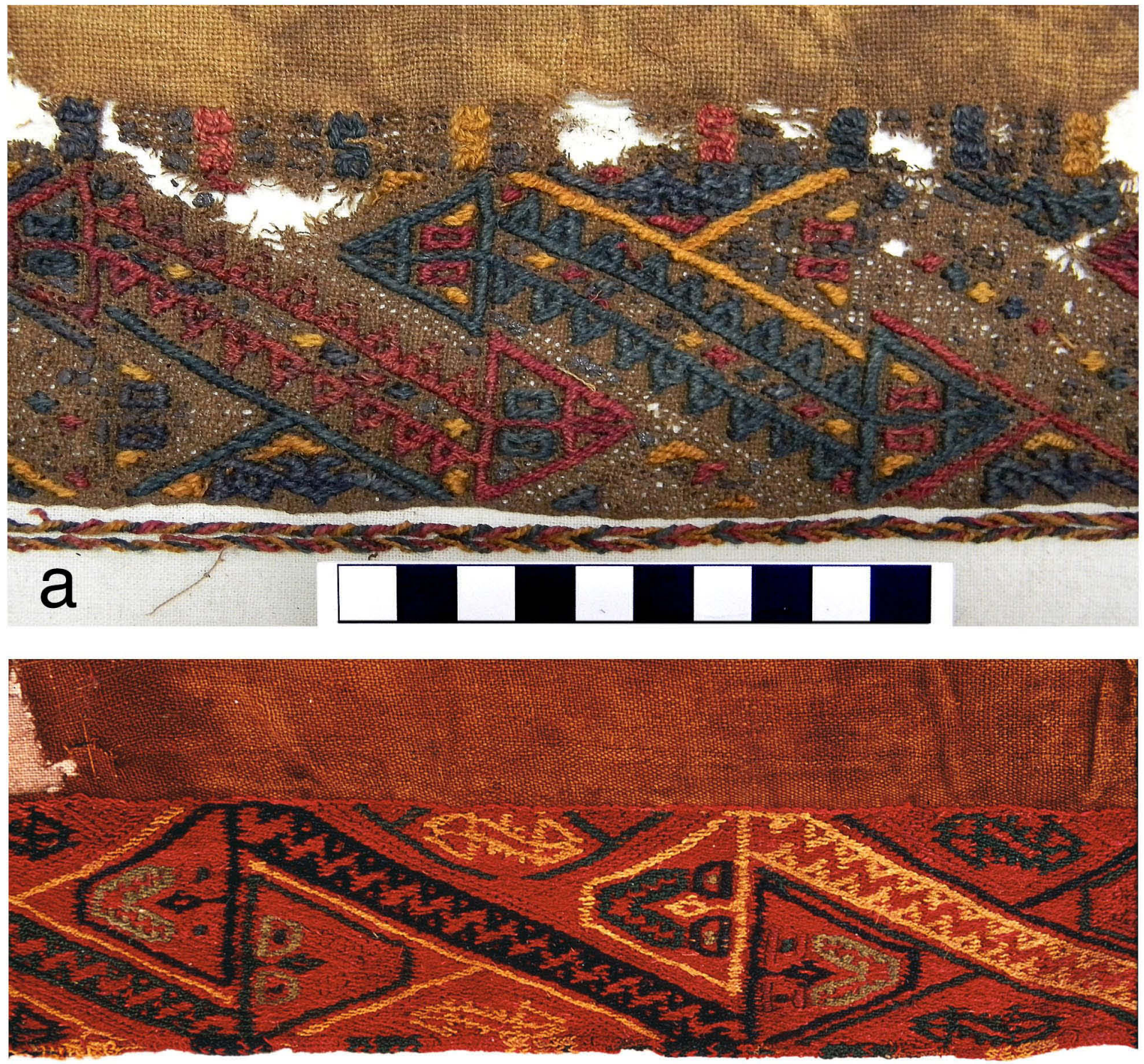

b

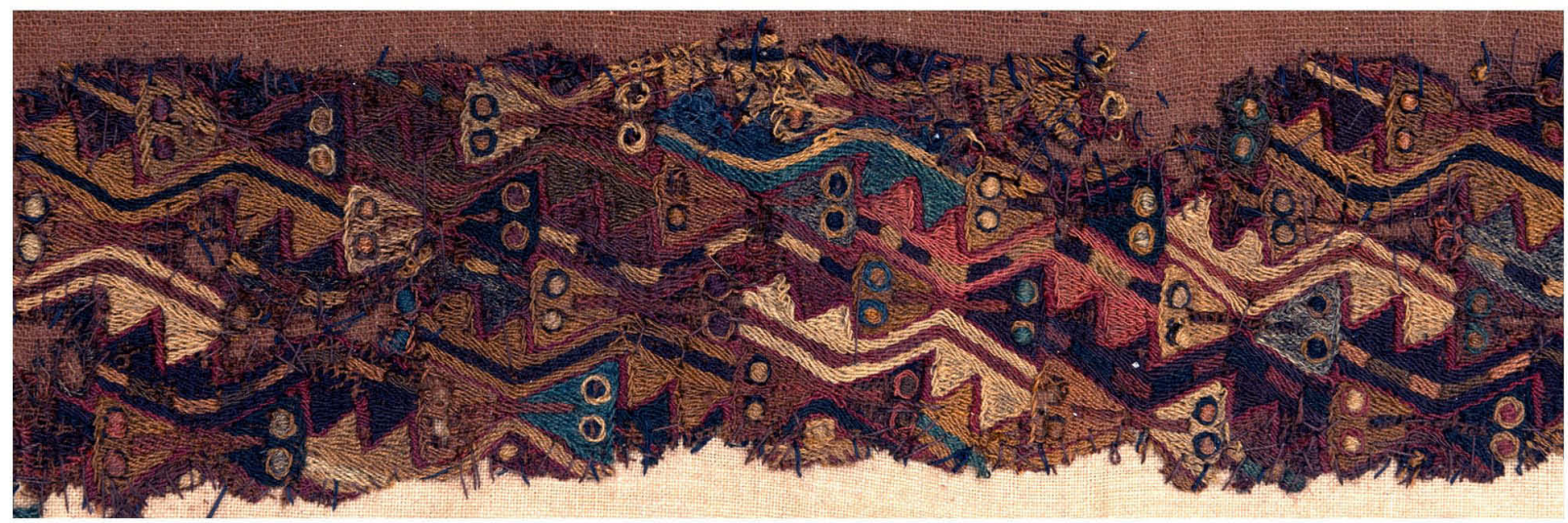

C

Figure 7. a. Wari Kayan 352 sp. 28/73 probable man's skirt, MRI DB-02, photo AHP; b. Wari Kayan 438 sp. 25, unkuña (Tunic 5), MNAAHP RT 2371, photo AP; c. Wari Kayan 319 sp. 49, unkuña (Tunic 5), MNAAHP 3233, photo M. Jhong/MNAAHP. 
blue, green, red, yellow-gold; (9) red cloth, dark purple background, dark blue, red, green, yellow-gold figures; $(10,11)$ red (carbonized) cloth, purple outlines, polychrome figures, (lost) red plied fringe.

Commentary: This icon is very similar to the motifs on the reduced-scale motifs on the paired transverse bands of the unkuña tunic WK $421 \mathrm{sp} .44$, which has the icon defined by linked diagonal bands with rayed heads and feline figures depicted on its borders. Moreover, it bears a strong relationship to the surface structure of the back-stitch embroidery used to create the imagery. Note that these examples range from two of the early phase 10 mortuary bundles, linked to Ocucaje 10, to one of the late phase 2 mortuary bundles, linked to Nasca 2-3. On the tunic and mantle in WK 438 it is depicted in two rows, and on the tunic and short headcloth in WK 319 the Block Color variant is reproduced in multiple rows and an array of pastel colors on a matching garment set that adorned an inner display layer (Archivo Tello, 2012, fig. 498). All are men's bundles (but for gender complexity, see Peters and Tomasto, 2017). In the phase $1 \mathrm{~A}$ and $1 \mathrm{~B}$ bundles, this icon has only been preserved on headcloths.

\section{Interconnected looped serpents: (Figure 8)}

Diagonally arrayed loop-like zigzag bands connected to triangular serpent heads, in pairs that interlock (Variants A and B) or share a single serpent head (Variant C). Tiny feline/simian figures or birds with spread wings (3) occupy triangular spaces at each margin. All examples are in Linear mode embroidery. Variant A, depicted on a garment set $(1,2)$, has simple diagonal lines that demarcate a pair of curving zigzag lines with one serrated margin, in contrasting colors, that each connect to a triangular serpent head at the apex of each loop. Small-scale versions in another pair of contrasting colors fit in the intermediate spaces. In the adjacent diagonals, the colors of the large and small motifs are reversed. Variant B (3) has diagonal arrays of U-shaped lines that pair at each end (one becomes serrated) and connect to a triangular serpent head. The central space of each

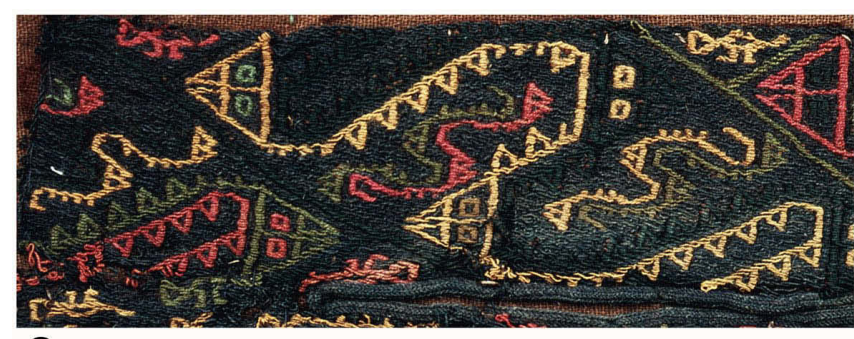

a

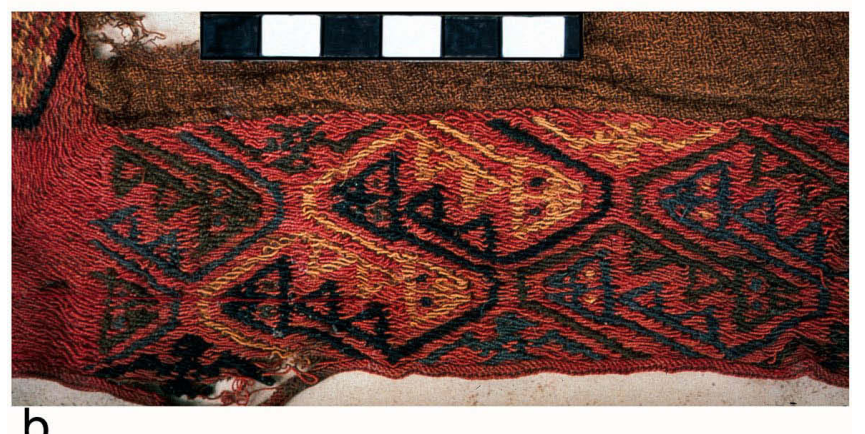

b

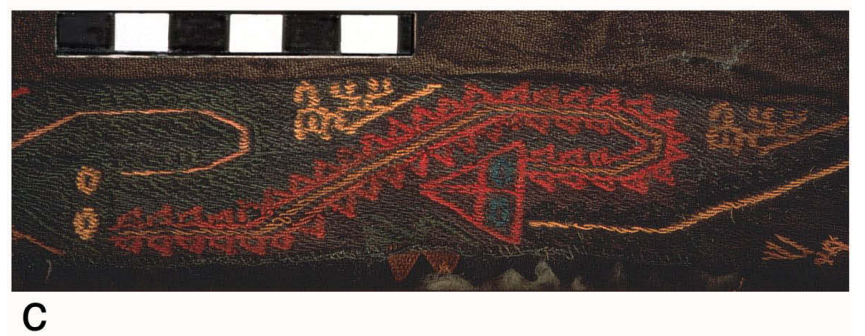

Figure 8. a. Wari Kayan 421 sp. 6o, unkuña (Tunic 5), MNAAHP RT 3101, photo M. Jhong/MNAAHP; b. Wari Kayan 190 (290) sp. 89, ñañaka (Headcloth 1), MNAAHP RT 2495, photo AP; c. Wari Kayan 310 sp. 54f, ñañaka, fragmentary headcloth, MNAAHP RT 2772, photo AP.

loop is occupied by the serpent heads and paired lines of an adjacent set in a contrasting color. Variant C $(4,5)$ has triangular serpent heads adjacent to the outer border margin, each connected to a serrated body that curves towards the inner border margin and hooks to end behind the head of the next serpent, which contrasts in color.

\begin{tabular}{llllll}
$\begin{array}{c}\text { Distribution: } \\
\text { Paracas sector }\end{array}$ & Context & Sp. & Object type & Form & Technique \\
\hline (1) Wari Kayan & 421 & 60 & unkuña tunic & Tunic 5 & Embroidery \\
(2) Wari Kayan & 421 & 72 & ñañaka, headcloth & Headcloth 1 & Embroidery \\
(3) Wari Kayan & $190(290)$ & 89 & ñañaka, headcloth & Headcloth 1 & Embroidery \\
(4) Wari Kayan & $292(190)$ & 54 & ñañaka, headcloth & Headcloth 1 & Embroidery \\
(5) Wari Kayan & 310 & $54 \mathrm{f}$ & ñañaka, headcloth & Headcloth 3 & Embroidery
\end{tabular}


Media: Textile, plain weave cotton with back-stitch and whipping-stitch used to create Linear mode imagery.

Color: $(1,2)$ dyed (absent) cloth, dark blue background, figures in dark green, light green, olive-brown, red, yellow; (3) ochre cotton cloth, red background, figures in dark blue, yellow, medium blue and green; (4) natural beige cloth, light red background, figures in dark blue, dark green, yellow-gold and red-brown; (5) dark brown cloth, purple background, figures in dark blue, dark green, red, yellow-gold and medium brown, looped triangular tab fringe in the embroidery colors.

Commentary: These motifs seem to represent a concept linked to the movement of yarns in needlework, but the three variants describe somewhat different motions and perhaps may not be considered a single icon. The motions are those of looping, either back-stitch (Variants A and C) or simple looping (Variant B). The three variants represent different concepts or different interpretations of a single concept. The examples that provide evidence of a direct precedent and its reinterpretation is an earlier and later headcloth $(4,5)$ that depict exactly the same motif on garments that differ in overall form, color scheme and finishes.

\section{Curving two-headed serpents: (Figure 9)}

Two variants are included. Variant A is a Z-curved band with marginal stripes and internal patterning, with a simple serpent-like head at each end. Variant B is a patterned band divided into segments that each emerges from beneath a three-dimensional head in the colors of the previous band and ends in its own three-dimensional serpentlike head.

Media: Dyed cotton plain weave $(1,2)$ or natural cotton (3) with back stitch used to create Block Color embroidery, and (3) embroidered yarns threaded through the fine central panel to create a linear pattern. Complex flat braiding (oblique interlace) in segments of different colors (4) with three-dimensional serpent heads in tubular looping at one end of each.
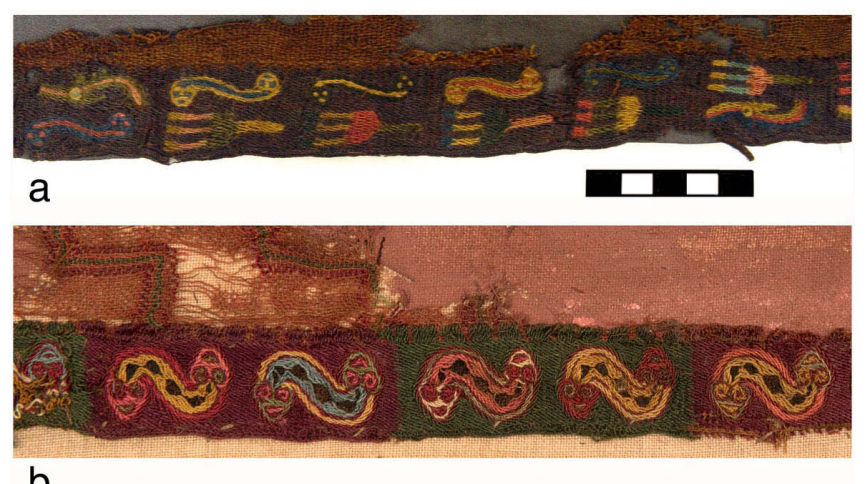

b

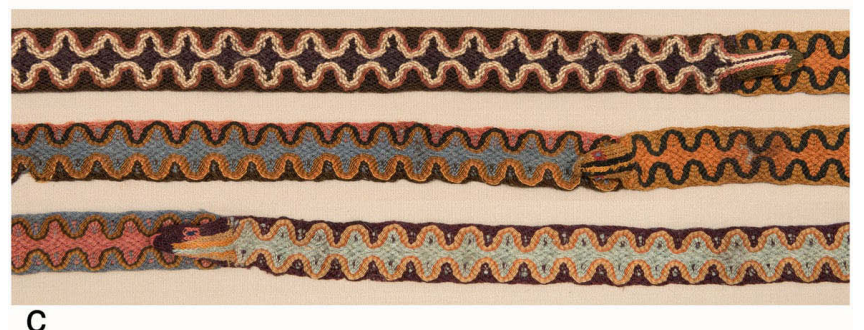

Figure 9. a. Wari Kayan 28 sp. 26, ñañaka (Headcloth 2), MNAAHP RT 2856, photo AHP; b. Wari Kayan 319 sp. 52, ñañaka, atypical headcloth, MNAAHP RT 3007, photo M. Jhong/MNAAHP; c. Wari Kayan 38 sp. 43 , llautu, flat braided and tubular looped headband, MNAAHP RT 1875, photo M. Jhong/MNAAHP.

Color: $(1,2)$ green dyed cloth, purple background, polychrome figures; (3) beige cloth, bright green and red-purple sectioned border and linear design, polychrome figures; (4) segment backgrounds in purple, dark, medium and pale blue, light red, yellow, and brown, with figures in contrasting colors.

Commentary: These are all headdress elements in 'foreign' styles. Double-headed Z-curved serpents are embroidered on narrow headcloth borders in bright colors in the Block Color style. The first occurs on two matching wide women's headcloths $(1,2)$, part of a layered set in the large female mortuary bundle WK 28. The tiny serpents alternate with long-jawed fish and tassel-like motifs on both

Distribution:

\begin{tabular}{llllll} 
Paracas sector & Context & Sp. & Object type & Form & Technique \\
\hline (1) Wari Kayan & 28 & 26 & woman's wide headcloth & Headcloth 2 & Embroidery \\
(2) Wari Kayan & 28 & 20 & woman's wide headcloth & Headcloth 2 & Embroidery \\
(3) Wari Kayan & 319 & 52 & small headcloth & atypical of WK & Embroidery \\
(4) Wari Kayan & 38 & 43 & Llautu braided headband & 3D looped heads & Flat braided \& \\
& & & & & looped
\end{tabular}


headcloths. In a second example (3), pairs of double-headed serpents are set in a green and red-purple sectioned border on a fine small headcloth with the center panel embroidered overall in stepped diagonal lines using the same colors, in the late Nasca 2 burial WK 319. On a segmented llautu headband in $\mathrm{WK} 38$, a series of patterned bands in different bright color schemes are patterned much like the serpent bodies, and on the upper side at one end a three-dimensional serpent head is worked in tubular looping. While it lies straight in the museum setting, such bands are depicted as curving serpents on the heads of embroidered figures.

\section{S-Z curved two-headed serpents with chin whiskers: (Figure 10)}

A double-headed serpent-like figure with hook-like chin whiskers that curves to form a figure resembling an ' $S$ ' or 'Z' shaped motif.
Media: Textile, plain weave natural cotton (1) dyed camelid hair $(3,4,5)$ with back-stitches alternating in direction and whipping-stitch used to create Linear mode imagery. Close simple looping (2), tubular with colors not in play carried within, ending in small tubular 'fingers' at each end.

Color: (1) natural beige cloth, red border background, figures in dark blue, dark green and yellow-gold, edging with polychrome 'S' motifs; (2) red background, figures dark blue, dark green and yellow-gold; $(3,4,5)$ dark blue cloth, red border background, central panels and outlines, figures dark blue, dark green and yellow-gold, edging with polychrome 'S' motifs, plied polychrome fringe.

Commentary: This icon is represented by a tight-knit group of Linear mode motifs from two contemporary male mortuary bundles of very early phase 1 . Moreover, the embroidery stitches on all garments are atypical of the Paracas Necropolis assemblage, appearing on very few other garments, one also being from tomb WK 26. The blocky style of

\section{Distribution:}

\begin{tabular}{llllll} 
Paracas sector & Context & Sp. & Object type & Form & Technique \\
\hline (1) Wari Kayan & 26 & 21 & unkuña, open tunic & Tunic 5 & Embroidery \\
(2) Wari Kayan & 421 & 9 & llautu looped headband & tubular w/ 'fingers' & Looping \\
(3) Wari Kayan & 421 & 110 & man's wrapped skirt & Skirt 2 & Embroidery \\
(4) Wari Kayan & 421 & 84 & unkuña, open tunic & Tunic 5 & Embroidery \\
(5) Wari Kayan & 421 & 133 & Mantle & Mantle 1 & Embroidery
\end{tabular}
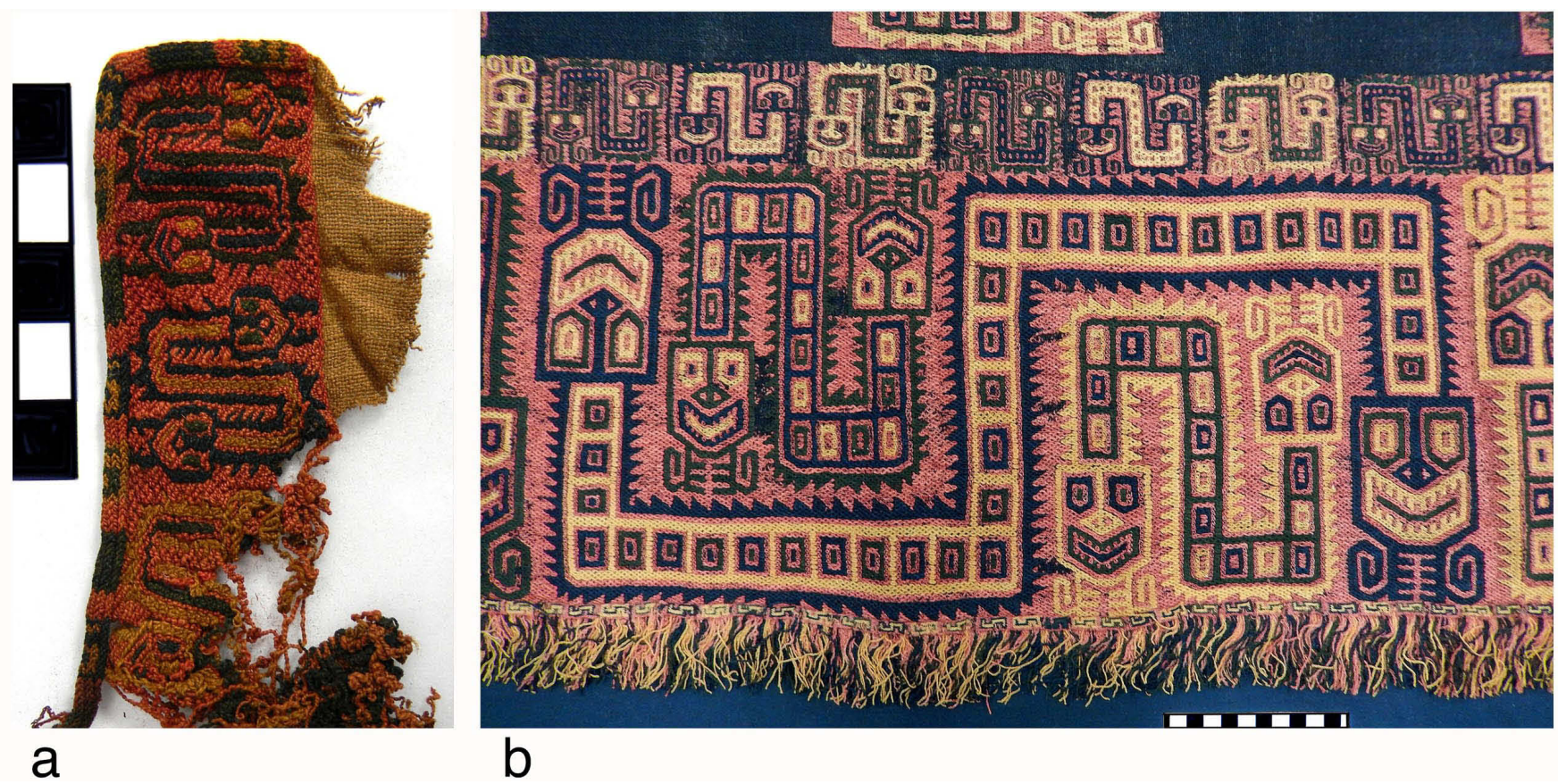

Figure 10. a. Wari Kayan 26 sp. 21, unkuña, Tunic 5 (fragment), MNAAHP RT 26625, photo AHP; b. Wari Kayan 421 sp. 133 (originally sp. 3), Mantle 1 with center panels, MNAAHP RT 1674, photo AHP. 
the WK 421 garment set is also unique, and extends to the matching looped llautu headband. Yet this famous garment set has been displayed as emblematic of Paracas Necropolis, on the frontispiece (Carrión 1949) and cover (Tello and Mejía 1979) of books published by members of the original research team. There is an antecedent for this icon in the Broad Line style, though without burial context.

The motif is repeated on the cross looped edging of the garments and the 'fingers' of the llautu headband. On the garment set in WK 421 is also appears in the intermediate spaces of the large version, on 'chessboard' rectangles across the central panel, and along the inner border margins. The ' $\mathrm{S}$ ' or ' $\mathrm{Z}$ ' motif is the most common motif represented on the cross-looped edgings that bind the margin and cover joins to plied fringe (or other types) from late phase $10 \mathrm{on}$, and is tattooed on the hands of the woman in phase 10 bundle WK 113 .

\section{Interlinked two-headed serpents: (Figure 11)}

Three variants, Linear Mode motifs differing in both stitching style and image style that possibly constitute a single icon. The first $(1,2)$ are bands with textured margins in an elongated $S$ position with a wide lozenge-shaped head at each end, that hook onto adjacent two-headed serpent motifs in contrasting colors, with small feline figures in the triangular spaces on each margin. The second (3) are bands with serrated margins in an elongated $\mathrm{Z}$ position with a feline-like head at each end, that hook onto adjacent twoheaded serpent motifs in contrasting colors, with small feline figures in the triangular spaces on each margin and S-motifs on the looped edging. The third $(4,5)$ are bands with serrated margins in an elongated $\mathrm{Z}$ position with a rounded human-like head at each end, that hook onto adjacent two-headed serpent motifs in contrasting colors, without 'filler' figures.

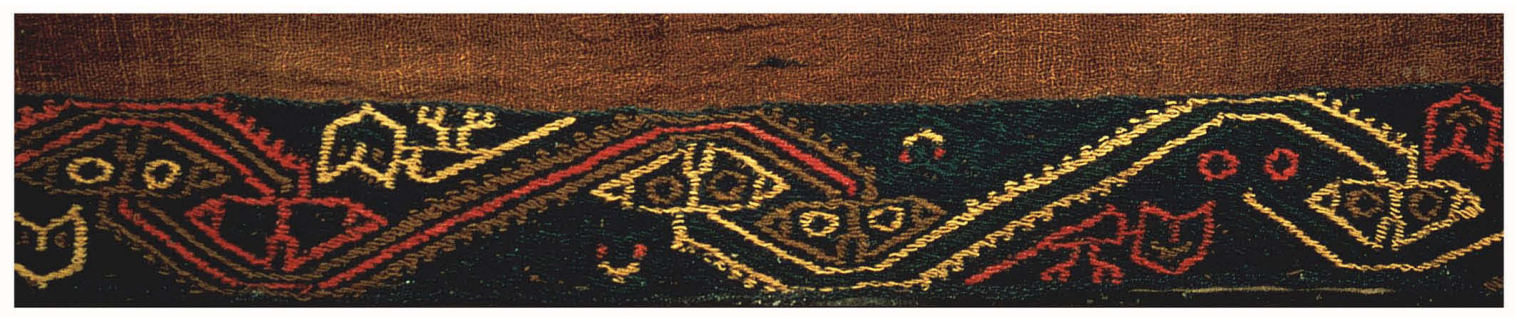

a

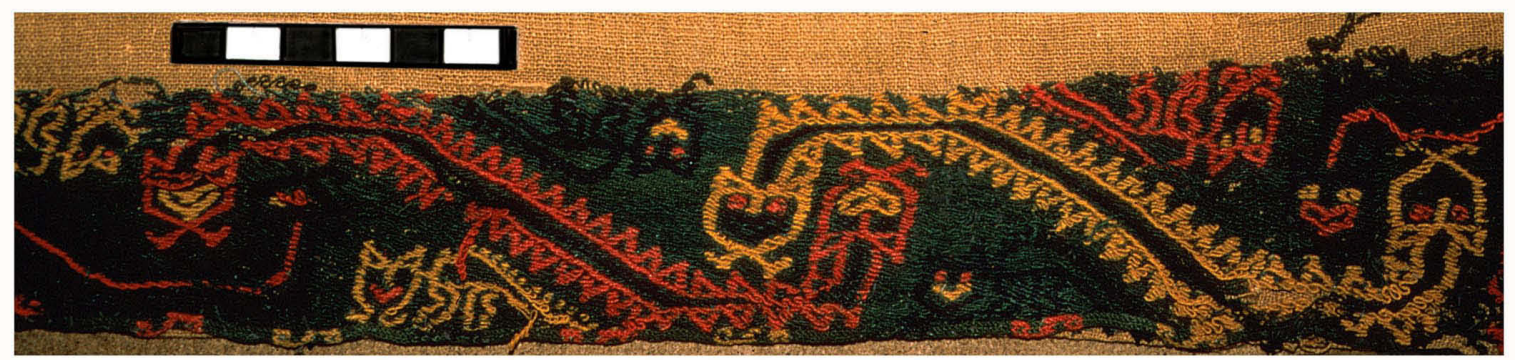

b

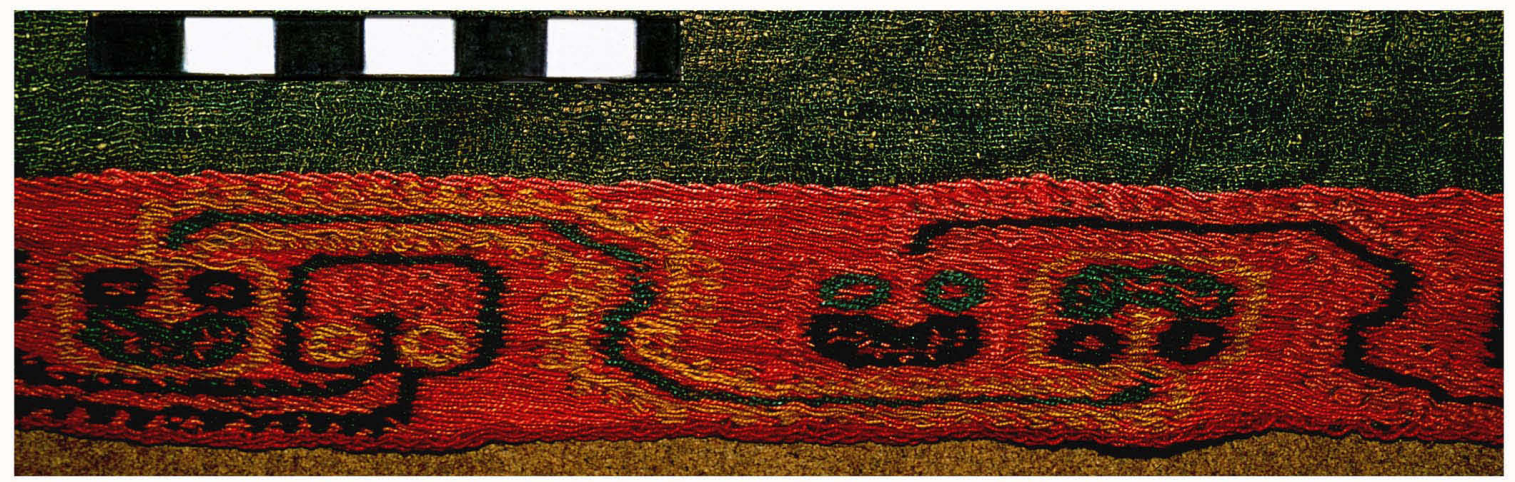

C

Figure 11. a. Wari Kayan 421 sp. 69, ñañaka (Headcloth 1), MNAAHP RT 3105, photo AP; b. Wari Kayan 12 (382) sp. 76, ñañaka (Headcloth 1), MNAAHP RT 672, photo AP; c. Wari Kayan 94 sp. 28, ñañaka (Headcloth 1), MNAAHP RT 1399, photo AP. 
Distribution:

\begin{tabular}{llllll} 
Paracas sector & Context & Sp. & Object type & Form & Technique \\
\hline (1) Wari Kayan & 421 & 69 & ñañaka, headcloth & Headcloth 1 & Embroidery \\
(2) Wari Kayan & $190(290)$ & 91 & ñañaka, headcloth & Headcloth 1 & Embroidery \\
(3) Wari Kayan & $12(382)$ & 76 & ñañaka, headcloth & Headcloth 1 & Embroidery \\
(4) Wari Kayan & 94 & 28 & ñañaka, headcloth & Headcloth 1 & Embroidery \\
(5) Wari Kayan & $190(290)$ & 84 & ñañaka, headcloth & Headcloth 1 & Embroidery
\end{tabular}

Media: Textile, plain weave dyed camelid hair with backstitch and whipping-stitch used to create Linear mode imagery.

Color: (1) brown (carbonized) cloth, dark blue background, red, dark green, olive-brown and yellow figures; (2) brown (carbonized) cloth, red background, green, dark blue and yellow-gold figures; (3) absent cloth, dark green background, dark blue, red, and yellow-gold figures, edging, fringe; $(4,5)$ dark (carbonized) cloth, light red background, dark blue, green, and yellow-gold figures.

Commentary: These motifs appear also to refer to the movement of yarns in needlework. Variants A and B resemble the usual back-stitch procedure, while Variant $C$ resembles the alternating back-stitch used in the two-headed serpents in WK 26 and WK 421 (Figure 9). Note that these headcloths were placed in some of the same male mortuary bundles that display other variants of the two-headed serpent. The different head forms appear to indicate distinctions in the metaphors at play, or the sphere of meaning. Each variant is also associated with differences in yarn qualities, stitching and of course color scheme and finishes, suggesting different production communities contributing a headcloth of this form added to each of these mortuary contexts, during a time period associated with phase $1 \mathrm{~A}$.

\section{Serpent-like creatures with forelimbs and hooked tails ${ }^{5}$ (Figure 12)}

Serpentine figures with small limbs flanking the head, at one or both ends: a range of motifs that may share a common linguistic referent (same icon) or not, as they demonstrate significant differences in representational conventions. Variant A $(2,3,4)$ is a pair of flanking figures in the Linear mode, positioned in mirror symmetry but shifted so their bodies are parallel and the heads extend at each end. The body is a band with zigzag margins, with a small serpent-like head at one end, curved back in a hook-like position, and a larger head flanked by small limbs ending in 'fingers'. Small motifs fill the triangular spaces at each margin.

Variant B is a serpentine figure $(5,6)$ composed of a straight band with zigzag margins with a head at one end with curling whiskers, flanked by small curved limbs. The back end has a small tail curved back in a hook-like position. Variant $C$ has pairs of adjacent straight serpent bodies with zigzag margins (1), a head with small flanking limbs at the opposing ends of each pair.

Media: Textile, dyed (carbonized or absent) cotton plain weave; dyed camelid hair with back-stitch and whippingstitch used to create Linear mode imagery $(2,3,4)$ or early Block Color imagery (1); dyed cotton plain weave and back

\section{Distribution:}

\begin{tabular}{llllll} 
Paracas sector & Context & Sp. & Object type & Form & Technique \\
\hline (1) Wari Kayan & 49 & 28 & tunic neck border & fragmentary & Embroidery \\
(1) Wari Kayan & $12(382)$ & 82 & ñañaka, headcloth & Headcloth 1 & Embroidery \\
(2) Wari Kayan & $190(290)$ & 79 & ñanaka, headcloth & Headcloth 1 & Embroidery \\
(3) Wari Kayan & $190(290)$ & 84 & ñañaka, headcloth & Headcloth 1 & Embroidery \\
(4) Wari Kayan & 310 & $56 a$ & probable headcloth & fragmentary & Embroidery \\
(5) Wari Kayan & 188 & $\mathrm{~s} / \mathrm{n}$ & headcloth borders & atypical at WK & Embroidery \\
(6) Wari Kayan & 254 & 7 & mantle center band & Mantle 3 & Cross looping
\end{tabular}

5. Caecilians are lizard species that have lost all limbs, or in some cases retain vestigial forelimbs (Peters 1991). They live underground in humid forest environments radically unlike the Paracas desert. Other candidates for natural inspiration for this imagery include centipedes and seaworms. 
b

a
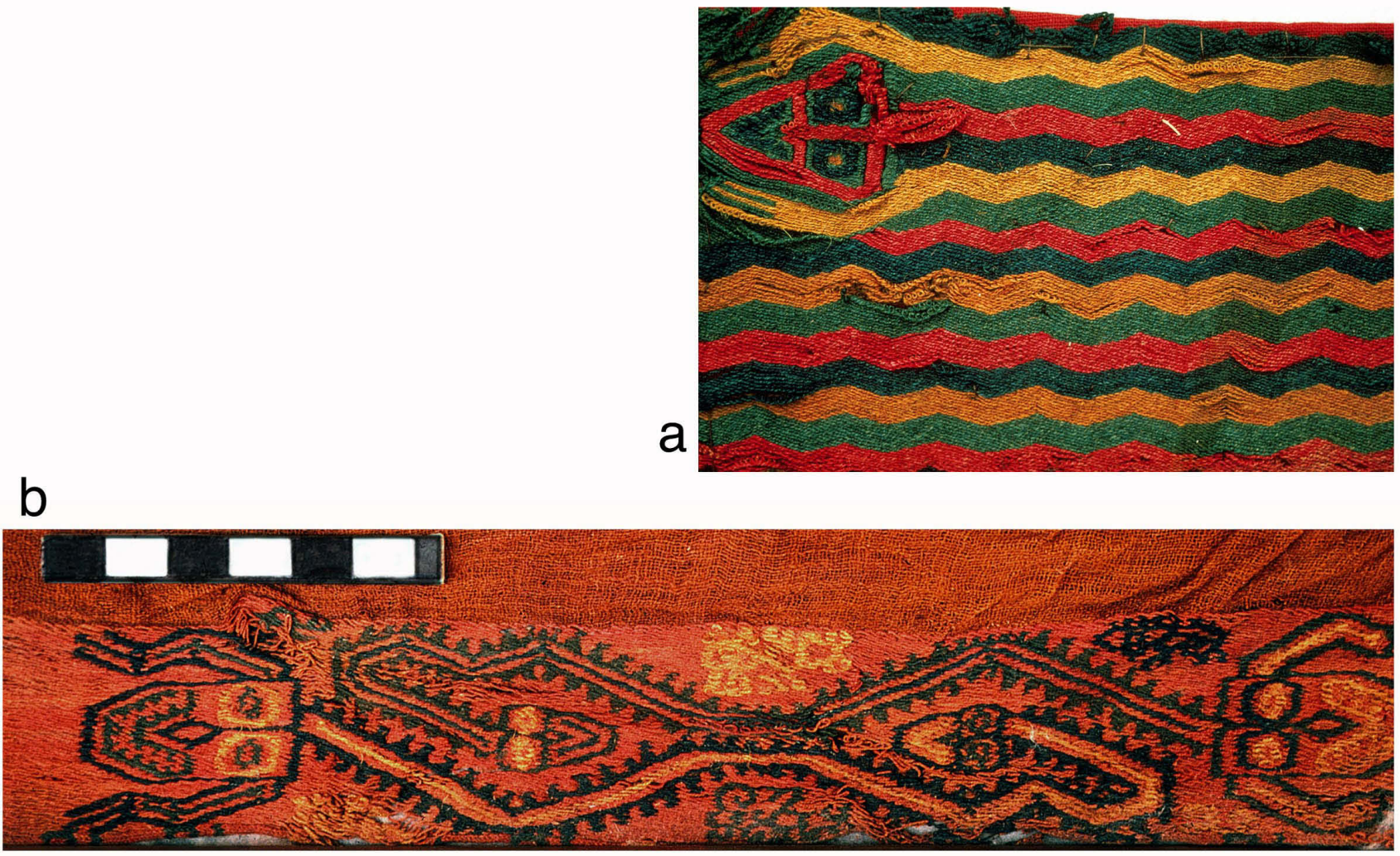

C

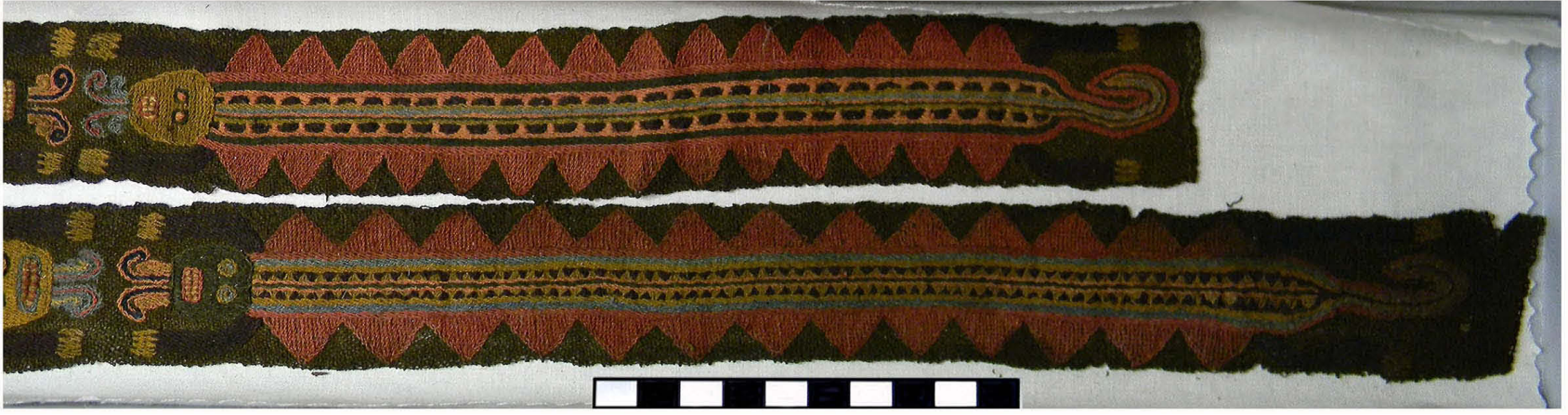

Figure 12. a. Wari Kayan 49 sp. 28, unku, tunic neck border, MNAAHP RT 4676, photo AP; b. Wari Kayan 12(382) sp. 82, ñañaka, Headcloth 1, MNAAHP RT 2793, photo AP; c. Wari Kayan 188 sp. s/n woven and embroidered borders, probably of a headcloth, AMNH 41.2/8898, photo AHP.

stitch used to create Block Color mode embroidery $(5,6)$; Cross-looping with tubular binding, typically used on garment margins, used to cover a central seam (7).

Color: (1) green outlines, overall pattern of stripes and figure elements in red, dark blue, yellow-gold or orangegold, and green; $(2,3)$ red embroidered background, figures in dark blue, green, yellow-gold; $(4,5,6)$ dark purple background, polychrome figures; (7) red with polychrome figures.

Commentary: Variant A's three examples are worked on the same type of headcloth, and two, with different background colors, come from the same mortuary bundle.
Because this motif has a principal head with forelimbs and a small head at the other end, it is related to single-headed serpents, which have many similar elements. The later Block Color depictions of Variant B are worked on unusual headcloths with a dark purple-brown background, one of which is a woven camelid band on which the figure is embroidered, an early Nasca style found in contemporary textiles of the lower Ica valley and Nasca watershed.

Variant $\mathrm{C}$ resembles this group as each band appears to end in one head, but it can also be interpreted as depiction of a two-headed serpent with tiny front limbs, like those below. 


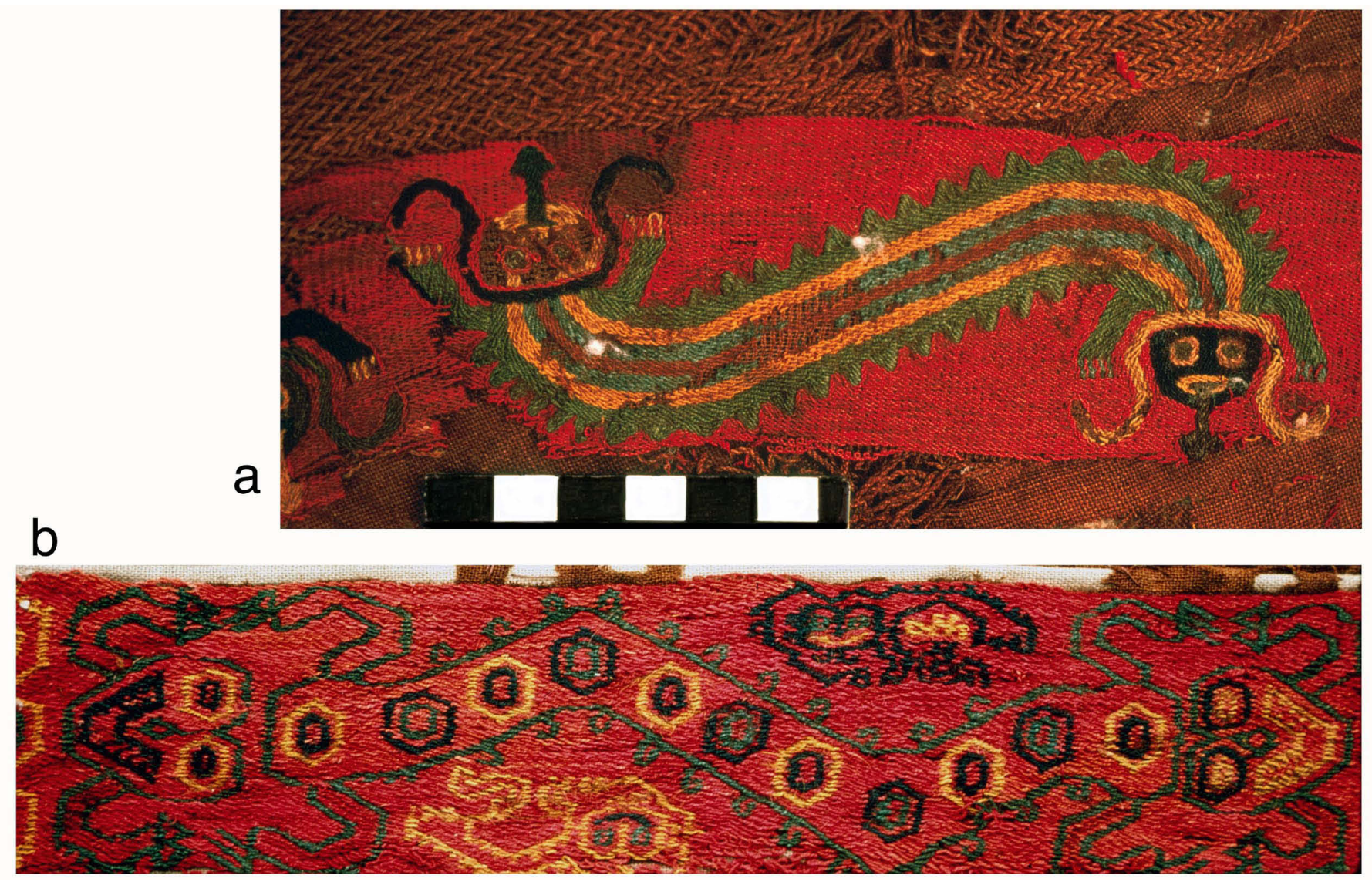

Figure 13. a. Wari Kayan 243 sp. 26, man's skirt, MNAAHP RT 154, photo AP; b. Wari Kayan 49 sp. 43, man’s skirt, MNAAHP RT 2674, photo AP.

\section{Zig-zag two-headed serpent-like creatures with fore- limbs: (Figure 13)}

Serpentine figures with small limbs flanking the head, at both ends and curving whickers (or feelers). A band with small protrusions along its margins has a serpent-like head at each end with a pair of curved chin whiskers flanked by small curved limbs ending in fingers. Variant A, in the Block Color mode, has an S-curved body with serrated margins and oval heads with a knife-like tongue. Variant B, in an unusual Linear mode style on headcloths, has a zigzag body with a pattern of concentric disks and small hooks on the margins, serpent-like heads and small feline or other motifs filling triangular spaces on each side.

Media: Textile, plain weave natural beige or ochre cotton $(2,3,5)$ and matching plied fringe $(3,5)$, or dyed (carbonized or absent) cotton; dyed camelid hair with back-stitch and whipping-stitch used to create Linear mode imagery $(3,4)$, back-stitch used to create Block Color embroidery $(1,2,5)$.

Color: (1) bright green background, figures in dark blue, red and yellow-gold; $(2,3)$ red embroidered background, figures in dark blue, green, yellow-gold; $(3,5)$ segmented background in purple, medium blue, pink, yellow, and brown, on each segment figures are worked in the contrasting colors.

\section{Distribution:}

\begin{tabular}{llllll} 
Paracas sector & Context & Sp. & Object type & Form & Technique \\
\hline (1) Wari Kayan & 243 & 20 & unkuña, open-sided tunic & Tunic 5 & Embroidery \\
(2) Wari Kayan & 243 & 26 & man's skirt or loincloth & fragmentary & Embroidery \\
(3) Wari Kayan & 49 & 43 & ñañaka, headcloth & Headcloth 1 & Embroidery \\
(4) Wari Kayan & $190(290)$ & 77 & ñañaka, headcloth & Headcloth 1 & Embroidery \\
(5) Wari Kayan & 310 & $56 b$ & man's skirt or loincloth & fragmentary & Embroidery
\end{tabular}


Commentary: The earliest version is probably the very early Block Color mode figures on a green background on the unkuña tunic WK 243 Sp. 20. An S-curved variant in a more developed Block Color style, on a fragmentary male skirt (or loincloth?), is from the same mortuary bundle. The motif is adopted into the phase 1 Linear mode headcloths in an unusual style with polychrome concentric circles along the body, reminiscent of the bodies of the S-curved two-headed serpents in WK 421 (above). The version in WK 49 is depicted in the color scheme typical of Wari Kayan Linear mode headcloths, while that in WK 190 (290) is on a border divided into rectangular segments of contrasting colors, a style associated with early Nasca color schemes and iconography. The Block Color version of this motif appears again on a border divided into bright-colored trapezoidal segments with stepped margins, a phase
1B style, on a fragmentary possible (anako?) loincloth from the core of WK 310.

\section{Two-headed serpent-bodied creatures with forelimbs, curving as a Z-like motif and overlapping other two- headed serpents: (Figure 14)}

A well-defined iconic group in the Linear Mode, with a bandlike body with serrated margins, strongly curving in the $\mathrm{Z}$ direction, that ends in two serpent-like heads with a pair of curved whiskers that also end in serpent heads, flanked by small curved limbs ending in fingers. Each end overlaps two curving double-headed serpents of different lengths. The rotational symmetry is broken in the central span of the band-body, where two bands ending in serpent heads emerge on one side.

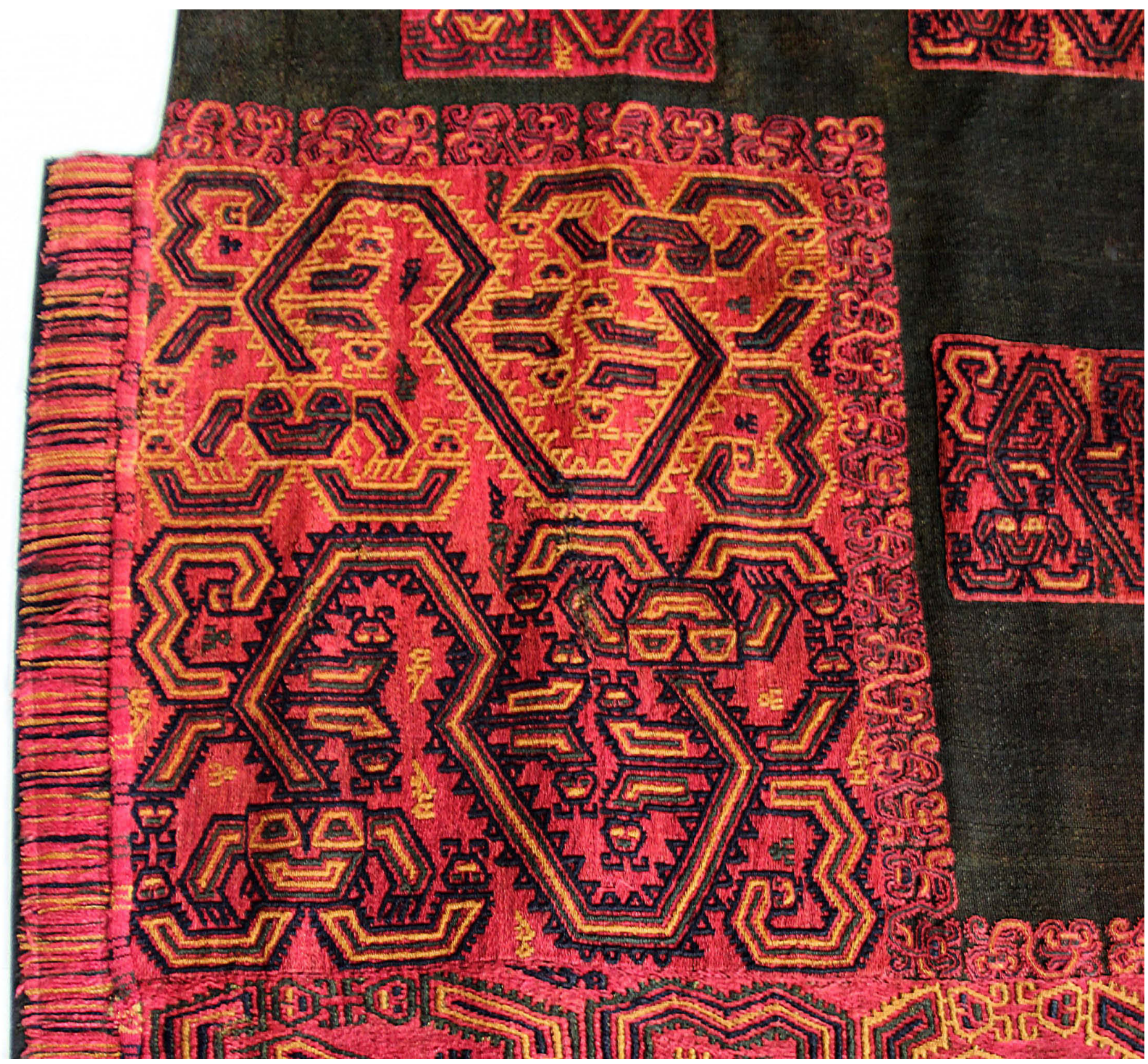

Figure 14. Wari Kayan 364 sp. 1, Mantle 1 with center panels, MRI oooo1-02. Photo courtesy of Museo Regional de Ica/ Ministerio de Cultura del Perú. 
Distribution:

\begin{tabular}{llllll} 
Paracas sector & Context & Sp. & Object type & Form & Technique \\
\hline (1) Wari Kayan & 392 & 5 & Mantle & Mantle 1 & Embroidery \\
(2) Wari Kayan & 364 & 1 & mantle, center panels & Mantle 1 & Embroidery
\end{tabular}

Media: Textile, plain weave cloth probably dyed (absent) in both central ground and border bands (1), dyed camelid hair cloth on center and cotton on borders with back-stitch and whipping-stitch used to create Linear mode imagery, cross-looped edging and plied yarn fringe.

Color: (1) red border background, with dark blue, green, and yellow-gold figures; (2) dark blue cloth, red border background, squares and outlining, dark blue, green, and yellow-gold figures, edging and fringe in the embroidery colors.

Commentary: This icon is represented on the borders of two large mantles. The mantle from the outer layer of WK 364 also has a smaller scale version depicted on 'chessboard' rectangles across its central ground, as well as small double-headed serpent figures lining the inner border margins. These two mantles depict the exact same motif, even repeating an odd detail in the center of each figure in which two ends of the (same?) serpent figure emerge from the same side of the band. It seems likely that the well-preserved mantle from WK 364 is a direct copy of the deteriorated mantle on the outer layer of WK 392.

\section{Serrated bands with a head at each end with two curved rays and small forelimbs: (Figure 15)}

Two variants, both on llautu headbands. Variant A has a band with margins lined by small hooks and ending in finger-like lines, bent at right angles to form a $\mathrm{Z}$, a head adjacent to each end with small lateral ears and a headdress of two curved loops and a central element, flanked by small upraised limbs ending in fingers. Variant B has a straight band with serrated margins, ending in a square head at one or both ends (on the same object) with two fret-like loops, flanked by small upraised limbs ending in fingers.

\section{Distribution:}

\begin{tabular}{llllll} 
Paracas sector & Context & Sp. & Object type & Form & Technique \\
\hline (1) Wari Kayan & 49 & 2b & llautu, looped headband & tubular band & Looping \\
(2) Wari Kayan & 89 & 6 & llautu, braided headband & flat band & Slit tapestry
\end{tabular}
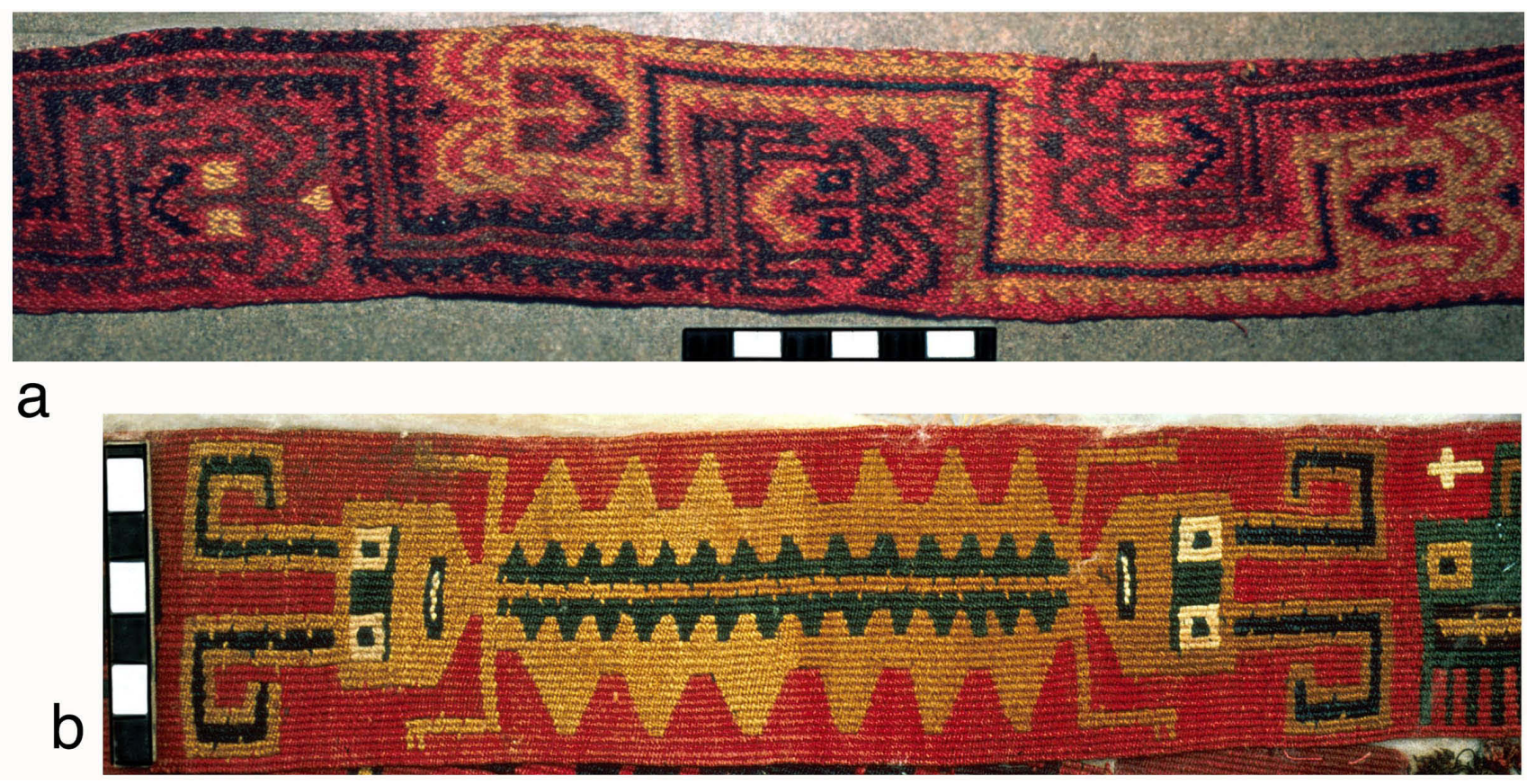

Figure 15. a. Wari Kayan 49 sp. 2a, llautu, tubular looped headband, MNAAHP RT 3634, photo AP; b. Wari Kayan 89 sp. 6, llautu, slit tapestry headband, MNAAHP RT 183, photo AP. 
Media: Textile, tubular looping (1) or slit tapestry (2).

Color: $(1,2)$ red background with dark blue, green, and yellow-gold figures, (2) with white facial details.

Commentary: The antecedent for these motifs may include the bands ending in rayed heads in the Wari Kayan assemblage, but they more closely resemble Paracas tradition versions of this icon, often represented on headbands of the close-knotted type.

\section{Straight-bodied two-headed creatures with zigzag mar- gins and four limbs: (Figure 16)}

Within this group of motifs four variants are distinguished which may be examples of the same icon, or perhaps not. Variant A is a small creature (1) with a straight bandlike body with serrated margins and a head at each end with insect-like features, flanked by small curving limbs. Variant $\mathrm{B}$ is a small creature $(2,3)$ with a straight band-like body with serrated margins and a head at each end with felinelike features, flanked by small curving limbs. Variant $\mathrm{C}$ is a larger-scale creature (4) with a wide lozenge-shaped body with serrated edges and more developed pairs of limbs and feline-like heads with sets of three long curving whiskers and a human head adjacent to each mouth. Variant D is a small creature (5) with a straight band-like body with serrated margins and a principal head at one end with felinelike features, a secondary oval eared head at the other end, both flanked by small curving limbs.

\section{Distribution:}

\begin{tabular}{llllll} 
Paracas sector & Context & Sp. & Object type & Form & Technique \\
\hline (1) Wari Kayan & 85 & 12 & man's wraparound skirt & Fragmentary & Embroidery \\
(2) Wari Kayan & 451 & 26 & anako, headcloth & Fragmentary & Embroidery \\
(3) Wari Kayan & 298 & 37 & band with looped tabs & atypical at WK & Embroidery \\
(4) Wari Kayan & 310 & 26 & mantle, center panels & Mantle 1 & Embroidery \\
(5) Wari Kayan & 38 & 39 & anako, mantle, tab fringe & Anako type & Embroidery
\end{tabular}

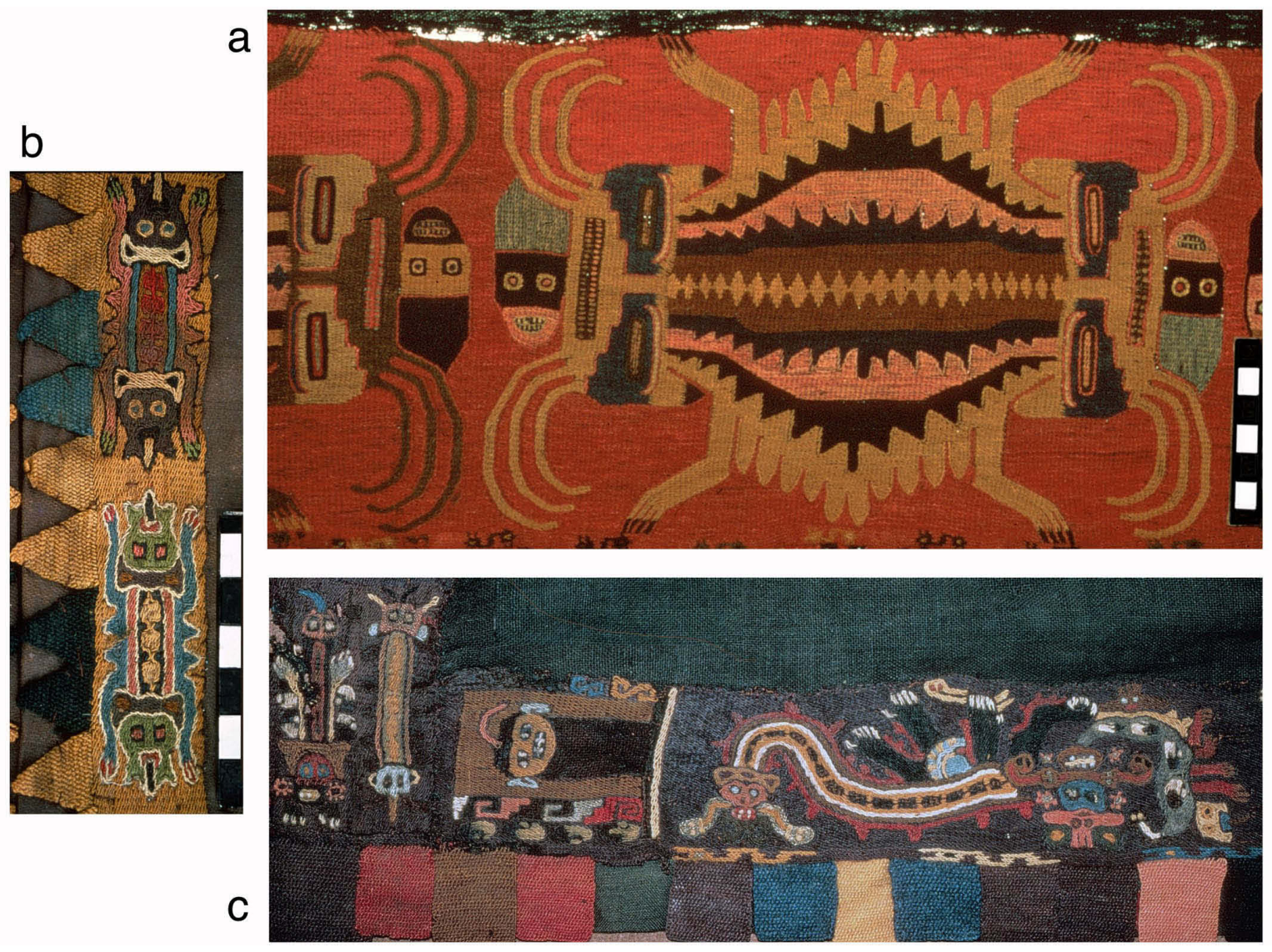

Figure 16. a. Wari Kayan 451 sp. 26, anako-type headcloth MNAAHP RT 2558, photo AP; b. Wari Kayan 310 sp. 26, Mantle 1 with center panels, MNAAHP RT 1532, photo AP; c. Wari Kayan 38 sp. 39, anako-type mantle, MNAAHP RT 2843, photo AP. 
Media: Textile, plain weave natural beige cotton (1), dyed (carbonized, absent) cotton or dyed camelid hair $(4,5)$, with back-stitch embroidery used to create Block Color mode imagery; with looped tab fringe $(2,3,5)$ or plied fringe (4).

Color: (1) natural beige cloth, red background, polychrome figures; (2) absent cloth, yellow border background, polychrome figures, triangular tabs in embroidery colors; (3) absent cloth, red background, polychrome figures, red rectangular tabs; (4) dark blue cloth, red background, polychrome figures, plied fringe in the embroidery colors; (5) dark green cloth, purple border background, polychrome figures, rectangular tabs in the embroidery colors.

Commentary: These motifs bear a close relationship to other two-headed serpentine figure, but also to others with insect features. With the exception of the phase $1 \mathrm{~A}$ man's skirt (which has innovative conventions and colors) most of these icons are associated with garment types like those of the Nasca region, such as the 'anako' type headcloth and small mantle and a central decorative band (3) in WK 298 , that probably was joined to two cloth panels of a large mantle. Mantle WK 310 Sp. 26 is more typical of the Wari Kayan assemble, and its motif is identical to a probably earlier mantle in the same color scheme and fringe type (though without the 'chessboard' panels over the central ground) - with uncertain contextual data, so not included in the chart. The motifs in the anako-type mantle WK $38 \mathrm{Sp} .39$ have a principal and secondary head, thereby resembling insect-like figures. They also resemble the large serpentine appendage that emits from the feline-like head of the complex figurative motif repeated on the rest of the mantle border.

\section{Twisted or intertwined two-headed serpents: (Figure 17)}

In this icon group, once again motifs vary in their depiction of 'two-headed' and in the presence of small forelimbs. Variant A depicts two bands that end in a serpent-like head at each end, contrasting in color, twisting four times in the ' $\mathrm{Z}$ ' direction. Variant B depicts two bands with zigzag margins that each end in a feline-like head with protruding tongue, contrasting in color and pattern, twisting four times in the ' $\mathrm{Z}$ ' direction so that one head protrudes at each end of the motif. Variant $C$ depicts two bands that end in a serpent-like head with two curling whiskers, flanked by small bent limb ending in fingers, at each end, contrasting in color, twisting twice in the ' $\mathrm{Z}$ ' direction; in the central space is a small bird/insect figure in dorsal splayed position with protruding curved whiskers, curved wings(?) and curved legs that create an outline similar to the rayed headdress or headdress ornament (Figure 3). Variant D depicts two bands in contrasting colors that twist in 'S' direction around oval spaces in a third color, both joining at each end at the top of a feline-like head.
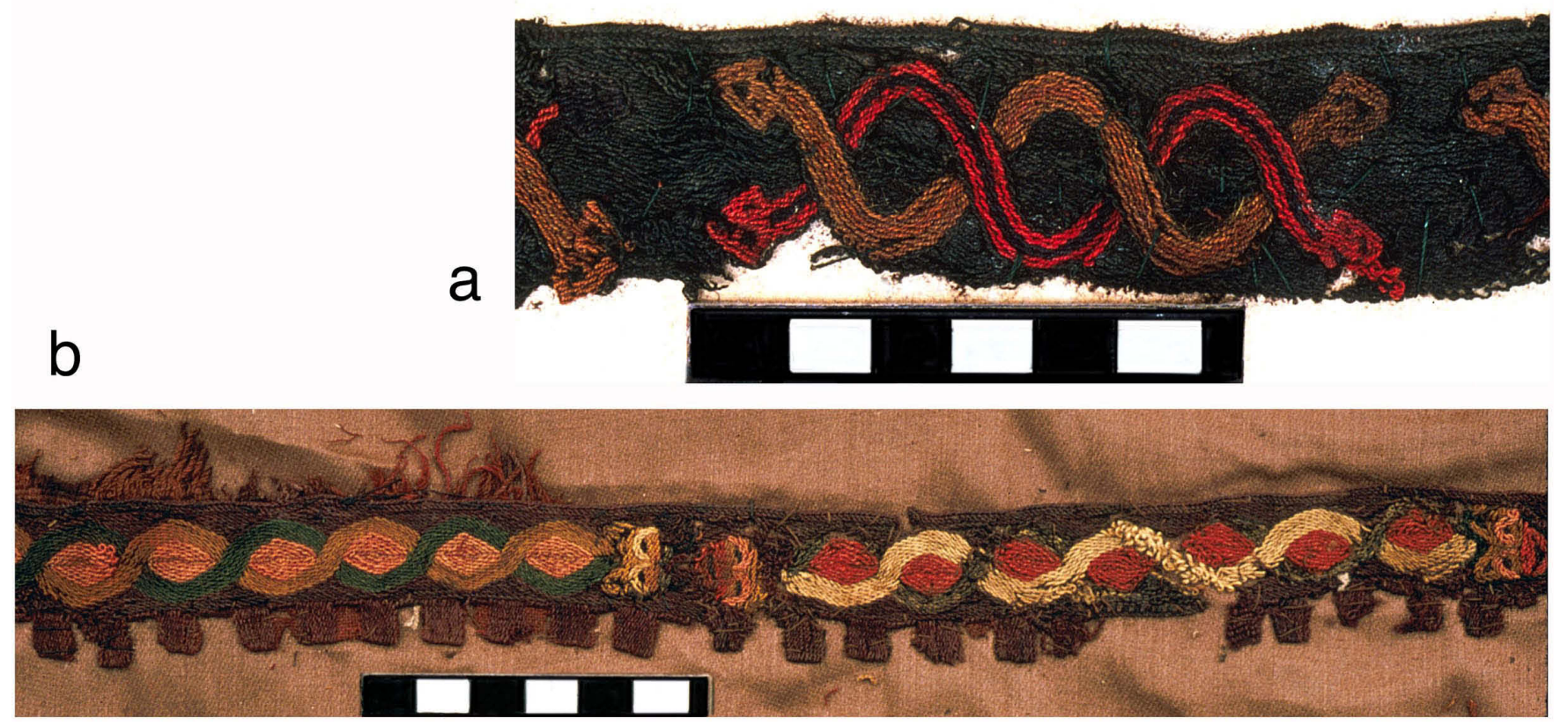

Figure 17. a. Wari Kayan 94 sp. 57, unkuña tunic (Tunic 5) MNAAHP RT 2414, photo AP; b. Wari Kayan 451 sp. 17, anako-type headcloth, MNAAHP, photo AP. 
Distribution:

\begin{tabular}{llllll} 
Paracas sector & Context & Sp. & Object type & Form & Technique \\
\hline (1) Wari Kayan & 94 & 17 & unkuña, open tunic & Tunic 5 & Embroidery \\
(2) Wari Kayan & 91 & 48 & wara loincloth & fragmentary & Embroidery \\
(3) Wari Kayan & 16 & $2-7$ & unkuña, open tunic & Tunic 5 & Embroidery \\
(4) Wari Kayan & 451 & 17 & probable headcloth & fragmentary & Embroidery
\end{tabular}

Media: Textile, plain weave dyed (carbonized, largely absent) cotton $(1,4)$, brown, deteriorated cotton (2), natural beige cotton (3), all with back-stitch embroidery used to create Block Color mode imagery, some with plied fringe $(2,4)$.

Color: (1) dark purple border background, red, green and brown-gold figures; $(2,3)$ red border background, figures in dark blue, green and yellow-gold; (4) red cloth, dark purple border background and inner tabs, polychrome figures.

Commentary: The four variants are each represented by one object and have significant differences, yet the first three are clearly reinterpretations of a single icon. The ply structure and direction correspond to the plied fringes found on contemporary garment margins. Variant D is depicted in a later, Nasca-related style, its body has the opposite twist, characteristic of yarns for weaving and embroidery, and it closely resembles patterns worked in complex flat braiding (diagonal interlace) on contemporary llautu headbands.

\section{Conclusions}

By examining all known examples of thematically related motifs in a single mortuary tradition, it is possible to demonstrate the importance of representational conventions and production techniques in a modern viewer's perception of similarity and difference among images. If one parts from a single object and compare it to a small sample of published objects with apparently similar imagery, it is too easy to fall into the fallacy of equating rather different icons because their makers shared similar representational conventions and production practices, or on the other hand fail to identify the iconic relationships among motifs created in different media or by different producer communities. By examining all known versions from a set of related contexts, we can see that similar motifs cluster in a group of interrelated near-contemporary contexts, sometimes in similar colors or on the same type of garment, demonstrating that both their conventions and meanings have been linked to social connections among those who produced, used and observed these textiles.
Examining sequences of reinterpretation of motifs such as the rayed head and the two-headed serpent, we can trace their 'first' appearance (in this assemblage, as preserved and recorded) on an object with certain materials, techniques, production style and color scheme, and their subsequent adaption to others. Many of the artifacts associated with this thematic group appear to mark influences from the south, both Ocucaje and the Nasca region, and their adoption and adaption by the contemporary producers, linked to the Topará tradition, who maintain and reproduce this mortuary tradition. However, we suspect that the influences also come from more diverse and geographically dispersed producer communities for whom we do not have an archaeological record with textile preservation.

While the original meanings of this imagery are not accessible, combining a thematic approach with a search for elements of the natural, anthropogenic and social environment referenced in mythic beings provides insights and questions for future research. This analysis did not assume the validity of the themes elucidated by previous researchers, so it is encouraging to note that our data and observations support Paul's proposed association between serpents, bands and hair, as well as observations by Frame (1986) and Desrosiers (2008) regarding relationships between textile imagery, textile structures, and the movements of needle and hand in creating them. By providing a more complete map of the incidence of this group of motifs in the known assemblage, it no longer seems problematic that early rayed heads seem related to insectivorous birds while later rayed heads seem to resemble a spider or crustacean: clearly the imagery is imbedded in complex spheres of reference within evolving mythic discourse.

\section{Acknowledgements:}

I thank Serge LeMaitre for kindly hosting our oral presentations in Brussels. I thank Lena Bjerregaard and Jessica Lévy Contreras for encouraging me in the search for a logical focus within a large set of interrelated data in order to demonstrate this analytic approach. I thank my museum-based colleagues, particularly Susana Arce of the Museo Regional de Ica "Adolfo Bermúdez Jenkins" and Carmen 
Thays and Maribel Medina of the Museo Nacional de Antropología, Arqueología e Historia del Perú, for their heroic and systematic efforts to safeguard and document these textiles.

\section{Abbreviations:}

AMNH - American Museum of Natural History

MI-UNSAAC - Museo Inka, Universidad Nacional San Antonio Abad de Cusco

MNAAHP - Museo Nacional de Antropología, Arqueología e Historia del Perú

MRI - Museo Regional de Ica "Adolfo Bermúdez Jenkins"

PMEA - Peabody Museum of Ethnology and Archaeology, Harvard University

Research photos by the author (AHP) or by Anne Paul (AP) of objects in the above museums used with permission; a photo provided by the museum is noted in the figure caption.

\section{References:}

Archivo Julio C. Tello (comp.)

2012 Wari Kayan. Cuaderno del Archivo Tello 9. Lima: Museo de Arqueología y Antropología, Universidad Nacional Mayor de San Marcos.

Bachir Bacha, Aïcha

2017 El edificio de los frisos de Ánimas Altas. Ser Paracas en el valle bajo de Ica. Boletín de Arqueología PUCP 22: 191-225. https://doi.org/10.18800/ boletindearqueologiapucp.201701.008

Carmichael, Patrick

2016 Nasca origins and Paracas progenitors. Nawpa Pacha 36(2):53-94.

Carrión Cachot, Rebeca

1949 Paracas, Cultural Elements. Corporación Nacional de Turismo, Lima.

Dawson, Lawrence E.

1979 Painted Cloth Mummy Masks of Ica, Peru. In A. P. Rowe, E. B. Benson and A.-L. Schaffer (eds.), The Junius B. Bird Pre-Columbian Textile Conference, pp. 83-104. Textile Museum and Dumbarton Oaks, Washington.

Desrosiers, Sophie

2008a Revisiting the Ocucaje Opened Tunic from the Textile Museum; Washington, D.C.: Textile Models and the Process of Imitation. In The Textile Society of America Symposium Proceedings, Paper 89. http://digitalcommons.unl.edu/tsaconf/8g.

Dwyer, Jane Powell

1979 The Chronology and Iconography of Paracas-style Textiles. In A. P. Rowe, E. B. Benson and A.-L. Schaffer (eds.), The Junius B. Bird Pre-Columbian Textile Conference, pp. 105-128. Textile Museum and Dumbarton Oaks, Washington.
Frame, Mary

1986 The Visual Images of Fabric Structures in Ancient Peruvian Art. In A. P. Rowe (ed.), The Junius B. Bird Conference on Andean Textiles, April 7th and 8th, 1984, pp. 47-8o. The Textile Museum, Washington, DC.

2007 Las prendas bordadas de la necrópolis de Wari Kayan. In E. León (ed.), Hilos del Pasado: El aporte francés al legado de Paracas, pp. 65-73. Instituto Nacional de Cultura, Lima.

Gell, Alfred

1998 Art and Agency. Oxford University Press, London and New York.

King, Mary Elizabeth

1965 Textiles and Basketry of the Paracas Period, Ica Valley, Peru. PhD. Dissertation, Department of Anthropology, University of Arizona, Tuscon. University Microfilms, Ann Arbor.

León, Elmo

2007 Cronología de los fardos funerarios de Wari Kayán, Paracas Necropolis. In E. León (ed.), Hilos del Pasado: El aporte francés al legado de Paracas, pp. 33-47. Instituto Nacional de Cultura, Lima.

Lévy Contreras, Jessica

2017 Los apéndices serpentiformes en la iconografía Nasca: repertorio y significado. Masters thesis in Archaeology, mention in Andean Studies, Pontificia Universidad Católica del Perú (PUCP).

Makowski Hanula, Krzysztof

2000 Los seres sobrenaturales en la iconografía Paracas y Nasca. In Krzysztof Makowski (ed.), Los Dioses del Antiguo Perú, pp. 277-311. Banco de Crédito, Lima.

Massey, Sarah

1991 Social and political leadership in the lower Ica Valley: Ocucaje phases 8 and 9. In A. Paul (ed.) Paracas Art and Architecture: Object and Context in South Coastal Peru, pp. 315-348. University of Iowa Press, Iowa City.

Menzel, Dorothy, John H. Rowe and Lawrence E. Dawson 1964 The Paracas Pottery of Ica: A Study in Style and Time. University of California Publications in American Archaeology and Ethnology 50. University of California, Berkeley.

Orefici, Giuseppe

2012 Cahuachi: Capital Teocrática Nasca. V. I. Universidad San Martín de Porres, Lima.

O’Neale, Lila M.

1937 Archaeological Explorations in Peru, Part III. Textiles of the Early Nazca Period. Field Museum of Natural History, Anthropology, Memoirs 2(3): 118-253.

1942 Textile Periods in Ancient Peru: II. Paracas Cavernas and the Grand Necropolis. University of California Publications in American Archaeology and Ethnology 39(2):143-202. 
Panofsky, Erwin

1960 Renaissance and Renascences in Western Art. Almquist and Wiksell, Stockholm.

Paul, Anne

1982 The Chronological Relationship of the Linear, Block Color and Broad Line Styles of Paracas Embroidered Images. In A Cordy-Collins (ed.), Pre-Columbian Art History: selected readings, pp. 255-277. Peek Publications, Palo Alto.

1986 Continuity in Paracas Textile Iconography and its Implications for the Meaning of Linear Style Images. In A. P. Rowe (ed.), The Junius B. Bird Conference on Andean Textiles, April 7th and 8th, 1984, pp. 81-99. The Textile Museum, Washington, DC.

1990 Paracas Ritual Attire: Symbols of Authority in Ancient Peru. University of Oklahoma Press, Norman.

1991a Radiocarbon dates for Paracas. In A. Paul (ed.), Paracas Art and Architecture: Object and Context in South Coastal Peru, pp. 22-53. University of Iowa Press, Iowa City

Peters, Ann Hudson

1991 Ecology and Society in Embroidered Images from the Paracas Necrópolis. In A. Paul (ed.), Paracas Art and Architecture: Object and Context in South Coastal Peru, pp. 240-314. University of Iowa Press, Iowa City.

2000 Funerary regalia and institutions of leadership in Paracas and Topará. Chungara 32(2):245-252.

2014 Paracas Necropolis: Communities of textile production, exchange networks and social boundaries in the central Andes, $150 \mathrm{BC}$ to $\mathrm{AD}$ 250. In D. Y. Arnold and P. Dransart (eds.) Textiles, Technical Practice and Power in the Andes, pp. 109-139. London: Archetype.

2016a The cemetery of Paracas Necropolis: Mortuary Practice and social network. In C. Sinclaire, A. Torre, J. Berenguer (eds.), Tres ensayos sobre Paracas Necrópolis. Historia de la investigación, tecnologías textiles y prácticas mortuorias. Arte Encuentro 2:43-66. Museo Chileno de Arte Precolombino, Santiago. http://www.precolombino.cl/biblioteca/ tres-ensayos-sobre-paracas-necropolis/

2016b Emblematic and Material Color in the Paracas-Nasca Transition. In S. Desrosiers and P. Nuñez-Regueiro (eds.), Textiles amérindiens. Regards croisés sur les couleurs. Mundo Nuevo - Nuevos Mundos, Colloques [en ligne]. https://nuevomundo.revues.org/69877

2017a Headdress Forms in the Paracas Necrópolis Mortuary Tradition. In L. Bjerregaard y A. H. Peters (eds.), PreColombian Textile Conference VII/ Jornadas de Textiles PreColombinos VII, Centre for Textile Research, University of Copenhagen, pp. 214-237. Zea Books, Lincoln. https://digitalcommons.unl.edu/pct7/13/

2017b El testimonio de una tumba: La presencia Nasca en Paracas; "Fardo WK 382", "Fardo WK 378” y "Fardo WK 319" en Anexo: Paracas y Nasca en Wari Kayan. En C. Pardo y P. Fux, (eds.) Nasca, pp. 62-69; pp.
292-299. Museo de Arte de Lima y Museum Reitburg, Lima.

2018a Travels of a rayed head: textile movement and the concepts of center and periphery in the southern Andes, in W. Isbell, M. Uribe and A. Tiballi and E. P. Zegarra, (eds.), Images in Action: The Southern Andean Iconographic Series. Cotsen Institute of Archaeology Press, Los Angeles.

2018b ¿Qué constituye la transición Paracas-Nasca en Paracas Necrópolis? Prácticas mortuorias, artefactos presentes, formas de indumentaria y diversidad sociocultural. Boletín de Arqueología PUCP 25: 91-135.

2019 Paracas Necrópolis: la estructura del fardo y teorías de la práctica mortuoria, in Marco Curatola Petrocchi (Ed.), El Estudio del Mundo Andino, pp. 59-72. Pontificia Universidad Católica del Perú, Lima.

Peters, Ann and Elsa Tomasto-Cagigao

2017 Masculinities and femininities: Forms and expressions of power in the Paracas Necropolis in S. E. M. Scher and B. J. A. Follensbee (eds.), Dressing the Part: Power, Dress, Gender, and Representation in the PreColumbian Americas, pp. 371-449. University Press of Florida, Gainesville.

2018 De Paracas a Nasca: ¿Porqué la necesidad de estudiar una época "transicional"? Boletín de Arqueología PUCP 25:5-18.

Proulx, Donald A.

1989 A thematic approach to Nasca mythical iconography. Faenz: Bollettino del Museo Internazionale delle Ceramiche in Faenza, 75 (4-6): 141-58, plus figures.

Roberts, Christopher M.

2011 Practical Identities: On the Relationship between Iconography and Group identity. In L. Amunsen-Meyer, N. Engel and S. Pickering (eds.), Identity Crisis: Archaeological Perspectives on Social Identity, Proceedings of the $42^{\text {nd }}$ (2010) Annual Chacmool Conference, pp. 86-95. University of Calgary, Calgary.

Rowe, Ann Pollard

2015 The Linear Mode Revisited, Nawpa Pacha 35/2:237-258.

Rowe, John Howland

1967 Form and meaning in Chavín Art. In J. H. Rowe and D. Menzel, Peruvian Archaeology, Selected Readings, pp. 72-103. Peek Publications, Palo Alto.

Sawyer, Alan

1979 Painted Nasca textiles. In A. P. Rowe, E. B. Benson and A.-L. Schaffer (eds.), The Junius B. Bird Pre-Columbian Textile Conference, pp. 129-150. Textile Museum and Dumbarton Oaks, Washington, DC.

Tello, Julio C. y Toribio Mejía Xesspe

1979 Paracas, segunda parte: Cavernas y Necrópolis. Universidad Nacional Mayor de San Marcos y Institute of Andean Research, Lima. 


\title{
Representaciones textiles en los iconos de la litoescultura Tiwanaku: distribución y significado
}

\section{Textile representations in the iconography of the Tiwanaku lithic sculpture: distribution and meaning}

\author{
Carolina Agüero ${ }^{1}$ \& Arturo Martínez ${ }^{2}$
}

\begin{abstract}
Resumen
Se presenta la síntesis de una investigación destinada a identificar representaciones textiles en los iconos de la litoescultura Tiwanaku. Previamente ya habíamos usado un análisis componencial para segregar motivos y elementos en sus tres principales figuras: Personaje Frontal, Personajes de Perfil y Banda Faja. Luego se ubicaron sus referentes textiles en colecciones arqueológicas de Chile, Perú y Bolivia para precisar patrones de distribución espacial de las prendas y su iconografía en las distintas zonas que estuvieron en la órbita de Tiwanaku. Además, este estudio ha sido complementado con una exploración de los saberes ancestrales acerca de los iconos que están plasmados en estas figuras y que dicen relación con "plantas medicina o plantas maestras”. Esto, junto a lo que su distribución diferencial puede estar indicando, abren nuevas e interesantes aproximaciones interpretativas.
\end{abstract}

Palabras claves: Tiwanaku, escultura lítica, representaciones textiles, plantas maestras, arqueología colaborativa.

\begin{abstract}
We present a synthesis of an investigation designed to identify textile representations in the icons of the Tiwanaku lithic sculpture, using a componential analysis to segregate motifs and elements in its three main figures: Frontal Personage, Profile Personage and Belt Band. Then the textiles depicted are identified in archaeological collections in Chile, Peru and Bolivia in order to define patterns of spatial distribution of the garment types and their iconography in different areas of the Tiwanaku sphere. In addition, this study has been complemented with an exploration of ancestral knowledge about the icons embodied in these figures that relates to medicine plants or master plants. Together with what the differential distributions may indicate, this opens up new and interesting interpretative approaches.
\end{abstract}

Keywords: Tiwanaku, lithic sculpture, textile representations, master plants, collaborative archaeology.

\begin{abstract}
Résumé
Nous présentons la synthèse d'une recherche destinée à identifier les représentations textiles dans les icônes de la sculpture lithique Tiwanaku en utilisant une analyse componentielle afin de distinguer les motifs et les éléments présents dans ses trois principales figures : Personnage Frontal, de Profil et Ceinture. Ensuite les textiles référencés ont été identifiés dans les collections archéologiques du Chili, du Pérou et de Bolivie pour définir les modèles de distribution spatiale des tissus et leur iconographie dans les différentes zones d'influence de Tiwanaku. Aussi, cette étude a été complétée par l'exploration

1. Arqueóloga. Instituto de Investigaciones Arqueológicas y Museo, Universidad Católica del Norte, San Pedro de Atacama, CHILE. CP 14100oo. Email: maguero@ucn.cl

2. Hombre Medicina.
\end{abstract}

DOI: 10.32873/unl.dc.zea.1204

Published in PreColumbian Textile Conference VIII / Jornadas de Textiles PreColombinos VIII, ed. Lena Bjerregaard and Ann Peters (Lincoln, NE: Zea Books, 2020). https://digitalcommons.unl.edu/zeabook/ 
des savoirs ancestraux sur les icônes reproduites dans ces figures et qui sont liées à la consommation de substances psychoactives. Ces éléments, ajoutés à ce que semble indiquer la répartition différentielle, ouvre de nouvelles et intéressantes approches interprétatives.

Mots-clés: Tiwanaku, sculpture lithique, représentations textiles, substances psychoactives, archéologie collaborative

\section{Introducción}

Varios autores habían notado relaciones formales entre la iconografía de la litoescultura Tiwanaku y los textiles (p.e. Conklin 1983; Cordy-Collins 1976). Las esculturas y sus figuras grabadas aparecen usando cintillos, tocados, túnicas y bolsas. Bennett (1946) consideró que los diseños textiles probablemente influenciaron la totalidad del estilo Tiwanaku al identificar patrones textiles en las esculturas del sitio-tipo, particularmente en el monolito que lleva su nombre. También Conklin (1983) sugirió que algunas bandas cefálicas encontradas en momias de Pisagua son las mismas representadas en las cabezas de los monolitos de Tiwanaku, y vió en un friso depositado en el Museum für Volkerkunde (actualmente Ethnologisches Museum), en Berlín, trazas de pintura que insinúan que la arquitectura Tiwanaku estaba pintada con colores similares a los usados en los textiles. Asimisno, Oakland (1986) y Berenguer y Dauelsberg (1989) observaron estrechas similitudes entre las túnicas de los Personajes Frontales y aquellas encontradas en los cementerios del norte de Chile, así como en los gorros de cintillo y casquete de algunos monolitos y aquellos de San Pedro de Atacama (Berenguer 1993). También Zighelboim (1991 Ms.) ha sostenido que la Puerta del Sol es en sí, la representación de un textil: una túnica con su faja. En suma, abundan las sugerencias respecto a que las esculturas Tiwanaku fueron pensadas como representaciones textiles (p.e. Puerta del Sol y Puerta de la Luna) y también como representaciones de personajes que usan prendas textiles (p.e. monolitos Bennett y Ponce).

En esta oportunidad hemos retomado un trabajo realizado hace varios años (Agüero 2001 Ms.; Agüero et al. 2003) proponiéndonos como objetivos principales identificar representaciones de textiles en los iconos de la litoescultura Tiwanaku, ubicar sus referentes en las colecciones arqueológicas, precisar sus patrones de distribución espacial, y con la actual ayuda y conocimientos de Arturo Martínez, aventurarnos en lo que esto probablemente signifique (Figura 1).

El análisis consideró los siguientes soportes líticos: Puerta del Sol, Puerta de la Luna, Monolito Bennett, Monolito Ponce, Monolito El Fraile, Estatuilla de Puno, Kochamama, Idolo del Sol, Bloque de Llojeta, Lito de Takiri, Receptáculo Lítico de Ofrendas, Dintel de Kantatayita y Dintel

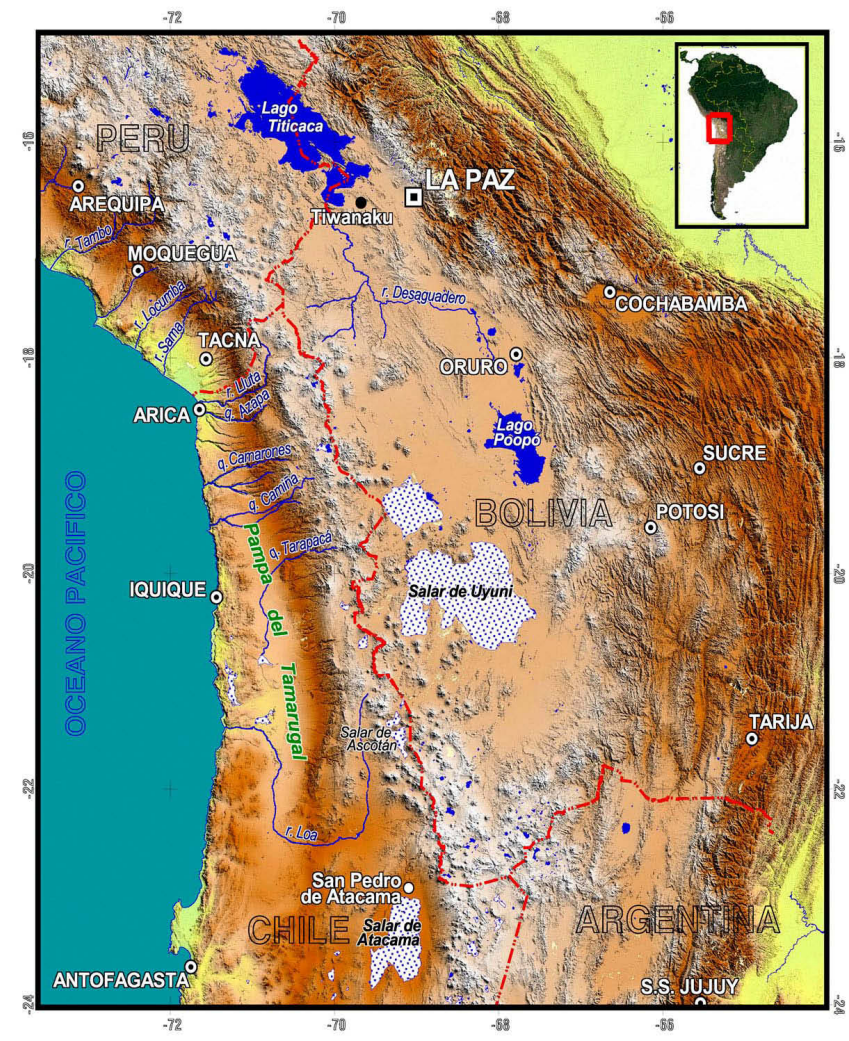

Figura 1. Mapa del área de influencia Tiwanaku en el que se indican los principales sitios mencionados en el texto (Agüero y Uribe 2018: 267, figura 1a).

de la calle Linares. En ellos se discriminaron cuatro niveles sucesivamente incluyentes de segregados: temas, figuras, motivos y elementos (Berenguer et al. 1998; Agüero et al. 2003) (Figura 2). Centrándonos en las tres principales figuras: Personaje Frontal, Personajes de Perfil y Banda-Faja, y los motivos presentes en ellas pudimos identificar motivos que tienen referentes en prendas textiles ayudando a determinar cuáles deben examinarse en las colecciones de la esfera Tiwanaku en Chile, Perú y Bolivia.

Oakland (1986) fue quien primero enfrentó los tejidos desde esta perspectiva, y definió el estilo textil relacionado a Tiwanaku a través de un análisis estilístico de 62 prendas encontradas en ocho sitios arqueológicos del Período Medio dentro del área de influencia de esta cultura altiplánica. El análisis de la iconografía, de la técnica, y en algunos casos, la consideración de los contextos - como en el caso 

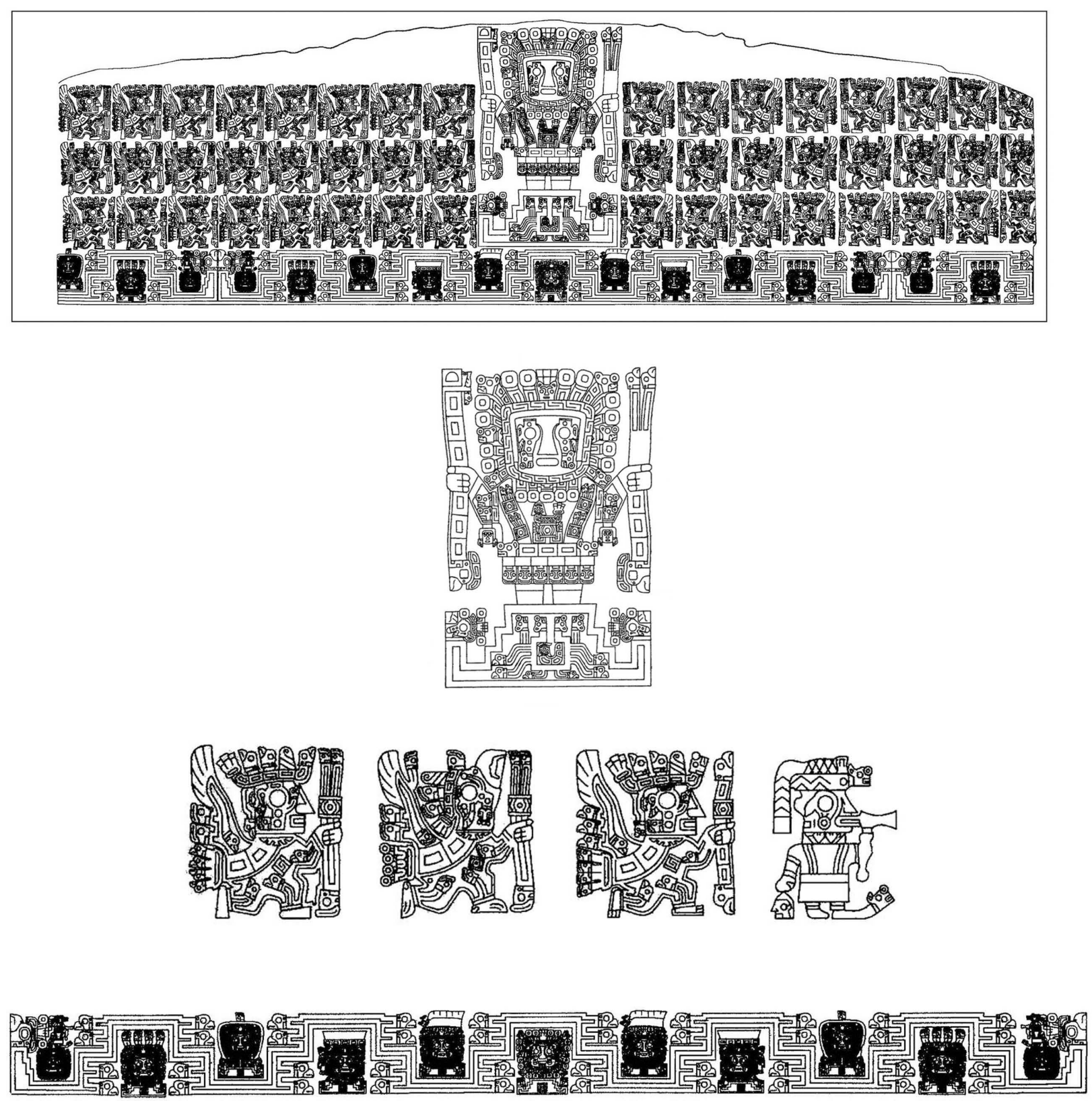

Figura 2. Tema Puerta del Sol y Figuras: Personaje Frontal, Personajes de Perfil y Banda Faja. Imagen basada en Posnansky 1946 Vol.I, Plates. XLV, XLVIa, y en Agüero et al. 2003: 8o, figuras 2, 3 y16.

de Coyo Oriente - podría identificar características formales compartidas con las esculturas líticas, ayudando a definir el estilo textil Tiwanaku el que contrastaría con los estilos, diseños y tecnologías locales. Las investigaciones de Ulloa (1982), Oakland (1986, 1986a, 1992, 1994), y las propias respecto a las tradiciones textiles locales (Agüero
1998, 2000) nos sirvieron de punto de partida para identificar los referentes textiles Tiwanaku; ya que se tuvo que identificar la textilería local - principalmente la de Arica y San Pedro - para segregarla de la Tiwanaku y poder explicar desde nuestra perspectiva las relaciones con la cultura altiplánica. 
Representaciones de textiles en los iconos de la litoescultura Tiwanaku y sus referentes en las colecciones arqueológicas

Las colecciones que estudiamos fueron las siguientes: Az1, Az-3, Az-13, Az-21, Az-103, Llu-51 (Colección Manuel Blanco Encalada); Az-6 (Focacci 1990), Az-71a (excavado por Focacci), Az-71b (Santoro 1980), Az-141 (excavado por Focacci) y PlM-9 (Focacci 1982) (Museo San Miguel de Azapa); Cementerio C (Tiwanaku) de Pisagua (Uhle 1919) (Museo Nacional de Historia Natural); Pica-8 (Instituto de Investigaciones Arqueológicas y Restauración Monumental de la Universidad de Antofagasta) (Zlatar 1984; Agüero 2015) y una prenda en el Museo Chileno de Arte Precolombino (Agüero y Uribe 2018); Tr-40B (Núñez 1981; Oakland 200o) entonces depositada en la Universidad Arturo Prat en Iquique; Coyo Oriente, Solcor-3, Quitor-2, Quitor-5 y Quitor-6 (Museo Arqueológico G. Le Paige, en San Pedro de Atacama); El Descanso y La Cruz (Minkes 2008) y Chiribaya
Baja (Clark et al. 1993) (Museo Chiribaya en Ilo), Algarrobal; M1 (Chen Chen) Cementerio (Vargas 1994 Ms.) (Museo Contisuyo, Moquegua); materiales exhibidos, sin referencia en el Museo Tiwanaku en La Paz y Tiwanaku, y en el Museo de Metales Preciosos en La Paz; Omereque y Mojocoya en el Museo Arqueológico de la Universidad Mayor de San Simón, Cochabamba y en el Museo Antropológico de la Universidad de San Francisco Xavier de Chuquisaca, Sucre. También pude dar un vistazo a la colección de Puqui (Oruro), una parte en el Museo Nacional de Etnografía y Folklore en La Paz, y otra en el Museo Arqueológico de la Universidad Mayor de San Simón en Cochabamba, aunque no hubo demasiado tiempo para hacer un registro sistemático. Finalmente, consideramos algunos textiles publicados por Ulloa (1982), Conklin (1983), Oakland (1986, 1986a), Goldstein (1989, 1990), Espoueys y coautores (1995), Wassén (1972), Strömberg (1956), Bird (1943) y Posnansky (1957).

En estas encontramos las siguientes prendas (Figuras 3 y 4):

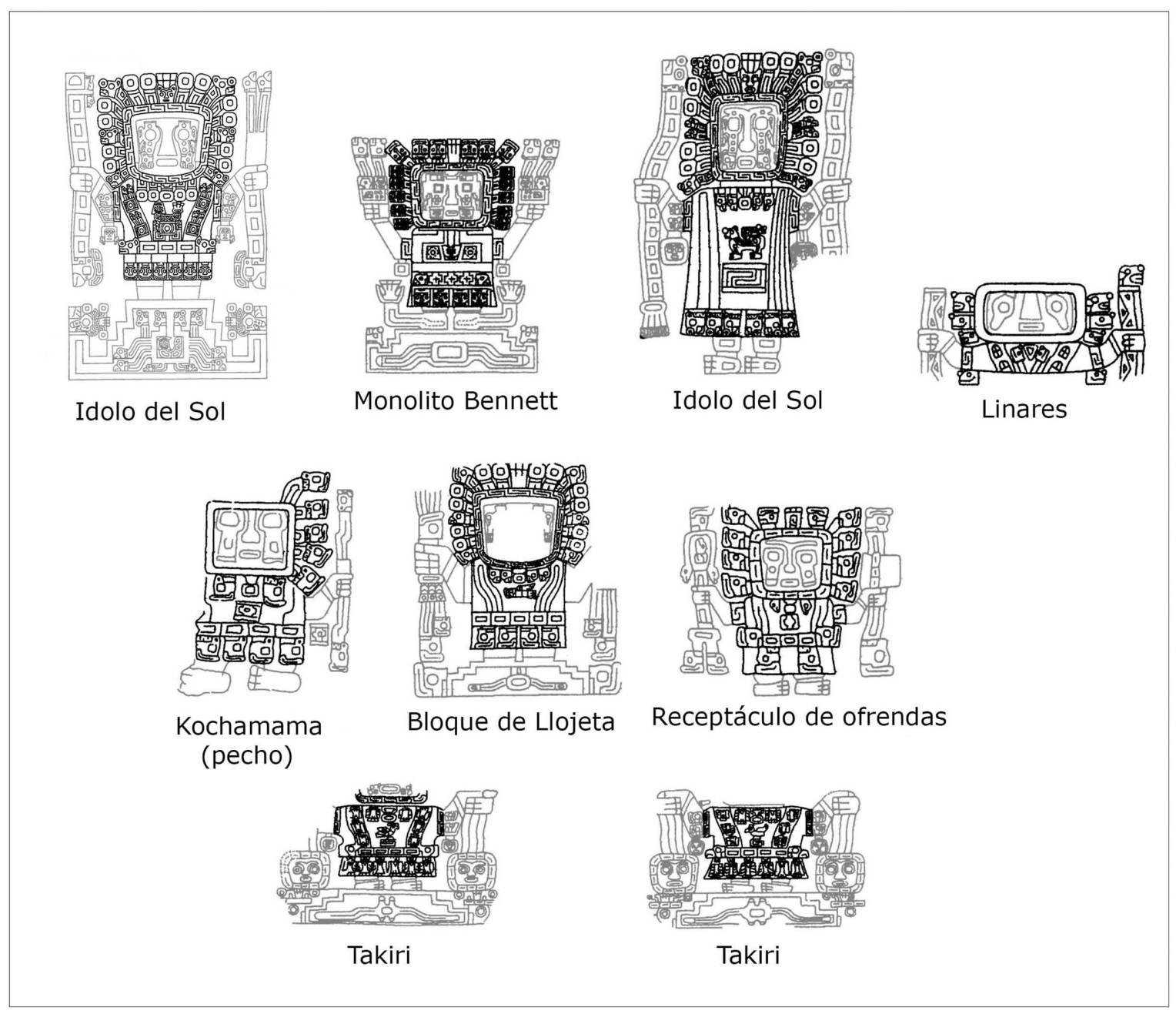

Figura 3. Personajes Frontales con sus túnicas y coronas. Adaptada de Agüero et al. 2003: 53, figura 2. 


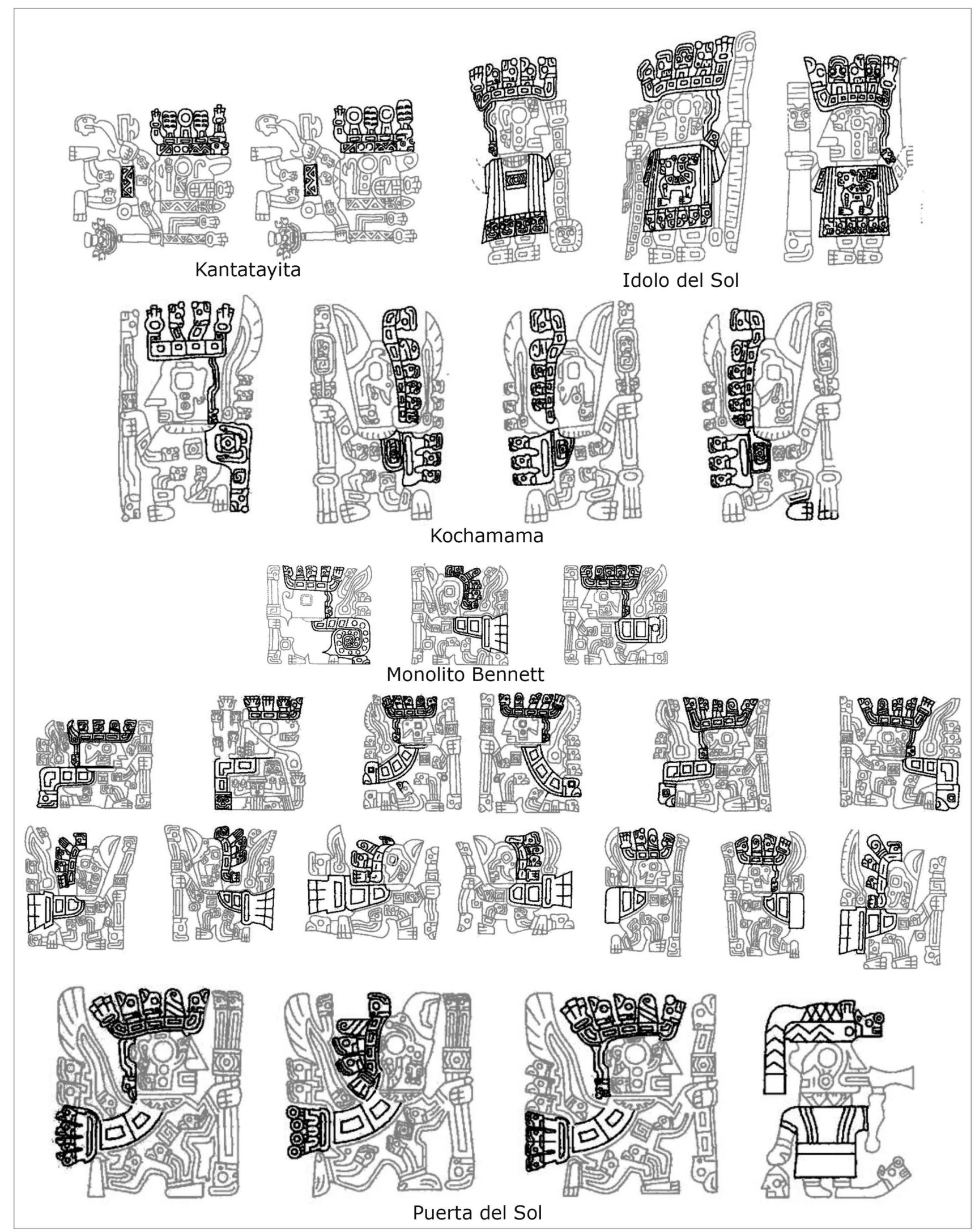

Figura 4. Personajes de Perfil con sus lauraques, bolsas y coronas. Solo los Personajes de Perfil del Idolo del Sol usan túnicas. Adaptada de Agüero et al. 2003: 54, figura 3. 
- Tocado: en los Personajes Frontales rodea la cara y está formado por un Marco facial, en tanto, en los Personajes de Perfil está constituido por una base con apéndices. Los monolitos llevan un tocado que ha sido identificado como de cintillo y casquete, por Oakland (1991) y Berenguer (1993). El tocado está presente en todos los personajes, tanto en los monolitos como en otros soportes líticos que tienen figuras frontales y de perfil, tanto humanas, animales y animalizadas, siendo un atributo de los seres vivos. Es interesante que estos tocados tienen representaciones de plantas "medicina" alucinógenas, como cebil o vilca (Anadenanthera colubrina), aguacoya o cactus San Pedro (Echinopsis pachanoi o Trichocereus pachanoi), así como un caracol de las tierras cálidas del oriente (Strophocheilus oblongus) (Figura 5).

Aunque también podrían tener forma de Bandas Cefálicas: En los Personajes Frontales se compone de los elementos Rectángulo con centro, o vacío, o cruz con/sin cabezas de pez, de aves de perfil o de felinos de perfil en sus extremos. No está en todos los soportes, faltando en el de Linares, Idolo del Sol y Lito de Takiri. En los Personajes de Perfil de
Kantatayita y Linares está representada vacía o con zigzag interior. En las colecciones textiles estas prendas no están puestas en un cuerpo, por lo que no se sabe si se trata de fajas o bandas cefálicas por lo que Uribe (1998) denominó "Bandas Faja" (Figura 6 y 7) a la sucesión horizontal de figuras intercaladas por un meandro o línea sinuosa. Esta adopta tres expresiones, pudiendo aparecer a) en forma independiente sin funcionalidad alguna (Receptáculo lítico de ofrendas), b) insinuando su uso como base o plataforma para figuras antropomorfas (Puerta del Sol y de la Luna), c) cumpliendo explícitamente la función de faja en lo que sería la vestimenta de los monolitos Ponce, Bennett, Kochamama, El Fraile, Idolo Plano e Idolo de Puno (Figura 8). Arturo Martínez piensa que se trata de la representación de cómo se manifiesta la ayahuasca en los (Banisteriopsis caapi), en los rituales en que se consume, es decir, de forma serpentiforme (Figura 9).

Aparte de lo anterior, se observan fajas propiamente tales en los Personajes Frontales, compuestas de elementos como rectángulo con centro, o vacío, o cruz con/sin cabezas de

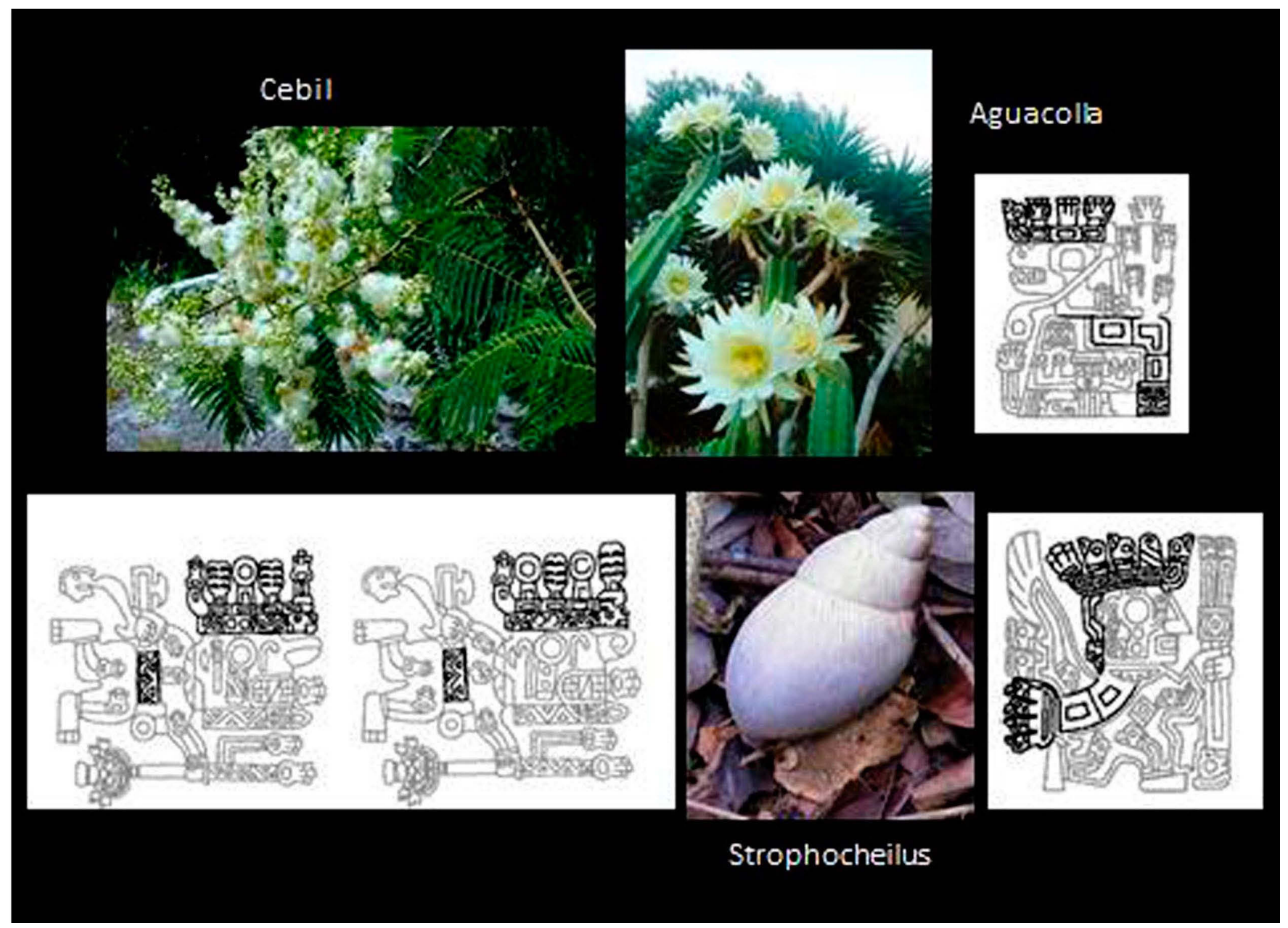

Figura 5. Representación de "plantas medicina o maestras" en algunos iconos. Imágenes producidas por Proyecto FONDECYT 1970073. 


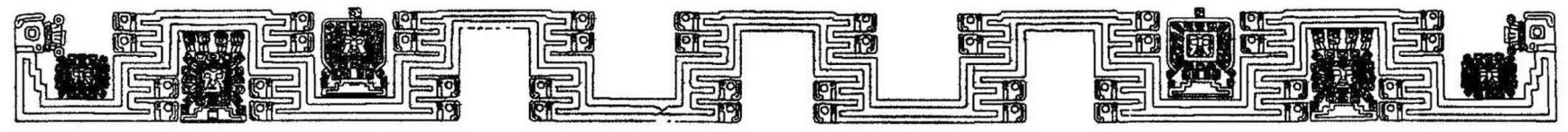

Puerta del la Luna

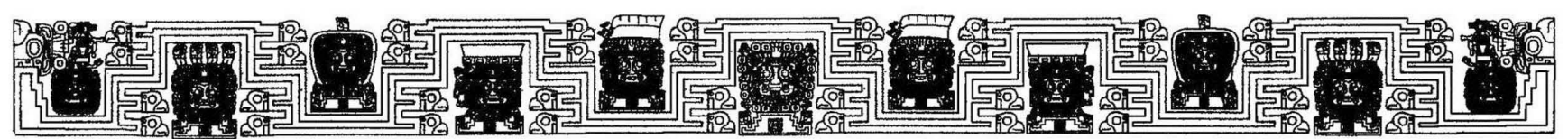

Puerta del Sol
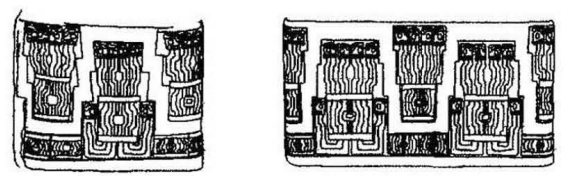

Kochamama

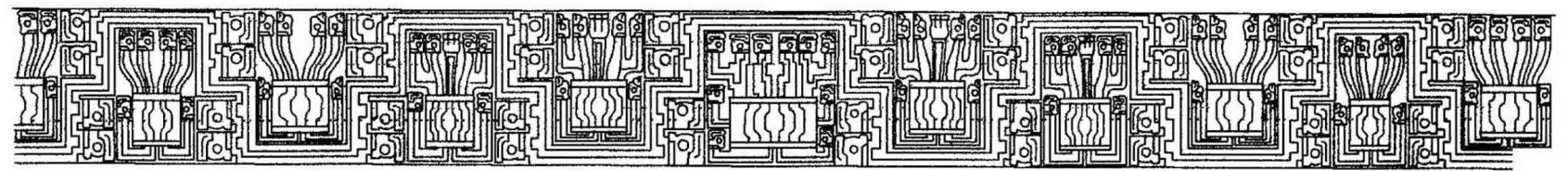

Bennet

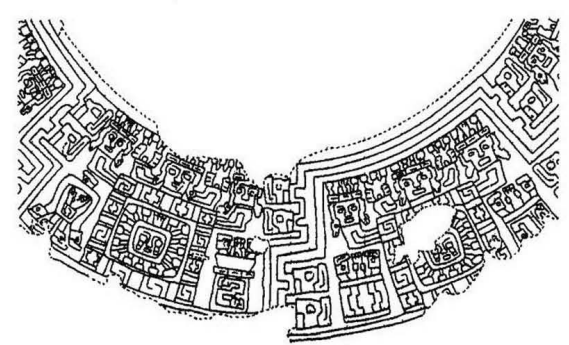

Receptáculo Lítico de Ofrendas

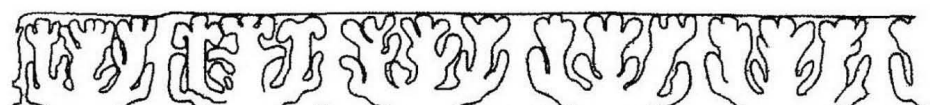

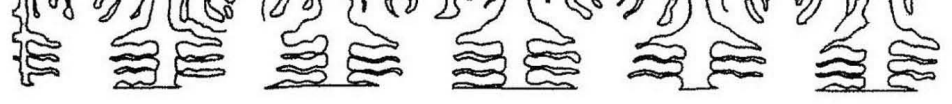

El Fraile

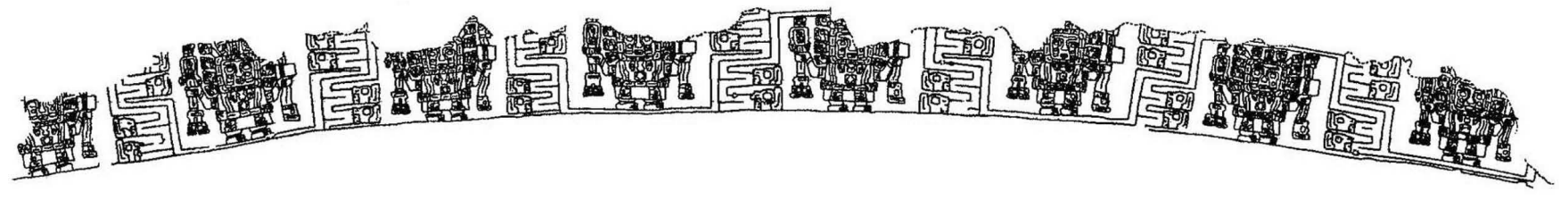

Receptáculo Litico de Ofrendas

Figura 6. "Bandas fajas" o meandros (Agüero et al. 2003: 68, figura 5). 


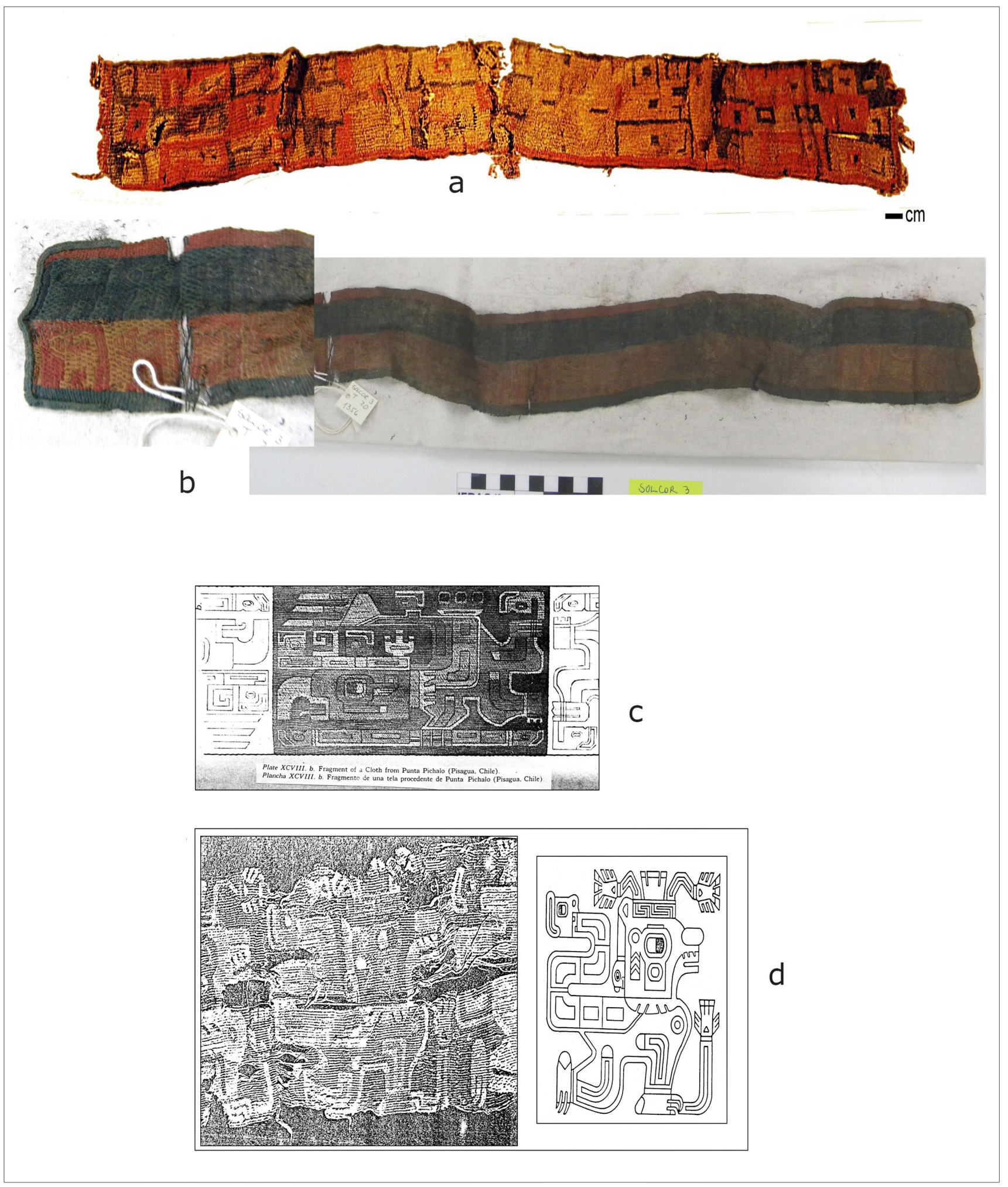

Figura 7. Bandas cefálicas: a y b) San Pedro de Atacama (fotografías de la autora, en Agüero y Uribe 2014: figura 5); c) Pisagua: ave (tomada de Posnansky 1957: Plate XCVIII); d) Pisagua: felino (tomada de Conklin 1983: 39, figura 34). 


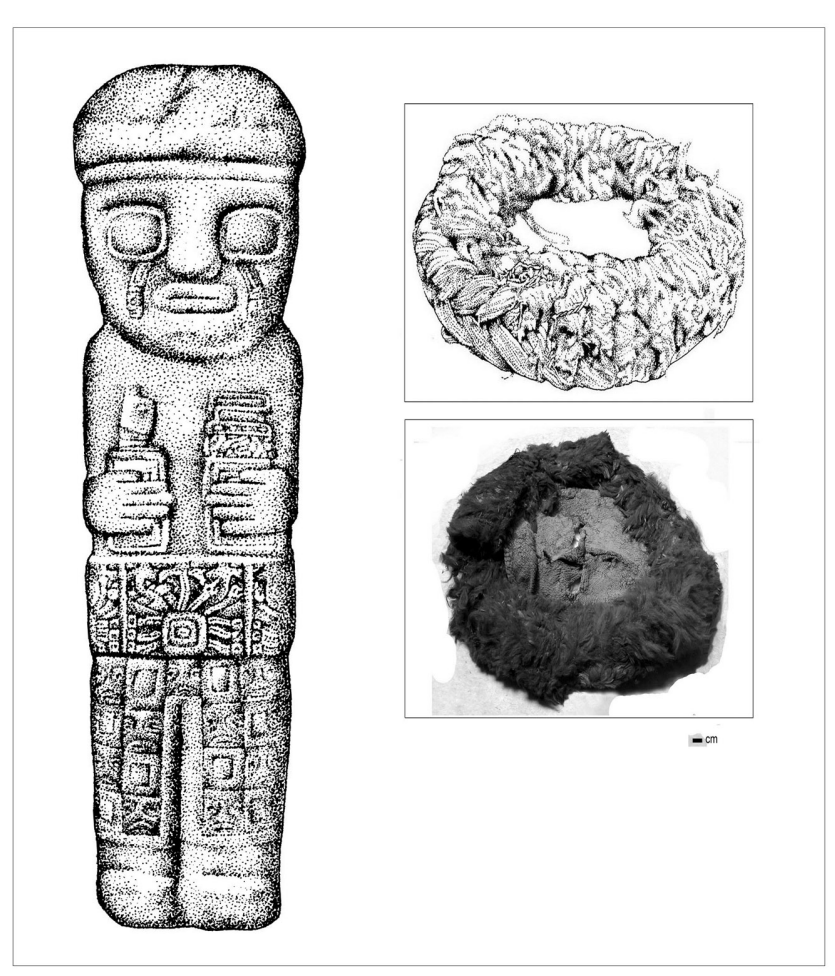

Figura 8. Estatuilla de Puno, y gorros de cintillo y casquete de San Pedro de Atacama. Imágenes producidas por Proyecto FONDECYT 1970073 basadas en Berenguer 1987: 42, figura 9; y en fotografías de la autora.

pez, de aves de perfil o de felinos de perfil en sus extremos. En los Personajes de Perfil más tempranos muestran un atributo de felino (Pucara), y en los dinteles de Kantatayita y Linares, la faja está vacia o con zigzag interior. Pero no se encontraron los referentes artefactuales.

Otra prenda identificada fue la Túnica: está formada por franjas y orillas inferiores (con cabezas de felinos frontales o de perfil, o cabezas de pez o de ave), y orillas laterales (vacías o con grecas o cabezas de ave, de pez o de felino de perfil). Se observa en los monolitos y portadas, y en todos los Personajes Frontales, pero sólo en algunos Personajes de Perfil del Idolo del Sol y Puerta del Sol tratándose, al parecer, de una prenda propia de los seres humanos, o que "humaniza". La Franja siempre está vacía en los Personajes de Perfil (siendo listas lisas), lo que no ocurre siempre en los Personajes Frontales. Las túnicas con Franja compuesta por motivos, parecen corresponder a aquellas tejidas en tapicería (Figura 10).

Por otra parte, la Bolsa: que puede estar formada por el elemento "bolsa" (convención), por un rectángulo, o por una gran cabeza de ave, pez o felino de perfil; los flecos (cuando hay) por apéndices con círculos, o cabezas de ave, pez o felino de perfil; el tirante por rectángulos con centro, o con greca. La bolsa la encontramos únicamente en ciertos

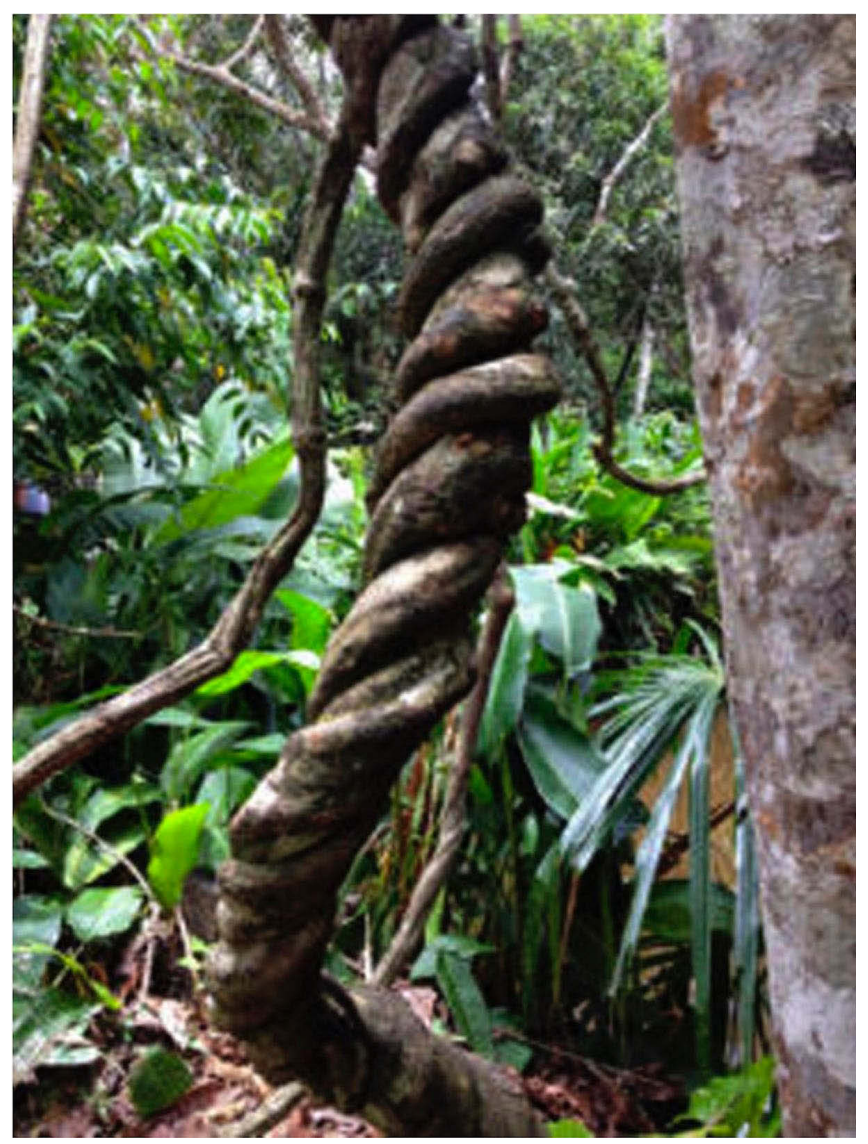

Figura 9. Ayahuasca o "abuela" (Banisteriopsis caapi) (ver Figura 6). Tomada de https://articulo.mercadolibre.com.mx/ MLM-666919007-ayahuasca-miel-pasta-500-gr-_JM

Personajes de Perfil (los Antropomorfos "ornitomorfizados"), es decir, los que integran algunos atributos anatómicos pertenecientes a las aves, tales como: ala, cabeza de ave y garras en una posición que se relaciona con el consumo de sustancias psicoactivas (según Berenguer 1987). Estos personajes se encuentran en Kochamama, Monolito Bennett y en la Puerta del Sol, en la cual tienen su parte inferior dentada y muestran estrechas similitudes con aquellas de estilo Wari registradas en el sur de Perú (Taullard 1949; Vanstan 1969). Resulta de interés que todos los personajes "ornitomorfizados" compartan la representación de la bolsa, que usada cruzando el cuerpo se asocia a viajes, y que eventualmente podríamos asociar a hombres medicina itinerantes, como los kallawaya del altiplano boliviano que actualmente llegan hasta Camiña en la región de Tarapacá (norte de Chile). Además de la posición anatómica, exhiben artefactos asociados a sustancias psicoactivas, como tableta, y por supuesto, las bolsas que las contendrían así como al resto de la parafernalia necesaria (Berenguer 1987). Lo anterior es reforzado por Oakland (1986) quien observa que tres bolsas de Niño Korín (Wassén 1972) contenían hojas de 


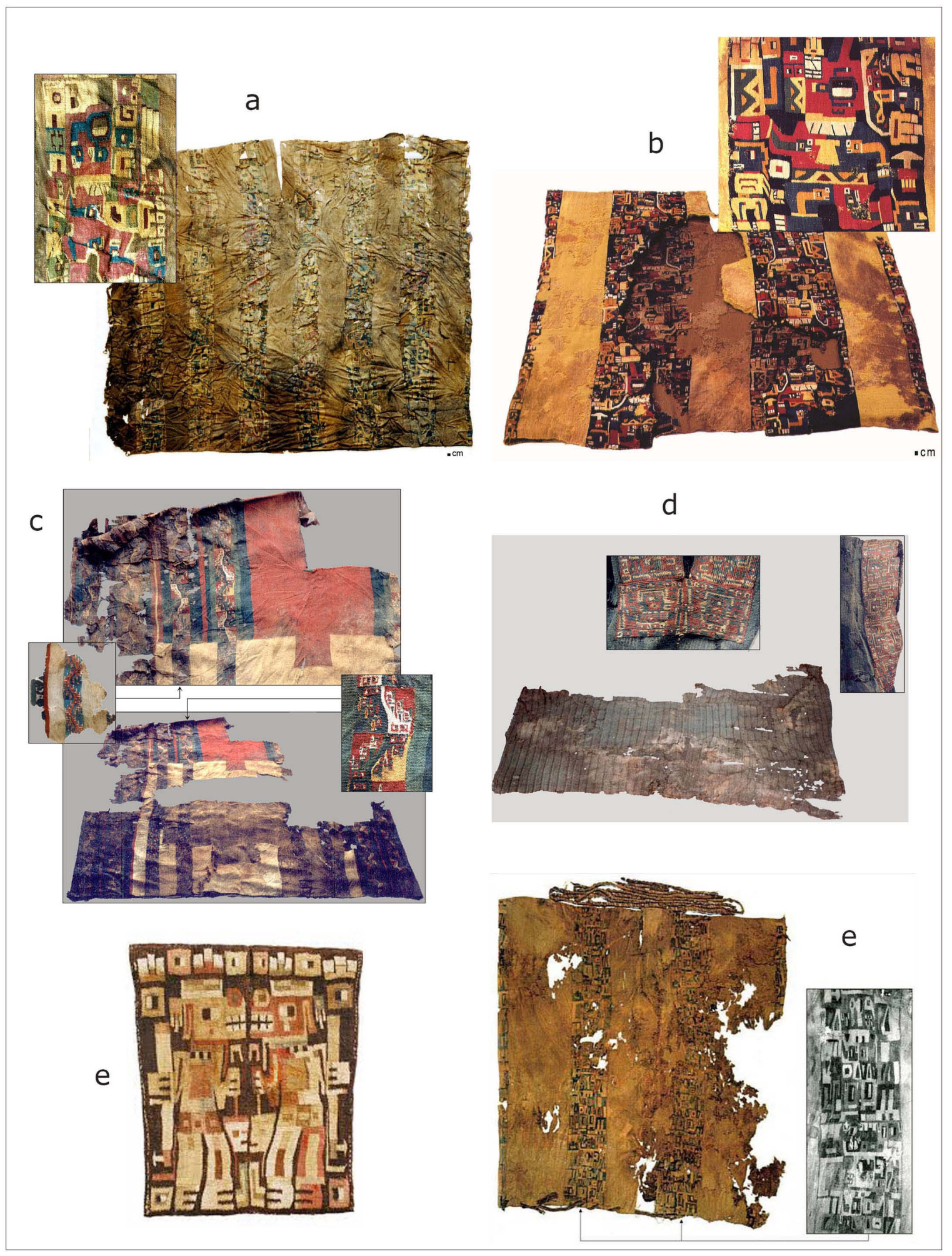

Figura 10. a) Túnica de San Pedro de Atacama con representaciones de aves de perfil (Agüero 2012: 42, figura 10; b) Túnica de Pulacayo con representaciones de Personajes de Perfil antropomorfos con colmillos de felino (Agüero 2007: 90, figura 7); c) Túnica de Tarapacá-40 con representación de la Banda Faja de la Puerta del Sol (Agüero y Uribe 2018: 271, figura 10.2); d) Túnica de Tarapacá-40 con representaciones bordadas de Personajes de Perfil antropomorfos (Agüero y Uribe 2018: 272, figura 10.3); e) Túnica procedente de Boca del río Osmore con representaciones de Personajes de Perfil antropomorfos con rostros de felino (tomada de Minkes 20o8: figura 5); f) Túnica de Pica-8 con representaciones de Personajes de perfil antropomorfos felinizados (Agüero y Uribe 2018: 272, figura 10.4). 
Ilex Guayusa, y recientemente por Miller y coautores quienes analizan el fardo de un niño encontrado en el altiplano de Lípez (Bolivia) hallando por primera vez evidencias del uso de múltiples plantas psicoactivas como ayahuasca, coca (Erythroxylum coca), tabaco (Nicotiana spp.) y cebil, tal como se observa en la iconografía que analizamos en este trabajo. En las colecciones encontramos bolsas como las de

\section{la Figura 11.}

Inkuñas y mantas: no han sido identificadas en la litoescultura, pero creemos que ciertas prendas de sitios arqueológicos del Período Medio en el norte de Chile, sur del Perú, altiplano y valles orientales de Bolivia, corresponden a textiles Tiwanaku, y son importantes de mencionar porque muestran patrones distribucionales diferenciales en las áreas consideradas.

\section{Discusión y conclusiones: patrones de distribución espacial de la iconografía y su probable significado}

Con la excepción de colecciones como Niño Korín (Wassén 1972) y Manzanani, Omereque, Mojocoya y Pérez (Strömberg 1956; Oakland 1986), la mayoría de los textiles con imágenes Tiwanaku se ha registrado en la costa o en los oasis del norte de Chile y sur de Perú (Conklin 1983; Oakland 1986, 1987, 1992, 2000; Berenguer y Dauelsberg 1989; Minkes 2008; Baitzel y Golstein 2014, Sharrat 2014).

Según los datos recogidos en los Valles Occidentales, Altiplano, Valles Orientales de Bolivia, y Atacama, los textiles y la iconografía, difieren en dos grandes áreas: al Oeste y Este de los Andes, y por lo tanto, suponemos que las motivaciones y el tipo de relaciones establecidas por Tiwanaku, con ellas.

Comprobamos que, en general, en los textiles se representan figuras de Personajes de Perfil Antropomorfos y Zoomorfos, siguiendo, al igual que en la litoescultura, ciertos principios, como el de repetición, simetría en espejo y el de jerarquía (este último, si consideramos que es sólo el Personaje Frontal quien usa túnica, con la única excepción de los Personajes de Perfil del Idolo del Sol).

Hasta el momento, gran parte de la iconografía figurativa de los textiles Tiwanaku se relaciona con aquella de los soportes líticos de todas las fases de la secuencia estilística planteada por Isbell y Cook (1987) y por Agüero y coautores (2003), pero especialmente con Tiwanaku III-IV. Aquella se ajusta casi por completo a las representaciones de Personajes de Perfil y Meandros de la litoescultura, siendo los primeros los que se privilegian para ser plasmados en túnicas, bolsas, inkuñas, fajas o bandas cefálicas y mantas. Estos son los tejidos que llegan a todas las zonas estudiadas, pero, en mayor cantidad a San Pedro de Atacama.
También pudimos observar algo de gran interés, y es que los Valles Occidentales concentran de manera exclusiva a las figuras de perfil de camélidos y felinos, a los Personajes de Perfil Antropomorfos y Antropomorfos Felinizados, en tanto, la vertiente más oriental y centro sur tienen exclusividad sobre las figuras de aves (ya sea aves de perfil volando y pedestales y meandros terminados en cabezas de aves con tocado), cobrando especial relevancia la presencia de Personajes de Perfil Antropomorfos Ornitomorfizados frente a la ausencia total de Personajes de Perfil Antropomorfos Felinizados.

También hay una relación entre el tipo de prendas y la iconografía registrada. Las prendas de los Valles Occidentales relacionadas a camélidos y felinos son bastante más "prácticas" que las del Este y Centro Sur de los Andes ya que predominan las túnicas con bordados. Del otro lado, las aves se relacionan a prendas rituales como las bolsas. En efecto, las aves en vuelo y las cabezas de ave coronadas unidas a escalerados o meandros se observan principalmente en bolsas, orillas de mantas, una banda faja, y una inkuña o manta de San Pedro. Estas prendas aparecen con otras con iconografía del Idolo del Sol (Personajes de Perfil Antropomorfos y Personajes Frontales) en túnicas con tapicería o faz de trama en la parte inferior imitando las túnicas de esos personajes.

En suma, en Bolivia y Atacama (en el norte de Chile) se aprecia una relación entre las bolsas, y la iconografía de aves y personajes antropomorfos con atributos de aves, lo que resulta coherente con que, en la litoescultura, la bolsa se representa únicamente en los Personajes de Perfil Antropomorfos con atributos de aves, como ala, cabeza y garras, y también una posición que se relaciona con el consumo de sustancias psicoactivas (Berenguer 1987). Esto se refuerza al ver que tres bolsas de Niño Korín contenían hojas de Ilex Guayusa, y que en toda esta zona de Valles Orientales, Altiplano Meridional y Atacama los artefactos del llamado “complejo alucinógeno" son frecuentes en los contextos funerarios (Horta 2014).

Por otro lado, en Cochabamba con la ausencia de textiles tanto Tiwanaku III-IV y V, y la presencia de textiles Tiwanaku Provincial (sensu Oakland 1986) se ve que algunos elementos de estilo Tiwanaku se reinterpretan con bastante libertad sugiriendo que aquí no habría población Tiwanaku asentada pero que ya habían relaciones establecidas con la cultura altiplánica, las que habrían sido de naturaleza diferente a las mantenidas con los Valles Occidentales, y nunca tan directas.

En suma, Tiwanaku temprano (III-IV) habría accedido a todas las zonas consideradas, pero introduciendo de manera diferencial prendas e iconografía en las subáreas AltiplanoValles Occidentales y Valluna-Circumpuneña (Figura 12). Es así como observamos tendencias en las representaciones 


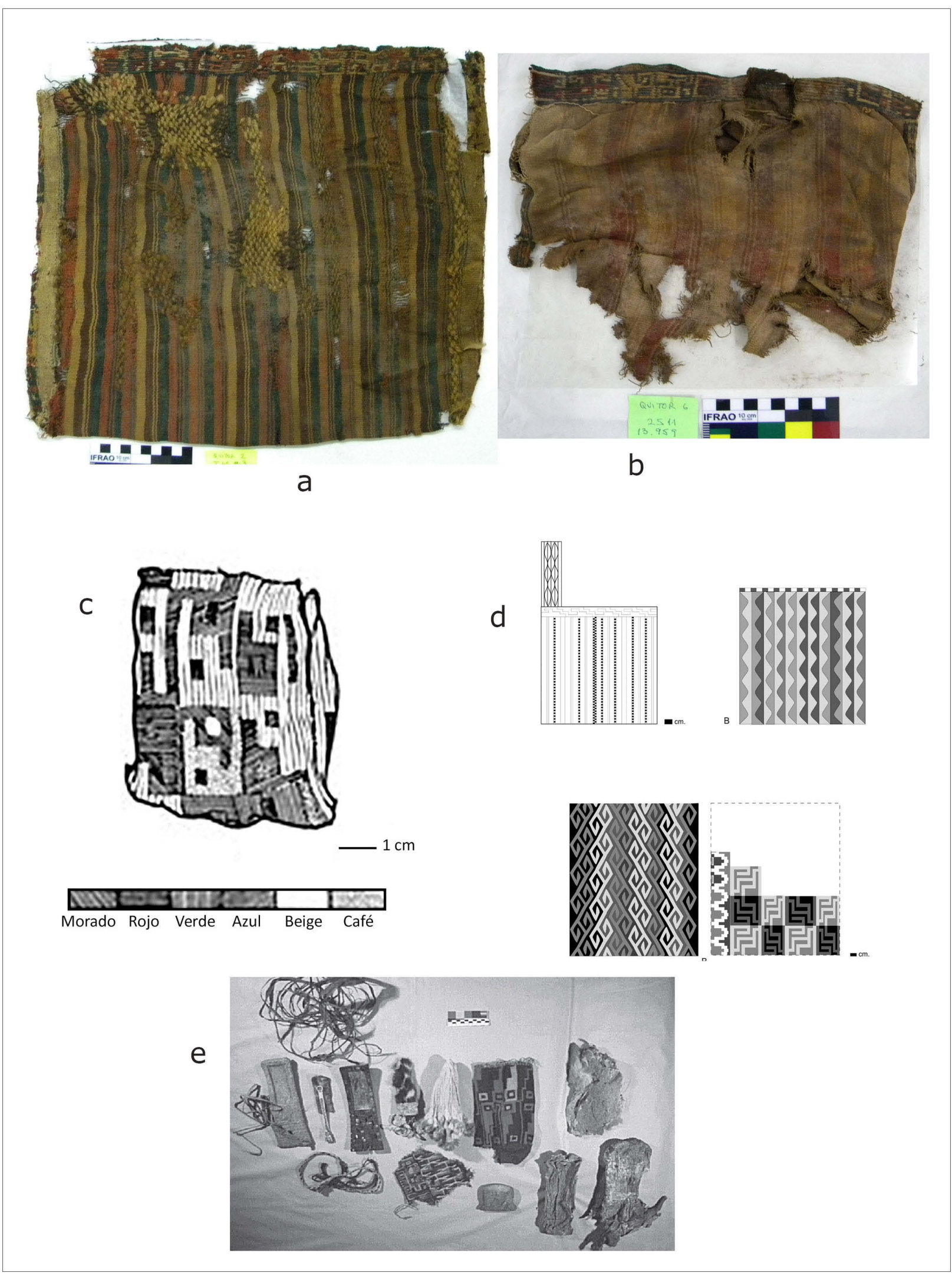

Figura 11. a y b) Bolsas de San Pedro de Atacama con bordados superiores con representaciones de aves (fotografías de la autora); c) Bolsa de Los Verdes (Región de Tarapacá) (dibujo de Paulina Chávez encargado por la autora); d) Bolsas de los valles cochabambinos (dibujo de Paulina Chávez encargado por la autora); e) Bolsa del conjunto de Amaguaya (tomado de Capriles 2002 (23):35, figura 2). 


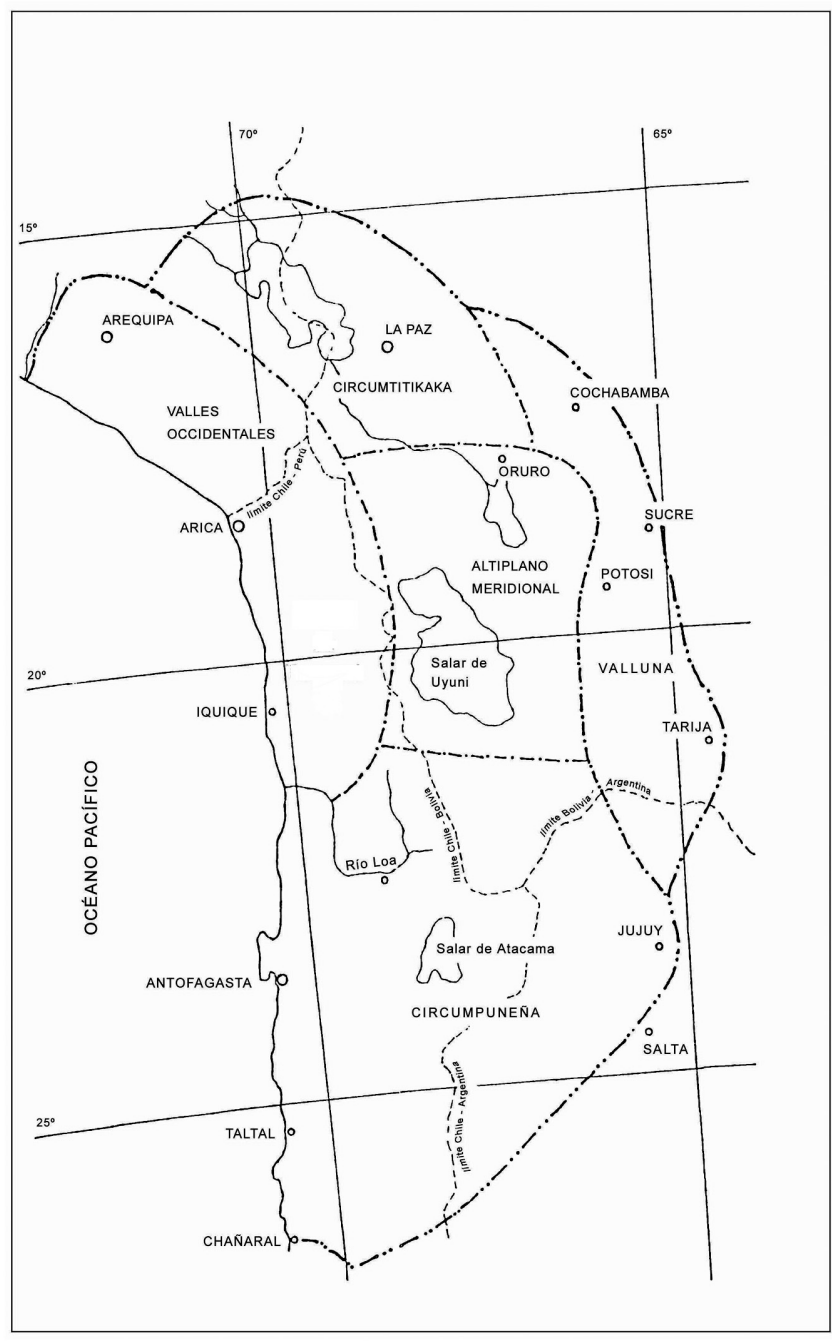

Figura 12. Mapa del Área Centro Sur Andina, en el cual se señalan las subáreas mencionadas en el texto. Adaptado de Núñez 1984 y publicado por Agüero 2015: 39, figura 1).

iconográficas (siempre de figuras de perfil) de felinos y humanos felinizados principalmente en túnicas de los Valles Occidentales, y aves y humanos ornitomorfizados en el Altiplano Meridional y en Atacama, principalmente en bolsas y túnicas de contextos relacionados con artefactos del "complejo alucinógeno", asociación que sugiere que estas últimas áreas parecen haber sido exploradas con intereses en aspectos rituales vinculados con el consumo de plantas maestras o plantas medicina.

Por su parte, la expresión textil Tiwanaku V está presente únicamente en los valles cochabambinos y en los Valles Occidentales, y se vincula a la producción de prendas de estilo Tiwanaku Provincial. Este último, contemporáneo a Tiwanaku $\mathrm{V}$ tiene principalmente dos centros de producción: Moquegua y Cochabamba. Ambas zonas evidencian, eso sí, relaciones diferentes con Tiwanaku, mientras en Moquegua la relación es directa, en Cochabamba es indirecta a juzgar por la libertad con que se toman y reinterpretan los programas textiles Tiwanaku. En Moquegua, salvo excepciones (p.e. Baitzel y Golstein 2014, Sharrat 2014) estos textiles son "cotidianos", están muy reparados, son monócromos o con listas de colores y como decoración a lo más presentan bordados geométricos (meandros, escalerados, ganchos, rectángulos con centro, entre otros) en las uniones laterales y orillas. La presencia de población Tiwanaku establecida en Moquegua explica la existencia de estas prendas "comunes y corrientes" carentes de iconografía figurativa o compleja, siendo durante esta fase que surgen los textiles en primera instancia catalogados como Tiwanaku Provincial, ya que los soportes son fabricados localmente. Se puede apreciar una iconografía tardía distinta a los referentes líticos, y vinculada a técnicas locales producto de la interacción persistente con las poblaciones cercanas al Pacífico.

En suma, en este trabajo observamos tendencias en la distribución de las prendas textiles y su iconografía lo que, sin duda, no es azarozo, sino que tiene un significado; esta proposición fue posible gracias al trabajo en colaboración con un hombre-medicina. Esperamos que este esfuerzo constituya un aporte para que en el futuro se desarrollen otras investigaciones con nuevas líneas interpretativas.

\section{Bibliografía}

Agüero, Carolina

1998 Tradiciones Textiles de Atacama y Tarapacá Presentes en Quillagua Durante el Período Intermedio Tardío. Boletín del Comité Nacional de Conservación Textil 3: 103-128.

Agüero, Carolina

2000 Las Tradiciones de Tierras Altas y de Valles Occidentales en la Textilería Arqueológica del Valle de Azapa. Chungara 32(2): 217-225.

Agüero, Carolina

2001 Ms. Textiles e Iconografía Tiwanaku: Patrones Distribucionales en Zonas de Frontera. Manuscrito en poder de la autora.

Agüero, Carolina

2007 Los Textiles de Pulacayo y la Relaciones entre Tiwanaku y San Pedro de Atacama. Boletín del Museo Chileno de Arte Precolombino 12(1): 85-98.

Agüero, Carolina

2012 Desarrollo de los Textiles Prehispánicos de la Región Atacameña. Canto Rodado 7: 29-54.

Agüero, Carolina

2015 Vestuario y Sociedad Andina, C. Agüero (Editora). Pp. 256. Santiago: Qillqa Ediciones. 
Agüero, Carolina y Mauricio Uribe

2014 Rethinking the Tiwanaku Phenomenon in San Pedro de Atacama Through the Study of Textiles of Solcor 3 and Their Associated Contexts (400-100o AD). 9-2014. Proceedings Textile Society of America. DigitalCommons@University of Nebraska - Lincoln

Agüero, Carolina y Mauricio Uribe

2018 Tiwanaku in the Tarapacá Region (Chile): ¿Realities or Illusions in the Desert? En Images in Action: The Southern Andean Iconographic Series. W. Isbell et al. (Editores). Pp. 261-286. Los Angeles: Cotsen Institute of Archaeology Press.

Agüero, Carolina, Mauricio Uribe y José Berenguer

2003 La Iconografía Tiwanaku: El Caso de la Escultura Lítica. Textos Antropológicos 14(2): 47-82.

Baitzel, Sarah y Paul Goldstein

2014 More than the Sum of its Parts: Dress and Social Identity in a Provincial Tiwanaku Child Burial. Journal of Anthropological Archaeology 35(1): 51-62.

Bennett, Wendell

1946 The Archaeology of the Central Andes. Handbook of South American Indians, J. Steward (Editor). Vol. II: 599-618. Washington D.C.

Berenguer, José

1987 Consumo Nasal de Alucinógenos en Tiwanaku: Una Aproximación Iconográfica. Boletín del Museo Chileno de Arte Precolombino 2: 33-53.

Berenguer, José

1993 Gorros, Identidad e Interacción en el Desierto Chileno antes y después del Colapso de Tiwanaku. En Identidad y Prestigio en los Andes: Gorros, Turbantes y Diademas. Catálogo de Exposición, pp: 31-64. Santiago: Museo Chileno de Arte Precolombino.

Berenguer, José

1998 Una Exploración de la Iconografía del Poder en Tiwanaku y su Rol en la Integración de Zonas de Frontera. Informe de Avance. Boletín de la Sociedad Chilena de Arqueología 26: 3.

Berenguer, José y Percy Dauelsberg

1989 El Norte Grande en la Órbita de Tiwanaku. En Culturas de Chile. Prehistoria, J. Hidalgo et al. (Editores). Pp. 129-180. Santiago: Editorial Andrés Bello.

Bird, Junius

1943 Excavations in Northern Chile. Anthropological Papers of American Museum of Natural History, New York.

Capriles, José

2002 Intercambio y Uso Ritual de Fauna por Tiwanaku: Análisis de Pelos y Fibras de los Conjuntos Arqueológicos de Amaguaya, Bolivia. Estudios Atacameños 23: 33-51

Clark, Nikki, F. Palacios y Nilda Juárez

1993 Ms. Proyecto Textil Chiribaya Baja: Cementerio 1. Fardos y Textiles. Informe preliminar.
Conklin, William

1983 Pucara and Tiahuanaco Tapestry: Time and Style in a Sierra Weaving Tradition. Nawpa Pacha 21: 1-33.

Conklin, William

1991 Tiahuanaco and Huari: Architectural Comparison and Interpretations. En Huari Administrative Structure, W. Isbell y G. McEwan (Editors). Pp. 281-291. Washington D.C.: Dumbarton Oaks

Cordy-Collins, Alana

1976 An Iconographic Study of Chavin Textiles from the South Coast of Peru: The Discovery of a PreColumbian Catechism. Ph.D. Diss., University of California, Los Angeles.

Espoueys, Oscar, Helena Horta y Vivian Reciné

1995 Estudio de una Pieza Textil de Filiación Tiwanaku del Valle de Azapa, Arica, Chile. Boletín del Museo Chileno de Arte Precolombino 6: 111-125.

Focacci, Guillermo

1982 Excavaciones en el Cementerio Playa Miller 9. En Documento de Trabajo 2, I. Muñoz y G. Focacci (Editores). Pp. 126-214. Arica: Universidad de Tarapacá.

Focacci, Guillermo

1990 Excavaciones Arqueológicas en el Cementerio Az-6. Valle de Azapa. Chungara 24-25: 7-55.

Goldstein, Paul

1989 Omo, a Tiwanaku Provincial Center in Moquegua, Perú. Ph.D. Diss., Dept. of Anthropology, University of Chicago, Illinois.

Goldstein, Paul

1990 La Ocupación Tiwanaku en Moquegua. Gaceta Arqueológica Andina V(18-19): 75-104.

Horta, Helena

2014 Lo Propio y lo Ajeno. Definición del Estilo San Pedro en la Parafernalia Alucinógena de los Oasis del Salar de Atacama. Chungara, Revista de Antropología Chilena 46(4): 559-583

Miller, Melanie, Juan Albarracín Jordán, Christine Moore y José Capriles

2019 Chemical Evidence for the Use of Multiple Psychotropic Plants in a 1,0oo-Year-Old Ritual Bundle from South America. PNAS June 4, 2019116 (23) 11207-11212; first published May 6, 2019 https://doi.org/10.1073/pnas.1902174116

Minkes, Wynne

2008 Warp the Loom-Wrap the Dead. Trapezoidal Shaped Textiles from the Chiribaya Culture, South Peru, AD 90o-1375. En Textiles as Cultural Expressions: Proceedings of the 11th Biennial Symposium of the Textile Society of America, September 24-27, Honolulu.

Museum of Primitive Art

1965 Ancient Peruvian Textiles from the Collection of The Textile Museum Washington D.C. New York. 
Núñez, Lautaro

1981 Emergencia de Sedentarización en el Desierto Chileno: Subsistencia Agraria y Cambio SocioCultural. Revista Creces II.

Núñez, Lautaro

1984 Tráfico de Complementariedad de Recursos entre las Tierras Altas y el Pacífico en el Área Centro Sur Andina. Tesis Doctoral, Departamento de Antropología Cultural, Universidad de Tokyo, Tokyo.

Oakland, Amy

1981 Ms. Tejidos Preincaicos en Cochabamba. Museo Arqueológico de la Universidad Mayor de San Simón, Cochabamba.

Oakland, Amy

1986 Tiwanaku Textile Style from the South Central Andes, Bolivia and North Chile. Ph.D. Diss., University of Texas, Austin.

Oakland, Amy

1986a Tiwanaku Tapestry Tunics and Mantles from San Pedro de Atacama, Chile. En The Junius Bird Conference on Andean Textiles, A. Rowe (Editor). Pp. 101-122. Washington D.C.: The Textile Museum.

Oakland, Amy

1992 Textiles and Ethnicity: Tiwanaku in San Pedro de Atacama, North Chile. Latin America Antiquity 3(4): 316-340.

Oakland, Amy

1994 Tradición e Innovación en la Prehistoria Andina de San Pedro de Atacama. Estudios Atacameños 11: 109-120.

Oakland, Amy

2000 Andean Textiles from Village and Cemetery: Caserones in the Tarapacá Valley, North Chile. En Beyond Cloth and Cordage, P. Drooker y L. Webster (Editors). Pp. 229-251. Salt Lake City: University of Utah Press.

Posnansky, Arthur

1945 Tihuanacu, la Cuna del Hombre Americano. Vols I y II. New York: Augustin Publishers.

Posnansky, Arthur

1957 Tihuanacu, la Cuna del Hombre Americano. Vols. III y IV. La Paz: Ministerio de Educación.

Proyecto FONDECYT 1970073

1997-200o. Una Exploración de la Iconografía del Poder en Tiwanaku y s Una Exploración de la Iconografía del Poder en Tiwanaku y su Rol en la Integración de Zonas de Frontera. A cargo de José Berenguer.
Santoro, Calogero

1980 Estudio de un Yacimiento Funerario Arqueológico del Extremo Norte de Chile, 1300 AC-130o DC. Tesis para optar al Título de Arqueólogo, Depto. de Arqueología, Universidad del Norte, Antofagasta.

Simileld, Katrina

1981 Ms. La Colección de los Tejidos de Puqui. Museo Arqueológico de la Universidad Mayor de San Simón, Cochabamba.

Stromberg, Elizabeth

1956 Textile Fragments from a Burial Cave at Pérez, Mizque Valley, Bolivia. En The Erland Nordenskiöld Archaeological Collection from the Mizque Valley, Bolivia (Stig Rydén). Etnologiska Studier 22, Etnografiska Museet, Göteborg.

Taullard, Alfred

1949 Tejidos y Ponchos Indígenas de Sudamérica. Buenos Aires: Editorial Guillermo Kraft Ltda.

Uhle, Max

1919 La Arqueología de Arica y Tacna. Boletín de la Sociedad Ecuatoriana de Estudios Históricos Americanos 7-8.

Ulloa, Liliana

1982 Estilos Decorativos y Formas Textiles de Poblaciones Agromarítimas en el Extremo Norte de Chile. Chungara 8: 97-108.

Uribe, Mauricio

1998 Ms. La Iconografía de las Bandas-Fajas de la Litoescultura de Tiwanaku. Anexo 4 del Informe del primer año del Proyecto FONDECYT 1970073.

Vanstan, Ina

1969 Six Bags with Woven Pockets from Pre-Columbian Perú. Ñawpa Pacha 16: 17-31.

Vargas, Berta

1994 Ms. Informe Sobre Tumbas Intactas (334) Excavadas Durante el Proyecto "Rescate Arqueológico en el Cementerio de Chen Chen - Moquegua.”

Wassén, Henry

1972 A Medicine Man's Implements and Plants in a Tiahuanaco Tomb in Highland Bolivia. Etnologiska Studier XXXII. Göteborg: The Ethnographic Museum.

Zighelboim, A.

1991 Ms. An Iconographic Study of Stela Bennett. Unpublished Paper, University of Illinois at Urbana-Champaign.

Zlatar, Vjera

1984. Cementerio Prehispánico Pica-8. Antofagasta: Universidad de Antofagasta. 


\title{
4
}

\section{Middle Horizon textiles from Chimu Capac, Supe Valley, Peru}

\author{
Amy Oakland
}

\begin{abstract}
This article presents an overview of the textiles Max Uhle collected between November 4 and December 3, 1904 in the Middle Horizon cemetery at Chimu Capac in the Supe Valley, Peru. The total collection of objects numbers over 830 with 278 textiles including woven fragments, complete garments, woven and painted pouches, and over 155 painted textiles. The article discusses a sample of Chimu Capac textiles included in Uhle's Supe field Notebook 67, in his hand-written Supe report, and textiles listed in the Supe Berkeley catalog. The Chimu Capac textiles compare with collections of Middle Horizon funerary objects made in coastal burials from El Castillo, Ancon, Pachacamac, Huaca Malena, and Monte Grande. Although most of the textiles from Chimu Capac have connections with the Middle Horizon burial tradition practiced along the Peruvian coast, the painted textiles exhibit many unique features and perhaps represent a local style at the site.
\end{abstract}

Keywords: Andean textiles, Chimu Capac, Supe Valley, Max Uhle, Hearst Museum, Middle Horizon.

\section{Resumen}

Este artículo presenta una visión general de los textiles coleccionados por Max Uhle en el período entre el 4 de noviembre y el 3 de diciembre 1904 en el cementerio del Horizonte Medio del sitio Chimú Cápac, en el Valle de Supe, Perú. El número total de los objetos de la colección excede a 830, entre ellos 278 textiles incluyendo fragmentos tejidos, prendas completas, bolsas tejidas y pintadas y más de 155 textiles pintados, algunos grandes, otros fragmentados. El artículo presenta una muestra de textiles de Chimú Cápac incluidos por Uhle en su cuaderno de campo 67 de Supe, en su informe escrito a mano sobre Supe, y en la lista de textiles en el catálogo Supe de Berkeley. Los textiles de Chimú Cápac son comparables con colecciones de objetos funerarios del Horizonte Medio encontrados en entierros del Castillo, Ancón, Pachacámac, Huaca Malena, y Monte Grande. Mientras que la mayoría de los textiles de Chimú Cápac tienen conexiones con la tradición funeraria del Horizonte Medio practicada a lo largo de la costa peruana, los textiles pintados muestran muchas características únicas y posiblemente representan un estilo local del sitio.

Palabras claves: Textiles andinos, Chimú Cápac, Supe Valley, Max Uhle, Museo Hearst, Horizonte Medio.

\section{Résumé}

Cet article présente une vision générale des textiles collectés par Max Uhle entre le 4 novembre et le 3 décembre 1904 dans le cimetière de l'Horizon Moyen du site de Chimu Capac, dans la vallée de Supe, au Pérou. Le nombre total d'objets de la collection dépasse 830, entre autres 278 textiles incluant fragments de tissus, vêtements complets, sacs tissés et peints, et plus de 155 textiles peints, certains de grande taille et d'autres fragmentés. L’article présente une sélection des textiles de Chimu Capac inclus par Uhle dans ses notes de chantier 67 sur Supe, dans son rapport rédigé à la main sur Supe, et une liste des textiles dans le catalogue Supe de Berkeley. Les textiles de Chimu Capac sont comparables aux collections d'objets funéraires de l'Horizon Moyen découverts dans les sépultures d'El Castillo, Ancon, Pachacamac, Huaca Malena et de Monte Grande. Bien que la majorité des textiles de Chimu Capac ait des liens avec la tradition funéraire de l'Horizon Moyen pratiquée de long de la côte péruvienne, les textiles peints montrent de nombreuses caractéristiques uniques et représentent probablement un style local du site.

Mots-clés: Textiles andins, Chimu Capac, vallée de Supe, Max Uhle, Musée Hearst, Horizon Moyen.

DOI: 10.32873/unl.dc.zea.1205

Published in PreColumbian Textile Conference VIII / Jornadas de Textiles PreColombinos VIII, ed. Lena Bjerregaard and Ann Peters (Lincoln, NE: Zea Books, 2020). https://digitalcommons.unl.edu/zeabook/ 
Max Uhle excavated the Middle Horizon burial site known as Chimu Capac in the lower Supe Valley between November 4 and December 3 of 1904. The site ruins consist of a series of stone-walled terraces constructed against low hills approximately two miles from the Pacific Ocean (Figure 1). The hillslope and the clay soil allowed for particularly good preservation of usually perishable material and Uhle sent more than 830 objects of ceramics, wood, reed, shells, and textiles to his benefactor Phoebe Apperson Hearst during this second Peruvian expedition for the University of California, Berkeley. Uhle's hand-written site report titled "Report on my explorations in the Valley of Supe"(1) and an object catalog titled "Beginning of the excavations at San Nicolas near Supe" (2) accompanied the collection.

In addition, Uhle kept a field notebook for Supe (Figures 2,3 ) that is preserved with many of his papers, photographs, and documents at the Ibero-American Institute, Berlin. (3) In the notebook Uhle recorded 28 graves during the period from November 4 to November 14. Excavations continued until at least December 3, the last notebook entry that discusses Chimu Capac excavations (Oakland 2010). The Supe catalog continues to record all Chimu Capac excavated material. The following section provides a brief, selected account from Uhle's Supe notebook 64 .

Uhle's field notebook begins with excavations from November 4,1904 where on November 5 he describes the ceramics and textiles from Graves 1and 2 that he discovered the day before. He did not record textiles in the next two tombs, but on November 8 he discovered a complete mummy bundle in Grave 5 that he opened and described:

"the mummy was fashioned in a cylindrical packet with a cotton fabric on the outside, inside a $6-8 \mathrm{~cm}$. layer of leaves. This layer surrounded the mummy packet that was found intact, conically wrapped in skins turned inside out and tied with ropes."

He sent this "mummy package" to Berkeley along with the "false mummy head" (Oakland 2010: Fig. 9), a carved wooden monkey figure (Oakland 2010: Fig. 10), and a "work basket with contents" that included spindle whorls, bone picks, and spindles wrapped with cotton and camelid-fiber yarns. A painted textile 4-7106 (Oakland 2010: Fig. 8) was attached to the bundle stretched along the outside, the first of the 155 painted textiles that Uhle discovered at Chimu Capac.
By November 10, Uhle had collected objects in 14 graves when he began excavating what he called Mummy A from one of the deepest tombs at Chimu Capac. He photographed Mummy A with some of the 43 objects from the burial and placed one of the painted textiles 4-72210n the ground in front. This textile 4-7221 is one of the most widely illustrated from Chimu Capac (Carrion Cachot 1959: Fig 113b; Isbell and Young-Sanchez 2000: Fig. 246; Menzel 1977: Fig. 57; Oakland 2010: Fig.17). The dating of this textile is discussed in the present article below. For this tomb Uhle wrote: “The outer layers of this mummy outside the pelts were much alike those of the first mummy in leaves, with a covering of cotton cloth" and he listed twelve stuffed "Medicine pouches, painted" discovered in the tomb (Oakland 2010: Fig. 3).

But on November 14 Uhle stopped recording tomb lots. He was excavating terraces on the north slope with at least two workmen and he cataloged 43 objects in four tombs, Graves 25-28 that included the complete "Mummy in poncho" from Grave 25 that he sent in a container to Berkeley. Uhle discovered many styles of ceramics in these tombs, Wari types (Kroeber 1925: Pl.73h) in Graves 25 and 26 along with well-preserved painted textiles (Oakland 2001; 2010). The stuffed, painted pouches in Grave 25 and double cloth pouches in Grave 26 are similar to the dozens of pouches with pendant bags that formed a large part of preserved textiles in Chimu Capac burials. Uhle appears to have abruptly stopped working at Chimu Capac on November 14 . He left the notebook page empty and when he began writing again on the next page it was to record columns of measurements, probably for a site plan. The Berkeley catalog also stopped in the middle of the page at the same last object 7213a. The catalog list began on the next page with a different system of recording in a different handwriting, possibly that of his wife Charlotte Grosse who he had married directly before this second Peruvian expedition. Several objects that he cataloged in the notebook on this day were never given the same field numbers, but instead were given new numbers later in the catalog. John Rowe (1959:11) reported that while in Supe, Uhle received a letter from Phoebe Hearst telling him that she would be terminating his employment after the present expedition. His future plans were undoubtedly placed in a precarious position at this moment with the unexpected news. The letter must have arrived November 14, 1904.

But the excavations at Chimu Capac continued and the Berkeley catalog begins to lists hundreds of objects by type

1. Max Uhle, 1905a, Supe Report. "Dr. Uhle, Expedition to Peru, Received from Mrs. Hearst Oct. 17 “/o5”.

2. Max Uhle, 1905b, Berkeley Catalog. "Sent with Cuzco report and Uhle catalogue".

3. Uhle Notebook 67, legacy of Max Uhle, Published with the kind permission of the Ibero-American Institute, of the Prussian Cultural Heritage Foundation, Berlin. Quotes are from an English translation that Heiko Prümers prepared and generously allowed me to use. 


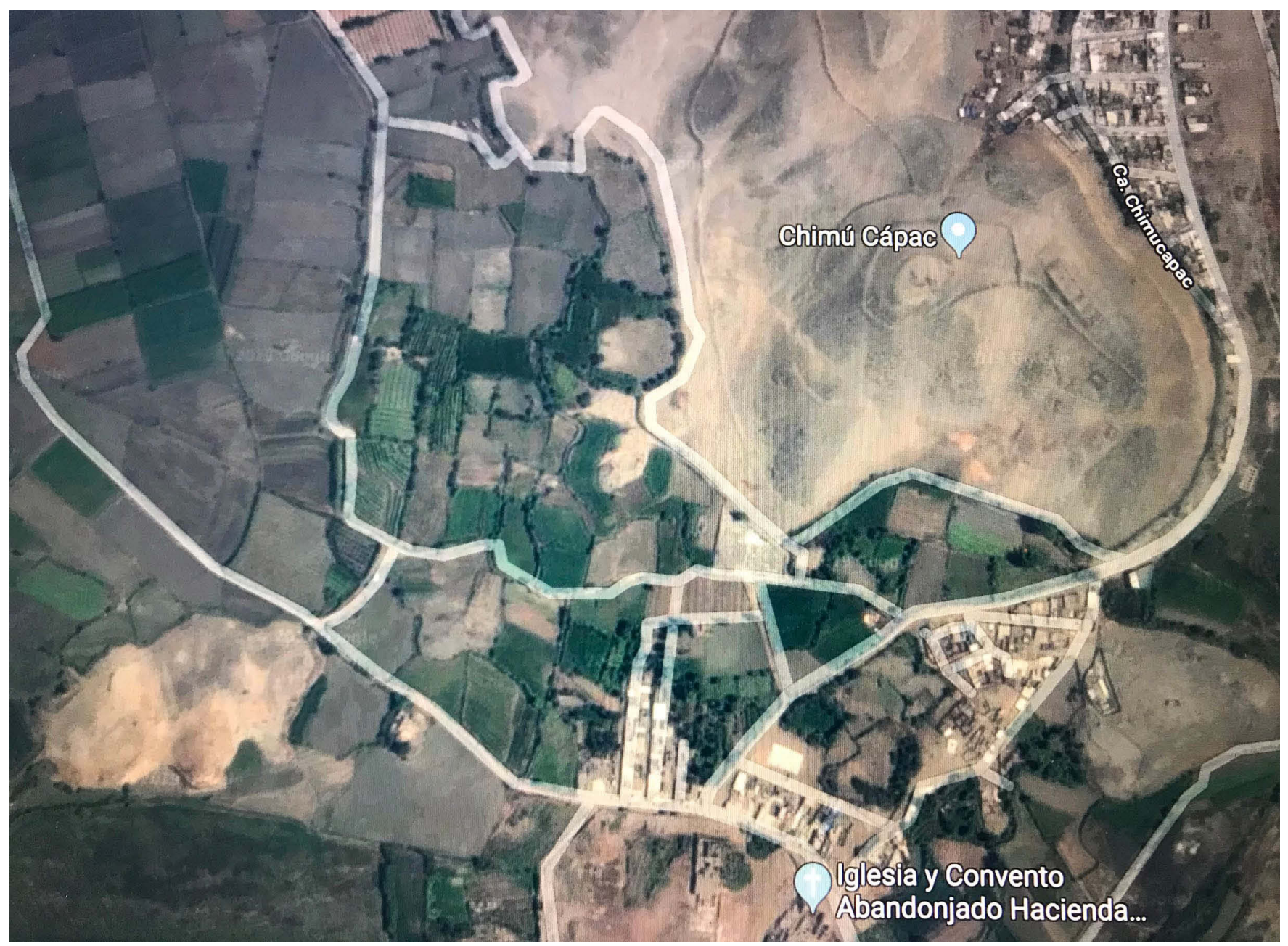

Figure 1. Google Map, 2019, Digital Imagery. Lower Supe Valley, Peru. Photo Amy Oakland.

instead of grave lot. While Uhle filled the following notebook pages with measurements he may have also used this time to excavate the "Chimu cemetery at Oliva" and the "Cemetery Puerto de Supe". Material of both these sites was added to the catalog. The Berkeley catalog continued with the object number 7214 listing large ceramic jars followed by other ceramic types. Textiles were grouped in categories such as "Tapestry fragments", "Double stuff", and "Painted textiles". Uhle returns to catalog the last objects arriving from excavations at Chimu Capac and these final catalog entries appear to be listed as tomb lots just as they were listed at the beginning of the Berkeley catalog. At this late period of the catalog Uhle brackets material related to Graves 4, 5, and 6 that Alfred Kroeber (1925) illustrated in his monograph about Uhle's ceramics from Supe.

The Chimu Capac excavations ended during the first week of December 1904. On notebook page 33 Uhle writes:

"3 December. This week Esteban and Eduardo continued the excavation at San Nicolas by themselves, because the type, the chronological position and the way of interment are the same in all the burials. Furthermore it is a useless waste of energy to sit quietly next to them in the great heat. They do have the following successes: 1 . nearly pure Tiahuanaco and related epigonal-style vessels; 2 . new types, beaker with faces, heads of cats, monsters etc.; 3 . some vessels that are identical with the oldTrujillo types. So there are in touch at Chimu Capac: Tiahuanaco, Epigonal, South to North and old Trujillo, North to South; 4. high quality epigonal textiles, among others such as those with sketchy abundant figurative painting; 5 . at least one fine tapestry, that is nearly pure Tiahuanaco."

With this last entry Uhle established that Chimu Capac was exactly what he reported in the Supe Report (discussed in this article below): a densely packed cemetery stacked so 
5. November 1904, San Nicolas

Excavation on the $2^{\text {nd }}$ terrace with the stone walled graves continued with two workmen. Yesterday with a workman we worked over there alongside a wall built up by two rows of stone under which we found burials that had been removed from their original position and had been placed under the wall without a pattern. The replacement may have happened in ance left the pottery with the burials and huaqueros wouldn't have put back the remains (bodies only partial, mainly only heads) into the ground. The time of the original burials was the later northern epigonal period. Remains 7055 - 7067.

We have searched for original stonewall-cists. Those are exquisitely built of quarried stones and mud mortar, the level side of the stones looking inside. One such empty grave was $1.35 \mathrm{~m}$ long, $1 \mathrm{~m}$ wide, aproximately $2 \mathrm{~m}$ deep, others are narrower and longer, otherwise in nearly all other forms up to nearly squares. General direction N-S.

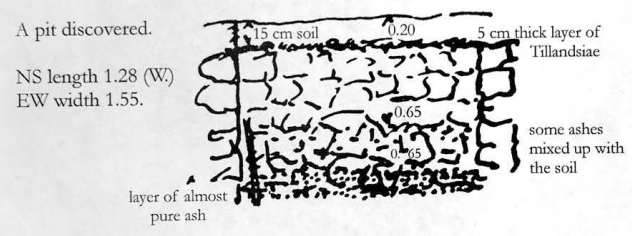

Depth $1.55 \mathrm{~m}$. [In the] SW-corner was found a board with fishes that served as a lid; beneath: 7075

Wooden bird (7081), boards in the shape of combs, snakes from wood, also human faces made from boards, sticks wrapped with yarn [page 2] (higher, in the layer of ash and the earth of the grave there was found a beaker (7069) (broken) and a bottle, black and coarser, but with rests of reliefs). 7068

I silverplate, painted board, all of it lay next to the southside of the pit

I bowl with some pattern on the outside, a comb (broken)

I spindle, little balls of yarn for weawing

I Spondylus sp. shell, 1 conchita shell with paint, 1 condor head - wood.

Total contents:

7068 black bottle with reliefs

7069 black beaker with reliefs broken

Figure 2. Max Uhle, Supe Notebook 67, p.1. Translated by Heiko Prümers. Published with kind permission of Heiko Prümers and the Ibero-American Institute, of the Prussian Cultural Heritage Foundation, Berlin. Photo Amy Oakland.

full that mummy bundles intruded one upon the other. He described and illustrated at least two mummy bundles in his notebook (Figure 3) and he sent to Berkeley three more complete mummy bundles where they remain unopened.

\section{Max Uhle Supe Report: Chimu Capac Site and Chronology}

Uhle chose to excavate Chimu Capac after a reconnaissance of the Supe and Pativilca valleys. He thought that the site was part of a town from the Tiahuanaco period and his Supe report makes it clear that the excavations were focused on burials.

"The various platforms of the principal building in the enclosure next to the hills are densely occupied by burials, which are missing only where the natural underlying rock is too near to the surface of the artificial constructions. The

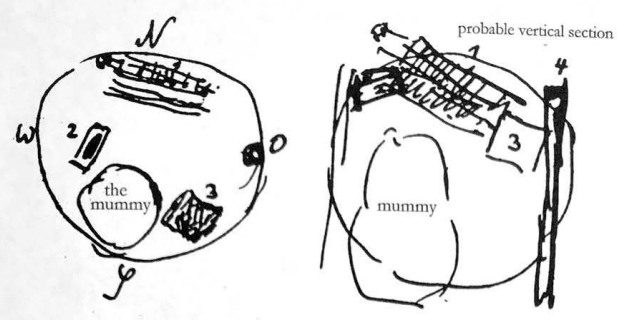

$4 \mathrm{a}$ big bole that stands upright at the east side of the grave, starting about a meter under the surface level and ist lower end [page 5] pointing to the North.

In 2 meters depth

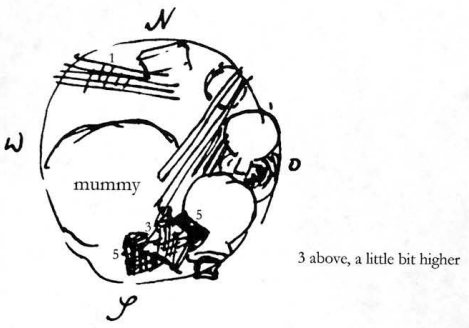

No. 3 was removed by the boys. Beneath was discovered only a similar plaiting-work, a real basket 5 .

Beneath the jars still more medium-sized bottles, bowls, one of those in the extreme N.E. filled with beans, maize and pods of pacay.

-7105 various bundles of reed

7114ab wooden box $(=2)$ with lid

$-7115 \mathrm{ab} 2^{\text {nd }}$ wooden box found deep on the N. side, containing 2 rolls

Figure 3. Max Uhle, Supe Notebook 67, p. 4. Translated by Heiko Prümers. Published with kind permission of Heiko Prümers and the Ibero-American Institute, of the Prussian Cultural Heritage Foundation, Berlin. Photo Amy Oakland.

burials follow two types: that of square chambers of masonry of stone, which contain one or two mummies, or that of mummies embedded with all their utensils without other provision in the soil. There is also a transitional type of burials, mummies placed into the ground near stone walls which utilized for one side of the grave" (Uhle 1905: 6-7).

He understood the site's chronology because he discovered that it compared to his earlier excavations at Pachacamac: "There is no other locality on the whole coast of middle Peru with so many remains reaching back to the period of Tiahuanaco or its immediate neighborhood, besides Pachacamac explored by me in 1896, than the ruins of 'Chimu Capac' near San Nicolas" (Uhle 1905: 5-6). But he states that unlike Pachacamac that continued to be used for burials through the Inca period, Chimu Capac was 
abandoned long before the Chimu and Inca entered the Supe Valley. This relatively short period of occupation is one of the very important aspects of Uhle's excavations at Chimu Capac. Later Sican and Chimu period material has been discovered in many similar funerary sites such as Pachacamac and Huaca Malena, but not material from this later period at Chimu Capac.

The most unique and probably "local" aspect of the site is the presence of an unusual quantity of painted textiles. Uhle (1905: 7-8) reported about this exceptional collection: "These are large common cotton clothes painted all over with mythological and talismanic designs. The collection contains an especially large number of them." He compares them to painted textiles from Ancon: "In the widest sense their technical appearance is nearest to that of the so called 'grave-tablets' of Ancon, a few of which are also represented in my collection from Ancon". Uhle had arrived in Supe in 1904 following his excavations in Ancon and Chancay.

Painted textiles have been discovered in other Peruvian locations, but the collection that Uhle made at Chimu Capac appears to have been the largest ever uncovered at any single site. Uhle's Supe report written directly to Mrs. Hearst gives more information about the finding circumstances of the painted textiles than anything he wrote in his notebook or catalog. Uhle (1905a: 9-10) tells Mrs. Hearst that he found them:

"laid upon the floor of the grave under the mummy or above upon its head outside of the mummy bale, if not inside of its exterior packing. Occasionally the mummy bales were found enveloped in one or more of such cloths. On others they were missing. One mummy was placed upon one large cloth of this kind while two other large ones were laid over it, and 16 smaller ones all with different signs were folded and arranged as in a storeroom one above the other above the head of the bale. Though only a small number of these cloths are now intact, all together they place a great variety of religious ideas before our eyes."

\section{Former Research}

Alfred Kroeber (1925) was the first to publish a monograph of Supe ceramics. Dorothy Menzel (1977) examined the larger group of collections that Uhle made for the University of California and discussed Chimu Capac as an important and "strategic" Wari center, however Menzel (1977:30) noted: "The platforms of the terraces of the pyramid at Chimu Capac were used as cemeteries, like the terraces of the Huaca del Sol in the Moche Valley, and like the forecourt of the Huari temple of Pachacamac". This feature appears to be repeated in other locations during the Middle Horizon where burials have been placed over earlier religious constructions in the Asia Valley over an Early Intermediate Period structure at Huaca Malena (Angeles and Pozzi-Escot 2001) and over the Moche Huaca Cao in the Chicama Valley (Oakland and Fernandez 2001; Oakland and Fernandez 2005). Menzel (1977:29-30) determined that Chimu Capac collection contained material representing all epochs of the Middle Horizon, but most from $\mathrm{MH} 2 \mathrm{~B}$ and 3. Menzel's description of the site as an important Wari outpost and settlement was influenced by Uhle's Supe report where he described Chimu Capac's terraces as part of an "old town”. Lisa Valkenier (1995) excavated the site and found no evidence of a Wari occupation at Chimu Capac. She did identify the Early Horizon temple constructions that formed the foundation for the site. (4)

Lila O'Neale (1933) was the first to examine and publish Chimu Capac textiles. She analyzes a single textile 4-7827 illustrated in Menzel (1977: Fig.76-76B) and in color in Isbell and Young-Sanchez (2012: Fig. 248). The textile is an elaborate sleeved cotton and camelid-fiber shirt woven in different patterns and multiple structures including discontinuous warp and wefts, supplementary wefts, cotton plain weave, and slit-tapestry for the border hem and sleeves. O'Neale noted that the shirt was woven in twelve individual textiles that she thought could have been created by different weavers and that the shirt had been torn in half lengthwise. O'Neale completed large preparatory drawings of the Chimu Capac painted textiles, nine that were published by Rebecca Carrion Cachot (1959). (5) Ina VanStan (1995) completed a general survey of the plain weave structure of the Chimu Capac painted cloth identifying the unusually large variation in spin and weave configurations.

4. Valkenier 1995 cited Kroeber 1925 not Uhle's 1905 Supe Report and stated, without evidence, that Uhle worked a few days and purchased material. She also stated that there were no other associated field notes or documents when, in fact the Ibero-American Institute, of the Prussian Cultural Heritage Foundation, Berlin houses photographs, personal papers, and field notes.

5. Carrion Cachot (1959) published the following figures that relate to O'Neale's drawings of Chimu Capac textiles: Fig. 113a: 4-7443; 113b: 4-7221; Fig. 115: 4-7282; Fig. 117a: 4-7449; Fig. 117b: 4-7165; Fig. 118a: 4-7225; Fig. 118b: 4-7224; Fig. 119a: 4-7276; Fig. 119b. 4-7281. 


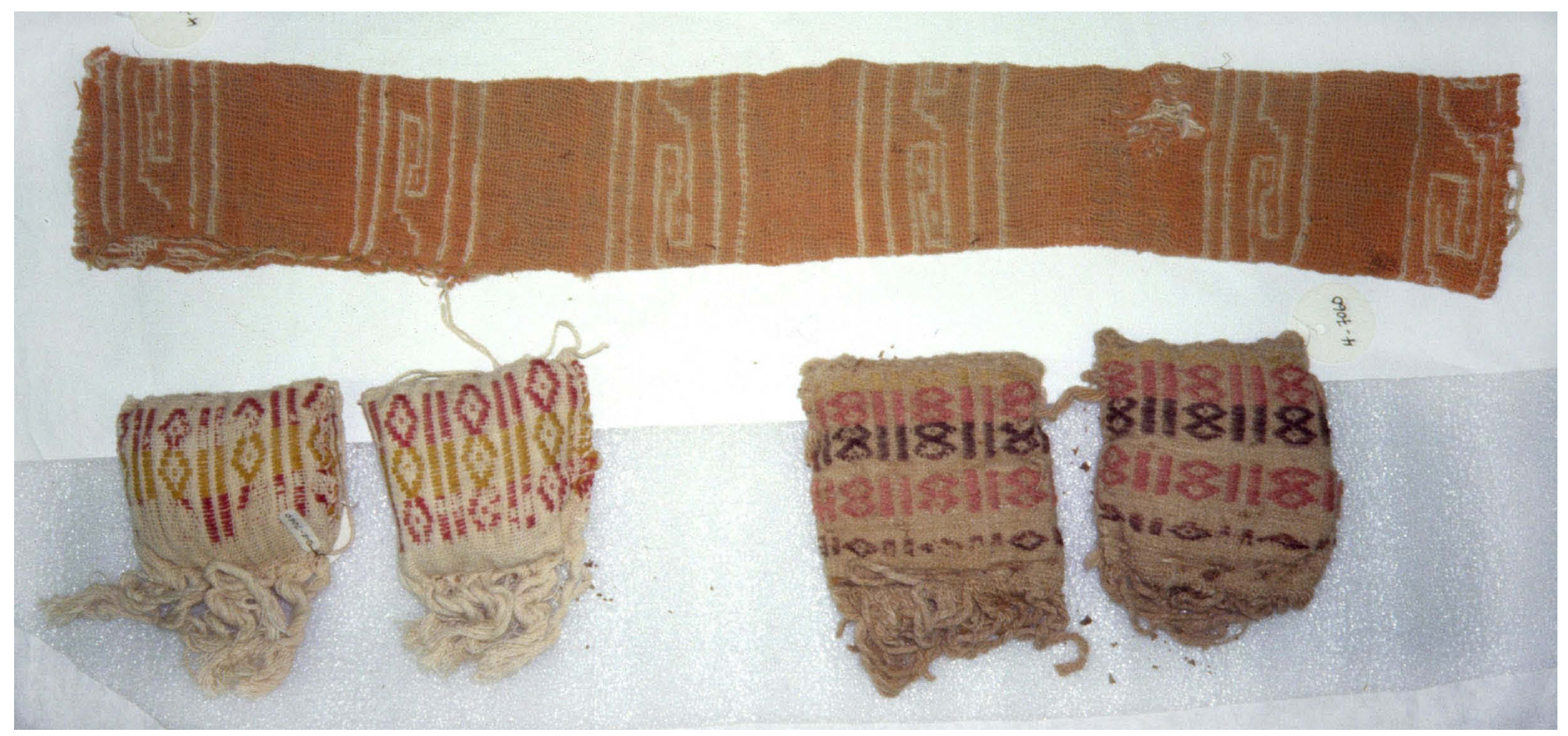

Figure 4. Grave 1, flat pouch 4-7057A (top) woven in incomplete double cloth and (bottom) 4-706o, four bags woven with supplementary-weft patterning. Courtesy of the Phoebe A. Hearst Museum of Anthropology and the Regents of the University of California. Photo Amy Oakland.

\section{Textiles in Chimu Capac Graves and in the larger Collection}

Uhle's notebook, report, and catalog identify that Chimu Capac was a large cemetery and that Uhle and his workers spent most of the month of November 1904 excavating burials in stone walled terraces. All of the textiles appear to relate to Middle Horizon types similar to those known from Uhle's own excavations in Pachacamac and to others that he knew from Ancon and that have now been identified from El Castillo in the Huarmey Valley (Prümers 1990; 1995; 2001) and Huaca Mallena in the Asia Valley (Angeles 2017; Angeles and Pozzi-Escot 2001; Frame and Angeles 2014). The textiles that Uhle described for the first Grave 1 relate exactly to the larger collection of textiles recovered at Chimu Capac.

\section{Pouch 4-7057 and Pendant Bags 4-706o}

Uhle gave three catalog numbers to the six textiles from Grave 1. He listed the long ( $44.5 \times 5.8 \mathrm{~cm}$ ), flat textile (Figure 4, top) 4-7057 "Double stuff" and cataloged the four small pouches (Figure 4, below) together as 4-7060 "Yellow pouch". (6) The flat double cloth textile was woven in incomplete double cloth with ochre and white Z-spun single yarns. The textile was folded and sewn together and may have been placed in the grave without stuffing. The four small bags called "Yellow pouch" 4-706o were woven in Z2S-spun camelid fiber and cotton and patterned with supplementary wefts in diamonds and bars. The bags were created as pairs. The first two $(6 \times 6 \mathrm{~cm}$. $+6 \mathrm{~cm}$ fringe) have a lighter white cotton warp and brighter yellow and red camelid fiber in the wefts. The second pair $(8.4 \times 7 \mathrm{~cm}+3-4 \mathrm{~cm}$ fringe) were woven on a darker tan cotton warp with yellow, pink, and dark purple dyed camelid fiber in the supplementary wefts. Each pair were finished on each loomend and cut in the middle with the cut warps forming the fringe. They were folded and sewn along the side and bottom above the fringe, stuffed with unspun cotton, and sewn closed along the top. Similar bags were attached as pendant to pouches in the collection, but these four may have been placed in the grave as separate bag offerings.

\section{Pouch 4-7057A with pendant bags}

Uhle called the Grave 1 textile 4-7057A "Red, ochre pouch" (Figure 5). The Z2S white cotton plain weave textile (47 $\mathrm{x} 7 \mathrm{~cm}$ ) appears to have been dyed, rubbed, or painted with an ochre pigment, folded, sewn, and finally stuffed with unspun white and brown cotton. Three small pendent pouches $(12 \times 8 \mathrm{~cm})$ were woven with natural brown and

6. The flat textile now labeled 7060 should be Uhle's "double stuff" 7057. The catalog number 706o and title "Yellow pouch" must be the four small pouches with bright yellow dyed camelid fiber. 


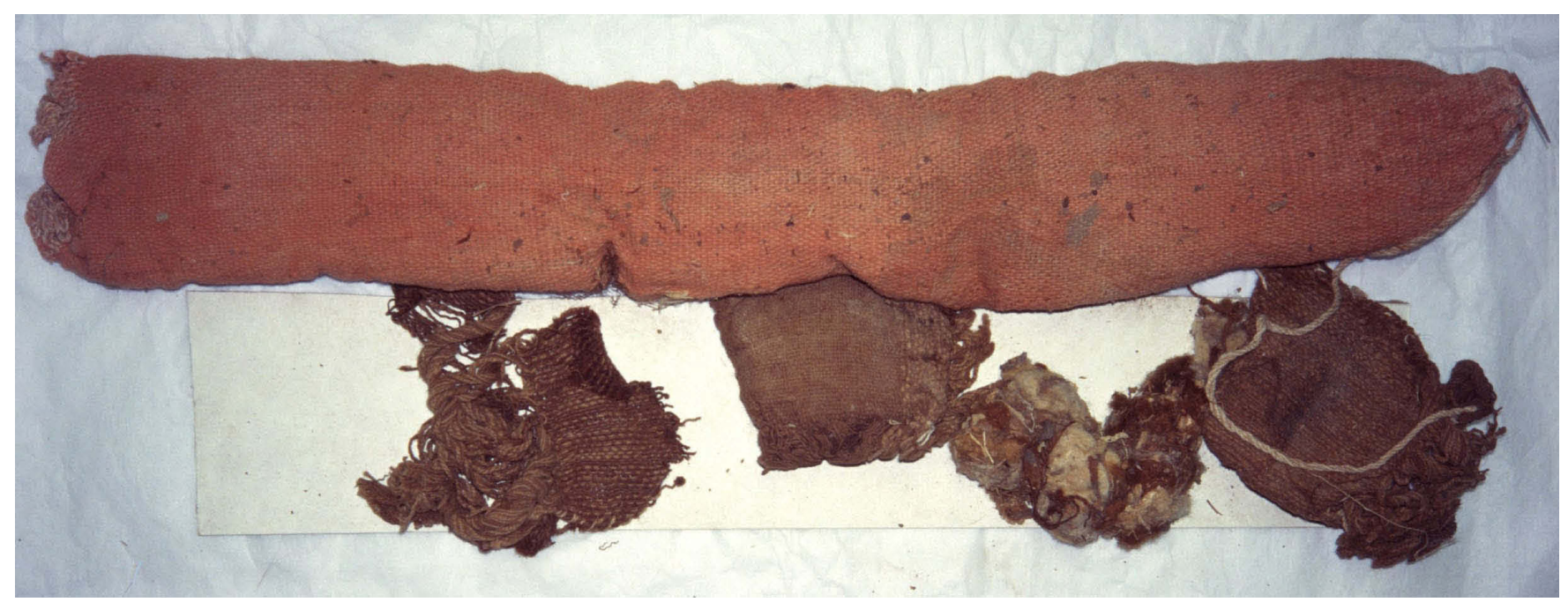

Figure 5. Grave 1, 4-7057 stuffed pouch, pigment-dyed orange with three brown cotton pendant pouches. Courtesy of the Phoebe A. Hearst Museum of Anthropology and the Regents of the University of California. Photo Amy Oakland.

tan cotton Z2S plain weave and cut from the loom leaving an unwoven portion to become fringe, sewn closed, and stuffed with unspun cotton.

These pouches from the first Grave 1 relate closely to twenty-six similar pouches that Uhle excavated, fourteen in the first 28 graves at Chimu Capac. All are woven in cotton plain weave or in double cloth and the pendant bags are woven in plain weave, double cloth, and in supplementary weft-patterning. Painted designs decorate at least eleven pouches and pendant bags (Oakland 2010: Fig. 3).

\section{Painted Pouch 4-7283 from Grave 25}

Uhle collected two well-preserved pouches in Grave 25, 4-7283 and 4-7286 "lying under the mummy". The long $(107 \times 9.9 \mathrm{~cm})$ "Painted medicine pouch" 4-7283 (Figure 6) was woven in $\mathrm{Z} 2 \mathrm{~S}$ cotton plain weave and painted before folding with interlocking frets in brown and bright orange leaving the white cotton surface as an outline around the images. The cloth was folded, sewn closed, and stuffed with unspun cotton and leaves. Seven pendant bags (8-11 x $6.5-8.5 \mathrm{~cm}$ ) were added along the sewn edge, each woven on one loomend, removed and folded, with the unwoven portion creating an un-cut fringe. All yarns are Z2S spun and in two bags dark brown and white cotton were woven in a checked plain weave pattern. Five pouches were painted with grey fret designs. This pouch has been dated to $\mathrm{AD}$ 940-1020. (7)

\section{Painted Pouch 4-7773 and bags 4-7775 from probable} Grave 32

Uhle collected a finely woven and painted pouch 4-7773 $(51 \times 13.5 \mathrm{~cm})$ (Figure 7) together with a series of textiles that appear to be a tomb lot related to the Wari tunic 7771 described below. The pouch has been painted in solid brown in large step images leaving the white $\mathrm{Z} 2 \mathrm{~S}$ plain weave for contrast. Three pendant pouches woven in log-cabin in plain weave have been preserved, each created with different cotton colors in brown and white, light brown and white and one woven with white cotton and dyed red camelid fiber.

The bags that Uhle cataloged as 4-7775 A and B (Figure 8) appear similar in color to other textiles in the same Berkeley catalog series suggesting that they are also part of a tomb lot Grave 32. The bags $(11.5 \times 8.5 \mathrm{~cm}$. and $14 \times 18.5$ $\mathrm{cm}$ ) have been woven with $\mathrm{Z}$ spun white cotton in warp and weft along with supplementary paired $\mathrm{Z} 2 \mathrm{~S}$ yarns in red and very dark green-black camelid fiber. The supplementaryweft pattern is very similar to the small bags 4-706o (Figure 4 from Grave 1.

These examples are a sample of the 28 pouches and bags that Uhle excavated at Chimu Capac. Similar pouches have been recorded from Middle Horizon burial sites from the central and south coast in Ancon (Reiss and Stübel 18801887:Pl. 72; Young-Sanchez 2006: Fig. 7) and in Pachacamac (Kaulicke 2001: Fig 2 "momia de atras"; VanStan 1967). Ann Rowe (1986) described small bags with diamond and

7. The painted pouch 4-7283, Grave 25 yielded age 980+-40 for CAMS55928. CAMS, Lawrence Livermore National Laboratory, June 1 , 1999. "Quoted age is in radiocarbon years using the Libby half life of 5568 years and following the conventions of Stuiver and Polach, Radiocarbon, v. 19, p.355, 1977”. 


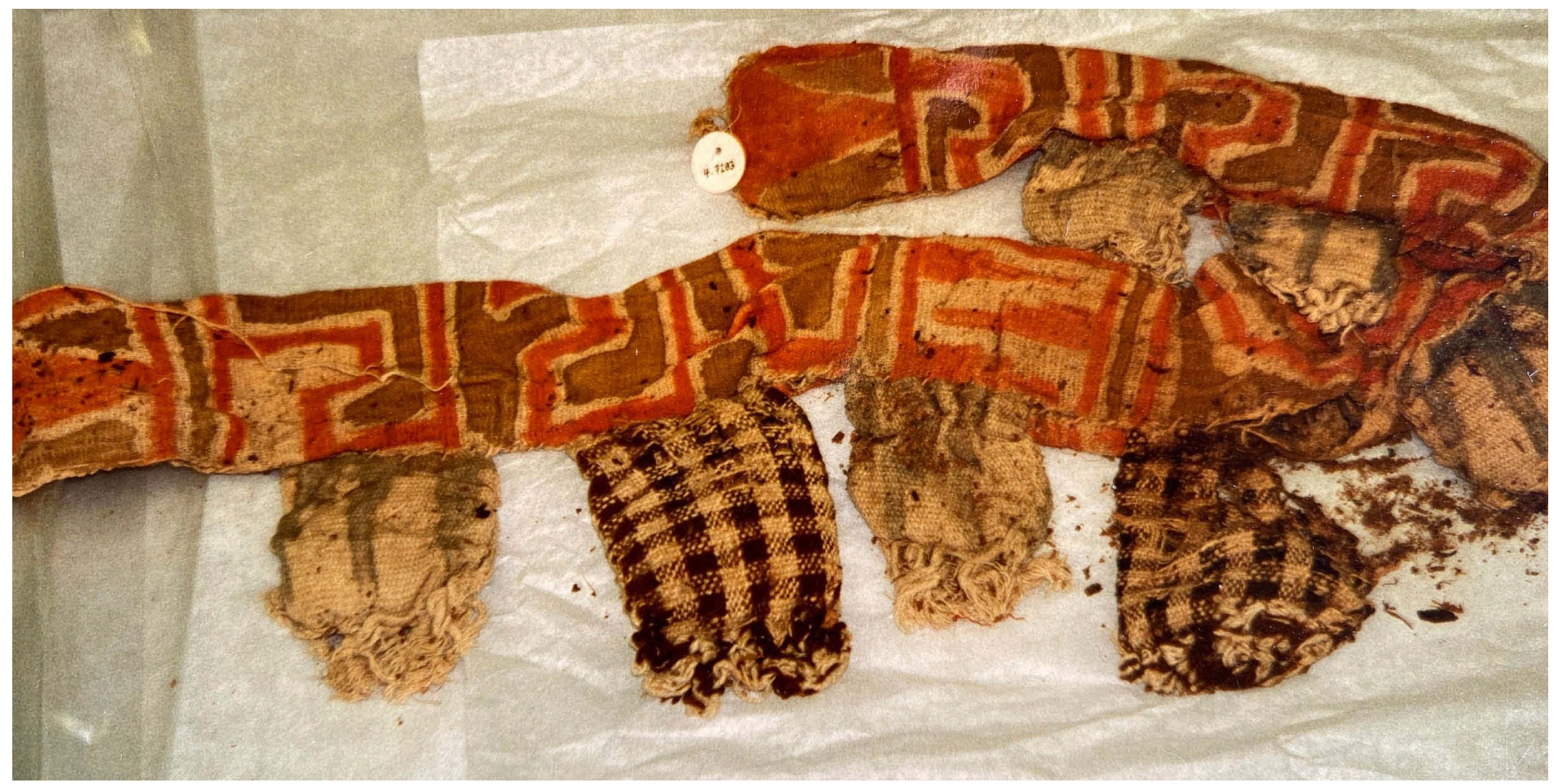

Figure 6. Painted pouch with pendant pouches 4-7283 discovered next to the mummy bundle in Grave 25. Courtesy of the Phoebe A. Hearst Museum of Anthropology and the Regents of the University of California. Photo Amy Oakland.

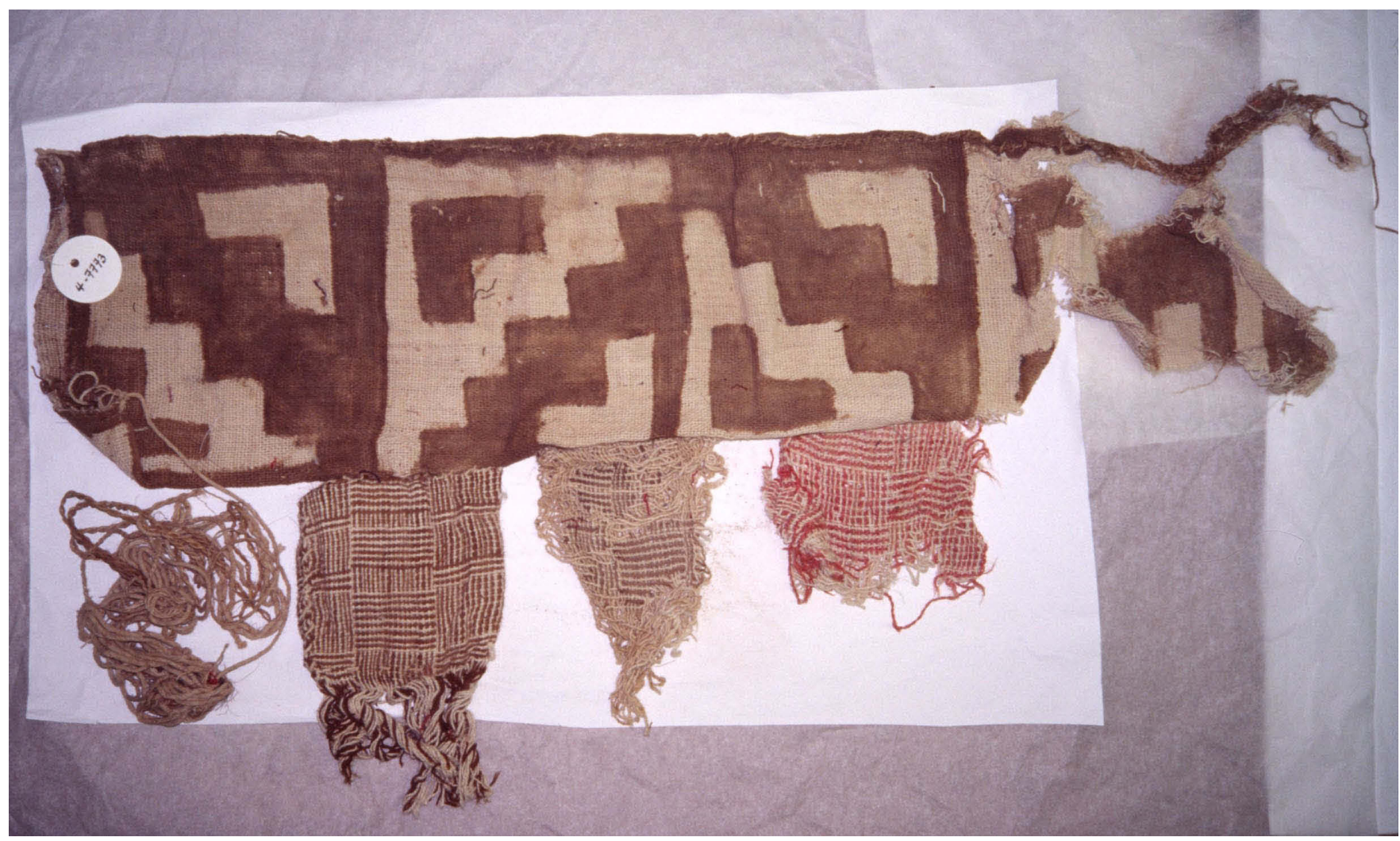

Figure 7. Painted pouch with pendant pouches 4-7773 found in possible Grave 32. Courtesy of the Phoebe A. Hearst Museum of Anthropology and the Regents of the University of California. Photo Amy Oakland. 


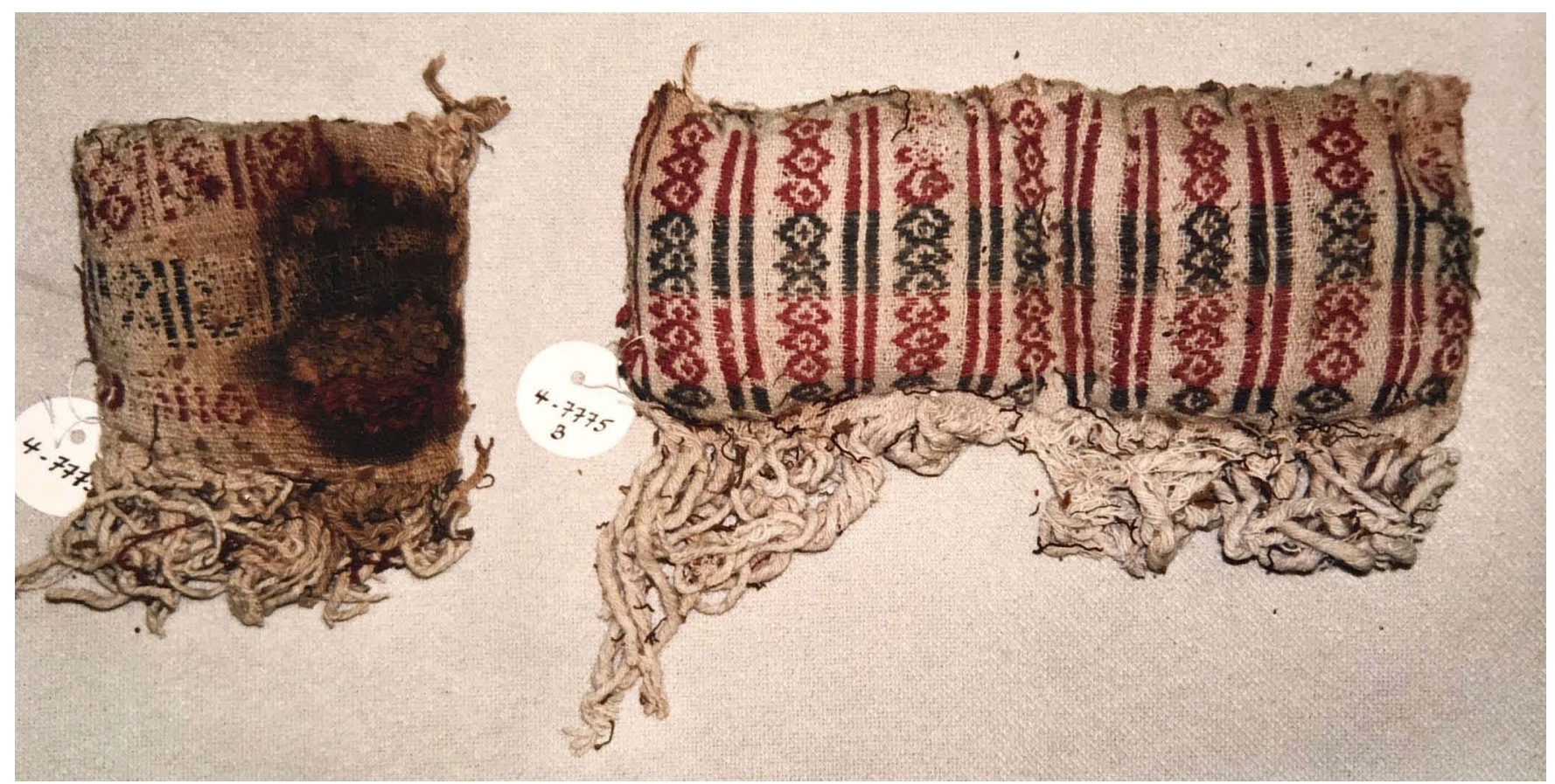

Figure 8. Small bags 4-7775 woven in plain weave with supplementary weft patterning found in possible Grave 32. Courtesy of the Phoebe A. Hearst Museum of Anthropology and the Regents of the University of California. Photo Amy Oakland.

bar designs in supplementary-weft patterning from Monte Grande in the Nasca Drainage that are very similar to the four small bags 4-706o from Grave 1 and to the small bags just described 4-7775 A and B.

Elite Chimu Capac burials that Uhle excavated at Chimu Capac must have originally appeared like those Uhle photographed at Pachacamac such as "Momia de frente" and "Momia con tapiz" (Kaulicke 2001: Fig. 1 and 5) and those illustrated by Reiss and Stübel (1880-1887: Pls. 15-17) from Ancon. Margaret Young-Sanchez (2000) compared many Ancon textiles to Chimu Capac such as the weft-interlocked Wari tunics, shirts woven in discontinuous warp and weft technique, and also large, all camelid fiber shirts from inside the mummy bundles, the scarves wrapped around the bundle's neck, and mummy pouches.

These excavations in Late Middle Horizon cemeteries identify elite burials with the individual's flexed body wrapped and packed with leaves, llama pelts, and ropes. The outside is covered with decorated clothing, a false face, headcloth, or headdress. At Chimu Capac Uhle lists many objects that were associated with funeral bundles such as carved and painted wooden faces cataloged as "False head of mummy" 4-7412 (Menzel 1977: Fig. 45), "False mummy head" 4-7116 from Grave 5 (Oakland 2010: Fig. 9), and another "False head of mummy" 4-7410 (Figure 9) similar to three more in the collection. These faces were carved from a single wood block with the nose in high relief and diamond-shaped eyes and mouth indicated in shallow carving. Eyes are painted white and black and the surface has been coated with a resin-like red pigment. The unpainted forehead would have been covered with a headband or cloth headdress.

Chimu Capac Men's Headdresses 4-7623, 4-7435 and 4-7435A

Uhle cataloged many headdresses like the "Red woolen crown" 4-7623 $(13.3 \times 24 \mathrm{~cm})$ (Figure 10) that was created with groups of long gold-colored loosely spun Z2S camelidfibers. The band was knotted with square knots in alternate rows into a circle that was dipped into red dye. The band's appearance seems to give an impression of hair or feathers, or perhaps both were intended. At least four "crowns of reeds" like 4-7435 (Figure 11) and 4-7435A (Figure 12) identify two different styles of plaited men's headbands. The heavier, solidly plaited band 4-7435 $(23.5 \times 15.2 \mathrm{~cm})$ has been folded and may have been placed in this form in the burial. Uhle describes finding "plaited crowns" in Grave 5 placed next to the mummy bundle and on the shoulder of the bundle. The openwork headdress 4-7435A is plaited with fine reed $\left(55^{+} \times 15.4 \mathrm{~cm}\right)$ and has been preserved in fragments. Each of these plaited headdress styles have been identified in Middle Horizon cemeteries at Huaca Cao (Oakland and Fernandez 2001: Fig. 8), El Castillo (Prümers 1990: 


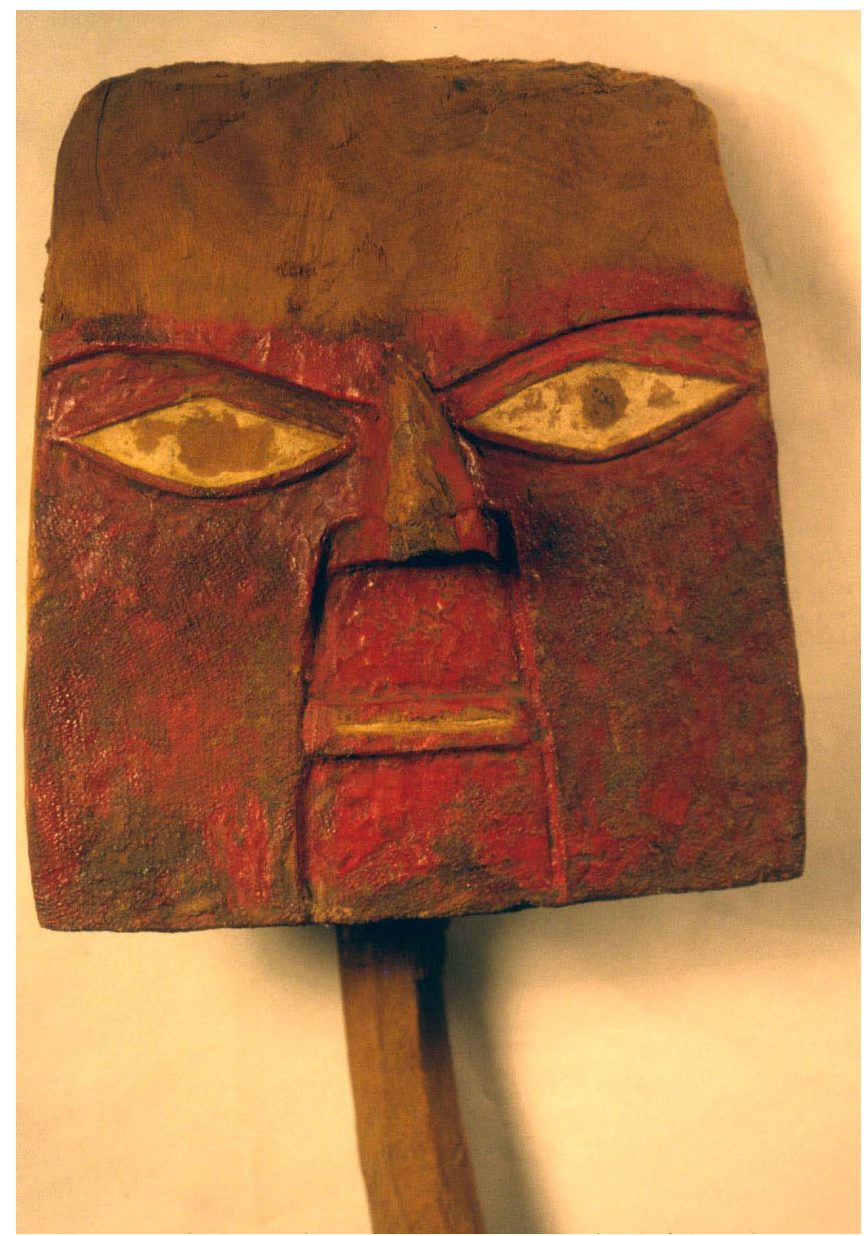

Figure 9. A carved and painted wood head or "mummy face" 4-7410 excavated in burials at Chimu Capac. Courtesy of the Phoebe A. Hearst Museum of Anthropology and the Regents of the University of California. Photo Amy Oakland.

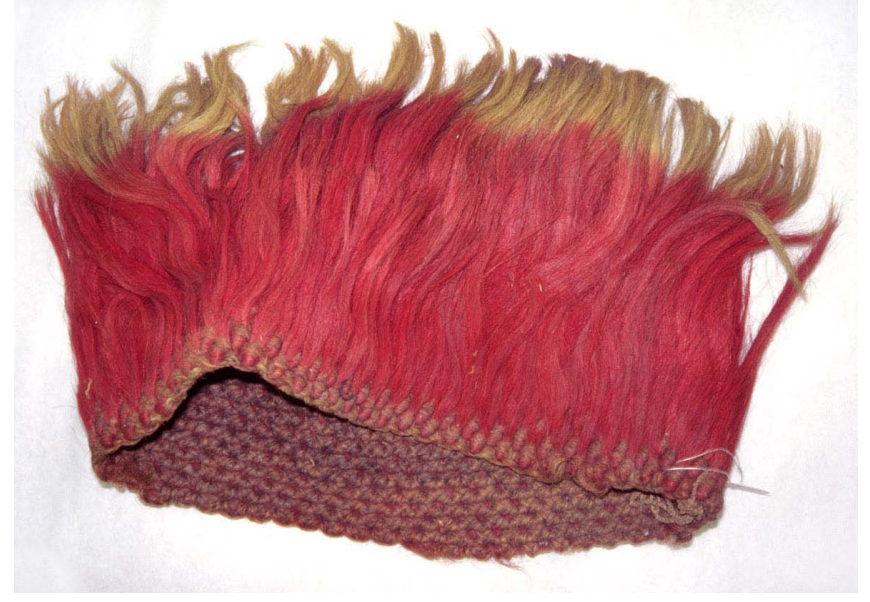

Figure 10.Knotted pile headdress 4-7623 dyed red cataloged "red woolen crown". Courtesy of the Phoebe A. Hearst Museum of Anthropology and the Regents of the University of California. Photo Amy Oakland.

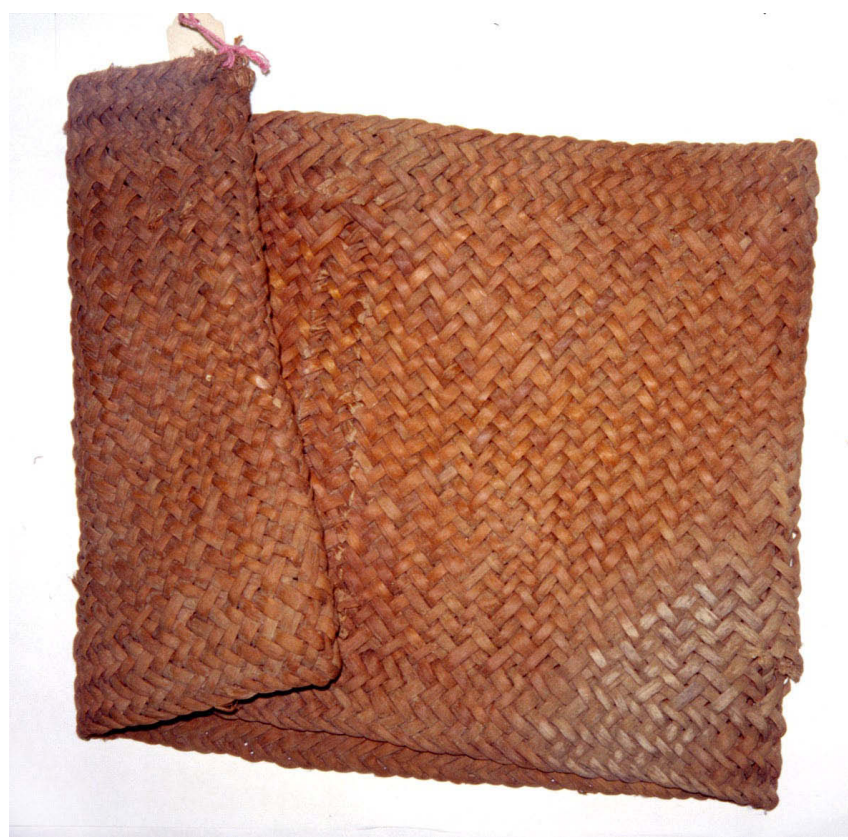

Figure 11. Reed plaited man's headdress 4-7435. Courtesy of the Phoebe A. Hearst Museum of Anthropology and the Regents of the University of California. Photo Amy Oakland.

Figs. 209-213; 2001: Fig. 26), and Huaca Malena (Angeles 2017: Figs. 4A-C and 5).

Uhle also collected headdress ornaments such as "bunch of plumes" 4-7708 (Figure 13) created with yellow feathers each wrapped with red Z2S camelid yarn attached at the base with reed. Uhle cataloged other headdress types like "ornament of flamingo feathers with headband", "knotted crown", and long red pile cords like similar headdresses described by Angeles (2017) from excavations at Huaca Malena.

\section{Wari Tunics 4-7825 and 4-7771 and Wig 4-7772}

Even before his own excavations in the cemeteries of Ancon and Pachacamac, Uhle had studied Peruvian textiles in Berlin. He was familiar with Middle Horizon textile types and in the Supe catalog he lists textiles with descriptive terms that often identify both textile construction and garment type. For example, he lists a Wari weft-interlocked tunic 4-7825 (Figure 14) as "Large red and yellow tapestry poncho", one of four different weft-interlocked tapestries collected at Chimu Capac. The Wari tapestry tunic 4-7825 was cut along each side-seam and opened for burial and the neck slot was stitched closed. As with most Wari tunics the warp is aligned horizontally as worn, the tunic is made in two separate parts, the textile is cut from the loom with one 


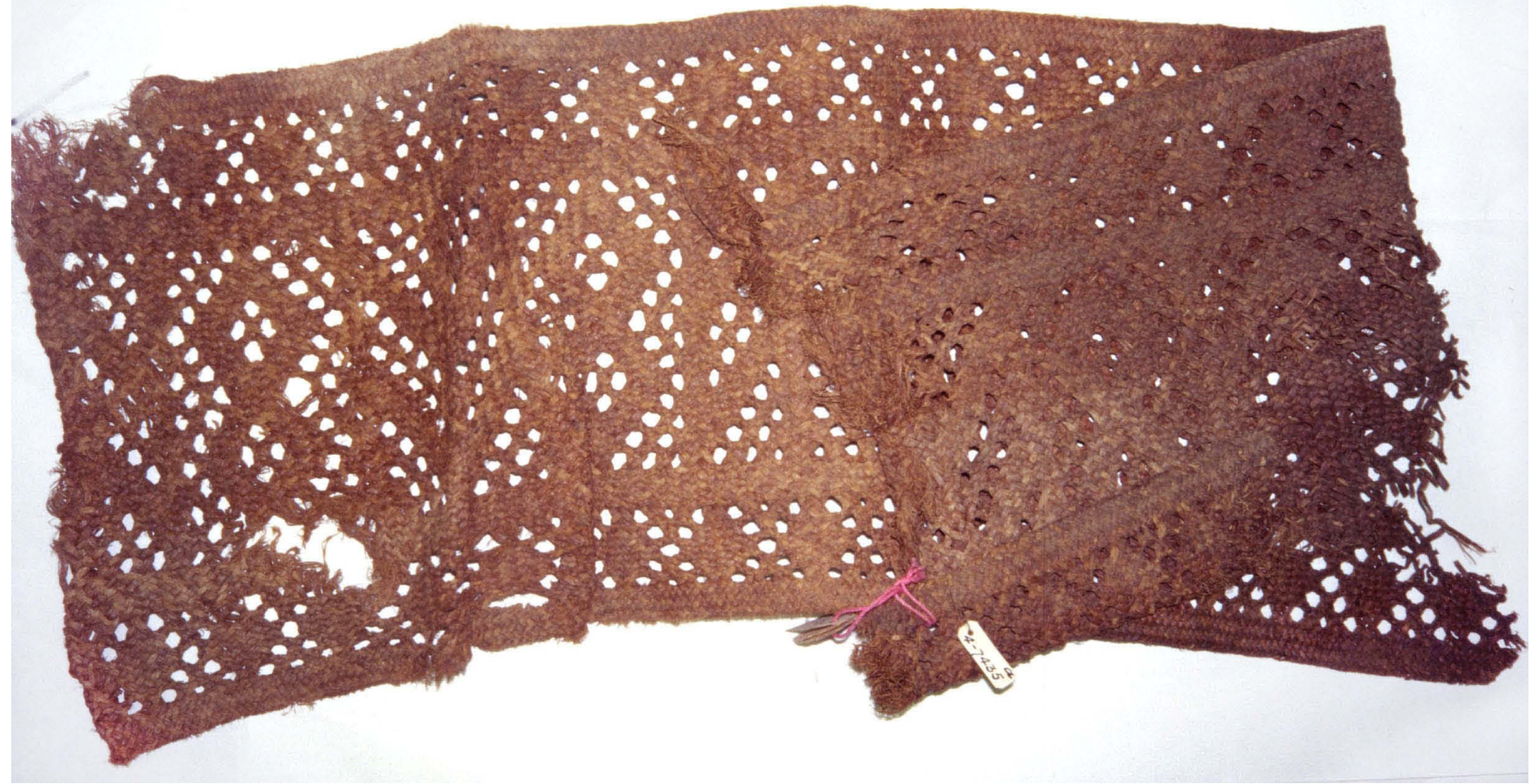

Figure 12. Plaited man's headdress 4-7435A. Courtesy of the Phoebe A. Hearst Museum of Anthropology and the Regents of the University of California. Photo Amy Oakland.

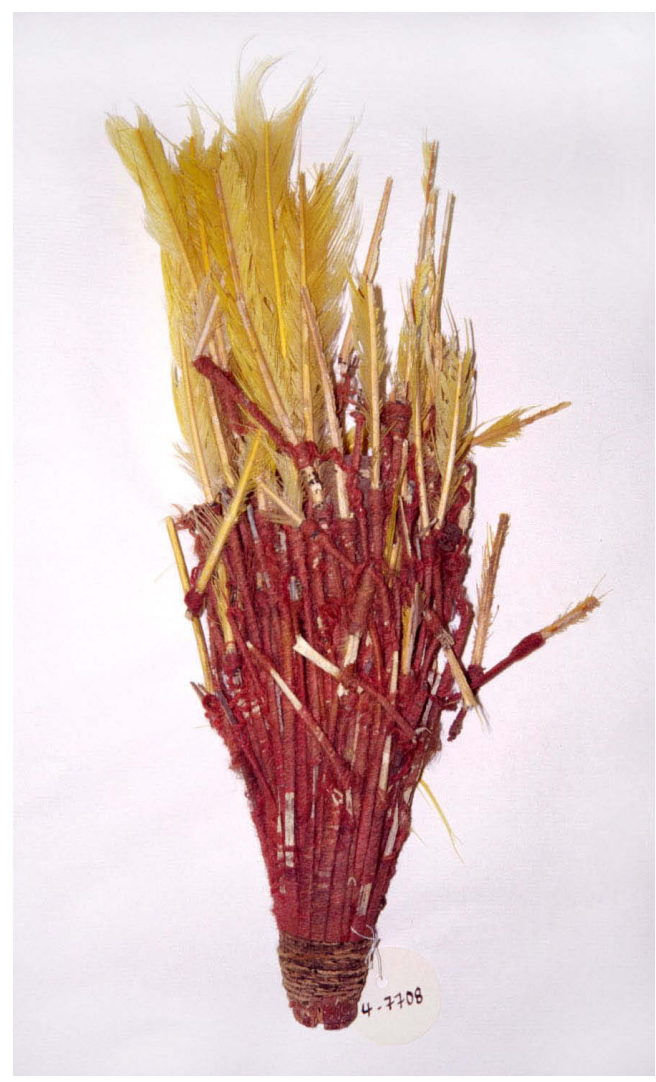

Figure 13. Headdress ornament cataloged as "Bunch of plumes" 4-7708. Courtesy of the Phoebe A. Hearst Museum of Anthropology and the Regents of theUniversity of California. Photo Amy Oakland.

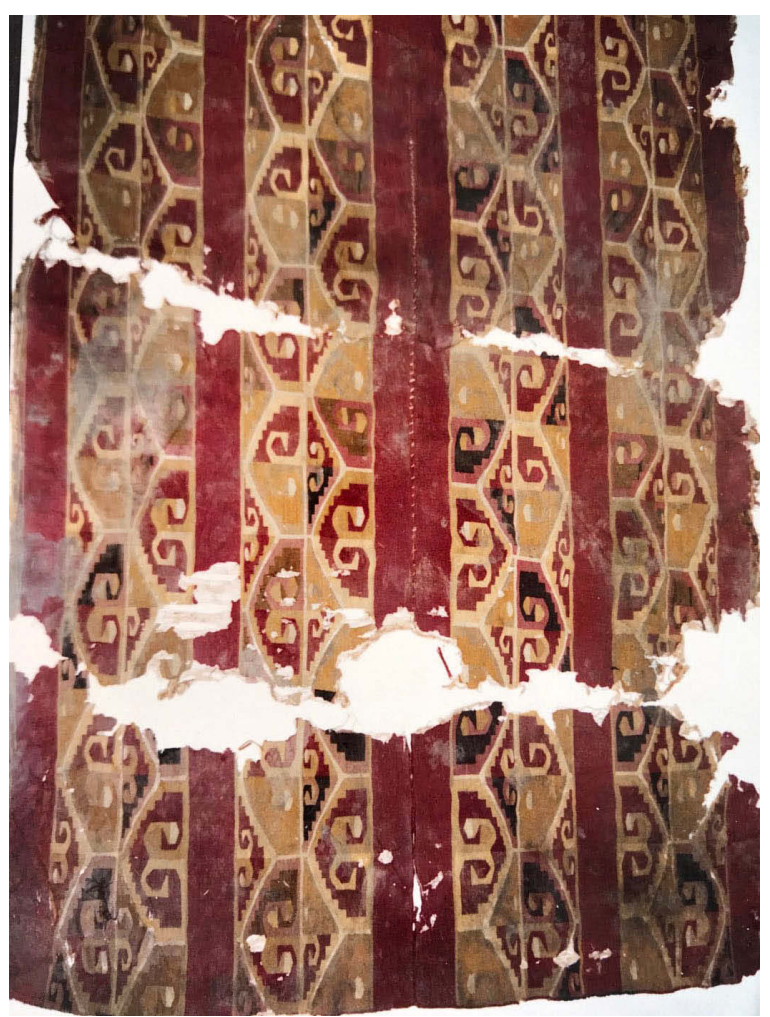

Figure 14. Wari weft-interlocked tapestry man's tunic 4-7825 opened for burial that Uhle cataloged as "Large red and yellow tapestry poncho". Courtesy of the Phoebe A. Hearst Museum of Anthropology and the Regents of the University of California. Photo Amy Oakland. 


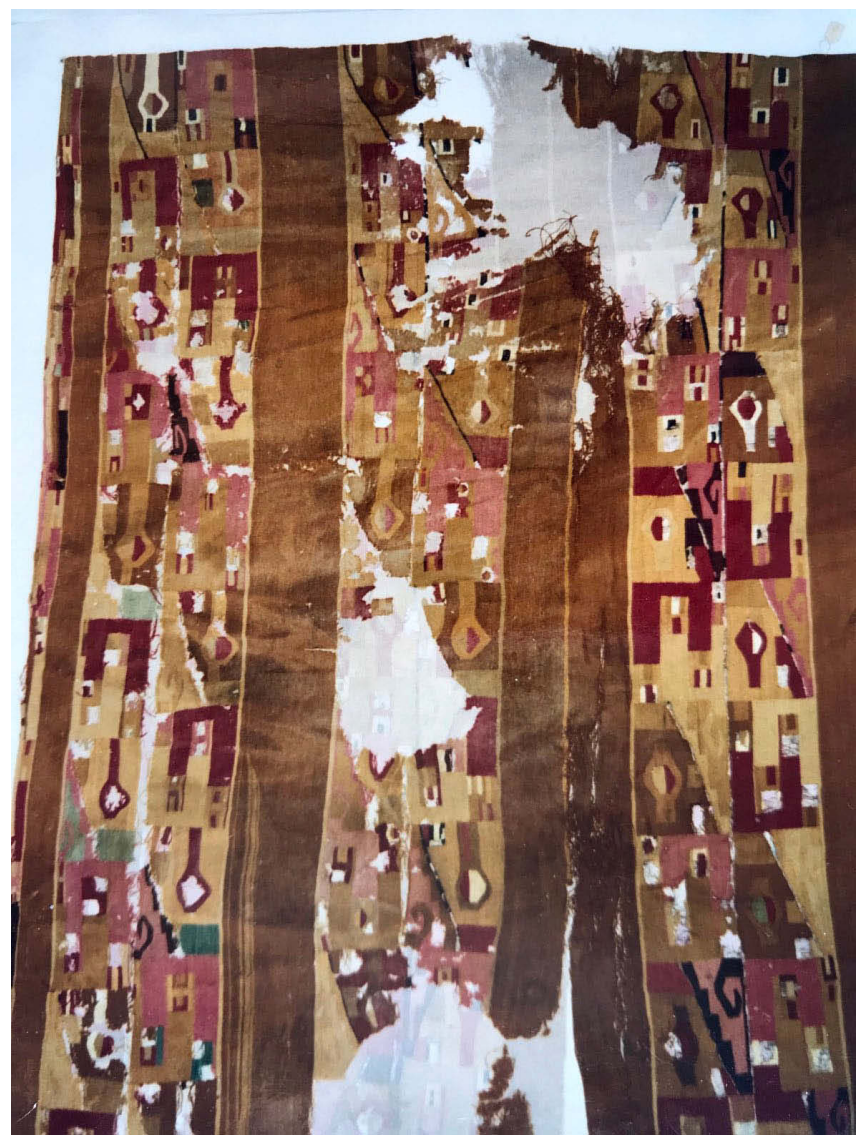

Figure 15. Detail of Wari weft-interlocked tapestry tunic 4-7771 cataloged as "Large tapestry poncho" along with Wari wig 4-7772 in possible Grave 32 from Chimu Capac. Courtesy of the Phoebe A. Hearst Museum of Anthropology and the Regents of the University of California. Photo Amy Oakland.

loomend chained and placed together along the vertical center and the cut end braided and covered with figure- 8 embroidery along the sides. The tunic $4-7825(52.3+52.6 \times 172$ $\mathrm{cm}$ or $86 \mathrm{~cm} . \mathrm{x} 104.9 \mathrm{~cm}$. as worn) is woven with Z2S cotton warp and $\mathrm{Z} 2 \mathrm{~S}$ camelid fiber weft. The design and coloring are familiar for Wari style with red solid vertical bands and repeating and opposing step-fret symbols woven in fine interlocked tapestry.

Uhle listed another Wari weft-interlocked tunic 4-7771 (Figure 15) as "large tapestry poncho" (Menzel 1977: Fig. 75). The tunic 4-7771 (48.7+48 x $206 \mathrm{~cm}$ or $103 \mathrm{~cm}$. $\times 96.7$ $\mathrm{cm}$. as worn) is woven in the same manner with two long, rectangular webs woven on short, cut warps. The design arrangement is the same, with four vertical patterned bands between solid pale brown vicuna-colored sections. The warp in tunic 4-7771 was prepared with both Z2S cotton and camelid-fiber.

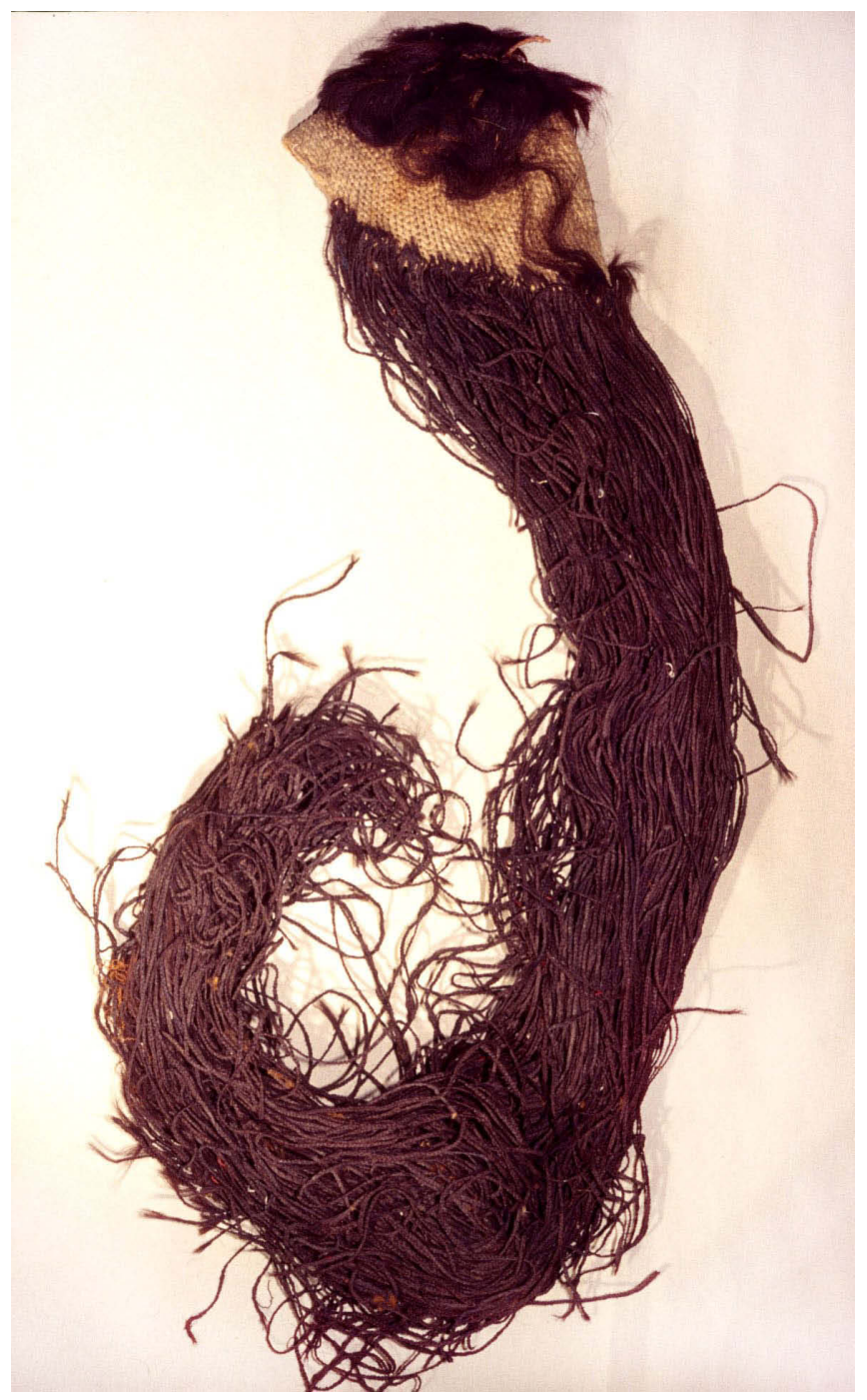

Figure 16. Wari style wig 4-7772 cataloged with a series of objects including miniature textiles, woven pouches, and Wari tapestry tunic 4-7771. Courtesy of the Phoebe A. Hearst Museum of Anthropology and the Regents of the University of California. Photo Amy Oakland.

Wari Wig 4-7772 and Four-Part Headdress Border 4-7779

The catalog numbers that follow this Wari tunic 4-7771 appear consistent with objects that may have constituted a tomb lot here called Grave 32 including a "wig of natural hair" 4-7772 (Figure 16). This Wari type is also known from excavations in Ancon (Reiss and Stübel 1880-1887: Fig.16) and El Castillo (Prümers 1990: Fig. 270). The Chimu Capac wig is formed from a Z2S cotton cap made of simple looping. Thick hanks of human hair are attached through the top of the cap and more than 250 humanhair strands were braided from the bottom cap edge reaching a length of $111.5 \mathrm{~cm}$. Following the wig, Uhle cataloged the painted pouch 4-7773 (Figure 7) described above 


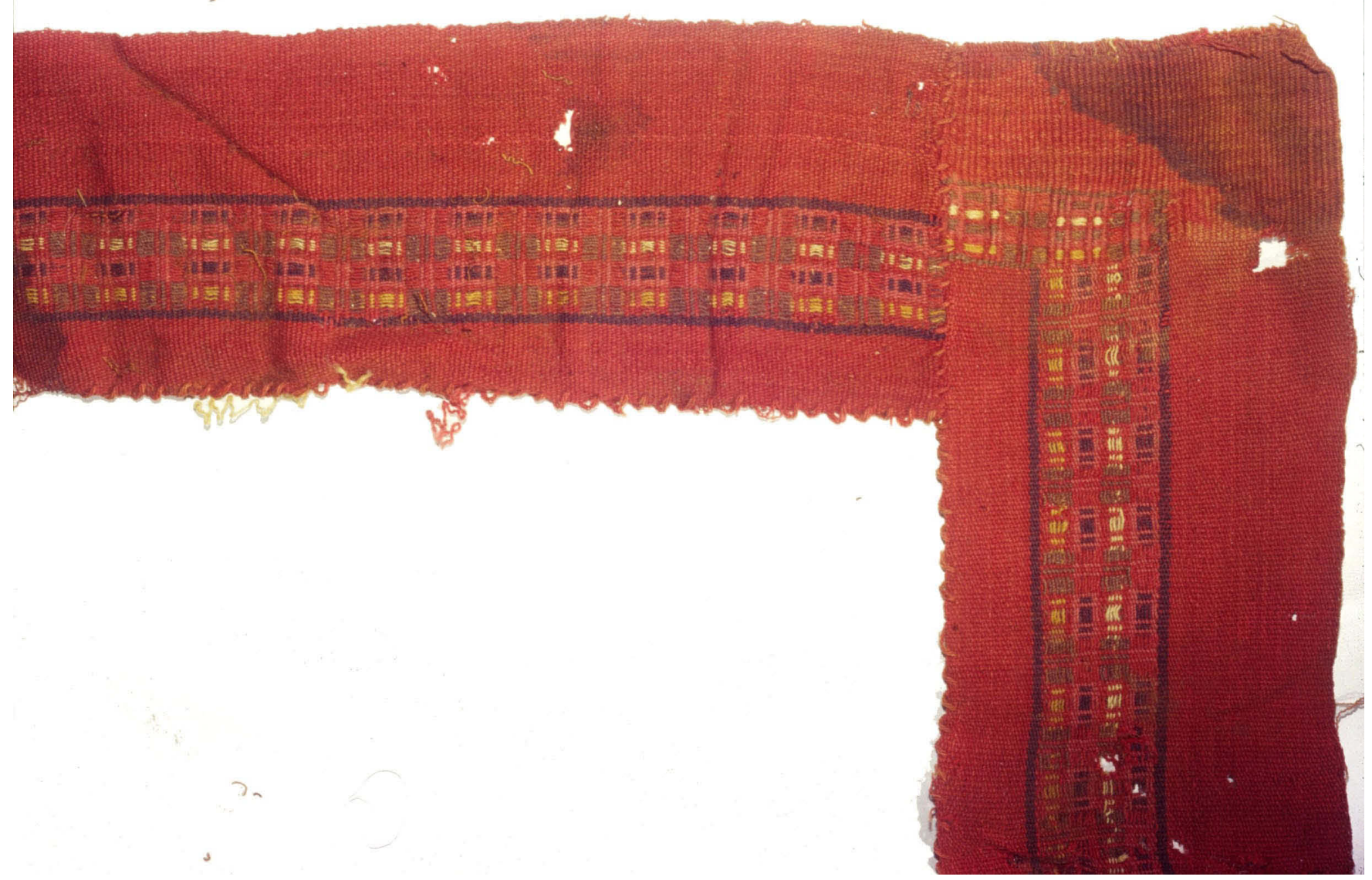

Figure 17. Detail of two sides of headdress border 4-7779 that has been re-used for burial and cataloged as "wrapped around the neck of the mummy", probably the mummy in possible Grave 32 with the Wari tunic 4-7771 and wig 4-7772. Courtesy of the Phoebe A. Hearst Museum of Anthropology and the Regents of the University of California. Photo Amy Oakland.

and 4-7774, 4-7775 described above (Figure 8). The warpstriped miniature tunics 4-7776-7778 must have also accompanied this burial.

Next, Uhle cataloged 4-7779 (Figure 17) that consist of two bands sewn together re-used for burial. He wrote in the catalog that he found this textile "Wrapped around the neck of the mummy". The bands are two sides of the border of a four-part headcloth like those described and illustrated by Young-Sanchez (2006) from Ancon, Chimu Capac, and other Middle Horizon burial locations from the central coast. The two sections ( $107 \times 9.5 \mathrm{~cm}$. and $98 \times 9.5 \mathrm{~cm}$.) illustrated in Figure 17 have been preserved in good condition for approximately $30 \mathrm{~cm}$. on each side of one corner. The ends of the band are complete, but brittle and creased as if just removed from the bundle. The image detail shows the particular feature of this band where the two border sections meet. The weaving structure changes from warpfaced with warp stripes and floats to weft-faced with supplementary weft floats and discontinuous wefts to suggest a continuous pattern around the corner.

Uhle collected a second very similar border fragment from Chimu Capac cataloged simply as "Red woolen fabric" 4-7610 (Young-Sanchez 2006: Fig. 20). This band is slightly wider and shorter and was woven in the same way as 4-7779 with both warp and weft stripes and float patterns. Very few of these four-part headdress cloths were placed intact in Middle Horizon burials. Instead, the borders were removed and divided in half and the four-equal center squares were separated saving only the single decorated square. Only one border has been preserved attached to a part of the original center (Young-Sanchez 2006: Fig. 12). (8)

8. Oakland and Fernandez (2005: Fig.16) illustrate a woman's mantle with the same camelid-fiber warp-face border construction, but the center is a single cotton square. 


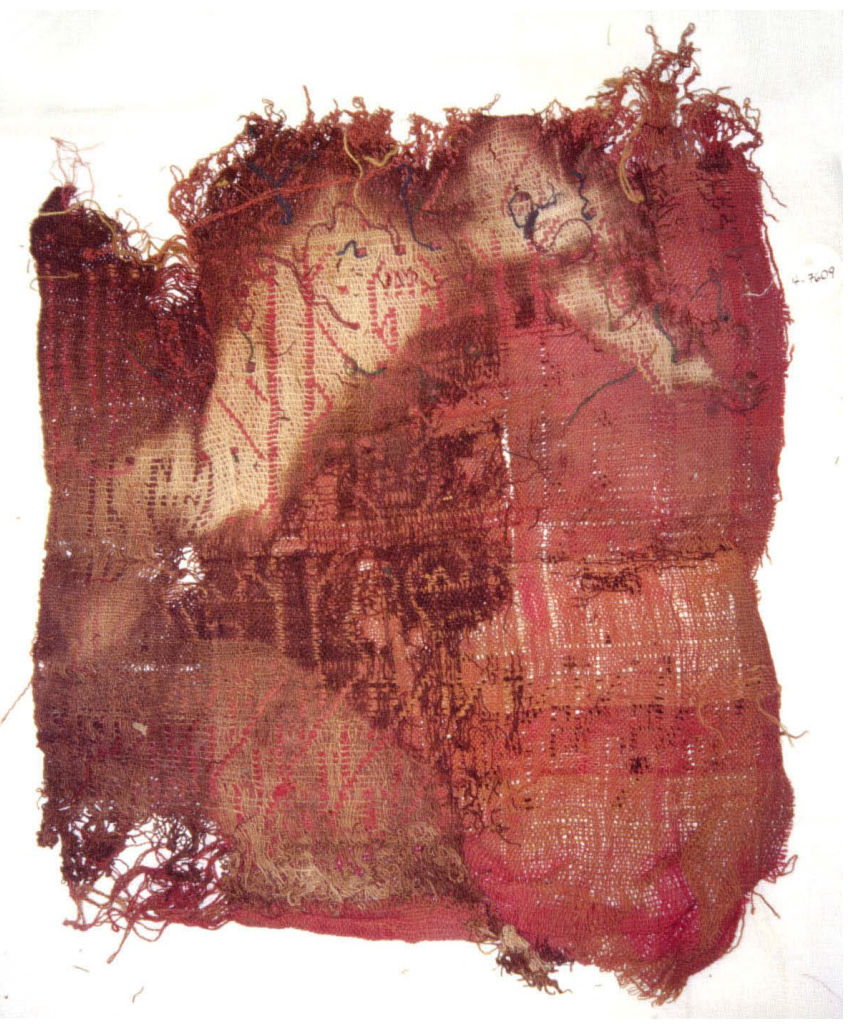

Figure 18. Double cloth square 4-76og cataloged "Red double stuff, San Nicolas" that is one of the four parts woven for the center of a four-part headdress. Courtesy of the Phoebe A. Hearst Museum of Anthropology and the Regents of the University of California. Photo Amy Oakland.

\section{Four-Part Headdress Panels 4-7609 and 4-7489}

The double cloth square $(41.5 \times 32.5)$ that Uhle cataloged 4-7609 "Red double stuff" (Figure 18) may have been discovered together with the band 4-7610 just described. The cloth is woven in $\mathrm{Z} 2 \mathrm{~S}$ red camelid-fiber and white cotton double cloth with discontinuous spots of color similar to at least five more double cloth square textiles that Uhle collected at Chimu Capac.

Uhle cataloged two slightly smaller $(36 \times 32 \mathrm{~cm}$. and 39 $\mathrm{x} 33 \mathrm{~cm}$.) square textiles with the same number $4-7489$ as "Fragments of red double stuff" (Figure 19). The holes remaining in the textile identify the pattern of repeating frets in diagonal rows. These two could have been part of the same textile, and each preserves part of a white plain weave section along one loomend, but the dimensions and patterns suggest that these represent two different headcloths, each with the decorated part that would have been connected with three other plain weave squares to form a fourpart center with decorated borders. Another panel (not pictured) 4-7704 ( $46 \times 46.2)$ was cataloged as "Fragment of red double stuff" with only the red side preserved, very similar to the panels 4-7489. Prümers (1995:353) discusses these diagonally woven designs in red and white double cloth from the central coast with Middle Horizon 3 and 4 associations. For this time period he notes the addition of embroidered, instead of woven color "spots" also noticed by Young-Sanchez (2006: 93).

\section{Unique Chimu Capac Four-Part Headdress Panels 4-7492 and 4-7747}

The Chimu Capac collection includes at least two more variations of four-part headcloth centers. One double cloth fragment 4-7492 (Figure 20) "Red and black double stuff with snake pattern" was woven with similar proportions (41 $\mathrm{x} 38 \mathrm{~cm}$.), although incomplete on three sides. The textile is woven with four color bands of two different color combinations: red camelid fiber and white cotton and purple camelid fiber and white cotton. All yarns are spun and plied Z2S. The designs repeat with profile animals with curled snout and tail, a four-part design ending with snake heads, and a border of frets along one side. A portion of a white $\mathrm{Z} 2 \mathrm{~S}$ cotton cloth is visible along one loomend.

Another complete square ( $47 \times 46 \mathrm{~cm}$.) textile 4-7747 "Fragment of a double fabric" (Figure 21) was woven in light brown and white cotton double cloth and is the only Chimu Capac example with evidence of all four sections of the four-part headcloth. The cloth repeated two white plain weave squares, one brown, and one brown and white double cloth square. The double cloth pattern repeats central images of interlocking snakes with smaller bird figures, serrated fish, and a fret border along the side and bottom. In this textile the camelid-fiber color spots were woven into the cloth along with the double cloth construction in discontinuous wefts over supplementary warps, a Moche textile type identified by Conklin (1979) and a textile structure that Prümers (1990, 1995, 2001) calls Moche-Huari for Middle Horizon textiles from El Castillo.

\section{Double cloth Sleeved Shirt 4-7702 and 4-7702B with Wari Tapestry}

At Chimu Capac, Uhle collected textiles woven in double cloth that appear different to the four-part squares. This textile group is woven with S-spun single cotton yarns paired in warp and used as singles alone or sometimes also paired in the weft. These yarn and weave constructions differ from the Z2S cotton yarns of the central and south coast, but Middle Horizon period north coast spinners spun $S$ yarns and used these as singles in warp and weft noted in MocheHuari textiles at El Castillo (Prümers 1990, 2001). At Chimu Capac Uhle collected many textiles woven in this north coast 

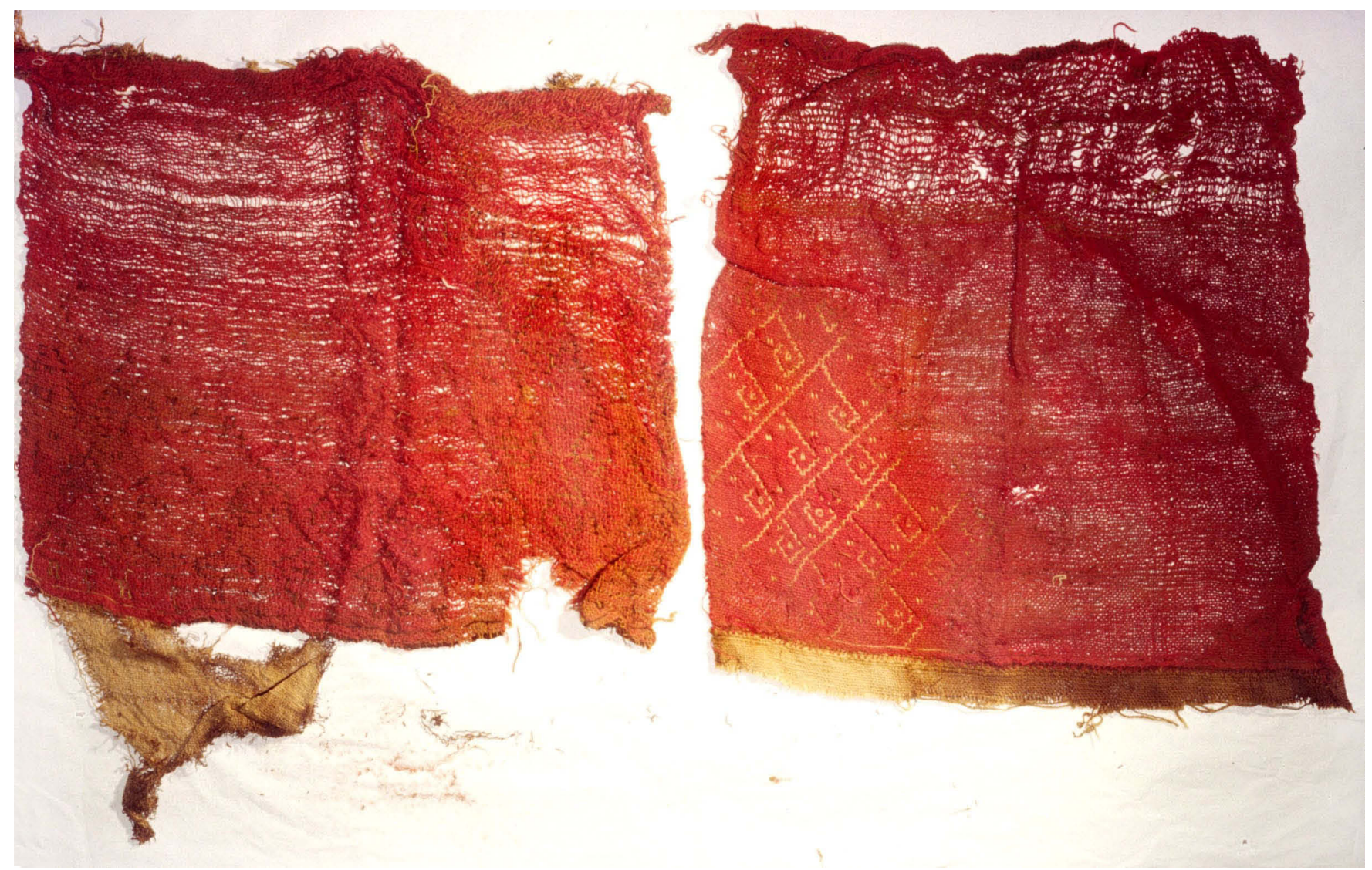

Figure 19. Two different double cloth headdress squares cataloged with the same number 4-7489 "Fragments of red double stuff". Courtesy of the Phoebe A. Hearst Museum of Anthropology and the Regents of the University of California. Photo Amy Oakland.

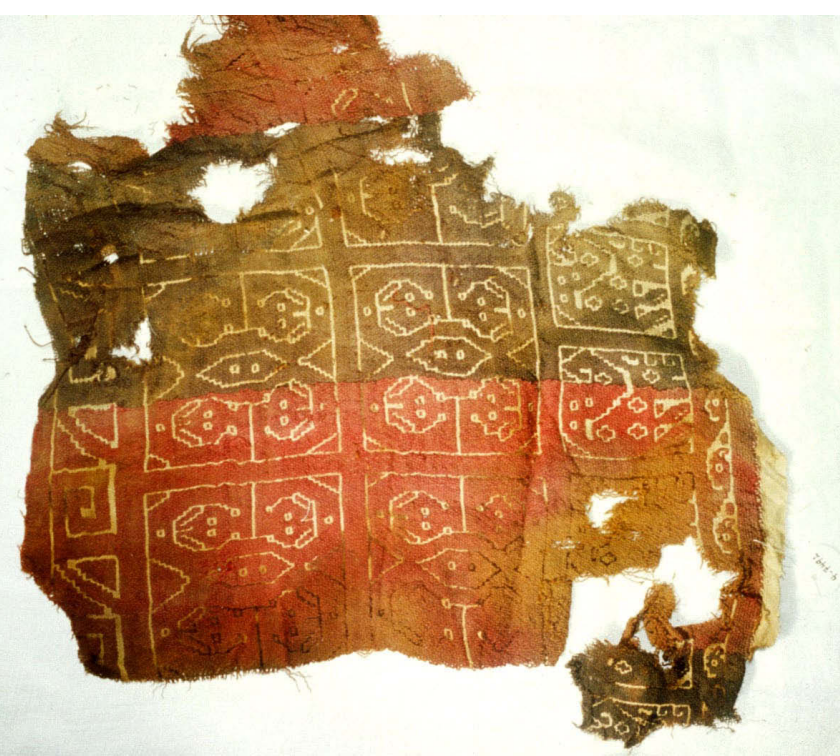

Figure 20. A unique double cloth square possibly woven as one part of a four-part headdress. Uhle cataloged the square "Red and black double stuff with snake pattern". Courtesy of the Phoebe A. Hearst Museum of Anthropology and the Regents of the University of California. Photo Amy Oakland.

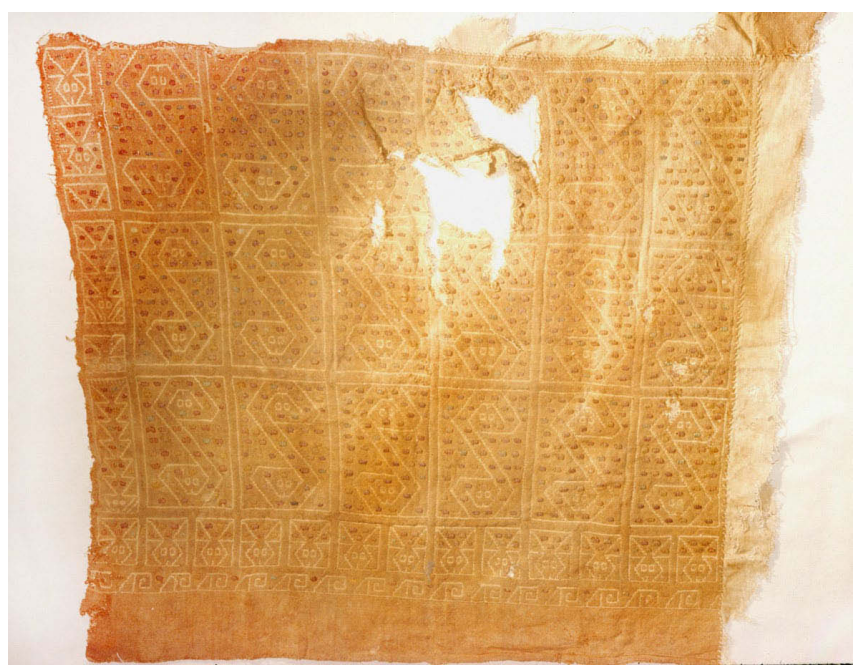

Figure 21. Cotton four-part headdress square 4-7747 with evidence of all four other parts cataloged as "Fragment of a double fabric". Courtesy of the Phoebe A. Hearst Museum of Anthropology and the Regents of the University of California. Photo Amy Oakland. 


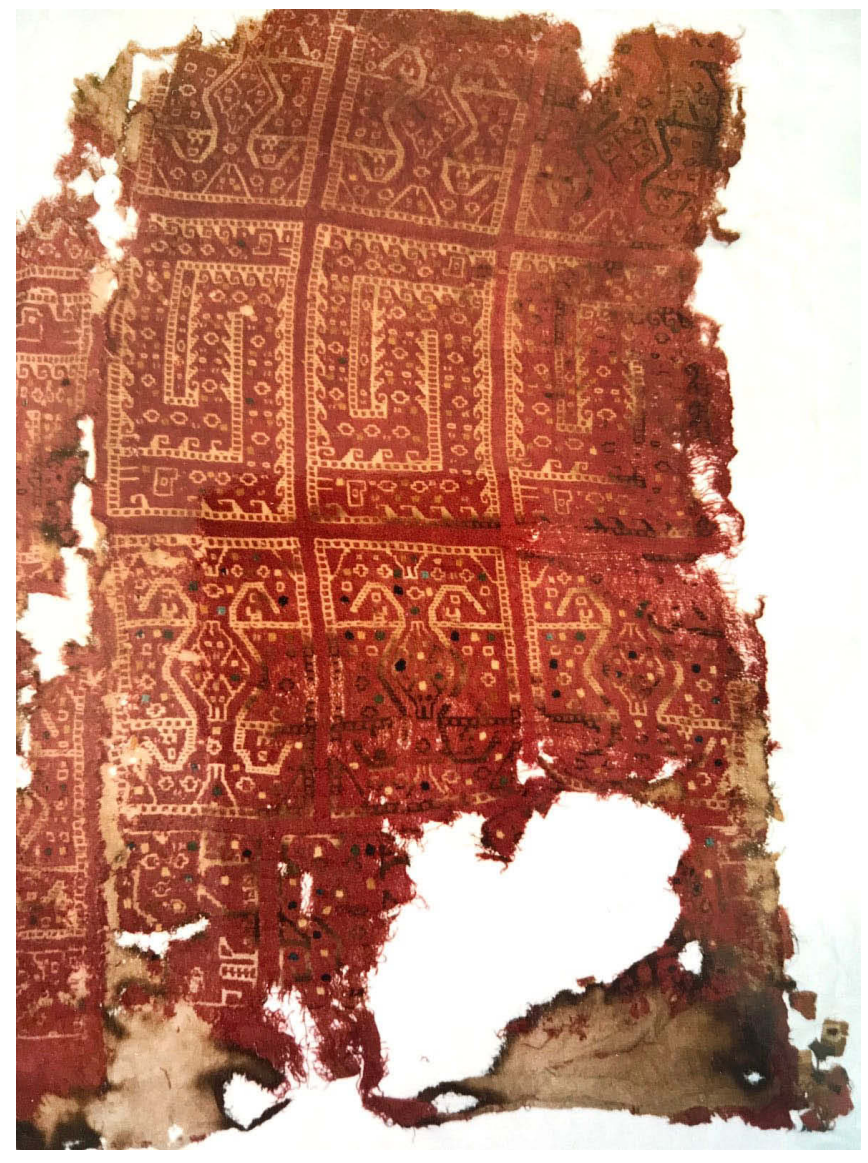

Figure 22. Detail of large section of 4-7702A the front of a sleeved shirt woven in fine double cloth panels with small fragments of highland Wari-style tapestry attached to the bottom corners and sides. Courtesy of the Phoebe A. Hearst Museum of Anthropology and the Regents of the University of California. Photo Amy Oakland.

red and white double cloth style such as a panel 4-7484 cataloged "Red double stuff with animal figures, epigonal style" (Oakland 2001: Fig. 25). Another similar double cloth textile from Chimu Capac 4-7491(not pictured) "Double stuff with brown animal figure” was woven as a rectangle, folded, and used as a sleeve. The cloth is all cotton in brown and white double cloth patterned with the same cat-like animal image.

The textiles illustrated here 4-7702A, and 7702B (Figure 22, 23) cataloged "Large poncho of red and white double stuff, incomplete, and sleeve" are important because they combine highland weft-interlock tapestry and coastal style double cloth. The wide $(95 \times 100.5 \mathrm{~cm}$ ) shirt 4-7702A has been preserved on one face woven in two vertical panels with three vertical design rows that repeat a curled snout and tail animal, double-headed snakes, and a large fourpart design. The sleeve (Figure 22) 4-7702B was woven as a single folded rectangle $(18 \times 16 \mathrm{~cm}$.) with one large

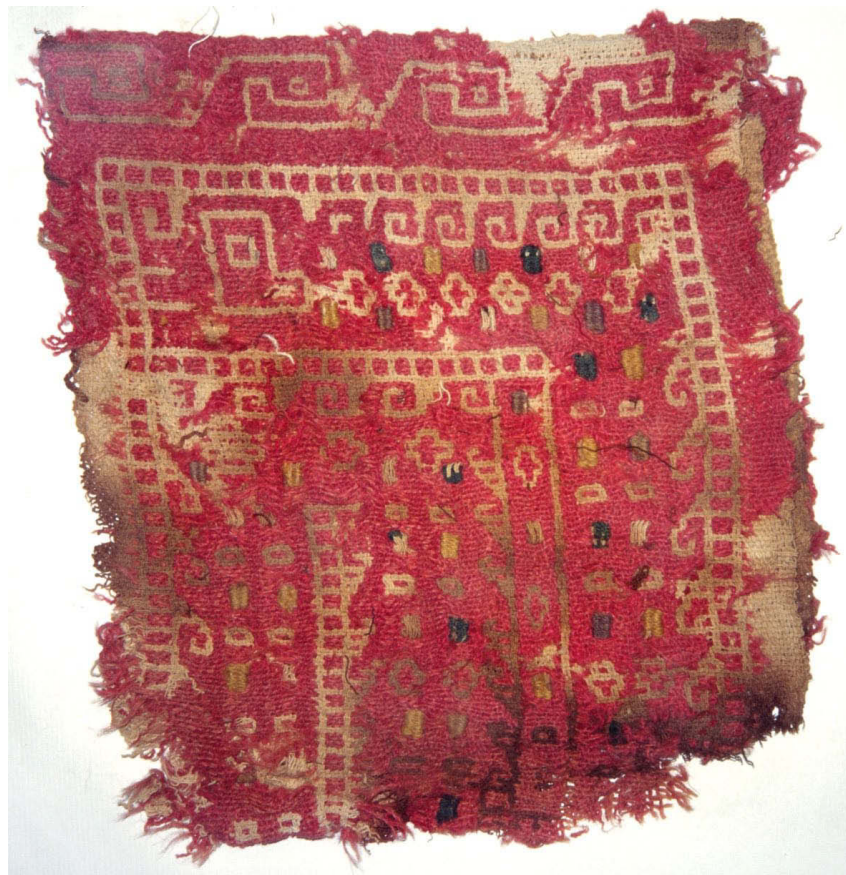

Figure 23. The double cloth sleeve 4-7702B of the large doublecloth shirt 4-7702A cataloged together as "Large poncho of red and white double stuff, incomplete, and sleeve." Courtesy of the Phoebe A. Hearst Museum of Anthropology and the Regents of the University of California. Photo Amy Oakland.

double-headed snake image. In both the shirt and sleeve the white cotton portion of the double cloth was woven with SS/ SS north coast construction with S-spun single yarns here paired in warp and weft with red Z2S camelid fiber double cloth. Discontinuous-weft "spots" in camelid fiber dyed gold, blue, green, and black were woven over supplementary warps. The designs are similar on the two panels, but the execution, color, and block size are dissimilar and the designs do not match between panels. These features suggest that each panel was woven by a different weaver. Fragments of fine camelid fiber weft-interlocked tapestry were sewn to the bottom sides of each panel identifying contemporaneity during the Middle Horizon also noted by YoungSanchez (2000).

\section{Slit-Tapestry Panel 4-7502}

In addition to double cloth, Uhle collected examples of coastal style slit-tapestry in burials at Chimu Capac, many that were woven with north coast style S-spun cotton yarns like 4-7502 (Figure 24). The textile cataloged as "Tapestry fragment" is a wide $(26.3 \times 58 \mathrm{~cm}$.) tapestry panel. Two rows of cross-knit loop stitch embroidery have been stitched over a part of the left side of the panel suggesting the edge finish of a neck or arm opening. Fine camelid fiber slit tapestry has been worked over six S-spun brown cotton yarns 


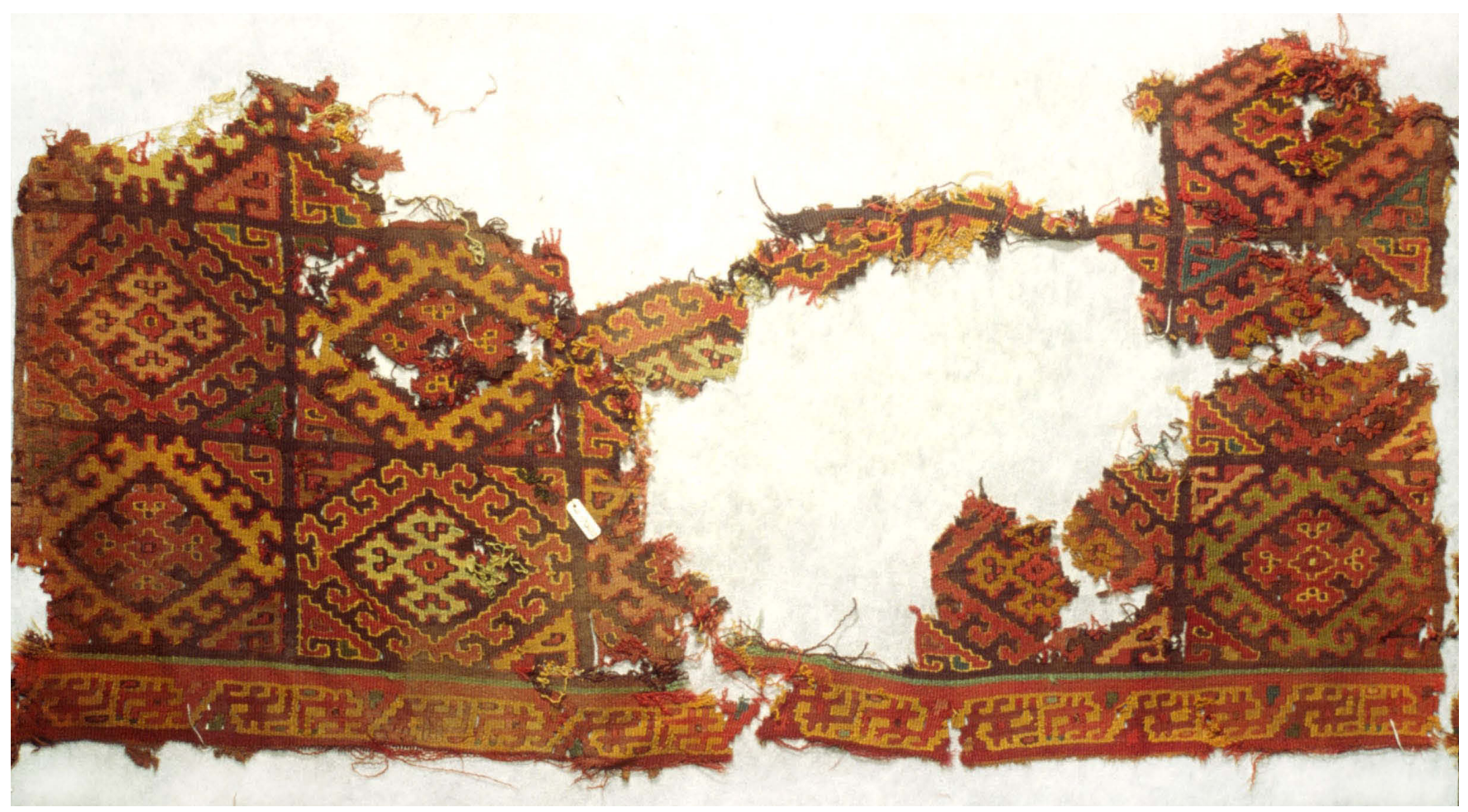

Figure 24. The decorated slit-tapestry portion 4-7502 "Tapestry Fragment" woven over the warp of a cotton plain weave textile visible above and below the fragment excavated by Max Uhle at Chimu Capac. Courtesy of the Phoebe A. Hearst Museum of Anthropology and the Regents of the University of California. Photo Amy Oakland.

grouped together originating from SS/S cotton plain weave below the pattern and visible along the torn bottom edge. The design of both the main block and the border are common to textiles of this period from El Castillo (Prümers 1990: Fig. 134), from Pachacamac (Kaulicke 2001: Figs. 3335; Penn Museum online 29683 "from beneath the temple") and from Huaca Malena where the image is recognized "relacionado con la costa central y la tradicion Huarmey" (Angeles and Pozzi-Escot 2001: Fig. 21).

\section{Slit-Tapestry Fragments 4-7496B, 4-7513}

Uhle gave the same name "Tapestry fragment" to at least ten slit-tapestry textiles like the textile 4-7513 (Figure 25) and two other bands cataloged 4-7496B (not pictured) that were given different numbers, but are borders of the same textile. (9) The fragment 4-7513 was woven on a warp of white S-spun cotton plied S2Z and was created as the side border for a SS/S white cotton plain weave cloth that is visible on one side. The openwork sections of slit-tapestry in 4-7513 are oriented horizontally above and below the figure. This tiny woven figure appears to be a principal Chimu Capac God as Menzel (1977) suggested. Many variations and associated features accompany this individual, but he most often is represented as male with legs spread to each side, genitals prominent, arms spread out and lifted, and sometimes, as in this image he wears a belt. The extremely fine spinning allows for much detail in this small image that is no more that $6 \times 8 \mathrm{~cm}$ tall. The figure stands inside an outlined square with rays or appendages ending in bird heads on each corner and other animal heads are attached to the sides.

Rectangular sections of openwork tapestry between slittapestry designs at Chimu Capac were used as borders on the sleeved shirt 4-7827 analyzed by O'Neale and illustrated by Menzel (1977:Fig.76B and in color by Isbell and YoungSanchez: Fig. 248). It is used in a sleeve border 4-7701C, (Menzel 1977: Fig.77) that was collected with a longer band of the same technique, and also the border of a discontinuous-warp and weft sleeved shirt 4-7789 (not pictured). Narrow bands with this same technique have been noted for collections from El Castillo (Prümers 1990: Figs. 56, 59, 66, $67,70,74,75$ ), Pachacamac (29681 "from beneath the temple" Penn Museum online), and from Huaca Malena (Angeles and Pozzi-Escot (2001: Fig.21). 


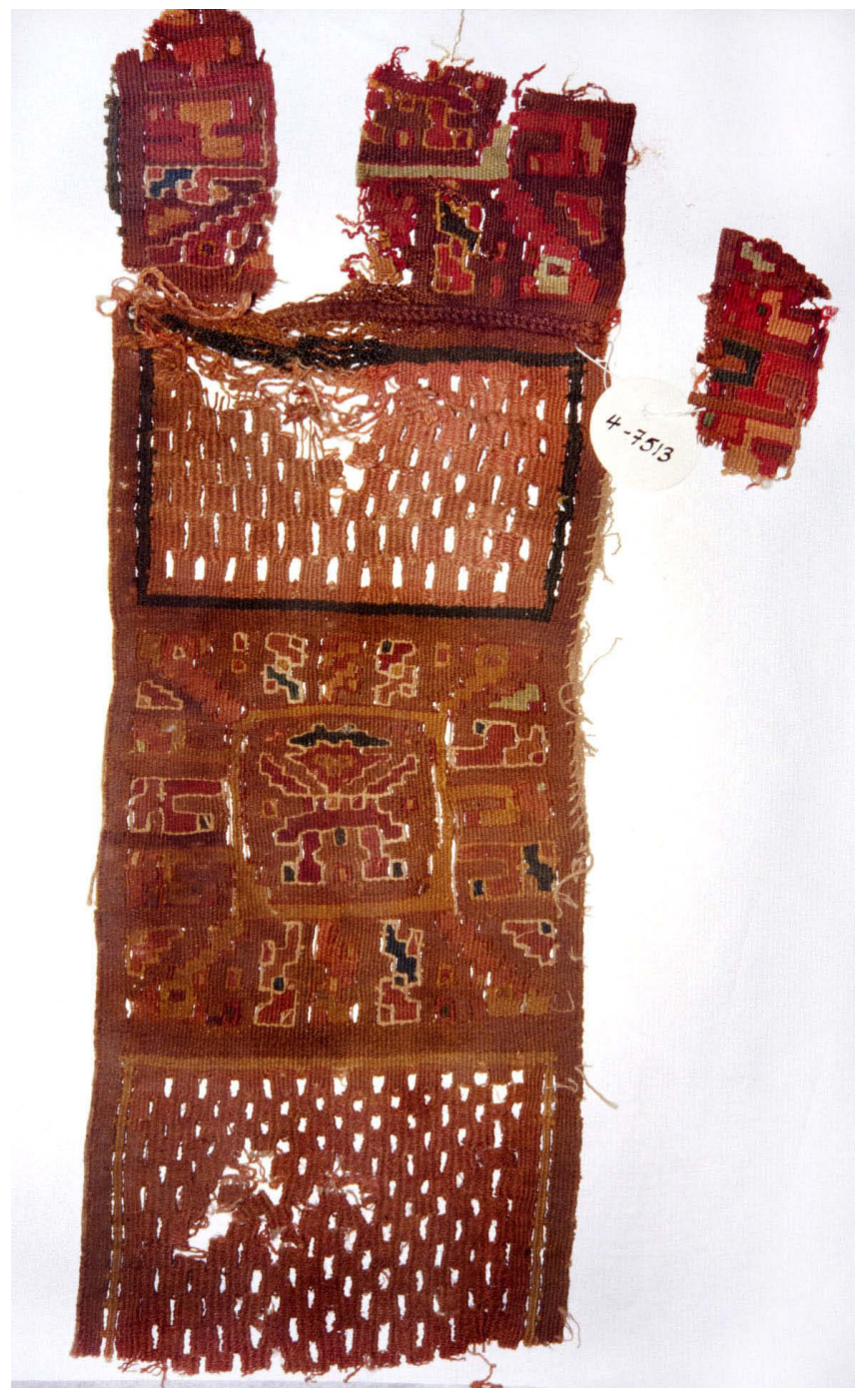

Figure 25. A fragment of openwork and slit-tapestry 4-7513 that was undoubtedly a border to the same plain weave textile with bands woven of the same image cataloged as 4-7496A. The tiny central figure woven in slit-tapestry is the most important icon at Chimu Capac modeled on ceramics and painted on large cloth. Courtesy of the Phoebe A. Hearst Museum of Anthropology and the Regents of the University of California. Photo Amy Oakland.

\section{Chronology and Radiocarbon dates}

Three Chimu Capac textiles 4-7221, 4-7165, and 4-7283 were chosen for radiocarbon dating, each recorded in graves with other textiles and associated material. All three of these textiles represent the types of pouches and painted textiles that are among the best-preserved textiles at the site. This group appears to have been specifically woven for burial and placed freshly made on and around the funeral bundles that Uhle describes in his field notebook. It is assumed that these plain weave types record the final period of interment for most burials in the terraces at Chimu Capac.

In the notebook Uhle records finding the painted textile 4-7221 (Isbell and Young-Sanchez 2012: Fig. 246; Menzel 1977: Fig. 57; Oakland 2010: Fig. 17) along with ten other painted textiles in Grave 15 "next to the mummy, underneath a painted drum, a bundle of many painted cloths". This textile 4-7221 was woven in two webs with Z2S cotton and it has been dated to AD 920-1020. (10) Four other painted textiles included in this large burial were woven with Z2S construction in warp and weft. The other six were formed each using different combinations in warp or weft: S/ZZ, SS,Z/Z, Z/Z, Z,Z2S/Z, ZZ/ZZ, ZZ/Z2S.

Another painted textile that has been dated from Chimu Capac is the large $(128 \times 67 \mathrm{~cm})$ well-planned and executed textile 4-7165 from Grave 12 (Oakland and Fernandez 2001: Figs. 20). Uhle found the large cloth together with two excellently preserved painted textiles (Oakland and Fernandez 2001: Figs. 21, 22). In the notebook he described this burial "the lowest mummy $x$, which had been destroyed, around 3 meters deep". The textile 4-7165 shares a similar iconography with the two other two painted textiles in the tomb. All are painted with two identical figures, but each painting shows a completely different style. The artist of textile 4-7165 painted the two figures in medium brown and lighter brown to fill most of the textile in solid color with the white cotton cloth for detail and as outline. The two principal figures stand facing one another with heads and feet in profile and body in front view and each hold a staff in front. A band of interlocking steps creates a border on three sides. The cloth was woven with both $\mathrm{Z}$ and S-spun single cotton yarns used in warp and weft. This textile was dated AD 96o-110o. (11) The painted pouch 4-7283 (Figure 6) from Grave 25 described above was also dated to a similar late Middle Horizon period, AD 9401020 (see note 7 ).

10. Painted textile 4-7221 yielded age 970+/-50 for CAMS55927. CAMS, Lawrence Livermore National Laboratory, June 1, 1999. “Quoted age is in radiocarbon years using the Libby half life of 5568 years and following the conventions of Stuiver and Polach, Radiocarbon, v. 19 , p.355, 1977".

11. Painted textile 4-7165, one of three painted textiles from Grave 12 (Oakland 2001: Fig. 20, 21, 22) yielded age 1030+/-70 for CAMS55926. CAMS, Lawrence Livermore National Laboratory, June 1, 1999. "Quoted age is in radiocarbon years using the Libby half life of 5568 years and following the conventions of Stuiver and Polach, Radiocarbon, v. 19, p.355, 1977. Comment: The larger uncertainty in CAMS55926 (4-7165) result is due to the small sample size". 


\section{Discussion}

The Late Middle Horizon period represented at Chimu Capac by these painted textiles and "medicine pouches" may not be, and indeed probably is not the same period represented by all of the textiles and ceramics that were placed in Chimu Capac tombs. Menzel (1977) noted ceramics at the site from all Middle Horizon epochs, but most pertaining to $\mathrm{MH} 2 \mathrm{~B}$ and 3. Wari interlocked highland tapestry and associated coastal styles like the red and white double cloth sleeved shirt 4-7702A and B (Figures 22, 23) discussed above undoubtedly relate to earlier burials and perhaps original clothing that was repurposed for the final internment in Chimu Capac graves. In contrast to the well-preserved plain weave made for burial, Uhle excavated many fragments of coastal tapestry and double cloth that was already worn and deliberately torn and cut. Highland styles such as Wari tunics also identify wear and repair as well as alterations for burial. Other highland garment types and additional Wari fragments such as knotted pile headbands and tie-dye textiles also derive from distant locations and undoubtedly earlier periods of use.

Textile preservation was excellent and the textile types collected at the site and discussed in this article will help establish contemporary Middle Horizon groups like those identified at Chimu Capac for ceramics by Menzel (1977) and outlined recently for the Middle Horizon by Eeckhout (2018:541-553). One important aid for scholars working with textiles from the Peruvian coast is the identification of long-standing coastal traditions in the simple method of spinning cotton. The S spinning traditions using the horizontally-held spindle have been described and illustrated by Vreeland (1986) for the contemporary north coast and by Ann Rowe (1984) for Late Intermediate Period Chimu textiles. This same tradition was used earlier on the north coast by Early Intermediate Moche spinners and weavers (Prümers 1995) and in Moche-Huari textiles from El Castillo in the Huarmey Valley (Prümers 1990; 1995; 2001). Many Chimu Capac textiles use this north-coast S spinning method and pair S single yarns in the warp and use S spun yarns as singles in the weft SS/S.

Uhle knew that he had discovered material from both northern and southern styles at Chimu Capac and he wrote Phoebe Hearst that:

"The ancient remains in the graves of the old town Chimu Capac are memorable for one more important circumstance in the development of my archaeological studies. The ruins of Chimu
Capac, about half way between Pachacamac and Trujillo are now memorable because in their graves both these early civilizations, that of the North and that of the South are meeting" (Uhle 1905: 10-11).

He was comparing ceramic types, but he found similar textiles at Pachacamac. Middle Horizon spinners on the central and south coast produced $Z$ spun yarn from the top, not the tip of spindles and these are usually plied Z2S as VanStan (1967) identified for Pachacamac. Many Chimu Capac textiles and most pouches were woven Z2S, perhaps a measure of the local style of plain weave at Chimu Capac like other central and south coast Middle Horizon funerary textile collections such those from Ancon (Young-Sanchez 2000) and Huaca Malena (Angeles 2017; Angeles and PozziEscot 2001; Frame and Angeles 2014).

At Chimu Capac the painted textiles are a very different group, not unique to the site, but exceptional in the 155 excavated in a single location. The yarn and weave structures are also very unusual with more than 65 different yarn combinations using either S or Z spun yarns or both and woven structures in single yarns, plied yarns and paired single and plied yarns, sometimes all at once in the cotton plain weave base cloth. Since archaeological excavations have not yet identified any Middle Horizon habitation site, it remains difficult to define the local textile style that would relate to a resident population in the lower Supe Valley. The excavations that Max Uhle made in 1904 provide the only evidence for Middle Horizon period activity at Supe and the contents of his excavation pertain specifically to funerary remains. For burial rituals it appears that people using traditions from both the north and the south were possibly together at the site to weave the cloth for painted textiles.

The mummy bundle form and many of the woven textiles are similar to those described for other communities along the Pacific coast of Peru during the Middle Horizon identifying people in the lower Supe Valley who practiced many of the same burial rituals at Chimu Capac. This article has been prepared to add to the analyses of the many investigators working today on similar collections from the same period and burial tradition.

\section{Acknowledgments}

This study began in 1989 and I was fortunate from the beginning to have worked with Nancy Porter at the Phoebe Apperson Hearst Museum of Anthropology. At the museum I appreciate the aid of Leslie Freund and all others who made objects available for 
analysis and to the Museum Staff who gave me permission to publish the images of the Chimu Capac collection. At California State University East Bay Malka Helfman helped in digitizing the original research slides. The work with Middle Horizon funeral bundles at Huaca Cao with John Verano, Vuka Roussakis, and Arabel Fernandez sponsored by the National Endowment for the Humanities during 1998-200o greatly expanded my understanding of the Chimu Capac collection. I appreciate the encouragement from the editors Lena and Ann and the two anonomous reviewers who helped focus this article. My most profound gratitude goes to Heiko Prümers who gave me permission to use his translation of Max Uhle's Supe Notebook 67 and to the Ibero-American Institute, of the Prussian Cultural Heritage Foundation, Berlin for their kind permission to publish the notebook.

\section{References Cited}

Angeles, Rommel

2017 Tocados del Horizonte Medio al Intermedio Tardio en la coasta central: Una vision desde el valle de Asia, Peru (Siglos VII-XII d.C.), PreColumbian Textile Conference VII (2016), edited by Lena Bjerregaard and Ann Peters, pp. 277-307.

Angeles, Rommel and Denise Pozzi-Escot

2001 Textiles del Horizonte Medio: las evidencias de Huaca Malena, valle de Asia. In Huari y Tiwanaku: modelos vs. evidencias, primera parte, Boletin de arqueologia PUCP, No.4 (2000), edited by Peter Kaulicke and William Isbell, pp. 401-424. Pontificia Universidad Catolica, Lima.

Carrion Cachot, Rebecca

1959 La Religion en el Antiguo Peru (Norte Y Centro de la Costa, Periodo Post-Clasico), Lima.

Conklin, William

1979 Moche Textile Structures. The Junius B. Bird PreColumbian Textile Conference, May $19^{\text {th }}$ and $20^{\text {th }}$, 1973, edited by Ann Pollard Rowe, Elizabeth Benson and Anne-Louise Schaffer, pp. 165-184. The Textile Museum and Dumbarton Oaks, Trustees for Harvard University, Washington, D.C.

Eeckhout, Peter

2018 The Middle Horizon and Southern Andean Iconographic Series on the Central Coast of Peru. In Images in Action, The Southern Andean Iconographic Series, edited by William Isbell, Mauricio Uribe, Anne Tiballi, and Edward Zegarra, pp. 533-569. UCLA Cotsen Institute of Archaeology Press.

Frame, Mary and Rommel Ángeles Falcón

2014 A female funerary bundle from Huaca

Malena, Nawpa Pacha, 34:1, 27-59, DOI: 10.1179/oo77629714Z.0oooooooo13
Isbell, William and Margaret Young-Sanchez

2012 Wari's Andean Legacy, Wari: lords of the ancient Andes, edited by Susan Bergh, pp. 251-266. The Cleveland Museum of Art, Cleveland and Thames and Hudson, New York.

Kaulicke, Peter

1997 Contextos Funerarios de Ancon, Esbozo de una síntesis analítica. Pontifica Universidad Catolica del Peru, Lima.

2001 La sombra de Pachacamac: Huari en la costa central. In Huari y Tiwanaku: modelos vs. evidencias, primera parte, Boletin de arqueologia PUCP, No. 4 (2000), edited by Peter Kaulicke and William Isbell, pp. 313358. Pontifica Universidad Catolica, Lima.

Kroeber, Alfred

1925 The Uhle pottery collections from Supe, University of California Publications in American Archaeology and Ethnology, 21(6) 235-267.

Menzel, Dorothy

1977 The archaeology of ancient Peru and the work of Max Uhle. R. H. Lowie Museum of Anthropology, University of California, Berkeley.

Oakland, Amy

2010 Telas pintadas de Chimu Capac, valle de Supe, Peru. In Max Uhle: evaluaciones de sus investigaciones $y$ obras, edited by Peter Kaulicke, Manuela Fischer, Peter Masson and Gregor Wolff, pp. 281-293. Fondo Editorial de la Pontificia Universidad Catolica del Peru, Lima.

Oakland Rodman, Amy and Arabel Fernandez

2001 Los tejidos huari y tiwanaku: comparaciones y contextos. In Huari y Tiwaaku: modelos vs. evidencias, primera parte, Boletin de arqueologia PUCP, No. 4 (200o), edited by Peter Kaulicke and William H. Isbell, pp. 119-130. Pontificia Universidad Catolica del Peru, Lima.

2005 North coast style after Moche: clothing and identity at El Brujo, Chicama Valley, Peru. In Us and them: archaeology and ethnicity in the Andes, monograph 53, edited by Richard Reycraft, pp. 115-133. Cotsen Institute of Archaeology, University of California, Los Angeles.

O’Neale, Lila

1933 A Peruvian Multicolored Patchwork. American Anthropologist.

Prümers, Heiko

1990 Der fundort "El Castillo" in Huarmeytal, Peru. Einbertrag zum problem des Moche-Huari textilstils. 2 vols. Mundus Reihe Alt-Amerikanistik, Band 4, 2. Holos Verlag, Bonn. 
Prümers, Heiko

1995 Ein ungewohnliches Moche-Gwebe aus dem Grab des "Fursten von Sipan" (Lambayeque-Tal, Nordperu), Beitrage zur Allgemeinen und Vergleichenden Arquaologie, 15, 309-369.

2001 "El Castillo" de Huarmey: una plataforma funeria del horizonte medio. In Huari y Tiwaaku: modelos vs. evidencias, primera parte, Boletin de arqueologia PUCP, No. 4 (200o), edited by Peter Kaulicke and William H. Isbell, pp. 289-312. Pontificia Universidad Catolica del Peru, Lima.

Reiss, Wilhelm, and Alfons Stübel 1880-1887 The Necropolis of Ancon in Peru: a contribution to our knowledge of the culture and industries of the empire of the Incas, being the results of excavations made on the spot. 3 vols. Translated by A. H. Keane. A. Ascher and Co. Berlin.

Rowe, John

1954 Max Uhle, 1856-1944, A memoir of the father of Peruvian archaeology. University of California Publications in American Archaeology, and Ethnology, Vol. 46, (1).

Rowe, Ann Pollard

1984 Costumes \& Featherwork of the Lords of Chimor, Textiles From Peru's North Coast. The Textile Museum, Washington, D. C.

1986 Textiles from the Nasca Valley at the time of the fall of the Huari Empire. In The Junius B.Bird conference on Andean textiles, April 7 and 8, 1984, edited by Ann P. Rowe, pp. 151-182. The Textile Museum, Washington, D.C.

Uhle, Max

1903 Pachacamac: report of the William Pepper, M.D., LL.D., Peruvian expedition of 1896. Department of Archaeology, University of Pennsylvania, Philadelphia.

1905a Supe Report: "Report on my explorations in the Valley of Supe", (received by Mrs. Hearst October 17, 1905. Unpublished, Phoebe Apperson Hearst Museum of Anthropology, University of California, Berkeley.

1905b Berkeley Catalog: "Beginning of the excavations at San Nicolas near Supe”, received by Mrs. Hearst October 17, 1905. Unpublished, Phoebe Apperson Hearst Museum of Anthropology, University of California, Berkeley.
Valkenier, Lisa

1995 New Evidence for Chimu Capac and the Early Horizon Period In The Supe Valley, Peru. Journal of the Steward Anthropological Society. Vol.23, Nos. 1 and 2: 289-286.

VanStan, Ina

1955 Peruvian domestic fabrics from Supe: a study of the Uhle Collection of Painted Cloths. Department of Anthropology and Archaeology Notes in Anthropology, 1:3. Florida State University, Tallahassee.

1967 Textiles from Peneath the Temple of Pachacamac, Peru: a part of the Uhle collection of the University Museum, University of Pennsylvania. Museum Monographs 7. The University of Pennsylvania, Philadelphia.

Vreeland, James

1986 Cotton Spinning and Processing on the Peruvian North Coast, In The Junius B.Bird conference on Andean textiles, April 7 and 8, 1984, edited by Ann P. Rowe, pp. 363-383. The Textile Museum, Washington, D.C.

Young-Sanchez, Margaret

2000 Textiles from Peru's Central Coast, 750-1100: The Reiss and Stübel Collection from Ancón. Ann Arbor, Mich.: UMI Dissertation Services.

2006 Four-part headcloths from the Peruvian Central coast. In Andean textile traditions: papers from the 2001 Mayer Center symposium at the Denver Art Museum, edited by Margaret Young-Sanchez and Fronia Simpson, pp. 75-98. Denver Art Museum, Colorado. 


\title{
Una prenda triangular con plumas en la colección del Museo de sitio de Pachacámac
}

\author{
Lourdes Chocano Mena
}

\begin{abstract}
Resumen
Las formas habituales de los tejidos son la cuadrangular o la rectangular. Sin embargo, existen casos de tejidos como los paños trapezoidales de algodón usados como prendas de vestir (taparrabos, turbantes, pañuelos). Aquí presentamos un estudio de una prenda de forma triangular hallada en Pachacámac. Su hallazgo no recibió mayor atención, pese a su gran dimensión y la manera de cómo ha sido confeccionada, es muy particular: sus bordes están recamados de plumas anaranjadas y moradas en hileras. Explicaremos la confección de cada una de sus partes, haremos comparaciones con otras vestimentas de forma similar, y propondremos las posibles funciones que pudo tener este tejido triangular con plumas en su contexto.
\end{abstract}

Palabras claves: Textiles andinos, Pachacámac, prenda triangular, textil plumario.

\begin{abstract}
The most frequent shape of textiles is either quadrangular or rectangular. However, there are cotton textiles in trapezoidal form worn as personal attire (loincloths, scarves, turbans). We present here a study of a piece in triangular shape from Pachacámac, which has not been analyzed before. Its dimension and its manufacture are peculiar: its hems were decorated with orange and purple feathers in rows. We will explain the making of each section, compare it with other triangular garments, and illustrate the possible functions of such a textile in its context.
\end{abstract}

Keywords: Andean textiles, Pachacámac, triangular garment, feathered textile.

\section{Résumé}

Les formes habituelles des tissus sont quadrangulaires ou rectangulaires. Cependant, il existe des tissus en coton de forme trapézoïdale utilisés comme vêtements (pagnes, turbans, étoffes). Nous présentons ici une étude d'un tissu de forme triangulaire découvert à Pachacamac qui n'a pas été analysé auparavant. Ses dimensions et la manière dont il a été confectionné sont particulières : ses bords ont été décorés de plumes orangées et mauves disposées en bandes. Nous expliquons l'élaboration de chacune de ses parties, en le comparant à d'autres formes de vêtements similaires, et nous proposons les possibles fonctions qu'a pu avoir ce tissu triangulaire à plumes selon son contexte.

Mots-clés: Textiles andins, Pachacamac, vêtement triangulaire, tissus à plumes. 


\section{Antecedentes}

Los tejidos andinos se han caracterizado por la constancia de su forma, siempre son paños rectangulares o cuadrangulares, los cuales algunas veces se juntan para obtener mayor dimensión. Esto sucede especialmente cuando los tejidos son elaborados en telares de cintura, porque los paños producidos por lo general tienen una anchura limitada, un máximo de unos $85 \mathrm{~cm}$. (Desrosiers 1992: 11); en estos casos lo común era unir dos o más paños hasta conseguir el tamaño deseado. Sin embargo, con los telares horizontales o verticales existe la posibilidad de obtener tejidos de mayor dimensión, por tener una trama más ancha.

No obstante, se presentan algunas variaciones formales, aunque no son frecuentes. Así se hallan textiles prehispánicos producidos en telar con formas diferentes, por ejemplo: paños ligeramente angostos en el centro y que se expanden en los bordes superior o inferior (hipérbolas); es el caso de algunos taparrabos procedentes de Pachacámac, así como los paños triangulares (VanStan, 1965, 1967), los paños trapezoidales de bolsas o chuspas (Huaca Malena), así como los paños que conforman algunos uncus (Agüero, 1998: 103, 128 Imágenes 122, 123). Asimismo hay tejidos de formas casi triangulares como ciertos taparrabos de Paracas (Carrión Cachot, 1931: 82,83 (fig. 20 E), y también textiles de forma definidamente triangular como algunos especímenes en la costa norte y central (Reiss y Stübel, $1880-1887$, vol. II: 146, 147 lámina 43), además de textiles en forma de triángulos escalonados confeccionados mediante la técnica de tapiz (Rowe, 1999: 445, lámina 20.) Finalmente, existen textiles de formas ovaladas, triangulares, oblongas realizados con técnicas sin telar.

\section{El tejido triangular de bordes recamados con plumas de Pachacámac ${ }^{1}$}

Teniendo como antecedente lo mencionado, estudiaremos un tejido de forma triangular cuya característica es la manera en que se ha elaborado para lograr esa forma: un triángulo de tipo obtuso, es decir, de dos ángulos agudos en los extremos y en el centro uno de más de $90^{\circ}$ grados. Además presenta una peculiar decoración de un recamado de plumas anaranjadas y azulado tornasol en dos de sus bordes (foto 1). Finalmente, plantearemos una serie de comparaciones y posibilidades y de qué manera pudo utilizarse.

Este tejido proviene del área de Pachacámac, el cual es conocido como uno de los más importantes santuarios de la época inca, ubicado estratégicamente a escasos metros del litoral. Su ocupación y fama data desde tiempos anteriores al imperio del Tawantinsuyo, como han demostrado los numerosos estudios y excavaciones realizados en este lugar, quedando en claro que hubo gran dinamismo e interrelación social entre los habitantes que residían y trabajaban en el mismo santuario, y aquellos peregrinos que iban a ofrendar al dios del santuario (Eeckhout, 2017).

El tejido que estudiamos fue hallado en el área conocida como la "Portada de la costa" formada por las murallas segunda y tercera del santuario, justamente donde fueron seccionadas para dar paso a la vía llamada antigua Panamericana (Ramos 2012: 179, fig. 76).

En retrospectiva la "Portada de la costa" fue intervenida tres veces, la primera vez en 1994/95 por los arqueólogos Daniel Guerrero y Hernán Carrillo, en esa oportunidad se encontraron fragmentos de mullus y figurinas de arcilla, los cuales se dataron en el periodo Inca. También se encontró un entierro de una mujer joven, orientada de forma paralela al eje del muro, sin embargo solo tenía un envoltorio de tejido llano de algodón y no presentaba ninguna otra ofrenda. Luego, en otro momento del mismo proyecto se hallaron recintos rectangulares sobre un muro, los que fueron utilizados en la época inca, y contenían abundante material orgánico, moluscos y diez porras circulares. Los recintos habían sido sellados, una vez depositados los objetos; por eso los arqueólogos plantearon que se trataba de ofrendas (Ramos, 2012).

En 1996, esta área vuelve a ser excavada por los arqueólogos Rocío Aramburu y Marco Machaguay (Ramos, 2012), quienes encontraron más recintos, algunos de los cuales estaba asociado a un basural con restos de actividades artesanales o de producción; también un sector mostraba fases de ocupación desde el período final de Yschma y la última ocupación Inca, igualmente con materiales culturales de esos estilos. Asimismo se identificaron vestigios de estilos foráneos como Chancay y Chimú. Ante estas evidencias, los autores plantearon que el abundante material correspondía a talleres de producción alfarera, a pesar de que había algunos textiles, sobre los cuales no se hicieron mayores propuestas o estudios en ese momento. Entre dichos tejidos se encontraba el paño triangular con plumas en que se centra el presente artículo.

Antes de continuar con la descripción del paño, daremos una visión general del tipo de colección textil recuperada procedente del Santuario de Pachacámac. Existen especímenes recolectados desde el siglo VII al XVI (6oo al 1500 d. C) correspondientes a los estilos Huari, Lambayeque, Yschma e Inca (Feltham y Ángeles 2017). Los tejidos de estilos tardíos

1. Este textil fue identificado en el transcurso de las labores de conservación textil de 2009 en el Museo de Sitio de Pachacamac. La autora agradece a dicha entidad, a su directora Dra. Denise Pozzi-Escot, a la responsable del gabinete textil Sra. María Luisa Patrón y a la encargada del área de Manejo de Colecciones, Lic. Sonia Quiroz Calle. 


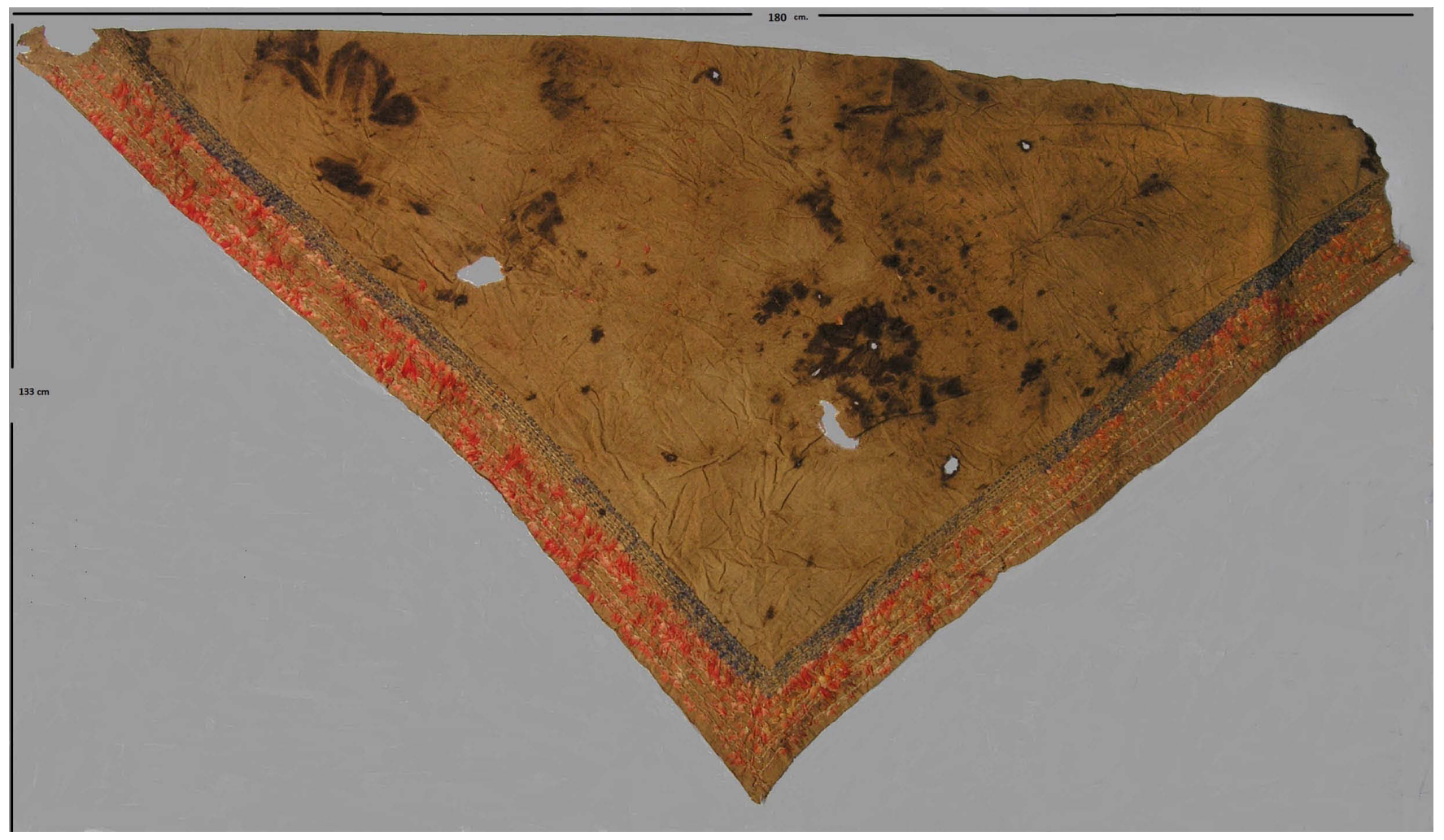

Foto 1: Tejido Triangular con Plumas de Pachacamac. (MSPAC/Foto L. Ch.)

encontrados en Pachacámac como Yschma, se caracterizan principalmente por el uso del algodón, aprovechando los colores naturales de su fibra (beige, crema, blanco y los diferentes tonos de marrón). El algodón también es teñido principalmente de color azul, encontrándose desde los tonos más oscuros hasta los más claros, (algunos variantes de verdes muy suaves). La fibra de algodón sirvió para elaborar paños, mantos para envoltorios, uncus, taparrabos, acsus (prenda femenina). Inclusive el algodón es usado para realizar tejidos con técnica de tapiz ranurado (kelim), característica de la costa central y de los textiles Ychsmas. Las telas pintadas de algodón también se han encontrado en regular cantidad.

El pelo de camélido fue usado preferentemente para la decoración de prendas, mediante técnicas como tramas suplementarias y complementarias (llamado a veces brocado), y tapices; para los cuales se mezclaron las urdimbres de algodón, con las tramas de pelo de camélido y otras veces de algodón. La poca presencia de fibra de camélido en Pachacámac en los períodos tardíos es notoria, si se compara con la abundante presencia de fibra de camélido en tejidos
Chancay, contemporáneos y costeños. La explicación según Feltham y Ángeles (2017) es que la fibra de camélido se conseguía a través del trueque con la etnia de Yauyos, con los cuales Pachacamac no había una buena relación, mientras que para el período inca, las fibras de camélido solo eran utilizadas para las elites. En cuanto a la presencia de plumas como parte decorativa de los tejidos, aparecen en aquellos de estilos foráneos, especialmente los que provenían del norte y de los incas. El trabajo de la aplicación de plumas es atribuido a mitimaes chimús (Feltham y Ángeles 2017). Los tejidos hallados, entre otros objetos, formaron parte de las ofrendas para los ancestros, pero también para el dios Pachacámac (Eeckhout, 2017).

En el catálogo de Pachacámac (Ministerio de Cultura Perú 2012, p. 64) se hace una breve referencia a paños triangulares con aplicaciones de plumas; precisamente se refieren al paño que analizamos, atribuyéndolo al estilo inca, por otro lado el arqueólogo Rommel Ángeles ${ }^{2}$ menciona que existe otro paño similar al que describimos, en la colección de Pachacámac, pero este segundo ejemplar triangular está incompleto y muy fragmentado.

2. Comunicación personal 2018. 


\section{Descripción del paño triangular (punta) ${ }^{3}$}

Como ya hemos mencionado, esta punta tiene la forma de un triángulo obtuso, cuya base mide $180 \mathrm{~cm}$. y cada lado $1.33 \mathrm{~cm}$. Ha sido elaborado de algodón de color beige-cremoso, sin teñir. En los lados más cortos presenta un recamado de plumas distribuidas en dos franjas: una ancha con plumas anaranjadas y una delgada con plumas azules/moradas con visos de tornasol. Las primeras son de mayor tamaño que las segundas. La orientación de las plumas aplicadas en los bordes nos indica la manera correcta de colocar el tejido, pues están dispuestas con los cañones hacia adentro del paño, por lo tanto, el paño debe haberse usado con el ángulo central hacia abajo. (Foto 1)

Material y técnicas de elaboración:

Algodón (gossypium barbadense, sp.) sin teñir, de color beige, ha sido muy notorio y difundido entre las sociedades costeñas prehispánicas. Las fibras utilizadas han sido solamente hiladas en dirección "S", se trata de hilos de un solo cabo, tanto las urdimbres como las tramas. Los hilos son bastante finos, con un hilado mediano, de $65^{\circ}$ a $60^{\circ}$ de inclinación en las urdimbres y tramas. Como resultado es un tejido suave y fino al tacto. El ligamento de confección es tela llana con la variante de 2 (dos) urdimbres $\times 1$ (una) trama, (llamado semibásquet). Es el típico tejido de urdimbres pareadas y tramas unitarias e hilos en dirección "S", cualidades que lo identifican como un tejido de origen chimú (Rowe, 1984).

\section{Confección del paño:}

Por lo general, los paños triangulares son el resultado de tejidos cuadrados que se doblan diagonalmente, como el descrito por Ina VanStan (1965). Menos frecuentes son aquellos que se tejen directamente de esta forma. El tejido triangular de Pachacámac, que estoy analizando, ha sido elaborado mediante dos paños rectangulares, los cuales fueron tejidos en telares de cintura, lo que se deduce de la anchura de cada paño, que es de $65.5 \mathrm{~cm}$. Una vez terminados, fueron sacados del telar y unidos por sus lados longitudinales mediante costuras diagonales pequeñas, realizadas con hilos de algodón de igual color del tejido y dirección del hilado. Los dos paños formaron un tejido cuadrangular, que fue doblado en diagonal por las puntas para obtener una forma triangular (ver esquemas: dibujo 1, 2, 3 y 4). El tejido doblado se cosió y cerró por los bordes con puntadas ligeramente diagonales de hilo de algodón de igual color y torsión que del paño (foto 2). El resultado es un tejido más grueso y más pesado.
El tejido triangular presenta algunos daños como manchas oscuras, arrugas, y pequeños desgarros. Las manchas se deben al contacto de otros materiales orgánicos que han provocado la oxidación de fibras, mientras el análisis de las arrugas no indica que formaran un patrón, pues no se pudo distinguir entre las que posiblemente estaban en el momento del hallazgo y aquellas que se produjeron en el almacenamiento posterior en las cajas de los depósitos del museo. El tratamiento de recuperación del tejido se hizo en el 2009. A pesar de estos problemas, las fibras de algodón en general se encuentran estables, si bien el tejido ha perdido gran cantidad de plumas.

\section{Decoración:}

El recamado de plumas se realizó solamente en una cara del tejido y se hizo una vez que este ya estaba doblado y cerrado en forma de triángulo. Las plumas se han colocado de forma paralela, son ocho sartas de plumas anaranjadas, y siete sartas de plumas azules tornasol. Las plumas anaranjadas están en el orillo de los bordes y en la parte interna las azules tornasol. Las sartas de plumas han sido fijadas desde el borde hacia el campo del tejido, la sujeción de cada sarta o hilera es cubierta por la siguiente sarta que se coloca de forma paralela (foto 3 ).

Las plumas anaranjadas probablemente provengan de guacamayos (ara, $s p{ }^{4}$ ), como el color es muy típico de estas aves, y muchas plumas en el tejido se encuentran incompletas, presentando un color más claro en la base. Christine Giuntini (2012: 63) observa que la base de algunas plumas se presenta de color oscuro pardo, o de color más claro, es indicio que no han sido teñidas y provienen de guacamayos. En el caso de las plumas azul tornasol van desde el azul al violáceo y algunas tienen la base de los cañones más claros. En relación a la procedencia, hay varias posibilidades: pueden ser del ave tangara paradisiaca (O'Neill, 1984:149), o tal vez por la dimensión de las plumas, que es de $2 \mathrm{~cm}$. podrían provenir del cuello o la cabeza de guacamayos. Para definir la proveniencia exacta de estas últimas se requiere un análisis especializado.

\section{Forma de sujeción de las plumas:}

El tipo de nudo o sujeción se realizó con hilos de algodón color crema; algunos hilos tienen hebras combinadas y jaspeadas (cabos beige y marrón o pardo), cuya torsión y grosor se diferencian de los usados en el tejido. Los hilos de sujeción de las plumas son de dos cabos con retorsión en ambas direcciones en $\mathrm{S}$ y retorcidos en $\mathrm{Z}$, y algunos hilados

3. Actualmente los tejidos de esta forma se les denomina punta, puntilla o "chal", y es una prenda femenina, usado para cubrir los hombros o a veces la cabeza.

4. Existen variedades de esta especie que provienen de los bosques tropicales de Sudamérica. 

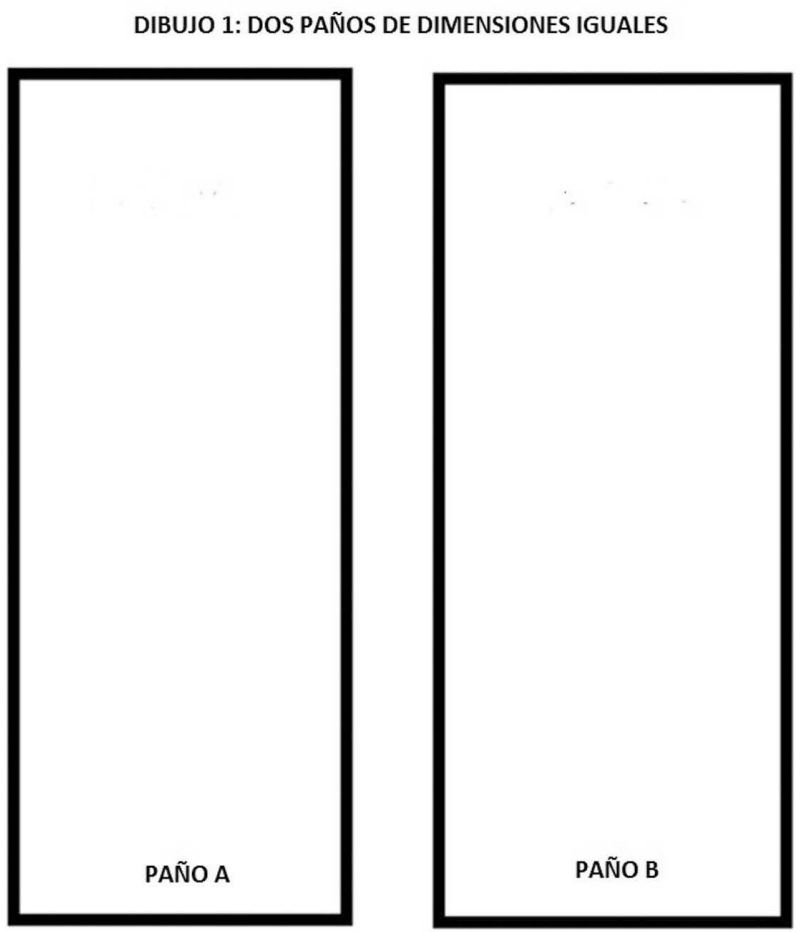

Dibujo: RLCHM

Dibujo esquemático 1: Dos paños iguales de forma rectangular A y B. (Dibujo: L. Ch.)

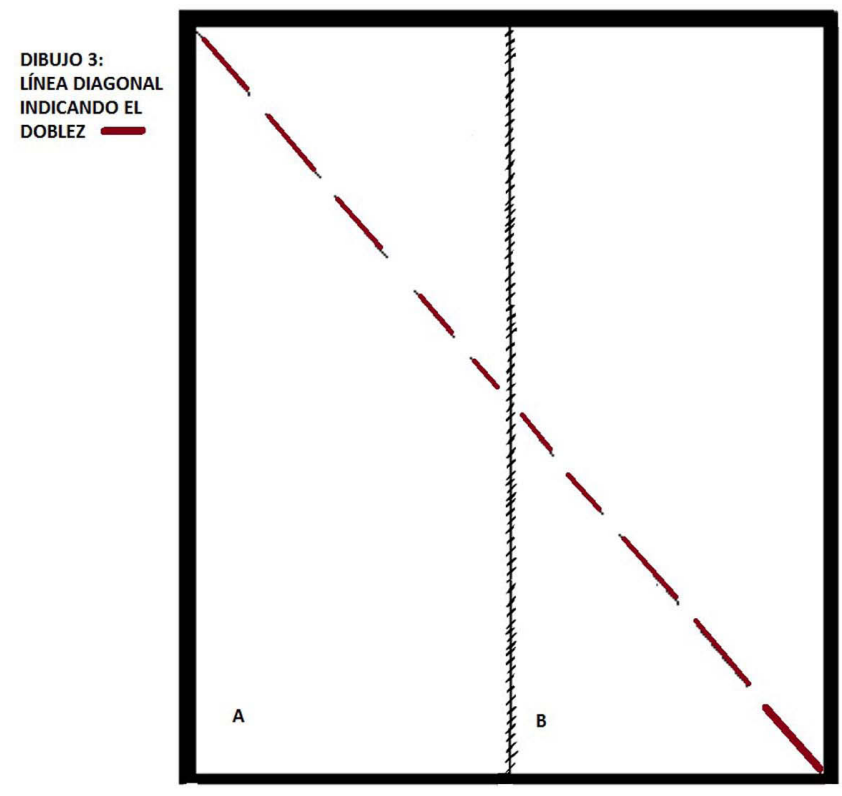

Dibujo esquemático 3: Indica la línea diagonal para doblar el tejido cuadrangular. (Dibujo: L. Ch.)

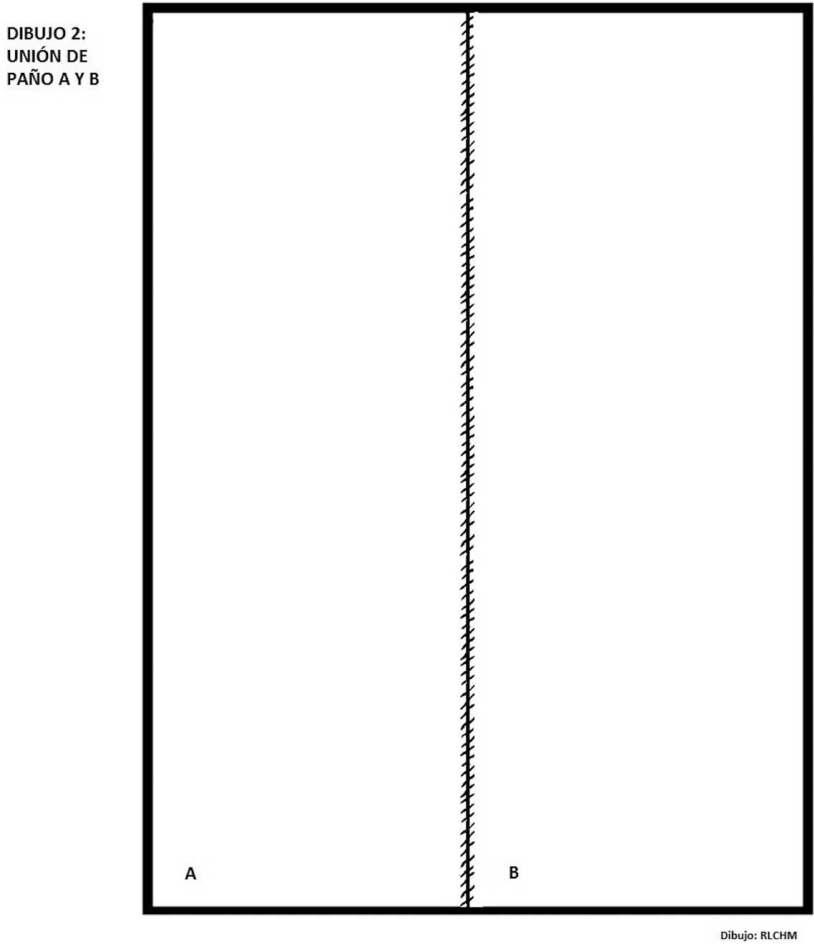

Dibujo esquemático 2: Los paños son unidos por costuras y forman un cuadrángulo. (Dibujo: L. Ch.)

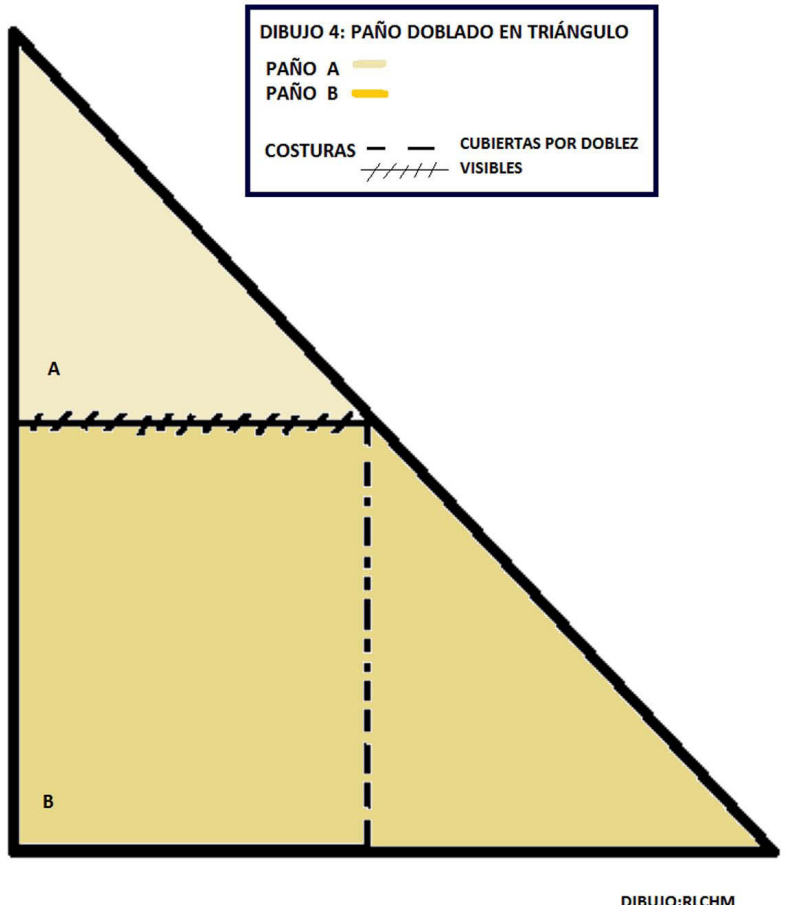

Dibuja esquemático 4: El paño doblado formado un triángulo. (Dibujo: L. Ch.) 


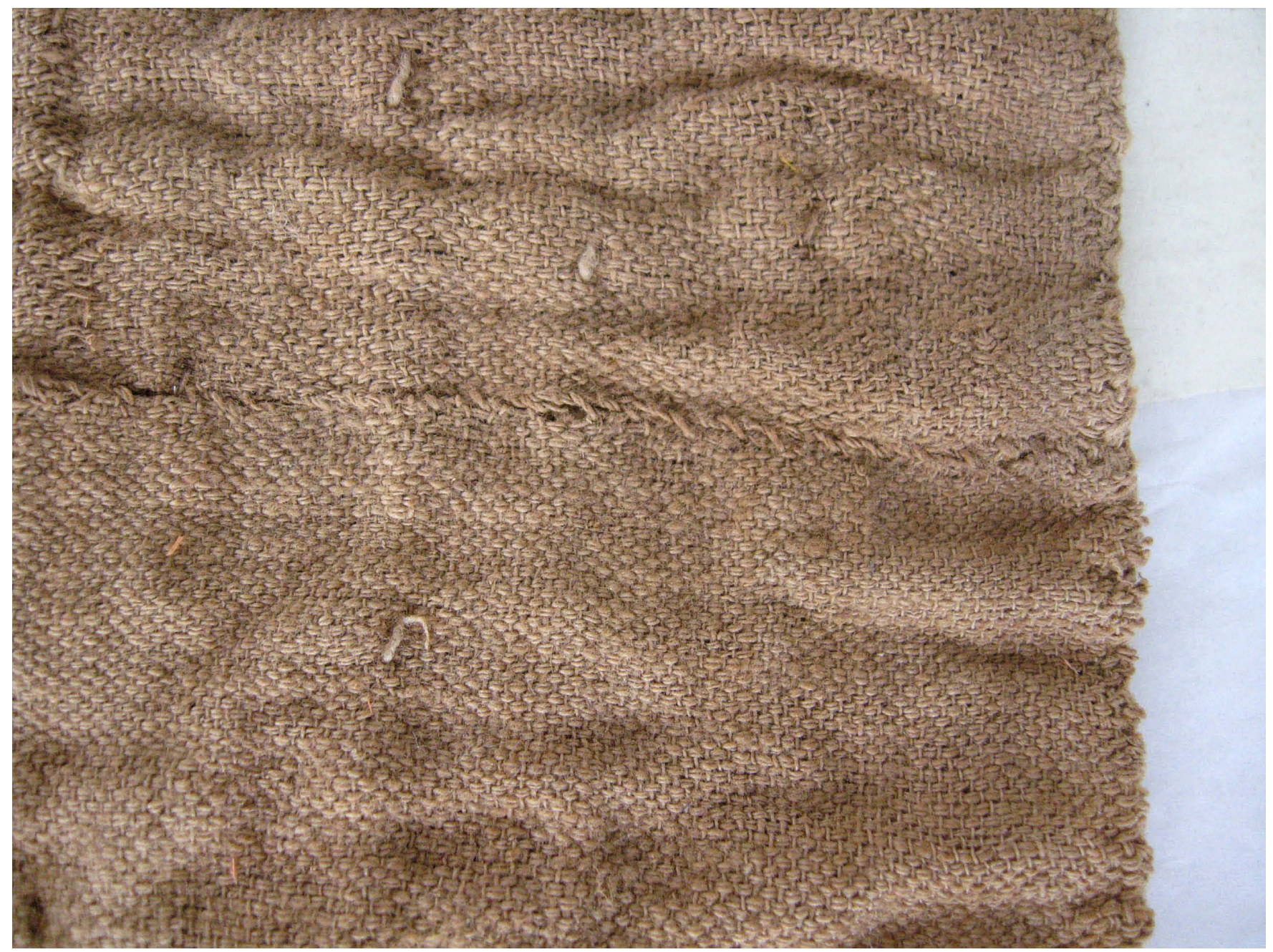

Foto 2: Detalle de las costuras de unión de los paños (a y b). (MSPAC/Foto L. Ch.)

en $\mathrm{Z}$ y doblados en $\mathrm{S}$, siendo este último el tipo de retorsión más frecuente (foto 4). Primero, las plumas han sido dobladas por la base del cañón, luego colocadas sobre un hilo de algodón, y con un segundo hilo o hebra se ha realizado un nudo alrededor del doblez de los cañones de la pluma, asegurando una a una cada pluma con el segundo hilo. Se usa un nudo sencillo, quedando el cañón fijo para formar una sarta o tira de plumas. Luego se ha colocado la sarta de plumas sobre el tejido, y se han fijado mediante puntadas o lazadas envolventes, cada una de ellas de forma continua, se trata de hileras de puntadas muy apretadas. Todas las plumas, tanto las más grandes como las pequeñas, han sido aplicadas de la misma manera (dibujo $\mathrm{n}^{\circ}$ ). En el revés del tejido se puede ver algunas de las puntadas de sujeción de las plumas a la tela, estas puntadas han traspasado los paños doblados, esto nos indica que no se siguió un patrón en cuanto si las plumas debían sujetarse a ambos paños o solo a uno (foto 5 ).
Existen diferentes procedimientos para fijar las plumas en los tejidos, los que han sido descritos y dibujados por varios autores, pero ninguno es completamente igual al que se usó en el paño triangular de Pachacámac. Raoul d'Harcourt (1974: figura 115) describe una forma de fijación de plumas que se parece en las lazadas de sujeción de las plumas a la tela pero es diferente en la forma en que se sujeta cada pluma individualmente. El dibujo publicado por Rowe (1984: 154) describe un tipo de fijación de plumas totalmente diferente. Los dibujos de Giuntini (2012: 96 fig. 65) muestran dos tipos de fijación de dos piezas con plumas respectivamente, pero tampoco se parecen a las del tejido triangular. El dibujo de Al de González en la publicación de Eugene Yacovleff (1933, p. 145, fig. 2) la fijación de las plumas de la parte superior es muy similar a la encontrada en el tejido triangular de Pachacámac, no así las puntadas de fijación, porque el material analizado por Yacovleff no pertenecían a tejidos recamados con plumas. 


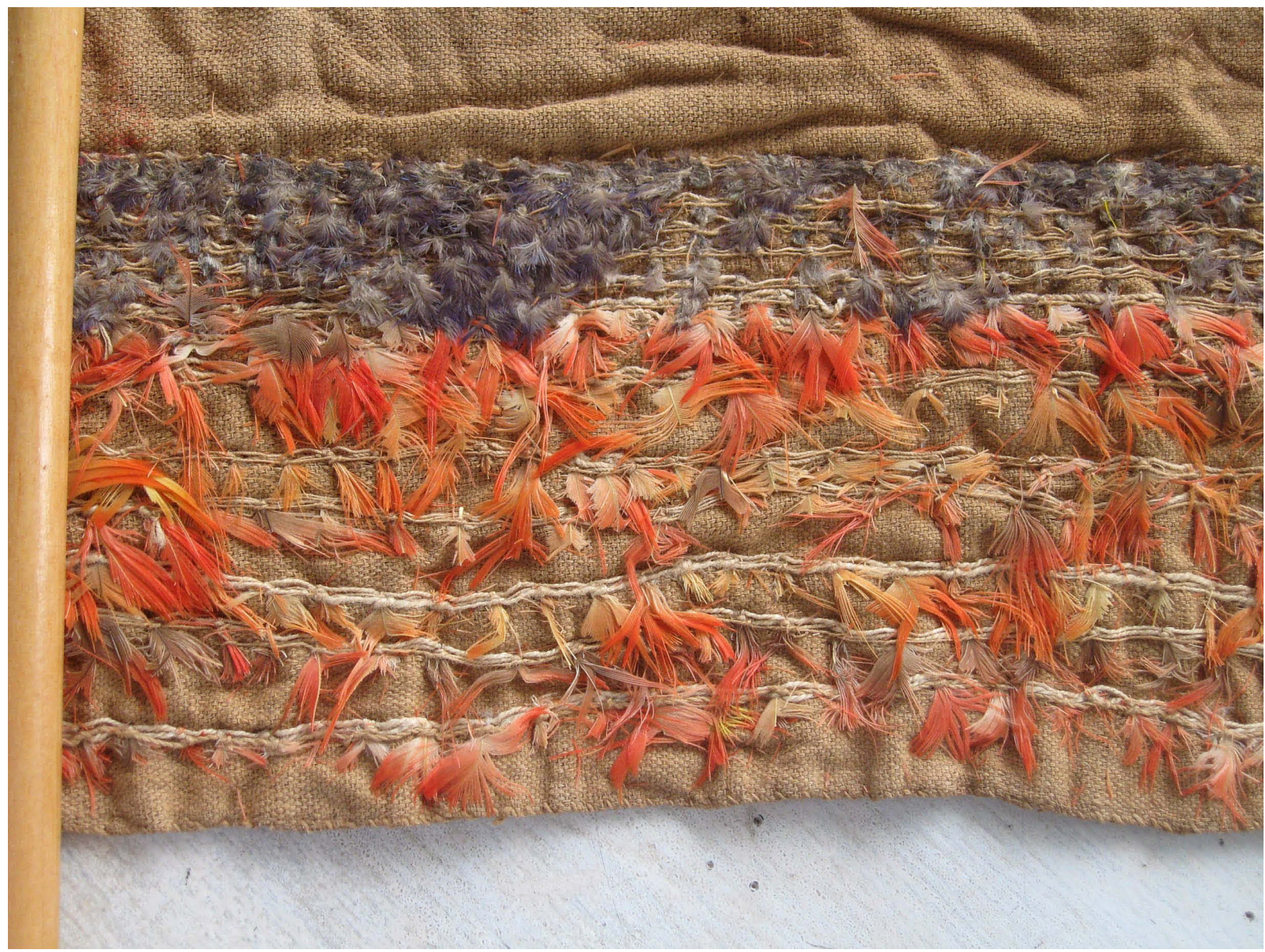

Foto 3: Detalle de la decoración de plumas. (MSPAC/Foto L. Ch.)

Finalmente, la fijación de plumas puede variar (Giuntini, 2012: 95), por lo que no podemos establecer un patrón muy definido, aunque hay algunas coincidencias en la manera como se han fijado las plumas de este paño triangular de Pachacámac y los modelos presentados anteriormente. Se observa además que el trabajo de recamado de plumas en dicho paño no fue muy prolijo porque los hilos de fijación son notorios, aunque quizá esto se deba a la pérdida de plumas ocurrida (foto 6).

\section{Hallazgos de tejidos triangulares}

Tal vez los más antiguos tejidos triangulares prehispánicos reportados son aquellos procedentes de las excavaciones arqueológicas de Paracas realizadas por Julio C. Tello y su equipo (1927 al 1930). Al realizar la clasificación de la vestimenta de Paracas, Rebeca Carrión Cachot (1931) dice que solo se encontraron waras (taparrabos) triangulares en dos de los diez fardos examinados, y que además eran muy pocos en comparación con las waras de forma rectangular. Otro detalle importante es que estos paños triangulares fueron elaborados de un solo paño, es decir que salieron en forma triangular del telar, sin que sea necesario hacerlos a partir de un paño cuadrangular doblado en dos. También en Paracas se encontraron otras formas, por ejemplo los taparrabos en forma de pentágono con un extremo más agudo (Carrión, 1931). Uno de ellos está expuesto en el Museo Regional de Ica y otro en la Sala Paracas del Museo Nacional de Arqueología, Antropología e Historia del Perú (MNAAHP) 5 .

En el fardo 89 de las Necrópolis de Wari Kayan, cementerio en Paracas se encontraron tres piezas triangulares con bordados de estilo Nazca tempano. Un ejemplar mejor conservado es un paño cuadrado doblado diagonalmente, y tiene una banda bordada y cosida en la margen más larga 


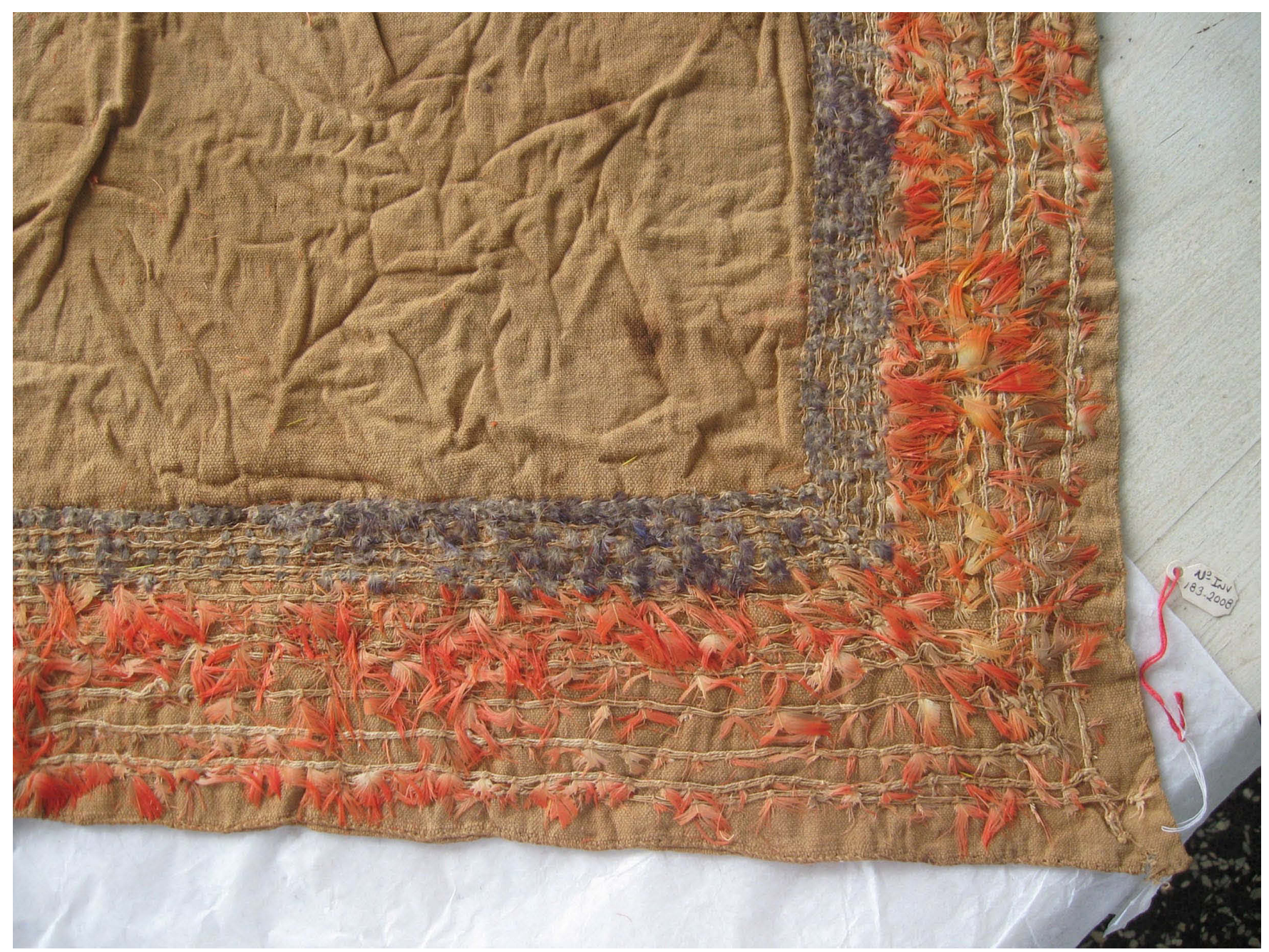

Foto 4: Detalle de fijación de plumas. (MSPAC/Foto L. Ch.)

del doblez, las otras dos prendas son similares, pero están muy fragmentadas. Fueron identificadas como taparrabos por Carrión (1931-49). Luego como posibles taparrabos (Paul 1991-19o) o telas de tocado (Peters, 2017), considerando que eran muy cortas y no había huellas de amarres (Paul, 1991-190).

En el catalogo en línea del MNAAHP aparece un paño de forma triangular ( $\mathrm{N}^{\circ}$ Registro 247917), el cual se elaboró a partir de un tejido cuadrangular, doblado por las puntas para formar un triángulo, tiene borlas largas de color rojo, el ligamento es un tejido llano de tramas y urdimbres parciales, atribuido a la cultura Nazca; este espécimen, cuyas dimensiones son de $26 \mathrm{~cm} \times 59 \mathrm{~cm}$, puede indicar que tal vez sirvió para envolver una ofrenda.

Reiss y Stübel publicaron la ilustración de un paño triangular, encontrado en Ancón, en las excavaciones realizadas entre $1880-1887$. El tejido está formado a partir de un paño cuadrangular, doblado por las puntas, elaborado con

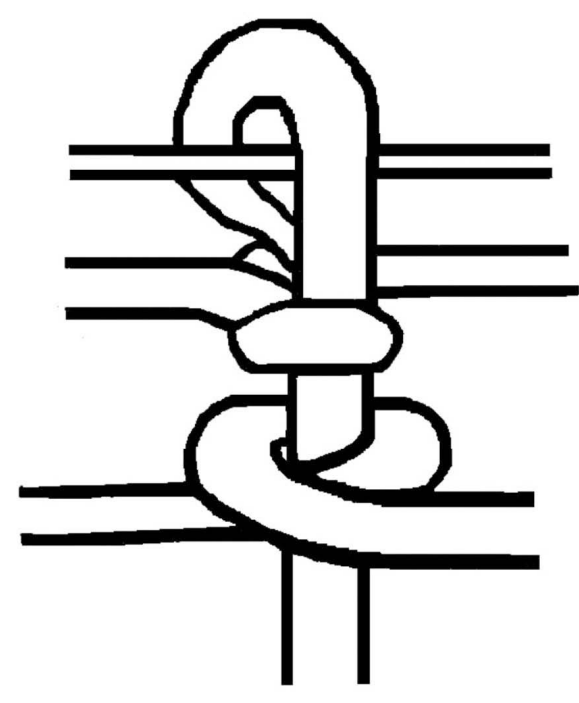

DIBUנO: RLCHM

FIJACION DE PLUMAS DEL TEIDO TRIANGULAR DE PACHACAMAC

Dibujo 5: Esquema de fijación de plumas. (MSPAC/Foto L. Ch.) 


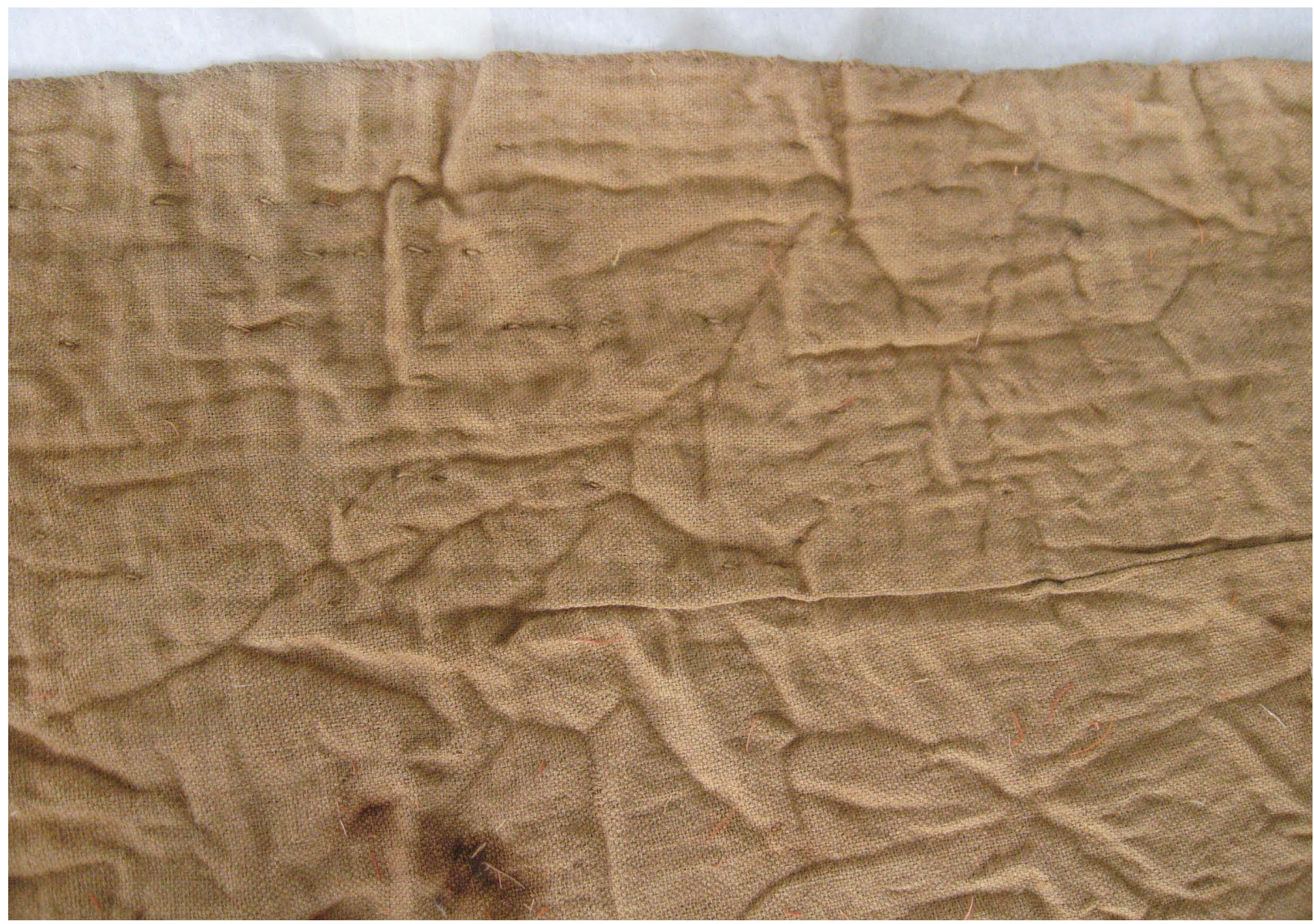

Foto 5: Detalle de costuras posteriores. (MSPAC/Foto L. Ch.)

ligamento de tejido llano ralo (open work) (tramas y urdimbres espaciadas), de algodón de color crema, con líneas más oscuras que forman cuadros, los dos bordes más cortos están decorados con una franja en técnica de tapiz, que termina con tiras en los extremos, lo que sugiere que fue usado para la cabeza, o para envolver y amarrar algún objeto (Reiss y Stübel, vol 2, pp. 146 y 147, lámina 43).

Ina VanStan (1965) reporta un paño triangular muy similar al que se halló en Ancón, pero que proviene de Pachacámac, encontrado en las excavaciones de Max Uhle entre 1896/97. Este tejido triangular, se ha elaborado a partir de un paño cuadrangular de algodón y luego doblado por las puntas. Se tejió mediante la técnica de gasa simple; los lados más cortos tienen bordes rematados por una guardilla elaborada en técnica tapiz ranurada o Kelim (VanStan, 1965: 430, fig. 3 y 4). En el dibujo de la elaboración del paño, se observa que los bordes decorativos de tapiz son añadidos al paño mediante pequeñas puntadas diagonales. Sus dimensiones sugieren que fue usado para la cabeza, a simple vista es similar al paño encontrado en Ancón. En la misma publicación, la autora menciona otro paño, como lo hemos señalado líneas arriba, cuya procedencia es de la costa central, pero no precisa el lugar exacto, este tejido ha sido elaborado de la misma manera que el tejido triangular de plumas de Pachacámac, mediante dos paños rectangulares, unidos y luego doblados, lamentablemente está incompleto, es de algodón de color pardo, con hilos de un solo cabo hilados en "S", y presenta bordes decorados añadidos, en técnica tapiz ranurado, elaborado en fibra de camélido, hilados en $\mathrm{Z}$ y doblados en $\mathrm{S}$ ( $\mathrm{Z} 2 \mathrm{~S}$ ).

En el caso de la Costa Norte específicamente para Moche en la colección del Museo Larco Herrera, hay varias vasijas "huaco retratos" en que los tocados están formados por un paño triangular. Los dos extremos se juntan sobre la coronilla y una punta del triángulo queda detrás. Se ve claramente en los siguientes especímenes: el ML-000036 a, vista c, y el ML-000021 a, vista c, (Catalogo Digital: https://www.museolarco.org/catalogo/ficha.php?id=36, y https://www.museolarco.org/catalogo/ficha.php?id=21).

Al parecer la producción de este tipo de paños fue muy común. Sin embargo, no podemos determinar cómo fueron elaborados. De todos modos, puede haber surgido un indicio 


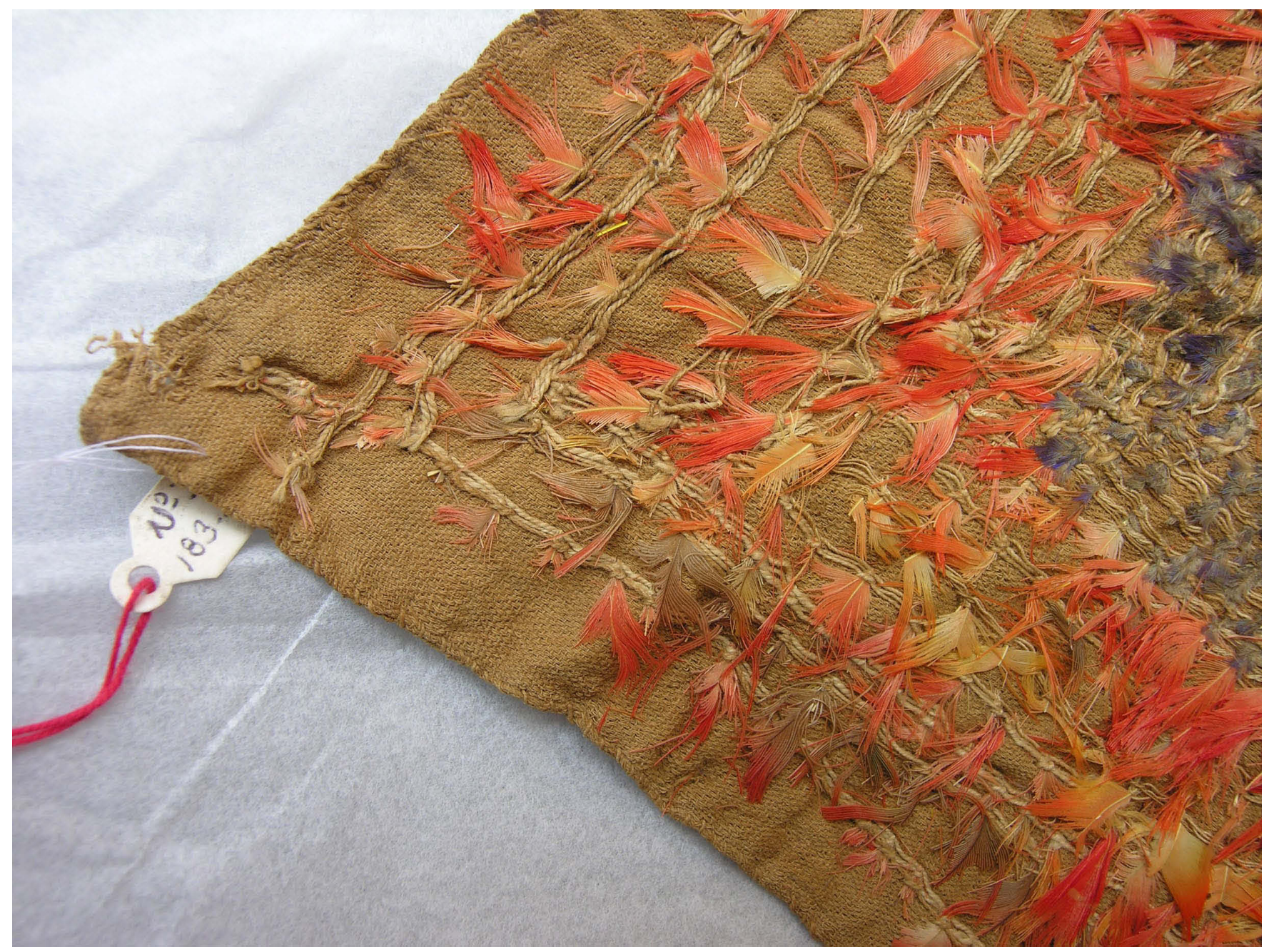

Foto 6: Detalle del paño y costura de fijación de plumas. (MSPAC/Foto L. Ch.)

en las excavaciones en Chornacap, Lambayeque, donde se encontraron contextos funerarios. Entre ellos se descubrieron los restos de una mujer perteneciente a la elite, asociados con objetos de metal, exquisitamente trabajados, y otros materiales ligados a las prácticas shamánicas. Y se le denomina "la Sacerdotisa de Chornacap" (Wester, 2012). En la corona de oro que llevaba dicha "sacerdotisa" aparece la representación de una mujer sentada sobre la media luna sosteniendo un objeto en forma de aspa (X) compuesto por dos triángulos, similar al dibujo del Dr. Zalles (Bjerregaard 2017-34). Se ha planteado que se trata de la representación de la deidad lunar (Wester, 2012: 41, 85), y se la relaciona con la imagen que se encuentra en el "Vaso de Denver" (estudiado por Christopher Donnan), una vasija de estilo Sicán, en que aparece la deidad femenina con similares características encontradas a las que figuran en la corona de la Sacerdotisa de Chornacap (Wester, 2012 85-87). La forma de aspa $\mathrm{o} \times$ que aparece en la corona y el vaso probablemente representa un telar tipo X. Según Feltham y Ángeles (2017) estos telares sirvieron para elaborar pequeños tejidos. Podría suponerse que eventualmente se usaron para confeccionar tejidos triangulares ${ }^{6}$.

En la colección de textiles prehispánicos del Museo Etnográfico de Berlín se encuentran fragmentos de textiles de estilo Sicán/Lambayeque. Lena Bjerregaard reconstruyó hipotéticamente uno de ellos que tenía un lado en punta (2017: 32 - 38) atribuyéndole una forma casi triangular (Bjerregaard, 2017: 35, fig. 5). Otro fragmento, (Bjerregaard 2017: p.106) presenta una figura de dos mujeres de perfil, que portan en la muñeca un hilo con retorsión "S", que acaba en una vara horizontal, que puede ser un huso. Parte de su vestimenta es un paño triangular amarrado alrededor de las caderas, que Bjerregaard ha denominado "paño para ceñir la cintura” (2017: 34). Estos paños triangulares son de Sicán/

6. Lo menciono en relación que artesanalmente se utilizan telares triangulares o bastidores para tejer paños. 


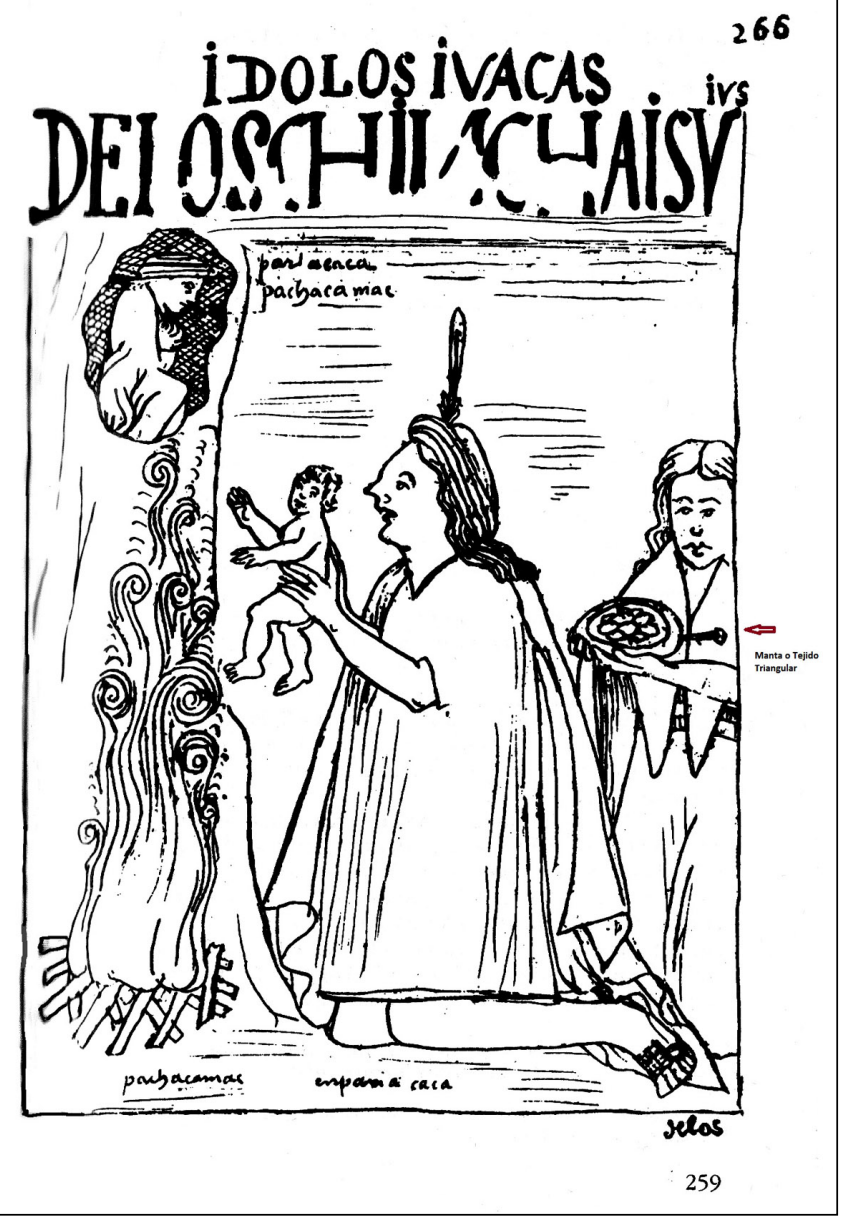

Foto 7: Dibujo por Guaman Poma de mujer con posible manta o tejido triangular. (F. Guaman Poma, 1987 [1615] p. 329)

Lambayeque y se aprecian mejor a través de la iconografía de los fragmentos publicados en el mismo catálogo (2017: 106) 7 . Dichos paños terminan en dos borlas o colgantes en forma de ave que quedan en la parte posterior del cuerpo humano y se ciñen a la cintura con unas cintas que terminan en colgantes con pequeñas cabezas de ave. Estos especímenes podemos relacionarlos con el tercer paño triangular presentado por VanStan (1965, fig. 5) que también tiene decoraciones de borlas.

Para épocas más tardías (Intermedio Tardío y Horizonte Tardío) hay pocos hallazgos de paños triangulares. Existe uno al que se le atribuye el estilo Chancay (Stone, 1994: 248 , fig. 247). Es de algodón en tela llana y presenta bordes tipo tapiz kelim (ranurado), parecido al encontrado en Ancón, con decoración naturalista de peces. Mide $120 \mathrm{~cm}$. $\times 90 \mathrm{~cm}$. incluidas las guardas o bordes decorativos, por lo puede tratarse de un paño cuadrangular doblado por las puntas para formar un triángulo. En la colección el MNAAHP aparece otro paño triangular $\left(\mathrm{N}^{\circ} 231839\right)$ elaborado de tejido llano de algodón, con dos orillos decorados, con técnica de tapiz Kelim (ranurado), y diseños de olas y rostros de serpientes. Presenta los típicos colores rojo y rosado de la cultura Chancay, y es muy parecido al estudiado por Stone (1994), aunque es de mayor dimensión $(120 \mathrm{~cm}$. $\times 116 \mathrm{~cm}$.), es probable que haya sido elaborado también a partir de un tejido cuadrangular. En la ficha del museo está asignado al Intermedio Tardío, y, de acuerdo con las características iconográficas, presenta un estilo marcadamente Chancay. Entre los tejidos de estilo Yschma que han sido estudiados en contextos funerarios no se han reportado formas triangulares, aunque sí hay registro del uso de plumas para algunos textiles (Frame, Vallejo, Ruales y Tosso, 2012: 437 - 478).

La vestimenta de los incas, especialmente la que caracterizaba a la población de la época del Tawantinsuyo, está muy bien representada a través de los dibujos de Guaman Poma de Ayala (1987 Vol. I y II). No aparecen tejidos de forma triangular: las ñañacas o paños para la cabeza, las mantas de los hombres y llicllas de las mujeres, son tejidos rectangulares y/o cuadrangulares. Solamente en una de las ilustraciones (1987 Vol. II: 259, fig. 266), aparece una mujer con una "manta" sobre los hombros, sujeta con un tupu, y parece tratarse de una "manta" triangular (foto 7).

\section{Conclusiones}

1. Los tejidos de forma triangular aparecen en los Andes en todos los períodos. De acuerdo con las indagaciones realizadas, la forma triangular más antigua aparece en el sur, en Paracas, valga mencionar nuevamente los hallazgos de Julio C. Tello y su equipo, y los trabajos sobre indumentaria de Rebeca Carrión Cachot. En este caso fueron usados como taparrabos, aunque cabe la posibilidad que algunos fueran para la cabeza.

2. Por otro lado, se pueden confeccionar paños triangulares siguiendo uno de estos tres procedimientos: 1 . directamente en el telar; 2. A partir de un paño cuadrangular, el cual se dobla diagonalmente por las puntas; y 3. Uniendo dos paños rectangulares para formaran un cuadrado que al ser doblado en diagonal queda en forma triangular; de esta última manera se obtienen tejidos triangulares de mayor dimensión.

7. También se han encontrado fragmentos en Pacatnamu, en las excavaciones de Ran Boytner, quien los menciona en The Pacatnamu Textiles: a study of Identity and Function, Ph.D. Dissertation, University of California, comunicación personal de Lena Bjerregaard, diciembre 2019 . 
3. Los paños triangulares elaborados directamente en los telares aparecen en Paracas y tal vez en Moche y Sicán/ Lambayeque, con el uso del telar en X. En cambio, los paños triangulares elaborados de la segunda forma son los más comunes y se han encontrado desde Intermedio Temprano (Nazca, tal vez en Moche y en Sicán/Lambayeque), pasando por el Horizonte Medio hasta el Intermedio Tardío. Se encuentran especímenes en la costa central (Chancay, Ancón y otros valles). Se han observado que los tejidos triangulares fueron usados para la cabeza, o para envolver ofrendas, también como parte de la indumentaria, en el caso de Sicán/Lambayeque y Paracas.

4. Tenemos algunas piezas elaboradas según el tercer procedimiento: el tejido recamado con plumas de Pachacámac, que hemos analizado; el tercer paño estudiado por Vanstan (1965); los tejidos de Sicán/Lambayeque (que probablemente serían de mayor dimensión, pues se ceñían alrededor del cuerpo).

5. El tejido triangular de plumas de Pachacámac ostenta características que lo identifican con el estilo Chimú: uso de algodón, fibras de un solo cabo, hilado en "S", ligamento de urdimbres pareadas y una sola trama (semibasquet) y la aplicación de plumas.

6. La escasez de tejidos triangulares realizados siguiendo el procedimiento 3 tal vez se deba a que realizarlos implica una planificación diferente a la confección de los paños triangulares realizados siguiendo el segundo procedimiento. Su elaboración debió obedecer a un motivo específico. Según Narváez (2017) la figura del triángulo desempeñó un papel importante en el momento de emplazar ofrendas en los templos incas. Esta disposición se ha encontrado en emplazamientos del norte ocupados por los Incas en territorios de Chimú. Esto puede indicar la importancia simbólica del tejido triangular que analizamos, pues fue encontrado en la "Portada de la Costa", que es la entrada al espacio sagrado de Pachacámac.

7. En el Intermedio tardío la decoración con plumas en muchos textiles de la costa norte, central y sur es frecuente. Muchos autores están de acuerdo con que la utilización de plumas se limitaba a determinadas prendas de algunos personajes importantes, o formaban parte del ajuar funerario, como lo han revelado los hallazgos arqueológicos. Por lo tanto, el tejido triangular presentado probablemente no pudo tener un uso doméstico. Tampoco la presencia de textiles recamados con plumas es extraña en Pachacámac, de alguna manera señala la relación con la región amazónica de donde procedían las plumas. Hasta es posible pensar que se importaran loros y guacamayos.
8. Otra posibilidad es que este tejido, dadas sus dimensiones, pudo servir de manto a alguna mujer, sea cubriéndola desde la cabeza o desde los hombros. Su uso estaría reservado al ámbito ceremonial o como signo de estatus. Es dudoso que se usara ceñido alrededor del cuerpo, porque las plumas se habrían quebrado. El recamado de plumas y el ligamento de su elaboración indican un origen norteño, aunque también cabe la posibilidad de que fuera elaborada en el mismo Pachacámac, siguiendo la tradición norteña.

\section{Referencias citadas:}

Agüero, Carolina

1998 Tradiciones Textiles de Atacama y Tarapacá presentes en Quillagua durante el Período Intermedio Tardío. Boletín del Comité Nacional de Conservación Textil (3): 103 - 128. Santiago.

Bjerregaard, Lena y Huss Torben

2017 Precolumbian Textiles in the Ethnological Museum in Berlin. Zea Books 52 http://digitalcommons.unl.edu/ zeaboook/52

Carrión Cachot, Rebeca

1931 La Indumentaria en la antigua cultura de Paracas. Wira Kocha: Revista Peruana de Estudios Antropológicos Vol. 1. (1): 37 - 86

d'Harcourt, Raoul

1974 Textiles of Ancient Peru and Their Techniques. Mineola New York.

Desrosiers, Sophie

1992 Las Técnicas de tejido ¿tienen un sentido? Una propuesta de lectura de los tejidos andinos. Revista Andina: Tejido Andino Pasado y Presente (1) 10: $7-46$

Eeckhout, Peter

2017 Ofrendas Rituales, Peregrinaciones y Ancestros. Pachacamac el Oráculo en el Horizonte Marino del Sol Poniente. 222 - 236. BCP Lima - Perú

Feltham, Jane, Rommel Ángeles

2017 Los Textiles de Pachacamac. Pachacamac el Oráculo en el Horizonte Marino del Sol Poniente. 251 - 273 BCP Lima - Perú

Frame, Mary, Francisco Vallejo, Mario Ruales y Walter Tosso

2012 Los textiles Ychsma del Horizonte Tardío en el entierro de Armatambo. Arqueología y Sociedad (24): 437-478.

Guamán Poma de Ayala, Felipe

1987 Nueva Crónica y buen gobierno. Crónicas de América $29^{a}$. Ed. John Murra. 3 Volúmenes. España. 
Giuntini, Christine

2012 Techniques and Conservation of Peruvian Feather Mosaics. Peruvian Featherworks. Ar of Precolumbian Era. 89 - 100. Ed. Heidi King. The Metropolitan Museum of Art, New York.

Ministerio de Cultura del Perú

2012 Textiles de Pachacamac. Ministerio de Cultura Perú.

Narváez Vargas, Alfredo

2017 Túcume y Pachacamac entre el Mito y la Arqueología. Pachacamac el Oráculo en el Horizonte Marino del Sol Poniente. 126 - 135. BCP Lima - Perú

Museo Nacional de Arqueología, Antropología e Historia del Perú 2013 Paracas. Ministerio de Cultural. Lima.

O’Neill, John P.

1984 Introduction: Feather Identification. Costumes and Featherwork of the Lords of Chimor: Textiles from Peru's North Coast. 144 - 150. The Textile Museum, Washington D.C.

Paul, Anne

1991 Paracas Necrópolis Bundle 89. Paracas Art \& Architecture. Object \& Context in South Coastal, Peru. Ed. Anne Paul. University Iowa Press.

Peters, Ann

2017 Headdress forms in the Paracas Necrópolis Mortuary Tradition. PreColumbian Textile Conference VII / Jornadas de Textiles PreColombinos VII, ed. Lena Bjerregaard and Ann Peters (Lincoln, NE: Zea Books, 2017). https://digitalcommons.unl.edu/pct7/1/

Ramos Giraldo, Jesús

2011 Santuario de Pachacamac Cien años de arqueología en la Costa Central. Municipalidad Distrital de Lurín. Cultura Andina.
Reiss, Wilhem y Adolph Stübel

1880-1887 The Necropolis of Ancon in Peru: a contribution to Our knowledge of Culture and Industries of the Empire of the Incas. Translated by A.H. Keane, 3 vols. Berlin. Asher and Co.

Rowe, Ann Pollard

1984 Costumes and Featherwork of the Lords of Chimor: Textiles from Peru's North Coast. The Textile Museum, Washington D.C.

1999 Textiles Chimú. Tejidos Milenarios del Peru. Ed. José Antonio Lavalle y Rosario Lavalle. AFP Integra. Lima. $425-479$.

Stone-Miller, Rebeca

1992 To weave for the Sun Ancient Andean Textiles. Thames and Hudson. New York.

VanStan, Ina

1965 A Triangular Scarflike Cloth from Pachacamac, Peru. American Antiquity, vol.30 (4): 428-433. JSTOR, www.jstor.org/stable/277942

1967 Textiles from beneath the Temple of Pachacamac, Peru. Philadelphia: The University Museum, University of Pennsylvania.

Wester La Torre, Carlos

2013 Misterio e Historia en la Cultura Lambayeque La Sacerdotisa de Chornacap. Ministerio de Cultura. Perú.

Yacovleff, Eugene

1933 Arte Plumario entre los antiguos Peruanos. Revista del Museo Nacional 2. (2) 137- 158. Lima. 


\title{
Las relaciones interculturales vistas a través de los textiles del Cerro La Horca, durante el Periodo Intermedio Tardío y Horizonte Tardío, valle del Fortaleza - Perú
}

\author{
Arabel Fernández L., Metropolitan Museum of Art \\ Luis Valle A., Qetzal SAC. Arqueología y Gestión Ambiental
}

\begin{abstract}
Resumen
A raíz de la ejecución del Proyecto de Rescate Arqueológico Parcial en Cerro la Horca, fue posible el registro de diversas evidencias materiales las cuales han puesto de manifiesto nuevas interpretaciones sobre la ocupación del sitio. La recuperación de material textil y su respectivo análisis ha permitido identificar y definir diversos estilos textiles, entre los que podemos citar: Lambayeque, Huarmey, Chancay, Serrano, Chimú e Inca los mismos que revelan la compleja y variada interacción socio-cultural de los diversos grupos étnicos que convivieron en esta parte baja del valle del Fortaleza, durante el Periodo Intermedio Tardío y Horizonte Tardío.
\end{abstract}

Palabras claves: Textiles arqueológicos, Cerro La Horca, diversidad sociocultural, Intermedio Tardío, Horizonte Tardío.

\begin{abstract}
During the execution of the Partial Salvage Archaeological Project at Cerro la Horca it was possible to record a variety of material evidence, which has revealed new interpretations of the occupation of the site. According to the textile analysis there are at least seven textile styles: Lambayeque, Huarmey, Fortaleza, Chancay, Chimú, Serrano and Inca which reveal a complex socio-cultural interaction between different ethnic groups who inhabited this lower part of the Fortaleza valley during the Late Intermediate Period and Late Horizon.
\end{abstract}

Keywords: Archaeological textiles, Cerro La Horca, sociocultural diversity, Late Intermediate Period, Late Horizon.

\section{Résumé}

Suite à la réalisation du Projet de Sauvetage Archéologique Partiel à Cerro la Horca, il a été possible de constater diverses évidences matérielles qui ont suscité de nouvelles interprétations sur l'occupation du site. La découverte des textiles et leur analyse a permis d'identifier et de définir différents styles textiles, parmi lesquels nous pouvons citer: Lambayeque, Huarmey, Fortaleza, Chancay, Chimú, Serrano et Inca qui révèlent une interaction socio-culturelle complexe entre les différents groupes ethniques qui habitent dans cette partie basse de la vallée de Fortaleza durant la Période Intermédiaire Récente et l'Horizon Récent.

Mots-clés: Textiles archéologiques, Cerro La Horca, diversité socioculturelle, Période Intermédiaire Récente, Horizon Récent.

DOI: 10.32873/unl.dc.zea.1207

Published in PreColumbian Textile Conference VIII / Jornadas de Textiles PreColombinos VIII, ed. Lena Bjerregaard and Ann Peters

(Lincoln, NE: Zea Books, 2020). https://digitalcommons.unl.edu/zeabook/ 


\section{Introducción}

Los tejidos motivo de esta comunicación proceden de diferentes contextos excavados durante el desarrollo del Proyecto de Rescate Arqueológico Parcial en el sitio Cerro La Horca, ubicado en la margen derecha del río Fortaleza, distrito de Paramonga, provincia de Barranca, a $215 \mathrm{~km}$ al norte de la ciudad de Lima (Fig. 1) ${ }^{1}$.

Hasta el momento se han podido identificar siete estilos textiles, cuyos desarrollos se dieron durante el Periodo Intermedio Tardío y Horizonte Tardío que corresponden tanto a expresiones locales como aquellas procedentes de otras latitudes del norte, sur y este. En este mosaico estilístico, procedentes de la costa norte, tenemos tejidos lambayeque y chimú; como estilos locales - del llamado Norte Chico-, están Huarmey y Fortaleza. Las interrelaciones e interacciones con grupos humanos de la sierra también quedaron evidenciadas con textiles pertenecientes al estilo que hemos denominado Serrano. Asimismo, contamos con un grupo de tejidos vinculados con el estilo Chancay, de la costa central. Por último, aunque hasta el momento sólo se cuenta con un solo registro, cerramos esta variedad estilística con la identificación de un textil de estilo Inca ${ }^{2}$.

Abordar el estudio de este grupo de textiles representa un paso importante en la comprensión de lo ocurrido durante el Periodo Intermedio Tardío no solo en el valle del Fortaleza, sino también en el Norte Chico o costa norcentral considerando, además, que lo publicado y discutido hasta el momento procede de estudios realizados respecto de la cerámica y la arquitectura, pero no así de los textiles.

\section{El sitio de Cerro La Horca}

Hasta el momento no se sabe con certeza qué sociedad construyó la arquitectura monumental en Cerro La Horca. Por las evidencias registradas en forma de grandes muros de adobe insinuado corte trapezoidal, pintura mural grandes plazas, entre otros elementos, es muy probable que pertenezca a los Chimú. Asimismo, contamos con la descripción del cronista Inca Garcilaso de la Vega (2005 [16o9]), quien escribe que una de las primeras batallas que pierden los chimú con los incas - durante el reinado de Inca Yupanqui -, se dio en Paramonga. Asimismo, de acuerdo con la narración previo a la llegada de los incas, en el valle se vivían momentos de conflicto con los curacazgos de la costa central, quienes se confabularon con los incas, facilitando su victoria sobre las naturales de Parmunca (o Paramonga). Los incas tomaron el control administrativo de los valles, erigiendo estructuras arquitectónicas monumentales.

Las excavaciones realizadas en Cerro La Horca aportaron datos interesantes sobre las relaciones interculturales que se dieron desde el Horizonte Medio Tardío hasta el Periodo Intermedio Tardío, que son hasta el momento las elocuentes, sin embargo, y a pesar de que las crónicas dan información sobre una conquista de este territorio por los Incas, hasta el momento las evidencias artefactuales pertenecientes al imperio Inca son bastante limitadas. Futuras excavaciones sistemáticas en el valle del Fortaleza irán develando estos misterios (Valle 2019:8-10).

\section{Evidencias textiles en el valle del Fortaleza}

Las investigaciones arqueológicas en el valle señalan que las ocupaciones humanas más tempranas provienen de sitios registrados en el valle medio y datan del Periodo Arcaico (Vega-Centeno et al. 1998; Vega-Centeno 2004; VegaCenteno et al. 2006; Piscitelli 2010). Los estudios reportan la existencia de estructuras monumentales correspondientes a procesos sociales y culturales de gran complejidad. Lamentablemente, es muy poco lo que se conoce sobre los textiles de esta etapa. La información que se tiene hasta el momento procede de un sacrificio humano (Vega-Centeno et al. 2006). Se recuperaron tres textiles confeccionados en algodón. Las torsiones de los hilos pueden ser en S o en Z; en algunos casos se encontraron hilos retorcidos en dirección contraria a la inicial. En los tres casos las estructuras corresponden a tela llana $1 / 1$.

Entre 1875 y 1877 el viajero francés Charles Wiener realizó una misión arqueológica y etnográfica entre Perú y Bolivia, como resultado de este viaje publicó en 1880 su libro Pérou et Bolivie. Récit de voyage. Wiener, a su paso por la hacienda Paramonga, se vio atraído por dos monumentos: la Fortaleza de Paramonga y Cerro La Horca. Se sabe que realizó algunas excavaciones de las cuales pudo recuperar artefactos, que los dibujó e incluyó en su libro. De esto podemos decir que algunos corresponden al estilo Chimú y otros a la costa central. Asimismo, se identificó una bolsa de estilo Serrano, además de camisas y fragmentos de estilo local. Lamentablemente, se desconoce cuál fue el destino final de estos valiosos materiales.

1. El proyecto de rescate se realizó a solicitud de la empresa Autopista del Norte S.A.C (AUNOR), y cubrió el tramo 4 de la Red Vial 4 , desde Pativilca a Salaverry. La ejecución de este se encontró a cargo de la empresa Qetzal S.A.C. Los materiales recuperados han sido entregados al Ministerio de Cultura.

2. El análisis textil de la muestra seleccionada, así como la propuesta estilística derivada de este estudio corresponden al aporte de Arabel Fernández. Los aportes de mi coautor Luis Álvarez corresponden a los resultados de las excavaciones y trabajos de campo. 


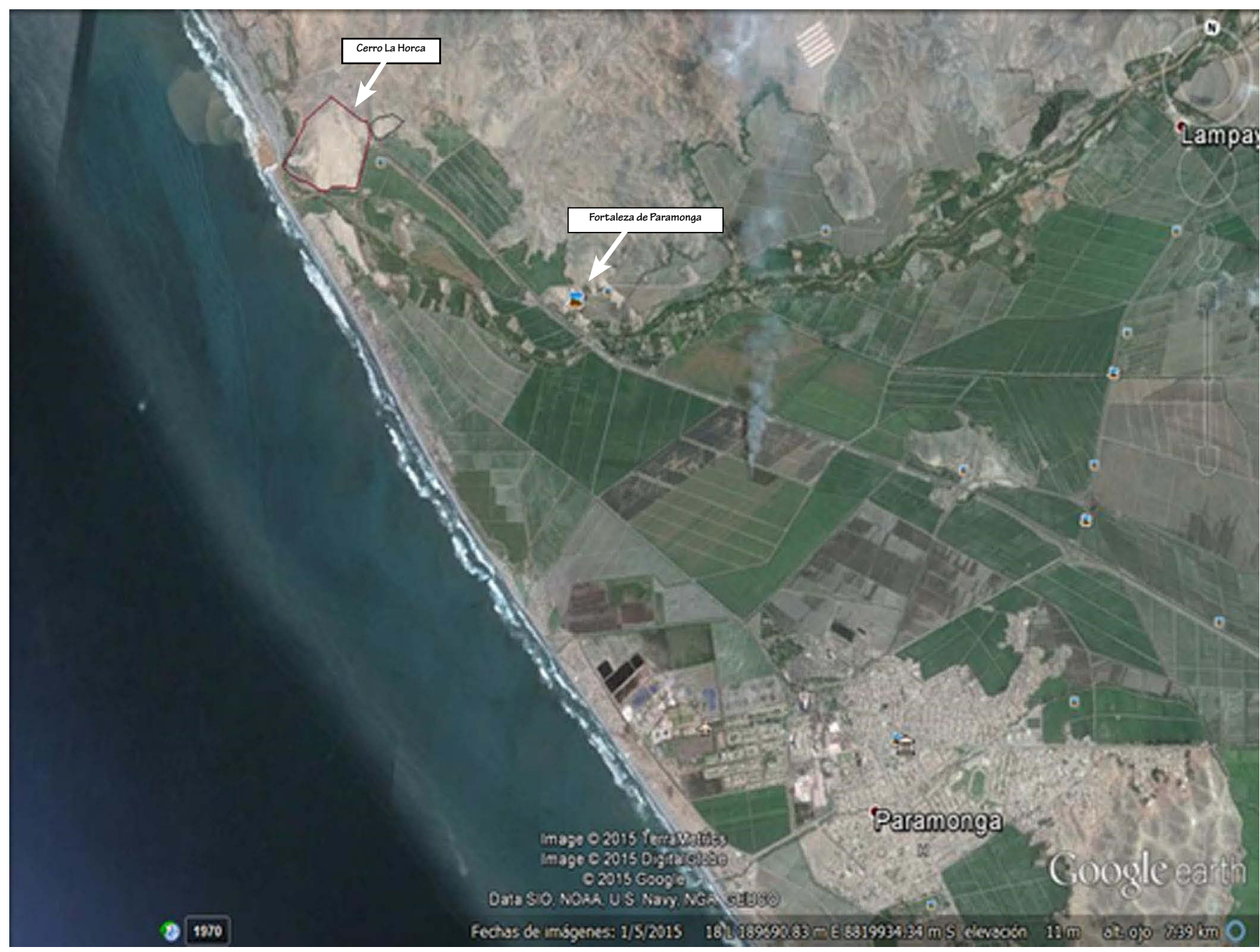

Figura 1. Mapa del area.

Fernández (2015) al realizar la catalogación de la colección textil del Museo Nacional de Río de Janeiro (Brasil), comprobó que algunas de las piezas textiles registraban como lugar de procedencia el sitio de Paramonga, identificándose los estilos Chimú, Huarmey, Costa Central ${ }^{3}$, e Inca.

\section{Investigaciones en Cerro La Horca}

Dentro del marco de ejecución del Proyecto de Rescate de Cerro la Horca fue posible intervenir diversos sectores que conforman este yacimiento. Como resultado del análisis estratigráfico de las diversas unidades de excavación se ha podido definir dos etapas de ocupación. En la primera etapa el área intervenida tiene un marcado uso funerario, pues desde la superficie estéril hasta la configuración de ambientes aglutinados existe una profusa actividad de enterramiento tanto de humanos como de animales. Destacan construcciones consistentes en celdas, patios y corredores, delimitados por muro de adobe y cantos rodados. Por lo general los entierros fueron depositados en las celdas de 1x1.5 mt. El patrón funerario consistió en enterrar a los individuos en posición flexionada o sentada, acompañados de ofrendas de cerámica, textiles, restos botánicos y de fauna, entre otros. Los entierros más tempranos corresponden a finales del Horizonte Medio. En lo que respecta a la cerámica se reconocieron piezas correspondientes a estilos locales como Pativilca y Chancay-Pativilca. Aunque el estilo Casma apareció posteriormente, este llego a predominar hasta el final de la ocupación. La segunda etapa se pudo determinar tras identificar que un amplio piso que cubría las estructuras de la primera etapa. Para esta etapa se registraron ambientes construidos en base a quincha, comprobándose su

3. Sobre estos textiles de la Costa Central que aún por establecer con precisión su filiación cultural y estilística. De allí que hayan sido catalogados de manera general como estilo local de la Costa Central. 


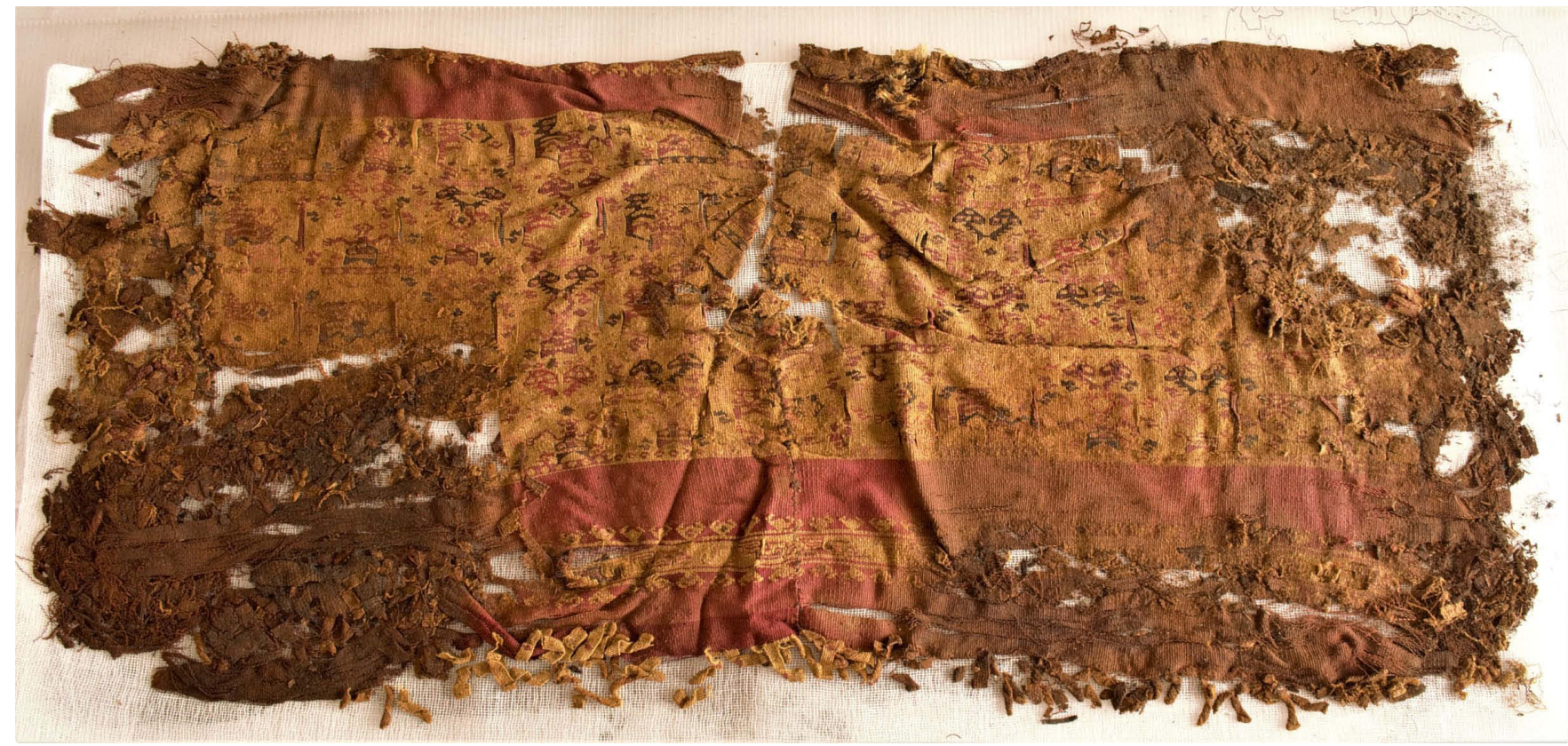

Figura 2. Camisa corta (espécimen [B.o63] U4/CC:16F/CF-4/C:D) (Foto Arabel Fernández. Publicado Fernández 2019, Fig. 2)

uso habitacional y doméstico. De este nivel solo provienen seis contextos funerarios de los 442 registrados durante las excavaciones (Valle et al. 2019:52-53).

\section{La muestra textil de Cerro La Horca}

De acuerdo con la naturaleza del contexto arqueológico, los textiles fueron clasificados en dos grupos: a) textiles procedentes de fardos funerarios, no alterados; $y \mathrm{~b}$ ) tejidos registrados en contextos funerarios y espacios arquitectónicos, ambos en condiciones de alteración antrópica.

\section{A. Textiles procedentes de fardos funerarios}

En total fueron cinco los fardos funerarios abiertos: $\mathrm{U}_{3}-\mathrm{CF}-2$, U1-CF-11, U2-CF-108, U4-CF-4 y U4-CF-13. A continuación presentaremos los textiles asociados a cada uno de estos.

Fardo U3-CF-2: se recuperó un total de cinco textiles, entre los que se identificaron un paño, dos mantos, una banda y un paño-harapo 4 .

Los tejidos de este entierro muestran características técnicas y estructurales vinculadas con la tradición norteña, como son los hilos de torsión en S, y estructuras correspondientes a tela llana $2 / 1$ y $1 / 1$. Sin embargo, el pañoharapo U3-CF-2.08.03 tenía fragmentos textiles empleados como parches elaborados con hilos 2Z-S, torsión característica de los hilos de la costa central. ${ }^{5}$ Podemos concluir que los textiles de este contexto corresponden a un desarrollo local, al cual hemos denominado estilo Fortaleza, el mismo que forma parte de la tradición textil de la costa norte.

Fardo U4-CF-4: procedente de este fardo se recuperó una camisa corta (U4-CF-4.03), completa y decorada en su integridad (Figura 2). Sus medidas son 39 por $86 \mathrm{~cm}$. Conformado a partir de la unión de dos tejidos de forma rectangular, cuyos extremos terminan en lengüetas.

En ambos lados de la camisa se aprecia un ser antropomorfo, visto de pie, que se reproduce formando hileras. Este personaje porta un tocado de doble punta; sus extremidades superiores son largas y delgadas y presenta los hombros encogidos, una mano ciñe un cetro y la otra coge el cuerpo de un animal, al que sostiene boca abajo. El torso adopta la forma de un rombo y la forma triangular del área de la pelvis sugiere una túnica corta. Sus extremidades inferiores también son largas y delgadas, con una marcada flexión en las rodillas que da paso a un espacio en el cual se inscribe un pequeño rombo. Al parecer, el

4. Se define paño-harapo como aquel textil conformado por retazos textiles con claras evidencias de uso. Los paño-harapo muestran además rasgaduras, roturas, remiendos

5. Los estudios realizados por Rowe $(1996,2014)$ indican que los tejidos chancay presentan hilos de algodón de torsión en Z y retorsión en S. Por su parte, Frame et al. (2012) señalan que los textiles de la tradición Ychsma también muestran esta característica técnica. 
personaje se encuentra al interior de una estructura ceremonial, decorada con diseños de rombos y serpientes bicéfalas que forman un arco. Forman parte de la escena tres aves representadas de perfil. Estos motivos se presentan combinando los colores rojo, rosado, granate y marrón de manera alternada (Figura 3). Este espacio central se define por una franja de color rojo que lleva motivos geométricos de color amarillo y escalonado con gancho entrelazado en la parte central.

Son varios los atributos que debemos analizar para poder determinar la posible filiación cultural y temporal de esta prenda. Por un lado, tenemos los atributos técnico-estructurales (tapiz ranurado) y los colores, que nos permiten sostener que correspondería al Periodo Intermedio Tardío. Asimismo, las lengüetas o flecos tejidos en cara de trama, detalle ornamental que se desarrolló durante el Periodo Intermedio Tardío, popularizándose entre los tejidos de la costa central. Sin embargo, la iconografía corresponde a elementos derivados de las escenas relacionadas a temas de reproducción, fertilidad y personajes masculinos vistos de frente que portan tocados diversos, sostienen cetros y están rodeados de animales; que se encuentran diseminados en un estilo de cerámica con decoración en altorrelieve que se distribuyó entre los valles de Casma, Pativilca y Moche (Carrión Cachot 1959) durante las épocas 3 y 4 del Horizonte Medio (Menzel 1977), sin embargo, el personaje de la camisa en cuestión sería un derivado de este periodo, considerando asimismo que la cerámica asociada al entierro presenta atributos identificados para el valle de Pativilca en asociación con elementos estilísticos que corresponden a la cultura Chancay de la costa central. Proponemos, de manera tentativa, que esta prenda correspondería a un estilo desarrollado hacia el sur del valle del Fortaleza durante el Periodo Intermedio Tardío.

Fardo U1-CF-11: se recuperó un textil que fue doblado formando un paquete. Debido a su fragilidad no se procedió a extenderlo. Exteriormente el paquete muestra la unión de bandas con patrón de urdimbre alternadas con finas bandas conformadas por pequeños paneles rectangulares. Las bandas en cara de urdimbre son de color rojo y llevan una franja central de urdimbres complementarias que forman diseños en forma de "S". Los paneles son en tela llana 1/1, de color azul y marrón.

Los tejidos con patrón de urdimbre se introducen en la costa norte a partir de los contactos con poblaciones de la sierra durante el Horizonte Medio; sin embargo, es durante el Periodo Intermedio Tardío que adquieren relevancia. Por lo registrado en el valle de Huarmey (Fernández 1998), estos tejidos, además, se caracterizan por el uso predominante de urdimbres de color rojo que forman anchas franjas y definen espacios centrales con diseños geométricos o de animales.

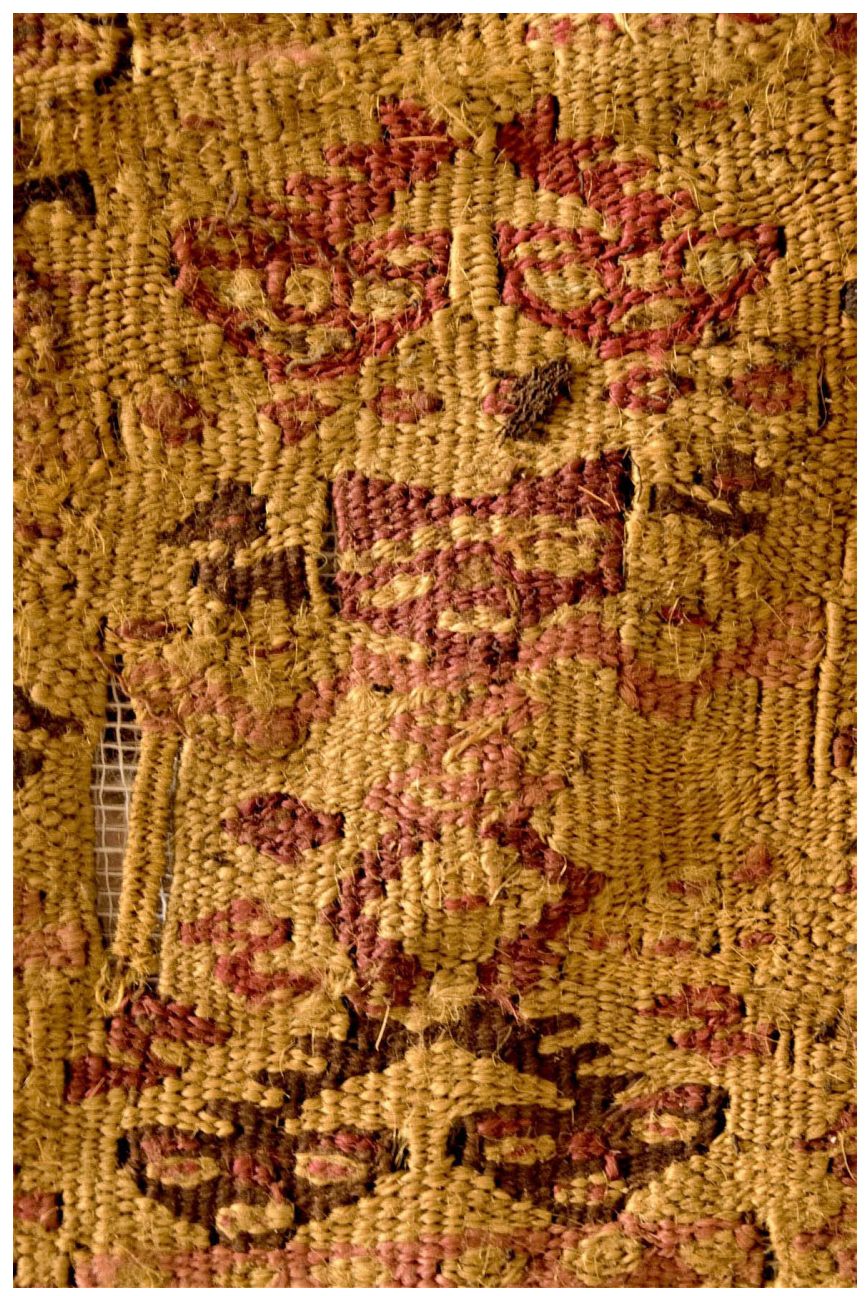

Figura 3. Detalle del personaje antropomorfo representado en la camisa corta (espécimen [B.063] U4/CC:16F/CF-4/C:D) (Foto Arabel Fernández. Publicado Fernández 2019, Fig. 3).

Una de las ofrendas del contexto funerario 26 , que corresponde a un cesto de fibra vegetal se encontró envuelto con un textil elaborado con bandas en patrón de urdimbre (Soto et al 2019:126).

$\mathrm{Al}$ igual que el entierro antes descrito, la cerámica muestra rasgos identificados para el valle de Pativilca en asociación con elementos de la costa central. Los tejidos pertenecientes a este entierro corresponden al estilo Fortaleza.

Fardo U4-CF-13: en este fardo funerario se registraron cinco textiles pintados. Todos ellos muestran escenas complejas que tienen como principal protagonista a un personaje antropomorfo. Ninguno de los mantos se encontró completo; estuvieron conformados por dos telas de algodón de color crema. Todos fueron elaborados en tela llana $2 / 1$, con excepción de uno que corresponde a un manto en tela llana 
2/2. A continuación describiremos de manera breve cada uno de los mantos.

Textil pintado 1 (U4-CF13.01): manto incompleto (Figura 4) que mide 162 por $88 \mathrm{~cm}$. Conformado por dos tejidos, ambos en tela llana 2/1, los hilos de algodón crema presentan torsión en S.

La escena tiene como figura principal a un personaje antropomorfo (incompleto debido a la pérdida de tejido), representado de pie y visto de frente. Presenta un tocado en forma de medialuna con plumas que tiene como soporte un casco semicircular, el cual se sujeta al mentón por medio de una cinta de diseños en forma de "V" invertida. El personaje luce una camisa corta de color azul, con motivos escalonados en la parte central y remata en una franja de diseños en forma de "V" invertida. Las piernas quedaron expuestas, observándose que una de ellas está semiflexionada; el miembro viril también es visible. El personaje porta, además, largos cetros; se observó que el cetro mejor conservado culmina en una representación estilizada de ave de cabeza circular, motivo característico de la iconografía Sicán/Lambayeque El cuerpo muestra las alas y cola extendidas. Asisten al personaje central seres antropomorfos y zoomorfos de menor tamaño. Hacia el exterior del cetro destacan tres personajes antropomorfos: dos de ellos están parados y vistos de perfil, y el tercero presenta el cuerpo en posición horizontal; aparecen rodeados de criaturas de menor jerarquía. Forman parte de esta escenografía objetos que aparecen dispersos entre los personajes, entre ellos cántaros, conchas Spondylus, artefactos circulares con sogas, rectángulos, triángulos y círculos. Grecas de escalonados con gancho de color azul definen este espacio central. A continuación, en el borde superior se observa una hilera de peces. El borde superior culmina en una procesión de personajes antropomorfos, cada uno de los cuales sostiene un cetro y sigue una misma dirección.

El manto no solo destaca por la escena representada, sino también por la maestría en la ejecución de los motivos y la calidad de la pintura empleada. El pintor recurrió al empleo de varios colores, como el marrón, amarillo, verde y azul, destacando este último no solo por la intensidad, sino también por lo recurrente de su empleo, pues aparece en todos los motivos.

Textil pintado 2 (U4-CF-13.02): manto incompleto, cuyas medidas son 145 por $130 \mathrm{~cm}$ y se conforma de dos tejidos, ambos tejidos fueron elaborados en tela llana $2 / 1$, para lo cual se emplearon hilos de algodón de torsión en S (Figura $5^{\mathbf{a}}$ ).

La parte central de la escena la ocupa un ser antropomorfo de pie y visto de frente. Con el personaje anteriormente descrito comparte atributos fisonómicos, así como de indumentaria. El rostro, tocado y collar son similares.

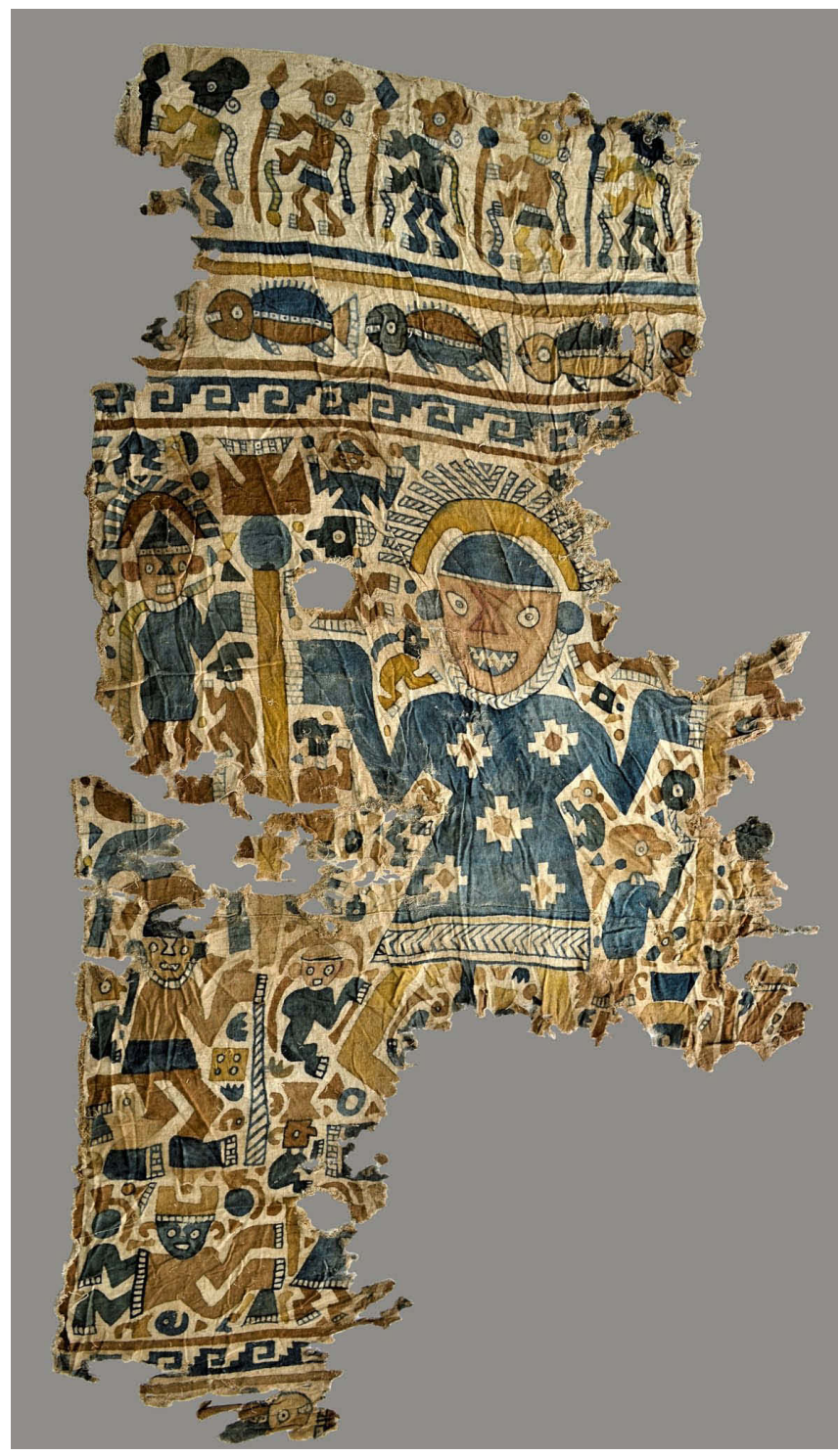

Figura 4. Manto pintado. Se destaca en el círculo la terminación del cetro, la cual corresponde al Ave en Picada, icono distintivo de la iconografía Sicán/Lambayeque (espécimen [B.o71] U4/ CC:14E/CF-13/C:F) (Foto Arabel Fernández. Publicado Fernández 2019, Fig. 4)

A la altura de las orejas aparece un rostro zoomorfo con apéndices en forma de medialuna que salen de la boca; de la mandíbula pende una borla multicolor (Figura $\mathbf{5 b}$ ). Viste una camisa corta, escalonada, con diseños de cruces y borde de rectángulos; viste, además, un faldellín de color azul. El personaje sostiene un cetro que alcanza su altura. A pesar de encontrarse incompleto, se puede decir que es el mismo cetro que porta el personaje del textil pintado 1. El personaje aparece sobre una plataforma en forma de "U". Alrededor de este aparecen personajes de tercer orden, en diversas actitudes: de pie, sentados, caminando, interactuando con objetos de diversa naturaleza (cántaros, borlas, palos, 


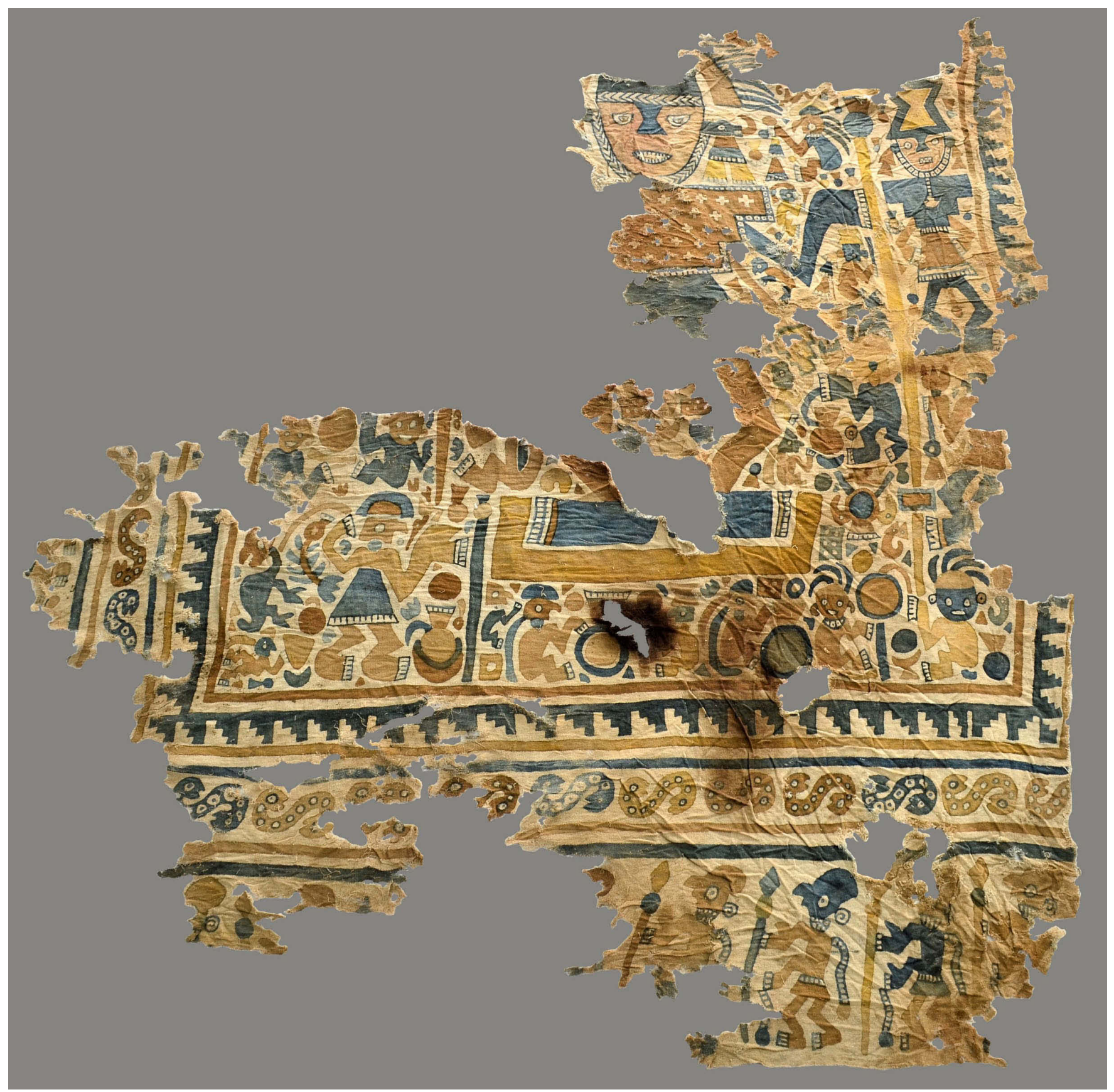

Figura 5a. Textil pintado 2 (espécimen [B.071] U4/CC:14E/CF-13/C:F) (Foto Arabel Fernández. Publicado Fernández 2019, Fig. 5).

entre otros) representados siempre de perfil. Los personajes de segundo orden o secundarios son aquellos de tamaño intermedio entre el personaje central y los de tercer orden. Están dispuestos de perfil y sostienen un cetro, o aparecen de frente sin él. En este textil destaca un personaje con tocado en forma de "reloj de arena" 6
(Figura 5c); lleva orejeras con borlas y un doble traje: una camisa corta escalonada debajo de la cual se aprecia una camisa de mangas largas de color marrón y decoración de flecos. Del collar cuelga un tumi o cuchillo ceremonial. Entre sus piernas flexionadas destaca su miembro viril. En el lado opuesto, en la esquina izquierda, el personaje antropomorfo

6. Personajes con este tipo de tocado aparecen representados en el kero de plata repujada con escenas mitológicas que actualmente se encuentra en el Museo de Denver (King 200o, pag. 42-43, Mackey y Pillsbury 2013, Fig. 16). Asimismo, como parte de la colección del Metropolitan Museum of Arte se tiene un tocado metálico con esta forma (Pillsbury 2017) 


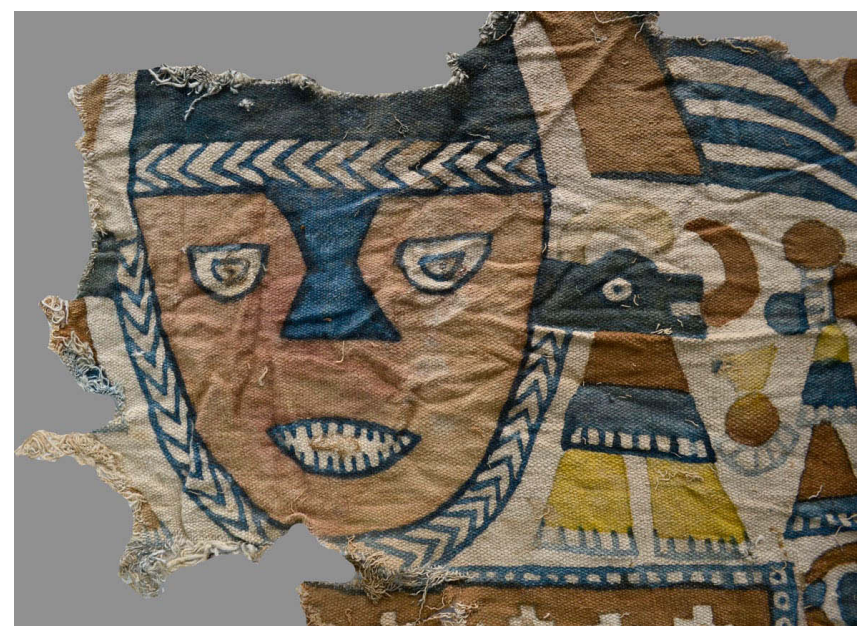

Figura $\mathbf{5 b}$. Detalle del rostro del personaje principal cuyo accesorio decorativo a manera de collar termina en cabezas de felino e incluyen adornos de borlas (Foto Arabel Fernández)

secundario aparece asociado a diversos elementos. El torso aparece desnudo; luce un faldellín de color azul y un tocado en forma de casco de color marrón y azul. Con una mano sostiene un largo cetro que termina en un círculo con triángulo y con la otra una soga que está atada al cuello de un camélido. Delante del rostro aparece un picaflor en picada.

Demarca este espacio central un listado de color marrón seguido de una greca de escalonados de color azul. A continuación, siguiendo la forma del espacio central, se tiene la representación de serpientes bicéfalas y debajo, rematando la escena, hay una procesión de individuos que sostienen cetros al igual que en el textil pintado 1.

Textil pintado 3 (U4-CF-13.03): se encuentra incompleto y sus medidas son de 124 por $103 \mathrm{~cm}$. El lienzo se conforma de dos tejidos; la unión se realizó tomando los orillos laterales. En este caso, los tejidos presentan estructura en tela llana $2 / 2$, y fueron elaborados con hilos de algodón crema con torsión en S (Figura 6).

La escena representada muestra cuatro áreas de diseño que se desenvuelven de adentro hacia afuera. La zona central, lamentablemente incompleta, exhibe un personaje antropomorfo visto de frente. El torso se encuentra exageradamente representado, con las extremidades inferiores minimizadas y los pies dirigidos hacia los lados. De igual manera sucede con las extremidades superiores. Luce un faldellín corto con decoración listada y sostiene un cetro. En el torso se aprecian dos aves pintadas; son pequeñas y diferentes a las que aparecen a los lados del personaje. A diferencia de los lienzos 1 y 2 , en este caso los motivos secundarios que rodean al personaje corresponden principalmente a aves, con la excepción de un personaje

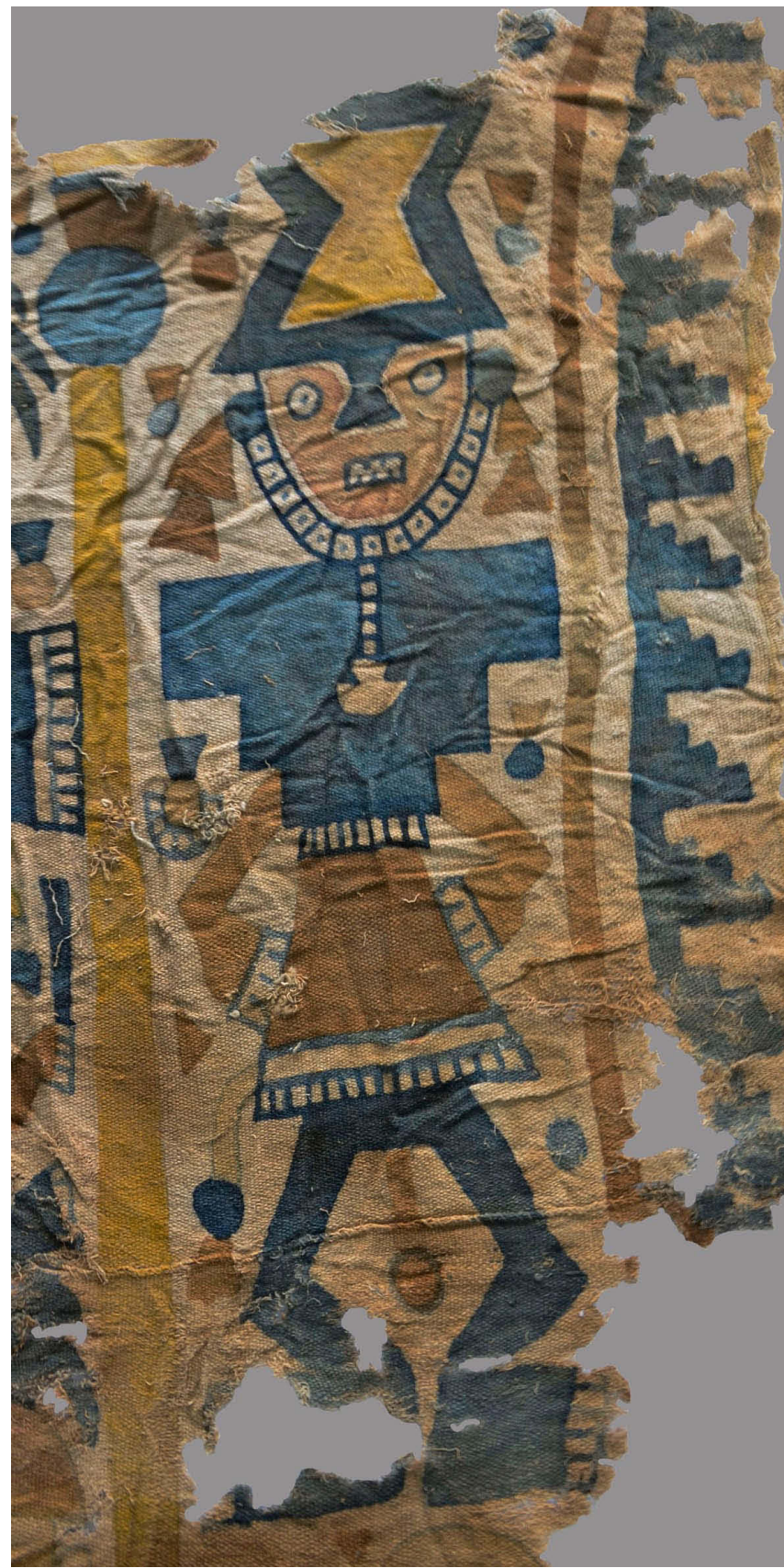

Figura 5c. Detalle que muestra al personaje secundario con tocado en forma de "reloj de arena" (Foto Arabel Fernández)

antropomorfo que aparece en la parte inferior en posición extendida y que también está representado en el lienzo 1. Hay aves míticas que se distinguen por su tocado en forma de medialuna, además de ser de mayor tamaño que las aves no míticas. El hombre en posición extendida es presentado con el rostro de frente, muestra los dientes, y sus orejas y ojos son circulares. Lleva un gorro tubular dispuesto hacia un lado. Alrededor de este aparecen cuatro personajes 


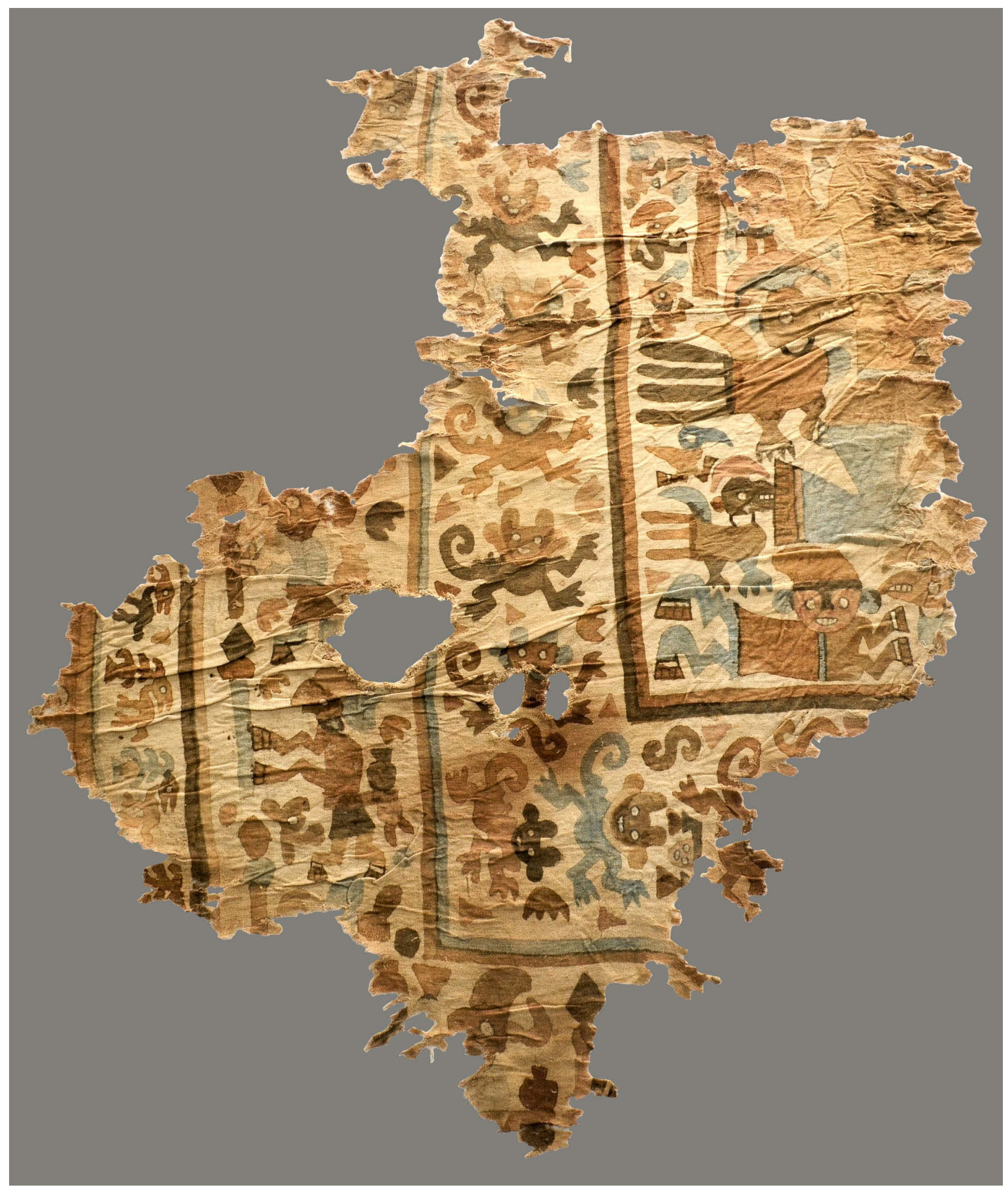

Figura 6. Textil pintado 3 (espécimen [B.071] U4/CC:14E/CF-13/C:F) (Foto Arabel Fernández. Publicado Fernández 2019, Fig. 6). 


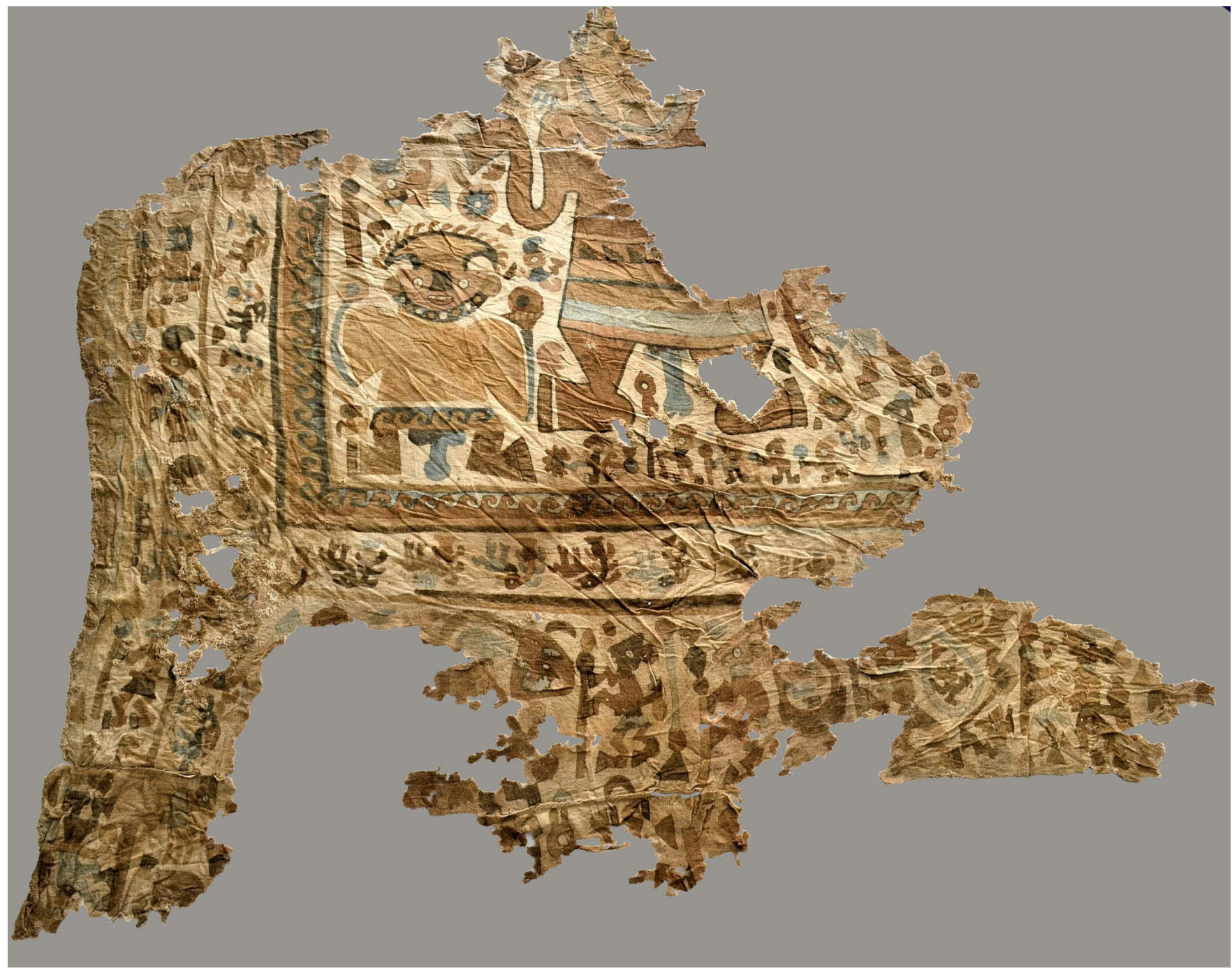

Figura 7. Textil pintado 4 (espécimen [B.071] U4/CC:14E/CF-13/C:F) (Foto Arabel Fernández. Publicado Fernández 2019, Fig. 7).

pequeños. Todos presentados de perfil, no aparecen bien definidos; uno de ellos tiene cuerpo en forma de "S".

En el siguiente sector se tiene la representación de monos vistos de frente, con las extremidades extendidas hacia los lados y la cola enroscada. Como elementos secundarios hay triángulos, motivos en forma de "S" y conchas Spondylus.

A continuación, se tiene el área de los personajes antropomorfos, presentados de perfil, que sostienen un cetro corto, el cual termina en una esfera y un rombo. Visten un faldellín corto, asegurado por una faja. Portan un tocado tubular tirado hacia atrás. Vasijas y conchas Spondylus rodean a los personajes. El último sector corresponde a una franja que muestra la representación de llamas que comen maíz.

Textil pintado 4 (U4-CF-13.04): lienzo incompleto que mide 138 por $152 \mathrm{~cm}$. El lienzo se halla conformado por tres tejidos, todos ellos en tela llana 2/2, elaborados con hilos de algodón crema y de torsión en S (Figura 7).
Como en los casos anteriores, la escena se desenvuelve por medio de la presentación jerárquica de los personajes o acciones. Se prioriza la representación de un personaje antropomorfo, de pie y visto de frente. Aunque gran parte de este sector del lienzo se ha perdido, se puede hacer una descripción del individuo. Comparte las facciones de los personajes antes descritos, aunque los accesorios ornamentales son diferentes. El collarín presenta una decoración en zigzag y las orejeras están conformadas por una esfera con borla y flecos. Lleva un traje largo con decoración listada y diseños geométricos en el borde inferior. No sujeta un cetro, pero sí un objeto circular que está atado a una cuerda. Hacia el lado derecho, un hombre-ave (denominado así por la forma de ala que adoptaron los brazos) sostiene esferas en cada una de las extremidades. Esta figura porta un tocado en forma de medialuna con plumas, orejeras circulares y un collar con decoración de círculos. Viste un faldellín 


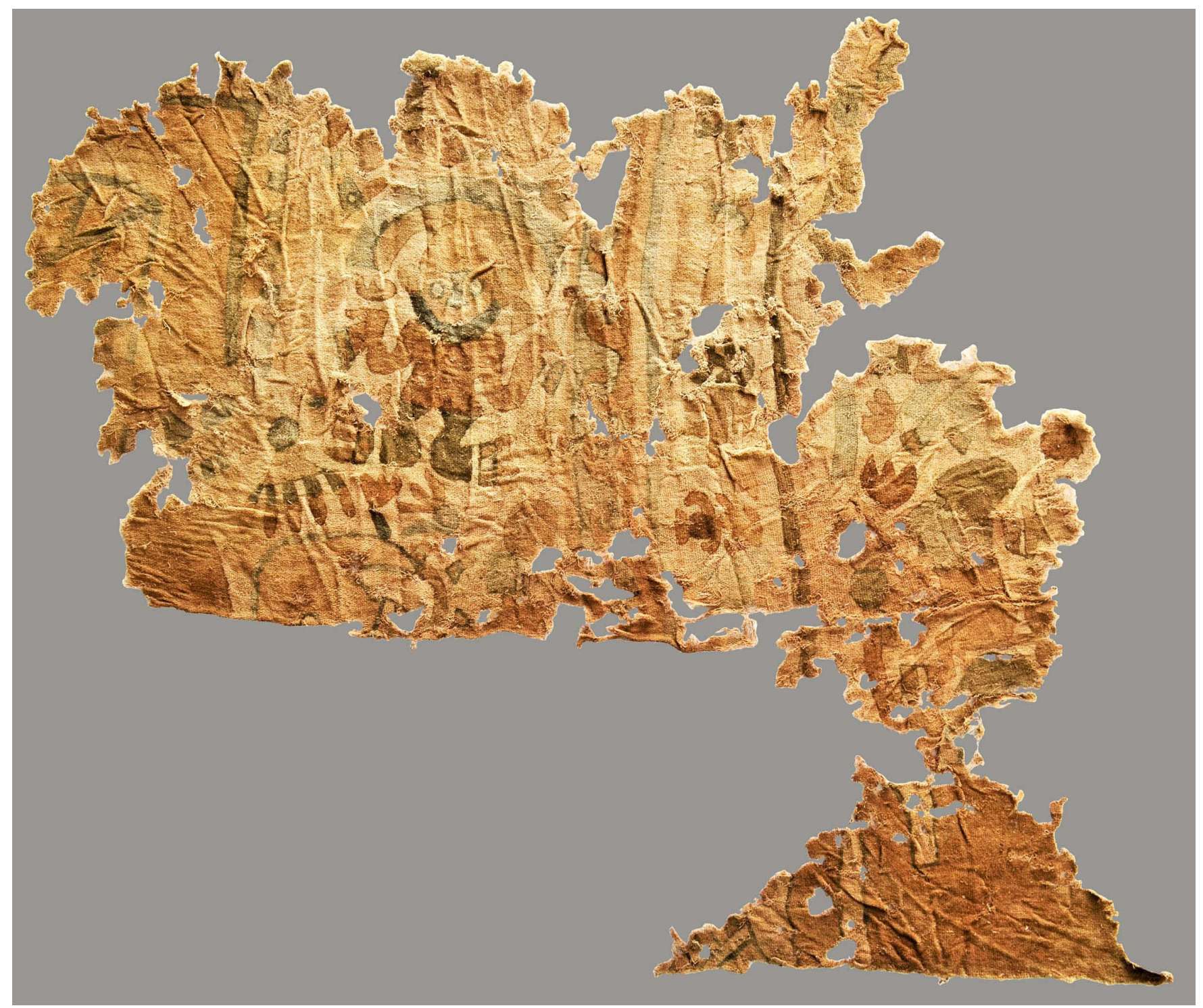

Figura 8. Textil pintado 5 (espécimen [B.o71] U4/CC:14E/CF-13/C:F) (Foto Arabel Fernández. Publicado Fernández 2019, Fig. 8).

ornamentado con diseño de olas. Entre sus piernas deja entrever su falo prominente, al igual que el personaje principal. Entre ambos personajes aparecen pequeños seres, los mismos que en la parte inferior conforman una hilera. Este espacio quedó demarcado por una greca de olas entrelazadas. A continuación, se tienen representaciones de crías de camélidos que se alimentan de plantas, probablemente maíz. Las siguientes imágenes corresponden a individuos de pie, vistos de perfil. Llevan un tocado alto; a la altura de su cintura se sujeta un bulto. Sostienen con ambas manos un cetro. Entre estos personajes aparecen otros tres, involucrados en lo que podría ser un ritual.

Textil pintado 5 (U4-CF-13.05): corresponde al tejido de menor dimensión, se encuentra incompleto y mide 66 por
$76 \mathrm{~cm}$. La estructura correspondiente a ambos tejidos es una tela llana 2/2 elaborada con hilos de algodón crema de torsión en S. (Figura 8).

En su escena, la configuración de los personajes difiere de los tejidos anteriormente descritos. En este caso no se identificó al personaje principal, sino, más bien, a un personaje que por el tamaño y lo sencillo de su representación podría categorizarse como secundario. Su indumentaria incluye un tocado en forma de medialuna, orejeras circulares, un collarín simple y una vestimenta corta. Las manos y los pies los muestra hacia los lados. Alrededor aparecen conchas Spondylus dispersas y otros objetos no identificados. Cierra este espacio una greca de olas entrelazadas. A continuación, se siguió con la representación de crías de camélidos que se 
alimentan de alguna planta. En seguida se tiene al personaje con cetro y gorro cónico.

Los cinco textiles pintados del fardo U4-CF13, son de clara filiación Sicán/lambayeque. Esta identificación tiene como fundamento elementos iconográficos distintivos de la cultura Sicán/Lambayeque, accesorios ornamentales y de jerarquía, tales como los ornamentos faciales laterales en forma de felino y el tocado en forma de "reloj de arena", así como la técnica de pintado empleada. Se conoce muy poco sobre los textiles sicán/lambayeque del área nuclear (región Lambayeque), lo que se debe a las condiciones climáticas poco favorables para su preservación, sin embargo, este tipo de evidencias se han registrado en los extramuros de la capital, ya que se conocen piezas procedentes de sitios de la costa central, como Pachacamac, Ancón y Huaca Malena. Los artistas textiles sicán/lambayeque se valieron de este arte para representar escenas relacionadas a su complejo sistema religioso, ya fuera mediante el pintado sobre lienzos de algodón o el tejido de intrincadas diseños en tapiz. El periodo Sicán Medio (90o-110o d.C.), de acuerdo con la cronología desarrollada por Shimada para la cultura Sicán (1990), representa el momento de mayor auge para esta cultura en el cual el arte fue eminentemente religioso. Esto se aprecia en la representación de un personaje sobrenatural con atributos ornitomorfos (alas y garras) y que constituye la máxima deidad sicán/lambayeque. De acuerdo con Shimada (2014: 31) esta deidad tendría su alter ego personificado en los lideres sicán (denominados por dicho investigador como Señor Sicán) e identificados por llevar una máscara con ojos en forma de coma u orientados hacia arriba. Su omnipresencia se hace eminente al ser representado de manera recurrente en diversos soportes artísticos.

De los cinco textiles pintados registrados en Cerro La Horca, los tejidos 1 y 2 conservaron en mayor proporción la representación del personaje principal, así como también la escenografía en la cual se desenvuelve. El personaje ha sido identificado como el Señor Sicán. Si bien los ojos de este personaje no muestran la forma de "coma”, atributo facial considerado diagnóstico para la identificación de la deidad o Señor Sicán, cabe indicar que los ojos no siempre fueron representados de esta manera, ${ }^{7}$ ya que pudieron aparecer también con círculos concéntricos, como los que se observan en estos personajes, quienes llevan, como distintivos de la elite sicán/lambayeque, destacados tocados de plumas y orejeras en forma de felino y que aparecen unidas al collar. Una de estas figuras (personaje del tejido 2) corresponde a un felino de lengua proyectada y borlas suspendidas, ornamento que caracteriza a la deidad-Señor Sicán/Lambayeque. Otro símbolo que debemos destacar en estos señores son los cetros, cuyo apéndice superior culmina en forma de "ave en picada”, identificada por Narváez (2014:26) como el "ave mítica”. La forma de los techos de los templos y determinados tocados, llegaron a adoptar esta forma.

Se sabe que en las tumbas de los individuos de elite como es el caso de las halladas en Huaca Loro y Huaca Las Ventanas (Shimada 2014: 174-178), y la de la Sacerdotisa de Chornancap (Wester 2012) - los muros estaban decorados con tejidos pintados. También se tiene información de tejidos pintados recuperados en Pachacamac, como aquel que pertenece a la Colección Wilhelm Gretzer y se encuentra actualmente en el Ethnologisches Museum Berlín (Schmidt 1929, lam. 42-45, Shimada 2014: figura 14), que corresponde a la imagen de la deidad sicán, y otro en el cual se representa una escena marina (Castillo 2017: fig.1), también en el Ethnologisches Museum Berlin. Estos tejidos comparten detalles técnicos y de policromía con los tejidos 3, 4 y 5 de Cerro La Horca. Nos referimos a los tonos de la pintura empleada, que corresponden al azul y el marrón; tenemos también la delimitación del área de color por medio de líneas de un tono más oscuro que el color de relleno. El trazo irregular, así como también la difuminación de la pintura que causa la superposición de los colores-, al parecer son el resultado de una preparación poco consistente de la mezcla empleada para la pintura. Por lo contrario, los tejidos 1 y 2 muestran gran maestría en la obtención de la pintura, y los colores son intensos y estables. La mezcla de los pigmentos y aglutinantes denota un gran conocimiento tecnológico.

Fardo U2-CF-108: entre los cinco fardos funerarios desenfardelados, este destaca por la cantidad de tejidos recuperados, entre paños, un paquete conformado por diversos retazos de telas, hilos y fibra de algodón y diversos tejidos empleados como mortaja. Los paños registrados se distinguen por su estructura en tela llana 1/1, elaborados con hilos de algodón, uno de ellos presenta decoración tipo cuadrilé que combina listas de color marrón claro y oscuro ${ }^{8}$ (paño rectangular U2-CF-108.4.1). El segundo paño (U2CF108.4.2) combina estructuras en tela llana 1/1 y urdimbres flotantes; la decoración corresponde a listas estructurales y listas de hilos flotantes en colores marrón, azul y celeste, respectivamente (Figura 9).

Mortaja compuesta (U2-CF108.12): se trata de cinco tejidos que fueron recuperados juntos. La secuencia de superposición es la siguiente: soguillas de fibra vegetal; debajo se

7. Por ejemplo, véase la figura 18 en Shimada 2014, en donde se muestra una pintura mural de la deidad sicán/lambayeque, representada con ojos formados por círculos concéntricos.

8. Se denomina decoración tipo cuadrilé a aquella obtenida por el cruce de listas de colores formadas por los hilos de trama y urdimbre. 


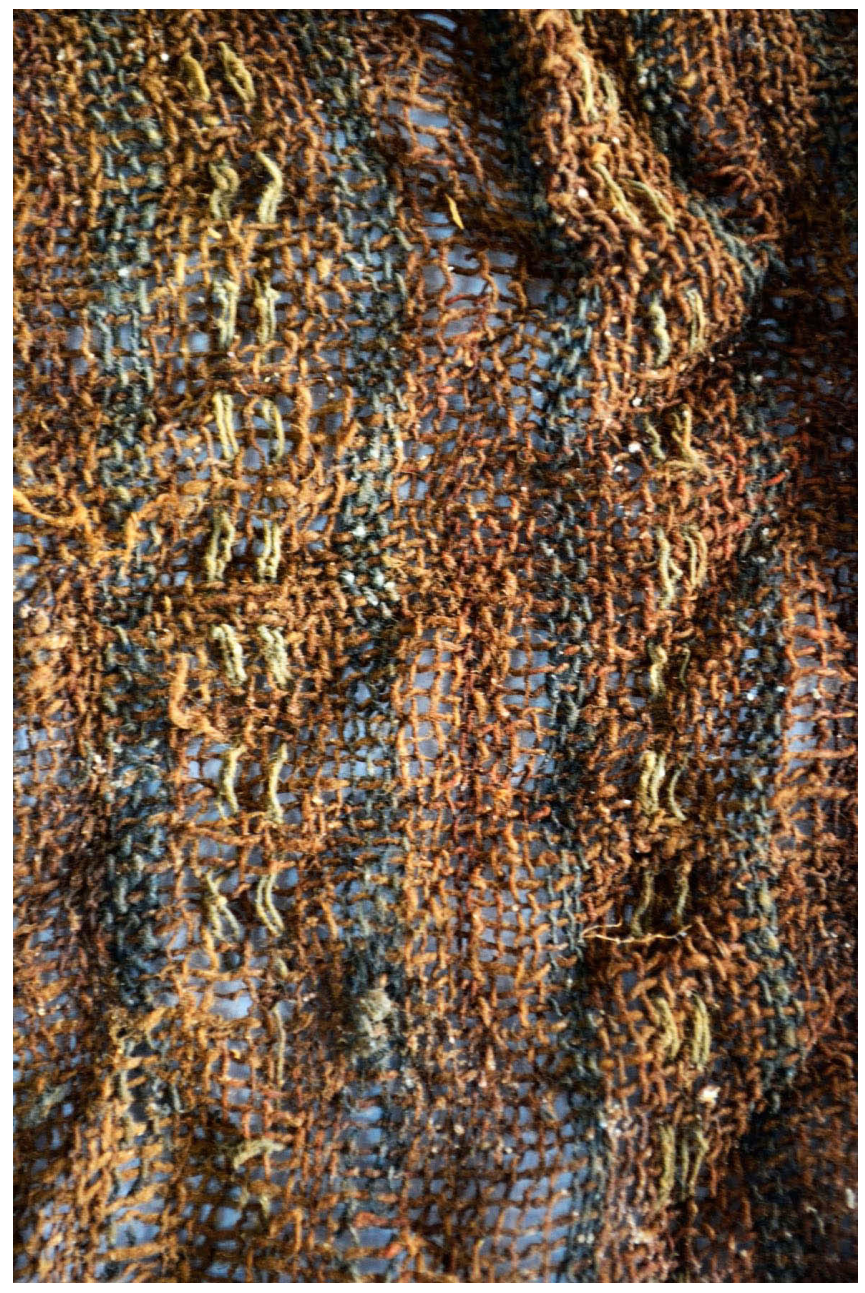

Figura 9. Detalle decorativo conformado por urdimbres flotantes (espécimen [B.178] U2/CC:9E,9F/CF-108/C:H) (Foto Arabel Fernández. Publicado Fernández 2019, Fig. 10).

registró un paño de plumas muy deterioradas de color anaranjado, verde-azul y marrón que parecen haber formado un patrón de listas horizontales. El tejido sobre el cual se colocaron las plumas corresponde a una tela llana 1/1, de hilos de algodón (2Z-S) de color marrón. Debajo de este plumario se registraron dos mantos bicolores unidos por puntadas que se dieron dejando espacios abiertos. Estos mantos comparten la particularidad de llevar una lista de color marrón oscuro y crema tejida de manera individual y que se unió al paño central en el borde lateral. Cabe indicar que mientras en un manto el paño central es de color marrón oscuro, en el otro manto este es de color crema. La estructura en todos los tejidos corresponde a tela llana $1 / 1$ en cara de urdimbre (banda bicolor) y predominio de urdimbre (paño central); los hilos son, en todos los casos, 2Z-S. Hay un tercer manto que combina estructuras en tela llana $2 / 2$ y $2 / 1$, de textura rala e hilos jaspeados de torsión en S. Finalmente, se registró una red anudada elaborada con cordones de fibra vegetal (cabuya) torcida en S.

Paquete textil (U2-CF108.17): conformado por retazos de textiles, hilos de fibra de camélido de color rojo y amarillo, y motas de fibra de algodón.

Este contexto funerario brinda información que puede analizarse desde la perspectiva de las interacciones surgidas entre la población local y aquella procedente de la costa central. Para esto tomamos en consideración la torsión de los hilos. Para este entierro se cuenta con hilos de torsión simple, siendo predominantes la torsión simple en $\mathrm{S}$ (nueve textiles). Debemos indicar, además, que estos hilos aparecen en asociación a telas llanas $1 / 1$ balanceadas y con predominio de urdimbres, presentando en algunos casos decoración listada o de tipo cuadrilé, mientras que aquellos tejidos de hilos retorcidos en 2Z-S (18 textiles) se asocian a telas llanas $1 / 1$ en cara de urdimbre y balanceada. Por último, tenemos los hilos de torsión 2S-Z (dos textiles) que conformaron una tela llana $1 / 1$ decorada con tramas suplementarias. Como atributo técnico diagnóstico se asume que los tejidos de la costa central están elaborados con hilos retorcidos (2ZS), por lo que los tejidos de este contexto funerario con este tipo de hilos procederían de la costa central. Si bien estos hilos requieren que la torsión inicial sea en $\mathrm{Z}$, se sabe que este tipo de torsión no fue una regla para la hilatura de hilos simples. Todo lo contrario: los estudios realizados en tejidos de estilo Chancay ${ }^{9}$ indican que la torsión predominante fue en $\mathrm{S}$, al igual que los hilos simples de la tradición costeña. Sin embargo, por el tipo de decoración que exhiben este grupo de tejidos proponemos que estos son de producción local. Con respecto a los tejidos con hilos en $2 \mathrm{~S}-\mathrm{Z}$, debido al tipo de torsión inicial, estarían también vinculados a una propuesta local, que la estamos definiendo como estilo Fortaleza. La cerámica asociada a este contexto corresponde a los estilos Chancay-Pativilca, Pativilca y Casma.

\section{B. Textiles de contextos removidos}

\section{Estilo Sicán/Lambayeque}

Destacan en este estilo el registro de bandas en tapiz con flecos laterales, una de las cuales complementó su decoración con

9. En el marco de estudios realizados por parte de Lothrop y Mahler (1957) en un grupo de textiles procedentes de Zapallan (valle de Chancay), las estadísticas indicaron un predominio de hilos simples de torsión en S. Por su parte, Kula (1991) informa que los hilos simples con torsión en $\mathrm{Z}$ alcanzaron un porcentaje bajo respecto de lo que se esperaba, ya que los hilos retorcidos siempre mostraban una torsión inicial en $\mathrm{Z}$. 


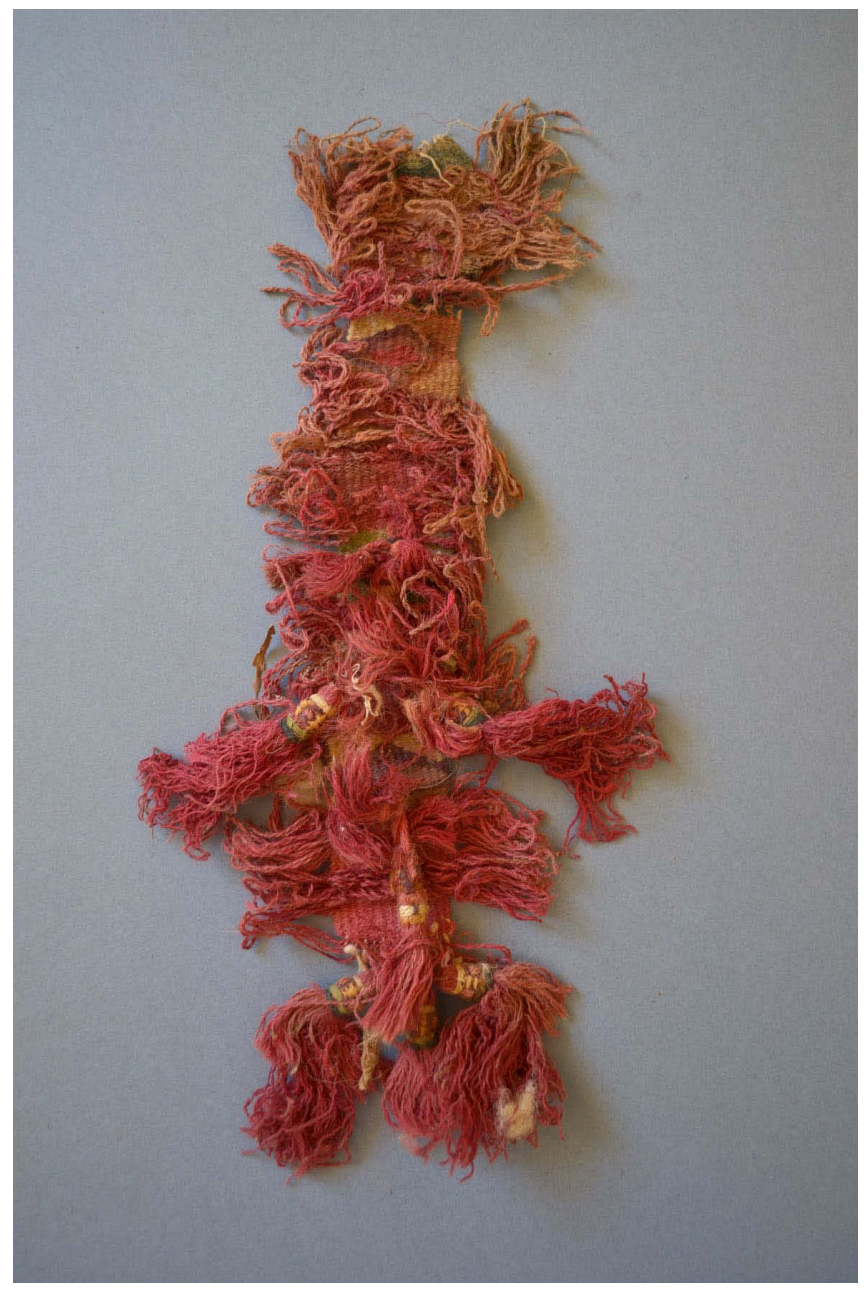

Figura 1o. Banda con flecos laterales y aplicación de borlas (espécimen [B.105] U3/CC:11C,11D,12C,12D /Ambiente 24/C:H) (Foto Arabel Fernández. Publicado Fernández 2019, Fig. 13).

la aplicación de borlas polícromas y bandas con flecos laterales ${ }^{10}$ (Figura 10). Se registró, además, un paño bicolor conformado por dos telas de colores contrastantes.

\section{Estilo Huarmey}

Identificado por primera vez en el valle de Huarmey (Fernández ms. 1998, 2006), bajo este estilo se registró una serie de piezas que hemos clasificado de acuerdo con sus características formales y estructurales.

Tejidos rojos multiestructuras: la denominación para este grupo de textiles parte de dos características técnicas particulares, como son: 1) el uso predominante de hilos de fibra de camélido de color rojo, y 2) la combinación de diferentes estructuras en una misma pieza, donde tanto la trama, como la urdimbre crean el patrón decorativo. En los fragmentos registrados, las estructuras tejidas con estos hilos corresponden a cara de trama, tramas complementarias, tramas suplementarias, cara de urdimbre y urdimbre complementaria, las cuales, al combinarse con otros ligamentos -como la gasa, bordado, urdimbres flotantes o tela llana 1/1- crean segmentos estructurales muy bien definidos (Figura 11). Los casos registrados son bandas, paños y fragmentos.

Tejidos con decoración brocada: en este grupo, el brocado define espacios decorativos por medio de franjas horizontales o formando cuadrículas. De esta manera se crean espacios decorativos en el borde inferior (orillo de urdimbre) de los tejidos o se cubre la superficie del textil. Los diseños geométricos se ordenan en una franja horizontal. Son diseños monocromos elaborados con tramas suplementarias continuas. En algunos casos, este patrón decorativo se complementa con flecos estructurales que se forman al dejarse sin tejer cierta porción de urdimbres o pueden tener el orillo de urdimbre tubular.

Adicionalmente, las tramas suplementarias forman cuadrículas por medio de listas horizontales y verticales hechas de motivos geométricos en sucesión. Al interior de estas cuadrículas se observan rombos pequeños dispuestos de manera equidistante entre sí (Figura 11).

Las estructuras son de tela llana 1/1, 2/2 o tela llana $2 / 1$, pero predomina esta última. Los hilos de urdimbre y trama son de algodón, siendo predominante la torsión en S; solo en un caso se reportaron urdimbres retorcidas (2S-Z). Las tramas suplementarias pueden ser de algodón de color marrón, crema, de torsión en S, o en fibra de camélido de color marrón o amarillo (2Z-S).

Bolsas: entre las piezas conservadas se hallaron nueve bolsas cuadradas. Existe un patrón en la confección de estas bolsas: fueron elaboradas a partir de un tejido rectangular hecho para este fin, doblado por la mitad y cosiéndose los lados. Los orillos tubulares del paño rematan en la abertura. Estas bolsas comparten el siguiente patrón decorativo:

a) Todo el cuerpo, con excepción del tercio superior, está decorado en brocado. Los diseños corresponden a aves inscritas en espacios romboidales o se presentan en hileras diagonales separadas por una línea aserrada. También hay motivos de rombos concéntricos. Los colores son rojo, marrón, morado y amarillo.

b) La decoración del tercio superior corresponde a una banda de color rojo elaborada en cara de trama; 


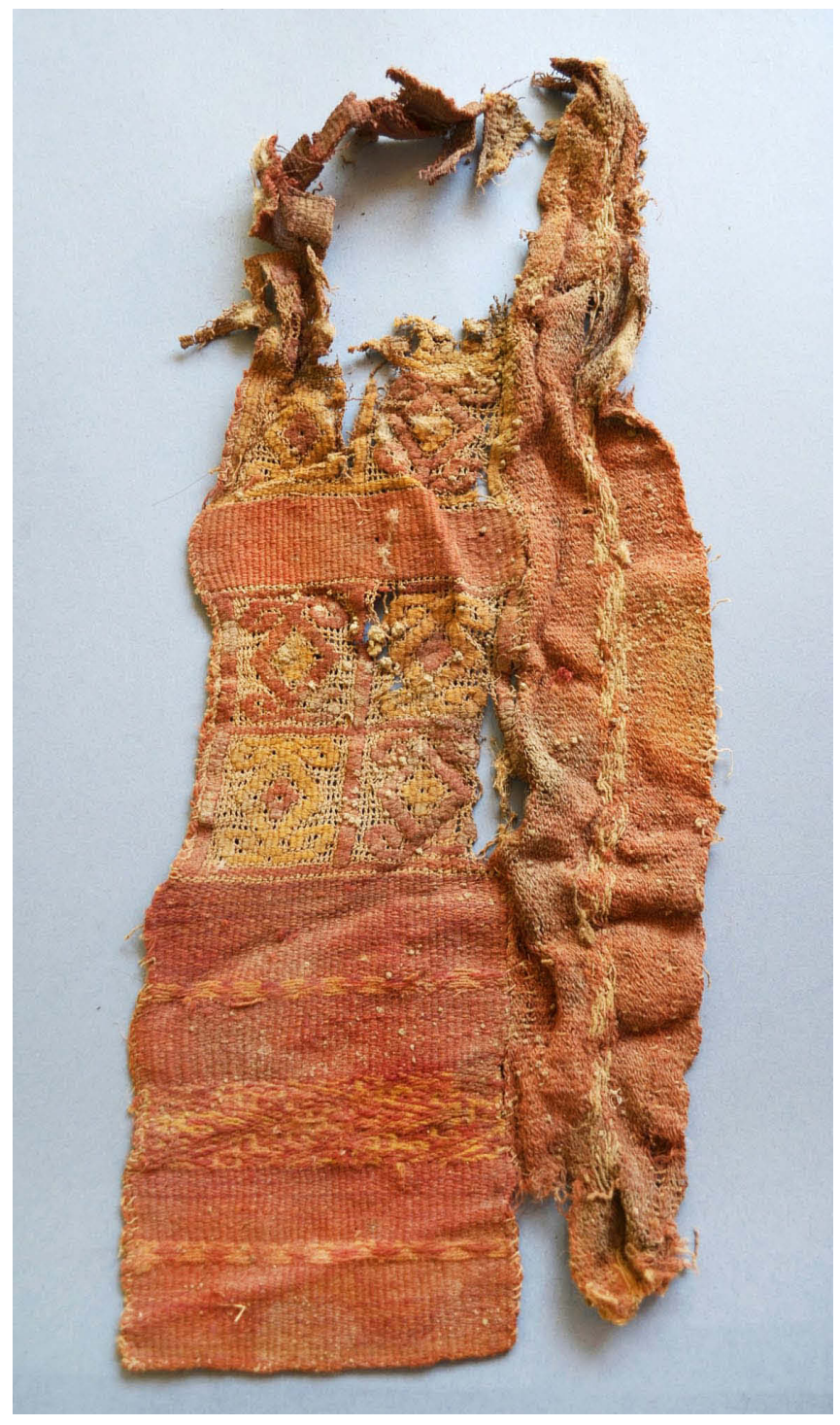

Figura 11. Banda en patrón de trama y urdimbre, combina las estructuras: cara de trama, tramas complementarias, cara de urdimbre, urdimbre flotante, gasa y bordado (espécimen [B.047] U4/CC:16I/C:C) (Foto Arabel Fernández. Publicado Fernández 2019, Fig. 19).

c) Pueden llevar una franja complementaria de diseño escalonado;

d) Presentan siempre el orillo tubular.

A nivel estructural verificamos tela llana 2/1, brocado de tramas suplementarias continuas y cara de trama. Solo dos ejemplares presentaron asa, hecha en un tejido tubular (Figura 12). Sin excepción alguna, los hilos de urdimbre y trama de algodón presentan torsión en S, mientras que las tramas suplementarias corresponden a hilos de fibra de camélido de color rojo, marrón, amarillo y morado; pueden ser hilos simples $(Z)$ o retorcidos (2S-Z).

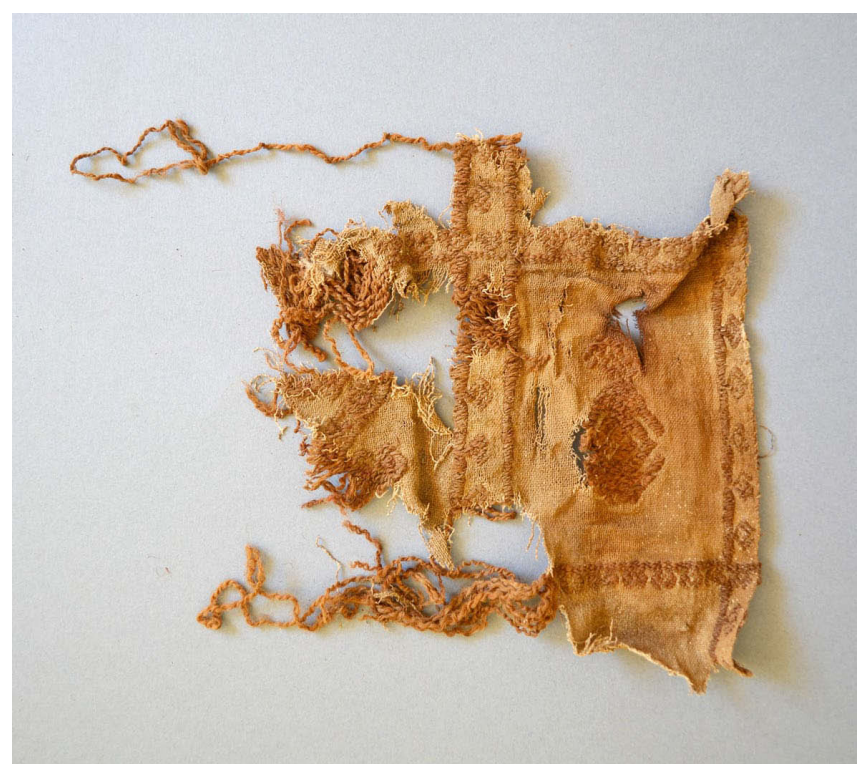

Figura 12. Fragmento textil que muestra la cuadrícula formada por medio de tramas suplementarias con diseño interior inscrito (espécimen [B.o89] U3/CC:10G/CF-56/C:G) (Foto Arabel Fernández. Publicado Fernández 2019, Fig. 21).

Otro tipo de bolsa en este grupo de accesorios corresponde a una pieza pequeña que no presenta decoración figurativa, sino, más bien, estructural al llevar flecos formados por urdimbres sin tejer, decoración que hemos podido identificar en otros textiles de este estilo. Esta bolsa fue hecha en hilos de algodón de color crema (S), formando una estructura en tela llana $2 / 1$.

\section{Estilo Fortaleza}

Como era de esperarse, entre el material registrado han aparecido nuevas evidencias textiles que difieren en el patrón decorativo, diseños y colores de los reportado para los textiles contemporáneos; ya sea Chimú, hacia el norte; o Chancay, hacia el Sur; así como también del valle Huarmey. Se trataría de un nuevo estilo y, ya que su hallazgo se realizó en este valle, lo hemos denominado Fortaleza. En la medida que no todos los textiles se encuentran completos se han conformado categorías de acuerdo con la forma, conformación o atributos técnico-estructurales.

Tejidos con decoración por teñido en reserva (tiedye): El soporte puede ser tela llana 2/1 o 1/1, de algodón de color crema. En estos tejidos los diseños se consiguen por el teñido en reserva o tie-dye. Se emplearon diferentes tonalidades de tinte de color marrón para crear rombos grandes y pequeños. La disposición de estos últimos dio lugar a motivos geométricos como los ganchos entrelazados, entre los cuales aparecen hileras de rombos grandes (Figura 13). Solo 


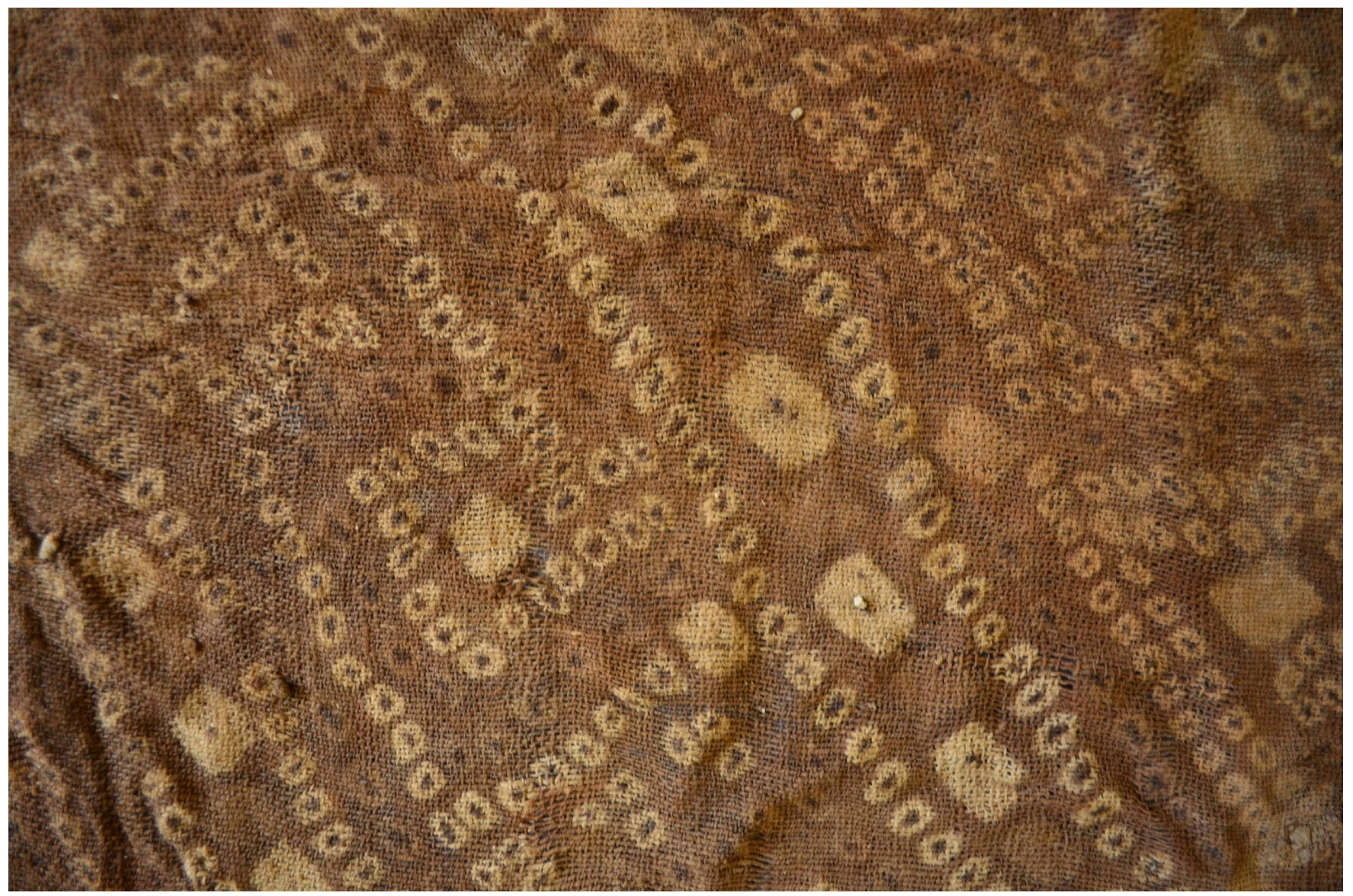

Figura 14. Detalle de diseños en tie-dye (espécimen [B.068] U3/CC:10E,10F,11E,11F/CF-14/C:E) (Foto Arabel Fernández. Publicado Fernández 2019, Fig. 24).

en un caso se reportó que el textil lleva cosida una banda con flecos, accesorio decorativo particular de los tejidos chimú, que, asumimos, sería una influencia en los tejidos locales. Entre los hallazgos relevantes uno de los entierros (contexto funerario 6) reporto una figurina antropomorfa hecha de fibra vegetal, retazos textiles y cabellos humanos, la cual se encuentra vestida con un retazo de tela con decoración en tie-dye. El retazo se adaptó al cuerpo de manera irregular, aunque no están bien definidas las aberturas, al parecer hubo la intensión de representar una camisa (Soto et al. 2019:128-129)

Tejido en tapiz: se registró una banda incompleta, elaborada íntegramente en tapiz ranurado. Lo interesante de este textil es que no solo comparte el diseño - ganchos entrelazados- de los tejidos en tie-dye, sino que también trata de simular la conformación de estos por medio de pequeños cuadrados con punto central (Figura 14).

Tejidos de bandas y paneles polícromos: se registraron fragmentos conformados a partir de la unión de bandas decorativas en cara de urdimbre con diseños en urdimbres flotantes o complementarias, entre las cuales se cosieron finas bandas de urdimbres discontinuas que forman módulos de color azul, marrón, crema y verde (Figura 15). Dentro de esta categoría también incluimos el tejido registrado en el entierro U1-CF-11.

Tejidos de bandas y paños monocromos: corresponden a mantos de fina y elaborada confección. Como el nombre lo indica, estos tejidos parten de la unión de bandas con patrón de urdimbre o de trama y paños rectangulares de color marrón elaborados en tela llana 1/1. El cuerpo principal del atuendo se constituye a partir de la unión alternada de estos tejidos; asimismo, a lo largo de esta conformación inicial, en ambos lados, se cosieron bandas similares a las del panel central. La decoración de las bandas parte de la combinación de estructuras en cara de trama y tramas complementarias, o cara de urdimbre y urdimbres complementarias. Estas bandas, además, presentan flecos laterales que forman grupos o estructuras escalonadas.

Tejidos con decoración de cuadrilé y urdimbres flotantes: se cuenta con fragmentos y piezas incompletas que corresponden a paños. Presentan decoración de listas de urdimbres y tramas de color azul, marrón y crema, cuyo cruce 


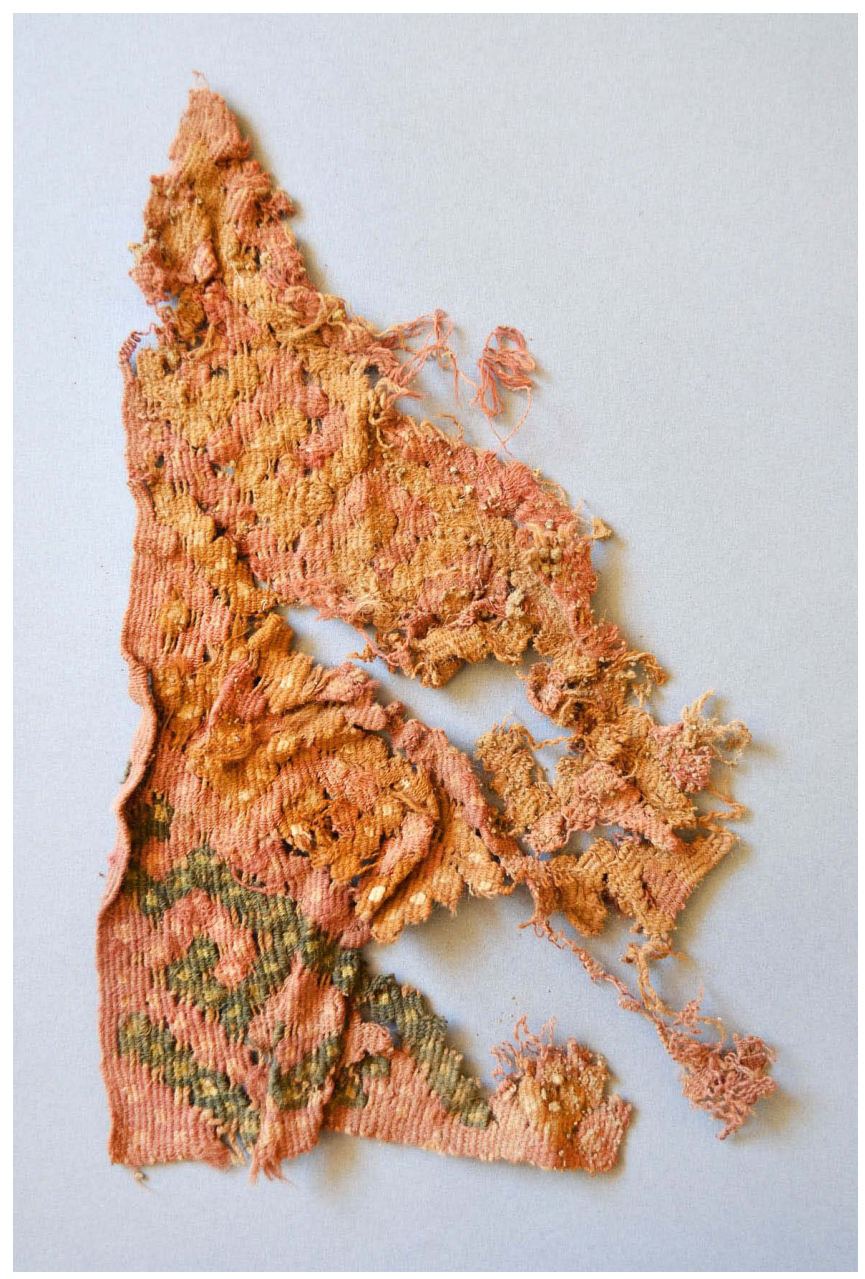

Figura 15. Banda en tapiz (espécimen [B.022] BU2/CC:9D/C:C) (Foto Arabel Fernández. Publicado Fernández 2019, Fig. 25).

al momento de tejerse da origen a una decoración de cuadrículas multicolores o cuadrilé; además de esto, se formaron listas de urdimbres flotantes que reproducen diseños geométricos. Estas listas pueden cubrir el ancho de la tela o aparecen de manera restringida en los orillos laterales. Estos tejidos se caracterizan, además, por estar elaborados íntegramente con hilos de algodón.

Tejidos elaborados en gasa y tela llana: se cuenta con fragmentos, paños y mantos incompletos. Presentan decoración elaborada exclusivamente bajo la técnica de gasa simple; los diseños geométricos pueden cubrir toda la superficie del textil o formar franjas en los bordes de urdimbre, entre los que se han identificado olas entrelazadas. Los diseños en gasa aparecen en combinación con estructuras en tela llana 1/1. Estos tejidos se elaboran con hilos de algodón de color marrón y crema. Como ya se había comentado líneas arriba, estos tejidos en gasa se distinguen de aquellos elaborados por los tejedores chancay, con lo que constituyen un estilo propio de estos valles del Norte Chico.

\section{Estilo Chimú}

Los tejidos chimú identificados ${ }^{11}$ en la muestra representan un grupo poco numeroso, considerando la información que se tiene respecto a su presencia en el valle del Fortaleza. Destaca, sin embargo, un fino manto incompleto decorado en la técnica tie-dye que muestra una escena compleja en la cual se ha podido identificar un personaje antropomorfo con tocado en forma de medialuna, un accesorio indicador de alto estatus social entre los señores chimú.

Otro ejemplar característico en la textilería chimú son los mantos o paños monocromos decorados con bandas de flecos. En la muestra se registraron al menos tres tejidos con estos rasgos.

\section{Estilo Chancay}

En la textilería chancay se distinguen los tejidos con decoración en tapiz ranurado y excéntrico, estructuras que formaron espacios decorativos en los bordes de urdimbre; en las esquinas de los mantos dan lugar a espacios escalonados. Los diseños frecuentes son aves y peces entrelazados. Lengüetas o flecos tejidos en cara de trama complementan la decoración (Figura 16).

Asimismo, los tejidos fueron elaborados con hilos simples (S) y/o retorcidos (2Z-S). Esto, probablemente, dependía del uso y función de las telas. Los mantos y los tejidos en tapiz fueron hechos con urdimbres retorcidas 2Z-S (elemento diagnóstico). Los hilos retorcidos fueron empleados para tejer mantos; estos presentan una estructura en tela llana $1 / 1$ cara de urdimbre y urdimbres complementarias, lo cual permite identificar cómo algunos fragmentos formaron parte de este componente estilístico.

\section{Estilo Serrano}

Los tejidos de este estilo se caracterizan por estar elaborados íntegramente con hilos de fibra de camélido. Asimismo, se trata de tejidos con patrón de urdimbre. Entre las estructuras se identificaron: cara de urdimbre, urdimbres complementarias y urdimbres discontinuas. Se registró una gran variedad de formas entre las que podemos mencionar: unkus o camisas (Figura 17), paños, fajas, cintas y bolsas.

11. La identificación de este estilo se sustenta en las investigaciones realizadas por Ann Rowe (1980, 1984), quien tuvo como muestra base los tejidos recuperados en la plataforma funeraria de Las Avispas en Chan Chan. 


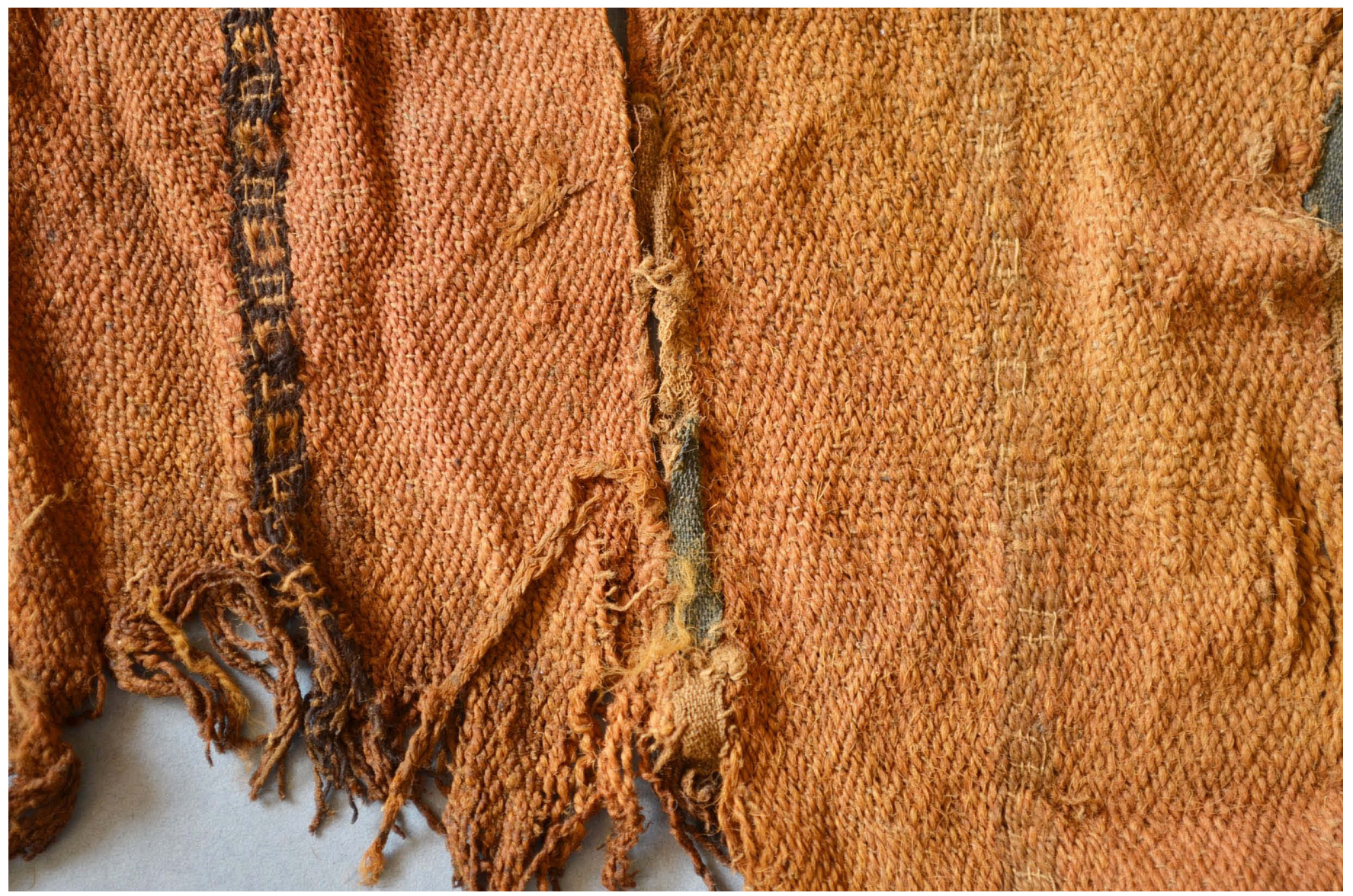

Figura 16. Detalle del textil conformado por bandas en patrón de urdimbre y urdimbres discontinuas (espécimen [B.oo4)] U3/CC:11D/ ED-3/C: Disturbada) (Foto Arabel Fernández. Publicado Fernández 2019, Fig. 26).

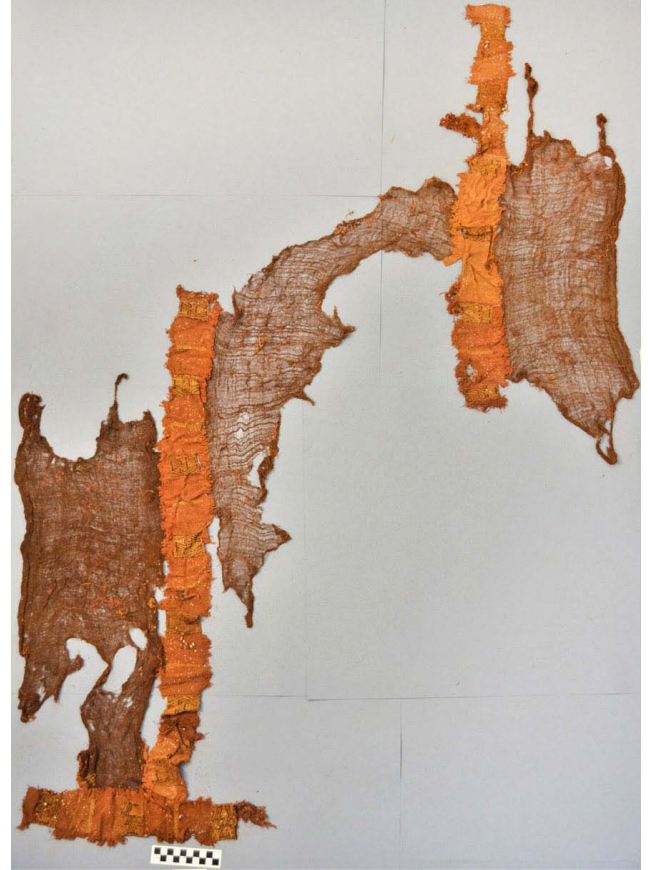

Figura 17. Manto incompleto conformado por paños y bandas (espécimen [B.83] U4/CC:15E/CF-64/C:M) (Foto Arabel Fernández. Publicado Fernández 2019, Fig. 27).

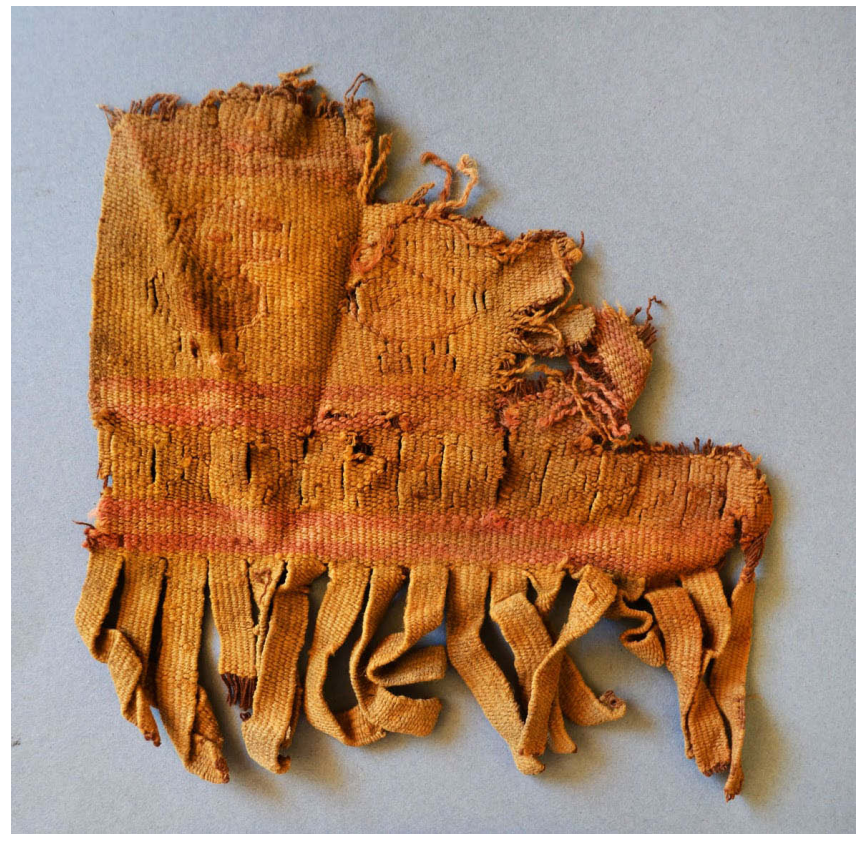

Figura 18. Esquina de manto con espacio escalonado y diseños de aves. Se observan, además, las lengüetas a manera de flecos (espécimen [B.o80] U3/CC:13F/C:E) (Foto Arabel Fernández. Publicado Fernández 2019, Fig. 36). 


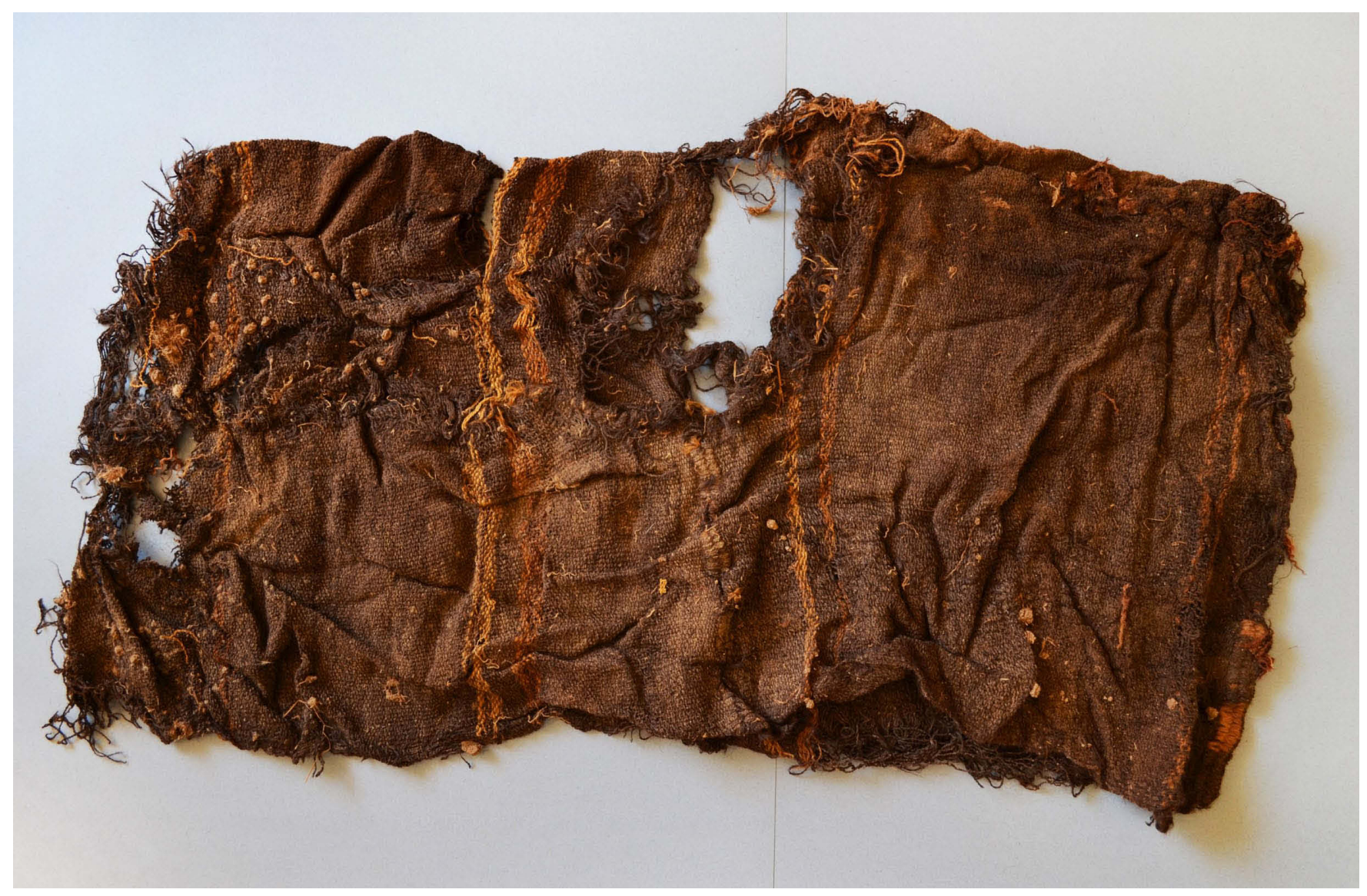

Figura 19. Unku corto, con decoración listada y bordado polícromo (espécimen [B.052] U1/CC:4D/CF-30/C:L) (Foto Arabel Fernández. Publicado Fernández 2019, Fig. 38).

\section{Inca Provincial}

Para este estilo hasta el momento sólo sea logrado identificar un unku o camisa incompleta ${ }^{12}$ (Figura 18). El fragmento conservado presenta una decoración escalonada, elaborada en tapiz entrelazado o trabado, atributos que caracterizan las prendas masculinas de la cultura Inca (Rowe 1999).

\section{Comentarios finales}

Los tejidos de Cerro La Horca constituyen un grupo heterogéneo y particular de estilos desarrollados especialmente durante el Periodo Intermedio Tardío que incluye aquellos de desarrollo local, como los estilos Huarmey y Fortaleza, y otros que vienen del norte, del centro y del este. Estas evidencias constituyen una prueba de la presencia multiétnica en el valle bajo del río Fortaleza.
En esta confluencia de estilos, los tejidos serranos resultaron ser los más conservadores, con atributos fáciles de identificar, mientras que los estilos procedentes de los llanos costeros mostraron ser más permeables a los cambios por contacto con las poblaciones aledañas. Por mucho tiempo prevaleció la idea que este valle se encontró ocupado por pobladores provenientes del reino chimor, el mismo que posteriormente fue conquistado por los Incas, sin embargo, las evidencias textiles en conjunto con la cerámica permiten sostener que pobladores de la costa central también llegaron a habitar esta región del Norte Chico, corroborándose lo anotado por el cronista Garcilaso de la Vega.

La cerámica asociada a los entierros, así como la procedente de contextos disturbados, corresponde a los estilos Lambayeque, Chimú, Casma, Chancay-Pativilca y Pativilca. Este último sería el estilo que caracterizó a esta región y, al cual, además, estamos vinculando el estilo textil Fortaleza, mientras que el estilo textil Huarmey estaría vinculado a la cerámica de estilo Casma. 


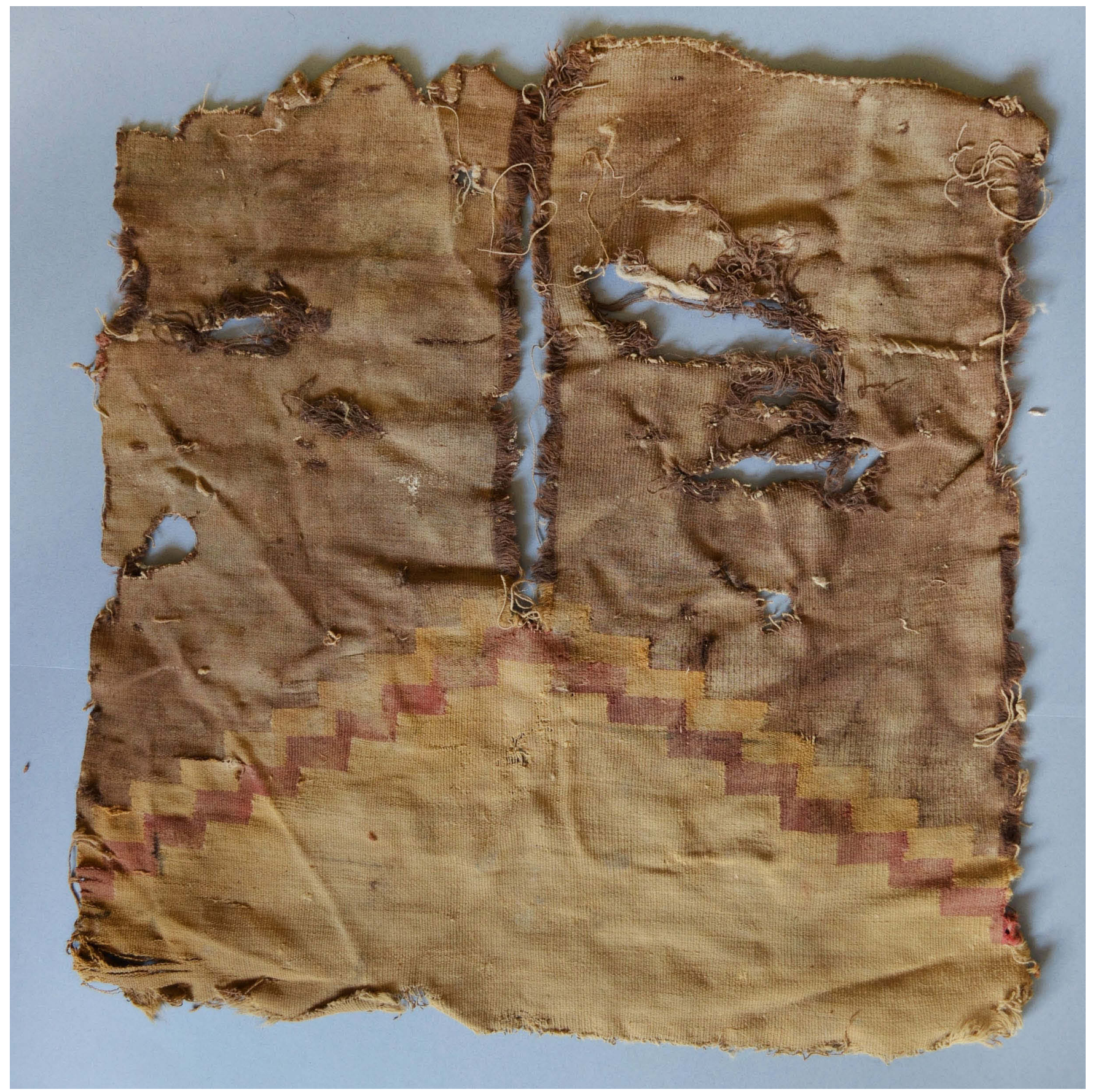

Fig. 2o. Fragmento unku en tapiz trabado. Probablemente fue parte de una camisa (espécimen [B.o26] U1/CC:4B/C:C) (Foto Arabel Fernández. Publicado Fernández 2019, Fig. 44).

Con respecto a las evidencias de estilo Inca en Cerro La Horca, a pesar lo mencionado en las crónicas y existencia de arquitectura monumental como la Fortaleza de Paramonga, que se encuentra muy cercana a Cerro La Horca, lo recuperado hasta el momento no representa un dato elocuente que nos permita concretar un dialogo de relaciones interculturales durante el Horizonte Tardío, en esta parte del valle bajo del Fortaleza.

\section{Bibliografía}

Castillo, Luis Jaime

2017 La costa norte durante el surgimiento de Pachacamac. En Pachacamac. El Oráculo en el horizonte marino del Sol poniente. Pp. 114-125. Colección Arte y Tesoros del Perú. Banco de Crédito del Perú. Lima. 
Carrión, Cachot

1959 La religión en el Antiguo Perú. Lima. Instituto Nacional de Cultura.

Fernández López, Arabel

2019 Textiles de Cerro La Horca durante el Periodo Intermedio Tardio, valle de Fortaleza. En Rescate Arqueológico Parcial en Cerro La Horca, Red Vial 4, distrito de Paramonga, provincia de Barranca, Lima. Tomo II: Análisis. Ed. Luis Valle, pp. 67-95. Ministerio de Transportes y Comunicaciones, Qetzal y Autopista del Norte.

2015ms. Catalogo de la colección de Tejidos Precolombinos Museo Nacional de la Universidad Nacional de Río de Janeiro. Presentado a la Dirección de Museología del Museo Nacional. Entregado a la dirección del Museo Nacional de la Universidad Federal de Río de Janeiro.

2006ms. Informe Final sobre análisis textil de la colección procedente del Cementerio Gallinazo, Puerto Huarmey. Presentado a la Dirección del Proyecto Arqueológico Cementerio Gallinazo. Entregado a la dirección del proyecto.

1998ms. Informe Final sobre análisis textil de la colección procedente de Punta Lobos, Puerto Huarmey. Presentado a la dirección del Proyecto Arqueológico Punta Lobos. Entregado a la dirección del Proyecto.

Frame, Mary, Francisco Vallejo, Mario Ruales y Walter Tosso 2012 Los textiles Ychsma del Horizonte Tardío en el entierro de Armatambo. En Arqueología y Sociedad, N 24. pp. 437- 478 .

Garcilaso de la Vega, Inca 2005 (1609) Comentarios Reales de los Incas. Libro sexto. Capítulos XXXII y XXXIII. Fundación Biblioteca Ayacucho. Caracas.

King, Heidi

2000 Rain of the Moon. Silver in Ancient Peru. The Metropolitan Museum of Art y Yale University Express.

Kula, Gulli

1991 A study of surface-collected Chancay textiles. En Estudios sobre la cultura Chancay, Peru. Ed. A. Krzanowski. Krakow. pp. 263-284.Universidad Jaguelona.

Lothrop Samuel y Joy Mahler

1957 A Chancay-style grave at Zapallar, Peru: an analysis of its textiles, pottery, and other furnishigs. En Paper of the Peabody Museum of Archaeology and Ethnology, vol. 1, N 1. Harvard University. Cambridge.

Mackey, Carol y Joanne Pillsbury

2013 Cosmology and Ritual on a Lambayeque Beaker. En Pre-Columbian Art and Archaeology. Essay in Honor of Frederick R. Mayer. Ed. Margaret Young-Sánchez. Denver Art Museum. Pp. 115-141.

Menzel, Dorothy

1977 The Archaeology on Ancient Peru and the work of Max Uhle. R.H. Lowie Museum of Anthropology, University of California. Berkeley.

Narváez, Alfredo

2014 Dioses de Lambayeque. Estudio Introductorio de la Mitología Tardía de la Costa Norte del Perú. Ministerio de Cultura del Perú.

Pillsbury, Joanne

2017 Luminous Power: Luxury Arts in the Ancient Americas. En Golden Kingdoms: Luxury Arts in the Ancient Americas, edited by Joanne Pillsbury, Timothy F. Potts, and Kim Richter. Los Angeles: The J. Paul Getty Museum. PP. 1-13

Rowe, Ann

2014 Technical reflections of highland-coastal relationship in late prehispanic tunics from Chillon and Chancay. En Textiles, Technical practice and power in the Andes. Ed. Denise Y. Arnold y Penelope Dransart. pp. 159-189. Archetype Publications.

1996 Central Coast Textiles. En Andean Art at Dumbarton Oaks. V. 2. Ed. Elizabeth Hill Boone. pp. 437-552. Dumbarton Oaks Research Library and Collection Washington, D.C.

1984 Costumes and featherwork of the Lords of Chimor. The Textile Museum, Washington D.C.

1980 The textile from the burial platform of Las Avispas, at Chan-Chan. En: Nawpa Pacha. Vol. 18. University of California, Berkeley. PP.81-150.

John, Rowe

1979 Standardization in Inca tapestry tunic's. En The Junius B. Bird Pre-Columbian Textile Conference, Rowe, A.P., Benson, E.P. and Schaffer, A (eds.). pp. 239-264. The Textile Museum and Dumbarton Oaks. Washington D.C.

Segura, Rafael e Izumi Shimada

2014 La interacción Sicán Medio-costa central, hacia 1000 d.C. En Cultura Sicán. Esplendor Preincaico de la Costa Norte. Ed. Izumi Shimada. pp. 303-322. Fondo Editorial del Congreso del Perú.

Max Schmidt

1929 Kunst y Kultur von Peru. Propyläen-Verlag, Berlin.

Shimada, Izumi

2014 Detrás de la máscara de Oro: La cultura Sicán. En Cultura Sicán. Esplendor Preincaico de la Costa Norte. Ed. Izumi Shimada. Pp. 15-9o. Fondo Editorial del Congreso del Perú. 
1990 Cultural Continuties and Discontinuties on the Northern Coast of Peru, Middle-Late Horizons. En The Northern Dynasties: Kingship and Statecraft in Chimor. A symposium at Dumbarton Oaks $12^{\text {th }}$ and $13^{\text {th }}$ October 1985. Ed. Michael Moseley y Alana Cordy-Collins. pp. 297-392. Dumbarton Oaks Research Library and collection. Washington, D.C.

Shimada, Izumi y César Samillan Torres

2014 Arte, Religión y cosmología de Sican Medio: Nuevos Enfoques. En Cultura Sicán. Esplendor Preincaico de la Costa Norte. Ed. Izumi Shimada. pp. 169-194. Fondo Editorial del Congreso del Perú.

Soto V., Alejandro, Sonia Rodríguez y Luis Valle

2019 Catálogo Cerro la Horca. En Rescate Arqueológico Parcial en Cerro La Horca, Red Vial 4, distrito de Paramonga, provincia de Barranca, Lima. Tomo IV: Catálogo. Ed. Luis Valle. Ministerio de Transportes y Comunicaciones, Qetzal y Autopista del Norte.

Valle A., Luis, José Montalvo y Daniela Touzet Málaga 2019 Excavaciones arqueológicas en Cerro la Horca, valle de Fortaleza. En: Rescate Arqueológico Parcial en Cerro La Horca, Red Vial 4, distrito de Paramonga, provincia de Barranca, Lima. Tomo I: Excavaciones. Ministerio de Transportes y Comunicaciones, Qetzal y Autopista del Norte.
Vega-Centeno, Rafael

2004 Arquitectura pública del Arcaico Tardío en el valle de Fortaleza. Reflexiones sobre las sociedades tempranas en la Costa Nor Central. En: Arqueología y Sociedad 15. Pp. 29-56

Vega-Centeno, Rafael, María del Carmen Vega y Patricia Landa.

2006 Muertes violentas en tierras de ancestros: Entierros tardíos en Cerro Lampay. En Arqueología y Sociedad. $\mathrm{N}^{\circ}$ 17. Pp. 255-272

Vega Centeno, Rafael, Luis F. Villacorta, Luis E. Cáceres y Giancarlo Marcone

1998 Arquitectura Monumental Temprana en el valle medio de Fortaleza. En Boletín de Arqueología PUCP, $\mathrm{N}^{\circ} 2$. Pp. 219-238.

Wester, Carlos

2012 Sacerdotisa Lambayeque de Chornacap. Una nueva visión de la cultura Lambayeque. Unidad Ejecutora oo5 Naylamp-Lambayeque y Museo Arqueológico Nacional Brunning de Lambayeque.

Wiener, Charles

1880 Pérou et Bolivie. Récit de voyage. Paris. Librairie Hachette Et. 


\title{
La Momia de Marburg: su recontextualización a través del ajuar y ofrenda textil
}

\author{
Isabel Martínez Armijo \\ Anna-Maria Begerock \\ Mercedes González
}

Isabel Martínez Armijo Responsable del Departamento de Análisis de Textil Arqueológico - Instituto de Estudios Científicos en Momias-IECIM- C/Cetrería, 24-28232 Las Rozas-Madrid, España (imartinez.iecim@gmail.com, Isabel Martínez Armijo) Dra. Anna-Maria Begerock Responsable del Departamento de Arqueología Andina -IECIM (abegerock.iecim@gmail.com) Mercedes González Presidenta del Instituto de Estudios Científicos en Momias -IECIM (mgonzalez.iecim@gmail.com)

\begin{abstract}
Resumen
El análisis textil es un aporte fundamental para la recontextualización de individuos momificados y dentro de este contexto un caso interesante es el de la momia exhibida en el Museo del Instituto de Anatomía de la Universidad de Philipps, Marburg, Alemania. Este individuo, de sexo masculino, confirmado por la tomografía computarizada realizada en el año 2018, y acompañado de un ajuar textil y diversas ofrendas, se encuentra en relativas buenas condiciones de conservación y, de acuerdo a la escasa información disponible, habría ingresado a dicha institución alrededor de 1892-1893 procedente de la ciudad de Arica.

En este trabajo se presentan los resultados del análisis de los textiles que forman parte del ajuar y la ofrenda asociadas a dicha momia, los cuales presentan la característica composición espacial, técnica de confección, materia prima, colores e iconografía de los tejidos de la cultura Arica (ca. 1000-1470 d.C.) que se desarrolló en la costa y valles de Arica en el norte de Chile en el período Intermedio tardío. La importancia de este estudio recae en que estos tejidos permitieron recontextualizar el conjunto a la sociedad de la cual formó parte y dar luces sobre el status o rol que pudo tener este individuo en vida.
\end{abstract}

Palabras claves: Cultura Arica, momias, ajuar funerario, ofrendas, recontextualización

\begin{abstract}
Textile analysis is a fundamental contribution to the recontextualization of mummified individuals. Within this context, the mummy exhibited in the Museum of the Institute of Anatomy of the University of Philipps, Marburg, Germany presents an interesting case. This male individual, confirmed by the CT scan made in 2018, received textile grave goods and various other offerings - all in good condition. According to the limited information available, the mummy and funerary goods are from Arica and entered the institution's collection around 1892-1893.

This paper presents the results of the analysis of the textiles that are part of the grave goods associated with this mummy. They present the characteristic spatial composition, manufacturing technique, raw material, colours and iconography of the Arica culture textiles that developed on the coast and valleys of Arica in northern Chile in the Late Intermediate Period (ca. 1000-1470 AD). The importance of this study lies in the fact that these textiles allowed a recontextualizing of the individual into the society to which it was a part and shedding light on the status or role that this individual could have in life.
\end{abstract}

Keywords: Arica Culture, Mummies, Grave Goods, Offerings, Recontextualization

DOI: $10.32873 /$ unl.dc.zea.1208

Published in PreColumbian Textile Conference VIII / Jornadas de Textiles PreColombinos VIII, ed. Lena Bjerregaard and Ann Peters (Lincoln, NE: Zea Books, 2020). https://digitalcommons.unl.edu/zeabook/ 


\section{Résumé}

L'analyse textile est une contribution fondamentale pour la recontextualisation des individus momifiés. Dans ce contexte, la momie conservée au Musée de l'Institut d'Anatomie de l'Université de Philips, Marburg, en Allemagne présente un cas intéressant. Cet individu de sexe masculin, confirmé par un CT scan réalisé en 2018, et accompagné de textiles et de diverses offrandes, a été découvert dans un état de conservation relativement bon. Selon le peu d'information disponible, la momie et ses offrandes proviennent d'Arica et sont entrées dans la collection de l'institut autour de 1892-1893.

Cet article présente les résultats de l'analyse des textiles qui composent le mobilier associé à la momie, lesquels présentent une composition spatiale caractéristique, une technique d'élaboration, des matières premières, des couleurs et une iconographie des tissus propre de la culture Arica (ca. 1000-1470). L'importance de cette étude repose sur ces tissus qui ont permis de recontextualiser l'ensemble, soit à la société à laquelle il appartenait soit d'éclairer le statut ou le rôle que cet individu aurait pu avoir durant sa vie.

Mots-clés: Culture Arica, momies, trousseau textile, offrandes, recontextualisation

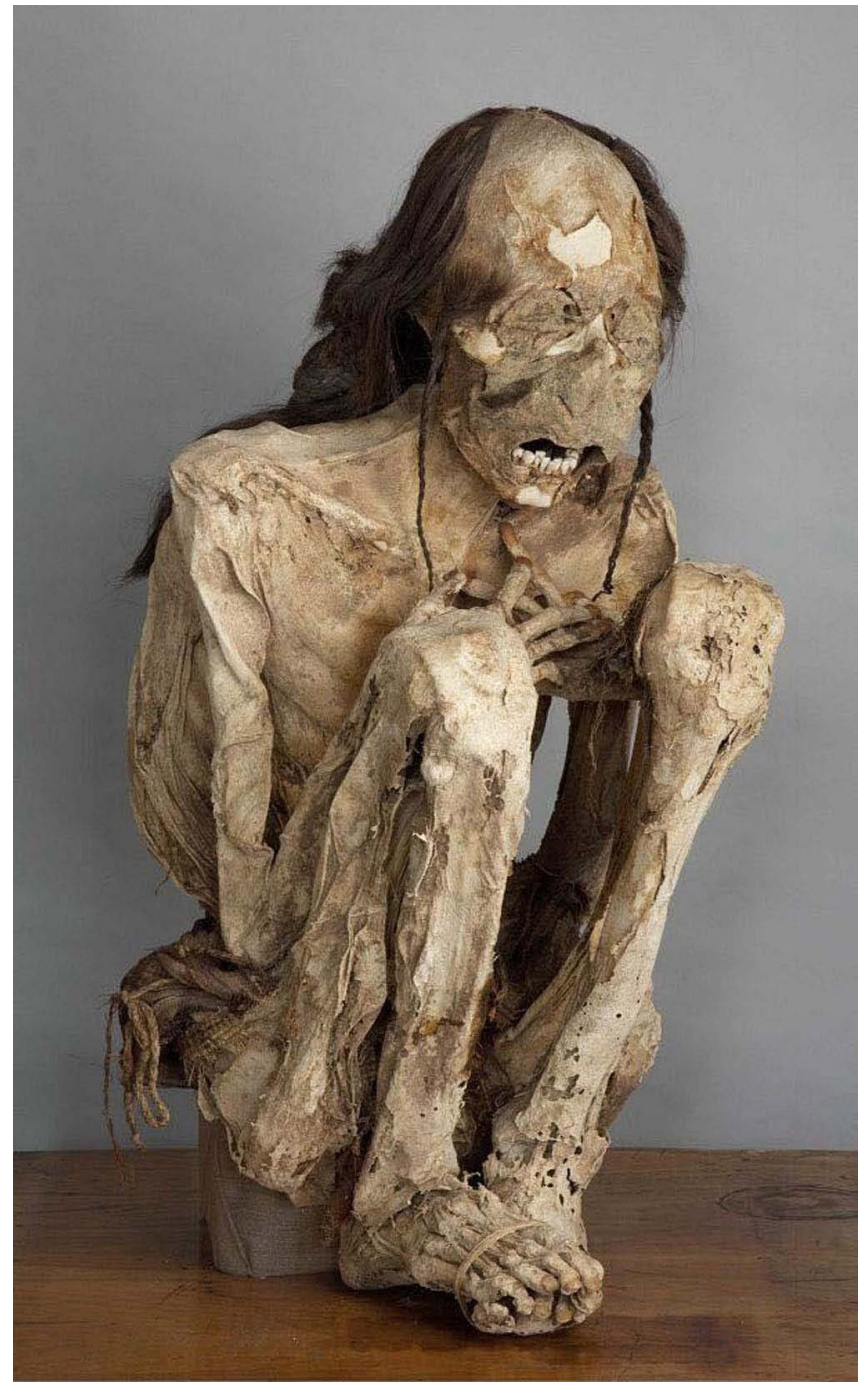

Figura 1. Vista frontal de la momia de Marburg (Fotografía AnnaMaria Begerock, 2016-2018).

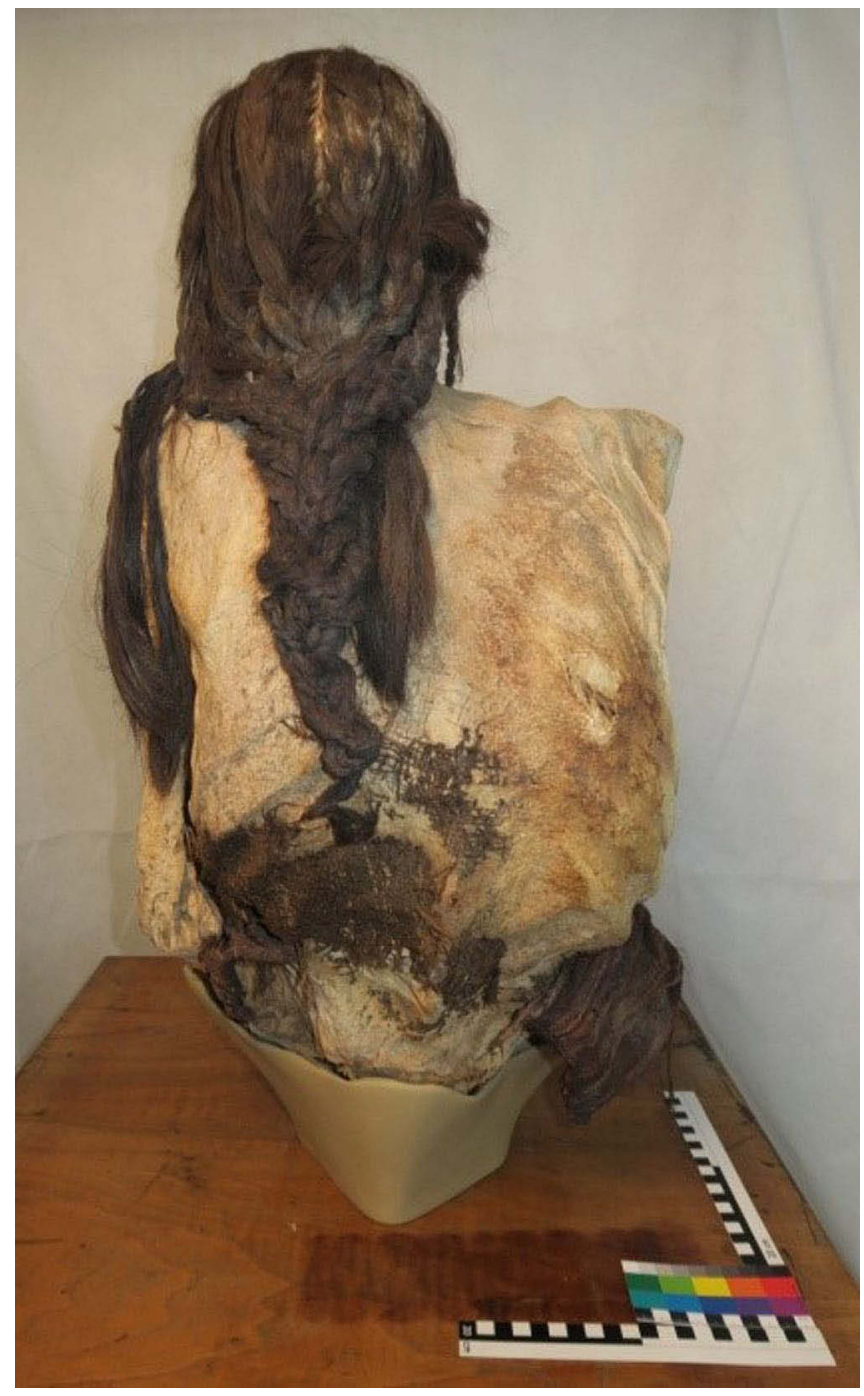

Figura 2. Vista posterior de la momia de Marburg (Fotografía Anna-Maria Begerock, 2016-2018). 
En el presente trabajo se expone parte de los resultados del análisis de los textiles del ajuar de la momia de Marburg, que pertenece a la colección del Museum Anatomicum de la Philipps Universität, Marburg, Alemania y que habría ingresado a dicha institución alrededor de 1892-1893, como regalo del fisiólogo Rudolph Eduard Külz, quien trabajaba en la Universidad de Marburg. En aquella ocasión fue presentada como una momia femenina -por su larga cabellera y su peinado de múltiples trenzas- procedente de la ciudad de Arica, con una gran cantidad de ofrendas asociadas. En el año 2016 la arqueóloga Dra. Anna-Maria Begerock tuvo la oportunidad de analizarla, constatando que corresponde a un individuo masculino(1), encontrándose en su conjunto en relativas buenas condiciones de conservación. Se halla en una posición sentada con las piernas fuertemente flexionadas hacia el pecho, con el pie derecho sobre el izquierdo, así como la mano derecha sobre la izquierda apoyadas en la parte alta del tórax (Figuras 1 y 2). Forman parte de la ofrenda, una serie de objetos de madera característicos de la ergología marítima de las poblaciones que habitaron la costa norte de Chile y sur del Perú durante el período Intermedio tardío, tales como cabezales de arpón, un capacho en miniatura y restos de una posible balsa de tres palos con franjas paralelas realizadas con pigmento rojo, así como cerámica no decorada y cuatro textiles completos, entre otros (Figuras 3 y 4). Directamente asociados al cuerpo se hallan los textiles que forman el ajuar.

Por los antecedentes a disposición respecto a la procedencia del conjunto funerario, así como por sus características generales, fue posible adscribirlo preliminarmente al período Intermedio tardío (ca. 100o-1470 d.C.) de la zona de Arica, extremo norte de Chile.

Siendo un conjunto funerario descontextualizado, el análisis de los componentes de su ajuar y ofrenda son de fundamental apoyo para su recontextualización. La iconografía plasmada en los textiles nos entrega valiosa información para determinar la filiación cultural a la cual pertenecieron, circunscribir temporal y geográficamente el contexto y más específicamente permite acercarnos a la cosmovisión de las poblaciones que los crearon y usaron.

\section{Textiles del Ajuar}

Las piezas textiles presentan de un regular a mal estado de conservación. Sin embargo, fue posible identificar el tipo de textil por la técnica, la forma, las terminaciones y la
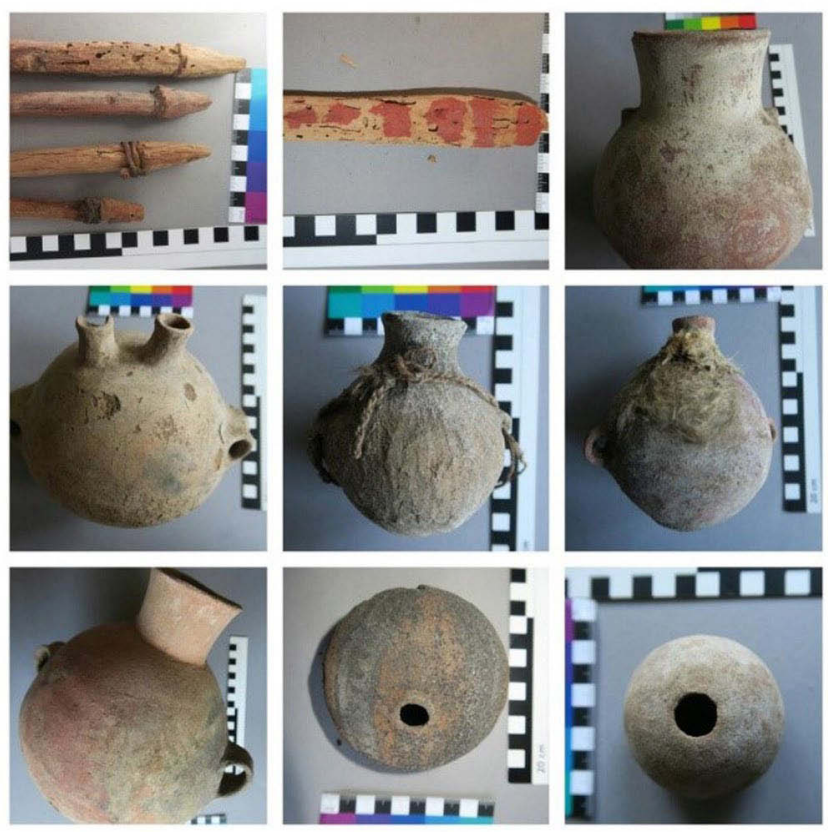

Figura 3. Parte de los objetos suntuarios que forman la ofrenda (Fotografías Anna-Maria Begerock e Isabel Martínez A., 2018).
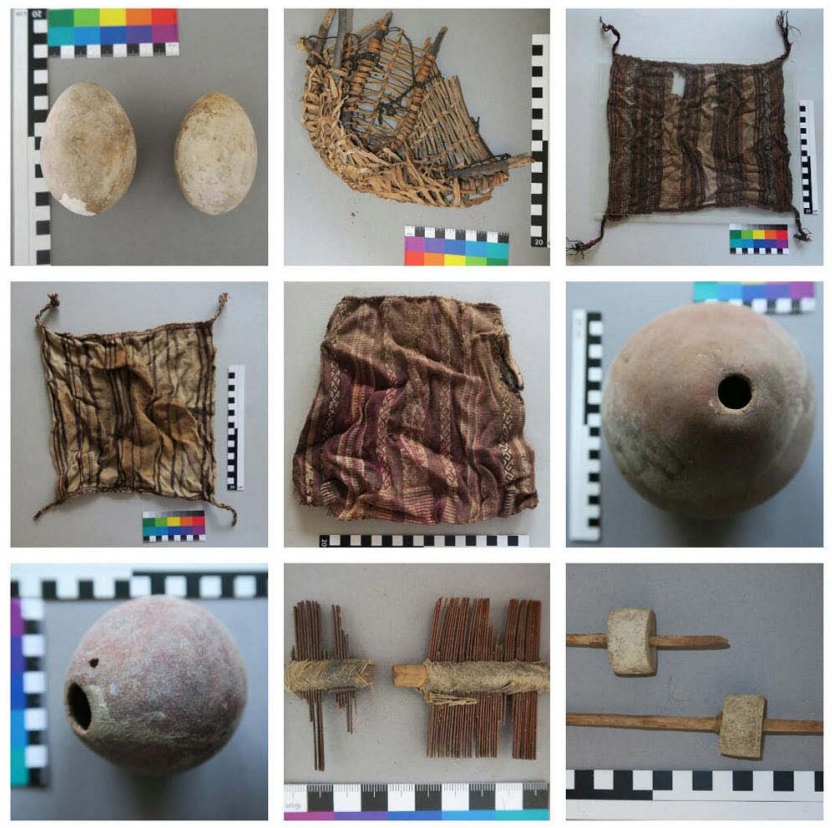

Figura 4. Parte de los objetos suntuarios que forman la ofrenda (Fotografías Anna-Maria Begerock e Isabel Martínez A., 2018).

1. Lo corroboran también el peinado, que corresponde al tipo $3 \cdot 3$ de la

clasificación de peinados precolombinos realizada por Bernardo Arriaza y colaboradores (1986:357), que se asocia a individuos masculinos del periodo Intermedio Tardío de la zona de Arica, y la tomografía axial computarizada realizada el 5 de junio de 2018 en la Universitätsklinikum, Marburg, Alemania. 

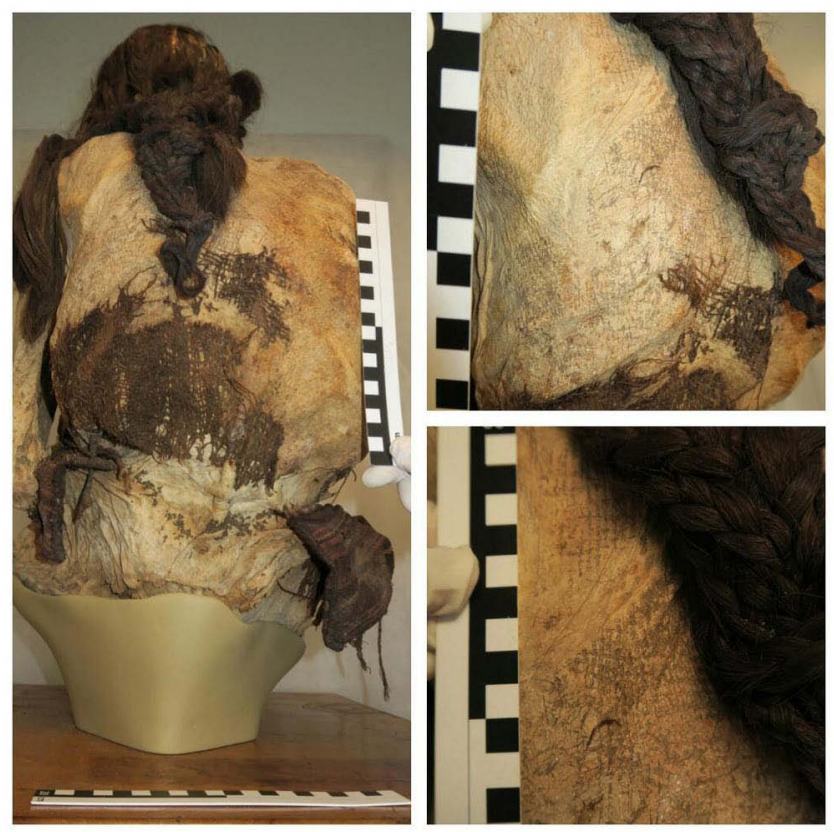

Figura 5. Vista de los restos e improntas en la piel de un unku que cubría el cuerpo del individuo (Fotografías Isabel Martínez A., 2018).

composición espacial. Todos estos tejidos fueron hechos con pelo de camélido y en el caso de la prenda con motivos, los apéndices son en fibra de algodón.

En la zona de la espalda se identificaron los restos de un unku de color natural café oscuro con franjas y/o listas en color crema, que cubría casi todo el cuerpo, que además dejó marcadas improntas en la piel (Figura 5). Esta pieza fue confeccionada con la técnica de tejido llano $2 \times 2$.

En la rodilla derecha y dorso de las manos, así como en ciertas zonas de las piernas, se observan los restos de otro textil, probablemente un segundo unku, de color café oscuro con listas y franjas en color crema, de factura más fina y realizado con la técnica de faz de urdimbre, que habría recubierto el cuerpo (Figura 6).

Ceñido a la cintura, in situ, se observa un textil de forma rectangular que, por su ubicación y posición en relación al cuerpo del individuo, su forma, terminaciones laterales, composición espacial y técnica de manufactura, corresponde a una bolsa-faja (Figura 7). Este tipo de textil, junto con la chuspa, era un complemento de la vestimenta y consistía en "una pieza rectangular, doblada por la mitad, cosida en tres de sus cuatro costados, aunque dejando en el centro del borde superior una abertura, para facilitar su uso como bolsa, a la vez que faja" (Horta 1997:108, nota ${ }^{\circ} 20$ )
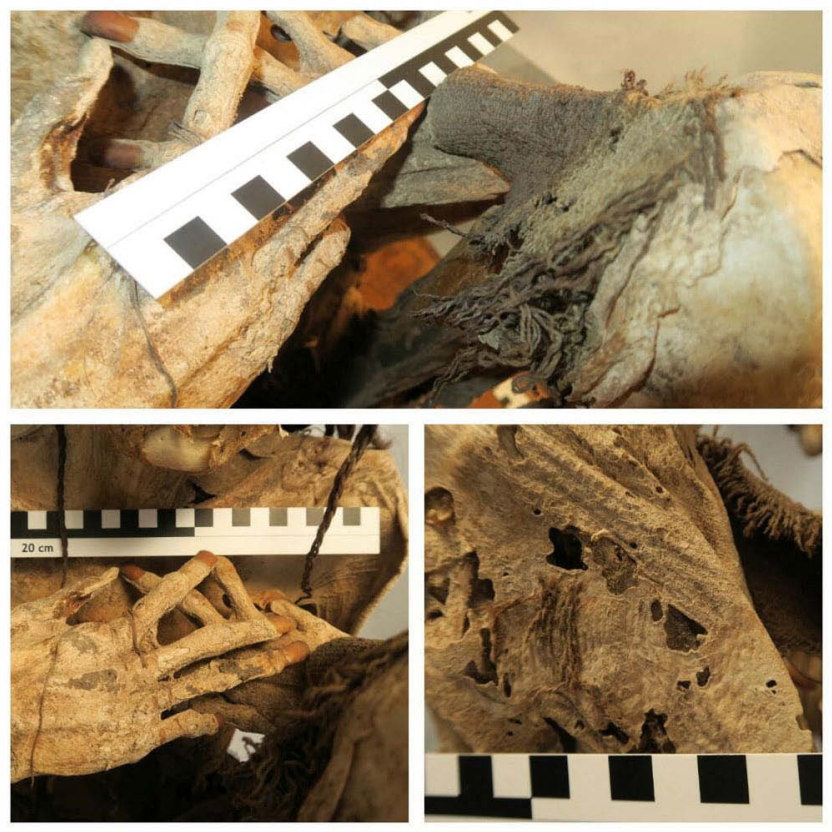

Figura 6. Vista de los restos de otro posible unku que cubría el cuerpo del individuo (Fotografías Isabel Martínez A., 2018).

con cordones que permitían su amarre alrededor de la cintura y en su interior se guardaban hojas de coca (Erythroxylum coca) y llipta(2).

La composición espacial de esta pieza consiste en una serie de franjas en el sentido más largo (horizontal), presentando ambas caras (externa e interna) un patrón distinto. La cara externa se divide en tres zonas o grupos con listas de diversos colores, café, café oscuro, crema y rojo, con diferentes anchos y estructuras, sobre una pampa monocroma de color café oscuro; mientras que la cara interna también es listada en el sentido horizontal de la pieza, pero a diferencia de la cara externa presenta solo dos combinaciones de colores que se alternan, café oscuro y café, con diferentes anchos (Figura 8). En el interior, hacia el borde lateral derecho, se observó una protuberancia indicando que contiene algún elemento y probablemente corresponda a hojas de coca.

El tercer textil que forma parte del ajuar se encontraba en la zona abdominal baja, también in situ, debajo de la bolsafaja, y presenta una rica y variada iconografía. Por su composición espacial, colores y terminaciones, realizadas con la técnica de torzal, es posible identificar esta pieza como una inkuña, la cual fue reutilizada para formar un taparrabo, evidenciado por los dos apéndices presentes en uno de sus

2. Es una masa hecha con una mezcla de cal y ceniza para potenciar la extracción del alcaloide de la hoja de coca. 

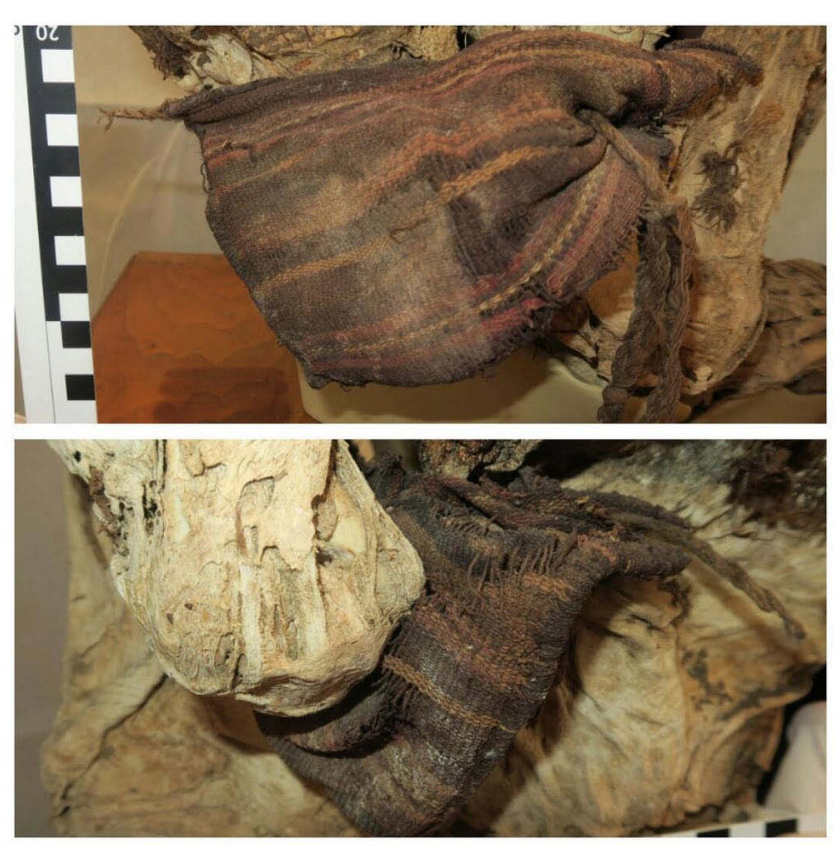

Figura 7. Vistas laterales derecha e izquierda, respectivamente, del cuerpo del individuo donde se aprecian los bordes laterales de la bolsa-faja aún ceñida a la cintura (Fotografías Isabel Martínez A., 2018).

bordes largos y por su ubicación en el cuerpo (Figura 9). Esta prenda, de forma cuadrangular o trapezoidal, se colocaba entre las piernas sujeta a la cadera mediante los cordones laterales. Según Horta (2005:17), no habría formado parte de la indumentaria de la cultura Arica por ser muy escaso y habría sido una manifestación foránea, sobre todo hacia finales del Intermedio tardío.

La inkuña (Quechua) o tari (Aymara) formaba parte de la indumentaria andina prehispánica del norte de Chile en el período Intermedio tardío y consiste en tejido:

"cuadrangular, cuyas dimensiones no superan los 45-6o cm. Las orillas de urdimbre presentan una terminación muy característica llamada 'trama en torzal' que se prolonga en las cuatro esquinas del textil, en forma de asas. En su gran mayoría son decoradas verticalmente con listas lisas de variados colores y franjas con diseños en la técnica de urdimbres complementarias" (Horta 2005:18)

Estas formaban un bulto amarrando sus cuatro esquinas, en cuyo interior se colocaban hojas de coca.

La decoración textil de esta pieza se da al interior de dos franjas verticales modulares, con una más ancha central, intercaladas por tres pares de listas monocromas en ocre, azul y

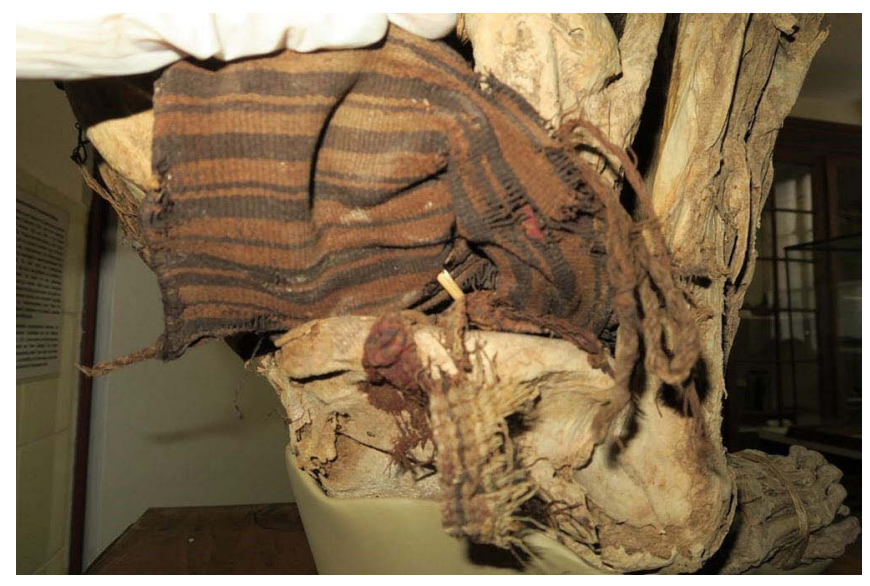

Figura 8. Vista de la cara interna listada de la bolsa-faja (Fotografía Anna-Maria Begerock, 2016).

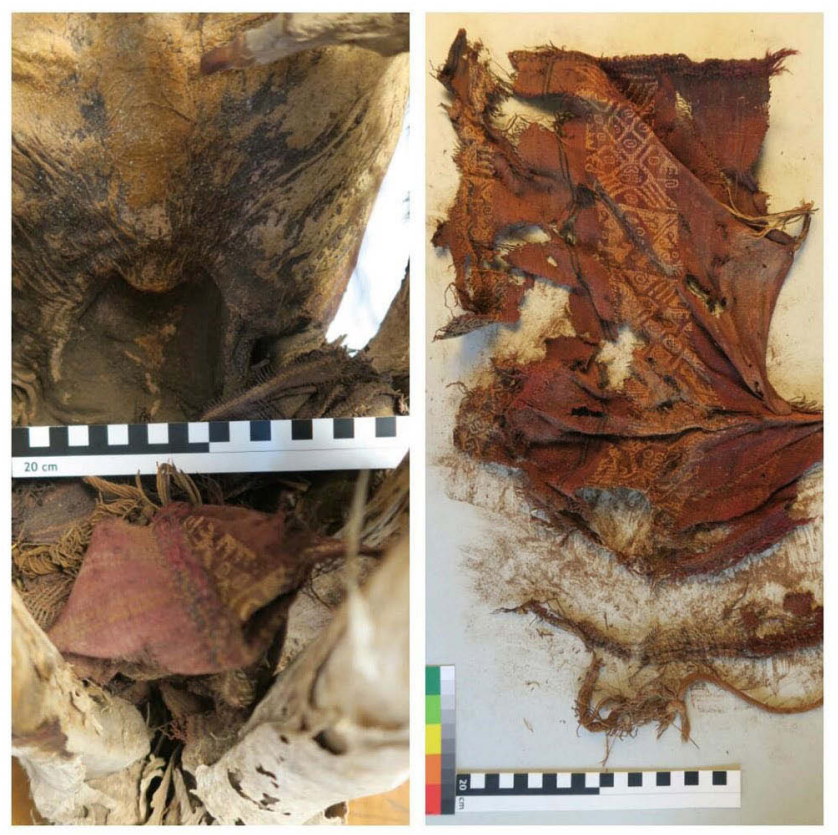

Figura 9. Vistas de la inkuña-taparrabo; derecha, in situ en las entrepiernas de la momia e izquierda, extendida (Fotografías Isabel Martínez A., 2018).

gris violáceo, sobre una pampa de color granate. En la franja central es posible observar cuatro módulos de diseño donde las figuras fueron realizadas en hilos de color crema sobre un fondo listado en morado oscuro/morado claro/ocre/morado oscuro/morado claro/morado oscuro/ocre/morado claro/morado oscuro, en su cara 'positiva' y de manera inversa en su cara 'negativa'. El motivo del primer y tercer módulo consiste en un ser antropomorfo rectilíneo bicéfalo con cuatro apéndices cefálicos que se prolongan hacia arriba de la cabeza en dirección diagonal, dos a cada lado de la cabeza, y dos líneas 


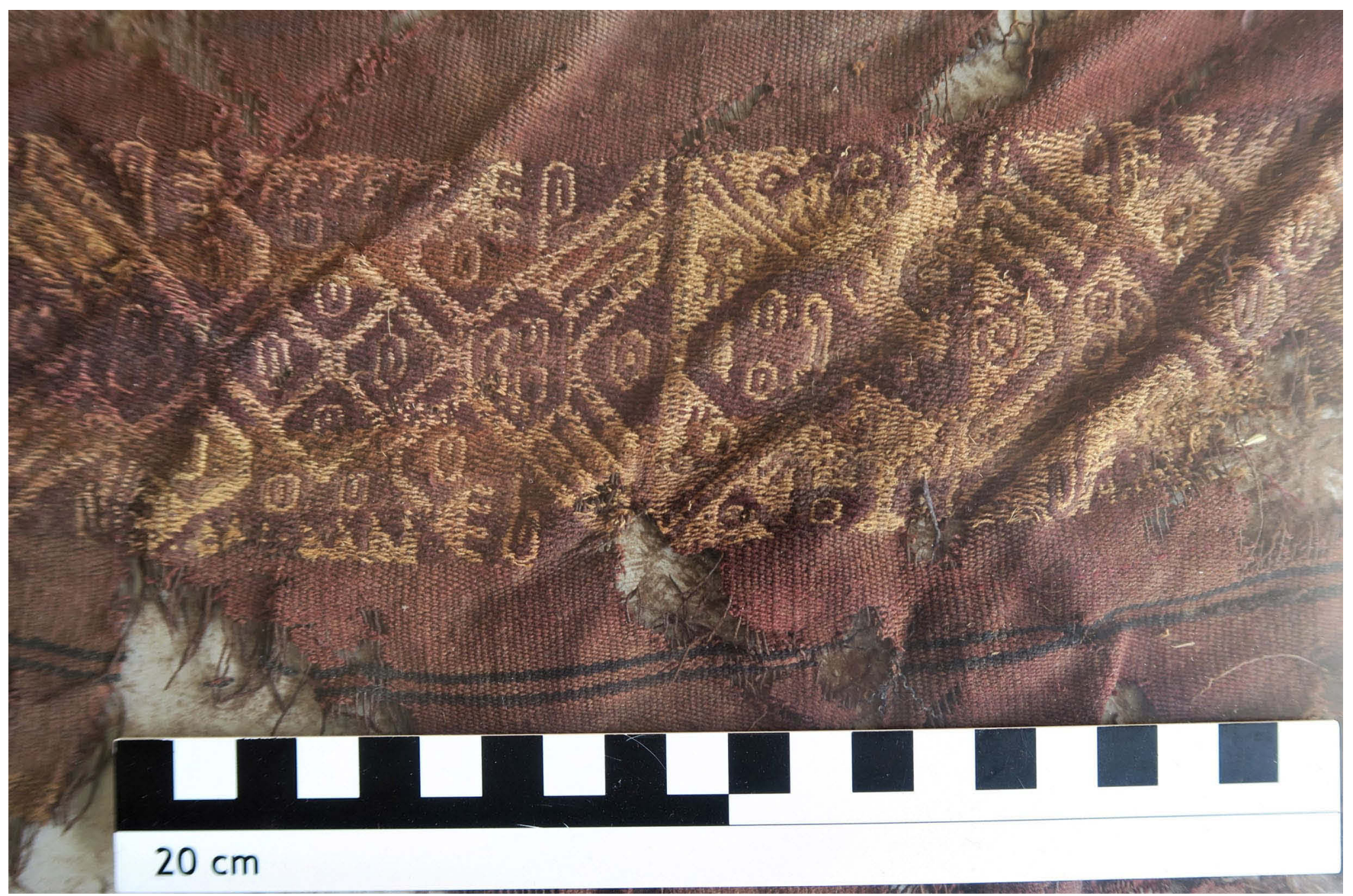

Figura 10. Ser antropomorfo bicéfalo del primer módulo de diseño, arriba y abajo (Fotografía Isabel Martínez A., 2018).

rectas laterales que parten de los apéndices externos y que terminan curvados en espiral hacia arriba. Presenta dos ojos y una boca 'sonriente', en cada una de las caras, y las cuatro extremidades superiores se encuentran flectadas en direcciones opuestas, terminando en una mano con cuatro dedos cada una. El cuerpo es de forma romboidal, cuatripartito con cuatro hexágonos concéntricos. Se observan elementos acompañantes alrededor de la figura que consisten en diez hexágonos concéntricos: uno sobre cada cabeza entre los apéndices cefálicos (total: 2); uno sobre cada una de las extremidades superiores (total: 4); dos a cada lado del cuerpo (total: 4) y dos motivos o bordes 'aserrados', uno a cada lado del cuerpo, en los extremos laterales de la franja (Figura 10). La figura del cuarto módulo corresponde a la mitad exacta de la figura apenas descrita.

En la clasificación de Helena Horta (2005) sobre la iconografía textil de la cultura Arica, esta figura pertenece al Grupo 1 de los antropomorfos, los cuales, "no presentan ni piernas ni pies, sino curiosas extremidades arqueadas que rematan en uno, dos o tres ganchos" (Horta 2005:30). En relación a los apéndices cefálicos, estos conformarían un tocado erguido de tipo radiado, el más común encontrado en las figuras antropomorfas y para los apéndices laterales que terminan en espiral, esta autora propone que pueden corresponder a orejeras.

En el segundo módulo el motivo principal se asemeja a una cara zoomorfa antropomorfizada, con dos ojos, una boca 'sonriente' y un triángulo truncado en la zona que correspondería a la frente; además de cuatro apéndices laterales finos, dos por cada lado, a nivel de los pómulos que se prolongan hacia arriba en dirección diagonal y otros dos, uno a cada lado, por debajo de los apéndices anteriormente mencionado. Presenta un largo cuello orientado diagonalmente con dos hexágonos concéntricos en su interior. En Horta (2005:60, 77 y 78; Figuras 141 y 144) se registra un motivo de similares características que corresponde a un felino humanizado. Esta figura en la pieza bajo análisis se halla rodeada por cuatro figuras zoomorfas: a) dos a cada lado de la cabeza por sobre los apéndices laterales que se presentan de perfil y especulares mirando hacia la cabeza de la figura dominante, que presentan cada uno un ojo, una boca alargada semejante al pico de un ave o a un hocico, y una especie de extremidad superior extendida hacia adelante rematada en ángulo recto hacia arriba; b) dos a cada 


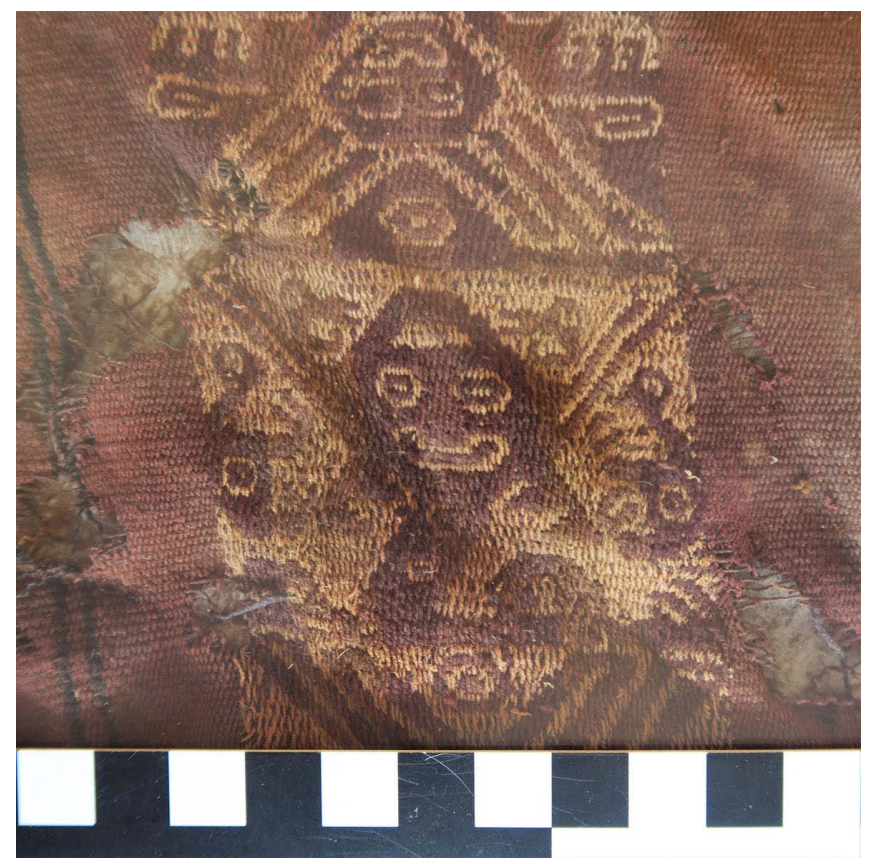

Figura 11. Cara de felino humanizado rodeada por seres zoomorfos no identificados (Fotografía Isabel Martínez A., 2018). lado de la figura dominante, pero por debajo de los apéndices faciales, en la misma posición y dirección de los anteriormente descritos, así como la misma forma de la cabeza, solo que estos presentan además un cuello largo y el cuerpo también de perfil y en posición aparentemente 'sentada', en cuyo interior se halla una especie de hexágono concéntrico, con cada uno dos extremidades, posiblemente superior e inferior, extendidas hacia adelante rematadas en dos especies de 'dedos' o ganchos en dirección al cuerpo (Figura 11). Estos cuatro acompañantes zoomorfos de perfil corresponderían a un animal no identificado por no poseer más rasgos distintivos y por su baja recurrencia (Horta 2005:65, 89 y 91, Figuras 190 y 205) y también se halla asociado a una figura del felino humanizado mencionado anteriormente en la clasificación de Helena Horta.

En la franja lateral se pueden apreciar seis módulos con motivos en hilos de color crema, que forman los motivos tanto en 'positivo' como en 'negativo', sobre un fondo listado en el siguiente orden: rojo/azul oscuro/ocre/rojo/azul oscuro/ocre/rojo (Figura 12).
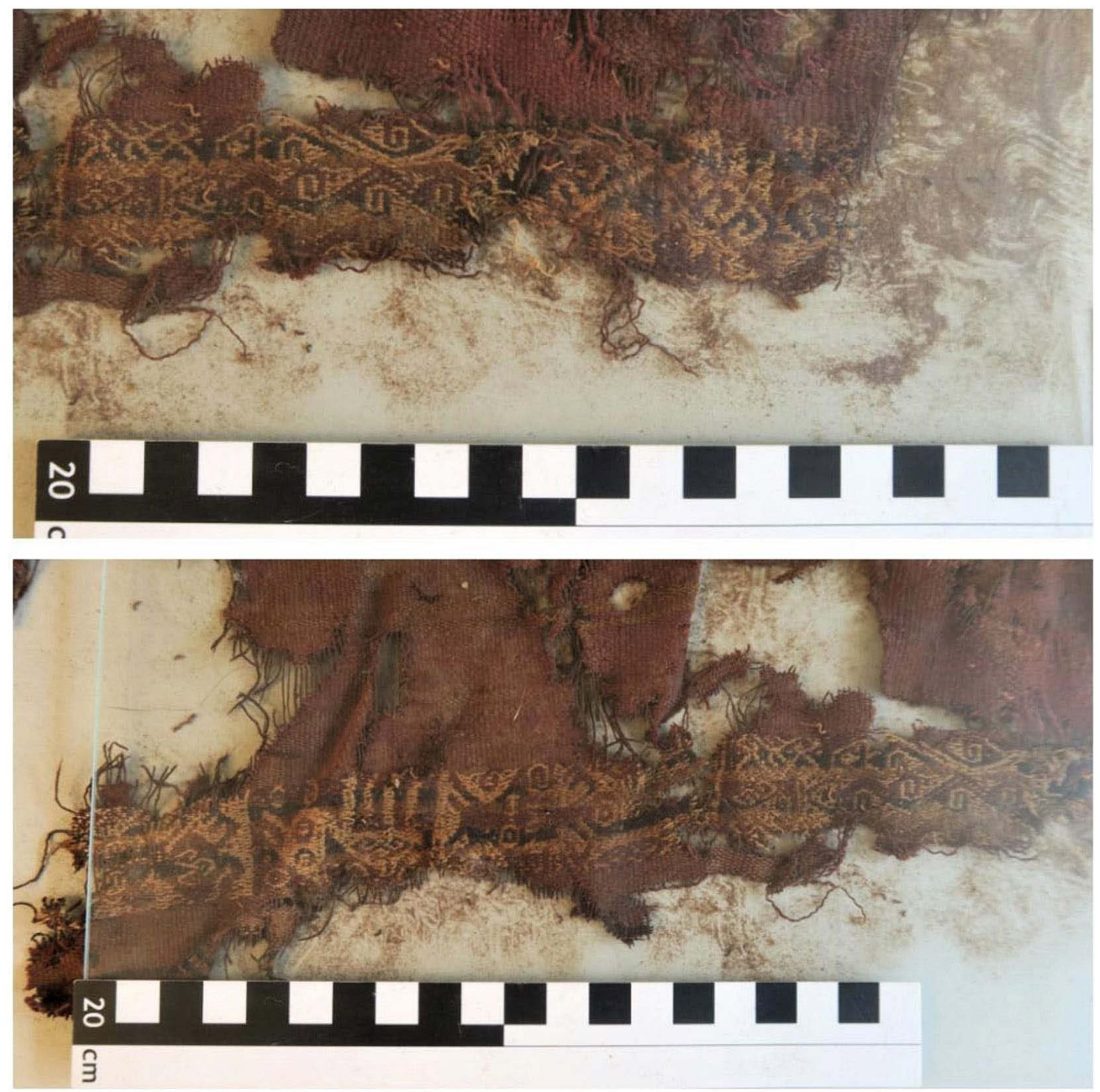

Figura 12. Franja lateral con seis módulos de diseño (Fotografía Isabel Martínez A., 2018). 

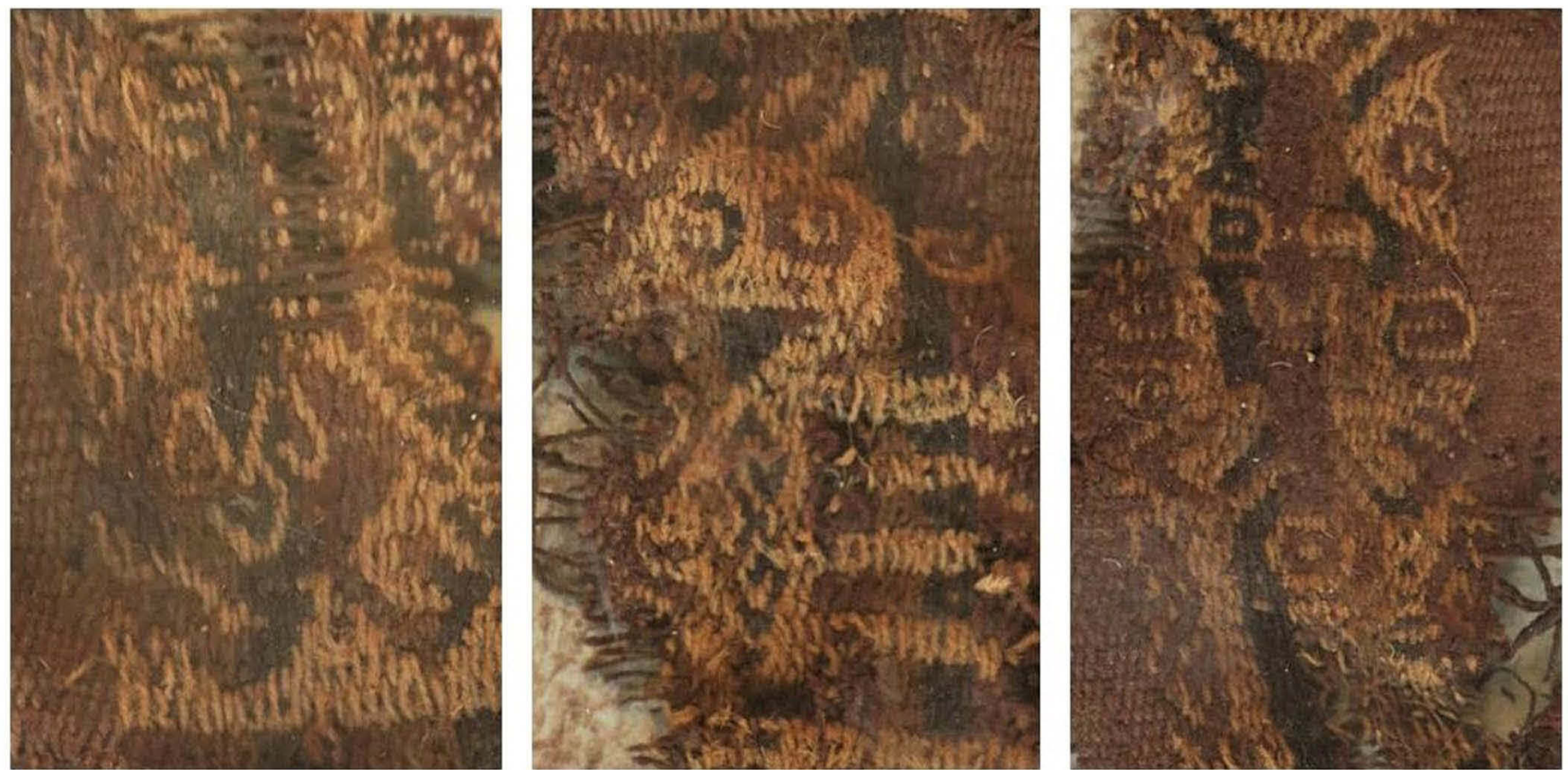

Figura 13. Motivos de los tres primeros módulos de la inkuña-taparrabo (Fotografías Isabel Martínez A., 2018).

El primer módulo contiene una figura antropomorfa erguida sobre pies de características muy similares a la Figura 58 del Grupo 3 la clasificación de Horta (2005:29 y 47). El siguiente módulo representa a un camélido de cuatro patas, de perfil (Horta 2005:63 y 86, Figura 180). El tercer módulo muestra una figura antropomorfa, erguida de frente, con un tocado de forma triangular en su base y en la clasificación de Horta (2005:44, Figura 48) existe un ícono muy similar donde la figura humana presenta tanto un "tocado erguido" como "orejeras", representadas por los ganchos (Figura 13).

El cuarto módulo contiene íconos no figurativos como "figuras geométricas independientes", específicamente "volutas 'S'” (Horta 2005:93, 96 y 107; Figuras 209 y 311) (Figura 14). El quinto módulo, también de íconos no figurativos, similares a ganchos terminados en puntas o triángulos. Se distribuyen en listas verticales, con ejes en forma de zig-zag desde los cuales emergen los ganchos. Estos motivos los encontramos en la clasificación de Horta (2005:93 y 102, Figuras 275 y 276) descritos como "íconos no-figurativos", "figuras geométricas independientes" y subcategoría "ganchos". Finalmente, el sexto, y último módulo, es otro ícono no figurativo que corresponde a una "franja diagonal aserrada" (Horta 2005:94 y 109, Figura 322), que entra en las "composiciones geométricas" (Figura 15).

La inkuña-taparrabo, apenas descrita, es un elemento importante para recontextualizar a la 'momia de Marburg', en cuanto nos permite, a través del estudio de su composición espacial e iconografía, acotar el fechado de su producción y utilización, como veremos en el siguiente apartado.

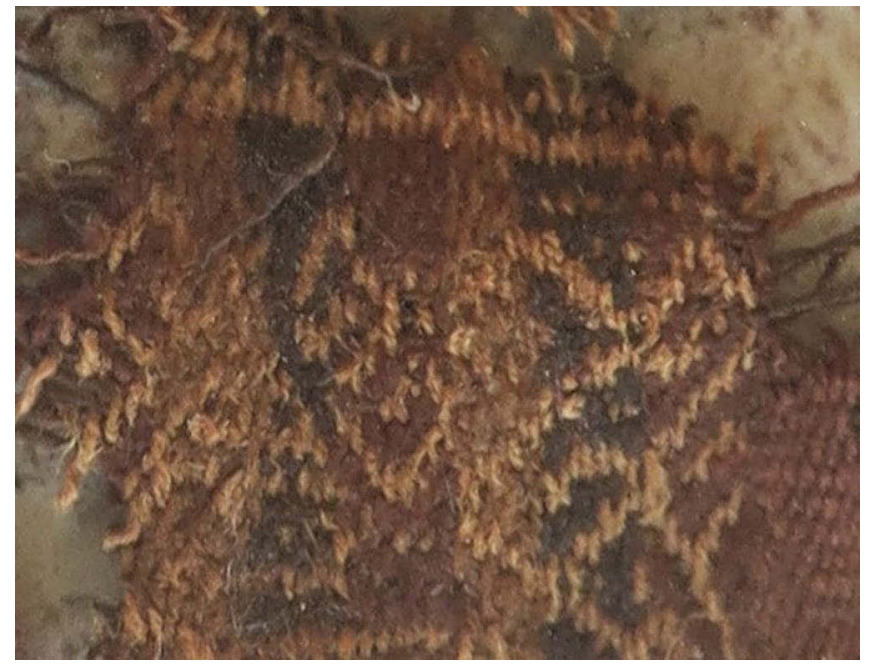

Figura 14. Íconos no figurativos del cuarto módulo (Fotografía Isabel Martínez A., 2018).

\section{Textiles de la Ofrenda}

Se compone de dos chuspas y dos inkuñas de fibra o pelo de camélido, en buen estado de conservación. La chuspa o ch'uspa formaba parte de la indumentaria andina y consiste en una bolsa sub-rectangular, cuadrada o trapezoidal, que generalmente se llevaba en bandolera, tejida en fibra de camélido, cuya función principal era la de guardar y transportar las hojas de coca (Erythroxylum coca) (Horta y Agüero 2000:48; Arriaza y Standen 2008:92). 

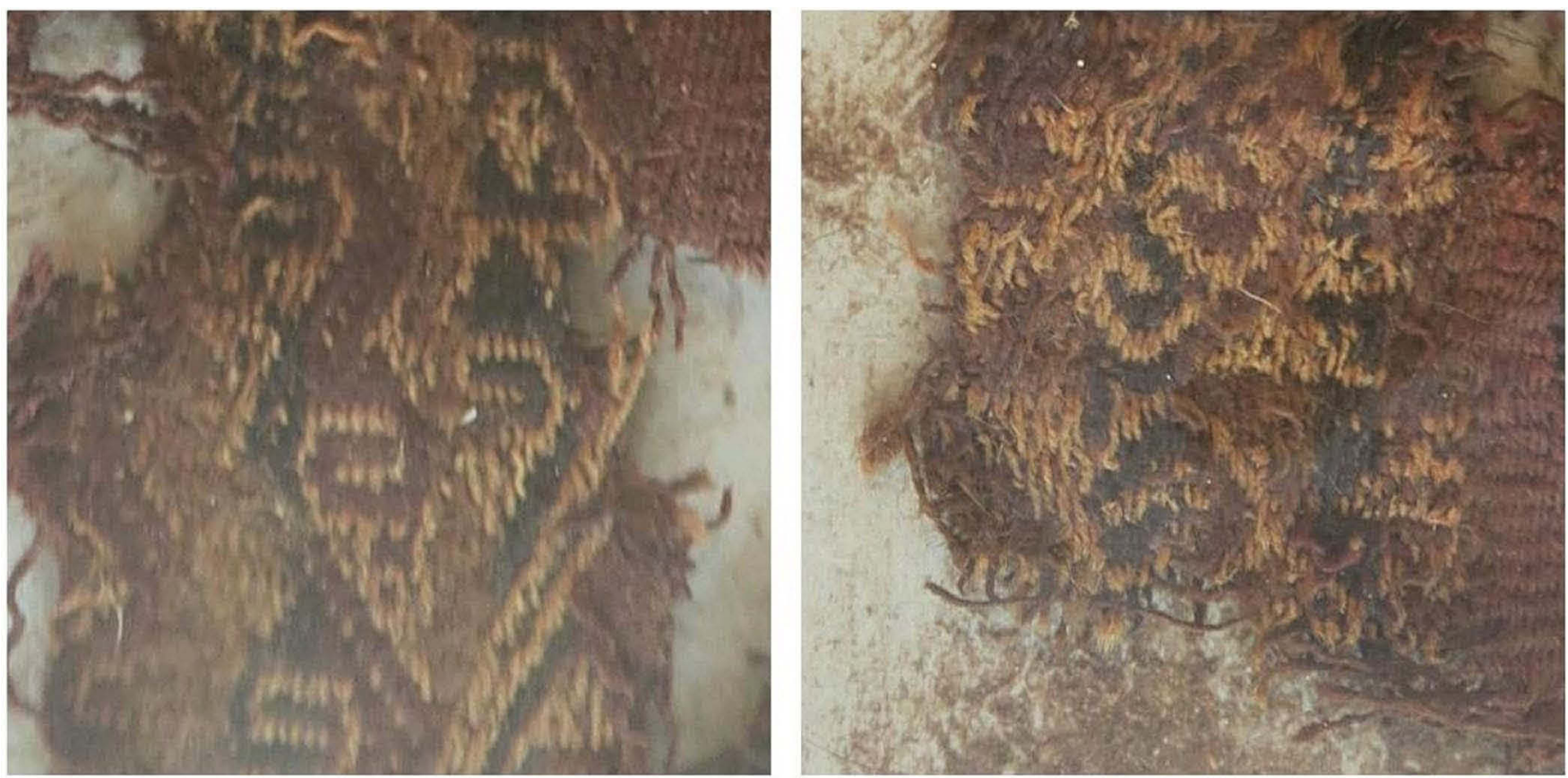

Figura 15. Izquierda, módulo con motivos no figurativos semejantes a ganchos dispuestos en hileras verticales; derecha, módulo con franja diagonal aserrada (Fotografías Isabel Martínez A., 2018).

La primera chuspa (Figura 16) presenta una disposición del cuerpo, tanto en su cara anterior como posterior, de tres franjas del mismo ancho, en el sentido vertical, que contienen íconos no figurativos similares a ganchos terminados en puntas o triángulos (cabeza triangular), que se distribuyen en listas verticales, con ejes en forma de zig-zag, desde los cuales emergen los ganchos de color crema sobre fondo color café oscuro, y rematan en un peinecillo largo o k'utu en color crema y café oscuro. En la clasificación de Helena Horta hay un motivo de similares características que está catalogado como "íconos no figurativos", categoría "figuras geométricas independientes" y subcategoría "ganchos" (Horta 2005:93 y 102, Figura 275). Estas franjas están intercaladas por cuatro bloques de listas monocromas de color verde-gris, verde y una más ancha central de color ocre sobre una pampa de color café oscuro. La distribución espacial en la cara anterior, de izquierda a derecha, es la siguiente, con cuatro bloques de listas monocromas café oscuro/verde-gris/café oscuro/verde/café oscuro/ocre/café oscuro/verde-gris/café oscuro/verde/café oscuro, intercalados por tres franjas con motivos en crema y café oscuro. En la cara posterior se invierte solamente la secuencia entre las listas verde-gris y verde.

El borde superior, o la boca, consiste en una primera, y última, pasada de trama de mayor grosor que en el resto del cuerpo y presenta un cordón de color rojo que se encuentra en parte cosido en ambos extremos de los bordes laterales superiores y con algunas puntadas a lo largo de la boca, terminando en una especie de mariposa que cuelga a lo largo de la pieza, encontrándose fijada por medio de una puntada en la base de la chuspa. Este cordón es característico de las chuspas de la cultura Arica y tiene como función la de cerrarla por boca (Horta 2005:17).

La cara anterior presenta una particularidad interesante y que puede ser diagnóstica para contextualizar temporal y geográficamente la pieza. Esta consiste en la presencia de dos pequeños bolsillos sobresalientes ubicados en la zona media de ambas franjas laterales con diseño, que fueron realizados durante el proceso del tejido de la chuspa.

La segunda chuspa (Figura 17) se halla con una deformación estructural y la composición espacial consiste en siete franjas verticales de diferentes anchos: una central modular con motivos figurativos; cuatro con íconos no-figurativos; y dos con peinecillo; con listas monocromas de diversos colores en los bordes laterales. La franja central, con hilos de urdimbre de color rojo y crema, se divide en tres módulos donde se repite el mismo motivo figurativo, que corresponde a un ser zoomorfo bicéfalo, con las cabezas dirigidas en orientaciones opuestas y con el cuerpo diagonal (Figura 18). En ambas cabezas, de forma hexagonal, se distinguen claramente un par de ojos y una especie de nariz larga en forma de clepsidra. Estas cabezas están unidas 


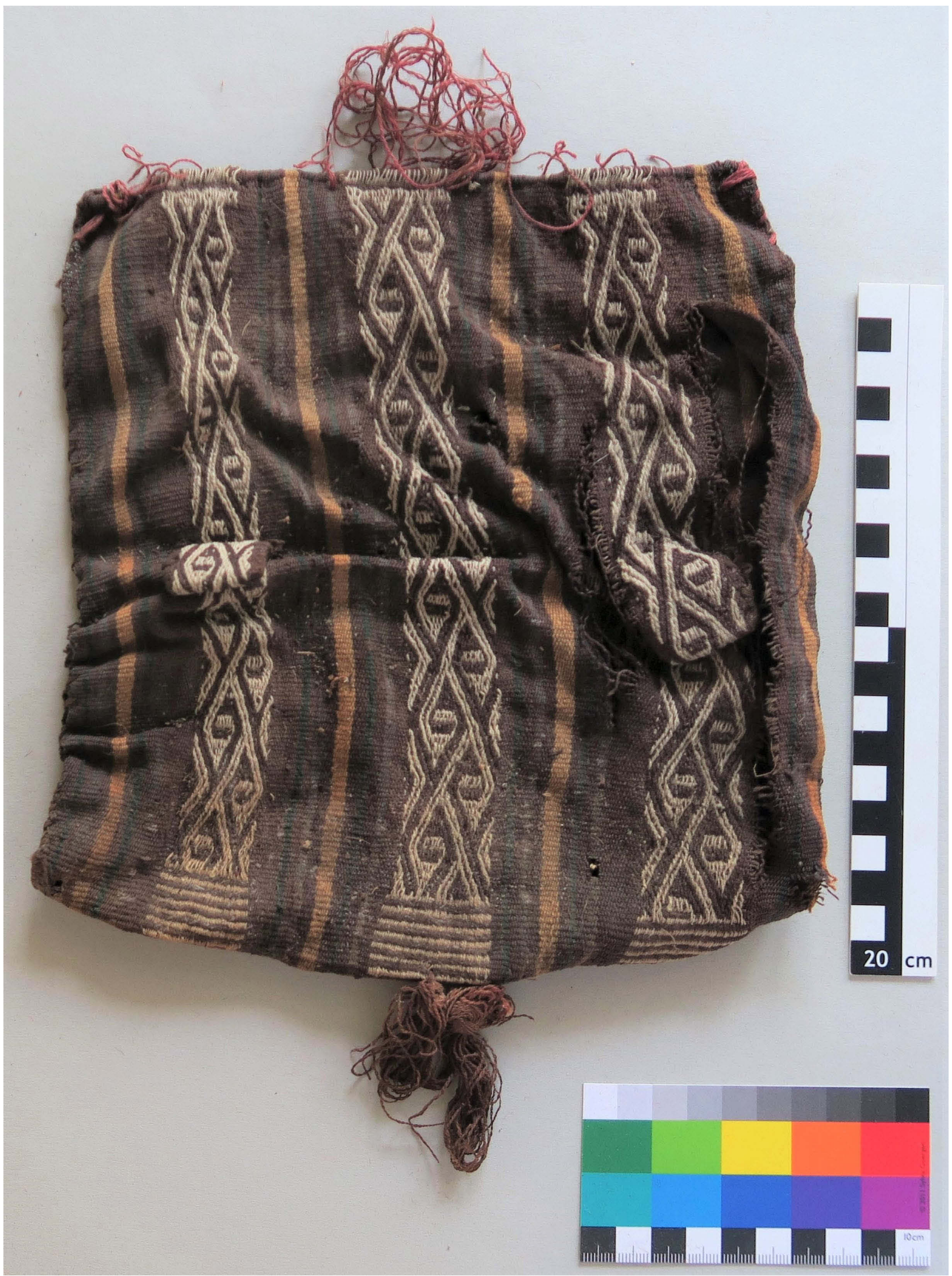

Figura 16. Vista de una de las chuspas que componen la ofrenda asociada a la momia de Marburg (Fotografía Isabel Martínez A., 2018). 


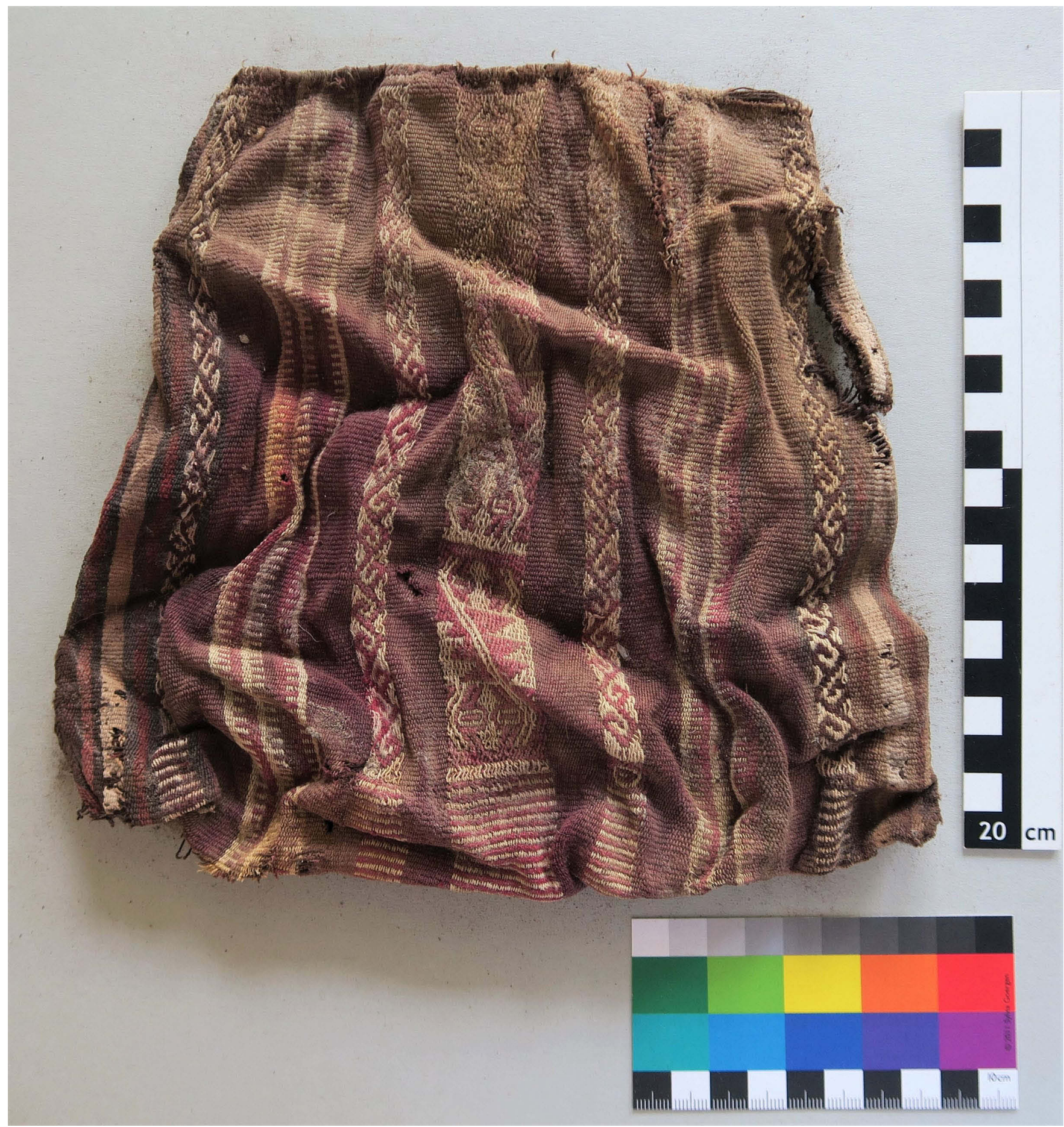

Figura 17. Vista de la segunda chuspa que forma parte de la ofrenda asociada a la momia de Marburg (Fotografía Isabel Martínez A., 2018).

mediante una línea diagonal flanqueada por líneas aserradas. La zona inferior de la franja termina en un peinecillo o k’utu largo y ancho, que da el efecto de líneas en crema y granate alternadas.

El ícono figurativo apenas descrito encuentra su correspondencia en la clasificación de Horta (2005:58 y 68, Figura
106), catalogado como una serpiente bicéfala de cuerpo diagonal.

Las franjas con íconos no-figurativos corresponden a cuatro que presentan el mismo diseño, dos de las cuales, que se hallan a ambos lados de la franja central separadas por la pampa de color granate, están formadas por hilos de 


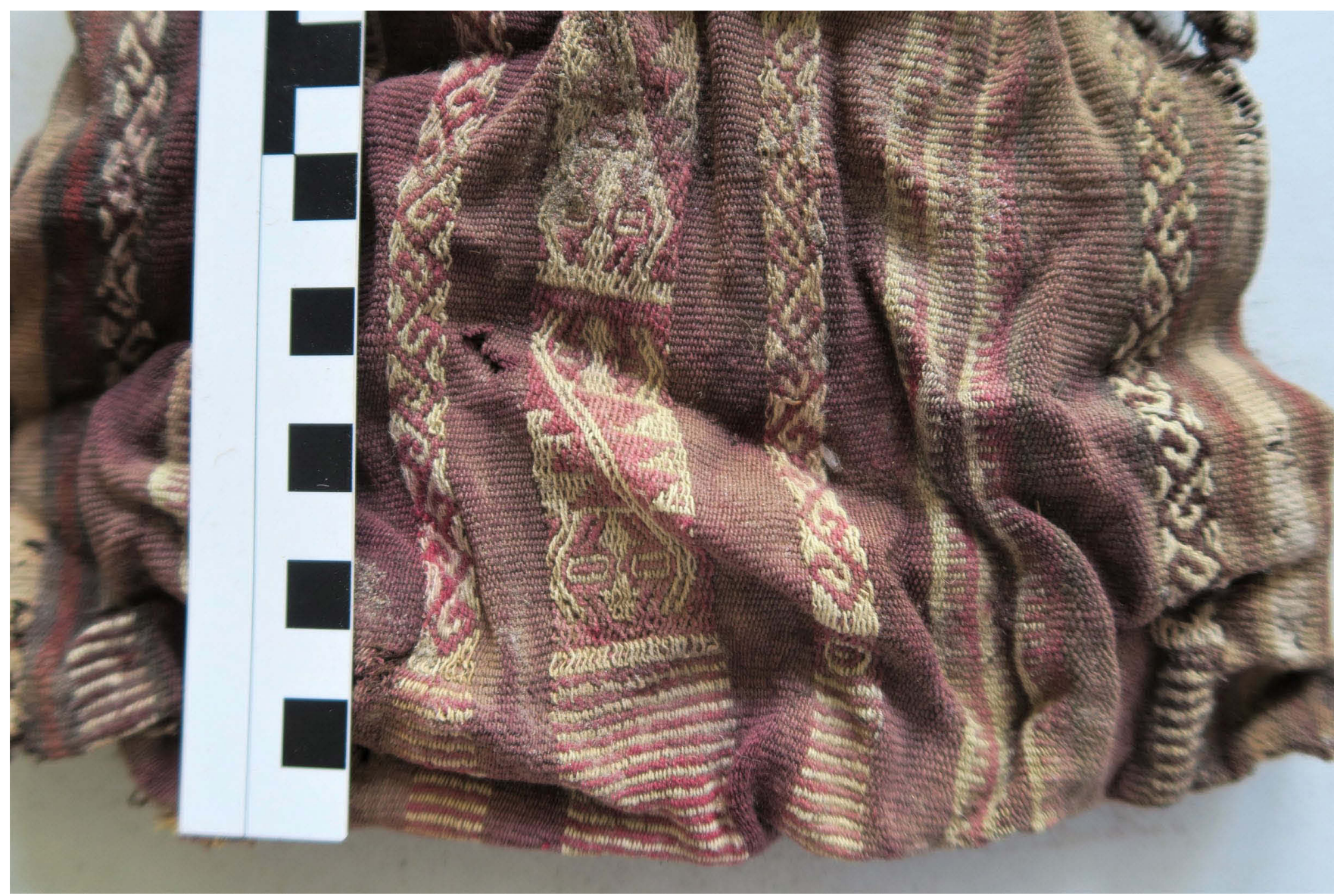

Figura 18. Detalle de la franja central con el motivo de la serpiente bicéfala de cuerpo diagonal (Fotografía Isabel Martínez A., 2018).

urdimbre de color rojo y crema, mientras que las otras dos, ubicadas cerca de los bordes laterales, fueron realizadas con hilos de urdimbre de color morado oscuro y crema. La zona inferior de la franja termina en un peinecillo largo y ancho, que da el efecto de líneas alternadas de color crema y granate, crema y morado oscuro. El ícono no-figurativo apenas descrito encuentra su correspondencia en la clasificación de Horta (2005:93 y 108, Figura 314) y corresponde a volutas en "S" que conforma una larga secuencia similar a guirnaldas con las cabezas entrelazadas.

Las dos franjas con peinecillo se posicionan entre las cuatro franjas con íconos no-figurativos, separados por la pampa de color granate y tienen, cada una, la siguiente composición de listas: crema/peinecillo en rojo y crema/rojo/ crema/peinecillo en granate y crema/granate/rojo/peinecillo rojo y crema/ rojo.

Finalmente, ambos bordes laterales del cuerpo de la chuspa terminan con ocho listas monocromas de diversos colores, presentando una división en tres partes: una lista central más ancha de color crema flanqueada por listas de menor e igual ancho. La secuencia de colores es la siguiente: rojo/morado oscuro/rojo/morado oscuro/crema/morado oscuro/rojo/morado oscuro.

La primera inkuña (Figura 19) presenta una decoración textil se da en listas verticales, de diferentes anchos, de color café sobre una pampa de color crema, con un total de diecinueve, de las cuales tres con peinecillo. La técnica textil corresponde a la faz de urdimbre para las zonas llanas sin decoración y listas monocromas, así como peinecillo.

Se evidencian los cuatro bordes, superior, inferior y laterales, y las cuatro terminaciones en las esquinas. Los bordes laterales son terminaciones simples de trama, mientras que los bordes superior e inferior están realizados con la técnica de trama en torzal, en crema y café oscuro, que forman en una fila central unas especies de rombo en crema unidos por líneas en café oscuro, y una primera y última pasadas de trama con un hilo más grueso. Las cuatro esquinas, prolongaciones de la trama de estos bordes en las orillas de urdimbre, fueron realizados con la técnica de cordón trenzado de dos colores con el motivo de zig-zag.

De acuerdo a lo que se observa en relación a la leve deformación que presenta en la zona central, por la dirección de 


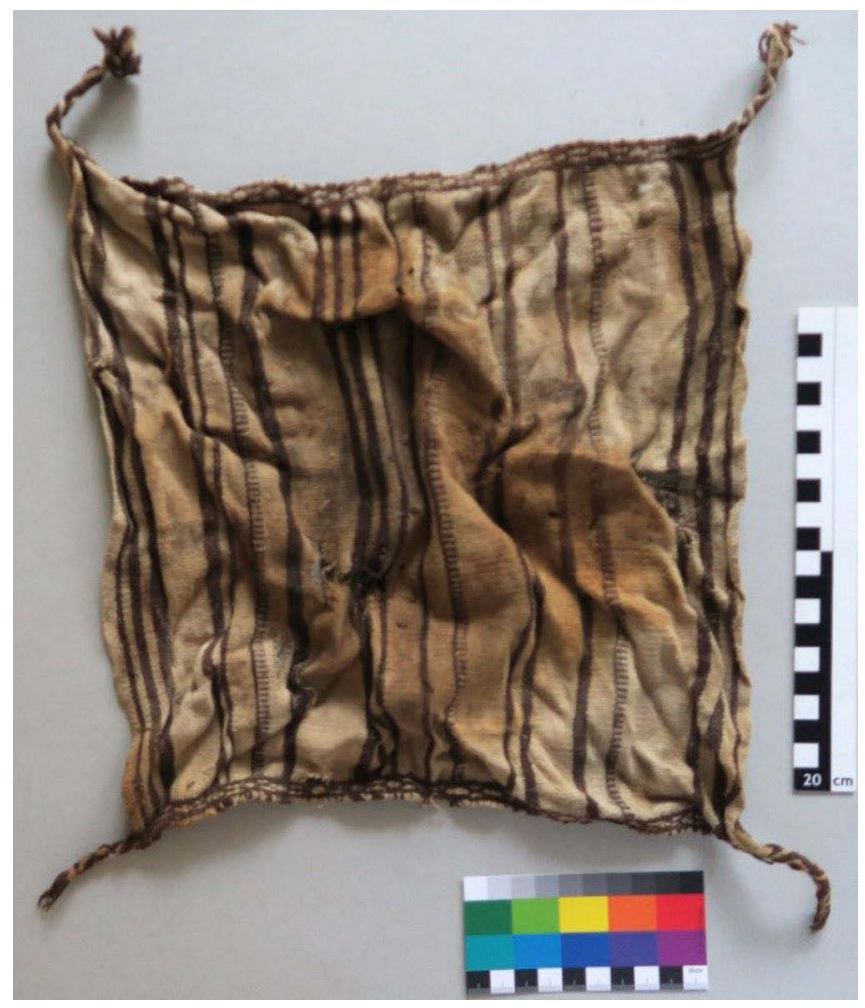

Figura 19. Vista de una de las inkuñas que componen la ofrenda asociada a la momia de Marburg (Fotografía Isabel Martínez A., 2018).

los pliegues y la mancha café, se puede conjeturar que esta pieza habría envuelto un contenido, tal como corresponde a su función, anteriormente citada. Pudo haber sido depositada en forma de bulto, probablemente conteniendo hojas de coca, pero no es posible determinar si el contenido se perdió con el traslado de la momia desde Arica a Marburg o a su posterior llegada al destino final.

La segunda inkuña (Figura 2o) presenta una decoración que se da en cuatro módulos, o bloques según la terminología usada por Horta y Agüero (2009:186), de listas verticales, de diferentes anchos y composición, separados por la pampa en color café claro, con una pampa central de color crema. Presenta dos módulos centrales, a ambos costados de la pampa de color crema, donde uno de ellos se compone de listas monocromas de diferentes colores y anchos, mientras que el otro está compuesto además por una serie de listas con peinecillo; y dos módulos laterales, siendo uno más ancho que el otro y lo forman listas monocromas, con peinecillo y una franja ancha con ajedrezado con líneas diagonales. La técnica textil con la cual fue confeccionada corresponde a la faz de urdimbre para las zonas llanas sin decoración y listas monocromas, y peinecillo para las listas con ese diseño y para el ajedrezado.

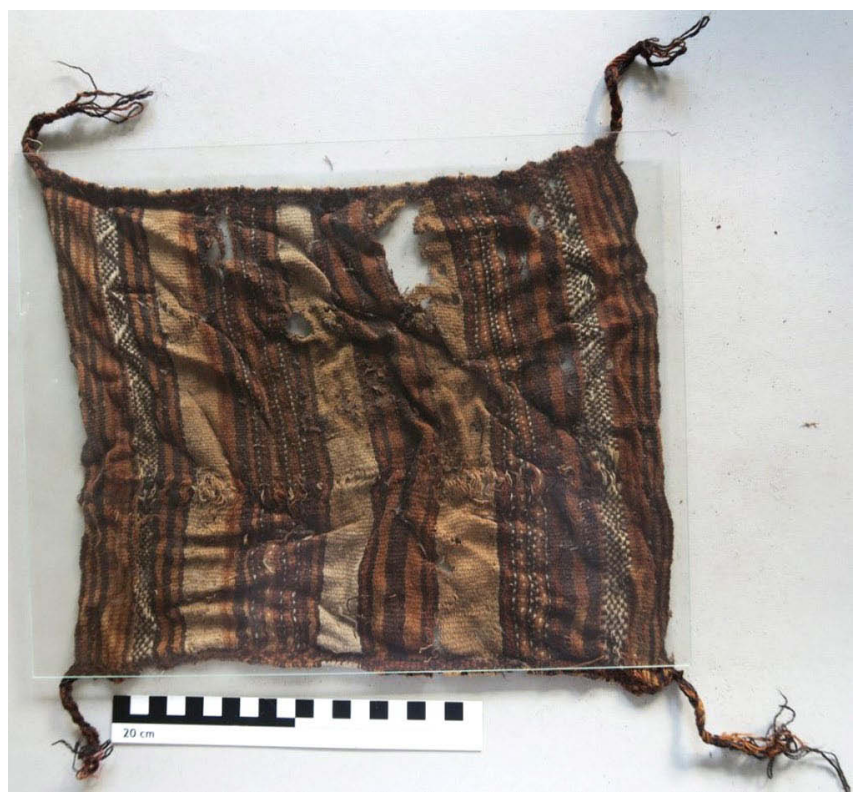

Figura 2o. Vista de la segunda inkuña asociada a la ofrenda de la momia de Marburg (Fotografía Isabel Martínez A., 2018).

Los bordes laterales son terminaciones simples de trama, mientras que los bordes superior e inferior estarían realizados con la técnica de trama en torzal en color café oscuro y café claro, que forman en una fila central unos rombos en color café vicuña unidos entre sí, con una primera pasada de trama con un hilo más grueso. Las cuatro esquinas, prolongaciones de la trama de estos bordes en las orillas de urdimbre, fueron realizadas con la técnica de trenzado simple de tres cabos.

De acuerdo a lo que se observa en relación a la leve deformación que presenta, por la dirección de los pliegues y abultamiento en la zona central, también se puede conjeturar que esta pieza habría envuelto un contenido y que pudo haber sido depositada en forma de bulto, probablemente conteniendo hojas de coca, pero que con el traslado de la momia desde Arica a Marburg o posterior a su llegada a destino final, se habría abierto, perdiéndose su contenido original.

\section{Recontextualización de la Momia}

En base al análisis realizado podemos circunscribir a este individuo, como ya se ha planteado en la introducción, al período Intermedio tardío (ca. 1000-1470 d.C.) de la zona de Arica, norte grande de Chile y, con más exactitud, como perteneciente a la cultura Arica. Muchos son los elementos que nos llevan a tal adscripción, como la forma y función de los textiles del ajuar y de la ofrenda, la materialidad y técnicas 
empleadas en su confección, pero sobre todo por la gama de colores empleada, la composición espacial y la iconografía de los mismos.

Dentro de la forma y función de los textiles, tanto del ajuar como de la ofrenda, tenemos la presencia de los más representativos y frecuentes tipos de la indumentaria de la cultura Arica, según lo señalado por Carolina Agüero (2000) y Helena Horta (2005): unku, bolsa-faja, inkuña y chuspa. Asimismo, las tres últimas piezas mencionadas son los tres tipos de tejidos que presentan mayor decoración figurativa en todo el desarrollo de la zona de Arica.

Por la técnica de confección del posible unku, cuyos restos e improntas en la piel se hallan distribuidos en toda la zona de la espalda y hombros del individuo, podemos plantear una prenda de estilo no-local, ya que en esa zona las túnicas eran realizadas con la técnica de faz de urdimbre, como los restos del segundo unku que presenta listas en el sentido vertical de color crema sobre fondo café oscuro, al menos hacia los costados, que se evidencia en la rodilla derecha y sobre ambas manos y que pudo cubrir todo el cuerpo, sobre las otras prendas.

Por otro lado, debido a la escasa bibliografía encontrada en relación a la bolsa-faja, no fue posible atribuirla a una determinada fase durante el período Intermedio tardío en la zona de Arica. En la colección Nielsen del Museo Regional de Iquique, norte de Chile, se encuentra un ejemplar de similares características en cuanto a la disposición espacial, aunque esta pieza varía en relación al patrón cromático donde predominan los colores teñidos (Méndez 2015:19, Bolsa-faja, $\mathrm{S} / \mathrm{P}, 1465)$ y no se hace referencia a un posible contexto ni fechado. Retomando a Horta, la bolsa-faja:

"es una prenda textil de uso restringido a través de todo el Intermedio Tardío: su recurrencia es mucho menor que la de los otros dos textiles decorados por excelencia, como son la chuspa y la inkuña. Todo indica que la bolsa-faja fue símbolo del elevado prestigio social de algunos miembros de la comunidad: su ausencia en la gran mayoría de las tumbas confirma lo manifestado, frente a un número muy menor de ajuares que presentan simultáneamente dos bolsa-fajas ricamente decoradas" (Horta 2015:193)

La bolsa-faja habría sido usada exclusivamente para guardar y trasladar las hojas de coca, vinculada a su consumo y circulación entre los miembros de la élite.

En cuanto a la inkuña, reutilizada como posible taparrabo, por las características observadas en la composición espacial es posible insertar esta pieza en la clasificación de Horta y Agüero (2009:203, Figura 16) como el grupo 2D, es decir, correspondería a una inkuña estilo San Miguel-Pocoma (Horta y Agüero 2009:217), que presentan rasgo de filiación estilística tanto de San Miguel como de Pocoma, con la innovación en las pampas listadas, lo que las autoras han denominado listado Pocoma, que corresponde al patrón cromático de la presente pieza.

Uno de los íconos más representativos es la figura antropomorfa bicéfala, siendo la que presenta mayores dimensiones y que se ubicaría en la franja central más ancha. Según lo expresado por Horta (2005:125), la influencia Pocoma sobre San Miguel se inicia alrededor del 1200 d.C., notándose tanto en la cerámica como en los textiles, con la introducción de nuevos íconos, entre los cuales figuran los primeros antropomorfos bicéfalos. Esta figura antropomorfa bicéfala que se encuentra también en algunos textiles de San Miguel tardío, pero sin su carácter rectilíneo, fue típica de las representaciones antropomorfas de los textiles de filiación Chiribaya (Horta 1997:94).

Además, en el caso de las dieciséis figuras antropomorfas bicéfalas registradas por Horta, seis de ellas presentan la coincidencia de "tocado erguido", conjunto de cuatro hexágonos concéntricos en el cuerpo y “orejeras” (2005:31), como es observado en la figura de esta pieza. Asimismo, entre los motivos decorativos más frecuentes de las inkuñas del grupo 2D se encuentran las figuras antropomorfas erguidas, el camélido de cuatro patas, el felino, los ganchos y la franja diagonal aserrada, que encontramos también en la pieza bajo análisis.

En relación a la procedencia de las piezas pertenecientes al grupo 2D analizadas por dichas investigadoras, tenemos que la mayoría, en total seis, proviene del cementerio Playa Miller-3 (PLM-3), una de Playa Miller-4 (PLM-4), ubicados en la costa al Sur de la ciudad de Arica, y una de Azapa-140 en el valle de Azapa. El sitio de PLM-3 es un cementerio de una población compuesta por pescadores, cazadores de lobos marinos y mariscadores que vivió en la costa de Arica hacia la segunda mitad del Intermedio tardío, lo que se evidencia por la presencia masiva de implementos de pesca, arponeo y extracción de mariscos en todos los ajuares funerarios (Focacci 1997; Horta 2000). Es a fines de ese periodo (ca. 1250-1450 d.C.) que surgen en esa zona la balsa, el capacho y el porta-arpón y "es entre las ofrendas costeras, que observamos una acentuada presencia de textiles de estilos foráneos (Chiribaya, 'Tarapaqueño', así como otros aún no definidos), mezclados con los locales (San Miguel, Pocoma y Gentilar)" (Horta 2000:240). Los fechados por termoluminiscencia de las cerámicas asociadas a este grupo de inkuñas varía entre $960 \pm 80,1.215 \pm 8$ o d.C. y $1.355 \pm 55$ d.C. (Horta y Agüero 2009:206; Uribe 1999).

La Cultura Arica se desarrolló en la zona geográfica de los valles interiores y franja costera del extremo norte grande 
de Chile, sub-área de los Valles Occidentales del área mayor centro-sur andina (Horta 2005:13). Esta área geográfica está sujeta a una gran aridez, por lo que la presencia de valles interfluviales como Lluta, Azapa, Vítor y Camarones permitieron, por sus condiciones favorables, el asentamiento humano (Horta 2015:31).

Esta cultura tuvo dos fases de desarrollo: San Miguel y Gentilar, con un periodo de transición denominado Pocoma (Horta 2005:12). Se caracterizaban por tener una economía mixta de subsistencia ya que eran agricultores, pastores y pescadores, existiendo un sistema recíproco de complementariedad ecológica para el Intermedio tardío en esa zona (Horta 2005:14; 2015:21-22). El panorama general del Intermedio tardío fue de multietnicidad en lo que respecta a la tradición de Valles Occidentales, representada por los grupos Maytas, San Miguel, Pocoma y Gentilar, y con presencia de otros grupos culturales, como por ejemplo provenientes del altiplano y del extremo sur del actual Perú (Horta 2015:24). Las poblaciones de la tradición de Valles Occidentales estaban organizadas en comunidades con autoridades propias, compartiendo el espacio con poblaciones altiplánicas "en el marco de relaciones simétricas" (Horta 2015:27; Santoro et al. 1987). Asimismo, la conjunción de las diversas actividades productivas de la zona llevó a "un estado de relativo bienestar general, que se tradujo en un incremento de los bienes poseídos individualmente por cada miembro de la comunidad" (Horta 2005:14), lo que se vería reflejado en la cantidad y calidad de los objetos que formaban parte del ajuar y ofrendas funerarios que acompañaban a cada individuo.

El patrón de enterramiento es la fosa cilíndrica o ampollar, sin ningún revestimiento de piedra, donde el cuerpo del individuo era enterrado en una posición fuertemente flexionada, envuelto en una o más túnicas y amarrado con cuerdas trenzadas de fibra vegetal o de camélido (Horta 2015:351), acompañado por un ajuar y ofrendas. El ajuar correspondía a la vestimenta de uso cotidiano -por la presencia de variados remiendos- aunque en algunos casos se hallaron también piezas textiles sin uso, lo que lleva a Helena Horta a inferir, por lo que concierne a la cultura Arica, que ciertos "miembros de la comunidad contaban con el privilegio de poseer prendas de uso no-cotidiano, o confeccionadas especialmente para el rito de la muerte" (2005:15).

En relación al estatus de los individuos del Intermedio tardío, reflejado en los diversos contextos funerarios, el prestigio del difunto "está directamente relacionado con el rol que cumple en el sistema socio-político en el cual se halla inmerso" (Horta 2015:176), tomando en consideración los bienes funerarios asociados al cuerpo, los cuales están relacionados con la actividad económica que habría ejercido en vida. Para el Intermedio tardío se registra un aumento en la calidad y en la cantidad de bienes funerarios, así como el carácter simbólico de los objetos, en relación al periodo anterior, período Medio, lo que podría ser interpretado como un "signos de una temprana diferenciación social" (Horta 2015:176).

Es en este periodo que se evidencia un incremento de ciertos tipos de textiles en la ofrenda mortuoria, como la bolsa-faja y la inkuña, cuya función era la de contener hojas de coca. Existe una diferencia en la cantidad de inkuñas por cementerio entre el valle y la costa, siendo mayor en esta última zona; la excepción de los cementerios de valle es Azapa 8 que se comporta en muchos aspectos como un cementerio de la costa. En los cementerios de los valles, la inkuña "funciona como un bien al cual los miembros de la comunidad tenían un acceso más o menos igualitario" (Horta 2015:184), registrándose generalmente una de estas piezas por tumba. En los cementerios de la costa, la diferencia en la frecuencia radica en la concentración de este ítem asociado a ciertos individuos, ya que al igual que en los cementerios del valle el estándar es de uno a dos por tumba. Esta diferencia en la frecuencia entre costa y valle es interpretada por Helena Horta como el reflejo del auge económico de la cultura Arica gracias a la explotación de los diversos recursos marinos "que en forma de excedente se intercambiaban con poblaciones vecinas y distantes en una compleja red de tráfico interregional" (Horta 2015:189), lo que habría llevado a un incremento del poder y prestigio de los jefes étnicos de la costa y donde las hojas de coca habrían jugado un rol fundamental en las ceremonias de reciprocidad.

La bolsa-faja, contenedora por excelencia de hojas de coca, hace su aparición a partir de la segunda mitad del Intermedio tardío (ca. 1200-1470 d.C.), a diferencia de la chuspa y de la inkuña que ya se registran en los inicios de este periodo. Sin embargo, son la inkuña y la bolsa-faja innovaciones representativas del Intermedio tardío en la zona de Arica, ya que su presencia no se evidencia ni antes ni después de ese periodo (Horta 2015:187) y como ya mencionamos su uso fue restringido ya que su recurrencia es mucho menor que los otros dos tipos textiles.

\section{Conclusiones}

Los resultados de este análisis nos ratifican, a grandes rasgos, su adscripción cultural y espacial al periodo Intermedio tardío de la zona de Arica, y más específicamente podríamos estar hablando, en primera instancia, sea por la composición espacial de la inkuña como por la presencia de la bolsa-faja, de un contexto funerario de filiación San Miguel-Pocoma con presencia de posibles bienes de intercambio, de filiación Maytas-Chiribaya, que forman parte de la 
ofrenda, con un fechado acotado aproximadamente entre 1200 y 1300 d.C., datación relativa que deberá ser posteriormente cotejada por los resultados del fechado de radiocarbono, así como por el análisis de los objetos no textiles.

Los componentes del ajuar, así como de las ofrendas, nos están indicando que el individuo habría tenido cierto poder y prestigio dentro de su comunidad. Esta aseveración se apoya, tanto en la presencia de la bolsa-faja, como por la rica iconografía presente en la inkuña-taparrabo. Estas piezas, como ya vimos, tenían como función la de contener hojas de coca, bien importante en las comunidades andinas precolombinas en los intercambios de reciprocidad, rituales y como ofrenda. Los íconos plasmados en la inkuña-taparrabo nos remiten a personajes con características específicas, como el uso de orejeras y tocado, símbolos de prestigio y status en todos los Andes y a seres zoomorfos que representan el poder y la fuerza naturales, tales como el felino. Asimismo, el intrincado peinado y posibles restos de metal en la mayor parte de la cara de la momia, nos podrían estar indicando que habría sido sepultado con una máscara funeraria, otro elemento de escasa recurrencia y vinculada a personajes de alto rango. Este individuo fue inhumado con un total de tres inkuñas (una en el ajuar y dos en la ofrenda), lo que nos lleva a proponer, debido a la concentración de este bien mencionado anteriormente, así como la presencia de objetos relativos a la ergología marítima en las ofrendas, que su entierro primario habría estado ubicado en alguno de los cementerios de la costa de Arica. Posteriores análisis nos permitirán acotar aún más esta circunscripción geográfica.

\section{Agradecimientos}

Agradecemos a Nina Ullrich, curadora del Museum Anatomicum de la Philipps Universität, Marburg, Alemania, por la confianza y por permitirnos analizar los textiles asociados a la momia que tienen en custodia.

\section{Referencias Citadas}

Agüero, Carolina

2000 Las tradiciones de Tierras Altas y de Valles Occidentales en la textilería arqueológica del Valle de Azapa. Chungara 32(2): 217-225.

Arriaza, Bernardo, Marvin J. Allison, Vivian Standen, Guillermo Focacci y Juan Chacama

1986 Peinados precolombinos en momias de Arica. Chungara 16-17: 353-375.
Focacci, Guillermo

1997 Evidencias culturales andinas en registros arqueológicos Playa Miller-3. Diálogo Andino 16: 101-122.

Horta, Helena

1997 Estudio iconográfico de textiles arqueológicos del valle de Azapa, Arica. Chungara 29 (1): 81-108.

2000 Diademas de plumas en entierros de la costa del Norte de Chile: ¿Evidencias de la vestimenta de una posible parcialidad pescadora?. Chungara 32(2): 235-243.

2005 Arte textil prehispánico. Diseños de los tejidos de la cultura Arica, norte de Chile (10oo-1470 d.C.). Serie Colección Estudios Regionales y Locales de la Universidad Bolivariana, Sede Santiago, Imprenta LOM.

2015 El señorío Arica y los Reinos Altiplánicos: complementariedad ecológica y multietnicidad durante los siglos pre-conquista en el Norte de Chile (100o-1540 d.C.). Ocho Libros Editores, Santiago de Chile.

Horta, Helena y Carolina Agüero

2009 Estilo, iconografía y diseño de las inkuñas prehispánicas del Norte de Chile durante el Periodo Intermedio Tardío (1.00o-1.40o d.C.). Chungara 41(2):183-227.

Méndez, Pablo

2015 Prácticas funerarias en las costas de Tarapacá. Colección Nielsen. Museo Regional de Iquique.

Minkes, Wynne

2008 Warp the Loom-Warp the Dead. Trapezoid shaped textiles from the Chiribaya Culture, South Peru, AD 900-1375. http://digitalcommons.unl.edu/tsaconf/116 (26/01/2018).

Phipps, Elena

2008 Woven to Shape: a Pre-Columbian Trapezoidal Tunic from the South Central Andes in the Metropolitan Museum of Art. http://digitalcommons.unl.edu/ tsaconf/233 (26/o1/2018).

Rosenzweig, Alfredo y Bat-ami Artzi

2011 A Chiribaya Textile Woven with Human Hair. Boletin del Museo Chileno de Arte Precolombino 16(1): 93-104.

Santoro, Calogero, Jorge Hidalgo y Alfonso Osorio

1987 El estado Inka y los grupos étnicos en el sistema de riego de Socoroma. Chungara 19: 71-92.

Uribe, Mauricio

1999 La cerámica de Arica 40 años después de Dauelsberg. Chungara 31(2): 189-228. 


\title{
A highland textile tradition from the far south of Peru during the period of Inka domination
}

\author{
Penelope Dransart \\ University of Aberdeen
}

\begin{abstract}
A group of garments and textile fragments is identified in this article as belonging to a particular textile tradition, with characteristics indicating an affiliation to communities in the highlands of the South-Central Andes. Different categories of gender-specific garments are presented. The characteristics include an all-camelid construction, warp-patterned stripes in blocks of alternating colours, the use of a discontinuous warp and transposed-warp weave. Pattern motifs include eightpointed stars, double-headed serpents and figures based on rhombuses. Distinctive geometric designs are analysed, including 'butterfly' motifs and narrow stripes, consisting of paired light- and dark-coloured right-angled triangles joined to make stacks of larger isosceles triangles or rhombuses. These are compared with pottery styles of the Collao, the region surrounding Lake Titicaca, and of the Inkas, who conquered the region c. 1440. Some textiles are reported in museum catalogues to have been found on sites in the Yauca, Majes and Sihuas valleys. It is hypothesized that the textiles preserved in museum collections are from funerary sites in southern Peru from the 1470 s onwards when Qolla and Lupaqa lordships established enclaves in coastal valleys under the aegis of the Inka empire.
\end{abstract}

Key words: Warp-woven textiles, gendered garments, South-Central Andes, Lake Titicaca kingdoms, Qolla (Colla), Lupaqa (Lupaca), Late Horizon

\section{Resumen}

En este artículo se identifica a un grupo de tejidos que corresponden a una específica tradición textil con características que pertenecen a las tierras altas del área Centro Sur Andina. Se presentan diferentes categorías de prendas según el género del usuario. Los textiles están tejidos con urdimbre y trama de fibra de camélido en listas ejecutadas en faz de urdimbre con dibujos en bloques de colores alternos, con el uso de hilos de urdimbre discontinuos y de hilos de urdimbre transpuestos. Los motivos incluyen estrellas de ocho puntas, serpientes de dos cabezas y figuras basadas en rombos. Se analizan los motivos geométricos distintivos de 'mariposa' y listas angostas, compuestas de triángulos ortogonales de colores oscuros y claros que se juntan para formar triángulos isosceles y rombos. Luego se comparan los motivos con los diseños de la cerámica del Collao, la región que rodea el Lago Titicaca, y de los Inkas, que conquistaron la región c. 1440. Según lo registrado en los catálogos de museo, algunos de los textiles se han encontrado en los valles de Yauca, Majes y Sihuas. Se presenta una hipótesis de que los textiles conservados en colecciones de museo provenían de sitios funerarios en el sur de Perú desde la década de 1470 en adelante, cuando los señoríos Qolla y Lupaqa establecieron enclaves en los valles costeros bajo los auspicios del imperio inca.

Palabras clave: Textiles faz de urdimbre, prendas masculinas y femeninas, área Centro Sur Andina, señoríos del Lago Titicaca, Qolla (Colla), Lupaqa (Lupaca), Horizonte Tardío

\section{Résumé}

Dans cet article est examiné un groupe de vêtements et de fragments de tissus appartenant à une même tradition textile et présentant des caractéristiques propres aux communautés des hautes terres de la région andine centre-sud. On y trouve différentes catégories de vêtements portés selon le genre. Les tissus sont tissés entièrement en fibres de camélidés et à dominante chaîne, avec des motifs organisés en blocs de couleurs alternées, des fils de chaîne discontinus et d'autres transposés.

DOI: 10.32873/unl.dc.zea.1209

Published in PreColumbian Textile Conference VIII / Jornadas de Textiles PreColombinos VIII, ed. Lena Bjerregaard and Ann Peters (Lincoln, NE: Zea Books, 2020). https://digitalcommons.unl.edu/zeabook/ 
Les motifs incluent des étoiles à huit pointes, des serpents à deux têtes, et des figures en forme de losanges. Des motifs géométriques sont analysés, en particulier des motifs de " papillons », et des rayures étroites composées de triangles orthogonaux de couleurs foncées et claires qui se joignent pour former des triangles isocèles de plus grande taille et des losanges. Ceux-ci sont ensuite comparés aux motifs présents sur la céramique du Collao, région autour du lac Titicaca, et sur la céramique des Incas qui conquirent la région autour de 1440. Selon les registres des catalogues des musées, certains textiles ont été découverts dans les vallées de Yauca, Majes et de Sihuas. Nous présentons l'hypothèse que les tissus conservés dans les collections muséales proviennent de sépultures du sud du Pérou, datant des années 1470 et au-delà, lorsque les señoríos Qolla et Lupaqa ont installé des enclaves dans les vallées côtières sous l'égide de l'empire Inca.

Mots clés: tissus à dominante chaîne, vêtements masculins et féminins, région andine centre-sud, señoríos du lac Titicaca, Qolla (Colla), Lupaqa (Lupaca), Horizon Récent

In the sixteenth century, Pedro de Cieza de León commented on the region surrounding Lake Titicaca, which he called Collao or Collas. Not only was it extensive in size, but the density of its population, he said, was greater than he had seen elsewhere in the Andes (Cieza de León 2005[1553]: 253). In describing its people, he commented 'Andan vestidos de ropa de lana ellos y sus mugeres', with the men also wearing long bonnets called chuco and the women a hood, which was nearly as long as those worn by mendicant friars (Cieza de León 2005[1553]: 255). ${ }^{1}$ South of the Collao region, he observed that 'andan vestidos los naturales de la provincia de Paria como todos los demás, y traen por ornamentos en las cabezas un tocado a manera de bonetes pequeños hechos de lana' (Cieza de León 2005[1553]: 267). ${ }^{2}$ As he travelled through the Andes, the people's headdress, in particular, attracted his attention and he referred to it as signalling the wearer's ethnic affiliation and gender identity. In contrast, he did not see the garments of the inhabitants of Paria as being particularly distinctive compared with those of other peoples in the Andean highlands.

This lack of ethnic distinctiveness, apart from the headgear, provides a significant starting point in an examination of people's dress from the highlands of the far south of Peru (Figure 1). In this article, I present descriptions of men's and women's garment types as well as of fragments of garments that have been considered to be 'provincial Inka' in style (Rowe 1992), dating from the period when highland communities established enclaves in coastal valleys. These textiles have a camelid fibre warp and weft, are woven in warp-faced or warp predominant techniques, and they make use of a particular iconographic repertoire that can also be detected in certain ceramic designs belonging to the Collao and to the Late Horizon, a period during which the highlands of the far south of Peru came under Inka control.
The textile tradition identified in this article was perhaps shared by different highland communities east of the western Cordillera de los Andes in the Department of Puno, including Qolla and Lupaqa peoples, who were named in documentary sources during the Colonial Period, and by inhabitants of the sierra in the Department of Arequipa west of the Cordillera. My interpretation of the available evidence suggests that this textile tradition was not the exclusive preserve of one discrete population. A warning is in order, lest readers of this article be tempted to make a one-to-one correspondence between the textiles and a historically named community of people. The difficulty Cieza de León had in distinguishing between the main garments worn by people is reinforced by the evidence I present here, based on the study of dress types, iconographic motifs and associated ceramic designs.

In what follows, I briefly review literature published on other textile traditions in the far south of Peru and far north of Chile, to provide a background for this newly identified textile tradition. Details are provided of some of the known places where the textiles have been found. Men's tunics are described, then women's dresses, plus other items, including bags. There follows a discussion of documentary and archaeological evidence, which provides contextual assistance to suggest where the textiles might have been woven. A concluding discussion considers how items of dress were gendered, using entries in the dictionary compiled by the Italian Jesuit Ludovico Bertonio (1612). Like Cieza de León, he found people's expressed their ethnicity in headgear, rather than in their main garments. His dictionary entries, however, provide extremely useful information on gender distinctions, helping to demonstrate how the textiles were worn.

1. 'They [the men] and their women go around dressed in wool'. All translations are mine unless otherwise stated. The 'wool' to which Cieza referred is likely to have been camelid fibre.

2. 'The natives of the province of Paria go around like all the rest, and wear for ornaments on their heads a headdress in the manner of small cap made from wool'. 


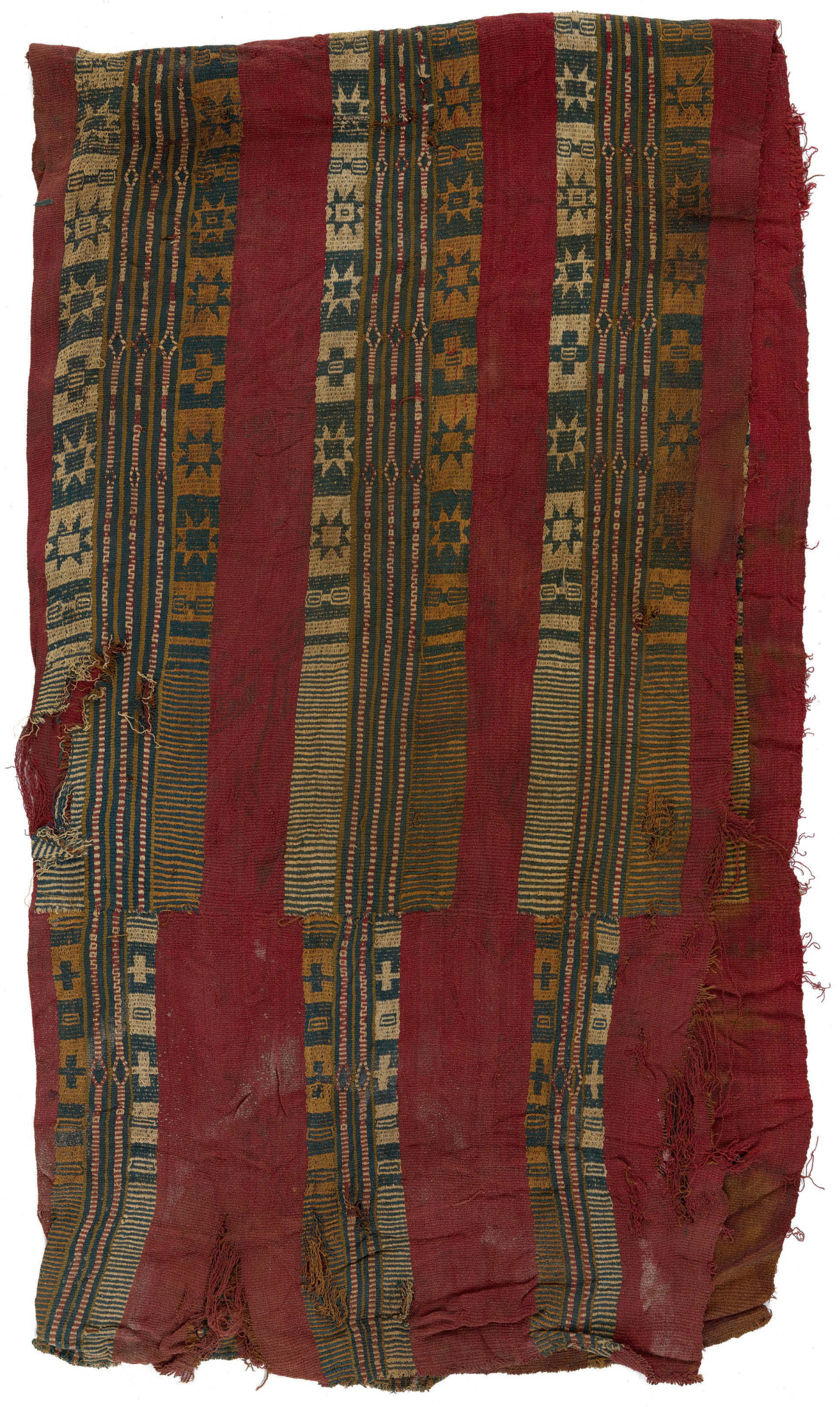

Figure 1. Half of a tunic from the highlands, far south of Peru, woven in warp-faced plain weave, complementary-warp weave pattern stripes (with an uneven warp count), transposed-warp rhombuses in narrow red and white stripes, and a discontinuous warp. A surviving portion of the seam is visible at the upper right of this view.Textile Museum, Washington DC TM1961.30.210, Burton I. Jones. 


\section{Textile traditions in the far south of Peru and far north of Chile}

Arid environmental conditions in coastal valleys favour the preservation of textiles whereas the finds of textiles on highland sites are extremely rare. Scholars have, in particular, made considerable advances in identifying the textile traditions of coastal peoples in the far south of Peru and the far north of Chile, especially after the disintegration of the Wari and Tiwanaku empires from about AD goo to 1000. In Peru, a tradition known as Ilo-Tumilaca became focused in the western valleys of the piedmont, with an equivalent called Cabuza in the far north of Chile (Boytner 1998). During the period between c.90o to c.1350, a different tradition called Chiribaya emerged and became strongly associated with people settled in coastal locations (Umire and Miranda 2001: 58-59; Minkes 2005). Chiribaya people were culturally related to other groups known as Maytas in the Azapa Valley, in the far north of Chile (Horta 1997: 81; Minkes 2005: 248). These textile traditions have analogous pottery styles. Aspects of the Chiribaya tradition were inherited in the San Miguel, Pocoma and Gentilar phases of a ceramic tradition lasting from c.1250 until c.1550. Its distribution was coastal, south of the Tambo Valley in Peru and northern Chile (Uribe Rodríguez 1999: 207-218; Covey 2000: 125). In the Lluta and Azapa Valleys these ceramic phases are associated with changing textile styles which, together, constitute what is known as the Arica culture (Ulloa 1982a, 1982b; Horta 2005).

Mary Frame's comprehensive study of male and female garment types belonging to a highland tradition known as Chuquibamba, dated between 1000 and 1475, provides another milestone in textile research from the south of Peru (Frame 1997-98; Tessier-Brusetti 2016). Chuquibamba ceramics occur with motifs painted in polychrome as well as black on red variants, having been identified in the 1940 s by Alfred L. Kroeber (1944: 19-22, 145-146). Linear pottery designs in black on red have a parallel in the black outlining that also occurs in some Chuquibamba textiles (Frame 1997-98: 4). The textiles were woven on a wide upright loom using camelid fibre warp and weft, the patterning executed in weft-faced techniques (Figure 2). While Chuquibamba itself is in the Río Ocoña drainage, other examples have been found in coastal locations where the Majes-Camaná and Sihuas-Quilca Rivers drain into the Pacific. The northernmost finds of Chuquibamba textiles are reported from cemeteries in the Nasca Valley and Ica, with the distribution reaching as far south as Mollendo.

The main garment of women and men in coastal and piedmont valley communities was a camisa or tunic that was seamed under the arms (Minkes 2005: 218-221). In the sierra of Arequipa and in Titicaca lakeside communities, women wore an untailored dress wrapped round the body, while their male counterparts wore tunics. This also was the practice of Chuquibamba women and men (Frame 1997-98) (see, again, Figure 2).

Although eight-pointed star motifs figure prominently in both Chuquibamba and the newly identified tradition, the styles are distinct. Many of the other motifs are unalike. In Chuquibamba textiles, motifs frequently appear in tabbed rectangles repeated in diagonal alignment (Figure 2), a patterning analysed by Frame (1997-98). This form of spatial organization is strikingly different from the vertical stacking of patterns in Titicaca textiles. There are also marked differences in the colour palettes used, because clear light green, yellow and bright red are characteristic of Chuquibamba textiles, while dark red, dark blue and yellow ochre combined with white appear in the warp-faced textiles (Rowe 1992: 33).

The eight-pointed star is a motif with ancient antecedents, but the form in which it occurs in late pre-Hispanic times acquired a particular currency during the period of Inka dominance in the second part of the fifteenth century (Rowe 1992: 31-33). Volutes in the shape of an 'S' or a reversed ' $S$ ' and rhombuses with four hooks also had a long currency going back at least to Tiwanaku or Nasca times. Motifs used characteristically in the belts, bags and carrying cloths of Chiribaya and Maytas textiles survived the decline of these traditions after c.1350. During the Late Horizon, weavers in both the highlands and coastal valleys adapted them for use in tunics, loincloths, dresses and other items. In addition to eight-pointed stars and rhombuses with four hooks, other motifs that spread widely include stylized serpents with a head at each end, 'frogs' with three digits, and a hexagonal 'eye' motif (Frame 1997-98: 13, figure 19c; Horta 1997: figures 4 and 36; Dransart 2000: 149, 153; Umire and Miranda 2001: figures 33 and 34; Minkes 2005: 142 and 249).

Recycled ancient motifs can make some of these textile traditions look superficially similar. Luis Lumbreras (1974: 197) included an image of a textile from the tradition defined in this article alongside two Chuquibamba textiles, labelling all three as Ica-Chincha in style. Despite Ann Rowe's (1992: 33) pertinent questions intended to help disentangle the relationships between the traditions, and Frame's (1997-98) precise definition of Chuquibamba textiles, some authors have categorized Late Horizon warp-faced textiles as Chuquibamba (Arnold and Espejo 2012: 203, 2015: 256), Chiribaya (Rosenzweig and Artzi 2011: 100, figure 9) or hybrid Chiribaya-Chuquibamba (Tessier-Brusetti 2016: 97, figure 2). María Jesús Jímenez Díaz (2004: 396-397) recognized that the warpfaced textiles discussed here belong to an Inka Provincial 


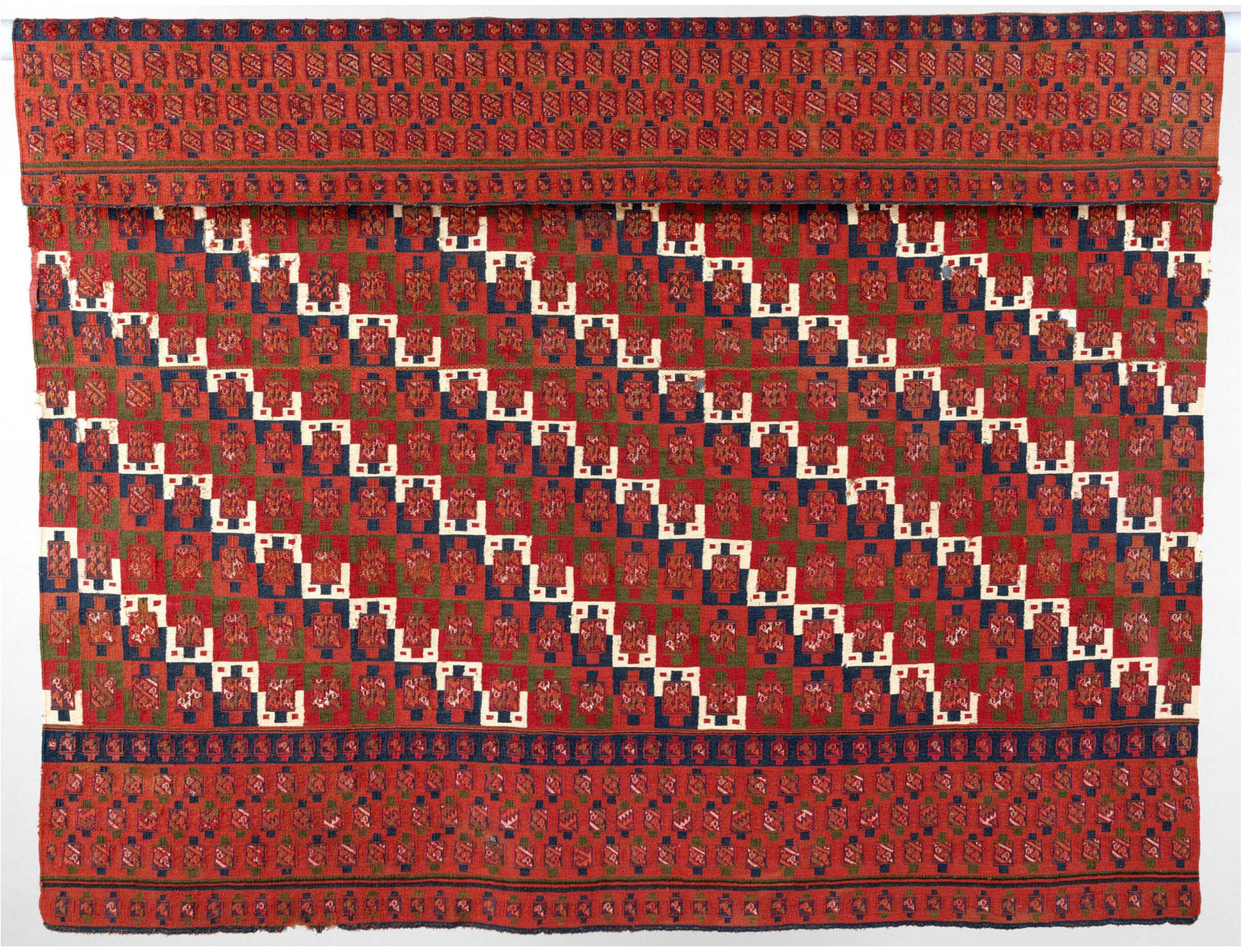

Figure 2. Chuquibamba style woman's dress, woven in weft-faced weaves. Metropolitan Museum of Art. Purchase, Pfeiffer Fund and Arthur M. Bullowa Bequest, 1995 .

category but regarded them as being possibly hybrid 'Chuquibamba-Inka. 3

The catalogue of the Museo Nacional de Arqueología, Arte e Historia del Perú provides an alternative attribution, assigning textiles of the type considered here to the Complejo Arqueológico de Churajón in the Chili Valley, in the Department of Arequipa. ${ }^{4}$ Churajón pottery includes polychrome wares with motifs cursorily painted in black and white on red. Other than an example of a six-pointed star with an elliptical centre (Szykulski 2010: Fig. 108H), there are few correspondences in the published literature between the motifs painted on pottery and those woven in textile. Because
Churajón polychrome wares are painted in similar colours to ceramics from Allita Amaya in Lupaqa territory (Tschopik 1946: 34), and from Mollo, in Bolivia, it might seem that stylistic analogies existed between them. Józef Szykulski (2010: 277, 298-300), however, argues that these apparent correspondences resulted from the independent development of these pottery styles after the collapse of the Tiwanaku state. As will be demonstrated below, there is a specific point of reference between Allita Amaya pottery and the textiles. The designs on Churajón pottery therefore do not provide a basis for lending their name to these textiles with their considerably more precise designs. This lack of

3. At the time of writing this article (2019), misattribution of warp-patterned textiles to the weft-patterned Chuquibamba tradition also occurs in some online museum catalogues. Such textiles include Am1954,05.450 and Am1971,02.8 in the British Museum; o0o0238629 in the Museo Nacional de Arqueología, Arte e Historia del Perú; and 2000.3.124.a, 2000.3.124.b, 2000.3.124.c and 2007.1.14 in Bryn Mawr College Art and Artifact Collections.

4. Museo Nacional de Arqueología, Arte e Historia del Perú online catalogue, accession numbers o0o0141843, 0000142724 and 0000252833. 


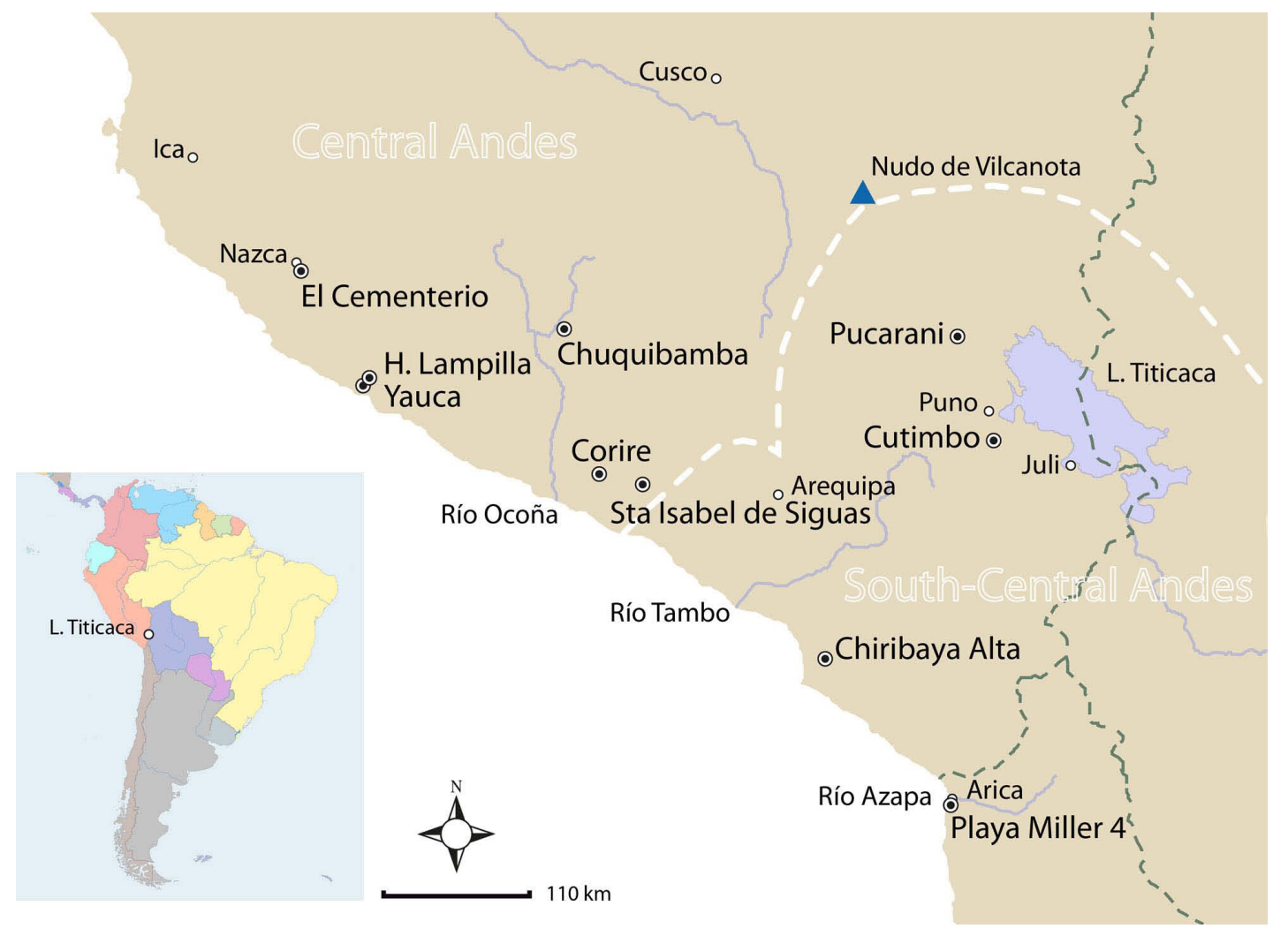

Figure 3. Map of southern Peru showing places mentioned in the text. The white dashed line shows the approximate division between the Central and the South-Central Andes. correspondence, however, does not preclude that the sierra of Arequipa formed part of the broader region in which the textiles were worn. I propose to call these Titicaca Lakeside textiles.

\section{Where textiles in the newly defined tradition have been found}

With few exceptions, most of the textiles studied in museum collections for this article lacked information concerning the location where they were found. Max Uhle recovered three fragments from a man's tunic and women's dresses from tombs on land at the Hacienda Lampilla, situated one mile below Mochica in the Yauca Valley (Figure 3). They are now in the collections of the Phoebe A. Hearst Museum of Anthropology (accession numbers 4-8216, 4-8217 and 4-8218), which has another fragment that Uhle found at Yauca (48164). ${ }^{5}$ The Inkas established an administrative centre at Tambo de Jaqui on what was later to become the Hacienda Lampilla, in an area that had not previously been subject to centralized administration (Menzel 1959: 128). ${ }^{6}$
The excavation of woman's tomb in the San Francisco necropolis near Corire, in the Department of Arequipa, produced a fragment of a woman's dress. Although the burial had been disturbed by grave robbers, archaeologists recovered the fragment, a textile bag and the remains of pottery, including Inka wares (Szykulski and Cárdenas Sumida 1999: 390-392, Figs 7 and 9).

A fringed bag in the collections of the Peabody Museum, Harvard, is reported to have come from the Majes Valley, near Santa Isabel de Siguas (46-81-30/5533). A tunic fragment, also in $\mathrm{PMH}$, is stated to have come from El Cementerio, a site south of the river near Nazca (46-77-30/7386). Another fragment in this museum's collections is said to have come from Huacho on the central coast of Peru (4212-30/3739). This last piece is an outlier in the distribution otherwise occurring between Ica and Mollendo.

One more Titicaca Lakeside tunic fragment occurring in an extraordinary context covers a folder-like container for storing the Exsul Immeritus Blas Valera Populo Suo e Historia, a manuscript dated 1618 , which was written in Latin and Quechua in the hand of Blas Valera (Laurencich Minelli 2000: 155 and 169, figure 1). According to Laura Laurencich

\footnotetext{
5. Henceforth the name of the museum is abbreviated after the first time it is used in this text. For a list of the museums and their abbreviations, as well as the URLs of their online catalogues, please see the list of Museum Collections and Abbreviations below. 6. A tambo, or tampu in Gonçalez Holguin (1608: 337), is glossed in Spanish equivalents as 'venta, o meson' [an 'inn'].
} 
Minelli (2005: 26), the use of the textile and the metaphorical language of the document combine to convey the idea of Inka culture on the periphery of empire that would have nourished its author, Blas Valera, who felt himself to be 'Indian' in colonial society.

\section{Forms of garments and accessories:}

\section{Men's Tunics:}

Of the textiles included in this study, men's tunics and bags are more likely to survive to a degree of completeness compared with other garments, such as women's dresses. Loin cloths have yet to be recognized in museum collections. Complete examples of tunics include one in the Textile Museum, George Washington University (Rowe 1992: figure 36), another in the MNAAHP (inventory no oooo141843), and a third in the Museo de América, Madrid (inventory no 14676; Jiménez Díaz 2004: 396-397). Two further examples, from the Ohara Gallery of Art, have been published in Misugi (1985: 90-91, Plates 155 and 157). Fragments are more frequently preserved (Figures 1, 4, 5 and 7).

Tunics were assembled from two or more panels, woven in warp-faced techniques and stitched together to make a garment broader than tall. The warp was oriented vertically in the garment as worn. Characteristically, the panels are subdivided through the use of a discontinuous warp dovetailed round a horizontal thread (Rowe 1977: 103). The garment is articulated internally in segments but, because the division between segments is not always marked by changing the colour of the warp threads, from a distance the articulation might barely be noticed (Dransart 2014: 226-227). The segments mark the shoulder line of the tunic or form a lower panel. The pattern stripes in the lower panel are usually narrower than in the upper, making the disjunction between the two segments more obvious.

A characteristic feature of the Titicaca Lakeside tunics is that the pattern stripes begin and end in horizontal bars, formed by alternating two different colours of warp threads in plain weave. This design is termed peinecillo in Spanish and k'uthu in Aymara (Espejo and Arnold 2014: 305-308). In contemporary Aymara textiles, which are woven with four selvedges, a short area of $k$ 'uthu often marks where the warp threads have become too short for the weaver to lift to form the pattern and she enters the final weft threads using a needle. The weavers of these textiles instead made extensive use of k'uthu to form part of the design. In tunics, $k$ 'uthu occurs at the lower edges of the upper and lower segments of panels separated through the use of a discontinuous warp (Figure 5).
The pattern stripes are grouped. Broader stripes containing decorative motifs stacked one above the other are separated by two or three narrow stripes executed in red and white $k$ 'uthu and embellished with other patterns. At intervals, the warp threads are transposed to form a rhombus shape (Rowe 1977: 104). Half of the threads in the narrow stripe take a diagonal trajectory to the left and the other half to the right, with both sides coming back together to complete the rhombus shape. This very distinctive form of patterning is characteristic of textiles produced across the highlands and coast of the far south of Peru, northern Chile and north-west Argentina (Rowe 1977: 104; Dransart in press). Figure 1 presents an example of how it was used in tunics of the newly identified tradition and Figure 6 in a carrying cloth from a coastal site south of the Azapa Valley, Chile, during the Period of Regional Developments, c.110o to c.1476 (also known as the Late Intermediate Period).

The broad pattern stripes are executed in a complementary-warp weave, alternating between light on dark and dark on light, using a technique of selecting warp threads based on an odd count (Arnold and Espejo 2015). Usually a vertical colour change divides the stripe; frequently dark blue alternates with tan or yellow ochre on one side of the stripe and dark blue alternates with white on the other (Figures 1, $4,5,7)$. Exceptions include one of the complete tunics in the OGA (Misugi 1985: 90, no 155), a fragment in the MNAAHP (T-19744 in Dransart 2014: 227), as well as the panel in Figure 7. These three examples lack a vertical colour division.

Eight pointed stars and cruciform shapes are the most commonly encountered design motifs in tunics. Ann P. Rowe (1992: 31) described the visual appearance of the star as a 'square with two right triangles projecting off each of the four sides' and commented that the term is purely conventional since it is not known what the motif was called in the past. Because Titicaca Lakeside textiles have sometimes been assigned to Chuquibamba, it is important to note that the centre of the star is of the same colour as the background, whereas in Chuquibamba textiles it is different. A different coloured centre in an eight-pointed star also occurs on Chuquibamba ceramics. This feature might have been inspired by the weave because tapestry gave the weaver more freedom to change the weft yarn than weaving the pattern in the warp using complementary pairs of yarns in two colours.

To term the cruciform shape a 'cross' is equally conventional (Figures 1 and 4). Similar motifs are known in textiles and stone carving from the pre-Tiwanaku culture of Pukara (c.400 BC - c.AD 350) (Cuynet 2010: 222, Fig. 6).

Another motif, which sometimes occurs in pattern stripes, appears to have a figurative referent because it is based on a rhombus with 'limbs' projecting at four corners, 


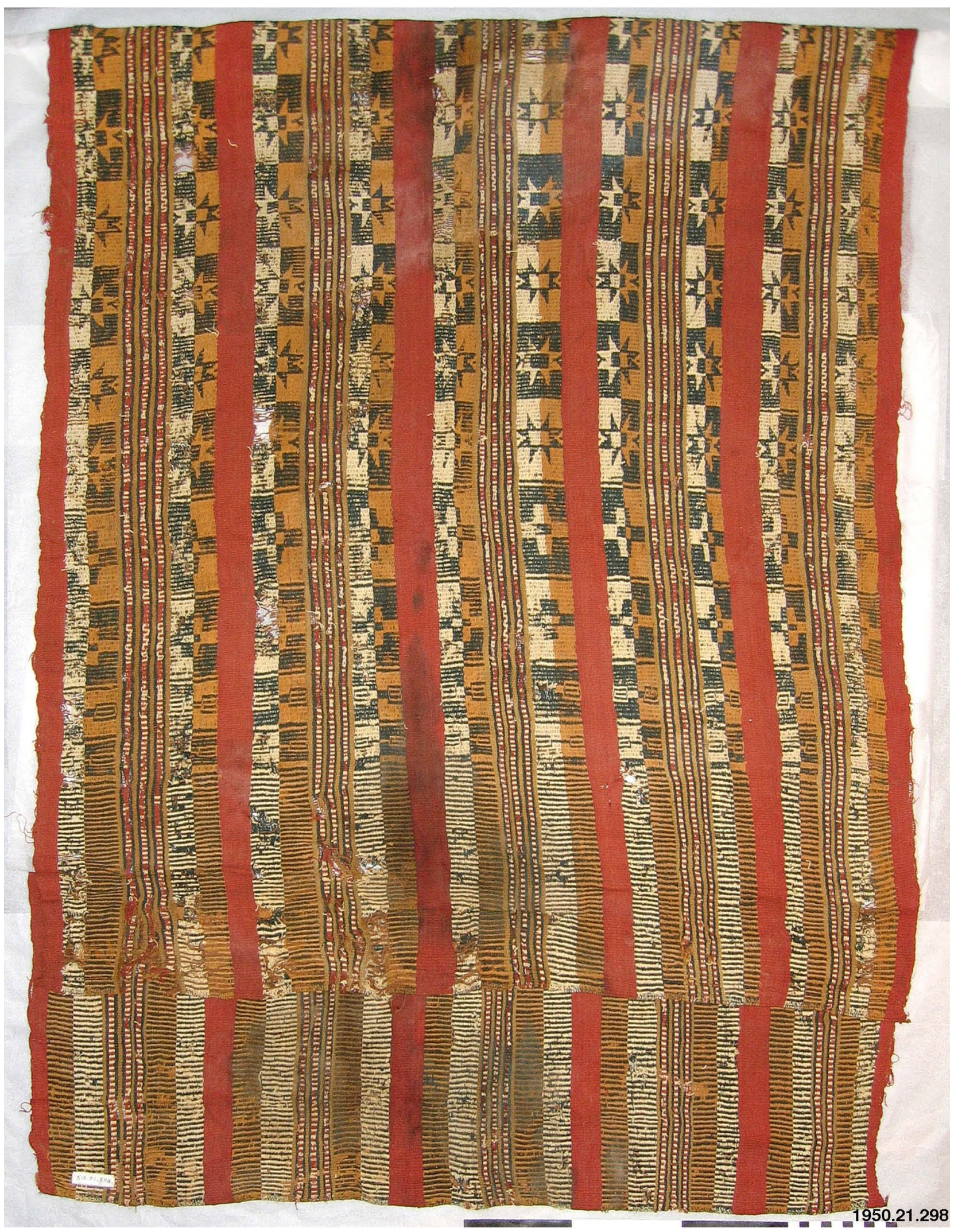

Figure 4. Tunic panel from the highlands, far south of Peru, woven in warp-faced plain weave and complementary-warp weave (with an uneven warp count). There are long areas of $k^{\prime} u t h u$ or peinecillo bars at each end of the panel. Varldskultur Museerna: Etnografiska, Stockholm, 1950.21.298 


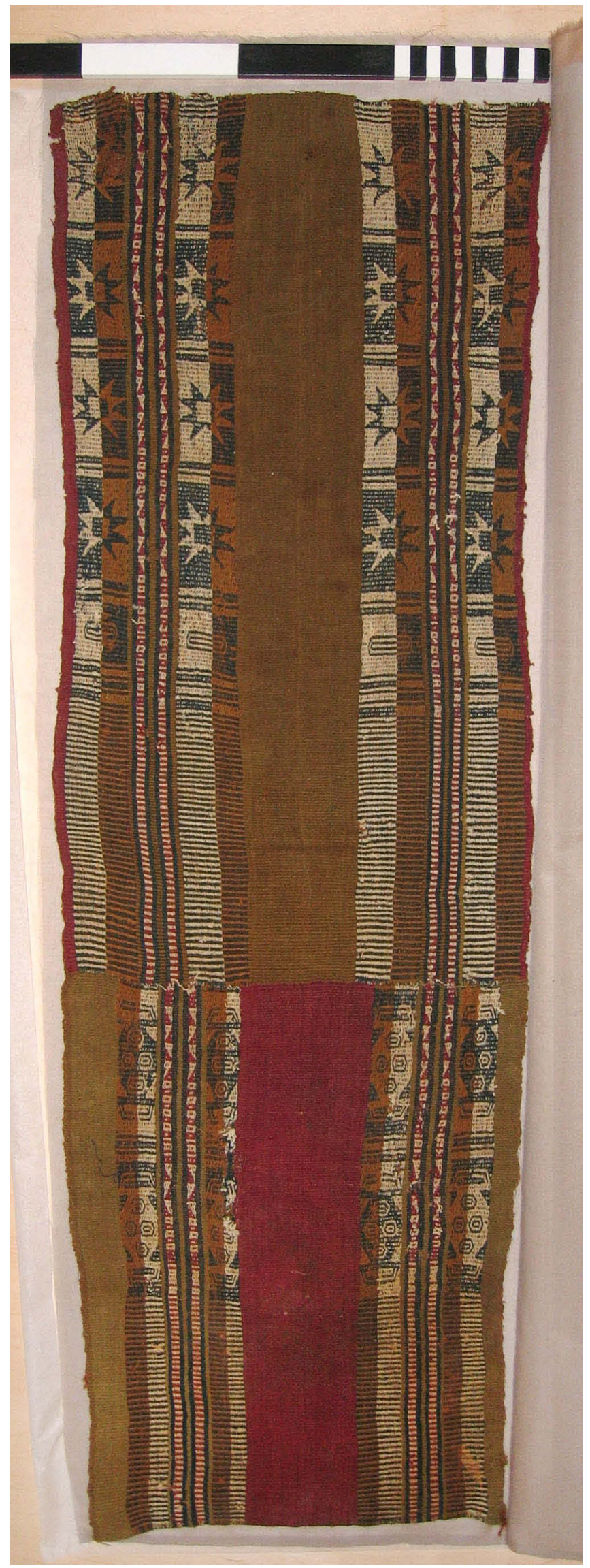

Figure 5. Fragmentary panel from the highlands, far south of Peru, woven in warp-faced plain weave, complementary-warp weave (with an uneven warp count) and a discontinuous warp. Varldskultur Museerna: Etnografiska, Stockholm, 1951.24.0025

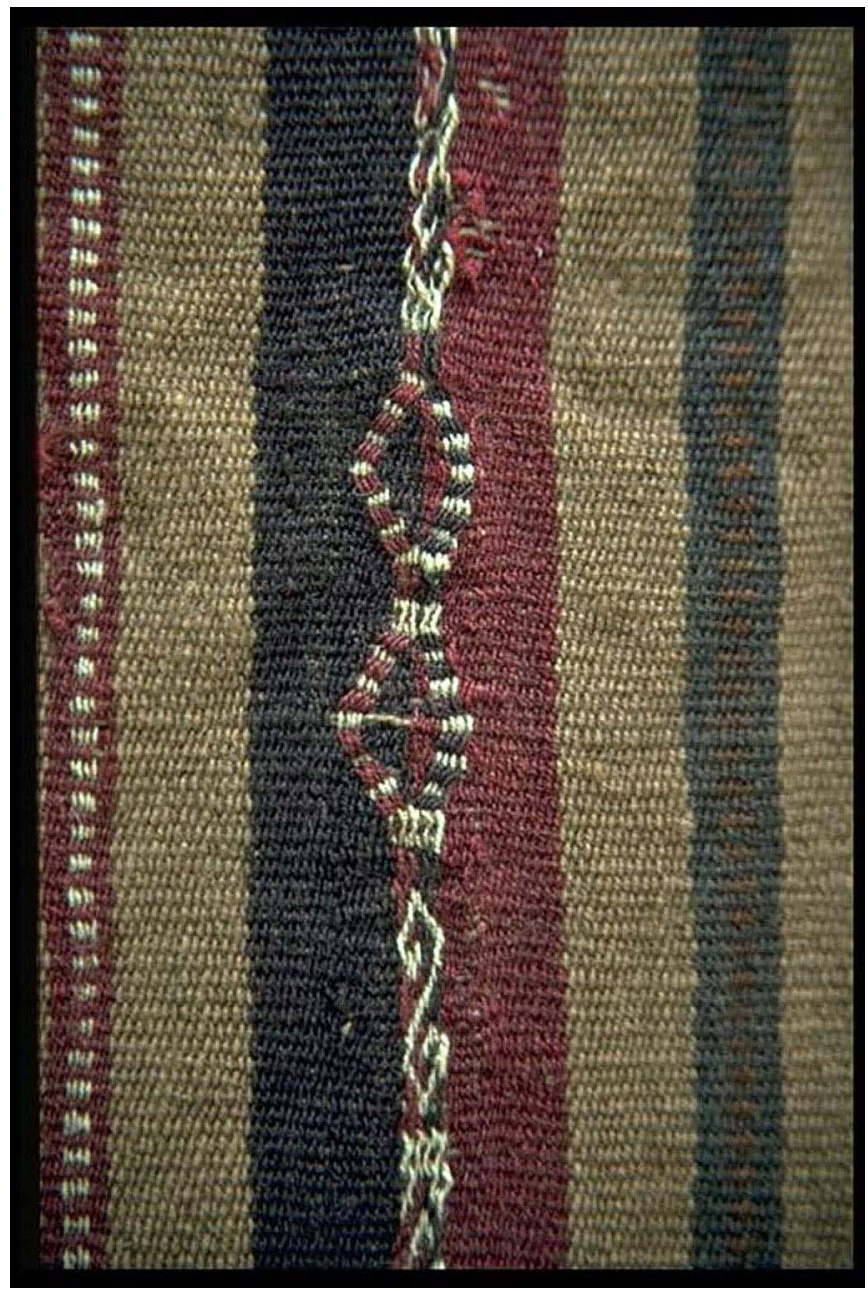

Figure 6. Detail of a carrying cloth belonging to the Arica culture, No 7003 from tomb 27, site Playa Miller 4 at the mouth of the Azapa Valley, northern Chile. This detail shows warp-faced plain weave stripes (including narrow stripes of $k^{\prime} u t h u$ ) and transposed warp rhombuses. Photograph: Penelope Dransart, by courtesy of the Museo Universidad de Tarapaca San Miguel de Azapa. 


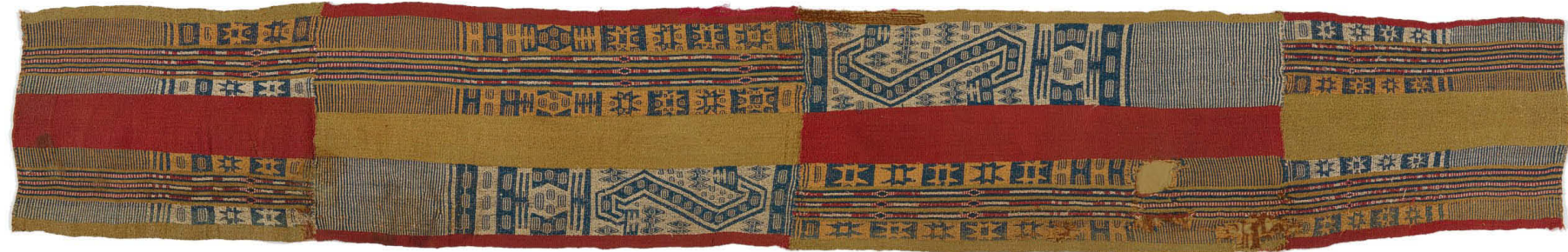

Figure 7. Tunic panel from the highlands, far south of Peru. It is woven in warp-faced plain weave, complementary-warp weave (with an uneven warp count), transposed-warp rhombuses in narrow red and white stripes, and a discontinuous warp. Textile Museum, George Washington University TM91.46o, acquired by George Hewitt Myers in 1950.

each limb having two or three 'digits' (Figure 7). It is, perhaps, a more stylised version of zoomorphic spiders or lizards that featured in the earlier Chiribaya and San Miguel textile traditions (Minkes 2005: 142, figure 7.33e and f). Less common in tunics than the star and cross motifs, it sometimes is incorporated into the lower part of a panel separated from the rest of the tunic through the use of a discontinuous warp (Figure 5). ${ }^{7}$ In a fragment in the collections of the PMH (46-77-30/7386), however, this motif features above the k'uthu bars in the main panel.

An elaborate double-headed serpent may accompany the four-armed rhombus motif. One of the OGA tunics is particularly rich in motifs and includes more than one variant of a double-headed serpent (Misugi 1985: 91, No 157). Some fragments in the collections of the TM also incorporate fourarmed rhombuses and double-headed serpents (Rowe 1977: 72-73 and 103, figures 83 and 122). ${ }^{8}$

The colours used in tunics include red, yellow ochre or tan, dark blue (which sometimes has a green cast) and white. There was a range of variation, however. OGA Tunic 155 and T-19744 in MNAAHP both display large areas of fawn vicuña-coloured plain weave ground combined with pattern stripes containing a simple iconographic repertory. In Figure 1, the iconography is also simple, but the ground is strong red in colour. OGA tunic number 157 (Misugi 1985: 91) and MNAAHP oooo141843 display a greater range of iconographic complexity combined, in the case of the former, on a red ground and, of the latter, on a broadly striped red and dark blue ground.

\section{Women's dresses}

The identification of women's wrap-around dresses presents a greater challenge than is the case with men's tunics. A large textile in MNAAHP (T-19534), now incomplete, might have been a woman's garment because it is made from three webs sewn together, the central panel narrower than the outer two (Dransart 2000: 136, 153, figure 11). Assembling a large cloth from two or three panels is characteristic of the main garment worn by Inka women (Rowe 1995/1996: 12-13; Acosta Luna and Plazas García 2011: 4).

In textile T-19534, pattern stripes in complementarywarp weave are repeated across much of the width of each web, with two plain weave stripes, in dark red and yellow ochre, running along the side selvedges. Some of the complementary-warp weave stripes are flanked by two narrow stripes of complementary-warp weave, consisting of right-angled triangles stacked on top of each other. The triangles, when paired together across the two stacks, form isosceles triangles composed of two different colours (PAHMA 4-8216, Figure 8). In some cases, triangles are reflected in mirror-image to form a rhombus consisting of four conjoined right-angled triangles (Figure 9). Another example using this configuration of right-angled triangles to create rhombuses occurs in the textile from the Necrópolis San Francisco near Corire (Szykulski and Cárdenas 1999: Fig. 9).

These triangles have a counterpart in narrow painted designs appearing on Inka pottery. Catherine J. Julien (1993: 194 and 195, figure 7.6) illustrated a large fragment of an aríbalo in Sillustani Museum, which she considered to be a local variant of Mode B Cuzco-Inka ware. Two narrow stripes containing the stacked triangles flank the vessel's main panel and the triangles, dark in colour, stand out against the light coloured right-angled triangles forming the ground.

Stacked triangles also occur on a sherd Marion Tschopik (1946: 33, figure 19c) assigned to an Inka-related ceramic style, which she termed Urcusuyu Polychrome, with one stack of three triangles painted white on black and a second stack of triangles painted red on white. These pottery designs are more simple than those of the textiles because, even in polychrome, the triangles are painted in a single colour without internal subdivisions. In the textiles, the two 


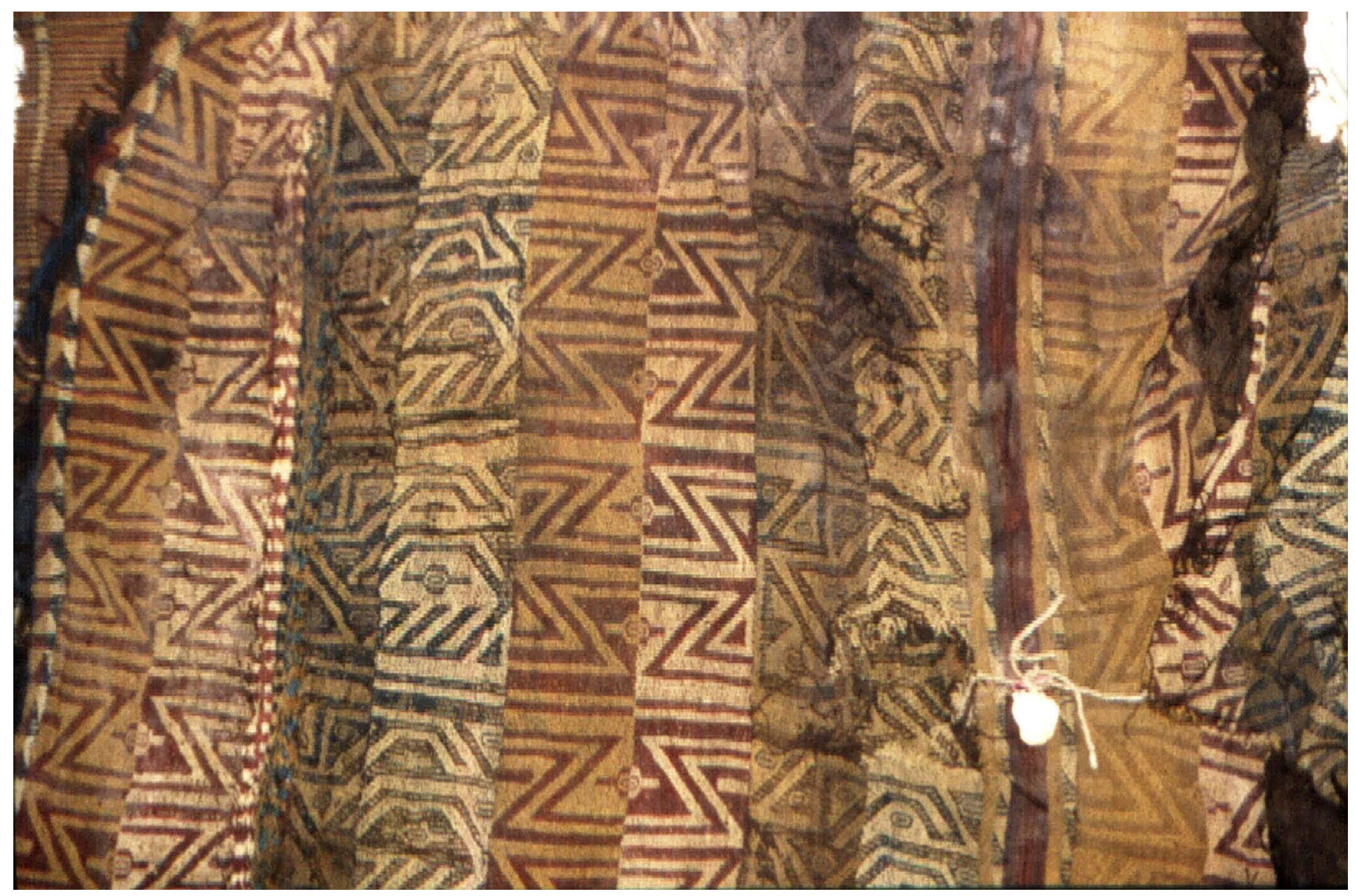

Figure 8. Fragment of a tentatively identified woman's dress from the highlands of the far south of Peru, depicting repeats of the 'butterfly' motif accompanied by a narrow stripe of paired right-angled triangles joined to form isosceles triangles. Phoebe A. Hearst Museum of Anthropology, 4-8216.
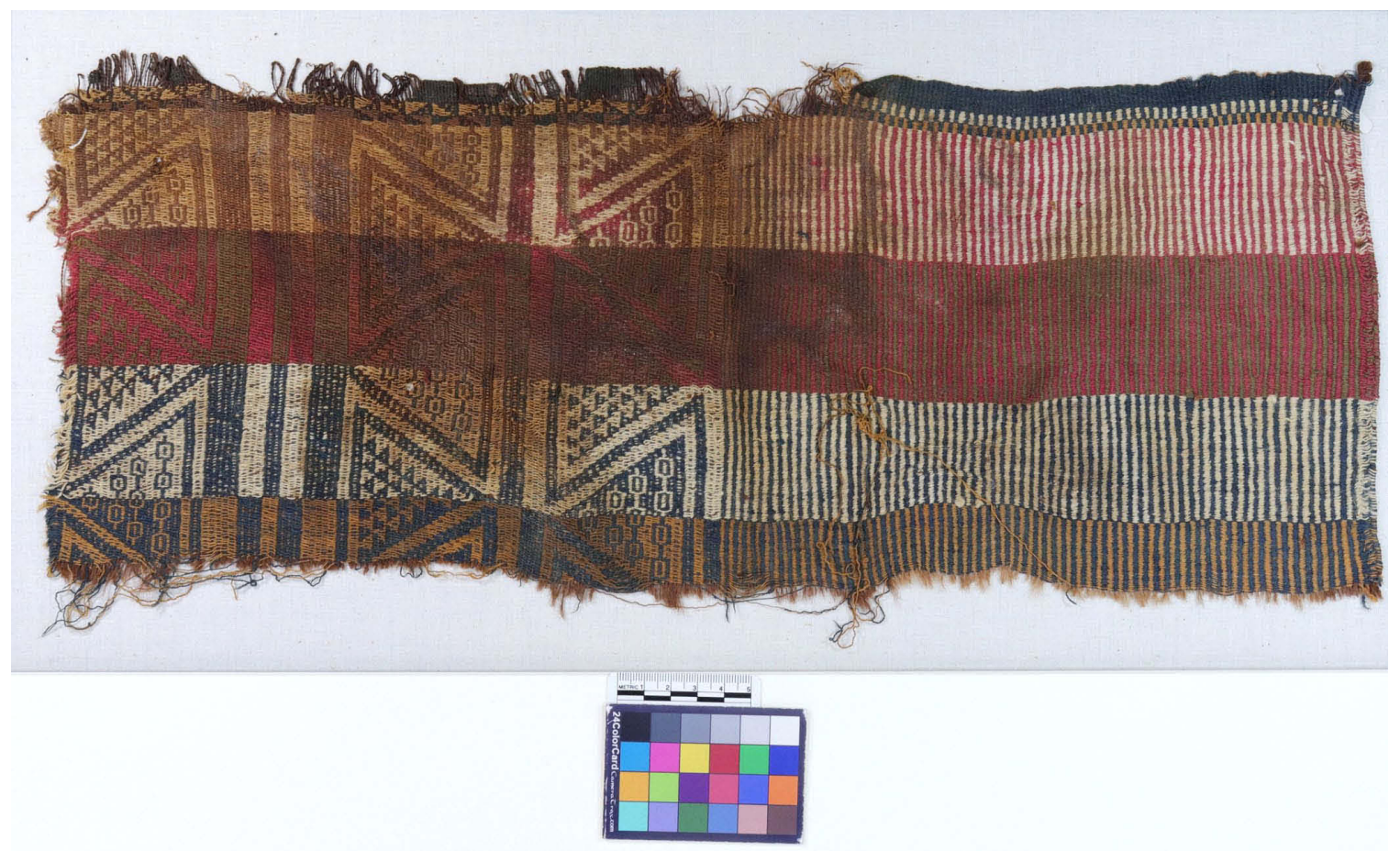

Figure 9. Fragment of a tentatively identified woman's dress, found by Max Uhle in tomb at Hacienda Lampilla, woven in warp-face plain weave and complementary-warp weave (with an uneven warp count). Note the narrow double stripe containing paired light- and darkcoloured right-angled triangles, reflected to make quadripartite rhombuses, close to the side selvedge at the top of the textile in this photograph. Phoebe A. Hearst Museum of Anthropology, 4-8217. 
different colours of right-angled triangle unite visually to form one isosceles triangle and may also be combined to form rhombuses. These narrow stripes seem to serve as a signature of highland identity under the spread of Inka dominance. They appear to be associated preferentially with women's dresses rather than men's tunics.

The broader pattern stripes in women's garments contain double-headed serpents similar to those occurring in men's tunics. Sometimes they are accompanied by another motif, which is only exceptionally present in the tunics. This second motif consists of two large isosceles triangles joined at the apex with a horizontal bar across the join. Both motifs appear on MNAAHP's T-19534 and the second motif features on fragments 4-8216 and 4-8217 in the Phoebe A. Hearst Museum of Anthropology (Figures 8 and 9). Because the design is bisected vertically by a colour change, one might be tempted to 'read' the design as a repeating series of ' $\mathrm{Z}$ ' shapes. In the card index files of PAHMA, textile 4-8216 was described as 'Fragment with white, yellow, blue, and red stripes containing "Z" design'. The design is possibly an extremely abstract rendition of a butterfly. ${ }^{9}$

Guaman Poma's early seventeenth-century drawing of the ninth Inka quya, or queen, shows Mama Ana Uarque wearing a shawl and a dress decorated with butterfly motifs (Figure 10). In his verbal description of the quya's garments, he wrote: 'y tenia su lliclla de rrosado y lo del medio blanco y su acxo de uerde y lo de auajo billpi[n]to y su chunbe de colorado' (Guaman Poma 1615: 137). ${ }^{10}$ His illustration seems to refer to the ninth quya's claim over the Collao by including a visual image associated with women's dress as worn in Titicaca Lakeside communities. Endemic butterfly species found in the south of Peru include the Neotropical polyommatine lycaenids with a pattern of dark spots under the wings. Examples are the Madeleinea colca, with spots on the underside of its fore and hind wings, and Nabokovia cuzquenha, with spots on the underside of the hind wings (Bálint and Lamas 1996: 130-131, figures 1-12). These butterflies feed on nectar in high altitude pasturelands. They are small and provide instances of possible sources of visual inspiration.

A characteristic feature of many of the woven butterflies is the horizontal bar at the point where the apex of one triangle meets the other to form the body. The weaver interchanged the warp threads in the complementary-warp weave to produce the butterfly's body as a simple bar (see Rowe 1977: 67). The wings of the butterfly display 'eyes' or spots, which are absent when painted on pottery.

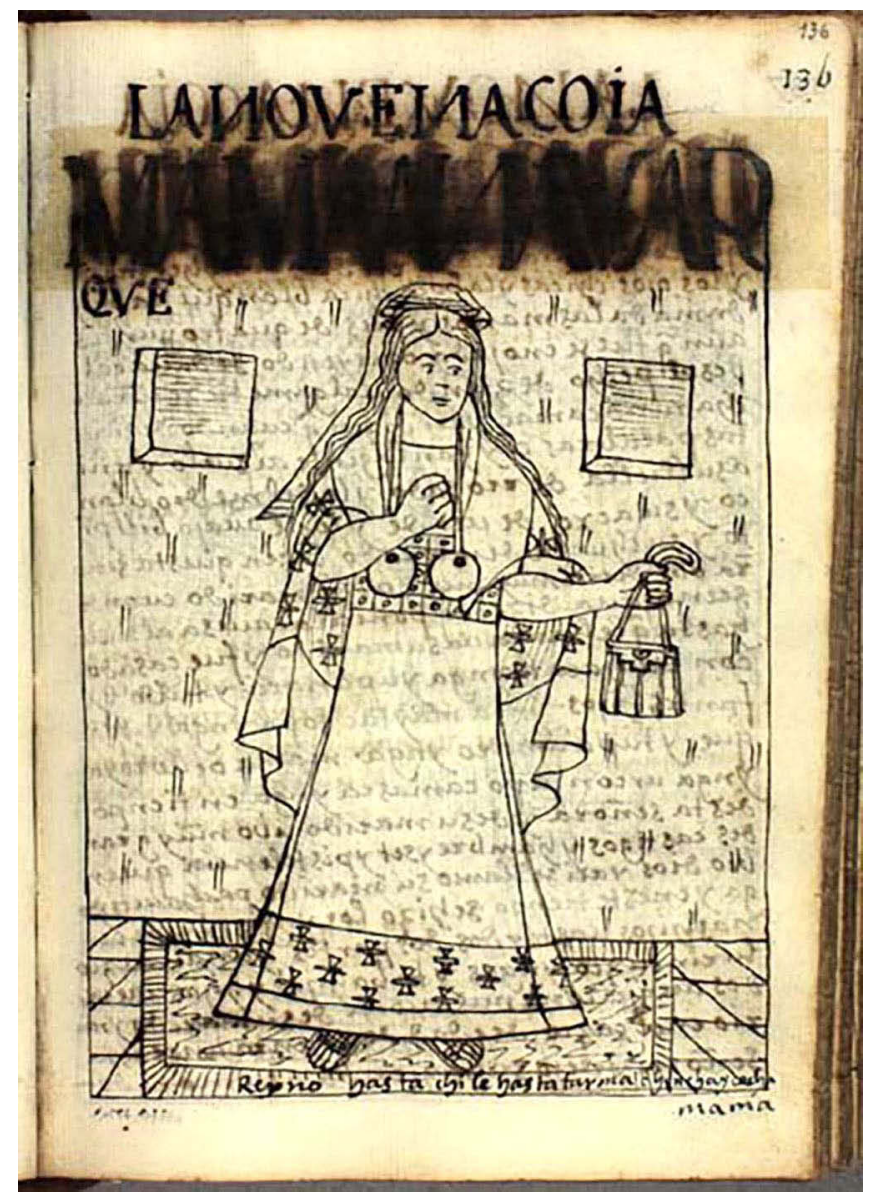

Figure 1o. The ninth Quya [queen] Mama Ana Uarque, with pillpintu ('small butterfly') motifs on her dress and mantle. By courtesy of Royal Danish Library, GKS $22324^{\circ}$ : Guaman Poma, Nueva corónica y buen gobierno (c. 1615), page 136.

In some textiles, the butterfly motif is further compressed with the omission of this horizontal bar. MNAAHP oooo252850 and TM 91.379 are both fragments in which a row of butterfly motifs is presented as paired isosceles triangles, joined at the point, with other triangles filling the negative spaces between the motifs. ${ }^{11}$ The body of the butterfly has disappeared, but the triangular wings are filled with up to fourteen 'eyes' or spots.

This compressed motif joined at the apex features in late pre-Inka pottery styles associated with the Collao. In reported examples, it is painted on the neck of Collao Black on Red jars (Tschopik 1946: 24, figures 9a, b, c, d and g; Arkush 2012: 312, Fig. 17) and on the body of Allita Amaya Polychrome jars, from a burial immediately south-east of Chucuito (Tschopik

9. I wish to thank Elena Phipps for commenting on the resemblance to a butterfly.

10. 'and her lliklla [shawl] of pink, and white in the middle, and her acxo [dress] of green with pillpintu [butterfly] below and her belt [chumpi] of red'. In the dictionary of Gonçalez Holguin (1608: 283), pillpintu is translated as 'mariposa pequeña' [small butterfly].

11. The fragment in the TM is illustrated in Rowe (1977: 72, figure 83). 
1946: 34, figures 20a, b and d). Collao Black on Red pottery is mostly encountered immediately north-west of Lake Titicaca, where it corresponds approximately to the area occupied by the Qolla people, with some indication that the distribution extends towards the south-east of the Lake (Carlevato 1988: $41,45)$. On the Collao and Allita Amaya vessels, the designs are cursive in appearance. Sometimes the butterfly motif has a solid infill or, alternatively, the interior space is crossed or hatched by a series of painted lines. The motif also is found neatly painted on the inside of an incomplete Taraco Polychrome bowl from Chucuito, a finely tempered ware with a white or cream-coloured paste (Tschopik 1946: 31-32, figure 18e). When the motif occurs in Inka aríbalos, it is painted in a controlled manner. ${ }^{12}$ The motif was known in communities surrounding Lake Titicaca before and during the period of Inka dominance. Dresses worn locally by at least some women in the highlands of the far south of Peru were therefore decorated with a motif associated with the Collao (the butterfly), flanked by a recognizably Inka design (the stacked triangles).

Long stretches of k'uthu are characteristic of the mostly fragmentary textiles cautiously identified here as having come from women's garments, which may be parts of the main dress or of the shawl that women surely used to cover the shoulders and arms. Unlike the men's tunics, however, these garments would have been worn with the warp oriented horizontally rather than vertically and the k'uthu bars would have appeared as vertical elements in the design.

\section{Belts, Bands and Pins}

Women's dresses were wrapped round the wearer's body, held in place at the waist by a belt and fastened with a long pin, one on each shoulder. Ludovico Bertonio (1612, I: 240, II: 185) stated that these pins were made from cactus spines or copper. Other materials are known from archaeological excavations. Two bronze dress pins were excavated from a burial of human remains inside a reused Inka urn at Cutimbo, near Puno, in Lupaqa territory (Tantaleán 2006: 137). Dress pins have also been reported from burials spanning the very end of the Late Horizon and early Colonial Period at an Inka-style building that was converted into a Christian church at Churajón, near Arequipa. These pins were made from cactus spine, bronze and silver (Szykulski 1998: 310-313).

Convincing examples of belts have yet to be identified in museum collections. The American Museum of Natural History has some narrow bands woven patterned with one or two narrow warp-faced stripes running along the length of the band. The narrow stripes split and diverge to form transposed-warp rhombuses. Catalogue number 41.0/3509 is $30 \mathrm{~mm}$ wide and, like the narrow k'uthu stripes and rhombuses on some of the men's tunics, the pattern stripe is woven in red and white yarns. This band is therefore related to the design of men's tunics.

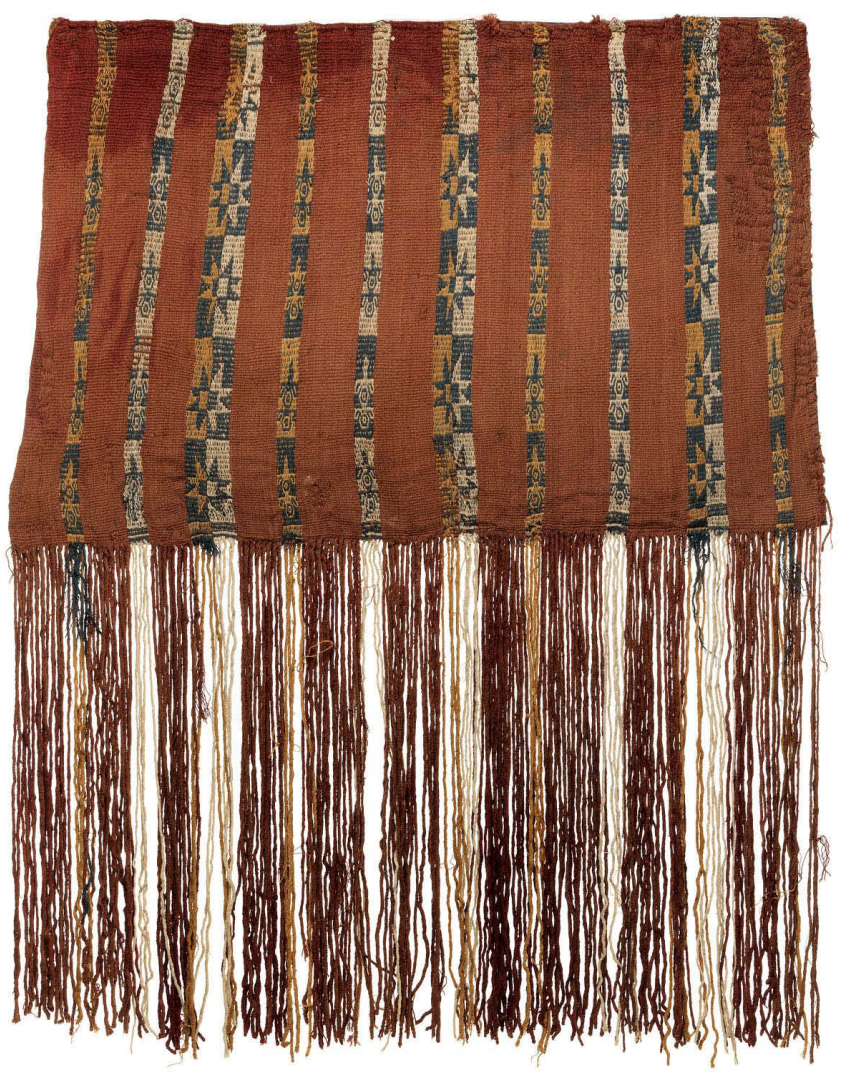

Figure 11. One side of a bag from the highlands of the far south of Peru, woven in warp-faced plain weave and complementary-warp weave (with an uneven warp count). Museum aan de Stroom, Antwerp, donated by Pollet Liban, AE.1999.0910.

\section{Bags}

Figures 11 and 12 show a bag in the collections of the Museum an der Stroom, Antwerp (AE.1999.0910), of which one side has survived. It is impressively large in size, measuring $400 \mathrm{~mm}$ deep (without the fringe), with a maximum width of $645 \mathrm{~mm}$. The patterning of the bag resembles that found in men's tunics. Plain red warp-faced weave stripes, now faded, are separated by wide complementary-warp woven stripes containing eight-pointed stars, the centre of which is the same as the ground, and narrow stripes containing stylized

12. See, for example, Matos (1999: 140) for an example of a Cuzco-Inca Mode A aríbalo in the Museo Inka del Cuzco, and catalogue numbers ooooo79577 and ooooo67122 in the MNAAHP. 


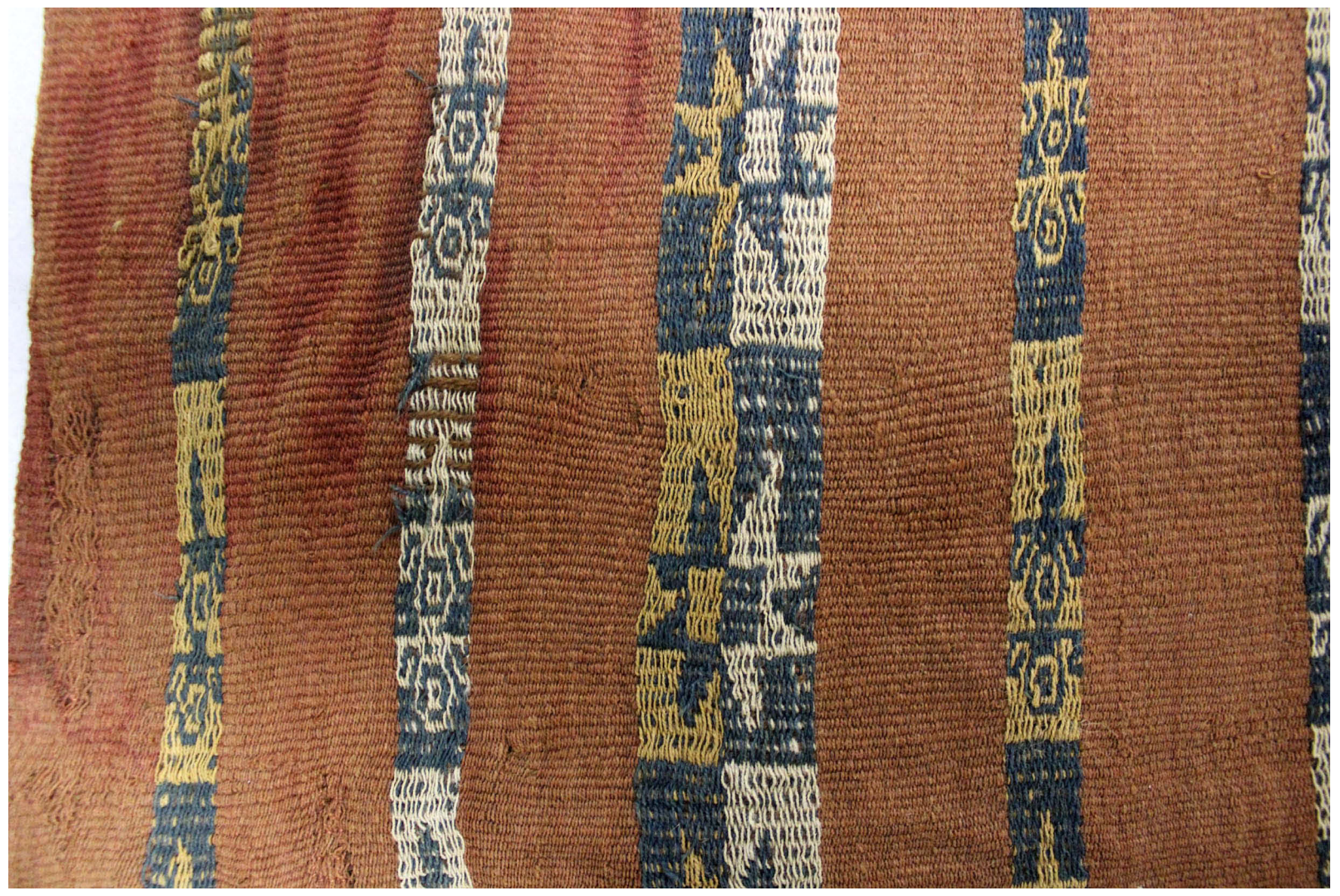

Figure 12. Detail of Figure 11, showing the faded red of the plain warp-faced stripes and the pattern stripes of complementary-warp weave (with an uneven warp count). The undyed brown weft is visible in the worn area of the second pattern stripe from the left. Extra weft threads can be seen crossing the third pattern stripe, inserted by the weaver to keep the weft at right angles to the warp. Photograph: Penelope Dransart.

lizard motifs. The wide pattern stripes are divided longitudinally with the design executed in dark blue and yellow ochre on one side of the stripe and dark blue and white on the other. Comparable in size, but rather more trapezoidal in shape, is a bag in the MA (inventory number 02-5-207, catalogue number 342 in Jiménez Díaz 2004: 373). It has a series of eleven narrow pattern stripes with similar lizard-like motifs, as in the Antwerp bag. The colour scheme is also closely comparable, with alternating colours of white and dark blue and tan and dark blue, although the plain red ground is of a much stronger hue. Because the MA bag is in a pristine condition, María Jesús Jiménez Díaz (2004: 373) suggested it might have been woven for a funerary or other ritual context. ${ }^{13}$ The size of such bags would make them suitable for containing sufficient coca leaves (or other items) for use in collective rites involving large numbers of participants.
A worn bag in the collections of Bryn Mawr College (2000.3.124.c) also has a red ground. It is patterned with two sets of paired stripes, in complementary-warp weave, containing eight pointed stars. Three narrow red and white stripes bearing transposed-warp rhombuses separate the two pairs of stripes.

These three bags are associated with the motifs used in men's tunics. A fringed bag in the Peabody Museum, Harvard, item 46-81-30/5533, is made from what looks like a piece taken from a women's dress. It has four broad stripes woven in complementary-warp weave in the following colour sequence: red and tan, dark blue and tan, dark blue and white, and red and tan. On one side of the bag, there is a double narrow stripe containing stacked isosceles triangles. With a width of about $440 \mathrm{~mm}$, this bag, too, is of a substantial size. 
To summarise the principal features in the textile tradition presented thus far, men's tunics were constructed from narrow panels and women's dresses are tentatively identified as consisting of a large wrap-around cloth made from three loom lengths sewn together. These textiles have patterning in the warp, which is oriented vertically in the tunics as worn and horizontally in the dresses. In both tunics and dresses, the pattern stripes in complementary-warp weave have long areas of k'uthu or peinecillo bars. Some tunics are articulated internally through the use of a discontinuous warp, forming lower panels reaching to the knee of the wearer. Tunics and belts/bands may also be patterned with narrow stripes of red and white k'uthu bars, in which the warp is transposed to form rhombuses. Motifs on tunics and bags often include eight-pointed stars, in which case the centre of the star is the same colour as the ground (unlike Chuquibamba stars). Double-headed serpents occur in the pattern stripes on both dresses and tunics. Dresses (and shawls?) may also be patterned in a stylized motif tentatively identified as a butterfly. A characteristic double narrow stripe containing right-angled triangles, which conjoin to form stacked isosceles triangles and rhombuses, tends to be associated with dresses and is associated with Inka pottery designs.

Warp and weft in all these garments are of camelid fibre. The colour palette usually consists of crimson red, dark blue (or dark green-blue), yellow ochre and/or tan and white in the warp, while the weft is undyed brown. Yellow ochre and tan play a more prominent role than in the earlier Chiribaya textiles, in which red and dark colours from purple to black predominate (Minkes 2005: 140). Green and yellow are much brighter in Chuquibamba textiles, but Chloé Tessier-Brusetti (2016: 101) suggests that during the period when Chuquibamba fell under Inka control, the colours became more 'terrosos' ('earthy').

\section{Locating the Producer Communities of the Textile Tradition}

In this section I turn to interpretations of archaeological and documentary evidence in the far south of Peru in order to contextualise the textile tradition defined in this article. This tradition made use of practices such as transposed warpweave, characteristically used in the South-Central Andes rather than the Central Andes (Figure 3). The alternation between light on dark and dark on light in positive-negative colour changes is also typical of the South-Central Andes (Minkes 2005: 141; Horta 1997: 88), as is cross-knit loop stitching in alternating blocks of light red and greenish-blue yarns at the arm and neck openings of the tunic in the MA (14676). This colour sequencing, combined with perpendicular stitching at the base of the neck slot, is a feature used to reinforce tunic openings in the South-Central Andes (Jiménez Díaz 2004: 396). It probably derives from Tiwanaku practices.

As two large, cultural-cum geographic units, the Central Andes and the South-Central Andes were defined by archaeologists on the basis of patterning observed in the material remains of pre-Hispanic societies. The division ran westwards from the Nudo de Vilcanota in Peru to the coast between the Sihuas and Tambo rivers (Lumbreras 1981; Lynch 1983: 1) (Figure 3).

The area Cieza de León (2005[1553]) called the Collao, in the South-Central Andes, consisted of a series of lakeside communities called Qolla, Lupaqa and Pacajes. ${ }^{14}$ They extended from Lake Titicaca's northern extent at Ayaviri, now in Peru, to as far south as Caracollo or Sicasica, now in Bolivia. Cieza de León referred to these communities as señoríos (lordships). Modern commentators understand them to have acquired political integration, but they de-emphasise the lordly role of an individual leader. Martti Pärssinen (1992: 261) regards the area as having the character of a Hatun apocazgo, or an 'interprovincial formation,' while Axel Nielsen (2008: 103-105) suggests these societies had a 'corporate mode of political action' and were led by 'hierarchies of groups rather than individuals.'

During the period of Inka domination, these communities gained considerably in political authority, exercising control over enclaves in the coastal valleys, where they settled their own people to engage in economic activities, including the cultivation of crops that could not be grown in the highlands. Prior to Inka expansion, the principal Lupaqa seat was perhaps at Cutimbo, south-west of Puno (Tantaleán 2006: 131). Based on the 'archipelago model of vertical control in the Andes' devised by John V. Murra (2002a, 2002b), the historian Carlos Sempat Assadourian (1995) characterized Lupaqa economic life during the early Colonial Period as combining a 'vertical archipelago,' of highland settlers established in discontinuous agricultural communities in the western valleys with 'horizontal trade' in the highlands. ${ }^{15}$

14. Alternative spellings used by different authors include Colla, Lupaka or Lupaca, Pacaxe.

15. To devise his model, Murra used evidence from Colonial Period documentation (especially Diez de San Miguel 1964[1567]) and ethnographically recorded accounts of contemporary communities in Peru and Bolivia. 
Whereas Murra argued that pre-Hispanic economic relationships were based on reciprocal exchanges between archipelagos and their parent communities in the highlands, Assadourian (1995) allowed for interethnic trading relations between the different highland communities. If such exchange relations existed in pre-Hispanic times, they would have facilitated the transmission of textile knowledge. Textile motifs in Late Horizon ceramics would have been shared 'horizontally' between interethnic contacts in the highlands and 'vertically' between parent and offspring communities established in the coastal valleys (Dransart 2014: 229).

Murra (2002a: 127) proposed that 'verticality' was a longstanding economic practice in the Andes and that Lupaqa enclaves at Sama, Moquegua and in the Azapa valley must have existed before the Inkas dominated the area. Archaeologists have explored Sama, in the middle reaches of the valley of the same name, and Torata Alta, in its eponymous valley, which drains into the Osmore River, for evidence of such enclaves (Trimborn 1977; Van Buren, Bürgi and Rice 1993). Torata Alta, however, appears to be a Lupaqa settlement made under the aegis of Inka domination because Van Buren (1996: 343) and Rice (2012: 9) demonstrate that it was intrusive, dating no earlier than about 1450/1475. It came under Spanish control after about 1535. Examples of possible Lupaqa settlements in the Azapa and Camarones Valleys have not been recognised. A bioarchaeological study of human remains suggests that genetic changes in populations living in these Chilean valleys are more like to have been the result of in situ microevolution rather than colonization by incoming people from the highlands (Sutter 2000: 63-64).

Hence the archaeological evidence does not support Murra's contention that there was a continuous process of highland settlement in the coastal valleys before the arrival of the Inkas. This important factor provides contextual assistance for identifying the textiles considered here because the chronological markers discussed above indicate that the textiles belong to the Late Horizon, as various authors have recognized (Rowe 1992: 33; Jiménez Díaz 2004: 396-397; Dransart 2014: 226).

The hillfort township of Pucarani, situated in Qolla territory north-west of Lake Titicaca, is an example of a large, nucleated settlement defended by monumentally constructed walling. It was characterised by a collective social organization without strongly marked internal hierarchy (Arkush and Ikehara 2019: 79). Study of its ceramics reveals various pottery types found in different sectors of the site, suggesting there were 'different practices of stylistic affiliation and ceramic use' among the inhabitants (Arkush and Ikehara 2019: 78-79). As is the case with the textiles, the ceramics do not convey a sense of ethnic exclusivity.
Shortly before Inka expansion into the area, highland communities began to acquire a more centralized political character than previously had been the case. During the reign of monarchs Pachacuti Inka and Ana Uarque, the Inkas claimed to have gained control of land as far as Chile 'and all its cordillera' (Guaman Poma 1615: 108, 136). Inka supremacy was first established in the highlands. Archaeologists have demonstrated that finds of highland ceramics, domestic architecture and burial customs in the coastal valleys date from after the onset of Inka dominance, when highland peoples were increasingly able to establish multi-ethnic enclaves at lower altitudes (Covey 2000: 125). The archaeological evidence demonstrates, nevertheless, that 'imperial control over the coast was never complete' (Covey 2000: 128). A consistent presence of highland peoples in coastal valleys only became possible when they served as allies under Inka rule. Inka settlements such as the Tambo de Jaqui (Hacienda Lampilla) date from the 1470 s onwards (Menzel 1959: 128), when members of Titicaca communities became empowered to carry out duties beyond their traditional highland domain.

The textile tradition defined in this article incorporated techniques and iconographic motifs that had been circulating in earlier traditions in the South-Central Andes. In particular, 'butterflies' can be seen in Collao and other pottery types found on sites north-west Lake Titicaca and near Chucuito, west of the lake. The butterfly was adopted as an Inka motif painted on polychrome pottery and, as mentioned above, Guaman Poma (1615: 137) referred to it in relation to the garments worn by the queen to whom he attributed the Inka conquest of the Titicaca lordships.

The stacked triangle motif and the eight-pointed star perhaps became incorporated into the textile tradition after the highlands in the far south of Peru came into contact with the Inkas. As explained above, the eight-pointed star also featured in weft-faced Chuquibamba textiles. At present, how this motif entered these two distinct traditions is not clear; it is possible they borrowed from sources independently.

Tunics, dresses and bags in the textile tradition defined here have been found in piedmont and coastal sites, suggesting that the people who wore the garments were interred in burials under Inka authority from a period beginning 14501475 that lasted until c.1540. These individuals had access to Inka and non-Inka pottery types. Burials in El Cementerio near Nazca, Hacienda Lampilla, Yauca, the San Franciso necropolis in the Majes Valley, and at Santa Isabel de Siguas occur in places within the western Cuntisuyu region of the Inka empire, rather than in Qullasuyu, which included the highlands from where the textile tradition is most likely to have emanated. The textiles have not been reported from coastal valleys between the Tambo and Azapa valleys, an 
area that retained a strong linguistic identity into the Colonial Period under the name of Colesuyo (Cañeda Argüelles 1993: 29).

Detailed exploration of the significance of this distribution does not fall within the scope of the present article. Suffice it to say that when people from the highlands, now in the Departments of Puno and Arequipa, occupied places in the coastal valleys of Cuntisuyu, their main garments indicated a highland origin in a tradition with Tiwanaku antecedents. Under Inka protection, they established themselves in Cuntisuyu. Waning Chuquibamba influence was, perhaps, a factor. By the end of the fifteenth century, the period of magnificence in Chuquibamba textiles was becoming a distant memory.

\section{Concluding comments}

This article has proposed a definition for a highland tradition based on textiles largely lacking in provenance. A few cases have been recorded from known burial places on the coast and in piedmont valleys. I began with Cieza de León's comments that people's main garments in the Collao did not clearly signal their ethnic affiliation, although their headgear did. Evidently, Ludovico Bertonio (1612), the compiler of an Aymara-Spanish dictionary, had a similar reaction. Working in the headquarters of the Society of Jesus at Juli, in Lupaqa territory, some seven decades after the European invasion, he recognized differences between Lupaqa and Qolla women's headdress known as phant'a (Bertonio 1612, II: 256). His entries on people's main garments do not convey information on ethnic dissimilarities.

On the other hand, Bertonio paid a great deal of attention to distinctions between women and men's attire. These entries are valuable for helping to demonstrate how garments of the tradition described above were worn. He listed the complete dress of a woman as 'manto y saya de muger, faxa', while that of a man included 'manta y camiseta' (Bertonio 1612, II: 304). ${ }^{16}$ This list mentions only the outwardly visible garments rather than items such as loin cloths. ${ }^{17}$ Women's dress had one opening, called pheque (p'iqi in modern Aymara spelling; see Arnold, Yapita and Aguilar 2014: 71). It was for both the arms and the head because the top of the fabric was folded over and pinned at the shoulders after the wearer wrapped the cloth round her body and wound a belt (or belts) firmly round the waist. She could then carry items placed in the bosom of the dress (Bertonio II: 263). In highland communities in the far south of Peru, women carried a baby inside the garment, as if in a pouch next to the naked skin. This customary practice met with disfavour during the Colonial Period and, on 6 November 1575, the Viceroy Francisco de Toledo (1929[1575]: 371) issued an edict in Arequipa forbidding women from doing so.

Men, in contrast, pulled the camiseta over the head through a neck opening called ccautata (q'awtata) and through an opening for each arm, called locusu (luqusu, from the Aymara luqu, an arm, Bertonio 1612, I:3, II: 41, 196). As mentioned above, stitching characteristic of the South-Central Andes reinforced the openings of tunic MA 14676 (Jiménez Díaz 2004: 396)

The textiles were woven and worn during a period when Inka goods in the region were gaining increased recognisability. Bird-headed plates and large aríbalo vessels were now circulating through the far south of Peru, whether in the form of Cuzco wares or of provincially produced versions (Covey 2000: 134). An Inka marker, a double narrow stripe containing stacked triangles, became a feature of the textiles. Other features derive from ancient traditions associated with the South-Central Andes employing warp-faced weaving, transposed warp rhombuses and colour alternations. This article has reported work in progress into the definition of a textile tradition. It is hoped that by sharing the results of this research, highland peoples of the far south of Peru and their interactions with peoples in the coastal valleys can be glimpsed with a little more clarity than has been the case up to the present.

\section{Acknowledgements}

A number of people have made this research possible and I wish to express my deepest gratitude to Sophie Desrosiers, Mary Frame, Ylva Frögéli, Mireille Holsbeke, Caitlyn Kennedy, Tessa Lummis, Elena Phipps and Ann Pollard Rowe. I thank Ann H. Peters and Lena Bjerregaard for their considerable help over editorial matters.

\section{Museum collections and abbreviations}

List of museums mentioned and abbreviations (where used in the text). URLs are provided for the online catalogues maintained by most (but not all) of these museums; these are correct as of 31 October 2019.

American Museum of Natural History, New York https://www.amnh.org/research/anthropology/collections British Museum, London (BM)

https://www.britishmuseum.org/research/collection online/search.aspx

16. Women's dress consisted of 'mantle and woman's garment, belt' and men's of 'shawl and tunic' (Bertonio 1612, II: 304). 17. Elsewhere in the dictionary Bertonio (1612 I: 345) listed 'Pañetes o bragas: Vecara [wiqara]' for undergarments. 
Bryn Mawr College Art and Artifact Collections

http://www.brynmawr.edu/collections/

Metropolitan Museum of Art, New York https://www.metmuseum.org/art/collection

Museo de América, Madrid (MA) http://www.culturaydeporte.gob.es/museodeamerica/ coleccion/acceso-a-catalogo2.html

Museo Nacional de Arqueología, Arte e Historia del Perú, Lima (MNAAHP)

http://mnaahp.cultura.pe/catalogo-en-linea

Museum aan de Stroom, Antwerp (MAS) https://search.mas.be/search/simple

Ohara Gallery of Art (OGA)

Peabody Museum of Archaeology and Ethnology at Harvard University (PMH) https://pmem.unix.fas.harvard.edu:8443/peabody/

Phoebe A. Hearst Museum of Anthropology, Berkeley, California (PAHMA) https://portal.hearstmuseum.berkeley.edu

Varldskultur Museerna: Etnografiska, Stockholm http://www.kringla.nu/kringla/

Textile Museum, George Washington University (TM)

\section{References cited}

Acosta Luna, Olga Isabel and Plazas García, María Catalina 2011. El manto o acso de la reina mujer de Atahualpa. ¿Una prenda de la última reina del Perú? Museo Nacional de Colombia, Cuadernos de Curaduría 12.

Arkush, Elizabeth 2012. Los pukara y el poder: los collas en la cuenca septentrional del Titicaca. In Arqueología de la cuenca del Titicaca, Perú. Edited by Luis Flores Blanco and Henry Tantaleán, 295-319. Lima: IFEA and Cotsen Institute of Archaeology.

Arkush, Elizabeth and Ikehara, Hugo C. 2019. Pucarani: Defensive Monumentality and Political Leadership in the Late Pre-Columbian Andes, Journal of Anthropological Archaeology 53: 66-81.

Arnold, Denise Y., and Espejo, Elvira 2012. Ciencia del tejer en los Andes: estructuras y técnicas de faz de urdimbre. La Paz: Fundación del Banco Central de Bolivia, Fundación Interamericana, Fundación Albó e ILCA.

- 2015. The Andean Science of Weaving: Structures and Techniques of Warp-Faced Weaves. New York: Thames \& Hudson.

Arnold, Denise Y, and Yapita, Juan de Dios, with Aguilar, María Juana 2014. Los términos textiles aymaras del siglo XVII de la región lacustre, en base al Vocabulario de la lengua Aymara por Ludovico Bertonio: Vocabulario semántico según la cadena productiva. La Paz: ILCA: Serie Informes de Investigación, II, No 10.

Assadourian, Carlos Sempat 1995. Exchange in the ethnic territories between 1530 and 1567: The Visitas of
Huánuco and Chucuito. In Ethnicity, Markets, and Migration in the Andes: At the Crossroads of History and Anthropology. Edited by Brooke Larson, Olivia Harris, and Enrique Tandeter, 101-134. Durham, NC: Duke University Press.

Bálint, Zs. and Lamas, G. 1996. On the Taxonomy of the Neoptropical Polyommatine Lycaenids (Lepidotera: Lycaenidae, Polyommatini), Annales Historico-Naturales Musei Nationalis Hungarici 88: 127-144.

Bertonio, Ludovico 1612. Vocabulario de la lengua aymara. Juli, Province of Chucuito: Printed in the house of the Society of Jesus by Francisco del Canto.

Boytner, Ran 1998. Textiles from the Lower Osmore Valley, Southern Peru: A Cultural Interpretation, Andean Past 5: 325-356.

Carlevato, Denise 1988. Late Ceramics from Pucara, Puno: An Indicator of Changing Site Function, Expedition 30(3): 39-45.

Cañeda Argüelles, Teresa 1993. La organización del poder indigena en el Colesuyo (siglo XVI). Revista Complutense de Historia de América 19: 21-51.

Cieza de León, Pedro de 2005 [1553]. Crónica del Perú. El señorío de los Incas. Selección, prólogo, modernización del texto, cronología y bibliografía by Franklin Pease G.Y. Caracas: Biblioteca Ayacucho.

Covey, R. Alan 200o. Inka Administration of the Far South Coast of Peru, Latin American Antiquity 11(2): 119-138.

Cuynet, François 2012. Las esculturas Pukara: sintésis del conocimiento y verificación de los rasgos característicos. In Arqueología de la Cuenca del Titicaca, Perú. Edited by Luis Flores Blanco and Herny Tantaleán, 217-224. Lima: IFEA and Cotsen Institute of Archaeology.

De Toledo, Francisco 1929 [1575]. Ordenanzas de Don Francisco de Toledo Virrey del Perú 1569-1581, with a preface by Roberto Levillier. Madrid: Imprenta de Juan Pueyo.

Diez de San Miguel, Garci 1964 [1567] Visita hecha a la Provincia de Chucuito por Garci Diez de San Miguel en el ano 1567. Lima: Casa de la Cultura del Perú.

Dransart, Penelope 200o. Vestirse en los períodos tardíos del centro-sur peruano. In Actas de la I Jornada Internacional sobre Textiles Precolombinos. Edited by Victoria Solanilla Demestre, 127-153. Barcelona: Grup d'Estudis Precolombins.

2014. Thoughts on productive knowledge in Andean weaving with discontinuous warp and weft. In Textiles, Technical Practice and Power in the Andes. Edited by Denise Arnold with Penelope Dransart, 216-232. London: Thames and Hudson.

in press. Una estética del hacer. Miradas sobre las bolsas prehispánicas tardías de Doncellas (Puna septentrional argentina), Estudios Sociales del NOA - Nueva Serie 22. 
Espejo, Elvira and Arnold, Denise Y. (2014). Woven techniques and social interactions in the South Central Andes: ladder designs and the visualisation of productive output. In Textiles, technical practice, and power in the Andes, edited by Denise Y. Arnold with Penelope Dransart, 303-326. London: Archetype.

Frame, Mary 1997-1998. Chuquibamba: A Highland Textile Style, The Textile Museum Journal 36 and 37: 3-47.

Gonçalez Holguien, Diego 16o8. Vocabulario dela lengua general de todo el Peru llamada lengua Qquichua, o del Inca. Corregido y renovado conforme ala propriedad cortesana del Cuzco. Ciudad de los Reyes [Lima]: printed for Francisco del Canto.

Guaman Poma de Ayala, Felipe 1615. Nueva corónica y buen gobierno. Royal Danish Library, GKS $22324^{\circ}$ http://www. kb.dk/permalink/2006/poma/info/es/foreword.htm

Horta Tricallotis, Helena 1997 (published 1999). Estudio iconográfico de textiles arqueológicos del Valle de Azapa, Arica, Revista Chungara 29(1): 81-108.

- 2005. Arte textil prehispánico. Diseños de los tejidos de la cultura Arica, norte de Chile (10oo-1470 d.C.). Santiago: Editorial Universidad Bolivariano.

Jiménez Díaz, María Jesús 2004. Tejidos y mundo textil en los Andes Centrales y Centro-Sur a través de la colección del Museo de América de Madrid: Períodos Prehispánico y Colonial. Doctoral thesis presented to the Universidad Complutense de Madrid.

Julien, Catherine J. 1993. Finding a Fit: Archaeology and Ethnohistory of the Incas. In Provincial Inca: Archaeological and ethnohistorical assessment of the impact of the Inca State, edited by Michael A. Malpass, 177-233. Iowa City: University of Iowa Press.

Kroeber, Alfred L. 1944. Peruvian Archaeology in 1942. Viking Fund Publications in Anthropology, No 4. New York.

Laurencich Minelli, Laura 200o. Los textiles peruanos del documento ‘Exsul Immeritus Blas Valera Populo Suo’: una propuesta de lectura. In Actas de la I Jornada sobre Textiles precolombinos, edited by Victòria Solanilla Demestre. Barcelona: Universitat Autònoma de Barcelona, Departament d'Art, 154-176.

- (ed) 2005. Exsul Immeritus Blas Valera Populo Suo e Historia et Rudimenta Linguae Piruanorum. Indios, gesuiti e spagnoli in due documenti segreti sul Perù del XVII secolo. Bologna: CLUEB (Cooperativa Libraria Universitaria Editrice Bologna).

Lumbreras, Luis G. 1974. The Peoples and Cultures of Ancient Peru, translated by Betty J. Meggers. Washington, D.C.: Smithsonian Institution Press.

1981. Arqueología de la América Latina. Lima: Milla Batres.

Lynch, Thomas F. 1983. Camelid Pastoralism and the Emergence of Tiwanaku Civilization in the South-Central Andes, World Archaeology 15(1): 1-14.
Menzel, Dorothy 1959. The Inca Occupation of the South Coast of Peru, Southwestern Journal of Anthropology 15(2): 125-142.

Minkes, Willy 2005. Wrap the Dead: The Funerary Textile Tradition from the Osmore Valley, South Peru, and Its Social-Political Implications. Archaeological Studies, Leiden University 11. Leiden, The Netherlands: Faculty of Archaeology, Leiden University.

Misugi, T. (ed.). 1985. The Collection of Ohara Gallery of Art: The Andes - Textiles and Ceramics. Kobe: Shikosha Publishing Co.

Murra, John V. 2002a [1977]. Los límites y las limitaciones del 'Archipiélago vertical' en los Andes. In El mundo andino. Población, medio ambiente y economía, John V. Murra, 126131. Lima: Instituto de Estudios Peruanos.

_ 2002b [1968]. Un reíno Aymara en 1567. In El mundo andino. Población, medio ambiente y economía, John V. Murra, 183-207. Lima: Instituto de Estudios Peruanos.

Nielsen, Axel 2008. Poor Chiefs: Corporate Dimensions of PreInca Society in the Southern Andes. In Against Typological Tyranny in Archaeology, edited by Cristóbal Gnecco, 99-120. New York: Springer.

Pärssinen, Martti. 1992. Tawantinsuyu. The Inca state and its political organization. Helsinki: Societatas Historica Finlandiae, Studia Historica 43.

Rice, Prudence M. 2012. Torata Alta: An Administrative Center and Spanish Colonial Reducción in Moquegua, Peru, Latin American Antiquity 23(1): 3-28.

Rosenzwig, Alfredo, and Artzi, Bat-ami 2011. A Chiribaya Textile Woven with Human Hair, Boletín del Museo Chileno de Arte Precolombino 16(1): 93-104.

Rowe, Ann P. 1977. Warp-patterned weaves of the Andes. Washington, D.C.: The Textile Museum.

- 1992. Provincial Inca Tunics of the South Coast of Peru, Textile Museum Journal 31: 5-52.

_ 1995-1996. Inca Weaving and Costume, Textile Museum Journal 34/35: 5-53.

Sutter, Richard C. 200o. Prehistoric Genetic and Culture Change: A Bioarchaeological Search for Pre-Inka Altiplano Colonies in the Coastal Valleys of Moquegua, Peru, and Azapa, Chile, Latin American Antiquity 11(1): 43-70.

Szykulski, Józef 1998. Churajón, nuevos datos sobre el período de transición en el sur del Perú. In 50 Años de estudios americanos en la Universidade de Bonn, edited by Sabine Dedenbach-Salazar-Sáenz, Carmen Arellano Hoffman, Eva König and Heiko Prümers, 291-320. Bonn: Bonner Amerikanistiche Studien 30 and Verlag Anton Saurwein.

2010. Prehistoria del Perú sur (costa extremo sur), Tambo. Boletín de Arqueología 2.

Szykulski, Józef and María del Carmen Cárdenas Sumida 1999. Prospección en la Necrópolis San Francisco, Provincia Castilla, sur del Perú, Slaskie Sprawodzdania Archeologiczne 45: 385-395. 
Tantaleán, Henry 2006. Regresar para construir: practicas funerarias e ideología(s) durante la ocupación inka en Cutimbo, Puno-Perú, Chungara Revista de Antropología Chilena 38(1): 129-143.

Tessier-Brusetti, Chloé 2016. Translaciones estilísticas de los textiles Chuquibamba: testimonios de la mutación de una sociedad (costa sur del Perú, Intermedio Tardío). In El Perú en su historia. Fracturas y persistencias, edited by Chatherine Poupeney Hart, Sebastián Ferrero and Juan C. Godenzzi, 93-113. Paris: Éditions Le Manuscrit.

Trimborn, Hermann 1977. Excavaciones en Sama (Depto. Tacna, Perú), Indiana 4: 171-175.

Tschopik, Marion 1946. Some Notes on the Archaeology of the Department of Puno, Peru. Papers of the Peabody Museum of American Archaeology and Ethnology 27(3). Cambridge, MA: Harvard University.
Ulloa, Liliana 1982a. Evolución de la industria textil prehispánica de la zona de Arica, Chungara Revista de Antropología Chilena 8: 97-108.

1982b. Estilos decorativos y formas textiles de poblaciones agromarítimas, extremo norte de Chile, Chungara Revista de Antropología Chilena 8: 109-136.

Umire, Adán y Miranda, Ana 2001. Chiribaya de Ilo. Un aporte a su diffusion. Arequipa: CONCYTEC.

Uribe Rodríguez, Mauricio 1999. La cerámica de Arica 40 años después de Dauelsberg, Chungara Revista de Antropología Chilena 31(2): 189-228.

Van Buren, Mary, Bürgi, Peter, and Rice, Prudence 1993. Torata Alta: A Late Highland Settlement in the Osmore Drainage. In Domestic Architecture, Ethnicity and Complementarity in the South-Central Andes, edited by Mark Aldenderfer, 136146. Iowa City: University of Iowa Press. 


\title{
Los tocapus de Llullaillaco
}

\author{
Beatriz Carbonell \\ Universidad Fasta Patagonia Argentina \\ beatriz.carbonell17@gmail.com
}

\section{Resumen}

En el hallazgo de Llullaillaco los motivos de tocapu y cumbi se reiteran en importantes textiles que visten a los niños ofrendados y en otros en forma de miniatura vistiendo a las estatuillas que conforman el ajuar.

Tanto las miniaturas antropomorfas de metal (oro y plata) como las de mullu (spondylus) están vestidas con uncu (túnica), yacolla (manto) y llautu (o vincha) y llevan una bolsa o chuspa con los mismos diseños que las prendas que visten los niños.

Nuestra comprensión del significado de tocapu se basa en cómo ha sido descrito por los cronistas, asociado a veces íntimamente con el textil y otras a la narrativa, aunque no conozcamos aún un sistema que nos permita descifrarlo.

Ha sido utilizado en forma radicalmente diferente: política, cultural y religiosamente.

Se identifica por tener a veces un patrón repetitivo y otras no, con formas abstractas, compuestos por figuras geométricas y líneas organizadas que representan un sentido.

Es transhistórico, podemos hallarlo hoy en diferentes regiones vinculado a la arquitectura, los símbolos rituales, al Inca, y en siglos posteriores influenciando vestimentas y mantos ricamente ornamentados (por ejemplo, en el período colonial).

Palabras claves: Sacrificios de Llullaillaco, capac qocha, tocapu, cumbi, simbolismo textil

\section{Abstract}

In the Llullaillaco contexts, the tocapu and cumbi designs are repeated in significant textiles worn by the sacrificed children and on the miniatures worn by the figurines that make up the offerings.

Both the anthropomorphic metal miniatures (in gold and silver) and those of mullu (spondylus) are dressed with an uncu (tunic), yacolla (cloak) and llautu (headband). They carry a bag or chuspa with the same patterns as the clothes the children are wearing.

Our understating of the meaning of tocapu is based on the descriptions of chroniclers. These descriptions are sometimes intimately linked to the idea of textiles, and at other times to the narrative of the designs, although we do not know yet a system that allows us to decipher its real meaning. Tocapu has been used radically differently in political, cultural and religious fields.

They are defined by having a repetitive pattern sometimes, though not repetitive at other times, with abstract shapes composed of geometric figures and organized lines that represent a meaning.

Tocapu is transhistorical, we can find it today in different regions linked to architecture, ritual symbols, to the Inca, and in later centuries influencing richly ornamental clothes and cloaks (for example, in the colonial period).

Keywords: Llullaillaco sacrifices, capac cocha, tocapu, cumbi, textile symbolism

\section{Résumé}

Dans les contextes Llullaillaco, les motifs tocapu et cumbi se répètent dans les textiles importants portés par les enfants sacrifiés ainsi que dans les éléments miniatures que vêtent les statuettes qui composent l'offrande.

Tant les miniatures anthropomorphes en métal (or et argent) que celles en mullu (Spondylus) sont revêtues d'un uncu (tunique), d'une yacolla (manteau) et d'un llauto (bandeau) et ont un sac ou chuspa avec les mêmes motifs que les vêtements que portent les enfants.

DOI: $10.32873 /$ unl.dc.zea.1210

Published in PreColumbian Textile Conference VIII / Jornadas de Textiles PreColombinos VIII, ed. Lena Bjerregaard and Ann Peters

(Lincoln, NE: Zea Books, 2020). https://digitalcommons.unl.edu/zeabook/ 
Notre compréhension de la signification des tocapu repose sur la façon dont ils sont décrits par les chroniqueurs, parfois en association étroite avec les textiles, et d'autres fois selon l'aspect narratif des figures, bien que nous ne connaissions pas encore de système permettant de véritablement déchiffrer leur sens.

Les tocapu ont été utilisés de manière totalement différente : politique, culturelle ou religieuse. Ils s'identifient par la présence d'un modèle répétitif occasionnel, comprenant des formes abstraites, composées par des figures géométriques et des lignes organisées évocatrices d'un sens précis.

Les tocapus sont transhistoriques, nous pouvons les trouver de nos jours dans différentes régions liées à l'architecture, aux symboles rituels, au pouvoir, à l'Inca, et dans les siècles suivants influençant les vêtements et les tuniques richement décorés (par exemple, à l'époque coloniale).

Mots-clés: Sacrifices de Llullaillaco, capac cocha, tocapu, cumbi, symbolisme textile

\section{Introdución}

\section{El hallazgo}

El volcán Llullaillaco está ubicado a latitud $24^{\circ} 43^{\prime} 05^{\prime \prime} \mathrm{S}$ y en longitud $68^{\circ} 32^{\prime} 10^{\prime \prime} \mathrm{O}$, en la Cordillera de los Andes, entre Argentina y Chile y mide 6739 metros sobre el nivel del mar.

En marzo de 1999, la Doctora Constanza Ceruti y el Dr. Johan Reinhard en el marco de una campaña arqueológica realizaron relevamientos y sondeos de la base del volcán (4.90o mts) con recuperación de material óseo en tumbas huaqueadas, explorando hasta llegar al conjunto de ruinas (6550 m).

En la plataforma se hallaron tres enterratorios con sus respectivos ajuares (173 piezas y artefactos) con recuperación de material óseo en tumbas huaqueadas.

Los elementos en el hallazgo arqueológico de Llullaillaco constituyen una de las colecciones incas mejor conservadas. (Ceruti 2015) quien indica que tres niños y sus ajuares asociados fueron descubiertas y recuperadas para su estudio y preservación, durante excavaciones por ella co-dirigidas en el noreste de Argentina.

En el contexto de una ceremonia capac hucha los niños ofrendados presentaban características de preservación especiales a pesar de llevar más de 500 años en su hábitat.

Estos sacrificios fueron realizados a causa de catástrofes, la muerte del Inca, o para auspiciar la fertilidad.

Molina (1989) destaca los sacrificios de niños traídos al Cuzco desde diferentes regiones del Imperio, participando primero de la celebración de los rituales estatales y llevados luego a sacrificio de acuerdo con el rango del pueblo, sus padres o jefes, delegados a las guacas más importantes y luego a todas las guacas y montañas sagradas del territorio, honrando así a las provincias ya que ninguna debía ser olvidada porque ello sería visto como una falta o deuda (hucha) del propio Inca con las jerarquías locales.

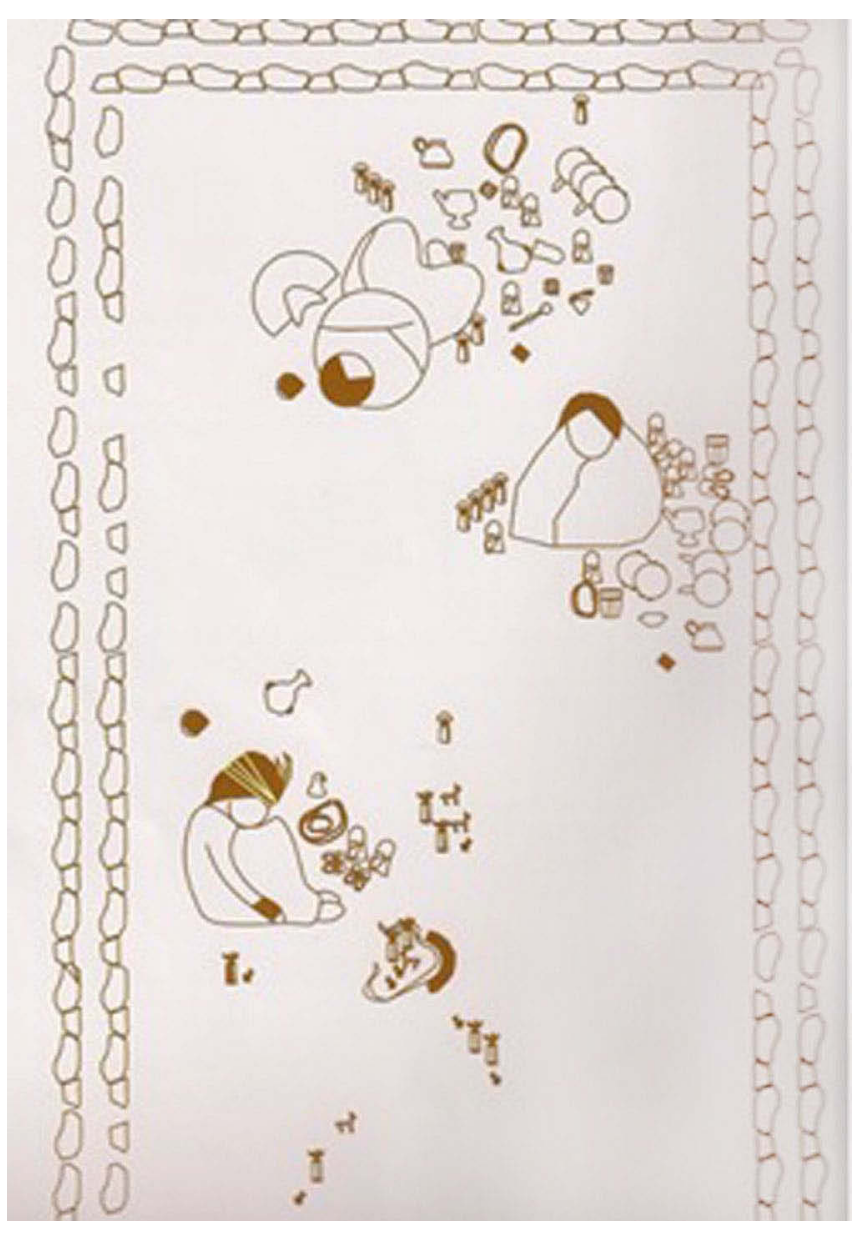

Figura 1. Dibujo que muestra la distribución del hallazgo de Llullaillaco, los tres niños con sus enseres enterratorios según fueran hallados. MAAM Museo Arqueológico de Alta Montaña, Ciudad de Salta, Argentina 


\section{Orden y Sistema ritual}

En las culturas preincaicas se manifiesta la importancia del agua y su distribución, pero en ningún lugar con tanta complejidad y elegancia como en el Cuzco donde el Inca integra las unidades de administración de las poblaciones relacionándolas directamente con la geografía hidráulica, creemos que por ello se elige Llullaillaco como guaca de ofrenda.

\section{Dimensión espacio-temporal}

Algunos aspectos de la dimensión espacial en Llullaillaco estarían determinados por su ubicación geográfica que ya describimos, por su condición de montaña más alta y volcán, por su situación en el sistema de ceques e hidrografia; estableciendo su posición concéntrica y de expansión exterior del Estado Inca hacia otros territorios, en este caso hacia el sur.

Ubicada en la región del hurin (mundo de abajo) la ofrenda en esa montaña manifiesta la necesidad del Inca de unir el hanan (mundo de arriba) con el hurin, es decir el centro ceremonial de Cuzco con el Collasuyu y a través de la capacocha o capac hucha, integrarlo a las otras regiones del Tawantinsuyu, a modo de cohesión territorial.

J. Sherbondy (1987) indicaba que las líneas radiales o ceques cumplían múltiples funciones, entre ellas señalar las fuentes de agua para las acequias de un pueblo y ligarlas mental y ritualmente a un punto central de la población por medio de líneas.

El pueblo de Socaire en el mapa une desde su sitio ceremonial para los ritos, con los cerros sagrados que según la cosmología inca lo proveen del agua para su canal.

\section{Llullaillaco: su condición de guaca}

Guaca o huaca o waka como aparece en diferentes escritos, Gonzalez Holguin (2007 [1608]) lo tradujo como "ydolos, figurillas de hombres y animales".

Otros autores refieren a guaca con diferentes significados espaciales:

Wak'a, guaca o huaca Ricardo lo traduce "ídolo, adoratorio, o cualquier cosa señalada por la naturaleza"

y Szeminski (1987) propone: "muchos de los significados (de guaca) muestran una asociación muy fuerte con tierra o con lugar (esconder debajo de la tierra, lugar peligroso, peña en forma especial (...), laguna) con el mundo de abajo en general”

Huaccap nam "Passo, o lugar peligroso, o espantable” Gonzalez Holguin 2007 [1608]

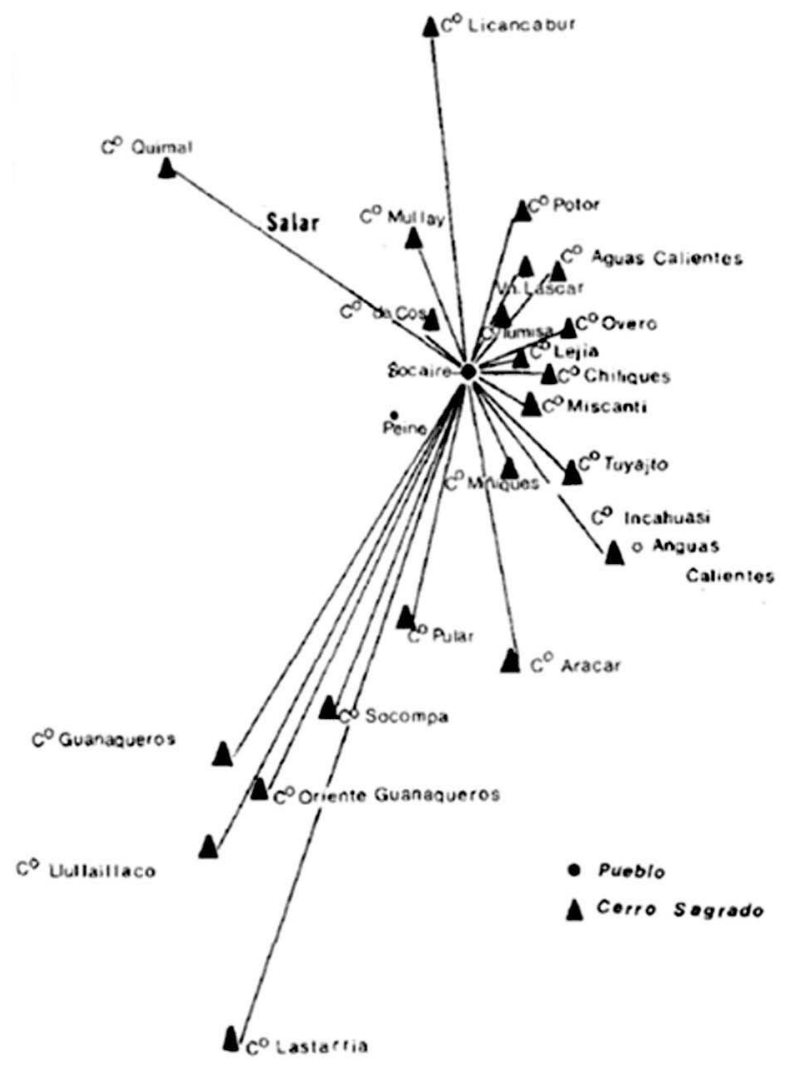

Figura 2 Mapa de Jeanette Sherbondy (1987), sistema de distribución hidraúlica en sitios de alta montaña, los que constituían probables guacas en cerros del Collasuyu, en el mismo se destaca el Volcán de Llullaillaco como Cerro Sagrado.

Muchos son los cerros que envían el agua al sistema de irrigación de Socaire, entre ellos el Llullaillaco.

La toponimia actual y sus significaciones lingüísticas permiten asociar el nombre de este río con el volcán más imponente de todo ese territorio, el Llullaillaco.

Su nombre, también quechua, significa "agua" o "aguas mentirosas". Se establecía que los volcanes y sus santuarios tenían profundas connotaciones no sólo en lo ritual sino también como elementos organizadores del espacio simbólico, social, político y económico.

El incumplimiento del grupo o del individuo de sus obligaciones frente a la guaca crea un estado de hucha con consecuencias de enfermedades, sequía, infortunios sobre las personas o poblaciones, por ello hasta el Inca debía respetar los contratos establecidos a través de las guacas.

Elena Phipps (2017) en importante trabajo sobre tradición en textiles andinos detalla que otros objetos fueron considerados wak'as o sagrados, o que contienen poder y fueron descriptos en Polo Ondegardo en el siglo XVI (d.1575); como ciertas mazorcas de maíz especiales llamadas 
zaramama que estaban envueltos en mantos de tela o vestidos con prendas de mujer.

\section{Capacocha o capac hucha}

Los términos capacocha o capac hucha describen un ritual estatal en Cuzco y en distintas regiones del Tawantinsuyu, expresando servicios recíprocos entre:

los individuos, el Inca y lo sobrenatural.

Varios cronistas describieron la función de los textiles identificando lugares sagrados y vistiendo las ofrendas, los ídolos y parafernalia que rodean a los mismos en las cumbres altas de guacas sagradas.

Hernández Príncipe (1923 [1622] pag 6o-61) "escribiré lo que de ello tengo entendido que es verdad.

Y así dicen que se tenía por costumbre en el Cuzco por los reyes que cada año hacían venir [a] aquella ciudad a todas las estatuas y bultos de los ídolos que estaban en las guacas, que eran los templos donde ellos adoraban; las cuales eran traídas con mucha veneración por los sacerdotes y "camayos" de ellas, que es nombre de guardianes, y como entrasen en la ciudad, eran recibidas con grandes fiestas y procesiones y aposentadas en los lugares que para aquello estaban señalados y establecidos; y habiendo venido de las comarcas de la ciudad y aun de la mayor parte de las provincias número grande de gente, así hombres como mujeres, el que reinaba acompañado de todos los Ingas y orejones, cortesanos y principales de la ciudad..."

Cieza de Leon en el "Señorío de los Incas" ([1553] 1986-Cap. XXIX).

Guaman Poma (1987) refiere que en las fiestas Capac Ynti Raymi [festejo del señor sol] (vacas, ídolos 265[267] ) llamando capac ocha a los sacrificios humanos y ofrendas:

"De cómo ordenó bestidos y rropa de sus dioses uacas le llaman capac ocha [afrenta al Inka, sacrificios humanos] Lo hazían de cunbi [tejido fino] y de auasca [corriente] y de su baxilla de oro y plata y de uarro y mullo [concha] y cobre y donde soterraua y tenía pastos y sementeras y ganados y yndios llamados yana yaco del sol y de las uacas ýdolos deste rreyno."

En el ritual capac hucha el soberano Inca podía conceder a cada grupo social del imperio o a su curaca (sacerdote) el privilegio de enviar al Cusco o cualquier otro centro ritual un niño sin mancha de nacimiento.

Allí el niño sería ofrendado o desde allí se reenviaba a otro lugar, incluso a su lugar de origen para ser ofrendado.

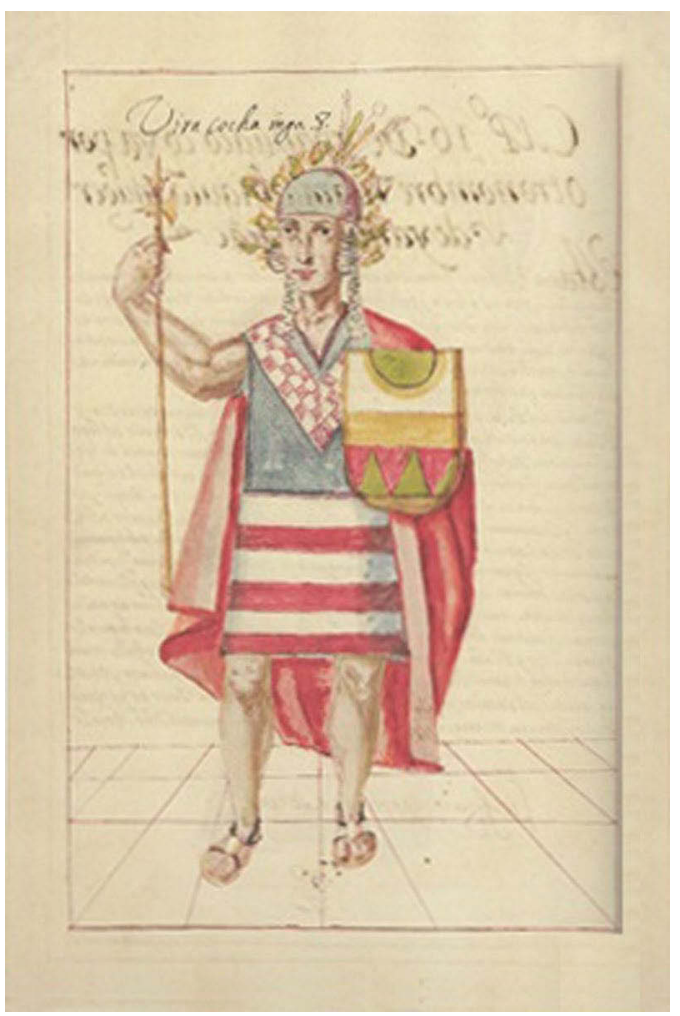

Figura 3 Viracocha Inca (en Murua Paul Getty publicación 2008) Octavo soberano Inca, conquistó territorios alrededor de Cusco iniciando el Imperio; amplió la producción textil y distribuyó los tocapus en la ropa de los nobles extendiendo su difusión.

Algunos cronistas ponen de manifiesto la dimensión de capacocha como un rito geográfico espacial y la entrega de una persona elegida como capac hucha a su lugar final (Molina 1989, Albornoz 1989, Juan Ossio Códice Murúa 2004).

Otra finalidad de capac hucha era consolidar el apoyo a través de sus guacas de todas las regiones del Incanato, el ritual como un medio de comunicación entre el sacrificado y el sacrificante; entre el Inca con sus poblaciones y de cada uno de ellos con sus divinidades.

\section{Las ofrendas}

"Relación" 1923 [1622] Hernández Principe entiende que existieron dos tipos de capacocha:

-la capacocha estatal inca,

-y los sacrificios de tipo local en los Andes

Norcentrales, en el espacio de grupos étnicos distintos.

La ceremonia en el Llullaillaco evidencia características que la muestra como un ofrecimiento de carácter real, no local, de las que se llevaban a cabo para la protección contra la adversidad del Inca, con carácter de procesión sagrada considerando la riqueza y diversidad regional de sus ofrendas. 


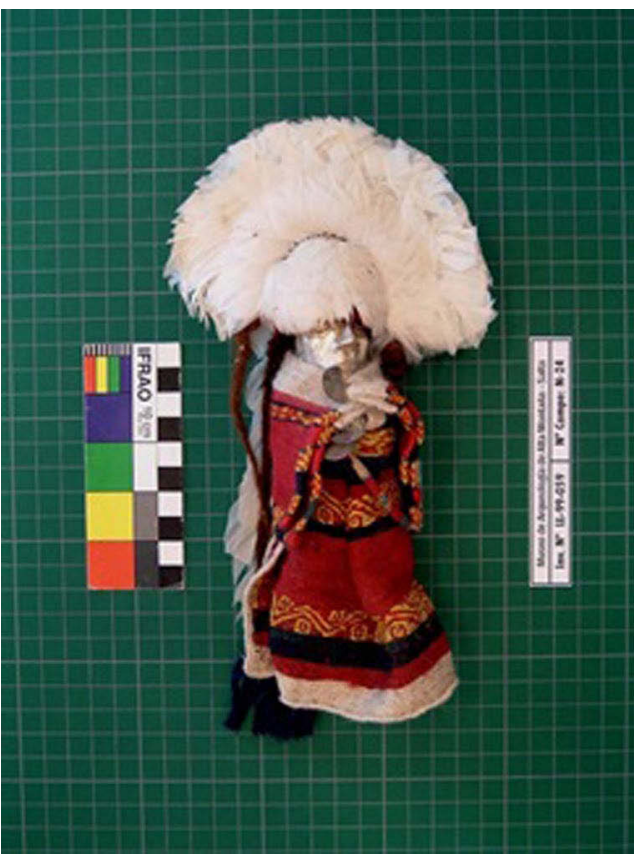

Figura 4a. Figura de plata hallada junto a la doncella, vistiendo su tocado de plumas blancas, representándola en vestimenta y detalles en miniatura.

Es que el término capacocha o capac hucha podría ser aplicado también al textil que identificaba y representaba una guaca; pudiendo incluso reemplazarla. Algunos ejemplos tratan de tejidos encontrados con las momias, los investigadores que han descrito estas circuntancias (Ceruti 2003; Gentile Lafaille 2010; Reinhard and Ceruti 2006) dan cuenta de ello y describen que en varios casos se colocan uncus al lado de la momia, frecuentemente estandarizados con tejidos de tocapus, descubiertos y preservados en diferentes hallazgos.

Los tocapus y telas cumbí se reiteran en textiles de gran dimensión y en forma de miniatura, diversos diseños en marcos o cuadrados utilizados en el arte Inca, tal vez y siempre de todas maneras como un sistema semántico.

Dicen que fue Viracocha Inca (octavo inca) quien difundió el diseño de tocapu en todas las regiones del Incanato (Margarita Gentile 2009).

\section{Tocapus y cumbí}

El significado de tocapu se basa en cómo ha sido descrito por los cronistas y en la actualidad por los numerosos investigadores que trabajan este tema.

Por ejemplo Martín de Murúa [1616] escribe: "el vestido que ordinariamente usaba, era una camisa de cumbí labrada, obra de las ñustas que lo hilaban sutilísimamente para

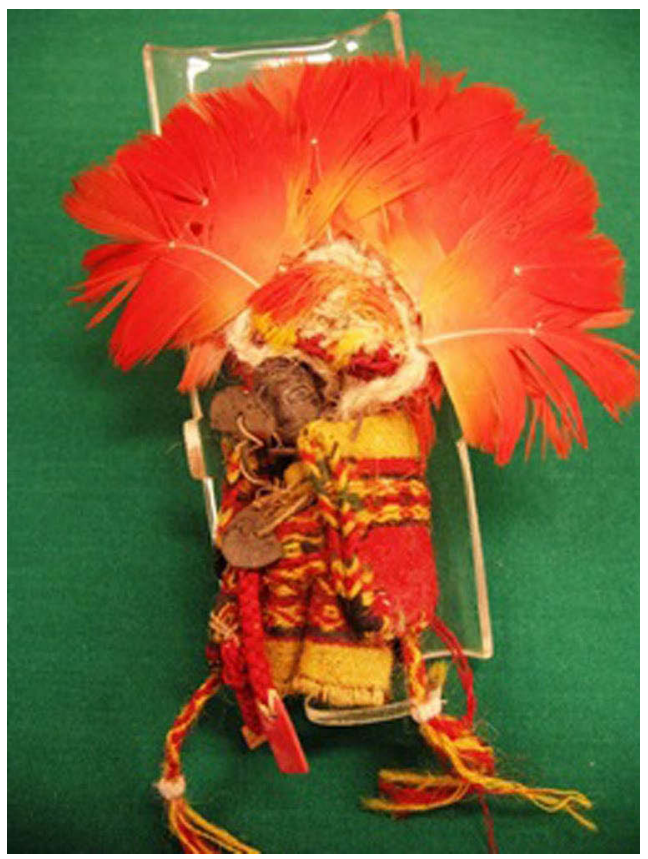

Figura 4b. Figura de plata en miniatura con vestimenta textil y diseño cumbí, lleva tocado de plumas. Posee terminaciones de spondylus en los cordones hallada junto a la doncella. Archivo Museo MAAM Salta Argentina

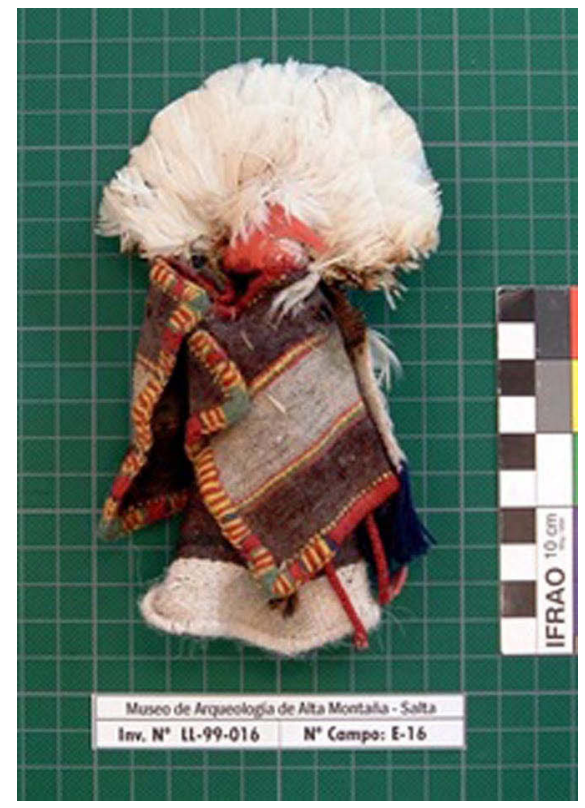

Figura 5. Idolo vestido con textiles y con tocado en miniatura. hallada junto a la niña del rayo textil en color gris, poco común en esta figura con terminaciones en hilos de color rojo amarillo verde y negro.

tejer los vestidos o uncus del Inca, esculpiendo en ellas maravillosas labores de tocapo, ellos dicen que significa diversidad de labores". 


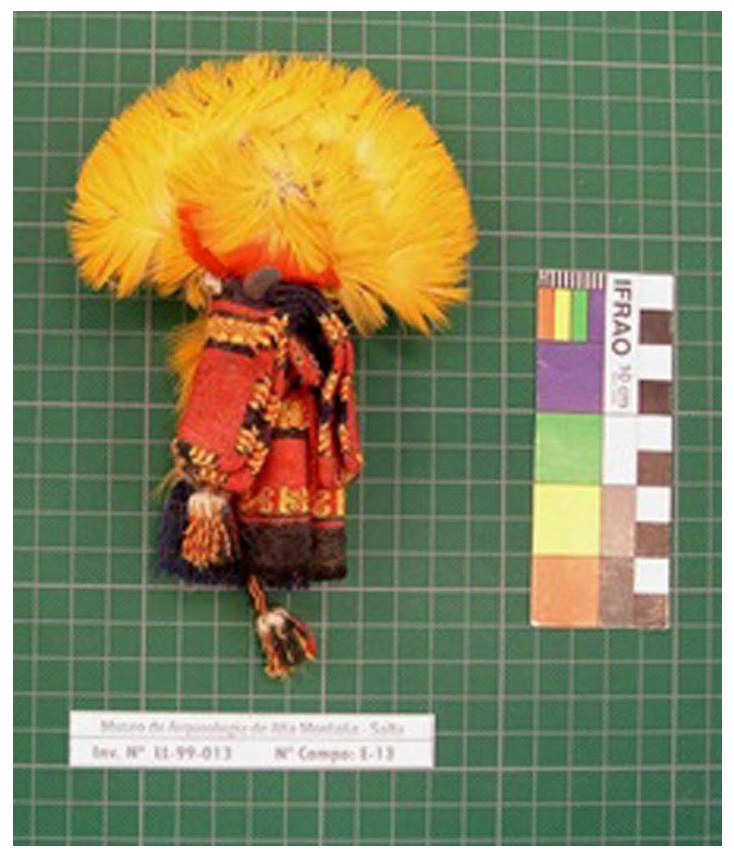

Figura 6a. Figura de plata con tocado de plumas amarillas, con diseño de llave inca en el ruedo textil

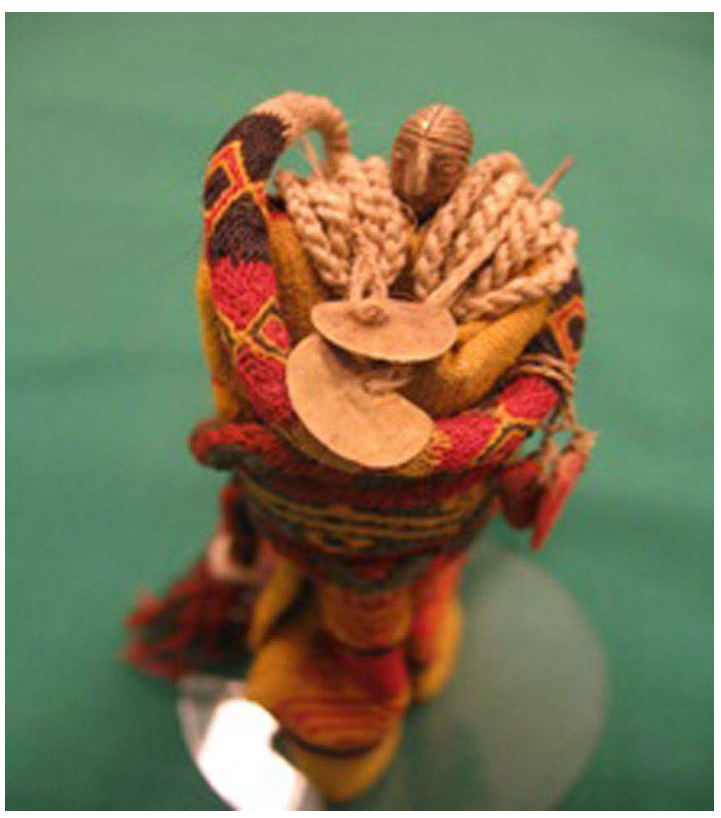

Figura 6b. Figura de plata con parafernalia, tupus de plata y diseño diamante en el textil

Cerrón Palomino (2008: 108-109) citado en Cummins (2011) traza la etimología del término tocapu, expresando que significa primero el poder y la riqueza de reyes incas y luego viene el concepto de elegancia y distinción que se expresa en la forma material de un textil.

Actualmente el tocapu como representación de textos completos ha inspirado indirectamente el trabajo de un número de académicos que han buscado y buscan darle diversos significados Frame (2005,2007); Gentile L. (2008, 2009a ); Silverman (1999, 2015); Ziólkowski et al. (2008).

Victoria de la Jara (1975) afirmaba que se trataba de una escritura logográfica en la que cada motivo representaba una palabra completa, en una representación gráfica del lenguaje similar a ideogramas chinos.

Mary Frame (1994) analiza la estructura y se refiere luego a un modo de codificar tocapu: "la presencia de estructuras textiles ampliamente complejas y un sistema de imágenes basado en ellas sugiere que los antiguos pobladores hicieron abstracción de un código, usando las distinciones de estructuras textiles para transmitir distinciones en cuanto a significado. La fibra puede ser el medio, pero el contenido de tal código podría ser más amplio.

Las distinciones de simetría, número, color, orden, y dirección podrían efectivamente describir conceptos espaciales y sincronizarse con conceptos temporales."

Se refiere a la forma en que el significado puede expresar es decir la lógica que dirige y ordena ese código.

Utilizando valores geométricos define tocapu (2009 editado 2014) como marcos diagramáticos de relaciones y que éstas están incorporadas en propiedades tales como simetría, dirección, número, concentricidad, color y brillo. Las propiedades y formatos mediante los cuales se organizan son semi-matemáticos y la combinación de propiedades tiene un potencial para expresar gráficamente ideas relacionales.

Zuidema (1991) ofrece una definición que resume bien lo que es un conjunto general de propiedades comunes: al tocapu

"Tocapu cuadrado y sobre todo abstractos signos utilizados en textiles incas y en otros medios." formaron parte del complicado sistema de representación aunque nadie ha informado de ello directamente (Zuidema 1991: 151)

Destaca dos conceptos: expresa la suposición de que el tocapu es un sistema gráfico aunque ningún cronista ha escrito nada que sugiera esto y en segundo lugar define la forma del tocapu como primordialmente abstracta.

La abstracción geométrica es una descripción más precisa ya que la mayoría de los textiles están compuestos por figuras-diamantes, cuadrados, rectángulos, líneas diagonales y horizontales, todas ellas organizadas dentro de un cuadrado, romboide o rectángulo bordeado.

El encuadre de cada composición geométrica permite que el tocapu sea visto simultáneamente como entidad individual y como elemento en relación con otros elementos.

Las características definitorias del tocapu no se han descrito aun completamente, no sabemos si existe una sola síntaxis que los ordena, si el dibujo en blanco y negro de Guaman Poma lo representan, creeríamos que el color no 
es necesario para decodificarlos como formas geométricas? (Cummins 2011).

E. Phipps (2017) descubre que hay mucho que examinar en la relación entre telas y prendas asociadas con actividades sagradas en los Andes. Podemos ver que sus materiales y colores forman una parte integral del uso y el significado, nos indica. La agencia de el paño generada en el contexto de su materialidad, ameritan un estudio más profundo.

\section{El tocapu como transhistórico}

La transhistoricidad es la cualidad de mantener a lo largo de la historia humana, no sólo dentro del marco de referencia de una forma particular de sociedad, ni en una etapa particular del desarrollo histórico.

Se dice que una entidad o concepto que tiene transhistoricidad se mantiene en una época y puede estar completamente ausente o llevar implicaciones opuestas en otra.

Las composiciones pictóricas, la aparición de narrativas pictóricas en el período colonial pueden haber sido una expresión de lo que el tocapu y el/ los objetos sobre los que aparecen pudieron comunicar antes y después de la conquista.

Esta relación entre tocapu y la imagen pictórica es probablemente contextual.

Frame (2007) indica que el modo nativo de expresión gráfica, usado por Guarnan Poma, transmite algunas informaciones que no están expresadas en el texto escrito español.

El tema del tucapu, el código gráfico de los incas, está tan ausente del texto en castellano que un estudio sugirió que éste quedaba oculto a propósito y retenía informaciones sobre el tucapu (Cummins 1997: 258-60). También muestra cambios en quienes visten ropas con tucapu en tiempos anteriores y después de la conquista.

Catherine Julien (2000) destaca la función heráldica del tocapu, y que las tunicas cumbí con diversos colores y motivos representan las provincias que poseía el Inca.

David de Rojas y Silva (2008) en un minucioso trabajo que analiza y determina el uso y función del tocapu, concluye que los mismos conforman una seriación documental heráldica, clasificando a las familias mediante símbolos gentilicios.

Este autor considera que los tocapu hallan su continuación cultural en el pallay de los tejidos actuales, que con adornos adicionales y contemporáneos precisan una identificación tradicional de comunidades campesinas.

Los motivos tocapus perduran en el imaginario de los pobladores, actualmente tejen imágenes derivadas ellos, aunque no conozcan los nombres de los diseños; porque los hayan olvidado o sustituido, aun asi las estructuras de los

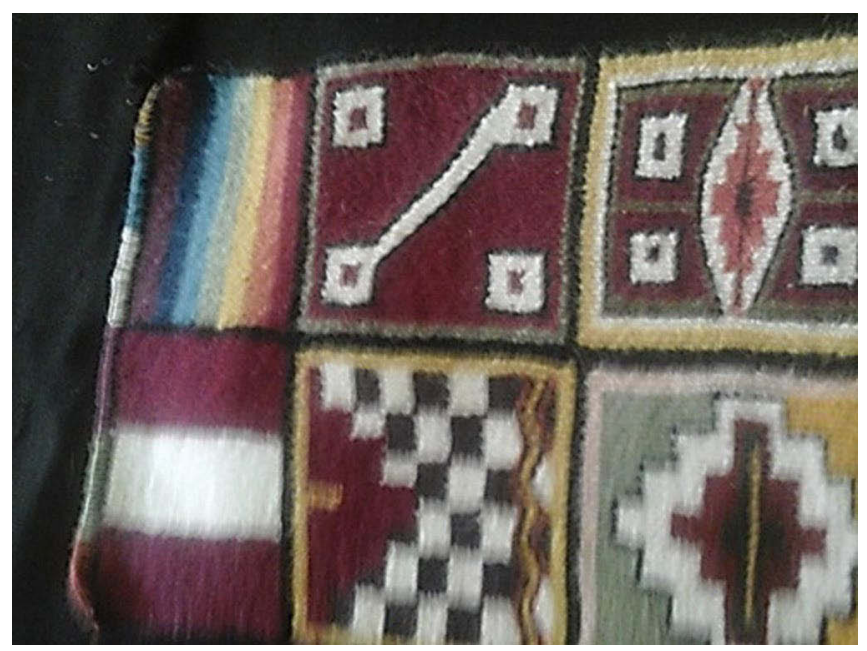

Figura 7. Tapiz tejido actualmente en Pitumarca (foto Carbonell 2016), reproduce figuras de tocapu tejidas recientemente, representando la parafernalia inca y agrupados según diseño y colores propuestos por el tejedor

textiles son entendidas detalladamente, también por quienes nunca han tejido.

\section{Tocapu: elemento comunicacional}

Gentile (2009b) argumenta que en las crónicas y diccionarios tempranos tocapu nombraba un tipo de trabajo textil de alta calidad "inventado" por el Inca Viracocha.

Guarnan Poma en el dibujo tucapu, representa gobernantes incas, sus esposas y nobles vistiendo los diseños geométricos en su vestimenta tejida. Haciendo esto, transmite informaciones importantes sobre el código gráfico en general, sin usar palabras, puede decirse que inventó un estilo híbrido de ilustración fusionando dos tradiciones gráficas.

Eeckhout et Danis (2004) en su investigación sobre los tocapus reales en Guaman Poma; determinan que pueden considerarse como una especie de heráldica incaica representados en uncus y queros. Siendo probable que los tocapus sí constituyen una forma de comunicación gráfica que abarca otros campos además de la heráldica: la toponimia, jerarquías de rango social y militar, símbolos para fiestas y períodos del año, culto a las divinidades.

Cummins (2004; 2011) en su trabajo de análisis del tucapu plantea la posibilidad de que a través de ellos se expresaran conceptos abstractos, cuyo significado simbólico debería entenderse de forma contextual. Este estudio tendrá que mirarse más allá de la interpretación de cualquier tocapu como signo existente en un contexto específico, como los de queros o cerámicos; será un estudio que considerará el rango histórico y la diversidad para llegar a una descripción funcional. 
Cummins (2011) plantea si el tocapu realmente un sistema histórico de notación? O es meramente idiosincrásico y básicamente mnemónico e históricamente específico, como lo sugirió George Kubler quien creía que el despliegue continuo de los tocapu en el período colonial era decorativo y que había perdido toda capacidad para transmitir significado.

Frame (2009) lo analiza como un tipo de código que opera en un nivel más abstracto, aunque expresa relaciones de carácter social con los pobladores, diseños que se reiteran y que actualmente pueden ser comprendidos aún por los nativos que no saben tejer.

El código de tocapu difiere notablemente de los sistemas de escritura antiguos que han sido descriptos, el sistema no parece alfabético, silábico, pictográfico o logográfico, pudiendo tener elementos de los últimos dos. Como diagramas, estos diseños exhiben marco de relaciones que no son conmensuradas con declaraciones fonéticas, es difícil configurarlos en palabras.

Los define como semasiográficos en tanto que representan grafemas, citando a G. Sampson (1985) quien reconoce la posibilidad abstracta de que los sistemas semasiográficos puedan ser expandidos hasta convertirse tan complejos y ricos en potencial expresivo como el lenguaje hablado.

\section{Dimensión tiempo y espacio}

Pino Matos (2014) propone que la existencia de algunos diseños geométricos, conocidos como tocapu, podrían estar haciendo referencia a fechas importantes del calendario inca, las que se encontrarían representadas en una arquitectura planificada y vinculada con el paisaje sacralizado de Huánuco, con dibujos de casana que en trajes rituales reproducían festividades de agosto el comienzo de la labranza (ejemplo manto calendario analizado por Urton fig 17). Ver posición de los colores y esquema del manto calendárico MFA325 (Urton 2007: 255-257 fig 17).

Al comparar la organización del espacio del manto calendárico MFA325 que analizó Gary Urton (ibid), podemos observar que este manto, gracias al uso de los colores rojo, amarillo y una combinación de los anteriores con el azulverde presenta una configuración del espacio de forma bidimensional muy similar al diseño de la construcción cuatripartita de Huánuco Pampa.

Indicando además que los diseños escalonados de las túnicas se han plasmado en la arquitectura de piedra, en la de barro, diseñaron y plasmaron conceptos e identidades arquitectónicas.

Makowski (2010) expresa que es posible que las composiciones que se plasmaron en textiles y en arquitectura, efectivamente, reflejen la idea de un orden natural y social, que organiza el universo en divisiones de dos mitades, o en cuatro suyus y que cada mitad y sus partes correspondan a tiempos del ciclo anual.

Referente a la noción tiempo y espacio en los tocapus estudiada por Zuidema (Códigos del Tiempo 2015), comparando almanaques cuádruples en túnicas comprobó que eran similares. Trátase de tocapus producidos por distintas culturas, incaica, huari y tihuanaco, y también nasca y moche.

Indica que el espacio es visible a través de la cultura material pero el tiempo es acción y es ahí cuando el calendario organiza las actividades de las gentes en patrones reconocibles(íbid).

En esa concepción de tiempo y espacio relacionados, la meta era comprender todas las figuras y diseños en las túnicas analizadas. Y cita a Young Sanchez (2004) referida a la Túnica de la Portada describiendo "que codifica mensajes sociales, políticos y religiosos dentro de una representación idealizada de la misma ciudad de Tiwanaku”.

\section{Los tocapus en Llullaillaco}

"Hase de advertir que todas las más guacas, fuera de sus haziendas, tienen bestidos de cumbe que llaman capaccochas del grandor de las guacas. Y lo primero que se ha de procurar es estas capaccochas porque, quedando en su poder, tornarán a bestir la piedra que quieren, de manera que no quede reliquia de la tal guaca."

(Un inédit de Cristobal de Albornoz,

Duviols P. 1967)

Elena Phipps (2017) al desarrollar el tema de los textiles en los ritos andinos, nos indica que los incas crearon textiles especiales, a veces tejidos al tamaño y forma para envolver los objetos rituales: pequeñas figuras de oro, plata y spondylus envueltas o vestidas de textiles, que contribuyen al valor de ofrendas a Yllapa (dios del rayo) en entierros sacrificiales de altas montañas.

Ann Peters (2015) afirma que las prendas en miniatura fueron modeladas a partir de características estéticas y técnicas usadas por las Coyas y mujeres especiales llamadas acllas, iguales a las prendas textiles de tamaño completo. Se refiere a piezas arqueológicas, documentadas provenientes de los sacrificios de niños capac hucha en las cumbres nevadas de las regiones de Qulla Suyu y Kunti Suyu.

Dice:

"Los niños que han sido estudiados no son incas étnicamente en origen, que han ofrecido a sus hijos e hijas como parte de relaciones de intercambio, anudando una red de alianzas políticas 

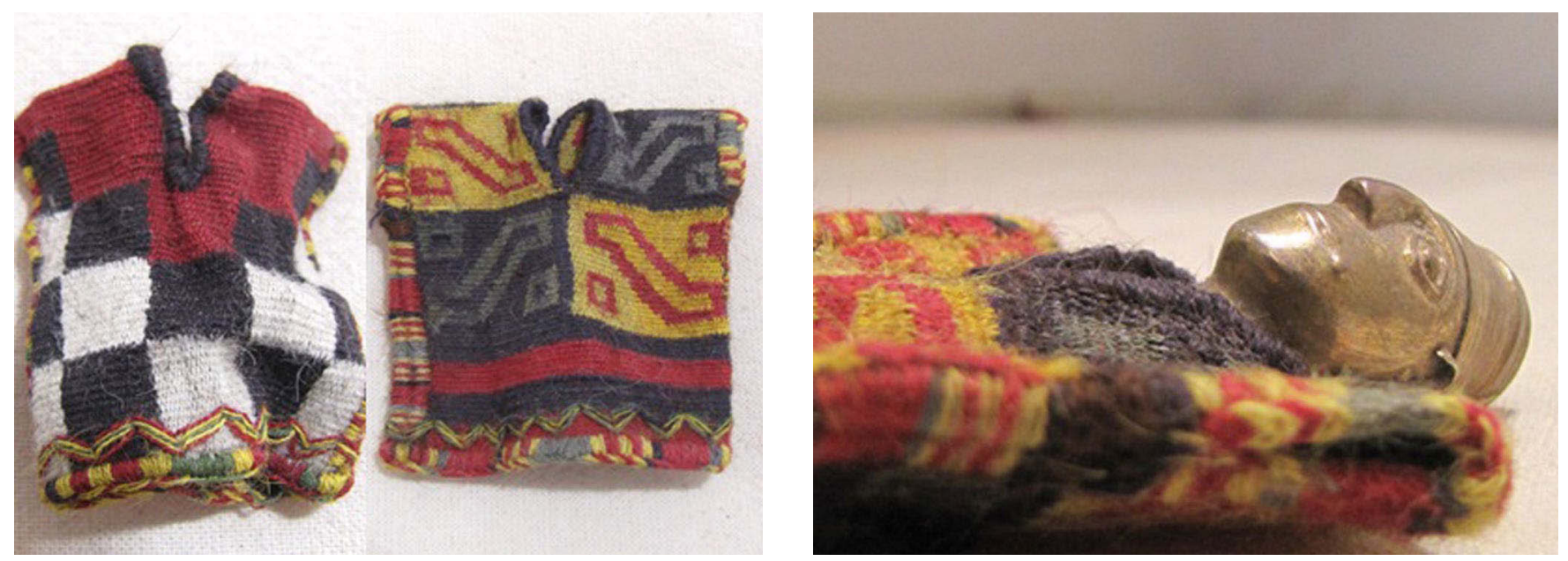

Figura 8a y 8b. Textiles en miniaturas en el ajuar de Llullaillaco, visten pequeñas figuras antropomórficas. Archivo MAAM Salta Argentina

que crearon y mantuvieron el imperio. Los niños usan vestimenta regional y tienen túnicas incas emblemáticas u otras prendas en la parte superior o dobladas y colocadas al lado (en Reinhard y Ceruti 2000; Schobinger 2001)."

\section{(Ann Peters ( ibid )}

Algunas prendas son honoríficas u ofrendas, ya que pueden ser del tamaño incorrecto para los niños hallados; figuras femeninas y masculinas en miniatura se colocan cerca de los sacrificados junto a otras ofrendas.

Estos entierros sacrificiales, conservados en condiciones glaciares se acercan más a la descripción de los mallquis incas. (ibid)

En distintos hallazgos, uncus, túnicas, fueron colocados junto a la ofrenda humana, éste es el caso de la Doncella, cuyo tucapu se halló doblado sobre el hombro.

Frecuentemente son de tipo estándar, incluso los podemos encontrar representados por uncus en miniatura en la que figuras masculinas de oro, femeninas de plata o spondyllus, están vestidos y que acompañan a las momias (ajuar).

Zuidema (1991) expresa que solamente los incas del linaje del primer rey, Manco Cápac, se muestran usando los diseños de tucapu. La característica de élite que no se repite en túnicas comunes fue el tejido con diseño de tapicería que define al tocapu, este rasgo distintivo se reservó solamente para las túnicas clásicas de élite, de las familias reales o de oficiales imperiales.

Mary Frame (2007) nos indica que el patrón llamado llave inca es una clase bien definida de túnica que alterna dos variantes de la llave inca con diseño tocapu en un patrón de tablero de ajedrez en la parte superior con la sección inferior que exhibe amplias bandas (seis) en dos colores alternantes.
Se han hallado en la costa del Perú, como indicativo de que fueron obsequiadas por el Inca a los dignatarios en las provincias costeras.

Se cree que manifiesta un mensaje gráfico de la organización Inca cuando la pieza de forma rectangular, concebida desde su elaboración como una unidad, reproduce:

- diseño conocido como damero, formado por 80 cuadrados, conteniendo cada uno de ellos el motivo de la llave inca.

- presenta dos variantes en las propiedades de la dirección y el color: una llave luminosa/brillante (rojo sobre amarillo) con una orientación y una llave oscura/opaca (azul/verde) con la orientación opuesta.

- cuatro colores que son usados invariablemente y dos de los cuatro colores son repetidos en las bandas de la mitad inferior de la túnica

- las costuras lateral y aberturas para los brazos están cosidas con rayas perpendiculares de distintos colores al igual que el orillo inferior de la túnica, con un diseño de rayas de tres colores formando un zigzag horizontal continuo por encima del orillo del ruedo.

Frame (2007) define llave inca como un diseño de simetría finita, con rotación. Indicando que el intervalo de rotación es denominado "doblado dos veces", siendo congruente consigo mismo en solo dos puntos en una rotación circular completa.

Pertenece a una clase de diseños denominados curvas invertidas, porque los dos finales tienden a ir en direcciones opuestas o inversas.

Estas curvas invertidas son zoomorfizadas como serpientes de dos cabezas, pueden verse más austeras geométricamente como las letras $\mathrm{Z}$ o $\mathrm{S}$. 


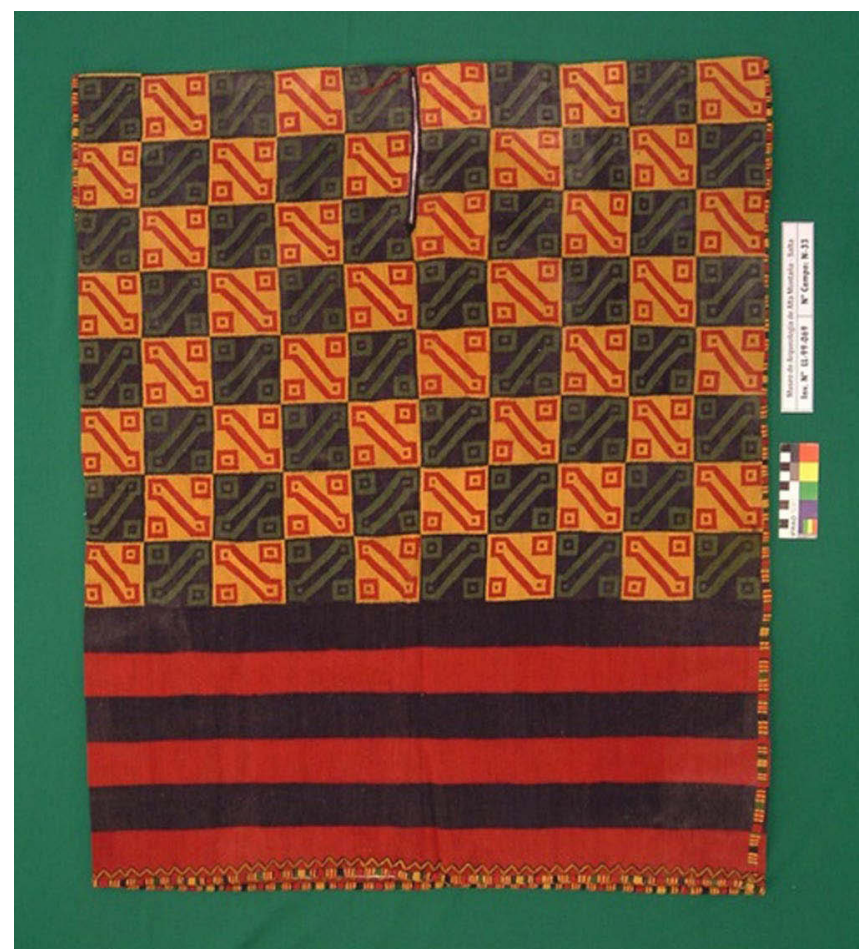

Figura 9. Uncu tocapu motivo llave inca encontrado doblado En el hombro derecho de la doncella. MAAM Salta Argentina.

Otros modos de discurso, aparte de los códigos gráficos textuales, enfatizan el patrón de figura de ocho y su ciclicidad alternada.

Es necesario recordar que el nudo khipu que denota el entero uno es un nudo en figura de ocho, usado también en los preparatorios para tejer, cuando se ordena la urdimbre,
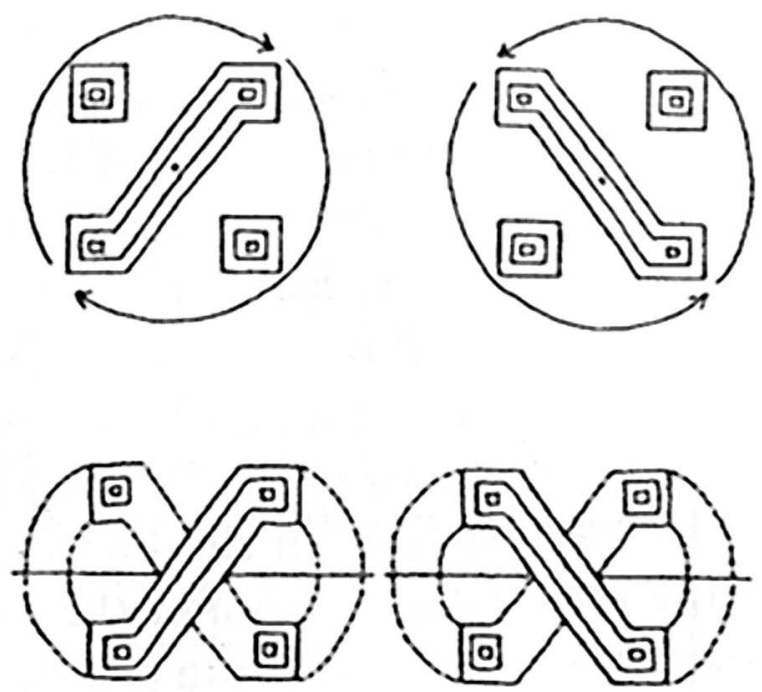

Figura 10. Dibujo Mary Frame (2003).
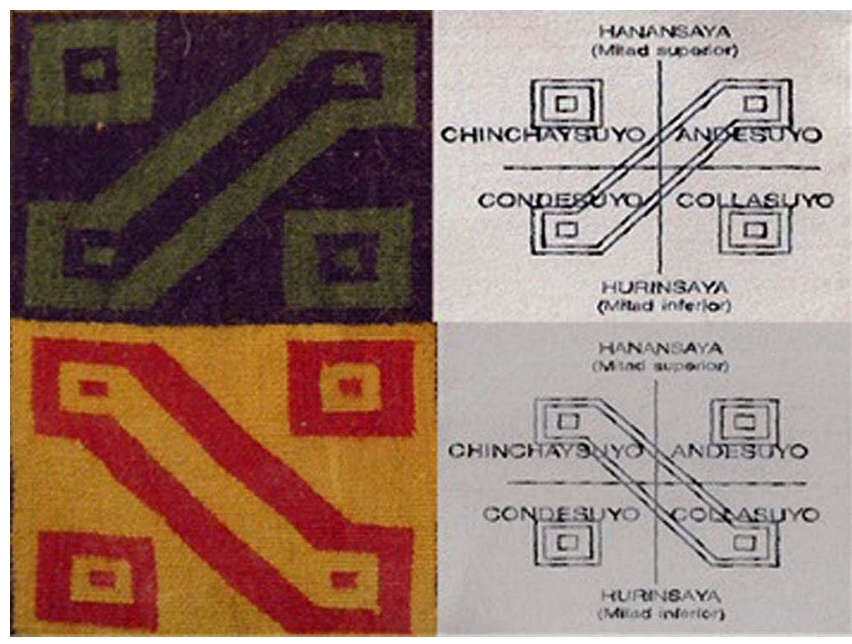

Figura 11. Cuadro realizado por B. Carbonell usando el ideograma de Mary Frame (2003) en tocapu de LLullaillaco

porque mantiene la urdimbre sin enredos, pero además intercala alternación binaria (arriba-abajo) con orden secuencial (corriendo de izquierda a derecha).

La misma ciclicidad alternada se señala en la estructura socio-política Inca, donde una de las secuencias jerárquicas de los cuatro suyus intercala una alternación binaria entre fracciones la secuencia de los suyus (ibid.):

\section{Chinchaysuyu (hanan) \\ Collasuyu ( hurin) \\ Andesuyu ( hanan) \\ Condesuyu ( hurin)}

Puede inferirse que al usar tales túnicas los dirigentes de las provincias conquistadas o asimiladas al Imperio imponían su posición en el nuevo orden y al mismo tiempo se conformaron con los nuevos niveles de autoridad del Estado que invalidaba su anterior autonomía y aceptando la autoridad del Inca.

\section{Considerando}

- que el uncu constituyó el elemento por excelencia de la indumentaria masculina incaica y que fue hallado entre el ajuar de una joven aclla

- en el hombro derecho de la doncella, prolijamente doblado, manifestando la pertenencia heráldica a alguna clase de jerarquía

- estas túnicas fueron utilizadas para extender una iconografía oficial del Imperio, con fin de consolidar una cohesión política, social, económica y tal vez religiosa. 


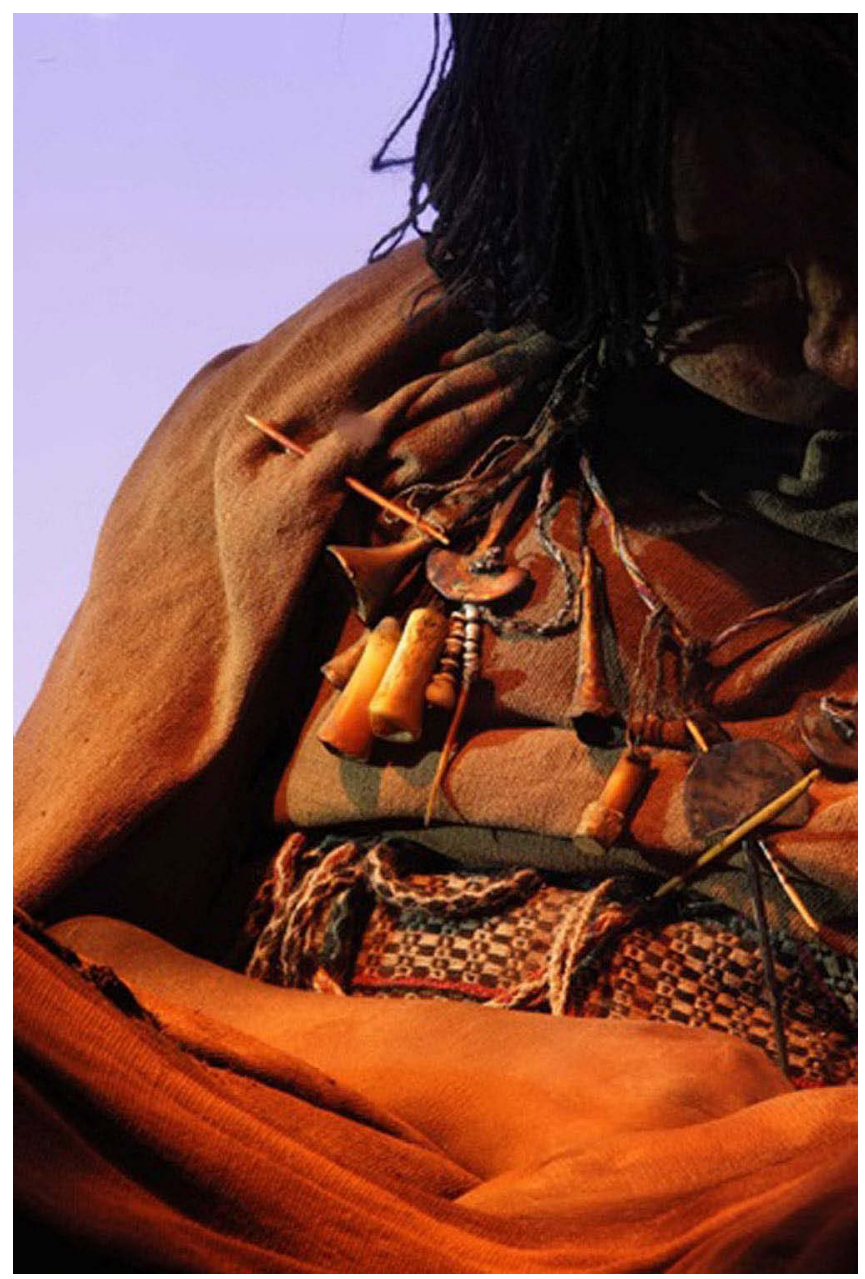

Figura 12. Fotografía Archivo Museo MAAM, vestimenta y parafernalia de la Doncella.

Ceruti (2015) y otros autores afirman que las túnicas finas fueron enviadas como regalos diplomáticos por los incas a los líderes locales o curacas. Los curacas a menudo tuvieron papeles importantes en las capacochas, incluso ofreciendo a sus propios hijos, según lo informado por los cronistas (Hernández Príncipe [1621] 1986).

Sería ésta la razón por la que se enterraron finas túnicas masculinas junto a las ofrendas femeninas en Llullaillaco y en otros lugares (Reinhard y Ceruti 2000)

\section{Vestía acsus color café:}

Este antiguo vestido femenino consistía en una gran tela cuadrada (ajsu) usada como falda, faja policroma enrollada a la cintura, por medio de la cual la tela era colocada en su sitio.

El ajsu se usaba sobre la piel, desde el costado derecho se envolvía en torno del cuerpo, cubriéndolo desde los hombros hacia abajo y desde las caderas hasta los pies (Cieza de Leon 1986 [1563] cap. 41), dejando libres los brazos. Se suspendía de ambos hombros por agarres.

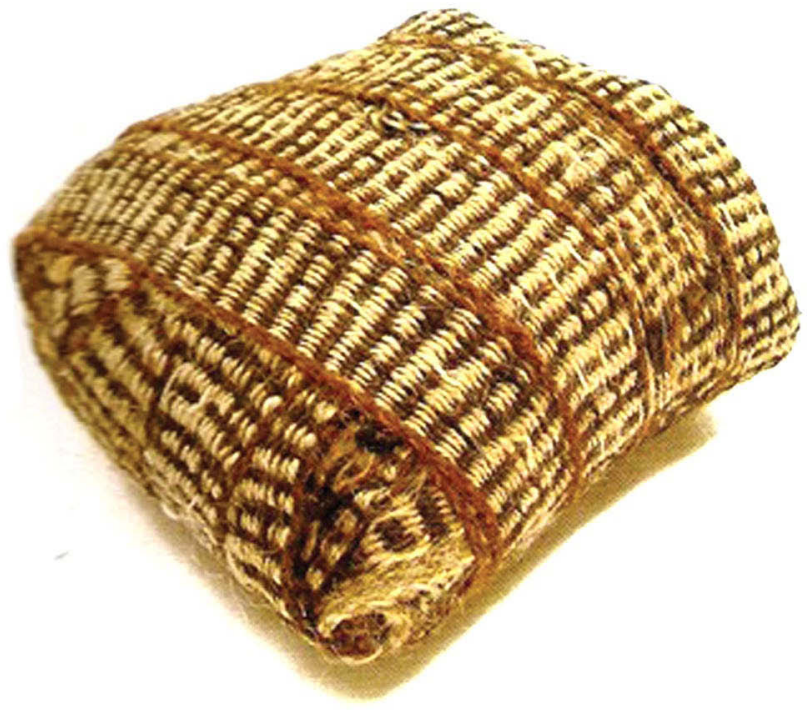

Figura 13. Faja tejida sujetaba el acsu de la doncella. Archivo MAAM Salta Argentina

El "cinturón madre" o mamachampi, pequeño, y de tejido grueso se usaba sobre el ajsu ajustando y dando forma a la cintura.

La faja policroma de tejido atrayente y enteramente largo, llamado chumpi

El manto lliclla, de color grisáceo, de forma cuadrada usada en torno del ajsu, por encima de los hombros se sujetaba por el pecho con un objeto llamado tupu o alfileres topo, de metal.

El color grisáceo comparado con textiles antiguos aparece como un nuevo color, tanto en lana como matiz natural y en algodón como tinte artificial, añadiéndose que sólo aparece durante el período incaico en textiles de la cultura costeña, apareciendo como introducido por contacto con la civilización de Cuzco.

Colgantes de hueso y tupus de metal completaban los objetos que adornaban a los niños; otorgándoles pertenencia a distintas regiones del territorio inca.

Textil color canela envoltorio externo y otro textil de color semejante cubriendo cabeza y parte superior del cuerpo:

Las túnicas de color canela presentan gran interés cuando como las túnicas clásicas se tejieron de un solo paño largo y muestran dimensiones más largas que anchas (1.40 × 1.45).

Se ha usado la técnica de cara de urdimbre y no de trama, han sido encontradas en gran número de ejemplares en sitios de la costa sur del Perú, sugiere su uso como una forma de distinguir a los funcionarios que servían al Inca. 
Las prendas de color castaño fueron usadas sólo por mujeres del rango de los altos jefes o funcionarios.

Cuatro ideas distintivas se representaban en los colores con que se vestía a las mujeres:

$1 \mathrm{El}$ sol : blanco correspondía a la yuraj ajlla

2 El Inca : roja correspondía a la wairuru ajlla

3 La provincia: castaño correspondía a la p'aqo ajlla

4 El jefe y el pueblo común: negro correspondiente a la yana ajlla

Santacruz Pachacuti Yampi (1879[1620-1630) escribe que "Inca Tupac trajo de sus campañas muchas mujeres jóvenes, principalmente las doncellas escogidas (ajlla) para Tiksi Qhapaj Wirqocha Pachayachachij, llamadas Yuraj ajlla"

"Había hecho construir casas para las cuatro clases: yuraj ajlla, páqo ajlla para los caciques (los apukurakas) y la Yuna ajlla para los indios comunes".

Fray Ramos Gavilan (1976 [1621] confirma claramente que las acllas wairuru, turaj y p' aqo eran sacrificadas al Sol.

Santacruz Pachacuti Y (1879) expresa que las yuraj ajlla y p'aqo ajlla estaban destinadas a los apucuracas quienes eran los encargados de seleccionar en el Imperio a todas las niñas que luego serían distribuidas en las acllahuasi.

Fue hallado en el ajuar de la Doncella, con las agujas e hilo pespunteando el borde, lo que nos permite suponer que su tarea de aclla continuó hasta el momento de ser ofrendada finalmente en altura.

Las muestras analizadas en laboratorio demuestran que se trata de una manta de lana de camélido. Tejida con técnica de faz de urdimbre presenta forma rectangular,

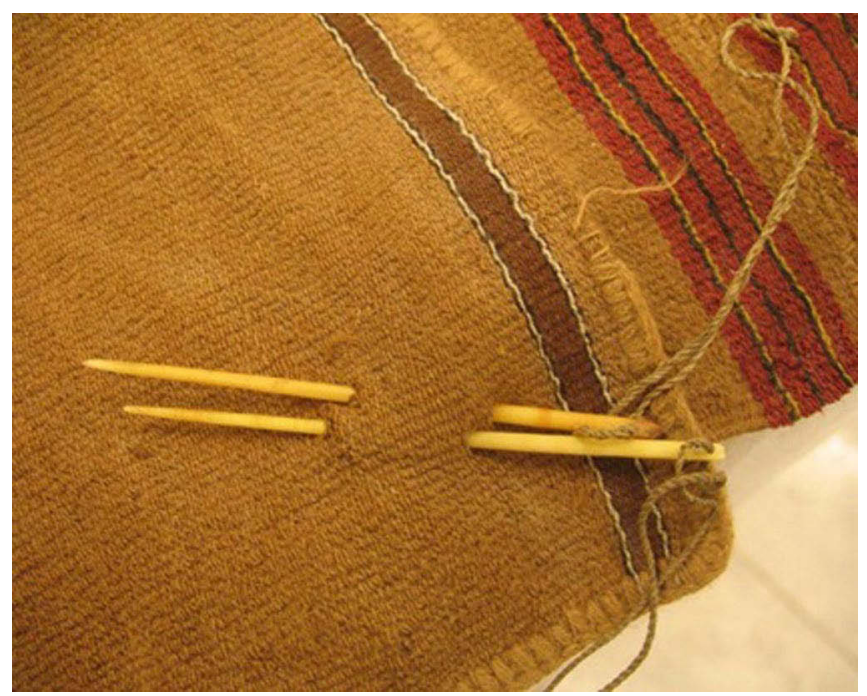

Figura 14 Textil con agujas de cardón que perteneció a la doncella en plena función de terminar los bordes mientras proseguía el ascenso al Llullaillaco. Archivo Museo MAAM. decorada con listas laterales predominando colores naturales (canela, ocre, natural) rojo y negro.

Cumplía una función ritual al envolver el cuerpo ofrendado, las agujas de cardón servían para realizar la terminación en las orillas que quedaran de modo inconcluso al ser sacrificada.

\section{Chuspas tejidas y plumas}

Las chuspas en Llullaillaco presentan características de tejido del Período Horizonte Tardío, de tamaño mediano, utilizadas para los rituales, conteniendo pigmentos de colores, plumas de color rojo, hojas de coca y otros elementos rituales.

Las bolsas de menor tamaño llamadas wayuña (de $10 \times$ $10 \mathrm{~cm}$ a $7 \times 7 \mathrm{~cm}$ de promedio) de forma cuadrada o rectangular, con superficie lisa o listada cumplían la función de contener hojas de coca, harina, maiz e implementos textiles.

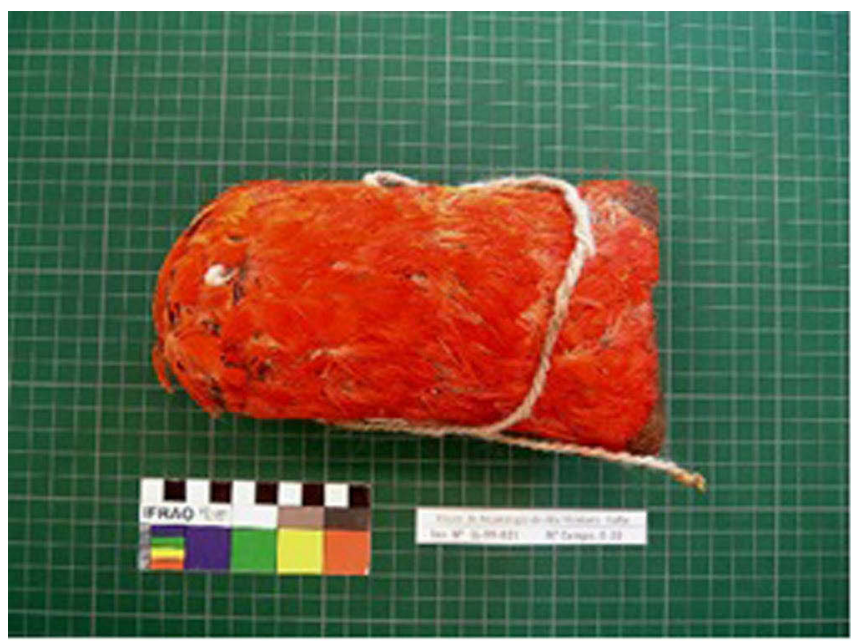

Figura 15a. Bolsa tejida cubierta con plumas rojas

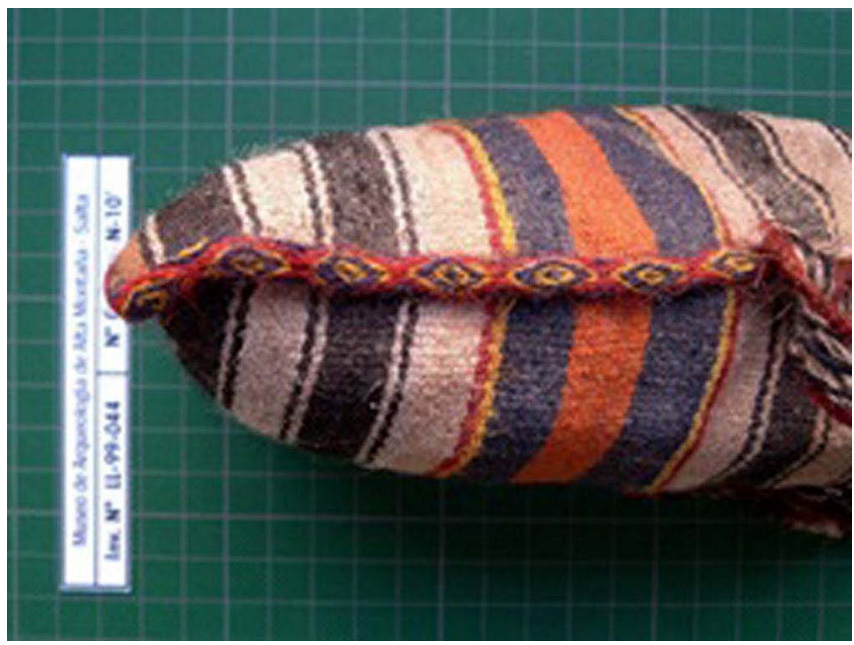

Figura 15b. Bolsa tejida con borde de diseño diamante Archivo Museo MAAM. 
Presentan mayores refuerzos en los bordes y orillas con festón anillado simple, las tiras son más gruesas, tejidas en telar y se observan diseños geométricos en franjas horizontales.

Disminuyen la cantidad de motivos haciéndose más comunes los motivos geométricos simples: la letra $\mathrm{Z}$ en sucesión vertical, ganchos en miniatura, etc.

Se utilizan colores naturales preferentemente, reservando los colores teñidos (gama limitada) para las franjas.

La aplicación de plumas en bolsas y mantos textiles ha sido bien documentada en las ofrendas en Llullaillaco, ya que se colocó una chuspa o bolsa cubierta de plumas rojas y presumiblemente que contenía hojas de coca en el entierro de la niña más joven, mientras que una bolsa de plumas blancas similar fue enterrada en asociación directa con el niño.

Encontramos en la bolsa con rayas horizontales, en su borde un diseño de tocapu diamante; con marco en forma de diamante y un centro de la misma forma.

El diseño diamante se produce en una amplia gama de variantes, con marco y sin marco en túnicas y otros artefactos, siendo recurrente en túnicas y textiles hallados en las zonas costeras lejos del centro del imperio inca.

Las bolsas chuspa en el Período Intermedio Tardío contienen sólo hojas de coca, las tiras o soguillas son acordes con el diseño general de la pieza, presentando sólo trenzado o cuerdas; es el Período Tardío cuando su contenido se amplía y varía desde hojas de coca a plumas, pelos, y otros.

\section{Spondylus yllas y collares}

Llamada mullu, fue singularmente apreciada por los incas considerándola un material más valioso que el oro.

Fue alimento simbólico de lugares sagrados elemento preferido para las huacas (Taylor 1999).

Rosing (1996) describe que el uso e importancia del spondylus permanece hasta el presente.

Este collar en particular con tejido de fibra de camélido y cabello humano, color negro es similar en formato a otros objetos hallados en culturas como Nasca (Museo Antonini Cahuachi) y en otros hallazgos de preincaicas.

Figuras en spondylus, miniaturas vestidas con tejidos cumbís, llamas talladas, acompañaban el enterramiento de Llullaillaco.

Reinhard y Ceruti (2010) sostienen que las miniaturas del Llullaillaco no son sacrificios sustitutivos ya que fueron enterradas junto a las ofrendas humanas y no en lugar de ellas.

Es probable que en la mayoría de los casos las estatuillas masculinas y femeninas representaran deidades asociadas con el volcán y otras montañas de la región (en Mignone 2015).

En algunas estatuillas de plata se encuentran adornos de spondylus en las terminaciones de los tejidos delicadamente y en miniatura completan el vestuario con diseños cumbís.

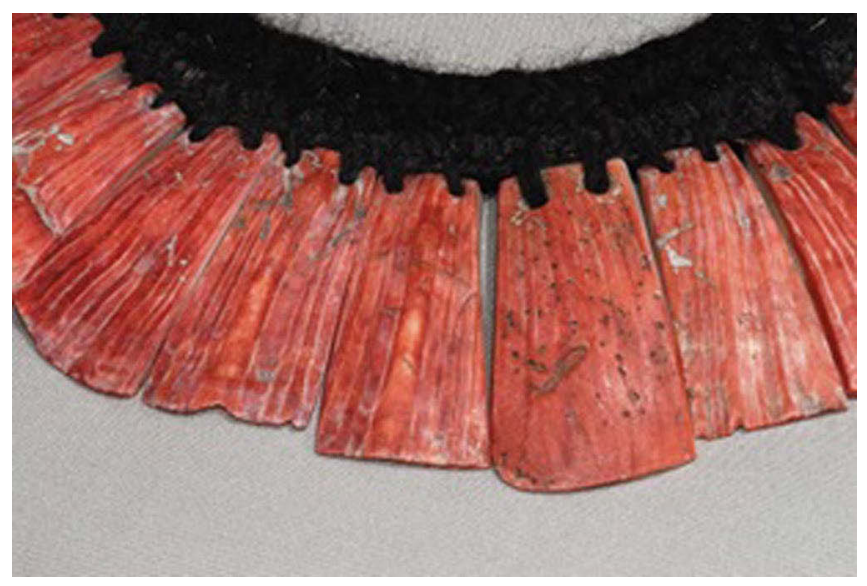

Figura 16a. Collar de spondylus hallado en el ajuar del niño engarzado en textil de lana negra y cabellos.
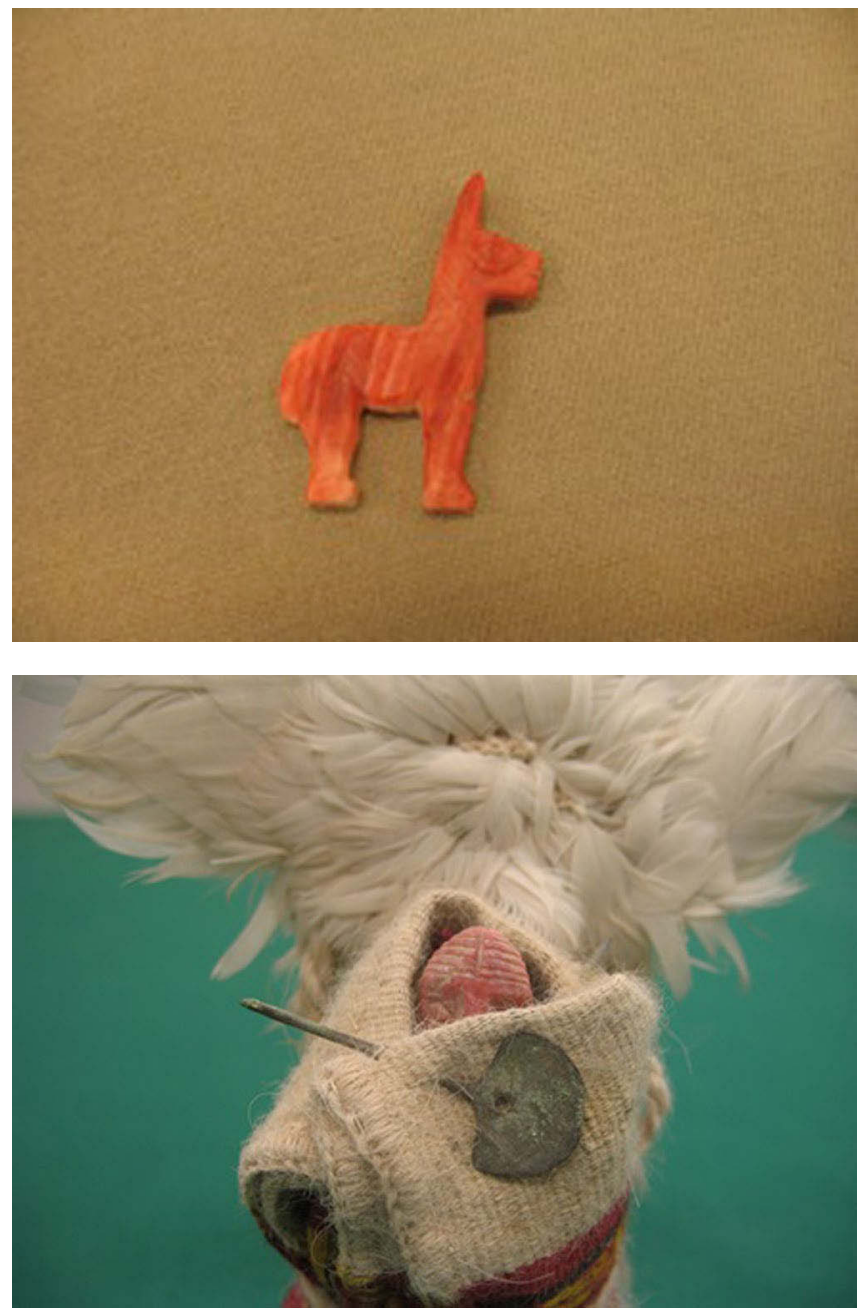

Figura 16b. Pieza camélido esculpida en spondylus. Figura 16c estatuilla de spondylus totalmente vestida con tupu y tocado de plumas blancas. Archivo Museo MAAM Salta Argentina 

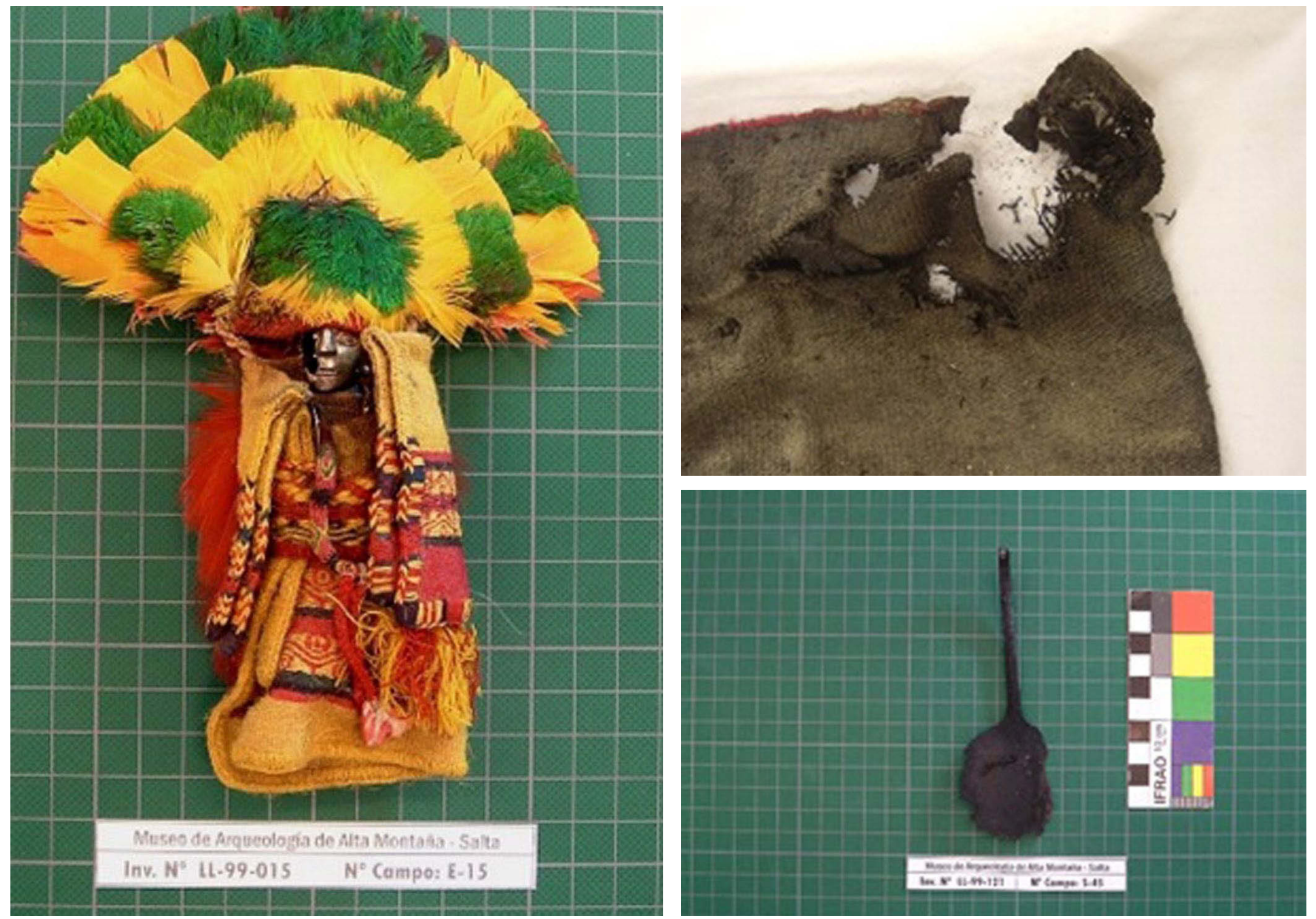

Figura 17 alcanzados por el rayo pertenecen al ajuar de la niña del rayo. 17a figura de metal con la cara quemada por un rayo; 17b gorro de la niña quemado por un rayo que alcanzara su cabeza; 17c tupu quemado por rayo. Archivo Museo MAAM Salta Argentina

También se hallaron conchas de spondylus junto a otros enseres del ajuar.

Los colores como el blanco, el rojo y el azul-negro, presentan guardas amarillas geometrizadas, signos utilizados en tucapu, se trata de guardas y dibujos finamente combinados, que han sido reproducidos en cerámicos y en madera en otro contexto y regiones.

Polo de Ondegardo (1916) describe al Dios del Trueno como el Hondero celestial

“[...] el trueno [...] es vn hombre que está en el cielo con vna honda y vna porra, y que está en su mano el llouer y granizar, y tronar [...]"

Las ofrendas y sacrificios al dios Illapa se daba en regiones de altura; en este caso la niña del rayo fue alcanzada por una descarga que quemó parte de su cara y gorro cefálico, tupu y prendas.

Junto a los niños fueron halladas hondas de cuero y lana; y curiosamente la niña del rayo tenía en su frente un adorno de metal, que sin duda atrajo al rayo que quemara su rostro y pertenencias.

Las túnicas comunes de Horizonte Tardío comparten con los ejemplares de las túnicas pertenecientes a la élite Inca un grupo de características, esto se debe a que las túnicas de élite sirvieron de modelo básico, estandarizadas en su forma, en el tejido, costuras de unión y de remates.

Se cree las rayas y bandas sin tocapus en los textiles pertenecían a los oficiales no Incas, Zuidema observa que las rayas o bandas verticales aparecieron en las túnicas de los oficiales de los cuatro suyus del Imperio, fuera del Valle de Cuzco.

Otra característica muy visible es que fueron tejidos con un tamaño mayor en el largo que en el ancho, fueron textiles que muestra una cara de trama muy fina que incluye diseños de tapicería geométrica, tejidos en un solo paño, incluyendo la abertura para el cuello.

Las costuras de unión por los lados son de listas y barras policromas en rojo, amarillo y otros colores contrastantes, rematados alrededor de la parte inferior y en las aberturas 
con puntadas de anillado cruzado con hilos de los mismos colores, bordeados con puntadas en forma de zigzag visibles en la parte inferior.

La fila de zig zag aunque no fuera un tucapu demuestra el status de élite de quien la vestía.

La túnica que vestía al niño es de color rojo puro, con algún detalle en azul, E. Phipps (2017) referido a los tintes dice que los pigmentos rojos parecen estar entre los primeros colorantes y asociados con espacios rituales.

\section{Consideraciones finales}

Se puede inferir que este hallazgo se enmarca en la ceremonia de capac hucha durante un ritual de ofrenda humana y de objetos de carácter real, destinados a las altas cumbres.

Así lo determinan las características de este sacrificio similar a otros en montañas cercanas.

\section{Respecto a la datación:}

Reinhard me escribe: "en ese entonces no hicimos un examen del C-14, pero olvidé que si lo han hecho en Gran Bretaña. Como escribí en el libro que estamos publicando sobre Llullaillaco (Reinhard and Ceruti 2010): "A calibrated accelerator mass spectrometer (AMS) radiocarbon (C-14) date obtained from the hair of one of the Llullaillaco mummies indicated she died between A.D. 1430 and 1520 (Wilson et al.2007:16,457), which is in basic agreement with the A.D. 1470 to 1532 time frame generally accepted for the Inca presence in northwestern Argentina."

Referente a Llullaillaco como guaca, dadas las condiciones de enterramiento en altas cumbres y la dificultad de ascender, podemos argüir que no constituyó este volcán una guaca a la que fueran ofrendados periódicamente otros niños, ni presenta condiciones de guaca a la que se le consultara como oráculo.

Creemos sí que fue elegida de manera preferencial, para elevar la ofrenda real a los dioses, pidiendo por el control político y económico del territorio, la fertilidad del ganado y la agricultura, por el bienestar del inca o ante algún fenómeno climático de trascendencia.

La transhistoricidad del tocapu está demostrada cuando puede expresarse en distintas épocas: inca, colonial, etc representando formas y diseños, geométricos y heráldicos, vinculados todos a la jerarquía del Inca.

Ann Peters (2015) define la condición de estos entierros conservados en montañas glaciarias cercanos a la descripción de mallquis, si bien los niños no están momificados sino conservados por el frío; sí existe en los envoltorios distintos tejidos superpuestos, todos significativos, que
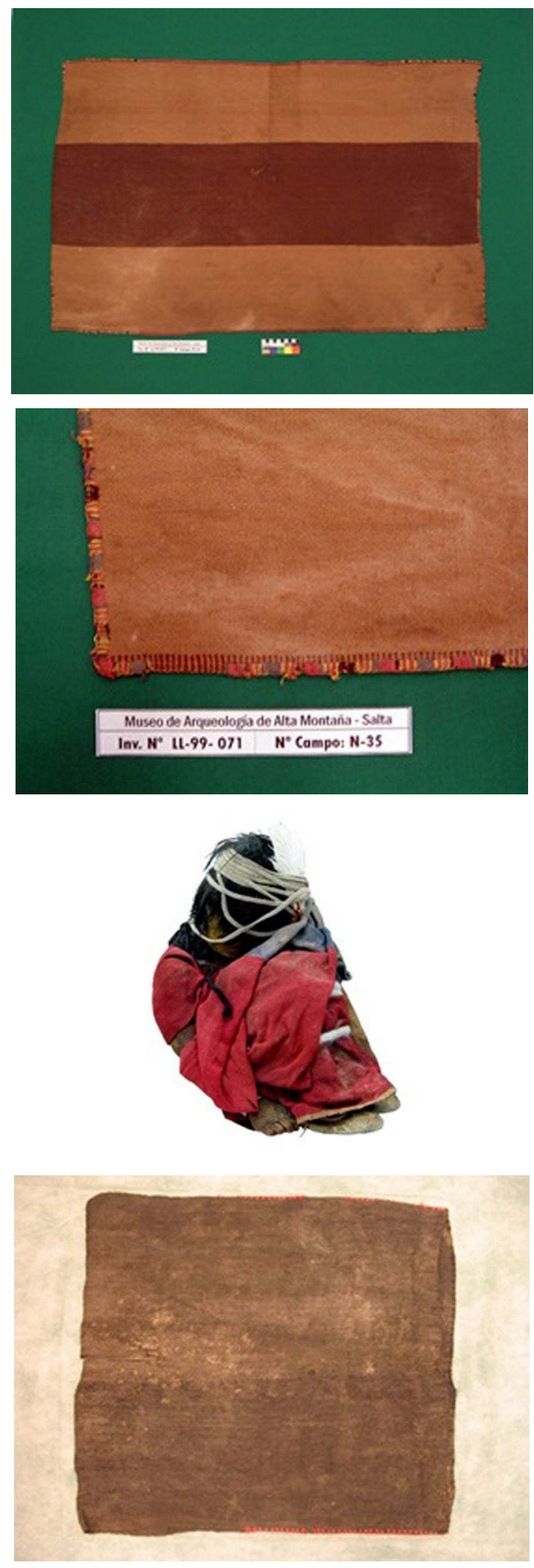

Figura 18. Túnicas en Llullaillaco: 18a Manto de la niña del rayo $\mathbf{1 8 b}$ Detalle de terminación y urdimbre del mismo; 18c Vestido rojo con detalles azul en el niño; 18d Uncu gris de uso exterior que cubría al niño. Archivo MAAM Salta Argentina 
envuelven, protegen y a la vez transmiten en sus tramas datos importantes sobre su identidad y genealogía cultural.

El reconocer calendarios en los tocapus instala una dimensión de tiempo y espacio que Zuidema (2015) ha relevado de manera magnífica, dejando abierto el camino para nuevos descubrimientos; puede leerse en los tapices la acción de perpetuar cogniciones anteriores que se repiten o se resignifican y que se reconocen como algo más que una narración estética; lo cual motiva descifrarlos porque incluyen implícito un legado.

E. Phipps (2017) preocupada por decodificar lo que sucede en el simple acto de tejer vislumbra una interrelación entre materiales y materialidad, cuando el proceso de fabricación de textiles transmite significado.

A través de los materiales, formulación de los hilos y estructuras del tejido, la articulación del diseño, su uso y contexto o en su materialidad se interconectan tradiciones técnicas con construcciones conceptuales (íbid).

Existe una relación primaria entre los textiles y la ceremonia, la piedra guaca o las illas, o las figuras antropomórficas, vegetales o minerales que dan color. Una mística que el tejedor experimenta y practica manipulando los elementos de hilar, agua, tierra, vegetal, mineral que lo convierten en creador comprometido.

La movilidad de los textiles ha permitido difundir técnicas y colores y modos de teñir más allá de la estandarización de las prendas; y todo ello vinculado con lo ritual.

$Y$ en esa acción de intermediarios entre los humanos y las deidades, los tocapus de Llullaillaco cumplen con la tarea de conservar, proteger, diferenciar y jerarquizar a los niños y objetos que visten.

\section{Referencias}

Carbonell Beatriz

2008 Fotografias de las fibras textiles del hallazgo de Llullaillaco.

2012 Registro exclusivo grabado en runa simi con fotografías propias, elaboración de cuadros comparativos. Informante Quispe en Paucartambo

2016 Memoria ritual en los textiles andinos Bariloche Argentina

Cerrón-Palomino, Rodolfo.

2008 Voces del Ande: Ensayos de Onomástica Andina. Lima: Pontificia Universidad Católica del Perú

\section{Ceruti Constanza}

1999 Cumbres sagradas del Noroeste Argentino. Avances en arqueología de alta montaña y etnoarqueologia de santuarios andinos Buenos Aires, Argentina: EUDEBA.
2003 Llullaillaco: Sacrificios y Ofrendas en un Santuario Inca de Alta Montaña. Publicación del Instituto de Investigaciones de Alta Montaña. Salta: Ediciones de la Universidad Católica de Salta.

2010 The religious role of children in the Andes - Past and Present AmS Skrifter; Lugar: Stavanger; Año: 2010 vol. 21/3 p. $123-131$

2015 Inca Offerings Associated with the Frozen Mummies from Mount Llullaillaco S onderband/Special Edition Perspectives on de inca I 2015. International Symposium from March 3rd to March 5th, 2014. Stuttgart

Cummins Thomas

1997 The Object of Imagery in Colonial Native Peru as seen through Guaman Poma's Nueva Corónica i Buen Gobierno. In: Journal of the Steward Anthropological Society, Volume 25, Numbers 1 and 21997

2004 Brindis con el Inca: La abstracción andina y las imagines colonials de los queros. Lima: Universidad Nacional Mayor de San Marcos, 2004. Print.

2011 Tocapu. What is it, What Does it Do, and Why Is It Not a Knot? In: Boone and Urton, Their Way of Writing. Dumbarton Oaks, Washington D.C.

De la Jara, Victoria,

1975 Introducción al estudio de la escritura de los Inkas. Lima: Instituto Nacional de Investigación y Desarrollo de la Educación.

De Rojas Silva, David,

1981 Los tocapu: un programa de reinterpretación. Arte y Arqueología 7: 119-132. Academia Nacional de Ciencias de Bolivia.

Duviols, Pierre

1967 Un inédit de Cristobal de Albornoz : La instrucción para descubrir todas las guacas del Pirú y sus camayos y haciendas, Journal de la Société des Américanistes Volume 56, Numero 56-1

Eeckhout, Peter y Danis Nathalie,

2004 Los tocapus reales en Guaman Poma: Una heráldica incaica? Boletin de Arqueologia PUCP Nro. 8

Frame, Mary

1994 Las Imágenes Visuales de Estructuras Textiles en el Arte del Antiguo Perú Revista Andina Año $12 \mathrm{~N}^{\circ} 2,2^{\circ}$ semestre: 295-372.

2005 What the Women Were Wearing: A Deposit of Early Nasca Dresses and Shawls from Cahuachi, Peru.

2007 Lo que Guaman Poma nos muestra, pero no nos dice sobre Tukapu Revista Andina Nro.44

2009 Tukapu, un código gráfico de los Inkas, Sistemas de notación inca : Quipu y Tocapu : actas del simposio internacional, Lima 
Fray Ramos Gavilan, Alonso

(1976 [1621]) "Historia de Nuestra Señora de Copacabana". Segunda edición completa. Academia Boliviana de la Historia, La Paz

Gentile Lafaille, Margarita

2009a Iconología del tocapu 119. Ponencia leída en las IV Jornadas de Arqueología Cuyana en homenaje al Dr. Juan Schobinger. Universidad Nacional de Cuyo.

2010 Tocapu: unidad de sentido en el lenguaje gráfico andino-Espéculo. Revista de estudios literarios. Universidad Complutense de Madrid

Gonzalez Holguin, Diego

2007 [1608] Vocabulario de la Lengva General de todo el Perv llamada Lengva Qquichua o del Inca”. Lima, imprenta de Francisco del Canto. (http://www.runasimipi.org) para publicación en el internet, 2007

Hernández Principe, R.

1923 [1622] Mitología Andina. Idolatrías de Recuay”. Lima 1986 [1621]. Idolatría del Pueblo de Ocros, cabeza desta comunidad. In Cultura Andina y Represión. Edited by P. Duviols, 442-448. Cuzco: Centro de Estudios Rurales Andinos, Bartolomé de las Casas.

Julien, C.

2000 Reading Inca History. University of lowa Press. lowa City.

MAAM Museo Arqueológico de Alta Montaña, Ciudad de Salta, Argentina

2007 Fotografías del Archivo del Museo Libro del Museo de Arqueología de Alta Montaña Edición 2007

Makowski, Krzysztof

2010 Vestido, arquitectura y mecanismos del poder en el Horizonte Medio, en Krzysztof Makowski (comp.), Señores de los Imperios del Sol. (Colección Arte y Tesoros del Perú), Lima:Banco de Crédito del Perú, pp. 57-72.

Mignone, P.

2015 Illas y allicac. La capacocha del Llullaillaco y los mecanismos de ascenso social de los "inkas de privilegio Museo Chileno de Arte Precolombino. Revista: Boletín del Museo Chileno de Arte Precolombino

Molina , Cristobal,

1989 [1573]Fabulas y ritos de los incas, en Los pequeños grandes libros de la historia americana 1ra. Serie 4 Lima

Murua, Fray Martín de

1616 Historia General del Perú, origen y descendencia de los Incas.
Ossio, Juan

2004 Códice Murúa: historia y genealogía de los reyes incas del Perú del padre mercenario Fray Martín de Murúa. Editores: Madrid Testimonio, España

Peters, Ann

2015 Visions of the inca dynasty. Narrative styles, emblematic dress and the power of ancestors tribus in Sonderband/special edición I, Perspectives on the inca pag 64-79

Phipps,Elena

2017 Andean Textile Traditions: Material Knowledge and Culture, Part 1 University of California, Los Angeles elena@ephipps.org

Pino Matos, Jose Luis

2014 El tocapu que narra el viaje del sol en el mes de agosto: la arquitectura inca como representación calendárica del orden . Una visión desde Huanuco Pampa. En Sistemas de notación Inca: Quipu y Tocapu. Lima 15-17 de Enero de 2009.

Polo de Odendargo, Juan,

1916 [1575] Informaciones acerca de la religión y gobierno de los incas, seguidas de las instrucciones de los concilios de Lima. En Colección de libros y documentos referentes a la historia del Perú tomo III Lima . Sanmartí y Cia.

Reinhard Johan and Constanza Ceruti

2000 Investigaciones arqueológicas en el volcán Llullaillaco: Complejo ceremonial incaico de alta montaña. Salta: EUCASA-Ediciones Universidad Católica de Salta

2006 [2005] "Sacred Mountains, Ceremonial Sites and Human Sacrifice Among the Incas.” Archeoastronomy XIX: 1 - 43. University of Texas Press. Austin.

2010 Inca Rituals and Sacred Mountains: a study of the world's highest archaeological sites. Cotsen Institute of Archaeology. LosÁngeles: University of California Press

Santa Cruz Pachacuti Yamqui, Juan

1879 Relación De Antiguedades deste reyno del Piru ( pp.242) Madrid publicada por Marcos Jiménez de la Espada.

Sampson, Geoffrey,

1985 Writing systems. A linguistic introduction, Stanford, Stanford University Press.

Schobinger, J. y Ceruti, C.

2001 Arqueología de alta montaña en los Andes argentinos. En Historia Prehispánica Argentina, editado por E.E. Berberián y A.E. Nielsen. Tomo U pp. 523-559. Editorial Brujas, Córdoba. 
Sherbondy, Jeannette,

1987 "Organización hidráulica y poder en el Cuzco de los Incas”. Revista Española de Antropología. Americana, 117.

Silverman, Gail

1999 Iconografia textil de Cusco y su relación con los tucapus incas en JA de Lavalle y

R. de Lavalle de Cardenas Ediciones. Lima

2015 Los signos del imperio: Tomo 1, La escritura pictográfica de los incas; Editorial Biblioteca Abraham Valdelomar Lima; Tomo 3 Capac Pallay: Lo invisible en el Tejido Andino, Editorial Biblioteca Abraham Valdelomar- Lima

Szeminski, Jan

1987 Un curaca, un dios y una historia Facultad de Filosofía y Letras UBA, MLAL, Jujuy

Urton, Gary

2007 "A Multi-Year Tukapu Calendar", en Clive Ruggles y Gary Urton (eds.), Skywatching in the ancient world. New perspectives in cultural astronomy. Studies in honor of Anthony F. Aveni. Boulder: University Press of Colorado, pp. 245- 268.
Ziolkowski, Mariusz S.

2008 Marco Curatola Petrocchi/ Mariusz S. Ziolkowski Adivinación y oráculos en el mundo andino antiguoColección Estudios Andinos IFEA- Lima

Zuidema, R. Tom

1991 Guaman Poma and the Art of Empire: Toward an Iconography of Inca Royal Dress In Cultural and artistic Encounters 151-202-

2011 Chuquibamba Textiles and Their Interacting Systems of Notation: The Case of Multiple Exact Calendars en Their Way of Writing, Pre Columbian America Elizabeth Hill Boone and Gary Urton editors

2015 Códigos del tiempo. Espacios rituales en el mundo andino. Apus Grhaps Ediciones. Lima Peru 


\title{
El tapiz colonial con tocapus del Museo Nacional de Arqueología, Antropología e Historia del Perú
}

\author{
Mg. Mónica Solórzano Gonzales \\ Universidad Nacional Mayor de San Marcos \\ msolorzanog@unmsm.edu.pe
}

\begin{abstract}
Resumen
Se estudia en este texto un extraordinario tapiz que resalta por una decoración que combina símbolos incaicos, con aspecto de tocapus, con una cruz cristiana. Forma parte de una investigación mayor dedicada al tapiz andino colonial próxima a divulgarse. Actualmente, no se conoce otro ejemplar semejante en el Perú ni en el extranjero y probablemente se trata de uno de los tapices coloniales más antiguos. Tuvimos la fortuna de darlo a conocer en los seminarios del Doctorado del Programa de Estudios Andinos de la Pontificia Universidad Católica del Perú y en otros eventos desde el año 2014.

Se halla en el depósito de textiles del Museo Nacional de Arqueología, Antropología e Historia del Perú y no cuenta con datos de contexto. Está tejido con técnicas y fibras andinas tradicionales (algodón y camélido). Sobresalen los colores contrastantes y principalmente el diseño híbrido en el que las formas geométricas y estilizadas del lenguaje gráfico inca aparecen junto a un símbolo católico. Analizamos tanto la iconografía, como la técnica del tejido, los usos y posibles propietarios.

La pieza muestra una continuidad del tejido andino ancestral pues varias características estructurales son parte del patrón de estandarización del tejido impuesto por el Estado inca para la elaboración de los uncus destinados a las élites. Ello revela que el tejido de cumbi (tejido fino de los incas) trascendió a los convulsos momentos de la conquista y pervivió en formato y función distintos.
\end{abstract}

Palabras claves: Tapiz colonial, tocapu, catecismo cristiano, sincretismo.

\begin{abstract}
We study here an extraordinary tapestry, unusual due to a decorative program that combines Inca symbols resembling tocapus with a Christian cross. It is part of a larger investigation dedicated to colonial Andean tapestry that is soon to be published. No other similar specimen is known in Peru or abroad and it is probably one of the oldest known colonial tapestry. We have been fortunate to first present it in the seminars of the doctoral program in Andean Studies of the Pontifical Catholic University of Peru and in other events since 2014.

It is located in the textile storage facility of the National Museum of Archeology, Anthropology and History of Peru and has no contextual data. It was woven with Andean traditional techniques and fibers (cotton and camelid). The contrasting colors stand out and particularly the hybrid design in which the geometric and stylized elements of the Inca graphic language appear next to a Catholic symbol. We analyze the iconography as well as the technique of the fabric, its uses and possible owners.

The tapestry shows continuity in the ancient Andean textiles as several structural characteristics are part of the policy of standardization of weaving imposed by the Inca State for the elaboration of uncu tunics for the elite men. This reveals that cumbi fabric (fine Inca cloth) transcended the convulsive first moments of the conquest and survived in a different format and function.
\end{abstract}

Keywords: Colonial tapestry, tuqapu, Christian catechism, syncretism.

DOI: $10.32873 /$ unl.dc.zea.1211

Published in PreColumbian Textile Conference VIII / Jornadas de Textiles PreColombinos VIII, ed. Lena Bjerregaard and Ann Peters

(Lincoln, NE: Zea Books, 2020). https://digitalcommons.unl.edu/zeabook/ 


\section{Résumé}

Nous étudions dans cet article un extraordinaire tapis qui attire l'attention par sa décoration combinant des symboles incas semblables aux tocapus, avec la croix chrétienne. Ce dernier fait partie d'une recherche majeure dédiée aux tapis andins coloniaux à paraître prochainement. Nous ne connaissons pas un autre exemplaire semblable au Pérou ni à l'étranger et probablement il s'agit du tapis colonial le plus ancien. Nous avons eu la chance de le faire connaître au cours des séminaires de Doctorat du Programme d'Etudes Andines de l’Université Pontificale Catholique du Pérou et dans d'autres évènements depuis l'année 2014 .

Il se trouve dans le dépôt textile du Musée National d'Archéologie, Anthropologie et Histoire du Pérou et mous ne possédons pas d'information sur son contexte. Il est tissé avec des techniques et des fibres (de coton et de camélidés) andines traditionnelles. Les colorants contrastants, et principalement le motif hybride, dans lequel se démarquent les formes géométriques et stylisées du langage graphique inca apparaissent près d'un symbole catholique. Nous analysons tant l'iconographie que la technique du tissu, ses usages et ses possibles propriétaires.

Le tapis montre une continuité du tissu andin millénaire étant donné que plusieurs caractéristiques structurelles font partie du modèle de standardisation du tissu imposé par l'Etat inca pour l'élaboration des uncu destinés aux élites masculines. Cela révèle que le tissu cumbi (tissu fin des incas) a dépassé les moments mouvementés de la Conquête et a perduré dans des formats et des fonctions différentes.

Mots-clés: Tapis colonial, tocapu, catéchisme chrétien, syncrétisme.

\section{Introducción}

En noviembre del 2013, cuando se inició la investigación sobre tapices coloniales, se halló un extraordinario ejemplar hasta entonces desconocido entre los estudiosos. ${ }^{1}$ La desazón inicial experimentada ante el reducido número de la colección fue desapareciendo con cada centímetro desplegado de la pieza que sorprendía por su apariencia inca, su tamaño, la fineza del tejido, el color y la cruz cristiana en el centro. ${ }^{2}$ El tapiz que está signado con el código de registro textil N. o 7788, (Figura 1) se ubica en el depósito del área de textiles del Museo Nacional de Arqueología, Antropología e Historia del Perú (MNAAHP) y es, posiblemente, el único en su tipo del grupo de tapices coloniales conocidos en Perú. No se sabe cómo llegó al museo, pero se considera que tal vez fue decomisado o que perteneció al grupo de piezas que Julio C. Tello entregó al museo que dirigió desde su fundación ${ }^{3}$. Lo cierto es que para la década de los ochenta ya se encontraba en el departamento de textiles, según consta en la ficha técnica.

Ante la falta de información sobre los propietarios, la antigüedad y el lugar de procedencia del tapiz, fue necesario establecer una cronología aproximada, identificar el lugar donde fue elaborado, determinar quiénes fueron los propietarios originales y las posibles funciones.

Se parte del análisis del objeto textil, observando las características del hilado en ambos elementos estructurales (trama y urdimbre), la torsión de los hilos, la cantidad de hilos por centímetro, el tipo de ligamento, entre otros. Estos datos se comparan con los de los uncus imperiales para establecer analogías y cambios. También se analiza la iconografía y los significados de los principales motivos ornamentales, que contribuye a determinar su procedencia y su función. Además, importante data aporta el estado de conservación, pues los tipos de deterioro muestran indicios del uso.

\section{Iconografía y principales motivos decorativos}

El diseño del textil está organizado en dos áreas enmarcadas por gruesas líneas de color rojo carmín4: el campo central (A), que resalta por estar cubierto de tocapus de colores intensos y contrastantes, es el fondo de una gran cruz de

1. Un avance del presente capítulo se publicó en Solórzano, M. (2016). El tapiz andino de transición. Estudio iconográfico y técnico. Escritura y Pensamiento, XIX (39), 327-353.

2. La experiencia fue compartida por las conservadoras del museo M. Medina y M. de la Cruz. Posteriormente, junto con otros investigadores nos encargamos de darla a conocer en los seminarios del doctorado del Programa de Estudios Andinos de la PUCP en Lima y Pisac, Cusco, durante los años 2014 y 2015 y en el 56. ${ }^{\circ}$ Congreso Internacional de Americanistas llevado a cabo en Salamanca, España, el año 2018.

3. El personal del museo realiza la organización del material de archivo que probablemente permita conocer la procedencia del bien.

4. El rojo carmín es producido por el insecto Dactilopius coccus (cochinilla, macnu en quechua) que se alimenta del cactus del género Opuntia entre ellos el Nopalea coccinellifera. El estudio de Noemí Rosario (1999) demostró que en los Andes se empleó la cochinilla para teñir fibras textiles desde los Huari y que durante el Periodo Intermedio tardío se generaliza su uso especialmente en los textiles Chancay e Inca, ante la desaparición de otros materiales tintóreos rojos. La autora llegó a esa conclusión a través del análisis de fibras de 42 tejidos pertenecientes a culturas del periodo Intermedio temprano hasta el periodo colonial temprano aplicando la Prueba de Cromatografía Líquida de Alta Resolución (CLAR). 


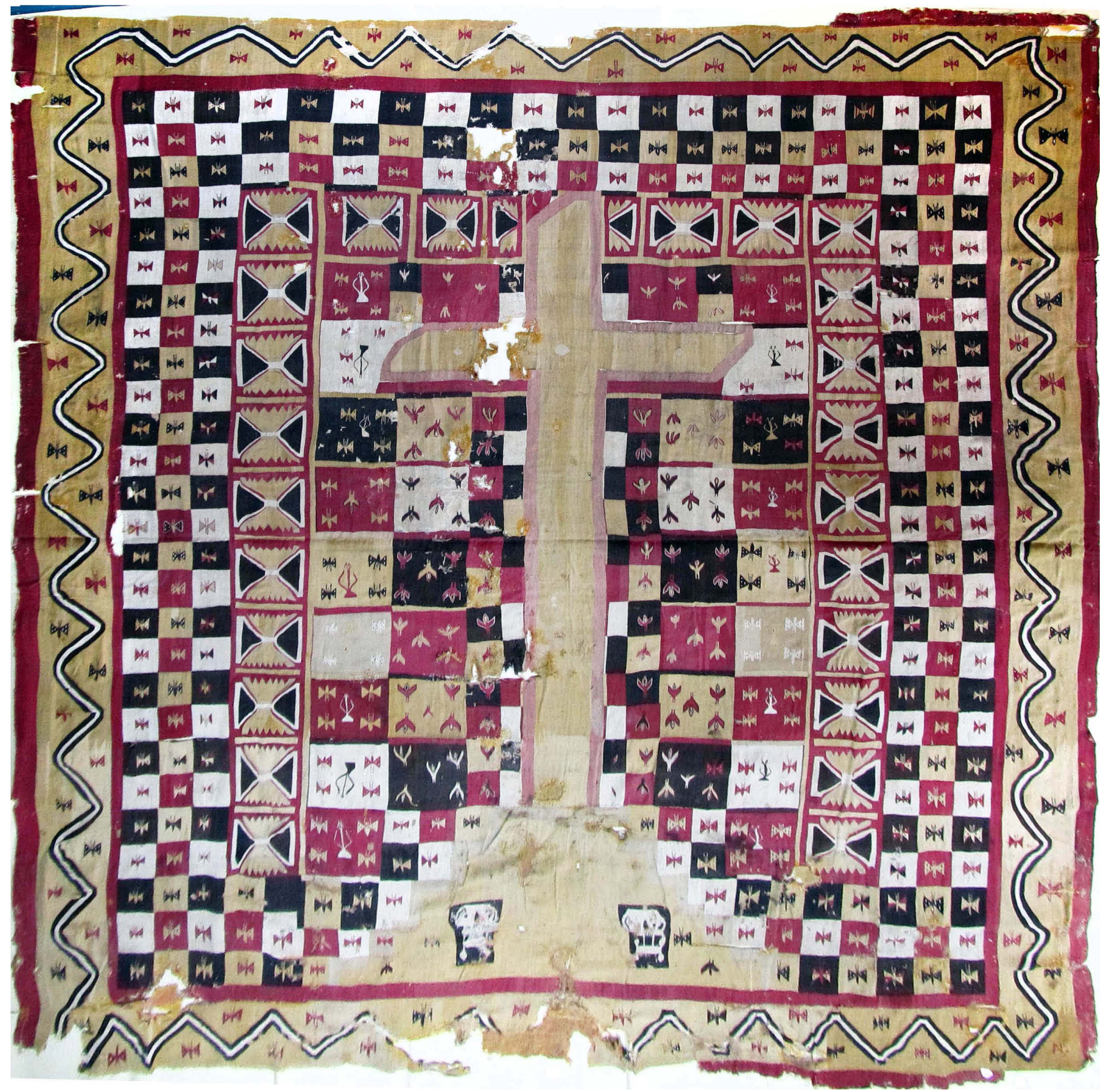

Figura 1. Tapiz colonial con tocapus. Museo Nacional de Arqueología, Antropología e Historia del Perú. R. T. 7788. Fotógrafo: Mónica Solórzano G.

base escalonada ubicada al centro; mientras que la zona (B) la conforman las bandas laterales que fungen de marco con una línea en zigzag continua que recorre sus cuatro lados.

La zona A (Figura 2 y Figura 3), a su vez está dividida en dos por un diseño también cuadrangular de formas estilizadas que se repite formando columnas en ambos lados y en la parte superior, enmarcando la cruz. El sector A1, cercano a la cruz, presenta tocapus grandes, que miden en promedio
$22 \times 20$ centímetros, los cuales forman dos columnas en cada lado de la cruz. Estas últimas presentan dos conjuntos de motivos, que en algunos casos aparecen en el mismo recuadro, agrupados en cinco e insertos en el interior: uno de ellos conformado por figuras ornitomorfas de cabeza alargada y alas desplegadas; el otro, por mariposas estilizadas con alas desplegadas y pequeños puntos como manchas. Un tercer motivo es una especie de tridente que aparece alguna 


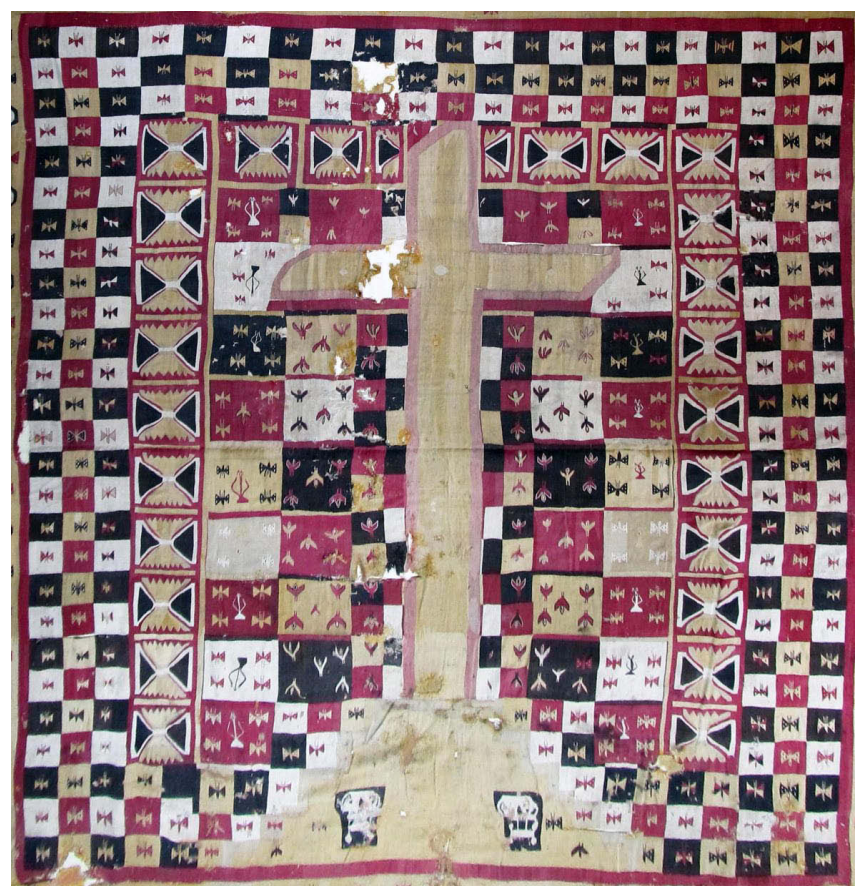

Figura 2. Campo central (zona A). Detalle del tapiz colonial con tocapus.

vez al centro de los recuadros. Dos columnas más de tocapus, de menor tamaño, se hallan junto al mástil de la cruz. Al centro del paño, ocupando todo el sector A1, resalta una gran cruz de tipo latina en color amarillo ocre con tres pequeños rombos blancos ubicados en el centro de la unión de ambos segmentos de la cruz y en los lados del transepto. La base es escalonada y en su interior se hallan dos cráneos sobre fondos rectangulares de color oscuro. Aunque no se trata de las típicas calaveras circulares, no hay duda de tal identificación, pues se reconocen los orificios de los ojos, la nariz, la boca, así como los dientes (Figura 4a y 4b). Una línea de color rosado pálido bordea todo el cuerpo de la cruz.

El sector A2 del campo central está formado por el tocapu más recurrente pues se pueden contar 242 de ellos en esta zona, mide aproximadamente $11 \times 10$ centímetros. Además, presenta una sola mariposa en el interior y forman tres columnas en los tres lados del tapiz en donde los cuatro colores señalados se alternan formando un damero. La primera columna alterna tocapus blancos de mariposas rojas con tocapus negros de mariposas amarillas, en la segunda columna se alternan los recuadros rojos de mariposas amarillas con tocapus amarillos de mariposas negras. En la tercera columna, la más cercana al centro, el color de las mariposas sigue un patrón distinto con mariposas de colores

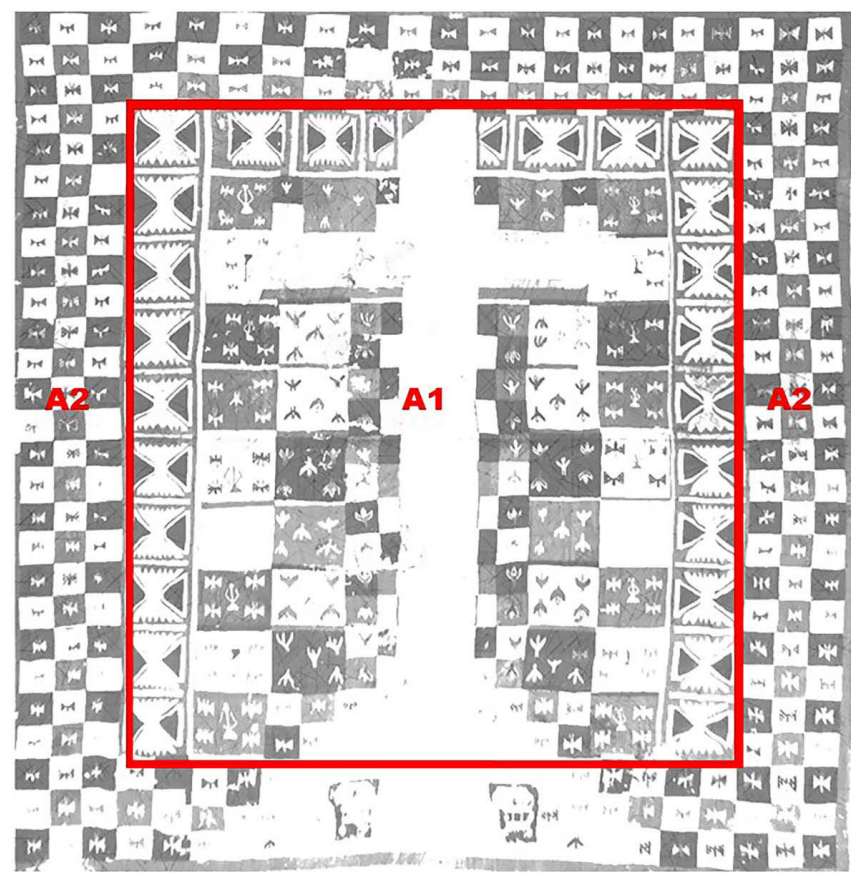

Figura 3. Esquema del campo central con sectores A1 y A2.

amarillo y rojo carmín sobre un fondo negro con variantes y mariposas de color rojo y negro sobre blanco también con variantes, que solo en algunos casos presentan manchas en las alas. Las líneas de color rojo que miden cinco centímetros, aproximadamente, delimitan el sector B donde, sobre el fondo de color amarillo, resalta la gran línea quebrada en blanco y negro/oscuro con 87 mariposas en negro y rojo dispuestas entre las ondas.

Durante la época de los incas, las formas cuadrangulares denominadas tocapus eran símbolo de la élite y su uso en textiles, cerámica, decoración mural y queros era controlado por el Estado. El diccionario de González Holguín define tocapus como «vestimentas con hermosos bordados o paños con bordados entretejidos» (González Holguín, 1608 [1989]: 344). C. Arellano los define como «rectángulos [o cuadrados] provistos de figuras geométricas que se resaltan por medio de colores contrastantes y que se hallan también en diversas vasijas y especialmente en vasos de cerámica, metal o madera, denominados qero [...]» (Arellano:, 1999: $253)^{5}$. Otros autores los identifican como signos o códigos gráficos ordenados y plasmados en los objetos con una intención comunicativa (Cummins, 2014; Frame, 2014; Ziólkowski, 2009; Ziólkowski, Arabas y Szeminski, 2008). Aunque aparecen en objetos diversos, son el elemento principal

5. La autora también señala la posible etimología del término, que derivaría de la sílaba tok y la palabra apu por lo que podría ser traducida como «aquello que destaca al apu, o aquello con que sale el apu» (Arellano, 1999: 253). 


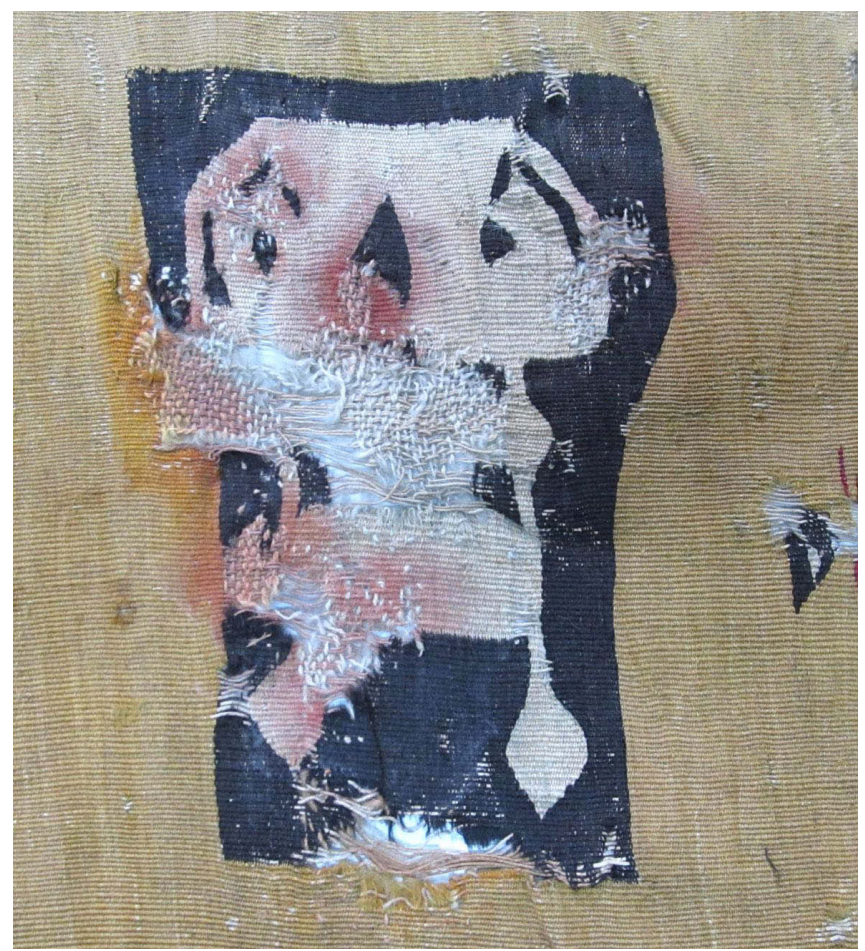

Figura 4a. Calavera en la base de la cruz. Detalle del tapiz colonial con tocapus. Fotógrafo: M. Solórzano G.

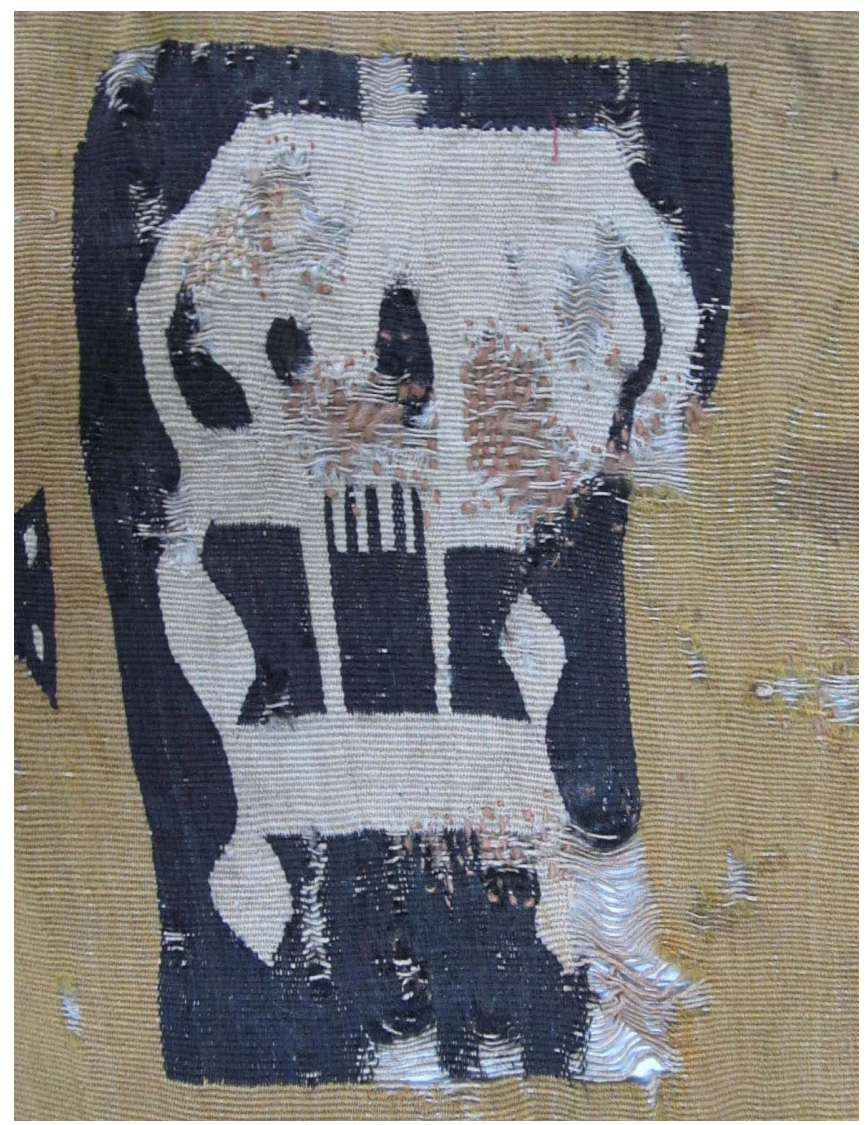

Figura 4b. Calavera en la base de la cruz. Detalle del tapiz colonial con tocapus. Fotógrafo: M. Solórzano G.

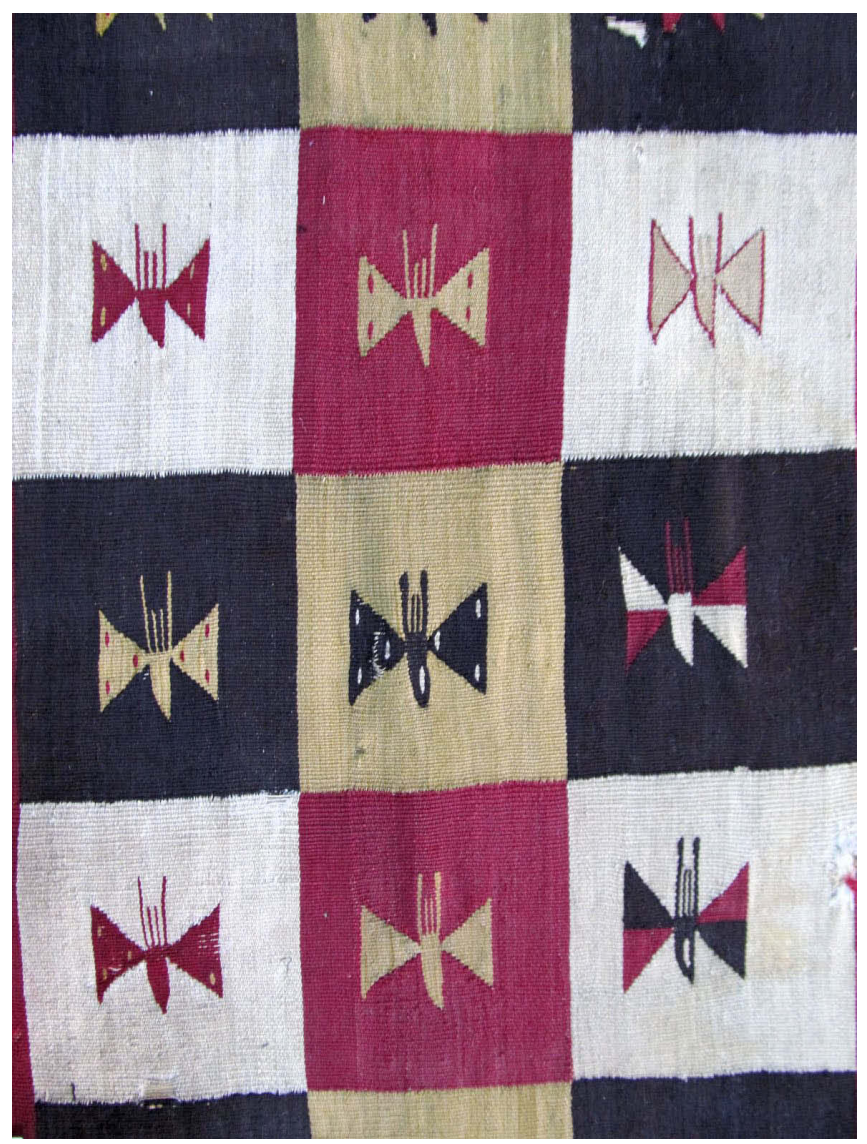

Figura 5. Mariposas en campo central (zona A). Detalle del tapiz colonial con tocapus. Fotógrafo: M. Solórzano G.

en la ornamentación de los uncus ('camisetas' en las crónicas y más recientemente también se denominan 'túnicas'), en tejido de cumbi, reservados al Inca, a las ceremonias religiosas y a los sectores privilegiados y elaborados de acuerdo sistema textil estandarizado impuesto por el Estado. Los colores organizados en pares (amarillo/rojo y blanco/negro) alternados e integrados formando un damero como en el caso del tapiz, aparecen, también, por lo menos, en dos ejemplos de uncus incas identificados y analizados por Mary Frame (2014).

La mariposa, junto con el tocapu, es el motivo más frecuente y aparece hasta cuatrocientas veces en el tejido. En los tocapus pequeños, las mariposas se hallan insertas por unidad al interior de los recuadros (Figura 5); en el tocapu grande, aparecen agrupadas, y se hallan dispersas entre las ondas de la línea en zigzag que circunda el tapiz. Su representación es estilizada, con las alas desplegadas formadas por dos triángulos que se unen a un cuerpo alargado del cual se desprenden cuatro filamentos a modo de antenas en dirección hacia la zona superior del tapiz generalmente.

El motivo conformado por el tocapu con mariposa aparece por lo menos en dos uncus incas que se encuentran en 


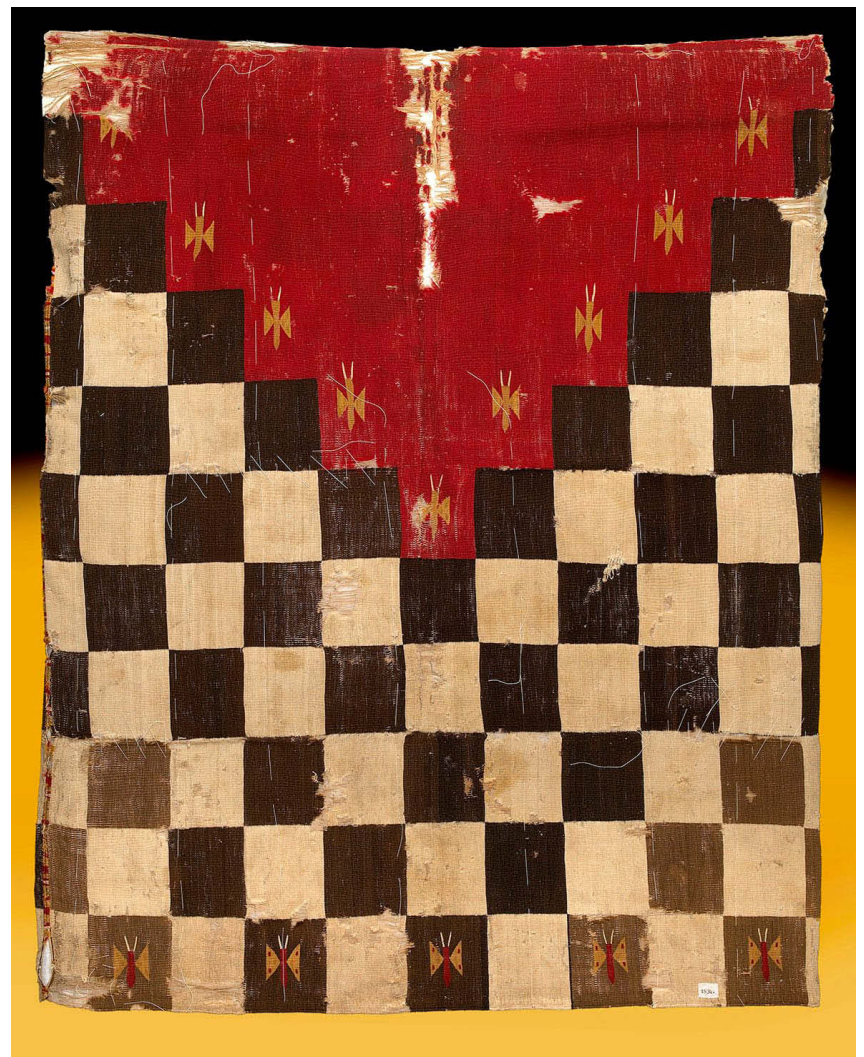

Figura 6. Uncu inca con diseño de damero y mariposas. Field Museum of Natural History, Chicago. Número de catálogo: 1534. nosub \{2\}. Procedencia: Ancón, Lima. Fotógrafo: John Weinstein.

el Field Museum de Chicago (Figura 6) y en una colección privada (Rowe, 1999: 581). Las prendas presentan la zona inferior en recuadros blanco/negro (a modo de un tablero de ajedrez), mientras que la zona superior escalonada es de color rojo. Se cree que estos uncus podrían haber sido usados por guerreros. Al respecto, J. Rowe, siguiendo a Miguel de Estete en Noticia del Perú, sugiere que «eran usadas como uniformes o libreas por la escolta de Atahualpa en Cajamarca en 1532» (Rowe, 1999: 614). Este diseño corresponde al primer patrón de túnicas estandarizadas estudiadas por John Rowe y Ann P. Rowe. Como se puede observar en las imágenes, el diseño de las mariposas es muy parecido al del tapiz que es objeto del presente estudio, principalmente, en el ejemplo del Field Museum de Chicago. También se ha señalado que, en tiempos precoloniales, las mariposas podrían haberse vinculado con los mensajes de muerte o con el alma del difunto (García, 2009: 12). Tal hipótesis puede ser acertada, más aún, si se tiene en cuenta que en hoy en día las mariposas suelen vincularse con presagios de muerte en distintas regiones de los Andes. En otros objetos (textiles y cerámica) del período inca, tal vez ofrendas, aparecen también mariposas como en la chuspa inca del Ethnologisches Museum de Berlín (Inventario N. o VA 53036) (Kurella y Castro, 2013: 253) o el plato de cerámica encontrado en Machu Picchu durante la exploración de Hiram Bingham (Aguilar Callo, 2011: 51).

En la zona A1, el motivo ornitomorfo, que presenta una cabeza alargada con un gran ojo, alas desplegadas y extremidades inferiores, es más complejo de identificar. Aunque no se cuenta con mayores datos que sustenten la idea, se cree que podría relacionarse con la trasformación en ave u otro animal que ciertos sacerdotes decían lograr con la ayuda de alucinógenos, como se ha sugerido en Chavín (Burger y Salazar-Burguer, 1994).

La línea en zigzag de la zona B es un elemento frecuente en la iconografía andina desde tiempos ancestrales y es un motivo persistente en casi todos los uncus elaborados de acuerdo al patrón estándar impuesto por el sistema inca. Aparece inscrita en recuadros, en bandas o bordada en el orillo inferior de la prenda. Tal línea también es frecuente en la cerámica imperial inca, unas veces asociado al concepto de serpiente "amaru", como en una vasija "aribaloide" del MNAAHP, (Matos 1999, 136). Para la investigadora M. Frame, dicha línea es un patrón gráfico o familia de tocapu que presenta variantes y pertenece a la familia de triángulos isósceles dispuestos en hileras horizontales (2014). Según la autora se trata de un motivo presente en tejidos de varias comunidades en la actualidad y se interpreta de manera diversa. Cerca de la ciudad de Cusco suele ser llamado "puntas" y es relacionado con la cumbre de un cerro, con una península o con todas las cosas que tienen forma puntiaguda. En la comunidad Q'ero, es afín a dientes y en otros pueblos de la misma región se interpreta como río zigzagueante o sendero zigzagueante (Frame, 2014: 255).

Al centro del tapiz se ubica el motivo principal de la composición y el único proveniente del lenguaje visual occidental. Se trata de la cruz del calvario, el símbolo cristiano católico más importante que representa la Pasión y Muerte de Jesucristo en el monte Gólgota o de la "calavera" ${ }^{\text {. Este }}$ tema ha sido representado en el arte desde la Edad Media en relieves de iglesias románicas y góticas, y luego pasaría a otros soportes para volverse frecuente durante el Renacimiento y en épocas posteriores. Suele ser representado con una calavera ubicada al pie de la cruz que alude al monte Gólgota7. Tanto la forma del crucero, así como los peldaños de la cruz aluden al monte escenario del sacrificio de Jesús; sin embargo, llama la atención la presencia de dos calaveras,

6. Gólgota es una palabra aramea que significa 'calavera'. 'Calvario' es la forma latina de esa palabra.

7. En el British Museum de Londres se conserva un dibujo realizado por Miguel Ángel, escultor y pintor del Renacimiento italiano, de un Cristo en la cruz donde aparece un cráneo ubicado en la zona inferior. 
cuando lo frecuente en el tema iconográfico cristiano es la presencia de solo una de ellas. El caso citado por la antropóloga V. Gavilán, quien estudió a grupos aimaras del norte de Chile, tal vez contribuye a comprender lo sucedido. La autora narra el caso de un comunero que al encontrar en un libro de catecismo referencias al hombre, lo considera un error y corrige agregando "y mujeres" (Gavilán Vega,1996: 104). Se puede interpretar que el uso del término hombres para expresar humanidad no es aceptado por el hombre andino por considerarlo incompleto. Tal vez sucedió lo mismo con el tejedor autor del tapiz que es objeto de este estudio. Considerando lo escrito por Gavilán, es posible suponer que el tejedor incluyó una segunda calavera que representara al género femenino. Así, ambas representaciones harían referencia a toda la humanidad ${ }^{8}$.

Entonces, la iconografía del tapiz representaría la muerte y resurrección con formas tanto cristiano/católicas como andinas. Mientras que la cruz del calvario es el símbolo cristiano, las mariposas y el motivo antropomorfo (hombre-ave) podrían ser los símbolos andinos de tales conceptos durante inicios del período colonial. Sin embargo, llama la atención que aparezcan los motivos propios del lenguaje visual andino fusionados con el símbolo cristiano-católico de la cruz para transmitir el dogma de la muerte y resurrección de Jesucristo. Como se sabe, las imágenes vinculadas a creencias y ritos ancestrales fueron prohibidas en los Andes en distintos momentos. ¿Porque se recurre entonces a símbolos que aluden a la cultura y religiones que la Iglesia católica estaba buscando erradicar? Se evaluarán posibles respuestas más adelante.

\section{La manufactura andina tradicional y su relación con el tejido fino de los incas}

No solo el uso de una iconografía de origen precolonial validaría una procedencia temprana para el tapiz del MNAAHP, también los detalles técnicos confirmarían tal hipótesis. La Tabla 1 contiene un resumen del análisis técnico. ${ }^{9}$

Hay varias coincidencias entre el tapiz colonial con tocapus y los uncus de cumbi de los incas. Como se sabe, estas túnicas eran fabricadas por especialistas de acuerdo a patrones controlados por el Estado, su uso como indumentaria se reservaba a hombres de la élite y al gobernante inca, quien se encargaba de distribuirlos; se empleaban también para los oficios religiosos (Rowe, 1999). Algunos ejemplos han sido tratados desde el punto de vista de su manufactura (A. Rowe 1995-1996, 7), gracias a ello se pudo deducir que el tejido que estudiamos aquí comparte con aquellos uncus no solo el uso de las fibras textiles más finas, como el algodón y el camélido teñido, preparadas en torsiones y densidad análogas, sino también la técnica de entrecruzamiento de hilos conocida como tapiz, entre otros aspectos que trataremos más adelante. Esta técnica se caracteriza por emplear tramas parciales o discontinuas (las tramas no se desplazan en toda la extensión del tejido) que forman los diseños y cubren completamente a la urdimbre ${ }^{10}$. Los hilos van fuertemente ajustados unos a otros, de manera que resulta un tejido denso y resistente (Ramos y Blasco, 1977; Emery, 1966; D’Harcourt, 1974). Mientras más finos sean los hilos de trama y más ajustados se encuentren, la pieza será de mejor calidad, de hecho, la calidad de la tela se puede medir

Tabla 1. Información técnica básica

\begin{tabular}{|c|c|c|}
\hline Denominación & \multicolumn{2}{|c|}{ Tapiz colonial con tocapus } \\
\hline Ubicación & \multicolumn{2}{|c|}{ Museo Nacional de Arqueología, Antropología e Historia del Perú-Lima } \\
\hline Código & \multicolumn{2}{|c|}{$\mathrm{RT}_{7788}$} \\
\hline Procedencia & \multicolumn{2}{|c|}{ Desconocida } \\
\hline Dimensiones & \multicolumn{2}{|c|}{ Trama $376 / 383 \mathrm{~cm}$, urdimbre $300 / 311 \mathrm{~cm}$} \\
\hline \multirow[t]{2}{*}{ Materiales, torsión y densidad } & Urdimbre & $\begin{array}{l}\text { Algodón. Hilos de tres cabos. o.6-o.8 mm de diámetro. Torsión Z retorsión S, 55- } \\
\qquad 65^{\circ}, 7-9 \text { hilos por } \mathrm{cm} \text {. }\end{array}$ \\
\hline & Trama & $\begin{array}{l}\text { Fibra de camélido. Hilos de dos cabos de 0.2-0.4 mm de diámetro. Torsión Z retor- } \\
\text { sión } \mathrm{S}, 10-20^{\circ}, 28-60 \text { hilos por } \mathrm{cm} \text {. }\end{array}$ \\
\hline \multirow[t]{2}{*}{ Colores } & Urdimbre & Blanco (natural) \\
\hline & Trama & $\begin{array}{l}\text { Blanco (natural), negro/marrón oscuro (natural), rojo (teñido), amarillo/ocre } \\
\text { (teñido) }\end{array}$ \\
\hline Técnica de manufactura & \multicolumn{2}{|c|}{ Tapiz ranurado, dovetail y excéntrico } \\
\hline Estado de conservación & \multicolumn{2}{|c|}{ Regular-malo } \\
\hline
\end{tabular}

8. Fue la historiadora del arte Bat-Ami Artzi quien me hizo tal observación y me proporcionó la citada fuente, por lo cual le agradezco. 9. El informe técnico fue realizado por la conservadora de textiles Yuki Seo.

10. Predominan en la pieza las variantes tapiz ranurado (ojal) y dovetail (unión de trama en la urdimbre) y el tapiz excéntrico. La técnica tapiz se ubica dentro de la clasificación de urdimbres y tramas entrelazadas como una variante de weft-faced plain weave (tejido plano cara de trama) (Emery, 1966: 78). 
por la cantidad de hilos por $\mathrm{cm}^{2}$. Así, se explica por qué el tejido de cumbi se hizo principalmente con este tipo de ligamento. Se trata de una técnica desarrollada ampliamente en el Antiguo Perú desde el Intermedio Temprano (Paracas y Nazca) y se conservan impresionantes ejemplos de uncus huari, así como incas.

El tapiz del MNAAHP ha sido realizado en una sola pieza, como varios de los uncus estandarizados, lo cual lleva a pensar que ello garantiza una mayor duración, pues se ha podido determinar que el deterioro se inicia en las uniones de los paños que forman una prenda. Los materiales (algodón y fibra de camélido) son los mismos de los uncus y la preparación de los hilos también es semejante. Las urdimbres son de algodón blanco natural de tres cabos y las tramas son de camélido de dos cabos. La torsión en ambos elementos estructurales del tejido es la misma que en las prendas imperiales: hilado en $\mathrm{Z}$ y retorsión (o plegado) en S. La densidad de hilos varía entre 7-9 urdimbres y entre 28-6o tramas por $\mathrm{cm}$, como buena parte de los uncus inca vistos por los especialistas señalados. Es decir, la densidad de hilos presente en el tapiz del MNAAHP está en el rango de los uncus del sistema textil de los incas. Aunque, existen algunos uncus extremadamente finos, como el de la colección Dumbarton Oaks, que llegan a tener entre 15-19 urdimbres por 98-108 tramas por $\mathrm{cm}$. Los colores blanco (natural), marrón oscuro-negro (natural) rojo (teñido con cochinilla) y amarillo-ocre (teñido) del tapiz son también frecuentes en los tejidos incas; la combinación del rojo y amarillo es la más común (Rowe A. P., 1995-1996: p. 9), aunque el negro y blanco fueron frecuentes (Roussakis y Salazar, 1999: 269).

Otra semejanza es la urdimbre que corre en sentido horizontal a la disposición de la pieza, que indica que el tejedor o tejedores trabajaron viendo el diseño en sentido lateral, característica presente también en las piezas incas. Por las dimensiones del tejido, el tipo de telar empleado fue el vertical, el mismo que se usó para tejer los uncus. B. Cobo describe este tipo de telares y compara la calidad del tejido de su tiempo con los de tiempos incas de la siguiente manera:

Los telares en que tejían estos cumbis, particularmente las piezas grandes para tapicería, eran diferentes de los comunes; hacíanlos de cuatro palos en forma de bastidores, y poníanlos levantados en alto arrimados a una pared, y allí iban los cumbicamayocs con muchos hilos y espacio

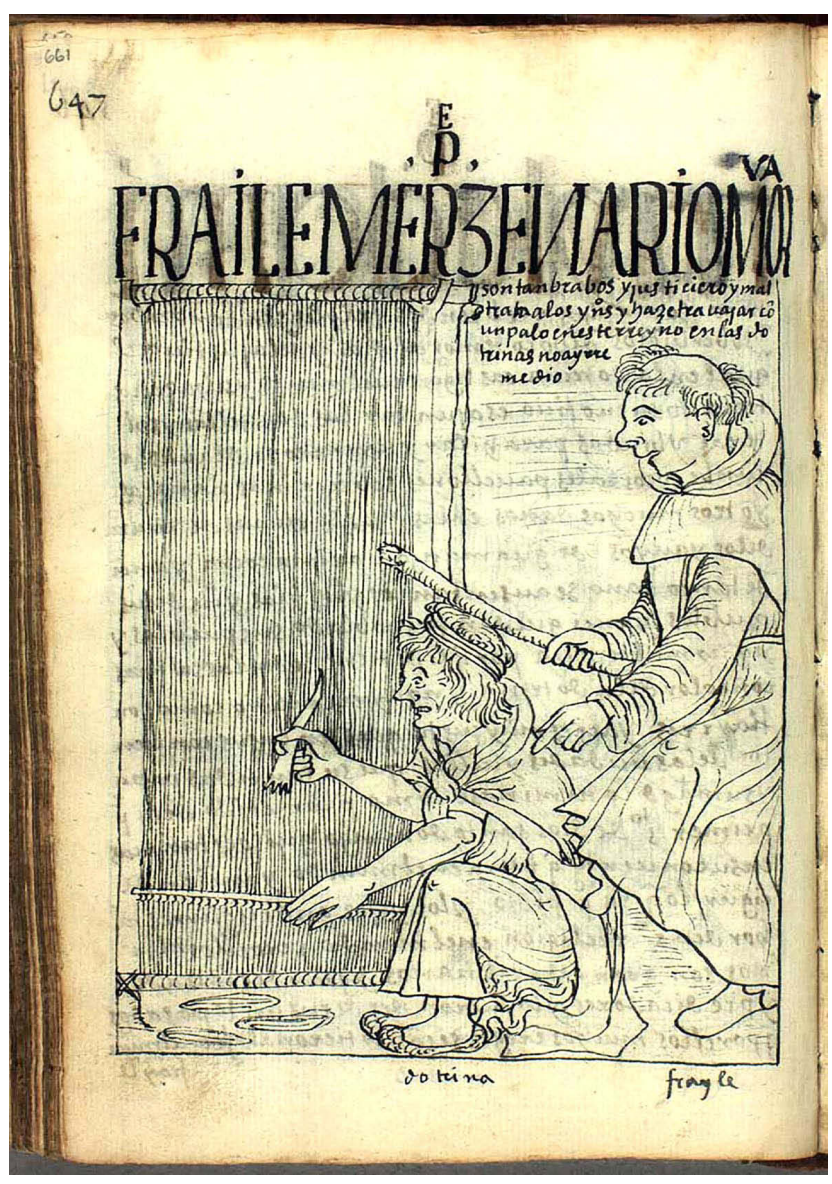

Figura 7. Fraile Merzenario Morua. Dibujo a tinta. Guamán Poma de Ayala, 2016 [1615], Royal Danish Library, GKS 2232 kvart: Guaman Poma, Nueva corónica y buen gobierno (c. 1615), pág. 647 [661].

haciendo sus labores, las cuales salían muy perfectas y acabadas, igualmente a dos haces; y el día de hoy suelen hacer reposteros de los mismos con los escudos de armas que les mandan; si bien el cumbi que ahora labran no llega con mucho a la fineza del antiguo (Cobo 1956 [1653]: 259).

Lo anotado por Cobo es relevante no solo porque describe el telar vertical, sino también porque comenta que los cumbicamayocs tejían hacia mediados del s. XVII tapices al gusto occidental, a los que Cobo llama también cumbi. De igual manera, Guamán Poma señala en varias secciones de su manuscrito piezas de tipo hispano elaboradas junto con las andinas tradicionales, que se van incorporando al repertorio textil en algunos casos a instancias de los sacerdotes de doctrina ${ }^{11}$ como se explica en un

11. «Frayle dominico: Los dichos rrebrendos frayles son tan brabos y soberbiosos, de poco temor de Dios y de la justicia, el qual en la dotrina castiga cruelmente y se haze justicia. Todo su oficio es ajuntar las donzellas y solteras y biudas para hilar y texer rropa de auasca [tejido corriente], cunbe [fino] y costales, pauellones, sobrecamas, nanacas [?] y otros muchos daños en las dichas dotrinas de Xauxa, de los Yauyos, de Guamanga, Parinacocha» (Guamán Poma, 2016 [1615]: 646 [66o]). 


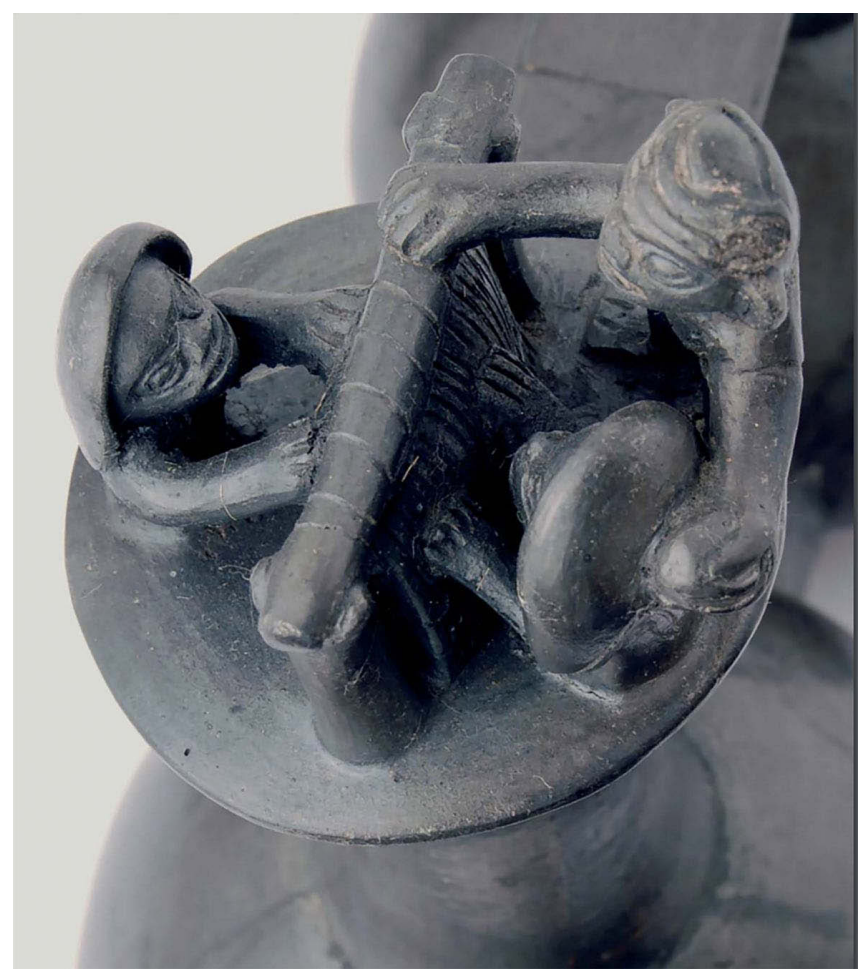

Figura 8. Detalle de vasija con escena textil. Procedencia Pachacamac. Estilo Chimú Inca R. N. 013673. Tomada de Angeles (2011: 53). Archivo Museo de sitio Pachacamac. Fotógrafo: Walter Hupiú

estudio que presentaré dentro de poco ${ }^{12}$. Aunque Cobo describe el telar vertical, Guamán Poma ofrece una representación gráfica (Figura 7) que guarda relación con el telar que aparece en una cerámica encontrada en Pachacamac de filiación chimú-inca (Figura 8) donde dos tejedores trabajan bajo supervisión. El dibujo del cronista andino también es prácticamente igual a los telares que se observan en la fotografía del equipo de Hiram Bingham tomada cerca de Macchu Picchu en 1911 (Niles 1992: 63) en la que los maestros tejedores se encuentran en plena labor realizando tapices de distintos tamaños.

Pero, no solo los materiales, la técnica, el telar y los colores son semejantes tanto en tejidos incas como en el tapiz de tocapus de esta investigación, lo es también el acabado. No existen hilos sueltos o terminaciones que no hayan quedado firmes y ocultas en la estructura del tejido. También es reversible, es decir, ambas caras del tejido se encuentran bien acabadas para ser utilizadas indistintamente. El hilado es muy delgado y parejo, salvo en algunas pocas secciones se ha identificado un grosor distinto del hilo de trama. Todo lo expuesto demuestra que los tejedores tuvieron conocimiento del sistema estandarizado impuesto por los incas para la elaboración de tejidos finos, o fueron formados en esa tradición textil.

Ciertos cambios con respecto al tejido andino ancestral se observan en la pieza colonial que se estudia. Con seguridad, dos o más tejedores trabajaron de manera simultánea, ello se deduce de los catorce tramos de labor que se ha podido identificar y en detalles, como la variedad de la densidad de hilos por $\mathrm{cm}$. Asimismo, distintos niveles de destreza se pueden encontrar en la ejecución de los diseños. Todo ello conlleva a argüir que este ejemplar fue elaborado por un grupo de tejedores dirigidos por un maestro, tal vez un cumbicamayoc con otros tejedores menos hábiles. Varios son los ejemplos de tapices coloniales que muestran distintos tramos de labor y cambios en los diseños, detalles que indicarían la intervención de más de un tejedor trabajando de manera simultánea en la misma pieza (Niles, 1992). Se ha sugerido que «los patrones de trabajo de los tapices coinciden con la interpretación de que fueron hechos por familias o pequeños grupos de trabajadores siguiendo las demandas de un recolector de impuestos, encomendero o propietario de hacienda, o para la venta» (Niles, 1992: 64).

Las diferencias con respecto a los tejidos incas se concentran en la falta de destreza de algunos de los tejedores observable en sectores como uniones de trama, que revelan descuido, detalle pocas veces visto en los uncus imperiales. La falta de una supervisión especializada sumada a la presión del nuevo comitente español son las causas probables del decaimiento de la calidad.

El estado de conservación que presenta el tapiz es de regular a malo debido a lagunas y faltantes de medianas y pequeñas proporciones (en los bordes principalmente), deshilachados, roturas y manchas. Estos deterioros han sido causados por tensión, manipulación y desgaste de fibras. Hasta el momento que observamos por última vez la pieza (noviembre de 2016) no había recibido ninguna intervención de restauración en el taller de conservación y restauración del museo. Ello ha permitido conocer cómo los usuarios del objeto prolongaron su uso. Varias zonas maltratadas han sido entretejidas (zurcidas) y parchadas en distintos momentos empleando materiales diversos como hilos de algodón, lana y otros en remiendos de distintas calidades.

\section{Usos y funciones del tapiz}

Al parecer el tapiz fue empleado en el ceremonial católico en distintos momentos del calendario religioso, tal vez en la 
Semana Santa y en las misas fúnebres, quizá como paño de púlpito o de altar, o también pudo ser usado como pieza de altar colgada en un retablo; es decir, como una herramienta o instrumento para la evangelización tlanto la pintura, la escultura y el arte en general fue parte de la estrategia de comunicación visual de la Contrarreforma.

Como se sabe, el virreinato peruano no estuvo al margen de la política religiosa de los siglos XVI y XVII, instaurada para enfrentar a las críticas de las Iglesias protestantes. Así, para adecuarse a las recomendaciones del Concilio de Trento (1545-1563), que exhortaba el uso de imágenes en la conversión de los herejes, se realizó el Segundo Concilio Limense (1567), en cuyas disposiciones se insiste también en el ornato de las iglesias y en el uso de las imágenes. Por eso, las distintas órdenes religiosas afincadas tanto en la Ciudad de los Reyes, como en el interior del país, fueron refaccionando sus casas y templos. Franciscanos, dominicos, jesuitas, entre otros, contaron con los mejores materiales y objetos de arte para engalanar sus iglesias: maderas nobles, como cedro de Nicaragua para artesonados y retablos; cerámica de revestimiento de Sevilla para zócalos y paredes y pinturas de los mejores talleres europeos, como Sevilla y Flandes. Cabe resaltar que los pintores de oficio activos en Lima eran escasos durante el período colonial temprano. Recién en el último cuarto del siglo XVI llegó el primer pintor con formación, el jesuita italiano Bernardo Bitti (Solórzano, 2012), quien es considerado el «padre de la pintura peruana virreinal» (Stastny, 2013). A falta de pintores de oficio con renombre, se contaba en cambio con muy buenos tejedores formados en la antigua tradición textil andina, a quienes seguramente se recurrió para la elaboración del material de apoyo en la tarea evangelizadora. Las imágenes tejidas se emplearían no solo para decorar los ambientes, sino que funcionarían también como vehículo de transmisión de contenidos religiosos católicos.

Los estudios de la historiadora Maya Stanfield-Mazzi coinciden con el planteamiento del uso de paños elaborados con las técnicas andinas ancestrales para el ritual religioso cristiano. Ella basándose en el análisis de documentación de archivo procedente de la sierra sur, afirma que abundan los frontales de altar elaborados con materiales y técnicas, seguramente, muy semejantes a los descritos en este estudio. Un ejemplo de relevancia es el frontal del altar principal de la iglesia de San Pedro de Juli, cuyo panel central presentaba una cruz al centro y bordes ajedrezados con recuadros en rojo y amarillo, según el inventario de objetos de la iglesia del año 156o (Stanfield-Mazzi, 2013: 44).

Uno de los aspectos más interesantes del paño, que es objeto de esta investigación, es que muestra el uso de elementos simbólicos de dos tradiciones culturales para transmitir un contenido cristiano-católico. El símbolo más importante de la fe cristiano-católica es representado acompañado de "símbolos" de la cultura andina. Cabe preguntarse ¿por qué el uso de la iconografía andina fusionada con la de la Iglesia católica? Recordemos que los símbolos vinculados con las creencias andinas ancestrales estuvieron prohibidos en distintos momentos. A raíz del movimiento mesiánico Taki Onqoy (década 156o), que anunciaba la destrucción del mundo hispano-occidental por una alianza de los dioses andinos y que promovía un retorno a la práctica de los antiguos ritos religiosos, se estableció una serie de medidas, en forma de reglas básicas para los visitadores con el fin de controlar y evitar la representación de imágenes relacionadas con las antiguas creencias:

Item, porque de la costumbre enjerida que los indios tienen de pintar ídolos y figuras de demonios y animales a quienes solían mochar, en sus tianas, vasos, báculos, paredes y edificios, mantas, camisetas, lampas y casi en todas cuantas cosas les son necesarias, parece que en alguna manera conservan su antigua idolatría, provereis, en entrando en cada repartimiento, que ningún oficial de aquí adelante, labre ni pinte las tales figuras, so graves penas, las cuales executareis en sus personas y bienes lo contrario haciendo. Y las pinturas y figuras que tuvieran en sus casas y edificios, y en demás instrumentos que buenamente y sin daño se pudieran quitar y señalareis que pongan cruces y otras insignias de xtianos en sus casas y edificios (Romero, 1924: 171).

También Cristóbal de Albornoz, quien fuera el más tenaz perseguidor en la lucha contra el "paganismo", aconsejaba destruir tanto queros como "los tejidos con un diseño de cuadros o pintados con imaginería de culebras”. Para Albornoz, estos objetos se relacionaban con la idolatría y «conjuraban recuerdos del pasado» (Cummins, 2004: 223). En una ordenanza de 1574 dirigida a la zona de Chuquisaca, el virrey Toledo de manera específica prohibió:

No se labren figuras en la ropa ni en los vasos, ni en las casas [...] por cuanto dichos naturales también adoran algún género de aves y animales y para el dicho efecto los pintan e labran en los mates que hacen para beber y de plata, y en las puertas de sus casas y los tejen en los frontales, dorseles [sic] de los altares e los pintan en las paredes de las Iglesias ${ }^{13}$. 
Como consecuencia de tales disposiciones, los andinos optaron por adecuarse a las formas de representación aceptadas y disfrazaron/ocultaron sus símbolos propios. Entonces, el tapiz de tocapus del MNAAHP pudo ser tejido antes de las disposiciones toledanas. Según T. Cummins, «Para los artistas nativos, el pretexto de la extirpación de idolatrías llevó a la desaparición de ciertos aspectos de su arte durante el último tercio del siglo XVI [...] la presentación de estas imágenes y la manera como expresaban un significado tenían que cambiar si aparecían públicamente, para que estuvieran de acuerdo con el gusto español en vez de contradecirlo» (2004: 227).

Si el tapiz fue elaborado antes de las ordenanzas del virrey Toledo, ¿por qué luego no fue destruido? Cabe considerar que, con las campañas de extirpación de las idolatrías, que se dieron con mayor intensidad en el siglo XVII, se produjo la destrucción masiva de millares de objetos considerados sagrados para la cultura andina. Sin embargo, la razón podría ser la indulgencia de la Iglesia local, pues los objetos híbridos con contenidos andinos e hispanos fueron permitidos en ciertas situaciones. Las formas andinas tradicionales se permitían siempre y cuando no se vincularan con sus antiguas creencias y, probablemente, el tapiz estudiado no fue destruido debido a que fue empleado en el contexto del culto cristiano.

La flexibilidad de la Iglesia en el Perú, que permitió iconografías híbridas, tiene antecedentes en la Iglesia europea, que luego del Concilio de Trento "estuvo lejos de mostrarse tiránica” y más bien fue "indulgente con la leyenda", al permitir temas extraídos de narraciones apócrifas de los evangelios sagrados (Mâle, 2001: 487). El extendido uso que tuvo el tapiz analizado en esta tesis, evidenciado en su desgaste, demuestra también que las disposiciones para el control de las formas andinas de representación no fueron tan estrictas en todas las regiones del Perú.

Cabe indicar también que existen otros objetos religiosos híbridos en los que se funden elementos de ambas culturas, como la cruz con tocapu del Staatliche Museen de Berlín, cuya cronología es discutida (Figura 9). Para algunos, data de los siglos XVII-XVIII (Kurella y Castro, 2013: 226), sin embargo, el destacado estudioso M. Ziólkowski afirma que podría ser del período colonial temprano (Comunicación personal, Pisac, Cusco 2014). También el uncu santo del Museo Nacional de Etnografía y Folklores de La Paz, (Figura 10a y 10b) una pequeña túnica para vestir la imagen del niño Jesús, tejida en tapiz con borde inferior de tocapus y campo central con formas geométricas, aves, símbolo mariano en el centro y también mariposas. Data de fines del s. XVI e inicios del s. XVII (Phipps, 2013: 42).

El tejido descrito en este apartado no es el único con tema religioso. Existen otros tres tapices andinos coloniales que

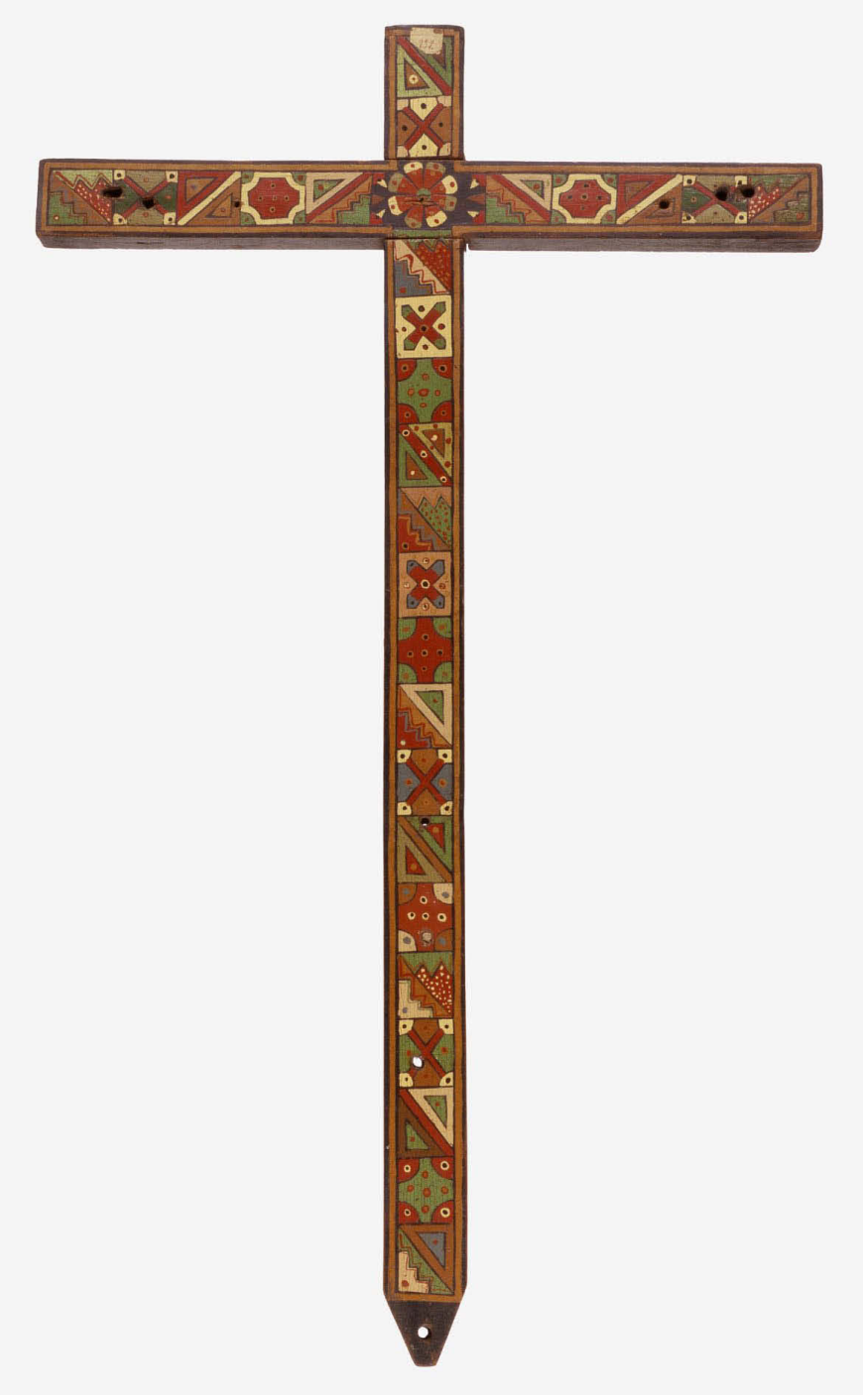

Figura 9. Cruz de madera con tocapu. Staatliche Museen zu Berlin, Ethnologisches Museum, V A 8951. Fotógrafo: Martin Franken

representan escenas del Antiguo Testamento Se trata de La creación de Eva (Círculo de Armas, Buenos Aires), El pecado original (Colección privada, Buenos Aires) y El rey David (Colección privada, La Paz) (Phipps, E., Hecht, J. y Esteras, C., 2004, p. 283, 72, 285). Al parecer todos pertenecen a la misma época y al mismo taller (Iriarte 1992). Todos han sido tejidos en la técnica de tapiz entrelazado simple con urdimbres de algodón y tramas de camélido hiladas en $Z$ y plegadas en S. Han sido datados entre fines del siglo XVI y principios del s. XVII, debido tanto a la iconografía como a los detalles técnicos y proceden probablemente de Cusco. Son tan complejos y tan finos que se ha sugerido que solo tejedores entrenados en la antigua tradición inca, o algunos de sus descendientes, pudieron haber sido los autores 


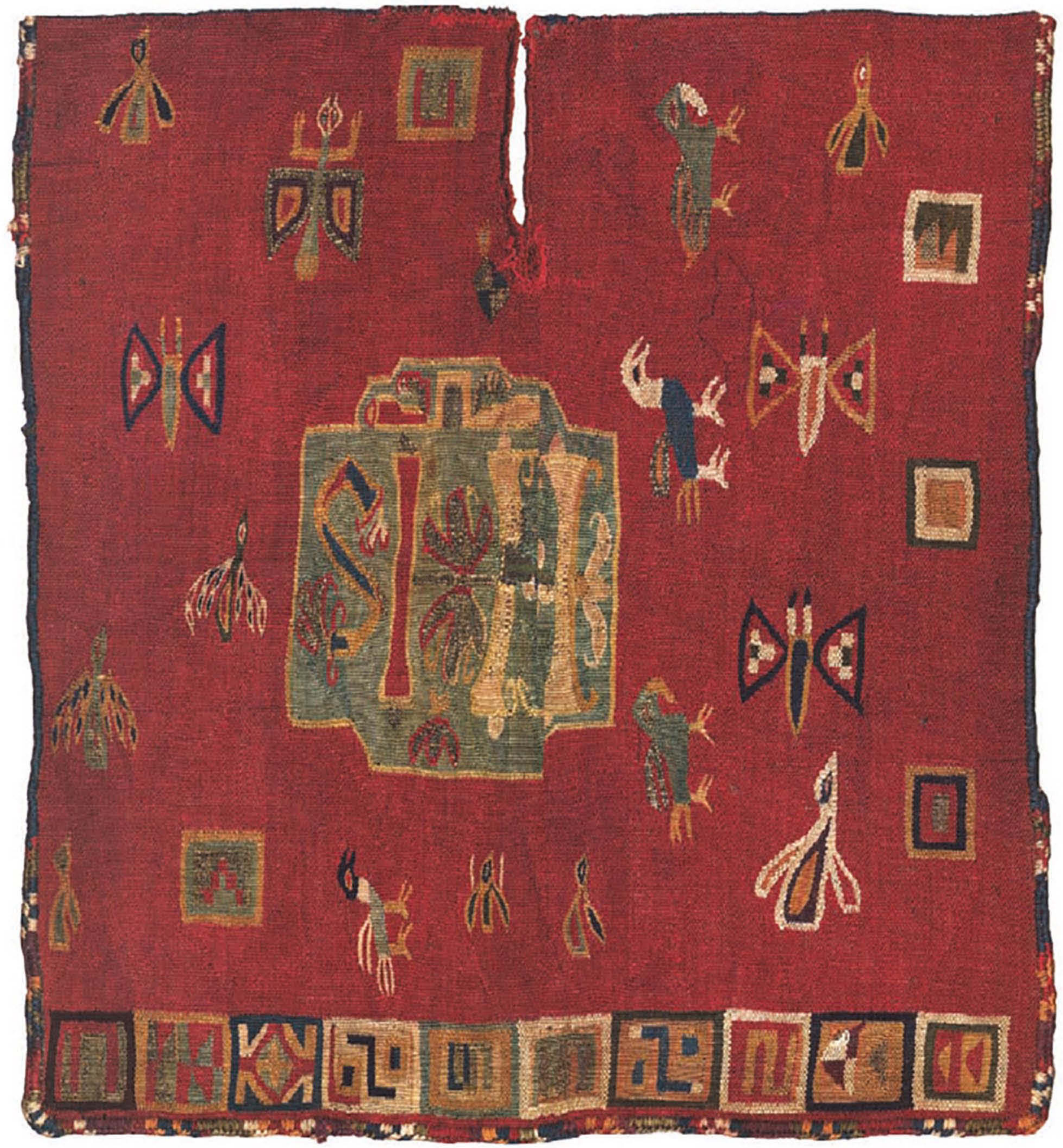

Figura 10a. Uncu santo, anverso. Fines del s. XVI e inicios del s. XVII. Museo Nacional de Etnografía y Folklores de La Paz, Bolivia. Tomado de Phipps, Hecht y Esteras (2004: 274)

(Iriarte, 2004, pp. 283,284). Coincido con la investigadora Iriarte, quien cree que fueron realizados a pedido de un comitente religioso, el cual, posiblemente, ideó la iconografía de los tapices, que habrían sido colgados en una iglesia o casa religiosa para que sirvieran de apoyo en el discurso evangelizador.
La Creación, en Postilles sur les libres de l'Ancien et du Nouveau Testament, obra de Nicolas de Lyre (127?-1349?) franciscano, exégeta y teólogo puede contribuir con la identificación de las fuentes de inspiración de los autores de la composición de los tapices con escenas bíblicas. El manuscrito que data de fines de la Edad Media contiene pequeñas 


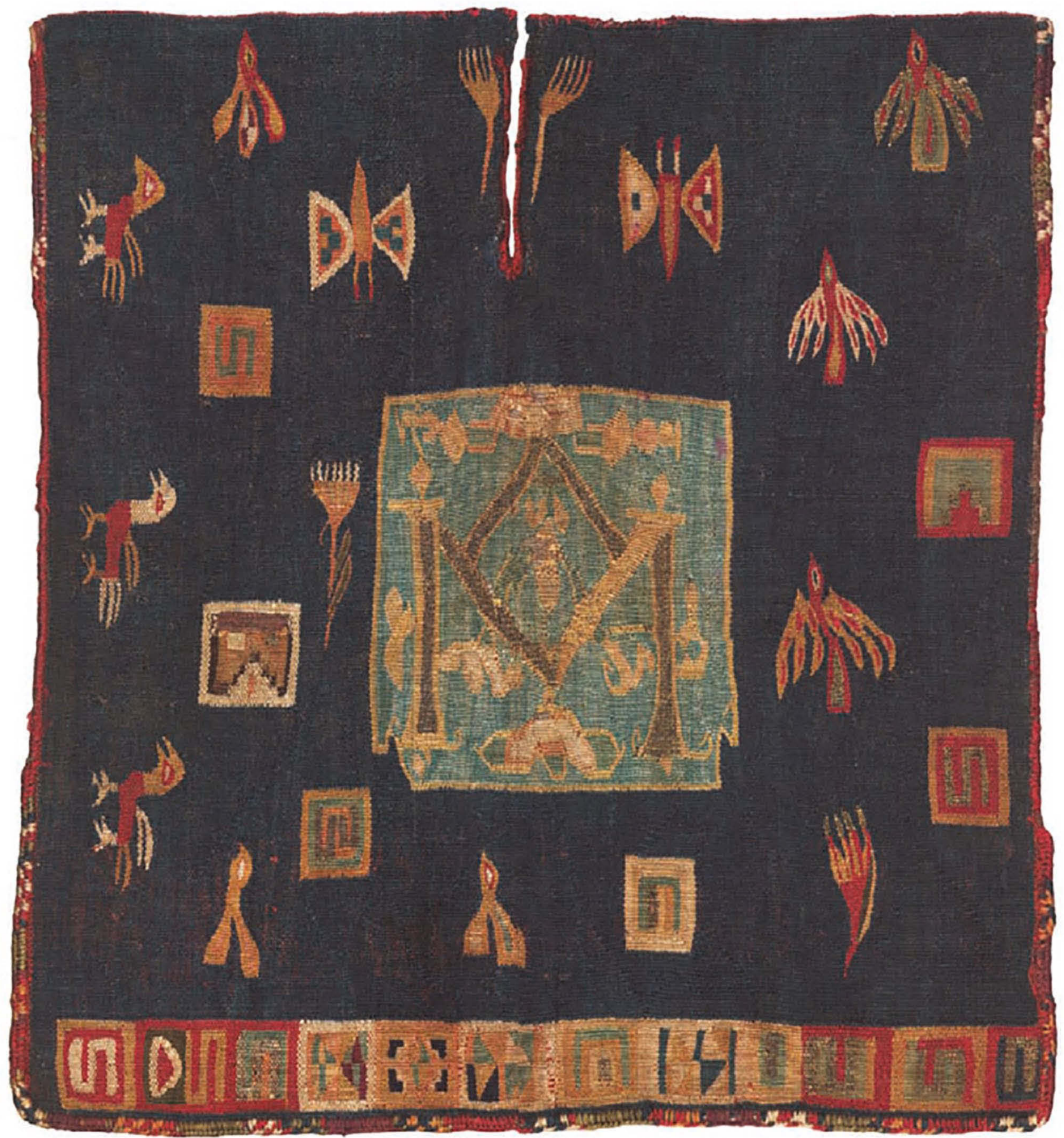

Figura 1ob. Uncu santo, reverso. Fines del s. XVI e inicios del s. XVII. Museo Nacional de Etnografía y Folklores de La Paz, Bolivia. Tomado de Phipps, Hecht y Esteras (2004: 275)

pinturas en los inicios de ciertos sectores con detalles y soluciones plásticas típicas de esa época. Es notable la composición y la disposición de los personajes rodeados por animales de la ilustración (Tesniere \& Delcourt, 2004, p. 38) que guarda estrecha relación con la composición de los personajes del tapiz La creación de Eva (donde Adán yace en el suelo recostado sobre su brazo izquierdo y desde su espalda se proyecta el cuerpo desnudo de Eva quien extiende su mano hacia la de Dios Padre). El tejedor del tapiz andino, siguiendo un modelo seguramente muy semejante a la viñeta iluminada, rodea a los personajes con animales cuadrúpedos de distinta especie, como elefante, camello, y reptiles, 
así como con flores y plantas que completan la escena de la creación bíblica de las especies y el paraíso. La autoría de la viñeta iluminada recae sobre el Maestro de la Policratica de Carlos V, quien fue un iluminador (ilustrador) activo en París, entre 1366 y 1403, lleva el nombre de la copia de dedicación de la obra traducida de Policratique de Jean de Salisbury por Denis Foullechat, realizada en 1372 (Calames 2007). La cronología de la imagen, que data de fines de la Edad Media, contribuye a entender la concepción del espacio y el tratamiento de las figuras de los tres tapices todavía lejos del lenguaje plástico renacentista.

\section{Posibles propietarios entre las principales órdenes religiosas}

Existe evidencia sobre distintas órdenes religiosas vinculadas a la confección de algún tipo de tapicería. Guamán Poma, por ejemplo, comenta sobre el mercedario M. Murúa, quien hacía tejer en su doctrina:

Este dicho Morúa fue comendador del pueblo de Yanaca de la prouincia de los Aymarays, el qual destruyyó grandemente a los yndios con el mal y daño y trauajos de ajuntar las solteras, hilar, texer y hazer cunbi [tejido fino] y de auasca [corriente], pauellón y sobrecama, uascas [soga] y frezadas y costales y de tiñir lana, amasejos de chicha y penas que le pone a los yndios de los pueblos y a los forasteros y al común de los yndios, yndias solteras, muchachos y muchachas (Guamán Poma, 2016 [1615], pág. 648 [662]).

Existen referencias de que en la zona Lupaca de Chucuito, la orden de Santo Domingo controló durante parte del siglo XVI la producción de tapices (Gisbert, Arze y Cajías, 1992: 29) y que los religiosos de la Compañía de Jesús que asumieron las doctrinas dejadas por los dominicos en el altiplano, establecieron talleres de tapices en Chile bajo la dirección de tejedores flamencos; sin embargo, nosotros no encontramos el sustento documental que corrobore tal información.

Los propietarios originales del tapiz estudiado pudieron ser franciscanos por la especial relación de la Orden con la devoción a la Santa Cruz, que tiene su origen en la predilección del santo fundador por la oración y la meditación frente al crucifijo ${ }^{14}$. San Francisco aconsejaba a los primeros frailes relegar los libros eclesiásticos para usar "el libro de la Cruz de Cristo" y orar delante del Crucifijo, observándolo fijamente en sus distintos aspectos. La difusión del culto a la cruz no solo fue especialmente predicada por los frailes franciscanos, sino que también fue representada en infinidad de motivos iconográficos (Sanchez, 2010). Se sabe también que el Vía Crucis, parte del ritual de la Semana Santa, fue difundido por la Orden, aunque antiguamente se pensaba que había sido instaurada por los franciscanos para honrar especialmente la pasión del Salvador (Barbier de Montault, 1898: 138,139).

Existen tres tapices vinculados con certeza a esta orden religiosa. Estos presentan cráneos con tibias cruzadas y las cinco llagas de Cristo, así como el emblemático diseño identificado con los estigmas del santo fundador. Proceden de la Sierra sur (uno de Cusco y dos de Arequipa), datan de fines del s. XVI e inicios del XVII, y fueron ejecutados en fibras locales por tejedores andinos que siguieron, probablemente, un mismo modelo (Phipps, Hecht y Esteras, 2004: 230, 231). Además, se ha sugerido que pudieron ser empleados como ornamento de los altares en servicios fúnebres o durante las celebraciones de la Semana Santa. Estos ejemplos destacan no solo por la destreza de los andinos en la ejecución de diseños foráneos, sino también por el colorido que se ha mantenido a pesar de los años.

Varios detalles llevan a pensar que el tapiz del MNAAHP procede también de algún lugar de la sierra sur. Saber en cuál de las iglesias se encontraba y cuál de los retablos decoraba es sumamente complicado; sin embargo, es posible plantear que proviene de alguna localidad de esta zona con mayoritaria población indígena. El clima también pudo haber favorecido a su conservación, así como se conservaron los tejidos citados con colores aún brillantes. Dado que los incas controlaron mejor el sistema del tejido en esa zona, es posible suponer que la tradición perduró allí por más tiempo.

Para concluir este acápite, conviene sintetizar algunos de los principales argumentos que se han vertido párrafos arriba. Primero, el estudio técnico e iconográfico del tapiz con tocapus del MNAAHP permite afirmar que tanto las técnicas textiles incaicas, así como sus símbolos continuaron vigentes mucho después de la conquista: el uso de las fibras locales, la tecnología ancestral y la iconografía, revelan pues una continuidad de la tradición textil andina. Segundo, el tapiz resultado de la tradición textil andina frente a la influencia hispana se convirtió en la pieza textil más valiosa y compleja, y llegó a cumplir distintos roles en las sociedades del período colonial temprano. Tercero, de lo evidenciado se propone una posible cronología temprana para el tapiz en cuestión, que puede datar del último cuarto del siglo XVI o de inicios del siglo XVII. El predominio de características del tejido andino ancestral revela que

14. El siguiente párrafo explica uno de los episodios más importantes en la conversión del santo: "El joven Francisco se encontraba orando ante el Crucificado de San Damiano, cuando escucha la voz de Dios que le ordena «Francisco vete para mi casa que, como ves, se viene del todo al suelo»". Settis, S. (1979), citado por Fraga Sampedro, M. (2003). Un calvario peculiar: el franciscano orante al pie de la cruz. Quintana, 2. 
tal vez fue tejido por cumbicamayocs, quienes continuaron con su labor décadas después de la conquista, o por tejedores entrenados en la antigua tradición textil. La calidad de la manufactura del tejido analizado no es la misma que la de los uncus incas imperiales. Hay cierto decaimiento de la misma, seguramente, debido a la intervención de varios tejedores con distintos niveles de dominio técnico y experiencia o, probablemente, por la falta de una supervisión especializada. Sin embargo, puede considerarse entre los objetos textiles más finos, complejos y valiosos del período colonial temprano.

Finalmente, se considera que el uso litúrgico fue una de las principales funciones que tuvo y, por ello, probablemente, las mayores órdenes religiosas, como franciscanos, mercedarios, dominicos y jesuitas, fueron los comitentes y propietarios originales. Debido a la escasez de pintores de renombre, es posible que la Iglesia recurriera a tejedores para la elaboración de paños de pared con temática religiosa. Así, el tapiz andino se convirtió en vehículo de apoyo para la transmisión del credo católico.

\section{Referencias}

Aguilar Callo, Víctor R.

2011 Machu Picchu: Catálogo de la colección. Editado por Yale, Ministerio de Relaciones Exteriores del Perú, United States of American Embassy, Universidad Nacional de San Antonio Abad de Cusco. Lima.

Barbier de Montault, Xavier.

1898 Traité D’Iconographie Chrétienne. Paris: Societé de Libraire Ecclésiastique et Religieuse, 1898.

Calames.

2007 Postilles sur les livres de l'Ancien et du Nouveau Testament. http://www.calames.abes.fr/pub/ms/ BSGA10061 (accedido 2019. 20 de abril)

Cobo, Bernabé

1956 [1653] Historia del Nuevo Mundo. Vol. II, de Obras del P. Bernabé Cobo, de Francisco Mateos. Madrid: Atlas.

Cummins, Thomas

2004 Brindis con el Inca: la abstracción andina y las imágenes coloniales de los queros. Lima: Universidad Nacional Mayor de San Marcos Fondo Editorial.

2014 El tocapu: el nudo gordiano en los Andes. En C. Arellano H., Sistemas de notación inca: Quipu y Tocapu. Lima: Ministerio de Cultura.

Emery, Irene

1966 The Primary Structures of Fabrics and Illustrated Classification. Washington D.C.: The Textile Museum.
De Lyre, Nicolas (s. f.).

Postilles sur les livres de l'Ancien et du Nouveau Testament. En Calames: Online catalogue of archives and manuscripts in French University and Research libraries. Recuperado de http://www.calames.abes.fr/ pub/\#details?id=BSGA10061

Frame, Mary

2014 «Tukapu, un código gráfico de los inkas.» En Sistemas de notación inca: Quipu y Tocapu, de Carmen Arellano Hoffman. Lima: Ministerio de Cultura.

García, María

2009 «El mundo de los muertos en la cosmovisión centroandina» Gaceta de Antropología.

Gavilán Vega, Vivian

1996 «Mujeres y hombres en Isluga y Cariquima: una aproximación a las relaciones de género entre los aymara del norte de Chile. Versión preliminar.» Tesis, Maestría en Antropología. Facultad Latinoamericana de Ciencias Sociales- Sede Ecuador.

Gisbert, Teresa, Arze, Silvia y M. Cajías

1992 Arte textil y mundo andino. Buenos Aires: Tipográfica Editora Argentina.

González Holguín, D.

1989 [16o8]) Vocabulario de la lengua general de todo el Peru llamada lengua qquichua o del Inca. Lima: UNMSM

Iriarte, Isabel

1992 «Tapices con escenas bíblicas del Perú colonial.» Revista Andina, $\mathrm{n}^{\circ}$ 10(1) (1992): 80-105.

2004 «The Creation of Eva \& King David» The colonial Andes: tapestries and silverwork, 1530-1830, Phipps, Elena; Hecht, Johana y Cristina Esteras, 283,284. New York: The Metropolitan Museum of Art, Yale University Press.

Kurella, Doris y Castro, Inés

2013 Könige der Anden. Stuttgart: Linden Museum, Staatliches Museum für Völkerkunde.

Mâle, Emile

2001 El arte religioso de la Contrarreforma. Madrid: Ediciones Encuentro S.A.

Matos, Ramiro

1999 «La Cerámica Inca.» En Los Incas Arte y Símbolos, de Carmen Arellano, y otros, 109-166. Lima: Colección arte y tesoros del Perú, Banco de Crédito del Perú.

Niles, Susan A.

1992 «Artist and Empire in Inca and Colonial Textiles» To Weave for the Sun. Ancient Andean Textiles in the $\mathrm{Mu}$ seum of Fine Arts, Boston, de Rebecca Stone-Miller, 50-66. Boston, Massachusetts: Thames and Hudson. 
Phipps, Elena

2013 «The Iberian globe. Textile traditions and trade in Latin America.» En Interwoven Globe. The Worldwide Textile Trade, 1500-180o, de Peck Amelia (Ed.), 2845. New York: The Metropolitan Museum of Art.

Phipps, Elena, Hecht, Johanna y Esteras, Cristina

2004 The Colonial Andes. Tapestries and Silverwork. New York: The Metropolitan Museum of Art, Yale University Press.

Romero, Carlos Alberto (Prol.)

1924 «Libro de la visita general del Virrey Don Francisco de Toledo (1570 - 1575).» Revista Histórica 7 (1924): 113-216.

Rosario, Noemí

1999 Tintes en el Perú prehispánico, virreinal y republicano. En Tejidos milenarios del Perú. Lima: AFP Integra, Wiese Aetna.

Roussakis, Vuka y Lucy Salazar

1999 Tejidos y tejedores del Tahuantinsuyo. En F. Pease G.Y, C. Morris, J. Santillana, R. Matos, P. Carcedo de Mufarech, C. Arellano, ... L. Vetter Parodi, Los incas, arte y símbolos (págs. 263-297). Lima: Banco de Crédito del Perú.

Rowe, Ann Pollard

1995-1996 «Inca Weaving and Costume» The Textile Museum Journal, 1995-1996: 5-53.

1995-1996 «Technical Features of Inca Tapestry Tunics » Textile Museum Journal, 1995-1996: 5-28.
Rowe, John

1999 «Estandarización de las técnicas de tapiz Inca» En Tejidos milenarios del Perú, 571-664. Lima.

Sanchez, José

2010 «La cruz como ícono protector en los espacios de tránsito.» Estudios del patrimonio cultural. http:// campaners.com/php/textos.php?text=1366. (último acceso: setiembre de 2016).

Solórzano Gonzales, Mónica

2012 La coronacion de la Virgen de Bernardo Bitti en el arte peruano colonial. Tesis para optar el grado de Magíster. Pontificia Universidad Católica del Perú.

Stanfield-Mazzi, Maya

2013 Object and Apparition. Envisioning the Christian Divine in the Colonial Andes. Tucson: The University of Arizona Press.

Stastny, Francisco

2013 Estudios de Arte Colonial. Lima: Instituto Francés de Estudios Andinos, Museo de Arte de Lima.

Tesnière, Marie-Hélène y Delcourt, Thierry

2004 Bestiaire du Moyen Áge. Paris: Somogy editions d'art. 


\title{
La cestería de los cazadores-recolectores, procedente de la cueva de la Candelaria, Torreón, Coahuila, México
}

\author{
Dra. Gloria Martha Sánchez Valenzuela ${ }^{1}$ \\ Dra. Alejandra Quintanar Isaías ${ }^{2}$ \\ Mtra. Ana Jaramillo Pérez ${ }^{3}$
}

1. Laboratorio de Conservación de Material Arqueológico de Origen Orgánico - Coordinación Nacional de Conservación Del Patrimonio Cultural del Instituto Nacional de Antropología e Historia. gloriamsv.cncpc@inah.gob.mx

2. Laboratorio de Anatomía Funcional y Biomecánica de Plantas Vasculares. Departamento de Biología -Universidad Autónoma Metropolitana Iztapalapa. aqi@xanum.uam.mx

3. Laboratorio de Anatomía Funcional y Biomecánica de Plantas Vasculares. Departamento de Biología -Universidad Autónoma Metropolitana Iztapalapa. jaramillo@xanum.uam.mx

\section{Resumen}

En 1953 se realiza la primera exploración arqueológica al Norte de la República Mexicana por parte del Instituto Nacional de Antropología e Historia (INAH), que conformó un grupo interdisciplinario para explorar la Cueva de la Candelaria, ubicada en el Valle de las Delicias en el estado de Coahuila. Esta cueva es una de las más importantes de México, dónde se logró recuperar -gracias a su característica de cueva seca- un vasto patrimonio arqueológico de origen orgánico que nos permite conocer mejor a los grupos de cazadores-recolectores que habitaron la región.

Dentro de la gran diversidad de objetos se encontraron un número considerable de cestas o canastas rígidas elaboradas con la técnica de enrollado en espiral (Sánchez Valenzuela, Gloria M; 2017:119), de diversos tamaños de forma cóncava y cónica. El estudio e identificación de los materiales permitieron ratificar la maestría y conocimiento que tenían los grupos de cazadores recolectores para aprovechar los materiales que les proporcionaba su entorno elaborando artefactos que utilizaban cotidianamente.

A través del estudio anatómico microscópico se identificaron las fibras empleadas en la manufactura de las cestas, provenientes del xilema secundario de plantas del género Jatropha sp. perteneciente a la familia Euphorbiaceae, y abundantes en la región de la Laguna.

La reconstrucción de estas técnicas puede tener impacto en la visión que se tiene de estos grupos nómadas: su tecnología, el conocimiento y uso de los recursos naturales de esta región.

Palabras Clave: Cestería, Cazadores-recolectores, fibras, Cueva de la Candelaria

\begin{abstract}
In 1953, the National Institute of Anthropology and History (INAH) carried out the first archaeological exploration to the North of the Mexican Republic, which formed an interdisciplinary group to explore the Cueva de la Candelaria, located in the Valle de las Delicias in the state of Coahuila. This cave is one of the most important in Mexico, where it was able to recover a vast archaeological heritage of organic origin that allows us to know better the groups of hunter-gatherers who inhabited the region.
\end{abstract}

DOI: $10.32873 /$ unl.dc.zea.1212

Published in PreColumbian Textile Conference VIII / Jornadas de Textiles PreColombinos VIII, ed. Lena Bjerregaard and Ann Peters

(Lincoln, NE: Zea Books, 2020). https://digitalcommons.unl.edu/zeabook/ 
Among the great diversity of objects found there are a considerable number of rigid baskets elaborated with the technique of spiral winding (Sánchez Valenzuela, Gloria M; 2017:119), of various sizes, both concave and conical. The study and identification of the materials allowed us to ratify the mastery and knowledge that groups of hunter-gatherers employed to take advantage of the materials provided by their environment by making artifacts that they used on a daily basis.

Through the microscopic anatomical analyses, it was possible to identify the plant species of the fibers with which the baskets were manufactured. These are secondary xylem sheafs of the genus Jatropha dioica belonging to the Euphorbiaceae family; species abundant in the Laguna region.

The reconstruction of these techniques can enrich the current vision of these nomadic groups: their technology, knowledge and use of the natural resources of this region.

Keywords: Basketry, Hunter-gatherers, fibers, Candelaria Cave.

\section{Résumé}

En 1953 est réalisée la première exploration archéologique du Nord de la République Mexicaine par l'Institut National d'Anthropologie et d'Histoire (INAH), qui a réuni un groupe interdisciplinaire pour explorer la Cueva de la Candelaria, localisée dans la Vallée de las Delicias dans l'Etat de Coahuila. Cette grotte est l'une des plus importantes du Mexique, où l'on a pu récupérer - grâce à sa caractéristique de grotte sèche - un vaste patrimoine archéologique d'origine organique qui nous permet de mieux connaître les groupes de chasseurs-cueilleurs qui ont habité la région.

Dans la grande diversité d'objets, ont été découvert un nombre considérable de paniers, ou corbeilles rigides, élaborées selon la technique de l'enroulé en spirale (Sánchez Valenzuela 2017 : 119), de diverses tailles et de forme concave ou conique. L'étude et l'identification des matériaux ont permis de ratifier la maîtrise et la connaissance que les groupes de chasseurscueilleurs avaient pour tirer profit des matières premières que fournissait leur environnement en produisant des artefacts qu'ils utilisaient quotidiennement.

Grâce à l'étude anatomique, il a été possible d'identifier les fibres utilisées dans la vannerie. Ces dernières, provenant du xylème secondaire des plantes du genre Jatropha sp., et appartenant à la famille des Euphoribiaceae ; sont abondantes dans la région de la Laguna.

La reconstruction de ces techniques peut enrichir la vision actuelle que nous avons des groupes nomades : leur technologie, leur connaissance et l'utilisation des ressources naturelles de cette région.

Mots-clés: Vannerie, chasseurs-cueilleurs, fibres, Cueva de la Candelaria.

\section{Introducción}

La cueva de la Candelaria está situada en la Comarca Lagunera, al pie de la sierra de la Candelaria, en el valle de las Delicias al suroeste del estado de Coahuila, México.

La cueva se abre a unos 3om sobre el nivel del bolsón y el orificio para ingresar es tipo chimenea; la cámara principal mide aproximadamente un metro de diámetro, el tiro se ensancha de forma irregular tanto transversal como verticalmente y se aproxima a la forma rómbica. "La cueva de la Candelaria nunca fue un sitio de habitación con acumulación estratigráfica de depósitos culturales, sino una simple grieta de grandes dimensiones, utilizada por los antiguos laguneros como un enorme depósito mortuorio" (González Arratia, Arqueología Mexicana Vol. 30, 1998:63)

La Cueva de la Candelaria fue descubierta por casualidad en 1953 por personas oriundas de la región quienes dieron aviso al Instituto Nacional de Antropología e Historia (INAH), que decide realizar allí el primer proyecto formal de investigación en el norte de México.
El proyecto implicó varias temporadas de campo con un equipo interdisciplinario conformado por: Manuel Maldonado Koerdell (geólogo y paleontólogo), Arturo Romano (antropólogo físico), Francisco González Rul (arqueólogo) y Pablo Martínez del Río (antropólogo).

Cabe resaltar que en 1953 la región norte de México era una zona poco estudiada; se sabía que estuvo habitada por grupos de cazadores recolectores y que existían numerosas cuevas que fueron utilizadas como casa habitación o bien como sitios de enterramiento. La escasa información existente, para el conocimiento de dichos grupos, era a través de los informes que anualmente rendían los padres misioneros a sus superiores Jesuitas (Aveleyra, Martínez del Río, Pablo; 1956:25-31).

El desarrollo del proyecto permitió conocer mejor a las culturas del norte: sus sistemas de enterramiento, alimentación, materiales empleados, flora, fauna; así como ciertas enfermedades que se observaron en algunos de los cráneos dónde son evidentes las lesiones sifilíticas (Pijoan Aguadé, 2000), así como el extraordinario trabajo sobre tecnología 
textil de la Dra. Johnson (1977). Los objetos descubiertos permanecieron, una parte en un pequeño museo de la Escuela Preparatoria Venustiano Carranza (EPVC) y otra en el antiguo Museo Nacional de Antropología. En 1976, algunos de los objetos del antiguo Museo se trasladaron a las instalaciones del nuevo Museo Regional de la Laguna (MUREL) y hasta el 2013 se incorporan los que estaban albergados en la Escuela Preparatoria. Por lo anterior muchos materiales quedaron pendientes de estudio y análisis como es el caso de la cestería.

Actualmente la colección de la Cueva de la Candelaria se encuentra resguardada, principalmente en dos depósitos: en el Museo Regional de la Laguna, (Torreón, Coahuila) y en el Museo Nacional de Antropología en la Ciudad de México, lugares en los que se ha podido tener acceso e iniciar estudios formales sobre los diversos objetos rescatados.

Los objetos de cestería encontrados son representaciones fundamentales de la vida cotidiana de los pueblos nómadas del norte. Se trata de cuencos u ollas manufacturados con materia prima poco convencional; excepcionales en el tejido y en el posible uso, dado que se trata de objetos que podrían haber sido empleados como contenedores de líquidos o para procesar alimentos. Sus formas sugieren una tecnología emblemática para la época dado que estos grupos nómadas tendrían necesidades de almacenamiento y transporte posiblemente de granos $\mathrm{u}$ otras materias primas en contenedores que al ser ligeros facilitarían su movilidad.

El estudio de la materia prima vegetal y la tecnología con la que se manufacturaron estos objetos puede dar luz sobre el gran conocimiento del uso de los recursos vegetales que tenían esos grupos humanos para resolver y procurar su subsistencia, por lo que el presente trabajo se ha enfocado a la descripción y estudio de la manufactura de estos objetos y enfatizando el tipo de material con el que fueron elaboradas.

\section{Antecedentes}

\section{Características del emplazamiento}

La cueva de la Candelaria se sitúa en la región cultural denominada de los Irritila o laguneros, dónde habitaron grupos nómadas dedicados a la pesca, recolección y caza. Vivían cerca de lugares con aprovisionamiento de agua y manufacturaban sus artefactos con los materiales que les proporcionaba su entorno, ambiente desértico caracterizado por bruscas variaciones de temperatura que han moldeado el tipo de vegetación y fauna de esa región.

La característica del contexto de la cueva estable y seco, permitió que en el interior se conservaran bultos mortuorios y materiales asociados a ellos; de acuerdo con Romano
(1953:4-12), los cadáveres de adultos e infantes fueron colocados en posición fetal dentro de grandes mantos donde eran envueltos y atados con cuerdas para asegurarlos.

El paquete funerario estaba formado por los restos humanos, acompañados de objetos que les habrían pertenecido como son utensilios, herramientas y vestimenta: navajas, raspadores, punzones, collares, pendientes. Así como tejidos diversos: redes, petates, enredos de cabeza, yahuales, sandalias, bolsas de pescador, bandas, lienzos y una gran variedad de cestos o canastas de diversos tamaños.

Según Luis Aveleyra los objetos denotan una larga ocupación de la zona y por consiguiente implican cierto sedentarismo, es muy posible que la cultura candelariense abarque un lapso del 1000 al 1600 d.C. La cronología se obtuvo por los materiales arqueológicos asociados y por dos fechas de radiocarbono 14 (Aveleyra,1964), una de un fragmento de textil que tiene una edad que fluctúa entre los años 1095 a 1315 d.C. y la otra de un hueso humano que dio una fecha entre 1100 y 1300 d.C. (Pijoan, Mansilla, 2000:213).

\section{Materiales y métodos en el estudio de las cestas}

\section{Descripción general de los objetos.}

Las cestas estudiadas proceden de la colección de la Cueva de la Candelaria bajo resguardo del Museo Regional de la Laguna, Torreón, Coahuila. Se trata de objetos tejidos con un material vegetal muy resistente, dada la época en la que pudieron construirse. Presentan un sistema horizontal de varillas que se amarran con un sistema vertical, usándose para ello fibras del mismo material vegetal. Estos objetos pueden presentar o no un recubrimiento negro en su interior y exterior. La presencia del recubrimiento sugiere una práctica para sellar la porosidad del tejido y servir como contenedor o recipiente de líquidos. Aquellas que no lo presentan cuentan con una decoración sencilla pintada de color rojo, sugiriendo otro tipo de función.

El estado de conservación de las cestas proporcionadas para este estudio es regular ya que presentan fibras quebradizas, con deformaciones, pérdida de tejido y de capa de recubrimiento; así como grietas, fisuras, manchas, polvo y tierra acumulada.

Es relevante señalar que entre los objetos estudiados por un lado se encuentran cestas que han perdido el fondo, y por el otro fragmentos de fondos sueltos que sugiere podrían ser correspondientes entre ambos.

También se observa que existen varias cestas con remiendos originales sobre todo en el área de la base o fondo, lo que sugiere una práctica de reparación y recuperación de este tipo de utensilios dada la complejidad en la manufactura, el procesamiento de la materia prima y posiblemente de la disponibilidad de la materia prima. 


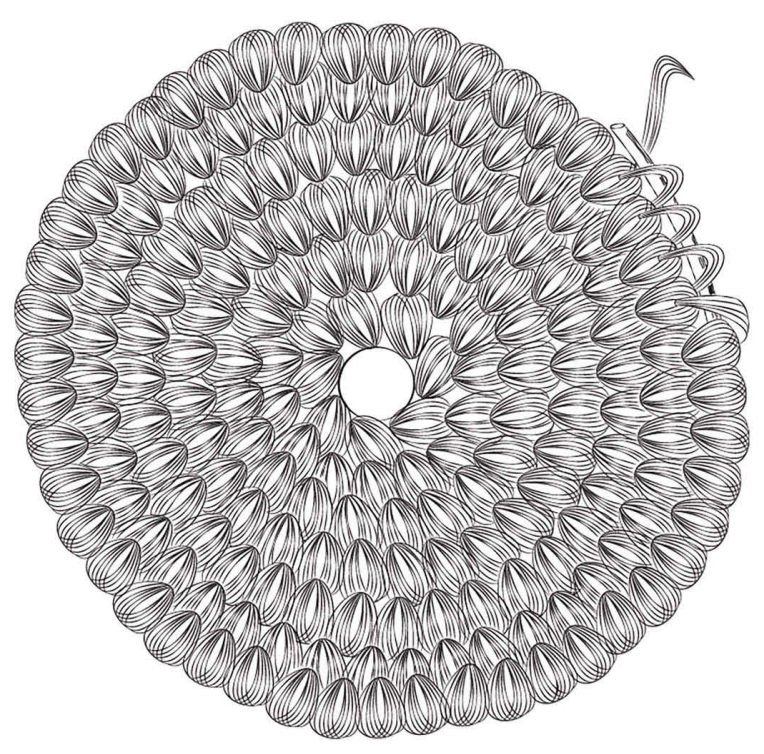

Figura 1a. Esquema de la técnica de enrollado en espiral.

\section{Descripción del tejido.}

Dentro de los bienes reguardados en el MUREL se localizan 15 cestas completas (algunas sin fondo), 11 fondos y varios fragmentos de cestería que tienen como común denominador estar elaborados con fibras rígidas o semiduras con la técnica de enrollado en espiral (coiled basketry).

De acuerdo con Adovasio (1977), las cestas están constituidas por dos elementos equivalentes a la trama y urdimbre de los textiles; denominando base o fundación a los elementos o fibras que se enrollan horizontalmente conformando una estructura en espiral, y puntos de sutura o sujeción a los elementos o fibras que se desarrollan verticalmente para unir los elementos horizontales a través de puntadas como se observa en las figuras $\mathbf{1 a} \mathbf{y} \mathbf{1 b}$.

Una vista general del trabajo de manufactura (figura 2a) permite observar cómo se unen la fundación con los puntos de sujeción, resultando un tejido que mantiene una estructura firme y cerrada. Los dos elementos unidos conforman el tejido dando estructura a las cestas (figura $\mathbf{2 b}$ ), lo que es relevante pues dado el origen del material, las fibras verticales no rajan el haz de fibras horizontales, por el contrario, garantizan una mejor sujeción. En la figura $2 c$ se muestra un corte transversal del tejido destacando una médula o región central conformada por un haz de fibras leñosas inicial sin huecos colocadas horizontalmente, sujetas de forma vertical, con el mismo material, dando soporte y resistencia al tejido.

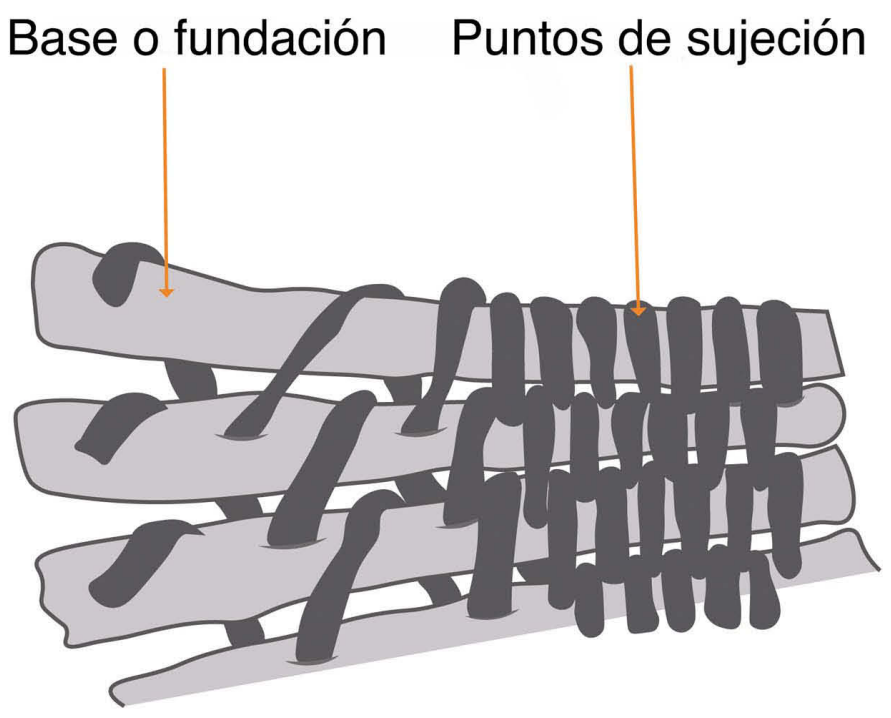

Figura 1b. Descripción de elementos de la técnica del tejido enrollado en espiral. Dibujos: Castro Rodríguez, Miriam; CNCPC-INAH, 2019.

3. Descripción del tejido empleando fibras xilemáticas.

La fundación está conformada por haces o paquetes de fibras xilemáticas con un diámetro de $5 \mathrm{~mm}$ de espesor aproximadamente, que conforman la estructura de la cesta y funcionan como las paredes que le dan resistencia. Aunque las fibras son semirrígidas al provenir del tallo de la planta, son notablemente flexibles, lo que permite dar la curvatura al enrollado en espiral.

Los puntos de sujeción están conformados por haces largos de fibras xilemáticas de aspecto lustroso, de un espesor de entre 1-2 mm, con los que se logra ejecutar muchas inserciones para sujetar, tensar y tejer amplias secciones a lo largo de la fundación. Los puntos de sujeción forman una puntada bifurcada en el tejido (figura 2b). El cosido resultante explica la forma que toma el objeto resultando cestas firmes de paredes duras, de forma cónica y base plana (Figura $5 \mathbf{a})$.

\section{b) Materia prima.}

1. Identificación de las fibras xilemáticas.

En el Laboratorio de conservación de material arqueológico de origen orgánico de la CNCPC se obtuvieron seis muestras (Figura $2 \mathrm{~b}$ y Figura 5) de $2 \times 1 \mathrm{~mm}$ de las fibras xilemáticas que conforman la estructura (fundación y puntos de sujeción) de tres cestas y de un fragmento suelto de cestería pertenecientes a la Cueva de la Candelaria. En el 


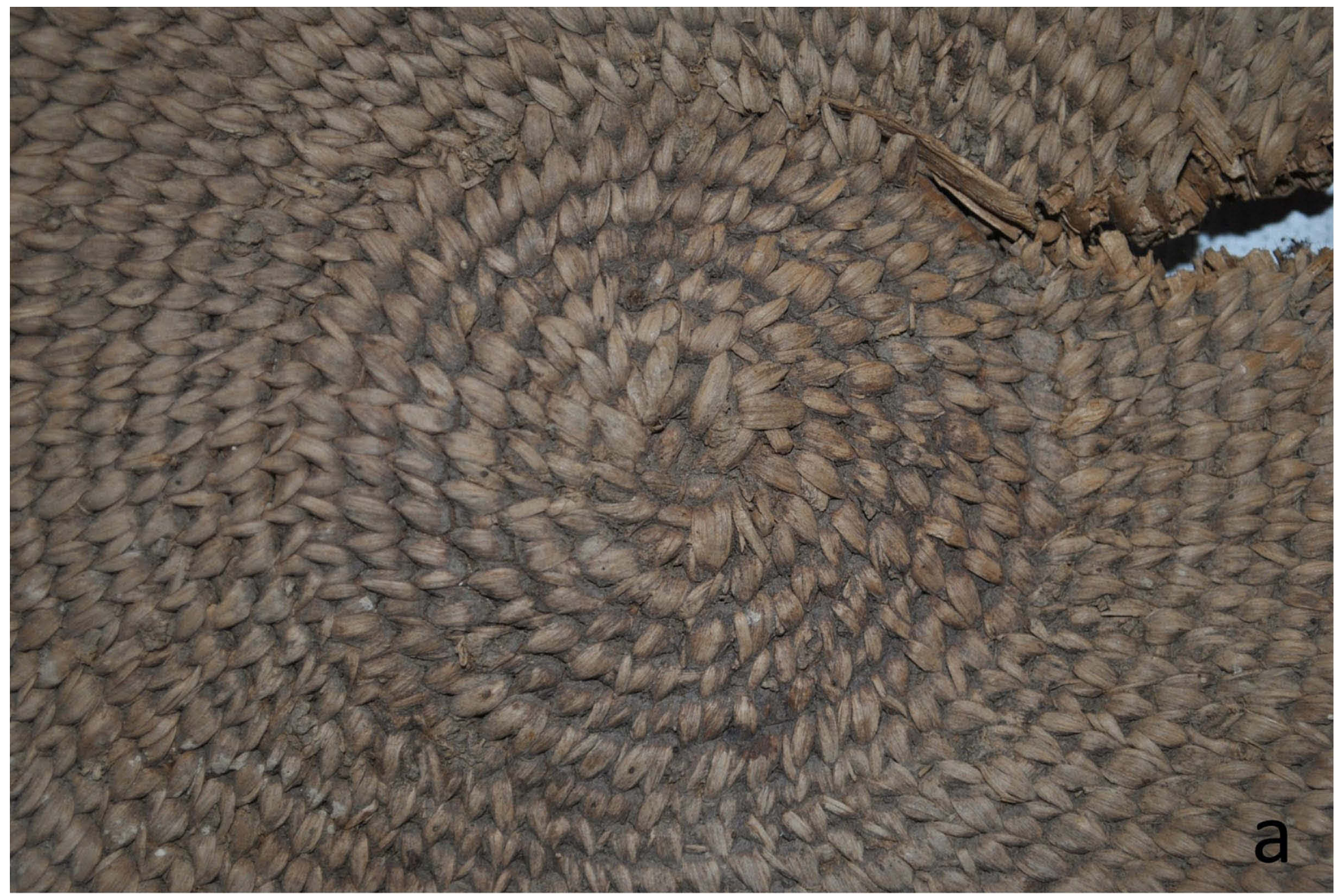

Figura 2a. Vista general de la cesta 10-423669 con tejido enrollado en espiral.
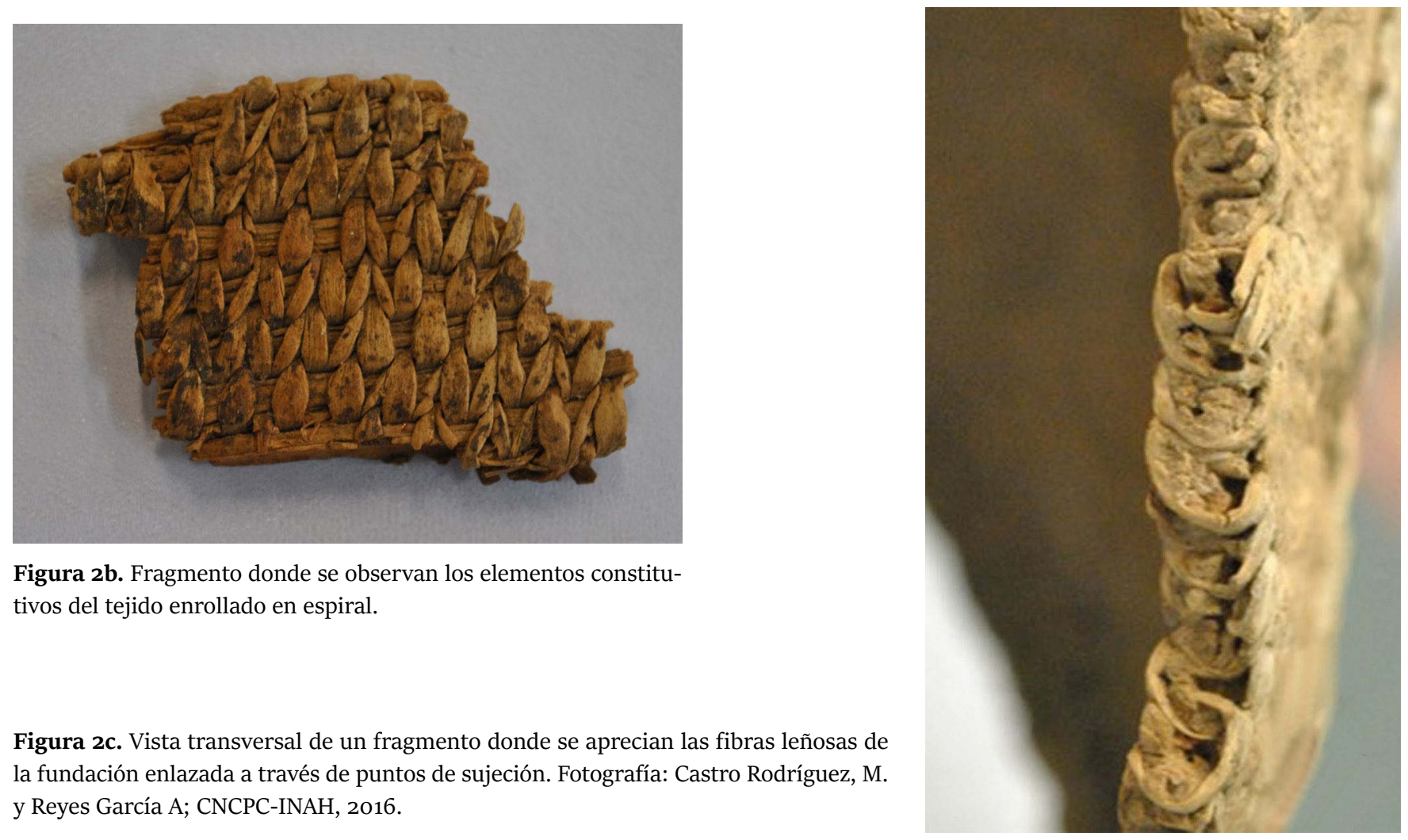

Figura 2c. Vista transversal de un fragmento donde se aprecian las fibras leñosas de la fundación enlazada a través de puntos de sujeción. Fotografía: Castro Rodríguez, M. y Reyes García A; CNCPC-INAH, 2016. 


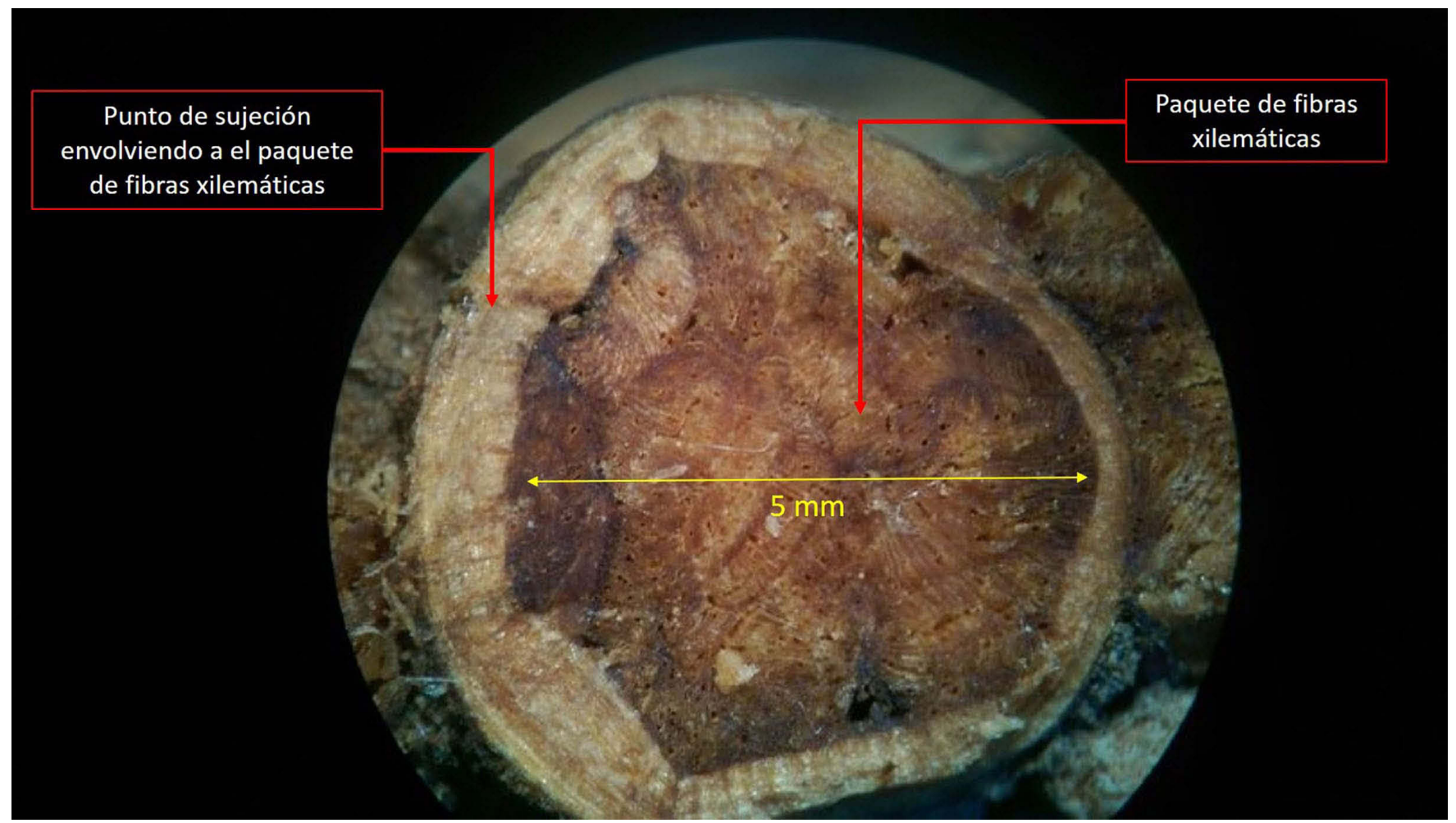

Figura 3. Sección transversal de la fundación que muestra haces xilemáticos sujetados con fibras en sentido longitudinal (40X). Fotografía: Dra. Alejandra Quintanar Isaías, Laboratorio de Anatomía Funcional y Biomecánica de Plantas Vasculares. Departamento de Biología -Universidad Autónoma Metropolitana Iztapalapa.

Laboratorio de anatomía funcional y biomecánica de plantas vasculares en la UAM-Iztapalapa se procesó el material muestreado. Las pequeñas muestras se hidrataron con agua e incluyeron en Tissue $T e c \AA$ para hacer secciones radiales, transversales y tangenciales del tejido usando un Criostato Leica a $-20^{\circ} \mathrm{C}$. Se hicieron laminillas permanentes del tejido vegetal. Se observaron los patrones celulares que componen el tejido y se describieron. La primera descripción del tejido arrojó que se trataba del xilema secundario (madera) de un género arbustivo perteneciente a la familia Euphorbiaceae.

\section{Trabajo de campo.}

Para hacer la identificación del género botánico de la madera se hizo un viaje de campo a la zona en el Valle de las Delicias. Se realizó un registro de los géneros representativos de la familia identificada en la zona. Se colectaron 15 ejemplares con raíces y tallos de estos géneros sobre las orillas de la carretera federal Bermejillo-Torreón, Coahuila, México.
En el laboratorio se siguió el mismo protocolo para preparar laminillas permanentes del tejido perteneciente a diversos géneros de la misma familia. Los patrones celulares que ajustaron a las fibras xilemáticas de las cestas fueron los del género Jatropha dioica, conocida en la región como Sangre de Drago, la que es una especie característica y presenta propiedades de elasticidad ad hoc para la elaboración de tiras finas, blandas y resistentes para tejer.

La identificación de las fibras ha dado luz acerca del avance tecnológico que representó en estos grupos humanos y su trascendencia a otros grupos que en la actualidad siguen usando estas plantas para la elaboración de cestas monumentales como es el caso de la Nación Comcaác ${ }^{4}$ en el estado de Sonora, donde usan el Torote (Jatropha cuneata), (comunicación personal Lic. Alejandrina Espinoza Reyna ${ }^{5}-$ Museo Comcaác). Ambas especies presentan patrones celulares correspondientes a los encontrados en las fibras xilemáticas de las canastas de las cuevas. 


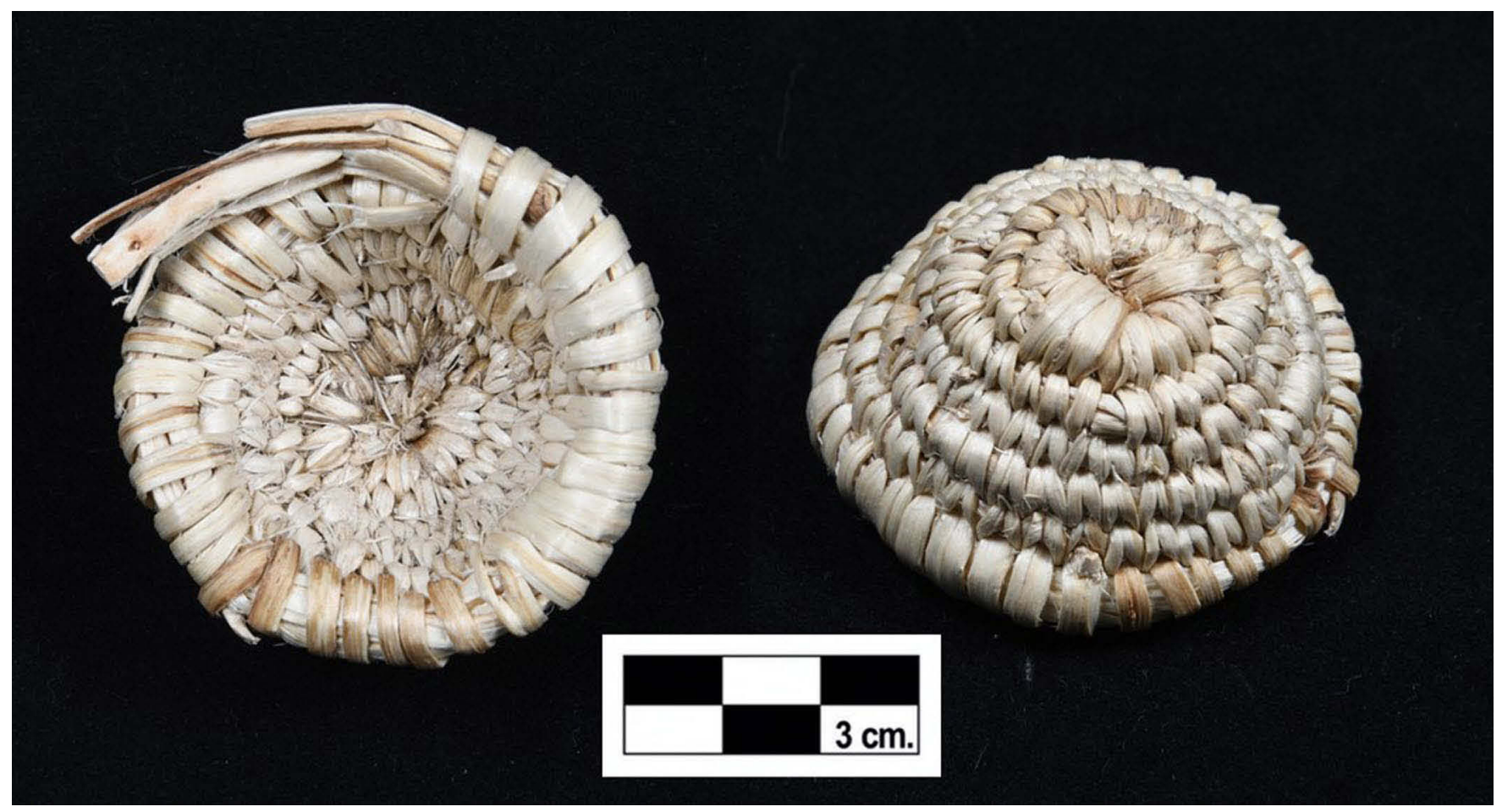

Figura 4. Cesta en proceso de elaboración siguiendo la técnica de enrollado en espiral con fibras de Jatropha dioica, vista general del interior y exterior. Fotografía: Julio Broniman, CNCPC-INAH 2020.

\section{c) Reproducción de la tecnología con fibras de sangre de drago.}

La reproducción de la técnica se realizó usando 12 plantas de sangre de drago de $20-30 \mathrm{~cm}$ de longitud.

\section{Eliminación de la corteza.}

Se plantearon tres procesos de manufactura para la eliminación de la corteza y la preparación de la fibra.

1) Eliminación de la corteza en verde. Cuatro tallos recién cortados se tallaron, sin embargo, la corteza quedó adherida. Fue difícil eliminarla y durante el tallado quedaron pedazos adheridos a la fibra xilemática.

2) Eliminación con pudrición de la corteza. Cuatro tallos se hidrataron en una tina con agua por una o dos semanas para que el tejido se pudriera sin lastimar las fibras.

En este método la corteza se eliminó fácilmente lavando con la mano, pero las fibras se deformaron. Con este proceso las fibras se secaron rápidamente. Las fibras quedaron quebradizas con rigidez y con dificultad para desprender "hebras o hilos" largos para tejer, dificultando su manipulación.
Adicionalmente las fibras que se obtuvieron eran cortas y algunas dañadas o podridas lo que las hizo perder flexibilidad.

3) Eliminación de la corteza con calor. Cuatro tallos se pusieron en anafres tradicionales con brasas recién prendidas. Los tallos se asaron para eliminar la corteza, tal como lo realizan los grupos Seris en Sonora (Alejandrina Espinoza, comunicación personal). Este método fue sencillo y rápido y se requirió poco calor para desprender. La corteza se eliminó fácilmente con la mano, las fibras quedaron lustrosas y flexibles; el cilindro de madera fue fácil de abrir o seccionar para jalar hilos o hebras largas. Estas últimas se emplearon para tejer o realizar las sujeciones de las fundaciones. Las fibras son fáciles de manipular y recuperan su flexibilidad cuando se hidratan.

2. Elaboración de la cesta con las fibras obtenidas con calor, siguiendo la técnica de enrollado en espiral.

La fundación se formó con las fibras obtenidas de la planta completa. Se conformó un haz de fibras de aproximadamente 5 hebras dando $5 \mathrm{~mm}$ de grosor; estos paquetes de fibras se enlazaron por medio de una sola hebra de fibras del xilema, a manera de hilo, siguiendo el método de enrollado en espiral. 


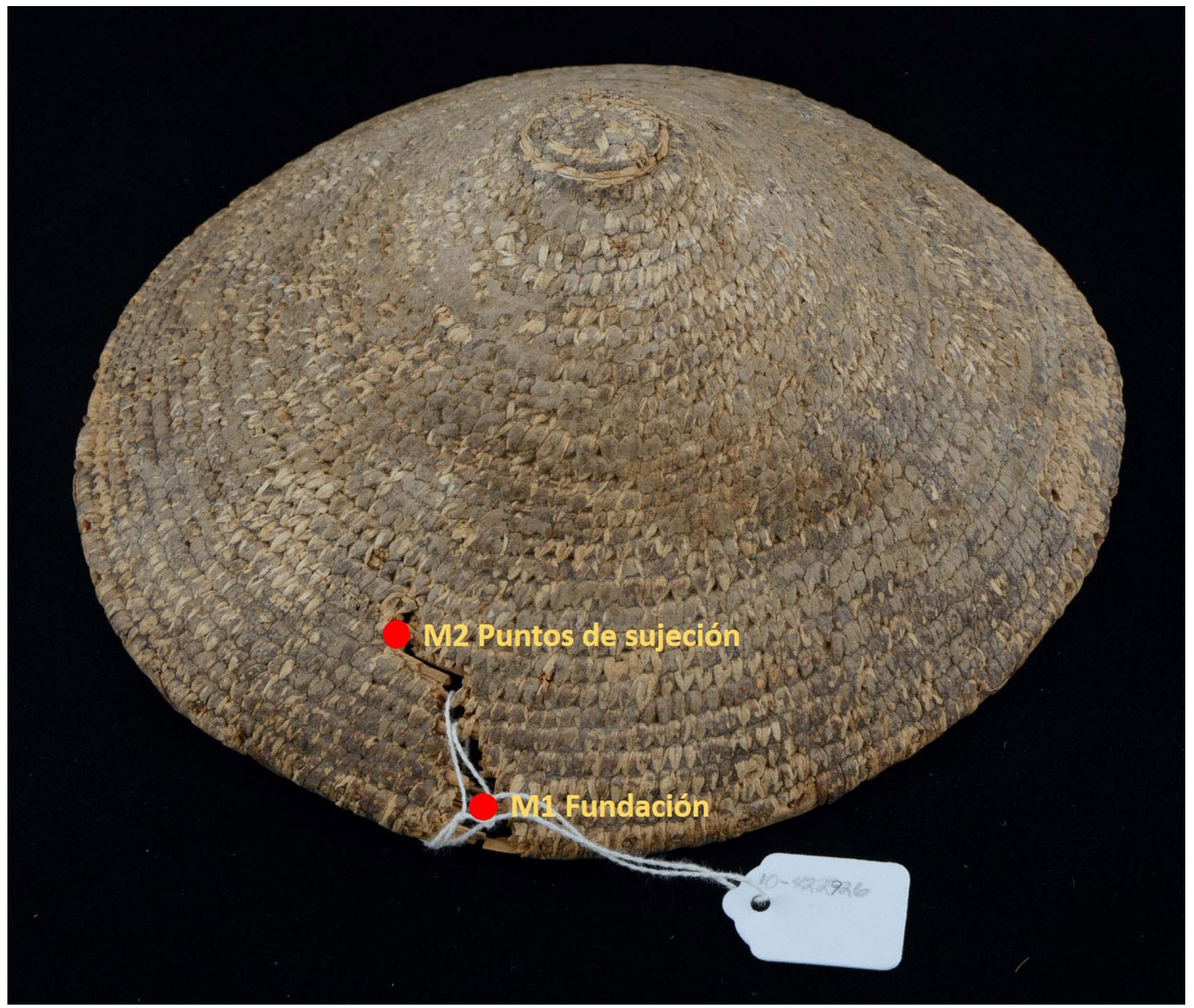

Figura 5. Cestas, antes de su intervención, en las que se ubica los sitios de extracción de las muestras. Fotografías: Julio Broniman, CNCPCINAH, 2015-2016.

La sujeción se logra enlazando la primera hilera de la fundación sobre la siguiente haciendo un orificio central en ambas fundaciones para que pase la puntada de forma envolvente, de manera consecutiva, hasta subir al siguiente nivel; dónde la puntada pasará por en medio del punto de sujeción anterior abriendo la hebra en forma de "V" como se observa en la figura $2 b$.

Para abrir o realizar el orificio que permite la sujeción se emplearon 2 tipos de espinas: una obtenida de la punta o espina de maguey y otra punta o espina de una planta de la región (Koeberlinia sp.).
La figura 4 muestra los resultados del proceso de elaboración de una cesta usando los materiales y la técnica ad hoc reproduciendo un objeto de aproximadamente $5 \mathrm{~cm}^{3}$, y que llevó alrededor de 7 horas de trabajo. Es posible que los grupos de nómadas recolectores del Norte de México podrían realizar estos objetos en mucho menor tiempo, con la maestría que con seguridad los caracterizaba.

La reproducción experimental de este objeto emplea la cocción como método de limpieza y preparación de la materia prima, esto permitió obtener fibras de excelente calidad. Este proceso es similar a lo que hoy en día realizan los artesanos de la Nación Comcaác en Sonora 

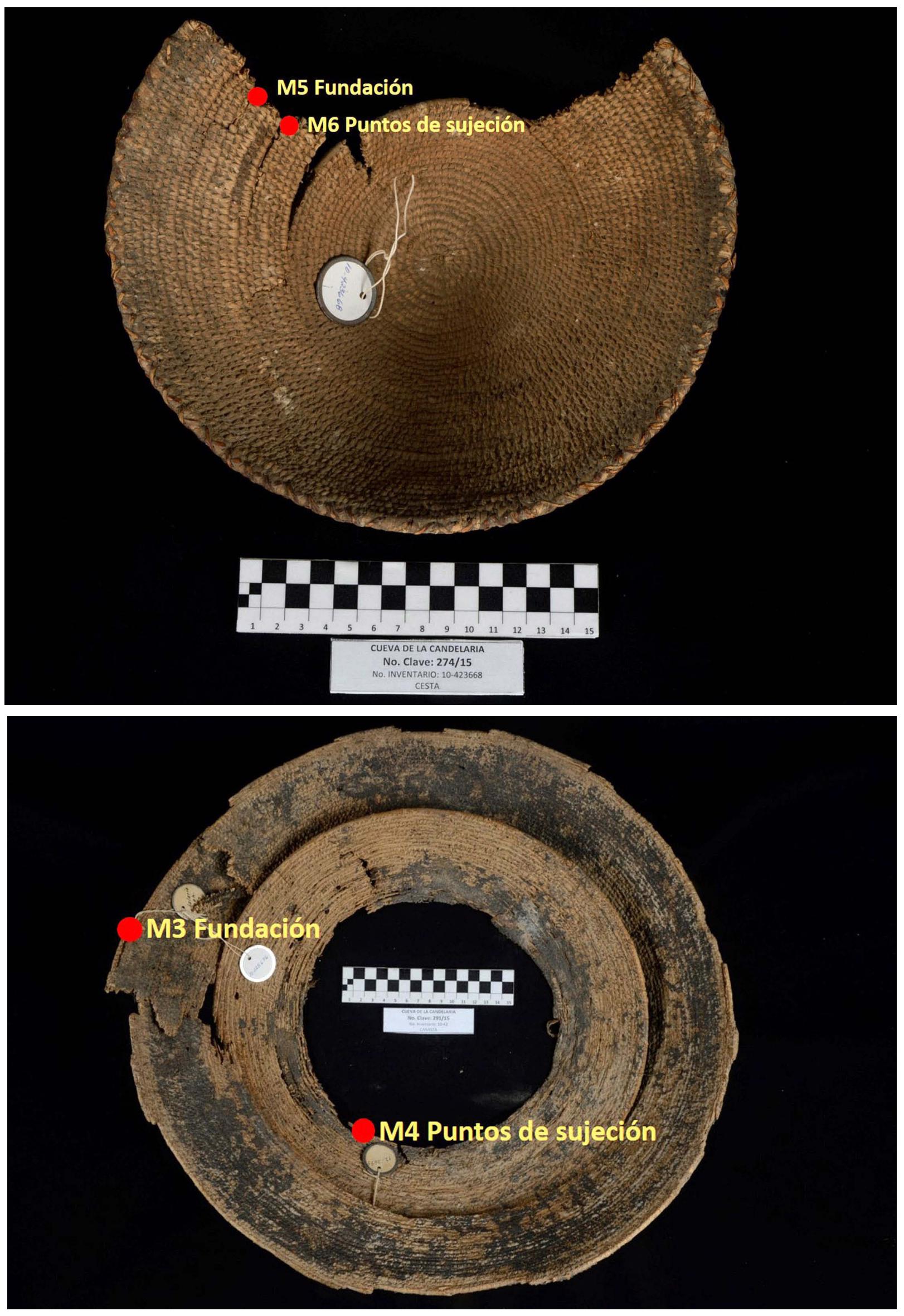


\section{Procesos de conservación y restauración de las cestas estudiadas}

Con respecto a los procesos de conservación y restauración, los bienes fueron intervenidos bajo los siguientes criterios de conservación:

- Respeto a la integridad del patrimonio cultural.

- Soluciones reversibles que permiten la retratabilidad de los materiales.

- Intervenciones reconocibles que se integran visual y estéticamente al bien cultural y que permiten su mejor comprensión a las generaciones actuales y futuras.

- Al ser patrimonio que forma parte de la colección de un museo se buscó resaltar la función didáctica y estética con la intención de proporcionar una visión clara del bien en la mente del interlocutor.

El MUREL cuenta con 62 registros de cestería en la base de datos; la mayoría de ellos son fragmentos y de las 15 cestas que se encuentran más completas, se han intervenido 7 cestas hasta el día de hoy.

Estos objetos experimentaron condiciones de enterramiento y almacenamiento desde su descubrimiento por lo que las fibras se encuentran sumamente resecas, lo que puede explicar la presencia de fisuras, grietas, roturas, deformaciones y pérdida de tejido o material.

Para iniciar el proceso de conservación las fibras se rehidrataron, lo que permitió la manipulación del objeto y ninguna pérdida del material. La hidratación flexibilizó las fibras de manera que se pudieron corregir las deformaciones $\mathrm{y}$ tratar las grietas y fisuras.

La consolidación se realizó paulatinamente usando derivados de polímeros naturales y semisintéticos: mezclas de polietilenglicol-almidón y methocel, en proporciones que se han desarrollado dentro del laboratorio de conservación arqueológica de material orgánico.

Para cerrar las grietas se emplearon injertos de bambú, así como refuerzos y retejidos de papel japonés, y finalmente, en los casos que fue necesario, se realizaron injertos removibles de resina epóxica con el fin de dar estabilidad a las piezas, y reintegrar la unidad estética al objeto.

\section{Conclusiones}

El grupo de cazadores recolectores que habitó en el valle de las Delicias, tenía un profundo conocimiento de su entorno.
Esto les permitió aprovechar los recursos presentes para la selección, recolección y transformación de los materiales.

De acuerdo con la base de datos de los bienes albergados en el MUREL se cuenta con aproximadamente 15 cestas cónicas, elaboradas con la técnica de espiral, de diversos tamaños, pero con las mismas características organolépticas.

El principal deterioro de los objetos se observa en los fondos, dónde la gran mayoría de éstos presenta pérdida de tejido, conservando sus paredes con grietas longitudinales y transversales.

La identificación anatómica microscópica de la planta sangre de drago fue fundamental para determinar la materia prima empleada en la elaboración de estos objetos, así como para experimentar en la reproducción de la manufactura y entender la tecnología cestera de este grupo de cazadores recolectores.

Las similitudes en las propiedades físicas y anatómicas de las fibras xilemáticas de Jatropha cuneata (Torote) y Jatropha dióica (Sangre de Drago), sugiere un aprovechamiento de las plantas del desierto basada en una tecnología ancestral preservada por los artesanos de la nación Comcaác.

El trabajo interdisciplinario permite el acercamiento al conocimiento de los materiales y técnicas que emplearon los antiguos mexicanos, para rescatar nuestra historia, promover y recuperar las tradiciones perdidas. En este ejemplo de interdisciplina, la Conservación no se centra únicamente en hacer perdurar los bienes culturales, la Botánica Estructural tampoco se reduce a la identificación de tejidos vegetales. La reproducción de objetos de la vida cotidiana de este grupo de cazadores recolectores se vuelve una vivencia completa que implica la reconstrucción del pensamiento y la práctica de estos grupos para entender cómo resolver los procesos de transformación de las materias primas para formular soluciones que expliquen el uso, en este caso, de plantas del desierto.

\section{Agradecimientos}

Queremos agradecer todo el apoyo brindado por parte de las restauradoras Adriana Reyes García y Miriam Elizabeth Castro Rodríguez para la elaboración de esquemas y tomas de muestras; así como a todo el equipo del Laboratorio de Anatomía Funcional y Biomecánica de Plantas Vasculares del Departamento de Biología -Universidad Autónoma Metropolitana Iztapalapa; a María Isabel Ambrosio Torres por su invaluable trabajo experimental con las fibras de la planta Sangre de Drago y especialmente a la Dra. Victoria Solanilla por sus atenciones, invitación y apoyo para la difusión del presente trabajo en la 8th Pre-columbian Textile Conference. 


\section{Fuentes consultadas}

Adovasio J. M.;

1977. Basketry Technology: A Guide to Identification and Analysis. Aldine Publishing Company. New York.

Aveleyra Arroyo de Anda, Luis; Maldonado-Koerdell, Manuel; Martínez del Río, Pablo;

1956. Cueva de la Candelaria, Vol. I, Memorias del Instituto Nacional de Antropología e Historia V, INAH-SEP, México.

1964. Sobre las fechas de Radiocarbono 14 para la Cueva de la Candelaria, Coahuila. Anales de Antrpología I, pp. $125-130$

González, Arratia Leticia;

1998. La cueva de la Candelaria, Arqueología Mexicana, Vol. 30, México.

1999. Museo Regional de la Laguna y la cueva de la Candelaria; CONACULTA-INAH, México.

2006. Las cuevas mortuorias de Coahuila; Arqueología Mexicana; Vol. XIV, Número 8o, pp. 61-65.

Johnson Weitlaner, I.;

1977. Los textiles de la Cueva de la Candelaria, Coahuila. Departamento de Monumentos Prehispánicos, Colección Científica, Arqueología, No. 51, INAH, México.
Mansilla Lory, Josefina; Pijoan Aguadé Carmen Ma.;

200o. Evidencia de treponematosis en la cueva de la Candelaria, Coahuila, con énfasis en un bulto mortuorio infantil; Chungara: Revista De Antropología Chilena, vol. 32, no. 2, pp. 207-210. www.jstor.org/stable/27802140.

200o. La Cueva de la Candelaria: Bultos Mortuorios y Materiales; Chungara: Revista De Antropología Chilena, vol. 32, no. 2, pp. 211-215

Pijoan Aguadé, Carmen Ma.; Mansilla Lory, Josefina;

200o. La cueva de la Candelaria: Bultos mortuorios y materiales; Chungara: Revista De Antropología Chilena, vol. 32, no. 2, pp. 211-215. www.jstor.org/ stable/27802141

Sánchez Valenzuela, Gloria Martha; Castro Rodríguez, Miriam Elizabeth; Reyes García, Adriana;

2017. Conservación de cestería en espiral, proveniente de la Cueva de la Candelaria, Torreón, Coahuila: criterios, tratamientos y líneas de investigación. Revista CR Conservación y Restauración, N11/12, abril-agosto 20017, pp. 115-129, Revistas INAH-CNCPC, CDMX. 


\title{
12
}

\section{Signos comunes en los textiles Andinos y los Mesoamericanos}

\author{
Victoria Solanilla \\ Universidad Autonoma de Barcelona
}

\section{Resumen}

Entre los recientes estudios sobre textiles Andinos, comienza a ser frecuente encontrar quienes se dedican a describir además de las técnicas, sus iconografías. Como eran sociedades ágrafas, nos hace pensar que con aquellas imágenes nos quisieron dejar su historia y pensamiento.

En el caso de Mesoamérica, se podría decir lo mismo de las técnicas e imágenes, pero en este caso, las sociedades que los tejieron sí tenían manera de comunicarse a través de sus lenguajes escritos. No se han conservado tantos tejidos a causa del clima por las condiciones no favorables para la conservación de materiales orgánicos, pero tenemos muchos ejemplos de figurillas de cerámica, de piedra o de grandes esculturas que nos muestran cómo iban vestidos y por lo tanto, como eran sus tejidos.

Esta ponencia pretende estudiar los casos de imágenes tejidas que se encuentran en ambas zonas geográficas y su significado.

Palabras clave: Textiles, Mesoamérica, Zona Andina, Iconografía, signos comunes.

\section{Abstract}

It is increasingly common to find recent studies on Andean textiles that look further past weaving techniques and that interestingly dig into iconography and their descriptions. The fact that Andean civilizations were preliterate suggests that these iconographies were meant to bequeath both their history and thought to succeeding generations.

Interestingly, some similar weaving techniques were found in Mesoamerica. And again we find the same intent in their images, even though they did have an alternative way of communicating through their written alphabets.

Not many Mesoamerican textiles have made it to the present day due to their location and climate. Still, a large number of ceramic figurines, stone figurines and larger sculptures have been found, which depict how their people dressed and subsequently what their textiles looked like.

This presentation aims to present a number of woven images found in both geographical areas (Andean and Mesoamerican), their iconographies and common traits.

Keywords: textiles, Mesoamerican, Andean zone, iconography, common traits

\section{Résumé}

Dans les récentes études sur les textiles andins, il est maintenant fréquent de trouver celles qui se dédient à décrire en plus des techniques, l'iconographie. Comme il s'agit de sociétés sans écriture, cela nous fait penser qu'à travers ces images ils ont voulu nous laisser leur histoire et leur pensée.

Dans le cas de la Méso-Amérique, nous pouvons dire la même chose des techniques et des images, mais dans ce cas, les sociétés qui les ont tissés avaient aussi comme moyen de communication leurs textes écrits. Peu de textiles ont été conservés à cause des conditions non favorables pour la conservation des matériaux organiques, mais nous avons de nombreux exemples de figurines en céramique, en pierre et de grandes sculptures qui nous montrent comment ils étaient revêtus et du moins comment étaient leurs tissus.

Cet article prétend étudier les cas des images tissées qui se trouvent dans les deux zones géographiques et leur sens.

Mots-clés: Textiles, Méso-Amérique, zone andine, iconographie, traits communs. 


\section{Introducción}

Los estudios actuales de textiles Andinos, se dedican a describir además de las técnicas con las que estaban hechos, sus iconografías. Si el primer punto es importante para saber los diversos tipos de técnicas textiles, el segundo no lo desmerece puesto que nos indica cómo era el mundo terrenal o el sobrenatural que los rodeaba. Al ser sociedades ágrafas, nos hace pensar en que con aquellas imágenes nos han querido dejar parte de su historia y pensamiento.

En Mesoamérica, se podría decir lo mismo de las técnicas e imágenes, pero en este caso, las sociedades que los tejieron si tenían manera de comunicarse a través de sus lenguajes escritos. A causa del clima y las condiciones no favorables para la conservación de textiles, no se han conservado tantos tejidos, pero tenemos muchos ejemplos de cómo vestían en figurillas de cerámica, de piedra o de grandes esculturas, así como en los dibujos de los Códices indígenas que nos muestran cómo iban vestidos y por lo tanto, como eran sus tejidos. (Filloy, 2017:7).

La región andina durante el largo proceso de desarrollo sociocultural logró amalgamar un extenso campo ideológico, que comportó la aparición desde períodos muy tempranos (período Arcaico Temprano: 8500 A.P. aprox.) de una religión consolidada, con un panteón politeísta, basada en la veneración de múltiples dioses de carácter naturalista, cuya máxima expresión, ya desde el Arcaico Tardío, se centró en el culto al dios de los báculos, ampliamente expandido por la cultura Chavín (período Formativo, 2000-500 a.C.), representado por la trilogía: aire (águila- arpía), agua (caimán) y tierra (serpiente y jaguar) ${ }^{1}$. Se sabe que esta divinidad «modernizada» aparece luego en la Portada del Sol de Tiahuanaco, para hacerlo más tarde en el Tahuantinsuyu, convirtiéndose en Wiraqocha. Era la divinidad universal.

Sin embargo, además de estas divinidades existían muchas otras de carácter regional, que eran adoradas en grandes extensiones territoriales, abarcando el ámbito de varias culturas. Entre estas tenemos a Pachacamac en la costa central, y Pariacaca, dios de la lluvia, entre muchas otras.

El sistema de culto religioso estuvo a cargo de un cuerpo jerárquico de sacerdotes andinos, encargados de dirigir el culto a huacas, santuarios, ídolos, mallquis, etc. Entre este cuerpo especializado de sacerdotes, se encontraron personajes de múltiples orígenes que consiguieron llevar a cabo toda una serie de rituales dirigidos a sus dioses, en los que los tejidos eran motivo principal.

Este mismo relato, se podría aplicar a las culturas de Mesoamérica, puesto que su cosmología también se centra en tres ámbitos verticales, como en los Andes: cielo, tierra e inframundo, con seres animados (animales) que habitaban estas zonas. La interacción entre los Mesoamericanos fue de naturaleza económica, política, religiosa y también cultural. De esta última surge una tradición cultural común, formada por Olmecas, Teotihuacanos, Mayas, Zapotecas, Mixtecas, Toltecas y finalmente Mexicas, que se dieron en tiempos y lugares distintos de Mesoamérica. Poseyeron pues una visión del mundo, religión y mitología comunes. También se inició en momentos tempranos como decíamos más arriba de la Zona Andina, hacia el 6500 AC cuando se comenzó a domesticar el maíz y a iniciar la agricultura. Cada cultura pues, mantendrá sus principios durante largos períodos de tiempo, que se repetirán como patrones normativos de los que muchos de ellos llegarán hasta nuestros días.

Viendo las diversas cosmovisiones y mitologías mesoamericanas, nos damos cuenta de que debemos tener una actitud abierta hacia un universo animado, en el que todo tipo de seres vivos, los elementos del paisaje y los fenómenos naturales están embebidos de un poder o fuerza invisible. Esta fuerza puede ser amorfa, pero a veces puede estar personificada en una deidad particular, que puede tomar forma humana o animal. Tomando una cita de SHARER (1994:514) nos dice:

\section{"El mundo es considerado un espacio ordenado y el orden se deriva de los movimientos previsibles de los astros que marcan el paso del tiempo. Los cuerpos celestes y el tiempo mismo, se conside- ran animados. El destino humano está ligado al de los cuerpos celestes".}

Por lo tanto, cuando el hombre toma algo de la naturaleza, debe dar algo igual a cambio. Respetar a los dioses (ofrendas, alabarlos y apaciguarlos si llegara el caso). Es a través el rito y las ceremonias que lo consigue; gracias a la acción de los sacerdotes.

Y en el caso de Mesoamérica, los dioses creadores que aparecen en los Códices tejiendo, explica claramente "el carácter primigenio y axial del acto de tejer. Y Tejer, en su dimensión simbólica, es una acción fundacional. A través del tejido, los dioses crean y dotan de orden el mundo" como afirma Alberto MORALES (2009:98).

Observando los diversos materiales de ambas zonas (textiles, cerámicas, esculturas...) se pueden apreciar signos que se repiten a ambos lados del continente Americano. Este hecho hace pensar pues en una relación entre ambas partes. Rieff Anawalt (1992:114) afirma que:”

1. Beatriz Barba de Piña Chan (Coord.)(200o) “Iconografía mexicana II. El cielo, la tierra y el inframundo: águila, serpiente y jaguar”. INAH. En esta publicación, se recogen una serie de artículos sobre esta temática, que se presentaron en el Seminario de Iconografía Mexicana, organizado por la UNAM y el INAH. 
El estilo del vestido, los diseños decorativos $y$ las técnicas de producción ilustrados en los códices, la cerámica y en fragmentos de tejidos, sugieren la difusión de elementos culturales de la costa norte de Sudamérica a la parte oeste de México y al suroeste de los Estados Unidos. Los trajes de origen no-mesoamericano ilustrados en un manuscrito del siglo dieciséis (relación de Michoacán), proveniente del oeste de México, y los mostrados en figuritas depositadas en tumbas más de un milenio antes, tienen parecido con los estilos del vestido presentes en Ecuador desde 1500 A.C. hasta el momento del contacto con los Españoles. La ropa y los diseños decorativos representados en las tumbas en forma de bota de Ixtlan del Rio, en Nayarit, indican que estos paralelos existían tan temprano como 400 A.C. Otra información diversa sugiere que hubieron persistentes contactos marítimos entre el Ecuador y el oeste de México durante todo este período y que continuaron hasta el siglo dieciséis”

A partir de esta rotunda afirmación de Anawalt, encontramos otros estudiosos que trataron este tema de las relaciones prehispánicas entre el norte de Suramérica y el oeste de México, vía Pacifico. ${ }^{2}$

\section{Signos comunes}

EL MEANDRO ESCALONADO (Zona Andina) (TIERRAAGUA). XICALCOLIUHQUI (Mesoamérica) (fig. 1)

xicalcoliuhqui. (Voz náh., de xicalli, jícara y coliuhqui, torcido, curvo). Mit. V. Greca escalonada...

Fray Bernardino de Sahagún comenta que el Xicalculiuhqui es uno de los motivos que lucen las faldas de las mujeres nobles ${ }^{3}$. También encontramos otro testimonio en el Códice Magliabechiano 4 de una manta con esta figura. El escribano dice: "Manta de xícara tuerta".

Beyer (1924:80) en su estudio específico de la greca escalonada dice: "Respecto a riquezas y hermosura de las formas, el meandro mexicano no pide favor al griego; hasta se puede afirmar que éste tiene un aspecto severo, rígido, frío, en comparación con el ornamento mexicano, de carácter

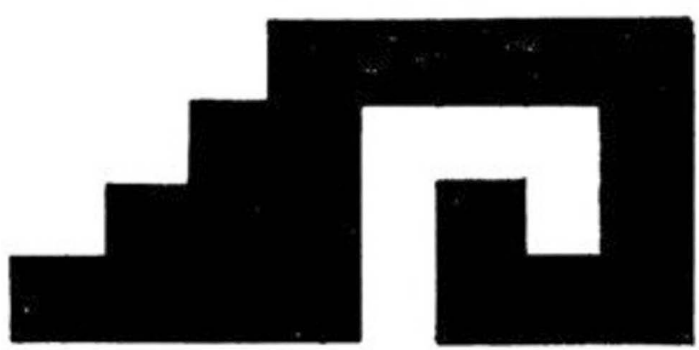

Figura 1. Meandro escalonado (Zona Andina). Chavin (hasta 8ooaC.). (con permiso de U. Carlson 2010:8).

más suave y ameno". Es curioso que este autor no hable de su significado sino de cómo fue hecha, escultóricamente. Para él fue un mero elemento ornamental. Aceptó una cierta significación en la época Preclásica, pero a medida que se avanzó en el tiempo, se convirtió en un elemento puramente decorativo (Postclásico).

En cambio, Caso (1992:37) en su estudio completísimo de este signo afirma:

"La greca escalonada es para la plástica prehispánica lo que el capitel para la cultura griega, o el arco ojival para el arte gótico. Es un símbolo que se ha encontrado desde Arizona en los Estados Unidos de América, hasta Perú y Argentina en el sur del continente."

Y esta afirmación refuerza nuestra creencia de que hay signos en Amerindia que son comunes a todas las partes. También dice que su significado es diverso, de las más sencillas (serpiente estilizada o corte transversal de un caracol marino) a las complejas (ideas cosmológicas). Pero Caso termina afirmando que para él, la greca escalonada representa en sí misma una dualidad de elementos antagónicos, la escalera y la espiral, que son opuestos polares inseparables como los polos de un imán o las caras de una moneda.

En un completo estudio sobre los diseños que se encuentran en la vestimenta de las "figuras sonrientes" de la Costa del Golfo, (Huckert 2006: 112-116) documenta principalmente la greca escalonada y la clasifica en cuatro tipos diferentes, según la distribución o modelo de las mismas en

2. Meighan: 1969 design motifs; Swadesh: 1967 language; Lapiner 1976:344. Donde cita gran cantidad de figuras humanas de cerámica encontradas en Los Esteros (Costa de Ecuador, fase Bahia (500 B.C.-100 A A.D.) . Afirma que estas esculturas huecas, llevan pendientes de múltiples anillos, como los que llevan las figuras de Ixtlan del Rio. Y también habla de otros paralelos, en las decoraciones geométricas que representan telas policromas, y en las formas y decoraciones de las faldas.

3. Primeros Memoriales (1993), fol.56r; 1997:205. Xumoiuiuipilli xicalculiuhqui cueitl quinamiqui: "Blusa de pluma de pato y falda con el diseño del meandro escalonado"

4. (1970, fol.6) 
las faldas. Hace referencia a la calabaza en forma de botella que riega y fertiliza, así como a seres ofidios celestes y acuáticos y también a figuras de agua. ${ }^{5}$

Respecto a la difusión que ha tenido este símbolo del meandro escalonado en la Zona Andina, tenemos muchos ejemplos de todas las diversas culturas que formaron parte de esta región durante muchos siglos. Parece que su plasmación fue en la zona septentrional andina, mostrándose sobre la base de estos dos elementos con gran variedad de representaciones: en forma dual o múltiple, relacionadas directamente con la imagen de la divinidad o solas, y formando patrones concretamente en los textiles. (Fig.2)

En el estudio de las piezas de la Colección Maiman ${ }^{6}$ en el vol.I de la Catalogación, se puede ver representado este

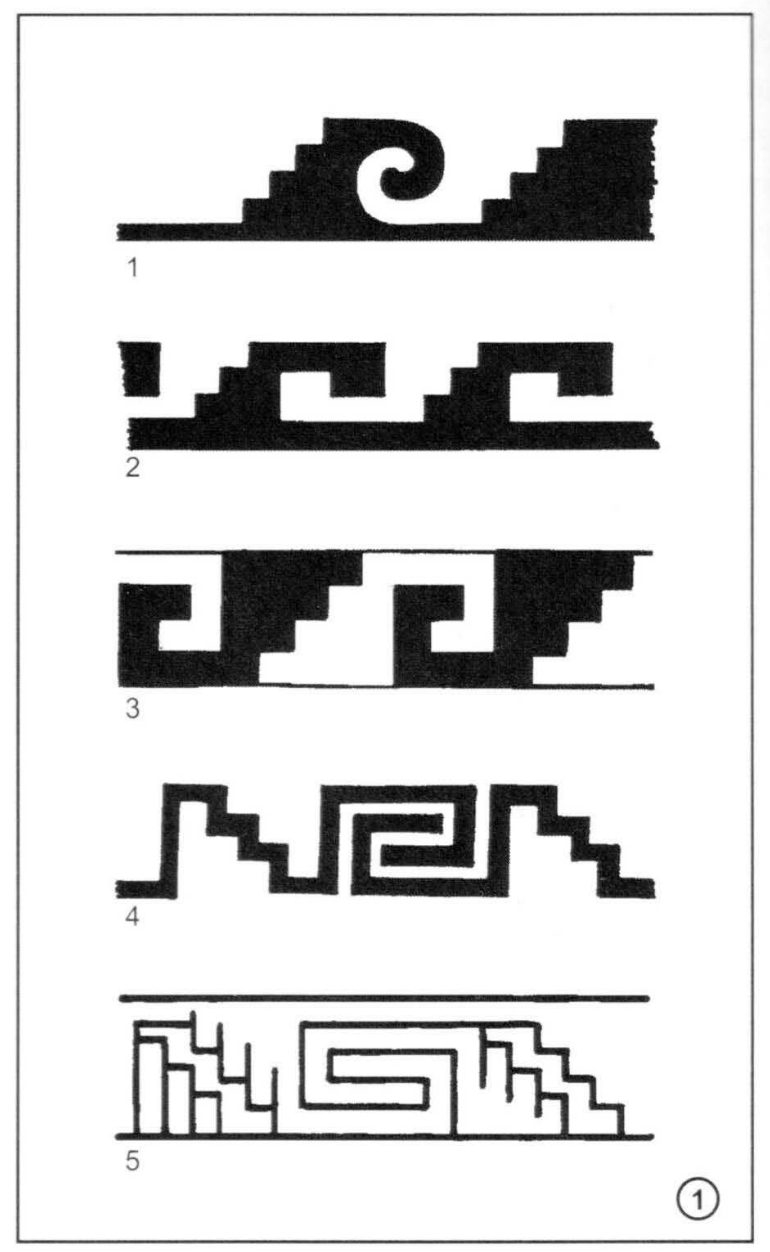

Figura 2. Difusión meandro escalonado en la Zona Andina. 1. Decoración mural, Huaca Choltuna, Lambayeque. 2. Tejido Moche. 3. Tejido Pachacamac. 4. Cerámica Recuay. Cerámica Nasca. (Con permiso de U. Carlson 2010:10). signo (stepped frets) en el período Intermedio Temprano (2006:71)-Moche; Horizonte Medio (2006:106)-NazcaHuari; en el Periodo Intermedio Tardío (2006: 132)Lambayeque con influencia Chimú; Chimú Antiguo (2006: 144); Chimu-Inca, estilo Pelícano (2006: 165).

Laurencich Minelli (1984:55/1984:138). Intermedio Tardío. Costa Centro-septentrional. Les llama "voluta escalonada". (1984:136) en que se ve una pequeña bolsa que tiene como motivo decorativo una única greca escalonada que ocupa toda su superficie.

Uwe Carlson ((2010:9) afirma que Kauffmann Doig "presume que en Mesoamérica estos signos (tierra/agua) pudieron tener igual significado que en el Perú" porque en aquella zona también se luchaba por la subsistencia de manera importante, ya que las lluvias eran cada vez menos frecuentes debido a la deforestación cada vez mayor de los bosques y porque aquel territorio tiene áreas claramente poco propicias para la agricultura.

Representa pues la fertilidad: forma escalonada -terrazas de cultivo (andenes) que se combina con la ola estilizada. Sobre este aspecto, volvemos a citar a U. Carlson (2010:11) donde dice que" este símbolo o en ocasiones una parte, se convirtió en un símbolo de identificación y en una característica”. Y añade que con su ayuda es posible interpretar una gran cantidad de representaciones en los tejidos. (Fig. 3)

Un estudio de Carlson (2014:11) propone que el meandro-escalonado de las cerámicas Chavín se representó hasta aproximadamente el 800 a.C. y representaba el simbolismo religioso. Y más tarde, a criterio de los sacerdotes y puesta en práctica por los artistas, pasó a primer plano el simbolismo del meandro-serpiente. Y desde esta cultura Chavín

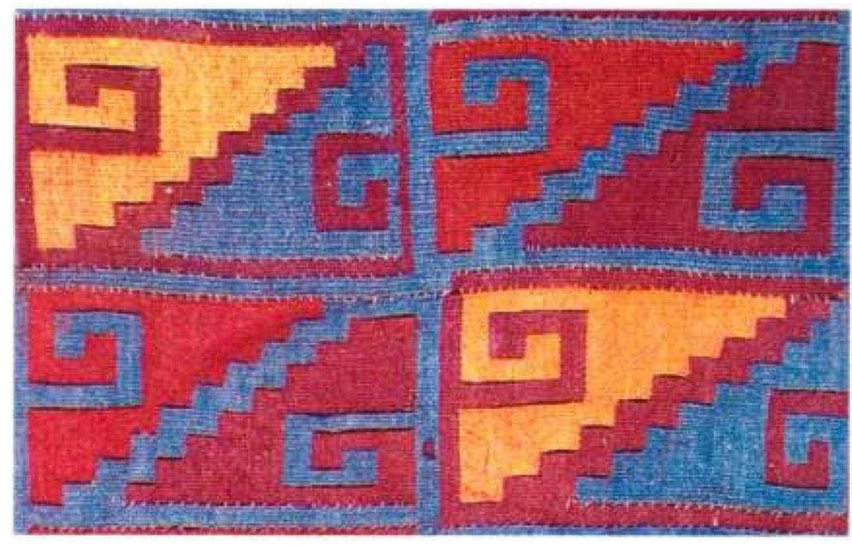

Figura 3. Forma escalonada = terrazas de cultivo. Más la ola estilizada. (Con el permiso de U. Carlson 2010: 19/ 2010:22/ 2010:47).

5. Códice de Madrid (1970: fol.3ob). Diosa O, demiurga maya de las lluvias. Viste una falda diseñada con bandas de agua y el diseño del Xicalcoliuhqui.

6. Makowski K, Rosenzweig A , Jiménez M.J. Weawing for the Afterlife (2006) 
que aplicó claramente los dos tipos de meandro correlativamente, se produjo una diáspora a otras culturas posteriores. (Fig. 4).

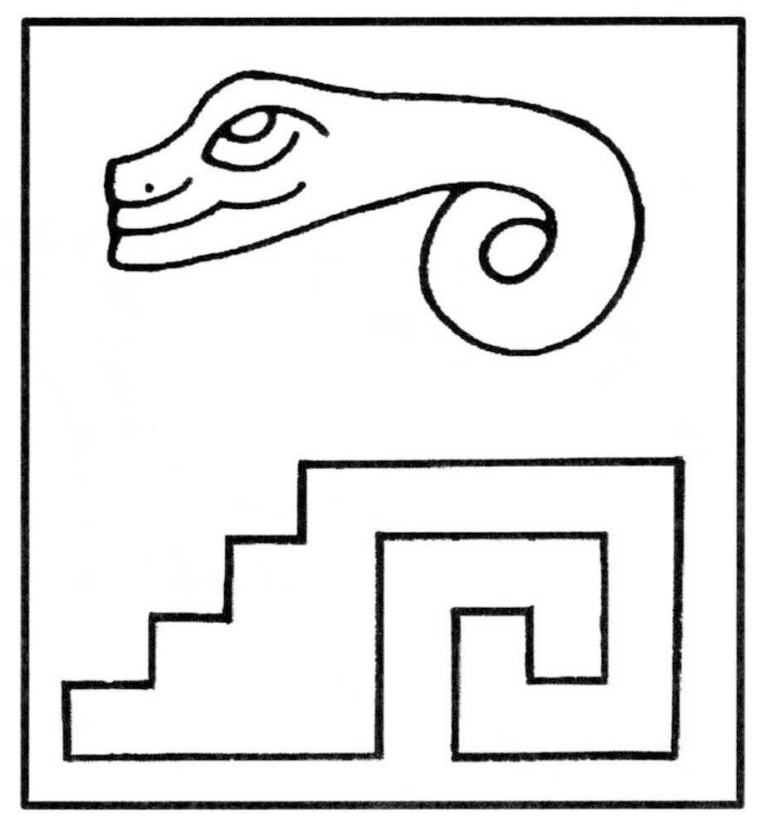

Figura 4. Meandro escalonado-meandro serpiente. (Con el permiso de U.Carlson 2006:11 )

\section{Simbolo de la "S" horizontal (nube)}

De este signo, encontramos muchos ejemplos en ambas zonas: tanto en Mesoamérica (en figurillas, pinturas murales y códices, principalmente) como en la Zona Andina (textiles).Puesto que eran culturas que tenían la agricultura como principal sustento, es lógico que con este diseño pidieran a sus dioses, la llegada de la lluvia que les fertilizara sus campos.

Podemos dar varios ejemplos que sustentan esta teoría.

Glifo maya “muyal” (nubes). Las formas en S desde el Preclásico Medio, describen nubes. Relieve 1 de Chalcatzingo. "Señor de la Tierra" o ·Señor del Cerro" (Montoya 2003:110).que es un grabado de tamaño natural en el que se observa a un hombre sentado en el interior de una cueva. El punto de vista de la escena es lateral, de modo que la caverna es representada más bien por un corte transversal que, además, es la representación de las fauces de un jaguar. La entrada a la cueva se localiza frente al personaje sedente, a la derecha de la imagen. De ella salen volutas (quizá indicando que el hombre está hablando o haciendo alusión al viento). Sobre la caverna se encuentran representados unos objetos estilizados que parecen ser nubes, de ellas caen gotas de agua. En la cueva, una persona con gran tocado se ubica en un trono de piedra. Sostiene un objeto rectangular con volutas (eses horizontales) con ambas manos, frente al pecho. Esta actitud se encuentra con frecuencia en representaciones olmecas.

En el glifo 632 del Códice Trocortesiano (D. Dupiech Cavaleri, 2016:201) afirma que la "S" también aparece como afijo del glifo del sol y del cielo. Dice que son nubes que traen la lluvia y fertilizan la tierra

En las "Bandas celestes” que aparecen en los bordes de los huipiles de las damas de la corte en monumentos del Período Clásico"( Montoya 2008:113)se encuentran diversos diseños entre los que está el "motivo nube" y la "Voluta (greca) escalonada). Principalmente en las estelas y dinteles de Yaxchilán. Están formando el marco de una escena. Lo envuelven. Ejemplo: la lápida funeraria de Pakal. Estas imágenes que forman la banda, adornan el cuerpo de la serpiente cósmica, estaban divididas en segmentos decorados con diversos símbolos entre los que se encuentran los antes citados. (Schele \& Miller, 1992:t282).

\section{Grecas en espiral}

Makowski et alt.(2006:192-193). Las grecas en espiral pueden representar las olas del océano, dibujadas frecuentemente en el arte de la Costa Norte del Perú.

\section{Animales}

\section{Los animales en la cosmovisión mesoamericana y andina}

El hombre de las sociedades antiguas (cazadores, pastores o agricultores) consideraba que los animales tenían una relación especial con lo divino, lo que les concedió un lugar importante en los mitos y en las leyendas; los convirtió también en representaciones de las ideas fundamentales de la cultura. Esta visión prevalecía en toda Mesoamérica y también en la Zona Andina.

Toda la iconografía mesoamericana está llena de figuras de animales que aparecen completos, solos o con algunos de sus elementos, como pueden ser las garras, la cabeza o las orejas, que aportan ciertas características a los dioses o a lo que están transmitiendo. Esta tendencia a tomar como fuente de inspiración las cualidades que tienen o se atribuyen a los animales es universal.

Es indudable que son precisamente los animales que comparten el hábitat de determinado grupo humano los que serán tomados como modelos, aunque a veces se recrean animales de los que se ha oído hablar vagamente, pero nunca se han visto. 
El uso simbólico de los animales en Mesoamérica y en la Zona Andina es sumamente amplio, quizá como en todas las culturas no industrializadas del mundo, pues como se ha mencionado, es la forma de encontrar al otro.

De los animales que están plasmados en los tejidos, destacan los felinos cuyo protagonista es el jaguar. Se encuentran en casi todas las culturas amerindias. Éstos se podrían englobar dentro de los animales: cuadrúpedos o de pelo; junto con los que vuelan o de plumas, y los que se arrastran con piel de escamas. En cambio los peces no desempeñaban un papel importante en la cosmovisión mesoamericana y si lo tenían en la Zona Andina, puesto que se creó una gran fuente de riqueza con la pesca, y así lo testifican los textiles.

\section{Felinos}

Jaguar

Simbolizaba la noche y el poder nocturno. Era el animal por excelencia, sobre todo de los chamanes y de los hombres de poder, como los reyes y los sacerdotes. El jaguar, ciertas aves y las serpientes sintetizaban lo más significativo de la naturaleza y de alguna manera cubrían los órdenes más importantes.

El maíz es la semilla vinculada al supramundo. El cacao es la semilla por excelencia vinculada al inframundo; entonces, el cacao está asociado al poder de los gobernantes. El jaguar está vinculado a los hombres del poder (a los del poder del inframundo).

Los jaguares son los que desestructuran, los que crean el caos. Porque este caos es esa otra parte de la realidad; está en el inframundo; es oscuro, salen de la norma.

El jaguar como el gran progenitor "como el padre" está en el fin de los tiempos y en el proceso de renovación siguiente, pues antes se veía así: de manera cíclica. Está en el principio y el final de los tiempos. Es el que reestructura los tiempos.

Makowski et alt. (2006:183) Felino, probable jaguar, pero con cabeza "añadida" (Stone-Miller 1992. To Weave for the Sun... Catálogo Maiman(2006:202) Felinos que tienen la cabeza de frente y una soga que les cuelga del cuello. Muy claras las manchas del cuerpo. Cortez Billet (1998)7 argumenta que en la Cultura Chancay, los felinos son animales totémicos, asociados a las fuerzas de la tierra y al poder. Durante el Periodo Intermedio Tardío, el felino se convirtió en una deidad secundaria, asociada a los dioses principales de este período. Laurencih Minelli (1984:57) felinos que tienen colas enrolladas que recuerdan la serpiente, tejidas a la derecha o a la izquierda alternativamente. Periodo Intermedio Tardío: Costa Centro-Meridional.(1984:70) es el mismo caso. (1984:67) En este caso son 12 felinos de cuerpo manchado, echado y mostrando sus dientes. Época Ica-Inca.

Carlson (2010:12) propone que el felino

"en su apariencia fascinante, muy superior a las propiedades del ser humano, representaba en otros centros de desarrollo Formativo del Perú, a un dios o demonio poderoso con afinidad al agua”.

Queda claro pues que el deseo de fertilidad respecto a plantas, animales y al hombre era su primera preocupación tanto en la Sierra como en la Costa de la Zona Andina en general. Esta preocupación y esperanza a la vez, fueron siempre los elementos fundamentales de su religiosidad. La falta de agua y/o el exceso de lluvias destructoras, siempre se solventaban con oraciones a sus dioses. El culto pues, se expresaba de varias maneras y se reflejaba en la piedra, el metal, y principalmente en los tejidos. Esta es pues la razón que se encuentren fragmentos textiles con las imágenes del felino desde épocas muy tempranas (Garagay, La Galgada, Caballo Muerto), como expresión del culto a la fertilidad (fig.Tejido probablemente Callango) (Fig. 5a). Y a continuación, en Chavín se encuentra su continuidad que no parará hasta los Incas. Veremos la combinación de felino y signo agua/ tierra en textiles tan interesantes como en este del Valle de Santa (fig. Textil y relieve de Recuay) que tiene un claro paralelo en un relieve de piedra (s.I d.C.) del mismo lugar. Son pues representaciones dualísticas, muy frecuentes en la Zona Andina. (Fig. 5b)

\section{Zorro}

\section{Zorro celestial y Plantas Cósmicas.}

Hay una tradición Andina que habla de un zorro con su cría en su boca y un ave. Itier ${ }^{8}$ en su artículo explica que este zorro que viaja al Mundo Superior sobre las alas de un cóndor, para participar en un banquete celestial, proporciona una explicación cosmológica del origen de las cosechas en los Andes. El zorro glotón se comporta tan mal que hace una larga cuerda de ichu hasta que encuentra a los loros. Como que los ridiculiza, los loros empiezan a picotearle la cuerda hasta que se rompe y cae a la tierra. El cuerpo del zorro revienta, esparciendo semillas, raíces y frutos por toda la tierra. Todo esto crece hasta llegar a convertirse en las cosechas de los Andes: cereales, patata y quinoa.

7. Cortez Billet,V. Arte Chancay. Concepción ritual del Mundo. En: Contemporaneidad del Arte Chancay, Lima, COSAPI.

8. Cesar Itier. "El zorro del cielo: Mito sobre el origen de las plantas cultivadas y los intercambios con el mundo sobrenatural”. Bull.IFEA,26,nº 3 . 1997. pp.308-328. 


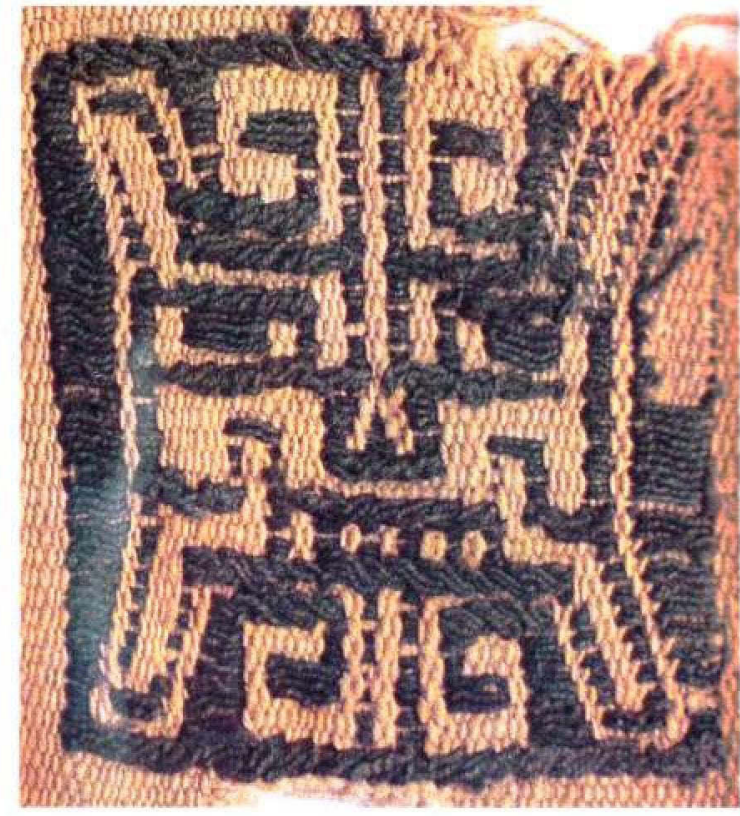

Figura 5a. Tejido probablemente Callango.(Con permiso de U. Carlson 2010: 14).

En Mesoamérica también está profusamente representado tanto en textiles como en los Códices. En el Códice Borgia aparece en forma de personaje vestido con traje ceremonial de jaguar ${ }^{9}$; también en el Códice Cospi, Códice Laud, Códice Fejérvary Mayer y Códice Vaticano B entre otros. En el mundo maya es recurrente, entre la vestimenta de los grandes personajes (príncipes, reyes o sacerdotes), cuando realizaban sus ceremonias. Por lo tanto, este felino era común en el territorio mesoamericano, convivía con otros animales y era relativamente fácil poderlo ver en sus selvas, junto a los ríos, durmiendo de día y atacando de noche.

\section{Aves}

Los pájaros han sido motivos textiles con frecuencia tanto en Mesoamérica como en la Zona Andina. En la primera, están pintados en sus Códices prehispánicos y coloniales principalmente. En la segunda, son tejidos con tanto esmero, que se puede saber muchas veces de qué ave se trata. Formaron siempre parte de su día a día. Y son exclusivamente aves marinas. Sus representaciones se sitúan en ribetes o esquinas de mantos; y también como motivos secundarios en otras representaciones de hombres o animales. (Fig. 6). Y se podría dar el caso de que estas aves eran adoradas porque su presencia prometía una buena pesca (son el indicador
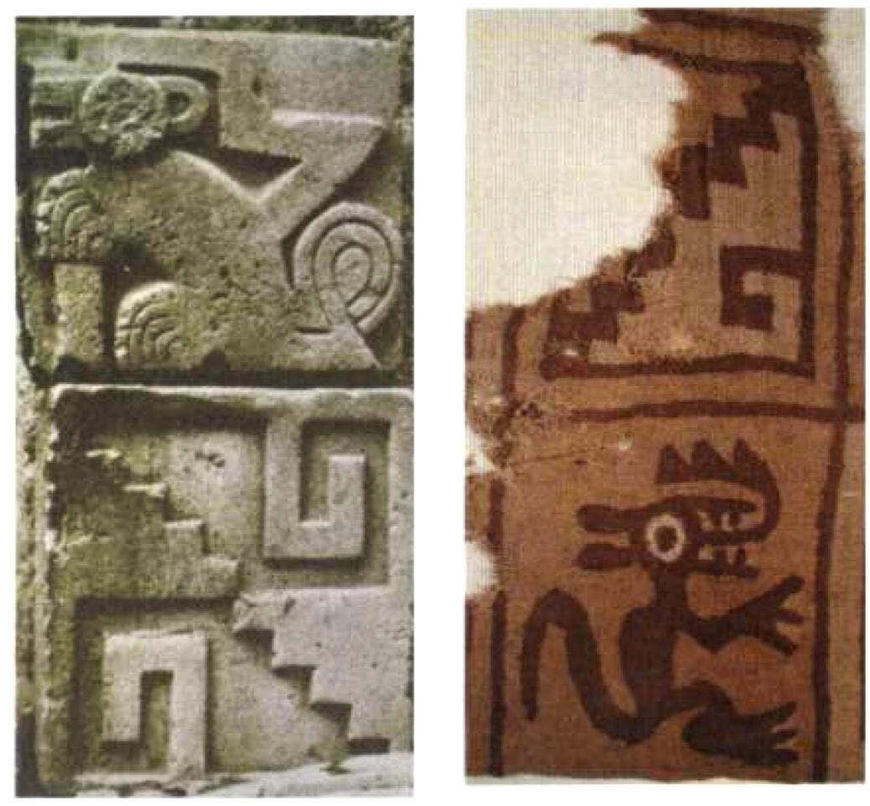

Figura 5b. Relieve de piedra (Recuay) y de tejido pintado (Costa Norte) donde se combinan para indicar los elementos agua y tierra (con permiso de U.Carlson 2010:15).

de la riqueza de la fauna marina). Por lo tanto, si no habían peces tampoco aves. Y por lo tanto, se adoraban para propiciar esta pesca. Por esta razón en textiles donde haya imágenes divinas acompañas de aves, éstas tenían un lugar específico que no era estético sino simbólico. "Eran mensajeras de las divinidades" (Carlson, 2010:43).

La golondrina, el halcón y el cóndor: son aves importantes y muy representadas en los tejidos, debido especialmente a su papel de progenitores en la mitología peruana.

Makowski et alt. (2006:214). Se trata de pelícanos muy frecuentes en la Costa peruana, a punto de volar o aterrizar. Costa Central, estilo local. (2006:116) El pelicano es una deidad secundaria en la Cultura Chimú. A pesar de ello, en este textil es un pelicano real de ancho cuerpo, puesto que lleva colgando del pico un pescado (corvina o un lenguado). Vivian en las islas de guano, era uno de los productores más importantes del mismo, y se usaba como fertilizante.

Laurencich Minelli (1984:51) también se representa un pelícano con algún objeto redondo que no parece un pez, colgando de su pico. (1984:88) en que aparecen cormoranes que son unas aves palmípedas marinas que viven cerca de la costa. Otros estan estilizados (1984:89) y no se puede precisar de qué pájaro se trata. O bien son papagayos, perfectamente tejidos (1984: 97). 


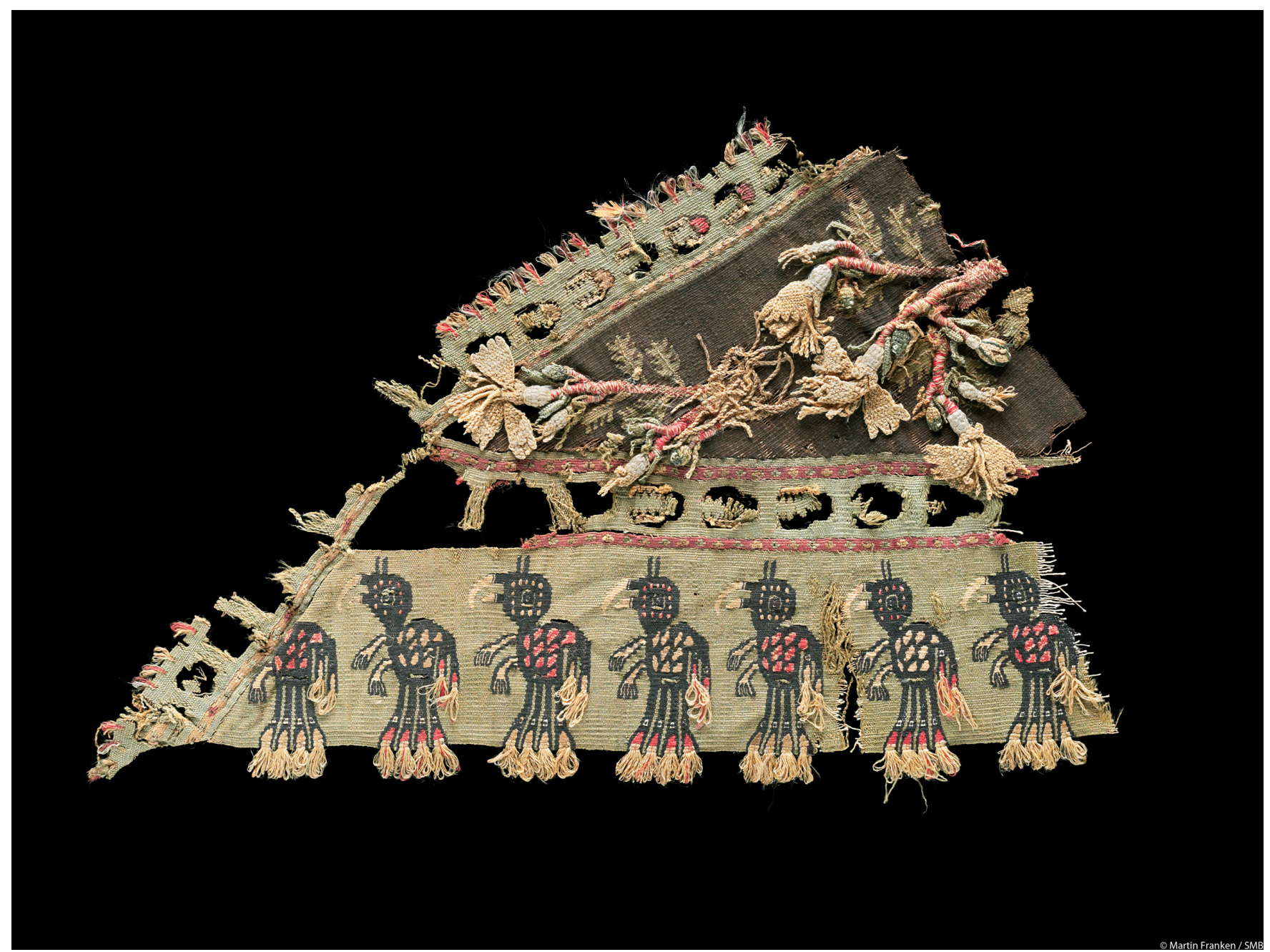

Figura 6. Pájaros (Picaflores). Staatliche Museen zu Berlin, Ethnologisches Museum, V A 58040, fotógrafo: Martin Franken.

\section{Serpientes}

También se encuentran profusamente representadas en ambas zonas: Mesoamérica y Andina. Es el animal terrestre por excelencia y desde los primeros tiempos. Convivían también con ellas y los dibujos de su piel, variados y bellos, les abrían nuevos campos de expresión artística como tejerlos en sus textiles, de uso diario, funerario o ceremonial.

En Mesoamérica, fue el que tuvo más complejidad de símbolos. Ya se encuentran fragmentos de textiles en la Cueva de la Candelaria, Coahuila, en los que se ha representado los dibujos de su piel ${ }^{10}$, pasando por Teotihuacan, donde simboliza el poder político, y también en el mundo Maya, donde por ejemplo, en Chichén Itzá está plasmada en sus muros $^{11}$, con una precisión extraordinaria. Y finalmente en los Códices, donde aparece la serpiente de cascabel (Crotalus sp) dibujada en los trajes de algunos de sus dioses. Ejemplo de ello, es la falda de Coatlicue. Y ya no digamos en Quetzalcóatl, la serpiente emplumada.

En la Zona Andina, también es frecuente que adorne ciertos tejidos desde los comienzos de su historia, hasta el final. Está representada en todas las épocas. Dobles serpientes en Makowski et alt._(2006:122-124). Es una S vertical que termina con dos cabezas de serpiente. Afirman que este motivo iconográfico está muy bien documentado en otros textiles de la Costa Sur. Frame (1984) dice que la iconografía de la serpiente en los tejidos, produce imágenes lineales y flexibles. En este caso, las serpientes con doble cabeza derivan de la estructura del tejido retorcido. Laurencich Minelli (1984:74/ 1984:76-77) muestra serpientes de doble cabeza en un textil 
del Periodo Intermedio Temprano y otros del Intermedio Tardío (Costa Central Perú) respectivamente. En estos textiles aparecen en sentido vertical (S), alternando sus colores.

\section{Simbolo de la "s" vertical}

Makowski et alt. (2006:188), La S del borde (banda) de la tela puede ser una repetición del mismo motivo de manera simplificada, o puede referirse a otro motivo generalizado desde el Período Pre-cerámico, el de la serpiente de dos cabezas con un cuerpo en forma de $\mathrm{S}$.

\section{Flores y plantas}

Sahagún (1982) afirma que los pueblos prehispánicos desarrollaron sus culturas en estrecho contacto con la naturaleza. De la flora y la fauna obtenían su alimento, vestido y curación. Y además muchos animales y plantas tenían valor y significado mítico-religioso.

Lot (1983) cita toda una serie de autores que interpretaron representaciones botánicas en documentos antiguos y en el arte $^{12}$. Se han encontrado el nopal, las flores de maguey, biznagas, todas ellas cactáceas. También el Dondiego de día, lirio de agua (nenúfar), atlacuetzon (flor de yerba de agua) como flores. Y plantas de calabaza, plantas de maíz y mazorcas y planta del cacao. Luna (1996: 38) "Las representaciones de flores o plantas tenían como propósito esencial evocar conceptos como fertilidad, lo sagrado. Muchos elementos fitomorfos fueron plasmados en calidad de signos o glifos".

González Torres (2001) afirma que los indígenas mesoamericanos por su cercanía con la naturaleza, han incluido al mundo vegetal y al animal como símbolo de principios y fuerzas cósmicas y como receptáculo de potencias divinas, dotaron a plantas y animales de poderes sobrenaturales e integraron en un cosmos viviente, en cuyo centro estaba el hombre.

Mesoamérica. Cueva del Buen Abrigo, Coahuila. Hay una pequeña blusa de niño que muestra en su parte frontal dos grandes flores (una a cada lado) pintadas, sobre un textil de tafetán. (Filloy 2017:33).Hay también muchas ilustraciones sobre flores en los códices (Codice Duran, cap.XVI, pág.152, párrafo 6).

Dupey (2015 : 53 ) afirma: "En los códices Borgia y Cospi, el perfume intenso que se desprende de las guirnaldas y coronas de flores se plasmó mediante el añadido de una o dos flores esquemáticas sobre estos adornos". Una o varias flores aparecen a veces coronando los platos llenos de comida y los recipientes que contienen bebidas como el cacao, así como rematando corazones, espinas y punzones ensangrentados. Por ello, cree que es posible que hayan simbolizado lo precioso, pues la flor encarnaba esta idea en varios aspectos de las culturas prehispánicas.

Vela (2006:46-47) afirma que pocos dioses en el panteón prehispánico no tienen asociación con las flores; algunos tenían una relación más estrecha y de hecho eran sus patronos. Xochipilli, "príncipe de las flores” era el dios de la danza, los juegos, las flores y el amor. Estaba asociado con la Tierra, la fertilidad y la vida. Al mismo tiempo, se le relacionaba con el Sol naciente, la procreación y el placer. Junto con Xochiquétzal, era quien permitía la germinación de las plantas y creador de las flores. Macuilxóchitl, “cinco flor" Su nombre hace alusión a una fecha del calendario. Es una advocación de Xochipilli y muchas veces se le atribuye la misma identidad. Dios de las flores, el juego, el canto y la música, también era patrón de los nobles. Es considerado el dios principal de los ahuiateteo, los cinco dioses asociados con el exceso, el placer y su respectivo castigo. Xochiquétzal, "plumas de quetzal florido”, "flor-quetzal" Era considerada la diosa madre joven y estaba relacionada con el placer, el amor y las flores. Era patrona de las tejedoras y de las artes que practicaban las mujeres nobles, del amor sexual, los quehaceres domésticos y las prostitutas; también protegía a los recién nacidos y a las madres embarazadas.

Velasco y Nagao (2006:29) afirman:

"En las sociedades prehispánicas, las flores ofrecen un amplio panorama de significados, que fueron adaptados a las diversas cualidades de las diferentes especies. Las antiguas representaciones de las flores, en gran variedad de materiales, no eran solamente decorativas, sino que formaban parte de un simbolismo basado en el respeto y la preocupación por el bienestar de los dioses, que se manifestaba en los elementos de la naturaleza.”

Las plantas y las flores han estado presentes en diversos periodos y culturas de Mesoamérica. Del Preclásico, hay representaciones de maíz y de brotes de vegetación en hachas olmecas de piedra verde y en relieves en las rocas de Chalcatzingo, Morelos. En las estelas de Izapa, Chiapas, se ven árboles, algunos dando frutos, en escenas que aparecen en la epopeya del Popol Vuh, obra de un periodo posterior.

En el Clásico proliferaron las imágenes de flores en varios contextos y con una mayor diversidad de connotaciones. Heyden escribió que la flor tetrapétala ha tenido un significado polifacético en las culturas antiguas y actuales de 


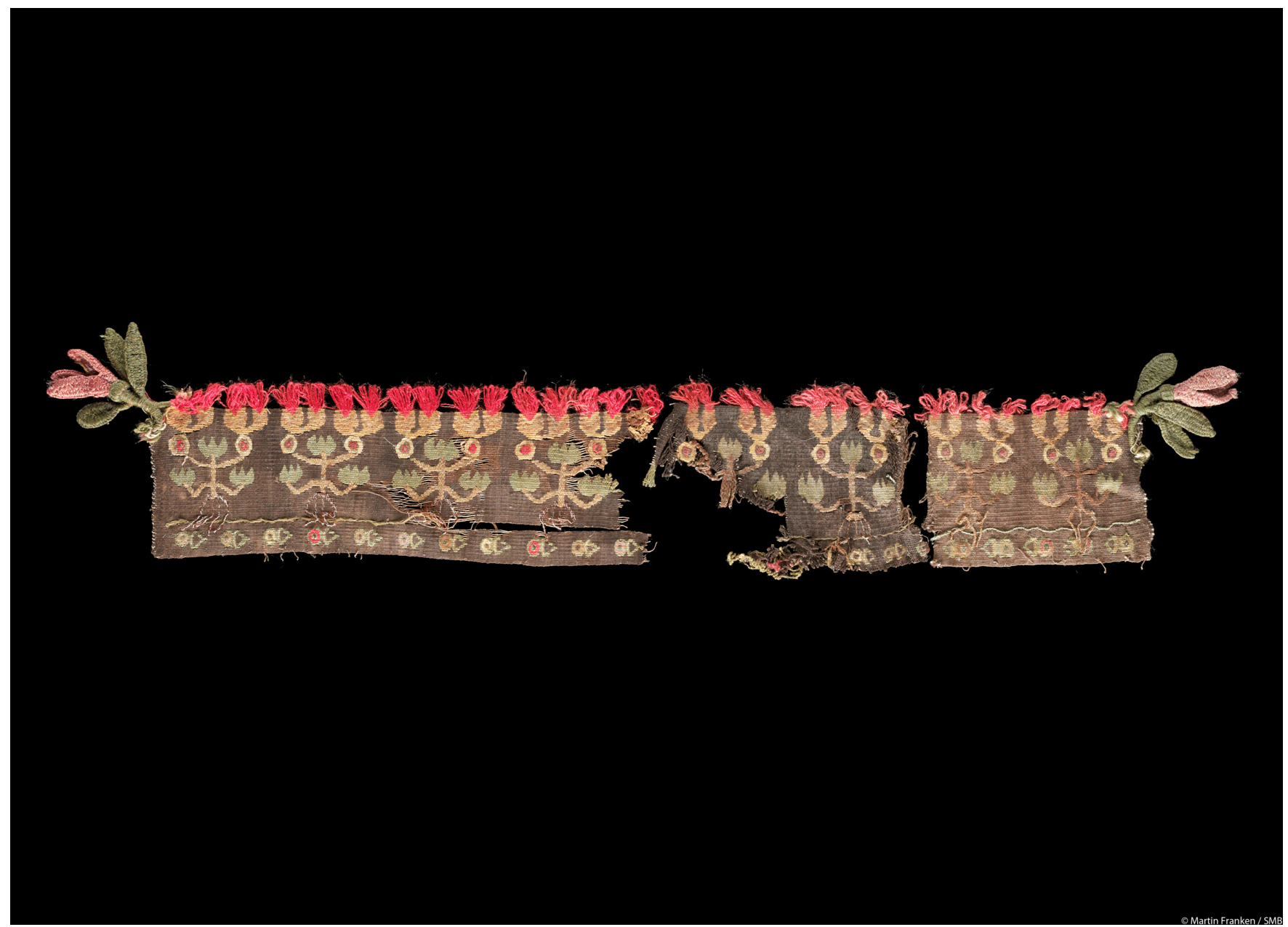

Figura 7. Textiles Lambayeque. Plantas. Staatliche Museen zu Berlin, Ethnologisches Museum, V A 58026, fotógrafo: Martin Franken.

Mesoamérica, y que es uno de los símbolos persistentes en la mente y en el lenguaje de sus habitantes. Hay numerosas representaciones de flores de cuatro pétalos en Teotihuacan, estado de México: en la arquitectura, esculpidas en la Subestructura de los Caracoles Emplumados; grabadas en las vasijas trípodes de barro; moldeadas en los adornos adheridos a los incensarios, o como tocado de figurillas de barro. De acuerdo con Heyden, esta flor aparece con tanta persistencia en Teotihuacan coronando algunas figurillas, que es probable que tenga un sentido dinástico. Heyden asoció este simbolismo con la cueva que se encuentra bajo la Pirámide del Sol, en Teotihuacan, la cual fue modificada para darle forma de flor y que posiblemente funcionó como lugar sacro, oráculo, punto de llegada de peregrinos, y es uno de los símbolos fundacionales de sitios sagrados y ciudades.

Las flores teotihuacanas también formaron parte de la iconografía de la pintura mural, a veces aludiendo a un lugar paradisíaco (como en el Tlalocan de Tepantitla), otras veces refiriéndose al canto y a lo bello de las palabras
- simbolizado en las vírgulas floridas que salen de la boca de diversos personajes - y como arbustos en plena flor como motivos centrales (en Techinantitla), tal vez en alusión a topónimos o a linajes.

En el caso de la Zona Andina también podemos decir que es muy frecuente encontrar flores plasmadas en sus textiles, en culturas principalmente de la Costa, como la Nazca. En sus mantos aparecen flores, claramente tejidas en líneas diagonales.

De la Cultura Lambayeque, hay una gran colección de textiles en el Museo Etnológico de Berlín que han sido recientemente publicados y que muestran la riqueza vegetal de aquella zona, plasmada en sus tejidos. (Bjerregaard,L 2017: 104/109-111). Se pueden ver plantas del algodón (V A 57033); personajes cuidando su jardín (V A 62275); todo tipo de plantas y de flores en esta colección que perteneció a Wilhelm Gretzer (V A 58040 a,b,c; V A 58026; V A 58018; V A 58021; V A 58028), viva presencia textil de los vegetales que representan. (Fig. 7) 


\section{Conclusiones}

Con este estudio que pretende tener continuidad, se quiere poner de relieve toda una serie de imágenes tejidas en los textiles de las dos grandes zonas habitadas de Amerindia, como son: Mesoamérica y la Zona Andina, que se repiten en ambas, con el mismo significado, a los que llamaremos signos comunes.

En este primer intento, se han escogido: el meandro escalonado/ Xicalcoliuhqui; la S horizontal /nube/ grecas en espiral. De entre los animales: el felino (jaguar y zorro), aves y serpientes. Y finalmente, flores y plantas. De esta manera se cubre un panorama bastante completo de la vida de los antiguos pobladores de estas dos zonas.

Y sin grandes sorpresas, puesto que el tema de la fecundidad ya está imbricado desde un buen principio, en el día a día de estas personas que tenían como base económica, la agricultura, y los animales, surge la FECUNDIDAD como eje de todos estos signos. Ellos la propiciaban y por esta razón está en todos sus actos sagrados, y en sus vidas diarias. Era el eje de la relación hombre/dioses desde un buen comienzo.

Todo este tema queda claro desde el comienzo del estudio y también que en cada lugar según sus circunstancias geográficas y climáticas, coincidan estos signos.

Es por lo tanto una contribución a la idea de que estas dos zonas se relacionaron en épocas parecidas, porque tenían que cubrir las mismas necesidades para poder vivir con una cierta comodidad, a pesar de que en Amerindia, en general, todo fue muy difícil de conseguir puesto que sus medios fueron limitados pero su inteligencia y voluntad consiguió grandes logros.

Y en el caso que nos ocupa, fueron los textiles, espejo de sus vidas y creencias, los que nos muestran estos signos comunes.

\section{Bibliografia}

BEYER, H (1924), El origen, desarrollo y significado de la greca escalonada, El México antiguo tomo 2, México. pp. 248.

BJERREGAARD, L (2017) Pre-Columbian Textiles in the Ethnological Museum in Berlin. Zea Books. Lincoln, Nebraska. https://digitalcommons.unl.edu/zeabook/52

CARLSON, U. (2010) Iconografía Andina. Interpretación del simbolismo en antiguos tejidos peruanos. Braunschweig.

CARLSON, U. (2014) El simbolismo de la iconografía emblemática Mochica. Braunschweig.

CASO, A (1992). “Reyes y Reinos de la Mixteca”. FCE, México 1992. pp. 246.
CODICE DE MADRID (1970) Codex Tro-Cortesiano. Codices Selecti. Vol. VIII. ADEVA, Graz, Austria.

CODIGO MAGLIABECCHIANO (1970) Intro y Sumario por F. Anders. CL XIII,3 (B.R. 232) Biblioteca Nazionale Centrale di Firenze. ADEVA, Graz, Austria.

DUPEY GARCIA, E. (2015) “De vírgulas, serpientes y flores. Iconografía del olor en los códices del Centro de México", Arqueología Mexicana núm. 135, pp. 50-55.

DUPIECH CAVALERI, D. (2016), Los textiles mayas contemporáneos de Yucatán en el espejo del Códice Trocortesiano. Anales del Museo de América, XXIV, pp.169-210.

FILLOY, L. (2017) Mesoamerican Archaeological Textiles: An Overview of Materials, Techniques and Contexts. En Jornadas de Textiles PreColombinos VII, Zea Books, Lincoln, Nebraska. pp.7-39. https://digitalcommons.unl.edu/pct7/3

GONZALEZ TORRES, Y, (coord.) (2001) Animales y plantas en la Cosmovisión Mesoamericana.

México, CNCA, INAH, Plaza y Valdés, ECN, vol. 33, 2002, pp. $375^{-}$ 389 (en colaboración con Martha Ilia Nájera).

HEYDEN, D.(1985) Mitología y simbolismo de la flora en el México prehispánico. UNAM. México. 176pp.

HUCKERT, CH. (2006) Representaciones textiles del México Precolombino: Variaciones en torno al motivo de Xicalcoliuhqui, en Actas III Jornadas Internacionales sobre Textiles Precolombinos, Victòria Solanilla (ed.), Barcelona, pp.111-128.

KERR, Justin, (1989) The Maya Vase Book. A Corpus of Rollout Photographs of Maya Vases, Volume 1. Nueva York: Kerr Associates 1989/1990/1992/1995/1997/2000

LAPINER, A.(1976) Pre-Columbian Art of South America. Abrams, New York

LAURENCICH MINELLI, L. (1984) Antichi tessuti Peruviani. Electa Editrice. Milano.

LOT, A y MIRANDA, G.M. (1983)," Nota sobre las interpretaciones botánicas de las plantas acuáticas representadas en los códices mexicanos", en Imágenes de flora y fauna en culturas precolombinas: iconografía y función. J.F. Petreson, ed. BAR International Series, England. 171:85-92.

LUNA, A. (1996) La flora representada en la iconografía pictórica, en "Pintura mural prehispánica" Estudios, t.II, pp. 37- 39. Bol. Informativo. Año $2, \mathrm{n}^{\circ} 5$, diciembre.

MAKOWSKI,K, ROSENZWEIG, A \& JIMÉNEZ DÍAZ,M.J. (2006). Weawing for the Afterlife, Peruvian Textiles from the Maiman Collection. Herzliya: Ampal/Merhav.

MEIGHAN, C. W. (1969) Cultural Similarities Between Western Mexico and Andean Regions. En Pre-Columbian Contact Within Nuclear America, edited by J. C. Kelley and C. L. Riley, pp. 1 1-25. Mesoamerican Studies No.4. University Museum, Southern Illinois University, Carbondale.

MONTOYA, J (2008) Los tejidos mayas. Espejos de una cosmovisión. Etnografisch Museum-Fundació Caixa de Girona. Cholsamaj. Guatemala. 
MORALES DAMIÁN, M.A. (2009) Tejer en el árbol florido. Análisis comparativo de la lámina de Atamalcualiztli, Primeros memoriales y las imágenes de las deidades tejedoras en el Códice Madrid, en Actas IV Jornadas Internacionales sobre Textiles Precolombinos, Victòria Solanilla (ed.) Barcelona, pp. 97-108.

PRIMEROS MEMORIALES (1993). Ed. facsimilar. F. Anders (fotos) University of Oklahoma Press, Norman.

RIEFF ANAWALT, P. (1992) Archaeology Ancient Cultural Contacts between Ecuador, West Mexico, and the American Southwest:Clothing Similarities, Latin American Antiquity, Vol. 3, No. 2 (Jun., 1992), pp. 114-129.
SAHAGÚN. F.D. de (1982) Historia General de las Cosas de Nueva España. Porrúa. México.

SCHELE,L. \& MILLER, M.E. (1992) The Blood of Kimgs: Dynasty and Ritual in Maya Art. Londres. Thames and Hudson.

SWADESH, M. (1967) Lexicostatistic Classification. en Linguistics, editado por N. A. McQuown, pp. 79-115. Handbook of Middle American Indians, vol. 5, R. Wauchope, general editor. University of Texas Press, Austin

VELA, E. (2006) “Los antiguos dioses y las flores”, Arqueología Mexicana 78, pp. 46-47.

VELASCO, A.M. y NAGAO, D (2006), Mitología y simbolismo de las flores, Arqueologia Mexicana 78, pp.28-35

Victòria Solanilla

Octubre 2019 


\section{Museum collections history}

Historia de colecciones

\section{Histoire des collections}

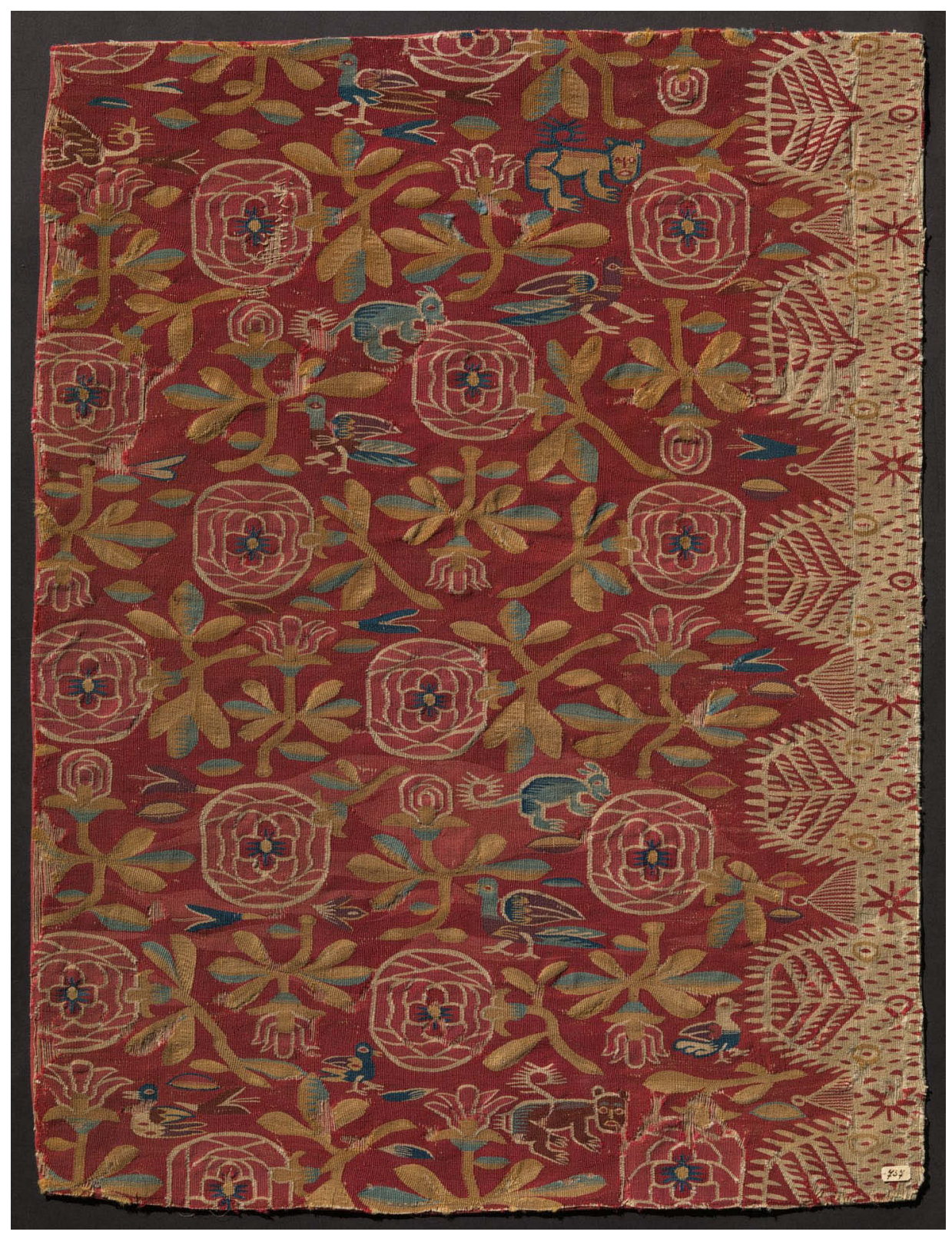




\title{
The pre-Columbian textile collection of the German Textile Museum Krefeld
}

\author{
Katalin Nagy ${ }^{1}$
}

\begin{abstract}
The German Textile Museum in Krefeld houses a considerable collection of pre-Columbian textiles. Most originate from graves in the narrow arid area of the Peruvian coast. The original aim was to build an assemblage with the pedagogical and methodological intention of presenting a broad range of very different textile techniques in the education for the future textile workers of the industry in said region. With this intention in mind samples were gathered, and soon a few samples turned into an impressive collection in which almost all established pre-Columbian cultures and periods of the area of the Central Andes are represented.

The Museum recently started a new research project within the South-American collection. The special aim of this project is a complete new restructuring of the collection, which means, first, the identification of all fragments as a part of a textile object and, second, the classification of the culture and the region they belonged to.
\end{abstract}

Keywords: Textile industry, Andean textiles, German Textile Museum, Krefeld, collection documentation .

\section{Resumen}

El Museo Textil Alemán en Krefeld alberga una no tan bien conocida pero considerable colección de tejidos precolombinos. Casi todos estos tejidos provienen de tumbas ubicadas en una estrecha e árida zona de la costa peruana. El objetivo inicial detrás de esta colección era el de construir un conjunto de piezas con la intención pedagógica y metodológica de disponer de un amplio abanico de muestras de muy diferentes técnicas textiles para la formación de las nuevas generaciones de trabajadores textiles de la región. La motivación original de aquellos que iniciaron la labor recopilatorio condujo a la construcción de una impresionante colección, en la que están representadas casi todas las culturas y períodos precolombinos establecidos del área de los Andes Centrales.

El Museo inició hace poco un nuevo proyecto de investigación en la colección de América del Sur. El objetivo específico de este proyecto es el de implementar una organización completamente nueva de toda la colección. Eso significa primero, la identificación de todos los fragmentos como parte de objetos textiles y, segundo, la clasificación según la cultura y la región a la que pertenecen. Objetivo de esta presentación es por un lado dar a conocer a un público mucho más amplio la existencia de esta colección de tejidos precolombinos, poniendo el foco de atención sobre algunas de sus piezas más reseñables.

Palabras claves: Industria textil, textiles andinos, Museo Textil Alemán, Krefeld, documentación de la colección

\section{Résumé}

Le musée allemand du textile de Krefeld héberge une collection méconnue, mais non négligeable de textiles précolombiens. Ceux-ci proviennent presque entièrement de tombes localisées dans la zone étroite et aride de la côte péruvienne. L'objectif initial de cette collection était de réunir un ensemble de pièces afin de, sur un plan pédagogique et méthodologique, présenter un large éventail de techniques textiles très variées pouvant servir à la formation des futurs employés

1. Katalin Nagy, Deutsches Textilmuseum, Krefeld (German Textile Museum, Krefeld); South American Collection, Project "Shed Light” (Projekt “Ans Licht”): katalin.nagy.berlin@gmail.com

DOI: 10.32873/unl.dc.zea.1214

Published in PreColumbian Textile Conference VIII / Jornadas de Textiles PreColombinos VIII, ed. Lena Bjerregaard and Ann Peters

(Lincoln, NE: Zea Books, 2020). https://digitalcommons.unl.edu/zeabook/ 
de l'industrie textile de la région. L'intention des collectionneurs qui ont commencé ce projet a abouti à la création d'une collection impressionnante dans laquelle la quasi-totalité des cultures et des époques précolombiennes établies de cette région des Andes centrales est représentée.

Le musée a récemment lancé un nouveau projet de recherche de la collection sud-américaine. Le but principal de ce projet est la réorganisation complète de la collection, ce qui signifie premièrement l'identification de tous les fragments liés aux textiles et deuxièmement, la classification de la culture et de la région auxquelles ils appartiennent. Cette présentation vise à rendre publique l'existence de cette collection de textiles précolombiens et de mettre en lumière certains de ces éléments les plus importants.

Mots-clés: Industrie textile, textiles andins, Musée Textile Allemand Krefeld, documentation des collections.

\section{Introduction}

The German Textile Museum in Krefeld houses an excellent collection of historical garments. This collection has over 30.000 objects from all parts of the world and from the Antique to the present time. The Peru-collection of Krefeld is not completely unknown. Many specialists for pre-Columbian textiles have at least heard, or already read about some objects, may be in an article or by studying its catalogue. A few of them already visited the museum's storage. Still, the collection in Krefeld, until this day, is not as well known as it should be.

The local financial institution, the Sparkasse Krefeld, has its own cultural fund. The current project "Shed Light" is sponsored by this fund. The project "Ans Licht" (in German), "Shed light" is still running. The aim of the project is to present the collection, not only to scientists and tourists, but also to the local population. The research conducted focuses on four groups in particular; they are going to be presented in an exhibition. These are the Peruvian textiles, the historical European garments, the East-Asian textiles, and the early-Islamic -collection. A digital catalogue will provide a summary of the collection. This paper will give you a first impression of the research done so far and its first results.

In the following I present the history of the museum, with an emphasis on the Peru-collection and some of its samples.

Krefeld itself is a part of the geographical and political Lower Rhine region, an economic entity with its own history. A larger part of its past was shaped by the textile industry. The production of textiles played a very significant role there in that almost every family was involved in some way or another. It provided an identity and a livelihood to a large percentage of the city population.
In the Middle of the $19^{\text {th }}$ Century Krefeld was an internationally renowned centre of textile production, especially for silk, but it was not the only one, since Lyon in France and Mulhouse in Alsace had similar importance. A response to this competition was the modernisation of the Royal School of Weavers. Besides the complete renovation of the building structure and modernising of the machinery, a library was added and a collection of textile samples was established. Such a collection should include samples from all historical periods and from all parts of the world. Although the collection was an archaeological, ethnological, and historical one, here, at the school, the objects were only considered as products of a technology, and should, first of all, serve to improve the technological knowledge and give an inspiration for design. This led to the purchase of the textile collection in 1880 .

This purchase was the foundation for the collection of the German Textile Museum. Its oldest part comes from the private collection of Jakob Krauth (1833 - 1890), a sculptor from Mannheim. In 1879 he owned 1500 textiles from Asia and Europe which he exhibited in Frankfurt. ${ }^{2}$

"It was possibly through this exhibition that the Prussian state representatives became aware of him. In the course of the negotiations, 3974 pieces were chosen for the Krefeld school, among them all kinds of textile qualities of various cultures and ages (...)."3 Jakob Krauth bought it in 1880 from the Prussian state and brought it directly to Krefeld where it was named "Königliche Gewebesammlung”, Royal Textile Collection. This collection was surely well known among other artists and collectors. In 1886 it was mentioned in a journal for applied arts, which was distributed in all of Germany. ${ }^{4}$ The author of the article was a scholar of cultural studies and the curator of the Museum of Applied Arts (Kunstgewerbemuseum) in Berlin ${ }^{5}$, Max Heiden. Max Heiden

2. Paetz gen. Schieck, 2013, 48

3. Paetz gen. Schieck, 2013, 48f, 59: notes 12-15

4. Max Heiden, 1886. Kunstgewerbeblatt. Periodical of the Associations for Applied Arts in Germany.

5. Kunstgewerbemuseum zu Berlin. The history of the textile collection and the activities of Jakob Krauth was intensively studied and presented by Annette Paetz gen. Schieck, 2013: 46-61. 
worked especially on garments and textile products. ${ }^{6}$ It is documented that the Museum of Applied Arts in Berlin acquired textiles from Jakob Krauth in $1880 .{ }^{7}$ Certainly, pieces from Berlin must have been part of the collection in Krefeld as the archive of the museum still stores the small old inventory labels of pieces from the collection of the Museum of Applied Arts in Berlin. This connection between Berlin and Krefeld had an important aspect especially for the founding of the pre-Columbian collection.

\section{The beginning of the collection of pre-Columbian textiles}

Taking a look at the background is important in order to trace movement of the textile objects, unearthed somewhere in Peru, to Europe, to Germany, and the change of their significance later in Krefeld. The Krefeld collection offers a view of a specific case of this process and cannot, therefore, be applied universally.

When I saw the collection for the first time, I saw a lot of rather small pieces and immediately recognized that they were fragments, mainly with a straight cut edge. I had earlier studied the textile collection of the Ethnological $\mathrm{Mu}$ seum of Berlin as well as a few other collections in Germany. I assumed at first that most of those fragments came from Berlin. (Fig. 2). However, more study of the documents has brought me to a different conclusion. I now think that some of the pieces became a part of the collection in a different way.

In the German Textile Museum the question of provenience is considered with privilege. The period after the Second World War is well documented. But in the case of the whole collection including the pre-Columbian textiles, which entered the collection partly before the Second World War, the study of the acquisition is difficult as the documentation was completely destroyed. The Project Shed Light gave the possibility to examine every piece with its still existent file cards and at least for some of them the provenience can be cleared.
The acquisition of the objects began towards the end of the $19^{\text {th }}$ century and the process was documented. ${ }^{8}$ Unfortunately, the school building where all the documents were stored was destroyed by bombs during the Second World War. ${ }^{9}$ Some of the documents that were thought to be lost, actually were not. Clarifying this way, it was possible to recover some pre-Columbian pieces from the collection of Reiss and Stübel that entered the collection in Krefeld. Beside this small group of fragments, the vast majority of the pieces in Krefeld have no archaeological documentation.

The decades of the historical process of the great industrialization were also very important in the history of preColumbian Archaeology. The geologist Wilhelm Reiss (1838 - 1908) and the mineralogist Alphons Stübel (1835 - 1904) went to South America in $1868 .^{10}$ Their aim was to study volcanology and mineralogy, but as a common practice for scientists on journey at that time they also conducted archaeological excavations. Wilhelm Reiss and Alphons Stübel excavated between December of 1874 and March of 1875 the necropolis of Ancón at the Peruvian Coast. The documentation and creation of prints by Reiss and Stübel regarding the excavated objects were subsequently put into three volumes and published with the title "The Necropolis of Ancon in Peru". ${ }^{11}$ Exactly at that time, in 1886, the "Königliches Museum für Völkerkunde" (Royal Museum of Ethnology) in Berlin was inaugurated. The excavated artefacts from Ancón are now stored in the Ethnological Museum in Berlin, Germany. Many of the archaeological objects are textile pieces. The first pre-Columbian pieces entered the textile collection in Krefeld probably shortly after the foundation of the collection. Fifteen small fragments were donated ${ }^{12}$ that belonged to the objects excavated by Reiss and Stübel at the necropolis of Ancón. The time and circumstance of their entering is still unknown, but they were registered as one group, and received the number $55 .{ }^{13}$ The specification of the archaeological site must have been made by Reiss and Stübel themselves: "Südamerika, Peru, Chimu, Totenfeld von Ancon”. Also, the Grassi-Museum in Leipzig (Leipsic, old) received a part of the Reiss-and-Stübel-Collection in $1887 .{ }^{14}$

6. Max Heiden, 1904. Some other historical evidences show the connection between these two collections. Further see: Paetz gen. Schieck, 2013, 59f, notes 21-22

7. Paetz gen. Schieck, 2013, 50 and 59, note 21

8. Paetz gen. Schieck, 2013, 48

9. Paetz gen. Schieck, 2013, 49

10. Fischer, 1992, 259

11. The Necropolis of Ancon in Peru. Published by A. Asher, Berlin 1880-1887

12. "Provenienz: Dr. Reiss and Dr. Stübel, Berlin, Geschenk" (English: donation)

13. „A.N. 55”, in German „Alte Nummer”. English: old number 55. See every object card from the inventory number 10440 till 10457. The object cards with the numbers 10453, -54 and -55 are missing today. All pieces have a measurement of some centimetres. and were very probably cut off for the donation.

14. Fischer, 1992, 260 
As no information exists from the beginning of the preColumbian textile collection from Krefeld, the next question was, if the collectors in Krefeld had any contact to the Museum in Berlin. The contact between the Krefeld collection and both scientists is unclear until this day. I presume that the information about the arrival of pre-Columbian textiles to Europe and to Berlin, as a part of a pre-Columbian collection, had reached the elite of Krefeld. This historical frame is key to understanding the origin of this exceptional textile collection, including the Peru collection. Future research can lead to more knowledge about the early contacts between the scholars and collectors. Today, this group of textile fragments from the excavations of Reiss and Stübel in Ancón is part of the Krefeld collection. ${ }^{15}$ The question of provenience follows every new exposition of the Museum in Krefeld. Until now these pieces from Ancón are unique among the preColumbian textiles because their provenience was directly named by the archaeologist.

The Krefeld collection had such a high status and was considered so valuable that it was moved to a secure place during the Second World War. The documents, however, were left behind at the school. Unfortunately, the school building was destroyed in a 1943 bombing. This is why there is no information about many of the collectors or possible origin of the textiles.

In 1949, after the war ended, a new institution, called the "Centre for the Restauration of Historical Textiles and Garments”, in German „Zentrale Forschungstelle für Restaurierung historischer Gewebe“, was established. It was tasked with the preservation of all damaged textile goods. It was led by the new director of the Textile collection, Dr. Renate Jaques. Renate Jaques, an art historian, was the first person who took care of the entire collection. She was well known amongst the textile institutions in Krefeld and kept close connection to the Textile Engineer School.

\section{The years of the extension}

Shortly after the Second World War the most important question that many European museums and collections asked themselves, was, what was lost and what could still be saved for expositions. Those years seem to have been an era when the curators of textile collections tried to intensify dialogues among themselves. In 1954 Renate Jaques belonged to a small international group of scholars who gathered in Lyon. They established the scientific association of the CIETA, the "International Research Centre for ancient textiles", which is still active in research of archaeological and historical textiles.

Some pre-Columbian objects, mainly fragments, were acquired, when the German-Peruvian collector and textile merchant Guillermo Schmidt-Pizarro brought them to Krefeld. His name appears in several European museums within their pre-Columbian textile collections ${ }^{16}$ as he offered objects with pre-Columbian origin to a number of European museums. The first time he came to Krefeld and presented pre-Columbian garments was shortly after the end of the Second World War. Later he presented more pre-Columbian garments and a number of smaller fragments. Guillermo Schmidt-Pizarro must have been aware that in a city with such a long textile tradition, the pieces with the most fascinating techniques would be highly valued and very welcomed. Some pieces were registered with a cultural assignment, it happened very probably on the suggestion of Schmidt-Pizarro himself. Regarding the pre-Columbian collection it is not possible to clear on which of the archaeological sites the samples were found.

He visited Krefeld between 1953 and 1960 a few times, the date of the first visit is indicated $1953^{17}$ and also the last one, 1962. The investigation of the documents has not been finished yet, but they span a period of 10 years. Presumably he brought the last piece on the $23^{\text {rd }}$ of May 1962 and the date of his denial was written down on the same document: “...Tod des Anbietenden am 20.1. 1964”. This was the last time he was mentioned. Actually, the source of this information is unknown.

This array of textiles was last presented publicly in an exhibition in 1959. Photographs of some of the objects were published, but later the collection sank into oblivion. The first catalogue from 1959 consisted of some printed pages and was no more than a list of the objects. Over the years the city-collection offered some objects to other museums for expositions. The most active cooperation was with the Ethnological Museum of the city of Cologne. The moment textiles were exhibited, the experience of the specialists from the Krefeld-collection also

15. Wilhelm Reiss was born in Mannheim where Jakob Krauth was also living before and after the three years of intensively phase of founding of the textile collection in Krefeld (Paetz gen. Schieck, 2013, 6o, note 22).

16. The British Museum offers a short information to Guillermo R. Schmidt-Pizarro, though he belonged to its collectors. He was born ca. 1881 and has diseased ca. 196o. See: Bibliographical details of Guillermo R. Schmidt-Pizarro: "Collector of predominantly Peruvian textiles, examples of which can now be found in numerous museums, including the British Museum.” (c) 2019 Trustees of the British Museum. (https://research.britishmuseum.org/research/search_the_collection_database/term_details.aspx?bioid=35776) 26.11.2019.

17. Registration on the object card of Inv. Nr. 04566. 


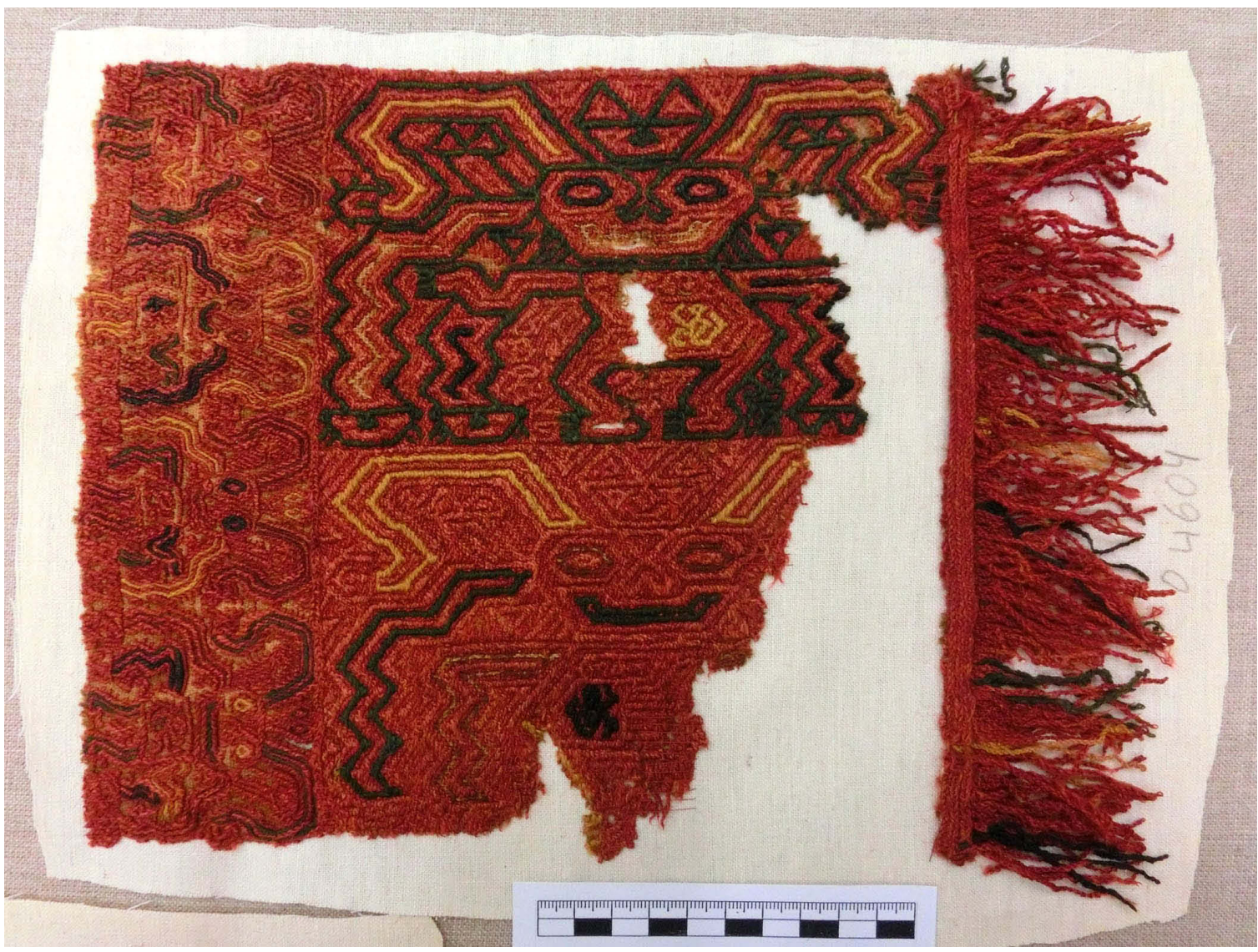

Figure 1. Late Paracas fragment ( $400-200 \mathrm{BC}$ ). Cotton plain weave, with embroidery in dyed camelid hair, $30 \mathrm{x} 21,5 \mathrm{~cm}$ with fringes, the fringes are ca. 6,5 cm (DTM Inv. Nr. 04604) (Katalin Nagy, DTM: Deutsches Textilmuseum, Krefeld) Except the two photos of the object DTM Inv. Nr. 12299 all photos were made by the author of this article. They are published here with the permission of the DTM (Deutsches Textilmuseum, Krefeld).

became important. Today the Peruvian collection itself counts about 800 pieces. ${ }^{18}$

Renate Jaques remained in Krefeld at her position until 1973 when she retired, and the city took over her institution. Since then, the collection has changed its name and location several times. It was eventually removed from the school in the late 1970s and stored in a new and modern building, where the collection received the status of museum sponsored by the city. The museum has been located in Krefeld-Linn since 1980 and it is called Deutsches Textilmuseum. The textile collection still constitutes the core of the museum. The development of cultural and social sciences led to the recognition by the elite of Krefeld that the textile objects were more than mere examples of textile techniques so the interest in their cultural and historical background began to grow and the next CIETA meeting in
1980 took place here in Krefeld.

\section{Some pieces from the pre-Columbian textile collection}

The collection includes pieces representing different techniques and designs and some selected pieces are presented here in chronological order.

\section{Early Intermediate Period (ca. 600 B.C. - 600 A.D.)}

Two pieces, one from the Paracas and another from the Nasca culture (Fig. 1 and Fig. 2).

The piece from the Late Paracas culture (DTM Inv. Nr. 04604) is a fragment from the border of a decorated shirt. Corresponding to other published examples it originates

18. According to the list of the inventory numbers 822 pieces came from Peru and 11 from Bolivia. The real number of objects can slightly differ, because pieces made of different parts and with different techniques received sometimes more than one number. Depending on the institutionally interests of the museum on textile techniques it seems that in the past not the object but the technique was registered. An example is a small bag, a chuspa, with the inventory number 11088-89-91. It will be presented later on in this paper, Figure 2. 


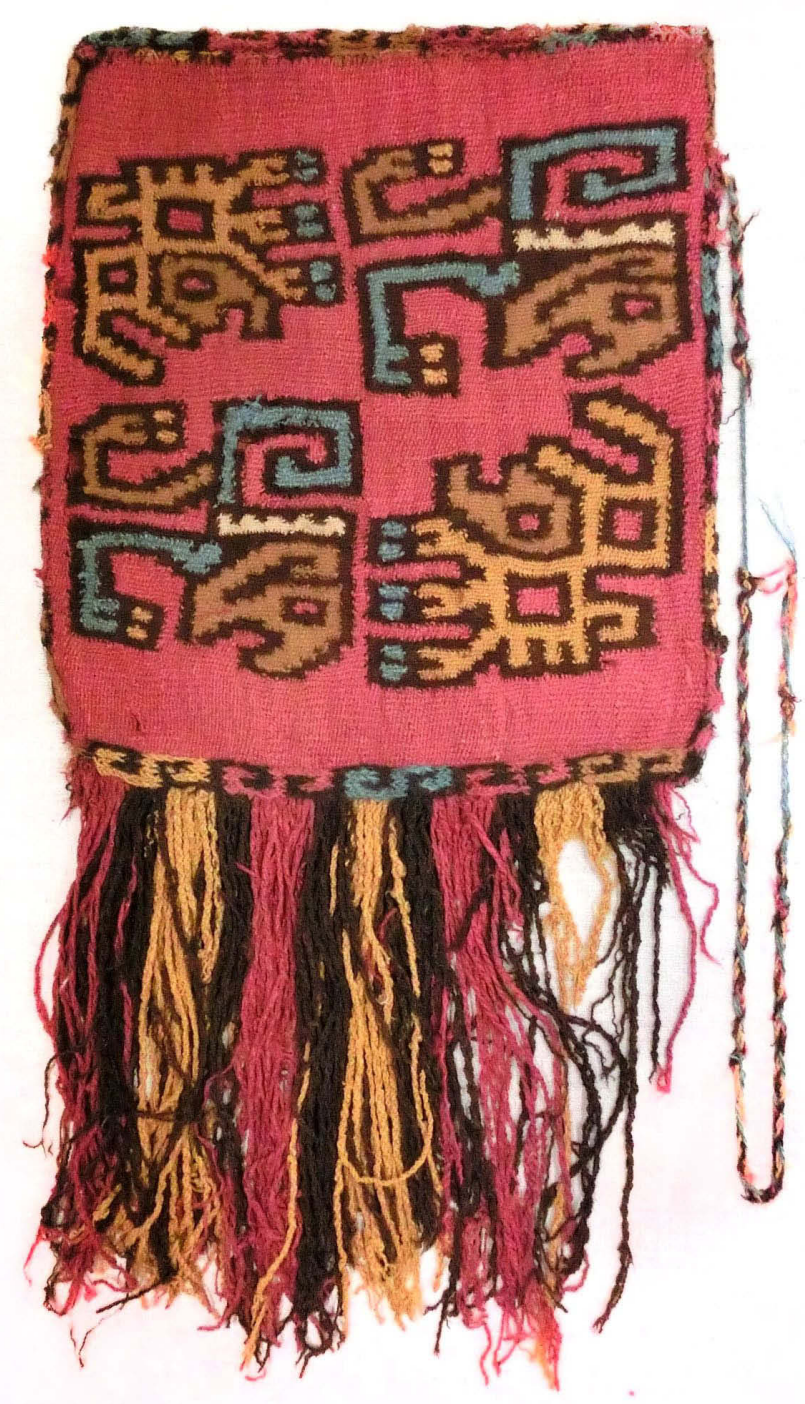

Figure 2. Small bag, chuspa, from the Late Nasca culture (500 700 AD). Dyed camelid hair, discontinuous warp and weft pattern, $22,5 \times 20,5 \mathrm{~cm}$. with fringes is ca. $41 \mathrm{~cm}$ long, the braided hanger is $50 \mathrm{~cm}$ (DTM Inv. Nr. 11088-89-90)

from the Paracas necropolis (400 - 200 B.C.). The decoration is embroidery on cotton plain weave with dyed $\mathrm{S} 2 \mathrm{Z}$ plied camelid hair, in the colours red, pink, yellow, black and dark green. The embroidery is an example of the linear style. The main motif is a combination of frontal anthropomorph and zoomorphic figures, in the stomach area of an anthropomorph figure there is a small zoomorphic figure. The outlines of the repeated motive were changed. The plied fringe is a common decoration on shirts. ${ }^{19}$
The next piece from the Nasca culture is a small bag, chuspa, (DTM Inv. Nr. 11088-89-90) with fringes and with its partly fixed braided hanger. The three inventory numbers for this object are a special phenomenon in the collection with its profile of textile techniques. Every part of the bag was made with different techniques, it means that every used technique obtains a number. The decoration of the bag was made with discontinuous warp and weft. The material used are dyed yarns of camelid hair. The fringes are multiple plied camelid hair. Two pairs of zoomorphic figures positioned diagonally to each other, are the decoration of the chuspa.

\section{Middle Horizon (ca. 600 - ca. 1000 A.D.)}

Several object groups are known to represent the Middle Horizon. I have chosen three objects: a Huari tapestry shirt, a tie-dyed-Huari-Nasca tunic and a feather-shirt. The Huari tapestry shirt (Fig. 3 and Fig. 4) is a complete piece. ${ }^{20}$ It is a tapestry on cotton warp with dyed camelid hair weft. After Susan E. Bergh the main motives presented are "camelid -or deer-headed staff-bearing creature in profile”. She mentions two related examples of Huari tunics from other collections decorated with similar main motives. ${ }^{21}$

\section{Nasca-Huari tie-dyed tunic}

A tie-dyed tunic with discontinuous warp and weft was described by Ann P. Rowe in the, already mentioned, Wari-Catalogue. She presented this tunic from the collection of the Textile Museum in Washington, and it is very similar in design to the example in Krefeld. It is said to have been found near Palpa in the Nasca-Drainage.

The Krefeld example is probably not complete, it measures $94 \mathrm{~cm}$ by $114 \mathrm{~cm}$. (Fig. 5) This example consists of small squares. But other tie-dyed tunics were made of stepped blocks or L-shaped pieces or a kind of hook. Further we read: "The diagonal rows of small diamonds in each unit combine with those of neighbouring units to form larger diamonds, and the colours repeat along diagonal axes. The colour units typically rotate from one diagonal row to another, adding kaleidoscopic variety." 22 This type of dye practice and construction is also presented on a smaller fragment in the Krefeld collection (Fig. 6). An enlarged photo of this fragment shows how the squares are placed (Fig. 7). To quote

19. More related examples are presented and detailed as described by Ann H. Peters, see Peters, 2014, 129ff

20. The first time it was presented was in 1971 on the occasion of an exposition of the Gewebesammlung Krefeld (Textile Collection Krefeld) and published in the catalogue "Kostüme Trachten Schmuck aus aller Herren Länder"(1971, Tafel 12, Kat. 81.). This object was last presented in the WARI - exposition in the Cleveland Museum of Art, and published in the catalogue, S. E. Bergh, 2012, 167, Figure 153.

21. S. E. Bergh, 2012, 167

22. A. P. Rowe, 2012, 196, Fig. 185. In: S. E. Bergh, 2012 

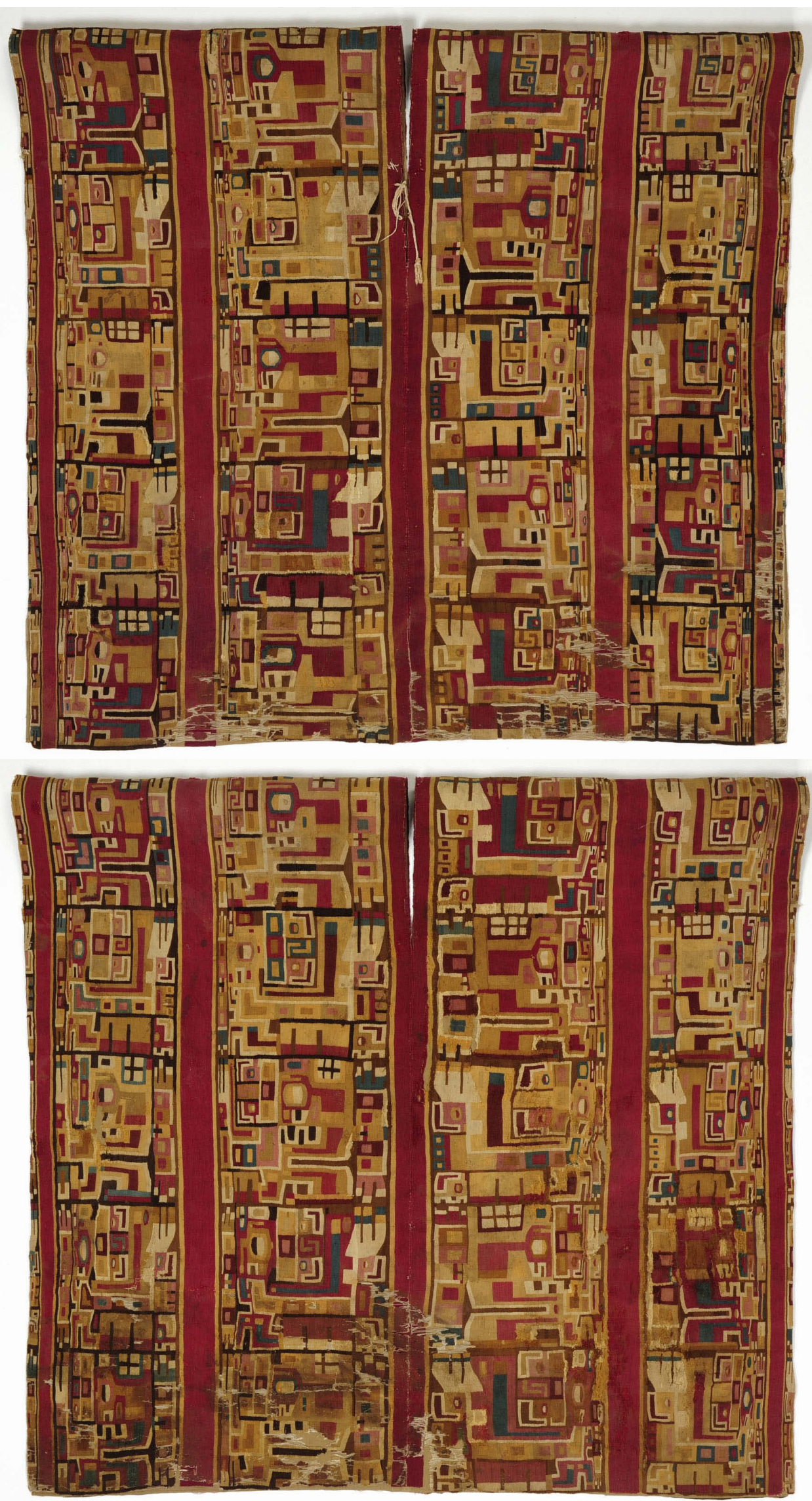

Figure 3. Shirt, uncu, from the Huari Culture (8 - 10 century AD). Dyed camelid hair weft on cotton warp, tapestry weave, $103,5 \mathrm{~cm} \times 108,5 \mathrm{~cm}$. (DTM Inv. Nr. 12299)

Figure 4. Backside of the same Huari shirt (DTM Inv. Nr. 12299) 


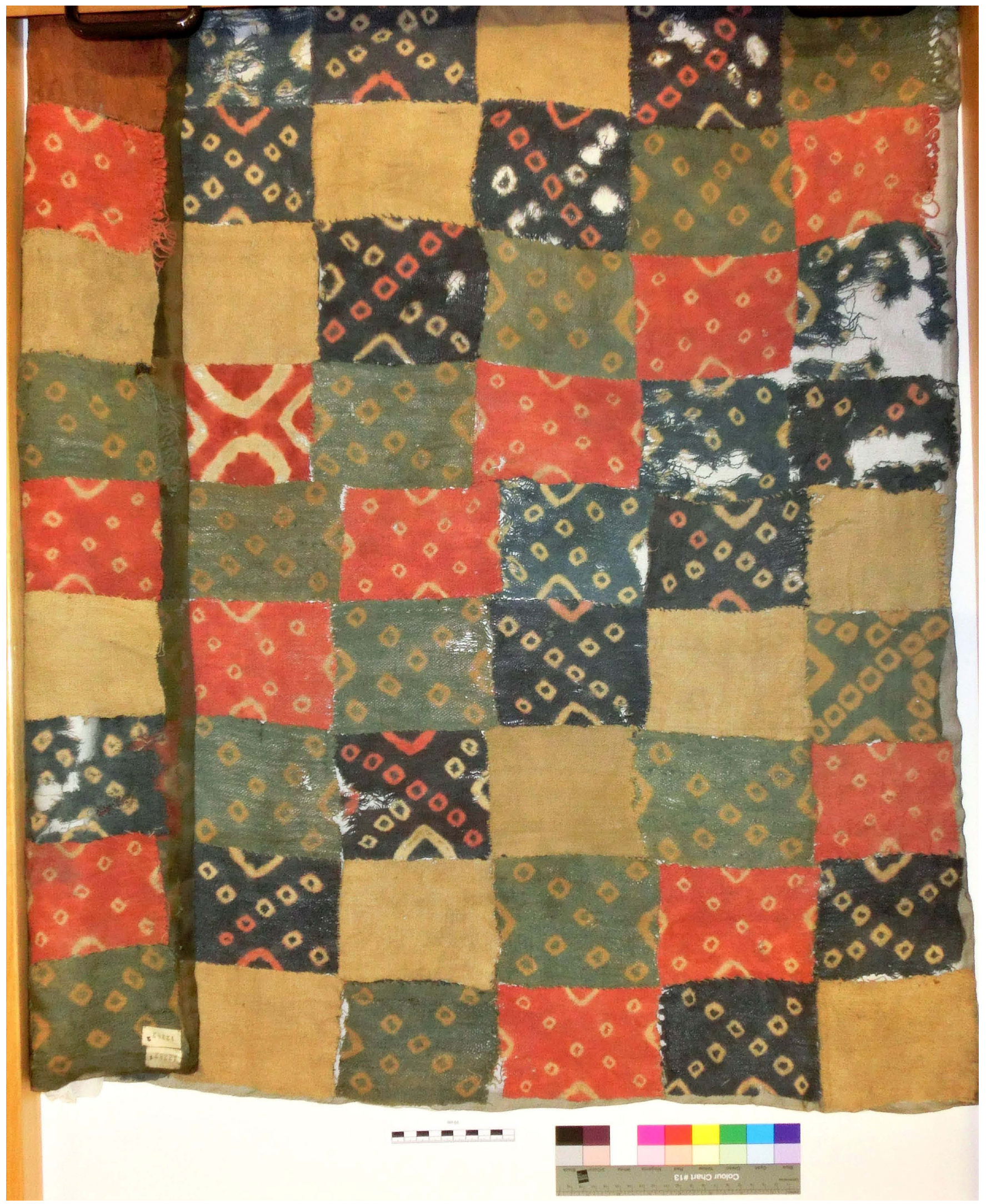

Figure 5. Nasca-Huari tie-dyed shirt. Camelid hair warp and weft, tie-dye and discontinuous weaving, 94 X $114 \mathrm{~cm}$ (DTM Inv. Nr. 12282) 


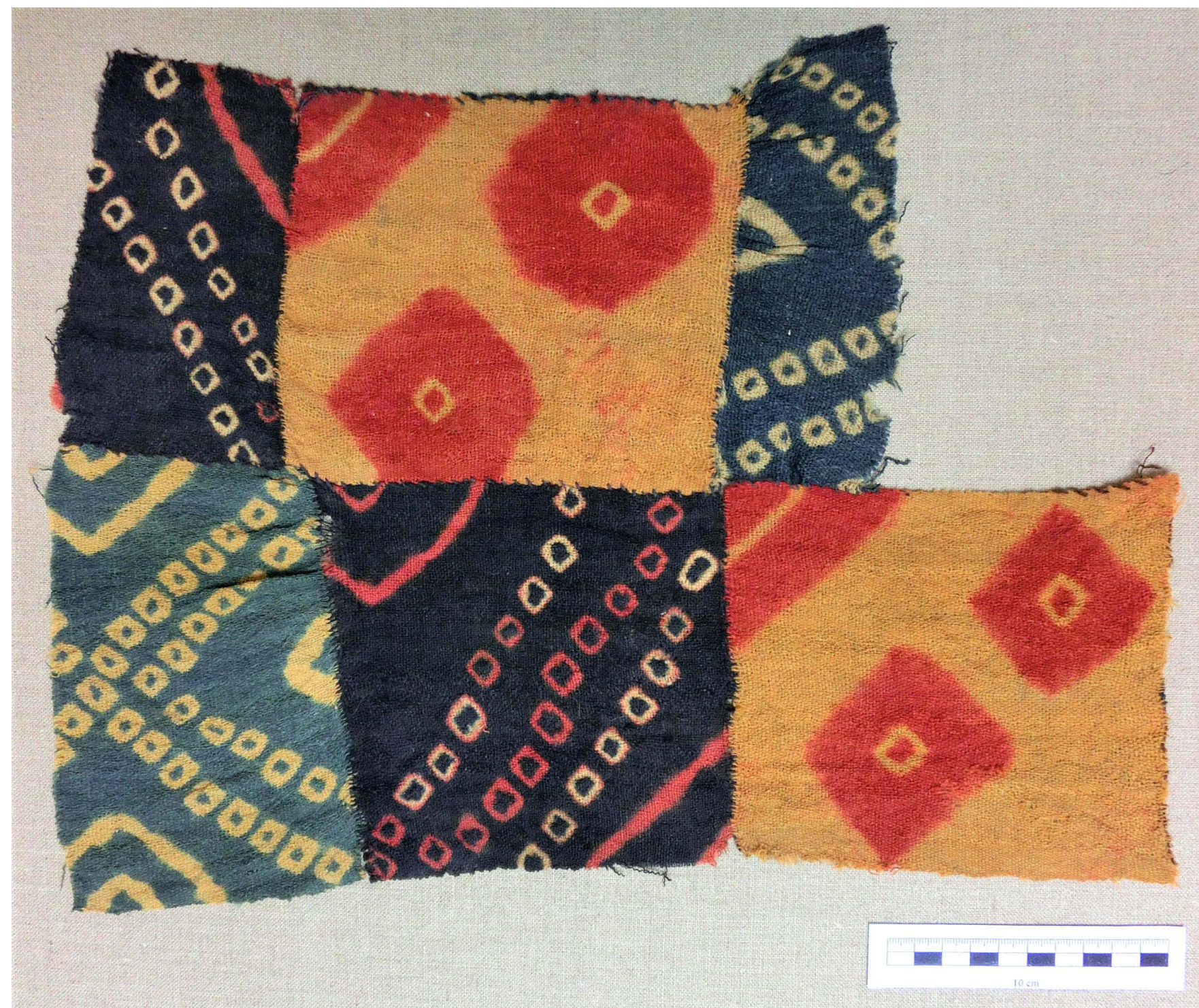

Figure 6. Fragment of a Nasca-Huari tie-dyed garment. Camelid hair warp and weft, tie-dye and discontinuous weaving, $41 \mathrm{x} 30 \mathrm{~cm}$ (DTM Inv. Nr. 11055)

Figure 7. Enlarged photo shoot of the Nasca-Huari fragment (DTM Inv. Nr. 11055)

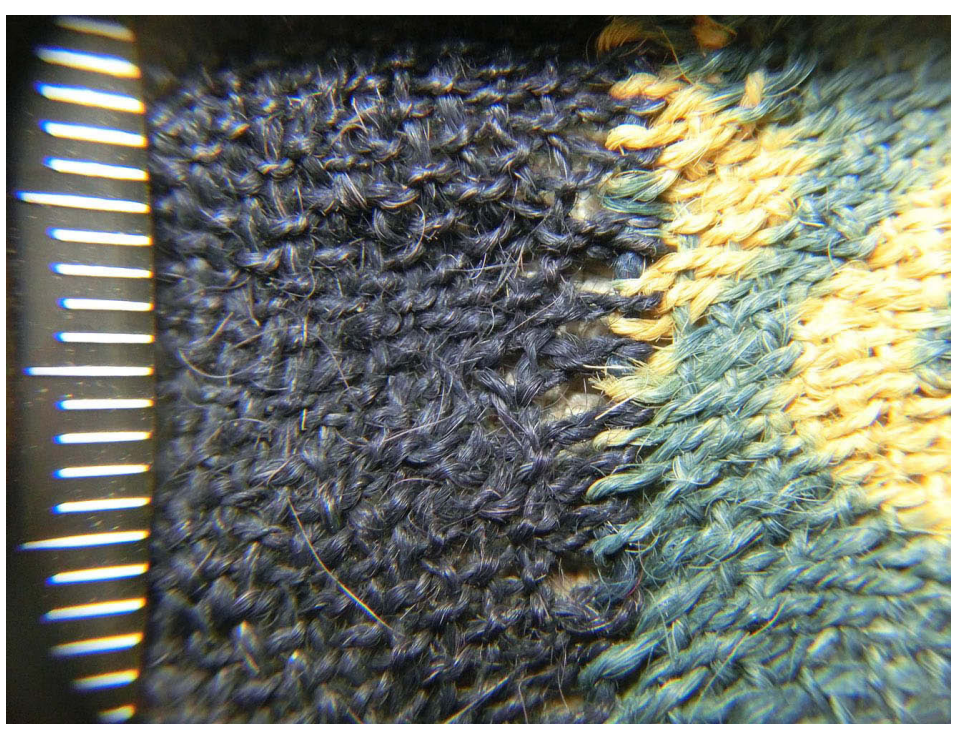


Ann P. Rowe: "Tie-dyed tunics are a coherent group technically and stylistically, and can be (...) described as Wari in style." (...) "The weaving method results in cloth in which both the warp and the weft are discontinuous, which simply means that no yarn runs continuously from top to bottom or from side to side." But we also read: "Not all discontinuous-warp-and-weft tie-dyed textiles are Wari either." The most recent excavations point on the possible existence of a South-Nasca style.

Multiple sketches and images show the attention paid to the documentation of the techniques. But this kind of interest in the complicated textile techniques led to a rather unusual composition in the collection. What is striking about the collection is that it does not include the important quipu and only two feather objects. We know that the quipus played an important role in the pre-Hispanic time. However, they were made of simple knots on a twined yarn, but it was seen as a technique not to pay much attention and interest to. I think this is the same reason that the collection includes only very few garments from the Inca Period, as tapestry, a relatively simple weaving technique, was used for the imperial uncus. Back then there was no reason, to collect any more items from that time period. In the 1950 s the knowledge about the textiles from the Inca Period was very limited, not only in Krefeld, but in Europe. The broad range of textile techniques used during the Inca Period was not present. Nevertheless, as other information is missing it is still possible that some other factors influenced the process of the collecting. The project "Shed light" will hopefully answer this question too.

\section{Feathers}

In the collection, there are only two feather objects and, in a certain way, they both have their peculiarities. A narrow feather-band belonged to the very early collection from before the war; its origin is unknown. The band has a simple but very stable narrow base woven or braided from thick cotton threads. Feathers in blue, red, and yellow were attached with stiches to its surface. The purpose of the band is unknown but it is possible that it served as a decorative element on a headdress.

Only one fragment of a feather-shirt, already heavily damaged, was bought in the 6os at an art auction. (Fig. 8) This purchase demonstrates the intention to make the collection more complex and it shows how the consideration of the value of the collection was changing at that time. The feathershirt is in rather bad condition. ${ }^{23}$ When I began to carefully examine the details of the feather textile, it soon became possible to make out feathers in many different colours and to reconstruct the original design. (Fig. 9) This closer examination helped to realise that other feather shirts, with similar design, exist and have already been published. ${ }^{24}$

\section{Late Intermediate Period (1000 - 1470 A.D.)}

\section{Chancay veils (gauze weave and knotted and looped nettings)}

Very sophisticated and outstanding techniques of different groups of the Late Intermediate Period, such as the Chancay textiles, are represented with more samples. The Chancay gauze weaves from the "Late Intermediate Period" is a truly fascinating collection and is the biggest object group among the pre-Columbian textiles in Krefeld. These garments, were maybe made for women as headgear and were very special due to their light weight and the fascinating techniques. We shall not forget, that the aim of the creation of this collection was to teach, to present more and more different, difficult, or complex techniques.

All pieces are finely made and many of them still have all four selvedges intact. They have a square shape, and are each sewed together from two panels - each with four selvedges. A dark blue specimen is presented here (Fig. 10). It was made from dark blue cotton yarns and the design was created through the crossings of the warps (gauze weave).

Other Chancay veils are made by knotting or looping a net-like ground that had stylized figures of animals embroidered on. It is possible that the pieces were sewn together to make even bigger objects. The biggest veil textile in the Krefeld Museum was composed from four complete square veils, all of them made from two panels. Two of these square veils are complete; there is a part missing from the third one, and the fourth only exists as a very small fragment. The item is $174 \mathrm{~cm}$ long and $148 \mathrm{~cm}$ wide. The four squares were originally nearly the same size. Every panel was made individually and each had its own design. Moreover, each square was sewn together from two seemingly identical parts. The stiches are hardly recognisable because the motives were perfectly fitted. ${ }^{25}$

Some documents show the effort made by Renate Jaques to deepen the knowledge about the cultural background and

23. The fragment of the museum is only one side of a whole shirt. It seems that this part has been laying on a board and the feathers have been damaged after a while.

24. I have found two other feather shirts with similar design: one in the book about pre-Columbian feather works (Heidi King, 2012, 136, Nr. 9.) and another one presented by Jose Alfredo Campos, 2015, 486: restauration and reconstruction of a strongly damaged feather tabard

25. DTM Inv. Nr. $12876,148 \times 174 \mathrm{~cm}$. 


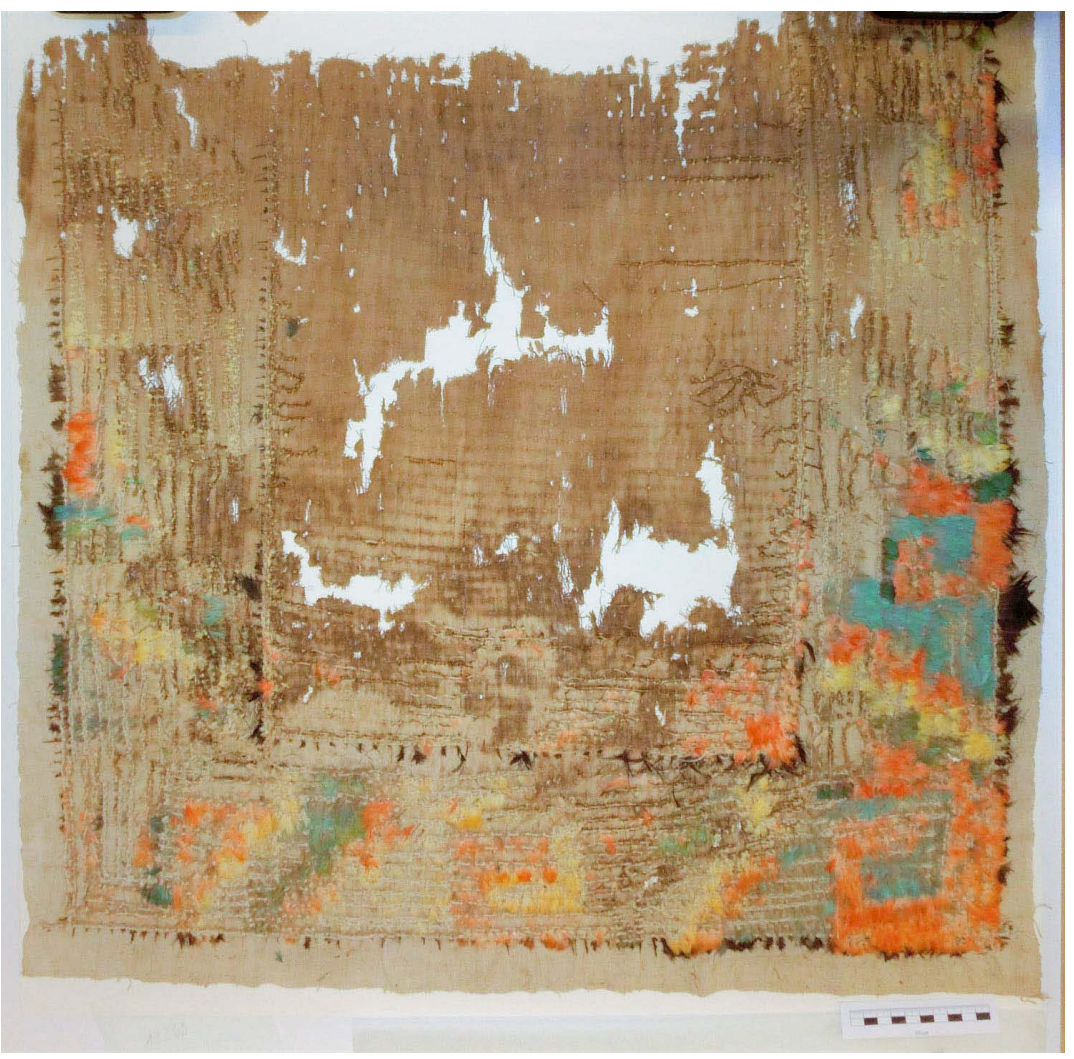

Figure 8. Feather tabard. Cotton plain weave, decorated with feathers of birds from the Amazonian rain forest, $74 \times 100 \mathrm{~cm}$ (DTM Inv. Nr. 12263)

Figure 9. Reconstruction of the design of the feather tabard (DTM Inv. Nr. 12263)

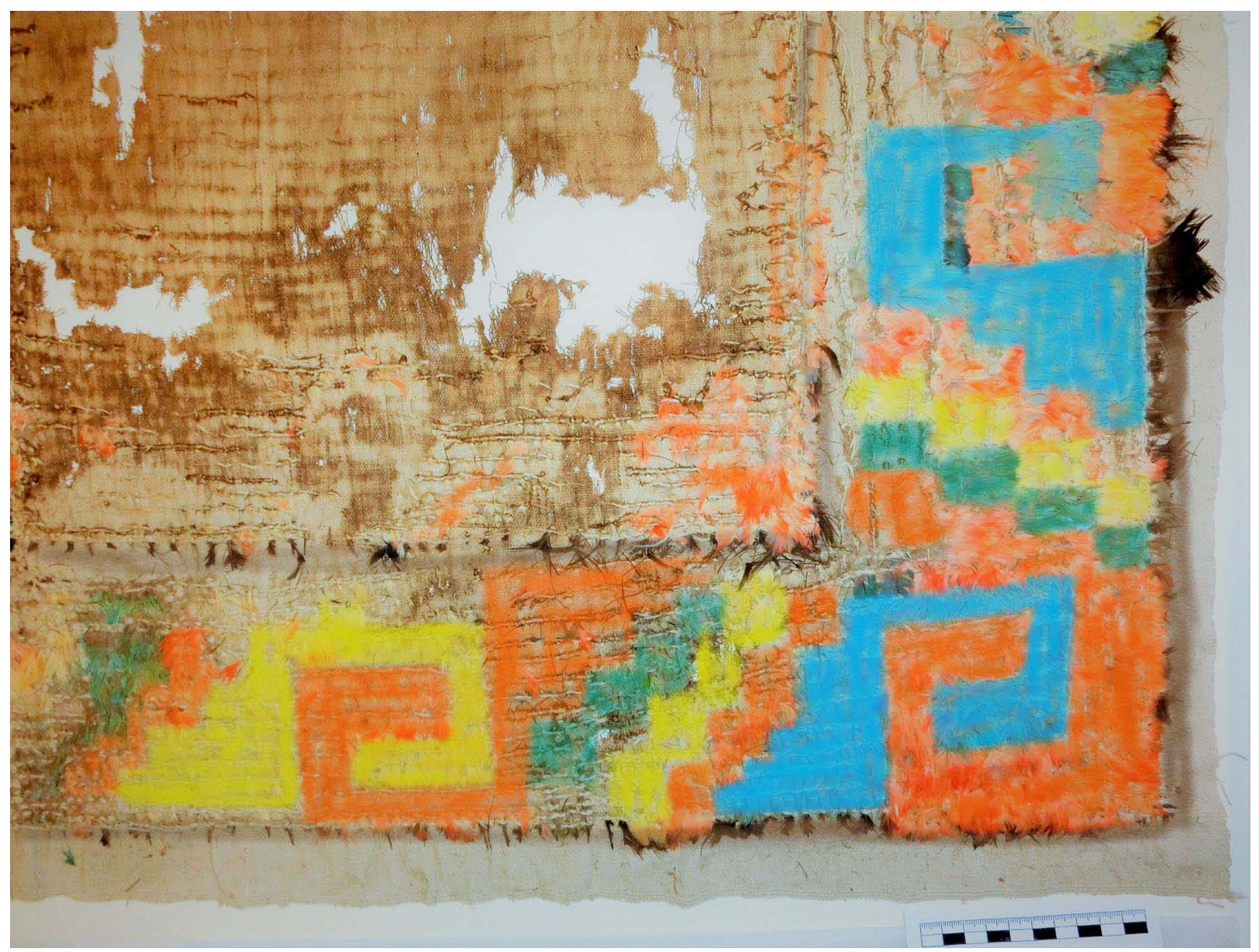




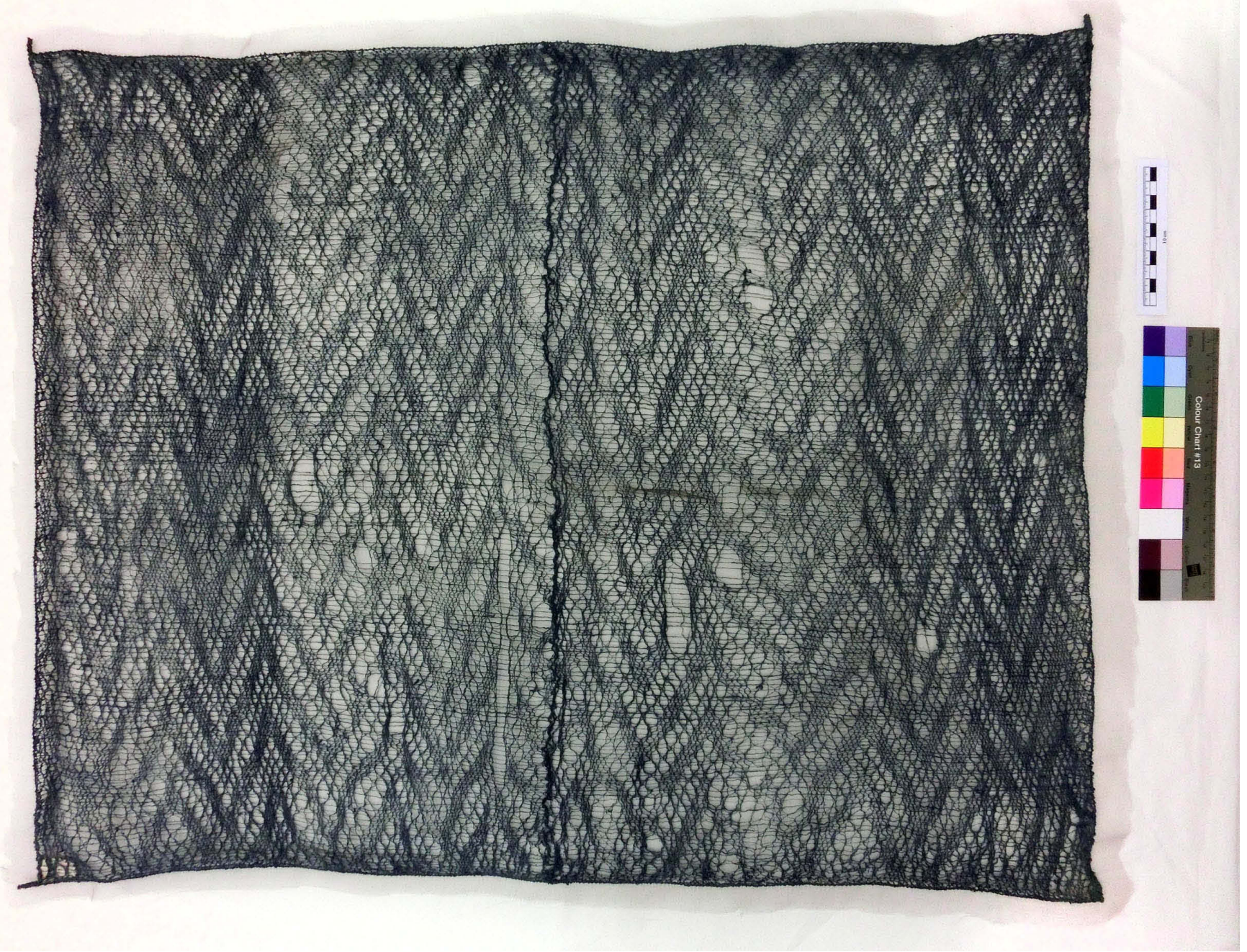

Figure 10. Chancay gauze weave with a chevron motif. Dark blue dyed cotton, 66,5 x 83 cm (DTM Inv. Nr. 12809)

to create a new catalogue. Hans-Dietrich Disselhoff, at that time director of the Völkerkunde Museum Berlin (today Ethnologisches Museum Berlin) was invited to Krefeld. He was asked for his scientific consultation and expertise about all pieces of the Peruvian textile collection. In June 1964, he spent a few days studying the pieces. Still in the first half of the 6os, perhaps on the advice of professor Disselhoff, Renate Jaques, the director of the collection, travelled to Peru twice. Her colleague from the textile collection, the textile engineer Miss Wencken, who was also responsible for the study and the identification of the textile techniques, accompanied her. They were very interested in the Chancay-veils and studied all the many veils in the Amano-collection in Lima. They compared eighteen pieces and created different groups based on the techniques used. In 1968, the results were presented at the 38th International Conference of the Americanists in Stuttgart, Germany. This article did not really create an echo, perhaps because it was written in German and I have not come across an English translation yet. ${ }^{26}$

\section{The Colonial Era (1530 - 1830)}

Some textiles in the collection belong to the Colonial era and some are ethnological. The next piece was definitely made in the Colonial Period. This intact woman's shawl is an example of the highland-style - warp-faced and warp patterned (Fig. 11). It is made from camelid hair in different colours, natural and dyed, with silver yarn added. This lliclla looks similar to many others made for rituals. ${ }^{27} \mathrm{Al}-$ though metal threads were already used in the $16^{\text {th }}$ century, 


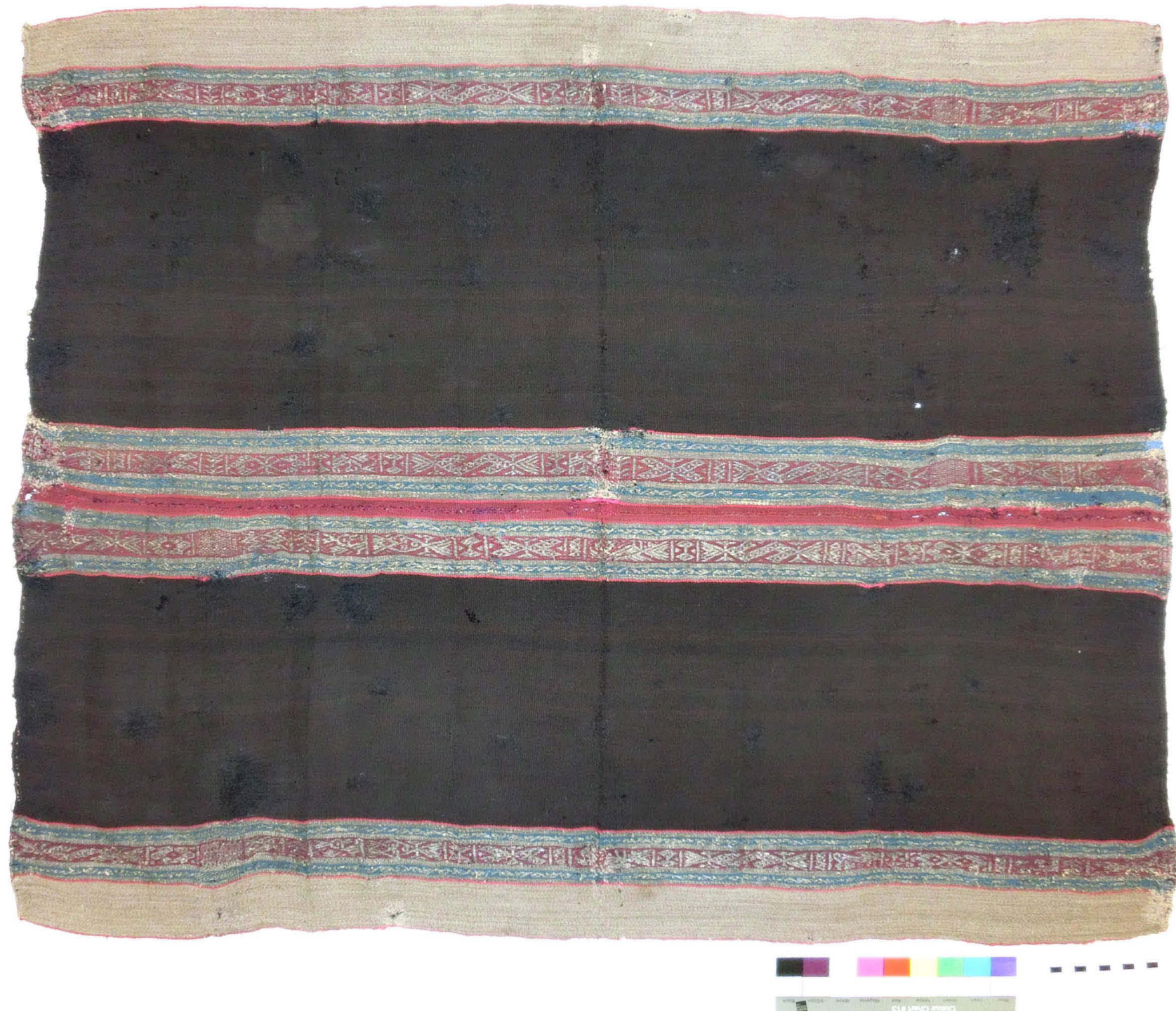

Figure 11. Lliclla, female shawl, with decorating warp pattern stripes with silver thread, probably $18^{\text {th }}$ Century. $96 \mathrm{x} 78 \mathrm{~cm}$ (DTM Inv. Nr. 12219)

a detail in the decoration, an anthropomorph motive points to it having been made in the $18^{\text {th }}$ century ${ }^{28}$. In the $16^{\text {th }}$ century gold and silver were already being shipped to Spain and metal threads from Europe were imported, where they were broadly used since about the $12^{\text {th }}$ century. ${ }^{29}$ "Metallic yarns were introduced into the weaving tradition of the Andes in the sixteenth century, after Spanish administrators and church officials began commissioning from native weavers tapestries derived from European models." ${ }^{30}$
"But documentary evidence suggests that it could also have been done in Peru, by artisans of varied ethnicities. For example, in Cusco in 1686, the goldsmith (tirador de oro y plata) Blas de Aguirre, likely a creole or mestizo, was contracted to work in a home over the course of four years. Part of his responsibility was to 'pull gold and silver into the state that it can be woven in silk or on thread." 31

What is special about this piece are the metal threads used for the traditional motifs on the broad warp pattern

28. The main motif of this lliclla, the "inkarrí" was appeared after 1780 .

29. Phipps, 2010, 9

30. Phipps, 2010, 4

31. In Spanish: "en hacer tirar oro y plata hasta poner en estado de que se hile en seda o en hilo." Stanfield-Mazzi, 2015,91 and note 43. 


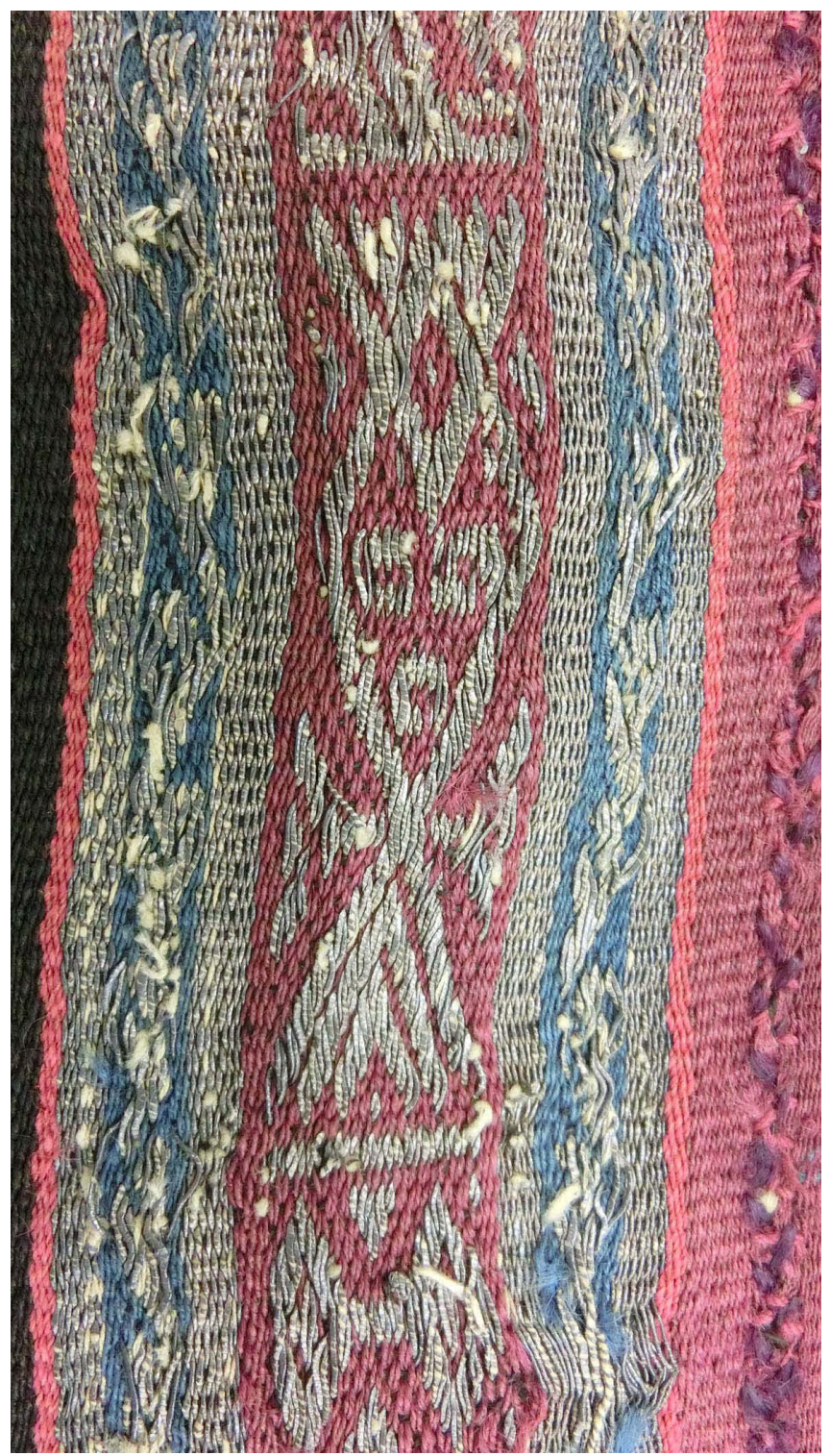

Figure 12. Enlarged detail of a decorated stripe (DTM Inv. Nr. 12219)

stripes, which is called pallay in Quechua. Which part was replaced with the silver thread? A close-up of the silver threads shows that they were used as pattern warps in the traditional way. The lliclla presented here is made from two four-selvedged cloths, with different widths: 36 and $41 \mathrm{~cm}$ wide. The motives in the stripes are both figurative and geometric (Fig. 12). Only the ends of the pallay-stripe carry recognizable anthropomorphic motives. ${ }^{32}$

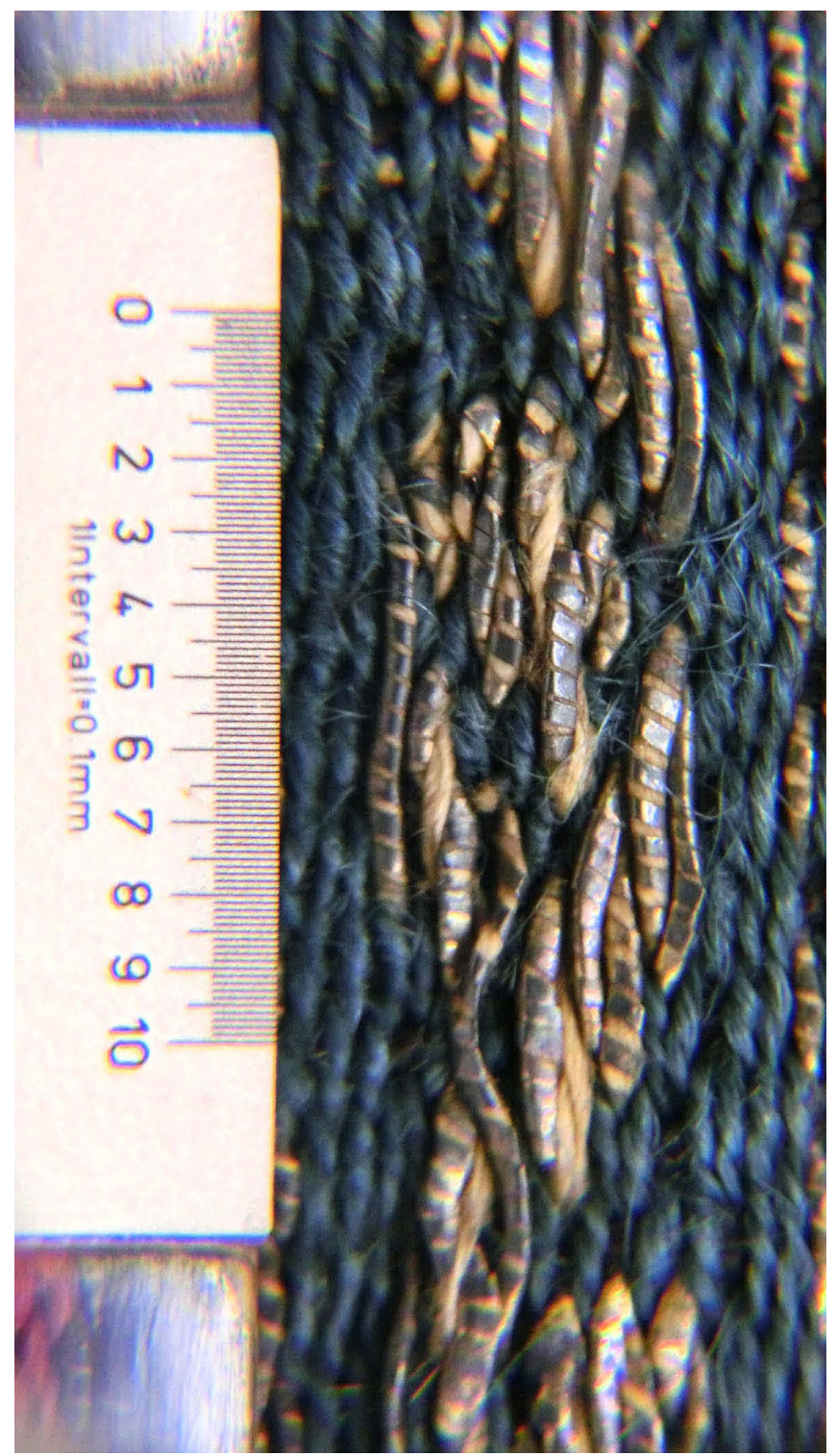

Figure 13. Enlarged photo of the silver threads. Two details of the decorated silver stripes of the two llicllas (DTM Inv. Nr. 12219 and DTM Inv. Nr. 11286)

This thread is made with solid, flat metallic strips cut from sheets of pure silver wound around the core yarn. The core material is silk. Elena Phipps describes different kinds of metal yarns. ${ }^{33}$ Depending on the amount of the metal, the core was covered completely or left with visible areas. In this example, the core is almost covered. This is obviously a highly valuable thread (Fig. 13).

Metal yarn is less flexible than camelid hair or woollen

32. To interpret this motive it is worth to look at the „ch' unchu“ motive of some llicllas of the Q'ero as symbol of the „inkarrí”. See: G. Silverman, 1994, 84, fig. 3.15 and 149, fig. 7.1 The word inkarrí is a composition of the Quichua word Inka and the Spanish rey, king. In the Andean collective memory this this mythical figure appears as a fusion of the last Incas killed by the conquerors. This historical moment was after the rebellion with the Andean leader Túpac Amaru II. was struck down in 1780. López-Baralt, 2011, 227.

33. E. Phipps, 2010, 7-9 


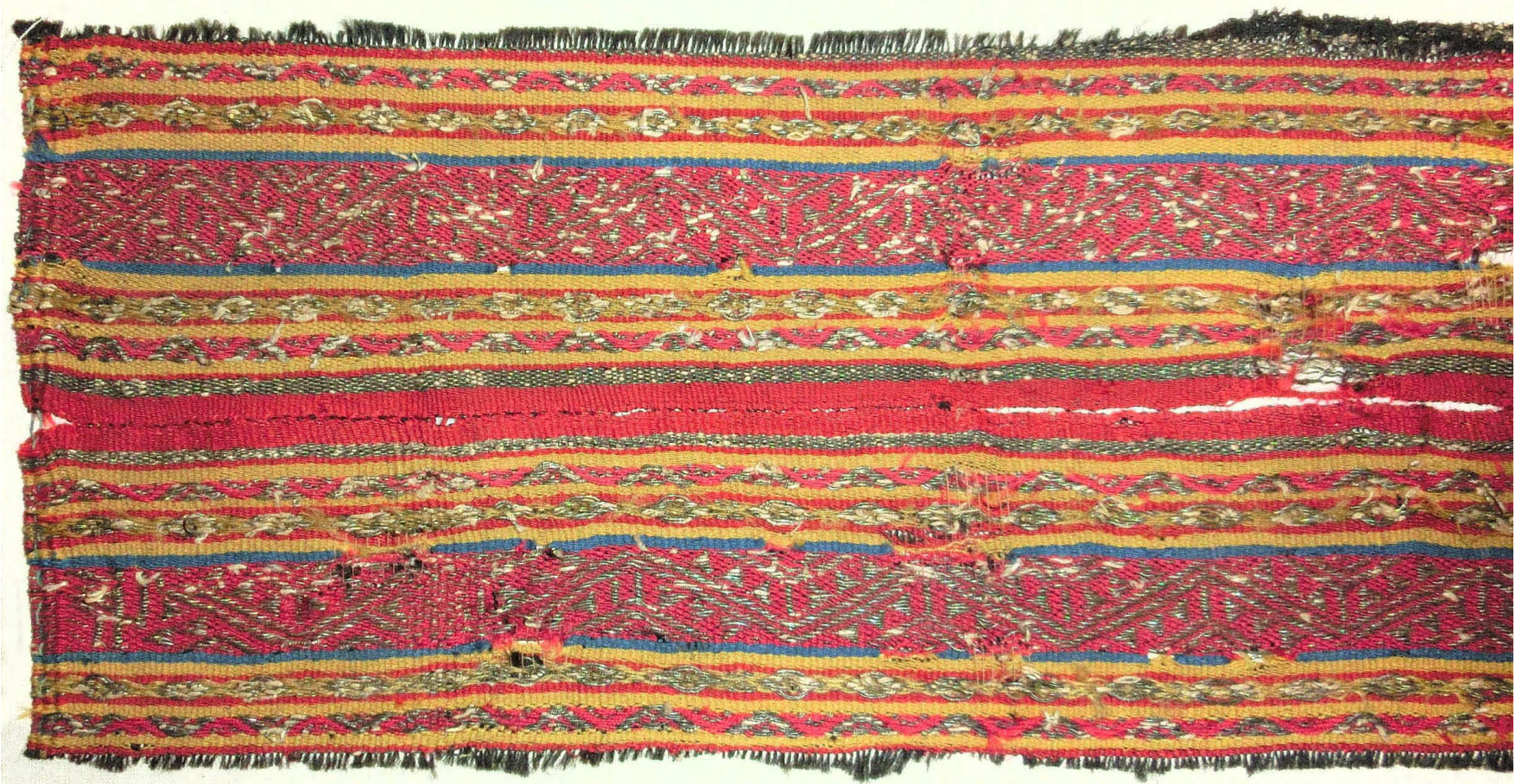

Figure 14. Decorated middle part of a women`s shawl, lliclla, fragment, probably $18^{\text {th }}$ Century. Camelid hair, natural and dyed, with silver threads, 93 x 16,5 cm (DTM Inv. Nr. 11286)

Figure 15. Enlarged photo shoot of the silver threads of the lliclla fragment (DTM Inv. Nr. 11286)

yarns, therefore, it is well suited for the warp pattern stripe with a constant direction. But metal threads were also used for weft, mainly in tapestries or for embroidery.

“Men's Inca-style garments, which continued to be worn by elite Andeans in the colonial era, often incorporated some metallic yarns." ${ }^{34}$ In tapestry they were used as weft elements for small scale designs, such as small animals, or faces of the sun. This kind of tapestry weaving was typical for the Inca-style garments, but during the pre-Columbian era metal yarns were never used. ${ }^{35}$

Another piece is presented here for comparison. It is a fragment of a similar lliclla and measures 93 by $16,5 \mathrm{~cm}$ (Fig. 14). The quality of this silver yarn is similar to the previous one but it is in a better condition (Fig. 15).

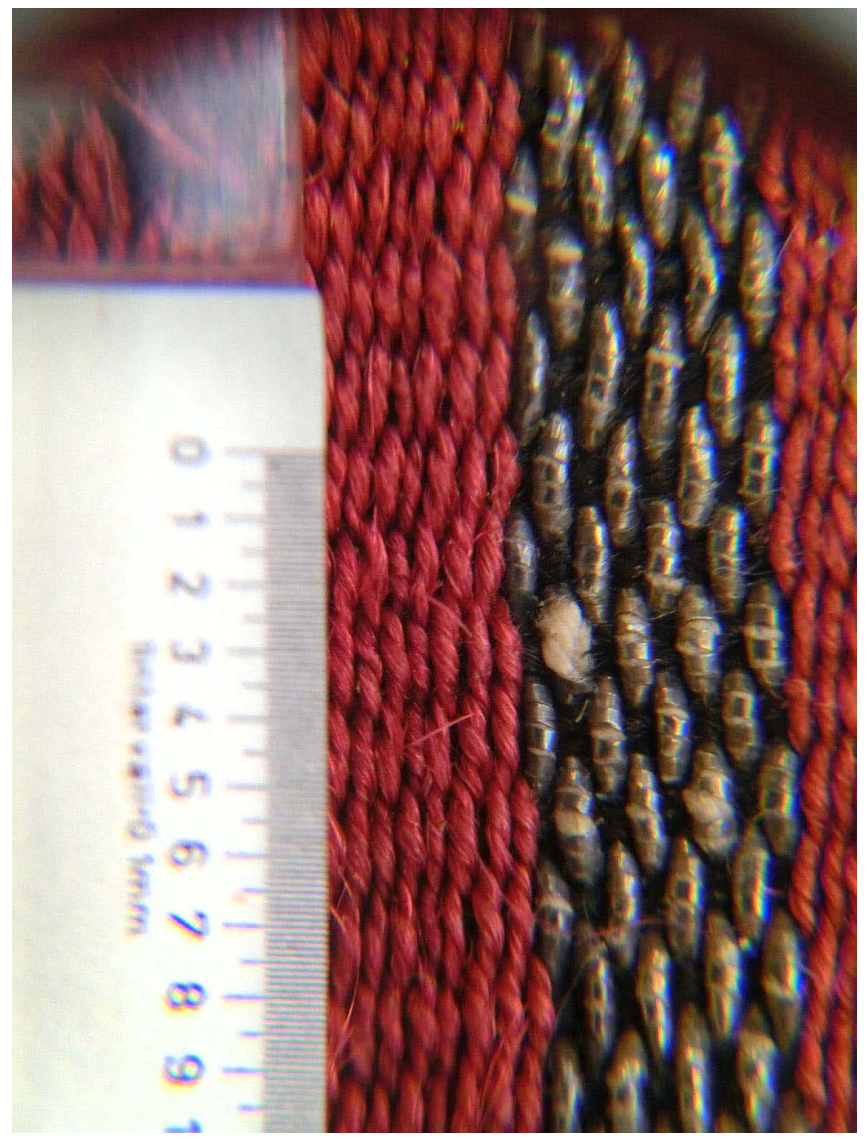




\section{Summary}

The facts above support the statement that the collection was not created because of a scientific interest in archaeological, historical, or cultural questions but rather due to the interest in the technical and technological possibilities to produce different textile objects and garments. The one and only reason to gather the items was to create a collection of textile techniques, which is, in fact, a collection of textile pieces. The school was created by the wealthy factory owners of Krefeld, a city, which at that time, had already had a very long textile tradition. Thus, the acquisition of such a collection and the modernisation of the education in the Weaving School (Crefelder Höhere Webschule) significantly added to the image of the city. ${ }^{36}$ With it, the city expressed its awareness of its history and pride in the source of its prosperity - textile manufacturing.

Today the museum is a place for scholars from all over the world to meet. The museum has several expositions of modern textile art, it also has a good library with special conditions for studying the history of textile culture in general and the history of pre-Columbian textiles.

\section{Acknowledgments}

The investigation on the pre-Columbian collection of the German Textile Museum is part of the current project "Shed light", funded by the cultural fund of the Sparkasse Krefeld. My cordial thanks to Annette Paetz gen. Schieck, the director of the German Textile Museum in Krefeld. Also, I would like to express my great gratitude to the team of the Museum in Krefeld. Their heartful welcome and comprehensive assistance helped me considerably in getting ahead. Also, many thanks to Lena Bjerregaard and Ann $\mathrm{H}$. Peters, their comments and questions helped me to make the text more clear.

\section{References}

Arnold, Denise Y. and Penelope Dransart (ed.)

2014, Textiles, Technical Practice, and Power in the Andes. Archetype Publications Ltd. London

Bergh, Susan E.

2012, Wari: Lords of the Ancient Andes. Cleveland Museum of Art, Cleveland. Thames \& Hudson, New York

British Museum, database

2019, https://research.britishmuseum.org/research/ search_the_collection_database/term_details. aspx?bioid $=35776$ (source 26.11 .2019 )
Campos, Jose Alfredo

2015, Conservación y restauración de bienes culturales en el MUSEF. In: Jaimes Betancourt, 2015:479-486)

Fischer, Manuela

1992, Amerika aus der Sicht des Sammlers: Die Sammlungen südamerikanischer Archäologica des Museums für Völkerkunde, Berlin. In: Amerika 1492 - 1992. Neue Welten - Neue Wirklichkeiten. Essays. (257-263). Ibero-Amerikanisches Institut Preußischer Kulturbesitz und Museum für Völkerkunde Staatliche Museen zu Berlin. Westermann, Braunschweig

\section{Gewebesammlung Krefeld}

1971, Kostüme, Trachten, Schmuck aus aller Herren Länder. Catalogue with an introduction by Renate Jaques. Gewebesammlung Krefeld, Krefeld

Heiden, Max,

1904, Handwörterbuch der Textilkunde aller Zeiten und Völker für Studierende, Fabrikanten, Kaufleute, Sammler und Zeichner der Gewebe, Stickereien, Spitzen, Teppiche und dergl., sowie für Schule und Haus. Verlag F. Enke, Stuttgart

Jaques, Renate,

1969, Jourtextilien aus dem Chancaytal in der Sammlung Amano in Lima. In: Verhandlungen XXXVIII. Internationalen Amerikanistenkongresses, Stuttgart - München, 12. bis 18. August 1968, Band I. Komissionsverlag Klaus Renner, München

Jaimes Betancourt, Carla,

2015, El poder de las plumas. Museo Nacional de Etnografía y Folklore, La Paz. La Paz, Bolivia

King, Heidi,

2012, Peruvian Featherworks. The Metropolitan Museum of Art, New York

López-Baralt, Mercedes,

2011, El Inca Garcilaso, traductor de culturas. Iberoamericana, Vervuert, Frankfurt am Main

Paetz gen. Schieck, Annette,

2013, Transformation Processes of the Jakob Krauth Textiles Collection into a Study Collection and Emergence of the Deutsches Textilmuseum Krefeld, Germany. In: Belleza Rosina, Margherita (ed.): Collecting Textiles. Patrons Collections Museum. 2013: 47-62. By Fondazione Ratti. Allemandi \& C., Torino

Peters, Ann H.,

2014, Paracas Necropolis: communities of textile production, exchange networks, and social 
boundaries in the Central Andes, $150 \mathrm{BC}$ to $\mathrm{AD} 250$.

In: Arnold and Dransart, 2014: $109-139$

Phipps, Elena,

2010, Woven Silver and Gold: Metallic Yarns in Colonial Andean Textiles. In: Source: Notes in the History of Art. Vol. 29, No. 3, Special Issue: Paradoxes and Parallels in the new World (Spring 2010: 4-11) The University of Chicago Press, Chicago

Reiss, Wilhelm und Alphons Stübel,

1880 - 1887, The Necropolis of Ancon in Peru. Published by A. Asher, Berlin
Rowe, Ann Pollard,

2012, Tie-dyed Tunics. In: Bergh, S. E., 2012: 193-206.

Silverman, Gail,

1994, El tejido andino: un libro de Sabiduría. Banco Central de Reserva del Perú, Lima

Stanfield-Mazzi, Maya,

2015, Weaving and Tailoring the Andean Church: Textile Ornaments and their Makers in Colonial Peru. In: The Americas. A Quarterly Review of Latin American History, Vol. 72, special issue 01. pp 77-102. Cambridge University Press, Cambridge 


\title{
14
}

\section{Ancient Peruvian textiles in the Vatican Museums and their link to the Musée du Trocadéro collections}

\author{
Jean-François Genotte \\ Assistant Registar, Ethnological Collections \\ The Vatican Museums, Vatican City State, jf.genotte@scv.va
}

\begin{abstract}
The Vatican Museums keep a small collection of about sixty textile fragments mostly Lambayeque, Chimu and Chancay dating back to Late Intermediate Period. Unfortunately, the archaeological provenance of these items is not known. This paper offers a first overview of the history of the collection, describing its contents and, in more details, its most interesting fabrics. We will then suggest that some fragments of the Vatican collection might have been part of textiles once kept in the Musée du Trocadéro, and nowadays preserved in the Quai Branly Museum in Paris.
\end{abstract}

Keywords: Vatican Museums, Musée du Trocadéro, Rodolphe Pfister, Fritz Iklé, Lambayeque, Chimu, Chancay, monkey, bicephalic serpent, feathered crescent-shape headdress, comma shaped eyes, Staff-bearing Deity

\section{Resumen}

Los Museos del Vaticano conservan una pequeña colección de unos sesenta fragmentos textiles, en su mayoría Lambayeque, Chimú y Chancay, que datan del Periodo Intermedio Tardío. La procedencia arqueológica de estas piezas lamentablemente no se conoce. Por primera vez, presentamos la historia de la colección, sus contenidos y las piezas textiles más interesantes. Proponemos entonces que algunos fragmentos de la colección del Vaticano probablemente podrían haber sido parte de tejidos, previamente conservados en el Museo del Trocadero, y hoy expuestos en las colecciones del Musée du Quai Branly en París.

Palabras claves: Museos del Vaticano, Museo del Trocadero, Rodolphe Pfister, Fritz Iklé, Lambayeque, Chimú, Chancay, mono, serpiente bicéfala, tocado de plumas en forma de media luna, ojos alados, Deidad con báculos

\section{Résumé}

Les Musées du Vatican conservent une petite collection d'une soixantaine de fragments de tissus, pour la plupart Lambayeque, Chimu et Chancay, datés de la Période Intermédiaire Récente. La provenance archéologique de ces pièces n'est malheureusement pas connue. Pour la toute première fois, nous présentons l'histoire de la collection, son contenu et les exemplaires textiles les plus intéressants. Nous proposerons ensuite comment certains fragments de la collection du Vatican auraient probablement pu faire partie de tissus, autrefois conservés au Musée du Trocadéro, et aujourd'hui présents dans les collections du Musée du Quai Branly - Jacques Chirac à Paris.

Mots-clés : Musées du Vatican, Musée du Trocadéro, Rodolphe Pfister, Fritz Iklé, Lambayeque, Chimu, Chancay, singe, serpent bicéphale, coiffe en plumes en forme de demi-lune, yeux en forme de virgules, Divinité aux bâtons

Photographs Foto Copyright (c) Governatorato S.C.V. - Direzione dei Musei: Jean-François Genotte (Fig. 1, 2); Alessandro Bracchetti (Fig 3 to 12).

DOI: $10.32873 /$ unl.dc.zea.1215

Published in PreColumbian Textile Conference VIII / Jornadas de Textiles PreColombinos VIII, ed. Lena Bjerregaard and Ann Peters 


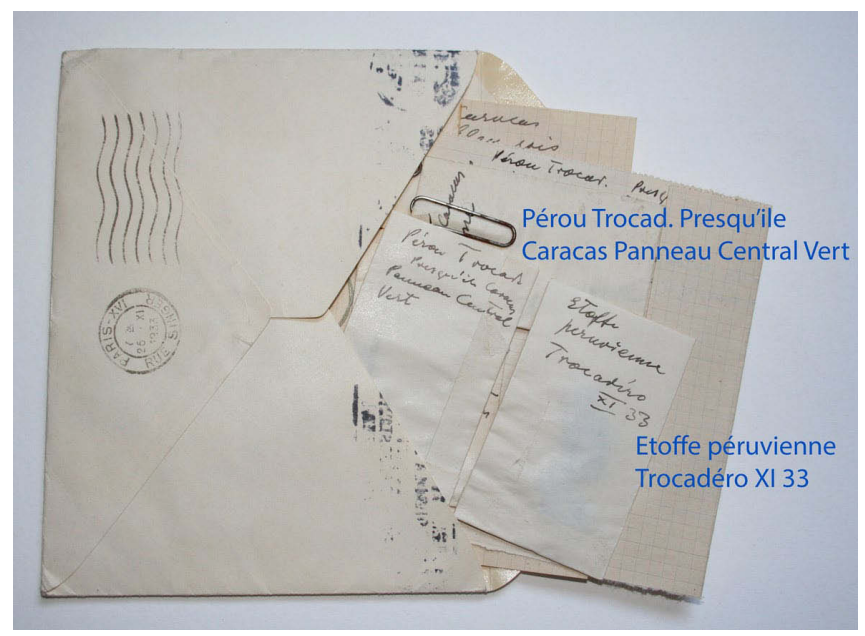

Figure 1. Notes on small sheets found with the Vatican fragments that suggest the provenience from the Musée du Trocadéro in Paris. Vatican Museums, Vatican City. Foto Copyright (c) Governatorato S.C.V. - Direzione dei Musei.

\section{The history of the collection}

In the Vatican Museums, there is a small collection of textiles from ancient Peru. While we cannot compare this small series of items to the large collections of pre-Columbian textiles of prestigious European and American museums, both in terms of number of pieces and aesthetic value, nonetheless it has a curious history. The small group of ancient Peruvian textiles, indeed, is part of a larger collection, the Pfister Collection, consisting of over 1600 textiles of oriental origin: most of the items come from Sasanid Iran, from Pharaonic, Fatimid and Coptic Egypt, and from Palmira. The Pfister Collection is part of the Tapestry and Textiles (Arazzi e Tessuti) department of the Vatican Museums.

The Peruvian Vatican collection consists of sixty-four small-sized fragments from twenty-six different textiles ${ }^{1}$, four cords of camelid fibers ${ }^{2}$ and nineteen samples of camelid fibers and cotton yarns of different colors (red, pink, gold and mustard yellows, green, blue, purple) ${ }^{3}$. These items are the only pre-Hispanic textile fragments preserved in the Vatican Museums, except for one Wari feathered panel (MV 103872) and three cotton fragments sewn together decorated with geometric patterns (MV 104358), perhaps of Wari style, preserved in the Ethnological department (Museo

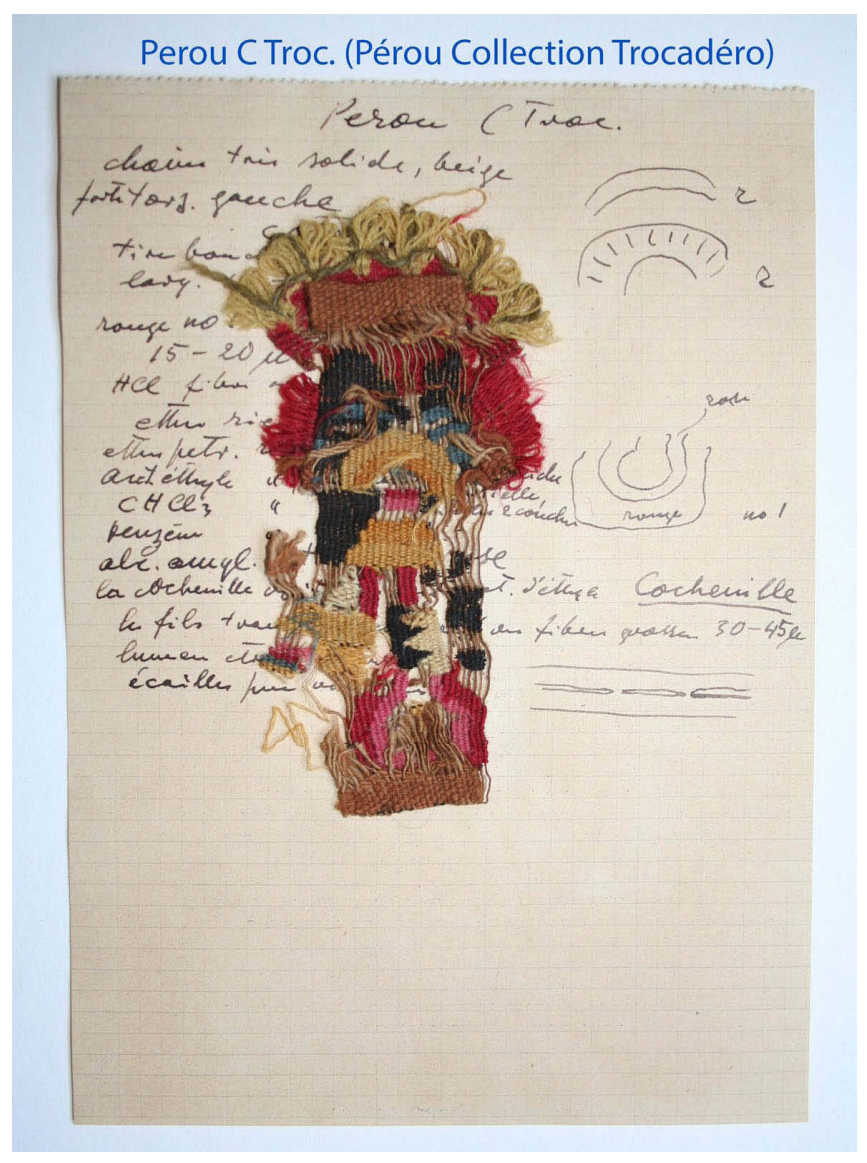

Figure 2. Notes found with fragment MV 63652 that suggest its provenience from the Musée du Trocadéro and show Pfister's interest to analyze dyes and textiles. Vatican Museums, Vatican City. Foto Copyright (C) Governatorato S.C.V. - Direzione dei Musei.

Etnologico "Anima Mundi"). The archaeological context of these items collected between the twenties and thirties of last century by Rodolphe Pfister (1867-1955), a Swiss chemist specializing in the study of the ancient textiles of Asia and the Near East, is unfortunately unknown.

As far as we know, Pfister, driven by a specific scientific interest in the chemical study of dyes, collected many fragments and textile samples from many countries, which he obtained through his large network of friends and acquaintances in museums and institutions worldwide.

In $1958^{4}$, the Pfister Collection was donated to the Vatican Apostolic Library by provisions of Rodolphe Pfister's last will; subsequently, in October 1999, it became integral part of the Vatican Museums ${ }^{5}$. Several notes (fig. 1, 2) written

1. MV 62407, MV 63625, MV 63626, MV 63643 to MV 63662, MV 63777, MV 66991, MV 67012.

2. MV 63627 to MV 63629, MV 63642.

3. MV 63630 to MV 63641, MV 63776, MV 63778 to MV 63783.

4. Legacy of Rodolphe Pfister to the Vatican Apostolic Library, 1958 (ASMV).

5. The collection moved to the Vatican Museums from the Vatican Apostolic Library according to the provisions in the Rescriptum of John Paul II, August 1, 1999. 
on small sheets ${ }^{6}$ have been found with three textiles ${ }^{7}$ and with most of the cords and samples of yarns ${ }^{8}$. Those notes suggest that before the items were collected by Pfister, they were kept at the Musée du Trocadéro ${ }^{9}$ in Paris, and have been most likely given to him in November $1933^{10}$. The fragment MV 63649 was donated to Pfister by the Swiss collector Fritz Iklé ${ }^{11}$ in November $1927^{12}$. We also know from a letter written in December $1936^{13}$ that Pfister planned a visit to the Musée du Trocadéro in order to see the Peruvian textiles of the Parisian collection.

Documents of the Pfister Archive ${ }^{14}$ that are kept in the Vatican Museums provide scarce clues as far as dating, origin, culture and description of the fragments in the collection are concerned. We do not even know if these items came from official archaeological excavations or lootings in necropolis. Origin of the items can be attributed to the Peruvian area thanks to some notes written in French that were found with some of the textile fragments. They provide the following (and unambiguous) information: "Peru"15, "Peruvian textile"16 and "Peruvian mummy"17.

Other notes indicate that some samples of yarns ${ }^{18}$ and the fragment MV 63777 are Peruvian and came from the Paracas Peninsula ${ }^{19}$; it seems that they were taken from the central panel of a large textile, of which we know nothing. Some letters ${ }^{20}$ kept in the Pfister Archive, however, show that Pfister sought to analyze dyes used in the tincture of pre-Columbian Peruvian textiles; therefore, he was interested in purchasing Peruvian textiles and wishful to visit the Musée du Trocadéro to examine Peruvian textiles and discuss with Raoul D'Harcourt.

Between 2008 and 2009, the textile fragments of the Pfister Collection have been carefully restored, under the responsibility of the Tapestries and Fabrics restoration laboratory of the Vatican Museums.

\section{The textile collection}

Most of the Peruvian textile fragments of the Pfister Collection date back to the Late Intermediate Period (900-1476 $\mathrm{AD}$ ) and almost all come from the North and Central coasts of Peru ${ }^{21}$. Three fragments ${ }^{22}$ seem to be dated about 8oo$1200 \mathrm{AD}$, between the end of the Middle Horizon and the

6. These sheets are preserved, together with their corresponding items, in the collections of the Vatican Museums.

7. MV 63626, MV 63650, MV 63652.

8. MV 63627 to MV 63642, MV 63776, MV 63778 to MV 63781, MV 63783.

9. The Musée du Trocadéro, or Musée d'ethnographie du Trocadéro (Ethnographic Museum of the Trocadéro), was the first anthropological museum in Paris, founded in 1878 as the Musée ethnographique des missions scientifiques (Ethnographic Museum of Scientific Expeditions) and housed in the Trocadéro Palace (1878-1935), then demolished in 1935. In 1937, it took the name of Musée de l'Homme (Museum of Mankind), and part of its collections were relocated in the Palais de Chaillot just built on the same site (1935-1937). In 2004, the vast majority of the collections preserved in the Palais were moved to the new Quai Branly Museum, opened in 2006 and renamed Musée du quai Branly - Jacques Chirac in 2016.

10. At the beginning of the twenty century private collectors, antique dealers and museum institutions used to cut fragments from pre-Columbian textiles to buy, sell or donate them to other museums and collectors (Bjerregaard et al. 2017, p. 33).

11. Fritz Iklé (1877 1946) was the younger son of Leopold Iklé, an important manufacturer, merchant and textile collector from St. Gallen (Switzerland). He formed its own collection from the early 1920s. During the same period, he became interested in the textile collection from ancient Peru preserved in the Musée du Trocadéro in Paris, and published his research on this topic in 1930: Über Alt-Peruanische Stickereien des Trocadéro, Paris. Mitteilungen der Ostschweiz. Geogr. Commerz. Gesellschaft, St Gallen (Iklé 1930; http://www.textilmuseum.ch/textilmuseum). 12. This date is written on an envelope containing the fragment MV 63649.

13. R. Pfister to H. Delbrueck, letter, 2 December 1936, ASMV, Carte Pfister, busta 24, fascicolo Europa I.

14. It is a significant amount of archive material, preserved in the Historical Archive of the Vatican Museums (ASMV): twenty-one boxes containing various notes by Pfister, two boxes of photos and a rich correspondence filed in six boxes, made up of hundreds of letters exchanged by Pfister with many scholars between 1920 and 1940 .

15. Spelled as "Pérou" on the sheets found together with the fragments MV 63626, 63650 and 63652.

16. Written as "Étoffe péruvienne" on the envelope containing the fragment MV 63649.

17. The note, relating to the MV 63630 to MV 63641 yarns, is written on a piece of paper and reads as follows: "Trocadéro 15 XI 33 / Échantillon de fils de différentes couleurs provenant de pelotes de fil trouvées dans une momie péruvienne"; that is: "Trocadéro 15 XI 33 / Sample of yarns of different colors from yarn balls found in a Peruvian mummy".

18. MV 63776, MV 63778 to MV 63783.

19. In the notes it is erroneously reported "Presqu'île de Caracas", but probably the site referred to it is the Paracas peninsula and not that of Caracas, which indeed does not exist in Peru.

20. R. Pfister to Fortunato L. Herrera, letter, 23 December 1933; R. Pfister to Fortunato L. Herrera, letter, 27 April 1934; R. Pfister to H. Delbrueck, letter, 2 December 1936 (ASMV, Carte Pfister, busta 24, fascicolo Europa I).

21. MV 63625, MV 63626, MV 63644, MV 63645, MV 63647, MV 63648, MV 63650, MV 63651, MV 63652, MV 63653, MV 63654, MV 63655, MV 63656, MV 63657, MV 63658, MV 6366o, MV 63662.

22. MV 62407, MV 63659, MV 67012. 
beginning of the Late Intermediate Period, while only one item MV 63649 may have been woven between the end of the Late Intermediate Period and the beginning of the Middle Horizon (1400-1500 AD). As far as two more items are concerned (MV 63661, MV 63777), they are probably of coastal origin, although it is not possible to propose a precise dating.

Four textiles ${ }^{23}$ have been attributed to Chancay culture, four items ${ }^{24}$ to Chimu culture, while a larger number of fragments are possibly of Lambayeque or Lambayeque/Chimu style $^{25}$. The fragment MV 63649 is probably of Chimu/Inca style while a last item (MV 63646), hardly identifiable, is attributed to one of the cultures of the Highlands or of the Coast between the Middle Horizon and the Recent Horizon (6oo- $1500 \mathrm{AD}$ ). It was not possible to attribute each of the Vatican fragments to a specific type of garment, because they are all very small. However, most of these could be fragments of borders ${ }^{26}$, decorative bands ${ }^{27}$ or appliqué decorative elements ${ }^{28}$.

As for the iconographic repertoire used in the decoration of the Vatican fragments, there is a remarkable homogeneity of motifs typical of the Lambayeque, Chimu and Chancay cultures; those patterns reflect a worldview based on a common religion, in turn closely connected to agriculture and to the resources and the economy of the coast, so important for local populations. First, there is a recurring presence of the sea in the form of stylized depictions of fish ${ }^{29}$ (fig. 9, 10), waves ${ }^{30}$ and birds ${ }^{31}$ (fig. 11). Other typical coastal motifs are anthropomorphic figures (fig. 4, 6, 9, 10) that represent deities, priests (shamans) and high-ranking dignitaries, depicted in frontal position, sometimes with a large elaborate crescent-shaped feather headdress or with a headdress adorned with a snake-shaped or a bird-shaped end double plume. The figures are dressed in fine clothing and often recognizable by their insignia of rank: ceremonial staffs or scepters and neckpieces or gorgets ${ }^{32}$. Less frequent, but also present in the Vatican textiles' decoration, are motifs such as the monkey (fig. 3), the flower (MV 63626) (fig. 5), the two-headed snake (MV 63625, MV 63662, MV 63647), the feline and the diamond (MV 63645, MV 63648, MV 63658) (fig. 12). The checkerboard pattern that decorates the two fragments of the probably Chimu ${ }^{33}$ or Chimu-Inca style item MV 63649, dating from ca. 1400-1500 AD, could suggest that they belonged to a tunic worn by a member of the local aristocracy, perhaps of military rank, or in connection with the latest Inca provincial administration.

We decided not to present and describe all the fabrics of the Vatican collection (see below, conclusions), but only some of those that have the most elaborate and interesting iconographic motifs, and some of the fragments of the collection that might have been part of textiles once kept in the Musée du Trocadéro, and nowadays preserved in the Quai Branly Museum in Paris. The main intent was so to dwell above all on the Vatican textiles associated with the Musée du Trocadéro collections.

This beautiful border fragment (fig. 4) is one of the nicest items of the collection. The warp yarns are cotton 2Zplied, while the weft yarns are camelid fiber plied $2 S$. It features a large green frontal male figure centrally placed inside a red rectangular panel, that wears a yellow and olive-green feathered headdress trimmed with green feathers; two earrings; and a green short tunic decorated with blue and yellow geometric patterns, probably metal plaques ${ }^{34}$, with a contrasting patterned band at the bottom ${ }^{35}$. The geometric motifs that we also find on the legs could also be interpreted as body paintings or tattoos because the short tunics worn by the men left their legs bare. These motifs could reproduce small spots therefore suggesting the spotted skin of a feline, perhaps the jaguar ${ }^{36}$, ubiquitous animal in Andean mythology that is associated with rain, agricultural production, sacrifice and fertility ${ }^{37}$.

23. MV 63643, MV 63644, MV 63645, MV 63657.

24. MV 63625, MV 63648, MV 63658, MV 66991.

25. MV 62407, MV 63626, MV 63647, MV 63650, MV 63651, MV 63652, MV 63653, MV 63654, MV 63655, MV 63656, MV 63659, MV 6366o, MV 63662, MV 67012.

26. MV 62407, MV 63625, MV 63648, MV 63658, MV 66991, MV 67012.

27. MV 63626, MV 63650, MV 63659.

28. MV 63647, MV 63651, MV 63652, MV 63653, MV 63654, MV 63655, MV 63656, MV 6366o, MV 63662.

29. MV 62407, MV 63625, MV 67012.

3o. MV 63648, MV 63658.

31. MV 62407, MV 63625, MV 63647, MV 63648, MV 63662, MV 67012.

32. MV 62407, MV 63647, MV 63650, MV 63662, MV 66991, MV 67012.

33. On the use of this motif in Chimu style fabrics, see King 202a, p. 140; Rowe 1984, pp. 31, 95-119.

34. For tunics with metal plaques, see Fleitman and Baginski 2017, pp. 351 (fig. 3-4), 353 (fig. 7); Rowe 1984, pp. 151-154 (fig. 148, 150, 152, pl. 23); Stone-Miller 1994a, p. 128, pl. 38; Jiménez Borja et al. 1987, pp. 244, 251.

35. This band surely represents the tapestry borders on surviving tunics (Bjerregaard 2016, p. 17).

36. Lambayeque (900-1100 AD) and Central coastal textiles (1000-1500 AD) preserved in the Ethnological Museum of Berlin are decorated with jaguars with spotted skin (Bjerregaard et al. 2017, pp. 38, 96-97, 99, 140).

37. Laurencich Minelli 1984, p. 24; Petrucci et al. 1982, pp. 17, 20. 


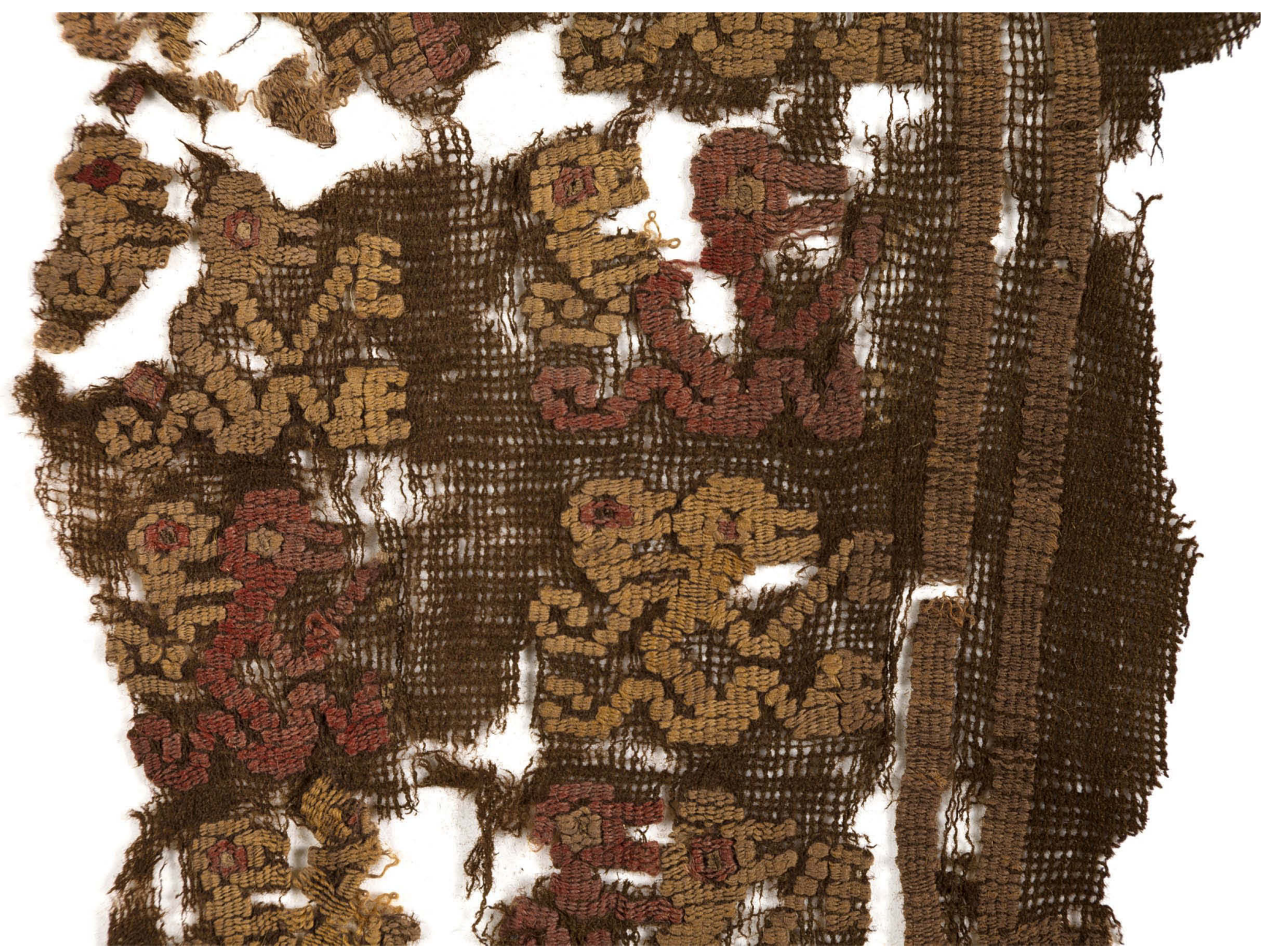

Figure 3. Fragment (detail) with depiction of monkeys. Chancay, Central Coast, Peru, 1000-1200 AD. Cotton (2 warps: S-plied, 1 weft: S-plied), camelid fiber (1 weft: Z-plied); gauze, brocade, 31 x $16 \mathrm{~cm}$. MV 63643, Vatican Museums, Vatican City. Foto Copyright (C) Governatorato S.C.V. - Direzione dei Musei.

The large figure presents some features considered characteristic of Lambayeque imagery: an hourglass nose ornament, spectacled eyes (or the so called "comma shaped eyes ${ }^{38}$ ), a tight neckpiece under the chin - reaching up the ears -, and holds a scepter or a ceremonial staff 39 in his right hand, and a trophy head with falling hair in his left hand. The figure hands and feet, shown in profile, are common to many figures depicted in Northern and Central Coastal textiles dating to the Late Intermediate Period ${ }^{40}$. The figure is depicted with naked feet or wears non-functional shoes with pointed toes ${ }^{41}$.

The image of a figure with an elaborate headdress and a staff in each hand can be found in Chavin art ${ }^{42}$ as well as in Wari and Tiwanaku art ${ }^{43}$. It is not clear if the Lambayeque

38. Figures with comma shaped eyes or upturned comma eyes are typical of the Lambayeque style (Bjerregaard 2016, p. 8, fig. 6, 15, 17; Bjerregaard et al. 2017, pp. 33, 119 (VA 54885), 120 (VA 54886), 121 (VA 54888); Medina Castro et al. 2005, p. 96). According to Young-Sánchez (1994, pp. 43-44, fig. IV.1) the comma shaped eyes may refer to the "mythical" status of the figure.

39. Scepters and ceremonial sticks of wood and metal, sometimes covered with gold and silver and showing a zoomorphic or anthropomorphic upper part have been found in Lambayeque and Chimu tombs belonging to high-ranking individuals (Biordi 2005, p. 89; Jiménez Borja et al. 1987, pp. 269-270; Fleitman and Baginski 2017, p. 354 (fig. 9); Wester La Torre 2013, pp. 108, 110 (fig. 1), 114).

40. See Amano and Tsunoyama 1979, pp. 52 (fig. 42), 68 (fig. 61), 103 (fig. 111); Desrosiers and Pulini 1992, pp. 149 (fig. 88), 150 (figg. 89, 90); Jiménez Díaz 2009, pp. 169 (fig. 119), 170 (fig. 120), 175-176 (fig. 123); Laurencich Minelli 1984, pp. 55 (fig. 42), 111 (fig. 119); Rowe 1984, pp. 71 (pl. 9), 120-121 (pl. 18), 124-128 (fig. 109-117), 129 (pl. 19), 134-135 (fig. 128-129); Stone-Miller 1994a, pp. 128-129 (pl. 38), 165-167 (pl. 6o). 41. Specimens of these shoes covered with silver plaques have been found in Chimu aristocratic tombs (Fleitman and Baginski 2017, pp. 353, 354 (fig. 9); Stone-Miller 1994a, pp. 134-135 (pl. 42).

42. See Hoces de la Guardia Chellew et al. 2007, p. 25; Burger 1992, fig. 147-155.

43. See Bjerregaard et al. 2017, pp. 25 (fig. 1a), 26 (fig. 1b); Jiménez Díaz 2009, pp. 145-148 (fig. 96-99); Lavallée and Lumbreras 1985, pp. 220227 (fig. 200-204), 268 (fig. 241), 274 (fig. 247); Stone-Miller 1994b, pp. 34-35, 37 (fig. III.7). 


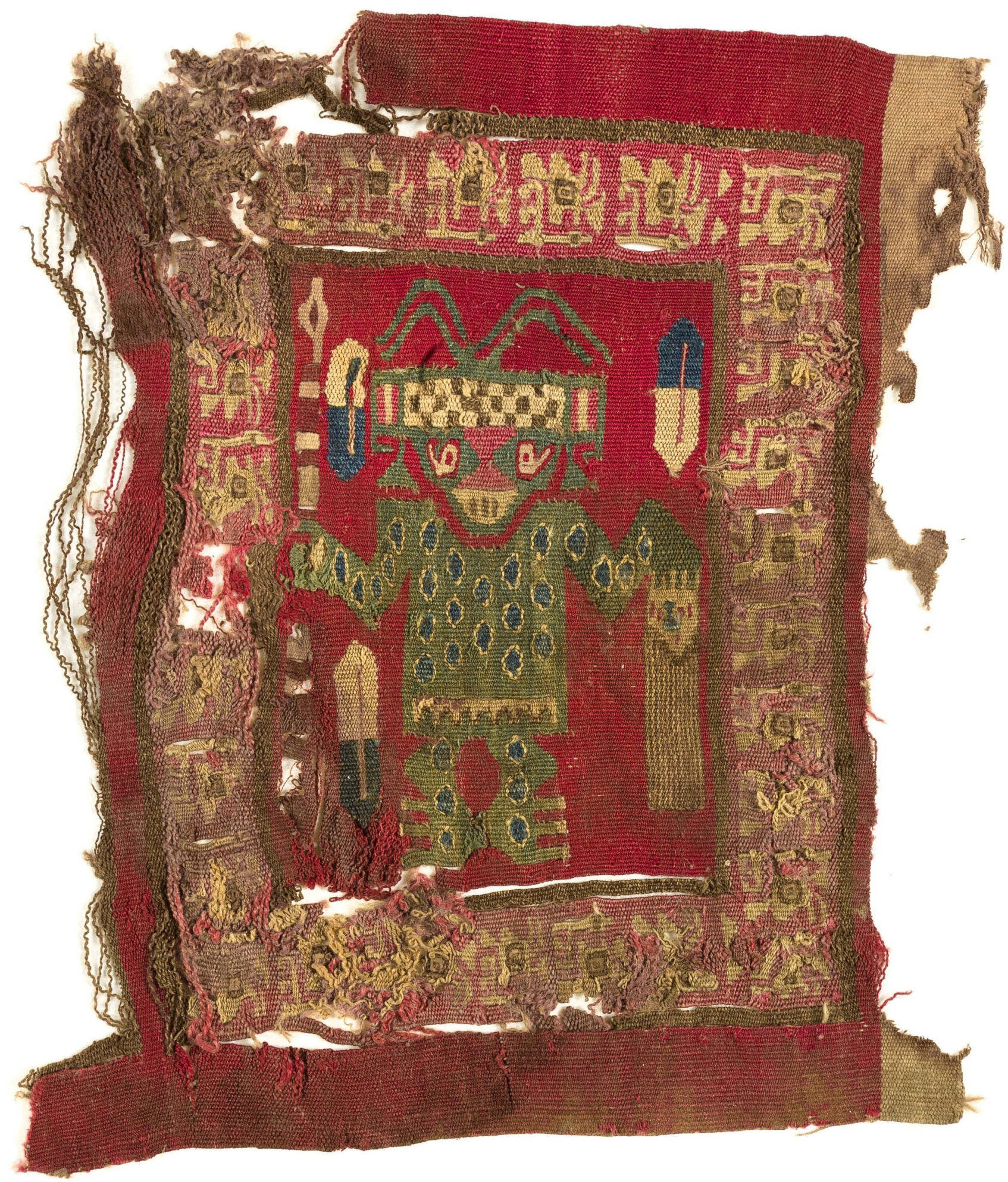

Figure 4. Border fragment with depiction of figures. Chimu, North Coast, Peru, 900-1300 AD. Cotton (warp: 2Z-plied), camelid fiber (weft: 2S-plied); tapestry, 23.5 x 18.5 cm. MV 66991, Vatican Museums, Vatican City. Foto Copyright (C) Governatorato S.C.V. - Direzione dei Musei. 
figure owes something to these earlier examples or not ${ }^{44}$. Some scholars proposed that the Lambayeque figure would be a coastal re-interpretation of the Staff-bearing Deity, an iconographic model introduced during the Wari occupation of the North Coast of Peru in the Middle Horizon. Others identified the figure with Naymlap, the legendary Lambayeque/Sicán ruler and conqueror who came from the sea ${ }^{45}$. Later, in the Chimu culture, the figure of Tacaynamo, the mythological founder of the Chimu dynasty, would have been inspired to the preceding Lambayeque figure, another iconographic influence of Lambayeque on Chimu culture ${ }^{46}$.

Recently, it has been proposed that the image of the Principal Deity of Lambayeque was based on, and developped after, the Andean bear (Tremarctos ornatus), more commonly known as the spectacled bear. The spectacled eyes (or the so called "comma shaped eyes") may have been inspired by the double line around the bear's eyes, while the hourglass nose and the neckpiece that looks like the white collar on the chest of the animal are also represented 47 .

It is tempting to suggest that this figure in the Lambayeque iconography is meant to depict Naymlap, while it is not sure at all that this is so. In any case, it is certainly an image of power ${ }^{4}$.

We suggest that the central figure of the Vatican fragment inv. 66991 is inspired to earlier depictions of the Wari Staff-bearing Deity, well represented by some carvings on the Sun Gate ${ }^{49}$ in Tiwanaku.
The red panel that contains the frontal figure presents a frame decorated with small yellow stylized figures, standardized in their design; they are in profile, depicted with an elaborate headdress and a ceremonial staff in hand. This decorative panel, with smaller figures arranged around a bigger central one, is typical of the Chimu iconography and can be also found on architectural friezes of raw brick of important ceremonial buildings ${ }^{50}$ as well as on tapestries ${ }^{51}$

Similar small figures are arranged in rows on the Sun Gate, apparently representing the attendants of the central frontal deity ${ }^{52}$. We may therefore assume that people wearing this picture on a tunic declared themselves as priests or administrators; in this way, they claimed a relation to a creator deity possibly fused with the state authority ${ }^{53}$. In my opinion, the central figure could depict an important divinity of the Lambayeque or the Chimu pantheon, or maybe one of her high-ranking priest.

The three large hexagonal motifs drawn in blue and yellow around the figure seem to represent stylized feathers ${ }^{54}$, a decorative pattern very popular along the North and Central Coasts between Late Intermediate Period and Late Horizon, especially in the Chimu, Chancay and Inca cultures. The motif of the feather could have an emblematic connotation and refer to political and territorial powers, since feathers were usually symbols of prestige among the coastal populations of pre-Columbian Peru.

Six other fabrics, similar in iconography and style to the Vatican item inv. 66991, can be found at the Museo Civico

44. Bjerregaard 2016, p. 14 .

45. Bjerregaard 2016, p. 14; Bjerregaard et al. 2017, p. 36; Jiménez Borja et al. 1987, p. 172; Fleitman and Baginski 2017, p. 350; Lavallée and Lumbreras 1985, pp. 275-276; Medina Castro et al. 2005, p. 96; Wester La Torre 2013, pp. 108-115.

46. Laurencich Minelli 1984, pp. 55 (fig. 42), 110 (fig. 118); Bjerregaard et al. 2017, pp. 124-125; Jiménez Borja et al. 1987, pp. 172, 174; Hoces de la Guardia Chellew et al. 2007, p. 75; Fleitman and Baginski 2017, p. 354; Lavallée and Lumbreras 1985, pp. 275, 297; Medina Castro et al. 2005, pp. 97-98; Rowe 1984, pp. 16, 66 (pl. 8), 70-72 (fig. 45-46, pl. 9); Stone-Miller 1994a, pp. 165-167 (pl. 6o); Young-Sánchez 1994 , p. 45. 47. Fleitman and Baginski 2017.

48. Bjerregaard 2016, p. 14 .

49. The Sun Gate is the most famous monument of the Tiwanaku culture. It is a monolithic gateway in andesite $3.80 \mathrm{~m}$ wide and $2.70 \mathrm{~m}$ high located on the large Kalasasaya's courtyard, one of the most important ceremonial buildings of the archaeological site of Tiwanaku. One face of the lintel is carved with a large central figure surrounded by three rows of eight winged characters, symmetrically arranged to the right and left; they are kneeling, hold distinct scepters and show other attributes specific to each of the overlapping rows (Bjerregaard et al. 2017, p. 25 (fig. 1a); Kolata 2004, pp. 800-801 (figg. 1186-1187); Lavallée and Lumbreras 1985, pp. 220-223 (figg. 200, 202)).

50. See Desrosiers and Pulini 1992, p. 22; Schaedel 1966, pp. 384-386, 390-391, 399-422.

51. See Hoces de la Guardia Chellew et al. 2007, p. 75; D’Harcourt 1934 [2008], p. 131 e (pl. XXVI); Desrosiers and Pulini 1992, p. 149 (fig. 88 ); Jiménez Díaz 2009, pp. 175-176 (fig. 123); MQB inv. 71.1878.2.578).

52. According to the Wari and Tiwanaku iconographic codes, these figures were always represented in profile to emphasize the hierarchical relationship with the main divinity (Bjerregaard et al. 2017, pp. 25 (fig. 1a), 26 (fig. 1b); Desrosiers and Pulini 1992, p. 20; Isbell 1988, p. 177).

53. Stone-Miller 1994b, p. 35.

54. See Amano and Tsunoyama 1979, pp. 35 (fig. 22), 102 (fig. 109), 192 (fig. 224), 202, 214; Bjerregaard et al. 2017 , p. 132 (VA 59900 a); Jiménez Borja et al. 1987, pp. 138, 215, 219; Hoces de la Guardia Chellew et al. 2007, p. 69; D'Harcourt 1934 [2008], p. 142, tav. LXXII (fig. 1-2); Jiménez Díaz 20o9, pp. 263, 334; MQB, inv. 71.1933.0.271.116 X, inv. 71.1933.0.271.117 X, inv. 71.1947.0.5.694 X; Rowe 1984, pp. 76, 78-80 (fig. 54-56, pl. 11), 92; Stone-Miller 1994a, p. 149. 
Archeologico Etnologico in Modena ${ }^{55}$, at the Ethnologisches Museum in Berlin ${ }^{5}$ (four items), at the Musée de l'Homme in Paris ${ }^{57}$ and at the Museum of the Americas in Madrid ${ }^{8}$.

\section{The Vatican Museums collection and its link with the Quai Branly Museum}

During the analysis of the Peruvian textiles in the Vatican collection, we found a remarkable similarity between fourteen Vatican items ${ }^{59}$ and some fabrics ${ }^{60}$ kept in the Quai Branly Museum in Paris. At the beginning of our paper, when discussing the origin of the Pfister Archive, we said that some Peruvian fragments of the Pfister Collection came precisely from the Musée du Trocadéro ${ }^{61}$. Unfortunately, we know practically nothing about the context of archaeological discovery and the historical course of the textiles preserved today in the Quai Branly Museum. Our research carried out in the Centre de Documentation et d'Archives of the aforementioned museum, only enabled us to discover that these textiles passed successively from the Musée du Trocadéro to the Musée de l'Homme, then to the Quai Branly Museum. We do know, however, that some of the Quai Branly fabrics similar to the Vatican textile fragments were donated in $1914^{62}$ and in $1933^{63}$ to the Trocadéro by Doctor Édouard Vergne $^{64}$. Based on these data, we suggest that the Vatican fragments could have been parts of textiles previously preserved in the Musée du Trocadéro, and now in the collection of the Quai Branly Museum.

We find clear evidence of this Parisian origin in two fragments of a decorative band with flower motifs (MV 63626) (fig. 5), eight fragments depicting anthropomorphic figures and ceremonial objects ${ }^{65}$ (fig. 6, 7, 8), two fragments with figures (MV 67012, MV 62407) (fig. 9, 10), a fragment with bird motifs (MV 63659) (fig. 11) and twelve small-sized fragments depicting geometric patterns (MV 63645) (fig. 12).

These two fragments of a Lambayeque or Lambayeque/ Chimu decorative band feature flower motifs made up of corollas with coloured stripes alternating with the pistil of another color, and tied together by a narrow band of beige yarns (fig. 5). The floral decoration is created by a bouclé effect through the untying of the wefts. The warp yarns are cotton S-spun, while the weft yarns are camelid fiber plied $2 S$.

The Vatican fragments inv. 63626 are identical in design, iconography and style to fragments of floral stripes that form part of a nowadays incomplete Lambayeque/Chimu textile preserved in the Quai Branly Museum in Paris ${ }^{66}$. The Paris fragments, however, show an idea of how the whole fabric was supposed to be. It features four decorative floral bands that act as a frame containing a composition of fourteen small figures ordered in three horizontal rows bordered internally by a double floral gallon. A fringe ends the lower edge of the item. The figures and the floral bands were probably first woven separately, then sewn and applied to the textile. The two Vatican band fragments as well as the Parisian fragments had probably both a function of attached decorative elements.

Fragment MV 63647 (fig. 6) is one remarkable example of the eight ${ }^{67}$ Lambayeque or Lambayeque/Chimu appliqué fragments depicting both anthropomorphic figures and two kinds of ceremonial objects (fig. 7, 8) preserved in the Vatican Museums collection. It features a frontal highranking male figure, maybe the so-called Principal Deity of Lambayeque (see above, item MV 66991). He wears a short tunic decorated with stylized zoomorphic motifs (bird or fish?), non-functional shoes with pointed toes (or naked feet), and has S-like patterns on the legs (perhaps snake

55. Desrosiers and Pulini 1992, p. 149 (fig. 88).

56. Jiménez Díaz 2009, p. 176.

57. Desrosiers and Pulini 1992, p. 149.

58. Jiménez Díaz 2009, pp. 175-176 (fig. 123); Ramos Gómez and Blasco Bosqued 1980, pp. 116-118 (tav. XXII).

59. MV 62407, MV 63625, MV 63626, MV 63645, MV 63647, MV 63651, MV 63652, MV 63653, MV 63654, MV 63655, MV 63656, MV 6366o, MV 63662, MV 67012.

6o. These items are available in the online catalogue of the Quai Branly Museum (see collections.quaibranly.fr).

61. The textile collections of the Musée d'ethnographie du Trocadéro (1878-1937) in Paris, as noted above, subsequently flow into those of the Musée de l'Homme in 1937, and finally moved to the Quai Branly Museum - Jacques Chirac in 2004.

62. MQB inv. 71.1914.24.53.1, inv. 71.1914.24.53.2.1-4.

63. MQB inv. 71.1933.0.271.315 X.

64. Édouard Vergne was a medical officer, major in the French military mission in Peru since 1913. Member of the Society of Americanists in France (Paris). He donated to the Trocadéro Museum 53 terracotta pots from Pachacamac in 1914 and 124 terracotta vases and fragments from Huaca Tina (Lambayeque) in 1920. The items then passed into the Musée de l'Homme collections in Paris (Riviale 200o, p. 337).

65. MV 63647, MV 63651, MV 63652, MV 63653, MV 63654, MV 63655, MV 63656, MV 63662.

66. MQB inv. 71.1914.24.53.1, inv. 71.1933.0.271.315 X.

67. MV 63647, MV 63651, MV 63652, MV 63653, MV 63654, MV 63655, MV 63656, MV 63662. 

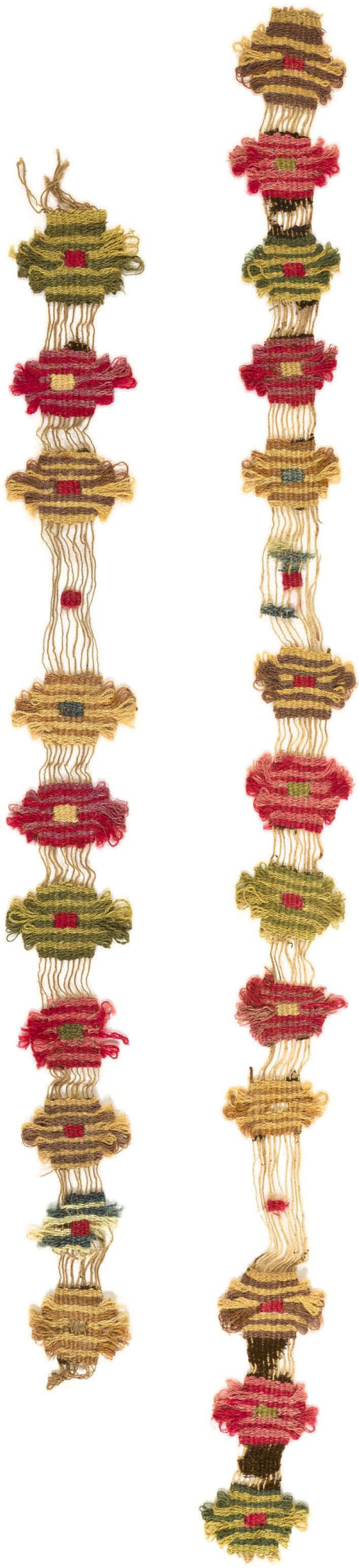

Figure 5. Two fragments of a strip with flower motifs. Lambayeque or Lambayeque/ Chimu, North Coast, Peru, 900-1375 AD. Cotton (warp: S-spun), camelid fiber (weft: 2S-plied); tapestry, 50 x $4 \mathrm{~cm}$ and 40 x $4 \mathrm{~cm}$. MV 63626, Vatican Museums, Vatican City. Foto Copyright (c) Governatorato S.C.V. - Direzione dei Musei.

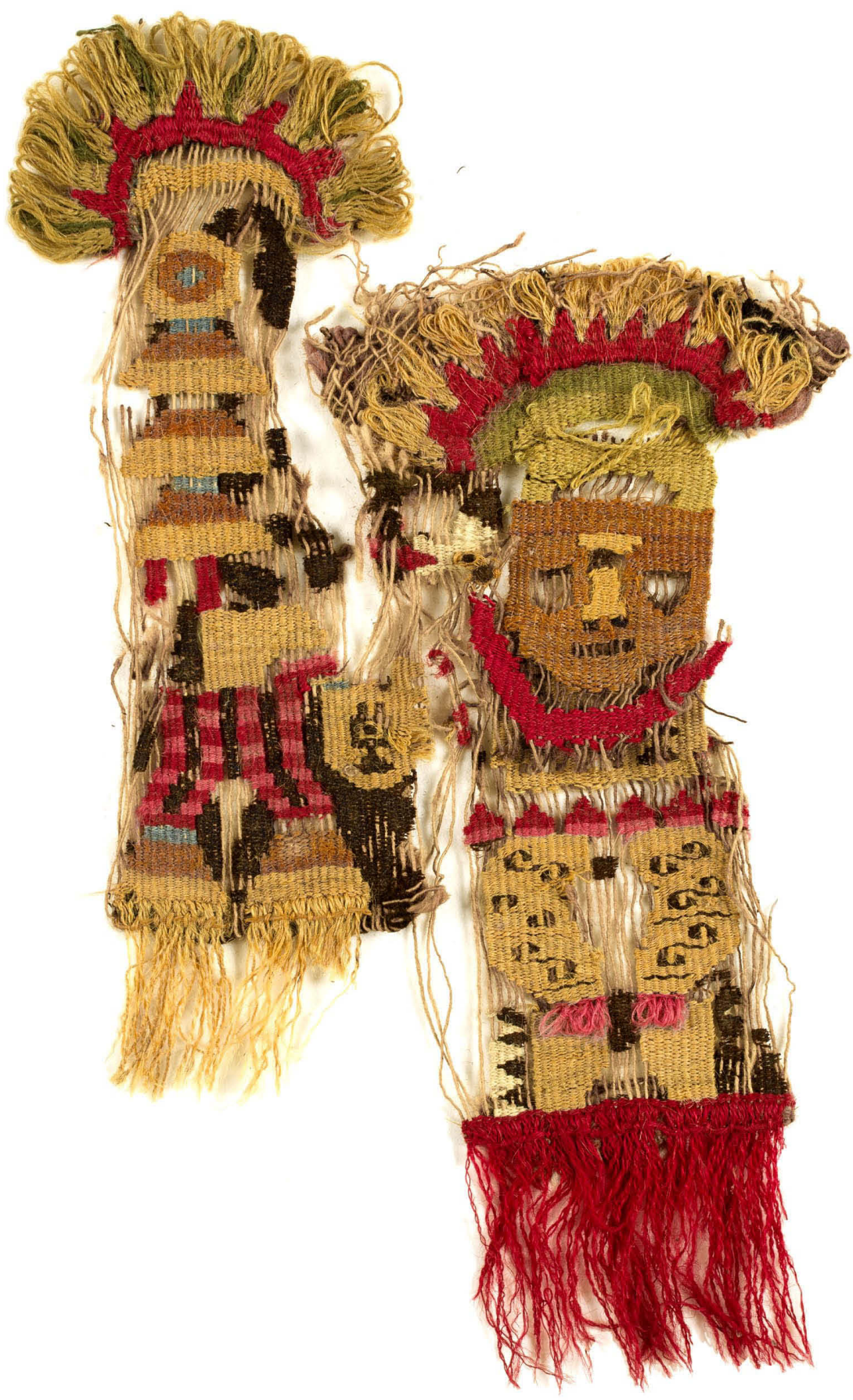

Figure 6. Fragment showing a figure with cerimonial staff. Lambayeque or Lambayeque/Chimu, North Coast, Peru, 1000-1476 AD. Cotton (warps: S-plied for figure, 2Z-plied for scepter), camelid fiber (wefts: 2S-plied for both); tapestry, 16 x $8 \mathrm{~cm}$ (figure), 15 x $6 \mathrm{~cm}$ (scepter). MV 63647, Vatican Museums, Vatican City. Foto Copyright (C) Governatorato S.C.V. - Direzione dei Musei. 

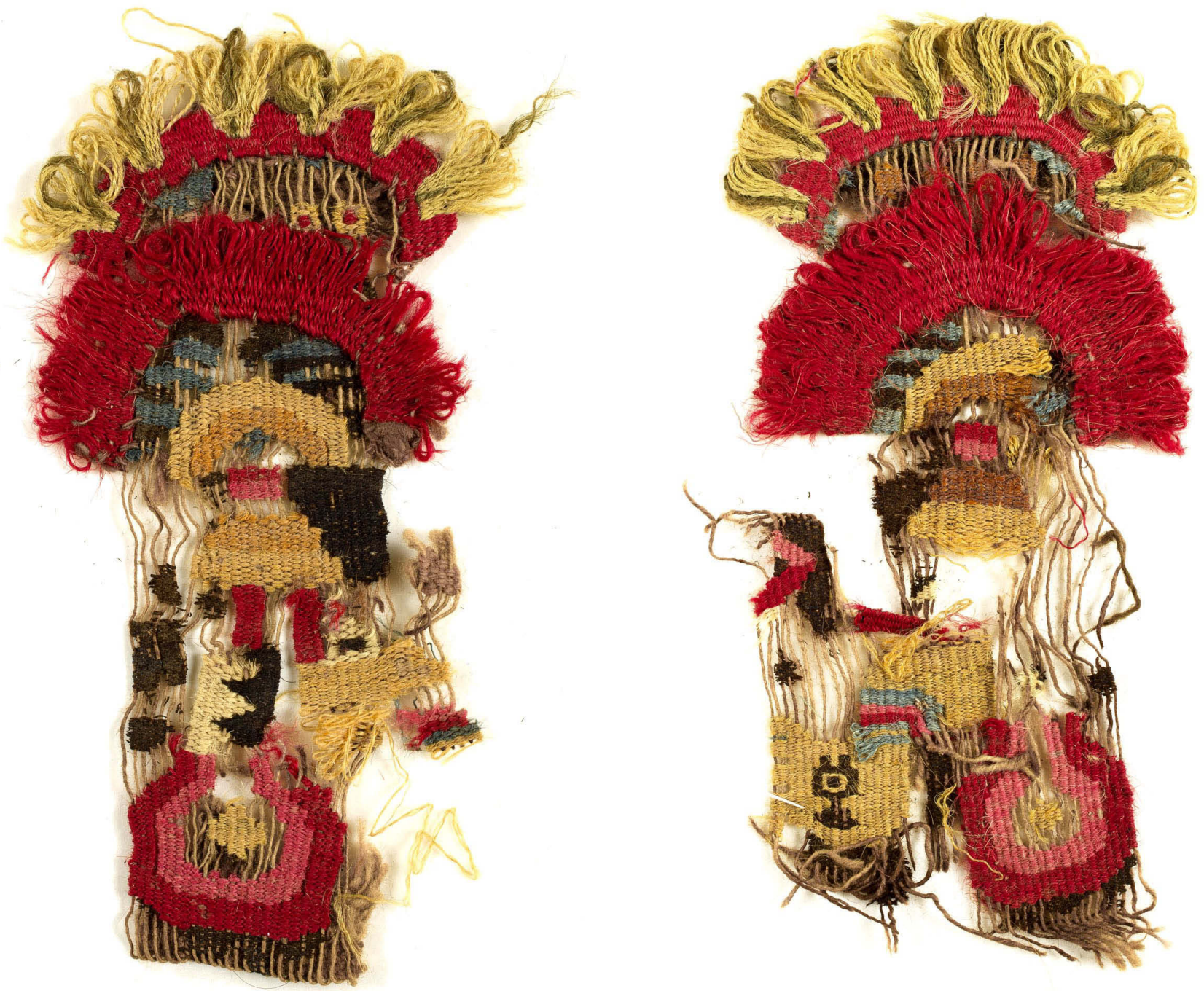

Figures 7-8. Two fragments with depiction of cerimonial object. Lambayeque or Lambayeque/Chimu, North Coast, Peru, $1000-1476$ AD. Cotton (warp: S-plied), camelid fiber (weft: 2S-plied); tapestry, 11 x 6 cm, 13 x $7 \mathrm{~cm}$. MV 63652, MV 63653, Vatican Museums, Vatican City. Foto Copyright (C) Governatorato S.C.V. - Direzione dei Musei.

motifs). He is therefore dressed in full regalia, with all his attributes: an elaborate crescent-like feather headdress; an hourglass nose; a red and white neckpiece in the form of a bicephalic serpent; a ceremonial staff or scepter in the right hand. The figure reflects the traditional iconography of the Northern Peruvian coast during the Late Intermediate Period. The warp yarns of the figure are cotton S-plied, while the weft yarns are camelid fiber plied 2S. The warp yarns of the ceremonial staff are cotton 2Z-plied, while the weft yarns are camelid fiber 2S-plied.

The ceremonial staff or scepter is an insignia of rank that we often find associated with anthropomorphic figures, identified as deities, priests (shamans) or high dignitaries, and depicted on Lambayeque/Sican, Chimu and Chancay textiles from the North and Central coasts ${ }^{68}$. According to Jiménez Díaz ${ }^{69}$ Rowe $^{70}$ and Bjerregaard ${ }^{71}$, these figures with

68. See Amano and Tsunoyama 1979, pp. 68 (fig. 61), 89 (fig. 90); Laurencich Minelli 1984, p. 99 (fig. 102); Desrosiers and Pulini 1992, pp. 149150 (cat. 88-9o); Jiménez Díaz 2009, pp. 169-172 (cat. 119-120), 175-176 (cat. 123); Rowe 1999, pp. 427-431; Stone-Miller 1994a, pp. 126-127 (tav. 37), 249 (cat. 253).

69. Jiménez Díaz 2009, pp. 169, 172.

70. Rowe 1999, pp. 428-430.

71. Bjerregaard et al. 2017, p. 33 . 
large feathered headdresses, dressed with elaborate tunics and loincloths, and holding scepters are more frequently depicted on Lambayeque fabrics dating about the first part of the Late Intermediate Period (1000-1375 AD). One of the two kinds of scepter depicted on the Vatican fragments seems to be an oar-shaped scepter surmounted with a double crescent-like feather headdress (fig. $7, \mathbf{8}$ ). In the Lambayeque culture, the oar was the hallmark of Naymlap, the legendary ruler, and symbolized his arrival from the sea by raft (see above); in the subsequent Chimu culture, indeed, the oarshaped scepter refers to Tacaynamo, mythological founder of the Chimu dynasty ${ }^{72}$.

The Vatican item inv. 63647 is identical to eighteen fragments of two Lambayeque/Chimu textiles ${ }^{73}$ preserved in the Quai Branly Museum at Paris, and is similar to other two beautiful Lambayeque fabrics preserved in Boston, at the Museum of Fine Arts ${ }^{74}$, and in the Montreal Museum of Fine Arts 75 .

The Parisian fragments depict small multi-coloured figures dressed in rich clothes, with an elaborate crescentshaped feathered headdress and an insignia of power in each of their hands (see above, item MV 63626). These fragments were fundamental to get an idea of how the Vatican figures ${ }^{76}$ were supposed to be, and to put back together the missing parts e.g. of tunics, headdresses, neckpieces and implements that each figure holds in his hands.

Similarities between Vatican ${ }^{77}$ and Paris items, as well as the historical fact that some Peruvian fabrics forming the Pfister Collection came from the Musée du Trocadéro in Paris, as we demonstrated in the introduction (see above), show that the Vatican fragments also came probably from the same French museum, and perhaps were originally part of the textile ${ }^{78}$ today preserved in the Quai Branly Museum.

Fragment MV 67012 (fig. 9) depicts a frontal anthropomorphic figure, maybe a high-ranking priest or a nobleman, with a large crescent-like feather headdress carrying hanging objects. It could also depict an important deity of the Lambayeque pantheon. He wears a short red tunic decorated with stylized fishes ${ }^{79}$ and triangles, a loincloth with horizontal multicolor stripes and non-functional shoes with pointed toes or has naked feet. Other attributes of power,

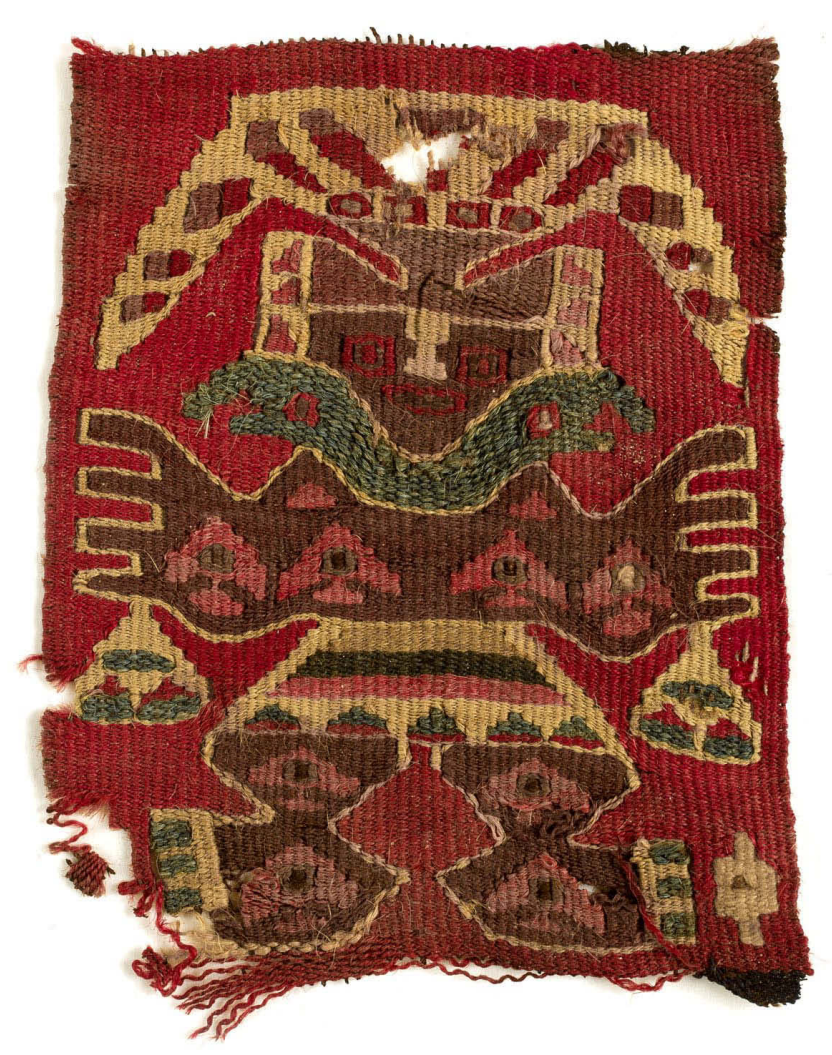

Figure 9. Border fragment showing an anthropomorphic figure. Lambayeque or Chimu, North Coast, Peru, 8oo-1200 AD. Cotton (warp: 2Z-plied), camelid fiber (weft: 2S-plied); tapestry, 8.5 x 6.5 $\mathrm{cm}$. MV 67012, Vatican Museums, Vatican City. Foto Copyright (C) Governatorato S.C.V. - Direzione dei Musei.

considered characteristic of Lambayeque imagery, are the hourglass nose; the green bicephalic serpent neckpiece; and the objects held in each hand, probably in my opinion trophy heads or bags to hold coca leaves ${ }^{80}$. The warp yarns are cotton 2Z-plied, while the weft yarns are camelid fiber 2S-plied.

The figure represented on fragment MV 62407 (fig. 10) is similar in style and iconography to the preceding image featured on item MV 67012 (see above). It depicts a frontal anthropomorphic figure with a tall elaborate crescent-shaped feather headdress; hourglass nose; a tight black neckpiece under the chin in the form of a bicephalic serpent; the figure

72. Fleitman and Baginski 2017, p. 354.

73. MQB inv. 71.1914.24.53.2.1-4, inv. 71.1933.0.271.315.

74. Stone-Miller 1994a, pp. 126-127 (tav. 37).

75. Pimentel 2013, p. 55 (cat. 37).

76. MV 63647, MV 63651, MV 63652, MV 63653, MV 63654, MV 63655, MV 63656, MV 63662.

77. MV 63651, MV 63652, MV 63653, MV 63654, MV 63655, MV 63656, MV 63662.

78. MQB inv. 71.1933.0.271.315.

79. The same motif is depicted on the legs of the figure.

8o. According to Laurencich Minelli (1984, p. 27), bags carrying coca leaves could be symbol of priesthood. 


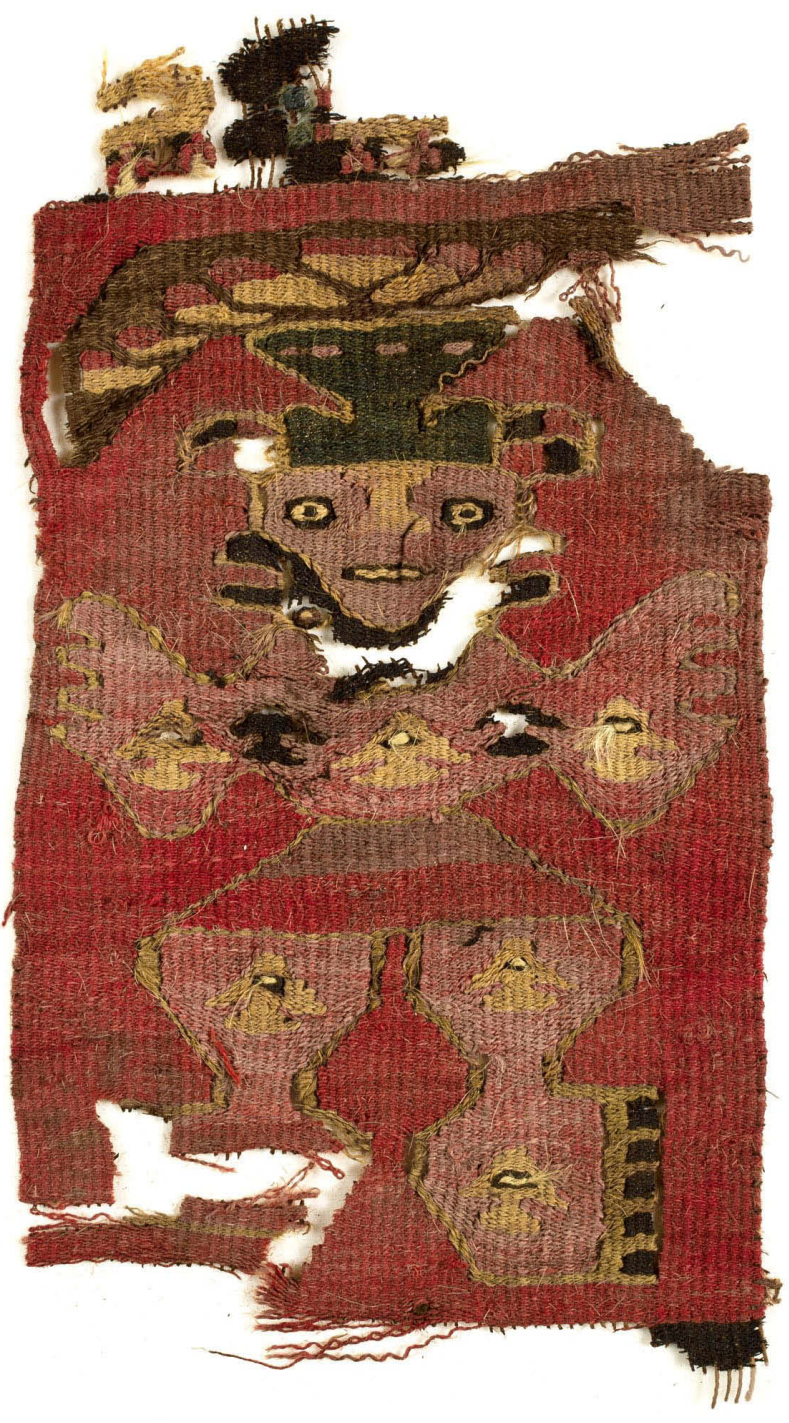

Figure 10. Border fragment showing an anthropomorphic figure. Lambayeque or Chimu, North Coast, Peru, 800-1200 AD. Cotton (warp: 2Z-plied), camelid fiber (weft: 2Z-plied); tapestry, 15 x 7.5 cm. MV 62407, Vatican Museums, Vatican City. Foto Copyright (C) Governatorato S.C.V. - Direzione dei Musei.

does not carry any object in the hands. He wears the same kind of clothes as the figure depicted on MV 67012: a pink tunic decorated with stylized yellow fishes, a loincloth with horizontal multicolor stripes and non-functional shoes with pointed toes, or he has naked feet. In the upper part of the fragment, the yellow body and red feet of two birds, with the green-blue tail of one of them, are partially recognizable (see below). The warp yarns are cotton 2Z-plied, while the weft yarns are camelid fiber 2Z-plied.

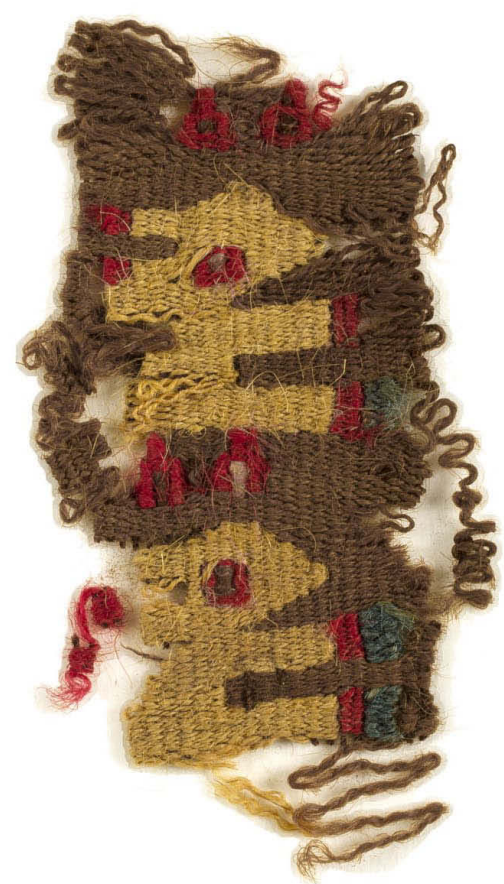

Figure 11. Decorative band fragment showing two birds. Lambayeque or Chimu, North Coast, Peru, 80o-1200 AD. Cotton (warp: 2Z-plied), camelid fiber (weft: 2S-plied); tapestry, 5 × $3 \mathrm{~cm}$. MV 63659, Vatican Museums, Vatican City. Foto Copyright (C) Governatorato S.C.V. - Direzione dei Musei.

The item MV 63659 (fig. 11) is a fragment of a decorative multicolor band that features two stylized yellow birds, depicted in profile and arranged vertically one above the other on a brown background. The eyes, the paws and the tip of the beak are red. The tail (maybe the wings) is shown on a flat surface ("flat perspective") by two yellow elements with red and blue ends. The warp yarns are cotton 2Z-plied, while the weft yarns are camelid fiber 2S-plied. Birds with a similar iconography are published in Jiménez Borja ${ }^{81}$, and are recognizable on some textile fragments preserved in the Quai Branly Museum ${ }^{82}$.

The Paris fragments (see above) and the Vatican item inv. 63659 give us an idea of how the birds of fabric item MV 62407 were supposed to look.

The two figures represented on Vatican fragments (inv. 67012 and inv. 62407) are iconographically comparable to 


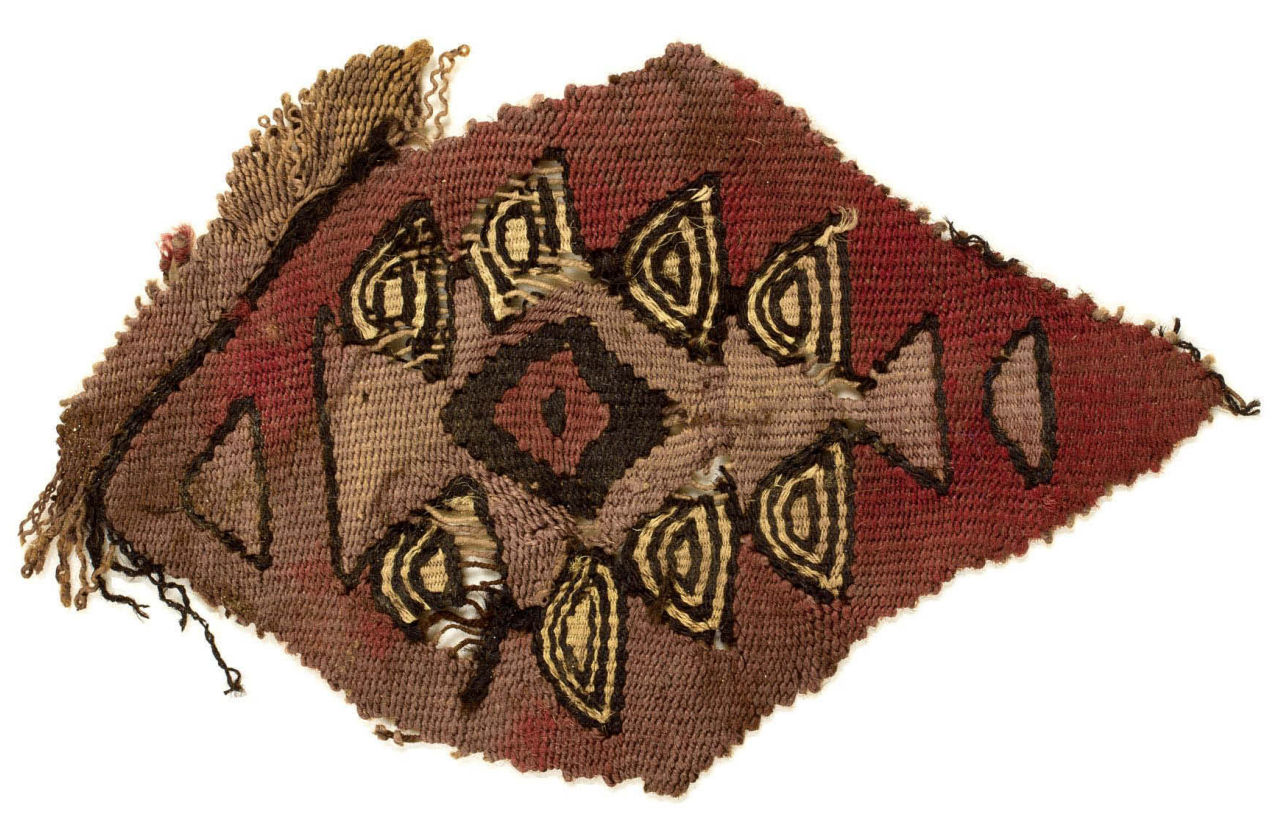

Figure 12. Fragment showing a geometric motif. Chancay, Central Coast, Peru, 1000-1476 AD. Cotton (warp: 2S-plied), camelid fiber (weft: 2S-plied); tapestry, $12 \times 8$ cm. MV 63645, Vatican Museums, Vatican City. Foto Copyright (C) Governatorato S.C.V. - Direzione dei Musei.

the ones depicted on five fragments of two Lambayeque or Chimu items ${ }^{83}$ preserved at the Quai Branly Museum in Paris. The Parisian fragments present a decoration made of small overlapped rectangular panels; each panel contains a frontal anthropomorphic figure with a crescent headdress and an implement in each hand. Furthermore, each panel shows a frame made up of a band of small, very stylized, yellow birds, depicted in profile on a brown background (see above, item MV 63659). Indeed one of the Parisian fragment ${ }^{84}$ reproduces the same design and uses the same colors found in the Vatican item inv. 62407.

We therefore suggest that the two figures depicted on MV 67012 and MV 62407 fragments were probably inserted inside a rectangular panel framed by a decorative band made of small yellow stylized birds (fig. 11).

The undeniable similarity between the two Vatican items (inv. 67012, inv. 62407) and the fragments from Paris, in our view, is not a casuality. We have already mentioned in the introduction that some of the Peruvian textile fragments from the Pfister Collection came from the Musée du Trocadéro in Paris; this could be the case also for the two Vatican fragments, whether they were part of one of the two Quai Branly Museum tapestries.
This conclusion could be confirmed by the very fact that, when the fragments MV 67012 and MV 62407 were kept in the Vatican Apostolic Library (see introduction), they were preserved together and had the same inventory number (inv. 7012) corresponding to the Bontempi BAV inventory catalogue; subsequently, each of them received a new inventory number when they moved to the Vatican Museums collections.

This fragment (fig. 12) is the biggest of twelve incomplete and small-sized fragments which are part of item MV 63645. The warp yarns are cotton $2 S$-plied, while the weft yarns are camelid fiber $2 \mathrm{~S}$-plied. It depicts, on a red Bordeaux color background, a brown jagged rhomboid-shape motif with eight yellow and black appendices along the edge; each appendice is formed by six concentric arc-shaped elements looking like eyes ${ }^{85}$. Three concentric diamonds ${ }^{86}$, two in black and one in red Bordeaux color, are at the center of the motif. Two trapezoidal shapes in brown with a black border decorate both the right and left sides of the main pattern.

Thanks to a comparison with two items preserved in the Quai Branly Museum ${ }^{87}$, it was possible to reconstruct the main pattern (fig. 12) as well as the decorative composition

83. MQB inv. 71.1947.0.5.646.1-5 X, 71.1947.0.5.745 X.

84. One of the four Quai Branly Museum fragments (MQB inv. 71.1947.0.5.646.1-5 X).

85. Similar motifs, presumably simbolic, decorate a Central-Andean coast fabric dating from 1000-1450 AD, but we do not know what they represented and exactly to what style they are to be connected (Jiménez Díaz 2009, p. 276 (cat. 217).

86. According to Amano and Tsunoyama (1979), pp. 73 (fig. 69), 203, the rhombus or diamond pattern could possibly represent a bird eye in a strongly stylized form.

87. MQB inv. 71.1947.0.5.632, 71.1947.0.5.750. 
of the original fabric. The Parisian specimens, indeed, reproduce exactly the motif depicted on the Vatican fragment and use the same colors.

Furthermore, one of the Paris items ${ }^{88}$ gives an idea of how the whole fabric was supposed to be. It probably showed, on a red background, a net decoration formed by lozenges bordered in yellow and black; each lozenge was filled with a rhomboid-shape pattern in yellow, red Bordeaux and black with eight yellow and black appendices. The rhomboid motif could represent a stylized fish caught in the mesh of a net.

Net-shape decorative compositions that look similar to these are found on textiles coming from the North and Central Peruvian coasts dating Late Intermediate Period ${ }^{89}$.

According to the aforementioned examples, therefore, we can assume that most ${ }^{90}$ of the Peruvian textile fragments of the Pfister Collection came from the Musée du Trocadéro in Paris, and were originally and integral part of fabrics now preserved in the Quai Branly Museum. We suggest at the moment that two Vatican fragments (inv. 63626) and other eight fragments ${ }^{91}$ were part of Quai Branly $\mathrm{Mu}-$ seum item inv. 71.1933.0.271.315; three Vatican items (inv. $67012,62407,63659$ ) were part of Quai Branly's fabric inv. 71.1947.0.5.646.1-5; while twelve Vatican fragments (MV 63645) were taken from Quai Branly's tapestry inv. 71.1947.0.5.750. To conclude, the intent of this paper was to offer a first overview of the unkown history of the Vatican Museums pre-Hispanic textiles collection, describing its content in its broad lines and, focusing only on some of its most interesting fabrics. A more complete and detailed catalog of the entire collection will be published shortly in Italy, around fall 2020.

\section{Abbreviations}

ASMV Archivio storico dei Musei Vaticani, Stato della Città del Vaticano (Historical Archives of the Vatican Museums, Vatican City State)

EAAO Enciclopedia Archeologica, Americhe - Oceania, Istituto della Enciclopedia Italiana Giovanni Treccani (ed.), Rome 2004

MNAAH Museo Nacional de Arqueología, Antropología e Historia, Lima

MQB Musée du quai Branly - Jacques Chirac, Paris (Quai Branly Museum, Paris)

\section{Bibliography}

Amano, Yoshitaro, and Yukikhiro Tsunoyama.

1979 Textiles of the Andes. Catalog of the Amano Collection. San Francisco: Heian/Dohosha, 1979.

Biordi, Maurizio,

2005 Museo degli Sguardi. Raccolte Etnografiche di Rimini, Rimini, 2005.

Bjerregaard, Lena.

2016 "Lambayeque-style textiles in the Ethnologisches Museum, Berlin”. In Sophie Desrosiers and Paz Núñez Regueiro (coord.), Colloques. Textiles amérindiens. Recherches récentes du présent au passé et inversement, Nuevo Mundo Mundos Nuevos, 16, 2016.

Bjerregaard, Lena ed., with articles of Beatrix Hoffmann, Ann Peters, Susan Bergh, Jane Feltham, Katalin Nagy, and Gary Urton.

2017 PreColumbian Textiles in the Ethnological Museum in Berlin. Lincoln: Zea Books, 2017. https:// digitalcommons.unl.edu/zeabook/52

Burger, Richard L.

1992 Chavín and the origins of Andean civilization. London: Thames and Hudson, 1992.

D’Harcourt, Raoul.

2008 Les textiles anciens du Pérou et leurs techniques. Paris : Flammarion, 2008. Originally published 1934, Editions Arts et Histoires, Paris.

Desrosiers, Sophie, and Ilaria Pulini.

1992 Musei Civici di Modena. Tessuti precolombiani. Modena: Franco Cosimo Panini, 1992.

Fleitman, Yvonne, and Alisa Baginski.

2017 "Lambayeque Textile Iconography and its Continuity in Chimu and Inca Cultures, and its link to modern Ecuadorian Pujilí Corpus Christi Celebrations". In PreColumbian Textile Conference VII / Jornadas de Textiles PreColombinos VII, Lena Bjerregaard and Ann Peters (ed.), Lincoln: Zea Books, 2017, pp. 34936o. https://digitalcommons.unl.edu/pct7/24

Iklé, Franz.

1930 Über Alt-Peruanische Stickereien des Trocadéro, Paris. St Gallen: Mitteilungen der Ostschweiz. Geogr. Commerz. Gesellschaft, 1930.

Isbell, William $\mathrm{H}$.

1988 City and State in Middle Horizon Huari. In Peruvian Prehistory. An Overview of pre-Inca and Inca Society, edited by R.W. Keatinge, pp. 164 - 189, Cambridge: Cambridge University Press, 1988.

88. MQB inv. 71.1947.0.5.750.

89. See Laurencich Minelli 1984, pp. 84-85 (fig. 85); MNAAH inv. 250416, 250418, 250427; MQB inv. 71.1933.0.271.90.

90. Maybe all of them.

91. MV 63647, MV 63651, MV 63652, MV 63653, MV 63654, MV 63655, MV 63656, MV 63662. 
Jiménez Borja, Arturo, Jorge Zevallos Quiñónez, and James W. Reid.

1987 Chimù. 1st ed. Lima: Banco de Crédito del Perú, 1987.

Jiménez Díaz, María Jesús.

2009 Tradición de tradiciones. Tejidos prehispánicos y virreinales de los Andes. La colleción del Museo de América. Madrid: Ministerio de Educación, Cultura y Deporte, 2009.

Hoces de la Guardia Chellew, Soledad, Paulina Brugnoli, and Carole Sinclaire Aguirre.

2007 Awakhuni. Weaving the History of the Andes. Santander: Museo Chileno de Arte Precolombino, 2007.

King, Heidi.

2012 Peruvian Featherworks. Art of the Precolumbian Era. The Metropolitan Museum of Art, New York, 2012.

Kolata, Alan L.

2004 “Tiwanaku (Tiahuanaco)”. In EAAO, pp. 798-802.

Laurencich Minelli, Laura (editor).

1984 Antichi tessuti peruviani. Tecniche, disegni e simboli. Exhibition catalog (Milan, September - November 1984), Milan: Electa, 1984.

Lavallée, Danièle, and Luis G. Lumbreras.

1985 Les Andes de la Préhistoire aux Incas. Paris: Gallimard (ed.), 1985.

Medina Castro, Maria Ysabel, and Roberto Gheller Doig.

2005 Textiles of Ancient Peru - Tejidos del Perù Antiguo. Lima: Forma e Imagen, 2005.

Petrucci, Valeria, Claudio Cavatrunci, Marco Curatola, Elisabetta De Costanzo, and Luciana Mariotti.

1982 Simbolo e tecnica nei tessuti dell'antico Perù. Exhibition catalog (Rome, February - April 1982), Rome: De Luca (ed.), 1982.

Pimentel, Victor (editor).

2013 Pérou: les royaumes du Soleil et de la Lune. Exhibition catalog (Montreal 2013 - Seattle 2014), Milan: 5

Continents Editions, 2013.
Ramos Gómez, Luis J., and Concepción Blasco Bosqued.

1980 Los tejidos prehispánicos del area central andina en el Museo de América. Madrid: Ministerio de Cultura, 1980 .

Riviale, Pascal.

2000 Los viajeros franceses en busca del Perù antiguo (1821-1914). Lima: Institut français d'études andines (ed.), 2000.

Rowe, Ann P.

1984 Costumes and Featherwork of the Lords of Chimor: Textiles from Peru's North Coast. Washington, DC: The Textile Museum, 1984.

Schaedel, Richard P.

1966 “The Huaca El Dragón”. Journal de la Société des Américanistes 1966, 55 (2): 383-496.

Stone-Miller, Rebecca.

1994a To Weave for the Sun. Ancient Andean Textiles in the Museum of Fine Arts, Boston. London: Thames and Hudson, 1994a.

Stone-Miller, Rebecca.

1994b "Creative Abstractions: Middle Horizon Textiles in the Museum of Fine Arts, Boston". In To Weave for the Sun. Ancient Andean Textiles in the Museum of Fine Arts, Boston, edited by Rebecca Stone-Miller, pp 3542. London: Thames and Hudson, 1994b.

Wester La Torre, Carlos.

2013 "La légende de Naymlap: entre mystère et histoire". In Pérou: les royaumes du Soleil et de la Lune, edited by Victor Pimentel, pp. 108-115, Exhibition catalog (Montreal 2013 - Seattle 2014), Milan: 5 Continents Editions, 2013.

Young-Sánchez, Margaret.

1994 Textile Traditions of the Late Intermediate Period. In To Weave for the Sun. Ancient Andean Textiles in the Museum of Fine Arts, Boston, edited by Rebecca Stone-Miller, pp. 43-50. London: Thames and Hudson, 1994. 


\title{
Hidden in plain sight. How 'disturbing' features found within two Peruvian textile fragments have turned into a 'significant guide' for conservation
}

\author{
Griet Kockelkoren* \& Emma Damen ${ }^{\dagger}$ \\ * Textile conservator and head of the Conservation Studio of Historical and Contemporary Textiles, Costumes and \\ Accessories of the Royal Institute for Cultural Heritage (KIK-IRPA) in Brussels \\ † Textile conservator at the Royal Institute for Cultural Heritage (KIK-IRPA) in Brussels
}

\section{Resumé}

Préserver non seulement 'l'objet matériel', mais préserver également les valeurs intrinsèques d'un objet n'est pas un nouveau concept dans la pratique de la conservation-restauration actuelle. Le défi de cette approche consiste à regarder au-delà de ce qui est visible à l'œil nu et à déterminer les traces de signification qui sont présentes dans l'objet. Au début d'une recherche ou une conservation, les aspects sont inconnues et parfois bien déguisés. Les traces essentielles peuvent être très difficiles à évaluer et à valoriser, en particulier avec des objets textiles ayant servi à une ou plusieurs fins pratiques au cours de leur vie avant de faire partie d'une collection patrimoniale.

A travers de deux cas pratiques, cet article décrit l'application pratique de l'approche choisie pour comprendre et dévoiler les aspects que nous voulions vraiment valoriser et préserver pour le futur en raison de leur signification et comment ils se sont avérés déterminants dans le choix de conservation.

Mots-clés : signification, valeur immatériel, risques, biographie matérielle, fragment textile péruvien, conservation de textile, recherche de textile, musée d'Art \& Histoire Bruxelles

\begin{abstract}
Preserving not only the 'material object', but preserving the intrinsic values of an object is not a novel concept within the contemporary conservation practice. The challenge of this approach lies in looking beyond what is visible to the naked eye and in determining the unknown and sometimes well disguised aspects and traces of 'significance' that are present within the object. Trace elements can be very difficult to assess and to value, especially within textile objects that have served one or more practical purposes during their 'active life', before becoming part of a heritage collection. Via two practical cases, this article describes the practical application of the chosen approach to understand and unveil those aspects we really wanted to value and preserve due to their 'significance' and how they turned out to be instrumental in the conservation choices.
\end{abstract}

Keywords: significance, intangible value, risks, active life, material biography, Peruvian textile fragment, conservation, textile conservation, textile research, Royal Institute for cultural heritage, Art \& History Museum Brussels.

\section{Resumen}

Preservar no solamente el 'objeto material', sino sus valores intrínsecos no constituye un concepto novedoso dentro de las prácticas de conservación 'contemporánea'. El reto de esta pauta queda en ver más allá de los que es visible al ojo y en determinar los aspectos desconocidos y, a veces, ocultos y las huellas de ‘significado’ presentes dentro del objeto. Al trazar estos elementos, puede ser difícil medirlos y valorarlos, especialmente para de objetos textiles que han tenido una función pragmática, o más de una, durante su 'vida activa', antes de entra a formar parte de una colección patrimonial. A través de

DOI: 10.32873/unl.dc.zea.1216

Published in PreColumbian Textile Conference VIII / Jornadas de Textiles PreColombinos VIII, ed. Lena Bjerregaard and Ann Peters

(Lincoln, NE: Zea Books, 2020). https://digitalcommons.unl.edu/zeabook/ 
dos casos particulares, este artículo describe la aplicación en la práctica de este método que se ha escogido para entender y hacer visible aquellos aspectos que hemos querido valorar y preservar, debido a su 'significado', y ver cómo han resultado ser instrumentales en las opciones del proceso de conservación.

Palabras claves: significado, valor intangible, riesgos, vida activa, material biográfico, fragmento textil peruano, conservación, conservación textil, investigación textil, Instituto Real para el patrimonio cultural, Museo de Arte \& Historia de Bruselas.

In preparation of the temporary exhibition "INCA dress code" (23/11/2018-21/04/2019) at the Art \& History Museum in Brussels, two Peruvian textile fragments from the collection of the museum were researched and treated at the textile conservation studio of the Royal Institute for Cultural Heritage (KIK-IRPA). The aim was to preserve not only the 'material object', but also its intrinsic value(s). The challenge lies in looking beyond what is visible to the naked eye and in determining the unknown and sometimes well disguised aspects and traces that are present within the object. This article describes the chosen approach to understand and unveil those aspects we really wanted to 'value' and preserve due to their 'significance' and how they turned out to be instrumental in the conservation choices.

\section{What should be preserved?}

There is no discussion concerning the importance of preserving heritage. It seems straightforward enough, but as a conservator confronted with an object, a much more pressing and challenging question is, what it is about the object that we want to preserve? Do we want to preserve as much material of the object as it is now, in its present state? Do we just want to preserve the first and most original state of the object and remove all later add-ons? Do we want to focus on the traces of use? Or is there something else?

Many objects that came to the textile conservation studio of the Royal Institute for Cultural Heritage (KIK-IRPA) in Brussels have raised these types of questions. When looking at objects, in most cases it actually comes down to, how we can make sure that we are preserving all the significant aspects of the object here before us and that we do not remove or take away anything that might have cultural-historical value, social value or value that tells something about the use. ${ }^{1}$

The consideration of these values is sometimes referred to as value-assessment ${ }^{2}$, but some colleagues feel that the word value is too closely associated in most of our minds with money, therefore the word 'significance' is often preferred.

Preserving not only the 'material object' but rather 'preserving what is valued'3 is not a new concept in 'contemporary' conservation practice. However, it does require a certain mind-shift and makes you think about the meaning of preservation, the meaning of use, the intrinsic meaning of an object and the meaning of the 'integrity' of the object. Taking all these into account in the conservation-approach, brings some uncertainties that need to be tackled before any hands-on conservation-action can be undertaken and often it necessitates more insights than can be found in just one person or specialism.

This concept aims to go further than preserving or actively conserving the physical integrity of the object. It also respects and takes into account its conceptual integrity and therefore also the beliefs and uses that the originator attributed to a specific object. ${ }^{4}$

This being said, it is also important to take into account the fact that heritage objects can have had more than one use(r) in, at times, very different cultures and periods during history. All these traces of use imprinted in the material biography, are considered to be of significance.

1. Significance 2.o. https://www.arts.gov.au/what-we-do/museums-libraries-and-galleries/significance-20 last consulted on the 3 th of October 2019.

2. See for example: Michalski, Stefan, Pedersoli Jr., José Luiz (2016) The ABC Method: a risk management approach to the preservation of cultural heritage, CCI, ICCROM; Brokerhof, A.W., Bülow, Anna E. (2016) The QuiskScan - a quick risk assessment scan to identify value and hazards in collection. Journal of the Institute of Conservation, Volume 39, pp 18-28; Waller, R.R. (2003) Cultural Property Risk Analysis Model: Development and Application to Preventive Conservation at the Canadian Museum of Nature, Göteborg Studies in Conservation 13, Göteborg: Göteborg Acta Universitatis Gothoburgensis; Ashley-Smith, Jonathan (1999) Risk Assessment for Object Conservation, Oxford: Butterworth-Heinemann.

3. Clavir, Miriam (2002) Preserving What is Valued. Museums, Conservation, and First Nations, UBC Press Vancouver.

4. For some objects and cultures, this could mean that both the continued use (intangible) and the material preservation (tangible) are (as) important within the preservation concept. Think for example of various ethnographic objects. However, this article only focusses on the preservation of the material integrity as well as the preservation of the material traces of previous use(s) found, their interpretation, the understanding of these traces within/on the objects in the case study. See Miriam Clavir, 2002. 
This approach goes well beyond what is usually stated in the various 'codes of ethics' that are omnipresent in the modern day conservation practice. These 'codes' represent guidelines rather than rules, to cater to the fact that every case and object is very different. But this also means they often remain very generic and that there is not one 'code' that really covers every aspect. ${ }^{5}$ To interpret them too literally could even pose a risk to the objects treated ${ }^{6}$. Therefore the challenging but also intriguing part is to be able to interpret and apply these guidelines ${ }^{7}$ and tailor them to specific objects in relation to their unique context and 'use'8.

Through these codes or guiding concepts such as minimal intervention, retreatability, reversibility, recognizability of any new added material during conservation, the field still aims to create unity and certain 'standards' within the conservation practice and process. But as most things in conservation and heritage science, you can never approach them as being solely black and white, but many more considerations are needed. For example, conservation treatments often start with cleaning the surface of objects. But cleaning inevitably implies removing something. This means cleaning can never be reversible. This is just one example, that illustrates that it is in all cases very important to very carefully consider every step of the treatment for each unique object by weighing the benefits versus the risks of loss, now and in the future, all starting with the question 'to clean or not to clean?'. As clearly stated by Jonathan Ashley Smith at the ICOM-CC conference in 2017 , the one aim of ethical guidance, is to require the conservator to consider all available options. But this unavoidably means maximum understanding of the object in its broadest possible sense.

So in addition to the well-known guidelines, we should recognize the need to aim within our conservation concepts to at least carefully consider the preservation of every aspect present within the material biography of an object, that can give more information about the object and its context. This is especially the case for objects such as historic ones, partially or fully constructed out of textiles, that served one or more practical purposes during their 'active life'. In addition, we want to keep these features researchable in the future so they can still be examined and maybe even be more correctly understood and therefore 're-valued' in the future when new methods, techniques or insights might become available.

\section{To look beyond the naked eye}

The challenge in 'unravelling' this material biography is to try and look beyond what the naked eye can see and to really understand what it is we are seeing. Not an easy task, but a very interesting one. With all the scientific knowledge and research-tools we have at the moment, there is no reason to let this aim, of understanding the unknown, scare us or hold us back. To recognize and understand is our first aim, but to be able to interpret and also to distinguish between traces of 'value' and traces of undesired change that could be referred to as damage is the following ste ${ }^{10}$. But there is never, or rarely, one simple answer to what appears to be such a simple question. Therefore it is so very important and often instrumental in our conservation-decision-making-process, to closely collaborate, communicate and create understanding between art historians, curators, conservations-scientists and conservators ${ }^{11}$.

As caretakers of objects and all that this or they may mean, we should encourage open discussion and broader understanding. We all try to achieve this in our own way, but during the actual practical application, this process often proves to be full of obstacles. We need to be aware and keep in mind that for example the curator-object relationship is rather different from the conservator-object relationship and different again from the conservation-scientist-object relationship. Each actor has different perceptions and experiences, but when combined, they complement one another immensely and it is through understanding each other, that we can start to understand the object more fully. And this kind of understanding is often very instrumental in the

5. Ashley-Smith, Jonathan (2017) 'A role for bespoke codes of ethics', Pre-prints of the ICOM-CC $18^{\text {th }}$ Triennial Conference Theory and History of Conservation. Copenhagen.

6. Ashley-Smith, 2017.

7. See for example: ICOM-code of ethics, the ethical guidelines of AIC, ECCO and many more.

8. See Figure 1: Triangle of collection management in: A. W. Brokerhof, 'Collection Risk Management - The Next Frontier', Presented at the Canadian Museums Association Cultural Property Protection Conference. Ottawa, 2006. p 2.

9. During the time before they became part of a museum's collection and before they were given a 'heritage' status.

10. S. Stansiforth (1994) 'Group report What are Appropriate Strategies to Evaluate Change and to Sustain Cultural Heritage', Report of the Dahlem workshop Durability and Change on 6-11 Dec 1992 in Berlin. New York, pp. 218-223; J. Ashley-Smith (1995) 'Definitions of Damage', Text of a talk given in the session 'when conservator and collections meet' at the Annual Meeting of the Association of Art Historians, Londen, April 7-8, 1995, not published. https://cool.conservation-us.org/byauth/ashley-smith/damage.html last consulted on the 3th of October 2019. 11. Depending on the case, it goes without saying that more input can be required than mentioned, for example of anthropologists and related communities. 


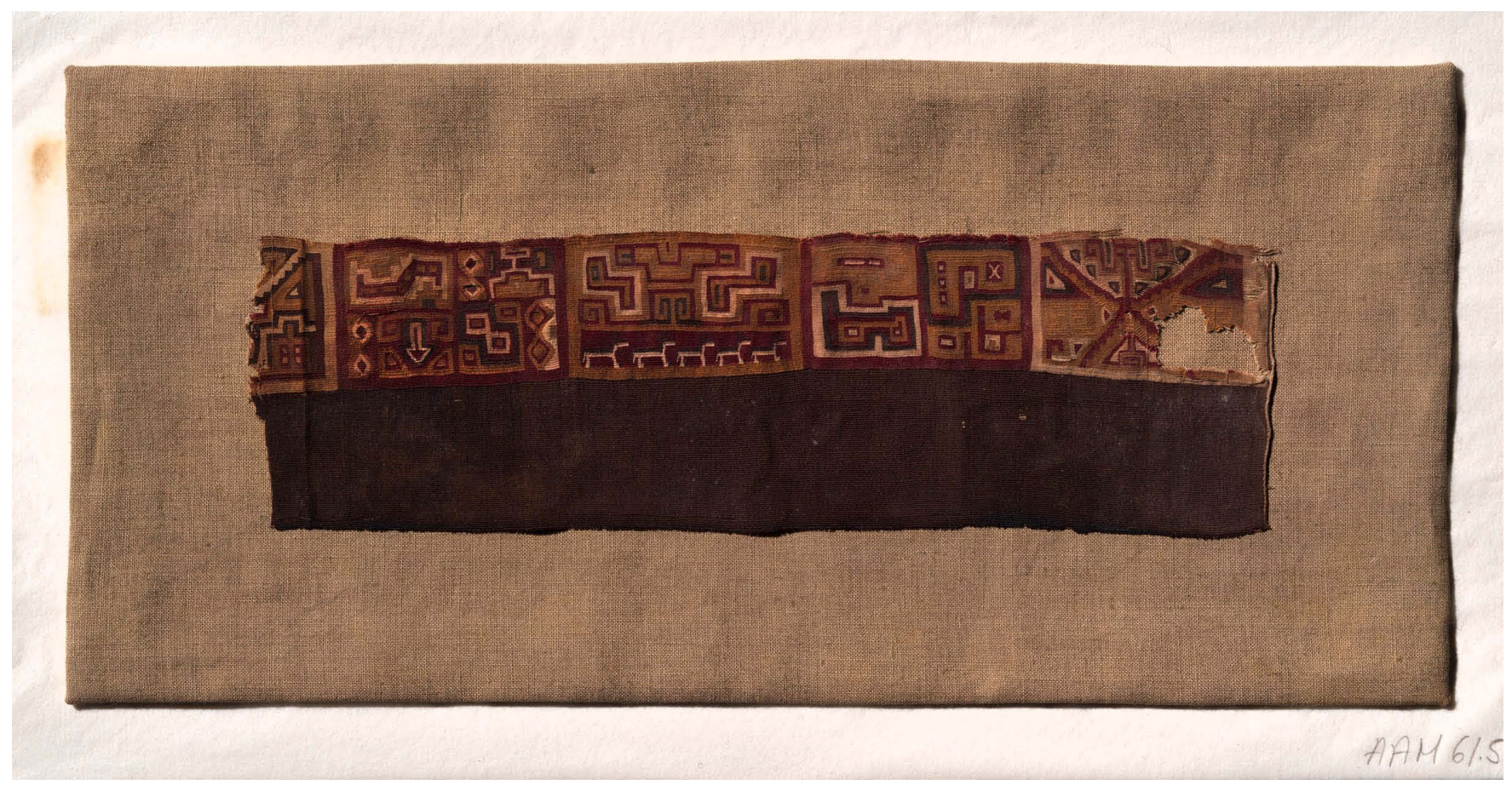

Figure 1: AAM61.5 before conservation treatment in 2017 (dimensions $24 \times 7 \mathrm{~cm}$ ) (C) KIK-IRPA x120596

conservation choices and treatments that follow. They are a guide to mitigate the risk(s) of loss of significance that could occur due to conservation treatment.

The two case studies of the conservation of Peruvian textiles, as described here below, proved vivid examples of this.

\section{Case-study: The conservation of two Peruvian textile fragments}

In preparation of the "Inca dress code" exhibition (23/11/2018-21/04/2019) at the Royal Art and History museum in Brussels, the Royal Institute for Cultural Heritage carried out the research and conservation treatment of two Peruvian textile fragments that were presented during this exhibition and that are both an example of 'significance hidden in plain sight'.

\section{The significant value of a "disturbing" haze}

The first fragment that was treated at the textile conservation studio of the KIK-IRPA can be dated between 1450$1532^{12}$. This exquisite textile fragment, that can be seen in figure 1, was woven in an extremely fine tapestry technique in vicuña wool (weft) and cotton (warp) ${ }^{13}$ with a density of 25-28 warp threads to 164 weft threads per $\mathrm{cm}$. In collaboration with Christophe Moulherat of the "Musée du Quai Branly" in Paris, several images were taken (in Brussels) with a Hirox-microscope that illustrates the density of this textile fragment very well, as can be seen in figure 2 .

Before this textile fragment entered the textile conservation studio in 2018, it had already undergone a very general conservation treatment in the 1980's when the fragment was mounted and consolidated on a beige support fabric with the result that the backside, except for a small cut out peephole in the support fabric, could not be consulted.

One of the most pressing conservation issues at the moment of entry in the studio in 2018 , was that, in several places at the front side of the textile fragment, a white disturbing haze could be seen giving the textile a strange appearance. Naturally, we did not want to start the cleaning process without knowing what we were confronted with, so, the primary focus of the preliminary research was to determine the nature and origin of this strange white substance.

The first assumption was that this might be mold but, after a negative ARA-kit test ${ }^{14}$, this assumption could be

12. Information provided by Serge Lemaitre, curator and collection caretaker of the Royal Museum of Art and History in Brussels. 13. Ina Vanden Berghe, conservation scientist at the KIK-IRPA, carried out a fiber identification 14. DG-18 ARA- Kit from Bio Trading 


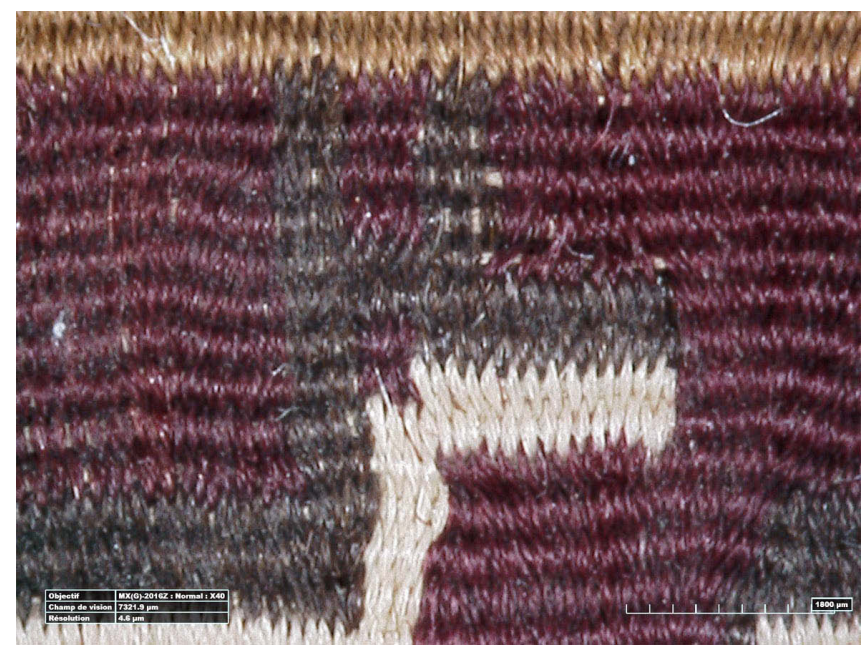

Figure 2: Detail AAM61.5 with Hirox-microscope (C) C. Moulherat

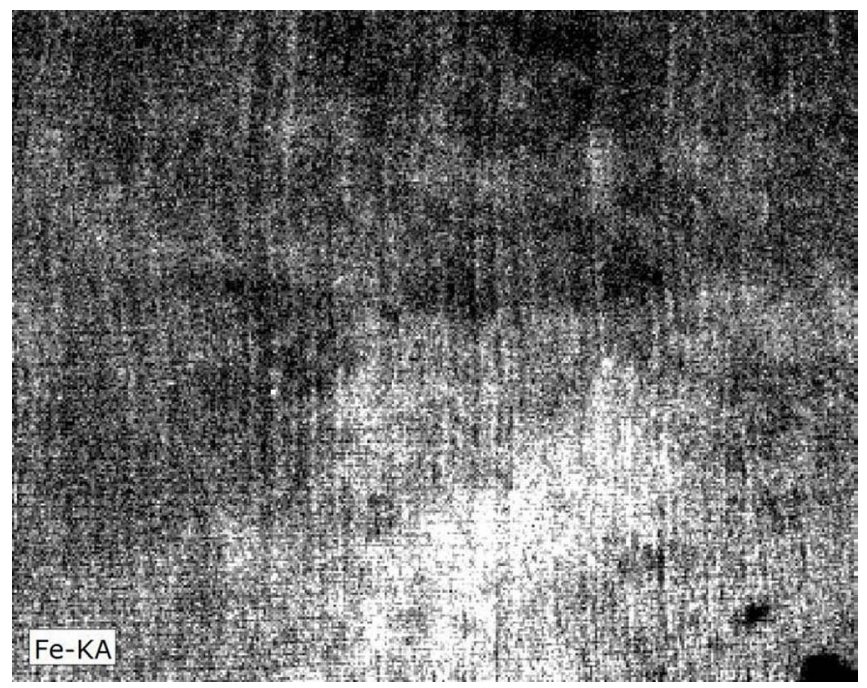

Figure 3: MA-XRF Fe \& KA mapping (C) KIK-IRPA

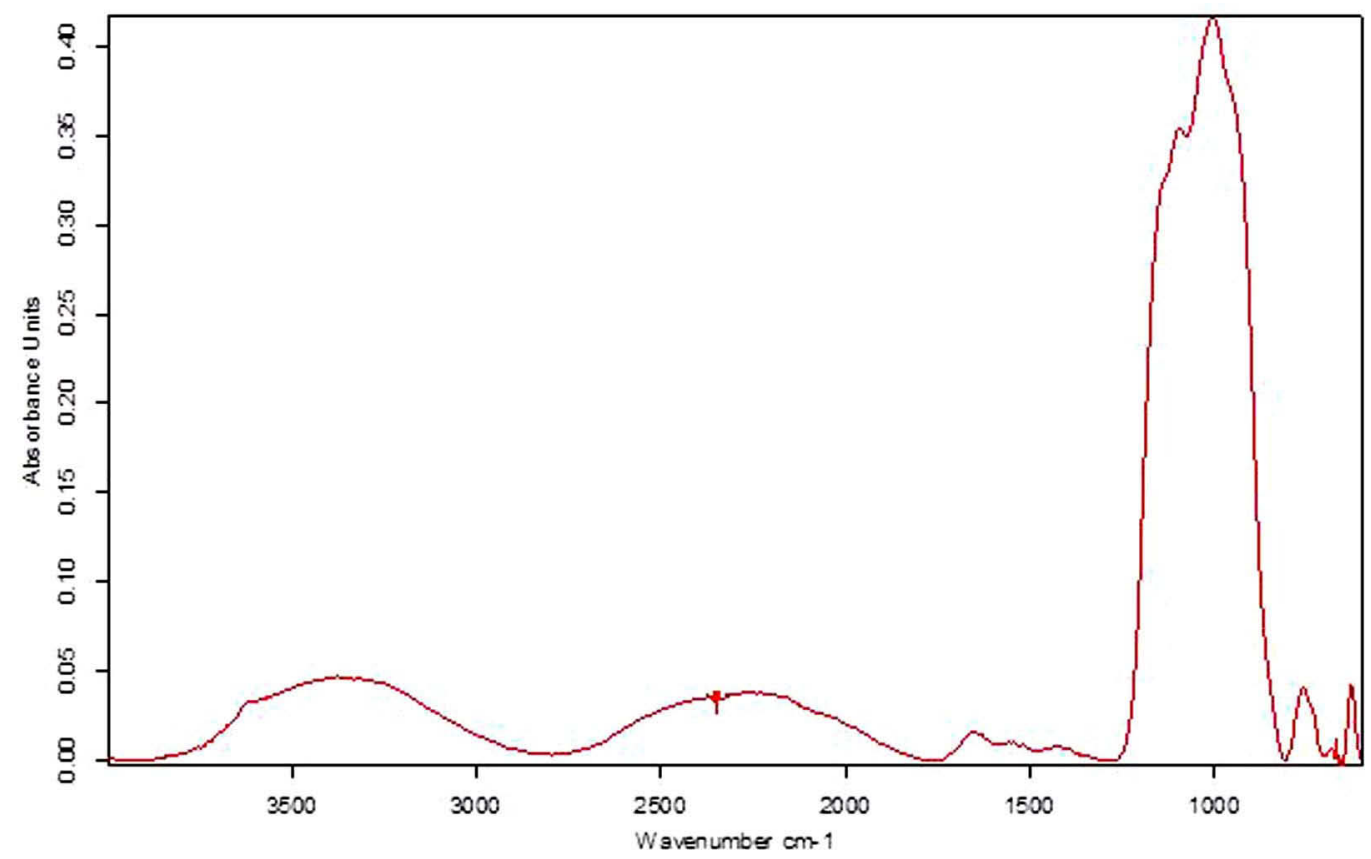

Figure 4: FTIR analyze (C) KIK-IRPA

discarded. Marina Van Bos, conservation scientist in our laboratory department, performed further analysis on the white haze in order to determine its nature.

The first analysis was conducted with the non-invasive technique of MA-XRF. This technique allows analyzing the chemical elements present on and in the textile surface without taking any samples. A small area that contained the white haze was analyzed with the Bruker M6 Jetstream. ${ }^{15}$
As can be seen in figure 3, results show a higher concentration of iron in these areas than in other parts of the textile fragment.

Additional Fourier Transform Infrared Spectroscopy was carried out, using the Vertex 70 spectrometer linked with the Hyperion 3000 - Bruker microscope. As can be seen in figure 4 , the results show an absorption from silicon-oxygen. In combination with the results of the MA-XRF, there 


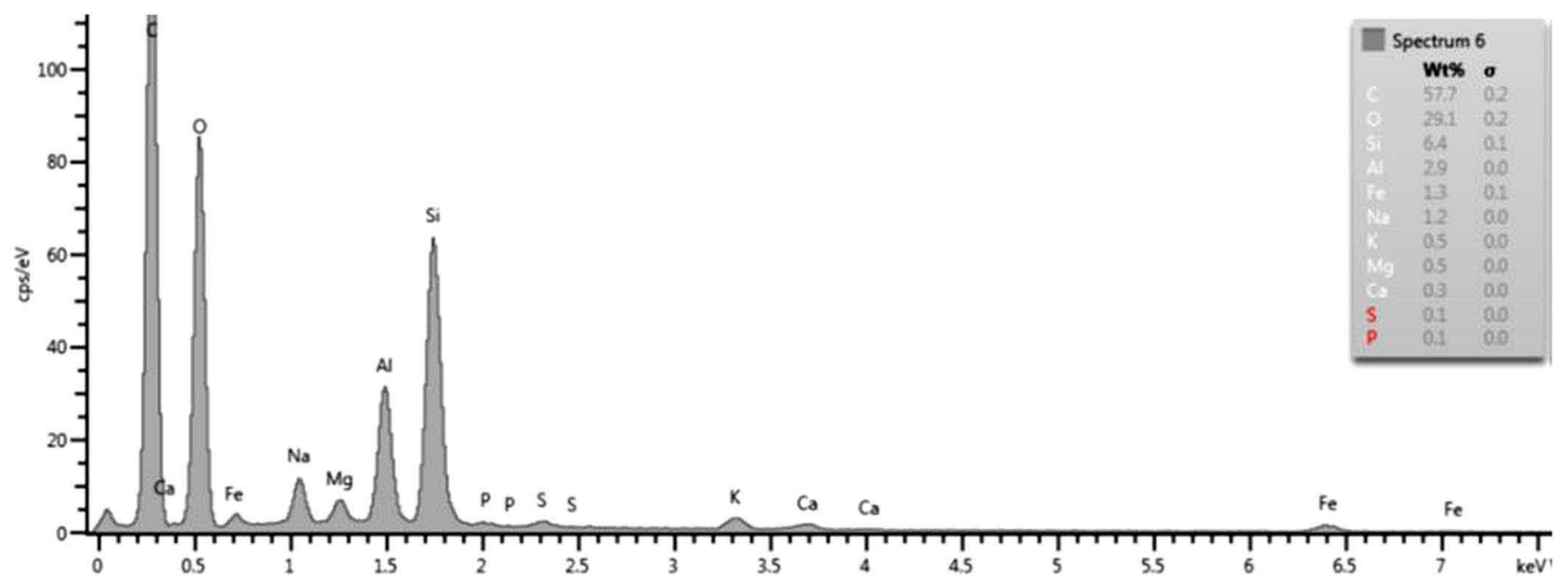

Figure 5: MEB-EDX spectrum of AAM.61.5 (C) KIK-IRPA

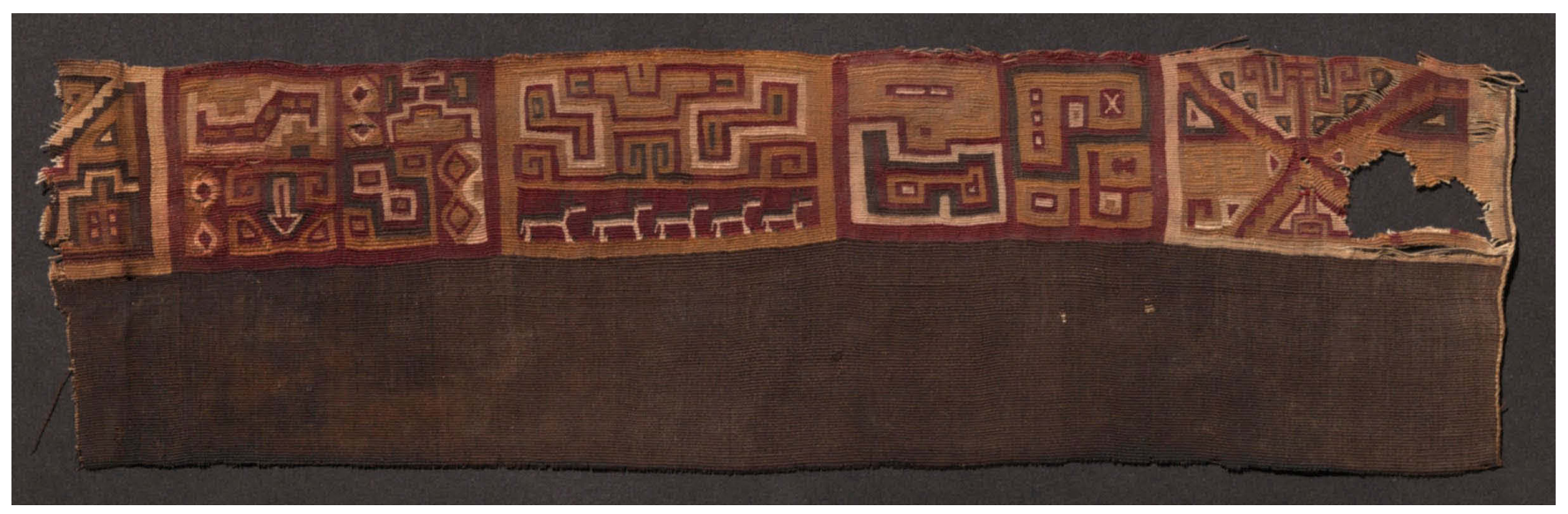

Figure 6: AAM61.5 after conservation treatment (dimensions 24 x 7cm) (C) KIK-IRPA x125816

was the assumption that the white haze might be a kind of soil, like clay. To confirm this assumption, a third and last analysis was carried out by using MEB-EDX analyses.

This was carried out using a Zeiss EVO LS15 and a detector of Oxford Instruments. The EDX spectrum presented in figure 5 shows the presence of oxygen, iron, aluminum, silicon and iron. The presence of these elements confirms the assumption that the white residue could be clay. A clay that probably can be traced back to the clay left from the environment where the object was found during its excavation. Therefore, this clay can be seen as a part of the storytelling of the history of the object, as a part of the "previous life" of the fragment. Hence, it is of 'significance'.

Before the results of these analyses, the first impulse was to remove the haze, but, after this better understanding, removing it would be an important loss of significant value. And although we are not exactly sure where this clay comes from, we want to keep the clay in order to make eventual future research on it possible. An additional factor that could support such a decision for these types of archeological objects and collections, is that when the provenance is uncertain or unclear, holding on to elements like these could be of great value in their future research.

Since a wet cleaning is an irreversible treatment that could remove significant value, we asked ourselves the challenging question “to clean or not to clean?". For this case study we decided to do a relaxation of the fibers in order to give more flexibility to the weaving structure by using humidity. This also improved the visual aspects of the fragment, but in no way did it remove the clay-matter. So the treatment was carried out in such a way that all the significant features of the fragment could be preserved and consulted in the future.

Because of the amazing craftmanship and the incredible weaving density of this small textile fragment, we found it most important that the entire backside of the textile could 


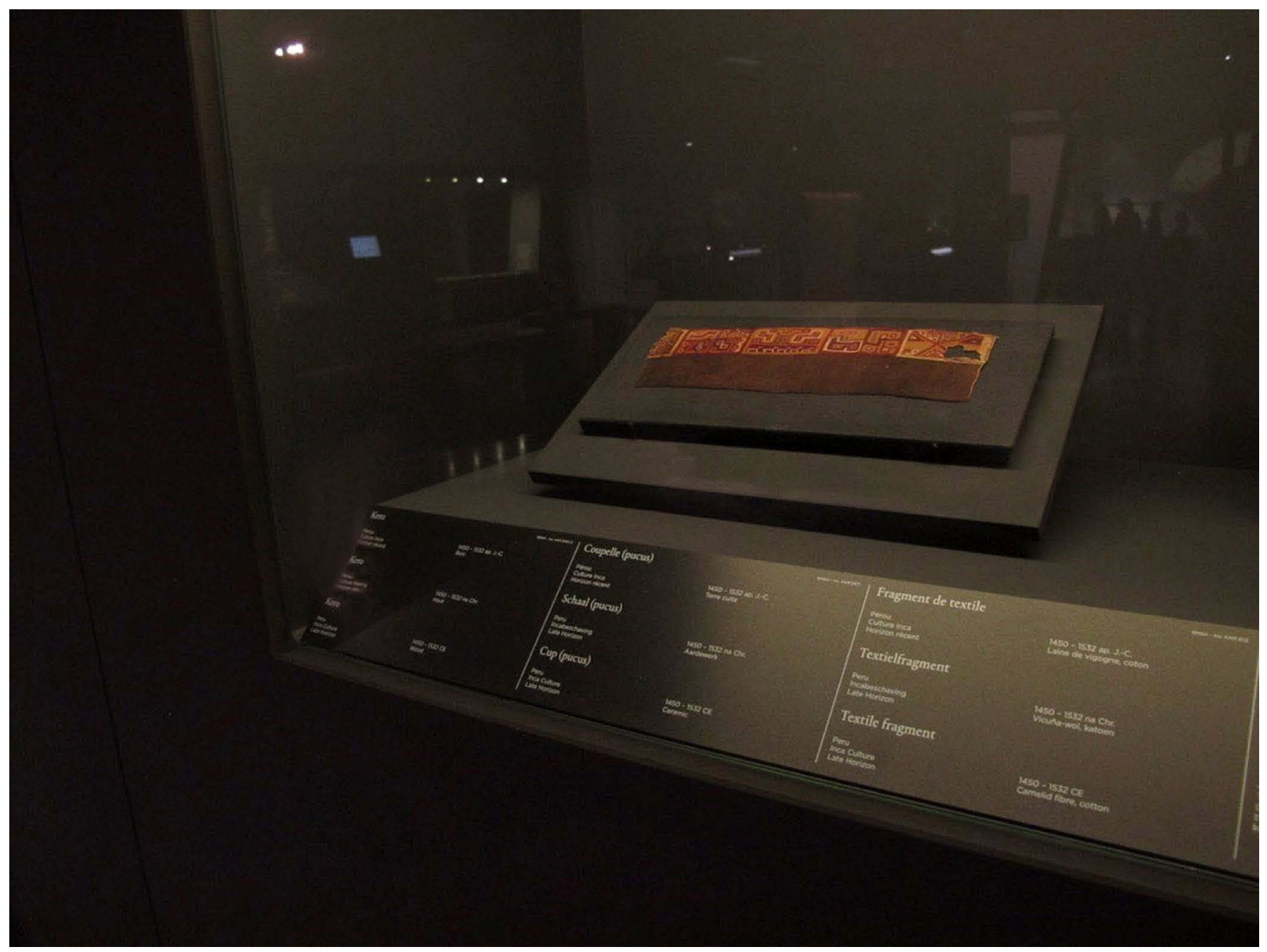

Figure 7: Textile fragment during exhibition INCA dress code (c) Emma Damen

be consulted from now on and for future research. That is why we decided to remove the beige support fabric and make a custom preservation-, transport- and presentation mount in order to minimize the handling of the fragment.

The final result can be seen in figure 6 and a picture of the object during exhibition in figure 7. The relaxation of the fibers resulted in brighter colors, a more vivid appearance and a general improved lecture of the geometrical figures in the fragment. The white haze is minimized, but certainly not entirely removed, in order to ensure the preservation of as much of the intangible values of this fragment as possible. The conservation treatment did not only contribute to the durable preservation, it also ensured keeping all material aspects of significance within of the object researchable for the future. Thanks to its new mount, it also ensures that further research can be carried out with an easier access for the researcher and in a safer way for the object.

\section{The significant value of "disturbing" stitches}

The second fragment, that was treated in the textile conservation studio of KIK-IRPA, in preparation of the same exhibition, can be dated at the end of the $16^{\text {th }}$ century. ${ }^{16}$ It is also woven in a tapestry technique with cotton applied for the warp and vicuña wool for the weft. ${ }^{17}$ Here, it was not a white haze that caught the eye and drew attention away from the object itself, but an old darning on the upper side of the fragment, together with additional sewing stitches all around the border of the textile fragment, as can be seen in figures 8 and 9 . 


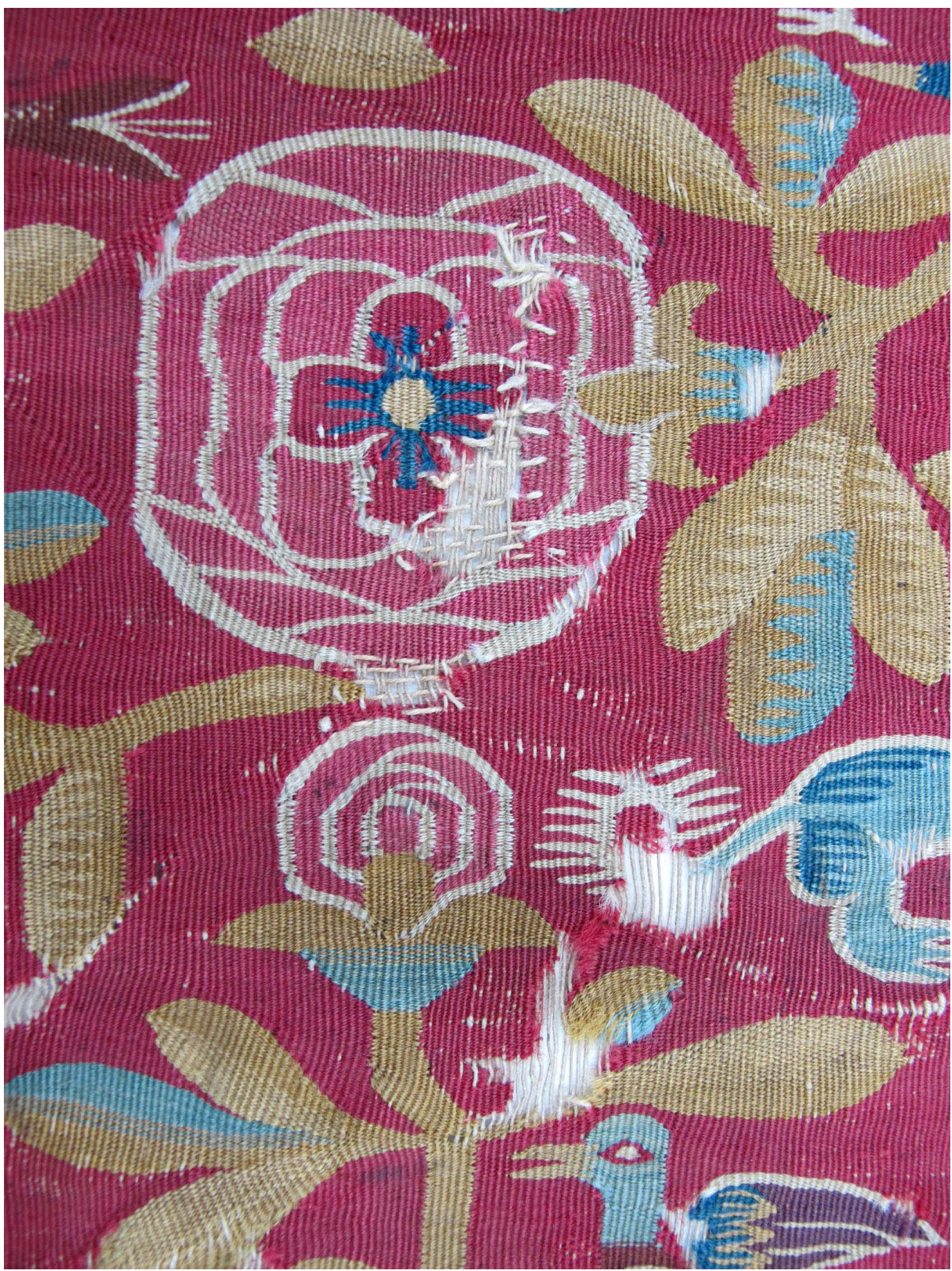

Figure 8: Detail old darning textile fragment 737 @ KIK-IRPA 


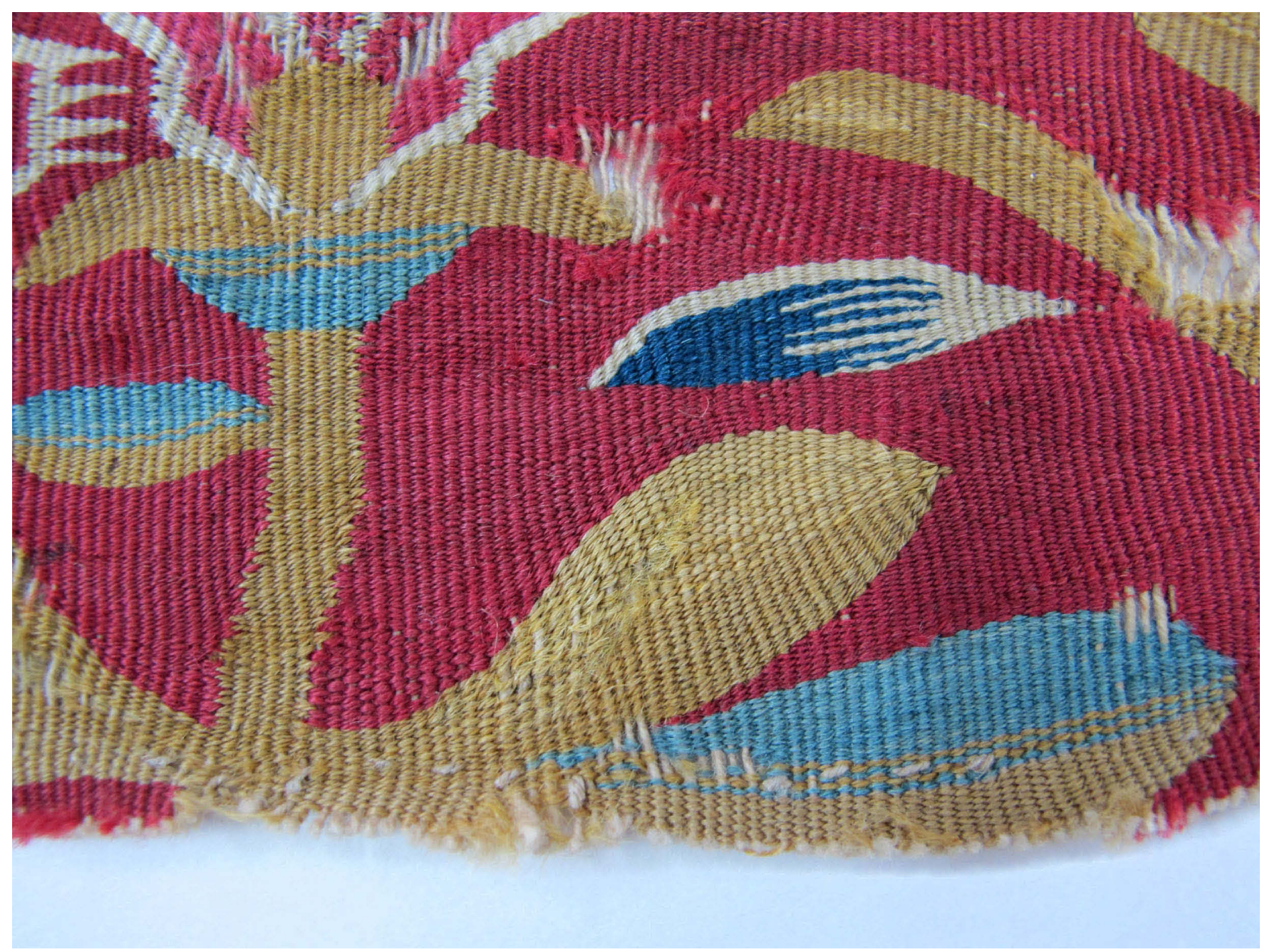

Figure 9: Detail old sewing stitches all around the border (C) KIK-IRPA

For the preparation of the exhibition, the question of the museum was to remove this somewhat disturbing darning, but, when we took a closer look, it could be determined that this darning was carried out when the backside of the fragment was not accessible. It gave us a first indication that this textile fragment was possibly used as a pillow cover or as another functional object during a part of its active life. The manner in which the stitches where applied shows that the person that applied the stitching had no access to the backside of the textile and therefore could only work from the front of the object. In addition, the sewing stitches that can be found all around the border of the textile fragment, could confirm this assumption. So again, a part of the intangible value could be lost if the darning and stitches would be removed. Because of this and because these later added stitches do not create any tension in the object, we decided to leave them in place, but to harmonize them so that these somehow "disturbing features" would be less visible, yet still consultable for the future. The chosen conservation treatment would have to support the weaker areas at the same time. Therefore, it was decided to consolidate the fragment as a whole.

The fact that the backside would no longer be easily consultable after treatment seems to point to an opposite logic from the one followed for the first, smaller textile fragment. But here, in consultation with the curator and collection caretaker, guided by the specific needs of this object, it was decided that, in this case, it was more important to conserve the weaker areas in order to preserve it as durably as possible for the future. As a compromise, we documented the backside elaborately with photographs in high resolution 


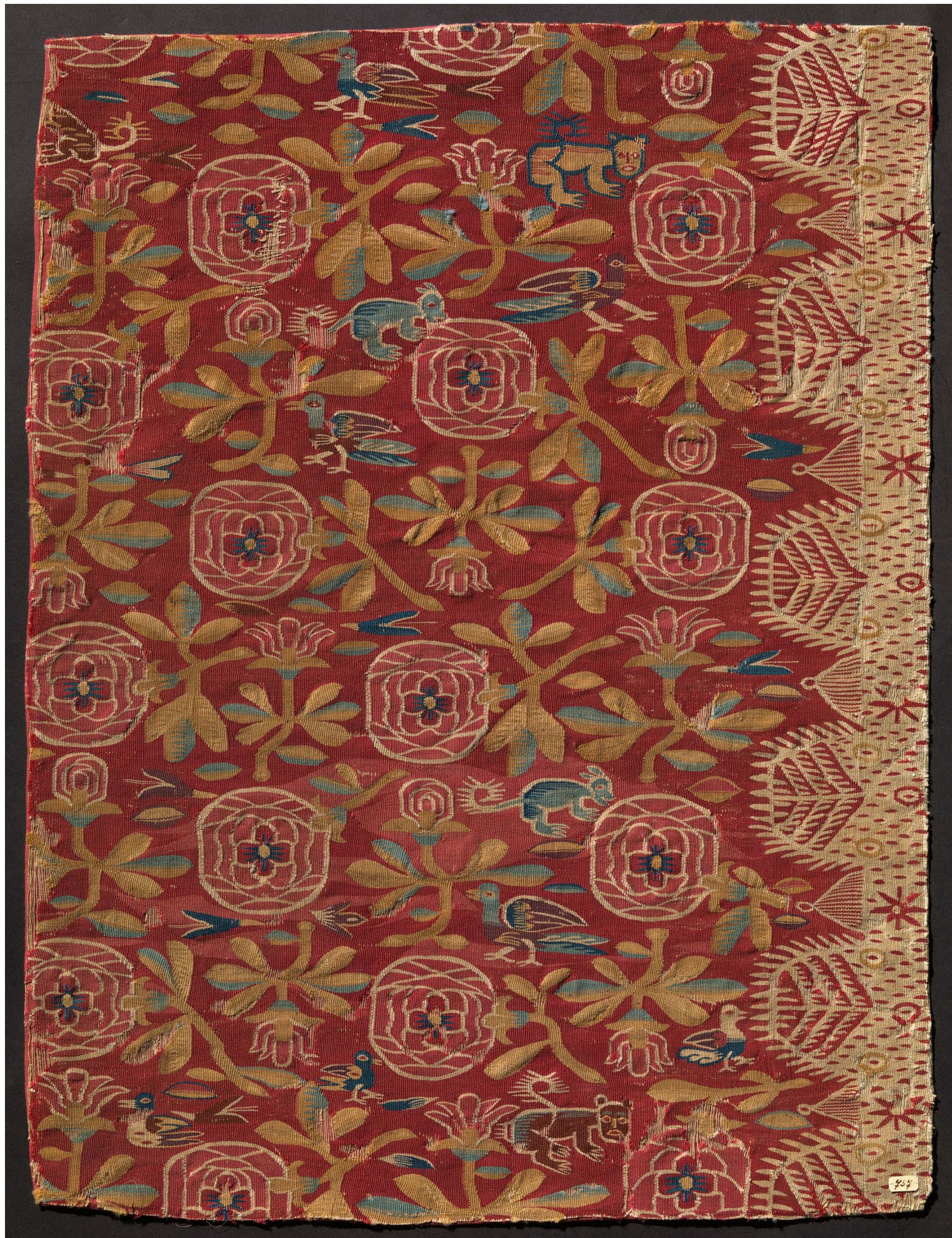

Figure 10: 737 after conservation (dimensions : 60 x 45 cm) (C) KIK-IRPA x125811 


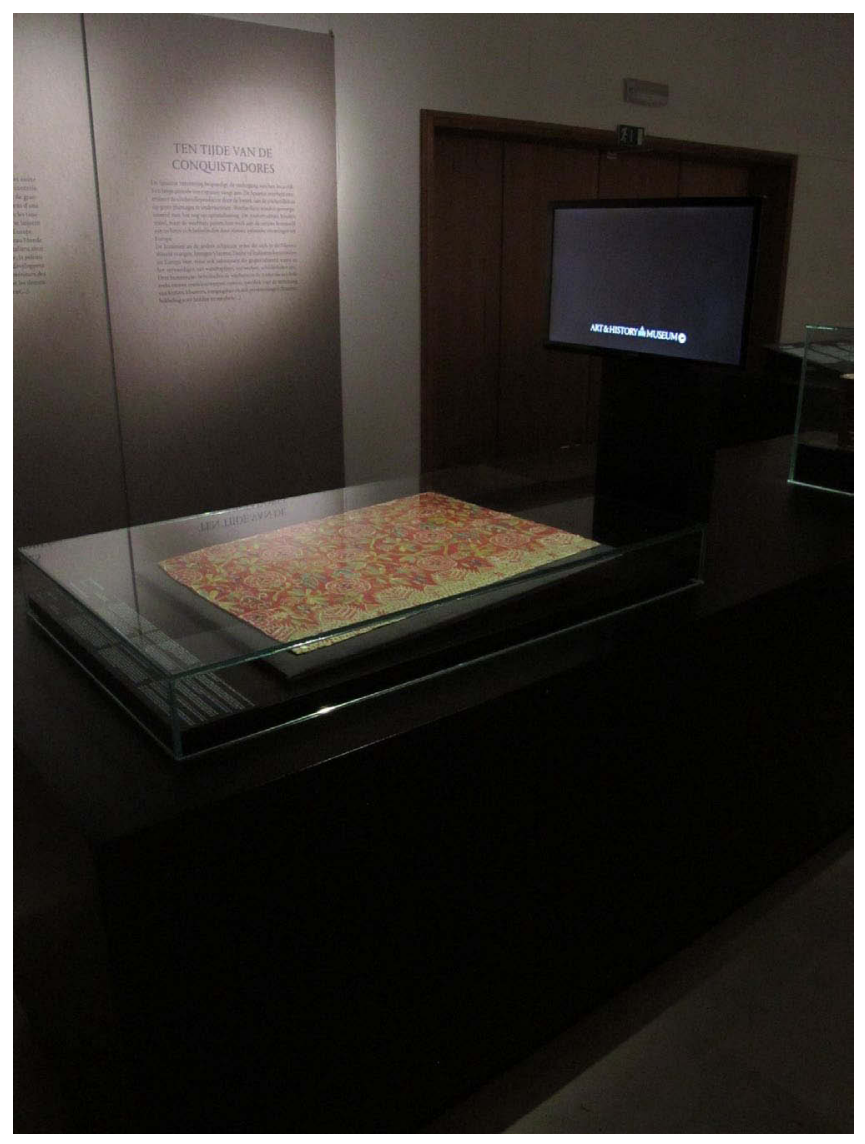

Figure 11: 737 during exhibition (c) Emma Damen

so future research can still be carried out without actually touching the object.

To harmonize the lacunas on each part of the textile fragment, we decided to work with a support fabric that consisted of two different colors. Consolidation stitches where used to attach the fragment to the support fabric. For the presentation and preservation mount we used the same method as the one applied on the first textile fragment. Together with the preservation box, there is no need to handle the object directly, which will be a great help in preserving all possible tangible and intangible features of the object in a durable way for the future.

\section{Conclusion}

These two case studies illustrate vividly, how unknown, seemingly disturbing and at first sight unwanted aspects in an object can turn out to be of significance and something really worth holding on to in conservation practice, despite all the facts that ruled against them. By looking at objects from a different angle, as these cases certainly show, great 'value' can even be found in 'dirt'. It all depends...

In order to ensure that we are not losing, or unknowingly and unwillingly removing 'valuable heritage' for future generations, it is more than worthwhile to consider every feature of an object, no matter how small, ugly or insignificant they may seem at a first glance.

\section{Acknowledgements}

We would like to give special thanks to our colleagues and in-house conservation scientists. Dr. Ina Vanden Berghe and Dr. Marina Van Bos with the assistance of Maaike Vandorpe. Dr. Mathieu Boudin with the assistance of Tess Van den Brande. The result of their research was invaluable at determining the conservation treatment for these two cases.

Thanks to Dr. Serge Lemaitre from the Art \& History Museum in Brussels for entrusting us with these extraordinary objects from his collection, for sharing their story and context so passionately, for inviting us to present our thoughts and experiences and to write this article. We would also like to thank everyone else who made this publication possible in any way or form.

Dr. Christophe Moulherat of the museum of Quai Branley also found his way to our conservation studio via Serge Lemaitre and via his approach he literally made us see the object in a whole new light.

Michelle De Brueker who shared her thoughts and experiences with us from within the conservation studio of the KIKIRPA.

And last but not least, Piet Veldeman and Karen Bonne for their razor-sharp insights at the development of this article. 


\title{
Life of a Peruvian art collector: Guillermo Schmidt Pizarro and the fostering of public collections of pre-Hispanic art in the first half of the $20^{\text {th }}$ century
}

\author{
Carolina Orsini and Anna Antonini \\ Museo delle Culture, Milano, Italia \\ Corresponding author: Carolina Orsini, Museo delle Culture, Via Tortona 56, 20144, Milano, Italia. Carolina.Orsini@comune.milano.it
}

\begin{abstract}
Guillermo Schmidt Pizarro was a famous collector of Peruvian origins, active in Europe and the United States beginning in the early twentieth century. He traded numerous pre-Hispanic and colonial artifacts to the most important museums of the time. The focus of this preliminary work is to trace his biography and the sales he dealt with over thirty years of activity. Thanks to provenance information, the authors have been able to sometimes "virtually build up" fragments of textiles that he scattered among diverse public and private institutions. The importance of this research is consistent with the efforts of museums to trace the origin of every artifact in their collections.
\end{abstract}

Keywords: Guillermo Schmidt Pizarro, Andean archaeology, ethnographic museums, history of collections, provenance, art dealers

\section{Resumen}

Guillermo Schmidt Pizarro fue un famoso coleccionista de origen peruano activo en Europa y en los Estados Unidos desde la primera mitad del siglo XX. Él estuvo en contacto con los museos más importantes de su época, ofreciéndoles numerosos artefactos prehispánicos y coloniales. El enfoque del presente trabajo preliminar es trazar su biografía y las ventas en las cuales estuvo involucrado durante más de treinta años de actividad. Gracias a los datos de provenance, las autoras en algunos casos han podido "reconstruir de forma virtual" los fragmentos de textiles que él ha disperso entre diversas instituciones públicas y particulares. La importancia de esta investigación queda en respaldar los esfuerzos de los museos para trazar el origen de cada artefacto en sus colecciones.

Keywords: Guillermo Schmidt Pizarro, arqueología andina, museos etnográficos, historia de colecciones, provenance, comerciantes de arte

\section{Resumé}

Guillermo Schmidt Pizarro était un célèbre collectionneur originaire du Pérou qui opéra en Europe et aux États-Unis au début du XX $\mathrm{X}^{\mathrm{e}}$ siècle. Il eut des rapports étroits avec les musées les plus importants de son époque auxquels il procura plusieurs artefacts préhispaniques et coloniaux. Le but de ce travail préliminaire est de tracer sa biographie et les ventes dont il s'occupa pendant plus de trente ans d'activité. Grâce aux informations de provenance, les auteures ont parfois pu « reconstruire virtuellement » les fragments de tissus dispersés parmi diverses institutions publiques et privées. L'importance de cette recherche constitue une contribution offerte aux musées pour retracer l'origine des artefacts de leurs collections.

Mots-clés: Guillermo Schmidt Pizarro, archéologie andine, musées ethnographiques, histoire des collections, provenance, marchands d'art 


\section{Introduction}

Beginning in the 1920's, Guillermo Schmidt Pizarro (1880 - 1964) (also here referred to as S.P.), a Peruvian antique dealer whose biography is still partly unknown, managed to sell a large number of Andean artifacts from different periods and types to over thirty museums and private collectors across the United States and Europe.

Thanks to informal relationships over the past five years with museums that house artifacts sold by Schmidt Pizarro, we have been able to uncover detailed information about this art dealer and his heritage in order to understand the methods, criteria and purposes by which he managed to supply a large amount of pre-Hispanic artifacts to Europe and the United States. In this preliminary essay, we trace his biography as a first step in tracking his collection.

This essay raises more questions than answers, yet stands as a first step toward understanding what type of Andean materials circulated in the antique market in Europe and the United States from the beginning of the $20^{\text {th }}$ century until the 1960's. This article seeks to shed light on the way the antiquities market was run, how power and economic strengths were stimulated through the sale of artifacts, and how the availability of specific artifacts and their circulation in exhibitions and sales affected taste regarding what was at the time considered "important" to collect in Europe and the United States.

Tracing Schmidt Pizarro's personal history and his way of maneuvering geographically is therefore crucial. His life experience, much like that of other art dealers of the time, his background and his contacts have been fundamental to the dissemination of pre-Columbian works, especially when considering the large quantity of artifacts that he managed to sell and the close ties he established with the principal museums of that time. Paradoxically, his history has remained for a long time in the shade, despite the fact that Schmidt Pizarro had also taken on public tasks besides his "work" as an antique dealer. Another key element to understand the mechanisms that ran the Andean art market of the time is the sales strategy endorsed by Schmidt Pizarro, which was certainly shared with other art dealers of the time, the principal features of which will be tackled in the final part of this article. Finally, the authors shall deal with the circulation of these artifacts through art exhibitions.

A great part of our research focuses on the textiles collected by Schmidt Pizarro. Notwithstanding his trade in all types of pre-Hispanic and colonial materials, textiles played a primary role in his activities. This preference is probably due not only to his taste, but also to the ease in transporting textiles, fundamental for the tireless traveler he was, and to the potential high revenues that he could earn from dividing (or even cutting?) the fabrics to then sell them parceled out to diverse museums (fig. 1). From the point of view of the authors, the study of textiles has enabled us to track his movements, following an imaginary Ariadne's thread that Schmidt Pizarro left unintentionally behind him, ${ }^{1}$ searching for fragments of the original textiles across the various museums, and thus being able to connect episodes and parts of his life. In fact, another purpose of this work, which will only be marginally tackled in this article and which will constitute an independent study, is the tracking of each textile, so parceled out that today it may belong to a number of diverse collections.

\section{About Objects Biography}

One of the approaches endorsed today by museums is that they are no longer a place where something is simply exhibited or conserved, but a place where objects can contribute to the construction of a community and personal growth (Weil 1999). The path leading to this assumption has been quite long. The commitment of museums toward the public begins from better understanding their own history so as to be able to convey it more honestly and openly to visitors and eventually turn it into a place of dialogue. Therefore, today, equal attention is paid to the material an object is made of, and to the technical and functional features of an object as an igniter of processes, at least since this phenomenon has been theorized by Kopytoff (1986) and many other scholars after him (e.g. Gosden - Marshall 1999).

Understanding the role played by an artifact as an igniter of social, legal, political and economic processes is achieved through tracing the history of the artifact and the multiple functions that it has assumed during time. Tracking the life of an artifact is today a vital element of museum research. This task entails a fundamental first step: tracing the biography of the people that have collected the artifacts (Hill 2012). This task is quite challenging when the origin of artifacts is unknown, as well as their collection history, because they have not been gathered during scientific expeditions or excavations, but through the activity of art dealers

1. As regards the tracing of collections, our thanks go to those museums that, besides their traditional catalogues, have published databases online which can be freely consulted. When the collection origin is not explicit in these catalogues, we start from works comparable to others previously identified. In some cases, thanks to archival documents, we have traced the probable origin of Schmidt Pizarro's collection. It has been a very long process that we hope to continue, thanks to the valuable collaboration of our peers. 

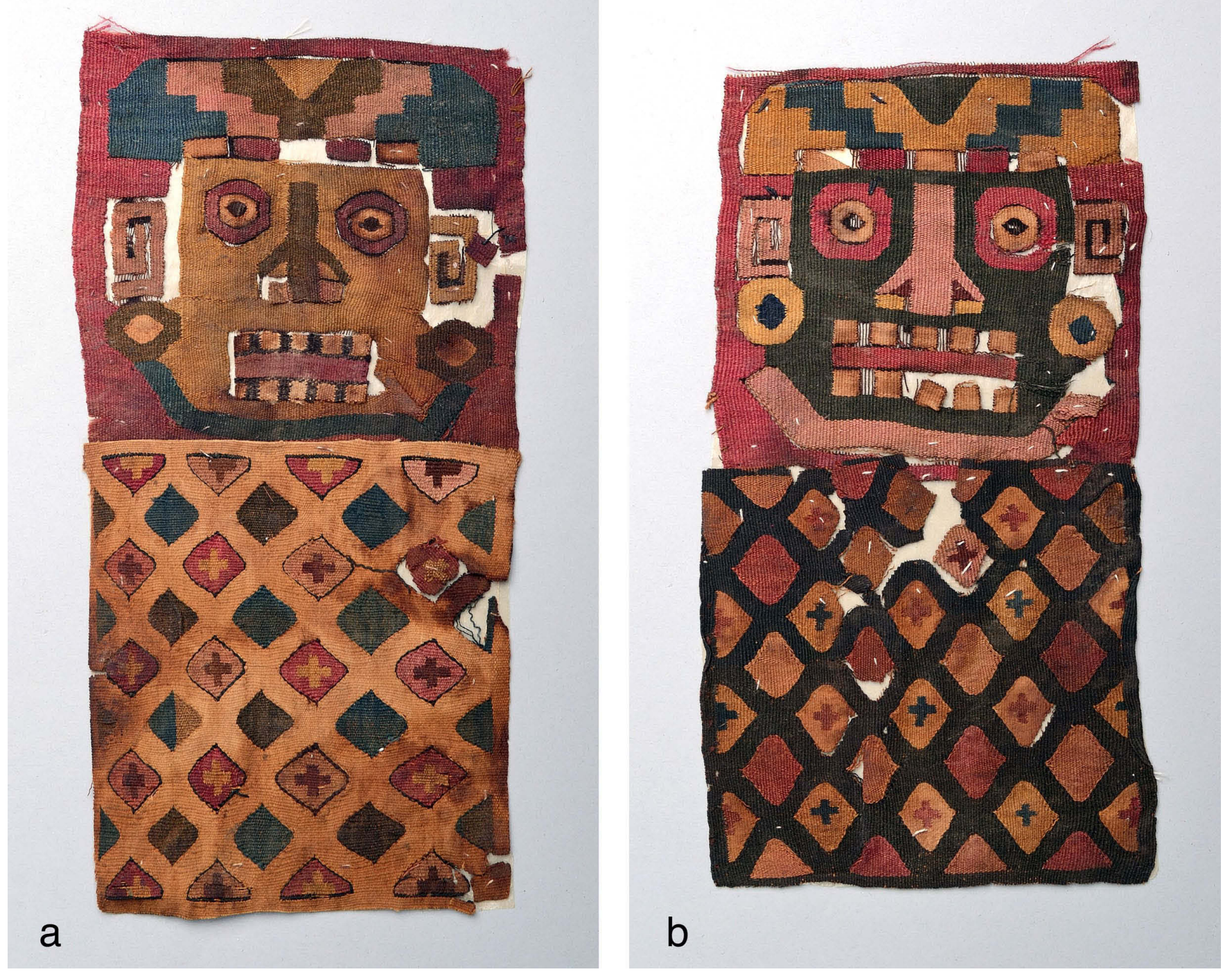

Figure 1a-b. Two emblematic tapestry fragments of faces and diamond motifs from the Schmidt Pizarro collection now at Mudec (South Coast of Peru, A.D. 500 - 1000). Inv. PAM 00143 (10,5X21cm) and PAM 00145 (11,5X23cm). Courtesy Mudec - Museo delle Culture, Milan. Other pieces of the same textile with Schmidt Pizarro provenance are conserved in: British Museum (Am1933,-..10.b, Am1933,-.10.c); Brooklyn Museum of Art (34.559.1 a-d); Boston Museum of Fine Arts (31.701-4); Castello d'Albertis (C.A.1483, C.A. 1493-4); Museum für Gestaltung Zürich (KGS-1952-0012); Rietberg (RPB 1303 a-d); Textile Museum (91.119 a-d); Welt Museum (98.243). See also the following pieces probably of the same garment but without an explicit Schmidt Pizarro provenance: Abegg Foundation (1147 a-d); Joseph and Anni Albers Foundation (1994.16.6); Koninklijke Musea voor Kunst en Geschiedenis (AAM ooo5881-4); Metropolitan Museum of Art (33.149.85b, 33.149.86 a-b); MuCiv - Museo preistorico etnografico Luigi Pigorini (182896); Museum der Kulturen Basel (92.96, 92.97); Rhode Island School of Design (50.383, 50.384); Royal Museums of Art and History (AAM 5881-5884); Victoria and Albert Museum (T.75-1933).

having scarce (or no) interest in documenting their work. In this case, the "biography" of an artifact is compromised in two ways: when cut into smaller fragments, its original features can hardly be tracked, likewise its place of origin or original provenience. The artifact's recent history is obscure and problematic, as well. Sometimes the denied history of people and things is the fruit of mere carelessness, sometimes it is the outcome of a well devised project aimed at willingly erasing stories of abuses, robberies or illegal actions (Thebele 2018 and quoted bibliography).

Today, modern museum ethics ${ }^{2}$ impose a radical change of trend, triggered also by several legal actions that have 
been filed by governments on the matter of cultural heritage over the last fifty years. ${ }^{3}$ Our aim is to trace the biography of an art collector as a first step in tracking the history of the objects that he collected. This is necessary in order to assess the legitimacy (or not) of his collection. Moreover, in trying to re-connect the fragments of his collection, we hope to give new instruments to other the researchers in order to repair the damage caused by this type of collecting.

This study is grounded in the search across secondary and informal sources, since the primary objective of Schmidt Pizarro's collection, likewise that of many other art dealers of the time ${ }^{4}$, was simply to get a revenue from his sales, by selling as many specimens as possible. The hints that he gave from time to time with regard to his "supplying" sources and to the places where he collected these objects are seldom reliable, because there was no scientific purpose in the descriptions that he left, but only the willingness to increase the value of "goods" being sold, perhaps highlighting their "rare" nature. Yet, as we will see, Schmidt Pizarro was undoubtedly a cultivated man, with many acquaintances among the scholars of the time (see below). His contradictory approach is not surprising and is a product of the attitudes in vogue at the time.

Being unable to rely on the history provided by Schmidt Pizarro himself, we have traced his biography step by step through the history of his collection, beginning with the correspondence made available to us by colleagues in several museums in Europe and the United States. Our research also included legal documents, such as deeds of sale, payment slips, invoices, ship passenger lists, lists of immigration or transit registers in the ports of Ellis Island (New York), San Francisco and Southampton/Plymouth (UK / 1900 - 196o); newspapers, magazines, parish church documents and registers of baptism.

\section{An Adventurous Life}

The biography of Guillermo Schmidt Pizarro is still very uncertain, especially in regard to the early years of his life. He had a long life, full of adventure, mostly spent traveling and frequenting environments linked to art and diplomacy. He was born in Tacna, Peru on September 27, 1880, ${ }^{5}$ the son of Federico Guillermo Schmidt (born in Osnabruck, Germany, and baptized a few days before his marriage celebrated in Tacna in 1876) ${ }^{6}$ and Mercedes Pizarro. Guillermo Schmidt Pizarro had two younger brothers, Federico Carlos, born in 1886,7 of whom we were unable to find other information, and Juan Oscar, who was born in $1883^{8}$ and died in Lima in $1967 . .^{9}$ The latter was vice-consul of Peru in Germany in the 1920's: he appears in the yearly Hamburg directory of 1922 and $1923 .{ }^{10}$ We also found Oscar referred to as "prok.", perhaps an agent in a company with interests in saltpeter mines, the H. Folsch \& Co. ${ }^{11}$ Guillermo died on January 20, 1964 in San Isidro, Lima (Fig. 2). ${ }^{12}$

The many relationships with Germany can be explained by his paternal origins. It is probable that the children maintained bonds with their father's home country and spoke German (Oscar married Ilse Achenbach, ${ }^{13}$ of German nationality, in Hamburg).

As is known, Chile was an important area of German immigration and the territory of Tacna was long disputed between Chile and Peru. Between the end of the Pacific War (1883) and 1929, Tacna was Chilean. Today it is still a few

3. The last European legislation effort is European Parliament Resolution of 17 January 2019 on cross-border restitution claims of works of art and cultural goods looted in armed conflicts and wars (2017/2023). See also Report A8-0465/2018 by Pavel Svoboda of 13.12.2018, https:// www.europarl.europa.eu/doceo/document/A-8-2018-0465 EN.pdf?redirect.

4. Other dealers or even museum curators cut textiles for different reasons. See, for example, the "doubletten” case documented by Bjerregaard (2001).

5. Register of baptisms, parish of San Pedro in Tacna, 1880. The data corresponds with a declaration to the US immigration office of Ellis Island and is found in the ship manifests of passenger arrivals in the years between 1911 and 1956.

6. Register of baptisms, parish of San Pedro in Tacna, 1876.

7. Register of baptisms, parish of San Pedro in Tacna, 1886.

8. Register of baptisms, parish of San Pedro in Tacna, 1883.

9. “Municipalidad de San Isidro" Peru. Lima, Civil records (1884-1996), Archivo General de la Nación, 1967, p.363.

10. Hamburger Adressbuch 1922, 1923, http://agora.sub.uni-hamburg.de/subhh-adress/digbib/start, retrieved 20.05.2019.

11. After the Saltpeter War in 1883 , Chile gained the monopoly of this precious raw material. Many companies settled in that difficult region that also included the southern portion of present-day Peru. During the Pacific War, the Hamburg merchant Hermann Conrad Johannes Fölsch established the company "Fölsch \& Martin" in Valparaiso active in the export of saltpeter from Chile. At the same time, he established the shipping company "H. Fölsch \& Co.” in Hamburg to import saltpeter. The company bankrupted after August 1921, after an accident.

12. The death is registered in "Municipalidad de San Isidro" Peru. Lima, Civil records (1874 - 1996), Archivo General de la Nación, 1964. The death date reported in Bernal Multon 2018 and in several online databases (National Museum of American Indian, British Museum) is 196o, but it is mistaken: this is also proved by the date of his latest sales, in the early sixties (see below).

13. Civil records (1884-1996), Archivo General de la Nación, 1941. Reports the deed of marriage celebrated in Hamburg in 1921. 


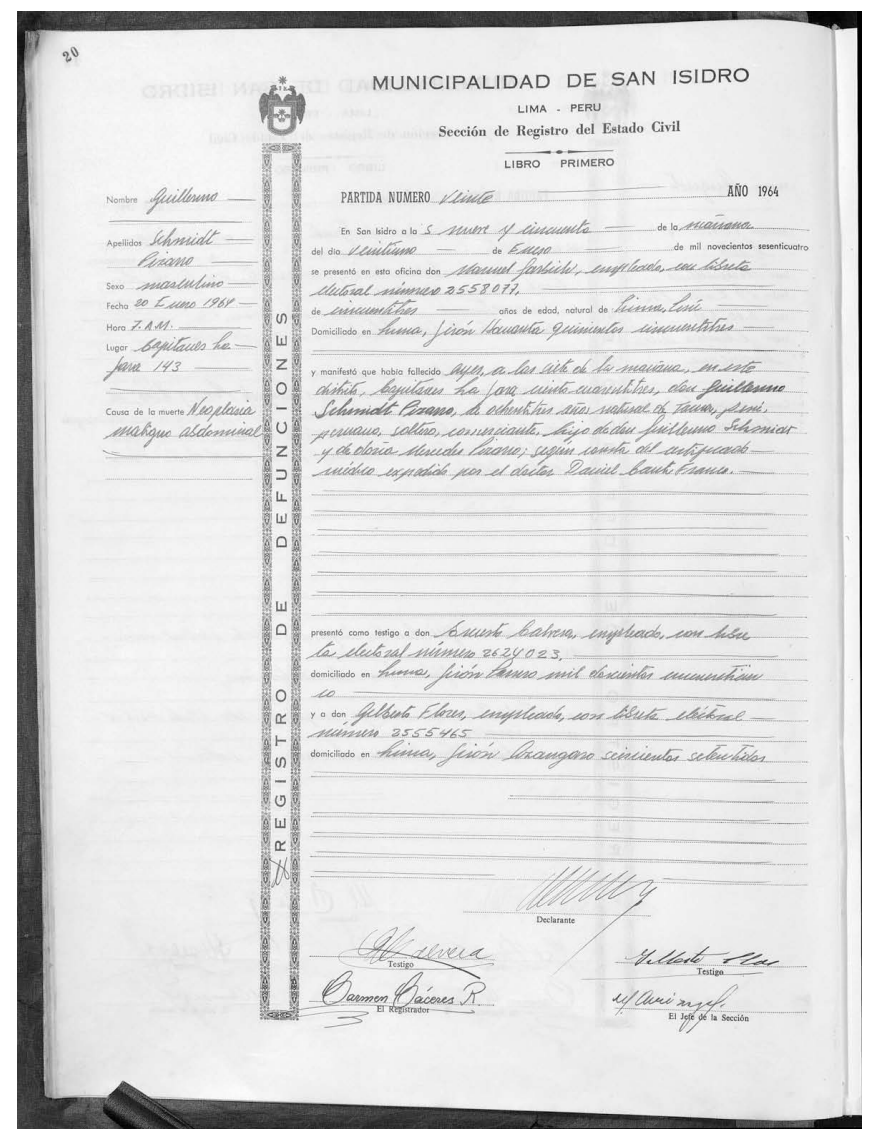

Figure 2. Death certificate of Guillermo Schmidt Pizarro. Courtesy Archivo General de la Nación, Lima.

miles from the border with Chile and it was a place of arrival for German immigrants in the nineteenth century (Hoerll 1910). The ties of the Schmidt Pizarro family with Chile are documented by Guillermo in the excerpt of a newspaper interview, probably El Mercurio. ${ }^{14}$ Guillermo is known to have been a resident of Iquique in $1909,{ }^{15}$ another disputed city that from 1884 became definitively Chilean, and in 1911 he lived in Santiago. ${ }^{16}$ His parents also lived in Iquique: his father until 1910 when he is presumed to have died, and his mother from $1911^{17}$ onward.
As of now, we have not been able to find any information relating to the education of either Oscar or Guillermo, even though they undoubtedly received a high level of education, given the positions they held in their future professional careers. Guillermo had some instruction on pre-Hispanic manufacturing techniques: Raoul D'Harcourt, ${ }^{18}$ in his famous book devoted to pre-Hispanic textiles, thanked Mr. Schmidt Pizarro of Lima for his help with images and information about textile techniques (1934: page VII). ${ }^{19}$ Subsequently, Guillermo wrote a short article on pre-Hispanic platería silversmithing (see below).

Apparently, Guillermo had no children and never married. In the immigration documents of Ellis Island, he always declared himself "S", or "single", and in the record of his brother's marriage, he declared himself soltero at the age of 61 . We only know of one image of Guillermo, but thanks to the extensive records of US Immigration, we know that he was very tall, over $6 \mathrm{ft}$, with brown hair and greenbrown eyes.

On several occasions, ${ }^{20}$ Guillermo declared himself to be a descendant, on his mother's side, of Francisco Pizarro, the famous conquistador of Peru: a fact that we have not presently verified. Apart from the veracity of the statement, this claim certainly allowed him to identify himself as a figure belonging to the elite and, consequently, with privileged access to objects of great artistic and historical value.

\section{Travels and Relations with Museums}

Guillermo Schmidt Pizarro began to travel as an adult. His first trips can be traced back to 1909 and 1911, voyages he made with his mother to England. In 1921, while they were residents of Valparaiso, ${ }^{21}$ he made another trip to Europe, once again accompanied by his mother. His first contacts with museums can be established beginning in the late 1920's. At the moment, there is still the question of how he supported himself before the age of 45 , when he began to sell the collection that he often referred to as belonging

14. Annex to the letter of February 16, 1946 sent by Schmidt Pizarro to Herbert Spinden, curator of the ethnographic section of the Brooklyn Museum (the Brooklyn Museum Archives, Director [02]. File \# 117. Spinden, Herbert J. (01 / 1939-12 / 1943).

15. Port of Ellis Island passenger manifest of the ship Santa Marta (Tropical Fruit Co.), May 4, 1911.

16. Port of Ellis Island passenger manifest of the ship Orinoco (unknown company), April 28, 1909.

17. Addresses of residence declared in the trips to New York of 1909 and 1911. In 1921, the mother declares herself widow Schmidt.

18. Born in 1879, Raoul D'Harcourt lived in Peru while he was working for the company Société Générale. The pre-Hispanic civilizations of Peru became the main focus of his studies, which he continued with his wife Margarite once he came back to Paris. In 1920, he began collaborating with the scholar Paul Rivet and became a prominent member of the Sociéte des Américanistes until his death, in 1971. See below for the relations between D'Harcourt and Pizarro.

19. Several pieces from the "Schmidt of Paris" collection appear in the same volume.

20. New Zealand Herald, 2 November 1935.

21. Incoming passenger manifest, port of Liverpool, May 1, 1921, ship Orcoma, Pacific Steam Navigation. 
"to his ancestors". ${ }^{22}$ The first information we collected relates to a sale of 74 objects to the Museum of Ethnography in Hamburg between the years 1926 and 1927. ${ }^{23}$ In August 1926, he gave 56 objects to the Ethnological Museum $(\mathrm{Mu}-$ seum für Völkerkunde) of Berlin, still declaring that he resided in Hamburg. ${ }^{24}$

In May 1928, he was in transit to New York on the ship "Santa Ana" originating from Valparaiso. It would seem that he had returned to South America and from there had left for the United States. Here, in December 1928, he sold some items to the famous antique dealer Joseph Brummer: ${ }^{25}$ a silver container ( $\mathrm{N} 2453$ ), and three Inca “embroideries" (NN $2454,2455,2456$ ). This is only the first of at least ten other transactions between the two antique dealers (for a total of 196 objects) made between May 1929 and October $1931 .^{26}$ The online catalog of the Metropolitan Museum of Art features two fragments of borders (31.20.2-31.20.1) entered in 1931 as a gift from George D. Pratt, ${ }^{27}$ but indicated as purchased from Joseph Brummer, who in turn had acquired them from Schmidt Pizarro. ${ }^{28}$ It is likely that some of the items sold to Brummer merged into Pratt's collection, and then arrived to the Metropolitan Museum but do not today appear in the online catalogue. Likewise, it is also possible that S.P. sold to Pratt without any trace of a record. Another possible proof is that some of the textiles belonging to the Metropolitan and catalogued as G.D. Pratt are apparently fragments of other textiles of Schmidt Pizarro origin, present in other museums (fig. 3a-b). ${ }^{29}$

Despite his intense commercial activity, in May 1930 Schmidt Pizarro was back in Chile, at the Hotel Crillon, as witnessed by the newspaper "La Nación" of May 3, 1930. On July 4, 1930, he landed again in Plymouth, probably intending to reinitiate sales to the major museums in Europe. It seems plausible that his returns to South America might have served to actually retrieve new items to sell, kept safely in the motherland. In 1930, he scored two of his most important sales.

In July, he sold a fabulous gold Nasca mask along with 21 other objects for 25,00o francs to the Musée du Trocadero in Paris. ${ }^{30}$ In November of the same year, in Madrid, he closed an important sale of 35 fabrics and objects from his collection, principally Nasca, Paracas and Supe, in addition to 13 colonial fabrics for a total of 9460 pesetas. ${ }^{31}$ In the documentation of the Museo Arqueológico Nacional in Madrid, there is a sort of rudimentary price list of the collection ${ }^{32}$ (fig. 4) that the antique dealer was willing to almost halve: from here we began to understand some of Schmidt Pizarro's sales strategies that will be a recurring practice.

22. Letter from Schmidt Pizarro to Nicodemi dated October 29, 1934, Dossier 49/1937 of the Education Section kept at the Citadel of the Archives (Cittadella degli Archivi) of the City of Milan; letter from Schmidt Pizarro to Underhill dated February 10, 1932 (CMA Archives). In several letters, he refers to the shared ownership with his brothers (the most direct proof is a letter from Schmidt Pizarro to Spinden dated November 16, 1946, The Brooklyn Museum Archives, Director [02]. File \# 117. Spinden, Herbert J. (01 / 1939-12 / 1943). See biographies of the cited scholars in the following pages.

23. The Museum of Ethnography in Hamburg suffered considerable damage during World War II and, unfortunately, the pre-Hispanic collection seems to have suffered enormous losses. We know that, in addition to Guillermo's materials, the museum purchased 917 objects from Chile, Africa and Oceania from the collection of his brother, the consul, see below.

24. Deed of Donation 901/1926, Ethnologisches Museum Archive, Staatliche Museen, Berlin.

25. Joseph Brummer (1883-1947) was a famous antique dealer of Hungarian origin. Together with his brothers Imre and Ernest, owned one of the most important art galleries in the world, with offices in New York and Paris dealing with objects from classical antiquity to art of the twentieth century. Since its inception in Paris in 1906, the Brummer brothers also focused on objects from Asia, Africa and America. He contributed to the construction of some of the largest US public and private collections including the Metropolitan Museum of Art (Brennan 2015, pp. 455-457).

26. The Brummer Gallery records (The Metropolitan Museum of Art): examination of technical files of works.

27. George Dupont Pratt (1869-1935). Descendant of oil magnate Charles Pratt, beyond his career was a philanthropist and sports enthusiast. A great lover of hunting and travel, he was the sponsor of various cultural institutes including the American Museum of Natural History and the Metropolitan Museum of Art (Allen Anderson 2019).

28. The exact wording is: Guillermo Schmidt y Pizarro, Peru and New York, until 1930; [Joseph Brummer, New York and Paris, 1930-1931]; George D. Pratt, Glen Cove, NY, until 1931. https://www.metmuseum.org/art/collection/search/308012?searchField=All\&amp;sortBy=relevance\&a $\mathrm{mp} ; \mathrm{ft}=\mathrm{schmidt}+$ pizarro\&amp;offset=o\&amp;rpp $=20$ \& pos $=5$ consulted on December 13, 2018.

29. For example, the fragments of Paracas borders from Metropolitan Museum of Art 33.149.9 and 33.149.7, which seem to be identical to PAM 135, 140 of the Mudec of Milan, respectively (purchase Schmidt Pizarro of 1934, see below), or even the rare fragment of Recuay fabric 30.16.7, which seems to be identical to a Schmidt Pizarro's Recuay fragment now kept at the Museo de América in Madrid (inv. 14525). As a caveat, to date the virtual "reconstruction" of fragments is based only on comparisons of photos and measurements.

30. Bernal Multon 2018: 16. These are objects with inv. 71.1930.49.1 - 21.

31. A descriptive note of the collection is in Vega 1933. Catalog of the Ibero-American collections of the Museum: nos. 14512, 14513, 14502, 14504, 14505, 14511, 14514, 14516, 14523, 14524, 14528, 14530, 14534, 14537, 14548, 14563, 14564, 14571, 14575, 14577, 14578, 14582, 14592, 14593, 146o5, 146o6, 14617, 14622, 14623, 14638. 

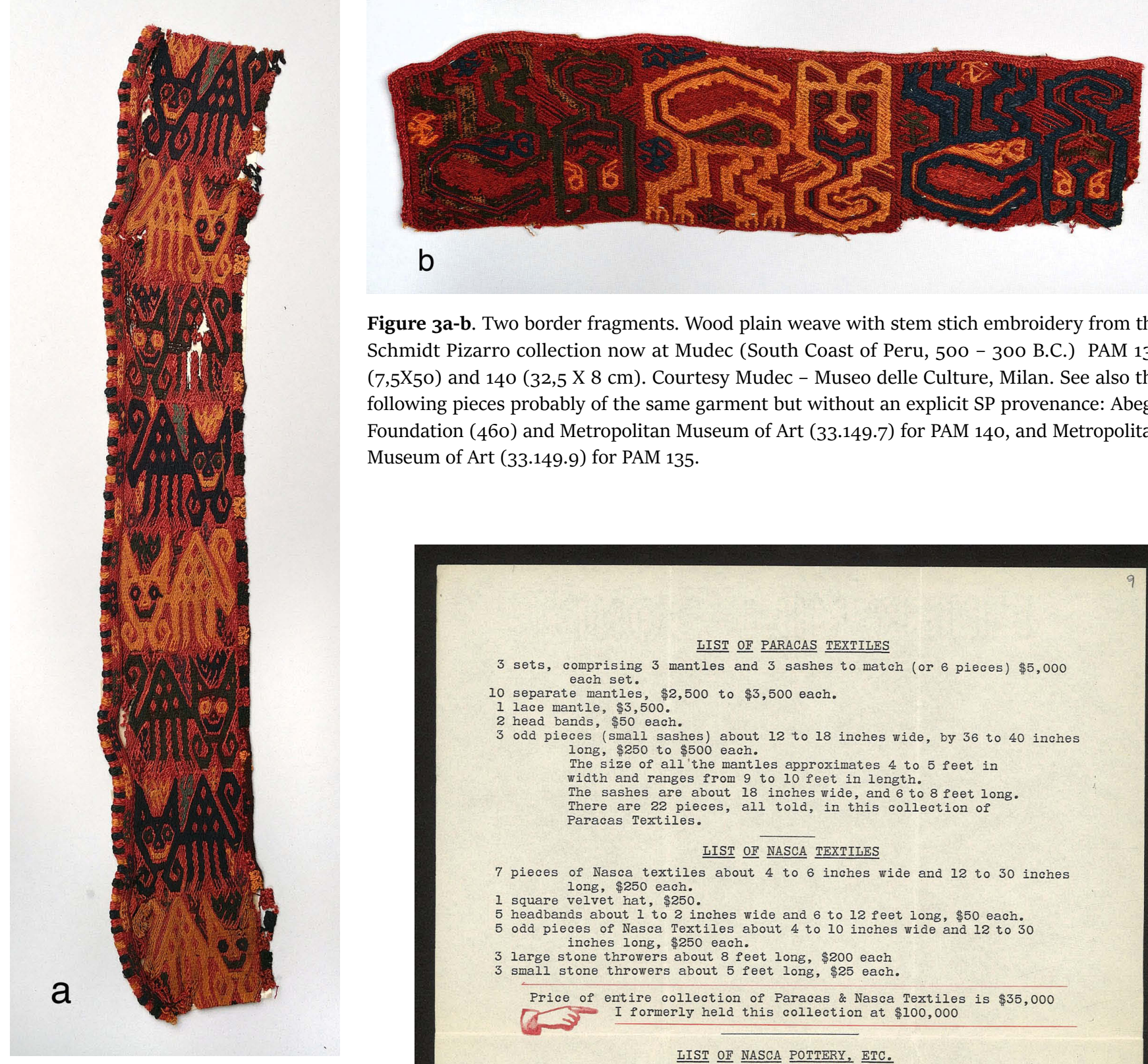

Figure 3a-b. Two border fragments. Wood plain weave with stem stich embroidery from the Schmidt Pizarro collection now at Mudec (South Coast of Peru, 500 - 300 B.C.) PAM 135 $\left(7,5 X_{50}\right)$ and $140(32,5$ X $8 \mathrm{~cm})$. Courtesy Mudec - Museo delle Culture, Milan. See also the following pieces probably of the same garment but without an explicit SP provenance: Abegg Foundation (460) and Metropolitan Museum of Art (33.149.7) for PAM 140, and Metropolitan Museum of Art (33.149.9) for PAM 135.

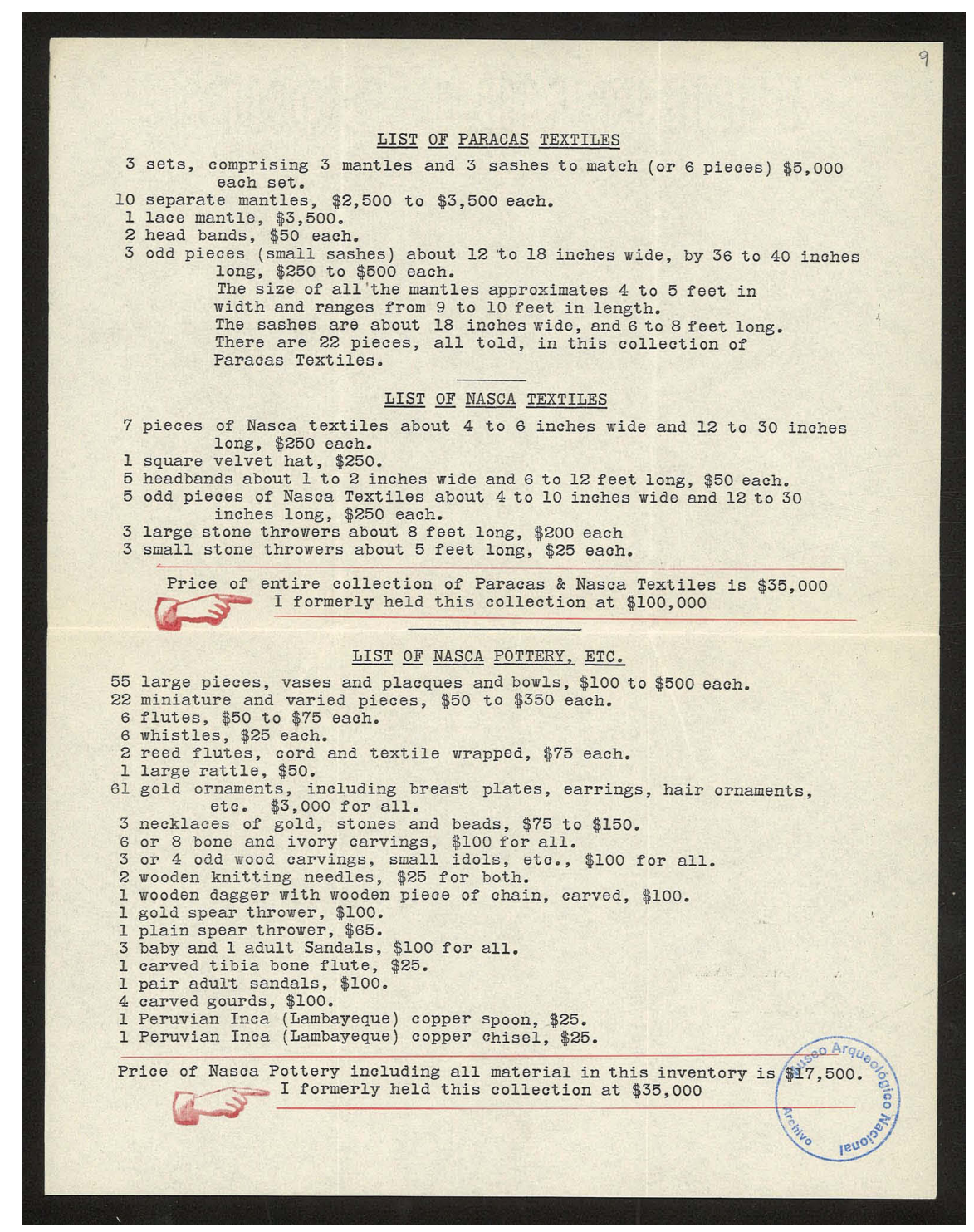

Figure 4. Price list of the Schmidt Pizarro collection around 1930. Courtesy Museo Arqueológico Nacional, Madrid. 
Probably starting from 1930 (until 1960), he began selling fabrics to George Hewitt Myers (1875-1957), founder of the Textile Museum in Washington DC, totaling 81 items sold. In August 1931, Schmidt Pizarro returned to the United States (passing through South America) where he began a lengthy negotiation for the sale of a lot of 30 objects to the Cleveland Museum of Art. In order to convince the conservator, Gertrude Underhill, ${ }^{33}$ of the purchase, he adopted a tactic that he also used later in many other cases: he left the objects on loan to the museum. Of the 30 objects, he managed to sell only two, and only after an extended correspondence with the conservator that ended years later in $1935 .{ }^{34}$

Between September and October 1931, he sold a batch of 12 textiles to the Boston Museum of Fine Arts. ${ }^{35}$ On April 12, 1932, he returned to New York after passing through Peru once again, explaining to Underhill that he had gone to retrieve "the last lot of the pre-Inca collection" 36 to be sold in the United States and in European museums. He referred to the Peruvian decree adopted on May $15^{\text {th }}$ of the same year, stipulating that it would be very difficult to take archaeological works out of the country. In effect, the Decree Law No. 7212 of 2 July $1931^{37}$ made the removal of archaeological objects from the country arduous, and forbidden in the case of a unique object, one for which the Peruvian government has no information regarding equivalent objects. Schmidt Pizarro continued to mention this law, sending it to senior officials of the institutions with which he was in contact in order to solicit the purchase of the works that were part of his collection until 1934 (fig. 5).38

Apparently, between 1932 and 1939,39 Schmidt Pizarro returned to Peru for just three months in 1934. At this point, we must ask ourselves where the collection - that he continued to sell in Europe for an entire decade - was stored. The most plausible hypothesis is that the works were already outside Peru, in the United States or in Europe, simply loaned to several museums or auction houses waiting to be sold, or alternatively in cases that Schmidt Pizarro

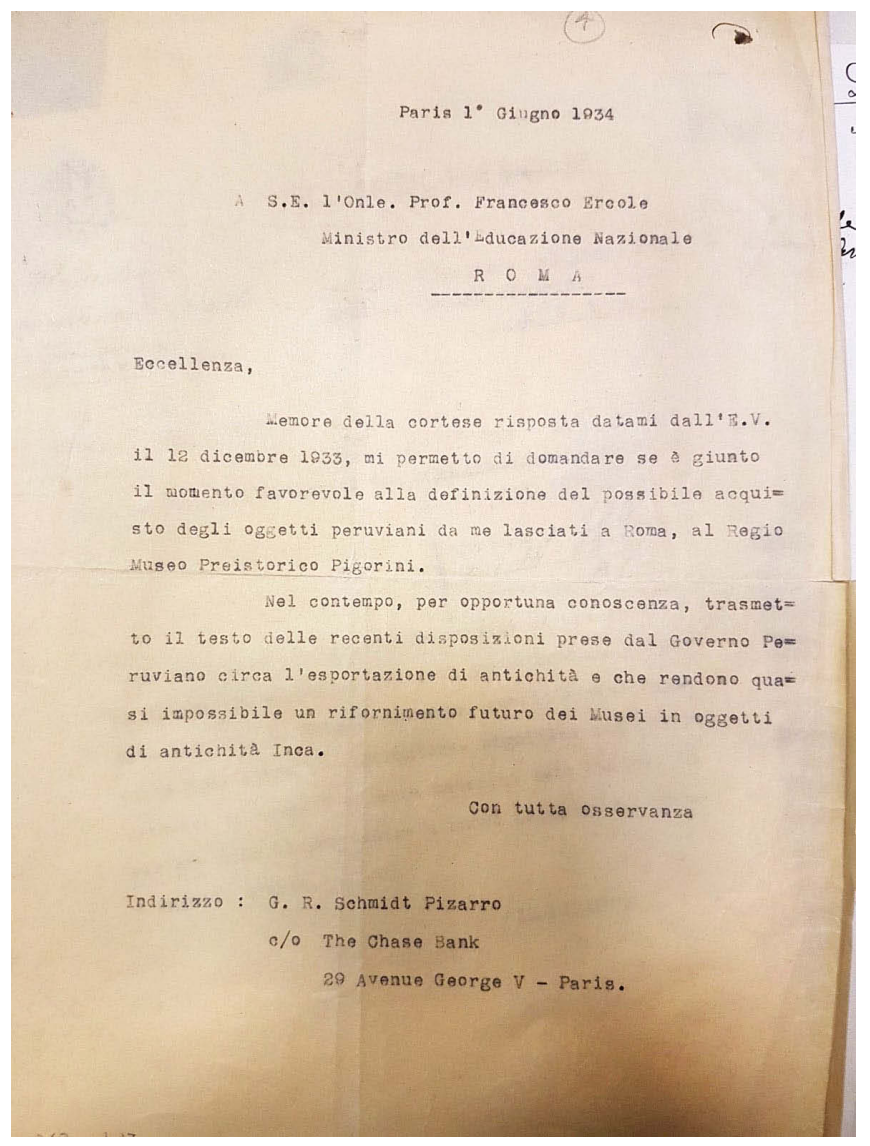

Figure 5. Letter from Schmidt Pizarro to the Italian minister Francesco Ercole (1st June 1934), where Schmidt Pizarro refers to the new Peruvian laws to convince him to buy a selection of objects from his collection for the Pigorini Museum suggesting that, from then on, it would have been very difficult to take archaeological works out of the country. Courtesy MuCiv Museum Archives, Rome. Photo Carolina Orsini.

carried with him. We know that he left objects for up to ten years for review at museums (e.g. at the Brooklyn Museum, where the loan with the purpose of assessing the purchase took place in various stages beginning April 23, $1932^{4^{\circ}}$

32. Archivo Museo Arqueológico Nacional, file 107 -1930- / 10.

33. Gertrude Underhill (1874 - 1954). Conservator for the textile section of the Cleveland Museum of Art since 1917, contributed significantly to the development of her section for the museum (Milliken 1954, pp. 115 - 116).

34. The conservator adduces as a justification that the museum was much involved in the bankruptcy of two US banks that occurred that same year. This is no. 1933.392, described as a "Pachacamac fish" [Ychsma fish appliqué] and 1933.393, described as a "Nasca tied and dyed piece" [Wari tie-dyed fragment] at the Cleveland Museum of Art. Letter of January 1, 1934 from Underhill to Schmidt P., CMA Archives.

35. We know that the textiles purchased were 16, Inv. 31.369 a - b and 31.699 - 31.710 sold on September 3, 1931 and Invv. 31,900 -31,901 sold on October 15, 1931. Boston Museum of Fine Arts website.

36. The same information is in another letter from Schmidt Pizarro to Gertrude Townsend, curator of textiles at the Boston Museum of Fine Arts: April 14, 1932, (Boston Museum of Fine Arts, Archives, TXTI Box 9).

37. The decree is from the previous year and sets May of the following year as a deadline for export of all non-registered archaeological objects. 38. Letter from Schmidt Pizarro to Minister Francesco Ercole, June 1, 1934, 363 Folder, MuCiv Museum Archives. Rome.

39. 1939 was the year during which he left Europe to return only after the end of the war.

40. Report by Herbert Spinden to Isabel Roberts dated April 10, 1943. For the first lot (Invv. 34.549 - 34.581), it took until 1934 to sell the objects. 
although the actual sale was only executed in the late-forties, or at the aforementioned Cleveland Museum of Art). Sometimes it happened that Schmidt Pizarro even forgot objects in these institutions, as occurred with two metal works left in Milan. ${ }^{41}$

In the second part of 1932, he traveled to Europe and from the beginning of September his residence was in Paris c/o The Chase Bank, 29 Avenue George V. ${ }^{42}$

In 1933, the British Museum in London bought ten textiles and some pre-Hispanic bone objects. ${ }^{43}$ It is really likely that, in the same year, S.P. was in contact with the Victoria and Albert Museum: using some specimens with a clear provenance as a reference, we were able to identify four or six other textiles (inv. T.70, 72, 73 and 74 and T.71 and T.75) and three more in the year 1936 (T.119, 120, 121). The same can be said for the Museum of Archaeology and Anthropology in Cambridge, where he sold objects to different Directors between 1933 and 1935.

From Paris, Schmidt Pizarro kept in close correspondence with various European cities, continuing relations with the United States (as evidenced by copious correspondence with the Cleveland Museum of Art and the Brooklyn Museum). At the beginning of 1933, he launched into contact with the directors of Italian museums. He began with Rome by writing to the then Director of the Pigorini Museum, Ugo Antonielli. The first traces of this correspondence date to March 1933, when negotiations began with the museum for the sale of a lot of works that would eventually be left on loan at that institution on March 16.44

At the same time, perhaps on the occasion of an exhibition called “Arte Antica dell'America Latina” (see below) held in Rome, Schmidt Pizarro established contact with the management of the Castello Sforzesco, and more precisely with the curator, Giorgio Nicodemi. 45 The report attached to the purchase procedure is dated March 1st, in which Nicodemi mentioned a collection "offered by Mr. Guillermo Schmidt resident in Paris. They come from a collection that was gathered in Peru by German scholars around 1820, and of which a part is kept in some German Museums." ${ }^{6}$ The collection is the one corresponding to the general inventory number IG 2281. It consists of, for the most part, the objects that were on display in Rome. The sale of this lot for 50oo Lire ended in March $1934 .{ }^{47}$ Concurrently, Schmidt Pizarro was negotiating a further lot of 14 objects (IG 2279), for which the report attached to the deed of sale mentions that the collection had been assessed to be of value by Professor Guido Valeriano Callegari. ${ }^{48}$ After a correspondence, of which probably only the final stages remain, Nicodemi and Schmidt Pizarro agreed to the sale of the 15 items $^{49}$ for 5000 Lire and the purchase was authorized by the City government on 10 February $1934 \cdot{ }^{50}$ What one deduces from the deeds is that these purchases were aimed at initiating the Castello Sforzesco collection of "pre-Hispanic antiquities"51 that, at the time, evidently began to arouse some interest, as is also evidenced by the Rome exhibition.

In 1933, the Castello d'Albertis of Genoa bought eight textiles (C.A. 1690-91-92) and two collars (C.A. 1693-1695), while in the following year it bought 24 ceramics (C.A. 16411664). The last acquisition by this museum was in 1938: five textiles (C.A. 1483-1488) and one collar. At the same time, the negotiations with Rome ended in September 1934 for 17 objects, including 11 textiles for 9000 Lire. ${ }^{52}$

The Brooklyn Museum Archives, Director [02]. File \# 117. Spinden, Herbert J. (o1 / 1939-12 / 1943).

41. Giorgio Nicodemi to Schmidt Pizarro, January 29, 1935, Issue 49/1937 Education Division, Citadel of the Archives (Cittadella degli Archivi) of the City of Milan.

42. CMA Archives, letter Schmidt Pizarro-Underhill of September 27, 1932. Following the same logic, his contact residence in New York was The Anglo South American Trust Co., 49 Broadway.

43. British Museum, catalog numbers: Am1933, - 5/6/7/8/9; Am1933, - 10.a/b/c/d/e; Am, 1933, - 11.a/b/c/d; Am1933, - 12; Am1933, - 13.

44. Letter from Schmidt Pizarro to Antonielli, dated September 23, 1934. 363 Folder, MuCiv Museum Archives, Rome.

45. Probably through Callegari. Both taught at the Università Cattolica del Sacro Cuore University in Milan.

46. Deed executed by Nicodemi in the file 166/1934 at the Citadel of the Archives (Cittadella degli Archivi) of the City of Milan.

47. Resolution of the City government dated March 10, 1934, contained in the dossier 166/1934 Education Department, kept at the Citadel of the Archives (Cittadella degli Archivi) of the City of Milan.

48. Dossier 175/1934 Education section, kept at the Citadel of the Archives (Cittadella degli Archivi) of the City of Milan. Born in Verona, Guido Valeriano Callegari (1896 - 1954) was among the first in Italy to approach the study of pre-Hispanic cultures, particularly in relation to Mexico and studies on astronomical knowledge. He was the holder of the first chair of American Antiquities, from 1925 to 1935, and was very active in dissemination to the general public. He made several study trips to Mexico (Venturi F. 1989).

49. Inventory numbers: PAMooo98-99, PAMooo47, PAMoooo7-8, PAMoooo1-05, PAMooo31-32, PAMo0114-164, PAMooo75, PAMooo13-15, PAMooo85, PAMooo26-29, PAMooo36-37, PAMo0166-167, PAMoo109-113a, b, c, d, e, f, PAMoo169-171. All objects are published in Laurencich - Aimi 1991.

50. Ibid. The same figure for two different lots of objects is not surprising: it is probably a stratagem to circumvent the spending limit imposed by Royal Decree 2839/1923, which is in fact mentioned in the resolution.

51. For a discussion of the formation of civic ethnographic collection, see Antonini-Orsini 2016.

52. Authorization issued by the Ministry of Education with Protocol 8885/1934, Directorate II of September 27, 1934, 363 Folder, MuCiv Museum Archives, Rome. 
In June 1934, Schmidt Pizarro left Italy and Europe for a period of about three months to return to Peru. ${ }^{53}$ In September he was back in Europe, where he also returned to Milan, and once again left a collection for examination by Professor Nicodemi. ${ }^{54}$ The negotiation for the acquisition of these objects continued until April 1935, but concluded only in 1937. The letters contained in the file related to this sale helped us to reconstruct the movements of these years, during which sales decreased.

We know that in 1935, 1937 and 1938, he sold a total of 19 textiles to the Montreal Museum of Fine Arts, 55 but we are still unable to verify if he visited that institution in person. In 1936, he was back in the US, this time in Miami: from there, he wrote to Gertrude Townsend of the Boston Museum of Fine Art (BMFA): "I so far have done well with the textiles I showed you, as I have sold the greater part to the museums in the West and here down in South." ${ }^{66}$ After a short break in New York, where he left some textiles to the Brooklyn Museum, ${ }^{57}$ he returned to Europe, in Budapest, "for business." ${ }^{8}$ In October 1936 , he finally met Gertrude Townsend and sold the textile registered as Boston MFA 36.625. After a short stay in Mexico, in March 1937 he was back in NY ready to go to Europe, ${ }^{59}$ where he landed on $22^{\text {nd }}$ of April. ${ }^{60}$

In 1937 he also sold to the Museum of Ethnology of Wien, now Weltmuseum Wien. ${ }^{61}$
At the end of 1937, he entered into an agreement for another sale at the Castello Sforzesco in Milan. ${ }^{62}$ In 1938, after having donated two gold plates to the same institution, ${ }^{63}$ he left (with a visa issued in Milan) to go to the United States, where sales promptly resumed. We have news of another sale or donation to the National Museum of Denmark in 1938. We have identified only one object, a paracas textile (inv. 0.5678), of which another fragment can be found in the Ethnological Museum (Ethnologisches Museum) of Berlin, with certified S.P. provenance. ${ }^{64}$

In that period the Cooper Union Museum for the Arts of Decoration (Smithsonian Institution, Washington) acquired a small amount of pre-Hispanic objects. ${ }^{65}$ The museum website shows one textile fragment (inventory number 1938 56 - 1 - a) depicting a stylized head: fragments of this same head are found in other collections. In the same year, the Peabody Museum of Archaeology and Ethnology acquired two "Tihuanaco" and "Chimu" painted fabrics ${ }^{66}$ along with other seven objects ${ }^{67}$ thanks to a gift of A. Tozzer, T. Barbour and D. Scott (the objects were selected by Samuel K. Lothrop). ${ }^{68}$ In May 1938, Schmidt Pizarro donated a preHispanic object ${ }^{69}$ to the National Museum of the American Indian in Washington.

At the end of 1938, Schmidt Pizarro was in Italy again, in Naples $7^{70}$ and later in Rome: his name appeared with a visa issued in the capital on passenger manifests of the ship

53. Letter from Schmidt Pizarro to Piero Barocelli dated December 3, 1934, 363 Folder, MuCiv Museum Archives, Rome. There is no evidence in passenger manifests of this trip.

54. These are the objects belonging to the General Inventory IG 2840, which will be acquired in 1937. Giorgio Nicodemi (1891-1967) was Superintendent of the Civic Museums of the Castello Sforzesco beginning in 1926. With this position he took care of the new set-ups of several rooms of the Castle, including the oriental and ethnographic sections in the Rocchetta del Castello Sforzesco, greatly expanding the collections with an acquisition campaign that took place between the 1920's and 1930's.

55. Erell Hubert, personal communication April 2019.

56. Schmidt Pizarro to Gertrude Townsend, March 5, 1936 Townsend (Boston Museum of Fine Arts, Archives, TXTI Box 9). So far, we have not identified these textiles, nor the museums involved.

57. Letter from Spinden to Roberts I., April 10, 1943. The Brooklyn Museum Archives, Director [02]. File \# 117. Spinden, Herbert J. (01 / 193912 / 1943).

58. Schmidt Pizarro to Townsend, May 12, 1936 (Boston Museum of Fine Arts, Archives, TXTI Box 9). We still do not know if that "business" was related to antiques or not.

59. These movements are traced in Boston MFA correspondence (Boston Museum of Fine Arts, Archives, TXTI Box 9).

6o. Southampton port passengers' list.

61. Barbara Poenighaus-Matuella, personal communication, March 2019.

62. Lot IG 2911, taken in charge on February 20, 1938.

63. Lot IG 2926, taken in charge on April 8, 1938.

64. Lena Bjerregaard, personal communication, April 2019.

65. Chronicle of the Museum for the Arts of the Cooperation Union works of art received by the museum; January - December $31,1939$.

66. Inventory numbers: 38-51-30 / 1696 and 38-51-30 / 1695.

67. Inventory numbers: $38-51-30 / 1988-1996$.

68. Inv. 38-51-30 / 1696 and 38-51-30 / 1695. Letter from S. Lothrop to Alfred Tozzer, May 17, 1938 (X File 38-51, Peabody Museum of Archaeology and Ethnology at Harvard Archives).

69. National Museum of the American Indian, catalog number 18/2877.

70. Letter from Schmidt Pizarro to Herbert Spinden, November 29, 1938. The Brooklyn Museum Archives, Director [02]. File \# 117. Spinden, Herbert J. (01 / 1939-12 / 1943). 
Vulcania, departing from Gibraltar and arriving in New York on March 22, 1939. This is interesting because at that time, a formality requested by US immigration was the listing of an acquaintance, and Schmidt Pizarro entered Count Pablo Mimbela ${ }^{71}$, consul of the embassy of Peru to the Holy See. This name confirms his attendance in diplomatic and ecclesiastical circles. Also, on this occasion, he had probably passed through Milan and had managed to sell a last lot of objects to Castello Sforzesco. ${ }^{72}$

Hence, he returned definitively to America, certainly also because of changing geopolitical conditions (Europe was now on the threshold of World War II). There, Schmidt Pizarro continued his activity as a salesman to American museums. Already in 1938, he had resumed correspondence with the Brooklyn Museum of Art's curator of Arts of the Americas, Herbert Spinden, ${ }^{73}$ and the director, Laurence Roberts, a correspondence that began with the previous director Philip Youtz in 1934. From an interesting report by the curator Spinden to the acting director, Isabel Roberts, ${ }^{74}$ we learn that after the first lot delivered in 1934, in 1935, 1936, and 1939, Schmidt Pizarro left 61 pieces (8 textiles and other works made of metal) on loan at the Brooklyn Museum. In 1941, Spinden claimed to have purchased other fragments for 1,318 US dollars directly from our antique dealer in Peru. In 1942, by way of the Stendhal Art Gallery, the museum acquired other pieces from the Schmidt Pizarro collection: these are probably two colonial objects ${ }^{75}$ with an inventory number referring to that year. Of the pieces left on loan in '35, '36, and '39, only three textiles were purchased in $1946 .{ }^{7}$ Schmidt Pizarro's relationship with the Brooklyn Museum was certainly not limited to sales negotiations. The Schmidt Pizarro pieces remained on loan for almost twenty years, in part because of the disruption of WWII, practically becoming part of the permanent collection. ${ }^{77}$ Contacts between Guillermo Schmidt Pizarro, Herbert Spinden and the director Roberts were quite frequent in the 40's. This correspondence, aimed only in part at the conclusion of the purchases begun in the 30's, tells us about the life of our antique dealer during and after World War II, when access to Europe was precluded to him.

In the meantime, as anticipated, pieces of the Schmidt Pizarro collection remained on loan at the Brooklyn Museum. In 1947, in a letter to Spinden dated November $16^{\text {th }}$, Schmidt Pizarro solicited the return of his collection to his homeland. On December $5^{\text {th }}$, Spinden declared himself willing, even if the operation would be quite burdensome for the museum (some of the works were on exhibit). On December $10^{\text {th }}$, Schmidt Pizarro agreed to leave the items on loan, probably still hoping to sell them. The correspondence was interrupted in 1951 when Schmidt Pizarro authorized the loan of a famous colonial tapestry for the exhibition "2000 Years of Tapestry Weaving. A Loan Exhibition” (Hartford, December 7, 1951 - January 27, 1952; Baltimore, February 27 - March 25, 1952). ${ }^{78}$

In Lima, where he apparently lived in that period with more stability than before, he continued his activity as art seller and dealer, with a greater interest in colonial art. In 1942 he participated in the Show of Virreinal art. ${ }^{79}$ On March 24, 1948, he donated 22 painted textiles to the Museo Nacional de Arqueología, Antropología y Historia del Perú (National Museum of Archeology and Anthropology) in Lima. The news of the donation confirms the position that Schmidt Pizarro held until a few years before as "Director de Industrias del Ministerio de Fomento."8o

We were able to follow the tracks of our man through a newspaper article in the Cuban newspaper Diario de la Marina: Schmidt Pizarro, defined as "experto en arte", traveled with the brother of the Peruvian president, Miguel

71. The name Mimbela (this time Mrs.) also appears as a member of the board of honour of the 1933 exhibition in Rome.

72. Lot IG 3258, taken in charge on March 18, 1940. Negotiations might have begun the previous year.

73. Herbert Spinden (1879 - 1967) was born in South Dakota. After earning a Ph.D. at Harvard, he was conservator in the anthropology section of the American Museum of Natural History in New York from 1909 until 1921. Later curator of the Mexican sections of the Peabody Museum and the Buffalo Museum of Science, in 1929 he was employed at the Brooklyn Museum. From 1935 to 1950, he was head of the Primitive Art department. He published numerous essays on Maya culture (Guide to the Records).

74. Letter from Spinden to Roberts I., April 10, 1943. The Brooklyn Museum Archives, Director [02]. File \# 117. Spinden, Herbert J. (o1 / 193912 / 1943).

75. A portable altar (Inv. 42.54) and a rug with coat of arm (Inv. 42.56) Provenance: Purchased in February 1942 from G. Schmidt and Pizarro, Bank of London and South America, NY for $\$ 100$.

76. The objects are as follow: a fragment of nasca-huari fabric (Inv. 46.46.1); a fragment of huari fabric with llama (Inv. 46.46.2) and a fragment of late nasca fabric (Inv. 46.46.3).

77. An undated list from a document of the Brooklyn Museum Archives entitled “Object offered on sale / Purchased by museum 1951 - 1952" lists the showcases where the pieces, marked with the letter L (lend), were exhibited on the permanent itinerary. The Brooklyn Museum Archives, Director [02]. File \# 117. Spinden, Herbert J. (01 / 1939-12 / 1943)

78. On page 86 of the catalogue, the famous colonial tapestry sold then to Metropolitan Museum was published.

79. Exposición de cuadros y objetos de arte virreinal realizada en los salones de la sociedad "Entre nous" del 2 al 14 de febrero de 1942.

8o. Donaciones 1948, p. 192. 
Bustamante Rivero to Italy where they were received by the Pope on July 17, 1948. It is reported that before visiting Rome, the illustrious travelers had passed through Spain, where they would return by plane. ${ }^{81}$ His presence in Europe is also confirmed by passenger manifests: on April $12^{\text {th }}$ from Callao to New York, on May $4^{\text {th }}$ he arrived in Southampton from New York, bound for France. According to records, he left Europe from Genoa on August $30^{\text {th }}$ of the same year. In this period, he contacted the Swiss Foreign Affair Museum, as he was trying to bring the colonial art show over to Europe. ${ }^{82}$

In 1950, he was in touch with Raoul D'Harcourt again, after a hiatus of nearly 20 years: he had found out that a piece he had left on loan at the Musée du Trocadero (de l'Homme from 1937) had never actually been paid. ${ }^{83}$ In the meantime, his brother Oscar sold 917 objects from Chile, Africa and Oceania to the Hamburg Museum in $1951 .{ }^{84}$ We do not know about Oscar's collection in detail, but it is also during those years that he obtained a role in diverse public offices as chair of the Colegio de Contadores Públicos de Lima. ${ }^{85}$

In 1951 Guillermo participated in the opening of the $R i$ etberg museum in Zurich selling them 20 pieces. ${ }^{86}$ Probably in the same years he got in touch with the Gestaltung museum (also located in Zurich) (18 pieces registered between 1951 and 1958, maybe one or two pieces passed to the Rietberg, and two that had entered the collection much earlier, in 1934). ${ }^{87}$

The tracks of Schmidt Pizarro are lost until his next sale to the Musée du Cinquantenaire, today the Musées Royaux d'Art et d'Histoire in Brussels. Negotiations began in August 1953 with conservator Elisabeth della Santa and director Charles de Borchgrave d'Altena. From reconstructions of correspondence from the archives, the museum bought three different lots: the first in 1955, composed of three fragments of fabrics for 7,000 Belgian francs, ${ }^{88}$ the second in 1957 consisting of a quipu and a Tiahuanaco fabric for 12,00o Belgian francs, ${ }^{89}$ and the third in 1958 of another three fragments of fabrics for 20,000 Belgian francs. ${ }^{90}$

In the years 1955, 1956 and finally 1962, Guillermo sold a total of over 60 objects, again to the Weltmuseum Wien. ${ }^{91}$ During the 50's, he also managed to visit the textile center in Krefeld, Germany (probably in 1953), where he sold several fabrics that are yet to be precisely identified..$^{22}$

Other information that we have been able to gather regarding Schmidt Pizarro concerns the sale of a beautiful $17^{\text {th }}$ century carpet to the Metropolitan Museum of Art in New York (Accession Number: 56.163). This carpet, as mentioned earlier, had been on loan for many years at the Brooklyn Museum. In the same year, he sold another textile, perhaps Moche (Inv. 56.127), to the Brooklyn Museum.

Despite his very advanced age for the time, from documents kept at Musées Royaux d'Art et d'Histoire de Bruxelles, we learn that our antique dealer was still in Europe in 1958, when he went to the Musées Royaux d'Art et d'Histoire de Bruxelles to sign the last sale negotiated with this institution. ${ }^{93}$ In 1958 , he also sold three colonial shawls to the Metropolitan Museum of Arts of New York (Inv. 58.66.1-58.66.3).

As far as we are able to discern, the last letter he wrote dates to October $5^{\text {th }}, 1958$, in which Schmidt Pizarro asks for administrative clarifications in Brussels. ${ }^{94}$ Several pieces are found in the collection of the Museum der Kulturen (Museum of Cultures) in Basel, purchased in 1958 (IV c 9487 and 9489), and one piece (IV c 9580) bought in 1960; other

81. http://ufdc.ufl.edu/UFoooo1565/14126/22? search=schmidt+pizarro Consulted on December 18, 2018.

82. Alexander Brust, personal communication, March 2019.

83. Schmidt Pizarro to D'Harcourt, November 22, 1950, Archive du Muséum d'Histoire naturelle, 2 AM 1 K86e -1930-1950.

84. Christine Chávez, personal communication, December 2018.

85. Report by Oscar Schmidt Pizarro on participation in the sixth International Congress on Accounting, held in London in June 1952, as well as his visits to similar institutions in Scotland and West Germany. Opac library of the Universidad Católica de Lima and also of the Biblioteca Nacional de Lima.

86. RPB 1001 - 1002, 1011, 1103 - 1106, 1204 - 1205, 1303 a b c d, 1307, 1311, 1407, 1410, 1414, 1805.

87. 1951-1958: KGS1951-0036, KGS1951 0048 -0049, KGS1952 ooo6 -0013, KGS1952 0016, KGS1952 0019 - o020, KGS1952 o022, KGS1954 0049, KGS1958 0046 - 0047. 1934: KGS-09555 and KGS-09555_1

88. AAM 55 - 1, AAM 55 - 2, AAM 55-3.

89. AAM 57 - 2. AAM 57 - 3. This lot was originally composed of another Quipu and another fabric (note of September 8, 1956, D 4626/2 Archive Musées Royaux d'Art et d'Histoire de Bruxelles).

90. AAM 58 - 1, AAM 58 - 2, AAM 58 - 3. (Elisabeth della Santa to Borchgrave d'Altena, July 2, 1958, D 4793/8, Archive Musées Royaux d'Art et d'Histoire de Bruxelles).

91. Barbara Pönighaus-Matuella, personal communication, April 2019. Weltmuseum Wien may have been Schmidt Pizarro's top client during those years, but we have not yet accessed the archival documentation to confirm it.

92. Katalin Nagy, personal communication, March 2019.

93. Letter from Schmidt Pizarro to Della Santa of June 16, 1958 (D. 4626/21, Archive Musées Royaux d'Art et d'Histoire de Bruxelles). 94. Letter from Schmidt Pizarro to Borchgrave d'Altena, October 5, 1958 (D 4793/12, Archive Musées Royaux d'Art et d'Histoire de Bruxelles). 
sales would follow in $1961^{95}$ and in $1963 .{ }^{96}$ This was, at the time, his last known sale; considering that he passed away in January of 1964, we can safely say that he worked "till the very end", at the age of 83 .

We are aware of other sales in Munich, Frankfurt, Detroit, Saint Louis and at the Rhode Island School of Design, but we are still waiting for authorization to verify this information in the archives, as will be the case for further information that is bound to emerge throughout the next phase of the project.

\section{The Sales Strategy}

In all these years, Schmidt Pizarro seems to have acted according to a tried and true scheme. First of all, he implemented a sales strategy focusing on pre-selected areas, where he lived for extended periods. Establishing a direct acquaintance with persons was fundamental to him. After the first contacts by mail with museum directors or conservators, who were often introduced to him by a common acquaintance, it is understood that Schmidt Pizarro visited the museums with which he was dealing. On these occasions, in more than one case, he left objects "in vision" on loan, as already mentioned, even for several years. ${ }^{97}$

By doing this, he achieved two goals: on the one hand, he gained the trust of the prospective buyer, who could assess the objects without haste and decide at a later time whether or not to proceed with the purchase; on the other hand, he left the objects in public institutions, guarded by professionals worthy of the utmost trust, rather than carrying them around. In the case of the Brooklyn Museum, there was even a sort of management from the point of view of valorization, as we have seen, with objects on permanent display, which certainly constituted an increase in the personal prestige of the antique dealer.

As seen above, especially in the correspondence with Milan, Rome, Brussels, Brooklyn and Cleveland, the negotiations continued for years, on many different "fronts" active at the same time. Our antique dealer never seemed to lose the thread of the discourse, he recalled price proposals for decades and, apparently (except in the cited case of the plaques left in Milan), he was always aware of where his works were located. He certainly had an accurate inventory system and a topographic register of the pieces of his collection that initially must have included over 1,0oo objects.

Negotiations were slow, but inexorable; years later, with discretion, a final answer was asked about the pieces on loan. Often, when the transaction for a specific type of object was unsuccessful, he would propose others of different types (as in Brooklyn).

With a profile that we could almost define as psychological, in order to convince the buyer of the value of his pieces, he played mainly on the fact that it was an antique collection, as he said, belonging to his family; almost as if he were not a professional antique dealer, but simply a refined connoisseur. Archival sources indicate that he knew his way around the scholars' circles: he was acquainted with eminent figures such as Rafael Larco Herrera ${ }^{98}$ and, as previously mentioned, Raoul D'Harcourt and Samuel K. Lothrop, who considered him an esteemed connoisseur.

Schmidt Pizarro often mentions his preference for selling his family's collection to public museums so that the utmost care might be taken to assure the conservation of indigenous artifacts. This will be highlighted when - as seen above - he took on the position of Director de Industrias at the Ministerio de Fomento y Obras Públicas of Peru. It is in this period that he dedicated himself to organizing exhibitions of Peruvian art abroad and to publishing writings on this topic. ${ }^{99}$ But, in addition to his statements, we know that this antique dealer not only parceled out works to multiply his earnings, ${ }^{100}$ but he even often sold them to private collectors.

To give credit to his positive reputation, in several instances he donated pieces: this happened in Berlin, Paris, Milan, and at Washington's Smithsonian Institution. Moreover, in the early 1930's, as a strategy to induce acquisitions, he emphasized the Peruvian heritage protection laws

95. IVc 9676 - IVc 9679 and IVc 9684 - IVc 9686.

96. Rebozos IVc 9722 - IVc 9729.

97. The same strategy was adopted by other dealers of the same period (e.g. Stolper, see Fischer et al. 2017).

98. Schmidt Pizarro to Della Santa, letter of October 3, 1958 (D4626/21 Archive Musées Royaux d'Art et d'Histoire de Bruxelles). S.P. mentions Rafael Larco Herrera as "my friend".

99. For example, the article on the platería peruana published on Il_Mercurio on February 4, 1946. Document annexed to the letter of February 16 , 1946 sent by Schmidt Pizarro to Spinden (The Brooklyn Museum Archives, Director [02]. File \# 117. Spinden, Herbert J. (01 / 1939-12 / 1943). 100. Regarding the specimen 36.625 MFA of Boston: in the letter dated October 28, 1936, in an attempt to convince her to purchase, Schmidt Pizarro wrote to Gertrude Townsend that only two fragments of the textile existed, and that he had already sold the other piece to the "Gobelin Museum" in Paris. The following year, in a letter dated April 4, 1937, he admitted that he had another piece of the same textile in Lima, hoping that Townsend would decide to buy the "twin piece" of the object already sold to the MFA. These letters, together with others, prove that dividing or even cutting textile was a strategy. (The Boston Museum of Fine Arts, Archives, TXTI Box 9) 
recently enforced, sending, as in the case of Rome, a summary of the Decree Law 6643/1931 to prove that the purchase of Peruvian archaeological pieces would become increasingly rare in the future.

This is, briefly, the strategy Schmidt Pizarro followed with public institutions. We do not know how his negotiations with private individuals in the United States took place, nor do we understand his relationship with the European antique market.

\section{A circular relationship: exhibitions, markets, museums}

From the beginning, Schmidt Pizarro realized that a fundamental factor for sales was the "reputation" that his objects could earn by appearing in various public exhibitions. Paris was particularly important for this purpose: as we have already said, the 1930's were "Les années folles de l'ethnographie" (Delpuech et al., 2017). The market was at its peak at the time: the city was the Eldorado for trade in pre-Hispanic artefacts (Saint-Raymond and Vaudry 2018), peaking between 1927 and 1930. As the flow of works from South America increased, prices did not go down (SaintRaymond and Vaudry 2018). The market began to drop just as S.P. arrived in the French capital, only to regain strength in the years between ' 37 and ' 39 . In the 1930's, moreover, most of the South American artifacts on sale at the Hotel Druout were Andean (Saint Raimond Vaudry, 2018).

It is possible, therefore, that S.P. had been attracted and ultimately decided to settle in Paris - because of this circumstance, which was not fortuitous, but the result of a deep interest in non-European arts, established in Paris for at least two decades. As early as 1924, the "Latin American Art Exhibition" had been held at the Palais Galliera and, ten years earlier in 1914, the famous antiquarian Joseph Brummer had opened his gallery where he sold many important works of European and native art. Little by little, the preHispanic objects wound up in the sight of the antique dealers most tied to the world of the avant-gardes, and so the perceived value - cultural and economic - of these objects began to rise.

The consecration took place in 1928, when the exhibition Les Arts Anciens de l'Amerique was held at the Decorative
Arts Museum. Curated by George Henry Rivière, and with a catalogue prefaced by Raoul D'Harcourt, the exhibition displayed more than 1200 objects and influenced the taste of art dealers and buyers over the following years: the outstanding art dealer linked with Primitivist avant-gardes (La Porte - Dagen 2013) Charles Ratton (1895 - 1986) was one of the major private lenders. The relationships with the gray eminences of the South American art market in Paris are made clear in a correspondence exchange between Pizarro and Rivière, ${ }^{101}$ in a memorandum from Rivière regarding the S.P. collection: "Some pieces have already been sold in the United States and to Mr. Brummer, antiquarian. Report to Mr. D'Harcourt, then to Mr. Heye, ${ }^{102}$ then to Mr. Ratton." ${ }^{103}$ From another exchange, ${ }^{104}$ we learn that D'Harcourt acted as an intermediary between S.P. and Rivière, and also managed payments on behalf of S.P. In a letter, D'Harcourt asks Schmidt Pizarro to help him with his book, scouting unknown woven techniques and analyzing them from a technical perspective.

While the Paris exhibition took place before the appearance of S.P. on the Parisian scene, he in the meantime successfully managed to enter into the organization of a temporary exhibit in Italy, which, in its format and even in the title, had many similarities with the French one: the Ancient Art of Latin America exhibition held in Rome between May and June 1933 (fig. 5). ${ }^{105}$ The precious illustrated catalog mentioned objects from S.P. that later became the property of the Castello Sforzesco of the City of Milan, today at the Museo delle Culture. Some objects also appeared in popular publications of the time. ${ }^{106}$ The organizer of this pioneering enterprise for Italy, which displayed the preHispanic heritage of the museums of Rome, Milan, Genoa, Turin and Florence, was Guido Valeriano Callegari, a Mexican art expert who held the Chair of Pre-Hispanic Antiquities at the Università Cattolica del Sacro Cuore University in Milan: a pivotal character in the Italian negotiations of Schmidt Pizarro.

The Rome exhibition, as we have said, owed much to that in Paris: the works were selected for their "artistic value" and their expressive force (according to canons close to Primitivism, a movement that is recalled in various points of a newspaper article focusing on this exhibit by Antonielli, 1933), all enhanced by a minimalist setup that

101. Archive du Muséum d'histoire naturelle, 2 AM 1 K86e 1930-1950, "Visites. 18 Juillet 1930".

102. George Gustav Heye (1874-1957) was the founder of the Museum of the American Indian (MAI), Heye Foundation, of New York City, now his collections are held at the Smithsonian Institution. Heye became a client of S.P..

103. Charles Ratton (1895 - 1986) was one of Paris most important dealers in ethnographic objects, from the 20 's.

104. Archive du Muséum d'Histoire naturelle, 2 AM 1 K86e -1930-1950, "Lettre 10 Juillet 1931" D'Harcourt to S.P.

105. The exhibition catalog (General Management for Antiquities and Fine Arts, 1933) is a gold mine of information: with over 200 exhibits, the exhibition is probably one of the first moments in which pre-Hispanic archeology is promoted in Italy.

106. Callegari 1933, pp.779 - 796 
780 LE VIE D' ITALIA E DEL MONDO

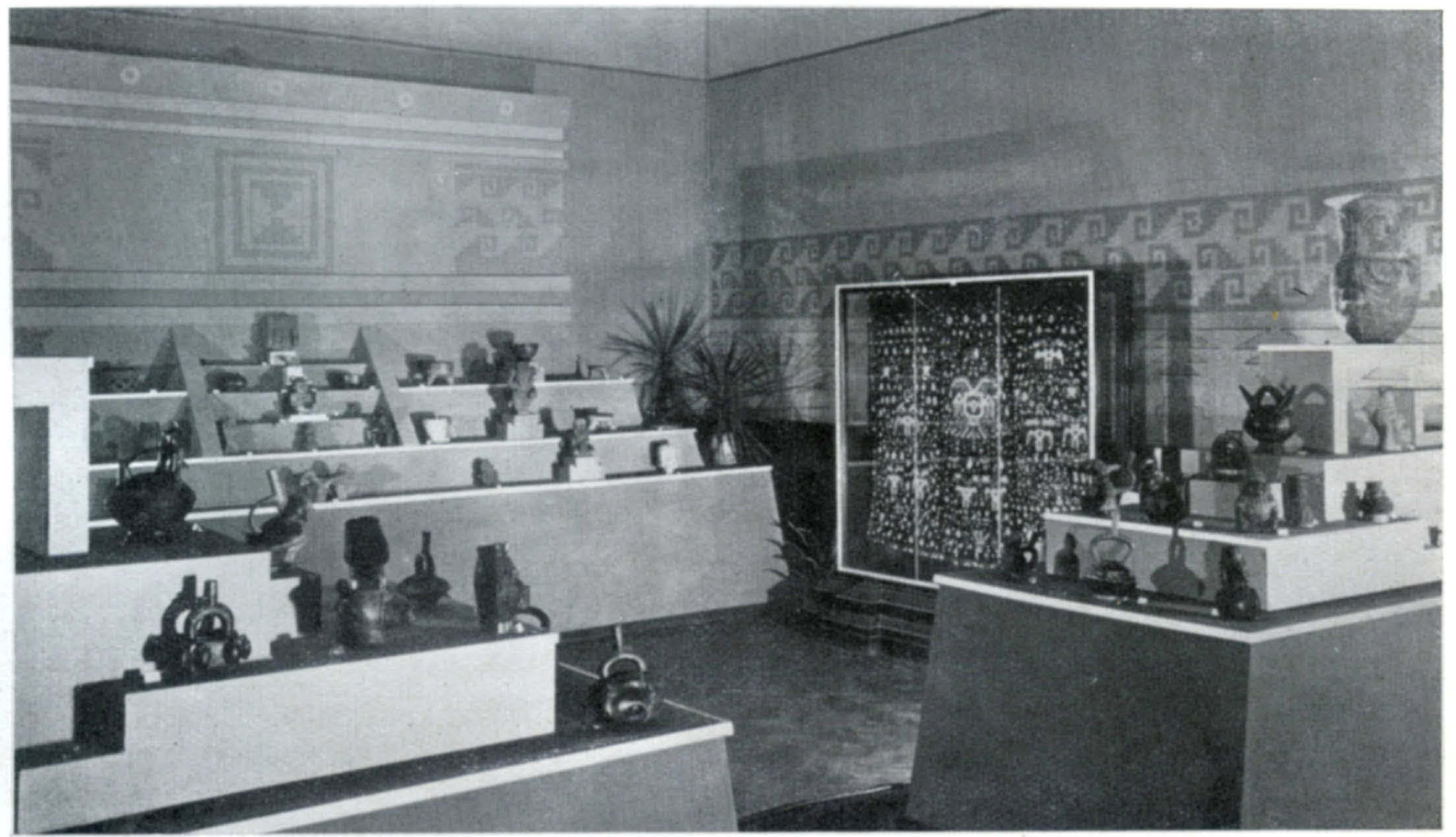

UNA SALA DELLA MOSTRA DI ARTE ANTICA DELl'AMERICA LATINA, IN ROMA In questa sala sono raccolti specialmente i cimeli provenienti dai Musei di Torino e di Roma.

Figure 6. One room of the exhibition Mostra d'arte antica dell'America Latina (Roma, 1933) where many objects from the Schmidt Pizarro collection were on display. Courtesy Touring Club Italiano, Milan.

respected aesthetic criteria similar to those of the Paris exhibition (ibid.).

A few years later, S.P. lent other works for a temporary exhibit of textiles to the Gobelin Manufacture in Paris (1935).

S.P.'s exhibition activity was also considerable in the United States: for decades, his objects appeared in various exhibits organized by the most important museums. First of all, the Brooklyn Museum: in 1939, some pieces were loaned to the exhibition "Masks: Barbaric and Civilized" (October 28, 1939 through January 1, 1940). Two other exhibitions followed, to which Schmidt Pizarro lent works: ${ }^{107}$ "Art Finds a Way" (November 1, 1940 through January 10, 1941), and "America South of U.S." (November 13, 1941 through January 2, 1942), where the colonial collection of our antique dealer was presented ${ }^{108}$ to the public and, finally, "Peruvian Costume, for the Living and the Dead", (October 11, 1946 through February 9, 1947). ${ }^{109}$ In the meantime, in 1942, in Lima, S.P. contributed substantially to the "Exposición de cuadros y objetos de arte virreinal" held in the premises of the company "Entre nous" (February 2-4, 1942).

At a certain point, S.P. was not content with simply lending his works to exhibitions, but became the organizer himself. A very interesting newspaper article ${ }^{110}$ - of which we

107. Brooklyn Museum Archives. Records of the Department of Public Information. Press releases, 1939 - 1941. o9-10 / 1939, 255-7. Not having been able to personally consult the archives, it is not possible to cite the pieces that are actually exhibited.

108. Collecting colonial and "modern" objects was the new trend in S.P. taste after WWII: "In the last year with patience I had collected plenty and very interesting material of early colonial, republican and modern folklore things". Letter from Schmidt Pizarro to H. Spinden of February 16, 1946. The Brooklyn Museum Archives, Director [02]. File \# 117. Spinden, Herbert J. (01 / 1939-12 / 1943).

109. Fane D. 1996: 187, describing a hat from the colonial era of the Brooklyn Museum (41.1275.103), quoting from a letter from Schmidt Pizarro to Herbert Spinden in which Schmidt offers a description of this type of headgear and its function: "Caps that the caciques of the villages near Cuzco used, in the time of the Inquisition, when they presided at court (tribunal). Each village had a different ...” 110. The Brooklyn Museum Archives, Director [02]. File \# 117. Spinden, Herbert J. (01 / 1939-12 / 1943) 
are unable to identify the heading - informs us that in 1946 Schmidt Pizarro organized an "Exposición de Arte Peruana" during the "Semana Peruana" in Viña del Mar (a renowned seaside resort) in Chile as a former member of the Fine Arts Council of Lima and recently retired from the role of Head of the Peruvian Manual Industries Department within the Ministerio de Fomento.

In 1948, he contacted several European institutions to organize a tour of Peruvian colonial art exhibitions in Europe. This entailed very intense activity, considering shortly after the umpteen loans to the traveling exhibition on textiles held between Hartford and Baltimore in the years 1951-52. ${ }^{11}$

As said above, from the 1940's onwards, Schmidt Pizarro began to introduce new objects dating from the colonial and republican period to the market, beginning a new phase in his life as an art dealer, perhaps aware of the fact that archaeology could no longer be exported. ${ }^{112}$ He considered this collecting trend as an innovation, a harbinger of great possibilities, despite the difficulty in procuring the objects to which high-ranking families were still attached. ${ }^{113}$ It is also thanks to his work as an indefatigable promoter of Peruvian craftsmanship, which undoubtedly allowed him to come into contact with different areas of traditional production, that the typology of artifacts now available to him seemed more varied, ranging from silverware to tapestries and furniture, without neglecting textiles. The role of S.P. is also made clear in the magazine Foreign Commerce Weekly, where he is cited as organizer of an exhibition of "manual" industries held in Lima in $1944^{114}$ and also as the promoter of many activities related to the recovery of traditional "Indian skills" (1944: 2).
He definitely found support in Spinden thanks to the exhibition "America South of U.S." (Brooklyn Museum of Art, 11.13.1941 - 01.02.1942), in which the colonial objects of the Schmidt Pizarro collection were given great prominence. ${ }^{115}$ The exhibition was promoted as the first of its kind where the value of Spanish America art was specifically highlighted. It can therefore be said that S.P. really did contribute to spreading and enhancing Peruvian manufactures, in compliance with his tasks at the Ministerio de Fomento, with the added benefit of increasing the market value of his colonial/republican collection.

It is no coincidence that his sales of colonial/republican objects from that moment surged: in addition to the sale of colonial objects to the Brooklyn Museum in 1946, we recall the sale of a colonial papelera to the Museo de América (Madrid) in 1957, the sales to the Metropolitan Museum in New York in 1958, and finally, the sale of republican ethnographic objects in Basel in the years 1958, 1961 and 1963.

Another interesting path, which will have to be investigated in the future, is the link between S.P. and Morris De Camp Crawford, journalist for "Women's Wear Daily”, Fairchild editions, and pre-Hispanic textile expert for the American Museum of Natural History in New York. ${ }^{116}$ Crawford and Spinden, as has recently come to light, were among the "inventors" of an American fashion style ${ }^{117}$ between the 1920's and 1930's in New York. Schmidt Pizarro probably played a role as an expert of pre-Hispanic textiles in the program conceived by Spinden and Crawford entitled "Designed in America" (1916-1922) (Whitley 1998), and the establishment at the Brooklyn Museum of a "Study Room" ${ }^{118}$ certainly made pre-Hispanic fabrics

111. “200o Years of Tapestry Weaving. A Loan Exhibition” (Hartford, December 7, 1951 - January 27, 1952; Baltimore, February 27 - March 25, 1952).

112. Although we know that he continued to sell archaeological objects throughout the 1940s and 1950s, as evidenced by sales in Switzerland and Brussels for example. Note that many pre-Hispanic objects of these last sales are fragments of objects previously seen: perhaps unsold stock from the pre-war period.

113. Letter from Schmidt Pizarro to Spinden, January 27, 1942. The Brooklyn Museum Archives, Director [02]. File \#117. Spinden, Herbert J. (01/1939-12/1943)

114. Foreign Commerce Weekly, vol. XVII, no. 9, p.11.

115. The director of the National Museum of Anthropology of Lima, Luis E. Valcarcel (1891-1987), stated in the report of his study trip to the United States in the winter of 1941, "In Brooklyn, I found new pieces such as: two magnificent mantles of Spanish-Indian art (which we called "gobelinos" from Cuzco), probably from the $16^{\text {th }}$ century; one of them has this annotation on the card: "Donation by Mr. Guillermo Schmidt Pizarro" [...] finally, another fabric (32-229-L), also given by Schmidt Pizarro, which is an extremely rare piece, with symbolic representations: you see flames and other animals in an embryonic state, inside the body of a monster" Valcarcel 1943, p. 290.

116. Morris De Camp Crawford (1882 - 1949) Journalist and researcher at the American Natural History Museum who published several manuals on pre-Hispanic and in particular Peruvian textiles. In both 1936 and 1938 Schmidt Pizarro declared his residence in New York as care of M.D.C. Crawford c/o Fairchild Editions (Ellis Island passenger manifest: Ship Hamburg 1936, October 9 and 1938, March 23rd). Together with Spinden, Mead and Wissler, Crawford was one of the promoters of the "Designed in America" program, aimed at stimulating the creation of an American style based on Native American artifacts (Whitley L. 1998).

117. Tartsinis 2013, exhibition catalog An American style: Global Sources for New York Textile and Fashion Design, 1915 -1928.

118. In 1918, Stewart Culin (curator of the BMA), in collaboration with Crawford of the American Museum of Natural History, opened a Study Room with ethnographic clothing and textiles to inspire contemporary artists and designers (see above). 
fashionable, a fact that probably also influenced the antiquarian market.

Through his activity as a vendor, S.P. therefore influenced not only the art market and the taste of museum directors, but also those who dealt with manufacturing at that time, as well as the intellectual environment, which in turn set the standards on art purchases in a restricted circle of buyers that included both public and private players.

And what were the objects "worthy" of being purchased, according to Schmidt Pizarro? It is still premature to formulate a definitive hypothesis because, as already mentioned, the process aimed at identifying S.P.'s pieces in museums around the world is still ongoing, but from the cases analyzed it is possible to hypothesize that Paracas textiles, which had appeared on the market in the decade before S.P. began his business, had a certain importance in the commercial proposals he formulated. ${ }^{119}$

\section{Final Reflections: Schmidt Pizarro and the Taste for Collecting pre-Hispanic Artefacts in the First Half of the $\mathbf{2 0}^{\text {th }}$ Century}

Considering the scattered nature of the studies of the antiquarian market of pre-Hispanic objects, it is difficult to make a comprehensive evaluation of S.P.'s influence on the evolution of taste for collecting these materials, but here we offer a few reflections. Between the early 1900 and the 1950s, an enormous quantity of Andean artefacts arrived in Europe and in the United States, e.g. the Theodor Wilhelm Gretzer (1847-1926) (Bjerregaard 2016; Daggett 2012: note 98), Eduard Gaffron (1861-1931) (Daggett 2012: note 96), and Mariano Macedo (1823-1894) (Gänger 2014a) collections: thousands of objects that suffered the same fate of scattering and fragmentation as the S.P. collection.

As already theorized by Guinchard and Savoy (2018), the colonial expansion in the nineteenth century caused an increase in demand and supply on the western market for objects from different cultures of the world. This created new "occupations," with many intermediaries contributing locally to the configuration of global markets and the mass dispersal of pre-Hispanic objects in the western world.
Among them, a small group of antique dealers were the ones who, with their taste, greatly influenced the supply and demand system of these objects. We could define them as "percipience makers" (and "prestige makers", we would add) regarding these artifacts, as was already theorized for the African art market of the same years (Biro 2018).

"Taste" is a subjective element and is not connected to the historical importance of an object. It can be built from scratch. The first exhibitions of South American art in Europe were based on the taste of just a few individuals, including various traders. S.P. tried from the beginning to be credited by them as another "percipience makers" both in Paris and in the United States: Joseph Brummer, Raoul D'Harcourt, Charles Ratton are the outstanding names with whom S.P. entered into more or less close relationships aimed at building a network of key individuals with whom he could redistribute his works. This mechanism highlighted quite recognizable and homogeneous objects, a narrow range of types, that are now found in different museums of the world.

The world of Andean art dealers and intermediaries such as S.P. have only recently been the object of studies and we are convinced that research into the personal stories of these "percipience and prestige makers" may mark a step forward in studies on provenance.

Through a mix (today ethically unacceptable ${ }^{120}$ ) of public service, private interests and genuine interest in native cultures, Schmidt Pizarro (and his colleagues) contributed in his own way to the spreading of knowledge about the material culture of the Andean world and its aesthetics. However, summarizing his activity, we must conclude that through the practice of indirect support to clandestine excavations, cutting of fabrics and dispersion of objects on the art market, the balance of his work cannot but be considered absolutely negative.

The archaeology of the Andes is a young discipline: in its beginnings, characters like S.P. played a key role in the formation of the collections that have been later studied by both native and foreign scholars. In the future, there will be a lot of work to do to unravel the biographies and modus operandi of these fundamental but little known intermediaries that, for better or for worse, are part of the history of Peruvian archaeology.

119. This was the area that was gaining great fame thanks to the findings in the necropolis of the Paracas Peninsula made by the pioneer of Peruvian archaeology Julio C. Tello (made public in the congress of the Americanists of Rome in 1926). Paracas became as famous as Pachacamac and Ancón near Lima; two areas where, next to the activity of tomb raiders or huaqueros, systematic work had also begun a few years earlier (Rowe 1954: 6 et passim and Kaulicke 1997:14-15). These sites had given shape to the large collections that characterized Lima of the late Nineteenth century (Gänger 2014b:7-8), and Pizarro, too, always boasted finds from Ancón and Pachacamac in his lists, besides objects from the southern coast.

120. In the past, the attitude was completely different. Museum specialists, as we previously said, cut off textiles in order to trade them with other museum. The emphasis was more on having the more complete range of different types of objects for documenting the "technological level" achieved by native populations instead of having a complete object in order to reconstruct its function and contest (see Bjerregaard 2001). 


\section{Acknowledgments}

Prior to this research, published works about Guillermo Schmidt Pizarro were almost nonexistent. Researches in Peru have been carried out by our colleague and friend Federica Villa, who examined archival sources about the Schmidt Pizarro family. A special thanks goes to Susan Bergh and Amanda Mikolic, who provided the detailed list of letter exchanges with the Cleveland Museum that served as a basis to trace S.P.'s movements through Europe and the United States. An impressive number of important documents is also preserved in the Brooklyn Museum archive: Nancy Rosoff, Molly Seegers and Georgia de Havenon opened a virtual window in those archives for us, and worked hard and selflessly on the draft revision. Victòria Solanilla Demestre believed in this research project right from the beginning and supported us enthusiastically. A great help was offered us by Giulia Bugada, a volunteer with Servizio Civile Nazionale (Civil Service Program) at Museo delle Culture di Milano, who assisted us in organizing sources and connecting various S.P. objects across online museum collections around the world.

The global nature of this study would have been impossible without the help of many colleagues, to whom we express our deepest gratitude. In Europe: Belgium: Serge Lamaitre (Musées Royaux d'Art et d'Histoire, Bruxelles); Denmark: Lena Bjerregaard (The Danish National Research Foundation's Centre for Textile Research, Copenhagen); France: Paz Nuñez and Emanuela Canghiari (Musée du Quai Branly, Paris); Germany: Manuela Fischer (Ethnologisches Museum, Berlin), Christine Chávez (Markk - Museum am Rothenbaum, Hamburg), Katalin Nagy (Deutsches Textilmuseum, Krefeld); Italy: Maria Camilla de Palma (Museo Castello D’Albertis, Genoa), Mario Mineo (Muciv-Museo delle Civiltà, Rome), Tommaso Bonfanti (Cittadella degli Archivi, Milan); Spain: Aurora Ladero Galán (Museo Arqueológico Nacional, Madrid); Switzerland: Alexander Brust (Museum der Kulturen, Basel), Peter Fux and Esther Tisa (Rietberg, Zurich), Sabine Flaschberger and Julia Klinner (Museum für Gestaltung, Zurich); United Kingdom: Clothworkers' Centre for the Study and Conservation of Textiles \& Fashion (London), Jason Cooper and James Hamill (The British Museum, London), Imogen Gunn (Museum of Archaeology and Anthropology, Cambridge). All the archival materials located in London have been checked by Gabriella Primi.

In North America: Canada: Erell Hubert (the Montreal Museum of Fine Arts); United States: Sumru Aricanli, Mary Lou Murillo, Kristen Mable (American Museum of Natural History, New York), Jennifer M. Swope (Boston Museum of Fine Arts), Nancy Rosoff, Georgia de Havenon and Molly Seegers (Brooklyn Museum of Arts), Laura Costello
(Peabody Museum of Archaeology and Ethnology, Harvard), Ann Pollard Rowe (The Textile Museum, Washington D.C.), Amy Clark (Saint Louis Art Museum). Ann Peters helped to identify some Paracas textiles and provided information about other Peruvian collectors.

\section{Online Catalogs and Resources}

H. Allen Anderson. Pratt, George Dupont; http://www. anb.org/articles/20/20-00818.html; American National Biography Online, Feb. 200o. Access Date: January 7, 2019

Informe de Oscar Schmidt Pizarro sobre la participación en el sexto Congreso Internacional de Contabilidad, realizado en Londres en junio de 1952, así como de sus visitas a instituciones similares de Escocia y Alemania Occidental. Biblioteca Universidad Católica de Lima.

\section{References Cited}

Antonielli, Ugo

1933 Arte primitiva d'America. Una grande mostra romana. L'Italia letteraria IX (20), May 14, 1933.

Antonini, Anna and Carolina Orsini

2016 A Brief History of Collections. In Museum of Cultures. Objects of Encounters. Catalogue of Works and Exhibit Guide, Carolina Orsini and Anna Antonini (eds.), pp.18-31. Il Sole 24 Ore, Milan.

Bernal Multon, Vanessa

2018 Formation des collections archéologiques et ethnographiques: notes sur des trajectoires d'objets latino-américains. Les Cahiers de l'École du Louvre, Recherches en histoire de l'art, histoire des civilisations, archéologie, anthropologie et muséologie 12:1-25. DOI:10.400o/cel.878, accessed May 22, 2019.

Biro, Yaëlle

2018 Fabriquer le regard: marchands, réseaux et objets d'art africains à l'aube du XXe siècle. Les presses du reel, Dijon.

Bjerregaard, Lena

2001 Doubletten - puzzles that could maybe someday be reconstructed. Baessler-Archiv, band 49, Berlin.

2016 Lambayeque-Style Textiles in the Ethnologisches Museum, Berlin. Nuevo Mundo Mundos Nuevos. DOI: 10.400o/nuevomundo.6929o, accessed May 27, 2019.

Brennan, Christine E.

2015 The Brummer Gallery and the Business of Art. Journal of the History of Collections 27(3):455-468. DOI 10.1093/jhc/fhuo44, accessed May 22, 2019. 
Brooklyn Museum

Guide to the Records of the Department of the Arts of Africa, the Pacific Islands, and the Americas, p.11. The Brooklyn Museum, New York.

Callegari, Guido V.

1933 Arte dell'America Latina. Le Vie d'Italia e del Mondo. Rivista del Touring Club italiano 7:779-796.

Daggett, Richard E.

2012 An Annotated Tello-Centric History Of Peruvian Archaeology, Volume One, (ca.1825-1925). Manuscript published online and accessed May 27, 2019.

Delpuech, André, Laurière, Christine and Christine Peltier-Caroff (eds.)

2017 Les années folles de l'ethnographie: Trocadero 2837. Publication scientifiques du Museum National d'Histoire Naturelle, Paris.

Direzione Generale Antichità e Belle Arti

1933 Mostra d'arte antica dell'America Latina: Roma, 4 maggio-3o giugno 1933 XI. Officine dell'Istituto Poligrafico dello Stato, Rome.

Exposición de cuadros y objetos de arte virreinal

1942 Exposición de cuadros y objetos de arte virreinal, realizada en los salones de la sociedad "Entre nous" del 2 al 14 de febrero de 1942. Talleres de la Compañía de impresiones y publicidad E. Bustamante y Ballivián, sucesor, Lima.

Fane, Diana (editor)

1996 Converging Cultures: Art \& Identity in Spanish America. Brooklyn Museum Bookshop, New York.

Faucourt, Camille

2017 L'annonce d'une renaissance: l'exposition les Arts anciens de l'Amerique. In Les années folles de l'ethnographie: Trocadero 28-37, André Delpuech, Christine Laurière \& Christine Peltier-Caroff (eds.), pp.51-77. Publication scientifique du Museum National d'Histoire Naturelle, Paris.

Fischer, Manuela; Röhrs, Stefan; Gómez-Sánchez, Elena; Pausewein, Regine-Ricarda; Born, Hermann; Reiche, Ina and Kai Engelhardt

2017 Product of the art market? The representation of silver corncobs at the Ethnologisches Museum in Berlin. Bulletin IFEA 46 (1): 291-305. DOI: https:// doi.org/10.400o/bifea.8301

Foreign Commerce Weekly

1944 Peru Is Expanding Manual Industries. Foreign Commerce Weekly 17 (9): 12 and 41.

Gänger, Stefanie

2014a Conversaciones sobre el pasado. Nuevo Mundo Mundos Nuevos. DOI:10.400o/nuevomundo.67124, accessed May 27, 2019. 2014b Relics of the Past. The Collecting and Study of PreColumbian Antiquities in Peru and Chile, 1837-1911. Oxford University Press. Oxford.

Gosden, Chris and Yvonne Marshall

1999 The Cultural Biography of Objects. World Archaeology 31(2):169-178. DOI 10.1080/o0438243.1999.9980439, accessed May 22, 2019 .

Hill, Kate

2012 Introduction: Museum and Biographies. Telling Stories about People, Things and Relationships. In Museums and Biographies: Stories, Objects, Identities. Heritage Matters Vol.9, edited by Kate Hill, pp.1-10. Boydell \& Brewer, Woodbridge.

Hoerll, Alberto

1910 La colonización alemana en Chile. In Los Alemanes en Chile, Sociedad científica alemana de Santiago (ed.), pp.1-62. Imprenta Universitaria, Santiago del Chile.

Kaulicke, Peter

1997 Contextos funerarios de Ancón. Esbozo de una síntesis analítica. Pontificia Universidad Católica Fondo Editorial, Lima.

Kopytoff, Igor

1986 The Cultural Biography of Things: Commoditization as Process. In The Social Life of Things, Arjun Appadurai (ed.), pp.64-91. Cambridge University Press.

La Porte, Sophie and Philippe Dagen

2013 Charles Ratton. L’invention des Arts «Primitifs». Skira, Milan.

Laurencich Minelli, Laura and Antonio Aimi

1991 Museo d'Arti Applicate. Raccolta Precolombiana. Musei e Gallerie di Milano. Mondadori Electa, Milan.

Milliken, William

1954 Gertrude Underhill (1874-1954). The Bulletin of the Cleveland Museum of Art 41(6):115-116.

Museo Nacional de Antropología y Arqueología

1948 Donaciones y decomisos. Revista del Museo Nacional de Antropología Arqueología 2(1):192.

Peltier-Caroff, Carine and Claudia De Sevilla

2016 Les objets de l'exposition Les arts anciens de l'Amerique, 1928: de nouvelles sources iconographiques et documentaire. Le revue des Musées de France 3:82-111.

Pilar, Vega F.

1933 Tejidos peruanos procedentes de la Colección de los Señores Schmidt y Pizarro de Lima. Nota descriptiva. [Adquisiciones en 1930]. Museo Arqueológico Nacional, Madrid. 
Rowe, John H.

1954 Max Uhle, 1856-1944: A Memoir of the Father of Peruvian Archaeology. University of California publications: American Archaeology and Ethnology Vol. 46(1). University of California Press.

Saint-Raymond, Léa and Élodie Vaudry

2018 A New Eldorado. In Acquiring Cultures: Histories of World Art on Western Markets, Bénédicte Savoy, Charlotte Guichard and Christine Howald (eds.), pp.101-120. De Gruyter, Berlin.

Tello, Julio C.

1926 Los descubrimientos del Museo de Arqueología Peruana en la Península de Paracas. Atti del XXII Congresso Internazionale degli Americanisti I:679690, Roma.

Thebele, Winani

2018 Depatriated objects. A reflection. In Acquiring Cultures: Histories of World Art on Western Markets, Bénédicte Savoy, Charlotte Guichard and Christine Howald (eds.), Bénédicte Savoy, Charlotte Guichard and Christine Howald (eds.), pp.9-14. De Gruyter, Berlin.
Valcarcel, Luis E.

1943 De mi viaje a los Estados Unidos. Revista Iberoamericana VI(11):271-296. DOI:https://doi. org/10.5195/reviberoamer.1943.1108, accessed May 22th, 2019.

Venturi, Franco

1989 Guido Valeriano Callegari, professor of American antiquities. Civiltà veronese II(IV):76-78.

Wadsworth Atheneum and Baltimore Museum of Art

19522000 Years of Tapestry Weaving: A Loan Exhibition. Wadsworth Atheneum Hartford, Dec. 7, 1951 to Jan. 27, 1952. The Baltimore Museum of Art, Feb.27, 1952 to Mar.25, 1952. Wadsworth Atheneum, Hartford.

Weil, Stephen E.

1999 From Being about Something to Being for Somebody: The Ongoing Transformation of the American Museum. Daedalus 128(3):229-258.

Whitley, Lauren D.

1998 Morris De Camp Crawford and the "Designed in America” Campaign, 1916-1922. Proceedings of the Sixth Biennial Symposium of the Textile Society of America, 215:410-419. New York. 


\section{Ethnographic textiles}

\section{Textiles etnográficos}

\section{Textiles ethnographiques}
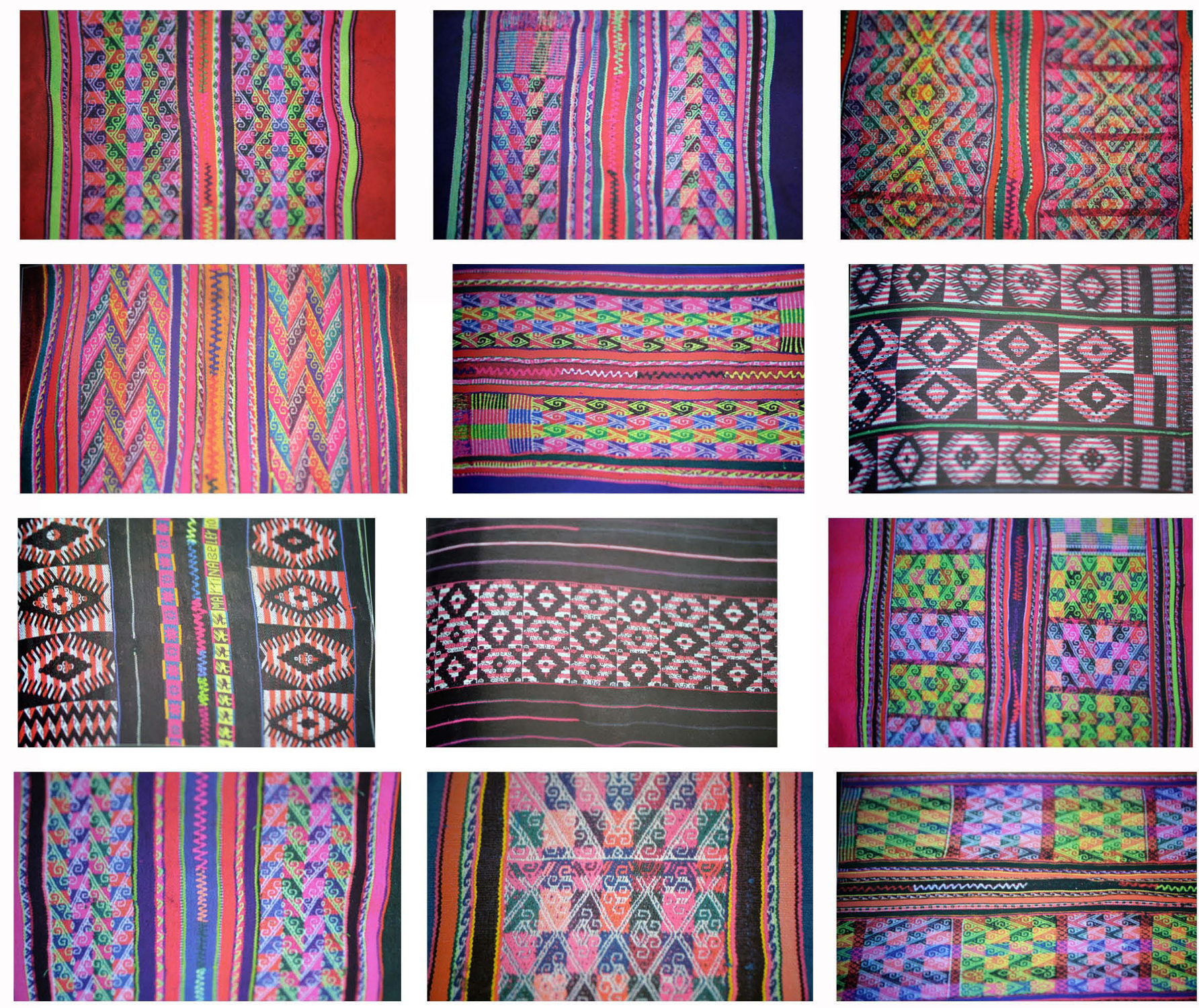


\title{
Colorantes presentes en mochilas Ika de la colección etnográfica del Världskulturmuseet (Antiguo Museo Etnografico) en Gotemburgo, Suecia, realizada por Gustav Bolinder
}

\author{
Beatriz Devia* \& Marianne Cardale de Schrimpff ${ }^{\dagger}$ \\ * Universidad Distrital Francisco José de Caldas, Bogotá, Colombia, bodeviac@udistrital.edu.co \\ † Fundación Procalima, marianne@procalima.org
}

\begin{abstract}
Resumen
El etnólogo sueco, Gustav Bolinder en los años 1914-1921 realizó una colección extensa de objetos elaborados por grupos indígenas del norte de Colombia, incluyendo a los Ika y otras etnias de la Sierra Nevada de Santa Marta. La colección incluye numerosas mochilas Ika. Estas son en fique, algodón y lana, para diferentes usos. Tanto los motivos de los diseños como los colorantes y las fibras utilizadas expresan cierto grado de sincretismo. Aunque la mayoría de los diseños son tradicionales, se observa algunos animales domésticos y la cruz, al parecer resultado de la influencia de la misión de padres capuchinos establecida en ese tiempo en la región.

El análisis de los colorantes presentes en mochilas de esta colección, proporcionó indicios sobre el empleo de especies de palo brasil (posiblemente Haematoxylum brassileto), Picramnia gracilis, Berberis meollacensis y Fridericia chica (Sin. Arrabidaea chica). Adicionalmente se encuentran otras moléculas sin identificar que posiblemente correspondan al empleo de colorantes sintéticos. Los resultados comparados con recientes estudios de colorantes de uso tradicional por la comunidad Ika, muestran una continuidad de más de cien años en el uso de especies tintóreas de la región y guardan una estrecha relación con los colorantes determinados en textiles prehispánicos del norte de la cordillera Oriental en Colombia.
\end{abstract}

Palabras claves: Análisis químico, Bolinder, Bignoniaceae, Picramniaceae, Berberidaceae, muestras etnográficas.

\begin{abstract}
During the years 1914-1941, the Swedish ethnographer, Gustav Bolinder, collected an extensive range of ítems from several Amerindian societies in northern Colombia, including the Ika and other indigenous groups of the Sierra Nevada de Santa Marta. The collection includes a large number of Ika bags (known as mochilas) made from agave fibre, cotton or wool and used for different purposes. Both the design motifs and the dyes and fibres employed reveal a certain degree of syncretism. Although the majority of the designs are traditional, some of the bags include domestic animals and the cross, possibly as a result of the influence of the Catholic mission founded by Capuchin monks in the region at this time. The analysis of the colorants in the mochilas from this collection indicates the use of species of brasil wood (possibly Haematoxylum brassileto), Picramnia gracilis, Berberis meollacensis y Fridericia chica (Sin. Arrabidaea chica). In addition, some unidentified molecules may be from synthetic colorants. When these results are compared with recent studies of the colorants still used traditionally by the Ika community, they demonstrate continuity in the use of certain dye plants from the region during a period of
\end{abstract}

DOI: $10.32873 /$ unl.dc.zea.1217

Published in PreColumbian Textile Conference VIII / Jornadas de Textiles PreColombinos VIII, ed. Lena Bjerregaard and Ann Peters

(Lincoln, NE: Zea Books, 2020). https://digitalcommons.unl.edu/zeabook/ 
more than a hundred years. At the same time, they reveal a close relationship with the colorants identified on prehispanic textiles from the northern region of the Eastern Cordillera in Colombia.

Key words: chemical analysis, Bolinder, Bignoniaceae, Picramniaceae, Berberidaceae, ethnographic samples.

\section{Résumé}

Dans les années 1914-1921, l'ethnologue suédois Gustav Bolinder a réalisé une vaste collection d'objets élaborés par des groupes indigènes du nord de la Colombie, incluant les Ika et d'autres ethnies de la Sierra Nevada de Santa Marta. La collection comprend de nombreux sacs Ika. Ces derniers sont en fique, coton et laine pour différents usages. Tant les motifs que les colorants et les fibres utilisés, expriment un certain degré de syncrétisme. Bien que la majorité des figures soient traditionnelles, on observe quelques animaux domestiques et une croix, probablement résultat de l'influence de la mission catholique fondée par les pères Capucins établie à cette période dans la région.

L'analyse des colorants présents dans les sacs de cette collection a fourni des indices sur l'emploi des espèces du palo brasil (possiblement Haematoxylum brassileto), Picramnia gracilis, Berberis meollacensis et Fridericia chica (Sin. Arrabidaea chica). De plus, ont été découvert d'autres molécules non identifiées qui probablement correspondent à l'emploi de colorants synthétiques. Les résultats sont comparés à de récentes études de colorants d'usage traditionnel par la communauté Ika, ils montrent une continuité dans l'usage des espèces tinctoriales de la région. En même temps, ils gardent une étroite relation avec les colorants identifiés dans les tissus préhispaniques du nord de la cordillère orientale en Colombie.

Mots-clés: Analyse chimique, Bolinder, Bignoniaceae, Picramniaceae, Berberidaceae, échantillons ethnographiques.

\section{Introducción}

Este trabajo se inició en la etapa final de la investigación "Contribución al conocimiento de las fuentes de colorantes precolombinos a partir del estudio de las especies colorantes de uso tradicional por la comunidad indígena Ika de Nabusímake, Sierra Nevada de Santa Marta, Colombia” financiado por la Fundación de Investigaciones Arqueológicas Nacionales (FIAN) y por la Universidad Distrital Francisco José de Caldas, Colombia.

Diferentes colecciones etnográficas se han realizado en torno a la cultura material de los grupos indígenas habitantes de la parte norte del territorio colombiano, como en el Museo Americano de Historia Natural en New York (USA), en el Museo de las Culturas del Mundo en Gotemburgo (Suecia), en el Museo Quai Branly en Paris (Francia) y el museo etnológico en Berlín (Alemania). Pero tal vez la más completa en torno a los materiales perteneciente a los indígenas Ika de la Sierra Nevada de Santa Marta es la realizada por el antropólogo Gustav Bolinder, para el entonces museo etnográfico de Gotemburgo, entre 1914 y 1924.

Para la investigación que se venimos desarrollando en torno a los colorantes presentes en textiles arqueológicos colombianos y sobre las especies promisorias de estos colorantes, es de gran importancia la información guardada en los materiales etnográficos. De ahí el gran valor que tiene poder contrastar la información adquirida por el trabajo realizado hace cinco años con la comunidad Ika de Nabusimake sobre especies colorantes de uso tradicional, con la información recopilada por Gustav Bolinder, 100 años atrás en la misma comunidad.
Con este trabajo se busca implementar el conocimiento sobre las propiedades y aplicaciones de las especies tintóreas de la región. Aportar evidencias experimentales sobre el uso de los materiales y técnicas ancestrales de tintorería, a la vez que resaltar el valor de este conocimiento en la comunidad Ika.

\section{Colorantes utilizados por la comunidad Ika de Nabusi- make, Sierra Nevada de Santa Marta.}

Los Ika junto con los Kogi, Wiwa y Kankuama habitan la Sierra Nevada de Santa, localizada entre los departamentos del Magdalena, Córdoba y Cesar (Figura 1). Pertenecen a la familia liguistica Chibcha (Uribe, 1990). Su territorio comprende diferentes pisos térmicos entre 1200 hasta 5600 msnm, con un ecosistema montañoso, seco y en algunas partes desértico, de coberturas naturales y alteradas. La población es de 14.799 individuos según el Departamento Nacional de Planeación de Colombia (DNP).

El trabajo de campo se realizó con la comunidad Ika de Nabusimake, en las veredas Sirkairo y el Pantano, municipio de Pueblo Bello. Especialmente con la asociación de mujeres Akitinkuchua, empeñadas en el rescate de la tintoreria tradicional y encargadas de la comercialización de diferentes productos, entre estos la venta de las mochilas que producen las mujeres de la comunidad. En la actualidad, las mochilas de mayor comercialización son las tejidas en fibras de lana con diseños tradicionales logrados con los colores naturales de la lana y en menor escala, las elaboradas con fibras de fique o maguey (Furcraea bedinghausii) teñidas con colorantes naturales. Debido a la poca disponibilidad 


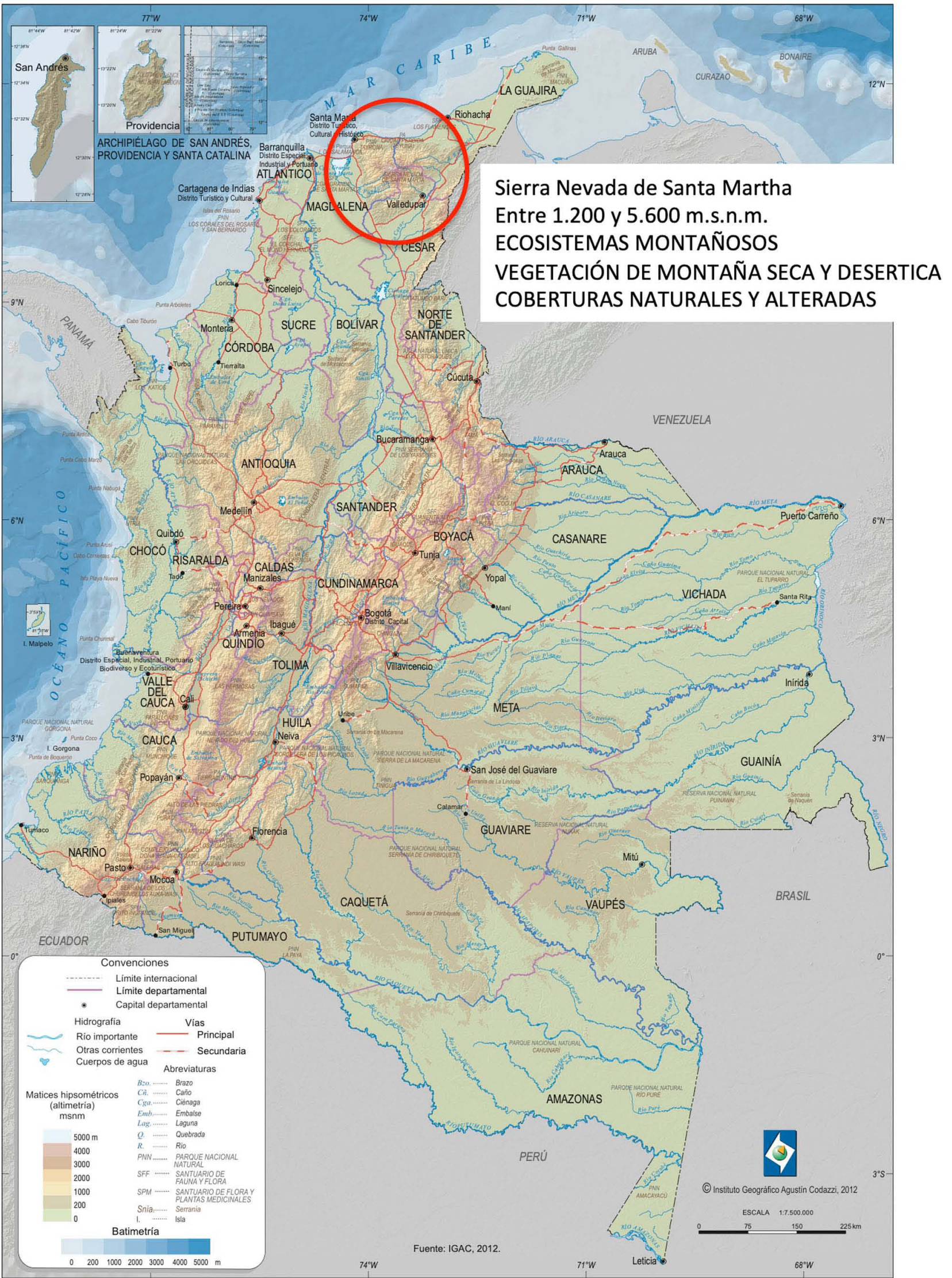

Figura 1. Localización de la Sierra nevada de Santa Marta, lugar donde habitan las comunidades indígenas Ika, Kogi, Wiwa y Kankuama. 


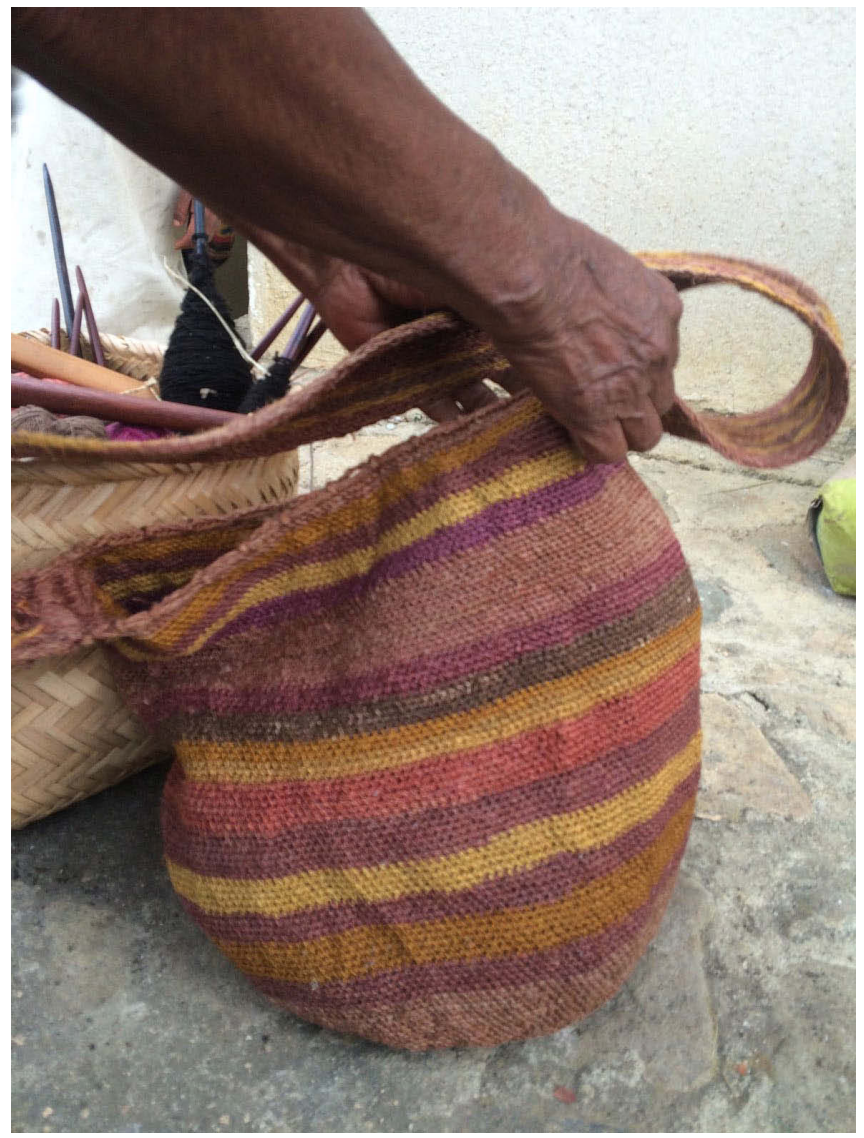

Figura 2. Mochila Ika actual, fibras de fique teñidas con Kugwinu (Weinmannia pinnata), Uru (Picramnia gracilis), Chunnu (Berberis meollacensis) Sorkuanu (Bocconia frutescens), y palo brasil (Haematoxylum brasiletto), hecha por la señora Ester Izquierdo de Nabusimake, fotografía de Marianne Cardale de Schrimpff.

de algodón se producen muy pocas mochilas con esta fibra. En el teñido del fique se conserva el conocimiento del teñido con plantas (Figura 2). Las plantas tintóreas y los colores que se obtienen tienen un alto significado en la cosmología de los Ika (Reichel-Dolmatoff, 1949-1950). El proceso de teñir y los individuos que participan en él están regidos por normas de la comunidad. Las fibras teñidas sobre algodón se utilizan para obtener ofrendas rituales (pagamentos) (Giraldo Jaramillo, 2014).

\section{Especies colorantes de uso actual.}

Trabajos anteriores realizados por Marianne Cardale de Schrimpff (Cardale de Schrimpff, 1972), Camilo Niño Izquierdo (Niño Izquierdo, 2011) y Beatriz Devia (Devia et al., 2016) permitieron identificar un grupo de dieciocho especies, entre las plantas tintóreas utilizadas en la actualidad por la comunidad como fuentes de colorantes, para la

\begin{tabular}{|c|c|c|c|c|c|c|}
\hline NOMBPE CIENTIEICO & & & \\
\hline NOMBRE CIENTIFICO & IKA & COLOR & ARBOL & ARBUSTO & LIANA & HIERBA \\
\hline Berberis meollacenses & Chunnt & & & & & \\
\hline Bocconia frutescens & Sorkwant & & & & & \\
\hline Curcuma longa & Batatilla & & & & & \\
\hline Chaetolepis alpina & Uchaba & & & & & \\
\hline Clusia multiflora & Gronu & & & & & \\
\hline Maclura tinctorea & Morita & & & & & \\
\hline Vismia baccifera & Mumkwinu & & & & & \\
\hline Bixa orellana & Achote & & & & & \\
\hline Weinmannia pinnata & Kugwinu & & & & & \\
\hline Fridericia chica & Sisita & & & & & \\
\hline Haematoxylum brasiletto & Barrasin & & & & & \\
\hline Escallonia paniculata & Manuzitinu & & & & & \\
\hline Galium hypocarpium & Kasira & & & & & \\
\hline Picramia gracilis & Uru & & & & & \\
\hline Mucuna sp. & Sikura & & & & & \\
\hline Piper aduncum & Gungunu & & & & & \\
\hline Senna pendula & Jumisai & & & & & \\
\hline Myrsine coriacea & Yeganu & & & & & \\
\hline Mucuna sp. & Sikura & & & & & \\
\hline Myrsine coriacea & Yeganu & & & & & \\
\hline Picramia gracilis & Uru & & & & & \\
\hline
\end{tabular}

Tabla 1. Especies tintóreas empleadas en la comunidad Ika

obtención de tonos que van desde el amarillo hasta el púrpura, ver Tabla (1) . Este grupo está formado por especies nativas con excepción de la Curcuma longa L. (Batatilla) especie introducida de origen indico-malayo, utilizada principalmente como aditivo colorante para alimentos y especia (Freire González y Vistel Vigo 2015). De acuerdo a su porte hay árboles como Haematoxylum brasiletto y Maclura tinctórea, característicos del bosque tropical seco; Bocconia frutescens y Picramnia gracilis comunes en el bosque andino, arbustos como Berberis meollacensis, característico del ecosistema de la sierra nevada, hierbas como el Galium hypocarpium comunes en el bosque andino $y$ lianas como Fridericia chica de la selva tropical húmeda.

Entre los tonos obtenidos prevalecen los amarillo y naranja, seguidos de los rojizo, verde y por último purpúra. No se observa el empleo de fuentes para la obtención del azul. Los colorantes se obtienen de diferente parte de la planta dependiendo de la especie: para los colores amarillo y anarajado se utiliza la raiz de Berberis meollacensis L.A. Camargo (Chunnu), los rizomas de Curcuma longa, la madera de Bocconia frutescens L.(Sorkwuanu) y Maclura tinctórea L. (Morita), los frutos en Vismia baccifera (L.) Triana \& Planch (Mumkwinu) y Clusia multiflora Kunth, las semillas en Bixa orellana L. y la planta entera en Chaetolepis alpina L. La madera de Weinmannia pinnata L. (Kugwinu), para tonos café rojizo, para el rojo madera de Escallonia paniculata (Ruiz \& Pav.) Roem. \& Schult (Manuzitinu) y Haematoxylum brasiletto Karst ( Barracin), para el rojo y anaranjado hojas de Fridericia chica (Bonpl.) L.G. Lohmann (Sisita) y raíz de Galium hypocarpium. L. (Kasira). Para el verde la planta 

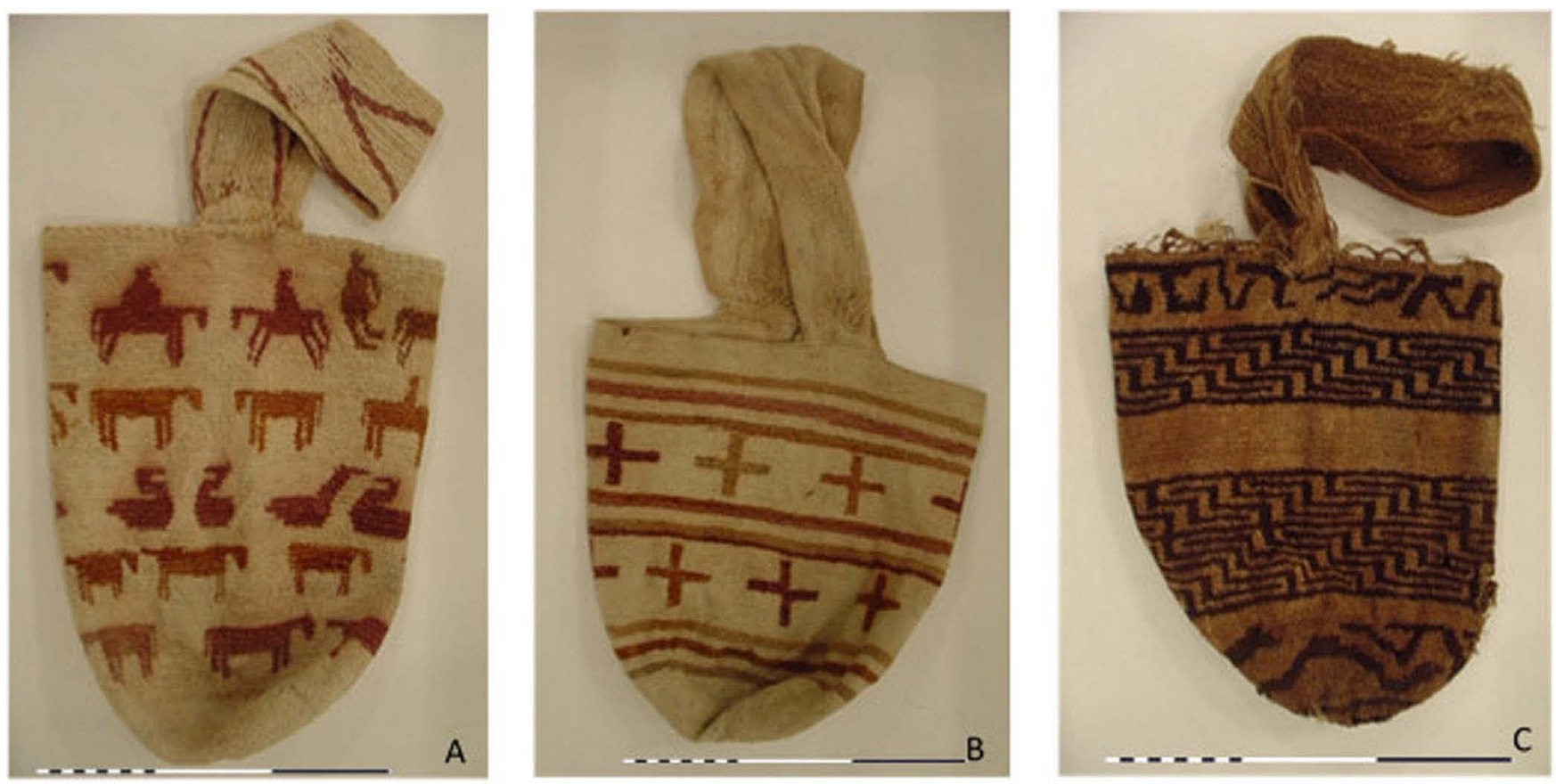

Figura 3. Mochilas Ika, Världskulturmuseet, Gotemburgo, Suecia, A) 1916.03.435 y B) 1916.03.786 poseen motivos diferentes a los tradicionales en los diseños Ika. En la mochila C) 1916.03.425 se conservan los diseños tradicionales.

entera de Mucuna sp. ${ }^{1}$ (Sikara), Senna pendula Willd (Jumisai) y Piper aduncun L.(Gungunu). Con los frutos de Myrsine coriaceae Sw.(Yeganu), se puede obtener grís y violeta, con la Sikara también se puede obtener gris oscuro casi negro. Y, con las hojas frescas de Picramnia gracilis Tul. (Uru) púrpura y violeta.

Algunas de las plantas tintóreas se cultivan para uso alimenticio como Bixa orellana y Curcuma longa, otras como Fridericia chica como especie medicinal y tintórea, con $\mathrm{Pi}$ cramnia gracilis de difícil domesticación, en algunos casos se ha logrado su cultivo para fines tintóreos. Otras como Haematoxylum brasiletto y Maclura tinctórea a pesar de ser conocidas como especies tintóreas (Patiño 1975-1976), ya no se cultivan y se usan especialmente como especies madereras. Las otras se emplean de acuerdo a la disponibilidad. Del grupo de especies registradas en la tabla 1, se destaca por la frecuencia en su empleo ${ }^{2}$ Picramnia gracilis (Uru).

\section{Materiales etnográficos relacionados con el uso de los colorantes en la colección etnográfica del Världskulturmuseet en Gotemburgo, Suecia.}

En sus temporadas en Colombia desde 1913, Gustav Bolinder hizo colecciones de textiles y otros materiales, entre estos los relacionados con la tintorería, de casi todos los grupos indígenas del norte de Colombia. En la Sierra Nevada de Santa Marta la mayor parte de su colección viene de Nabusimake, en aquella época llamado San Sebastián de Rabago, donde una comunidad de monjes capuchinos había establecido una misión (Bolinder 1925). Aunque hay un buen número de mochilas elaboradas en algodón y en fique, también hay varias en lana. Al parecer, no hay datos en cuanto a cuando se empezó a utilizar esta última fibra para las mochilas, pero parece posible que su uso fue fomentado por la misión. Los monjes establecieron un gran internado donde funcionaba una escuela para los niños indígenas. Las niñas seguramente seguían tejiendo sus mochilas y algunos de los motivos como animales y posiblemente, la cruz, parecen ser el resultado de la influencia de la misión (Figura 3). Sin embargo, se encuentran también otros diseños, por los menos algunos de los cuales como el "pensamiento de la mujer" que todavía forma parte del archivo tradicional (Aroca 2009).

Entre los materiales etnográficos relacionados con el uso de los colorantes, por la comunidad Ika, en la colección de Gustav Bolinder se encuentra: mochilas, prendas de vestir, muestras de fibras teñidas y de plantas tintóreas. Entre las mochilas, de acuerdo a las fibras empleadas en su elaboración, se encuentran dieciocho en algodón; diecisiete en fique

1. En la Sierra Nevada hay registros de Mucuna mutisiana, cerca al rio Donachui, información tomada de la base de datos del herbario nacional colombiano

2. Información obtenida en el trabajo de campo realizado entre el 2013 y 2015 en Nabusimake 

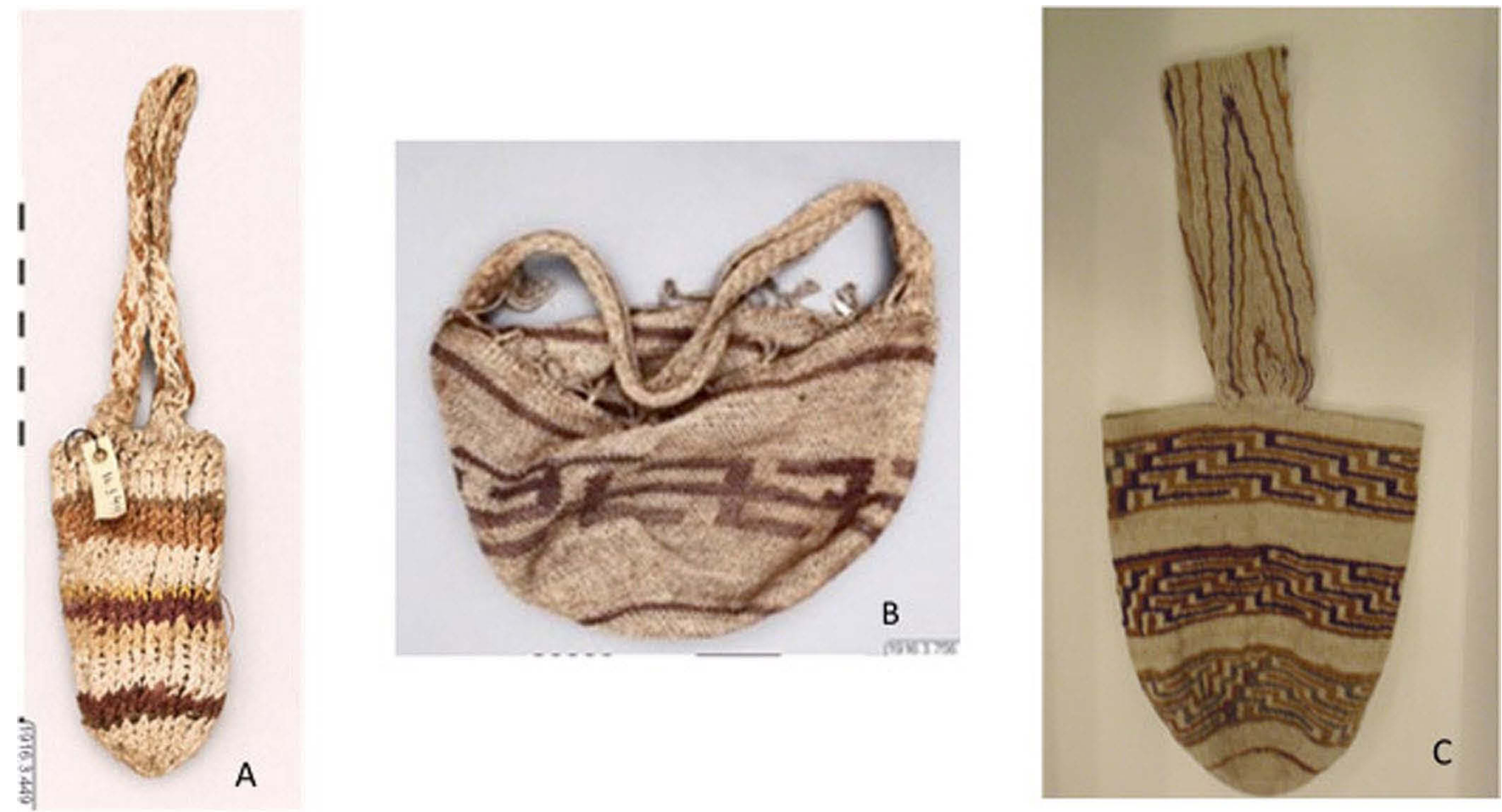

Figura 4. Mochilas Ika, Världskulturmuseet, Gotemburgo, Suecia A. Mochila de algodón 1916.03.0449, 28 cm, utilizada para guardar el hayo. B. Mochila de fique 1916.03.7056, $73 \mathrm{~cm}$, utilizada para transportar y almacenar los productos de intercambio y regalo. C. Mochila de algodón, $60 \mathrm{~cm}, 1916.03 .0433$, utilizada para guardar y transportar objetos personales.

y diecisiete en lana, con diferente tamaño. Los motivos de las mochilas en algodón y fique al igual que en las mantas, pantalones y otros objetos tejidos están hechos con fibras teñidas. Los motivos en las mochilas de lana en la mayoría de los casos fueron hechos con los diferentes colores naturales de la lana, estas son las mochilas más comercializadas en la actualidad.

La revisión de la información sobre las diferentes mochilas de la colección y la consulta con miembros de la comunidad Ika, permite observar que existe una relación entre la forma y los materiales con los que fueron elaboradas con su uso. Como se puede apreciar en la Figura (4), con tres ejemplos, en A) la mochila de algodón 1916.3.449, de $28 \mathrm{~cm}$ de largo, es utilizada para guardar el hayo (hojas secas de coca), en B) la mochila de fique $1916.3 .756 \mathrm{de} 73 \mathrm{~cm}$ de largo, es utilizada para transportar y almacenar los productos de intercambio y regalo y en C) la mochila de algodón, 1916.3.433, de $60 \mathrm{~cm}$ es utilizada para guardar y transportar objetos personales, entre estos la mochila que contiene el hayo.

Además de la colección de objetos materiales, en la base de datos del museo se encuentra el registro fotográfico de la permanencia de Gustav Bolinder en Nabusimake, que muestra la importancia del uso de las mochilas en la vida cotidiana de los Ika (Figura 5). Este material está a disposición del público a través de la página web del museo: http://collections.smvk.se/carlotta-vkm/web.

Para establecer la relación entre los diferentes objetos de la colección y las especies colorantes de uso actual por la comunidad, se desarrolló una metodología que consistió en hacer la toma de muestras de un grupo de mochilas seleccionadas en la colección Bolinder, establecer la correspondencia entre el nombre común de las plantas de la colección y el nombre en Ika de las especies de uso tradicional, ya identificadas. Asignar el nombre científico a las plantas utilizadas en las muestras etnográficas teñidas. Finalmente, realizar el análisis químico para buscar identificar las fuentes de colorantes presentes en las muestras etnográficas.

\section{Metodología}

\section{Actividades desarrolladas en el Museo etnográfico.}

1.1. Toma de muestras de un grupo de mochilas seleccionadas. La toma de muestras se realizó en enero del año 2015 en las instalaciones del museo etnográfico, de acuerdo a la disponibilidad y al estilo del material.

1.2. Relación entre el nombre común de las plantas de la colección y el nombre en Ika de las especies de uso 


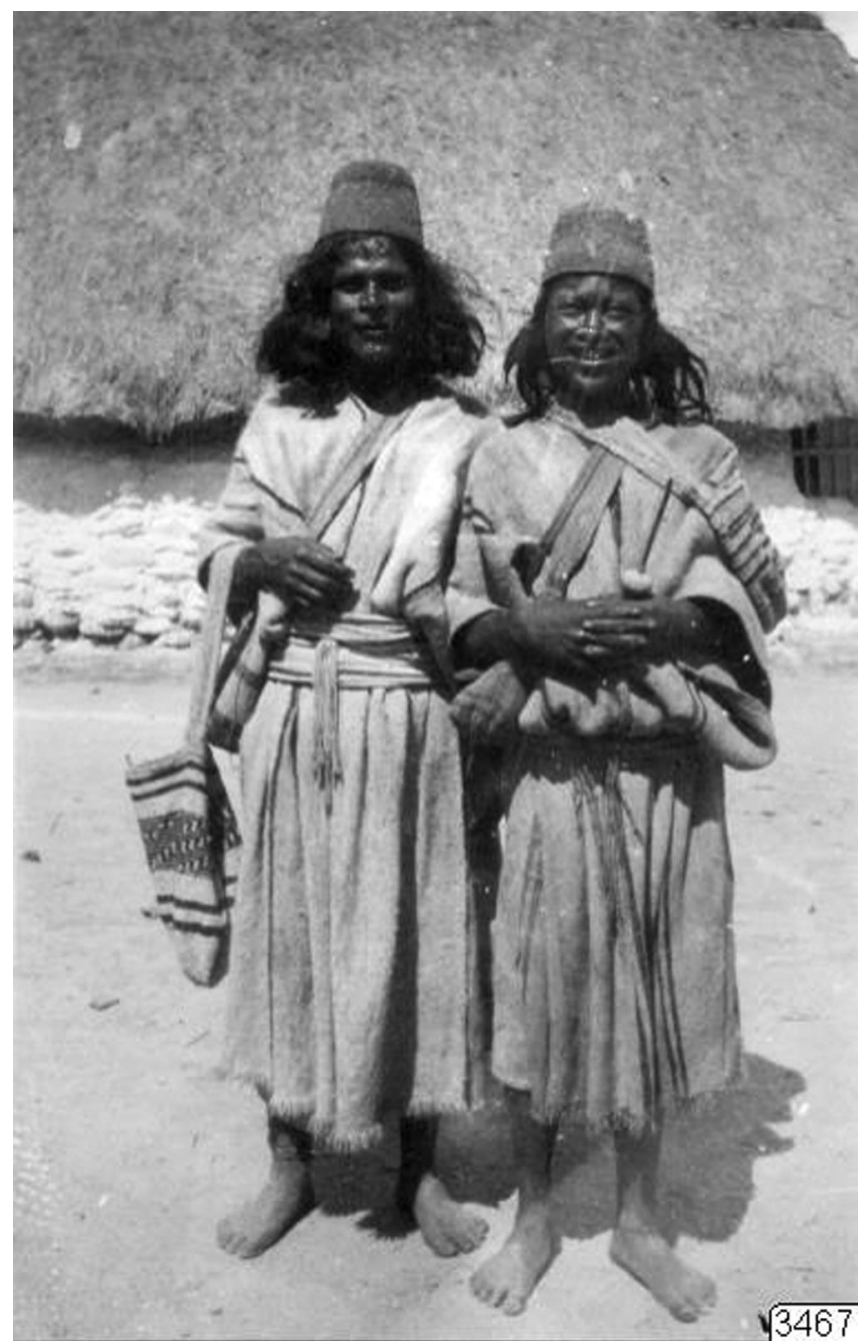

Figura 5. Jovenes Ika en Nabusimake, fotografía tomada del archivo de Gustav Bolinder (oo3467).

tradicional ya identificadas. Debido a que los nombres Ika de las plantas de la colección están transcritos a ortografía sueca la relación con el nombre Ika se hizo inicialmente por semejanza en la escritura y por la muestra de la planta, si esta se encontraba en la colección. Por ejemplo, para el nombre de la ficha original 1916.03.070o Sikkara, esta corresponde a una fibra teñida con Sikara y para 1916.03.0651 Orh, esta corresponde a una fibra teñida con Uru que a la vez tiene la muestra de la planta 1916.03.0778, ver Tabla (2).

1.3. Correspondencia entre el nombre común y el nombre científico de las plantas utilizadas en las muestras etnográficas teñidas. Esta se realizó con la información disponible sobre las especies tintóreas de uso tradicional identificadas previamente (Devia et al. 2016) y en algunos casos por las muestras de las plantas presentes en la colección.

\section{Actividades desarrolladas con la comunidad.}

Actividades desarrolladas con la comunidad, corresponden a la información sobre las especies colorantes y el teñido de uso actual, desarrollada durante el proyecto ${ }^{3}$.

\section{Trabajo de laboratorio}

Para el análisis de los colorantes presentes en materiales etnográficos se siguen los métodos desarrollados para el estudio de los colorantes en materiales arqueológicos, que involucran la preparación del material de referencia y la selección de sistemas de extracción y análisis (Devia y Cardale de Schrimpff 2017). En este caso el material de referencia esta formado por las muestras preparadas con las plantas tintóreas.

3.1. Preparación de muestras con las plantas tintóreas. Para determinar los compuestos colorantes en las especies tintóreas se prepararon muestras teñidas con estas especies sobre algodón y fique, variando algunos parámetros como temperatura en las que se considero $20^{\circ} \mathrm{C}$ como temperatura ambiente y $92^{\circ} \mathrm{C}$ la temperatura de ebullición a $560 \mathrm{mmHg}$ de presion, con teñido directo (sin mordiente) y con alumbre como mordiente. Se determinaron las condiciones óptimas de teñido y se tomaron las muestras para el análisis.

3.2. Identificación de los colorantes presentes en las especies tintóreas. La extracción de los colorantes de las muestras teñidas se realizó mediante hidrólisis suave con ácido oxálico, una adaptación del método de Guinot (2006). La composición en moléculas colorantes fue analizada por cromatografía líquida con el empleo de un detector de arreglo de diodos, HPLC-DAD con una base de datos de compuestos puros colorantes. Tomando como criterio de identificación la correspondencia con el tiempo de retención y espectro UV-VIS (Devia y Cardale de Schrimpff, 2017).

En el caso en que no se conocía la química de los extractos colorantes de algunas de las especies tintóreas, se siguieron los métodos de extracción, separación y aislamiento de la fitoquímica convencional y de la química instrumental para la identificación y elucidación de estructuras. Luego se procedió a

3. "Contribución al conocimiento de las fuentes de colorantes precolombinos a partir del estudio de las especies colorantes de uso tradicional por la comunidad indígena Ika de Nabusímake, Sierra Nevada de Santa Marta, Colombia. Terminado en el año 2015. 


\begin{tabular}{|c|c|c|c|c|}
\hline \multicolumn{2}{|c|}{ Especie } & \multicolumn{2}{|c|}{ Muestra teñida (ficha /nombre) } & \multirow{2}{*}{\begin{tabular}{|l}
$\begin{array}{c}\text { Muestra de la } \\
\text { planta tintórea }\end{array}$ \\
Ficha o código
\end{tabular}} \\
\hline Nombre científico & Nombre Ika & Algodón & Fique & \\
\hline Picramnia gracilis Tul. & Urú & 1916.03.0651 Orh & $\begin{array}{l}1916.03 .0694^{\mathrm{a}} \\
\text { Orh }\end{array}$ & 1916.03.0778 \\
\hline Weinmannia pinnata $\mathrm{L}$. & Kuwigne & $\begin{array}{l}\text { 1916.03.0652 } \\
\text { Kogoina }\end{array}$ & & 1916.03.0780 \\
\hline Chaetolepis alpina Naudin & Uchaba & $\begin{array}{l}\text { 1916.03.0653 } \\
\text { Otjava }\end{array}$ & - & 1916.03.0779 \\
\hline Mucuna sp. & Sikura & $\begin{array}{l}\text { 1916.03.0654 } \\
\text { Sikkará }\end{array}$ & $\begin{array}{l}\text { 1916.03.0694b } \\
\text { Sikkara }\end{array}$ & \\
\hline $\begin{array}{l}\text { Fridericia chica (Bonpl.) L.G. } \\
\text { Lohmann }\end{array}$ & Sisita & $\begin{array}{l}\text { 1916.03.0698 } \\
\text { Sisita }\end{array}$ & & \\
\hline Curcuma longa L. & Batatilla & $\begin{array}{l}\text { 1916.03.0650 } \\
\text { Batatilla }\end{array}$ & - & - \\
\hline Myrsine coriaceae $S w$. & Yeganu & $\begin{array}{l}\text { 1916.03.0655 } \\
\text { Tjannung }\end{array}$ & $\begin{array}{l}\text { 1916.03.0693 } \\
\text { Tjannung }\end{array}$ & - \\
\hline
\end{tabular}

Tabla 2. Muestras de fibras y plantas de la colección Gustav Bolinder

determinar la presencia de las moléculas colorantes identificadas en las fibras teñidas, como en el caso de Picramnia gracilis nombre común Uru (Devia et al., 2019).

3.3. Análisis de muestras etnográficas. Se siguió un procedimiento de extracción y análisis de colorantes similar al de las muestras teñidas con las plantas tintóreas.

\section{Resultados}

\section{Muestras de mochilas etnográficas.}

Se seleccionó un grupo de diez mochilas y una manta, para un total de dieciseis muestras,con un peso entre 0,2 y $0,5 \mathrm{mg}$.

\section{Muestras de fibras y plantas.}

En la Tabla (2) se observa la correspondencia entre el nombre asignado a las muestras de la colección Bolinder, el nombre Ika actual y el nombre científico de las especies para un grupo de siete especies que son: Picramnia gracilis (Uru), con muestras teñidas sobre algodón y fique, y una muestra de la planta; Weinmannia pinnata (Kugwine) y Chaetolepis alpina (Uchaba), una muestra sobre algodón y una de la planta; Mucuna sp. (Sikura) y Myrcine coriacea (Yeganu) fibras teñidas sobre algodón y fique; Fridericia chica (Sisita) y Curcuma longa (Batatilla) fibras teñidas sobre algodón. Se puede considerar como un indicio de la importancia del teñido sobre algodón en ese momento ${ }^{4}$ el hecho de que se tengan muestras de algodón teñido con las siete especies consideradas.

Es importante anotar que en la base de datos del museo se encuentra la muestra 1916.03.0780 que contiene hojas de Weinmannia pinnata y la muestra 1916.03.0779 con ramas de Chaetolepis alpina, con los nombres de las especies cruzados en sus fichas de identificación. También hay muestras de una planta con el No. de inventario 1916.03.0670 con el nombre de Dinga, descrito como un tinte de color violeta, que aparece en la lista de especies tintóreas en Cardalle de Schrimpff (1972). Fuente de colorantes que hasta el momento no ha sido identificada.

\section{Identificación de los compuestos colorantes presen- tes en las especies tintóreas.}

En la Tabla (3) se observa el resultado del análisis de las fibras de algodón teñidas, con el empleo de la cromatografía 


\begin{tabular}{|l|l|l|}
\hline Nombre científico & Nombre Ika & $\begin{array}{l}\text { Principales compuestos recuperados de las fibras } \\
\text { teñidas y analizados por HPLC-DAD }\end{array}$ \\
\hline Berberis meollacensis & Chunnu & Berberina, jatroricina, barbamina, sanguinarina \\
\hline Bixa orellana & Achote & Bixina y norbixina \\
\hline Bocconia frutescens & Sorkwanu & Sanguinarina y quercetina \\
\hline Chaetolepis alpina & Uchaba & Apigenina y derivados \\
\hline Escallonia paniculata & Manuzitinu & Ácido elágico, quercetina y derivados, kaemferol \\
\hline Fridericia chica & Sisita & Carajurina, arrabidina, 3' hidroxiarrabidina, luteolina, \\
\hline Galium hypocarpium & apigenina, feoforbinde y carotenos \\
\hline Haematoxylum brasiletto & Barrasin & Brasileina y orh \\
\hline Maclura tinctórea & Morita & Morina, maclurina y kaemferol \\
\hline Mucuna sp. & Sikura & Ácido elágico y catequina \\
\hline Myrsine coriacea & Yeganu & Miricetina, kaemferol y cianidina \\
\hline Picramnia gracilis & Uru & Nat-aloeemodina y crisofanol \\
\hline Piper aduncum & Gungunu & Ácido elágico \\
\hline Senna pendula & Jumisai & Ácido elágico y quercetina \\
\hline Weinmannia pinnata & Kugwinu & Ácido elágico y ácido dihidroxibenzoico \\
\hline
\end{tabular}

Tabla 3. Resultado del análisis por HPLC-DAD de los extractos tintóreos obtenidos de especies de uso tradicional por los indígenas Ika de la Sierra Nevada de Santa Marta.

HPLC-DAD, en el laboratorio de colorantes naturales de la Universidad Distrital, Colombia. Para especies como Berberis meollacensis, Bixa orellana, Bocconia frutescens, Fridericia chica, Galium hypocarpium, Maclura tinctórea, Myrsine coriaceae y Picranmia gracilis, la presencia de componentes específicos se puede considerar como marcadores quimiotaxonómicos que evidencian el uso de estas especies en los resultados del análisis químico de muestras de fibras teñidas de materiales etnográficos, históricos y arqueológicos. La presencia de brasileina y el componente orh, se pueden atribuir en general al empleo de especies denominadas "palo brasil" (Nowik, 2001), pero solo considerando otros aspectos como procedencia de las muestras, se podría atribuir exclusivamente al empleo de Haematoxylum brasiletto. Piper aduncun, Mucuna sp., Senna pendula, Weinmannia pinnata y Escallonia paniculata (Torres, 1983) tienen en común el ácido elágico, compuesto que pertenece a los taninos hidrolizables y es frecuente en los extractos vegetales. Como los taninos sirven de mordientes es usual encontrarlo en el análisis de colorantes. Senna pendula y Scallonia paniculata tienen además la quercetina, un flavonol de amplia distribución en la parte aérea de las plantas, en este caso para diferenciar el empleo en el teñido de estas dos especies, se podría utilizar como criterio la determinación de kaemferol y los porcentajes en la composición.

\section{Análisis de los extractos colorantes de Picramnia gracilis}

De la fitoquímica de esta especie se conocía muy poco cuando se abordó la investigación sobre las especies colorantes utilizadas por los indígenas Ika y, considerando que es una de las especies más apreciadas en el teñido tradicional, se realizó una investigación paralela con el fin de determinar sus principales moléculas colorantes.

Picramnia gracilis Tul, Picramniaceae. Sin. Picramnia dwyeri D.M Porter y Picramnia monninifolia Rusby. Nombre común: Pakaburwi (Panamá); Uru (Ika, Colombia). (Figura 6)

Nativa del continente americano, está presente en bosques húmedos, en la región tropical del norte del Ecuador, con distribución en Centro América, Panamá y Costa Rica y en el norte de Suramérica Ecuador, Venezuela y Colombia. Se encuentra en la Sierra Nevada de Santa Marta, como también en las montañas de los Andes colombianos en la Cordillera Central. Investigaciones en Colombia han mostrado una fuerte acción contra la leshmaniosis de una flavona aislada de los frutos de la especie (Robledo et al 2015). Otras especies del mismo género son utilizadas como colorantes en el Trapecio Amazónico (Klinger 1998) y en Perú y Ecuador (Riveros y Inga 2014).

Picramnia gracilis es un árbol con hojas verdes que una vez secas se vuelven rojizas, las cuales son ampliamente 


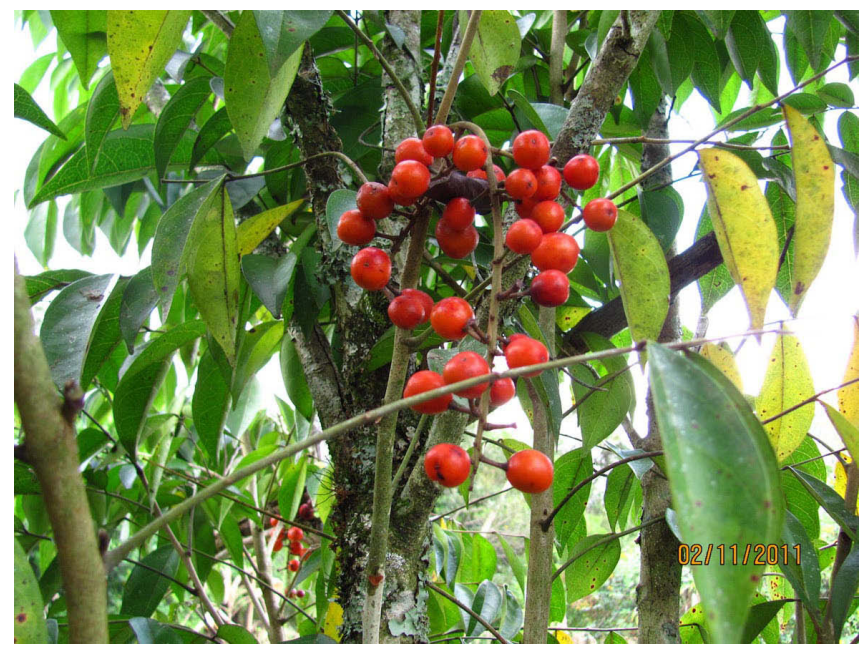

Figura 6. Picramnia gracilis Tul. (Uru) con frutos, árbol de aproximadamente 5 m. Fotografía tomada por Ricardo Niño Izquierdo.

utilizadas para el teñido en tonos rojos y violetas. El análisis del extracto etanólico de las hojas de Picramnia gracilis por HPLC-DAD indicó la presencia de crisofanol, emodina, aloemodina y nataloemodina. La partición liquido-liquido de este extracto con solventes de diferente polaridad y, separación por cromatográfia de columna utilizando Silica gel H (6o Mesh) y Sephadex LH-2o permitió el aislamiento y elucidación por RMN ${ }^{1} \mathrm{H} \mathrm{y}{ }^{13} \mathrm{C}$, FTIR, EM de nataloemodina y crisofanol. Compuestos que junto con emodina y aloemodina se reportan por primera vez para la especie (Devia et al 2019).

La Figura (7) muestra el perfil cromatográfico, por HPLCDAD, del extracto etanólico y sus principales componentes. Los resultados indican la presencia de antraquinonas como aloemodina, nataloemodina, emodina y crisofanol. En el cromatograma A, se observa la nataloemodina como el principal componente. El cromatograma de la parte inferior muestra a nataloemodina y crisofanol como los componentes obtenidos en el extracto tintóreo de las fibras de algodón mordentadas y teñidas a $20^{\circ} \mathrm{C}$, como se describe más adelante en la parte correspondiente a las mejores condiciones para el teñido.

\section{Teñido con Picramnia gracilis}

Se sumergió un textil de algodón mordentado con alumbre (sal doble de Aluminio y Potasio) en una solución preparada con hojas frescas y molidas en una proporción 1:3, tres

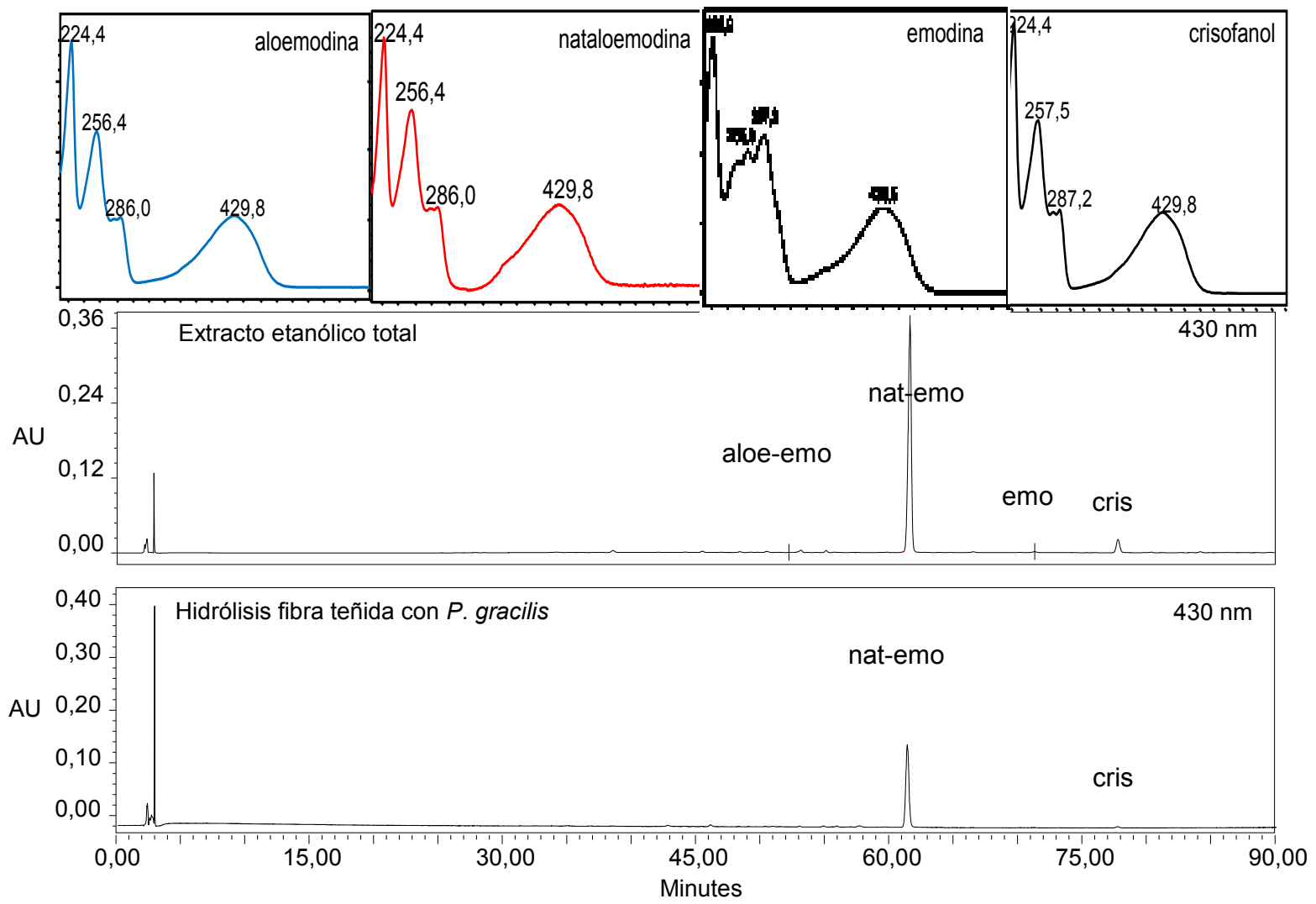

Figura 7. Análisis por cromatografía HPLC-DAD del extracto etanólico de hojas de Picramnia gracilis y del extracto tintóreo de fibras teñidas con las hojas de Picramnia gracilis. Cromatogramas a $430 \mathrm{~nm}$ y espectros ultravioleta-visible, UV-VIS. Aloe-emo: Aloemodina, nat-emo: nataloemodina, emo: emodina, cris: crisofanol. 

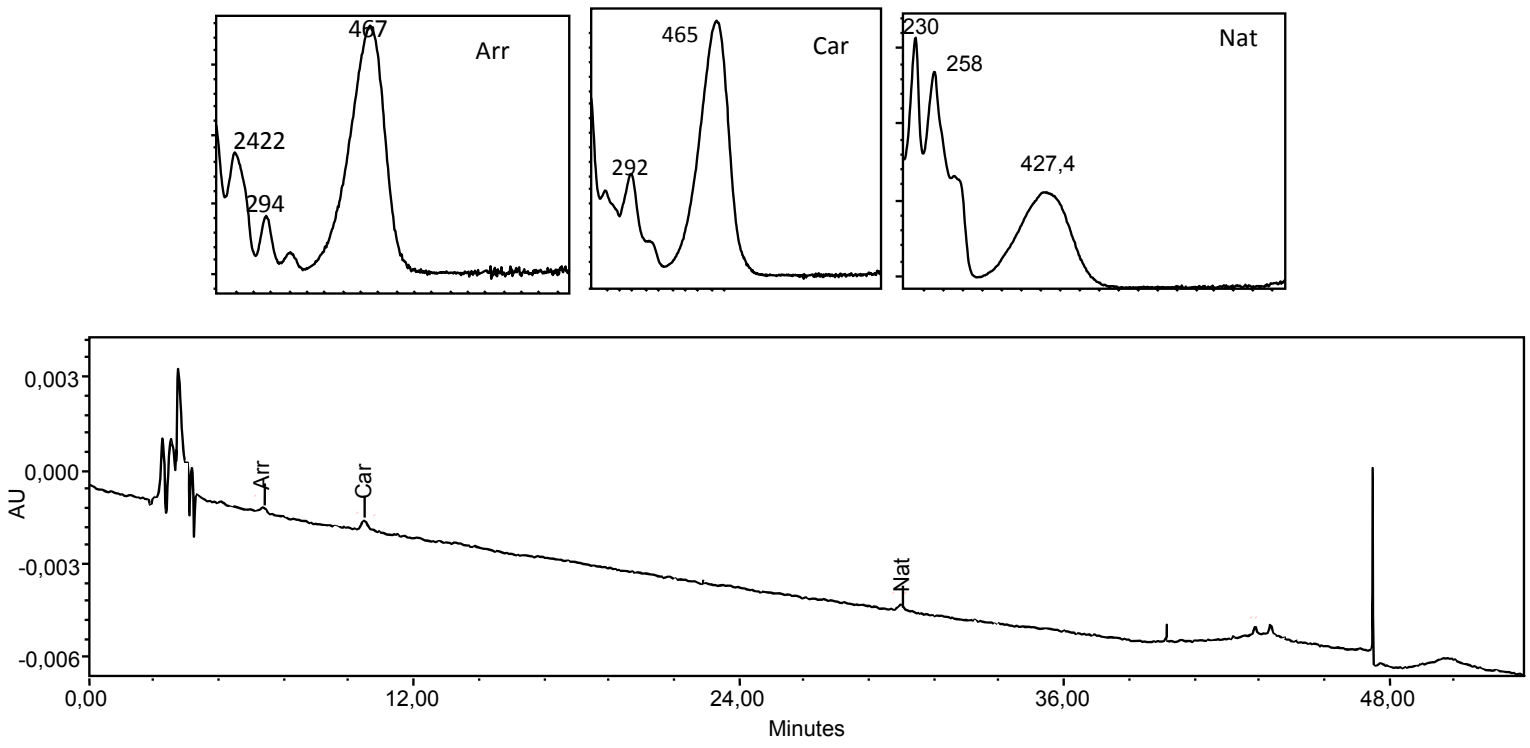

Figura 8. Cromatograma a $470 \mathrm{~nm}$ y espectros UV-VIS tomados de la muestra TE1916 .03.499, fibras marrón. Arr: Arrabidina, Car: Carajurina, Nat: Nataloemodina

veces el peso de las hojas respecto a una vez el peso de las fibras, durante 12 horas a a $20^{\circ} \mathrm{C}$. Se retiró el textil teñido y se lavó con abundante agua, hasta observar las aguas de lavado incoloras y se secó a la sombra. El resultado obtenido se observa en la tabla 1.

\section{Análisis del material etnográfico.}

En la tabla (4) se encuentra el registro de los objetos textiles analizados por código, el color y número de muestras tomadas, la clase de fibra, los compuestos colorantes determinados y la posible fuente de estos colorantes. Se tomaron muestras de fibras coloreadas de diez mochilas y de los hilos coloreados de una manta para un total de 16 muestras.

El material etnográfico se analizó con el mismo método y bajo las mismas condiciones que el material de referencia. En la Figura (8), se muestra el resultado del análisis por HPLC-DAD de las fibras coloreadas tomadas de la mochila TE 1916.03.499. Los resultados indican en las fibras marrón la presencia de: Fridericia chica (Sisita) y Picramnia gracilis (Uru). La identificación de F. chica se hizo de acuerdo a los espectros UV-VIS y los tiempos de retención de sus principales componentes descritos en (Devia et al. 2017). En la Figura (9), se observa el resultado del análisis de las fibras marrón de la mochila TE 1916.03.433 (Figura 4, C). En este caso la identificación del espectro UV-Vis de Orh, conocido como un producto de degradación en el teñido con especies de palo brasil, (Nowik, 2001), evidencia el empleo de una de estas especies. La presencia del ácido elágico se considera como indicio del uso de fuentes de taninos, posiblemente empleadas como mordiente durante el proceso de teñido.

En las fibras marrón de la muestra 1916.03.786 (Figura 10), se determinó indigo al lado de un colorante azul sintético. Es interesante observar el empleo del azul en los colorantes Ika de esta colección, porque en la actualidad no se dispone de información etnográfica sobre el empleo de fuentes de este color. Los tonos más similares a los logrados con el índigo son los grises oscuros que proporciona Mucuna sp. (Sikura) (Barranco Perez, 2010 ). Por lo que es muy posible que se trate de índigo sintético porque no se observan otras absorciones características del empleo de una indigófera como es el caso de la Indirubina en los materiales arqueológicos (Devia y Cardale de Schrimpff, 2017).

En las muestras color marrón de las mochilas en fibra de lana 1916.03.421 ( Figura 11C) y 1916.03.425, con diseños sobre fondo blanco la primera y habano la segunda, no se detectarón colorantes, por lo que el color observado muy posiblemente corresponde a al color natural de la lana, utilizada para reemplazar las fibras teñidas en los diseños.

De la mochila en algodón 1916.03.423 (Figura 11A) se tomó dos muestras de los diseños de lineas paralelas horizontales coloreadas sobre fondo blanco. En la muestra color purpúra se evidenció el empleo de Picramnia gracilis por la presencia de nataloemodina y de una fuente de taninos por el ácido elágico. En la muestra rosada los perfiles de los espectros UV-VIS observados son similares pero no iguales a diferentes categorias de colorantes sintéticos (de Keyser, 2017). 


\begin{tabular}{|c|c|c|c|c|}
\hline Código & Color de la muestra* & Fibra & Resultados & Fuente de colorantes \\
\hline 1916.03.421 & Marrón & Lana & No se detectaron colorantes & No se detectaron colorantes \\
\hline \multirow{2}{*}{1916.03 .423} & Púrpura & \multirow{2}{*}{ Algodón } & Nataloemodina y ácido elágico & $\begin{array}{l}\text { Picrammia gracilis y fuente } \\
\text { de taninos }\end{array}$ \\
\hline & Rosado & & $\begin{array}{l}\text { Colorantentes sintéticos no } \\
\text { identificados }\end{array}$ & $\begin{array}{l}\text { Colorantes sintéticos no } \\
\text { identificados }\end{array}$ \\
\hline 1916.03 .425 & Marrón & Lana & No se detectaron colorantes & No se detectaron colorantes \\
\hline 1916.03 .433 & Marrón & Algodón & $\begin{array}{l}\text { Brasileina, ácido elágico y } \\
\text { colorantes sin identificar }\end{array}$ & Palo brasil y fuente de taninos \\
\hline 1916.03 .499 & Marrón & Algodón & $\begin{array}{l}\text { Arrabidina, Carajurina, } \\
\text { Nataloemidona }\end{array}$ & $\begin{array}{l}\text { Fridericia chica y } \\
\text { Picramnia gracilis }\end{array}$ \\
\hline \multirow{3}{*}{1916.03 .685} & Marrón & \multirow{3}{*}{ Algodón } & $\begin{array}{l}\text { Nataloemodina y una quinona } \\
\text { desconocida }\end{array}$ & Picramnia gracilis \\
\hline & Rojo & & $\begin{array}{l}\text { Colorantes con UV-VIS similar } \\
\text { al de los antocianos }\end{array}$ & Colorantes sin idenificar \\
\hline & Habano & & Berberina, carajurina y brasileina & $\begin{array}{l}\text { Berberis meollacensis, } \\
\text { Fridericia chica y palo brasil }\end{array}$ \\
\hline 1916.03.756 & Marrón & Fique & Nataloemodina & Picramnia gracilis \\
\hline \multirow{3}{*}{1916.03 .758} & Habano & \multirow{3}{*}{ Fique } & Nataloemodina & Picramnia gracilis \\
\hline & Marrón & & $\begin{array}{l}\text { Nataloemodina y derivados } \\
\text { de la apigenina }\end{array}$ & $\begin{array}{l}\text { Picramnia gracilis y derivados } \\
\text { de la apigenina }\end{array}$ \\
\hline & Amarillo & & Berberina y ácido elágico & $\begin{array}{l}\text { Berberis meollacensis y fuente } \\
\text { de taninos }\end{array}$ \\
\hline 16.03 .786 & Blanco-Amarillento & Algodón & $\begin{array}{l}\text { Indigotina y colorante } \\
\text { sintético azul }\end{array}$ & Índigo y colorante sintético azul \\
\hline \multirow{2}{*}{$1916.03 \cdot 745$} & Marrón & \multirow{2}{*}{ Algodón } & Ac. elágico y berberina & $\begin{array}{l}\text { Berberis meollacensis y fuente } \\
\text { de taninos }\end{array}$ \\
\hline & Marrón rojizo & & Ac. elágico y berberina & $\begin{array}{l}\text { Berberis meollacensis y fuente } \\
\text { de taninos }\end{array}$ \\
\hline
\end{tabular}

*Muestras tomadas de los diseños de las mochilas, excepto para las muestras de la manta 1916.03.745

Tabla 4. Identificación de colorantes y fuentes de colorantes en las muestras analizadas de la colección Gustav Bolinder.

P. gracilis está presente, como ya se discutió, en las fibras de algodón marrón de la muestra 1916.03.499 y en las del mismo color en fique de la muestra 1916.03.756 (Figura 4B) y en la muestra color habano 1916.03.758. (Figura 11B). La combinación de los colorantes de esta especie con otras fuentes de colorantes se pueden observar en la muestra de algodón marrón 1916.03.499, donde la presencia de las deoxiantocianidinas arrabidina y carajurina son indicios de una mezcla con los colorantes provenientes de Fridericia chica y en el caso de las fibras en fique color marrón 


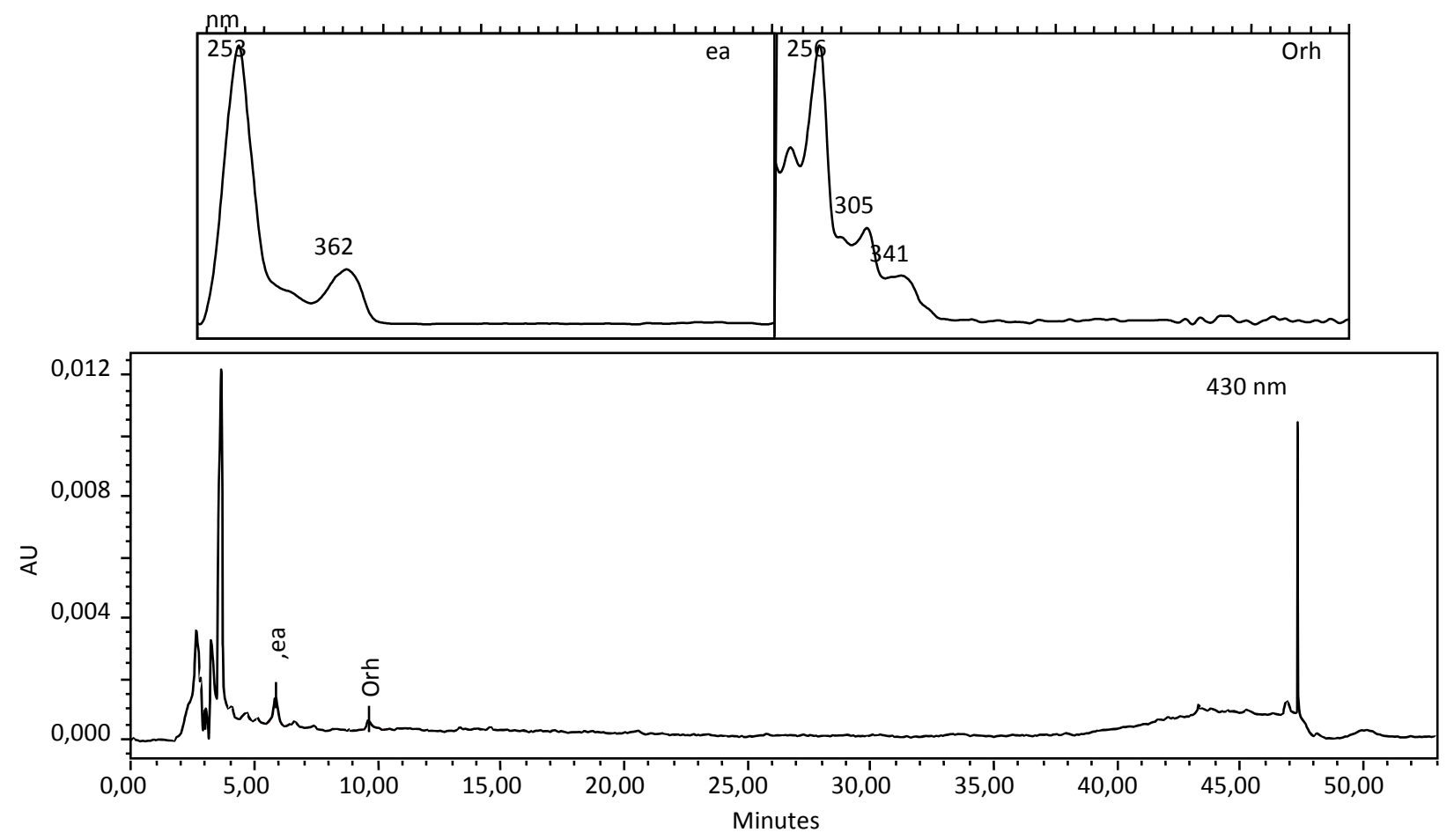

Figura 9. Cromatograma a $430 \mathrm{~nm}$ y espectros UV-VIS tomados de la muestra TE 1916 .03.433, fibras marrón. Orh: producto de degradación en el teñido con especies de palo brasil, ea: ácido elágico.

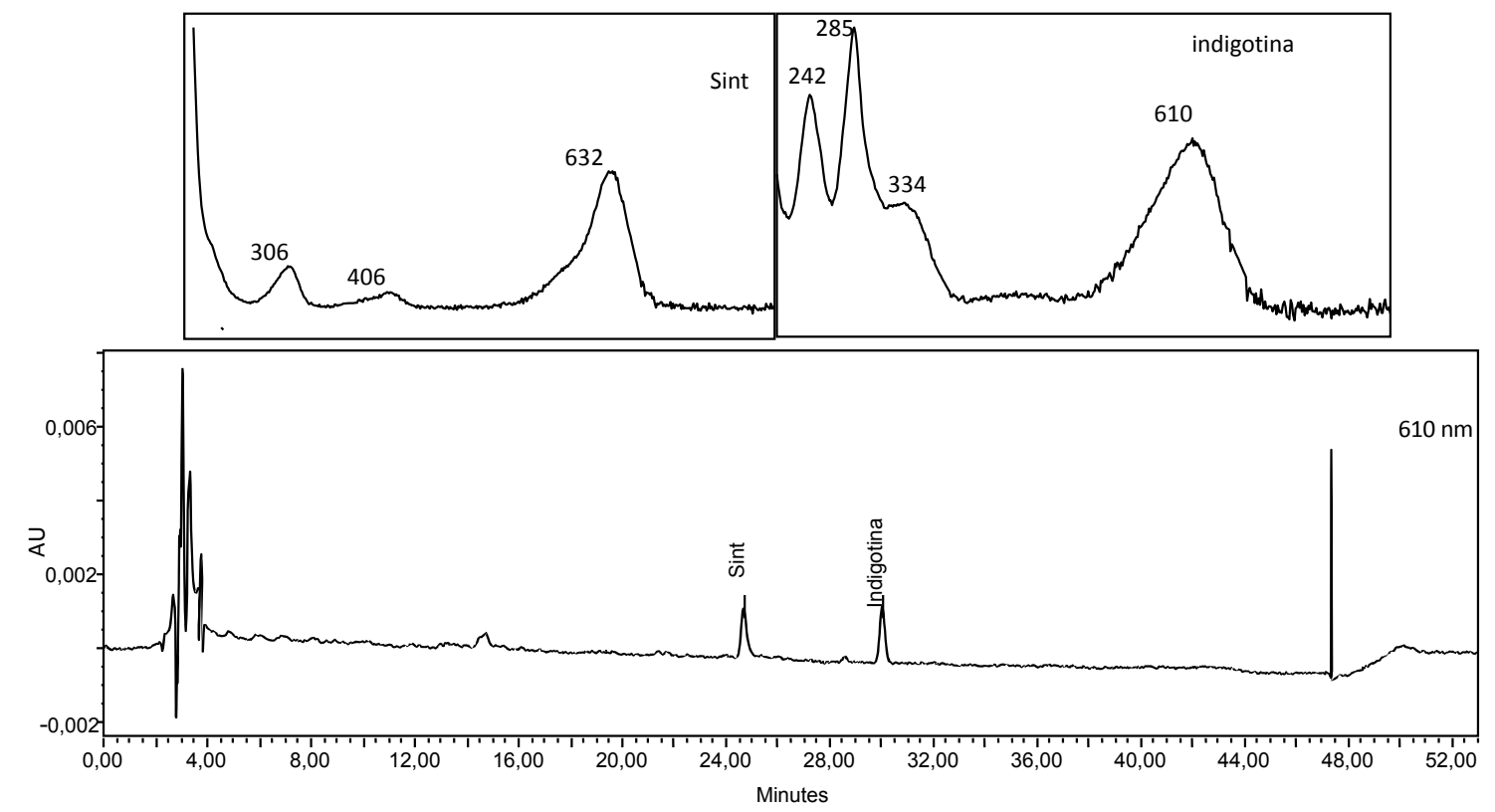

Figura 10. Cromatograma a $610 \mathrm{~nm}$ y espectros UV-VIS tomados de la muestra TE 1916 .03.786, fibras marrón. Sint: colorante sintético sin identificar. Indigotina: Indigotina. 

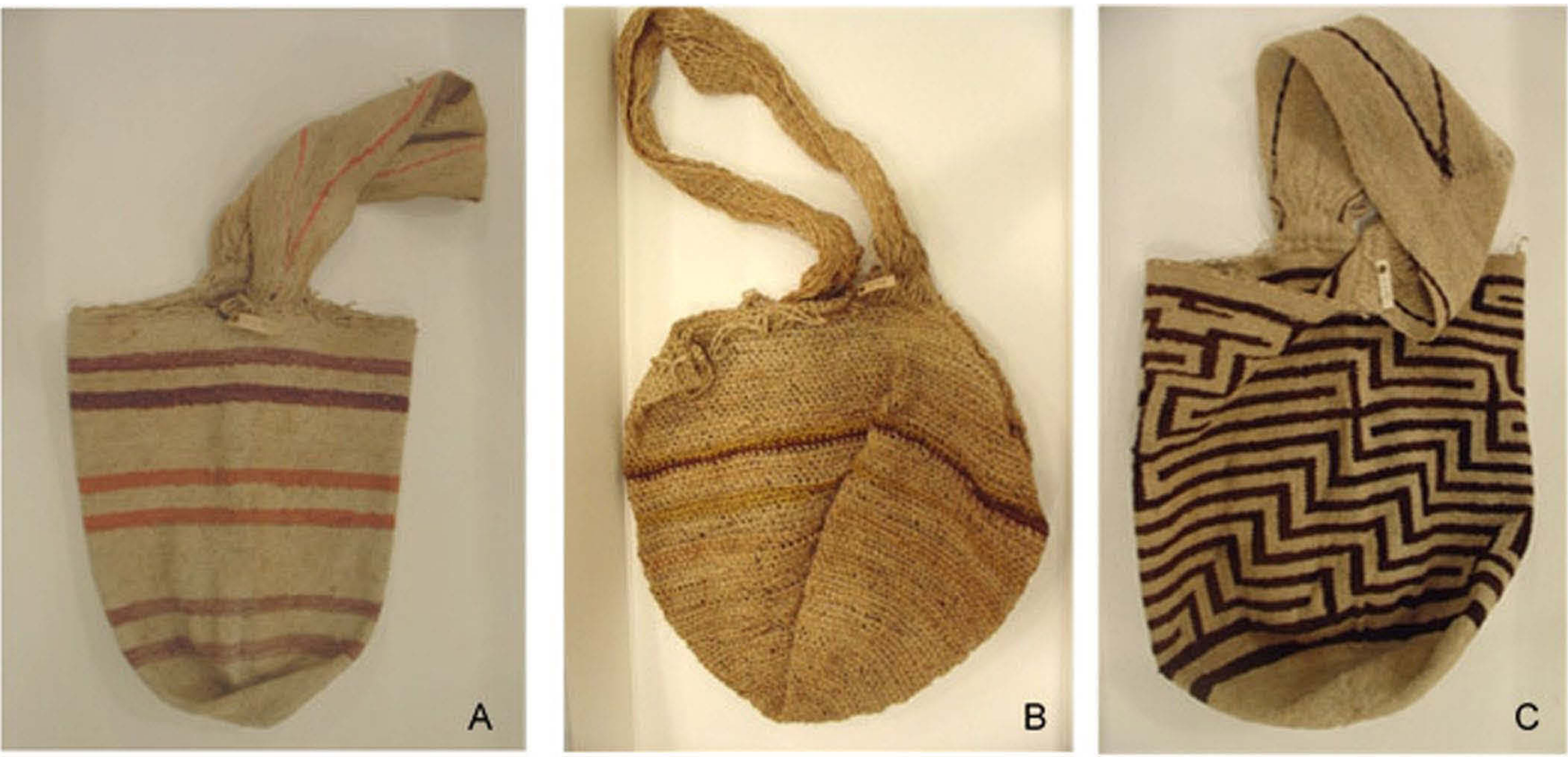

Figura 11. Mochilas Ika, Världskulturmuseet, Gotemburgo, Suecia, A) En la muestra de algodón color purpúra 1916.03.423, se determinó Picramnia gracilis con una fuente de taninos y en la muestra de algodón rosada posiblemente colorantes sintéticos. B) En las fibras de fique amarillas 1916.03.758 se determinó Berberis meollacensis C) En la mochila en lana 1916.03.421, los diseños fueron realizados con el color de la lana natural.

1916.03.758, por la presencia de derivados de la apigenina de una fuente de flavonas como Chaetolepis alpina.

Otras mezclas de fuentes de colorantes se pueden observar entre Fridericia chica, Berberis meollacensis y palo brasil en la muestra en algodón color habano 1916.03.685. El palo brasil también se observa con una fuente de taninos en la muestra de algodón marrón 1916.03.433, en el cromatograma de la (Figura 9). La atribución de Berberis meollacensis en tres de las muestras estudiadas, algodón color habano 1916.03.685, fique amarillo 1916.03.758 y algodón marrón y marrón rojizo en 1916.03.499, se hizo por la determinación en el análisis de la Berberina, alcaloide característico de ese género de plantas (Manosalva et al. 2014).El género Berberis de amplia distribución en las regiones tropicales y en el sur de Europa y Asía, se conoce por el empleo de sus especies como plantas ornamentales, por sus propiedades medicinales y en algunas regiones del mundo como fuentes de colorantes amarillos (Zhang et al. 2010). En Colombia existe cerca de 45 especies, entre las cuales Berberis meollacensis es considerada endémica de la Sierra Nevada de Santa Marta (Camargo1981).

Algunas caracteríscas que se manifiestan en los procedimientos de teñido es el empleo de sustancias tánicas al lado de los colorantes de Picramnia gracilis y Berberis meollacensis. El empleo de mezclas de diferentes fuentes de colorantes para la obtención de un determinado color en las fibras y el uso de fuentes naturales conocidas al lado de posibles fuentes naturales desconocidas como en la muestra 191603.685. Empleo de fibras teñidas con colorantes naturales y de posibles colorantes sintéticos para la elaboración de los diseños, muestra 1916.03.433 de la figura (4C).

\section{Observaciones finales}

En las mochilas ika de la colección etnográfica realizada por Gustav Bolinder se pudo determinar el empleo de fuentes de colorantes vegetales.

Entre las fuentes de colorantes vegetales se encuentra: Picramnia gracilis, Fredericia chica, Berberis meollacensis, especies de palo brasil y de taninos. Picramnia gracilis fue la especie determinada en un grupo mayor de muestras y presenta además en la colección evidencias de su empleo en una muestra de la planta y en fibras de algodón y fique teñidas. Las fuentes de taninos en el teñido pueden ser Weinmannia pinnata, que tiene en la colección muestras de algodón teñidas y de la planta y Mucuna sp. para la que también existe fibras de algodón teñidas en la colección. Fredericia chica y especies de palo brasil son fuentes de colorantes comunes con los colorantes prehispánicos.

En la colección de Gustav Bolinder se puede apreciar la influencia de la misión de los capuchinos, en la sustitución de los materiales y técnicas ancestrales para la elaboración 
de las mochilas, como ha sido el uso de las fibras de lana por las de algodón y la elaboración de los motivos con fibras del color natural de la lana, disminuyendo el teñido del algodón. Se observa también evidencias del empleo de colorantes sintéticos. Es importante iniciar el estudio sistemático de los colorantes sintéticos, que puede proporcionar información sobre su introducción en el país.

La lista de las especies tintóreas utilizadas por la comunidad Ika de Nabusimake pasará a ampliar la lista del material de referencia para el estudio de los colorantes en los textiles prehispánicos Los objetos de esta colección contienen información valiosa sobre otras fuentes de colorantes naturales que se debe continuar investigando y sobre el uso de los colorantes sintéticos y su introducción en el país.

\section{Agradecimientos}

Asociación de mujeres Ika, Akitinkuchua, Nabusimake, Pueblo Bello, (Cesar).

Camilo Niño, écologo, mienbro de la communidad Ika.

Estudiantes del grupo Colorantes Naturales de la carrera de Licenciatura en Química de la Universidad Distrital Francisco José de Caldas, Bogotá, Colombia.

Carlos Devia, asesor en el proyecto realizado con la comunidad IKA, profesor -investigador de la Universidad Javeriana.

Jan Amnehall, centro de documentación del Världskulturmuseet en Gotemburgo.

Adriana Muñoz, curadora del Världskulturmuseet en Gotemburgo.

Manuela Fischer, curadora, Museo Etnológico, Berlín.

Fundación de investigaciones Arqueológicas, FIAN, cofinanciadora del proyecto

\section{Referencias citadas}

Aroca Araújo, Armando.

2009 Una propuesta de enseñanza de geometría desde una perspectiva cultural. Caso de estudio: Comunidad Indígena Ika - Sierra Nevada de Santa Marta. Universidad del Valle, instituto de educación y pedagogía, Santiago de Cali.

Barranco Pérez, Wilmar.

2010 Especies vegetales de uso antiofídico en las estribaciones de la Sierra Nevada de Santa Marta: inventario etnobotánica y evaluación biológica. Tesis de maestría. Facultad de Ciencias Agrarias. Universidad Nacional de Colombia, sede Medellín.
Bolinder, Gustaf.

1925 Die Indianer der tropischen Schneegebirge: Forschungen im nordlichsten Sudamerika. Editorial: Strecker \& Schroder, Stuttgart.

Camargo, Luis A.

1981 Especies nuevas del género Berberis. Caldasia. 13, 62, 203-223.

Cardale de Schrimpff, Marianne.

1972 Techniques of hand-weaving and allied arts in Colombia (with particular reference to indigenous methods and, where possible, including dyeing, fibre preparation and related subjects). I: 205-214. University Microfilms International.

de Keijser, Mathijs and Maarten R. van Bommel.

2017 New colours: the history and analysis of fluorescein, eosin, erythrosine, rodhamine and some of their derivatives. The diversity of Dyes in History and Archaeology Edited by Jo Kirby Archetype Publications Ltda, pp. 326-338. London.

Devia, Beatriz, Marianne Cardale de Schrimpff, Carlos Devia y

Camilo Niño Izquierdo.

2016 Aproximación al conocimiento de los colorantes en la comunidad indígena ika de la Sierra Nevada de Santa Marta (departamento del Cesar, Colombia). Nuevo mundo Mundos Nuevos. https://journals. openedition.org/nuevomundo/69205 consultado el 10 de agosto 2019 .

Devia, Beatriz y Marianne Cardale de Schrimpff.

2017 Los textiles precolombinos de Nariño y del Ecuador: similitudes y diferencias en colorantes, técnicas $y$ diseños. Cuestiones \& Diálogos, 1. Instituto Colombiano de Antropología e Historia. Bogotá.

Devia, Beatriz, Marianne Cardale de Schrimpff, Monique Tits and Jan Wouters.

2017 Arrabidaea chica: 3-deoxyanthocyanidins and their degradation products found in Colombian archaeological textiles of the 1oth-17 th centuries. The diversity of Dyes in History and Archaeology Edited by Jo Kirby Archetype Publications Ltd, pp. 54-68. London.

Devia Castillo Beatriz, Oscar J. Yepez, Mónica A. Rey, Diego A. Silva.

2019 Primer reporte de antraquinonas en hojas de Picramnia gracilis Tul. Revista Cubana de Química. 31:3 Santiago de Cuba sept.-dic. versión On-line ISSN 2224-5421.

Freire-González, Rosa y Marlén Vistel-Vigo

2015 Caracterización fitoquímica de la Curcuma longa L. Rev. Cubana Quím. 27(1): 9-18. 
Giraldo Jaramillo, Natalia.

2014 Camino en espiral-Yo'sa ingunu: territorio sagrado y autoridades tradicionales en la comunidad indígena Iku (Arhuaco) de la Sierra Nevada de Santa Marta. Colombia. Colección Laurea. Universidad de Caldas. Manizales, Colombia.

Guinot Pauline, Aline Rogé, Annick Gargadennec, Michel García, Daniel Dupont, Edwige Lecoeur, Laurent Candelier y Claude Andary.

2006 Dyeing plants screening: an approach to combine past heritage and present development. Society of Dyes and Colourist, Color. Technol., 122: 93-101.

Klinger, William.

1998 Estudio de las Especies Promisorias Productoras de Colorantes en el Trapecio Amazónico. COLOMBIA Forestal 5 (11): 15-33.

Manosalva Loreto, Ana Mutis, Juan Díaz, Alejandro Úrzua,Victor Fajardo y Andrés Quiroz.

2014 Identification of isoquinoline alkaloids from Berberis microphylla by HPLC ESI-MS/MS. Bol Latinoam Caribe Plant Med Aromat 13 (14): 324-335.

Niño Izquierdo Camilo.

2011 Organización y uso del territorio por la comunidad Indígena Arhuaca de Nabusímake Sierra Nevada de Santa Marta (Colombia). Trabajo inédito.Trabajo de investigación presentado como requisito para optar el título de Ecólogo. Facultad de Estudio Ambientales y Rurales, Pontificia Universidad Javeriana. Bogotá.

Nowik, Witold.

2001 The possibility of differentiation and identification of red and blue 'soluble' dyewoods. Dyes in History and Archaeology 18: 129-144.

Patiño, Victor.

1975-1976 Historia de la Cultura Material en la América Equinoccial. Fondo de Cultura Económica. VI(XIII): 252-255.
Reichel-Dolmatoff, Gerard.

1949-1950 Los Kogi, Revista del Instituto Etnológico Nacional. 1949-1950. I: 259 y II: 87.

Riveros, Luisa y Lylyams Inga.

2014 Caracterización química de los extractos colorantes de siete especies forestales del fijador natural, utilizado en 19 comunidades indígenas de Ucayali, Perú. Ciencia Amazónica (Iquitos). 4(1): 29-36.

Robledo Sara, Wilson Cardona, Karen Ligardo, Jéssica Henao, Natalia Arbeláez, Andres Montoya, Fernando Alzate, Juan Pérez, Victor Arango, Ivan Vélez y Jairo Sáez.

2015 Antileishmanial Effect of 5,3'-Hydroxy-7,4'dimethoxyflavanone of Picramnia gracilis Tul. (Picramniaceae) Fruit: In Vitro and In Vivo Studies, Advances in Pharmacological Sciences 1:1-8.

Torres, Jorge H.

1983 Contribución al conocimiento de las plantas tánicas registradas en Colombia. Bogotá: Instituto de Ciencias Naturales -Museo de Historia Natural, Biblioteca José Jeronimo Triana, No. 3. Universidad Nacional de Colombia - COLCIENCIAS. Bogotá.

Uribe, Carlos.

1990 Nosotros los hermanos mayores: Continuidad y cambio entre los Kaggaba de la Sierra Nevada de Santa Marta. Bogotá Universidad de los Andes.

Zhang, Xian, Chika Mouri, Masayuki Mikage and Richard Laursen.

2010 Preliminary Studies Toward Identification of Sources of Protoberberine Alkaloids used as Yellow Dyes in Asian Objects of Historical Interest. Studies in Conservation 554: 177-185. 


\title{
Colecciones textiles etnográficas del Gran Chaco Sudamericano del Museo Etnográfico “J. B. Ambrosetti” y el estudio de su materialidad: un desafío a la mirada occidental sobre los otros no-occidentales
}

\author{
Mariana Alfonsina Elías ${ }^{1}$ \\ 1. Área de Colecciones Etnográficas, Museo Etnográfico “J. B. Ambrosetti”, Facultad de Filosofía y Letras, Universidad de \\ Buenos Aires. E-mail: alfonelias75@gmail.com
}

\begin{abstract}
Resumen
El Museo Etnográfico “J. B. Ambrosetti” (Facultad de Filosofía y Letras, Universidad de Buenos Aires) guarda en su acervo un conjunto amplio, diverso y poco conocido de producciones textiles de distintos pueblos originarios del Gran Chaco Sudamericano. Las mismas han ingresado a la institución entre fines del siglo XIX y las primeras cuatro décadas del siglo XX.

El estudio que vengo desarrollando de varios aspectos de la materialidad de los objetos textiles que conforman dichas colecciones- materia prima, técnicas/ estructuras textiles, diseños, colores, evidencias de uso, etc.- ha implicado la necesaria problematización de nuestra mirada occidental y de nuestras representaciones sobre los pueblos "no- occidentales" que los produjeron y los usaron en el contexto temporal e histórico mencionado.

En este sentido, en este trabajo me interesa dar cuenta de un corpus particular de objetos textiles etnográficos de los pueblos originarios del Gran Chaco Sudamericano presentes en las colecciones abordadas. El estudio de distintos aspectos de su materialidad pone en cuestión, siguiendo a James Clifford, la categoría de lo "típicamente tradicional" que ha guiado a los "recolectores de cultura antropológicos" y el ocultamiento, en el relato del museo occidental moderno, de sus historias específicas de producción y adquisición.
\end{abstract}

Palabras claves: Textiles, Gran Chaco, colecciones etnográficas, apropiación, mercantilización.

\begin{abstract}
The Ethnographic Museum “J. B. Ambrosetti” (Faculty of Philosophy and Letters, University of Buenos Aires) keeps in its collection a wide, diverse and little-known set of ethnographic textiles, products of different peoples originating in the South American Grand Chaco. They have entered the institution between the end of the 19th century and the first four decades of the 2oth century.

My study of several aspects of the materiality of the textile artifacts that make up these collections - raw material, textile techniques / structures, designs, colors, evidence of use, etc. - has implied a necessary problematization of our western gaze and of our representations about the "non-western" peoples that produced them and used them in this temporal and historical context.

In this sense, I am interested in giving an account of the particular corpus of ethnographic textile objects of the original peoples of the South American Grand Chaco present in the collections. The study of different aspects of their materiality calls into question, following James Clifford, the category of "typically traditional" that has guided "anthropological culture collectors" and concealment, in the narrative of the modern western museum, of its specific stories of production and acquisition.
\end{abstract}

Keywords: Textiles, Gran Chaco, ethnographic collections, appropriation, commodification.

DOI: $10.32873 /$ unl.dc.zea.1218

Published in PreColumbian Textile Conference VIII / Jornadas de Textiles PreColombinos VIII, ed. Lena Bjerregaard and Ann Peters

(Lincoln, NE: Zea Books, 2020). https://digitalcommons.unl.edu/zeabook/ 


\section{Résumé}

Le musée ethnographique "J. B. Ambrosetti” (Faculté de Philosophie et des Lettres, Université de Buenos Aires) conserve dans ses collections un ensemble vaste, divers et peu connu de textiles ethnographiques, produits par différentes personnes originaires du Gran Chaco sud-américain. Ils ont été intégrés au musée entre la fin du XIX siècle et les quatre premières décennies du XX siècle.

Mon étude sur les différents aspects de la matérialité des textiles qui composent la collection -matière première, techniques/structures textiles, motifs, couleurs, traces d'utilisation, etc. - a impliqué la problématisation de notre regard occidental et de nos représentations des peuples "non-occidentaux" qui les produisent et les utilisent dans ce contexte temporel et historique.

En ce sens, il m'intéresse de prendre en compte un corpus particulier de textiles ethnographiques des peuples du Gran Chaco sud-américain présents dans la collection. L'étude sur les divers aspects de leur matérialité remet en cause, en accord avec James Clifford, la catégorie du "typiquement traditionnel" qui a guidé les "collectionneurs d'anthropologie culturelle" et la dissimulation, dans le récit du musée moderne, de leurs histoires spécifiques de production et d'acquisition.

Mots-clés: Textiles, Gran Chaco, collections ethnographiques, appropriation, marchandisation.

El Museo Etnográfico “J. B. Ambrosetti” (Facultad de Filosofía y Letras, Universidad de Buenos Aires) guarda en su acervo un conjunto amplio, diverso y poco conocido de objetos textiles de distintos pueblos originarios del Gran Chaco Sudamericano que ingresaron al mismo entre fines del siglo XIX y las primeras cuatro décadas del siglo XX. El estudio de distintos aspectos de su materialidad ha implicado una necesaria problematización de nuestra mirada occidental y de las representaciones de los pueblos no-occidentales que los produjeron y los usaron así como de dichos objetos textiles. La materialidad de los mismos en relación con sus historias de recolección y producción pone en cuestión la categoría de lo "típicamente tradicional" que ha guiado a los "recolectores de cultura antropológicos" así como el ocultamiento, en el relato del museo occidental moderno, de sus historias específicas de producción y adquisición (Clifford 1995: 274), y evidencia las relaciones históricas de poder tras las mismas (Clifford 1995: 262).

Este ocultamiento de las historias específicas de la producción y adquisición se observa en la forma en que generalmente se piensan y estudian los objetos etnográficos producidos por los otros no-occidentales, exigiendo que los mismos respondan a un criterio de autenticidad basado en dos aspectos: producidos para ser específicamente usados por las sociedad en las que se produjeron y con materiales "propios" de aquellas sociedades, quedando ocultas las relaciones con Occidente, es decir, con la instancia colonial y hegemónica.

En este trabajo desarrollaré dos casos de objetos textiles producidos por distintos pueblos indígenas del Gran Chaco Sudamericano, de las primeras décadas del siglo XX, y pertenecientes a las colecciones etnográficas del Museo Etnográfico “J. B. Ambrosetti”, cuyas evidencias materiales cuestionan los dos aspectos del criterio de autenticidad que he mencionado en el párrafo anterior. En primera instancia desarrollaré el caso de un corpus de bolsas de lana cuya técnica de elaboración no integra el catálogo de técnicas consideradas "tradicionales" para la producción de bolsas entre los pueblos originarios del Gran Chaco. En segundo lugar, me centraré en una colección de fajas compradas por el Museo Argentino de Ciencias Naturales "Bernardino Rivadavia” al etnógrafo suizo Alfred Métraux en el año 1934, cuyas escasas evidencias de uso nos permite preguntarnos si su producción ha estado sólo destinada a su uso dentro de la sociedad que las creó o también a su venta a los "blancos".

\section{Marco teórico}

En su libro Dilemas de la cultura, James Clifford se concentra en la recolección de objetos por parte de los museos, abordando críticamente ciertas características de dicha práctica. Citando el estudio de Stewart On longing, señala que éste muestra el modo que las colecciones, y en forma más notable, los museos, crean la ilusión de la representación adecuada de un mundo arrancando primero los objetos de sus contextos específicos y haciendo que ellos "representen" totalidades abstractas y aisladas: una máscara bambara, transformándose en una metonimia etnográfica de la cultura bambara. El sistema de clasificación para almacenar y exhibir los objetos oculta las historias específicas de la producción y apropiación de los mismos. Stewart argumenta que en el museo occidental moderno "la ilusión de una relación entre cosas toma el lugar de una relación social”, de este modo se ocultan las relaciones históricas de poder tras el trabajo de la adquisición (Clifford 1995: 262). En estrecha relación con lo anterior, Clifford señala: 
"Los recolectores de cultura antropológicos han reunido lo que parece ser típicamente "tradicional”, lo que por definición se opone a la modernidad. Desde una compleja realidad histórica (que incluye los encuentros etnográficos actuales), seleccionan lo que da forma, estructura y continuidad a un mundo. Lo que es híbrido o "histórico" en un sentido emergente ha sido recolectado y presentado como sistema de autenticidad con menos frecuencia." (Clifford 1995: 274)

En estos párrafos de James Clifford se señalan algunas problemáticas sobre cómo Occidente representó a través de las colecciones de sus museos a los otros-no occidentales: por un lado dando prioridad a lo considerado "típicamente tradicional" (puro), aislando, en sus narrativas, a los objetos de sus contextos coloniales de recolección y también de producción, y de esta manera ocultando la relaciones sociales, históricas de poder inscriptas en los mismos.

Distintos estudios antropológicos y especializados en textiles, han puesto en cuestión la categoría de lo "tradicional" y puro para la representación y el reconocimiento de las culturas no occidentales, dando relevancia a las categorías de "apropiación” y “agencia” en la producción de su cultura material.

Guillaume Boccara habla de una "antropología diacrónica” que rechaza la perspectiva de la "pureza original” para pensar las culturas como objetos de reelaboración permanente, rebatiendo la concepción de que una sociedad, cuando adopta un elemento de otra, sufre necesariamente un proceso de aculturación impuesta, deculturación o de contaminación. Señala que “(...) las culturas dominadas utilizan significantes de las sociedades dominantes para producir otros significados. De modo que resulta equivocado pretender explicar la transformación de una tradición como si se tratase de una extinción, de una decadencia o de una contaminación" (Boccara 2005: 10-11). En estrecha relación con estos planteos, Janet Catherine Berlo sostiene que el "arte textil" de Latinoamérica no es una mera respuesta pasiva y defensiva a cinco siglos de colonialismo y propone considerar los procesos de apropiación implicados, posicionando a los pueblos indígenas como agentes activos de sus propios estilos artísticos y no como simples recipientes pasivos de una cultura hegemónica que constantemente erosiona y socava su cultura "tradicional" (Berlo 1996: 452-453).

En estos abordajes, mediante la consideración crítica de los conceptos de aculturación (Boccara 2005) y el acento en los procesos de apropiación (Berlo 1996), juega un rol central la noción de agencia de los indígenas en sus relaciones con las sociedades coloniales, pensándolos no como sujetos pasivos frente a una cultura hegemónica sino como sujetos activos que a través de cada una de sus prácticas sociales resignifican y se apropian de aquello que proviene de dicha cultura hegemónica. Siguiendo a Sherry Ortner, “[...] está en juego la importancia de cuestionar el efecto totalizador de formaciones como el colonialismo o el racismo y de tratar de observar la manera en la que los actores dominados conservan la 'agencia' (...)” (Ortner 2016: 170).

Se debe señalar que, estas propuestas, a su vez, permiten dar cuenta de las relaciones históricas de poder en las que se producen y produjeron los objetos de distintos pueblos no-occidentales. Pese al interés señalado por Clifford de los recolectores de cultura antropológicos por lo "puro" y "tradicional", las colecciones etnográficas de distintos museos están integradas por objetos "híbridos” más comúnmente de lo que podemos llegar a imaginar. Esto se evidencia en el estudio de distintos aspectos de su materialidad; son necesarias herramientas teóricas para poder abordarlas.

En relación con esto último, nos interesan los planteamientos de Ruth Phillips y Christopher Steiner cuando señalan que los objetos de los otros culturales, desde fines del siglo XIX, han sido apropiados principalmente dentro de dos categorías: el artefacto o espécimen etnográfico y el trabajo de arte, y que ambas clasificaciones (construcciones) enmascararon "lo que se había convertido, hacia fines del siglo XVIII, en uno de los rasgos más importantes de los objetos: su funcionamiento como mercancías (commodities) circulando en el espacio discursivo de una economía capitalista emergente." (Phillips y Steiner 1999: 3) Estos autores señalan que ha habido un sorpresivo silencio sobre los procesos de mercantilización en las historias del arte estándar y en las etnografías (Phillips y Steiner 1999: 3). Estos procesos de mercantilización relacionados con la producción, uso y circulación de los objetos de los otros no-occidentales han sido uno de los aspectos relevantes de la extensión global del poder colonial occidental; sin embargo, tanto los estudiosos como los consumidores occidentales los han obviado y, donde el hecho de la mercantilización podía ser ocultado, los objetos ocupaban las categorías del esquema binario de arte y artefacto. Mientras que, cuando la naturaleza mercantil era muy evidente, los objetos eran calificados de inauténticos o falsos (Phillips y Steiner 1999: 4).

Considero que abordar actualmente colecciones etnográficas, recolectadas a principios del siglo XX, requiere tener en cuenta estas problematizaciones puesto que también nos plantea y nos cuestiona sobre las representaciones que los profesionales de museos antropológicos e investigadores occidentales hemos construido respecto a los otros nooccidentales y su cultura material. 


\section{Metodología}

Un medio para el estudio de estas problemáticas es el abordaje de distintos aspectos de la cultura material de los otros no-occidentales guardada en los museos, ya que a través de la aplicación de distintos métodos de análisis de la misma se pueden encontrar indicios de estas realidades híbridas, coloniales y complejas de producción, uso y consumo.

En el caso específico de los textiles, nuestro abordaje de las colecciones textiles del Gran Chaco Sudamericano del Museo Etnográfico “J. B. Ambrosetti” se basó, en primera instancia, en el análisis de distintos aspectos, a saber: materias primas, estructuras textiles/ técnicas, formatos, medidas, configuraciones de diseños, ubicación de los mismos en el campo textil y colores. Por otro lado, se llevó a cabo el relevamiento de las evidencias de uso presentes en ellos. Se ha trabajado con fichas de registro de textiles específicas y se ha organizado la información obtenida en archivos Excell que permitieran su puesta en comparación y recuperación de la misma.

Simultáneamente, se ha llevado a cabo el relevamiento bibliográfico, de fuentes y diverso tipo de documentación escrita y visual de archivo y catálogos de ingreso originales de los objetos al museo con el fin de recuperar información sobre el uso y la producción de los mismos entre las poblaciones indígenas a las que son atribuidos y sobre las historias de recolección e ingreso al museo. Esto nos permitió recuperar los contextos históricos de recolección y formación de las colecciones, entre otras cosas.

\section{Bolsas tricotadas de lana}

A partir del estudio de las estructuras textiles presentes en los objetos tejidos de distintas poblaciones indígenas de la región Gran Chaco Sudamericano que se encuentran en las colecciones etnográficas del Museo Etnográfico "J. B. Ambrosetti", he podido diferenciar un corpus de bolsas que presenta una estructura textil particular a causa de su probable procedencia y por su diferenciación respecto a las estructuras textiles presentes en objetos con funciones similares.

Me refiero a un corpus de 107 bolsas de lana atribuidas en su mayoría a grupos Wichí. La particularidad que presentan es que en el recipiente de las mismas he registrado una estructura de tricotado (knitting en Emery 2009: 40). ${ }^{2}$ Esto las diferencia de otras bolsas de formato cuadrangular, elaboradas la mayoría de ellas con caraguatá/ chaguar ${ }^{3}$ en tejido de malla (ver looping en Emery 2009: 31) (Figura 1). ${ }^{4}$ Este último tipo de bolsas son las que han merecido un tratamiento más extendido por parte de los estudiosos en diversas publicaciones debido a ser consideradas una producción "tradicional” de los pueblos indígenas del Gran Chaco.

Este corpus de bolsas de lana ha ingresado en su mayoría, al Museo Etnográfico “J. B. Ambrosetti”, a través de la donación de las colecciones etnográficas y arqueológicas del Museo Argentino de Ciencias Naturales "Bernardino Rivadavia” en el año 1947. Desarrollaremos brevemente la historia de ingreso de éstas a este último museo, intentando dar cuenta de una parte de sus contextos de recolección y formación.

Las bolsas más tempranas que registré con esta estructura textil corresponden a la colección formada por el etnógrafo Enrique Palavecino en su expedición del año 1929. Una de ellas atribuidas al pueblo Pilagá del oeste de Formosa (Argentina), nueve a los Wichí de Las Lomitas (provincia de Formosa, Argentina) (Catálogo de ingreso de objetos al Museo Argentino de Ciencias Naturales "Bernardino Rivadavia”, 1929-1945).

Cinco bolsas del corpus fueron recolectadas por este mismo etnógrafo en su expedición del año 1935, tres de ellas entre los Wichí de Bazán (Formosa, Argentina) y dos entre el grupo Wo Pelaj (Wichí) en la provincia de Salta (Argentina) (Catálogo de registro de objetos al Museo Argentino de Ciencias Naturales "Bernardino Rivadavia”, 1929-1945).

En el año 1937, Palavecino realiza otra expedición al Chaco argentino, y recolecta, en la localidad de Embarcación (Salta, Argentina), 63 bolsas atribuidas a los "Matacos del Pilcomayo" (Wichí). En una nueva expedición etnográfica del año 1938, Palavecino forma una colección que

2 Decidimos usar el término tricotar en lugar de knitting tal como lo propone Ann P. Rowe en "Términos textiles en castellano" (Rowe 20o6: 448). El tricotado integra el conjunto de estructuras textiles formadas por un elemento continuo que trabaja consigo mismo formando hileras horizontales; cada lazada es hecha con la parte del hilo más cercana al borde del tejido y es llevada a través de una lazada anterior. El trabajo, entonces, avanza hacia arriba, en dirección opuesta a las otras estructuras de malla (Ver knitting en Emery 2009: 40).

3 Caraguatá o chaguar son los nombres dados, en las zonas de influencia guaraní y quichua, respectivamente, a plantas pertenecientes a la familia de las bromeliáceas. Las fibras textiles se obtienen de las hojas (Arenas 1997: 127).

4 Con este término nos referimos a las estructuras formadas por un elemento continuo (generalmente, un hilo) que trabaja consigo mismo formando hileras horizontales de mallas que se ligan a las mallas de las hileras anteriores. Para elaborar una malla es necesario que el hilo pase, en toda su longitud, por la malla de la hilera anterior (Emery 2009: 30). Las estructuras textiles de malla registradas en las bolsas de caraguatá/chaguar de formato cuadrangular de las colecciones estudiadas, según la terminología de Emery, son: simple looping (Emery 2009: 31), double interconnected looping, figure-8 (Emery 2009: 33); por otro lado, también se registra cord looping (Seiler-Baldinger 1994: 17). 


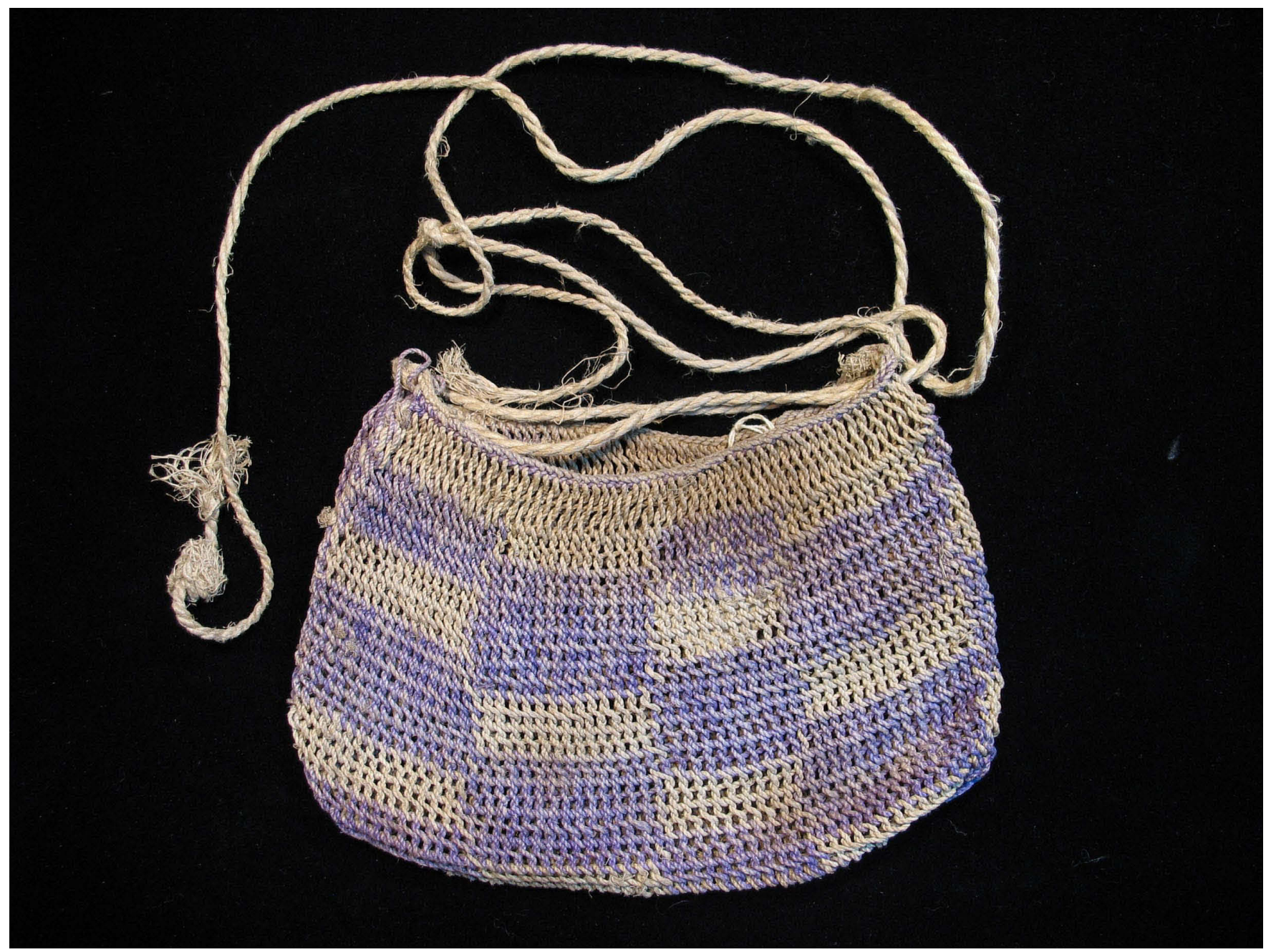

Figura 1- Bolsa de caraguatá/ chaguar en tejido de malla (double interconnected looping) con diseño de damero- Wichí- Colección Excursión E. Palavecino, 1935- Museo Etnográfico “J. B. Ambrosetti”. Fotografía: M. A. Elías

incluye tres bolsas de este tipo. En dos excursiones subsiguientes, en los años 1942 y 1945, este etnógrafo recolecta respectivamente, ocho bolsas atribuidas a los "Mataco del Río Pilcomayo" (Wichí) y tres bolsas, también de los "Mataco del Río Pilcomayo" (Wichí), pero recolectadas en la localidad de Embarcación (Catálogo de registro de objetos al Museo Argentino de Ciencias Naturales "Bernardino Rivadavia", 1929-1945).

Además de las colecciones formadas por Enrique Palavecino, se registran cuatro de estas bolsas en la colección que el Museo Argentino de Ciencias Naturales "Bernardino Rivadavia” compra a la exploradora Wanda Hanke en 1938, recolectadas en Algarrobal (cerca de Embarcación) y atribuidas a los Wichí. Luftensteiner, secretario privado de dicha exploradora, vende al Museo de Ciencias Naturales, en el año 1938, una bolsa de este tipo. Finalmente, se relevan también doce bolsas con estas características en la colección “Comprada a los indios Macá” en el año 1939 por el Museo Argentino de Ciencias Naturales (Catálogo de ingreso de objetos al Museo Argentino de Ciencias Naturales "Bernardino Rivadavia” 1929-1945).

Distintos etnógrafos han realizado breves referencias sobre la presencia de bolsas con estas características entre distintos grupos indígenas del Gran Chaco, aunque en escasos casos se menciona la particularidad de la técnica. Eric von Rosen, en su libro Ethnographical Research Work During the Swedish Chaco-Cordillera Expedition, 1901-1902, presenta el dibujo de una bolsa Chorote con estas características y refiere que las mismas son de uso masculino (Von Rosen 1924: 123 y 125). Max Schmidt, en un artículo sobre los "Matacos Guisnais" (Wichí), menciona que un tipo de bolsa utilizada son las de lana, y es el primero que hace referencia 
a que están fabricadas en "labor de punto" (Schmidt 1937a: 34); también hace mención de su uso y características similares para el pueblo Tapieté (Schmidt 1937b: 50). Alfred Métraux da información sobre la tecnología empleada en la elaboración de estas bolsas de lana, señalando que implicaba el empleo de dos y hasta cuatro agujas de espinas de cactáceas (Métraux 1946: 286).

Más tardíamente, María Delia Millán de Palavecino menciona las bolsas de lana, señalando que están realizadas en "técnica de calceta" y atribuyendo, por primera vez, su difusión, entre los “Matacos del Teuco y Teuquito" (Wichí), a la enseñanza misionera (Millán de Palavecino 1973: 81). José Braunstein muestra, para los Maká, el dibujo de una bolsa de lana similar a las realizadas en tricotado; la denominación dada a estas bolsas era t'otoi witilkuki jukhewle y las usaban los hombres en los bailes, cruzadas en bandolera; en ellas guardaban la pipa, el tabaco y los escarificadores de huesos de animales (Braunstein 1982: 394-397).

A partir del análisis de las estructuras textiles presentes en los recipientes de las bolsas guardadas en el Museo Etnográfico de Buenos Aires se puede señalar que sus características permiten relacionar su elaboración con lo mencionado y descrito por Max Schmidt para los "Matacos Guisnais" (Wichí) y por aquellos estudiosos que hablan de "labor de punto", "técnica de calceta”, etc. Los recipientes del corpus que se desarrollan en este apartado, atribuidas a grupos Pilagá, Wichí y Maká, presentan una estructura de tricotado que corresponde al llamado punto de media (Emery 2009: 40, "stocking stitch"), ya que el tejido que se observa en ellas es tubular. En el mismo, todas las lazadas, que son abiertas, se encuentran sobre una de las caras del tejido y las dos caras de éste presentan apariencias disímiles. En la decoración estructural de estas bolsas se observa un tipo de técnica denominada por Cintia Le Count weaving para los tejidos tricotados andinos (Le Count 1990: 78); la misma consiste en el empleo de dos elementos simultáneos de colores diferenciados, donde el elemento no usado para realizar el diseño en el anverso del tejido es enlazado en cada lazada realizada por el hilo del color usado en el diseño. Las bolsas analizadas presentan mayormente el empleo de dos hilos de dos colores y como máximo tres hilos de tres colores; en este último caso, el hilo que realiza las lazadas del diseño enlaza los dos hilos no usados. En todos los casos analizados por nosotros, el sentido del tejido en los recipientes es desde la base hacia la boca de los mismos, presentando la costura de cierre del recipiente en la base. ${ }^{5}$

La técnica de tricotado es una invención reciente, la cual primero apareció en la Edad Media, probablemente en el mundo Islámico, y se expandió hacia Europa y desde Europa a América (Rowe 1997: 3). Aquí es importante volver a mencionar la referencia de Millán de Palavecino que señala que la técnica fue enseñada por los misioneros entre los "Mataco del Teuco y Teuquito" (Wichí) en Argentina (Millán de Palavecino 1973: 81). Es decir, que esta técnica de tejido, presente exclusivamente en los recipientes de estas bolsas de lana, fue incorporada probablemente entre los pueblos indígenas de la región del Gran Chaco a través de su interacción con distintos actores sociales "blancos" de la sociedad hegemónica.

Resulta importante mencionar que un artefacto socioeconómica y simbólicamente relevante entre distintas poblaciones indígenas del Gran Chaco son las bolsas. La mayoría de ellas están elaboradas en caraguatá/ chaguar en distintos puntos de tejido de malla. Presentan dos formatos básicos (rectangular o cuadrangular y semiesférico) (Millán de Palavecino 1944; Von Koschitzky 1992; Susnik 1982; Braunstein 1982; Arenas 2003; Elías 2012). Según distintos autores, las de formato rectangular o cuadrangular presentan distintos tamaños respondiendo a diversas funciones relacionadas especialmente con su uso por parte de los hombres, a excepción de las de mayor tamaño empleadas también por las mujeres (Millán de Palavecino 1944; Von Koschitzky 1992; Susnik 1982; Braunstein 1982; Montani 2007).

Los recipientes elaborados en tricotado del corpus de bolsas que se analizan en este trabajo sólo presentan un formato rectangular o cuadrangular. Sus medidas máximas son 24cm de alto y 23,5cm de ancho (Elías 2008: 44); sólo se relevan ejemplares de tamaño reducido. Esto coincide con lo señalado por la etnógrafa Branislava Susnik que las bolsas en labor de punto desplazaron a las pequeñas bolsas de caraguatá usadas por los hombres para guardar las leznas, pipas, tabaco o amuletos de caza y usadas en ocasiones festivales (Susnik 1982: 189).

Pese a la diferencia tecnológica implicada en esta técnica en relación con los tejidos de malla o red de las bolsas de caraguatá/chaguar - además de la diferencia entre las estructuras de malla empleadas en las bolsas cuadrangulares de caraguatá ${ }^{6}$ y la estructura de tricotado de las bolsas de lana, en las estructuras de malla o red el hilo debe pasar en toda su longitud por la malla de la hilera anterior, en el tricotado cada lazada es hecha con la parte del hilo más cercana al borde del tejido y es llevada a través de una lazada anterior; el trabajo, entonces, avanza hacia arriba, en dirección

5 Estas características también se observan en corpus de bolsas atribuidos a pueblos Nivaklé (Elías 2012).

6 Remitirse a la nota 4 del presente trabajo para ver las estructuras textiles de malla registradas en las bolsas cuadrangulares de caraguatá/ chaguar. 


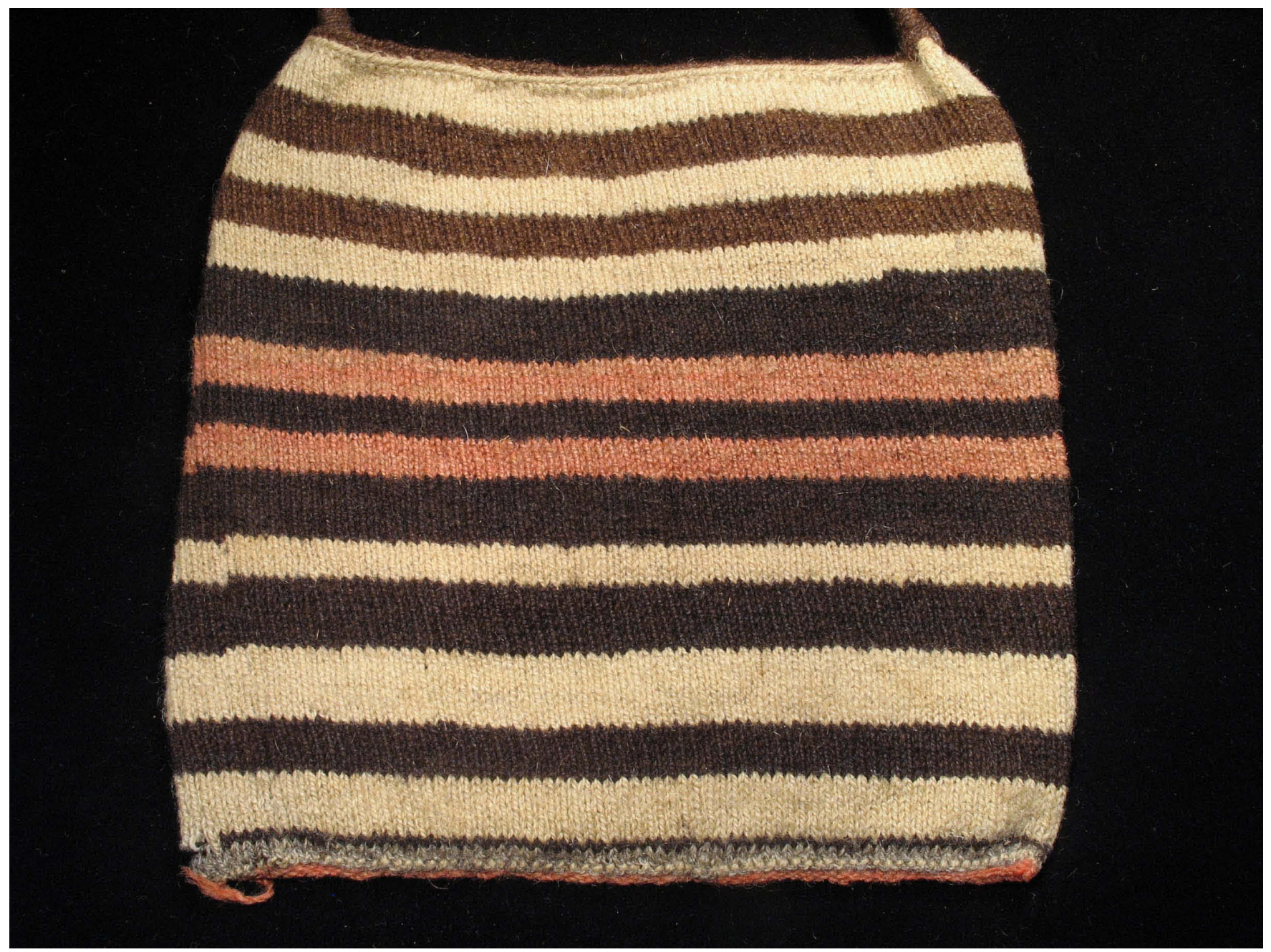

Figura 2- Bolsa tricotada con diseño de líneas y bandas paralelas- Wichí- Colección Excursión E. Palavecino, 1937- Museo Etnográfico “J. B. Ambrosetti”. Fotografía: M. A. Elías.

opuesta a las otras estructuras de malla (Emery 2009: 40; Rowe 1997: 3, 10)-, los pueblos originarios del Gran Chaco la incorporaron para la elaboración de objetos relevantes de su cultura material. Es decir, se evidencian procesos de apropiación de esta técnica procedente de la sociedad hegemónica por parte de las poblaciones originarias de la región .

Esto último se confirma por las características de los motivos y configuraciones de diseños que he relevado en los recipientes tricotados de las bolsas de lana. Se observan líneas y/o bandas rectas horizontales paralelas de dos o tres colores alternas (Figura 2); dameros o ajedrezados formados por cuadrángulos alternados de dos colores (Figura 3); triángulos o trapecios de dos colores, organizados alternadamente sobre un eje horizontal (Figura 4); líneas zigzag verticales (Figura 5); configuraciones de líneas verticales quebradas en ángulos rectos formadas por dos líneas o dos grupos de líneas en relación especular, con un motivo cruciforme en el eje de simetría (Figura 6) . Finalmente, configuraciones de diseños con rombos se registran frecuentemente en las bolsas de lana con recipientes tricotados, con diversas organizaciones: rombos lineales y concéntricos, alineados vertical y horizontalmente o formando una retícula (Figura 7).

Estos motivos y configuraciones de diseños también se registran en las bolsas cuadrangulares en tejido de malla de caraguatá/ chaguar. Distintos autores los describen y nos informan sobre las significaciones de los mismos. Entre los Wichí, los diseños de bandas paralelas se observan en pequeñas bolsas rectangulares elaboradas en enlazado en cordón, son denominados athlutset'aj (panza de iguana) (Von Koschitzky 1992: 45; Montani 2007: 39). Según Montani, entre los pueblos Wichí del oeste de Formosa, distintos di- 


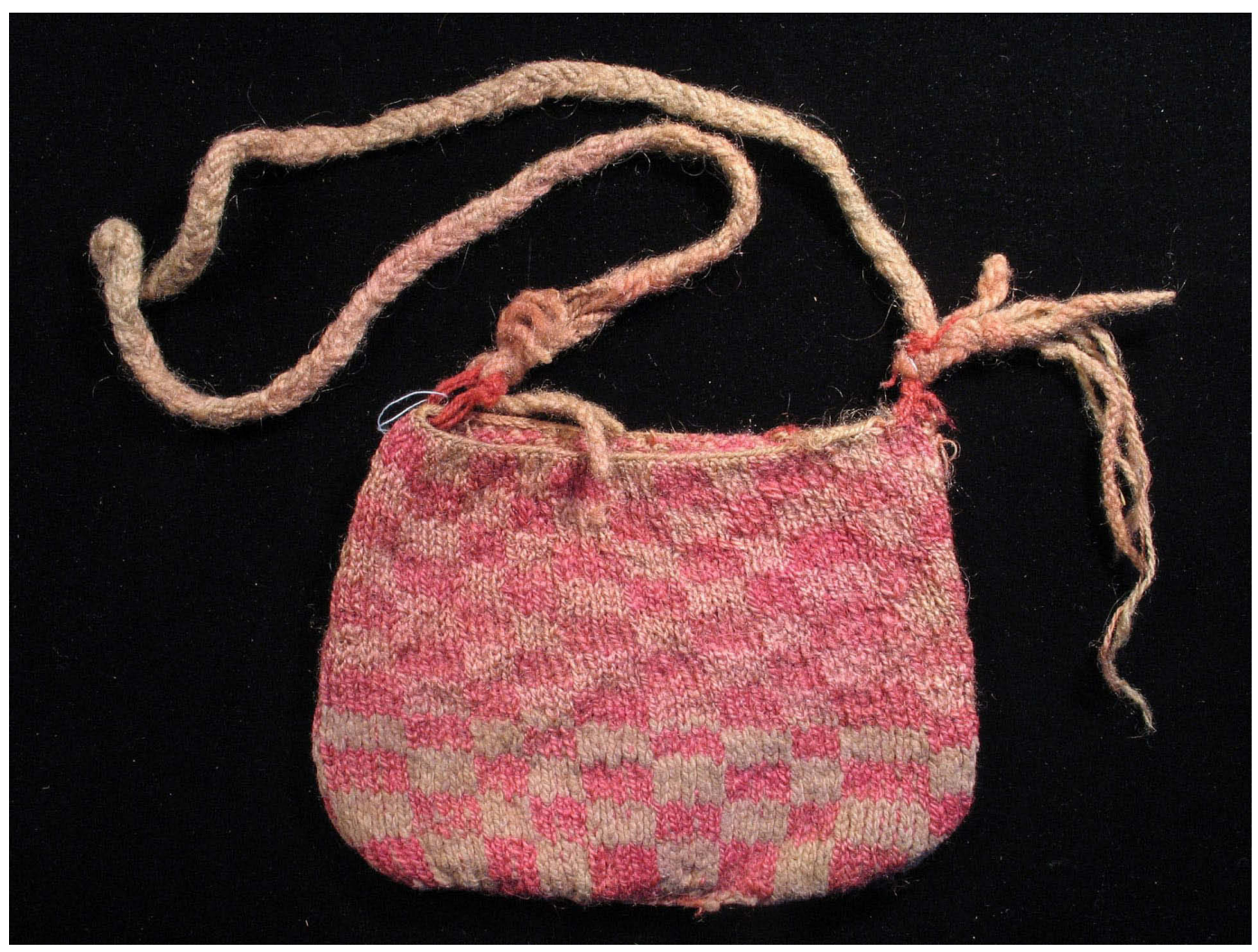

Figura 3- Bolsa tricotada con diseño de damero- Wichí- Colección Excursión E. Palavecino, 1929- Museo Etnográfico “J. B. Ambrosetti”. Fotografía: M. A. Elías

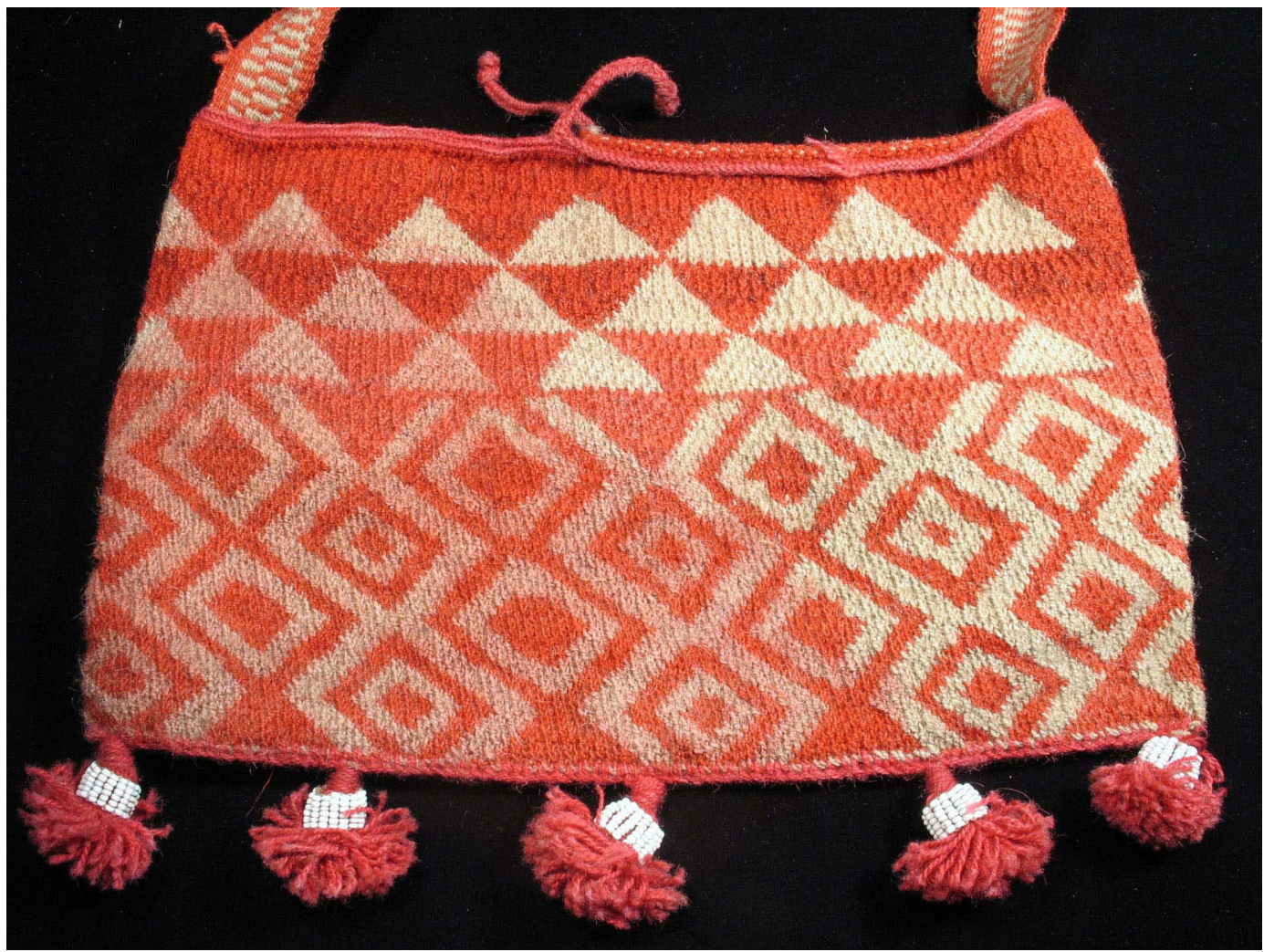

Figura 4- Bolsa tricotada con diseño de triángulos- Maká- Colección comprada a los Maká por el Museo Argentino de Ciencias Naturales, 1939- Museo Etnográfico “J. B. Ambrosetti”. Fotografía: M. A. Elías. 


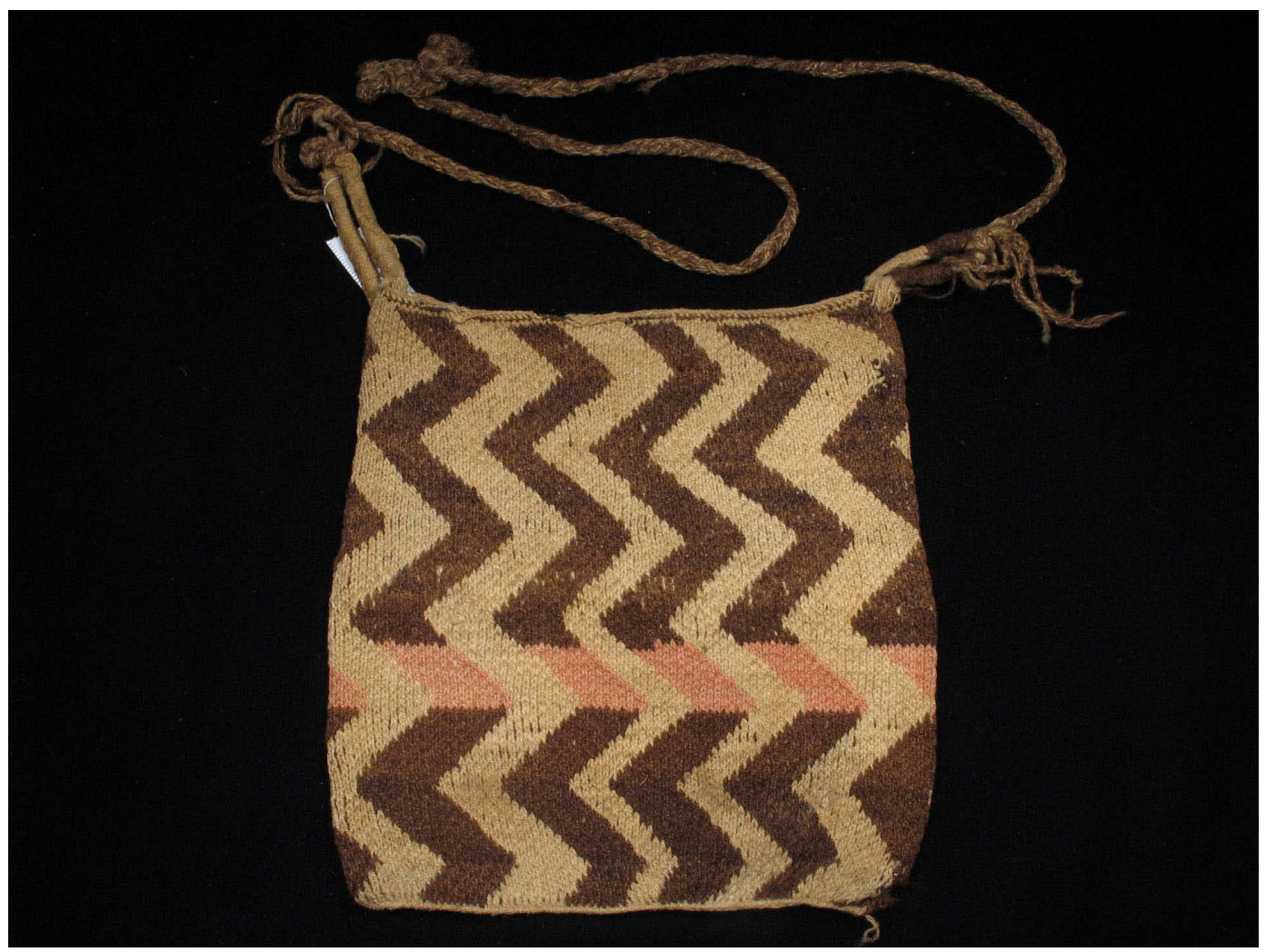

Figura 5- Bolsa tricotada con diseño de líneas zigzag- Wichí- Colección Excursión E. Palavecino, 1937- Museo Etnográfico “J. B. Ambrosetti”. Fotografía: M. A. Elías.

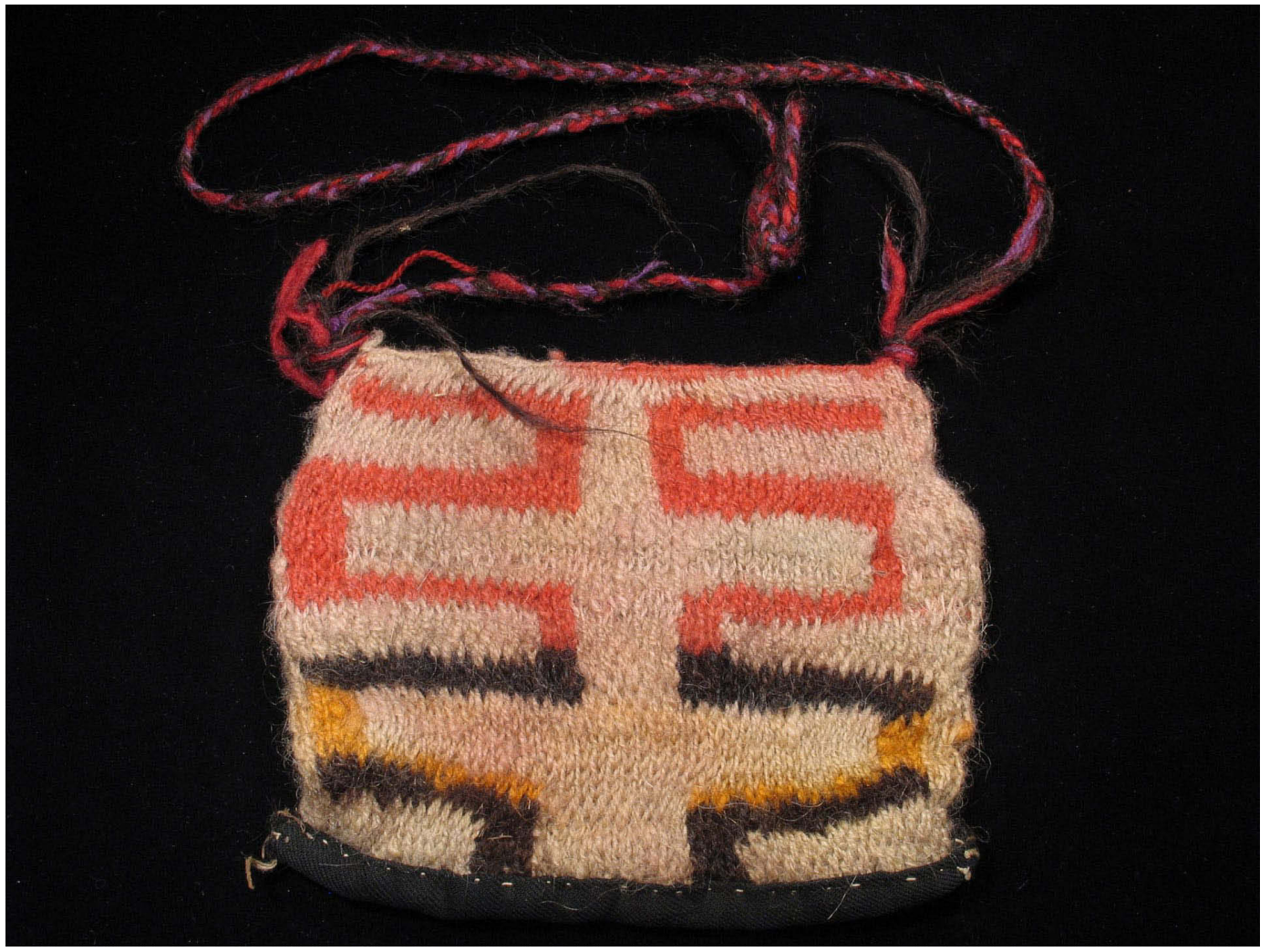

Figura 6- Bolsa tricotada con diseño de líneas quebradas en ángulos rectos- Wichí- Colección Excursión E. Palavecino, 1929- Museo Etnográfico “J. B. Ambrosetti”. Fotografía: M. A. Elías. 


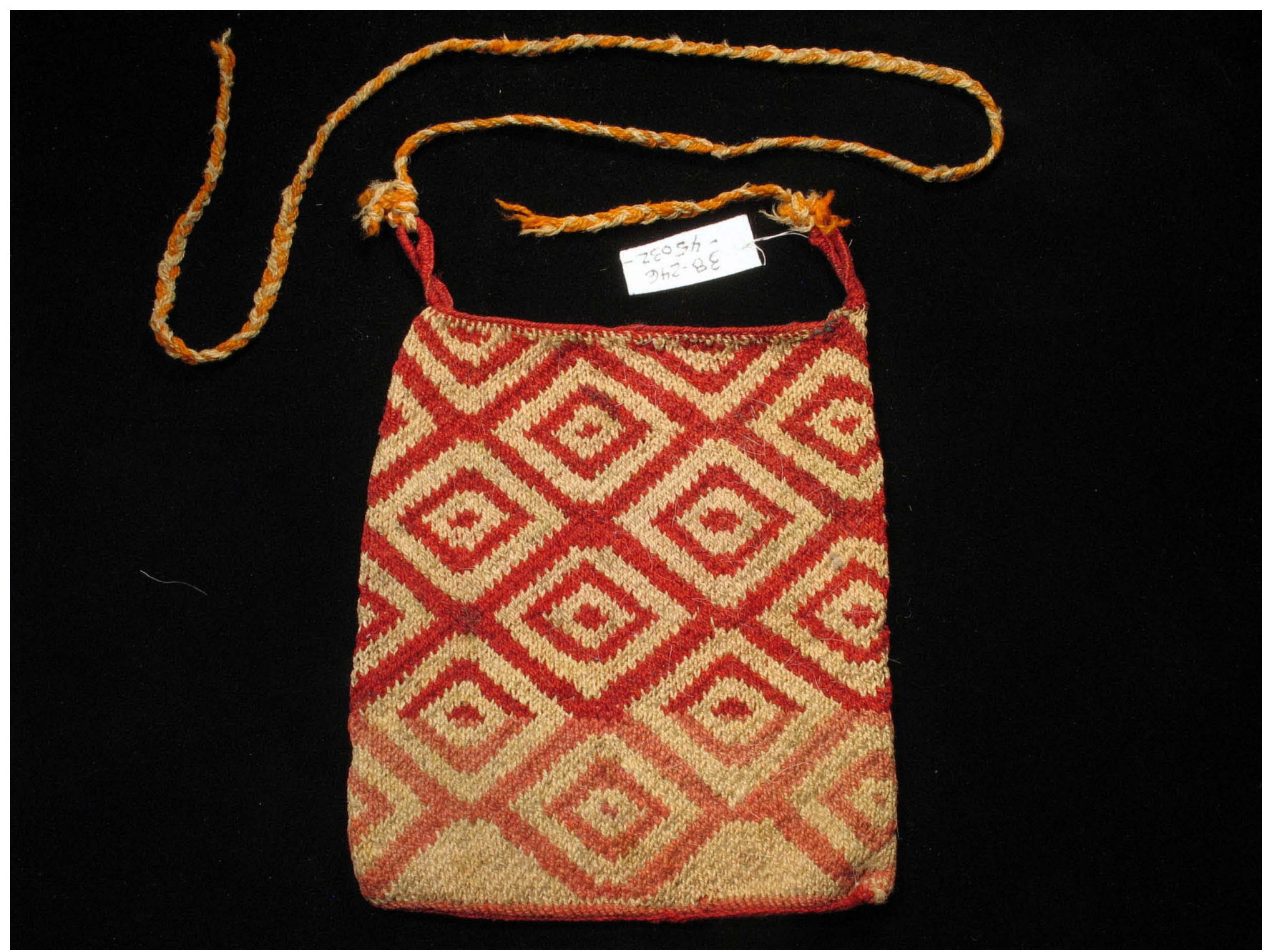

Figura 7- Bolsa tricotada con diseño de retícula de rombos concéntricos- Wichí- Compra a Wanda Hanke, 1938- Museo Etnográfico "J. B. Ambrosetti”. Fotografía: M. A. Elías.

seños romboidales de las bolsas en tejido de malla de caraguatá/ chaguar representan ojos de pájaros (Montani 2007: 48). La denominación de los Wichí para los diseños de líneas zigzag verticales de las bolsas de caraguatá se traduce como "codos" (katoltas, katul-tas)7 (Von Koschitzky 1992: 55; Llorente 1996: 23; Montani 2007: 50). Las mujeres Wichí llaman "lomo de suri o avestruz" (huantlaj huó, wanlohj-hu) a las líneas verticales quebradas en ángulos rectos; Montani señala que se trata de un motivo de difícil ejecución en las bolsas de malla de chaguar y poca frecuencia, pero de una forma estable; la variante más típica es aquella formada por líneas quebradas en relación especular en torno a una o varias cruces (Montani 2007: 47-48). Los diseños de damero representan el "caparazón de la tortuga" p'ataxlax para los Maká (Braunstein 1982: 451) y las mujeres Wichí los lla- man “caparazón de tortuga” (kitadni ahäs, chitahni-t' oj) (Von Koschitzky 1992: 54, 59; Montani 2007: 45). Las bolsas Wichí en enlazado simple de caraguatá/ chaguar llevan el diseño de triángulos, cuyo nombre es "orejas de mulita" (huak'atsaj kiotéi, huaqtsaj-ch'utey) (Von Koschitzky 1992: 46-47; Montani 2007: 46-47).

Como se puede observar, los nombres de los diseños presentes en las bolsas de caraguatá/ chaguar tejidas en malla o red, corresponden, en su mayoría a partes de animales, aunque también en algunos casos que no he mencionado acá, hacen referencia a semillas (Millán de Palavecino 1944; Braunstein 1982; Von Koschitzky 1992; Llorente 1996; Montani 2007).

Nos resulta relevante una observación que realiza Rodrigo Montani sobre las bolsas tejidas en malla rectangula-

7 Aclaramos que cuando aparecen dos formas de escribir el nombre del diseño en la lengua originaria, corresponden a las diferentes maneras que han sido escritas en la bibliografía citada. 
res de chaguar/ caraguatá usadas por los varones entre los Wichí. Señala que además de hilú, también se las llama lalhey ("su nombre"). Cita a John Palmer quien propone que el hecho de que las mujeres Wichí den bolsas cuadrangulares a sus hombres implica que ellas nombran a sus hombres con sus bolsas a través de los diseños predeterminados que aparecen en ellas. Montani se pregunta, entonces, si el hecho de que las mujeres entreguen bolsas a hombres que en los tiempos originarios tuvieron formas de animales no daría una explicación al repertorio de nombres de diseños de las mismas, cuya mayoría hacen referencia al reino animal (Montani 20o8: 173-174). De esta manera hay una asociación entre los bolsos enlazados de caraguata/ chaguar, los nombres de los diseños presentes en ellos y la escena mítica del origen de la humanidad según los Wichí, que permite pensar que las mujeres nombran a sus hombres con sus bolsos y tejen éstos como metáforas de los animales que ellos fueron (Montani 2008: 175).

Pensando en la relevancia señalada por Montani de los diseños que aparecen en las bolsas enlazadas de caraguatá, el nombre de los mismos y su significación mítica y social $\mathrm{y}$, considerando que se relevaron motivos y configuraciones de diseños similares en las bolsas tricotadas Wichí, se puede proponer que, aún elaboradas con una técnica procedente de la sociedad hegemónica, la presencia de tales diseños las hace parte de esta significación mítica y social, evidenciando aún más el complejo proceso de apropiación implicado en su elaboración.

\section{Las fajas “Toba del "Pilcomayo” de la colección Alfred Métraux de 1934}

En este apartado desarrollaré el estudio de una colección formada exclusivamente por 20 fajas atribuidas a los "Tobas del Pilcomayo" (Qom). Ésta colección fue comprada por el Museo Argentino de Ciencias Naturales "Bernardino Rivadavia” al etnógrafo suizo Alfred Métraux en el año 1934 (Catálogo de registro de objetos al Museo Argentino de Ciencias Naturales "Bernardino Rivadavia" 1929-1945).

En el año 1933, Métraux realiza un viaje en el que contactó con distintos grupos Qom del oeste de Formosa. Durante este viaje recorre el Estero Patiño con apoyo de la gendarmería argentina, sobre la margen derecha del río Pilcomayo, pasando por Fortín Salazar, Fortín Lugones, Salto
Palmar y Yoma (dominio del cacique Garcete), luego visita a los toba (Qom) del cacique Cernasol, establecidos en Labagan y llega a la misión anglicana cercana a Sombrero Negro, donde el misionero John Arnott lo contacta con Kedok, su informante básico para sus estudios de etnografía TobaPilagá (Bilbao 2002: 69-77).

Siguiendo a Gastón Gordillo, los Qom del noroeste de Formosa se distinguen de otras parcialidades Qom; una de las diferencias es idiomática. Una experiencia histórica que marcó profundamente a este grupo es la evangelización iniciada en 1930 por misioneros ingleses. Ello explica que éste sea el único grupo toba (Qom) en la Argentina cuya identidad religiosa es predominantemente anglicana, a diferencia de las diversas identidades pentecostales hoy dominante en el Chaco oriental (Gordillo 2005: 15-16). Este antropólogo señala que cuando en 1930 los misioneros ingleses Alfred Leake y Alec Sanderson comenzaron su trabajo en lo que luego sería Misión El Toba, ubicada a un par de kilómetros de Sombrero Negro, se fueron consolidando varias comunidades junto al río que agrupaban a gente de distintos grupos tobas (Qom). Las más importantes fueron Laguna Martín (con gente chiyadi'pí), Misión El Toba (con gente kedoco'pí), La Bolsa (loliagadi'pí), Cañaveral (jelcaic'pí y mañigodi’ pí), Jesús María (con gente piogodi’ pí) y Laguna de las Paces. Gordillo señala que los sábados, mucha gente de estas comunidades iba a Misión El Toba para asistir al culto del domingo y además vender cueros de animales en Sombrero Negro y artesanías en el almacén de la misión (Gordillo 2005: 78-79). Es en el año 1933 cuando Alfred Métraux visita la misión anglicana y permanece realizando estudios y formando colecciones en ella. Probablemente, las fajas compradas en 1934 por el Museo Argentino de Ciencias Naturales a Métraux hayan sido parte de estas colecciones.

En primera instancia, haré una breve descripción de las mismas basada en los resultados del estudio de diversos aspectos de su materialidad. Todas ellas presentan estructuras textiles de tejido en faz de urdimbre con urdimbres complementarias (doble faz) alternas en relación $1 / 1$ y 2/2. ${ }^{8}$ Se caracterizan por presentar el orillo de urdimbre en uno de sus extremos, a través del cual pasa un lazo retorcido o trenzado y, en el extremo opuesto, flecos estructurales retorcidos o trenzados cuyos extremos no se encuentran cortados (Figura 8); los tejidos han sido retirados del telar sin ser cortados. ${ }^{9}$ Todas ellas están elaboradas con hilos de lana formados por dos cabos Z/S, composición del hilado que se

8 Las denominaciones se basan en las propuestas por Rowe (Rowe 1977, 2006).

9 La elaboración de tejidos en cuatro orillos que pueden ser retirados del telar sin necesidad de cortarlos es una técnica que se registra entre distintos pueblos originarios de Sudamérica con anterioridad a la llegada de los españoles hasta nuestros días. En el caso específico de los pueblos del Gran Chaco, la tecnología empleada es un tipo de telar conformado por un marco con una cuerda tensa extendida entre los palos transversales; sobre dicha cuerda las urdimbres se enlazan de forma tal que, al terminar el tejido, la cuerda se retira obteniendo un tejido con sus cuatro orillos (ver Métraux 1946) 


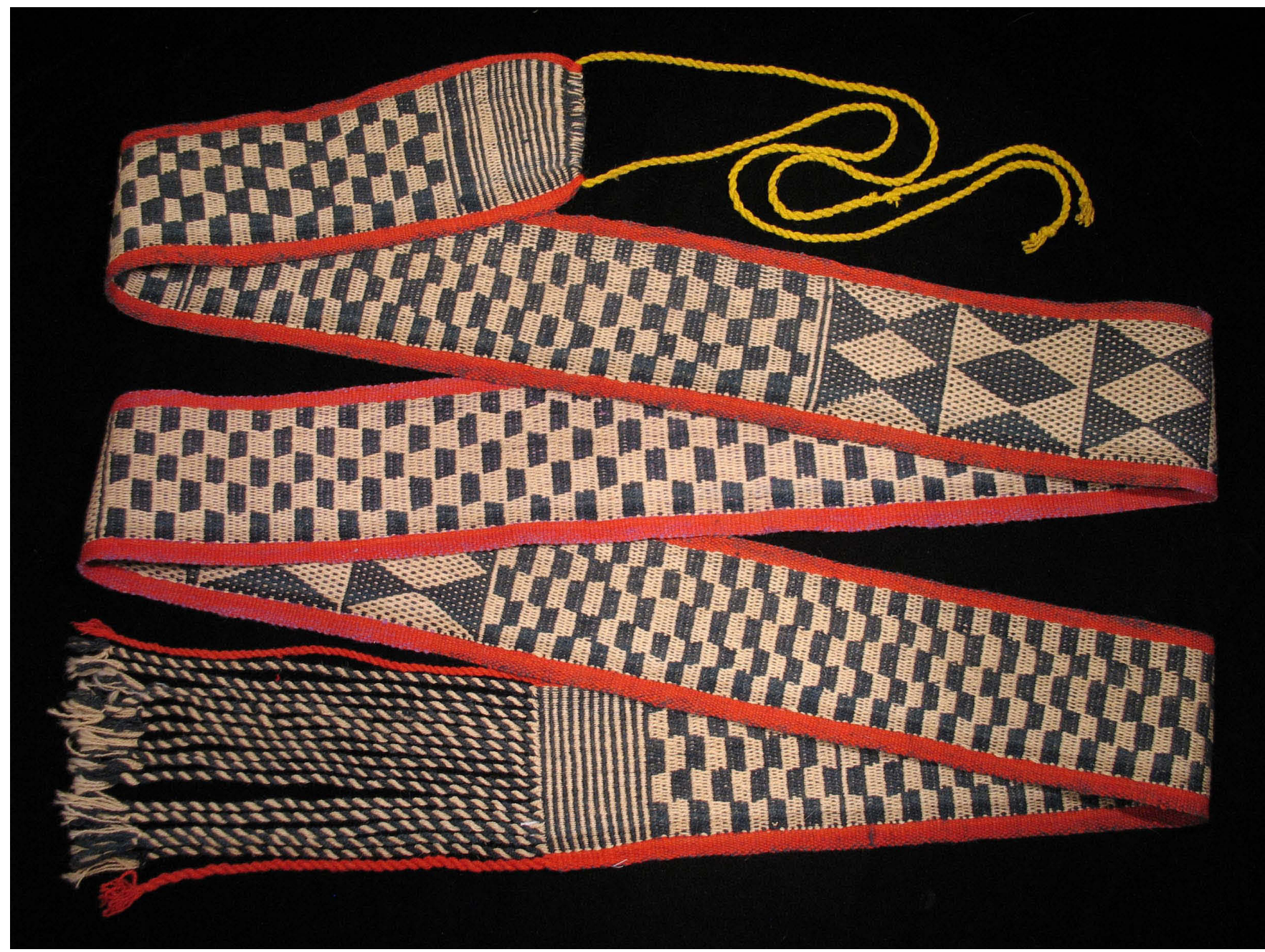

Figura 8- Faja de lana- "Toba del Pilcomayo"- “Toba del Pilcomayo” (Qom)- Colección comprada a Alfred Métraux, 1934- Museo Etnográfico “J. B. Ambrosetti”. Fotografía: M. A. Elías

releva en los hilados de lana de distintos pueblos chaqueños (Elías 2012 : 31-32).

Siguiendo las características de las estructuras textiles y materia prima de estas fajas, las descripciones sobre el uso de objetos similares entre distintos pueblos indígenas del Gran Chaco, así como las evidencias de uso en fajas con características similares, he definido seis variables para el registro de sus evidencias de uso: 1) arrugas y pliegues horizontales en el sentido de la urdimbre; 2) desgaste o abrasión en el cuerpo; 3) roturas, desestructuración, arreglos en el cuerpo; 4) roturas, desestructuración, arreglos en los flecos estructurales; 5) roturas, desestructuración, arreglos en el lazo del orilla de urdimbre; 6) manchas.

En cuanto a las variables 1) y 2), no se ha registrado en ninguna de las fajas de la colección la presencia de arrugas y pliegues horizontales o indicios desgaste o abrasión. Considerando la variable 3), sólo en una de las fajas se ha observado rotura y faltantes de algunas urdimbres sobre uno de los orillos de trama cercano a los flecos estructurales. Ninguna de las fajas presenta la presencia de la variable 4). En cuanto a la 5), en una de ella se observó la rotura en dos fragmentos del lazo del orillo de urdimbre y la unión de ambos por anudado; una segunda faja presenta la faltante del lazo; una tercera faja presenta el lazo retorcido desestructurado; finalmente, dos fajas no presentan roturas, desestructuración ni arreglos en sus lazos, pero sí el anudado de los mismos. Sólo una de las fajas del corpus evidencia una mancha negra en el cuerpo (variable 6).

De todo el conjunto, sólo la faja, con número de inventario anterior 34-3, muestra la presencia de dos de las variables: rotura y arreglo por anudado del lazo (Figura 9) y evidencia de rotura y faltantes de urdimbres en un sector del cuerpo. En el resto de las fajas del corpus, las variables sólo aparecen en orden de una por faja. Del conjunto de 20 fajas, sólo 5 presentan una de estas variables. A partir de estos resultados, se puede señalar que son casi inexistentes los 


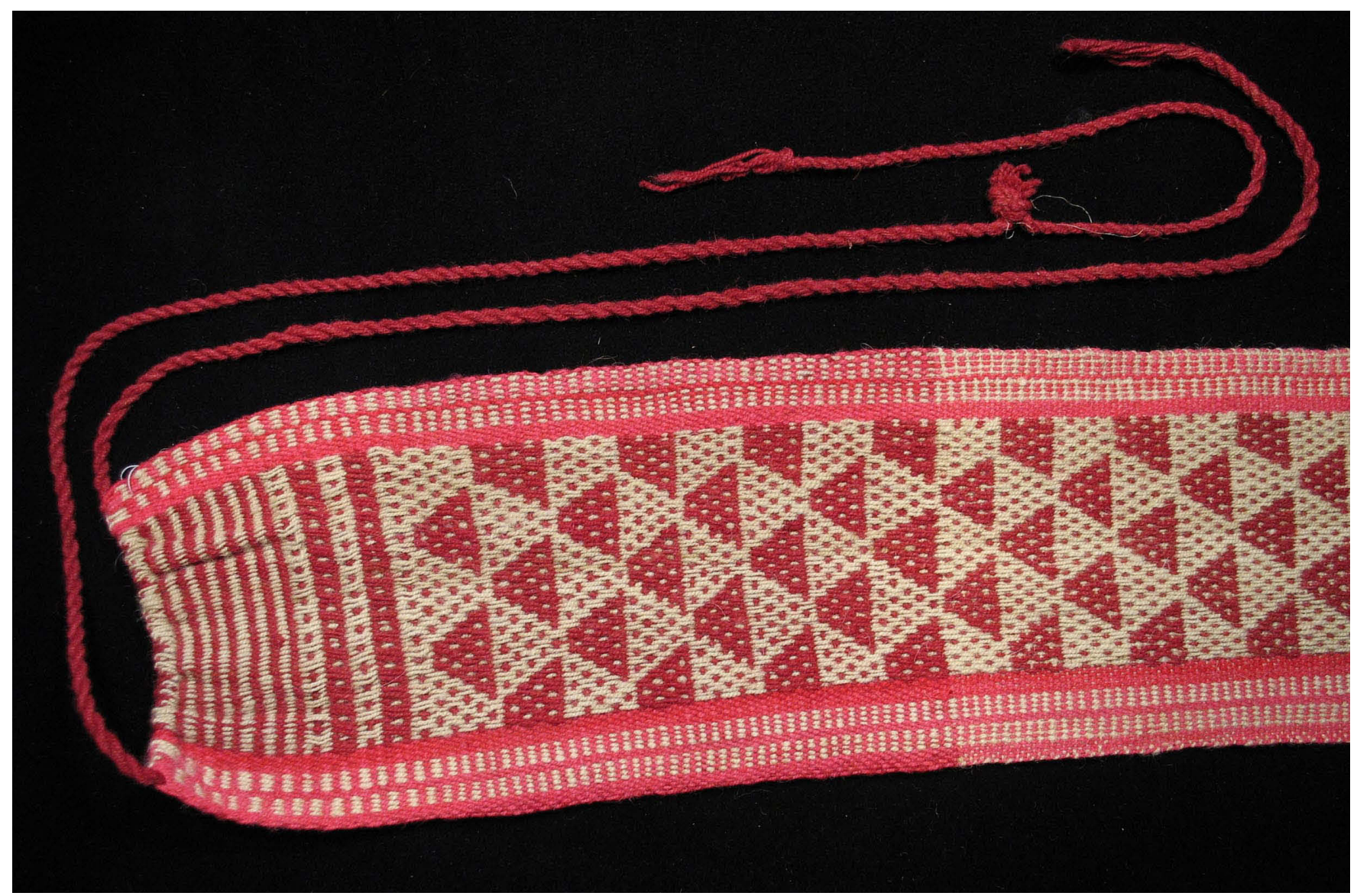

Figura 9- Detalle de rotura y anudado para arreglo del lazo de la faja 34-3- "Toba del Pilcomayo" (Qom)- Colección comprada a Alfred Métraux, 1934- Museo Etnográfico “J. B. Ambrosetti”. Fotografía: M. A. Elías.

indicios de uso previo de la mayoría de las fajas que conforman esta colección, sobre todo considerando que ninguna de ellas presenta pliegues de uso entorno a la cintura y desgaste o abrasión en algún sector del cuerpo.

Esto nos permite plantear la posibilidad de que entre los fines para los que fueron producidas estaba incluida su probable venta. En relación con esto, en su libro Nosotros vamos a estar acá para siempre. Historias tobas, Gastón Gordillo menciona la venta de artesanías en el almacén de la Misión anglicana El Toba por parte de las mujeres Qom del oeste de Formosa (Gordillo 2005: 79). Transcribo lo contado por la gente toba-qomle'ec a Gastón Gordillo en cuanto a la creación y la vida en relación con la Misión El Toba:

"Venía uno que se llama Enrique Grubb ${ }^{10}$. Eran dos los que venían. Venía Alfredo ${ }^{11}$ con una mula blanca y el otro misionero con una mula baya. (...) Hasta que terminaron una casita, dos, tres, no sé cuántas. Entonces recién hicieron trabajar a la gente para cortar adobe. Recién hicieron una casa linda. Y bueno, ya había misionero. Empezó a enseñar. Había escuela. Hizo todo; hizo un boliche para comprar las artesanías: yica, faja, poncho, alfombra, vincha, piola. Todo compraban. (...) (Emilio Rivero, en Vaca Perdida, 1999)." (Gordillo 2005: 85; el subrayado es mío)

"Alfredo compraba artesanías, porque tenía un almacén. (...) Las mujeres meta trabajar con las artesanías. En esa época el hombre no tenía trabajo, pero una mujer tenía trabajito. (...) Les daba plata a las mujeres, no a los hombres. Era el trabajo de ellas, entonces compraban algo. (Fabreciana Luis, en Vaca Perdida, 1996)" (Gordillo 2005: 86; el subrayado es mío)

10 Misionero inglés (Gordillo 2005: 79)

11 Misionero inglés cuyo nombre era Alfred Leake. Otros misioneros ingleses fueron Alfred Tebboth y John Arnott (Gordillo 2005: 79) quien pone en contacto a Métraux en su viaje de 1933 con su informante qom Kedoc (Bilbao 2002: 69-77). 
"Alfredo compraba asinito, no era mucho. Veinte centavos, cuando valía la plata. (...) Le vendían por ahí la alfombra a la señora de Alfredo y después ella compraba remedios para traer, para que no falten remedios. Ella le avisaba a la gente: "Bueno, les voy a comprar artesanías. Entonces cuando las vendo voy a comprar los remedios”. Estaban contentas, bien contentas, las mujeres. Se amontonaban bien en el almacén. El día sábado ¡uh! (Cristina Saravia, Laguna Cancino, 1999) (p. 86)

A partir de esta información, se puede proponer que, la mayoría de las fajas de esta colección - atribuidas a los pueblos “Tobas del Pilcomayo" (Qom) y probablemente recolectadas por Alfred Métraux en su viaje a la zona del noroeste de Formosa en 1933, en contacto con los misioneros anglicanos presentes en la región - fueron producidas para su venta/ intercambio con los misioneros, entre otros fines. Recordemos que Emilio Rivero cuenta a Gordillo que en la Misión El Toba Alfred Leake hizo un boliche para comprar las artesanías: yica, faja, poncho, alfombra, vincha, piola (Gordillo 2005: 86).

Appadurai define la situación mercantil en la vida social de cualquier "cosa" como la situación en la cual su intercambiabilidad (pasada presente o futura) por alguna otra cosa se convierte en su característica socialmente relevante (Appadurai 1991: 29). En el caso de este conjunto de fajas, se podría aplicar la definición de Appadurai. Lo mencionado por Fabriciana Luis lo reafirma: "Alfredo compraba artesanías, porque tenía un almacén. (...) Las mujeres meta trabajar con las artesanías. (...) Les daba plata a las mujeres" (Gordillo 2005: 86).

Usando las palabras de Phillips y Steiner, se puede pensar que estas fajas, de alguna manera, están inscriptas en modos occidentales de producción mercantil, de hecho dicha inscripción ha sido uno de los aspectos más importantes de la extensión global de poder colonial occidental (Phillips y Steiner y 1999: 4). Esta parte de su naturaleza, mercantil, no ha sido evidenciada en su historia de recolección ni en la documentación que sobre ellas se ha llevado a cabo hasta el momento en el Museo Etnográfico “J. B. Ambrosetti”. Sin embargo, existen ejemplos de que los etnógrafos compraban objetos y que los indígenas del Gran Chaco los vendían. Salvador Debenedetti, para mencionar un caso temprano, en su expedición al ingenio Ledesma en el año 1909, menciona el haber comprado objetos a los indígenas del Gran Chaco que iban allí como mano de obra estacional (Carta de Debenedetti a Ambrosetti, Ledesma, 25-09-1909, Archivo Debenedetti, Archivo Fotográfico y Documental, Museo Etnográfico “J. B. Ambrosetti”).
Por lo tanto, probablemente, la producción de estas fajas estuvo destinada a un mercado externo a los "Toba del Pilcomayo" (Qom), y ello no pone en cuestión su autenticidad, en tanto la producción de las mismas, tal como intenté dar cuenta al inicio de este apartado con su descripción, evidencia la presencia de saberes, prácticas y conocimientos de gran trascendencia entre estos grupos del noroeste de Formosa en particular y entre distintos grupos del Gran Chaco en general. Sin embargo, resulta relevante dar cuenta de esta posibilidad de pensarlas como "mercancías", en tanto recupera las relaciones sociales históricas en las que fueron producidas, es decir, la elaboración de objetos por parte de las mujeres Qom del oeste de Formosa para ser vendidos a los misioneros anglicanos. En palabras de Phillips y Steiner:

\begin{abstract}
"Las acusaciones de inautenticidad estaban también basadas en la aserción que las mercancías [commodities] eran producidas para mercados externos y no usadas por los mismos productores. Este alegato ignoraba hechos llanos. Las poblaciones colonizadas alrededor del mundo a menudo vestían el mismo tipo de prendas y ornamentos que vendían como souvenir, y muchas formas de expresión estéticas en las comunidades indígenas fueron profundamente transformadas por el involucramiento intensificado de sus productores en la producción de mercado.” (Phillips y Steiner 1999: 10).
\end{abstract}

\section{Conclusiones y consideraciones finales}

Este artículo se denomina "Colecciones textiles etnográficas del Gran Chaco Sudamericano del Museo Etnográfico 'J. B. Ambrosetti' y el estudio de su materialidad: un desafío a la mirada occidental sobre los 'otros no-occidentales'”. El análisis de distintos aspectos de la materialidad de los objetos textiles que integran las colecciones del Museo ha implicado el cuestionamiento de la forma de pensar - documentar investigar y clasificar la cultura material textil de las poblaciones originarias del Gran Chaco Sudamericano y, con ello, las representaciones sobre sus productores.

El relevamiento de la técnica de tricotado para la elaboración de las bolsas de lana atribuidas a distintos pueblos del Gran Chaco presentes en las colecciones, ha planteado la necesidad de dar cuenta y pensar la presencia de elementos materiales - técnica - procedentes de la sociedad hegemónica en los objetos textiles etnográficos chaqueños. Más que cuestionar su autenticidad o pensar que implica la pérdida de tradiciones, el análisis de sus aspectos materiales como formato y configuraciones de diseños, nos ha permitido recuperar sus contextos coloniales de producción 
y dar cuenta de complejos procesos de apropiación y agencia indígena implicados en su elaboración en dichos contextos. Por otro lado, el relevamiento de los documentos de registro de ingreso de las mismas al Museo y sus posteriores descripciones y clasificaciones, evidencia lo señalado por Clifford respecto a que lo híbrido no ha sido empleado como categoría de clasificación en las prácticas de los museos occidentales.

En relación con esto basta con mencionar que en los catálogos de ingreso de objetos, estas bolsas son denominadas "bolsas de lana" o "bolsas de lana (tipo rectangular)", sin señalar su técnica particular de elaboración (Catálogo de ingreso de objetos al Museo de Ciencias Naturales "Bernardino Rivadavia”, 1929-1945). Por otro lado, la documentación posterior expresada en la Base de datos hasta el momento en que comencé a estudiar las colecciones textiles del Gran Chaco, sólo mencionaba en el campo de información Técnica de manufactura la categoría “tejido”. El dar cuanta de esta estructura textil en el inventario y la documentación de este corpus de bolsas de los pueblos originarios del Gran Chaco nos corremos de la exigencia de "pureza" aplicada por Occidente a las poblaciones no-occidentales.

Algo similar se puede señalar para el corpus de fajas recolectadas por Alfred Métraux entre los "Tobas del Pilcomayo" (Qom). Hasta el momento, esta colección ha sido empleada para estudios de la cultura material de los grupos Qom que recuperan sus funciones al interior de dichas sociedades, las cuales son valorables y aportan información sobre este patrimonio, sin embargo, no se ha dado cuenta de sus contextos de recolección y producción y cuáles eran los complejos vínculos de quiénes las crearon con la sociedad hegemónica. Las casi nulas evidencias de uso de dichas fajas permiten plantear la pregunta sobre el destino de su producción, ingresando en nuestra representación de sus productores y de su cultura material el concepto de "mercancía” o del estado mercantil de las mismas. El aplicar esta categoría a estos objetos guardados en las colecciones del Museo Etnográfico no pone en duda su autenticidad ni su valor, por el contrario, permite dar cuenta de sus contextos históricos de producción, en los que los Qom del oeste de Formosa estaban relacionados con los misioneros anglicanos que establecieron una Misión en su región, lo cual implicó modificaciones en sus formas de producción y consumo de objetos.

James Clifford propone pensar a los museos como "zonas de contacto", recuperando el concepto de Mary Louis Pratt en su libro Ojos imperiales: viajes y transculturación. La expresión "zona de contacto" es un intento de convocar la copresencia espacial y temporal de sujetos previamente separados por disyunturas geográficas e históricas y cuyas trayectorias se cruzan ahora. Una perspectiva de contacto enfatiza de qué modo los sujetos están constituidos en y por sus relaciones recíprocas, subrayando la copresencia, la interacción, la trabazón de entendimientos y prácticas, a menudo dentro de relaciones de poder radicalmente asimétricas. "Cuando se ve a los museos como zonas de contacto, su estructura organizadora como colección se vuelve una relación permanente histórica, política, moral: un juego de tira y afloja, un conjunto de intercambios cargados de poder." (Clifford 1999: 238). Esta relación permanente histórica, política, moral, este conjunto de intercambios cargados de poder es lo que, considero, queda evidenciado en el presente trabajo sobre dos corpus específicos de las colecciones textiles del Gran Chaco Sudamericano del Museo Etnográfico “J. B. Ambrosetti”, al punto que me atrevo a proponer que los objetos que las integran son ellos mismos "zonas de contacto" en tanto su materialidad constituye un indicio de copresencia, interacción, trabazón de entendimientos y prácticas, en el marco de relaciones de poder radicalmente asimétricas.

\section{Referencias citadas}

Arenas, Pastor

1997 Las bromeliáceas textiles utilizadas por los indígenas del Gran Chaco. Parodiana, 10 (1-2): 113-139.

2003 Etnografía y Alimentación entre los TobaNachilamole\#ek y Wichí-Lhuku'tas Chaco Central (Argentina). Edición Pastor Arenas, Buenos Aires.

Appadurai, Arjun

1991 Introducción: Las mercancías y la política del valor. En La vida social de las cosas. Perspectiva cultural de las mercancías, editado por Arjun Appadurai, pp. 1787. Grijalbo, México.

Braunstein, José

1982 El problema de la significación de la cultura material de los indios Maká. Tesis de Doctorado, Facultad de Filosofía y Letras, Universidad de Buenos Aires.

Berlo, Janet

1996 Beyond Bricolage: Women and Aesthetic Strategies in Latin American Textiles. En Textiles Traditions of Mesoamerica and the Andes, editado por Margot Blum Schevill, Janet Catherine Berlo y Edward B. Dwyer, pp. 437-479. University of Texas Press, Austin, TX.

Bilbao, Santiago

2002 Alfred Métraux en la Argentina. Infortunios de un antropólogo afortunado. Comala, Caracas.

Boccara, Guillaume

2005 Antropología diacrónica. Dinámicas culturales, procesos históricos y poder político. Nuevo Mundo Mundos Nuevos. Recuperado de https://nuevomundo. revues.org/589 
Museo Argentino de Ciencias Naturales

1929-1945 Catálogo de inventario de objetos etnográficos del Museo Argentino de Ciencias Naturales "Bernardino Rivadavia".

Clifford, James

1999 Itinerarios transculturales. Gedisa, Barcelona.

1995 Dilemas de la cultura. Antropología, literatura $y$ arte en la perspectiva posmoderna. Gedisa, Barcelona.

Debenedetti, Salvador

1909 Carta de Salvador Debenedetti a Juan Bautista Ambrosetti, Ledesma, 25 de septiembre de 1909. Archivo Debenedetti, Archivo Fotográfico y Documental, Museo Etnográfico “J. B. Ambrosetti”, Buenos Aires.

Elías, Mariana Alfonsina

2008 El universo textil etnográfico del Chaco argentino: los tejidos chaqueños a principios del siglo XX. Informe Final de Beca Individual del Fondo Nacional de las Artes. Buenos Aires.

2012 Textiles indígenas del Gran Chaco Sudamericano. En Textiles del Chaco. Catálogo del MEAB, Mariana Alfonsina Elías y Ariel Mencia, pp.28-105. Museo Etnográfico “Dr. Andrés Barbero", Fundación La Piedad, Asunción.

Emery, Irene

2009 The Primary Structures of Fabrics. Thames and Hudson, The Textile Museum, Washington D.C.

Gordillo, Gastón

2005 Nosotros vamos a estar acá para siempre. Historias tobas. Editorial Biblos, Buenos Aires.

Le Count, Cynthia

1990 Andean Folk Knitting. Traditions and Techniques from Peru and Bolivia. Dos Tejedoras Fibers Arts Publications, Minnesota.

Llorente, María Mercedes

1996 Tejiendo historia con piolas de chaguar. Formosa.

Métraux, Alfred

1946 Ethnography of the Chaco. En Handbook of South American Indians, 1, editado por Julian Steward, pp. 197-370. Smithsonian Institution, Washington D. C.

Millán de Palavecino, María Delia

1944 Forma y significación de los motivos ornamentales de las 'llicas' chaquenses. Relaciones de la Sociedad Argentina de Antropología, IV: 69-77.

1973 Tejidos Chaqueños. Relaciones (Nueva Serie), VII: 6583.
Montani, Rodrigo

2007 Formas y significados de los diseños de los bolsos enlazados por los wichí del Gran Chaco. Separata, 12: 35-66.

2008 Metáforas sólidas del género: mujeres y tejido entre los wichí. En Mujeres indígenas en la Argentina. Cuerpo, trabajo y poder, coordinado por Silvia Hirsch, pp.153-177. Biblos, Buenos Aires.

Ortner, Sherry

2016 Antropología y teoría social. Cultura, poder y agencia. UNSAM Edita, Buenos Aires.

Phillips, Ruth B. y Steiner, Christopher

1999 Art, Anthenticity, and the Baggage of Cultural Encounter. En Unpacking Culture. Art and Commodity in Colonial and Postcolonial Worlds, editado por Ruth B. Philllips y Christopher B. Steiner, pp.3-19. University of California Press, California.

Rowe, Anne

1977 Warp patterned weaves of the Andes. Textile Museum Washington D. C.

1997 Looping and Knitting. Textiles Museum, Washington D. C.

2006 Términos textiles en castellano. En Actas III Jornadas Internacionales sobre Textiles Precolombinos, editadas por Victória Solanilla Demestre, pp. 443-469. Grup d' Estudis Precolombins, Departamento de Arte de la Universidad Autónoma de Barcelona, Barcelona.

Schmidt, Max

1937 a Los Guisnais. Revista de la Sociedad Científica del Paraguay, IV (2): 1-35.

1937 b Los Tapietés. Revista de la Sociedad Científica del Paraguay, IV (2): 36-85.

Seiler-Baldinger, Annemarie

1994 Textiles. A classification of techniques. Smithsonian Institution Press, Washington D.C.

Susnik, Branislava

1982 Los aborígenes del Paraguay. Cultura Material. Museo Etnográfico “Andrés Barbero", Asunción.

Von Koschitzky, Mónica

1992 Las telas de malla de los Wichí/Mataco. Su elaboración, su función y una posible interpretación de los motivos. Centro Argentino de Etnología Americana, Buenos Aires.

Von Rosen, Eric

1924 Ethnographical Research Work during the Swedish Chaco-Cordillera Expedition, 1901-1902. Fritze Limited, Estocolmo. 


\title{
Documentando y conservando las colecciones plumarias del Museo Etnográfico Juan B. Ambrosetti; Facultad de Filosofía y Letras, Universidad de Buenos Aires
}

\author{
Silvana Di Lorenzo* \& Silvia Manuale ${ }^{\dagger}$ \\ * Museo Etnográfico Juan B. Ambrosetti, FFyL, UBA (sildilor@hotmail.com) \\ † Instituto de las Culturas (IDECU - CONICET)
}

\begin{abstract}
Resumen
Los pueblos originarios de la región sur de América hicieron y hacen uso de las plumas de aves locales para la elaboración de indumentaria y artefactos rituales, a través de complejas manufacturas que combinan conocimiento de técnicas textil y plumaria. En este trabajo presentamos la problemática de conservación y documentación de las colecciones plumarias del Gran Chaco, actualmente conservadas en el Museo Etnográfico Juan Bautista Ambrosetti, señalando la importancia del registro gráfico y fotográfico, herramientas metodológicas fundamentales para la documentación y la conservación de colecciones etnográficas.
\end{abstract}

Palabras claves: Conservación textil, documentación textil, Gran Chaco, Museo Ambrosetti, artefactos plumarios.

\begin{abstract}
The indigenous peoples of the South American region made and make use of the feathers of local birds for the manufacture of clothing and ritual artefacts, through complex manufactures that combine knowledge of textile and featherwork techniques. In this paper we present the problem of conservation and documentation of the feather collections of the Gran Chaco, at this moment preserved in the Juan Bautista Ambrosetti Ethnographic Museum, pointing out the importance of the graphic and photographic record, fundamental methodological tools for the documentation and conservation of ethnographic collections.
\end{abstract}

Keywords: Textile conservation, textile documentation, Gran Chaco, Ambrosetti Museum, feather ornament.

\section{Résumé}

Les peuples originaires de la région sud-américaine ont fait et continuent de faire usage des plumes d'oiseaux locaux dans l'élaboration des tenues et des artefacts rituels, à travers des manufactures complexes qui combinent la connaissance des techniques textiles et celles associées aux plumes. Dans cet article nous présentons le problème de la conservation et de la documentation des collections d'objets en plumes du Gran Chaco, actuellement conservés au Musée Ethnographique Juan Bautista Ambrosetti, en soulignant l'importance des registres graphiques et photographiques, outils méthodologiques fondamentaux pour la documentation et la conservation des collections ethnographiques.

Mots-clés: Conservation textile, documentation textile, Gran Chaco, Musée Ambrosetti, artefacts en plumes.

DOI: $10.32873 /$ unl.dc.zea.1219

Published in PreColumbian Textile Conference VIII / Jornadas de Textiles PreColombinos VIII, ed. Lena Bjerregaard and Ann Peters

(Lincoln, NE: Zea Books, 2020). https://digitalcommons.unl.edu/zeabook/ 


\section{Introducción}

El Museo Etnográfico de la Universidad de Buenos Aires almacena y exhibe un amplio acervo de origen arqueológico y etnográfico procedente de varias partes del mundo. Desde los objetos locales, tales como los textiles arqueológicos de las sociedades del noroeste argentino, las miniaturas incas halladas en Catamarca, pasando por los tejidos andinos provenientes de Perú, hasta los objetos etnográficos, productos de los pueblos nativos de los cinco continentes; entre ellos, es destacable un conjunto de objetos etnográficos plumarios de la región que Argentina comparte principalmente con $\mathrm{Pa}$ raguay y Bolivia, denominada Gran Chaco.

El objetivo de este artículo es presentar la modalidad de trabajo para la preservación de las colecciones plumarias, haciendo referencia al proceso de documentación utilizado durante las prácticas de conservación y enmarcándolo en el concepto más amplio de la conservación preventiva. Se señala además, la metodología de investigación relacionada con la adquisición de información para documentar y realizar adecuados diagnósticos del estado de conservación de los objetos patrimoniales, teniendo en cuenta la materialidad, el contexto de uso pasado y reconociendo el uso actual por parte de las comunidades originarias.

Finalmente, se hace específica mención a las acciones de conservación preventiva para el manejo de las colecciones etnográficas cuyo componente principal es la pluma, un material de origen orgánico, altamente sensible a la degradación debido a múltiples factores.

\section{Documentar para conservar y conservar para documentar}

El trabajo de conservación en los museos o instituciones que resguardan objetos patrimoniales implica diferentes procedimientos a partir de un plan de preservación para el manejo de las colecciones. La documentación atraviesa todo el desarrollo de conservación del patrimonio, constituyéndose en procesos entrelazados con el fin de obtener un registro de todo lo que concierne a cada objeto, desde la materialidad, la técnica de manufactura, la forma, hasta la información o biografía del objeto, relacionada con los usos pasados y la historia del objeto dentro de la institución (Alvarado Pérez y Azócar Magüida 1994). De esta manera, es importante conocer y registrar la naturaleza o la composición química de cada objeto de la colección, analizar la forma de elaboración, los posibles rastros de uso y los diferentes tratamientos a los que fue sometido durante su estancia en la institución, para poder preservar el objeto en sí mismo y a la información contenida. Y esta tarea de documentación antecede a cualquier tipo de intervención, como así también todo el proceso de conservación y restauración debe ser documentado para que en el futuro otros profesionales puedan evaluar los cambios en el estado de conservación y discernir los agregados durante la restauración de los objetos.

\section{La fotografía y el dibujo como herramientas para la documentación en conservación:}

La manipulación del material plumario es uno de los factores principales en la producción de deterioros del componente proteico, teniendo en cuenta la alta fragilidad estructural de la pluma; por lo que se torna imprescindible la aplicación de una metodología singular que permita minimizar las alteraciones físicas y químicas.

La fotografía y el dibujo se sugieren como herramientas metodológicas adecuadas para la documentación y a la vez la preservación de las colecciones de origen orgánico.

El registro fotográfico es fundamental para la identificación de un objeto patrimonial en el inventario de una colección, y además es de suma importancia para documentar toda la información relacionada con el estado de conservación y los diferentes tratamientos de conservación y restauración. Por otro lado, es un recurso importante para evitar la excesiva manipulación, facilitando el acceso a los objetos para la consulta y la investigación (Roubillard Escudero 2008).

Aunque se ha planteado que la fotografía es un recurso más objetivo para el registro de un objeto que el dibujo (Icon News 2015), es importante señalar que existe una diferencia sustancial entre el dibujo científico y el artístico, lográndose mayor objetividad de representación del material a través de diferentes convenciones con el primer tipo de representación gráfica.

La fotografía es útil para obtener un registro acabado del objeto y también nos posibilita cierto detalle a través de sus lentes macro. Mediante la observación de estas imágenes es posible realizar los registros gráficos sin manipular directamente el objeto.

El dibujo no copia sólo la apariencia de un objeto sino que recrea una imagen artificial del mismo. Este es el resultado de la práctica de la observación sobre el objeto, seguida por la deconstrucción analítica mental y luego su reconstrucción sobre el papel en una manera que presenta más claramente los rasgos observados ${ }^{1}$ (Icon News 2015:11).

La constante observación del objeto real se va tornando abstracta en la mente del dibujante y esa abstracción a su vez se vuelve real; y esa realidad es la copia del objeto concreto. 


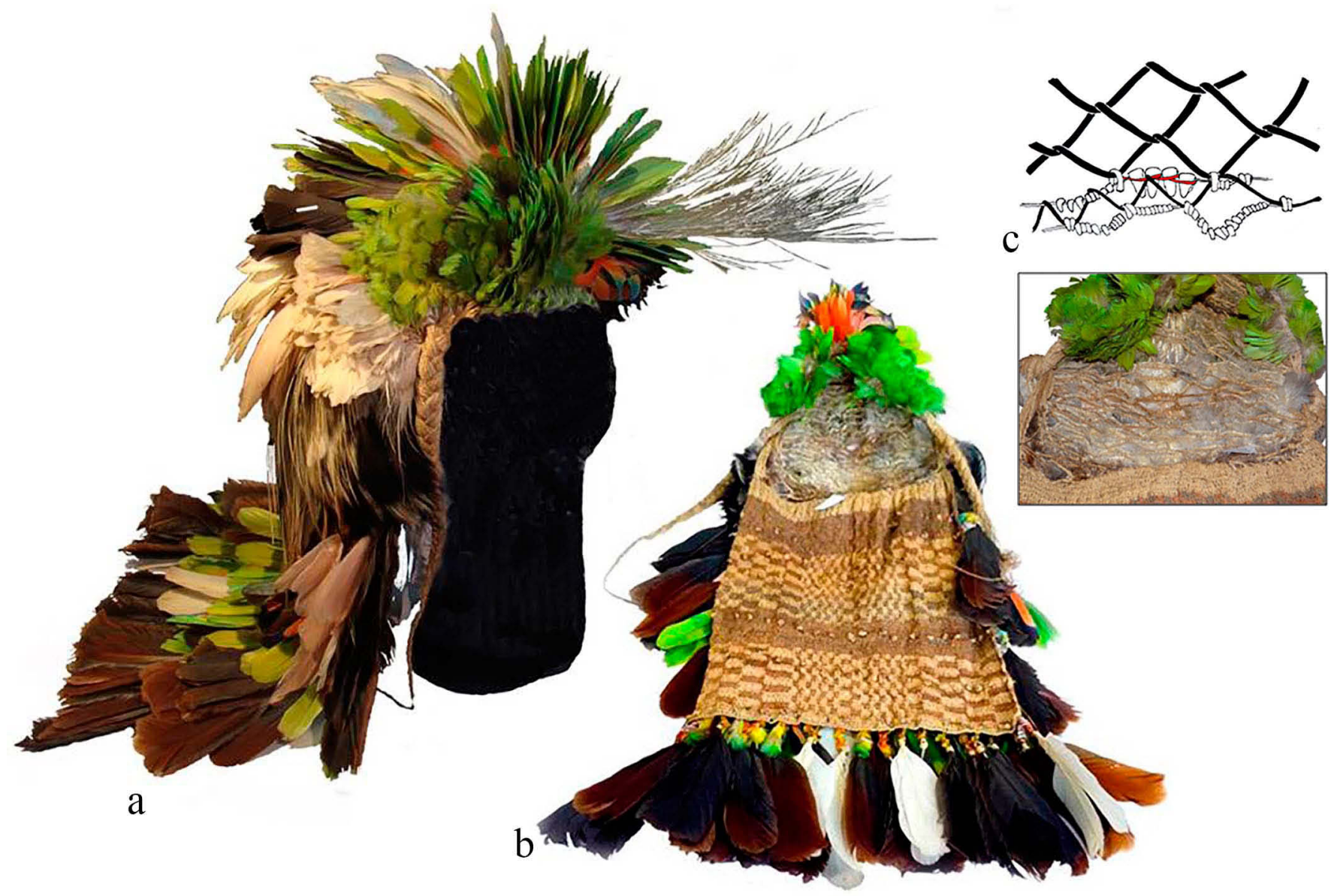

Figura 1. Tocado ishir $N^{\circ} 6265$ (ME, FFyL, UBA). a. Anverso; b. Reverso; c. Técnica plumaria: enlaces de hileras de plumas en el gorro y unión de gorro con cubrenuca (dibujo por Silvia Manuale).

Según la mirada y el conocimiento del dibujante, se pueden mostrar de forma clara, precisa y simple los detalles, las formas y los diseños de un objeto. Además, el dibujo es una herramienta útil para mostrar el proceso de manufactura de un objeto en una secuencia de tiempo (Icon News 2015). Por ejemplo, en el caso particular de un tocado ishir (Figura 1), la parte superior puede ser representada en sus diversos pasos de manufactura: la técnica de las hileras de plumas sobre cordel base, los enlaces y anudados de las hileras; en la parte media, la unión del gorro con el cubrenuca y en la parte inferior queda registrada el tejido de malla junto a la inserción de los fustes o manojos de plumas mediante nudos.

Largas explicaciones textuales pueden ser simplificadas a través de un simple dibujo que muestre "una secuencia de movimientos dentro de una imagen única" (Icon News

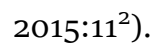

Así como el arqueólogo tiene su libreta de campo, el dibujante posee su libreta de apuntes donde plasma bocetos, notas diversas, medidas e ideas que ayudarán a la elaboración del trabajo final. Como afirma John Berger (2017: 61): "Dibujar no es sólo medir y disponer en el papel, sino que también es recibir". Podríamos agregar, recibir aquello que nos cuenta sobre lo que observamos, estableciéndose un diálogo permanente, una empatía tan profunda entre el dibujante y lo observado, que la mano parecería estar guiada por el alma del objeto, capturando con la mirada, intención y compromiso esa primera toma que llevará a la imagen definitiva.

A partir del análisis minucioso pueden surgir dudas, preguntas acerca de cómo habría sido confeccionado el objeto; aparecen las primeras hipótesis de las técnicas de manufactura, se aproximan las medidas o dimensiones y se las plasma en el papel. Se compara la bibliografía disponible y se buscan antecedentes ya publicados con las posibles 
denominaciones de las técnicas, la normativa, las convenciones y las clasificaciones ya establecidas, en el caso de que las hubiera; también se pueden realizar interconsultas con otros especialistas.

Es necesario volver a señalar que para la realización del trabajo detallado han sido muy útiles las fotografías obtenidas a través de lentes macro, las cuales nos acercan a detalles que difícilmente puedan ser vistos a simple vista.

\section{Las colecciones plumarias del Gran Chaco}

El Museo Etnográfico de la Universidad de Buenos Aires, cuyo creador y primer director fuera el naturalista y arqueólogo Juan B. Ambrosetti fue concebido como un lugar de formación, investigación y difusión a partir de la exhibición de colecciones procedentes de excavaciones arqueológicas y de aquella cultura material contemporáneamente producida por los pueblos originarios (Pegoraro y Elías 2010). De esta manera, parte del patrimonio etnográfico procedente del Gran Chaco fue recogido y donado durante las dos primeras décadas del siglo XX, y otra gran parte, provino de las expediciones del etnógrafo Enrique Palavecino, en la década de $1940^{3}$.

El denominado Gran Chaco americano es una extensa región que abarca la parte nordeste del territorio argentino, el sudeste de Bolivia, una muy pequeña porción de Brasil y un gran sector del Paraguay, cuyo límite oeste es el río homónimo (Figura 2). En este gran y diverso territorio, los pueblos originarios viven desde épocas ancestrales; producen y han producido una compleja cultura material, y algunos de sus objetos son actualmente conservados en este museo universitario.

Una variedad de textiles y partes de la indumentaria con plumas proceden de los pueblos pilagá, chorote, wichí, qom, ishir y ayoreo. Mantas, ponchos, fajas, bolsas, vinchas, tocados, brazaletes, diademas, tobilleras y cinturones constituyen el patrimonio etnográfico chaqueño preservado en la institución de Buenos Aires. La materialidad presente en el soporte textil de lana o de chaguar abarca la pluma, las mostacillas o cuentas de vidrio, las cuentas de valvas, los botones, y hasta aves disecadas (Figura 3).

Es de interés en este trabajo señalar aquellas partes de la vestimenta que utilizaron plumas, que en el caso de los pueblos del chaco paraguayo y boliviano, son de origen natural, aprovechando la gran variedad de aves locales de la región; y que en el lado argentino, algunas son utilizadas de forma natural y otras se tiñen para lograr colores difícilmente alcanzables en la naturaleza local.

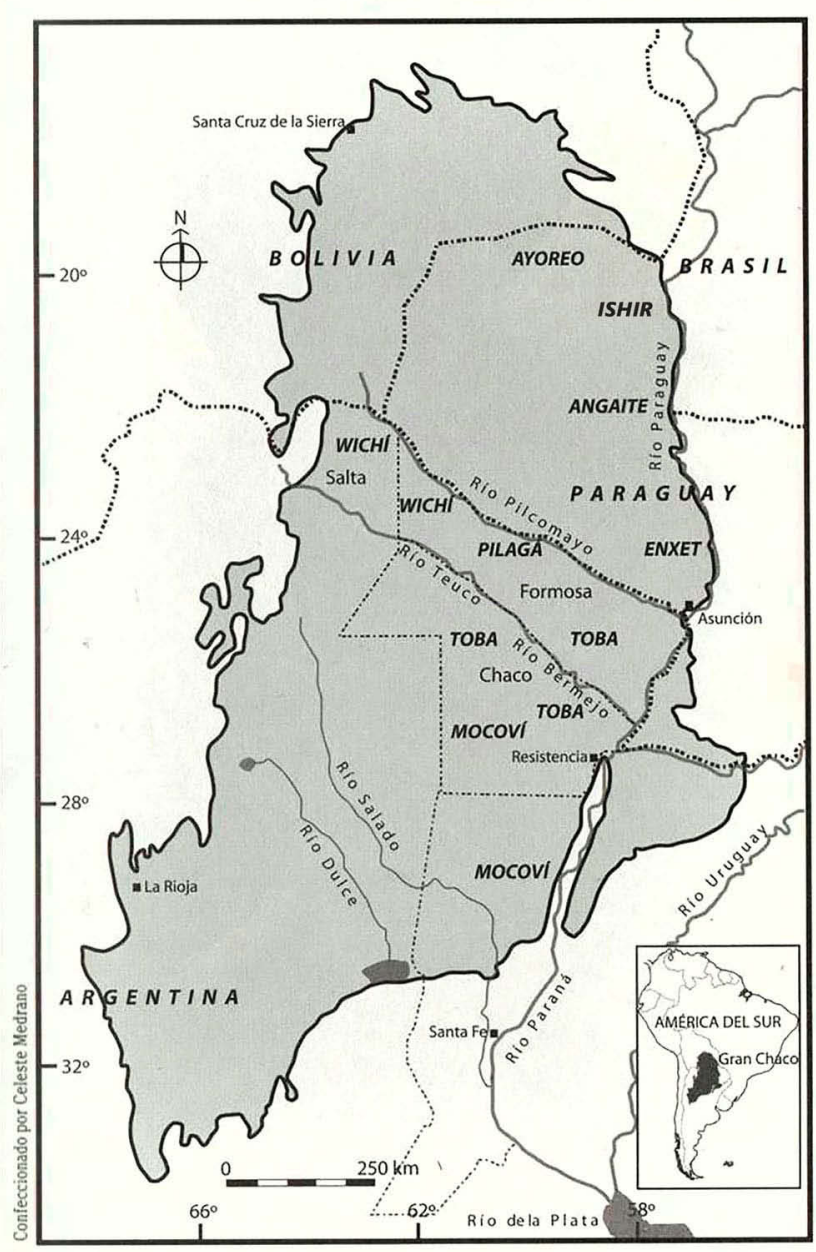

Figura 2. Mapa del Gran Chaco, realizado por Celeste Medrano (Tola F. 2016. Una historia más que humana. En: El teatro chaqueño de las crueldades. Memorias qom de la violencia y el poder, comp. F. Tola y V. Suárez. Ethnographica. Asociación civil Rumbo Sur - Consejo Nacional de Investigaciones Científicas y Tecnológicas -CONICET- Instituto de Investigaciones Geohistóricas - IIGHI: 34).

El estudio y análisis de la técnica plumaria en las diferentes áreas de la región nos permitió encontrar similitudes y diferencias entre las técnicas plumarias de los pueblos del chaco argentino y el paraguayo.

La técnica plumaria general y básica presente en vinchas, tocados, diademas y cinturones es la hilera de plumas sobre un cordel base con doblez del cálamo (Figura 4). De esta manera, se realiza la sujeción de las plumas enlazando a través de un cordel de fibra vegetal, el caraguatá o chaguar y doblando la parte inferior de la pluma, de modo tal que la unión quede firme a través del cordel. A partir de esa

3. Los objetos recolectados por Palavecino ingresaron originalmente al Museo de Ciencias Naturales B. Rivadavia, y por decreto del Ejecutivo, en 1947, se hizo el traspaso de todas las colecciones antropológicas al Museo Ambrosetti. 


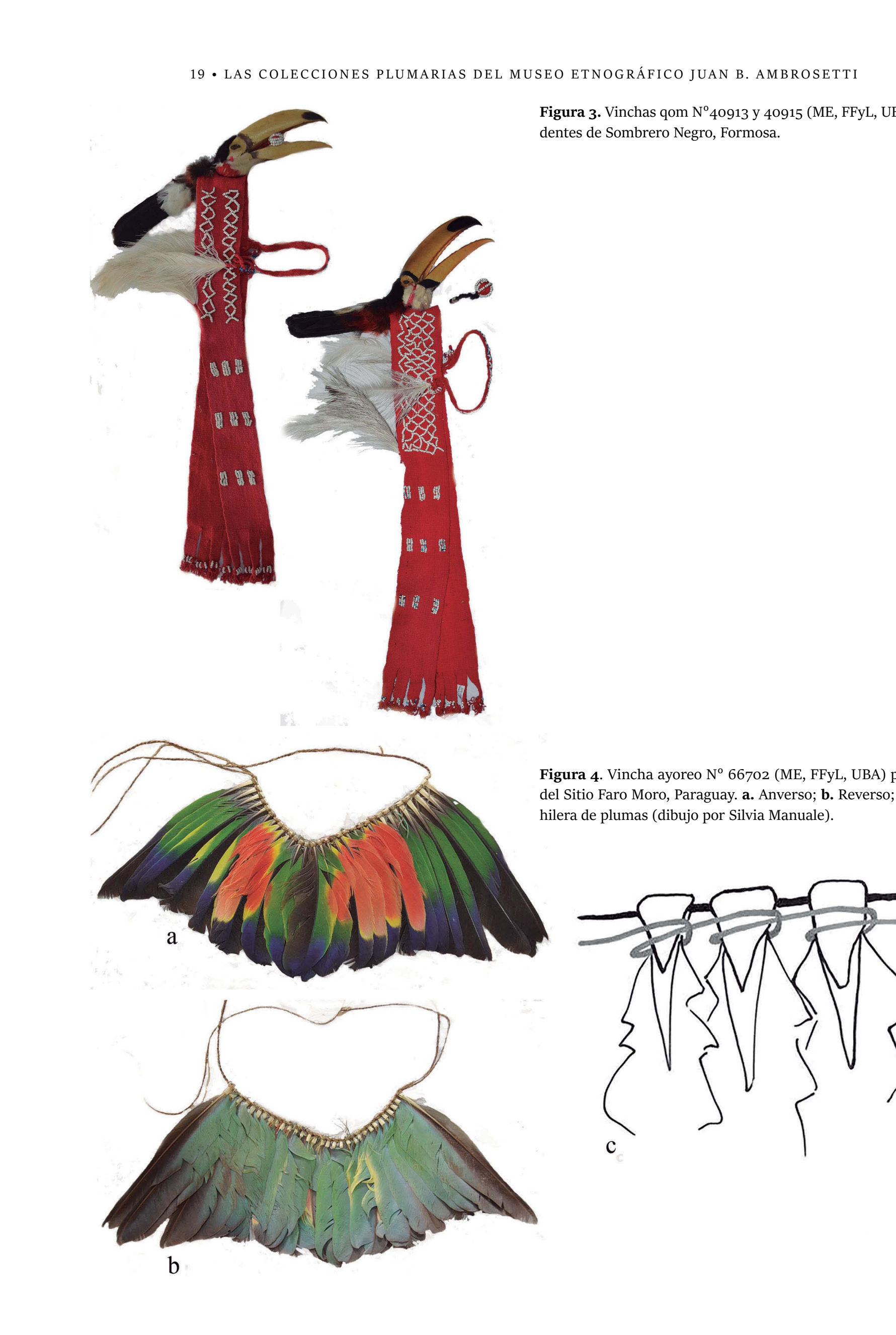



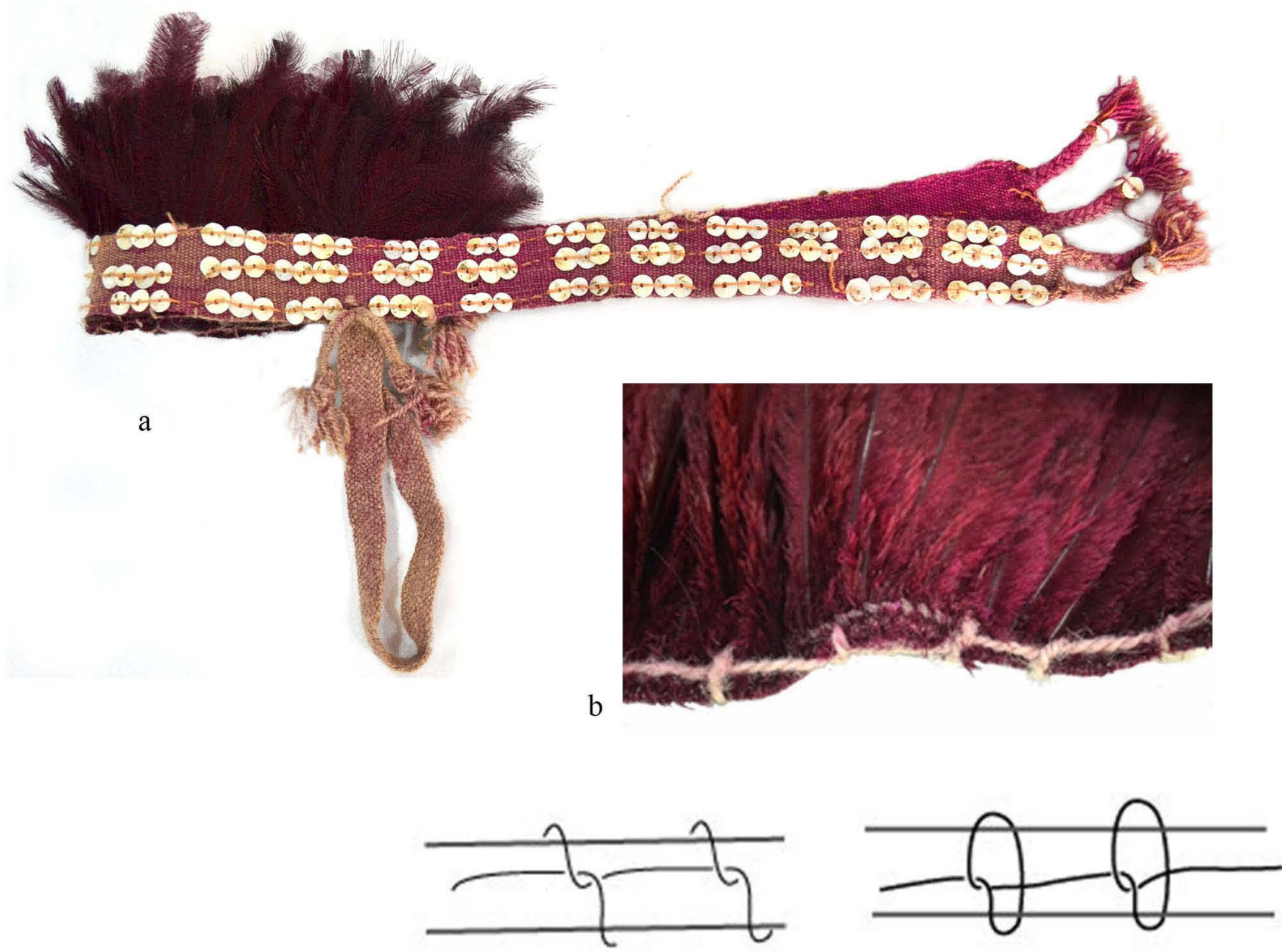

c

Figura 5. Vincha chorote $\mathrm{N}^{\circ} 44414$ (ME, FFyL, UBA), colección Debenedetti a. Vincha; b. Detalle de la sujeción de las plumas al textil; c. Técnica de sujeción, punto festón (dibujo por Silvia Manuale).

técnica de base se realizan otro tipo de amarres al tejido, como el festón en la vincha chorote (Figura 5) o los enlaces en los tocados ishir.

En el caso de la vincha pilagá tejida en lana teñida de roja, la sujeción de las plumas al textil se realiza mediante simples amarres con enlaces y nudo simple por medio de un cordel de caraguatá (Figura 6). Cuando la pluma es la protagonista principal, otro tipo de sujeciones más complejas pueden observarse en los cinturones y los adornos para miembros ishir. En uno de los cinturones, a partir de un cordel principal, se desprenden haces de plumas, que están sujetos mediante un wrapping o enrollado y nudo simple, mediante doblez del cálamo (Figura 7). En otro de los cinturones, con apliques de plumas coloridas del loro hablador, sobre cordel base, se enlazan pequeños fustes o manojos de plumas mediante enlaces con nudo simple (Figura 8). En las muñequeras, brazaletes o tobilleras, plumones verdes son sujetos en los intervalos de los nudos de una retícula (Ribeiro 1988) formada por los diferentes cordeles de chaguar (Figura 9).

Las técnicas textiles empleadas en las colecciones plumarias del Gran Chaco están representadas por la faz de urdimbre como es el caso de la vincha chorote realizada sobre un tejido de lana teñida (Figura 10); y la técnica de malla o enlaces interconectados figura en ocho (Seiler Baldinger 1994), como es el ejemplo de los tocados ishir, confeccionados sobre la fibra del caraguatá (Figura 11).

La indumentaria con plumas ha sido registrada en contextos de uso ceremonial y generalmente quienes la portan son líderes religiosos que en la literatura científica han sido denominados shamanes o chamanes, como entre los ishir del chaco paraguayo (Cordeu 1980; Escobar 2012). Existen registros publicados sobre el uso de vinchas con plumas con las características ya mencionadas así como otros tipos de 


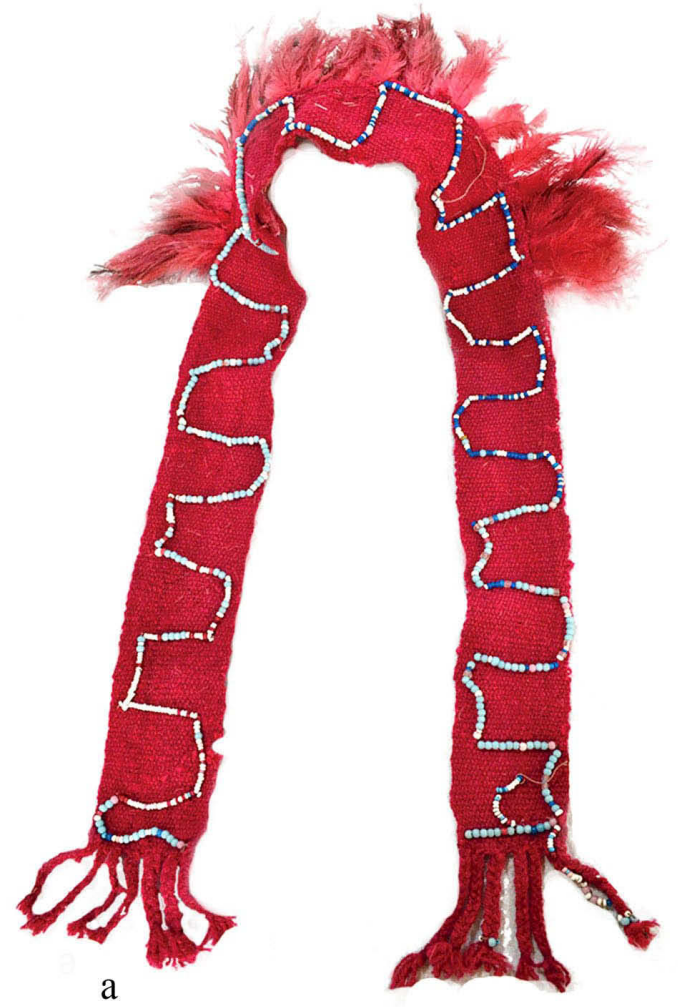

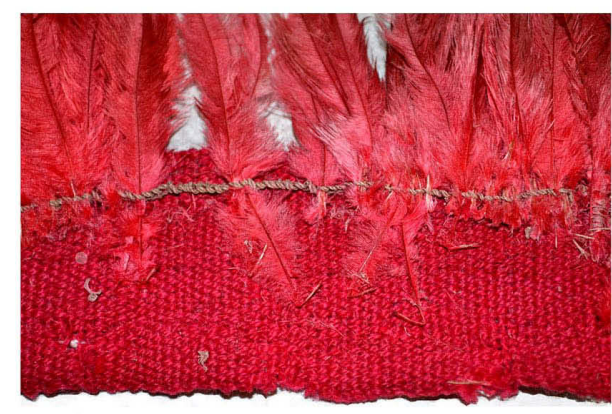

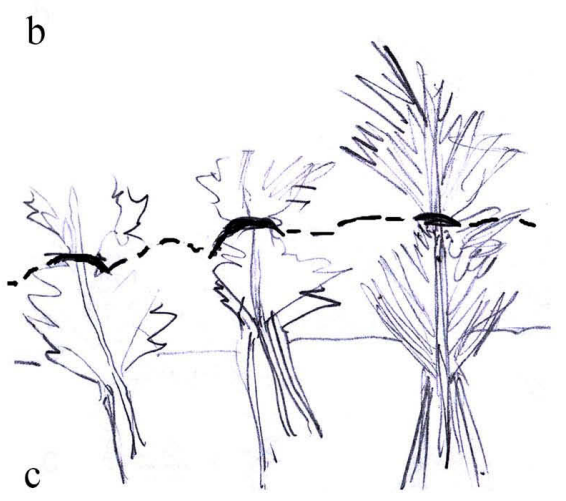

Figura 6. Vincha pilagá No 44904 (ME, FFyL, UBA), colección Palavecino. a. Vincha; b. Detalle de la sujeción de plumas al textil; c. Técnica de la sujeción de plumas al tejido (dibujo por Silvia Manuale).

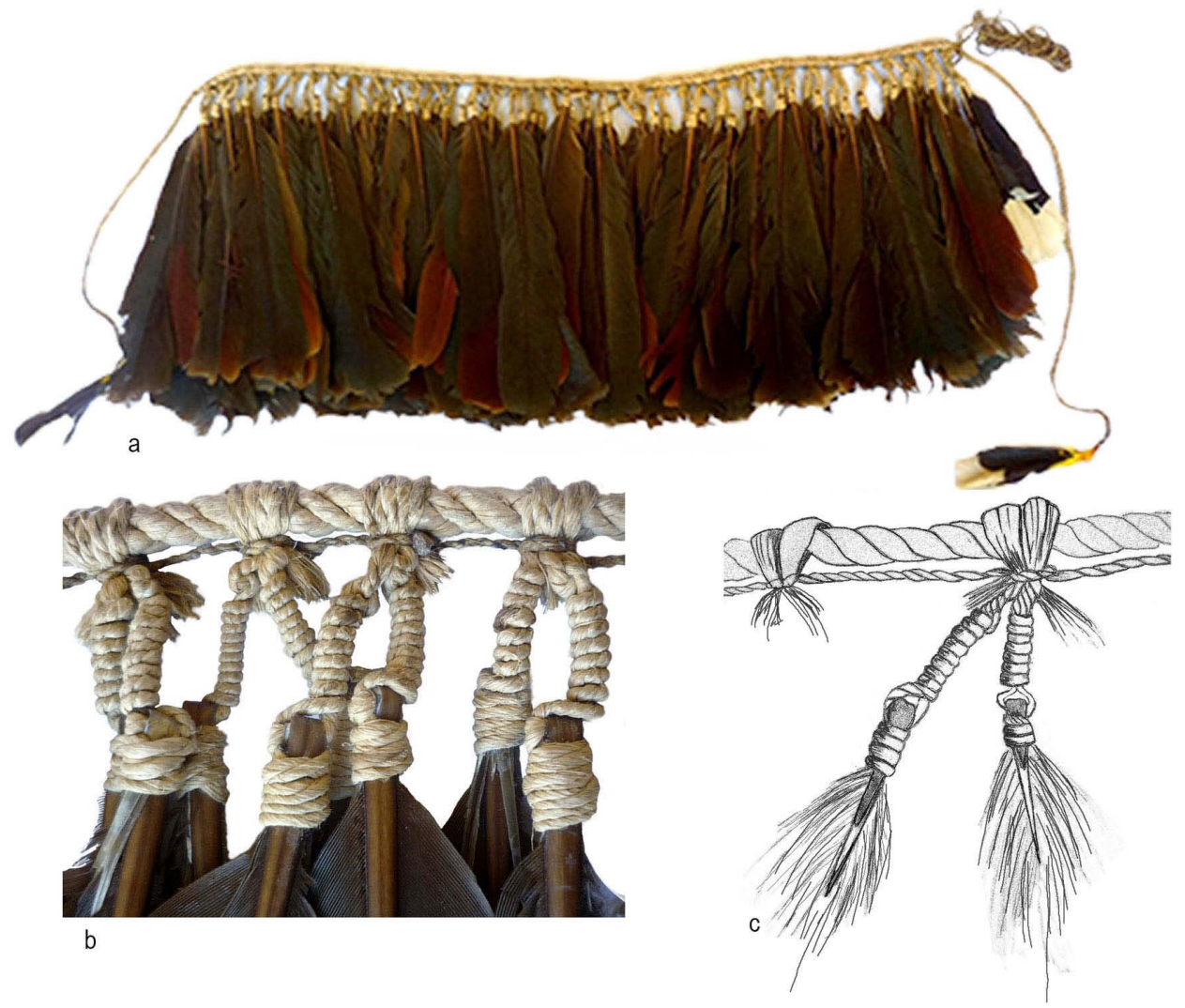

Figura 7. Cinturón ishir N 23461 (ME, FFyL, UBA), colección Ambrosetti a. Cinturón; b. Detalle de la sujeción de los haces de plumas; c. Técnica de sujeción de los haces de plumas (dibujo por Silvia Manuale). 
Figura 8. Cinturón ishir $\mathrm{N}^{\circ}$ 2346o (ME, FFyL, UBA), colección Ambrosetti a. Cinturón; b. Técnica de sujeción del haz de plumas (dibujo por Silvia Manuale).

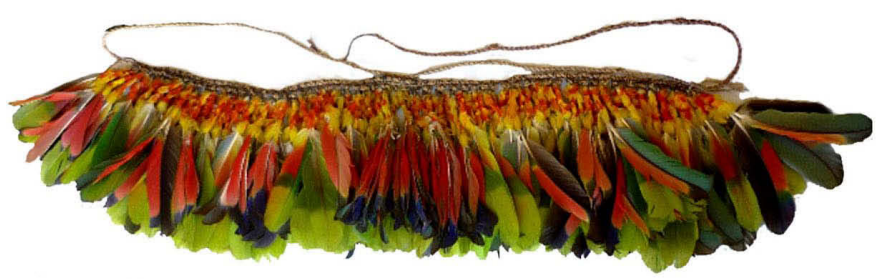

a

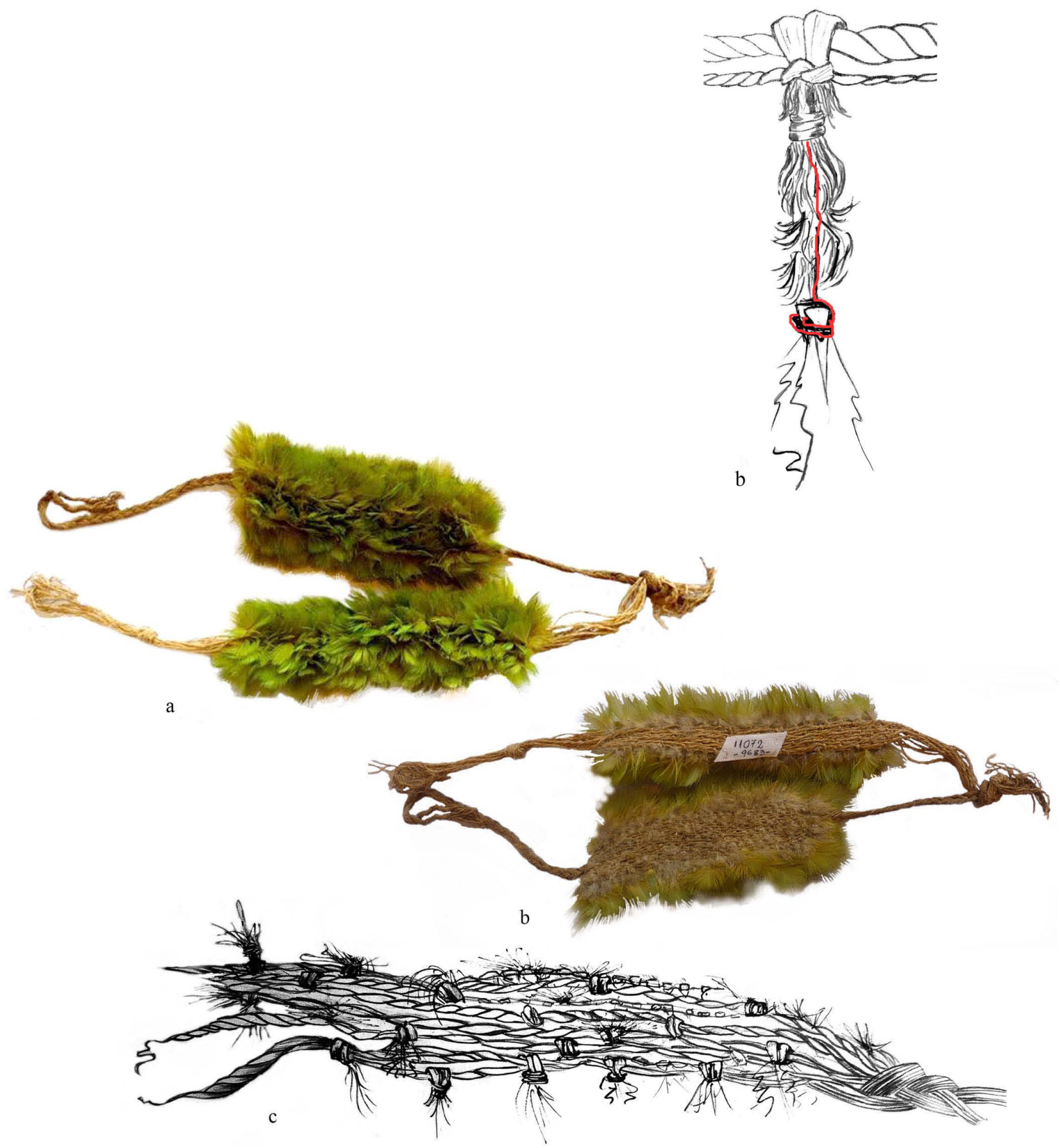

Figura 9. Adorno para miembros $\mathrm{N}^{\circ} 11072$ (ME, FFyL, UBA), colección Aguirre. a. Anverso; b. Reverso; c. Técnica de sujeción de plumas (dibujo por Silvia Manuale) 
Figura 10. Vincha chorote $\mathrm{N}^{\mathrm{o}} 5664$ (ME, FFyL, UBA), colección Debenedetti. a. Vincha; b. Detalle de la técnica faz de urdimbre; c. Dibujo de la técnica faz de urdimbre (Seiler Baldinger 1994: 89).
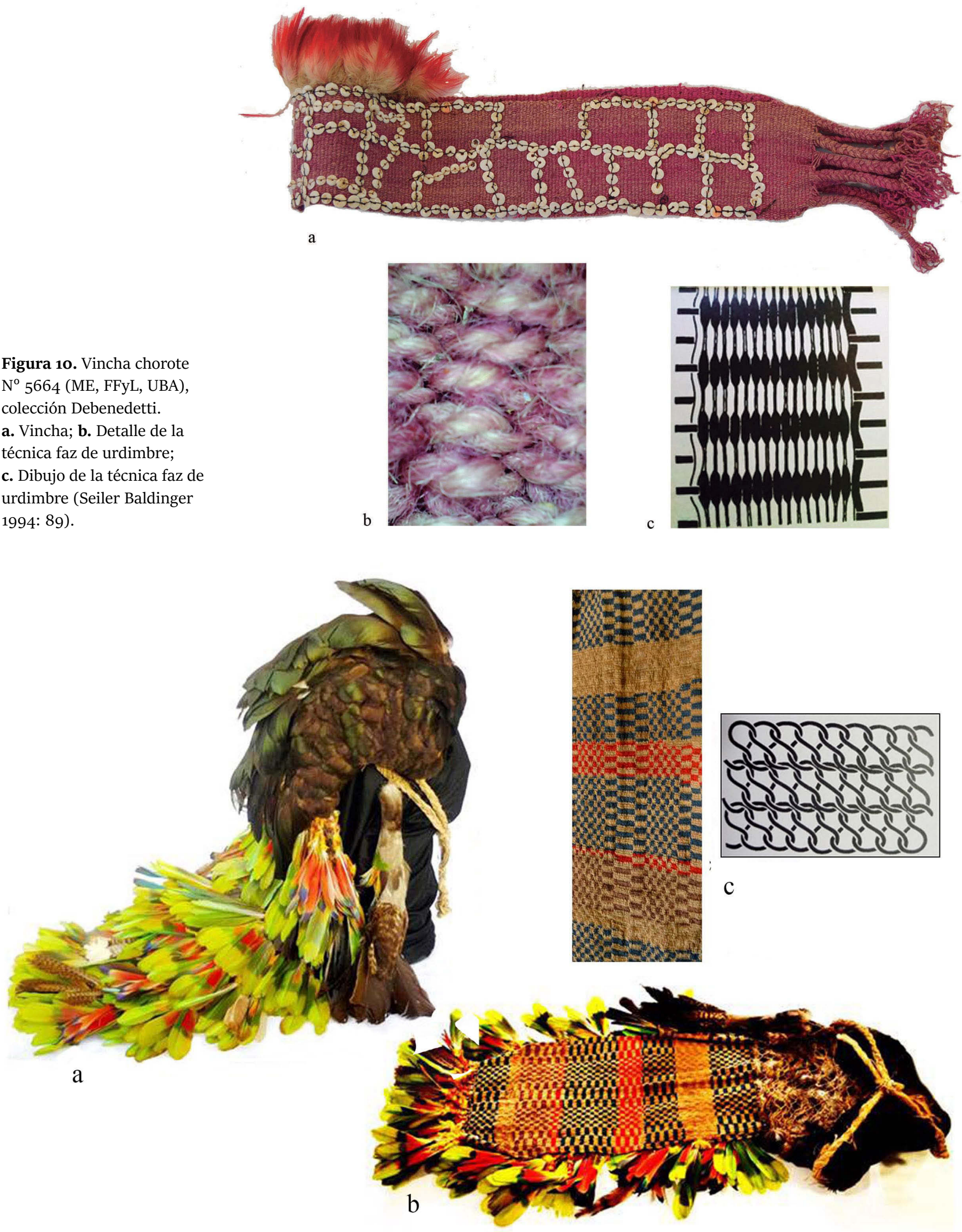

Figura 11. Tocado ishir 11074 (ME, FFyL, UBA) a. Anverso b. Reverso c. Dibujo de la técnica de malla (Seiler Baldinger 1994: 15). 

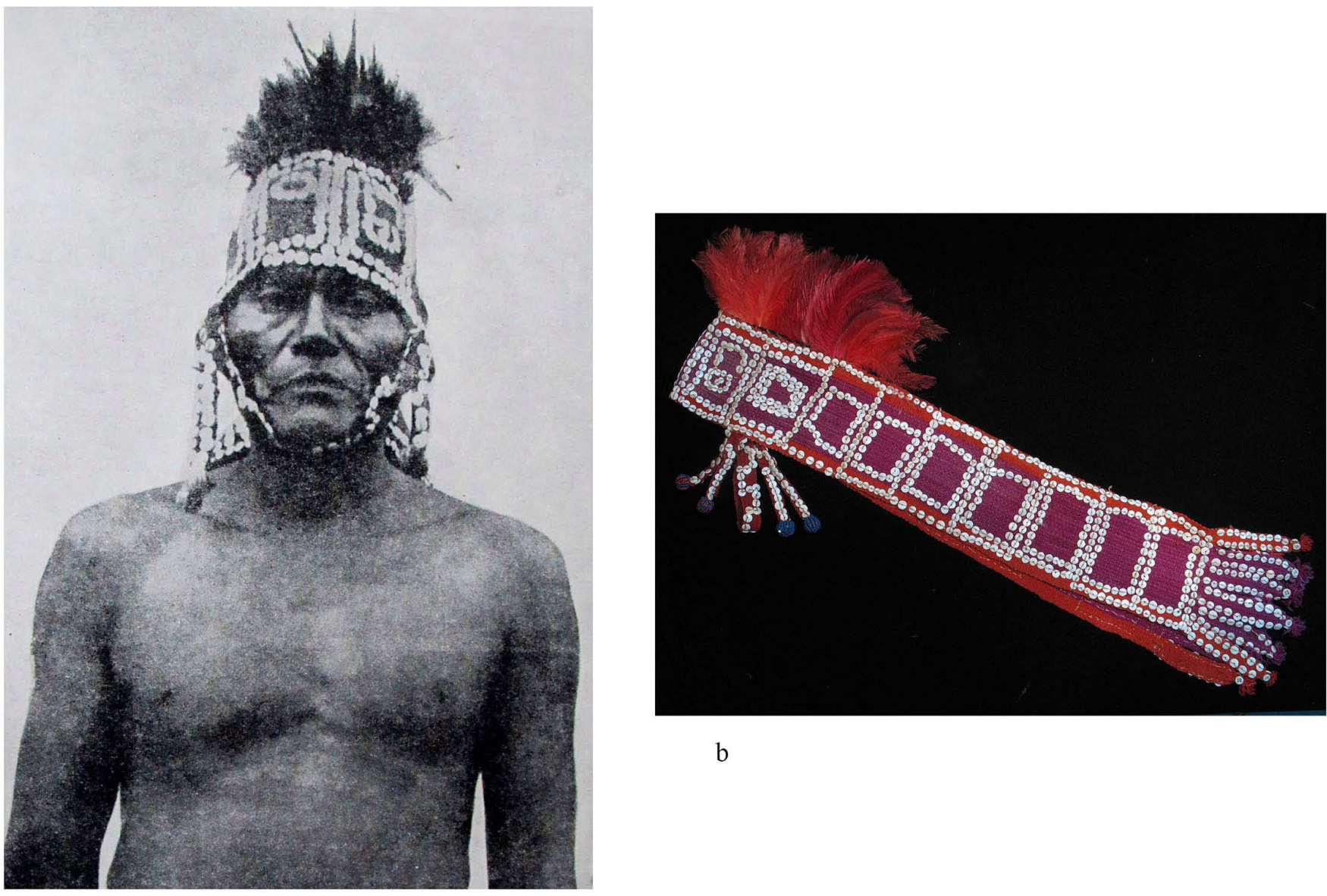

b

a

Figura 12. a. Shamán wichí, publicado por Palavecino (1936: 409) como "Hechicero mataco de Bazán (Formosa)”; b. Vincha wichí N 41800 (ME, FFyL, UBA).

objetos con plumas entre los wichí de Formosa (Palavecino 1936). Este último autor se refiere al usuario de una vincha roja con plumas y con apliques de conchas como "hechicero"; aquel objeto hoy se halla conservado en el Museo Ambrosetti (Figura 12). El empleo de los diferentes tipos de accesorios plumarios para la vestimenta, tales como los tocados, las tobilleras y muñequeras, ha sido investigado en territorio ishir; donde se han registrado los nombres en su lengua originaria y los significados del uso de cada accesorio y de los tipos de plumas y especies de aves (Escobar 1999, 2012). En el chaco argentino, las vinchas o tocados con plumas también habrían sido utilizados por los guerreros, es decir, en contextos de conflictos como los registrados entre los toba - pilagá y los nivaclé (Bossert y Siffredi 2011).

Actualmente, diferentes tipos de tocados con plumas son portados por los líderes pertenecientes a diversos pueblos originarios del Gran Chaco (Figura 13); este tipo de prenda hoy representa la autoridad política y la identidad indígena en contextos de diálogo con el estado o en manifestaciones diversas por las demandas relacionadas con la defensa del territorio.

\section{Metodología de investigación del patrimonio etnográfico con plumas}

El trabajo de documentación de las colecciones plumarias del Gran Chaco implicó varias etapas de investigación, algunas de las cuales aún están en pleno desarrollo. Se inició con el Proyecto de documentación de colecciones plumarias ishir del Museo etnográfico de la UBA (Di Lorenzo 2007), el cual abarcó la revisión bibliográfica sobre el pueblo ishir y los usos del acervo plumario; el estudio de las técnicas plumarias de manufactura de cada parte de la indumentaria y sus accesorios; la identificación de las especies de aves utilizadas en la confección de los mismos; la observación de patrimonio plumario ishir exhibido en los museos de San Lorenzo y Asunción en Paraguay con el objetivo de recabar datos sobre la materialidad y los significados atribuidos al uso de la plumaria (Figura 14); y finalmente, la realización de entrevistas a representantes ishir para el registro de información referente a los usos pasados y actuales de la cultura material plumaria (Di Lorenzo et al 2016). La consulta en el archivo institucional de Buenos Aires nos brindó 

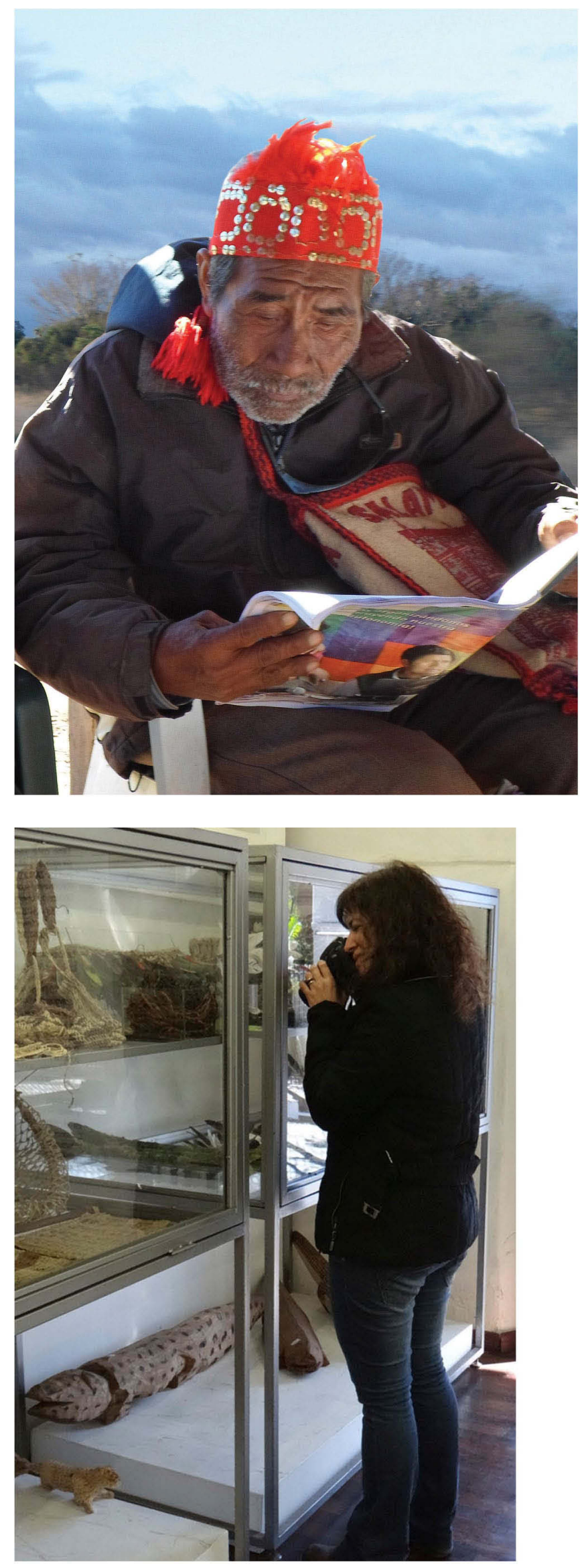

Figura 13. León Ramírez, nivaclé de Formosa (foto de Alicia Blanco) usando vincha de lana roja con apliques de lentejuelas metálicas doradas.

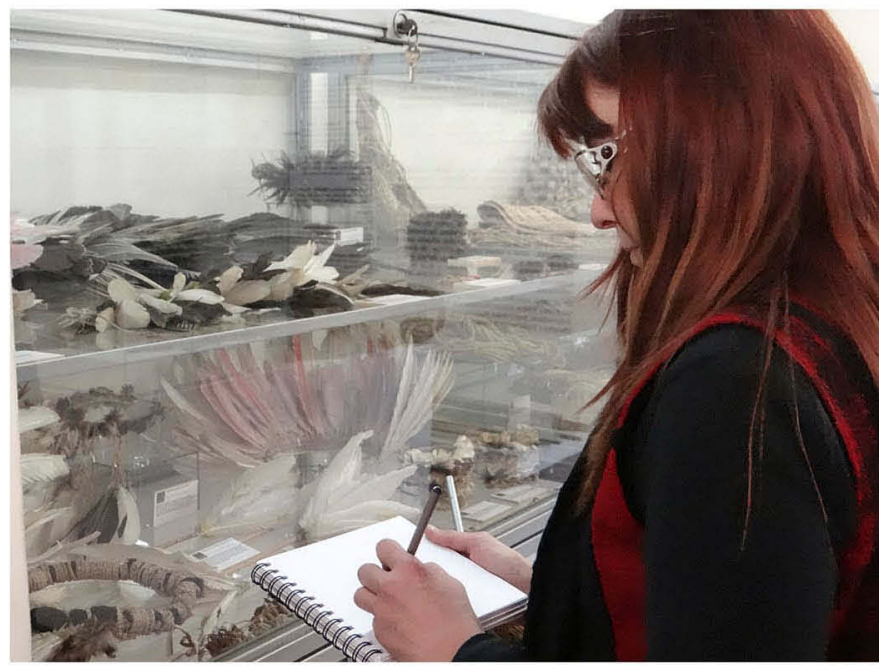

Figura 14. Registro de datos en el Museo Guido Boggiani, San Lorenzo, Paraguay. 
$a-b$
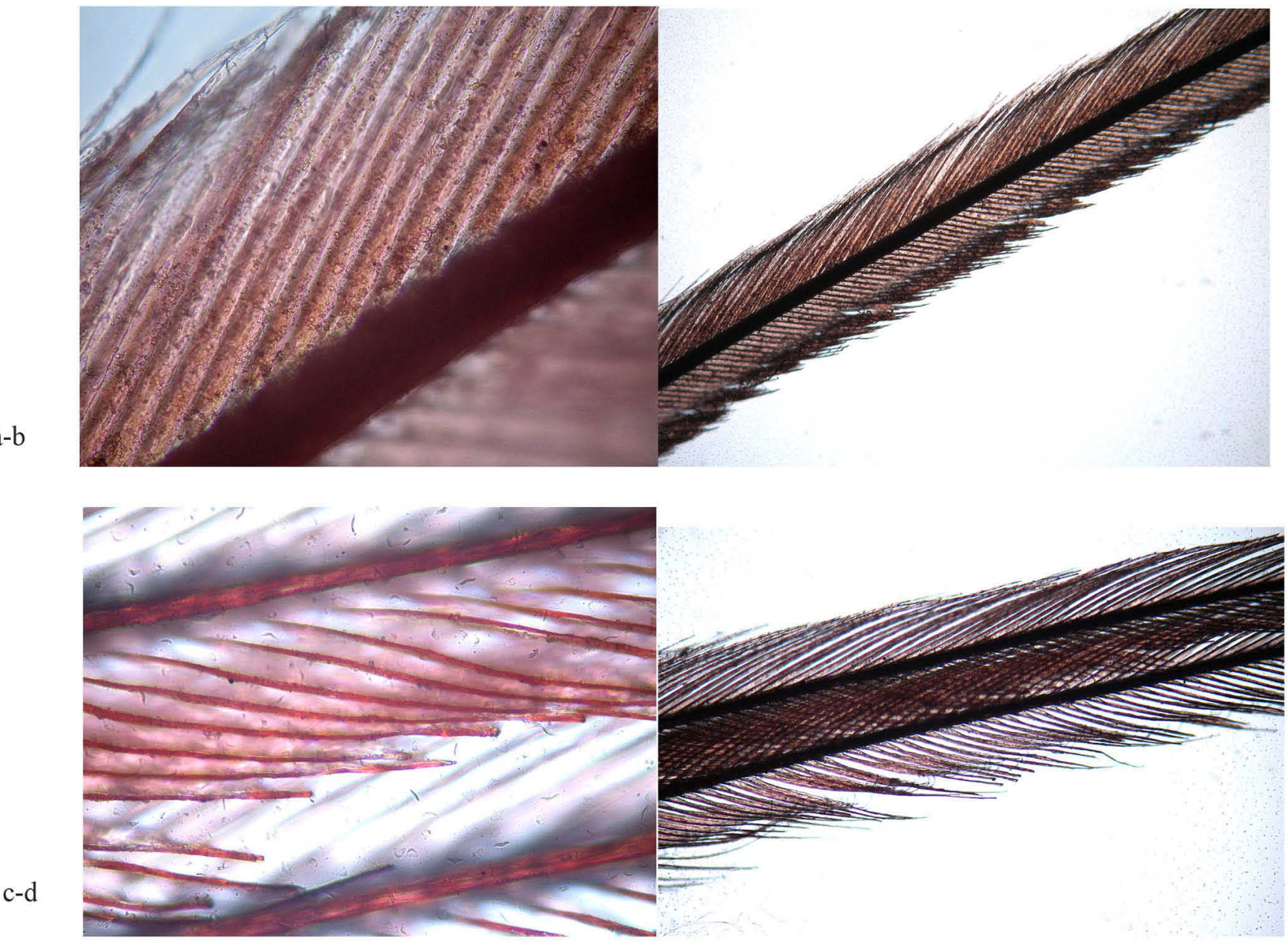

Figura 15. Plumas observadas con microscopio óptico: a y b. Pluma remera de loro hablador (40X y $5 \mathrm{X}$, respectivamente); c y d. Plumones observados con microscopio óptico (40X y 5X, respectivamente).

principalmente la posibilidad de analizar las fuentes procedentes del chaco argentino, a través del Fondo Documental Enrique Palavecino. Entre los relatos míticos del pueblo wichi recogidos por este etnógrafo en la década de 1930, es interesante señalar la alusión a las aves como parte de la cosmovisión originaria en territorio ancestral formoseño (Di Lorenzo 2016). El registro y análisis de las técnicas plumarias de los pueblos del chaco argentino junto a la lectura de las publicaciones de Palavecino, pertenecientes a los pilagá y wichi completan hasta ahora la información buscada para la documentación del patrimonio etnográfico plumario.

\section{Características del material plumario y algunas} consideraciones para su conservación:

La pluma (Figura 15) se considera como uno de los materiales más sensibles a las alteraciones físicas y químicas. De naturaleza orgánica, la pluma está constituida por un $91 \%$ de proteína, $8 \%$ de agua y $1 \%$ de lípidos (Bishop Museum
1996). El tipo de proteína es la queratina, pero de una clase diferente a la de la lana, ya que comparten diferente proporción de aminoácidos (Tímár-Balázsy 1998).

Una pluma típica, del estilo cobertera posee un cálamo en su parte inferior y un raquis que lo continúa, eje desde el cual nacen numerosas barbas y bárbulas; a este sector de las barbas se lo denomina vexilo o estandarte (Hickman et al 1986).

Existen diferentes tipos de plumas, las cuales tienen diferentes funciones en las aves (Figura 16). Es importante conocer esta clasificación ya que los tratamientos de conservación pueden variar según sea por ejemplo, una pluma cobertera o un plumón, siendo este último caracterizado por tener un aspecto enmarañado debido a la inexistencia de ganchos entre las barbas (Van Tyne y Berger 1966). En este sentido, en un trabajo publicado sobre limpieza de plumas se sugiere el uso de solventes polares para el tratamiento en plumones, mientras que en plumas con vexilo y 


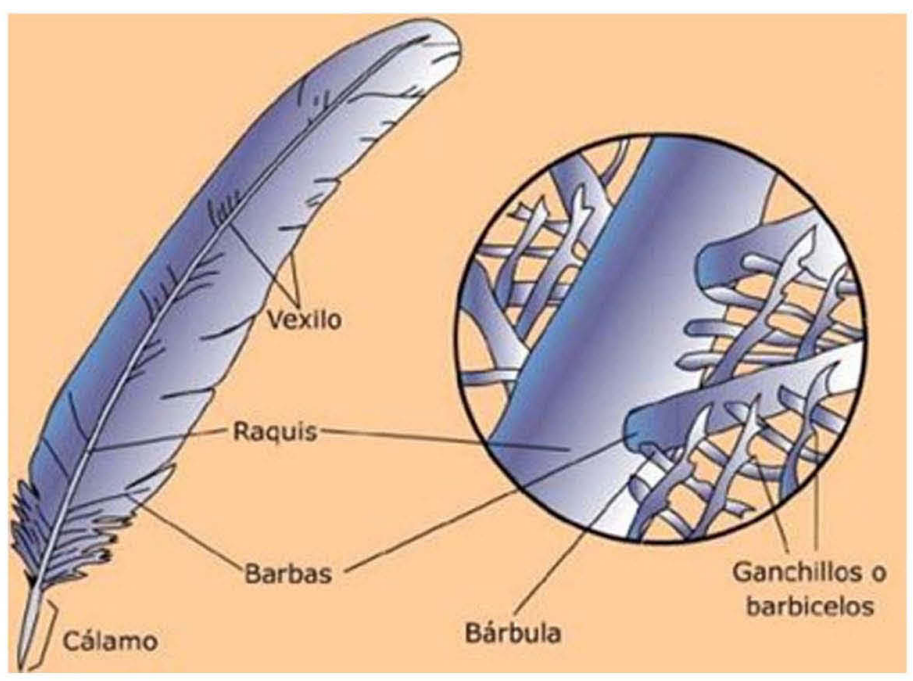

a

Figura 16. a. Partes de una pluma (http://entrepinosysembrados.blogspot.com/2014/11/tipos-de-plumas-en-las-aves.html, accedido el 10 de septiembre de 2019).

b. Tipos de plumas (modificado de https://askabiologist.asu.edu/explore/feather-biology, accedido el 10 de septiembre de 2019).

raquis sería más adecuado la aplicación de solventes no polares para minimizar posibles deterioros (Macías Flores y Blas Rojas 2012).

Es importante conocer también el origen de los colores de las plumas antes de la realización de tratamientos invasivos, con el objetivo de evitar nuevos deterioros, muchas veces no observables a simple vista. Así, los de origen pigmentario como los carotenoides, aquellos que dan los colores rojos, amarillos y naranjas, son lipocromos o de origen graso, por lo tanto deben evitarse las limpiezas con solventes orgánicos como el alcohol a riesgo de remover el pigmento (Pettingill 1958). Las melaninas, que otorgan los colores oscuros como los negros, marrones y grises, están conformadas por gránulos que podrían ser solubles en ácidos (Wallace 1959). Los colores de origen estructural como los azules se producen por la incidencia de la luz sobre la superficie de las barbas.

En otras palabras, no hay pigmentos azules; si observamos con luz transmitida de un microscopio podemos ver que las plumas azules son marrones y que las plumas verdes aparecen como amarillas; esto es consecuencia de la visibilidad de los pigmentos subyacentes (Wallace 1959 en Di Lorenzo 2018).

Los colores iridiscentes también son de origen estructural y se relaciona con el fenómeno óptico de reflexión de ondas de luz sobre las superficies opacas de las barbas (Pettingill
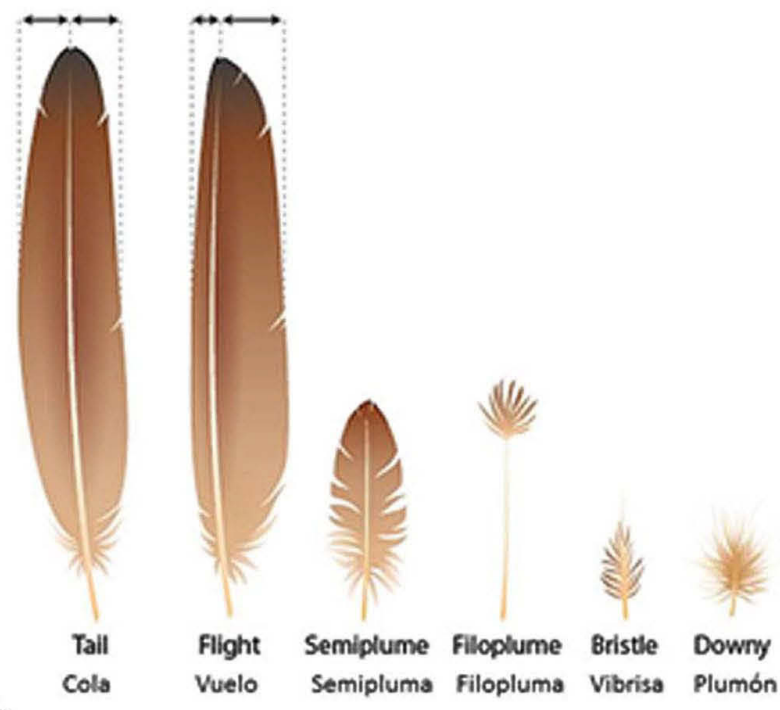

b

1958). Muchas veces, la limpieza de este tipo de plumas puede ocasionar el desorden de las barbas y bárbulas y consecuentemente retirar el brillo iridiscente de las mismas.

La actividad de acicalamiento de las aves, principalmente de las acuáticas, las cuales frotan sus picos contra la glándula uropígea haciendo que su aceite sea distribuido sobre las plumas para lubricar y limpiarlas (Wallace y Mahan 1975) es un dato importante que ha sido tenido en cuenta por algunos trabajos que han replicado de alguna forma este tipo de limpieza. El trabajo con geles en tratamientos húmedos (Amezaga Ramos 2006) y la aplicación de aceites cítricos esenciales para la recuperación de la iridiscencia de las plumas (Macías Flores y Blas Rojas 2012) constituyen ejemplos de intervención que han sido evaluados con resultados positivos por sus autores y que tomaron en cuenta la necesidad de no retirar en lo posible la grasa constitutiva de la pluma.

\section{Acciones de conservación preventiva para el cuidado de colecciones plumarias:}

La conservación de patrimonio plumario es considerada dentro de un plan de manejo integral de las colecciones, el cual comprende diferentes pasos para su preservación a largo plazo, disponible y accesible a las generaciones presentes y futuras. 
La documentación, como se mencionó en este trabajo, es fundamental para la obtención de datos que ayuden a elaborar adecuados diagnósticos del estado de conservación y realizar propuestas de tratamientos para prolongar la existencia de objetos con materialidades vulnerables.

Es importante la contemplación de requerimientos concretos de los tipos de objetos compuestos por materiales orgánicos, tales como la pluma y el textil para el almacenaje en la reserva técnica, el transporte y la exhibición.

La guarda de esta clase de patrimonio en contenedores realizados con material inerte evita su exposición innecesaria a las partículas de polvo; y la construcción de bandejas y soportes de guarda reduce su manipulación, a la vez que ofrece un apoyo ergonómico y suave, adaptable al espacio de la reserva técnica. El uso de envoltorios como el papel libre de ácido contribuye a una mayor protección, principalmente en sectores donde el ambiente no está controlado. El mobiliario apto para su guarda permanente debería ser metálico con pintura epóxica, por su alta resistencia química y por carecer de disolventes que podrían afectar las colecciones.

La exhibición en vitrinas de formato cerrado es una barrera contra el ingreso de contaminantes y plagas, a la vez que es una medida de seguridad frente al vandalismo. Los objetos, principalmente los tridimensionales, como por ejemplo los tocados ishir, deberían ser expuestos sobre soportes adecuados, de manera tal de amortiguar la acción de las fuerzas físicas y así evitar posibles deterioros provenientes de la abrasión, aplastamiento y posterior rotura de las barbas de las plumas. Por otro lado, el descanso de los objetos sobre soportes evitaría las tensiones originadas por la concentración de las fuerzas en uno o dos puntos.

El transporte de objetos patrimoniales es uno de los momentos en que aumenta el riesgo de deterioro y pérdidas que son irreversibles. Por este motivo, es importante evitar en la medida de lo posible el movimiento de los objetos durante el traslado y colocar material que amortigüe pequeños desplazamientos, para minimizar probables desprendimientos de las barbas plumarias. Existe una categoría de material de conservación temporario o semipermanente, que es amortiguador como la espuma de poliuretano de alta densidad, que no son inertes pero que puede colocarse en los contenedores de transporte, sin estar en contacto directo con los objetos. Una vez realizado el traslado, este material inestable debe ser retirado y los objetos, guardados con material de calidad permanente.

Así, los materiales de conservación utilizados para la reserva como para exhibición deben cumplir con las características de estabilidad química y física, propiedad que los hace relativamente durables en el tiempo.

El monitoreo sistemático de humedad relativa y temperatura también debe ser un requisito para la preservación de las colecciones; ya que es necesario conocer las condiciones ambientales existentes y los requisitos que presenta la materialidad implicada para así poder prever acciones que ayuden a mantener las colecciones en condiciones lo más adecuadamente posible. La pluma, al ser de naturaleza higroscópica, requiere de unas condiciones estables, es decir no fluctuantes de humedad relativa, en un rango que no sea inferior al $40 \%$, a riesgo de tornarla frágil y promover roturas, pero que no sobrepase el $65 \%$, por su disposición a ser afectada por microorganismos (Schaeuffelhut et al. 2002).

La manipulación del patrimonio siempre tiene que ser a través del empleo de guantes, preferiblemente de nitrilo o de látex sin polvo, para protección personal y para resguardo de las colecciones.

Dentro de una perspectiva de gestión de colecciones, la contemplación de directrices, procedimientos y normas ayudarán a la toma de decisiones para la adecuada preservación del patrimonio plumario etnográfico.

\section{Consideraciones finales}

El patrimonio plumario etnográfico, en ocasiones combinado con otras materialidades representa un material altamente sensible que para ser preservado necesita de una determinada metodología de conservación, estudio y análisis. La documentación es un paso fundamental para la preservación de las colecciones y en este camino, se plantea el uso del dibujo científico y de la fotografía, como herramientas adecuadas que contribuyen a la obtención de información, a la vez que mejoran o sirven para hacer un uso racional de objetos con materialidad sensible, al minimizar la manipulación. El trabajo con este tipo de colecciones implica una responsabilidad considerable, que debe contemplar los criterios de acción de la conservación preventiva, en las diferentes etapas de estadía del patrimonio, es decir, en las reservas, exposiciones y traslados. Así como también se torna necesaria la realización de estudios analíticos en las colecciones plumarias para la detección de posibles pesticidas colocados en el pasado, con el objetivo de establecer estrategias de acción para la manipulación de objetos contaminados y evaluar adecuados tratamientos.

Finalmente queremos señalar que es hora de aceptar el desafío de conservar productos materiales de las sociedades originarias actuales que hoy se custodian en los museos y permitir su uso frente a la demanda actual por parte de las comunidades representadas. Desafío que implica encontrar la manera de hacer accesible un patrimonio, muchas veces considerado sagrado fuera de la institución, realizando un uso seguro para los pueblos actuales y cuidadoso para el patrimonio, es decir, disponible para las generaciones futuras. 


\section{Referencias citadas}

Alvarado Pérez, Margarita y Miguel A. Azócar Magüida.

1994 Documentación y conservación: dos aspectos de la conservación preventiva. Boletín del Comité Nacional de Conservación Textil 2: 19-24.

Amezaga Ramos, Mercedes.

2006 Restauración de plumería sobre tejido en el Museo de América: aplicación de nuevas tecnologías. Anales del Museo de América 14: 381-406.

Berger, John

2017 Sobre el dibujo. Gráficas 92, Barcelona.

Bishop Museum.

1996 The care of feathers. The State Museum of Natural and Cultural History, Honolulu. http://www.bishopmuseum.org/research/pdfs/cnsv-feathers.pdf, accedido el 11 de septiembre de 2019.

Bossert, Federico y Alejandra Siffredi.

2011 Las relaciones interétnicas en el Pilcomayo medio: la guerra indígena y sus transformaciones (1882-1938). Población \& Sociedad 18 (1): 3-48. ISSN 0328-3445, accedido el 10 de septiembre de 2019.

Cordeu, Edgardo.

1980 Aishnuwérhta. Las ideas de deidad en la religiosidad chamacoco. Tesis doctoral. Facultad de Filosofía y Letras, Universidad de Buenos Aires. Copia cedida por el autor.

Di Lorenzo, Silvana

2007 Proyecto de documentación de colecciones plumarias ishir del Museo etnográfico de la UBA. Manuscrito en Área de Conservación y Museografía, Museo Etnográfico Juan B. Ambrosetti, Universidad de Buenos Aires.

2018 Conservación de material plumario en bienes culturales. Caso de estudio: el tocado de plumas ishir del Museo Etnográfico Juan Bautista Ambrosetti (FFyL), Universidad de Buenos Aires. Tesis de maestría inédita. Tarea-IIPC Investigaciones sobre el Patrimonio Cultural, Universidad Nacional de San Martín.

Di Lorenzo, Silvana, Silvia Manuale y Diego Olivera.

2016 El pueblo ishir y las plumas sagradas del Chaco paraguayo. Una mirada a las colecciones del Museo Etnográfico "Juan B. Ambrosetti” de la Universidad de Buenos Aires. Actas de la XXIX RAE 2015 La rebelión de los objetos. Arte plumario: 223-250, La Paz.

Escobar, Ticio

1999 La maldición de Nemur. Acerca del arte, el mito y el ritual de los indígenas Ishir del Gran Chaco Paraguayo. Centro de Artes Visuales / Museo del Barro, Asunción. 2012 La belleza de los otros. Arte indígena del Paraguay. Servilibro, Asunción.

Hickman, Cleveland; Larry Roberts y Frances Hickman. 1986 Zoología. Principios Integrales. EMALSA, S.A., Madrid.
Icon News

2015 A drawing is worth a thousand words. Julio 59: 11-13, accedido el 10 de septiembre de 2019.

Macías Flores, Samira y Claudia Blas Rojas.

2012 Restauración de objetos con plumas en las colecciones del acervo etnográfico del Museo Nacional de Antropología. IX Foro Académico de Ciencia, Creación y Restauración. Escuela de Restauración y Conservación de Occidente. Guadalajara, Jalisco, México, http://www.ecro.edu.mx/pdf/pdf memorias/samira macias.pdf, accedido el 11 de septiembre de 2019.

Palavecino, Enrique.

1936 Las Culturas aborígenes del Chaco. Historia de la Nación Argentina I: 387-418. Academia Nacional de la Historia de Buenos Aires.

Pegoraro, Andrea y Mariana A. Elías.

2010 Documentación de colecciones etnográficas: los desafíos de los tiempos actuales. El caso de las colecciones etnográficas del Museo Etnográfica “J. B. Ambrosetti” de la Universidad de Buenos Aires. $1^{\circ}$ Congreso Nacional de Museos Universitarios, Universidad de La Plata. http://sedici.unlp.edu.ar/bitstream/handle/10915/41723/Documento completo. pdf? sequence $=1$, accedido el 15 de septiembre de 2019.

Pettingill, Olin Sewall.

1958 A Laboratory and Field Manual of Ornithology. Burgess Publishing Company, Minnesota.

Roubillard Escudero, Marcela.

2008 Fotografía documental. En: Manual de registro y documentación de bienes culturales, editado por Lina Nágel Vega, pp. 30-40 Centro de Documentación de Bienes Patrimoniales, DIBAM, Santiago de Chile.

Schaeuffelhut, Stephanie; Helen Tello y Simone Schneider.

2002 Cleaning of feathers from the Ethnological Museum, Berlin. En The Conservation of Fur, Feather and Skin, editado por Margot M. Wright, pp. 63-68. CEA Series 3, Archetype Publications, London.

Seiler Baldinger, Anne Marie.

1994 Textiles. A Classification of Techniques. Smithsonian Institute Press, Washington DC.

Timár-Balázsy, Agnes y Dinah Eastop.

1998 Chemical Principles of Textile Conservation. Butterworth - Heinemann, London.

Van Tyne, Josselyn y Andrew Berger.

1976 Fundamentals of Ornithology. Science Editions, by John Wiley and Sons Inc., New York.

Wallace, George.

1959 An Introduction to Ornithology. The Macmillan Company, New York.

Wallace, George y Harold Mahan.

1975 An Introduction to Ornithology. Macmillan Hungry Minds, New York. 


\title{
20
}

\section{Textil y territorio: sobre los tejidos intrincados de Poroma, Norte de Chuquisaca, Bolivia}

\author{
Verónica Auza Aramayo
}

\section{Resumen}

La presente propuesta pretende comprender cómo el sistema territorial andino está manifiesto en el lenguaje visual de los tejidos; específicamente en el estudio de los tejidos de Poroma, Norte de Chuquisaca, Bolivia. Cultura andina caracterizada por una larga historia que evoca diversos movimientos y procesos multiétnicos, que estableció, en un valle de características tórridas, una auto denominación cultural que la designa como «llameros», vale decir, gente que desde las altas punas antiguamente y hasta la década de 1980 se desplazaba con sus caravanas de llamas, marcando un mercado de bienes a lo largo de la cordillera. Esta forma de nombrarse y de ser nombrados evoca conocimientos, desplazamientos y el manejo de la geografía y de los territorios que las comunidades del sur andino de Poroma dispusieron a través de su historia para habitar este espacio y para forjarse un sentido de pertenencia cultural.

Habida cuenta de ello, se trata de comprender la relación que se establece entre el complejo sistema territorial y el signo textil de Poroma, para comprender no va cómo el lenguaje visual ofrece, precisamente, a través de las representaciones textiles de diseños, patrones, simbologías, formas y sentidos cromáticos de la vestimenta, la identidad multiétnica y entreverada de esta cultura.

Palabras claves: Textiles andinos, Chusquisaca, Poroma, territorialidad, llameros, semiótica.

\begin{abstract}
The present proposal aims to understand how the Andean territorial system is exhibited in the visual language of cloth; specifically in the study of the textiles from Poroma, northen of Chuquisaca, Bolivia. This Andean culture is characterized by a long history looking back on diverse movements and multi-ethnic processes, which established, within a very warm valley, a cultural self-designation that designates them as «llameros» meaning people who from the high plateaus since old times until the eighties of the last century moved with their caravans of llamas, defining a market of goods along the mountain range. This way of naming themselves and being named by others evokes knowledge, patterns of movement and expertise in the geography and territories that communities of the Andean south of Poroma managed throughout their history, in order to inhabit this space and forge for themselves a sense of cultural belonging.

Given this framework, the aim is to understand the established relationship between this complex territorial system and the textile or semiotic of Poroma, to realize how visual language offers, particularly, through textile representations including designs, patterns, symbolism, forms and chromatic sense of clothing, the multiethnic and mixed identity of this culture.
\end{abstract}

Keywords: Andean textiles, Chusquisaca, Poroma, territoriality, llama caravans, semiotics.

\section{Résumé}

La présente étude prétend comprendre comment le système territorial andin se manifeste dans le langage visuel des tissus, particulièrement dans l'étude des textiles de Poroma, au Nord de Chuquisaca, en Bolivie. Cette culture andine se caractérise par une longue histoire reflet de divers mouvements et processus multiethniques, qui a établi, dans une vallée très accueillante, une autodénomination culturelle. Ses habitants sont désignés comme "llameros", les personnes qui, autrefois et jusqu'aux années 1980, se déplaçaient avec leurs caravanes de lamas, définissant un marché de biens le long de la cordillère. 
Cette façon de se nommer et de nommer par autrui évoque à la fois les connaissances, les déplacements et le maniement de la géographie et des territoires que les communautés du sud andin de Poroma ont répandus à travers leur histoire pour habiter cet espace et se forger un sentiment d'appartenance culturelle.

Compte tenu de ce contexte, le but est de comprendre la relation établie entre ce système territorial complexe et la sémiotique des tissus de Poroma afin de comprendre comment le langage visuel reflète, en particulier grâce aux représentations textiles incluant conceptions, modèles, symbolismes, formes et sens chromatiques des vêtements, l'identité multiethnique et variée de cette culture.

Mots-clés: Textiles andins, Chusquisaca, Poroma, territorialité, caravanes de lamas, sémiotique.

Empiezo indicando que este ensayo se basa en el testimonio de la tejedora de Poroma: Claudina Torres ${ }^{1}$. Convengamos que toda destreza textil expresa el pensamiento y la creatividad de las tejedoras andinas, así, constituye un sistema de sentido que se erige cuidadosamente al entrecruzar hilos en órdenes y diseños tejidos; sí, todo tejido es un sistema de sentido visualmente plasmado, estéticamente emotivo y simbólicamente exuberante de un modo de ser y de estar en el mundo. En definitiva, en el espacio; en definitiva, y a partir de lo cual, podemos asumir al textil como un arte y como un arte femenino de habitar el mundo.

Cuando miramos a los textiles andinos, es dable pensar que no solamente estamos frente a vestimentas y prendas vistosas, los textiles en el mundo andino no solo son ropajes ornamentados o decorados para vestir los cuerpos, sino y sobre todo los textiles expresan y materializan un lenguaje visual cuya belleza de sus signos definen y recalcan identidades culturales, es decir, los modos de ser andinos.

De tal manera, se trata de entender el arte textil como expresión vívida y sentida que las tejedoras ofrecen como grafías de identidad, desde lo simbólico de sus diseños culturales, desde sus estructuras que representan el habitar los espacios de la territorialidad andina, desde el sentido de sus formas, desde la complejidad cromática que sustentan, en fin, desde la semiología de su lenguaje plástico destinado histórica y culturalmente a envolver, proteger, vestir y de dotar de identidad a los cuerpos. En otras palabras, un lenguaje de piel, que solo podemos conocerlo y comprenderlo a través de sus creadoras, las tejedoras, pues son ellas y sus pensamientos, sus destrezas, sus intelectos y sus capacidades sensibles hacia los signos vertidos (difundidos, volcados) en los hilos, las que por muchos siglos, han dotado de sentido de identidad y de sentido estético al mundo andino a través de los textiles.

El arte textil que toda tejedora brinda en sus prendas, hace que cada textil exprese una carga simbólica específica, una suerte de "espíritu, cuerpo y ser", por lo tanto una existencia, un sentido y una transcendencia, así cada prenda tejida refiere a una forma de habitar el mundo además de un conocimiento de quien lo habita, las tejedoras organizan la urdiembre y la trama desde la destreza y proliferación de sus lenguajes visuales, brindando sentido en cada uno de los hilos empleados, en el orden de los colores y sus alternancias, en la definición de los diseños y las soluciones formales que desde tiempos precolombinos y hasta la fecha marcan la distinción de cada cultura en el mundo andino, de ahí, lo axial y el poder de la imagen que el arte textil nos sigue ofreciendo día a día en Bolivia.

Antes de empezar debo mencionar que este análisis se basa en los estudios, imprescindibles de Verónica Cereceda, Denise Arnold, Sophie Desrosiers y Teresa Gisbert.

Precisemos. Todo tejido en el mundo andino contiene una gran profusión de lenguajes visuales, los cuales contienen y expresan una emoción estética indiscutible en el diseño de sus imágenes, en sus órdenes cromáticos y en sus estructuras y técnicas que los tejen. A partir de ello, se trata de comprender y explicar el sentido que transmiten y contienen los tejidos desde "adentro", como establece Verónica Cereceda (2017); vale decir, desde sus propios lenguajes y sistemas de significación; tarea difícil debido a las muchas espesuras que el tiempo y la gramática visual del textil han tenido que sobrellevar las sin comunidades andinas a lo largo de la historia. Sin embargo, deshacer lo cifrado de este lenguaje visual es posible en la medida que sepamos reconocer la labor creativa de las tejedoras, el sistema de significación que las tejedoras plasman en sus tejidos y a su vez las representaciones de mundo que subyacen en cada uno de los textiles, es por ello que cada una de mis investigaciones parten y caen en los saberes de primera mano que las tejedoras me brindan, como es este ensayo que realice con el testimonio de Claudina Torres. Sabemos que cada prenda tejida: awayos, las llikllas, aqsus, taris y fajas; que las mujeres andinas mantienen en sus vestimentas, las distingue y las engalana en fiestas, rituales y vidas cotidianas. Así, en cada prenda tejida, hoy todavía late y se manifiestan concepciones, pensamientos y modos de ser y de estar, lo cual 
nos lleva a volcarnos a su "interior" intentando comprender sus propias estructuras formales y significantes expresadas en la composición del orden manifiesto de sus colores, formas, diseños y estéticas.

Al conversar con Claudina, ella me transmite el alcance del lenguaje visual que dominan en Poroma, así, con ella, podemos permitirnos conocer y reconocer los sistemas de significación que se manifiesta en cada uno de sus diseños, es a través de ella que logramos advertir las profundidades históricas de estos lenguajes, la profundidad en el tiempo de cada uno de sus diseños y sus órdenes cromáticos, a la par que podemos advertir las sendas de transformación para su remezón y sus actualizaciones formales; así, Claudina nos permite abordar la espesura semántica de su arte textil, que pervive y se mantiene vigente.

Antes de continuar por la singularidad de los tejidos de Poroma, señalo que mis estudios de la sociología del arte textil se basan en el análisis e interpretación del lenguaje visual que nos ofrece y de las explicaciones que sus creadoras me dan de los mismos, así, es relevante precisar:

- la estructura textil: diseño, colores, espacios de cada prenda tejida,

- los aprendizajes y el desarrollo de las técnicas que se aprecian en cada una de las destrezas textiles de las tejedoras,

- de los caminos de conocimientos que las tejedoras sortearon en sus vidas para afinar la técnica y el dominio de los hilos en urdiembres y tramas; quehacer, obra, práctica, ejercitados una y otra vez para dar lugar a la creación femenina del arte textil.

Abordar cada una de las piezas del universo textil andino, es aprender su lenguaje plástico, su sintaxis visual, la gramática de signos; lo cual implica, más allá de su sentido de identidad, comenzar a entender en su lenguaje visual, en su imagen, la expresión artística plasmada (o tejida) en los siguientes elementos:

- El orden cromático y la significación del color de cada textil;
- la definición de bandas entre espacios de pampa ${ }^{2}$ y espacios de pallay o salta ${ }^{3}$;

- la demarcación de espacios: centros, límites y disposiciones de franjas o bandas;

- la estructura del color que permite la construcción de contrastes, de fondos y de figuras, que dan paso a patrones entre lo oscuro y lo luminoso (y a la inversa) y la sucesión de tonalidades diferentes que realzan las bandas y sus extensiones;

- la composición de diseños que proyectan animales, ríos, lagunas, plantas, estrellas, fuerzas de la naturaleza y órdenes culturales, diseños que en definitiva, evocan los sistemas de significación de cada uno de los territorios y de las diversas culturas del mundo andino;

- la expresión simbólica y el singular sentido visual que cada tejido transmite como pieza terminada.

Volcando la mirada al pasado y siguiendo el registro iconográfico legado en la temprana colonia por Guamán Poma (1615), se puede apreciar la distinción textil de las diferentes culturas que habitaban el territorio andino. Quizá las láminas que retratan a las Coyas o reinas andinas con la vestimenta que primaba en esa época, son las que mejor nos permiten apreciar la importancia no sólo de cultural, sino también política que se establecía con las prendas tejidas. Vemos llikllas que definían el prestigio, la soberanía y con ella la territorialidad desde el sistema de la vestimenta, e iconográficamente, dentro del incario. Lo primero que muestran estas láminas es la suerte de epítome de feminidad en los Andes ${ }^{4}$ que es el tejer. En la lámina 23, vemos a una mujer con huso en la mano, hilando, ella, dice Guamán Poma, expresa a las mujeres que tenían 33 años y eran consideradas como doncellas vírgenes "perpetuas para el sol, la luna, los templos, los dioses y para el inca”. En la imagen la vemos con el atuendo completo que esas doncellas vestían: aqsu, que era el vestido originario que las mujeres andinas

2. La pampa es el espacio de un sólo tono que carece de diseño y dibujo.

3. Pallay en quechua, salta en aymara, son los verbos empleados para definir la técnica que introduce diseños y dibujos en la trama de los textiles. 4. Varios estudios señalan que el tejido marcaba la distinción genérica de la feminidad en los Andes, lo sugiere estructuralmente John Murra (1975) cuando habla de la función del textil en el mundo andino antes de la llegada de los españoles o Irene Silverblatt (1990) y Maria Rostowrowski (2000) que de un modo más acucioso se detienen en el universo femenino que dependía en las mujeres andinas antes y después de la colonia, estas dos autoras nos llevan a los universos sagrados, de ritual, de territorio, de poder y de omisión que las mujeres en los Andes fueron definiendo con el paso de los diversos regímenes dominantes que les tocaron vivir. Tema complejo y polémico, del cual podemos considerar, para este ensayo, la función de género que el tejido instaló en las acllawasi del incario y el trastoque que la empresa colonial estableció en el textil como tributo y explotación de las mujeres aún las sucesivas prohibiciones que se dictó sobre esta destreza andina, haciendo que el tejido, el rol textil y las creaciones de las tejedoras perdure con un lenguaje que ha sufrido un sinfín de variaciones y adecuaciones en sus signos, en su gramática, en su sistema de vestido y en su impacto visual, llegando hasta nuestros días. Paradoja histórica que no se puede dejar de considerar para entender el alcance comunicacional que la plástica de los textiles sigue transmitiendo en los diferentes paisajes y escenarios actuales. 


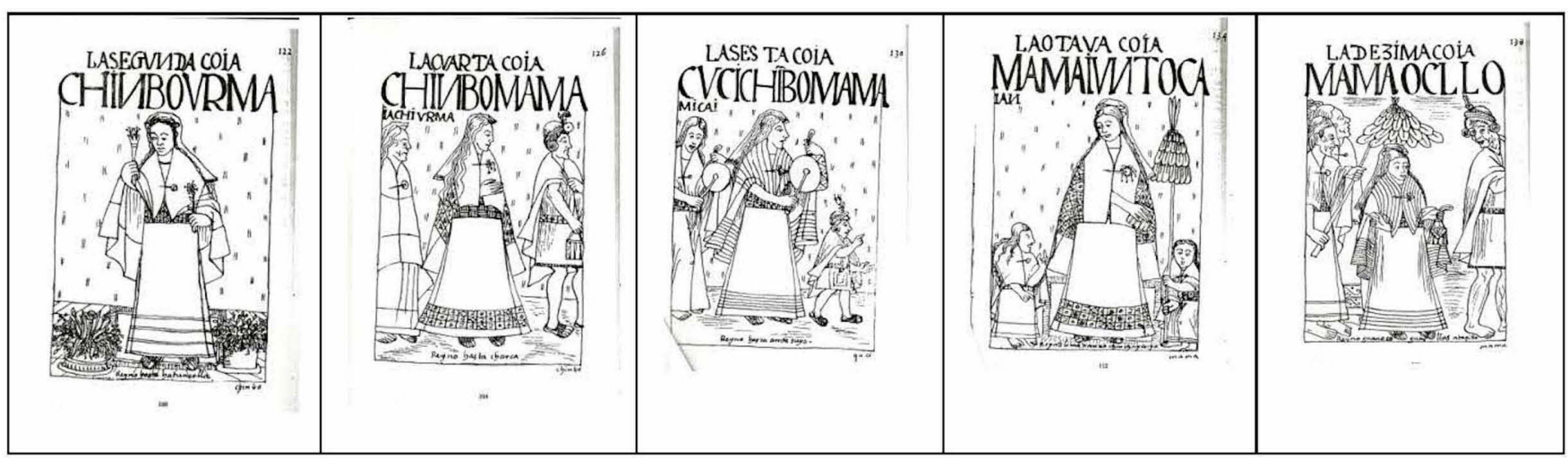

Ilustración 1: Láminas de Collas de la Crónica de Guamán Poma de Ayala, 1615.

vistieron hasta el siglo XVIII, una faja ataviada por muchos diseños ${ }^{5}$, lo cual connota una verdadera destreza textil que a estas mujeres las caracterizaba y una llijlla sujetada con un topu, llijlla que a lo largo de la crónica Guamán Poma marca la distinción de las reinas y sus estatus expresado en los diferentes de colores y diseños que exhibían. Todo ello nos da cuenta, que al menos hasta el inicio de la colonia, existía un sistema de vestimenta en el cual las mujeres mostraban su posición de poder desde el dominio textil que vestían. Siguiendo el repertorio iconográfico de Guamán Poma, encontramos una secuencia de Reinas o Coyas, que es muy explícita para entender como la vestimenta textil exponía las jerarquías y las distinciones que las mujeres y también los hombres advertían en la usanza de todas las prendas tejidas que vestían. Se observa que una de las piezas claves en la vestimenta de las Coya era la llijlla, que son prendas cuyo fin era la exposición, son las piezas que de todo el atuendo saltan inmediatamente a la vista; en definitiva, vestir estas llikllas establecía y remarcaba el poder de estas mujeres, su poderío como reinas (Ilustración 1).

Con estas láminas comprendemos que las llikllas eran las prendas indispensables para definir a estas mujeres como reinas destinadas a los ámbitos de poder y ejercicios dominantes de lo sagrado y lo social.

Para profundizar, añado a este universo a este universo de sentido que sostienen y construyen las tejedoras y sus creaciones textiles, la noción brindada por Arnold, et al (2007) que nos enseña a entender los textiles de la región con la siguiente premisa: lo corporal del textil, lo territorial, lo bélico, lo religioso y sagrado, lo cognitivo, lo textual, lo subversivo y lo femenino del copioso lenguaje plástico y visual de las prácticas textiles vivas que se manifiestan, en las comunidades andinas de Bolivia. Siguiendo ambas nociones he procurado comprender en cada prenda tejida estos niveles de sentido y de significación, perfilando en cada una de sus imágenes estas concepciones que se esmeran por reconocer en cada expresión textil las relaciones político-históricas que sostienen las comunidades existentes. Siendo así, cada diseño encontrado y detallado, contiene un pasado que convoca a comprender el sustrato arqueológico que late en su simbología, el régimen territorial que motiva su mensaje, la trayectoria etnográfica presente en su estructura textil y el lugar en lo que Arnold (2007) retomando a Cereceda (2017) y Dransart (1996) expone y define como la historia del arte del textil andino.

Con todo esto en mente es posible advertir los horizontes de la memoria textil, aquella que está presente en cada técnica y tejido expresada de manera continua o con variantes, sí, traer el pasado, saber cómo las hijas o las nietas recuerdan y actualizan los modos en que tejían sus abuelas, quiénes les enseñaron, para poder entender los caminos visuales, estéticos, textiles y culturales por donde ellas tejen en el presente. Ver cómo tejen ahora y reconocer los motivos por qué lo siguen haciendo, evoca los imperceptibles territorios por los cuales las interrelaciones o los roces e influencias con las otras dinámicas textiles siguen vivas. Todo ello, nos procura la certeza de un presente activo y nos brinda la manifestación más amable del pasado para el porvenir, ya que ellas, al seguir tejiendo esperan y mantienen las expectativas que auguran un presente y un futuro a la producción textil y al rol creativo, simbólico, femenino y cultural que viene con ella.

En ese sentido, y realizando una suerte de ejercicio cartográfico (como se vera en las ilustraciones: 3 - 14 sobre la variedad textil de Poroma; realizadas en base a las fotografías del libro: Diseño de los textiles de Poroma. Asur, 2010),

5. Esta prenda todavía se usa y ostenta notoriamente por las mujeres de Charazani, a diferencia de la mayor parte de las zonas andinas, donde las fajas no están a la vista. 
podemos construir una imagen cual topología espacial de la producción textil, en la cual podemos ver la geografía del arte textil y ahí percibir y entender la memoria visual de las tejedoras, los signos estéticos de sus identidades y sus manifestaciones tejidas que no cesan de erigir estas representaciones como un lenguaje visual que marcó, como marca, la transcendencia y la diferenciación cultural por y para los Andes.

Siendo parte de esta geografía textil, los tejidos de Poroma traducen la fuerza y la emoción estética viva que en los Andes, desde tiempos inmemoriales, ha tenido no solo la virtud de marcar distinciones culturales de cada una de las identidades étnicas, sino también la potencia de modificar las realidades sociales, construyendo y luchando por nuevas apropiaciones del espacio o por recomponer el devenir comunitario perdido y así, una vez más, lograr que el espacio sea habitable y se convierta en territorio, Poroma y sus tejidos, exponen francamente todo ello, en su devenir histórico de la puna al valle y en sus signos textiles multiétnicos, diversos, a la vez novedosos y a la vez ancestrales, donde como más adelante se verá, el aywira de Bertonio (1984 $\{1612\})$, es posible también advertirlo en los jatun ch'aska chawpimpi ch'uru ñawiyuq y los elefantes de las llikllas de Claudina Torres.

El universo textil trasmite visualmente tanto el modo político como la manera estética de habitar el espacio: "Los lenguajes plásticos de los colores y las formas son la materia para que la sociedad [andina] exprese sus propia y específica percepción sobre su sociedad y su cultura, sus tiempos $y$ sus condiciones de existencia" (Martínez, José Luis, 1992). Es por ello que los textiles son como topografías portátiles que se hallan indisolublemente asociados a la naturaleza, a los ciclos del cosmos y a las intervenciones culturales que definen y hacen habitable al territorio. En definitiva, la materialidad entretejida del textil nos trasmite una suerte de topografía visual, una cartografía textil, donde destacan cada uno de los lenguajes plásticos y diferenciales plasmados en los tejidos. La imagen en mi mente queda cual distinción visual que respeta los sentidos y diferencias de cada uno de estos paisajes culturales, son golpes a la vista y a los sentidos, extraordinario sistema simbólico, que se nos brinda a través de la viva usanza andina del tejido, una cultura textil que convoca desafiantemente a ahondarla.

\section{Del arte textil para habitar el territorio: los hilos llameros de Poroma.}

Detengámonos en los orígenes de la complejidad étnica de Poroma. La problemática del territorio en los Andes explicada por John Murra (1975), Thierry Saignes, (2015) y, recientemente, Vincent Nicolas (2015) nos permite comprender la importancia y transcendencia de las modalidades políticas y culturales que los pueblos andinos han desarrollado desde tiempos precolombinos para habitar y hacer habitable el espacio, a partir del establecimiento de los límites entre comunidades y a partir de la compleja dotación de sentido que estas culturas realizan sobre la accidentada geografía que cruza la cadena de montañas de elevadas punas, cálidos valles y expansiones subtropicales ya amazónicas en sus estribaciones.

Para entender el vínculo que se da entre textil y territorio, tenemos que pensar en aquellos mecanismos para habitar el espacio, que el mundo andino, se fueron superponiendo a lo largo de la historia en sus sentidos y estrategias precolombinas, coloniales y republicanas. Hecho complejo que Verónica Cereceda (2010), interpreta a cabalidad para el caso de Poroma:

“... para entender lo que ahora sucede en Poroma, que los grandes ayllus antes de la llegada de los españoles y en los tiempos de la colonización, poseían tierras que no eran continuas, es decir, cada ayllu, los Macha, por ejemplo, o los que ahora como T'inkipayas que no se llamaban todavía de ese modo, u otros, buscaban tener acceso a distintos climas y a distintos productos. Es así como ayllus de la puna, poseían chacras en ambientes más bajos para poder cultivar maíz, y no sólo quinua y las variedades de papa o criar llamas, que son las posibilidades de las alturas... El ir y venir de la población indígena a localidades que no eran los territorios centrales del ayllu, donde algunos grupos se quedaban por tiempos largos para cuidar y recolectar cosechas, no fue bien visto por la administración española durante la colonia. Exigieron que cada persona tuviese residencia fija donde se le podía ubicar para cobrar tributo, especie de impuesto que debían pagar todos os que vivían en el campo por el uso de sus tierras. De este modo se fue frenando cada vez más el acceso de los ayllus, como tales, a sus chacras en lugares más cálidos. Luego ya fue tarea de las familias como unidades domésticas y no de los jilaqatas o mallkus, continuar trabajando en esos lugares que les habían pertenecido desde tiempos ancestrales o fijar definitivamente su hogar en ellos, ya sin regresar necesariamente al territorio central de su grupo natal.

Así se fue poblando Poroma con gente venida de diferentes partes... Habitan en este municipio (de Poroma) gente venida de T'inkipaya, de Marcha, de Pocoata, de Laymi, y otros llegados de más cerca como Janina, Ravelo, como muchos que se consideran originarios de estas tierras o han olvidado 
su origen. Poroma es así un mosaico multiétnico que testimonia las prácticas culturales que tenían los antepasados -abuelos de los abuelos de abuelos- de cultivar distintos climas y distintos niveles de nuestro territorio para obtener directamente todos los productos que les hacían falta para su subsistencia...”.

\section{Ilustración 2:}

A partir de este mapa étnico cultural que nos ofrece ASUR (2010), podemos advertir que los grupos culturales que hoy se encuentran en Poroma, son específicamente: Llameros de Potosí, J’alqas, y Q'aqchitus y Mestizos en menor número. Antes de detenerme en el grupo de los Llameros, veamos la compleja diversidad textil y cultural de Poroma, a partir del libro: Diseños de los textiles Poroma. Investigación y fotografías. ASUR, 2010, el cual, como se puede apreciar nos expone de modos singulares la variedad y diversidad textil del complejo Poroma y la complejidad de este diseño textil (Ilust. 3).

Con este mosaico textil en mente, detengámonos en el diseño textil de Llameros de Poroma. Siguiendo las palabras de Verónica Cereceda (2010), los Llameros tienen su origen en las culturas de puna, muchos de ellos dicen haber llegado de T'inkipaya, dato que está corroborado por los propios t'inkipayas, otros provienen de Macha, de Killakas, de Urmiri, de Laymi, de Pocoata, indudablemente de las punas de Potosí y Oruro. Lo importante a tener en cuenta es la concepción que se manifiesta de parte de los pobladores de Poroma cuando evocan el pasado de los llameros y dicen: "Los llameros son del lado de T'inkipaya, no son oriundos de estas tierras. Siempre se trasladan de un lugar a otro, de otro lado vienen y van...”. Palabras de Jerónimo Aguilar Guzmán, citado en Cereceda (2010).

Por su parte, por ejemplo, Moíses Puma, afirma: “... me han traído cuando era bebé, en la cara de mi mamá... dicen que andaban de nómadas..." citado en Cereceda (2010), o el relato de Gabriel Quintín, quien comenta que su abuelo era de Jukumani y dice "según comentarios se escucha que ellos habrían venido de la puna y por eso tendríamos parentesco en la puna. En la puna hay una cultura similar a la nuestra, aunque no es igual, sino varía en alguna medida. Fíjese las figuras no son igual, las de ellos tienen más colores amarillentos como los de T'inkipaya, lo propio pasa con los tejidos de Macha y Tumaykuri, son distintos los tejidos. Mi persona ha ido por esos rumbos comparando, con mi ropa queriendo igualar, pero no se asemeja en lo absoluto. Es distinto, un poco oscuro, no puedo describirlo. De ellos sus colores son más vivos..." citado en Cereceda (2010). Otro atributo que vale la pena advertir que también a los llameros los llaman "tulqas", o sea, los yernos que vinieron de la puna

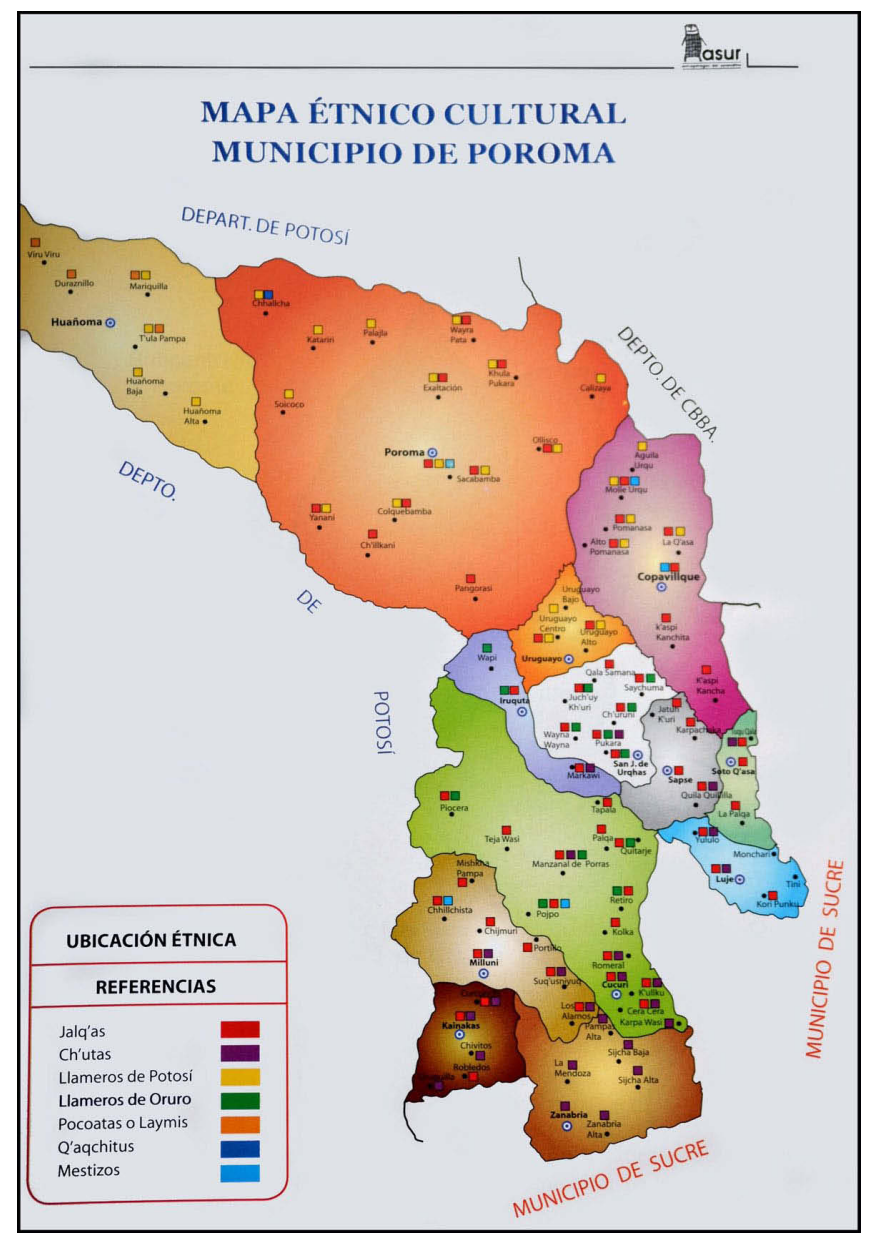

Ilustración 2: Mapa de Poroma. Poroma: Composición étnica y culturas. ASUR, 2010. Pág. 33.

para casarse y se dice que tienen cualidades de curanderos, porque "hacen soltar los ánimos".

Para finalizar, el origen j’alqa, quizá es el que mejor explica la distinción textil que se evidencia en los tejidos "un poco oscuros” Poroma, así Valerio Vázquez afirma: “... Antes a ellos los llamaban 'purirantes', mi padre había sido uno de los luchadores por la libertad... a los que se llamaban 'puriq runa' o 'antiguos caminantes'. Este grupo de luchadores se organizó justamente en zonas Jalq'as de Poroma, antes de la Reforma Agraria. Era gente que caminaba de noche, de comunidad en comunidad, hablando de la necesidad de recuperar las tierras de origen que las Haciendas se habían apropiado. Un símbolo de esta relación ancestral con las tierras eran los textiles. Las antiguas imágenes Jalq’a, con khurus (animales extraños y silvestres) indomables, dispuestos con gran libertad en el espacio del pallay (diseño), representa ese mundo sin constricciones que este grupo de los puriq anhelaba como meta de su lucha. Los textiles jalq'a fueron así, como una bandera de los antiguos caminantes" (Cereceda: 2010). 

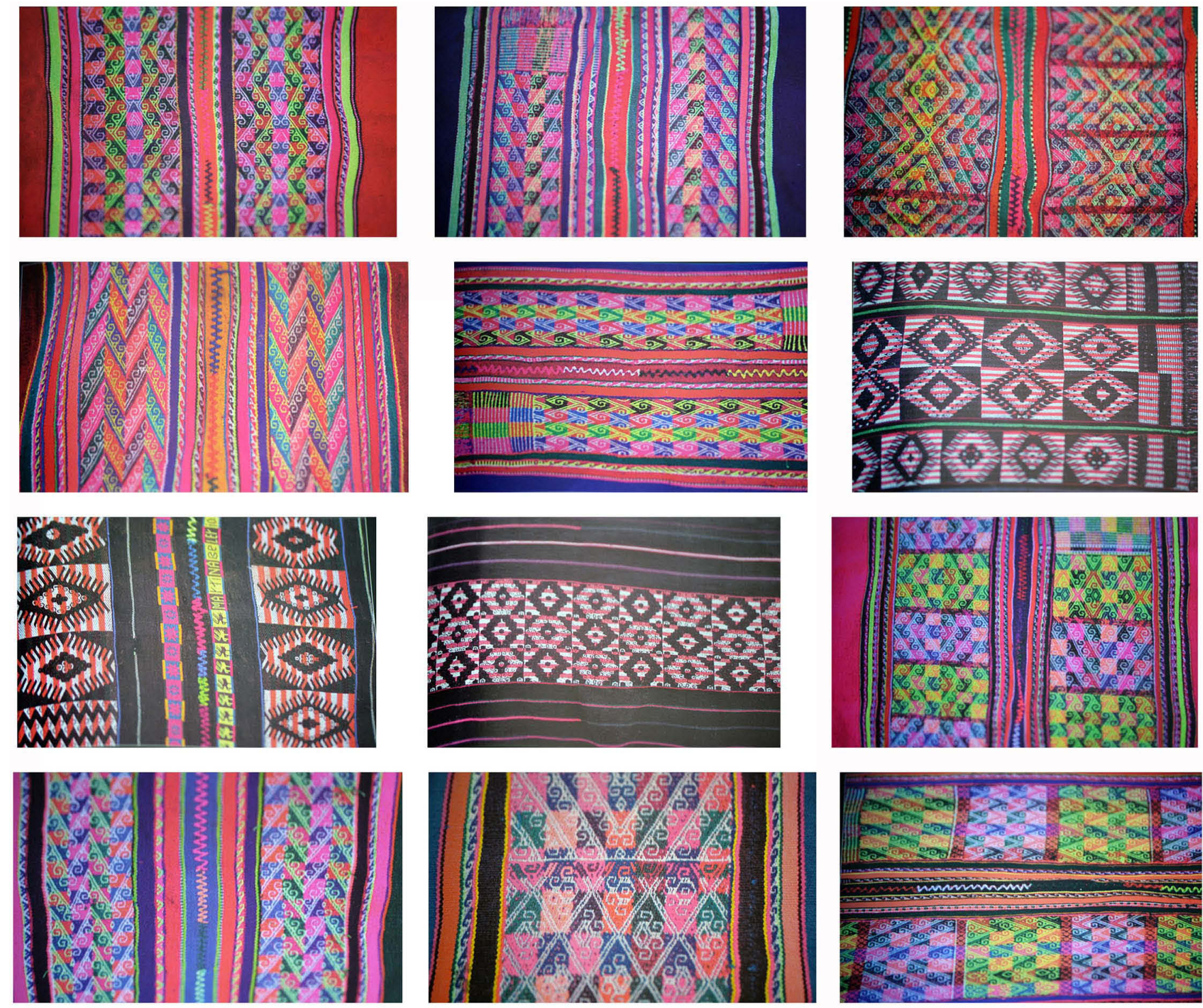

Ilustración 3: Llikllas de Mariquilla, Duraznillo, Viru Viru y Huañoma Alta, del libro: Diseños de los textiles Poroma. Investigación y fotografías. ASUR, 2010. Págs. 7, 33, 39, 41, 73, 83, 107, 109 y 113.

Vemos que este origen de puna y el caminar por la noche, el caminar luchador, por sobrevivencia, del bajar de las alturas al valle en procura de tierras propias, de distinciones propias, de libertad, de habitar esa frontera estética entre el cielo y los colores vivaces de la puna, siendo un poco oscuros, teniendo como bandera o meta lo indomable del manqa pacha jalq'a, hace definitivamente que las tejedoras siendo "llameros de Poroma" hoy en día, nos traigan en su creación textil ese mismo sentido intrincado, que afectivamente desde el textil procura ir y venir en un andar sin amo, en un andar libertario, como lo hicieron los abuelos luchadores, dando pasos en la noche, de comunidad en comunidad, esos antiguos caminantes que forjaron caminos, algo desviado del constreñido republicano, ese andar nómada en procura de tierras propias para habitarlas a su modo.

Visto así, la simbología y el arte textil en Poroma, solicitan una apertura visual y mental para abordar todos los sentidos de la imagen que en ellas funcionan. De ese modo, con los tejidos de Poroma tenemos que conjugar la energía de las dinámicas étnicas, sus flujos, sus desplazamientos y enfrentamos de entrada con un signo intrincando, complejo y singular que continúa dando vigencia a un lenguaje visual que evoca los procesos imperceptibles, constantes y mezclados de esta cultura.

Al interior de este complejo cultural cabe también preguntar: ¿cómo el lenguaje y la memoria visual de los tejidos 
de Poroma expresan en el orden de sus hilos, su cromática y sus diseños esta cultura móvil, de caravanas, de trajines? Y ¿será que la cultura textil, su alcance visual y afectivo que todavía sienten las tejedoras por las prendan que tejen, congenia y se despliega con la espesura de un saber que requiere dominar el espacio y los recorridos por el territorio? Estas cuestiones me hicieron reflexionar sobre las superposiciones, imbricaciones, tensiones y pugnas que laten en el arte textil y la simbología creada por las tejedoras de Poroma hoy en día.

\section{Claudina Torres: De la puna al valle y "se teje de tres".}

Como ya mencione, la presente propuesta pretende comprender el complejo sistema territorial andino a partir del lenguaje visual de los textiles de Poroma. Para ello, me apoyare en la conversación que sostuve con Claudina Torres, tejedora de la comunidad T'ula Pampa, Poroma. Claudina, actualmente tiene 29 años y vive en la ciudad de Sucre desde hace 7 años. Claudina teje desde sus 7 años y a los 14 hizo su primer aqsu y lliklla, en la fotografía Claudina nos muestra su lliklla; ella nos cuenta que aprendió a tejer con su mamá y hasta el día de hoy disfruta tejer con sus amigas, paisanas, comadres y primas en la ciudad (Foto 1). Viaja constantemente a su comunidad y me dice que aunque por sus guaguas se vino a Sucre a ella le encanta vivir en el campo, al igual que ella su mamá, nunca dejaron de sostener su doble residencia: urbana y rural.

Lo primero que se tiene que mencionar es que esta comunidad presenta dinámicas culturas venidas de Pocoata y Laymis, ambas culturas "beligerantes" en la región nor chuquisaqueña. Este arte textil evoca precisamente la singular transcendencia y antigüedad de los trajines en los Andes, pues mantiene y desarrolla sistemas textiles con fuertes cargas simbólicas y semánticas que se expresan por los diseños, los usos de listados simétricos en sus bordes, la estructura que la distingue cada que establece la pampa binaria y el kimsa pallay, lo cual denota una característica central para distinguir a estos tejidos en todo el entorno cultural que los rodea (Foto 2). En los cuales destacan la importancia de los desplazamientos espaciales para el arraigo y la apropiación del territorio. El diseño trae entre sus hilos, el sentido visual de un territorio habitado por los andares de los «llameros» y cada uno de los recorridos que definieron el accionar cultural de los «antiguos caminantes» por un territorio libre y propio.

La forma de auto nombrarse «llameros»y de ser nombrados «llameros», sin duda, evoca todo el caudal del conocimientos, desplazamientos en el manejo espacial, de la geografía, y de los territorios, propio de las comunidades del sur andino (Foto 3), que a lo largo de los siglos desarrollaron y

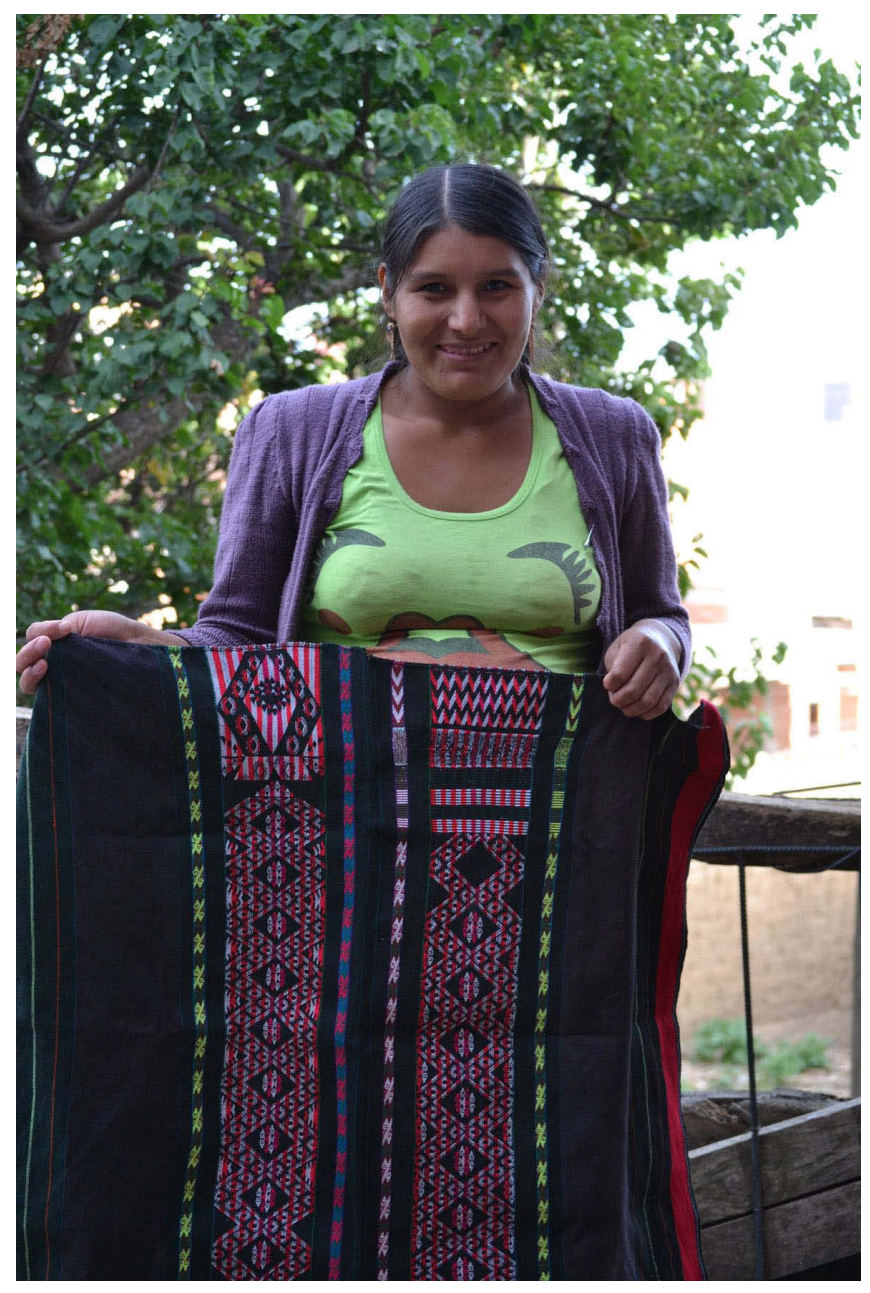

Fotografía 1: Claudina Torres. Fotografía de Verónica Auza Aramayo.

ejecutaron un modo de habitar el espacio diverso y expansivo, diseñado además para dotar de un sentido de pertenencia a los pueblos andinos.

Este sistema territorial, además de las complejas prácticas culturales, sociales y políticas, estuvo desde siempre acompañada por la sofisticada trama del lenguaje visual del textil, así encontramos que cada cultura, en el amplio y accidentado territorio andino, configuro su propia estructura visual para su distinción a partir del signo textil (Foto 4), precisamente y sobre todo desde la diversidad de tejidos que imponen diferencias de identidad a partir de los órdenes visuales de tramas, diseños, colores en cada una de sus vestimentas portadas y ostentadas en las realidades comunitarias del pasado y del presente.

Analizar tejidos, implica interpretar el sistema de sentido que ofrecen sus tejedoras, lo que quiere decir, desentrañar el quehacer creativo y el lenguaje visual de la feminidad andina contemporánea (Foto 5). En ese entendido, procuraré entender la relación que se establece entre tejido 


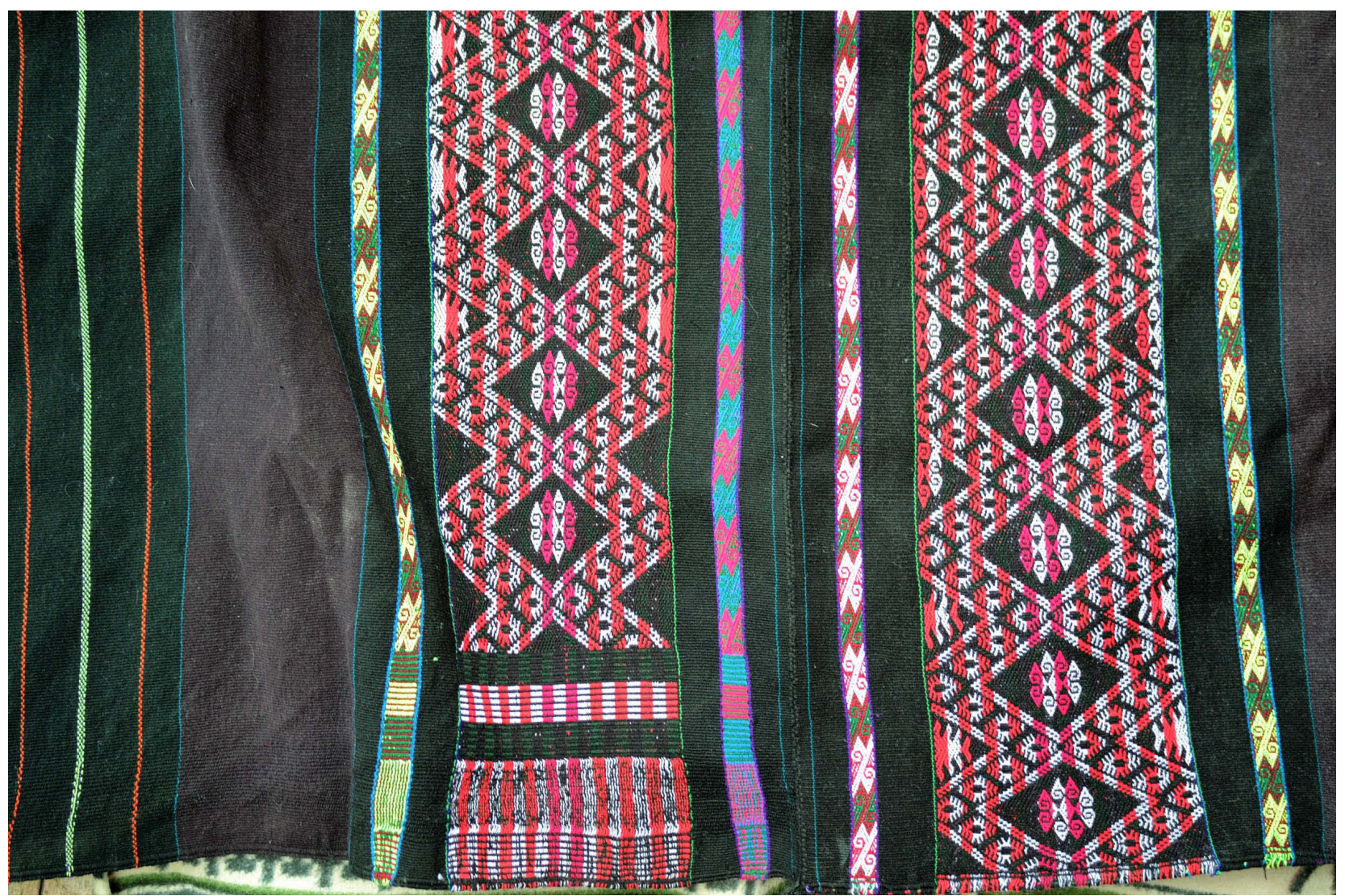

Fotografía 2: Detalle de la lliklla de Claudina. Fotografía de Verónica Auza Aramayo.
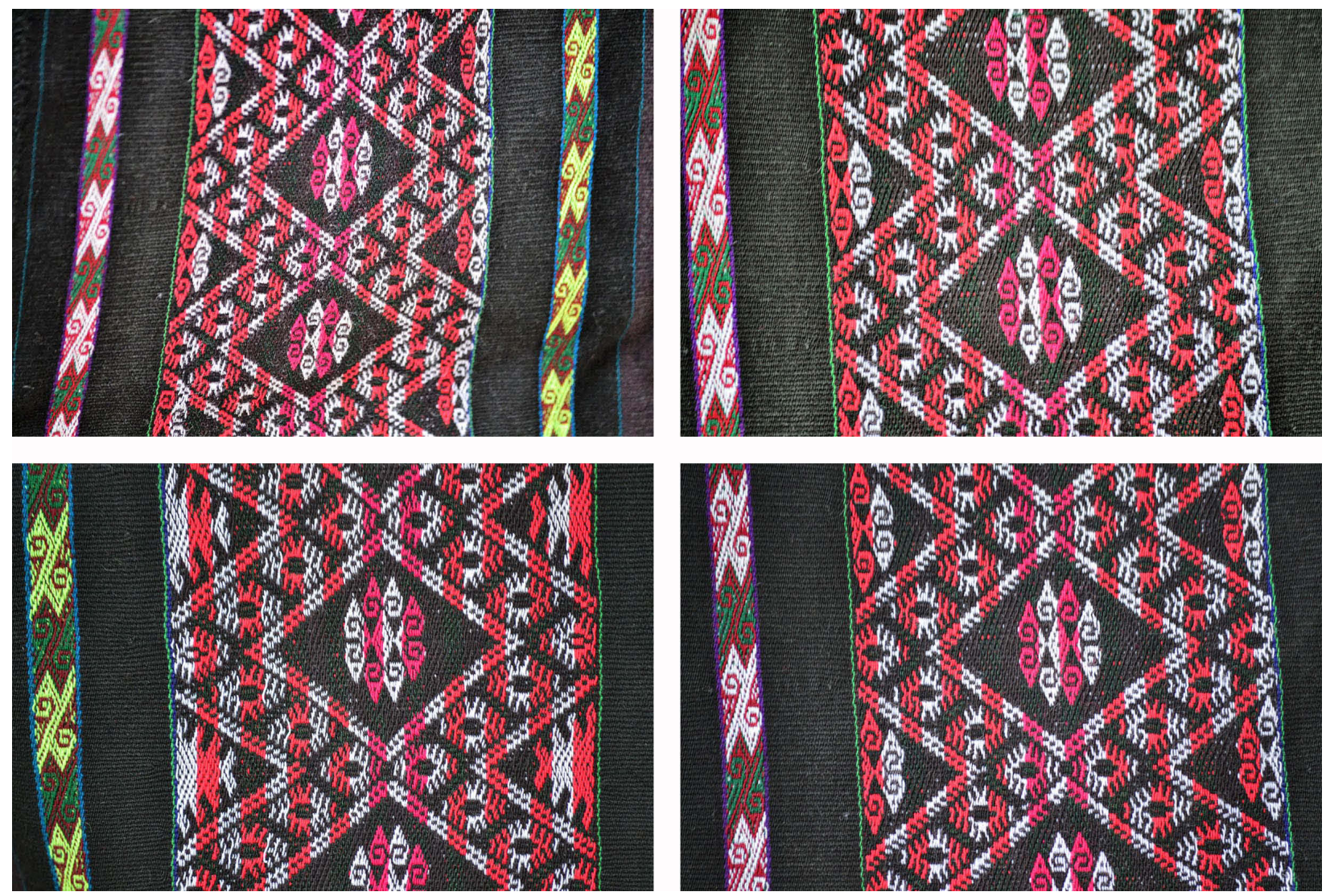

Fotografía 3: Cuatro detalles de la lliklla de Claudina. Fotografías de Verónica Auza Aramayo. 


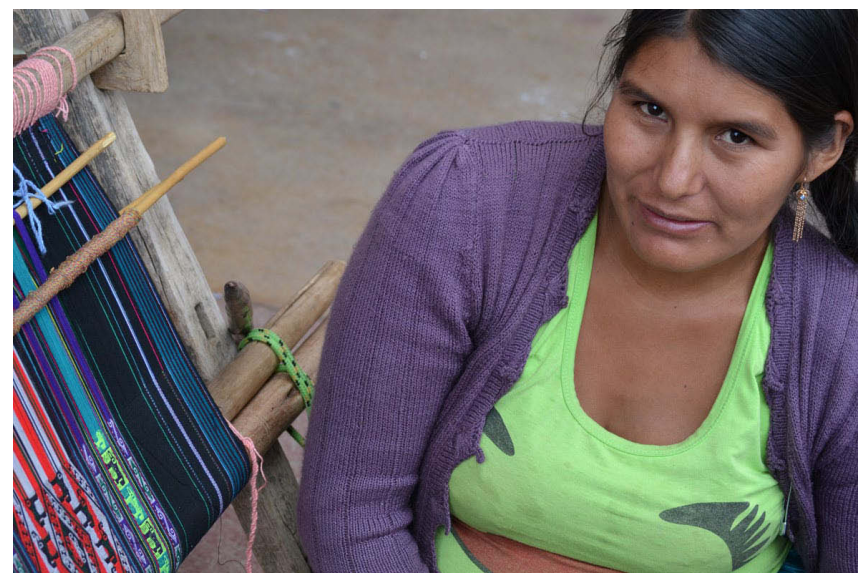

Fotografía 4: Claudina Torres y su telar. Fotografía de Verónica Auza Aramayo.

y territorio, en los textiles de Poroma, a partir de las conversaciones con Claudina Torres, de la comunidad de T'ula Pampa, Poroma. Claudina, tiene 29 años aprendió a tejer de niña con su mamá y a sus 14 años, tejió su primera lliklla para la fiesta de carnaval, desde entonces fue ganando destreza, actualmente Claudina puede tejer una lliklla en un mes. Cuando Claudina reflexiona sobre las formas y diseños que teje, me dice que siempre ha tejido así, "desde siempre así tejían, antes el color era así siempre”. Claudina, afirma: "llamero soy, como mis abuelos, somos llameros, mi abuelita, que no la conocí y mi abuelo de Macha venían, llameros somos, ellos han venido, hace tiempito ya, mucho tiempito ya, y me contaba mi mamá que en la Revolución Nacional (de 1952) los abuelos, grave han peleado por las tierras, bien dice que enfrentaba para ganar la tierra ahora de nosotros, desde Macha ha venido, cuando eran jóvenes, mucho había peleado mi abuelo para que las tierras de nosotros, sean nuestras". Como vemos, los abuelos de Claudina eran parte

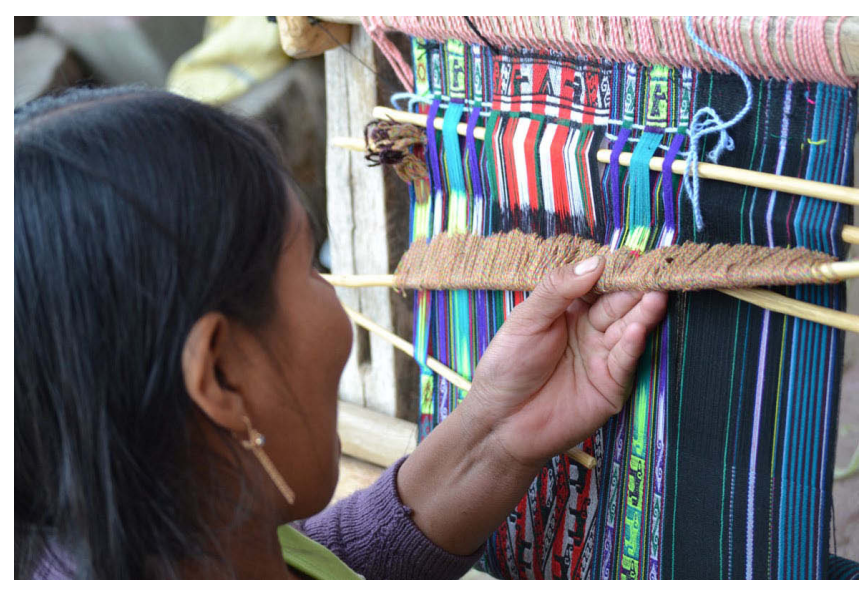

Fotografía 6: Detalle del telar de Claudia. Fotografía Verónica Auza Aramayo.

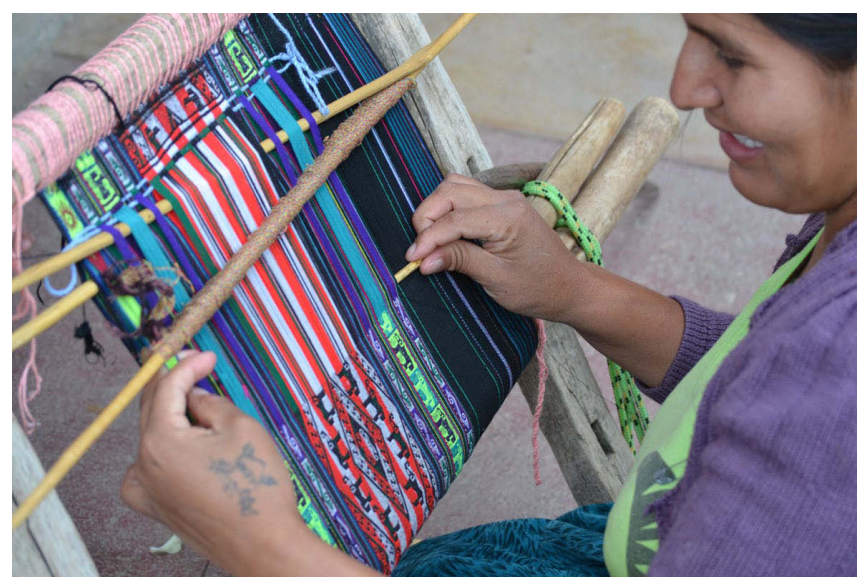

Fotografía 5: La técnica "kimsa pallay" de los Llameros. Fotografía Verónica Auza Aramayo.

de aquellos luchadores, aquellos caminantes nocturnos.

$\mathrm{Al}$ verla tejer a Claudina, noto la urdiembre copiosa de su lliklla, entonces, ella me explica: "Mira, si, cuanto más delgadito, pequeño es el hilo, se tarda más, mi mamá dice que mi abuela, tejía mejor que nosotros (Foto 6), pues harto hilo ponía, y acababa más bonito, más finito, mi mamá nunca podía tejer como mi abuelita, aunque ella sabe también... yo, entonces, siempre tejer así, un mini va de canto a canto, ves, el otro mini, solo está en el pallay... Ch'ulla, k'achito, kimsa, impar, de tres, se teje de tres, ¡ves!, así es bonito, así tiene que ser, otro siempre se pone, parte por parte, (aquí Claudina indica la diferencia entre pampa y pallay, estableciendo que esta distinción en los tejidos de Poroma no solo es visual, sino también técnica); así se teje, así siempre, así torcido, tiene que estar bien torcido los hilos (Foto 7), es un grosor medio, porque si es grueso peor se rompe y delgado cuesta mucho tejer... Nuestro pallay, chumpi, uskara, también, mi mamá le decía cochala pallay ch'ulla...

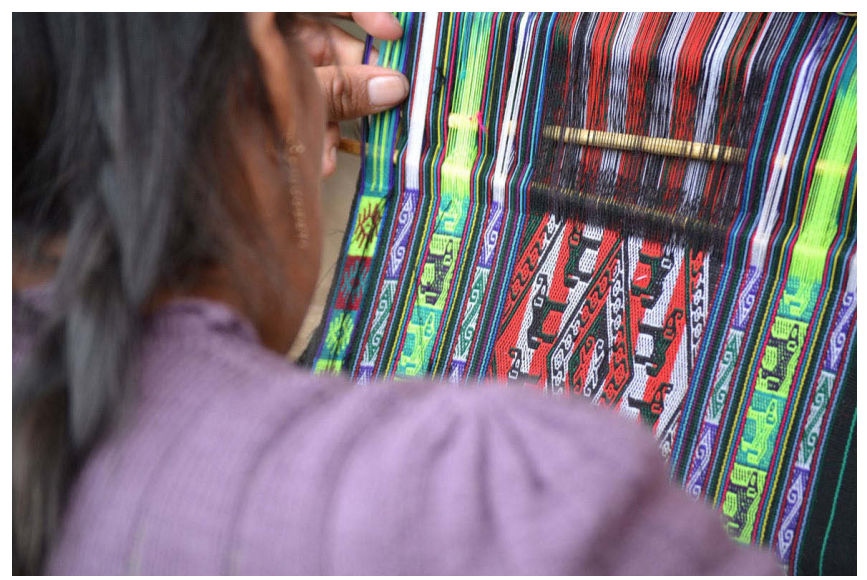

Fotografía 7: Detalle del kimsa pallay. Fotografía de Verónica Auza Aramayo. 

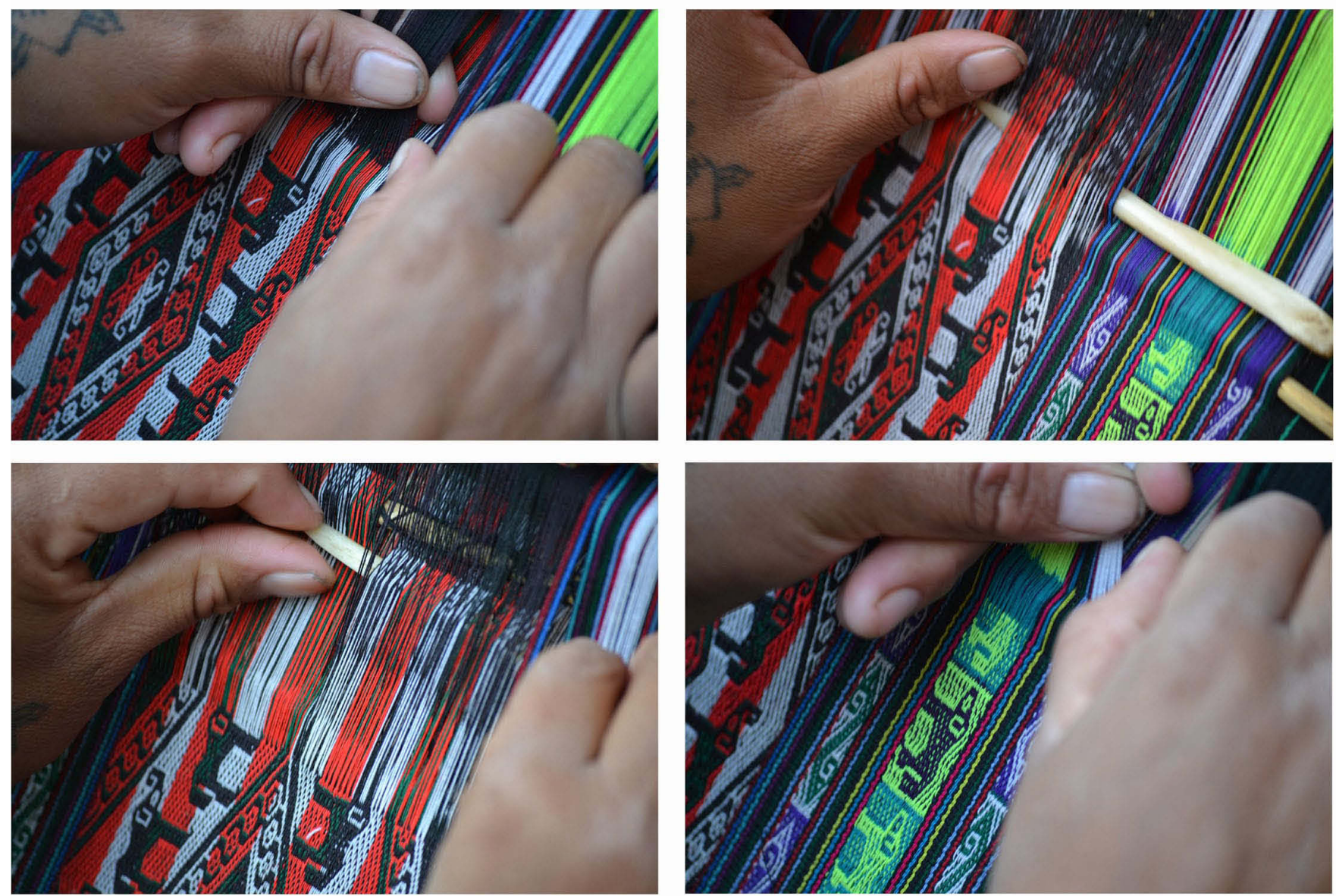

Fotografía 8: Cuatro detalles de los elefantes en los escenarios festivos de T’ula Pampa. Fotografías de Verónica Auza Aramayo.

Siguiendo este vasto repertorio visual femenino, la lliklla de Claudina es festiva por excelencia, lo que quiere decir que además de ser prolija en sus diseños y en sus colores, está destinada a celebrar la fecundidad, el poder de la preservación de la vida y el universo femenino fascinante del arte textil de Poroma. Como se puede apreciar en estas cuatro fotografías, vemos como Claudina ha incorporado en la trama festiva de su pallay a elefantes, que este año hace parte de su diseño para celebrar los bailes del carnaval. Además, en esta prenda podemos apreciar la complejidad técnica del kimsa pallay con prolíferas bandas diseñadas contemporáneas que evocan ese pasado de los antiguos caminantes llameros en el presente colorido del carnaval en T'ula Pampa.

Claudina, nos dice que los tejidos siempre han sido así en sus diseños, estructuras cromáticas y sentidos visuales (técnica, formas y creatividad) particularmente intrincados (Foto 8), puesto que su pallay llevan tres colores, lo cual implica una técnica singular, puesto que necesita dos hilos madres, uno para toda la trama y el adicional solo va en el pallay de la pieza, es este hilo madre adicional, el que posibilita tramar la urdiembre del pallay con tres colores y así distinguir el resto del textil que solo lleva dos.

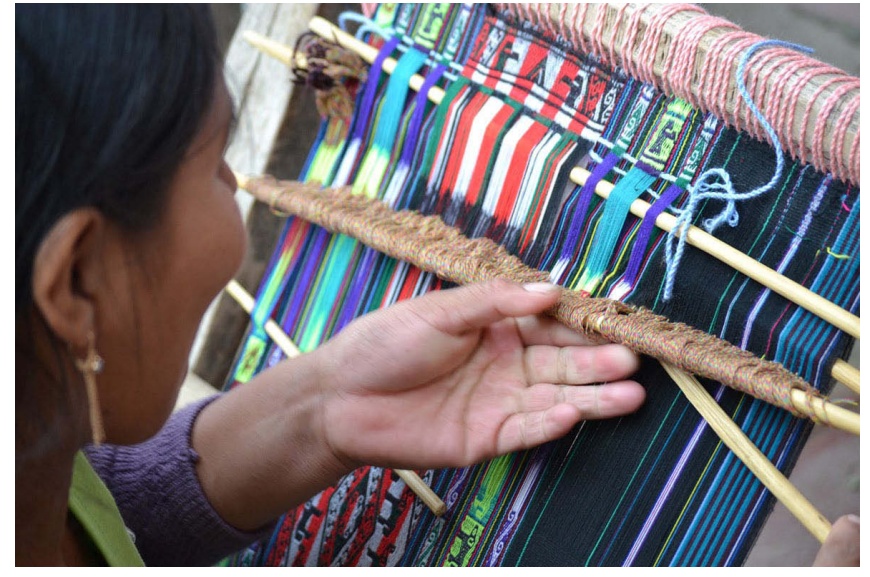

Fotografía 9: Detalle de la técnica del kimsa pallay de los llameros. Fotografía de Verónica Auza Aramayo.

Como ya he mencionado Poroma, siendo zona valluna, se destaca por autonombrarse "llameros", denominación o concepción que nos remonta a una dinámica espacial notable en sus alcances, la de los trajines de los llameros y sus caravanas desplazadas en extensos kilómetros de norte a sur 

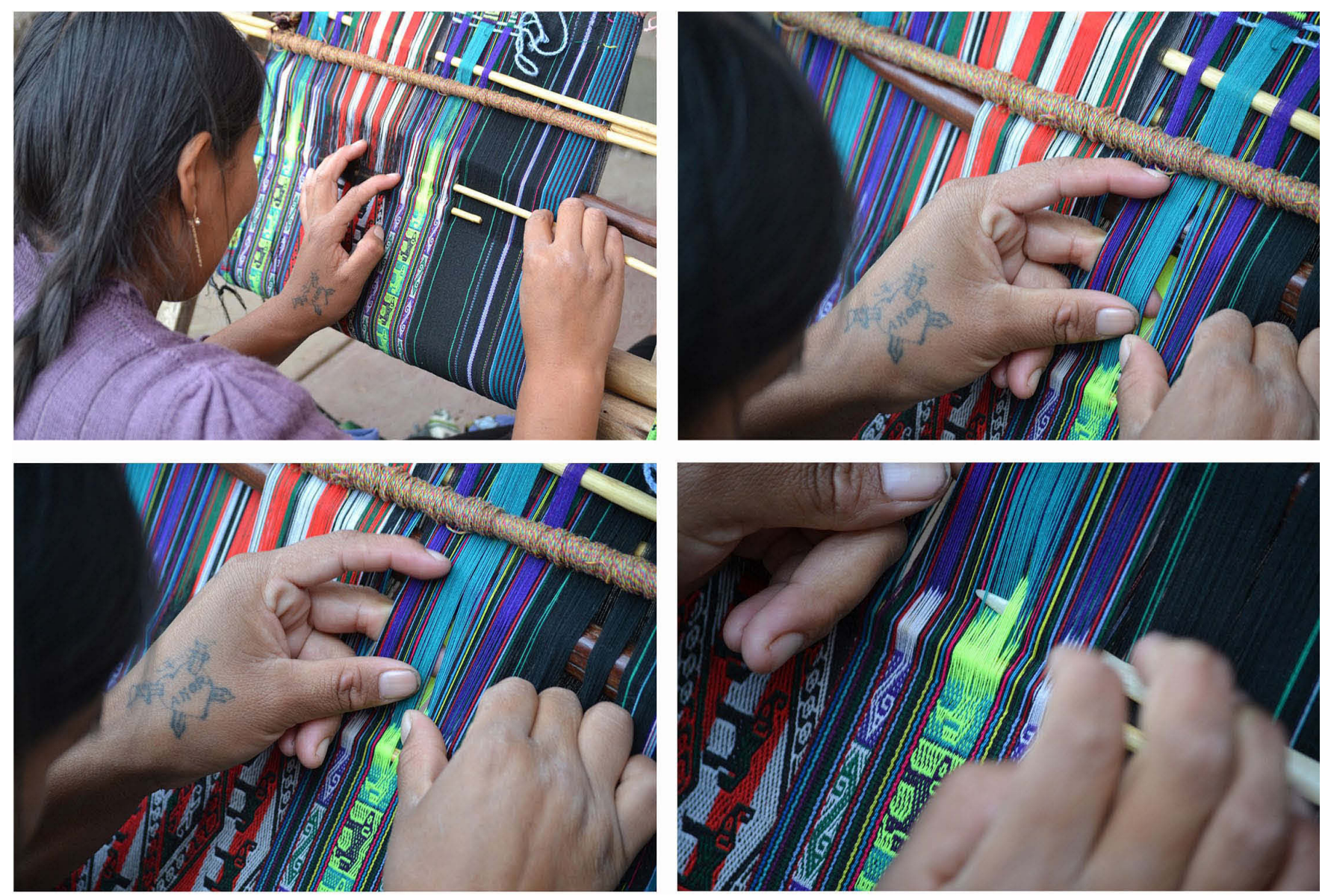

Fotografía 10: Cuatro detalles de la técnica textil de las tejedoras de Poroma. Fotografías de Verónica Auza Aramayo.

por el territorio andino (Foto 9). Seguir siendo "llameros" implica una identidad en la cual de cierto modo no ha dejado de latir la evidente presencia de la Puna que, a su vez, nos remite a aquellas prácticas donde el trajín trazaba mapeos culturales, que desde épocas prehispánicas hicieron a la vida andina y que actualmente todavía perdura como imaginario cultural de esta identidad étnica.

En fin, me atrae particularmente este contrapunto (Foto 10) que subyace en esta distinción étnica, cargada de entrada de una compleja dinámica multiétnica que sucede y que sucedió en estas comunidades; viendo los diseños textiles, considero que el entresijo de sus signos también evocan de un modo particular esa multiplicidad y superposición de este modo de configuración territorial y étnico (Foto 11), lo cual claro, aborda el complejo tema del territorio andino y el sentido que las tejedoras brindan con sus tejidos.

Abordar a las tejedoras de las comunidades de Poroma, con las cuales he establecido contacto, me permite reflexivamente, atar mi interpretación teórica desde el abordaje semiótico de sus textiles (Foto 12) y todo lo que sus signos contienen del modo de habitar y significar su territorio. Sin duda, este ensayo es parte del campo de conocimiento

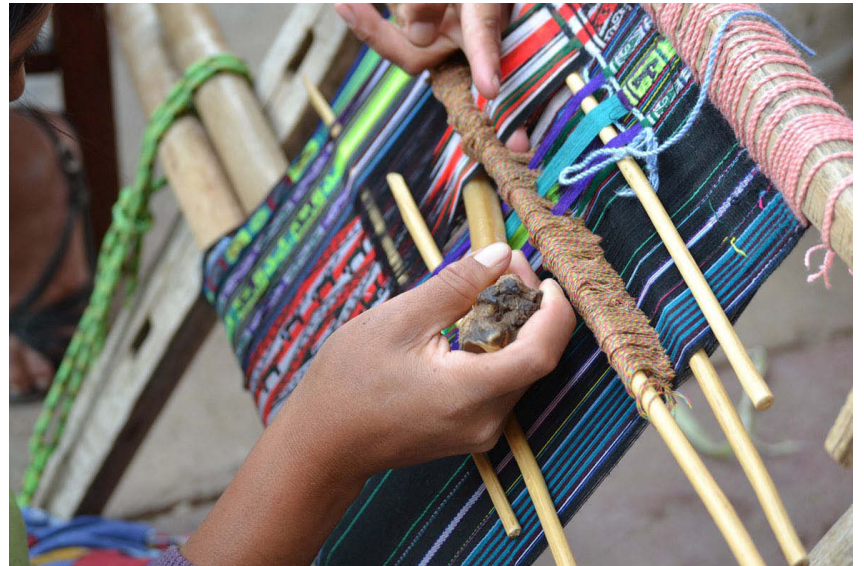

Fotografía 11: En Poroma, el pallay se teje de tres. Fotografía de Verónica Auza Aramayo.

que comprende el léxico que nos ofrecen los textiles, como "textos" (Verónica Cereceda, 2010), con sus mensajes precisos, sus convenciones, sus unidades mínimas, el porqué de sus órdenes cromáticos y la figuración de sus diseños; en definitiva, mi análisis procura acercarse a la 

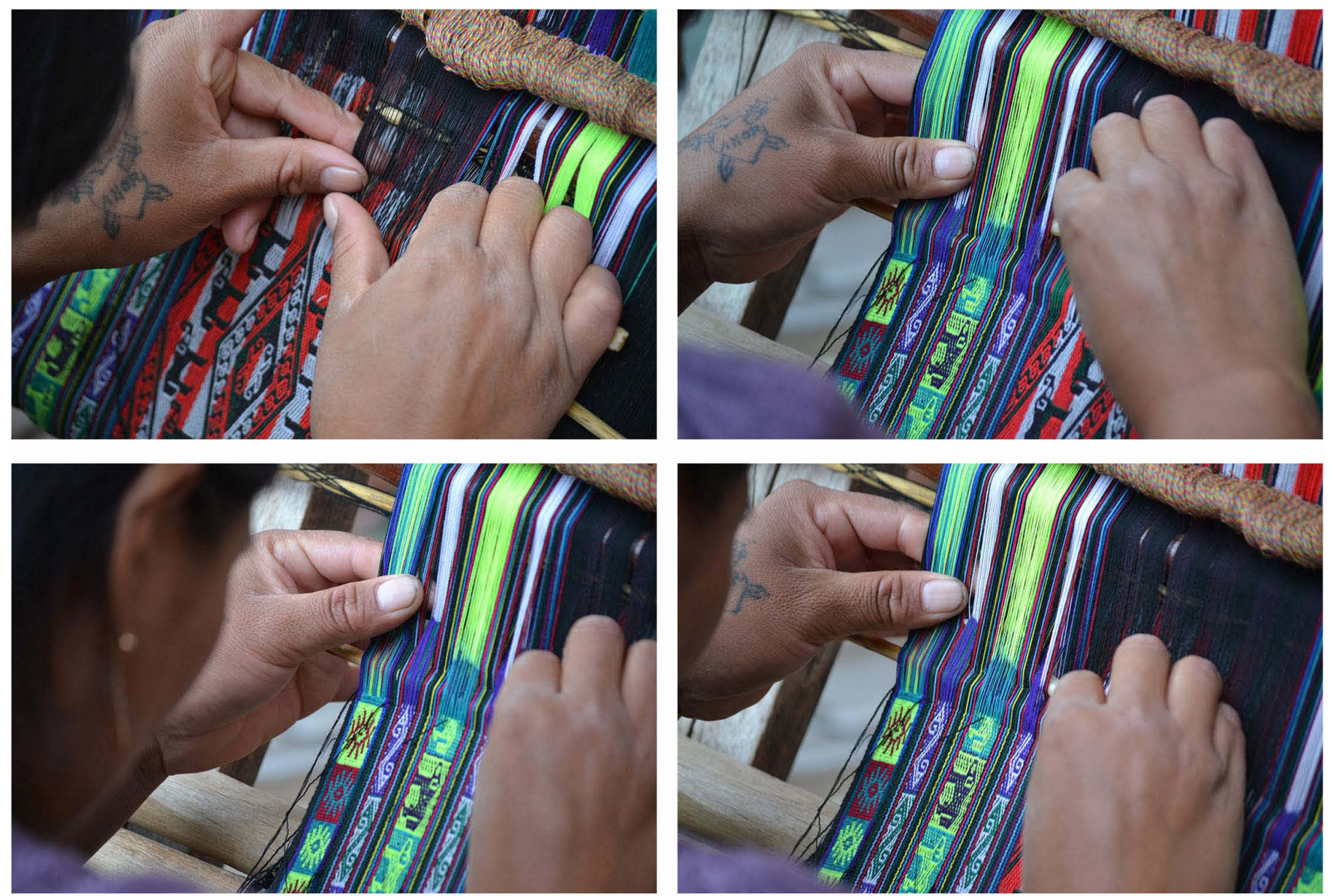

Fotografía 12: Secuencia de cuatro detalles del arte de tejer de Claudina. Fotografías de Verónica Auza Aramayo.

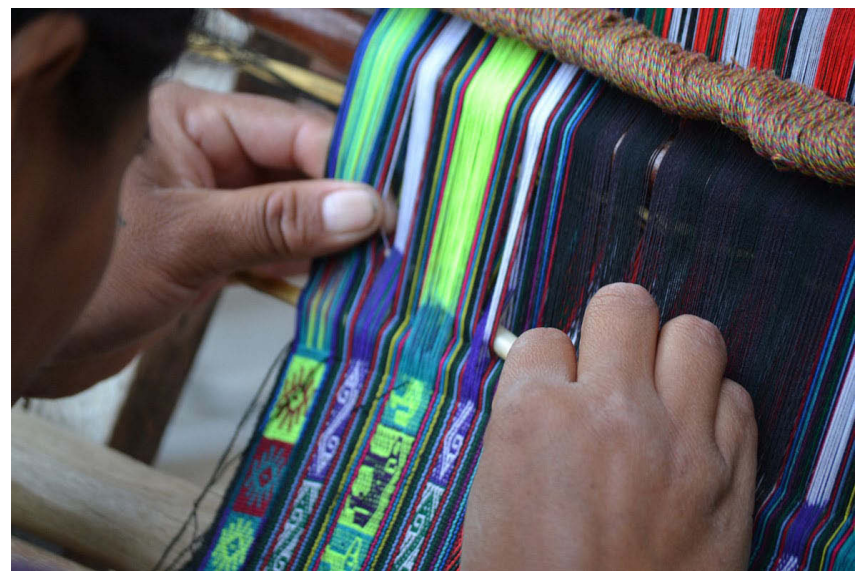

Fotografía 13: Se teje de tres. Fotografía de Verónica Auza Aramayo.

significación textil del cosmos y de la vida, a este lenguaje no letrado que no cesa de expresarse desde sus contextos más íntimos y sensibles.

En ese sentido, las líneas que seguirán, por un lado, serán un intento para comprender el cómo a pesar de la marginalidad y casi desaparición de textiles y tejedoras (Fotos 13, 14), ambos, siguen manteniendo y haciendo efectivo el

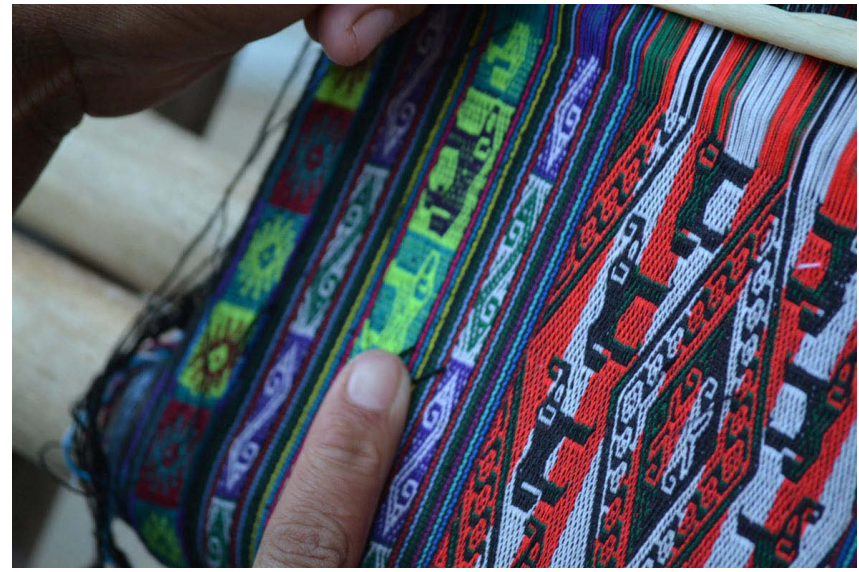

Fotografía 14: Se teje de tres... Fotografía de Verónica Auza Aramayo.

modo de hacer habitable el espacio y de dotar de sentido de identidad a un territorio desde un lenguaje emotivo, visual y femenino.

Cada una de las imágenes, muestra como los hilos de la trama de los textiles de Poroma (Fotos 15, 16), conllevan en su orden cromático, en su técnica y su diseño, los caminos, lo recorridos que se llevaron a cabo a lo largo de los 


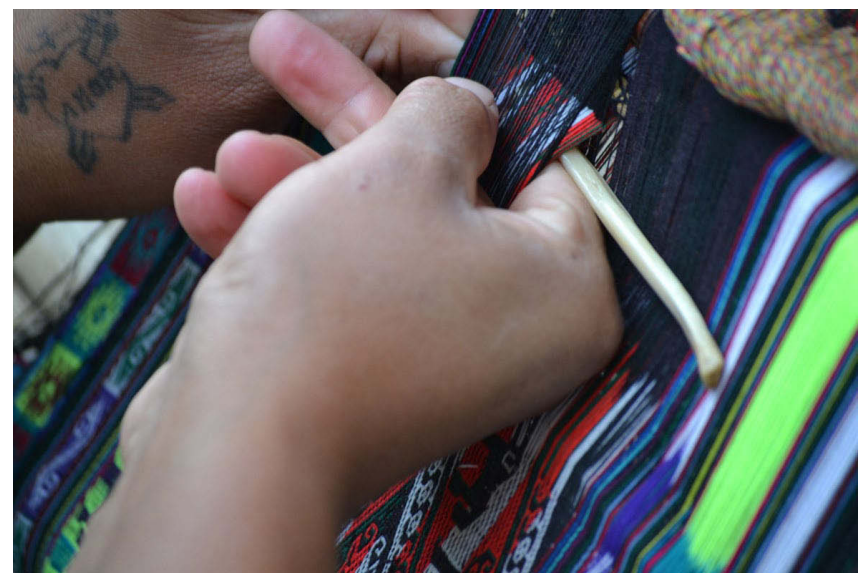

Fotografía 15: Los hilos del kimsa pallay. Fotografía de Verónica Auza Aramayo.

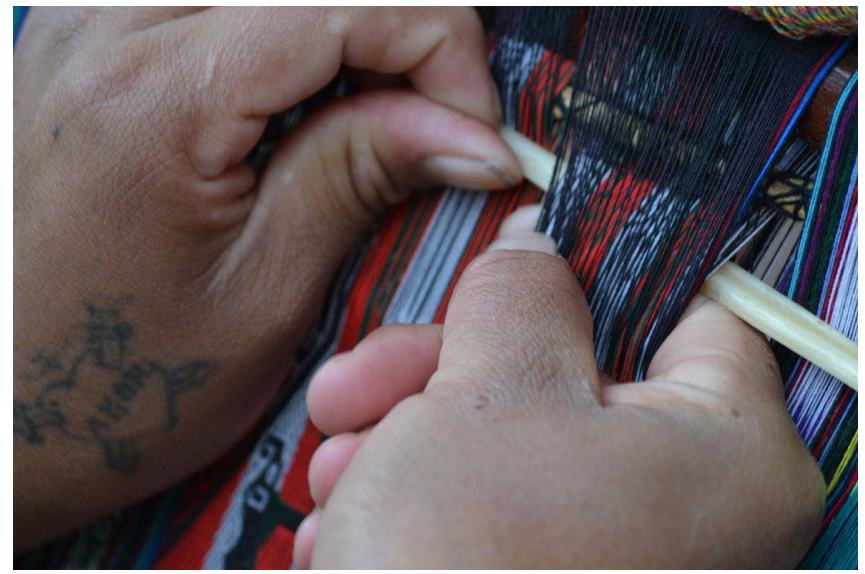

Fotografía 16: Los hilos de la puna al valle. Fotografía de Verónica Auza Aramayo.

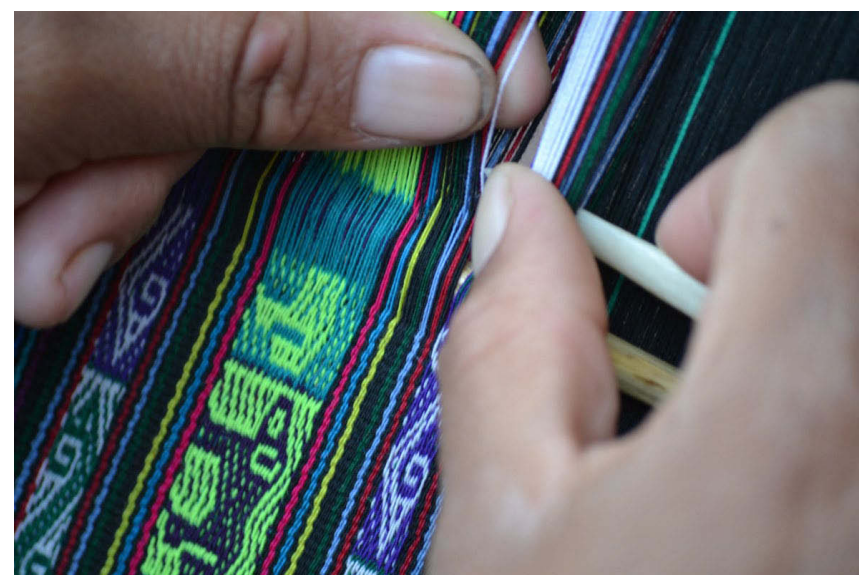

Fotografía 17: De la puna al valle: el diseño textil de Poroma. Fotografía de Verónica Auza Aramayo.

tiempos para pasar de habitar la puna al valle (Foto 17, 18, 19). La técnica del kimsa pallay, ese tejer de a tres, implica, una técnica que requiere dos hilos madres para tramar la

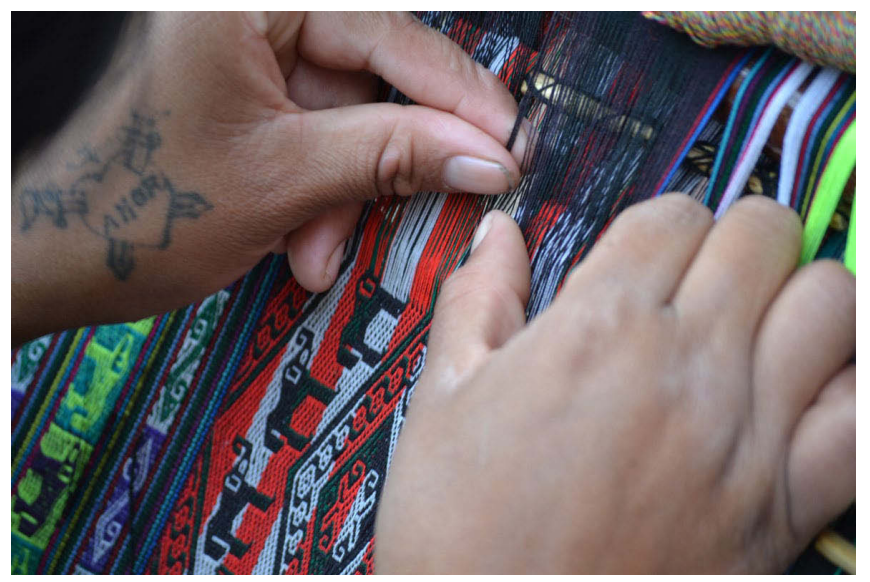

Fotografía 18: De la puna al valle... Fotografía de Verónica Auza Aramayo.

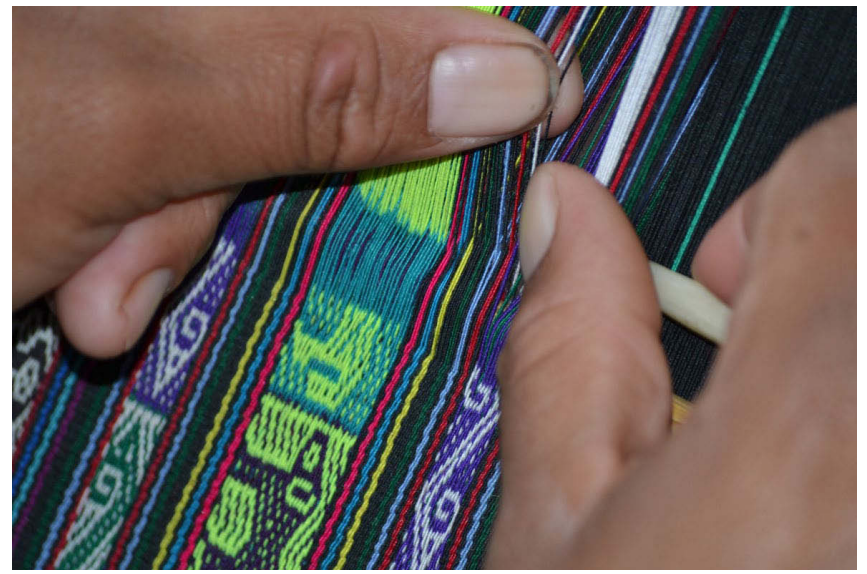

Fotografía 19: De Macha a T'ula Pampa. Fotografía de Verónica Auza Aramayo.

urdiembre, esto nos habla de una cultura textil, desde donde las tejedoras de Poroma, nos expresan una forma de habitar el territorio, el mundo, con un principio esencial de tres, la presencia de estos dos hilos madres, nos dan cuanta que solo es posible tejer el pallay así, no de otra manera, pues como lo recalca Claudina, "siempre se teje de tres", es esta la configuración textil y cultural que distingue los tejidos de Poroma, al interior de los Andes.

De ese modo, se comprende como las formas de desplazarse y ocupar el espacio y el territorio en los Andes (Fotos 20,21 ), tiene un impacto en el lenguaje visual de los diseños textiles andinos, puesto que cada distinción textil de un modo u de otro, marca su diferencia en el espacio, su diferencia de diseño, orden cromático y una semántica, la cual con el apoyo de las técnicas que, en el caso de Poroma, implica dos hilos madres en el pallay de las prendas (Foto 22), logran construir y trasmitir su mensaje étnico, su "texto" étnico, como bien señala Verónica Cereceda (2017). Pues bien, bajo este kimsa pallay podemos advertir el lenguaje 


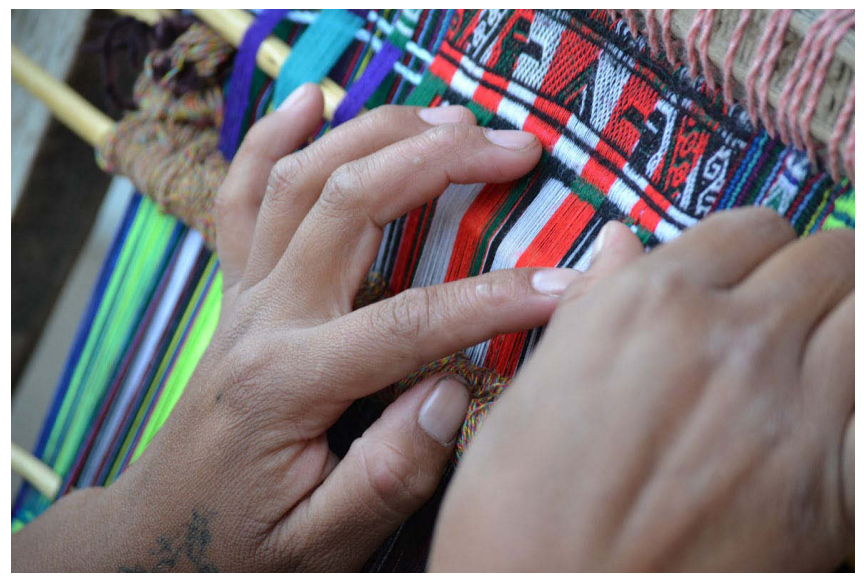

Fotografía 20: Los lenguajes territoriales del textil. Fotografía de Verónica Auza Aramayo.

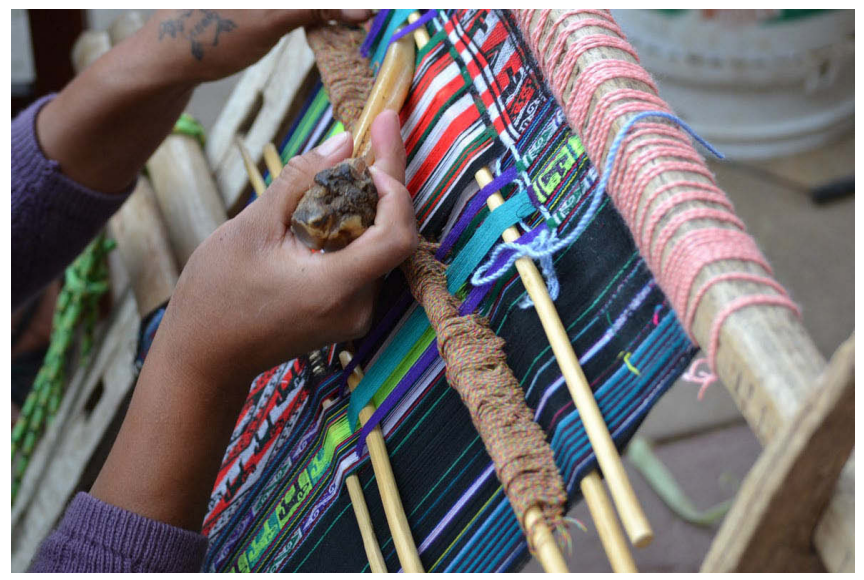

Fotografía 21: Los dos hilos madres del pallay de los tejidos de Poroma. Fotografía de Verónica Auza Aramayo.

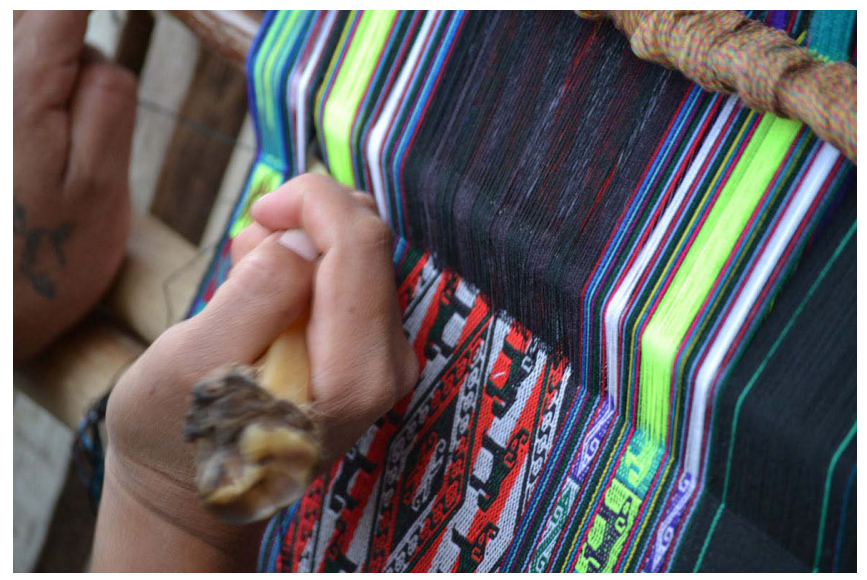

Fotografía 22: Los de los hilos madre del pallay de Claudina. Fotografía de Verónica Auza Aramayo.

visual (Foto 23), la gramática textil que los tejidos de Poroma trasmiten con el arte textil que a lo largo de los tiempos, las tejedoras y sus culturas han venido desarrollando

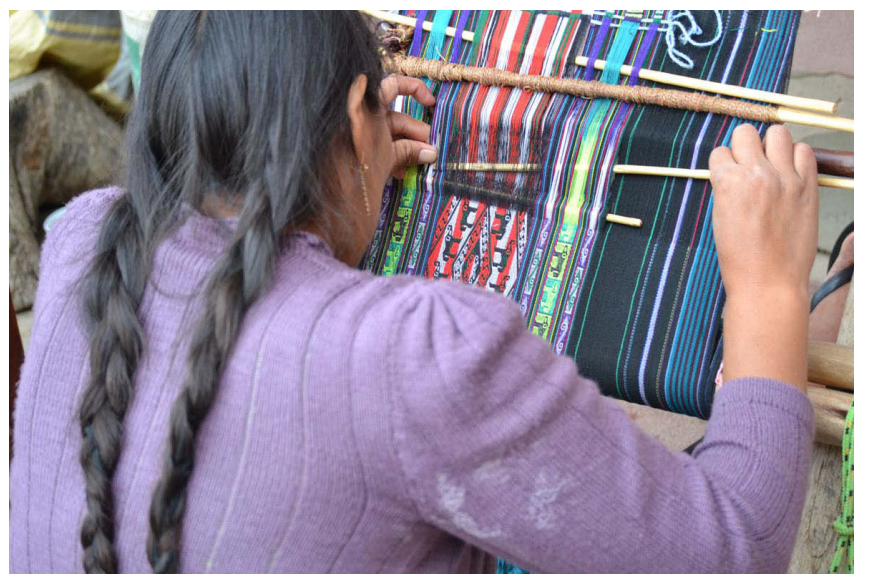

Fotografía 23 Urdiembre y trama del kimsa pallay de la lliklla de Claudina. Fotografía de Verónica Auza Aramayo.

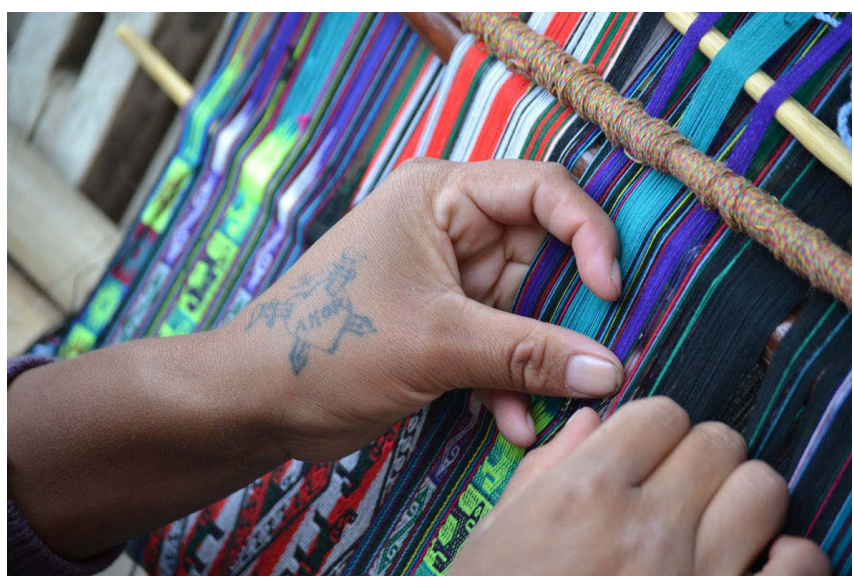

Fotografía 24: Detalle de la lliklla de Claudina. Fotografía de Verónica Auza Aramayo.

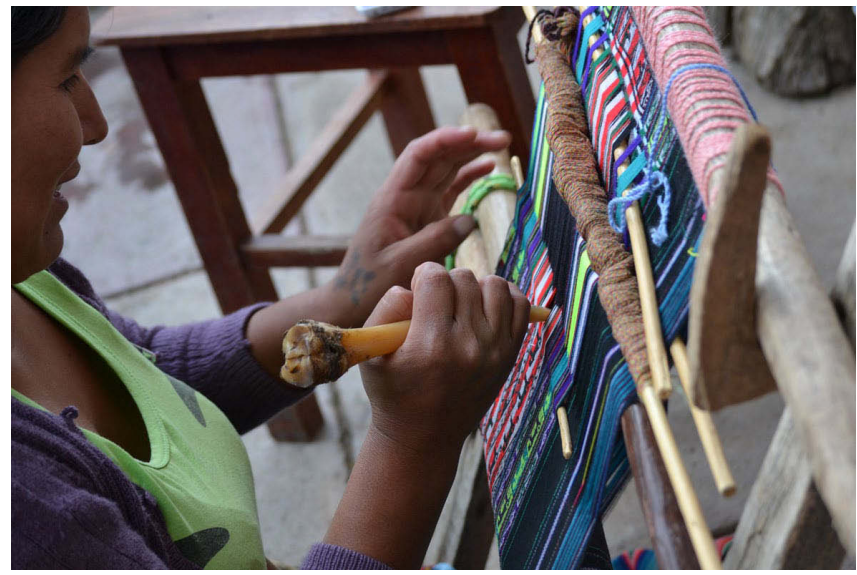

Fotografía 25: Claudina tejiendo su lliklla para el carnaval. Fotografía de Verónica Auza Aramayo.

habitando el territorio desde las pautas visuales y los distintivos repertorios de cada uno de los textiles andinos (Foto $24,25)$. Hecho que también puede ser pensado bajo una 


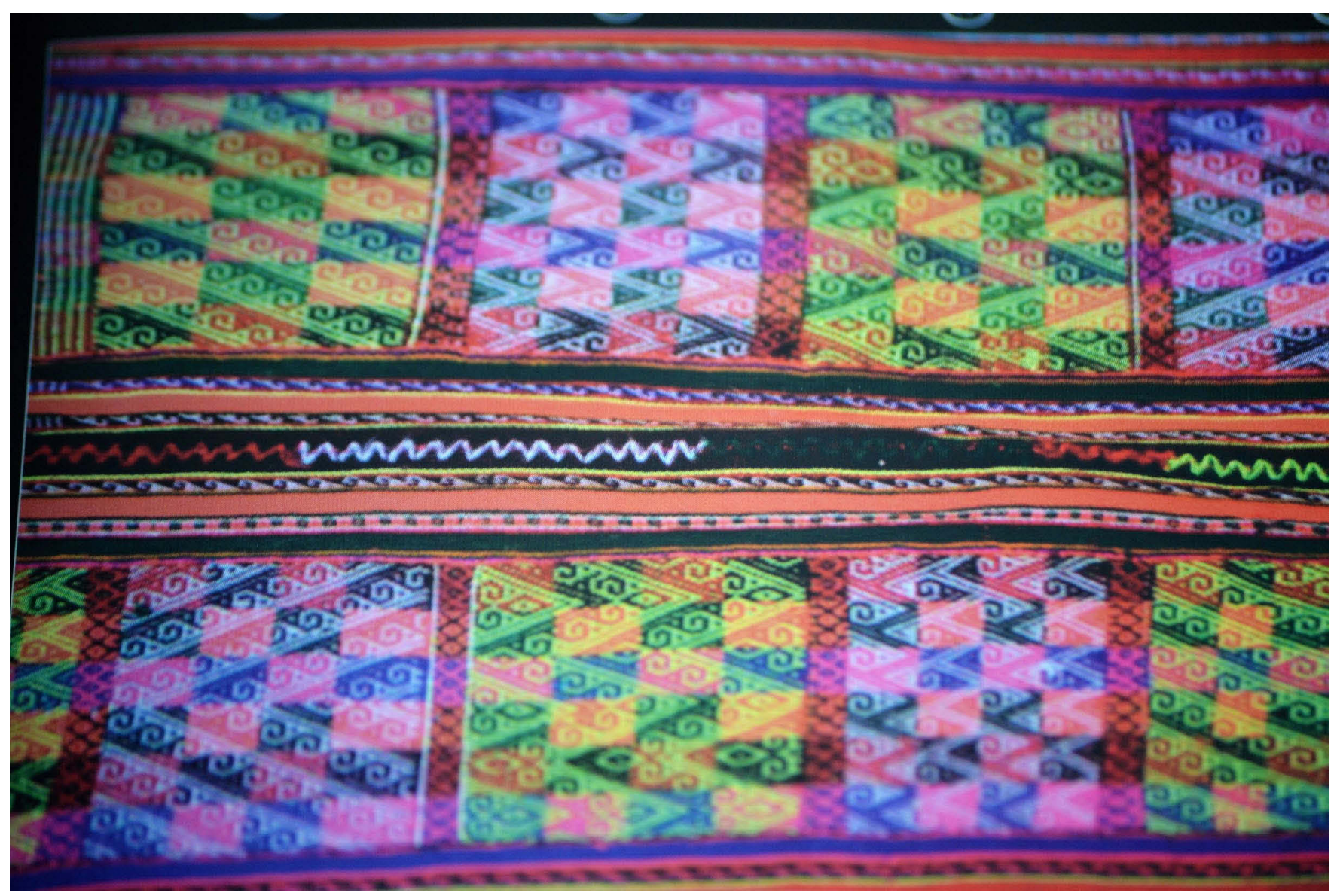

Fotografía 26: Detalle del diseño de Aywira de la lliklla de Viru Viru, Poroma. Fuente: Diseños de los textiles Poroma. Investigación y fotografías. ASUR, 2010. Pág. 93.

mirada arqueológica, que nos recuerda como las palabras de creación de Viracocha que impartían una distinción de vestimenta y con la diversidad textil que hoy en día, supone, como también lo señala, el sistema territorial de archipiélago vertical que nos legó Murra (1975), pues, en definitiva, en los Andes, se habita el territorio desde los lenguajes plásticos y la semiótica visual de los textiles.

\section{Aywira: un diseño textil de los andares de los llameros.}

De manera genérica, el diseño que más resalta y distingue a los tejidos de Poroma es el aywira, la mayoría de los diseños son nombrados así por las tejedoras. Según Ludovico Bertonio: "aywiratha, significa: desviarse un poco de donde están"; "aywiracatha: ir contra la voluntad del capitán, o pastor”. Los diccionarios más contemporáneos, señalan que aywira significa caminar o ir en grupo, andar en conjunto de un lugar a otro; andar a otro lugar sin dirección.

Para las tejedoras de Qaqachaca, aywira es una figura textil del camino celestial de las llamas (Arnold: Hilos sueltos: 309), curiosa denominación, ya que la gente de
Poroma se autonombra como "llameros". De esa manera, el diseño de Aywira (Foto 26), es un diseño textil que teje y representa muy bien los andares de los llameros, andares que resultan un movimiento contrario al establecido, un tanto desviado, que oscila de un lugar a otro en franca deriva, siguiendo, en pero, el camino celestial de las llamas.

La técnica de los textiles de Poroma, también dan cuenta de la dinámica étnica que la definió a los hilos del aywira a través de la historia, puesto que la parte de sus pallay lleva dos hilos madres, lo cual establece una trama doble y hasta triple en sus ejes principales del diseño, ello claramente expresa aquello que Sophie Desrosier (1992) concibe como un sentido o una ideología volcada en la técnica (Foto 27). En la imagen se ve una lliklla de la comunidad de Viru Viru, con diseños ch'uritos de 4 pares de hilo y Nawi aywira de 90 pares, con bordes linku y divisiones jark'achis o k'utus.

Siguiendo el argumento de Desrosier, sin duda, la singular característica técnica empleada por las tejedoras de Poroma para tejer sus llikllas, tiende a confirmar la existencia implícita del kimsa, el hilo ch'ulla que distingue su trama como el código textil de T'ula Pampa y su trama nos permite 


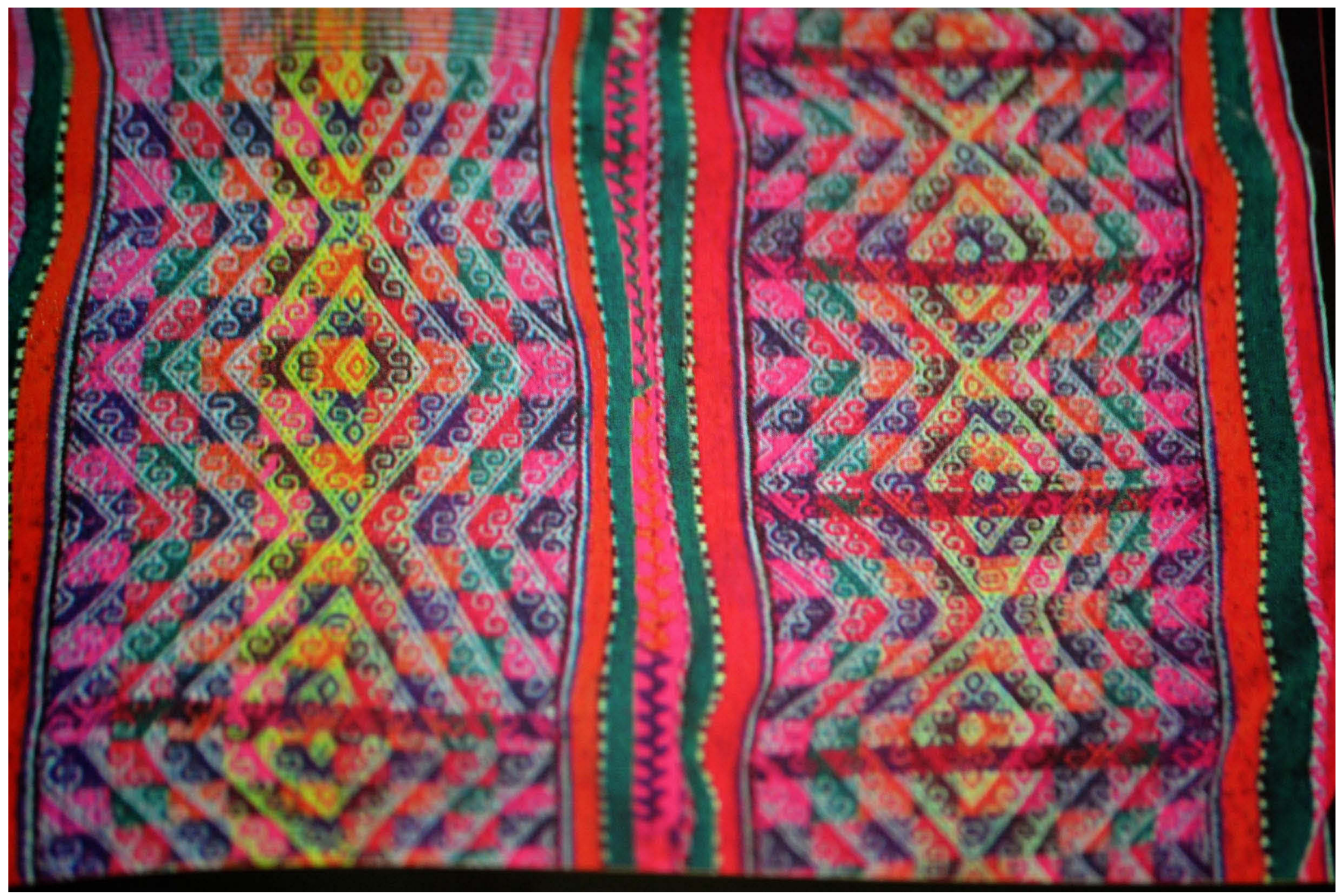

Fotografía 27: El diseño aywira de la lliklla de Viru Viru, Poroma. Fuente: Diseños de los textiles Poroma. Investigación y fotografías. ASUR, 2010. Pág. 93.

comenzar a interpretar su sistema y mensaje étnico como aquel que rompe la dualidad o el esquema dualista de faz urdiembre y con ello, transmitir ese solo "ser viviente" en cursivas, el resto del texto no de los caminos, de los desplazamientos que los antiguos luchadores realizaron para dotar de un territorio a su cultura nómada; así la técnica de Claudina ofrece todas las construcciones simbólicas que los llameros vaciaron en sus tramas y urdiembres para dotar sentido al espacio y habitar este valle con aires de la otrora puna que los cobijaba.

\section{A modo de conclusión.}

Pensar en la transcendencia del uso y apropiación del espacio en el mundo andino, nos permite comprender el paso de la puna al valle en los tejidos de Poroma, que traen al ahora, la distancia temporal, y al mismo tiempo los andares y los desplazamientos que los abuelos, aquellos caminantes de la noche desde la puna potosina, en franca clandestinidad, idearon principios comunitarios para volver al territorio con un sentido propio. Fueron, estos abuelos y también las abuelas las que idearon sentidos de pertenencia en sus desplazamientos, cual dinámicas nómadas, replanteando su identidad étnica, en procesos multiétnicos, donde el tercero, el otro, no puede estar excluido, todo lo contrario, como dice Claudina "se teje de tres", como se vive y convive en las comunidades contemporáneas de Poroma, convirtiendo a su expresión pallay, en un kimsa pallay desde el cual observamos lo que dice Bertonio del diseño aywira, bañado con estrellas, con luz de noche, como aquel umbral del cielo de la puna Macha y la oscuridad encendida del mensaje jalq'a, llevándonos en esta trama, aquellos andares, de llameros, de caravanas, del control vertical (Murra, 1975), donde las comunidades lucharon, resistieron, y en cierto sentido "se desviaron" para no perder su territorio. Todo ello late y lo vemos expresado en la diversidad étnico cultural de Poroma y en las tramas de los tejidos de Duraznillo, Viru Viru, T'ula Pampa.

Mismo lenguaje visual que enlaza los órdenes cromáticos del amarillo guerrero de Pocoata, el blanco y rojo 
intercalado de cultura luchadora de Macha y los diseños estrellados, brillantes en sus destellos como las altas punas desde que emprendieron el viaje y la decisión de quedarse para habitar un valle que traía en sus estribaciones el legado de los abuelas de los abuelas... viendo esta singular construcción de sentido visual y de distinción textil, se puede seguir estos caminos y devenires que desde la técnica y los recorridos emprendidos, las llikllas pasaron y se detuvieron en el signo de aywira, del jatun chas'ka, del churasqa, para llegar a la nomadología actual de elefantes y perros que acompañan su andar en un espacio que a pesar de ser accidentado encuentra su lugar, su eje, su hogar, y podemos convenir que todavía, hoy en el mundo andino textilmente se habita y textilmente la identidad es vestida de color, de sentido, de diseño y de signos.

Los textiles son una imagen del territorio, igualmente podemos considerar el lenguaje visual y la estética de la técnica textil como un modo de territorializar el estar en el mundo, un tejido a los ojos andinos es una fábrica de sentidos que forjan las identidades en el espacio, solo ahí, los hilos, sus tramas, sus colores y su estructura pueden amplificar visualmente el espacio y configurar territorios.

Los tejidos hacen nacer la imagen de un mundo y nos permiten interrogar en ellos los modos de ser y estar en el territorio que se habita... de la puna al valle, sí, pero bajo la condición histórica de valorar el nombre de sus ancestros, la gente de Poroma son «llameros» y no dejaron de ostentar ese afecto por las alturas, finalmente, éstas son su origen, su principio, su nacimiento cultural y es en el tejido, donde este intrincado principio se colma y se explaya bajo los kimsa pallay, porque para esta cultura siempre se teje de tres.

En definitiva, los textiles en el mundo andino no se reducen a ser objetos bellos en sí mismos, ya que todo textil transmite, evoca y promueve un sentido de identidad, de poder, de prestigio, de afecto $\mathrm{y}$, como hemos podido ver, de territorialidad, de ser en el espacio. Es por ello, que es axial interpretar el devenir y las transformaciones de los diseños y de los órdenes cromáticos concibiendo sus procesos de territorialidad en cada mirada sobre esta etnología del arte, sobre el alcance de cada una de sus fuerzas vivas, mágicas y espaciales que los tejidos tienen el don de expresar.

El paso de la puna al valle, nos exige analizar esos caminos étnicos por donde los pueblos andinos libraron su lugar en el mundo, trajines, desplazamientos por el territorio que desde tiempos precolombinos se fueron sucediendo y, como se ha visto en el caso de Poroma y de sus textiles, podemos atisbar la forma en que los textiles traducen la manera de hacer habitable los espacios, cuando nos enfrentamos a leer y entender los signos textiles y sus variedades de diseños y ordenes cromáticos que a lo largo y ancho del mundo andino se fueron explayando a través de nuestra historia. Hemos visto como léxico textil es también un léxico territorialque creo que es posible remontar a los estudios y análisis de los textiles arqueológicos.

Para terminar, considero que los tejidos de Poroma traducen la fuerza y la emoción estética viva que en los Andes, desde tiempos inmemoriales, ha tenido la virtud de marcar distinciones textiles en su ocupación del espacio y del territorio. Como hemos visto, los diseños textiles de Poroma, evocan el paso de Macha a T'ula Pampa que los abuelos de Claudina realizaron en su historia, recorrido territorial que los llameros de Potosí libraron para establecerse en el valle de Poroma y que sus tejedoras le crearon un distintivo diseño textil. Mi aporte radica en llevar esta lectura a los estudios de la exhaustiva arqueología textil existente, y así ir ampliando significativamente nuestra mirada visual y nuestro repertorio histórico cada vez que profundicemos el análisis de los textiles desde sus modos de tejer los diferentes desplazamientos y dominios del espacio que las diferentes textiles evocan y actualizan en todos sus devenires comunitarios que al construir y apropiarse del territorio, hacen que éste sea habitable y se convierta en signo de identidad. Tras este breve análisis, pienso que las tejedoras de Poroma y sus tejidos, exponen francamente el campo de sentido de la dupla: textil y territorio, campo que implica el devenir histórico de la puna al valle tejido en los intrincados diseños del kimsa pallay, a la vez novedosos y a la vez ancestrales, pues en ellos, apreciamos el aywira de Bertonio, los andares nocturnos y clandestinos de los abuelos y el desvío festivo del jatun chaska y de los elefantes para el carnaval que se mueven oscilantes en la lliklla de Claudina.

\section{Bibliografía.}

Arnold, Denise, Yapita, Juan de Dios y Elvira Espejo.

2007. Hilos sueltos: Los Andes desde el textil. La Paz: ILCA y Plural.

Bertonio, Ludovico.

1984 (1612). Vocabulario de la lengua aimara. Cochabamba: Edición Facsimilar Cochabamba, CERES.

Cereceda, Verónica.

2017. De los ojos hacia el alma. La Paz, Plural editores.

(Santiago Pórcel y Román Flores).

2010. Diseños de los textiles de Poroma. Sucre: ASUR.

- Prólogo. (Santiago Pórcel, Román Flores y Juan

Arancibia).

2010. Poroma: Composición étnica y culturas. Sucre: ASUR. 
Desrosiers, Sophie,

1992. "Las técnicas del tejido ¿tienen un sentido? Una propuesta de lectura de los tejidos andinos” En: Revista Andina. Tejido Andino: Pasado y Presente (I). Año 10 No 1, julio de 1992. Pp.: 7-46.

1997. "Lógicas textiles y lógicas culturales en los Andes" En: Bouysee-Casagne, T (comp.) Saberes y memorias en los Andes. In Memoriam Thierry Saignes. Lima: CEDRAL-IFEA. Pp.: 325-349.

Dransart, Penélope.

1996. “Iconografía en el arte textil del sur del Perú y del norte de Chile: Algunas consideraciones sobre las formas figurativas y abstractas". Ponencia presentada a la Conferencia "Bodas de Oro en el Museo de Ica.

Gisbert, Teresa, Martha Cajías y Silvia Arze.

2006. Arte Textil y Mundo Andino. 3era edición. La Paz: MUSEF/PLURAL/Embajada de Francia en Bolivia.

Guamán Poma de Ayala, Felipe, (1615).

1980. El primer Nueva Crónica y buen gobierno. Ed. John Murra y Rolena Adorno. México: Siglo XXI editores.
Murra, John.

1975. Formaciones económicas y políticas del mundo andino. Lima: IEP.

Nicolas, Vincent.

2015. Los ayllus de Tinguipaya. Ensayo de historia a varias voces. La Paz: Plural editores.

Rostworowski, Maria.

200o. Estructuras andinas del poder. Lima: IEP.

Saignes, Thierry.

2015. Desde el corazón de los Andes. Indagaciones históricas. La Paz: Plural editores y IFEA.

Silverblatt, Irene.

1990. Luna, sol y brujas. Género y clases en los Andes prehispánicos y coloniales. Cusco: Centro de Estudios regionales andinos "Bartolomé de las Casas". 


\title{
21
}

\section{Un fundamento de la textualidad textil: los colores Tarabuco}

\author{
Ricardo Cavalcanti-Schiel \\ Departamento de Antropología, Universidad Federal de Río Grande del Sur (UFRGS), Porto Alegre, Brasil.
}

\section{Resumen}

El presente artículo tiene por objetivo presentar la lógica de funcionamiento de una gramática del color en los textiles tarabuco de los Andes Meridionales (centro-sur de Bolivia). Poniendo foco en el sistema de k'uychi, un dispositivo prescriptivo de gradación cromática (degradé), se pretende demostrar como él funciona como mecanismo de construcción de un lenguaje expresivo, coherente con los fundamentos cosmológicos andinos.

Palabras claves: Andes, Tarabuco, textiles, semiótica, colores.

\begin{abstract}
The purpose of this article is to present the logic of operation of a color grammar in Tarabuco textiles of the Southern Andes (south-central Bolivia). Focusing on the system of k'uychi, a prescriptive device of chromatic gradation (dégradé), it is intended to demonstrate how it works as a mechanism for building an expressive language, consistent with the Andean cosmological foundations.
\end{abstract}

Keywords: Andes, Tarabuco, textiles, semiotics, colours.

\section{Résumé}

Le but de cet article est de présenter la logique de fonctionnement d'une grammaire des couleurs dans les textiles tarabuco du sud des Andes (centre-sud de la Bolivie). En se concentrant sur le système de k'uychi, un dispositif normatif de gradation chromatique (dégradé), il essaie de démontrer son fonctionnement en tant que mécanisme de construction d'un langage expressif, cohérent avec les fondements cosmologiques andins.

Mots clés: Andes, Tarabuco, textiles, sémiotique, couleurs.

"El mundo es lo que vemos y, sin embargo, tenemos que aprender a verlo."

Maurice Merleau-Ponty (Lo visible y lo invisible. Barcelona: Seix Barral, 1966, p. 20).

\section{Los Tarabuco y el objeto del presente análisis}

Lo que se puede llamar los Tarabuco es un conjunto de alrededor de siete decenas de comunidades indígena-campesinas de habla quechua, ubicadas en el entorno del pueblo que lleva este nombre, situado a $55 \mathrm{Km}$ a estesudeste de la ciudad de Sucre, capital del Departamento de Chuquisaca, en el centro-sur de Bolivia. La región en la que se encuentran estas comunidades se constituye como la más oriental de las estribaciones de la Cordillera de los Andes, en terrenos accidentados entre los 3.100 y los 3.400 m.s.n.m. Acerca de esta precisa serranía, que recibe el nombre de Cordillera de Mandinga (cuyas cumbres alcanzan los 3.750 m.s.n.m.), el naturalista y explorador francés Alcide d'Orbigny observó en 1832 tratarse de "la cresta divisoria de las aguas de la

DOI: $10.32873 /$ unl.dc.zea.1221

Published in PreColumbian Textile Conference VIII / Jornadas de Textiles PreColombinos VIII, ed. Lena Bjerregaard and Ann Peters

(Lincoln, NE: Zea Books, 2020). https://digitalcommons.unl.edu/zeabook/ 
cuenca del Plata y la del Amazonas" (d'Orbigny 1844:274. Traducción mía). En otra perspectiva, esta gente a la que llamamos Tarabuco está ubicada en el tercio norte del arco quechua que voltea por oriente, hacia el sur, el Altiplano aymara, y se ha conformado, a lo largo de varios siglos (uno de ellos, al menos, antes de la llegada de los europeos), como una fusión de gente local - que algunos creen ser los Yampara (minoritarios ${ }^{1}$ ), sin que se sepa exactamente qué significaba esta referencia - con contingentes venidos de varias partes de los Andes, en especial con la implantación de colonias estatales (mitmaqkuna) en el incario en todo este arco quechua. De no ser así, no habría otra razón para la masiva persistencia de la lengua quechua.

A lo largo del período histórico, este "amasijo étnico"- si se puede decirlo así, de modo muy precario y equivocadamente pasivo- se fue consolidando, bajo el lenguaje reciprocitario y en el marco del proceso de provincianización de los indios (Cavalcanti-Schiel 2008), como una gobernación dual (pero, al parecer, no dualista - acorde el referente antropológico clásico), que conformó códigos y discursos propios y distintivos. El textil es el soporte de uno de ellos. El otro es su calendario ritual. De este modo, aunque el uso de los textiles tradicionales se pueda ir perdiendo en varias partes, incluso en comunidades enteras, la gente Tarabuco comprende su lenguaje. Es acerca de una parte de la semiótica de este lenguaje, la que se refiere al color, que este texto tratará.

Los Tarabuco son muy visibles en el escenario turístico boliviano. La feria dominical en el pueblo cuyo nombre le sirve de referencia - comúnmente se los dicen tarabuqueños- , además del evento músico-coreográfico del Pukllay que ocurre cada año una semana después del carnaval, con su masiva presencia indígena, son atractivos que llenan el lugar de turistas, a semejanza (aunque en menor escala) de Chivay, en el Valle del Colca, del departamento peruano de Arequipa. Si el "carnaval de Tarabuco" ha sido tomado prestado del calendario ritual, los ponchos rojizos a bandas horizontales (los únicos usados con esta disposición en los Andes) - acompañados de las monteras masculinas que se semejan a morriones españoles- y la vistosa iconografía de algunas de las prendas vestimentarias, son los elementos del otro código expresivo que atraen la atención de la gente de afuera y se disponían, hasta hace unas décadas, como la expresión visual paradigmática de una Bolivia "profunda”.

Curiosamente, son hasta ahora bastante escasos los documentos iconográficos de más de 70 u 80 años que permitan acceder a un reconocimiento preciso de los patrones textiles más antiguos de esta gente. Esto incluye a los propios textiles preservados, ya que eran enterrados con sus dueños o entonces, una vez muertos sus dueños, se transformaban, también ellos, en piezas "muertas", sin uso vestimentario, empleados para cargar leña o carbón, en lo que se iban paulatinamente destrozando. La comercialización de estas piezas para la gente de afuera no ha sido siempre un hecho trivial como es hoy. En la mitad de la década de 10 del siglo $\mathrm{XX}$, en una visita a la región, el antropobiólogo belga Georges Rouma, que vivió varios años en Sucre, registra, junto con media docena de imágenes posteriormente publicadas, que los indígenas se negaban de forma vehemente a vender sus tejidos (Rouma 1933:27).

En 1911, el explorador y economista francés Paul Walle hace un registro de un par de indios cargadores de Sucre para su obra La Bolivie et ses mines - publicada tres años después- en que se trata casi seguramente de gente Tarabuco (Walle 1914:facing page 132). En 1903-1904 Julien Guillaume registra imágenes - similares a las que Rouma haría diez años después- para la misión de la Sociedad de Antropología de París, publicadas por Arthur Chervin (1908:42-43, fig. 27-28). Antes de estas imágenes de los albores del siglo XX, sólo disponemos de un muy ambiguo grabado de tipos nativos, bosquejado por Alcide d'Orbigny hacia 1832 y terminado por Jules Boilly para la obra Voyage dans l'Amérique Méridionale (D’Orbigny 1847: lámina “Costumes $\mathrm{n}^{\mathrm{0}} 13$ ”). El grabado está titulado "Indios y mestizos de la nación quechua, de Chuquisaca y su entorno", y muestra, entre cuatro tipos, una pareja portando sombreros como los de la Figura 1 (abajo) y tejidos a rayas de color que sugieren vagamente que pudieran ser gente Tarabuco.

Ya casi a mitad del siglo XX, entre 1939 y 1946, es decir, poco antes de la Revolución Nacionalista del 52 y de la Reforma Agraria que le siguió, el fotógrafo y etnólogo francés Pierre Verger registró 119 imágenes en Tarabuco. Estas, custodiadas por la Fundación Pierre Verger en Salvador (Bahia, Brasil), son probablemente las primeras en las que se puede apreciar con precisión los detalles textiles (salvo por la ausencia capital de color), además de, en cierta medida, consagraren lo que, en los registros precedentes, estaba todavía dubio y variable: el uso del poncho masculino con las bandas cromáticas en la posición horizontal.

La técnica textil y la iconografía tarabuco han sido exploradas de forma precursora por Lynn Meisch en los años 80 del pasado siglo (Meysch 1985a, 1985b, 1986, 1987). Enseguida, el sentido del diseño textil ha sido sistemáticamente explorado por los investigadores de la Fundación Antropólogos del Surandino (ASUR), que mantiene un museo textil

1. Para el caso del "Repartimiento de Indios de Tarabuco y Presto", por ocasión de la Visita General del Virrey Francisco de Toledo en 1573, el contingente advenedizo llegaría a un 92\% de la población (Archivo General de la Nación, Buenos Aires [AGN], División Colonia, Sección Gobierno IX-17.2.5, "Libro de Retazas Libradas por el Ex. ${ }^{\circ}$ S. Toledo, 1785", f. 197v). 


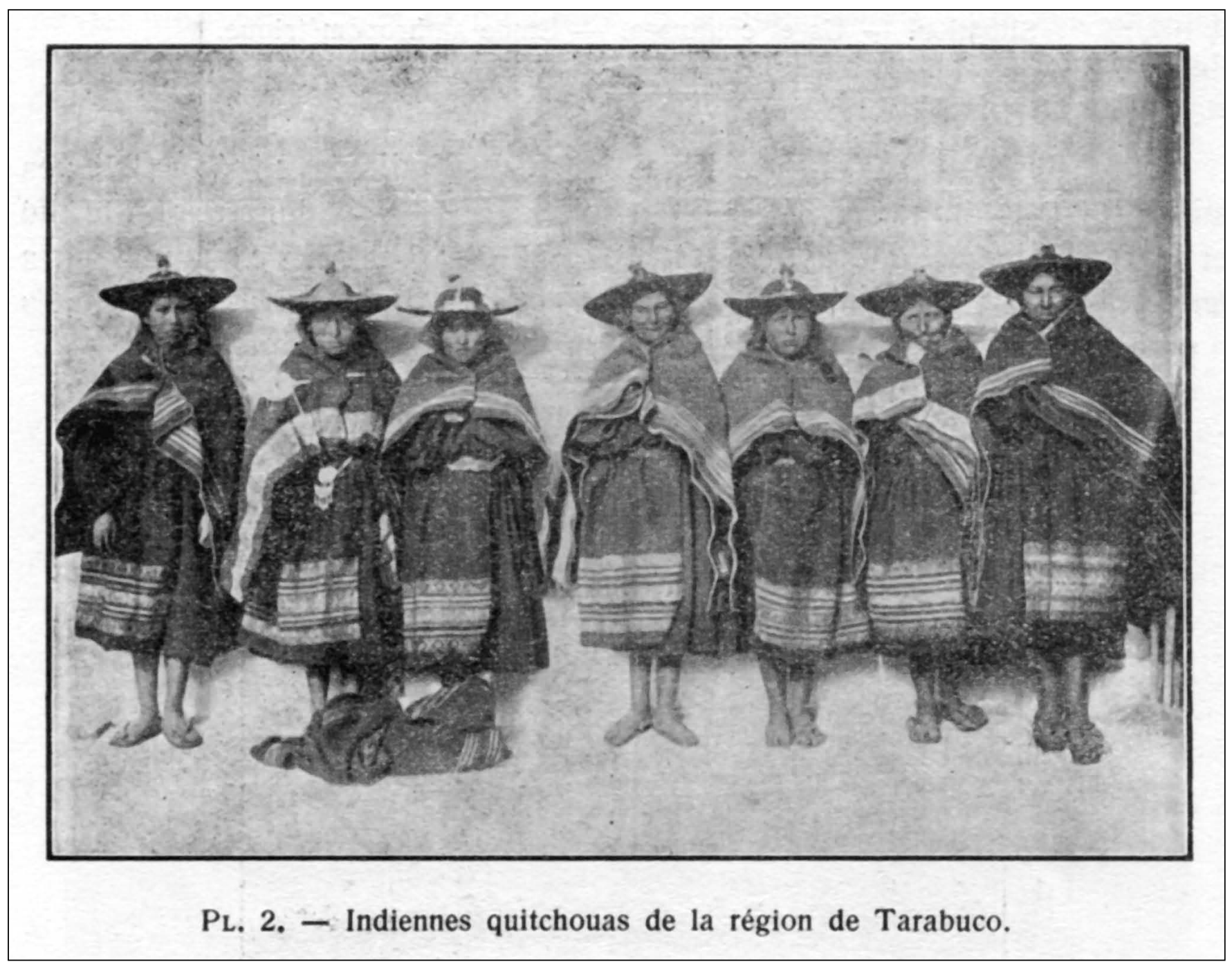

Figura 1. Foto realizada por Georges Rouma entre 1913 y 1916 entre los comuneros de Cororo y Vila-Vila, región de Tarabuco (Rouma 1933:22).

en Sucre y un programa de valoración y apoyo a la tradición textil indígena en el norte de Chuquisaca (Dávalos, Cereceda \& Martínez 1992; Cereceda 1993; Cereceda, Pórcel, Quispe \& Coronado 2013). Todos estos trabajos han explorado el sentido general de la relación entre técnica e iconografía, pero no llegaron a detenerse en la semiótica constitutiva del mensaje textil y su lenguaje de color - salvo en el ejercicio comparativo, hecho por los investigadores de ASUR, con los textiles Jalq'a de la región norte del departamento (cuyos circuitos de comunicación mutua en tiempos pasados todavía se desconoce).

De otra parte, el tema del color (y no de los colorantes) en los textiles históricos y etnográficos andinos (y no en los arqueológicos) ha sido objeto de relativamente pocos trabajos (Femenias 1987; Cereceda, 1987, 1990; Dransart 2002,
2016, 2018; Phipps 2003; Havenon 2004; Fernández López 2008; Espejo 2010; Arnold \& Espejo 2012). El caso Tarabuco nos parece precisamente aquél en el que este tema asume una dimensión de lenguaje particularmente relevante, en donde, como propondré aquí, un cierto código organizativo parece estar a medio camino entre un sistema clasificatorio y un sistema de tipo fonético - sin avanzar hacia el debate sobre si esta condición acerca o no ese código al polémico concepto de semi-simbólico (Greimas 1984:20-22; Floch \& Thürlemann 1986)- , para conformar una semiótica de la memoria social anclada en una cierta percepción ordenada del espacio. En este sentido, la presente nota sigue las huellas de los análisis fundacionales de Verónica Cereceda $(1978,1987,1990)$ sobre la semiótica de los textiles andinos, pero le da otro énfasis analítico, hacia más allá del 


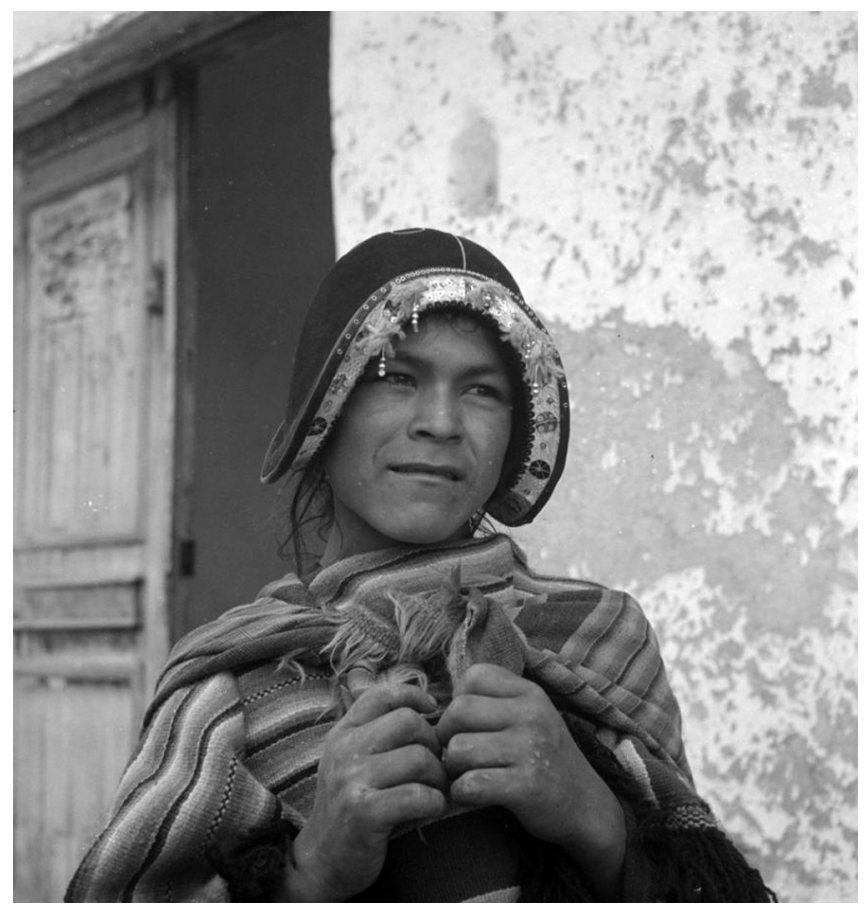

Figura 2: Muchacho Tarabuco. Foto de Pierre Verger (1939-46), cedida por la Fundación Pierre Verger.

paradigma de los grandes contrastes (el paradigma del allqa - Cereceda 1990) como principio e ideal virtuoso del reconocimiento de la imagen y de lo "plástico" en el mundo de los humanos (andinos), volviendo un poco más de atención hacia lo que Lévi-Strauss (1964) designó como la dialéctica entre los pequeños y los grandes intervalos, asimismo que hacia la virtud del discernimiento que se inscribe en la discontinuidad sutil.

\section{El lenguaje textil}

En el mercado de arte étnico, los tejidos tarabuco son conocidos, antes que todo, por su riquísima figuración. La parte figurativa de los textiles tarabuco - aunque pueda ser predominantemente geométrica- recibe la designación quechua pallay. El término se refiere tanto a "diseño" (en la forma nominal) cuanto (en la forma verbal) a "recoger", "cosechar los frutos". En la terminología textil, el pallay contrasta con la pampa, la porción monocromática, donde no se inscribe la diferenciación visual. Pampa es el vocablo que a su vez expresa también la concepción "agrícola" de campo llano, abierto, limpio, en el que la Pachamama puede dispensar fertilidad, ya sea para los cultivos o bien para los rebaños. Desde su acepción cosmológica, Verónica Cereceda concluye: "Pampa, pues, se refiere a un /continuo uniforme/ que nos recuerda la percepción disminuida [por oposición a 'aguda'] de la época sin sol” (Cereceda 1990:93).
Estos dos elementos complementarios (pampa y pallay) componen la pieza femenina por excelencia de la vestimenta tarabuco, una sobrefalda llamada aqsu (véase la Figura 1). De otra parte, en la pequeña bolsa masculina destinada a cargar hojas de coca sólo hay pallay. En la manta que las mujeres portan alrededor del torso, la lliklla, predomina la pampa, complementada por franjas de color (véase también la Figura 1). En ninguna pieza masculina se inscribe la complementariedad pallay-pampa. Se puede decir que el pallay juega un rol decisivo en el horizonte complementario cuando tiene que ver con el cuerpo femenino. Para el cuerpo masculino, este juego se da de otro modo.

El presente texto no tratará específicamente de la figuración tarabuco, el ámbito del pallay, donde potencialmente la tejedora puede inscribir cualquier imagen visible del mundo (o cualquier imagen del mundo visible y discernible, que es este mundo, el kay pacha, que la narrativa cosmológica andina asigna a la era/espacio que se sigue al surgimiento del sol), incluso imágenes estilizadas y geométricas, bajo un sentido de orden multitudinario y abundante. Aunque parezca menos interesante, este texto tratará de otro par complementario de la semiótica textil tarabuco: el que se establece entre franjas de color ordenadas y la misma pampa monocromática. Es este el par que constituye la pieza masculina por excelencia, el poncho.

Si la gramática textual de la composición del pallay supone orden, secuenciación y repetición de los motivos iconográficos, como las hileras de trigo, cebada, papa, maíz, habas, arveja y quinua sembradas en el suelo fértil de la pampa, también las franjas de color de los ponchos (y unkus - otra pieza masculina, una suerte de poncho en miniatura que se lleva sobre los hombros y sobre las nalgas) son ordenadas de un modo específico. El elemento o, más bien, el régimen de ordenamiento de las franjas de color es el k'uychi. Esta voz quechua se reporta precisamente al arcoíris. Pero el arcoíris es más que un fenómeno meteorológico; es más que una metáfora o un ícono sustantivo. Como en muchos otros casos de la cosmología andina, estamos frente a un sujeto de potencia, como los apus (los cerros protectores) y los remolinos de viento (los vientos malos, saqra wayra, que pueden enfermar y robar el alma).

El k'uychi, en el mundo Tarabuco, es a un tiempo forma, manifestación y potencia genésica; es una fuerza vital, que también es potencialmente descontrolada. Se dice que el arcoíris nasce en una fuente de agua y muere en otra, es decir, transita entre dos espacios liminales, entre el mundo iluminado y bien perceptible de la superficie y el mundo oscurecido y difuso (o, más bien, difusamente oscurecido, indiscernible) del "más adentro", el pasado primordial. Si alguien se encuentra con un arcoíris, este puede entrarle por la boca, hacerle caer los dientes y resecarle el 


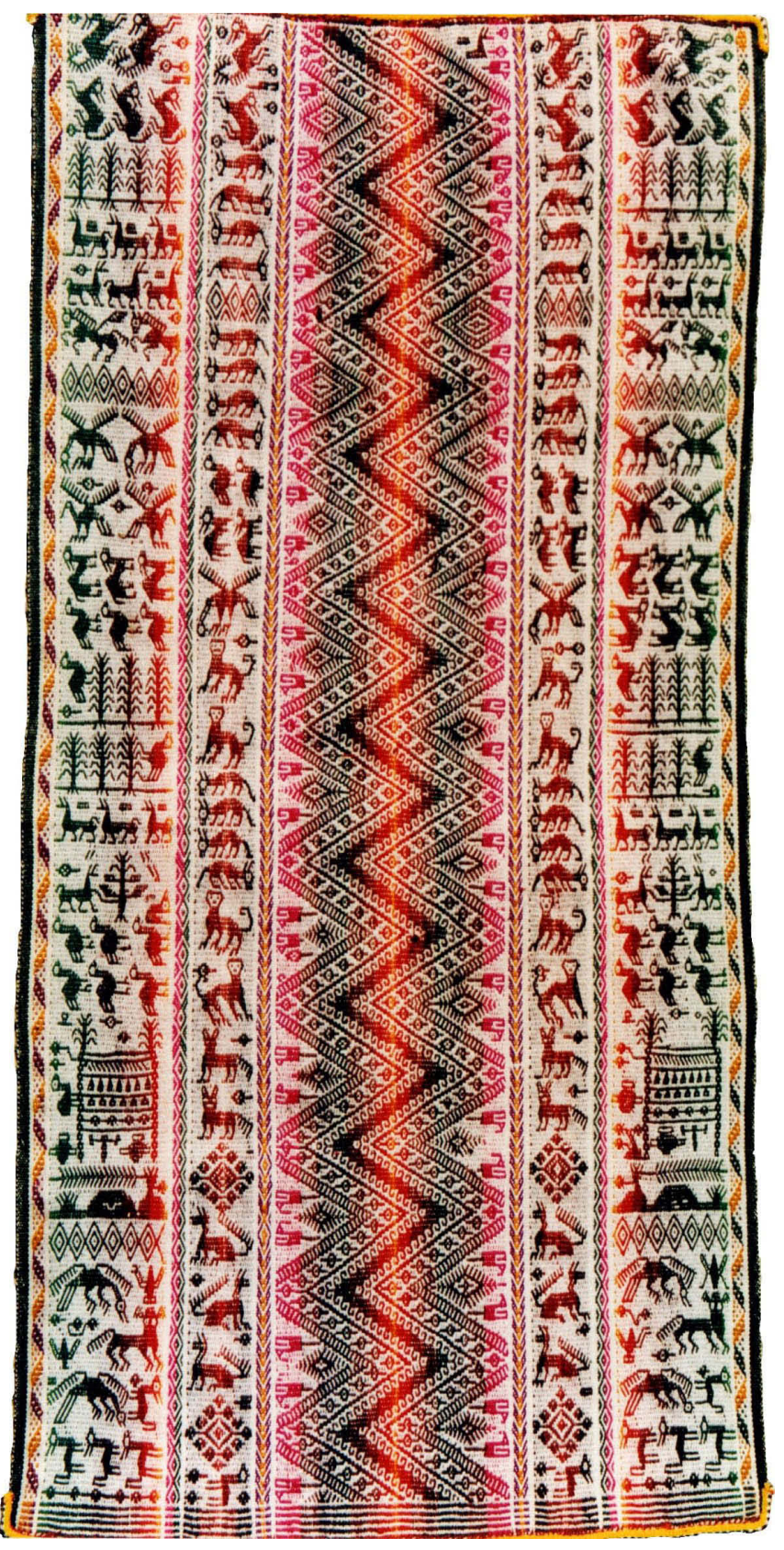

Figura 3. Pallay tarabuco como ejemplo de figuración. Esta clase de pieza no tiene valor vestimentario una vez que no tiene pampa; es tejida tan sólo para vender a los turistas como ícono de "arte étnico". Foto del autor.

estómago, llevando la persona a la muerte. Por eso se dice que cuando está un arcoíris en el cielo uno no puede reírse, es decir, enseñarse los dientes brillantes, o entonces corretear de una parte a otra, atrayendo al arcoíris, por una suerte de simpatía cromática, con los colores de sus ropas, dando margen a que sea perseguido por él. Todo esto conforma el arcoíris como una potencia característica de los sujetos de una otra naturaleza, la del mundo otro paradigmático, el mundo de adentro, el ukhu pacha, donde se encuentran también las demás fuerzas genésicas primordiales, como la Pachamama, es decir, las que comparten la condición de wak’a.

Acercarse a esta potencia por medio del trabajo textil resulta ser entonces una forma de entablar un negocio con ella (un negocio que parte de lo sensible y va hacia lo inteligible), "domesticarla" (en el sentido de traerla hacia el ámbito "de acá"), hacerla fértil y productiva, inscribirla en una cartografía vestimentaria de este mundo (kay pacha). Toda la tejeduría tarabuco - aunque casualmente produzca una pieza que se destine a los hombres- parece estar ensamblada en los términos de un laborioso ejercicio femenino de la fertilidad; una fertilidad que se la recibe de las wak'a, de las potencias de un pasado que entrega al presente su posibilidad de continuidad. El k'uychi, mientras esfuerzo "domesticador" (por medio del discernimiento), resulta ser, como el encadenamiento de los motivos iconográficos del pallay, una gramática del ordenamiento de la luminosidad; ordenamiento que, de su parte, puede ser reconocido como el negocio visual por antonomasia entre las potencias de los dos mundos complementarios.

Grosso modo, el k'uychi es una secuencia preestablecida de tonos, utilizada como una suerte de leimotiv visual. A diferencia de las k'isas aymaras, objeto del análisis de Cereceda (1987:184-216), los k'uychis textiles tarabuco no son, en regla, ni estrechos ni económicos en cantidad, ni tienen función de enlace. Abundan a punto de conformarse como elemento principal de la construcción de la imagen textil de los ponchos y unkus que, de igual modo a la figuración de los pallays, están constituidos precisamente por esta abundancia, ya ahora, en color. Sin embargo, hay seis, y sólo seis, de estas secuencias de tonos, que van agrupadas en tres conjuntos, conforme la destinación socio-ritual de los tejidos que conforman.

Los tres grupos de k'uychis son el de: (1) los de uso diario (genéricamente dicho "grupo rojo", en quechua, puka); (2) los de uso en trajes de luto; y (3) el indiferente (se puede utilizar tanto en tejidos para vestimentas corrientes cuanto en aquellas de luto). El k'uychi es materializado, en lo que respeta a la cadena operatoria de producción textil, por la disposición de hilos de urdimbre, que van a conformar la cara visible del tejido (mientras la trama queda escondida adentro de la estructura textil, como es tradicional en el patrón textil de cara de urdimbre). Las secuencias de tonalidades de los hilos que componen los k'uychis son las que se siguen: 


\begin{tabular}{|c|c|c|}
\hline “ARCOÍRIS” & DESIGNACIONES NATIVAS MÁS USUALES DE LOS TONOS & TRADUCCIÓN APROXIMADA \\
\hline \multicolumn{3}{|c|}{ 1. Grupo puka ("rojo"), uso a diario } \\
\hline $\begin{array}{l}\text { q'illu k’uychi } \\
\text { (“amarillo”) }\end{array}$ & $\begin{array}{c}\text { guindo (o q'illu maman) } \\
\text { yana prusela (o puka prusela) } \\
\text { puka } \\
\text { prusela } \\
\text { aruma } \\
\text { muruchi } \\
\text { q'illu }\end{array}$ & $\begin{array}{c}\text { carmesí oscuro } \\
\text { carmesí o guindo } \\
\text { rojo } \\
\text { leonado } \\
\text { anaranjado } \\
\text { amarillo oro } \\
\text { amarillo azufre }\end{array}$ \\
\hline $\begin{array}{l}\text { rosado k’uychi } \\
\text { ("rosado") }\end{array}$ & $\begin{array}{l}\text { yana guindo (o rosado maman) } \\
\text { puka guindo } \\
\text { rosado qhipan (o puka rosado) } \\
\text { rosado }\end{array}$ & $\begin{array}{l}\text { púrpura oscuro } \\
\text { rosado-purpúreo } \\
\text { magenta } \\
\text { rosado vivo }\end{array}$ \\
\hline $\begin{array}{c}\text { panti k’uychi } \\
\text { ("vino") }\end{array}$ & $\begin{array}{c}\text { yana morado (o panti maman) } \\
\text { yana panti } \\
\text { panti } \\
\text { yakupanti }\end{array}$ & $\begin{array}{l}\text { tannat } \\
\text { cabernet } \\
\text { gamay } \\
\text { rosé zinfandel }\end{array}$ \\
\hline \multicolumn{3}{|c|}{ 2. Grupo luto } \\
\hline $\begin{array}{l}\text { morado k'uychi } \\
\text { (“morado") }\end{array}$ & $\begin{array}{c}\text { yana (o morado maman) } \\
\text { yana morado } \\
\text { morado } \\
\text { morado t'ukra }\end{array}$ & $\begin{array}{l}\text { morado oscuro } \\
\text { morado } \\
\text { lila } \\
\text { lila claro }\end{array}$ \\
\hline $\begin{array}{l}\text { celeste k'uychi } \\
\text { ("azul”) }\end{array}$ & $\begin{array}{c}\text { yana (o celeste maman) } \\
\text { yana azul } \\
\text { celeste qhipan (o yana celeste) } \\
\text { celeste (o celestecito) }\end{array}$ & $\begin{array}{c}\text { añil } \\
\text { marino } \\
\text { turquesa } \\
\text { celeste }\end{array}$ \\
\hline \multicolumn{3}{|c|}{ 3. Grupo indiferente } \\
\hline $\begin{array}{l}\text { q'umir k'uychi } \\
\text { ("verde") }\end{array}$ & $\begin{array}{c}\text { yana (o q'umir maman) } \\
\text { yana q'umir } \\
\text { q'umir (o laqhitun q'umir) } \\
\text { q'ichichi }\end{array}$ & $\begin{array}{l}\text { laurel oscuro } \\
\quad \text { laurel } \\
\text { verde bandera } \\
\text { verde manzana }\end{array}$ \\
\hline
\end{tabular}

En la práctica, tenemos algo así:

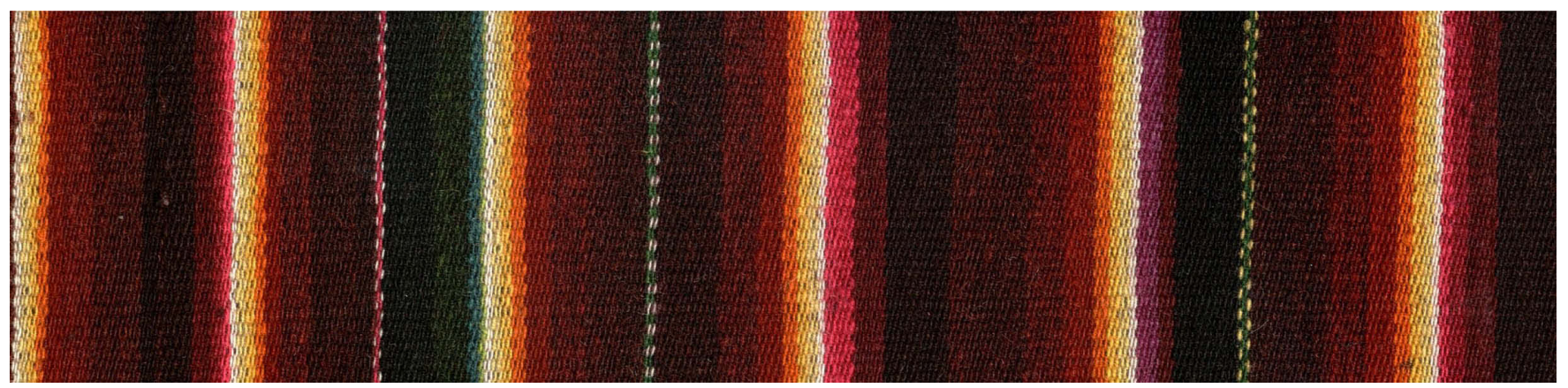

Figura 4. Secuencia de k'uychis del grupo puka en la que se interponen tres q’utus (la mediación de hilos mesclados de larga utilización en los textiles andinos). La secuencia de k'uychis es (de izquierda a derecha; la flecha indica el sentido del tono más oscuro hacia lo más claro): amarillo $(\leftarrow)$, rosado $(\rightarrow)$, amarillo $(\leftarrow)$, q'utu, verde $(\rightarrow)$, amarillo $(\leftarrow)$, q'utu, amarillo $(\rightarrow)$, rosado $(\leftarrow)$, amarillo $(\rightarrow)$, vino $(\leftarrow)$, q'utu, amarillo $\rightarrow$ ), rosado $(\leftarrow)$. Foto del autor. 
Caben algunas observaciones:

1. Estas secuencias y sus conjuntos de tonos son restrictivas: no se puede inventar k'uychis; no se puede intercambiar tonos. Sin embargo, puede que una tejedora no necesariamente aplique todo el espectro de tonos de un $k$ 'uychi en una pieza. Los casos más notables de "falta" de tonos ocurren, en general, en los k'uychis verde y vino. Pero lo más importante es que se mantenga el orden: el "degradé" de tonos.

2. La construcción operatoria del k’uychi dispone siempre más hilos de urdimbre para los tonos más oscuros, considerados los tonos "madre" (maman), bajando la cantidad progresivamente, conforme se va hacia los tonos más claros.

3. En la disposición de los hilos de la urdimbre, los k'uychis se encadenan encontrándose o en sus tonos "madre" (más oscuros) o en sus tonos más claros, de modo a producir la impresión - en los textiles actuales particularmente valorada (pero no tanto en los más antiguos) - de la emergencia de una faja estrecha de luminosidad a partir de un fondo más amplio de oscuridad, como se percibe en la Figura 5 (abajo).

4. Como se puede notar en el cuadro precedente, en algunos k'uychis la designación "negro" (yana) simplemente puede repetirse, ocupando el lugar del maman. El uso corriente de una misma designación de tono (yana, "negro") en varios k'uychis sugiere que ahí la proximidad del negro es tan grande que los tonos maman se acercan a la indiferenciación. Sin embargo (o quizá precisamente por eso), las tejedoras tratan de diferenciarlos. Este cuidado no es gratuito, como se va a notar enseguida. Él se hace en contexto, y en un contexto en el que las gradaciones son deliberadamente sutiles. Lo más importante no es la designación singular de un tono ni un reconocimiento preciso de tonos (en términos teóricamente absolutos de frecuencia de onda luminosa), sino el hecho de que los tonos siempre van "emparentados”, se disponen

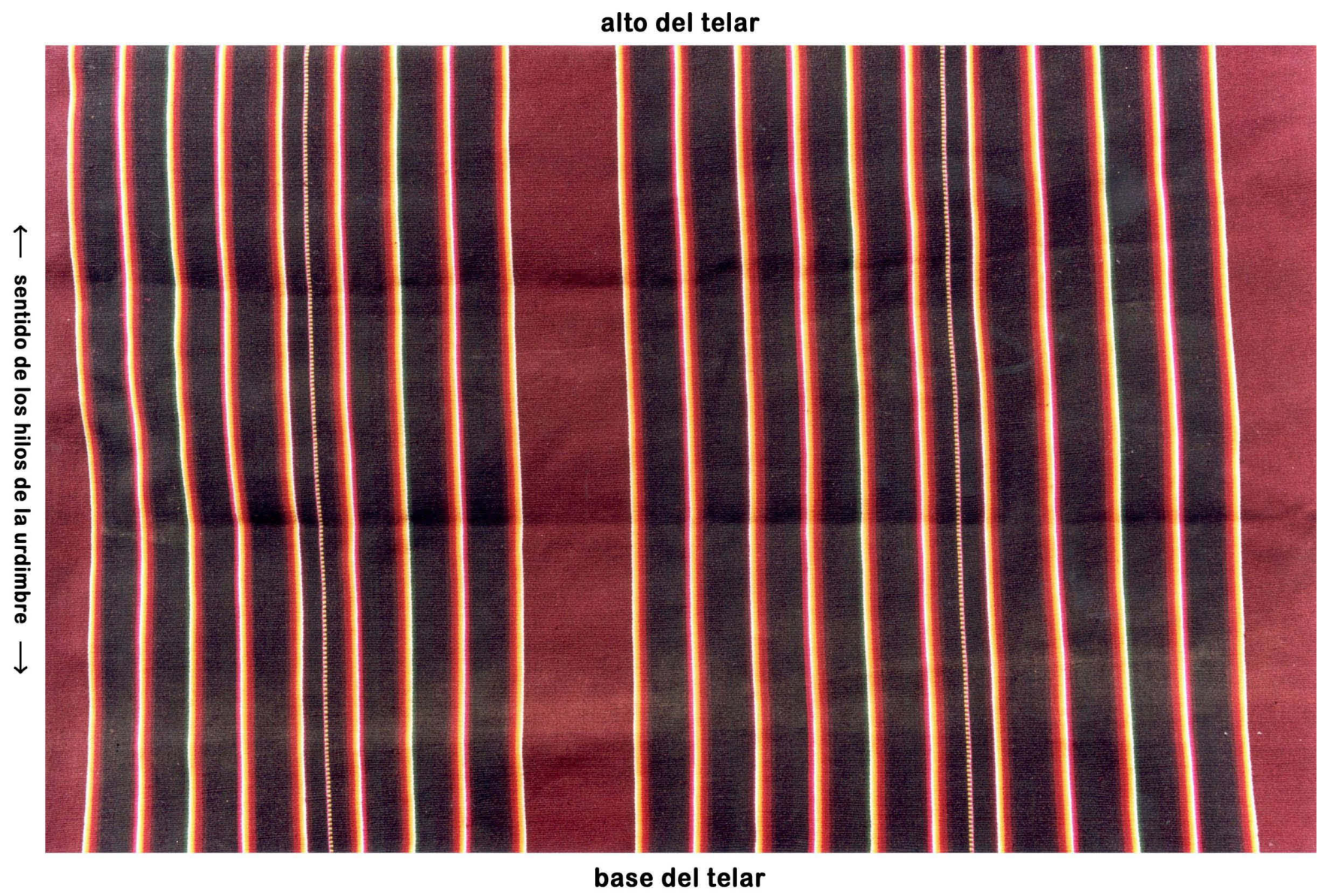

Figura 5. Conjunto completo de k’uychis en una mitad (khallu) recién tejida de un poncho en hilo de lana sintética (más fina). Las fajas oscuras, en las que aquí poco se distingue la gradación de tonalidades son, en realidad, el encuentro de los tonos más oscuros de cada k'uychi. En los extremos y entre estos dos grande conjuntos de k’uychis se interponen fajas de pampa en color guinda, característica de los ponchos de la porción sur de la región de Tarabuco. Foto del autor. 
en relación. Por esta razón, utilicé deliberadamente para el k'uychi "vino" designaciones que se remiten a castas vinícolas europeas, a modo de un código de lenguaje que, como nos sugiere Mary Douglas (1986:91-109), es relativamente arbitrario en lo que toca a las designaciones singulares para los términos, pero donde lo que vale son las relaciones clasificatorias entre los términos.

5. Un cierto tono de negro opaco a veces puede ser usado, con pocos hilos de urdimbre, para insertar un corte entre dos franjas oscuras (maman) de k'uychis iguales dispuestos simétricamente. En este caso, se asegura que los k'uychis mantengan su singularidad de agrupación al mismo tiempo en que se maneja la herramienta de la sutil diferenciación como recurso dispositivo.

6. El blanco (yuraq) actualmente siempre acompaña al k'uychi amarillo y podría ser considerado como parte de este $k$ 'uychi si no sirviera genéricamente como color base sobre el que se inscribe la figuración en la piezas donde ella es realizada (véase la Figura 3). En las piezas actuales, k'uychis y figuración tienden a excluirse mutuamente. Así, se podría decir que donde comparecen k'uychis, el blanco sería el último color del k'uychi amarillo. En algunos casos más raros, en ponchos más antiguos y con flecos de un solo color (que les hace ser llamados fullus - la misma designación que se le da a las frazadas-, y no ponchos), una muy estrecha faja de blanco podía ser usada para separar un k’uychi de otro, lo que nos sugiere que, una vez reconocida la base prescriptiva, siempre se pueden introducir modismos ocasionales. Por evidente, habría que investigarse mejor (si es posible) el contexto de esta clase de piezas antiguas. Estos casos existen, pero son escasos y en ellos los q'utus tienden a ser sustituidos por esta estrecha faja de hilo(s) blanco(s). Así que el blanco parece insinuar, en este caso, la intromisión de una relativa exterioridad, en lugar de la continuidad o la contigüidad.

7. En el grupo puka, el k'uychi amarillo es sobradamente lo más utilizado (véase la Figura 4) y es, por coincidencia, el que tiene más "tonos". Le siguen el rosado, el verde y el vino. En el grupo luto, el k’uychi azul es lo más utilizado, siguiéndole el morado y, más parsimoniosamente, el verde.

Con estas observaciones, creo que se hace claro que el sentido del k'uychi no es otro que el de la necesaria contigüidad de la diferencia sutil, pero una diferencia previamente organizada en términos de relaciones. En esto está el arte del color y del manejo de la modulación perceptiva de la luminosidad, el reconocimiento más fino de la visualidad del kay pacha, que los hombres Tarabuco reconocen como un atributo "cognitivo" esencialmente femenino - así como para ellos, de su parte, les toca mejor el ejercicio de la "música”, que tiene que ver con el ámbito del otro (y complementario) régimen textual de memoria de su gente: el calendario ritual (Cavalcanti-Schiel 2015). Las variaciones cromáticas "sustantivas" adentro de cada k’uychi - sea en el tiempo sea de un subgrupo local de comunidades a otropueden ser considerables. Pero no es esta sustantividad que constituye el fundamento de la discursividad textil tarabuco en términos de color. En base a una gramática prescriptiva, lo que en realidad se ejercita es la sutileza; una sutileza que se ensancha todavía más cuando se "sube" del nivel de k'uychi hacia la composición de agregados de k'uychis, que es lo que, finalmente, constituye el poncho. Es toda esta semiótica que le otorga al color su debido lugar.

Si tomamos el khallu de la Figura 5, podemos observar la forma básica como se compone el juego de asimetrías complementarias de los conjuntos de k'uychis.

En el primer conjunto (el de la izquierda del khallu) tenemos una suerte de centro compuesto: a la derecha de él un q'utu, seguido a su izquierda de un k'uychi vino; a la izquierda de este grupo está un otro k'uychi amarillo. Este centro representa, por si mismo, una complementariedad asimétrica que se replica hacia adentro. No son simplemente dos k'uychis. Una de las “mitades” que compone el centro lleva un q'utu que desestabiliza todo. Sin embargo, si desde este centro compuesto seguimos hacia las extremidades exteriores del conjunto, vamos a encontrar la misma secuencia de $k$ 'uychis con los degradés espejados: amarillo, rosado, amarillo, verde, amarillo, rosado, amarillo. Esto conformaría una simetría - o, en el decir de Catherine Seibold (1992:194), una simetría bilateral frente a un centro destacado- si no fuera por el centro conformarse desde ya como asimétrico, de modo que cualquiera que sea la parte del centro que se considere como componiendo una de las mitades, la otra va a ser siempre distinta de la primera, del mismo modo como el "centro" se constituye, intrínsecamente, de partes desiguales y complementarias.

Si confrontamos este primer conjunto con el segundo (el de la derecha del khallu, que en la Figura 6 está abajo), vamos a encontrar, en primer lugar, que el mismo centro está invertido (o espejado). Desde él, hacia la derecha, vamos a encontrar la misma secuencia de k'uychis del conjunto anterior. En la otra "mitad”, es decir, hacia la izquierda, lo mismo, pero ahora añadido de más cuatro k’uychis (que en la figura van indicados como "sobra"), que son precisamente los cuatro que se desplazan desde la "mitad" del centro hacia la izquierda, en este conjunto, o hacia la derecha, en el otro conjunto, pero, en ambos, sin el q'utu.

Se hace perceptible todo un juego de espejos. Pero en este segundo caso ya no se puede más encontrar simetrías bilaterales. Estamos definitivamente en el ámbito de las 
conjunto de $k^{\prime} u y c h i s$ de la izquierda

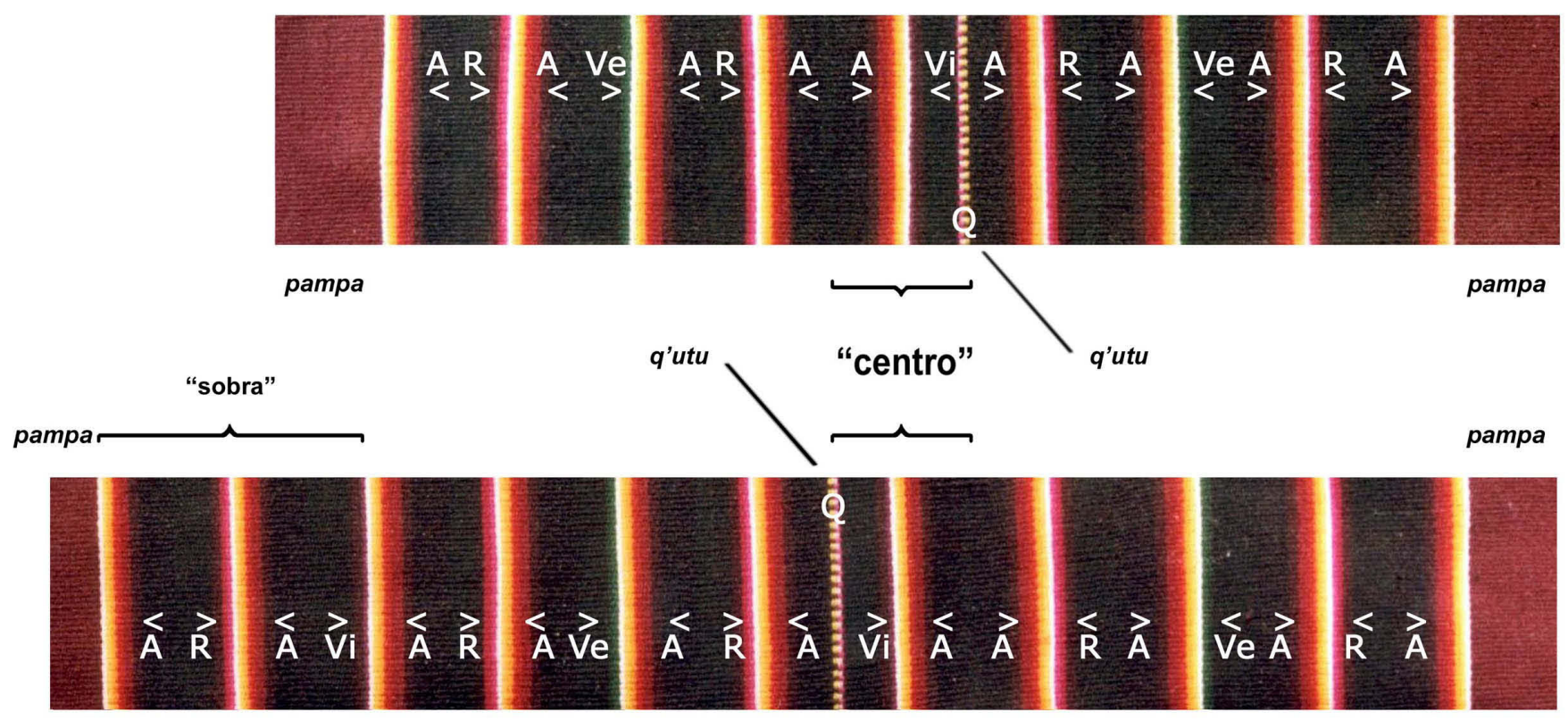

conjunto de $k^{\prime} u y c h i s$ de la derecha

Figura 6. Los conjuntos de k'uychis de una mitad (khallu) de poncho, donde: Q es q'utu; A es k'uychi amarillo; R es rosado; Ve es verde; Vi es vino; $<$ y > indican el orden de los tonos del más oscuro hacia lo más claro. A partir de foto del autor.

asimetrías y reflexiones. Estas últimas no son las especulativas, que atañen al ejercicio de los conceptos, sino que las visuales, las sensibles... y muy sutiles. Ellas hacen con que, al disponerse el segundo conjunto de k'uychis (el que está abajo en la Figura 6) efectivamente a la derecha del primero, como está en realidad en el poncho, lo que encontramos es que sus extremidades hacia afuera, desde los q'utus, se espejan perfectamente. Todo lo que en un momento parece centro, se desplaza enseguida hacia la asimetría, de modo que la sola "solución" es reconocer todo como complementario.

En el mismo sentido, se puede concebir a los conjuntos de k'uychis como complementarios a la pampa (o al revés). De otra parte, no deja de ser interesante notar que si, como regla general de composición, adentro de un pallay (el índice de lo femenino) hay siempre tres franjas figurativas (véase la Figura 3), adentro de un khallu de poncho (el índice de lo masculino) hay siempre tres franjas de pampa monocromática.

El ejemplo ilustrativo que nos permitió el precedente ejercicio no es resultado del trabajo de una tejedora experimentada, en el desempeño de su maestría para la producción de un texto textil particularmente refinado. Bien al revés, se trata de la primera lección de elaboración de un poncho por parte de una muchacha, que la recibió de una mujer más vieja y esta, de su parte, dispuso los hilos de la urdimbre en el telar. En realidad, lo que parece a primera vista razonablemente complejo, para las mujeres tarabuco es tan sólo el punto de partida. Por varias veces, después de intentar "leer" una considerable cantidad de ponchos tarabuco y creerlos regularmente comprensibles, no era raro que me llegara una pieza tejida por alguna viejita y que echara mis pretensiones de comprensión al borde del vértigo.

\section{Hacia una semiótica del cromatismo}

A modo de resumen, se puede decir que, en el contexto textil tarabuco, el k'uychi, como operador de lenguaje, es: (1) organizativo: especifica una relación entre tonos, por medio de cantidades diferidas de hilos de urdimbre para cada uno; (2) prescriptivo: no se pueden crear k'uychis arbitrarios, el conjunto de los k'uychis posibles es fijo y constituye la base por donde se empieza la construcción del textil masculino en que va aplicado (el pocho o el unku), disponiendo una orientación clasificatoria general de la coloración, en la que no se puede utilizar matices de luto en la vestimenta corriente y al revés; y (3) clasificatorio: salvo para el blanco "puro" o el negro "puro", no existe color aislado, todo color sólo existe adentro de un sistema de relaciones. Conclusivamente: en cuanto unidad composicional de la semiótica textil, el k’uychi engendra un sistema lógico. 
De una parte, la lingüística estructural de la Escuela de Praga defendió que la noción de "sistema fonético" se conforma como un conjunto de mutuas relaciones diferenciales entre los sonidos (resultados articulatorios) del habla que instituye posiciones significantes para términos singulares. Si se cambia el término (sonido), cambia el sentido de la enunciación. En este caso, las relaciones especifican términos. En la medida que sirve de base para el reconocimiento de la luminosidad acorde un cierto orden, disponiendo el reconocimiento del matiz en el contexto de una sintaxis complementaria desde elementos mutables, el sistema de k'uychi se acercaría (aunque, en la práctica, de modo un tanto limitado) al principio que rige el sistema fonético, insinuando que, análogamente a los fonemas y morfemas - mientras el motivo del arcoíris mismo no deja de ser un mitema (Lévi-Strauss, 1964, 1968) - , el k’uychi, de su parte, pudiera ser una suerte de "luminema".

De otra parte, Lévi-Strauss (1962) consideraba que la forma más elemental de atribuir un orden de inteligibilidad al mundo es la agrupación de elementos a partir de la intuición sensible. Este orden está entonces determinado por la necesidad intelectual de reconocer, que precede y sólo después especifica la "utilidad" de los elementos. La noción de "sistema clasificatorio" supone que las relaciones especifican grupos en este "ámbito" de lo sensible. Sin embargo, aquí no estamos frente a grupos conformados por cosas distintas, sino que conformados por una misma cosa que se va distinguiendo, de una parte, en parcelas fraccionarias que sólo subsisten por sus reducidas diferencias intervalares (adentro del k'uychi) y, de otra, por su utilidad social de destinación y uso (entre los k'uychis), de modo que si lo sensible es el término del reconocimiento, su organización demanda la instauración de una regla en la que el énfasis recae sobre la relación entre relaciones, más que en la relación entre términos (Lévi-Strauss 1968:13).

Se puede decir, de modo general, que en ambos casos (fonético y clasificatorio), estamos frente a sistemas de producción de sentido operados desde el principio lógico de la discontinuidad y de la precedencia lógica de la relación. Como nos demostraban los trabajos de Verónica Cereceda, la gramática textil andina es un ingenio discursivo coherente con la lógica simbólica de la cosmología. Sin embargo, algo más debe ser añadido e esta proposición general de que no se puede producir discurso sin que sea adentro y acorde a un lenguaje. Y es aquí, en lo que toca a la gramática de este lenguaje, que el sistema de k'uychi nos informa algo acerca de la escala de la discontinuidad, algo que nos permite reforzar el reconocimiento que hizo Cereceda (1987) de una (o la) noción andina de "belleza".

Acorde las proposiciones de Cereceda (1990), el dispositivo más elemental de la semiótica de lo visible en los Andes es la oposición maximizada entre lo claramente distinguible, reconocido como atributo de este mundo solar, y lo difuso y obscuro, atributo del mundo presolar: discreto versus continuo; elaboración humana versus condición prehumana; discernimiento versus imprecisión semántica. Al paradigma del máximo contraste, de la maximización de lo discontinuo hasta alcanzar un dualismo diametral, idealmente simétrico (o lo que Lévi-Strauss (1964) llamó "diatónico"), Cereceda le reconoce la pertinencia de la categoría aymara allqa. El término se reporta, desde los vocabularios de comienzos del siglo XVII, a la distintividad de colores, la oposición tonal, la no miscibilidad, alcanzando el campo semántico de la contrariedad y de la disyunción: "Allqa es la parte sensible de un código que expresa ópticamente 'aquello que no puede estar junto' (...), es decir, lo 'dis-junto'” (Cereceda 1990:67). $\mathrm{Su}$ contrario es suwa, lo indistinto, lo indiscernible y, por extensión, lo "rudo de ingenio".

En el curso de las Mitológicas, Lévi-Strauss nos demuestra que, en el ámbito amerindio, el paso del continuo al discontinuo (análogo a nuestra idea del paso de la naturaleza a la cultura) es estratégico para la fundación del entendimiento humano. Pero de igual modo, son estratégicos sus mediadores. Como mitemas, los venenos (de caza y pesca) y el arcoíris son signos por excelencia de esta mediación. Estos "seres cromáticos" operan

\section{“(...) una dialéctica de los pequeños y grandes inter- valos o, tomando prestados términos convenientes del lenguaje musical, de lo cromático y de lo diató- nico. Todo sucede como si el pensamiento sudame- ricano, decididamente pesimista por su inspiración, diatónico por su orientación, atribuyera al croma- tismo una suerte de maleficencia original, y tal que los largos intervalos, esenciales en la cultura para que exista, y en la naturaleza para que sea pensa- ble por el hombre, sólo puede ser el resultado de la autodestrucción de un continuo primitivo, cuyo po- der se siente todavía hoy en los raros puntos donde ha sobrevivido: ya sea en beneficio de hombre, en la forma de los venenos que ha dominado; ya sea con- tra él, en el arcoíris que no puede controlar". (Lévi- Strauss 1964:285-286. Traducción nuestra).}

Si es cierto que en otras partes el arcoíris no se puede controlar, entre los Tarabuco nuestro sistema de k'uychi resultaría ser su apropiación como pharmakon (veneno/remedio) del discurso textil. En efecto, el cromatismo de sus pequeños intervalos hace mover un juego de emergencia de la luminosidad desde una "profundidad materna", para enseguida generar una profusión fractal (y abundante) de entronques complementarios con los que, al fin y al cabo, se va a reconstituir la complementariedad elemental y generativa 
entre las potencias de los pacha: entre conjuntos de k'uychis y la pampa. Quizá ahí esté, en esta cartografía expresiva del espacio, que a su vez se inscribe sobre la integridad orgánica de los cuerpos, la dialéctica entre los grandes y los pequeños intervalos operada por la mediación de aquél pharmakon.

No se trata entonces tan simplemente de restaurar la disyunción fundadora del allqa, pero de instaurar en su seno una escala en donde el dualismo ya no puede más ser diametral. En el movimiento de los k'uychis, la asimetría puede que no sea otra cosa que sucedánea lógica de la presencia implícita del cromatismo (en el sentido musical lévi-straussiano). En las palabras de Verónica Cereceda, siendo el contrario de la disyunción

(...) la mediación se inscribe entonces al interior de la 'conjunción', pero representa tan sólo una parte de ella; el mundo de la conjunción es el mundo del contacto y la mediación no es todo contacto posible sino tan sólo aquel que, siendo difícil de lograr o siendo peligroso, requiere un intermediario: Es a este contacto 'riesgoso' que se asocia una idea de belleza” (Cereceda 1987:218-219).

La semántica general del discurso textil tarabuco parece apuntar, como insinuamos en algunos momentos, hacia una cartografía expresiva en la que la fertilidad como potencia se despliega en un mensaje acerca de la reproducción de las cosas de este mundo claramente visible y de la existencia misma. La complementariedad generativa, que tiene en el par hombre-mujer (qhari-warmi yanantin: Platt 1978) su referente paradigmático, se traduce aquí en el lenguaje textil en términos de posibilidad de un discernimiento igualmente generativo, al mismo tiempo en que traduce el propio textil como sujeto vivo (Cereceda 1978; Desrossiers, 1982, 1997; Zorn 1987; Arnold 2000), es decir, potencialmente reproductivo y que puede incluso morir. En este sentido, el textil tarabuco parece conformar una cartografía de la potencialidad reproductiva que, al expresar un sentido general de la continuidad en términos de fertilidad y reproducción, no deja de ser una específica cartografía de la memoria social (Cavalcanti-Schiel, 2015).

\section{Bibliografía}

Arnold, Denise.

2000 'Convertirse en persona'. El tejido: la terminología aymara de un cuerpo textil. In Actas de la I Jornada Internacional sobre Textiles Precolombinos, editado por Victòria Solanilla D., pp. 9-28. Department d'Art - Universitat Autònoma de Barcelona, Barcelona.

Arnold, Denise \& Elvira Espejo.

2012 The intrusive $k$ 'isa. Bolivian struggles over color patterns and their social implications. World Art 2(2): 251-278.

Cavalcanti-Schiel, Ricardo.

2008 Por qué los Tarabuco no son descendientes de los Yampara. Anuario de Estudios Bolivianos, Archivísticos y Bibliográficos del Archivo y Biblioteca Nacionales de Bolivia 14: 99-141.

2015 Relativizando la historicidad. Memoria social, cosmología y tiempo en los Andes. Quaderns-e de l'Institut Català d'Antropologia 20(2): 84-104.

Cereceda, Verónica.

1978 Sémiologie des tissus andins: les talegas d'Isluga. Annales ESC 33(5-6): 1017-1035.

1987 Aproximaciones a una estética andina: de la belleza al tinku. In Tres reflexiones sobre el pensamiento andino, Th. Bouysse-Cassagne, Olivia Harris, Tristan Platt \& Verónica Cereceda, pp. 133-226. La Paz: Hisbol.

1990 A partir de los colores de un pájaro... Boletín del Museo Chileno de Arte Precolombino 4: 57-104.

1993 Una diferencia, un sentido: Los diseños de los textiles tarabuco y jalq’a. Fundación Antropólogos del Surandino (ASUR), Sucre.

Cereceda, Verónica, Santiago Pórcel Gira, Román Quispe Flores \& Brígida Coronado A.

2013 Diseños en aqsus Tarabuco-Yampara. Fundación Antropólogos del Surandino, Sucre.

Chervin, Arthur.

1908 Anthropologie bolivienne Tome I. Imprimerie nationale, París.

D’Orbigny, Alcide.

1844 Voyage dans l'Amérique Méridionale Tome Troisième $1^{\text {ère }}$ partie. P. Bertrand/ V Levrault, París/ Estrasburgo.

1847 Voyage dans l'Amérique Méridionale Tome Huitième. P. Bertrand/ Ve Levrault, París/Estrasburgo.

Dávalos, Johnny, Verónica Cereceda \& Gabriel Martínez.

1992 Textiles Tarabuco. Proyecto Norte ChuquisacaCORDECH, Sucre.

Desrosiers, Sophie.

1982 Métier à tisser et vêtement andins, ou, le tissu comme être vivant. Centre Culturel Latino-Américain (CETECLAM), Paris.

1997 Lógicas textiles y lógicas culturales en los Andes. In Saberes y Memorias en los Andes, editado por Th. Bouysse-Cassagne, pp. 325-349. Institut des hautes études de l'Amérique Latine (IHEAL) - Université Paris III / Institut français d'études andines (IFEA), Paris/Lima.

Douglas, Mary.

1986 How institutions think. Syracuse University Press, Syracuse, NY. 
Dransart, Penelope.

2002 Coloured knowledges: vision and the dissemination of knowledge in Isluga, northern Chile. In Knowledge and learning in the Andes, editado por Henry Stobart \& Rosaleen Howard, pp 56-78. Liverpool University Press, Liverpool.

2016 The sounds and tastes of colours: hue and saturation in Isluga textiles. Nuevo Mundo Mundos Nuevos. Dispinible en: https://journals.openedition.org/ nuevomundo/69188

2018 Mind's Eye and Embodied Weaving: Simultaneous Contrasts of Hue in Isluga Textiles, Northern Chile. Textile Society of America Symposium Proceedings 2018. Disponible en: https://digitalcommons.unl. edu/tsaconf/1126/

Espejo, Elvira.

2010 Una experiencia en la práctica textil. Una visión desde adentro. In Ciencia de las mujeres, editado por Denise Arnold \& Elvira Espejo. Instituto de Lengua y Cultura Aymara, La Paz.

Femenias, Blenda B.

1987 Color and Design in Andean Warp-Faced Fabrics. The Weaver's Journal 12(1): 44-46.

Fernández López, Arabel.

2008 Simbolismo multicolor. La artesanía textil de San Ignacio de Loyola. Gaceta Cultural del Perú 35: 12-13.

Floch, Jean-Marie \& Félix Thürlemann.

1986 Semi-symbolique. In Sémiotique: Dictionaire raisonné de la théorie du langage Vol. 2, editado por Algirdas J. Greimas y Joseph Courtés, pp. 203-206. Hachette, Paris.

Greimas, Algirdas Julien.

1984 Sémiotique figurative et sémiotique plastique. Actes Sémiotiques- Documents Vol. 6o. Group de Recherches Sémio-linguistiques (GRSL)- EHESS, Paris.

Havenon, Georgia de.

2004 Appropriating Color: Discontinuous Warp and Weft Textiles. In Tejiendo sueños en el Cono Sur. Textiles andinos: Pasado, presente y futuro, editado por Victòria Solanilla Demestre, pp. 83-88. Grup d'Estudis Precolombins- Departament d'ArtUniversitat Autònoma de Barcelona, Barcelona.

Lévi-Strauss, Claude.

1962 La pensée sauvage. Plon, Paris.

1964 Le cru et le cuit (Mythologiques 1). Plon, Paris.

1968 L'Origine des manières de table (Mythologiques 3). Plon, Paris.
Meisch, Lynn Ann.

1985a. Symbolism in Tarabuco, Bolivia, Textiles. In Weaving and Symbolism in the Andes. Andean Studies Occasional Papers Vol. 2, editado por Jeanette E. Sherbondy, pp. 1-25. Center for Latin American and Caribean Studies Indiana University, Bloomington.

1985b Fullus. Ikat blankets of Tarabuco, Bolivia. The Weavers Journal X(1): 54-58.

1986 Weaving Styles in Tarabuco, Bolivia. In The Junius B. Bird Conference on Andean Textiles, editado por Ann Pollard Rowe, pp. 243-26o. The Textile Museum, Washington.

1987 The living Textiles of Tarabuco, Bolivia. In Andean Aesthetics: Textiles of Peru and Bolivia, editado por Blenda Femenias, pp. 46-58. Elvejhem MuseumUniversity of Wisconsin, Madison.

Phipps, Elena J.

2003 Color in the Andes: Inka Garments and 17th-Century Colonial Documents. Dyes in History and Archaeology 19: 51-59.

Platt, Tristan.

1978 Symétries en mirroir. Le concept de yanantin chez les Macha de Bolivie. Annales ESC 33(5-6): 1081-1107.

Rouma, Georges.

1933 Quitchouas et Aymaras. Étude des Populations Autochones des Andes Boliviennes. Société Royale Belge d'Anthropologie et de Préhistoire, Bruselas.

Seibold, Katharine E.

1992 Textiles and Cosmology in Choquecancha, Cuzco, Peru. In Andean Cosmologies through Time. Persistence and Emergence, editado por Robert Dover, Katharine Seibold \& John McDowell, pp. 166-201. Indiana University Press, Bloomington.

Walle, Paul.

1914 Bolivia. Its People and Its Resources, Its Railways, Mines, and Rubber-Forests. Traducción de Bernard Miall. T. Fisher Unwin, Londres.

Zorn, Elayne.

1987 Un análisis de los tejidos en los atados rituales de los pastores. Revista Andina 5(1): 489-526. 


\title{
Los "diseños verdaderos" en los tejidos de las mujeres cashinahuá del Alto Purús
}

\author{
María Elena del Solar ${ }^{1}$
}

1. Antropóloga. Consultora independiente. Ha participado en diversos proyectos de investigación y desarrollo con organismos privados y públicos, en el ámbito de la producción textil de los Andes y la Amazonía.

\section{Resumen}

El presente trabajo constituye una aproximación a la cultura textil del grupo étnico cashinahuá con la finalidad de documentar las características particulares de los tejidos elaborados en las comunidades nativas ubicadas en los territorios de reserva del Parque nacional Purús. El arte del kené -que refiere a los diseños geométricos representados en tejidos, cestería y pintura corporal de ciertos grupos pertenecientes a la familia lingüística pano- es desarrollado específicamente en la textilería cashinahuá por mujeres especialistas, responsables de todos los niveles de decisión involucrados en la actividad y dueñas de los jardines de algodón, de donde obtienen la materia prima.

Los primeros resultados nos permiten una perspectiva bastante completa de la complejidad del pensamiento cashinahuá, expresado en la versatilidad de sus técnicas textiles - particularmente en la técnica que hemos identificado como 'varillas de memoria'- y en la singularidad de los diseños que nos remiten a la realidad cotidiana de su relación con el medio ambiente, a la vez que a los refinamientos de una estética singular.

Palabras clave: Amazonía - tradición textil cashinahuá - kené - sarga - telar con 'varillas de memoria' - diseño con simetría en espejo - geometrías simbólicas.

\begin{abstract}
This essay seeks to characterize the textile culture of the Cashinahuá ethnic group in order to document the particular characteristics of the textiles created by native communities living on reserved territories within the Purús National Park. The art of kené -which refers to the geometric designs represented in textiles, basketry and body painting of certain groups belonging to the Pano linguistic family- is specifically developed in Cashinahuá textiles by women who are specialists, responsible for every level of decision-making involved in this activity and owners of the cotton gardens from which the raw material is obtained.

These initial research results provide quite a complete vision of the complexity of Cashinahuá thought, expressed in the versatility of their textile techniques - particularly in the technique that we have identified as 'memory sticks'- and in the singularity of patterns that reference the day to day reality of their relationship with the environment, and at the same time their refined and singular aesthetic.

Key words: Amazon Basin -Cashinahuá textile tradition - kené - twill - loom with 'memory sticks' - design with mirror symmetry - symbolic geometries.

\section{Resumé}

Le présent article propose une première approche de la culture textile du groupe cashinahuá. Il a pour objectif de documenter les caractéristiques particulières des tissus réalisés dans les communautés localisées sur le territoire de la réserve du Parc national Purús. L’art du kené - terme qui se réfère aux dessins géométriques présents sur les tissus, la vannerie et les peintures corporelles de certains groupes de la famille linguistique pano - apparaît tout spécialement dans la production
\end{abstract}

DOI: $10.32873 /$ unl.dc.zea.1222

Published in PreColumbian Textile Conference VIII / Jornadas de Textiles PreColombinos VIII, ed. Lena Bjerregaard and Ann Peters

(Lincoln, NE: Zea Books, 2020). https://digitalcommons.unl.edu/zeabook/ 
textile de tisserandes spécialisées, responsables de toutes les décisions prises dans le déroulement de cette activité et, en même temps, propriétaires des jardins de coton d'où elles tirent la matière première pour cette activité.

Les premiers résultats offrent une perspective assez complète de la complexité du mode de pensée des cashinahuá tel qu'il s'exprime dans la façon de tisser, dans la versatilité des techniques et dans la singularité des dessins. Tous ces éléments témoignent de la réalité quotidienne de leur relation avec leur environnement, en même temps que des aspects raffinés de leur esthétique.

Mots clés: Amazonie - tradition textile cashinahuá - kené - sergé - métier à tisser avec 'baguettes de mémoire’ - dessin avec symétrie en miroir - géométries symboliques.

\section{Contextos}

El pueblo cashinahuá se encuentra ubicado hacia el sud este de la Amazonía peruana, en los territorios de la Reserva Comunal del Parque Nacional Purús, en la provincia de Purús, departamento de Ucayali, con una población aproximada de entre 2,500 y 3,00o habitantes asentados en las riberas de los ríos Curanja y Alto Purús. (Lámina 1) Un sector importante de la misma familia étnica vive en Brasil, en las riberas de los ríos Alto Embira y tributarios, en el estado de Acre, constituyendo una mayor concentración de población que la que se encuentra en territorio peruano. Ambos sectores se encuentran comunicados por vía fluvial, mantienen relaciones de parentesco y se suelen reunir en ocasión de festividades.

Los cashinahuá pertenecen a la familia lingüística pano y constituyen el grupo de población más numeroso que habita en la Reserva comunal del Purús, en relación a los yaminahua, sharanahua, mastanahua y culina. El término cashinahuá se traduce como "gente murciélago" y aunque se trata de una denominación formal, de uso oficial, la misma población se reconoce entre sí con el apelativo huni kuin, que significa 'gente verdadera', y es la voz que suelen emplear al hacer referencia directa y coloquial.

Los cashinahuá habitaron tradicionalmente en una amplia área interfluvial conformada por las nacientes de los ríos Purús y Yurúa. Hacia fines del XIX, tiene lugar la fiebre del caucho, que tuvo su auge entre 1879 y 1912, experimentando, tiempo después, un renacimiento entre los años de 1942 y 1945, con la segunda guerra mundial. La población conserva en la memoria colectiva los sufrimientos y abusos cometidos por empresarios brasileros y peruanos en aquellos tiempos, donde fueron sometidos a condición de explotación, de esclavitud, de epidemias y de desplazamientos forzados, en territorio brasilero y peruano, que trajeron como consecuencia una fuerte baja demográfica. Más adelante, el contacto con habilitadores de madera, shiringueiros y compradores de pieles de animales silvestres con la finalidad de obtener herramientas, ropa y alimentos trajo nuevos

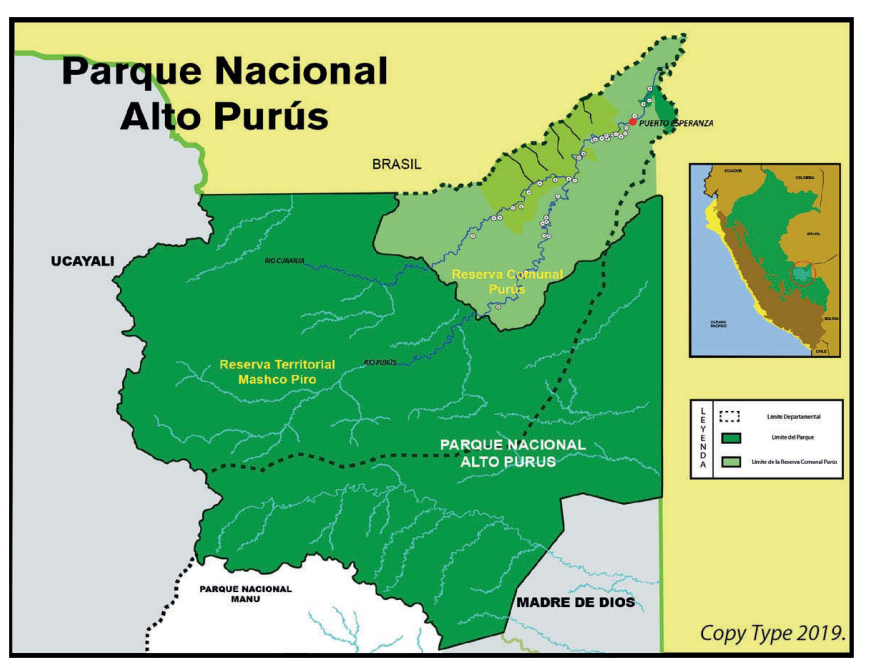

brotes epidémicos que diezmaron la población adulta desapareciendo cerca de un $75 \%$ de sus habitantes.

Los cambios en los patrones de asentamiento y la adaptación al hábitat ribereño se estabilizaron aproximadamente a partir de la década de 1970, aunque persisten a la fecha nuevas movilizaciones y la fundación de nuevas comunidades, motivados mayormente por la necesidad de encontrar espacios con mayores recursos de caza y también para acercarse al centro poblado de Puerto Esperanza, con acceso a servicios de salud, a bienes de comercio y de subsidios sociales. ${ }^{2}$

Las comunidades cashinahuá comparten una serie de rasgos culturales como, la organización social basada en mitades que ordenan la filiación de los individuos, el sistema de nombres, la selección de la pareja, la transmisión de conocimientos, así como las ceremonias y el universo ritual. Las mitades tienen una estructura exogámica y patrilineal, esto es, cada uno de los miembros de la pareja debe de pertenecer a una mitad, Inubake y Duabake (jaguar y luz radiante respectivamente). El lugar de residencia de una nueva pareja es la casa de los padres de la esposa, estableciendo un patrón uxorilocal. Son muy apreciados los conocimientos herbolarios y diversas técnicas terapéuticas. 


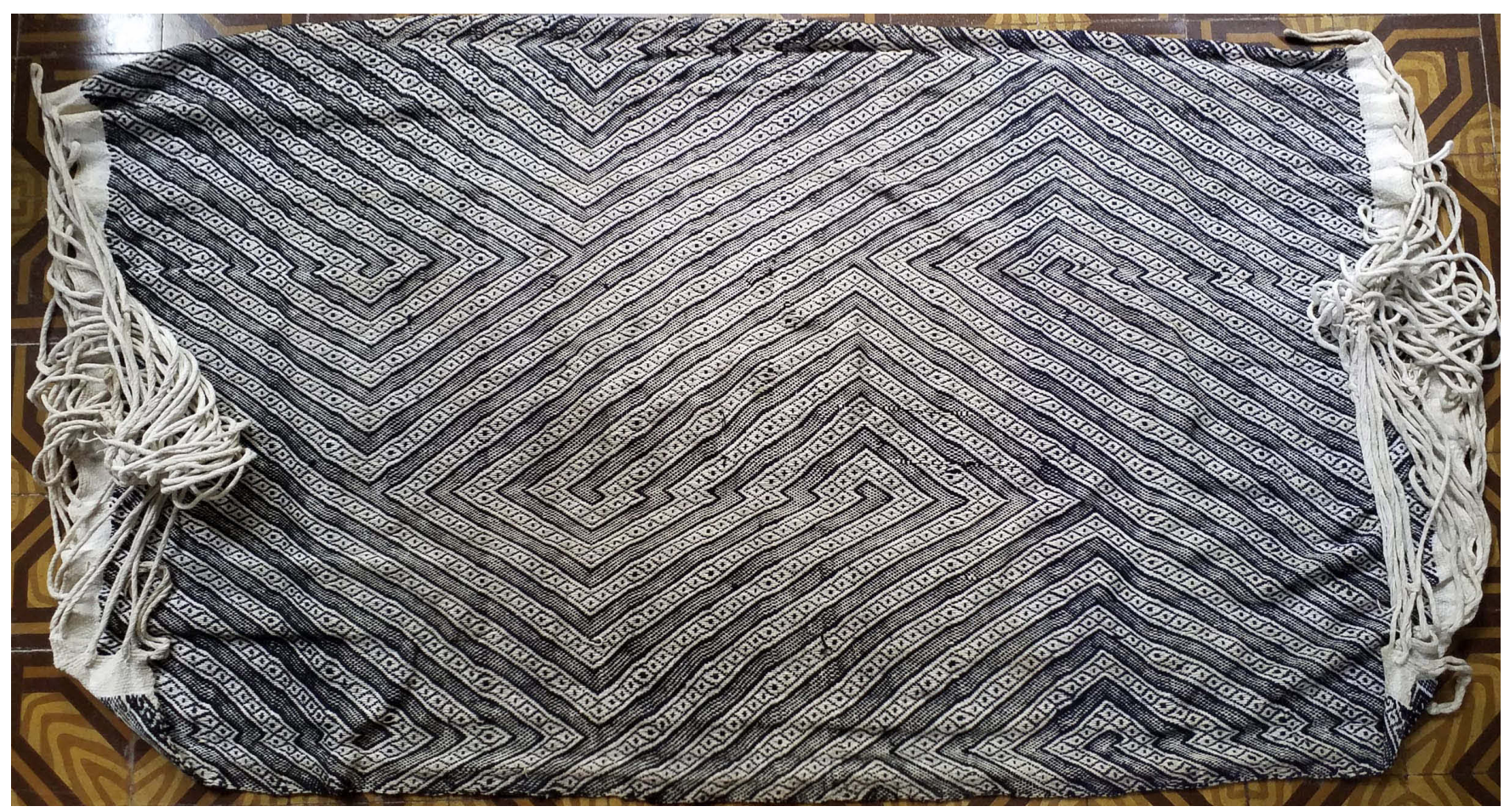

Foto 1 Hamaca de un solo paño. Hilda Pinedo, CCNN Colombiana. Foto: M.E. del Solar

Hoy en día, la caza de aves y carne de monte, a cargo de los hombres, es la principal fuente para el sostenimiento de las familias, aunque las actividades de pesca y la producción de yuca, maní y frutales (plátano, papaya, pacae) en las chacras a cargo de las mujeres, complementan una ingesta de alimentos equilibrada.

\section{Los tejidos cashinahuá}

Vengan hermanas, acérquense, vamos a aprender, vamos a observar, el diseño de la mantona.

Mirar nos dará inteligencia y sabiduría.

$Y$ cuando estemos juntas no se muevan, todas quietas como loro.

Porque el loro, cuando escucha aprende rápido.

No se muevan, no hagan bulla, como el loro se está quieto para aprender. ${ }^{3}$

La importancia del tejido en la sociedad cashinahuá es evidente si se consideran los múltiples espacios en los que mantiene una presencia importante como marcador de identidad. Es parte fundamental del espacio doméstico, pocas casas familiares visitadas no cuentan con un telar instalado o con una tejedora en plena actividad. La producción de textiles en las comunidades es fundamentalmente una tarea femenina y mantiene un fuerte carácter etnográfico; la calidad y complejidad de sus técnicas y diseños destaca especialmente frente a expresiones de la cultura material de otros pueblos de la región. ${ }^{4}$ (Foto 1 )

El vestido tradicional cashinahuá ha desaparecido hoy de la vida cotidiana, se viste exclusivamente en ceremonias festivas tradicionales, maridi hatxamawa, para la cosecha de productos de la chacra (plátano, yuca, maíz), y en general para toda ceremonia referida a la fertilidad, a la multiplicación -de la tierra, de los hombres, de las cosas- o en los rituales de iniciación. Una parte de la producción textil se destina a la comercialización en la ciudad brasileña cercana de Santa Rosa, sobre el mismo río Purús, punto de referencia social y comercial de los cashinahuá y de mestizos peruanos. Otra pequeña parte se comercializa con el apoyo de las hermanas evangélicas que visitan las comunidades.

3. Canción propiciadora del aprendizaje del tejido cantada por la tejedora Sandra Pinedo, 26 años. CCNN Colombiana 2019. Traducción: Jacob Torres, huni kuin. Guardaparque de la Reserva Comunal Purús. Servicio Nacional de Áreas Naturales Protegidas, SERNANP.

4. Los estudios etnográficos de Kensinger (1975) constituyeron una fuente de información relevante para la colección representativa de tejidos, plumarios y otros artefactos de la cultura material cashinahuá que fueron adquiridos, en las décadas de 1960-70, por el mismo Kensinger, para la colección Haffenreffer, hoy en la Universidad de Brown, en los EEUU, así como para Temple University, Pennsylvania Museum, Musée du Quai Branly, posiblemente entre otros. 
Presentamos una relación de las diversas prendas del vestido tradicional cashinahuá: (Tabla 1)

\begin{tabular}{|l|l|l|}
\hline \multicolumn{2}{|c|}{$\begin{array}{c}\text { Los tejidos de algodón } \\
\text { Xapu tima }\end{array}$} \\
\hline En telar de cintura & Kapanka / kapu & $\begin{array}{l}\text { Empleado para portar implementos de caza por } \\
\text { los hombres. }\end{array}$ \\
\hline Morral & Tadi hidabi & Túnica de hombre. \\
\hline Cushma & Txinexeti xampana & Empleada por los hombres en ceremonias. \\
\hline Falda & Tudu tadi & Antiguamente cubría hasta las rodillas. . \\
\hline Chaleco hombre & $\begin{array}{l}\text { Yumen huxe } \\
\text { puxti }\end{array}$ & $\begin{array}{l}\text { Sujetan las junturas alrededor de muñecas, bra- } \\
\text { zos, tobillos y debajo de las rodillas. }\end{array}$ \\
\hline Brazaletes & mabi & Para decorar los brazos en las fiestas. \\
\hline Muñequera & Yumen hash kanti & $\begin{array}{l}\text { Se porta cruzada en diagonal sobre el pecho, tanto } \\
\text { hombres como mujeres. }\end{array}$ \\
\hline Banda & Pampana & Indistintamente para hombres y mujeres. \\
\hline Cinturón & Maxti & $\begin{array}{l}\text { Plumas y banda en algodón sobre estructura de } \\
\text { caña }\end{array}$ \\
\hline Corona & $\begin{array}{l}\text { Plumas y banda en algodón sobre estructura de } \\
\text { caña }\end{array}$ \\
\hline Corona mujer & Yumen maiti & $\begin{array}{l}\text { De uno o dos paños, para dormir o para descansar } \\
\text { durante el día. }\end{array}$ \\
\hline En telar diagonal & Tanka, turukare & Para abrigo. Se tejen poco en la actualidad. \\
\hline Hamacas & Disi tima & Patrón tubular \\
\hline Mantas & \multicolumn{2}{|l|}{} \\
\hline En telar de urdimbres contínuas &
\end{tabular}

Si bien no es parte de la vestimenta cotidiana, se acostumbra preparar con cuidado los atuendos y complementos que serán vestidos durante festividades y ceremonias. El ingreso económico por su comercialización es eventual y precario pero constituye una posibilidad de dinero para adquirir ciertos bienes de consumo que no producen en la chacra (ropa, alimentos, medicinas).

La riqueza del vocabulario textil constituye un argumento importante para valorar la vigencia de la actividad del tejido -su cualidad, textura, apariencia- fuertemente ensamblado al sistema de pensamiento ritual y a los aspectos formales de la identidad cashinahuá.

\section{Tipos de telares, descripción y funcionalidad}

Las tejedoras cashinahuá emplean el telar tradicional como herramienta básica para la producción de tejidos de algodón, común a diversos pueblos de la región amazónica, tanto de las familias pano como arawak y jíbaro.

Se han identificado tres variantes del telar tradicional, adecuados funcionalmente al tipo de prenda que se teje, especialmente en cuanto a las dimensiones de la pieza se refiere. Primero, se observan dos variantes que producen tejidos con cuatro orillos. Uno tiene la tensión de la urdimbre ejercitada por el cuerpo de la tejedora. Es el telar de cintura usado para tejer morrales, camisas y túnicas, y prendas de menor tamaño como bandas de pecho y coronas o vinchas, que servirán, estas últimas, como base para los tocados de plumas. Este telar no tiene lizos, los hilos se escogen manualmente en cada cruce de la trama, pero tiene la particularidad del empleo de finas varillas para memorizar en la zona superior de la urdimbre los hilos escogidos que componen el diseño en la zona inferior. Esas varillas permiten reproducir 'en espejo' el mismo diseño sin tener que escoger los hilos y, de esta manera, se logra una importante economía en el tiempo y esfuerzo invertidos.

La segunda variante tiene una tensión estable para sustentar una urdimbre de dimensión mucho mayor. Es el telar diagonal empleado para la confección de paños para las hamacas, y en décadas pasadas para la confección de mantas destinadas a ceremonias y para abrigo. ${ }^{5}$ En el caso de que no se trabajen diseños, o parcialmente combinados con franjas de tela llana, el telar puede tener un lizo y un separador. Cuando hay un diseño escogido que se repite en la urdimbre 'en espejo' (no siempre es el caso), la tejedora puede usar varillas para memorizar los hilos escogidos en la parte superior 
de la urdimbre, mientras se compone el diseño en la zona inferior. ${ }^{6} \mathrm{Si}$ el empleo de varillas parece común en el telar de cintura, es de uso menos regular en el telar diagonal.

La tercera variante, el telar de urdimbre continua, se caracteriza por el urdido de una urdimbre circular necesaria para producir las faldas tubulares que llevan las mujeres.

- Telar de cintura.- Es la técnica más difundida y consiste en un sistema de barras, anterior y superior, sobre las que se montan los hilos que van a formar el urdido. La trama, como elemento activo, complementa la estructura del tejido, y la técnica de entrecruzamiento de los ligamentos definirá el diseño. No se emplea el lizo, mas sí es frecuente el empleo de las varillas que replican la selección de las urdimbres en espejo, hacia el extremo superior del tejido. Una faja a la cintura, de allí el nombre del telar, enganchada a ambos extremos de la barra anterior, permite a la tejedora tensar o soltar a voluntad las urdimbres, con el peso de su cuerpo, para permitir pasar la trama a través del espacio de la calada. La barra superior del telar se suele amarrar a alguna saliente de las paredes de la vivienda. (Foto 2)

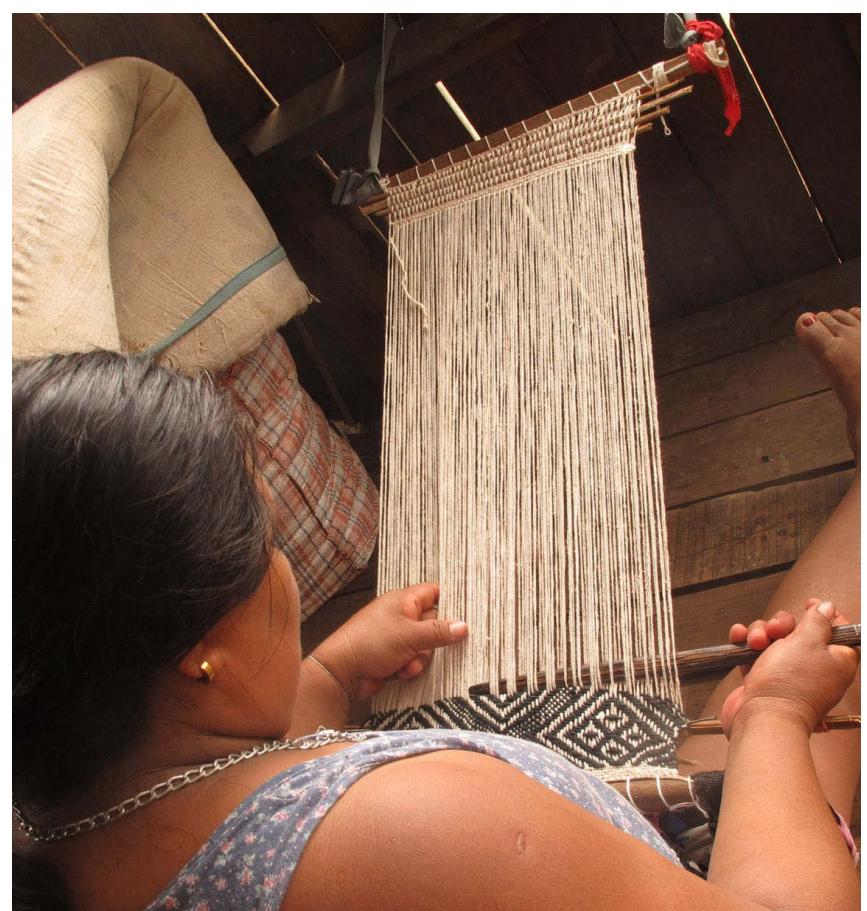

Foto 2 Doris Salomón escogiendo las urdimbres para confección de un morral en telar de cintura. CCNN de San Martín 2018. Foto: M.E. del Solar

-Telar diagonal.- Este telar se asegura, o se cuelga, en el centro de la vivienda, a una viga especialmente acondicionada, y se fija directamente al piso para quedar inmovilizado. Los tejidos desarrollados en este tipo de telar diagonal pueden alcanzar un ancho máximo de $1.25 \mathrm{~m}$. lo que requiere de una especial pericia de la tejedora, que puede optar por la técnica de escogido en todo el paño, por el armado de lizos o por el empleo de varillas para guardar la memoria del diseño. En estos telares, se mantiene la estructura de cuatro orillos para la confección de hamacas; estas pueden ser de un paño para usar durante el día o de dos paños, cosidos longitudinalmente, para lograr un mayor ancho y mayor comodidad para el descanso. (Foto 3)

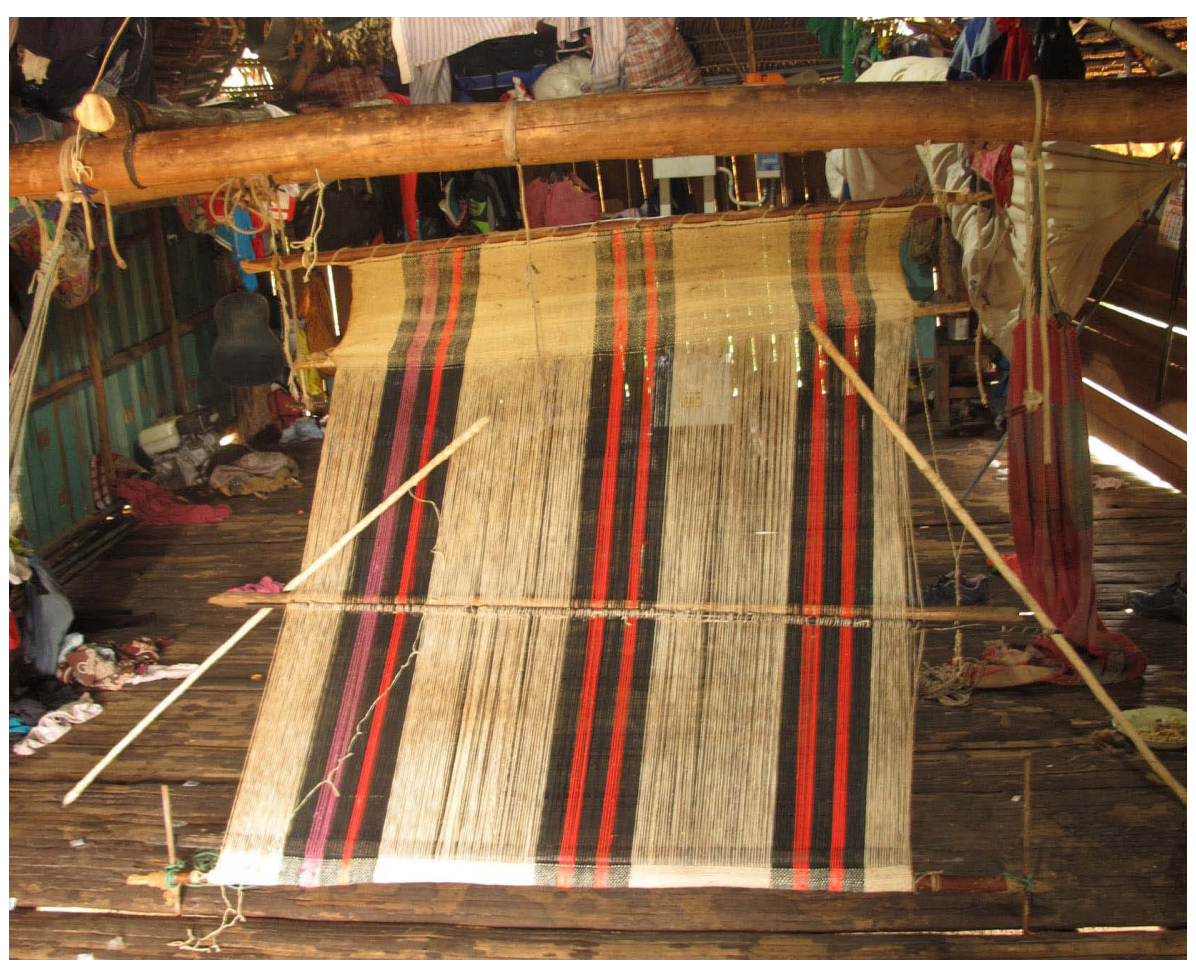

Foto 3 Telar diagonal para tejer hamacas. Elena López Nacimiento, CCNN San Martín 2018. Foto: M.E. del Solar 
-Telar de urdimbre continua.- Consiste en un telar horizontal cuyas barras delantera y posterior se sujetan con cuerdas a cuatro estacas que se plantan en el suelo. La construcción del diseño implica la manipulación de las urdimbres con la ayuda del escogedor, yume tupikin, excluyéndose, en este caso, el empleo de lizos o varillas para guardar la memoria del diseño, como se ha señalado en los casos anteriores. El producto final será un tejido de patrón tubular, empleado especialmente en la confección de faldas. Es la única prenda tejida en donde las urdimbres, en la vestimenta, pasan a la posición horizontal. ${ }^{7}$ (Foto 4)

\section{Técnicas tradicionales de elaboración de tejidos}

\section{Los recursos del bosque:}

El algodón nativo es el principal recurso para el tejido. La variedad identificada, gossypium barbadense, es originaria de América del sur y de amplia distribución en poblaciones silvestres en climas tropicales. Es muy apreciado por su fibra larga, suavidad y brillo, así como por su resistencia a las plagas.

Es cultivado en pequeña escala en las chacras cercanas a la vivienda y cuidado por las mujeres cashinahuá, donde se identifica un indudable servicio ambiental ya que su manejo a través del arte textil tradicional contribuye a la preservación de las variedades nativas, por tanto a la conservación in situ del material genético del Parque. Su característico tono crema se emplea en combinación con el negro o azulgrisáceo oscuro para obtener el contraste definido que mejor destaca los diseños. El algodón de color pardo se emplea en menor cantidad. La huerta familiar, a cargo de la mujer, provee de especies tintóreas, entre las más difundidas están el huito (Genipa americana) de donde se obtiene el color azul grisáceo oscuro y el negro, que también se emplea en la pintura corporal; las semillas de achiote (Bixa orellana), maxe, para el rojo y anaranjado oscuro; el palillo (Curcuma longa), raíz comestible de la que se obtienen varios tonos de amarillo y ocre.

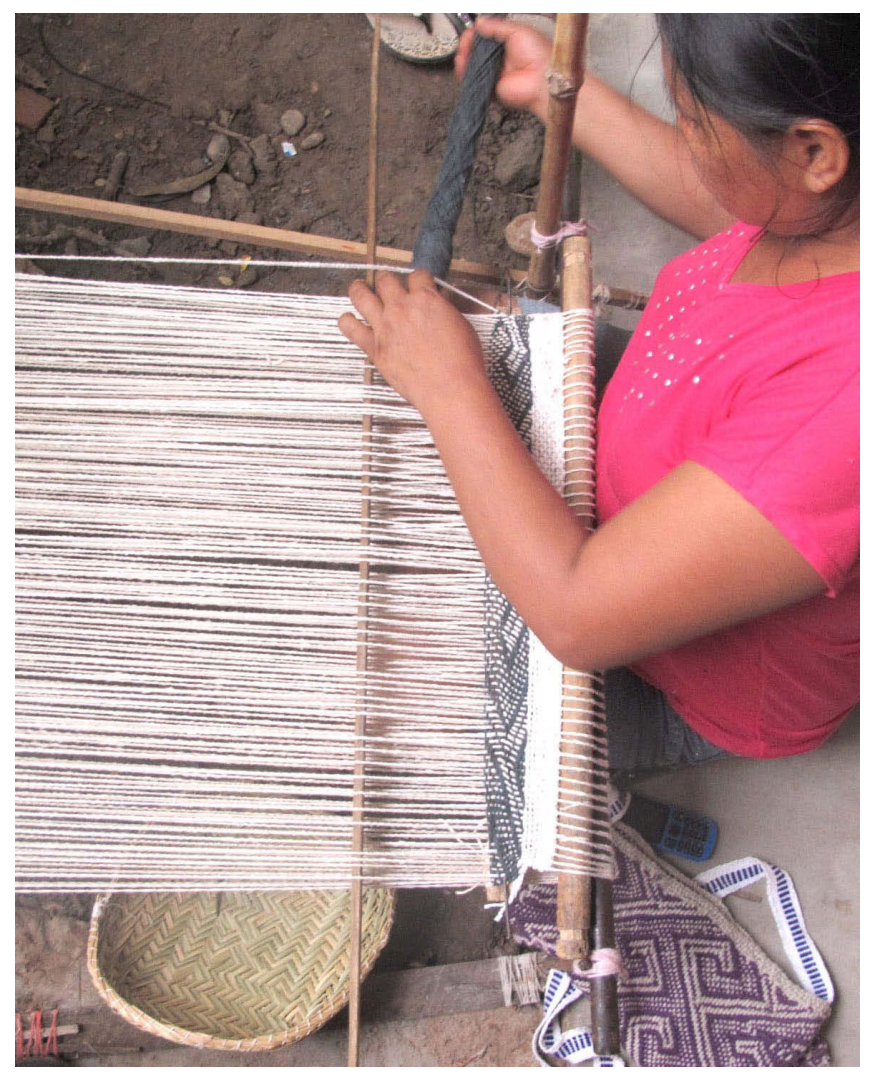

Foto 4 Florinda Torres Montes, iniciando el tejido de una falda en telar de urdimbre contínua. CCNN Conta 2018. Foto: M.E. del Solar

Las incursiones más profundas al bosque suelen estar a cargo de los varones de la familia donde se combina la caza con la cosecha de semillas diversas para la confección de adornos para la decoración personal y/o la venta menuda; también para la extracción de trozos de corteza de caoba (Swetenia macrophylla), ischinanti, o palos de árboles u hojas conocidos, de donde se obtienen otros colores como rosa, azul, morado o verde. Estos colores suelen aparecer como fondo en paneles alternados, especialmente en las hamacas, sobre los que va a destacar con mayor intensidad el diseño construido en el contraste claro-oscuro.

\begin{tabular}{|l|l|l|}
\hline \multicolumn{1}{|c|}{ Tono de algodón } & \multicolumn{1}{c|}{ Nombre cashinahuá } & \multicolumn{1}{c|}{ Nombre científico } \\
\hline Blanco marfil & xapu jushipa & Gossypium barbadense \\
\hline Marrón (más obscuro) & xapu junishipa / jushinepa & Gossypium barbadense \\
\hline Marrón (más claro) & xapu kurupá & Gossypium barbadense \\
\hline
\end{tabular}

7. La estructura de las cushmas ashaninka, túnica femenina, lleva igualmente las urdimbres horizontales en dos paños unidos horizontalmente. Para ampliar información ver: Desrosiers 1992. 


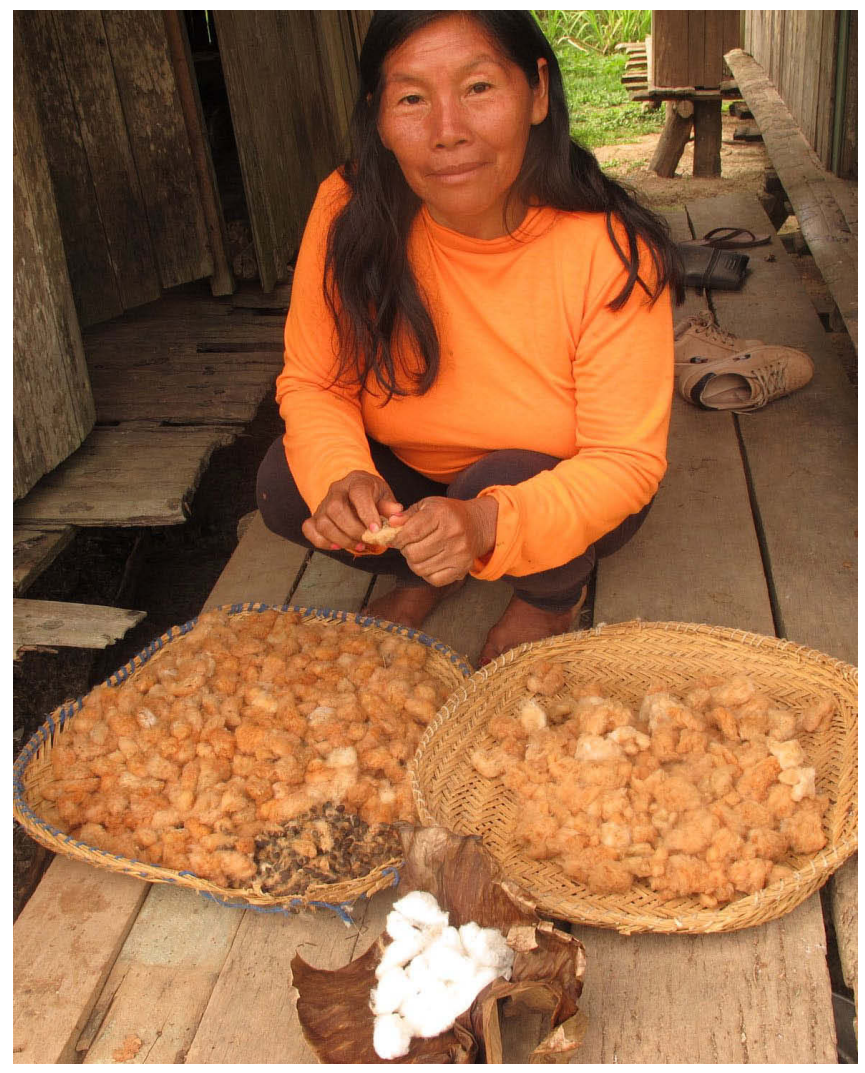

Foto 5 Experta tejedora Débora Pedro Hermes, despepitando algodón pardo. CCNN Nueva Luz 2019. Foto: M.E. del Solar

Desde las últimas décadas no es extraño observar la presencia de material sintético en el tejido, así como el empleo de anilinas para teñir el algodón, aunque resulta difícil y bastante costosa su provisión por la distancia con centros comerciales. En la pequeña colección de tejidos adquirida especialmente para el presente estudio, podemos identificar la presencia de hilo sintético de color, imitando a los tonos que tradicionalmente se emplean para la realización de los kené, especialmente el pabilo de algodón blanco industrial. Es interesante constatar con ello que existe un interés en pasar desapercibidos los nuevos materiales de origen industrial ya que la pequeña demanda existente prioriza los productos tradicionales.

\section{El hilado:}

Un buen hilado consiste en la base fundamental de una prenda de calidad. Un valor importante para calificar un buen hilado, tal como es apreciado por las mismas hilanderas, es que este sea delgado, parejo y esté bien limpio de pajillas e impurezas. La diferencia de calidad entre un tejido hecho con hilo parejo y otro con hilo desigual se observa a simple vista, mostrándose este último en una prenda de tejido flojo y rústico, con el diseño poco definido. Hemos

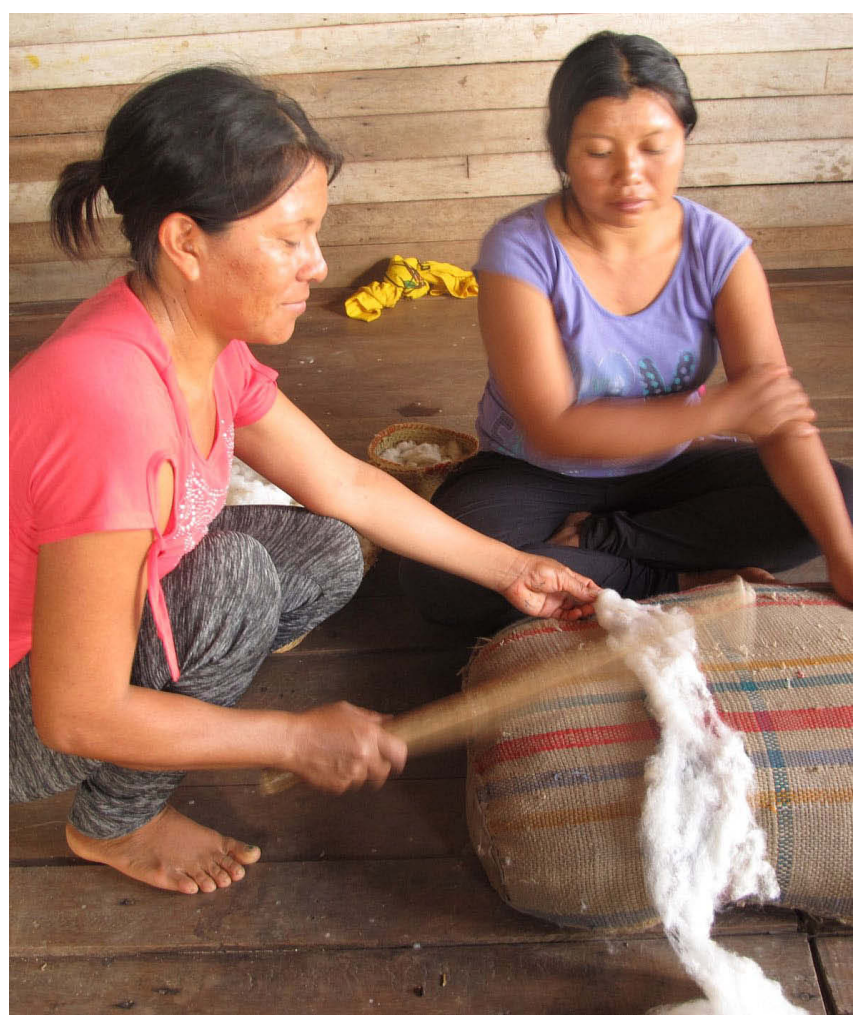

Foto 6 Batiendo la fibra para limpiar de impurezas y airear las hebras. Eleana Torres Montes, CCNN Conta 2018. Foto: M.E. del Solar

observado que la mayoría de las mujeres logran un hilado fino y parejo cuando se lo proponen ya que manejan una extraordinaria pericia para ello, producto de un aprendizaje y práctica desde muy jóvenes, aunque muchas veces no lo producen fino ni parejo ya que implica mayor inversión de tiempo.

Para producir el hilo, la primera operación es la limpieza de las semillas, agrupadas en el corazón de la cápsula (Foto 5); enseguida la fibra se extiende, se coloca sobre una almohadilla para golpearla con una varilla con la finalidad de limpiar de impurezas y separar e individualizar las hebras. (Foto 6) Se forma una mecha vaporosa y continua (Fotos 7 y 8) que se deposita amontonándola sobre una cesta de palmera -denominada localmente shapaja- asociada al depósito y procesamiento del hilo de algodón. En este punto la fibra ya está lista para iniciar el hilado propiamente, con la ayuda de un huso (varilla recta con un contrapeso de arcilla), que gira en un cuenco de cerámica decorado. (Foto 9)

El huso se sostiene siempre con la mano izquierda, no es necesario realizar una lazada hacia el extremo de la varilla, tal como se realiza en el sur andino, porque en ningún momento esta pende suelta. En primer lugar se estira la mecha, limpiando a la vez la fibra de cualquier impureza 


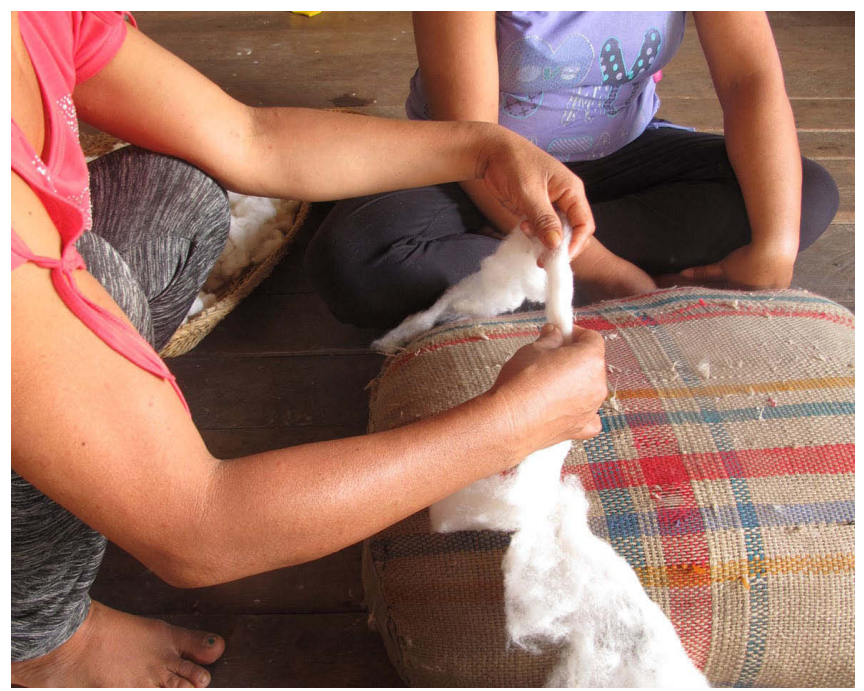

Foto 7 Se forma una mecha aireada y pareja. Eleana Torres Montes, CCNN Conta 2018. Foto: M.E. del Solar

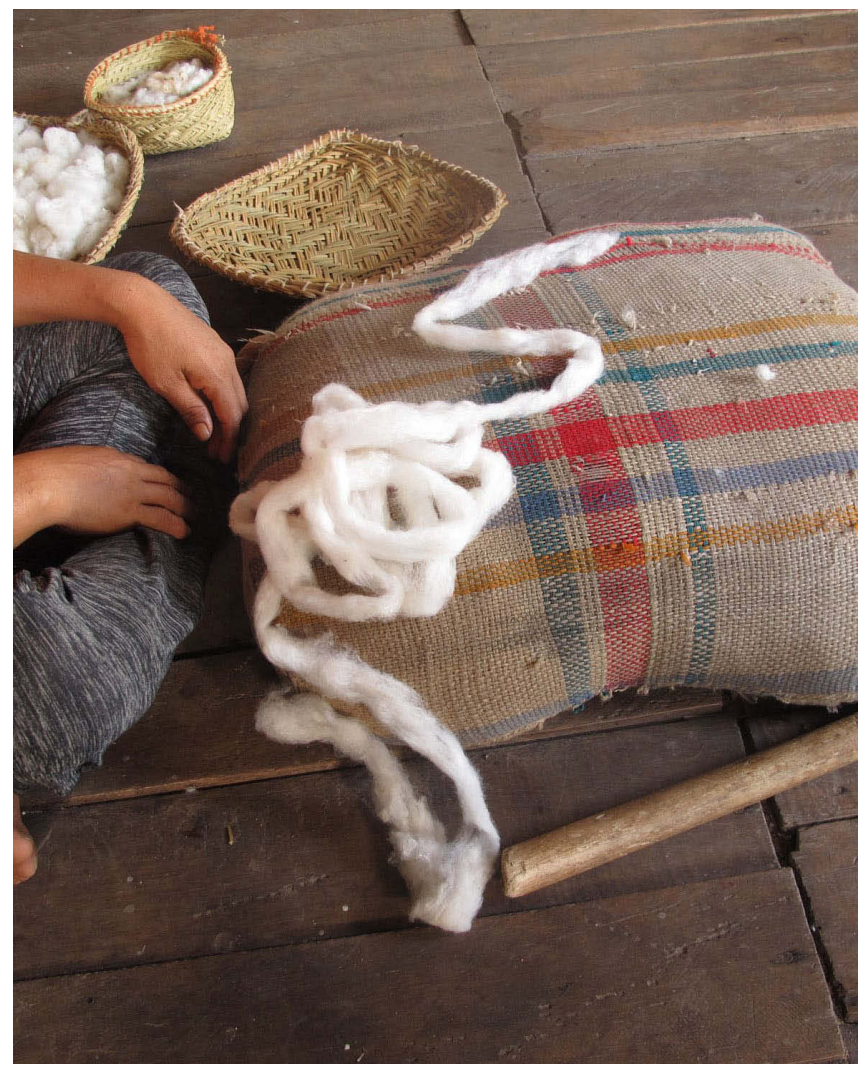

Foto 8 La mecha queda lista para el hilado. Eleana Torres Montes, CCNN Conta 2018. Foto: M.E. del Solar

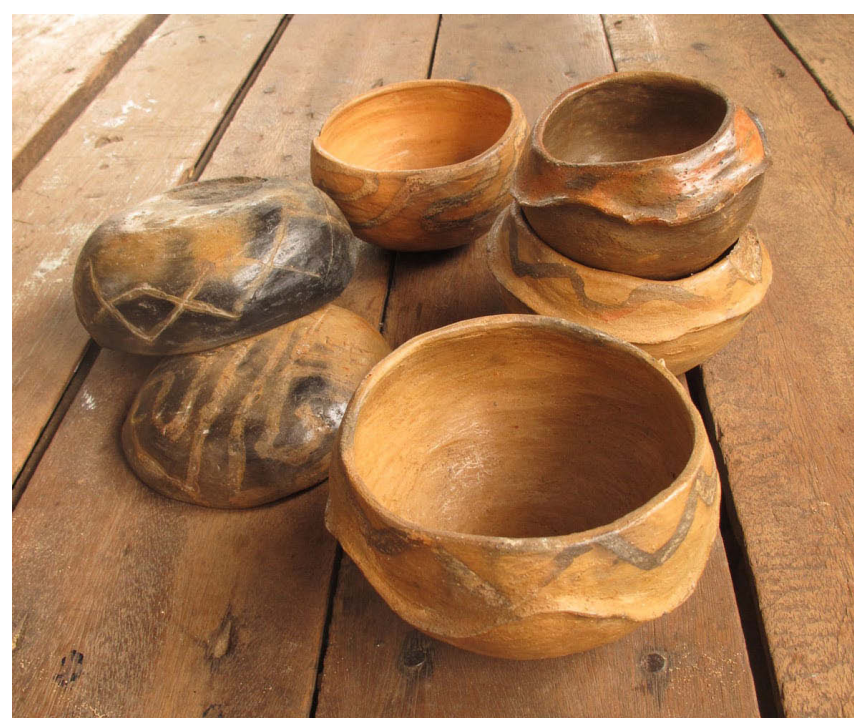

Foto 9 Cuencos de cerámica decorados, preparados por Doris Salomón, sirven para rodar el huso durante la acción del hilado. Puerto Esperanza 2018. Foto: M.E. del Solar

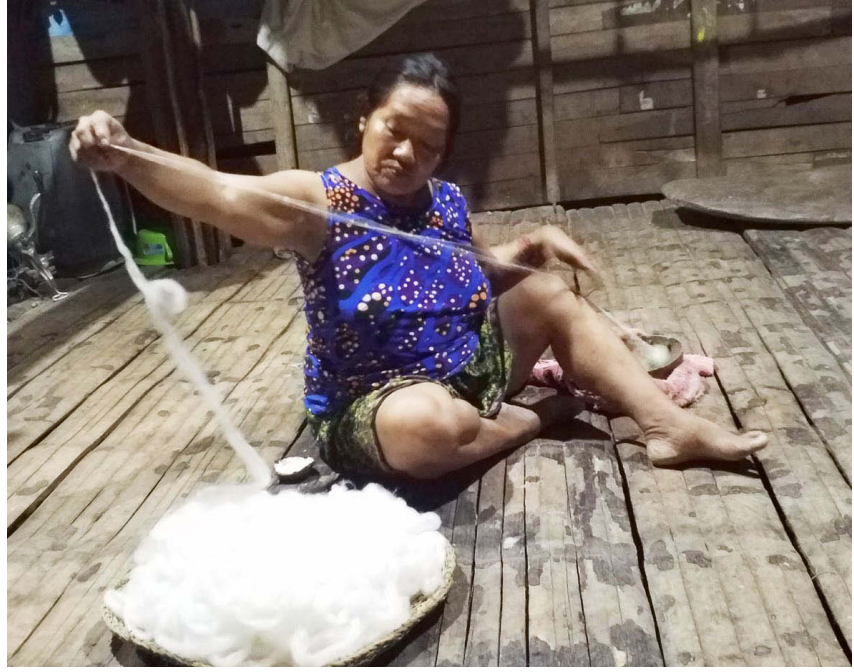

Foto 10 Proceso de adelgazamiento de la mecha para formar el hilo, obsérvese que el huso no pende durante la acción del hilado. Hilda Pinedo, CCNN Colombiana 2019. Foto: M.E. del Solar

o imperfección; acto seguido, se tuerce la fibra mediante un movimiento contra la pierna (entre el tobillo y la rodilla), haciendo girar el huso hacia la izquierda lo que produce una torsión en 'S', para finalmente enrollar el hilo obtenido sobre el huso. ${ }^{8}$ (Foto 10) Para obtener una mayor consistencia del hilo, se pliegan dos cabos y se retuercen en el sentido opuesto, llegando así a una torsión final en 'Z' para un hilo descrito 'Z2s. ${ }^{9}$

8. Las hilanderas de algodón de la costa norte del país producen igualmente un torcido en dirección 'S' mediante una manipulación horizontal del huso con la mano derecha, el hilo torciéndose en la parte inferior del huso.

9. Donde el sentido de la torsión inicial es en minúscula y el sentido del retorcido en mayúscula, para evitar toda malinterpretación. 
Las técnicas:

Todas las técnicas registradas para los tejidos cashinahuá analizados son constructivas, no se ha encontrado evidencia de técnicas supra estructurales. La técnica de construcción de la tela va a determinar su decoración, enfatizada en la alternancia de colores contrastantes para la urdimbre y la trama. Se ha constatado que por lo general en los morrales llegan a combinar entre dos y tres técnicas en la misma prenda. ${ }^{10}$

Un componente adicional está constituido por las características de los hilos, en términos de combinación de grosores, grado de torsión y cantidad de cabos (pareados o torcidos), que otorgan un relieve particular a la prenda, distinción que también será plenamente visible inclusive en tejidos con hilos de una sola tonalidad, como es la tonalidad cremosa del algodón natural.

La construcción del diseño se realiza mediante el escogido manual de los hilos de urdimbre durante todo el desarrollo del tejido. Se ha observado el empleo de lizos especialmente para el tejido de hamacas, es decir en superficies de mayor ancho y específicamente para las secciones de tela llana.

Técnica y diseño se encuentran perfectamente integrados en la noción de estilo ya que el diseño está involucrado en la misma construcción de la estructura, mediante la elección de una manera de cruzamiento de los ligamentos, que responde a un conjunto de normas culturales que rigen al grupo. Al respecto, la arqueóloga Carolina Agüero (2015:58), argumenta algunos interesantes conceptos aplicables igualmente al dato etnográfico:
Cabe señalar que muchas tipologías privilegian la decoración, pero en varios contextos el estilo decorativo es mucho menos diagnóstico de identidades sociales que las tradiciones tecnológicas. En este sentido, no es deseable separar "estilo" de "función" o decoración de tecnología. La decoración es simplemente un atributo más de la elección técnica. Entonces, estilo no es algo agregado a los objetos, sino el resultado de elecciones técnicas y decorativas, lo que en términos metodológicos entenderé como una manera característica de ejecutar, construir y diseñar...

El cruce de las tramas y urdimbres forma un ángulo recto, $90^{\circ}$, desarrollado en dos dimensiones del plano, y al tener mayormente una densidad similar en la urdimbre y en la trama el empleo de la técnica sarga genera diagonales en un ángulo de $45^{\circ}$. Esta técnica consiste en la organización de tramas y de urdimbres flotantes en tramos y dirección regulares -saltas sobre tres o cuatro urdimbres- que pueden ser hacia la derecha o izquierda, que determinan el ángulo de las líneas diagonales y, a la vez, limitan las posibilidades del diseño y van a dar lugar a una marcada tradición tecnológica regional. Por tanto, se trata de dos lecturas de una misma acción pero que separamos en dos temas, o secciones, para efectos del presente estudio: de un lado las técnicas y de otro los diseños o motivos.

Las técnicas analizadas son descritas y graficadas a continuación a partir de una muestra de 27 piezas:

\begin{tabular}{|c|c|}
\hline Técnicas decorativas & Función en el tejido \\
\hline \multicolumn{2}{|r|}{ Estructuras en los tejidos } \\
\hline Tela llana, con hilos $1 \times 1$ & Cuerpo de morrales en combinación con otras técnicas. \\
\hline Variante: con hilos $1 \mathrm{x} 4$ & Inicio y final de tejido de bolsas. \\
\hline Variante: con hilos $2 \times 2$ & $\begin{array}{l}\text { Cuerpo de morrales en combinación con otras técnicas. } \\
\text { Una hamaca con diseño de cuadros producidos por franjas } \\
\text { de urdimbres de colores diferentes y franjas de trama de } \\
\text { colores diferentes. }\end{array}$ \\
\hline $\begin{array}{l}\text { Tela llana combinada con } \\
\text { urdimbres entrelazadas }\end{array}$ & $\begin{array}{l}\text { En cuerpo de morrales (único espécimen identificado con } \\
\text { esta técnica). }\end{array}$ \\
\hline $\begin{array}{l}\text { Tela llana combinada con sarga } 3.3 \\
\text { y } 3.1\end{array}$ & En cuerpo de morrales \\
\hline $\begin{array}{l}\text { Sarga } 3.3 \text { y derivados en chevrones, } \\
\text { rombos o ganchos }\end{array}$ & Motivos geométricos en cuerpo de bolsas y hamacas. \\
\hline \multicolumn{2}{|c|}{ Estructuras en las asas } \\
\hline Tela llana, con hilos $1 \mathrm{x} 1$ & En combinación con otras técnicas. \\
\hline Variante: con hilos $2 \times 1$ & Asas. \\
\hline Tela llana, cara de urdimbre & Más compacto para tejido de asas. \\
\hline $\begin{array}{l}\text { Tela llana, cara de urdimbre, con } \\
\text { hilos flotantes alternados sobre } 3 \\
\text { hilos de trama }\end{array}$ & Más compacto para tejido de asas. \\
\hline
\end{tabular}

10. No fue posible documentar en detalle el proceso del armado de urdimbres por falta de coincidencia y oportunidad. Es un pendiente importante para nuestra próxima visita a la zona. 


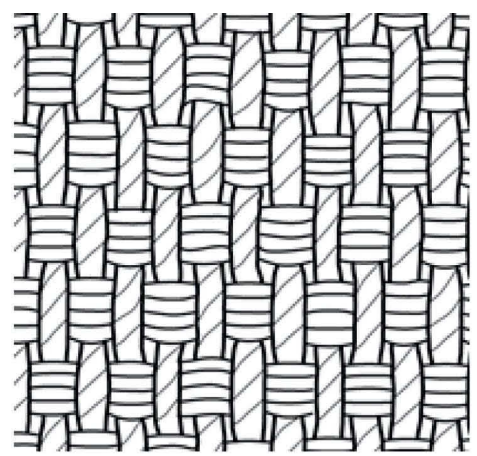

Cuerpo de morral

Tela llana. Z2s/4s

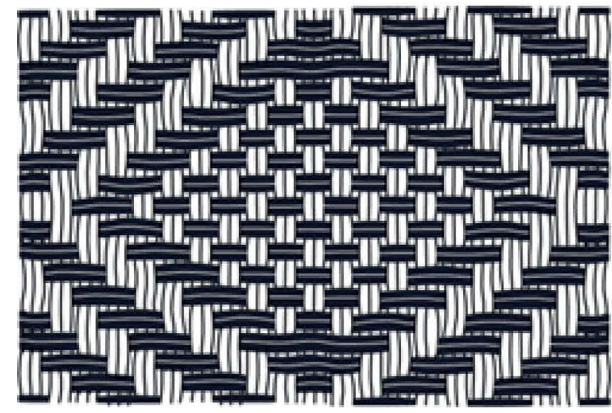

Cuerpo de morral

Combinación de tela llana y de sarga 3.3. Hilos dobles en la urdimbre y en la trama

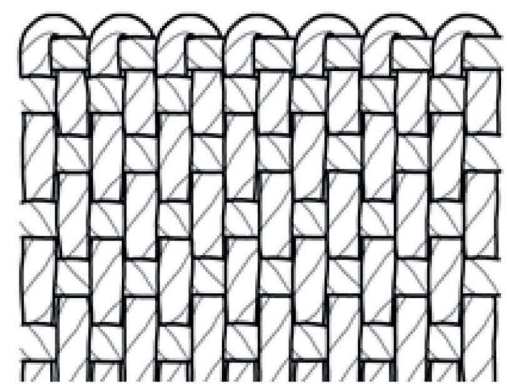

Asa de morral

Tela llana. Z2s/Z2s

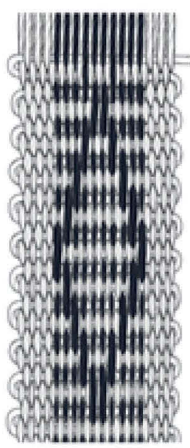

Asa de morral

Tela llana cara de urdimbre con hilos flotantes alternados sobre 3 hilos de trama

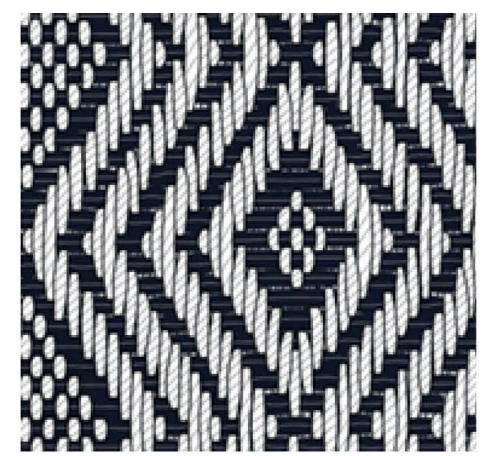

Cuerpo de morral

Combinación de tela llana y de sarga 3.3 y 3.1

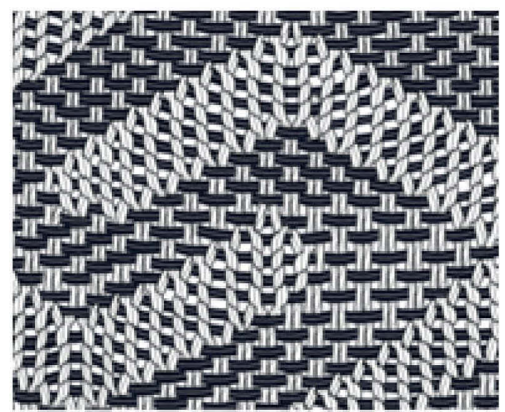

Cuerpo de morral

Tela Ilana y urdimbres entrelazadas

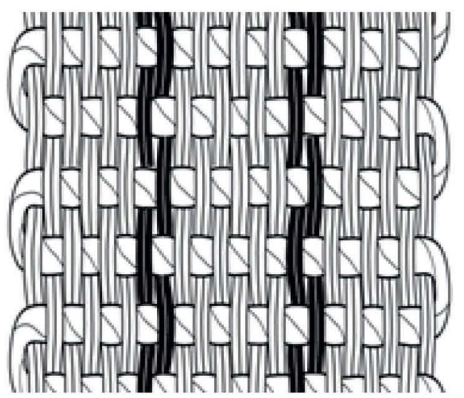

Asa de morral

Tela llana con listas de dos hilos en la urdimbre

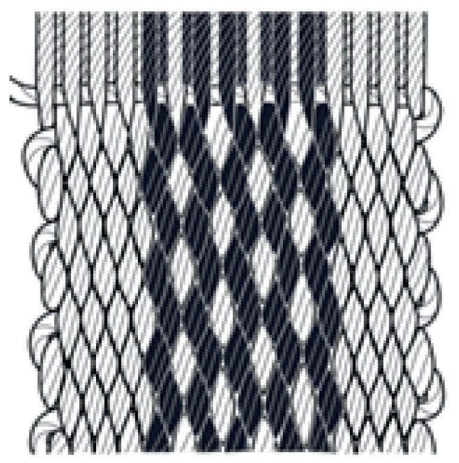

Asa de morral

Tela llana cara de urdimbre con finas listas de dos hilos separados por un hilo del color principal 


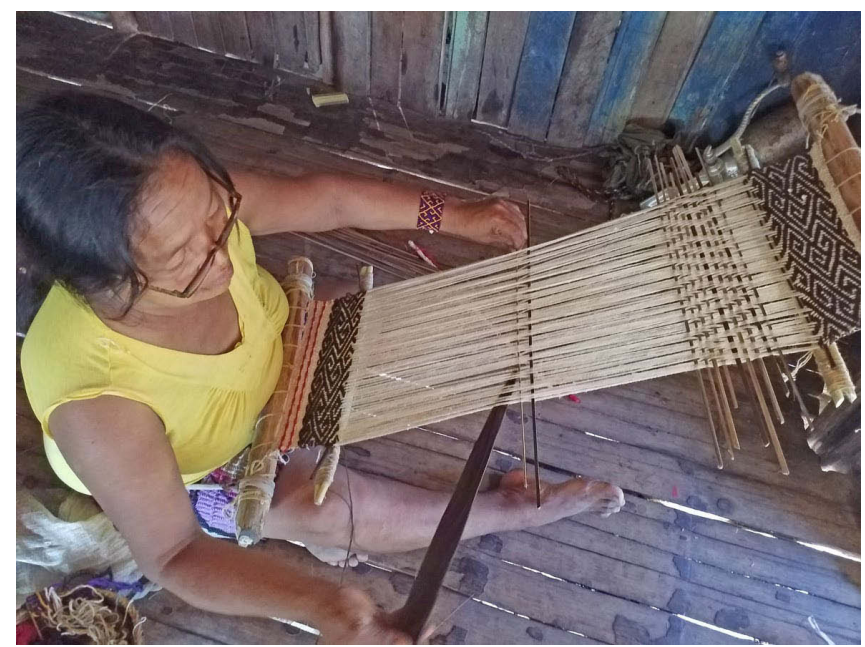

Foto 11 Aplicación del método de tejido de 'varillas de memoria' para la confección de un morral. Hilda Pinedo, CCNN Colombiana 2019. Foto: M.E. del Solar

Los hilos de urdimbre de los productos analizados están constituidos en su mayoría por dos hilos pareados; la cantidad de hilos de trama es variable pudiendo llegar hasta una cantidad de cuatro, otorgando así una mayor fortaleza a la estructura de la tela. En las asas aparecen en mayor cantidad los hilos torcidos, Z2s.

En la ejecución de la técnica sarga, recurrente en las secciones con decoración de los tejidos, se emplean dos colores contrastantes, como ha sido señalado, por lo general blanco/ negro-gris azulado. Para las tejedoras, la trama resulta más importante que el urdido (por lo general de color blanco), en la medida de que el hilo de color, es decir la trama, define el diseño por contraste.

El patrón de urdimbres flotantes alternadas sobre tres hilos de trama está directamente asociado a la estructura del cuerpo del tejido y, en algunos casos, a la generación de diseño en las asas. Esta técnica produce en las asas de los morrales un tejido más compacto, adecuado a su función de carga.

En general, la combinación de tela llana con sarga constituye la técnica decorativa más difundida. Aparece siempre cubriendo todo el cuerpo del morral, también cubriendo toda la superficie de camisas y de faldas, o en las bandas que se alternan con secciones de tela llana, en las hamacas. ${ }^{11}$

La aplicación de la técnica del entrelazado de urdimbres (warp twining), con un ritmo de cuatro torsiones hacia cada lado, combinado con tela llana, ha sido particularmente interesante.

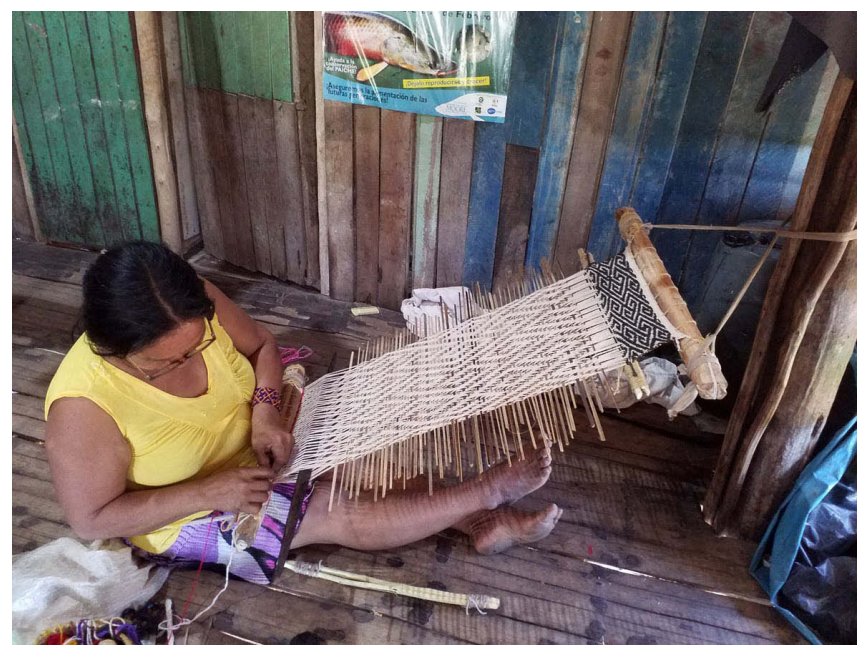

Foto 12 Una vez escogidas las urdimbres se inserta la trama y una delgada varilla en la misma calada. Esta lleva la memoria del diseño hacia la parte superior y será tejida una vez que se da vuelta el telar. Hilda Pinedo, CCNN Colombiana 2019. Foto: M.E. del Solar

\section{Técnica especial: 'Varillas de memoria'}

Se ha identificado un método de tejido entre las tejedoras cashinahuá que implica una racionalización del tiempo invertido y se aplica tanto a tejidos grandes (hamacas) como a prendas de menor tamaño. Conocemos de la existencia de este método en otros grupos de la Amazonía pero no lo hemos documentado personalmente. Sería importante constatar si aparece exclusivamente entre los grupos de la familia pano o se encuentra difundido a un nivel más amplio de la Amazonía. (Foto 11)

Durante el proceso del tejido, las urdimbres se escogen manualmente con la espada para construir el diseño por cada inserción de la trama. Una vez ajustada esta con la espada, se inserta una varilla de hoja de palma en la calada para controlar y subir el diseño a la parte superior del telar -si se teje con lizos, la varilla se insertará inmediatamente después de estos- donde se van acumulando las varillas que van guardando la memoria del diseño. En este punto, el telar se da vuelta y se teje la sección con varillas, donde el diseño ya se encuentra escogido, simplemente introduciendo la espada para retirar una a una las varillas e insertar la trama sin tener la necesidad de escoger los hilos de urdido nuevamente. (Foto 12) Este proceso permite acelerar el tejido, ahorrando tiempo y esfuerzo, ya que el diseño se encuentra planteado en las varillas, a modo de espejo. (Foto 13)

A continuación, se procede a la misma operación, subiendo las varillas con la información del diseño que ha sido

11. En el artículo de Helen Tanner (1975:119 y 121), aparece también una manta totalmente decorada, así como otra con decoración de franjas con plumas y conchas superpuestas, supuestamente parte del ajuar empleado por el maestro en ceremonias de iniciación. 


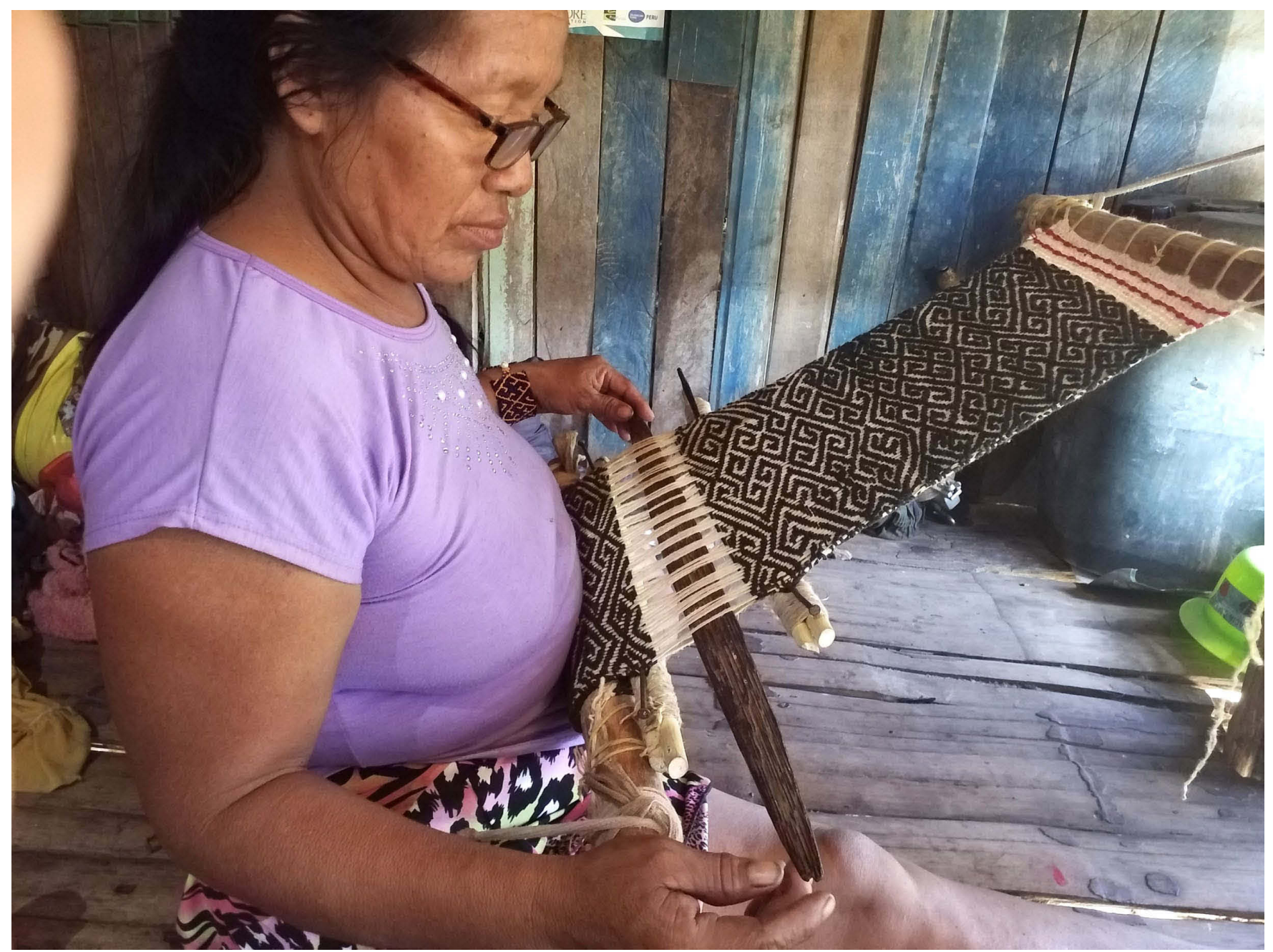

Foto 13 La información del diseño queda planteada a modo de espejo. Hilda Pinedo, CCNN Colombiana 2019. Foto: M.E. del Solar

tejido en la parte inferior, tantas veces como se considere conveniente y que el espacio libre lo permita.

Cuando se alcanza el eje de simetría, ya sin mayor espacio para introducir la espada, se continúa con el desarrollo del tejido mediante el empleo de una aguja, replicando el diseño hasta alcanzar la coincidencia adecuada.

La cantidad de varillas empleadas varía en función al diseño que se aplique, aunque en tejidos de mayor dimensión, particularmente en las hamacas, con diseños de mayor envergadura, se puede llegar hasta 100 varillas, señala la Sra. Hilda Pinedo de la CCNN Colombiana.

Se ha documentado la técnica de telar de 'varillas de memoria' con todas las tejedoras cashinahuá entrevistadas en el alto Purús y en el Curanja, así como en las poblaciones migrantes de los poblados de Puerto Esperanza y Pucallpa, por lo que consideramos el empleo de las varillas que retienen el diseño como un patrón común a esta cultura textil. Hay una racionalidad creativa en esta manera de tejer que representa una reducción importante del esfuerzo invertido con relación al tiempo de trabajo.

Encontramos este mismo sistema de trabajo pero con diferente propósito en otras zonas de Perú y América. Es similar entre las tejedoras yaminahua, ubicadas en la misma región, para la elaboración de hermosos brazaletes en fibra de chambira, en rústicos telares armados sobre ramas torcidas, conocidos como 'telares de arco'.12 (Foto 14) Es probable que toda la región de los ríos Curanja y Alto Purús presente similar procedimiento. ${ }^{13}$

\section{Agradezco la observación a Ann P. Rowe.}

13. Inclusive hacia el norte de la Amazonía peruana se tiene referencia de los tejidos matsés elaborados con la misma técnica, lo que permite plantear una distribución bastante más amplia, es probable que a nivel de tradición Amazónica, aún pendiente de documentar para enriquecer los estudios en la línea de trabajo iniciada. 


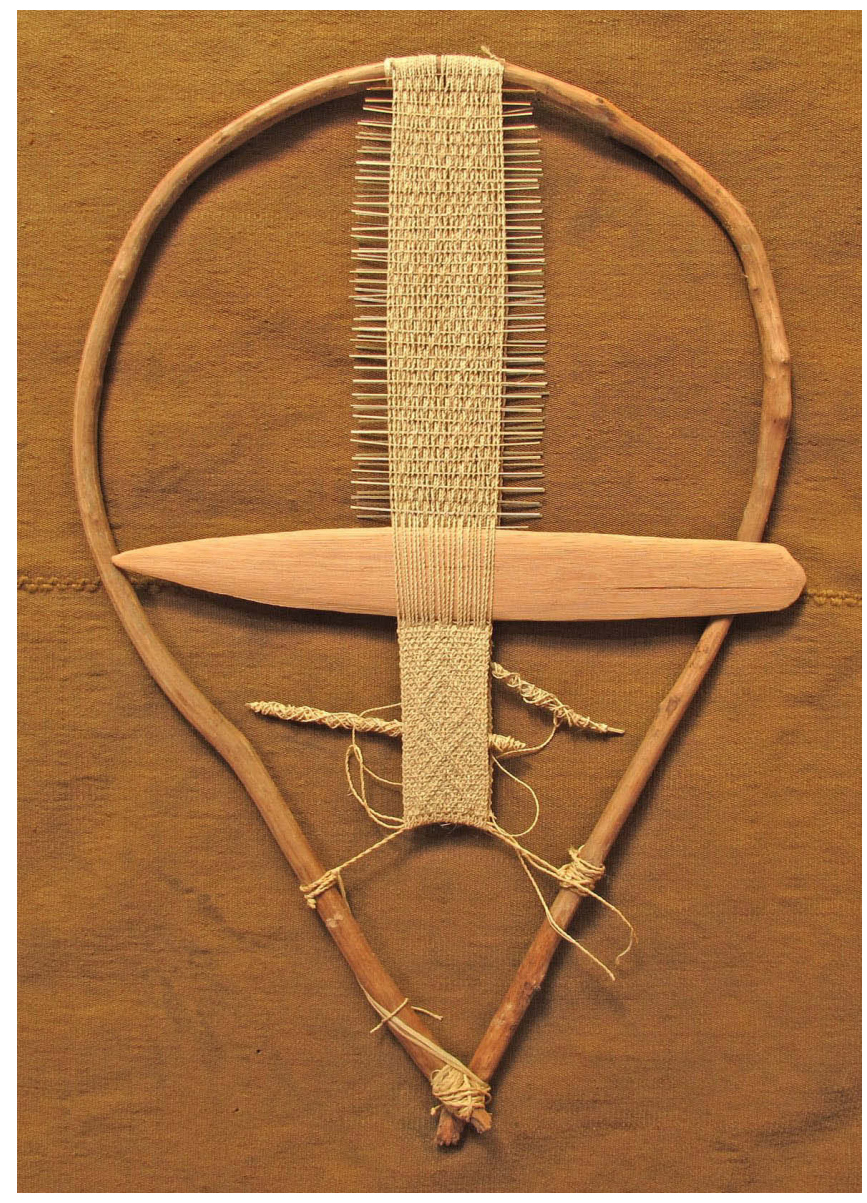

Foto 14 Pulsera de chambira en 'telar de arco'. Pueblo yaminahua, río Purús. Foto: M.E. del Solar

En el tejido de la bolsa en técnica sprang de las tejedoras Mosetene de Bolivia, los palillos memorizan el diseño temporalmente hasta la finalización de la obra en que las urdimbres quedan fijas por lo cerrado del tejido. (Foto 15)

Un sistema diferente se observa en el tejido de las fajas 'sara' en San Ignacio de Loyola, en la sierra norteña peruana. (Foto 16) Allá, las urdimbres se escogen y disponen sobre varillas destinadas a plantear el diseño, previo a la elaboración de los lizos o chuguays, que permiten repetir el diseño memorizando el número de veces que se quiera sin la necesidad de invertir más tiempo en el escogido. ${ }^{14}$ Por ejemplo, una faja de $395 \mathrm{~cm}$ de largo (área tejida), puede tener el mismo diseño repetido 61 veces. ${ }^{15}$

Los cashinahuá emplean estas varillas solamente para el tejido del cuerpo de las bolsas o de las bandas con diseño de las hamacas. En este último caso, el telar puede llevar

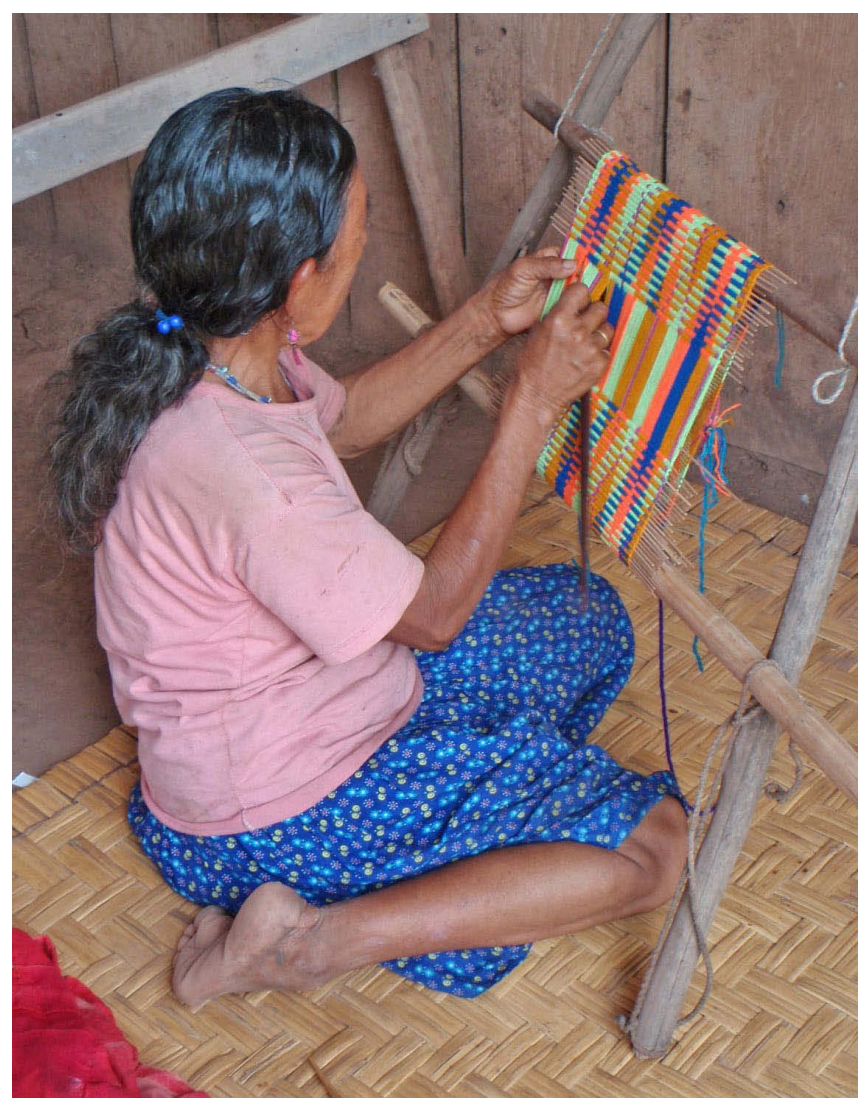

Foto 15 Bolsa, técnica sprang. Tejedora Mosetene. Tierras bajas. Bolivia. 2009. Foto: I. Daillant

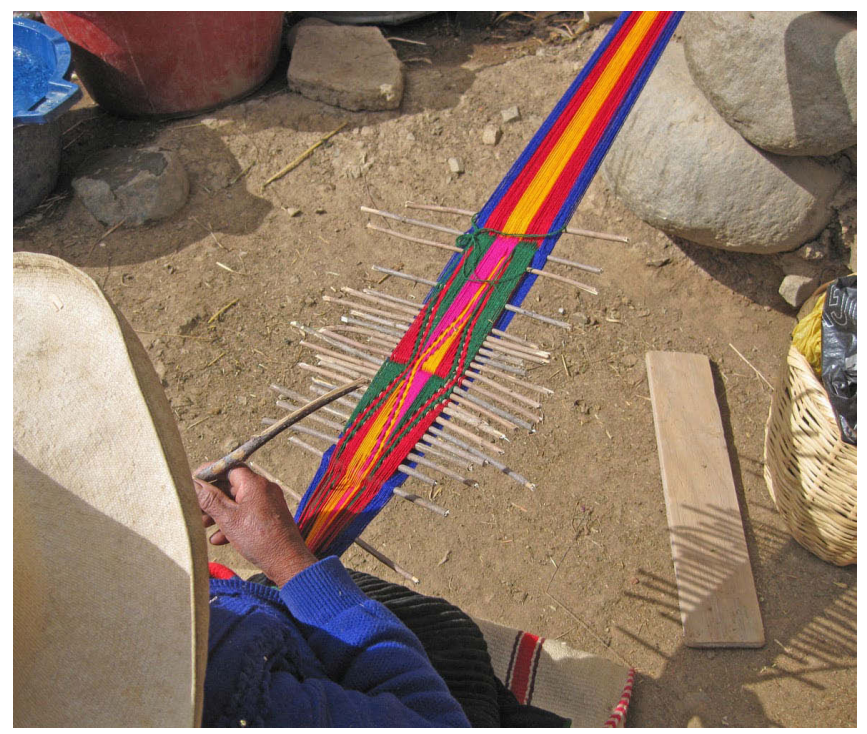

Foto 16 Faja sara. Proceso de montado de los lizos a partir del diseño levantado en las varillas. Sierra norte. La Libertad, 2012. Foto: S. Desrosiers

14. El tema ha concitado la atención de estudiosos como: Fernández 2007, 2014; Meisch 2006, 2007.

15. Se tuvo la oportunidad de apreciar en campo a la tejedora Filomena Escobal Dionicio comprobando la efectividad del sistema al realizar correcciones durante el proceso de preparación del apartado de las urdimbres, previo al tejido. 
tanto lizos como varillas, de acuerdo a su función diferenciada: ayudar en la producción de la estructura para los lizos o memorizar el diseño para las varillas.

\section{Los “tejidos verdaderos" de los cashinahua}

\section{Geometría simbólica e interpretación social:}

Uno de los mitos de origen de los cashinahuá narra que el grupo decide abandonar sus tierras en el centro del mundo en busca del metal para producir armas y herramientas necesarias para su subsistencia. Encuentran un gran río en su camino y un enorme caimán dormido, Kape, les sirve de puente para alcanzar la orilla opuesta a cambio de alimento. Todo el grupo no logra atravesar pues el caimán se enfurece al ver que han matado a su hermanito caimán, que le ofrecen como alimento. Los que logran atravesar el río van a una tierra buena y tendrán acceso al metal para adornos y herramientas; son los antepasados de los Incas y de los blancos, por lo tanto nawan, no indios, foráneos, mestizos. Aquellos que no lograron pasar regresan al centro del mundo, sin metal; son los antepasados de los indígenas, huni kuin, es decir personas verdaderas.

(Fuente: Deshayes y Keifenheim 2015)

Entonces, de esta manera, el kuin representa el punto de vista de los huni kuin, o del hombre verdadero, que es así como se llaman a sí mismos en la actualidad. De otro lado, kené significa diseño, escritura, gráfica, por tanto kené kuin va a representar entonces al diseño auténtico, propio. Así, el apelativo de 'tejidos verdaderos' se entiende asociado al diseño, kené, en contraposición al nawan kene, siendo nawan principalmente, un gentilicio empleado para denominar al 'otro', al 'foráneo', al mestizo, al 'no-pariente'. Por tanto es una voz empleada para señalar los tejidos ajenos, los tejidos no reconocidos como propios. (Foto 17)

El tejido cashinahuá se diferencia notablemente de otras expresiones textiles contemporáneas de la Amazonía peruana por la complejidad de sus técnicas y el carácter de sus diseños. El kené es un patrón decorativo esencialmente gráfico que se aplica a la cerámica, la cestería, la pintura corporal y los tejidos, común a los grupos pertenecientes a la familia pano, nos referimos especialmente a los diseños que distinguen a los shipibo-conibo del Ucayali y a los cashinahuá de las cabeceras de los ríos Purús y Curanja. Aunque, se observa una marcada diferencia en el tratamiento técnico contemporáneo de ambas interpretaciones del kené

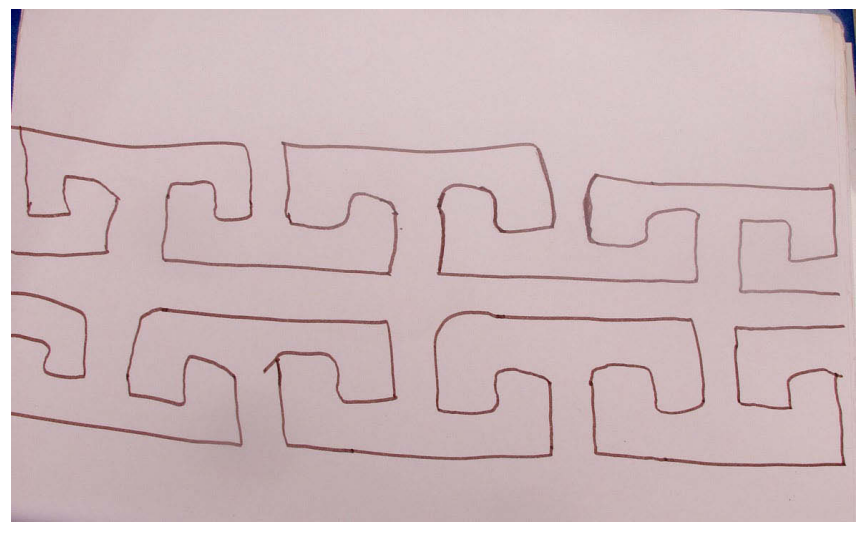

Foto 17 Dibujo de nawan kene. Eliana Torres Montes, CCNN Conta 2018. Foto: M.E. del Solar

en los tejidos de ambos grupos. En el primer caso, se destaca la complejidad del kené shipibo-conibo, pintado o bordado sobre la superficie de la tela - tela industrial de tocuyo o cañamazo, o, con una presencia cada vez más reducida, confeccionada en telar de cintura - , con respecto del segundo caso, la modalidad cashinahuá, que consiste en la ejecución del kené mientras se construye la tela, como parte de su estructura, es decir se diseña al mismo tiempo que se teje.

Sea cual fuere el soporte material, cerámica, cestería, tejidos de algodón o el cuerpo humano, el kené cashinahuá es un arte practicado exclusivamente por mujeres, aunque los objetos puedan ser empleados por toda la comunidad. La estudiosa Luisa Elvira Belaunde (2009:18) observa que en las dos últimas décadas algunos hombres shipibo-conibo han aprendido a pintar y bordar diseños kené debido a la demanda de un mercado creciente.

En la misma fuente, Belaunde (2009:22), explica que la finalidad del kené shipibo-conibo es estética y terapéutica, embellece a las personas y las cosas con los grafismos de la energía de las plantas. También las cura de males de origen físico, psicológico, social y espiritual, tanto en cuanto a la materialidad de los diseños sobre los cuerpos como en la visión inmaterial de los diseños durante las sesiones chamánicas con ayahuasca. Al respecto señala Els Lagrou (2009:90), la función del diseño cashinahuá sería la de distinguirlos de sus vecinos marcando su especificidad estética.

El diseño funciona como una metáfora, señala Lagrou (2009) para los cashinahuá de Brasil; es decir, traza caminos entre mundos separados o entre lados complementarios del mismo mundo, así como entre los estados complementarios del ser o de la conciencia humana. Los diseños son vistos en estado de vigilia y en los sueños. Concordamos con lo que subraya Lagrou (2009:87), en donde el arte gráfico aplicado en la decoración corporal sirve para señalar una relación entre el mundo de los humanos y el mundo de 
los espíritus. Podemos aplicar la misma noción, destacada por las tejedoras de la zona de estudio cuando explican los diseños textiles en relación a la importancia del conjuro, es decir, a la necesidad de recordar a los espíritus fuertes del bosque invocando su protección.

La iconografía de los grupos que habitaron en la región del alto Purús y alto Curanja debió nutrirse sin duda de fuentes muy diversas, como diverso es su territorio, en amplitud y en recursos de flora y fauna, así como variadas fueron las actividades desarrolladas por el hombre para resolver su subsistencia hasta el día de hoy. Todo ello deja una impronta en el modo de vida de las sociedades, que va a plasmarse a nivel simbólico en su cultura material, expresando al mundo que los rodea. Figuras y diseños similares se repiten en los textiles kené, en la decoración de la cerámica y en la pintura corporal, con ligeras variaciones estilísticas o debidas al grado de habilidad de las tejedoras. Su interpretación sufre modificaciones o las nomenclaturas se han perdido en el tiempo. En otros casos, la tejedora describe puntualmente la imagen sugerida por el grafismo textil pero no la reconoce por un nombre dado.

La representación de ideas propias de la sociedad que las origina se puede asociar igualmente a mitos de origen, tal es el caso de la presencia de caminos (sepi) en el mito mencionado anteriormente, tanto en la imagen textil como en el apelativo y sus variantes, especialmente en el caso de los morrales. Aquellos hombres y mujeres cashinahuá que consiguen atravesar el río van a conforman el conglomerado del apelativo mestizo, nawan, que incluye a los no parientes, los ajenos y hasta a los Incas. Los hombres y mujeres que no alcanzan atravesar regresan al mundo de sus antepasados, son huni kuin, es decir 'hombres verdaderos'. De allí la importancia de los caminos para la identidad huni kuin. Los caminos que conducen a través de la selva a la lupuna, dice otro mito, árbol de gran tamaño, xunu, sembrado y cuidado celosamente por el Inka, y cargado de bellas cuentas coloridas. ${ }^{16}$ (Foto 18 )

El mundo que les rodea está especialmente representado en su iconografía textil, es decir la densidad del bosque en las diversas capas y texturas del tejido, la vegetación exuberante y profusa en la representación recargada de diseños sin descanso de los morrales, a modo de 'horror al vacío'. El estilo geométrico-abstracto desarrollado en el arte textil cashinahuá guarda diseños que son explicados por las tejedoras como: cabeza o espalda de mantona, cola de lagarto, costado de boa, ramas de árbol de lupuna, semillas, hojas de palmera, escamas de pez, etc., llevados a un extraordinario nivel de estilización, que a la vez permite reconocer,

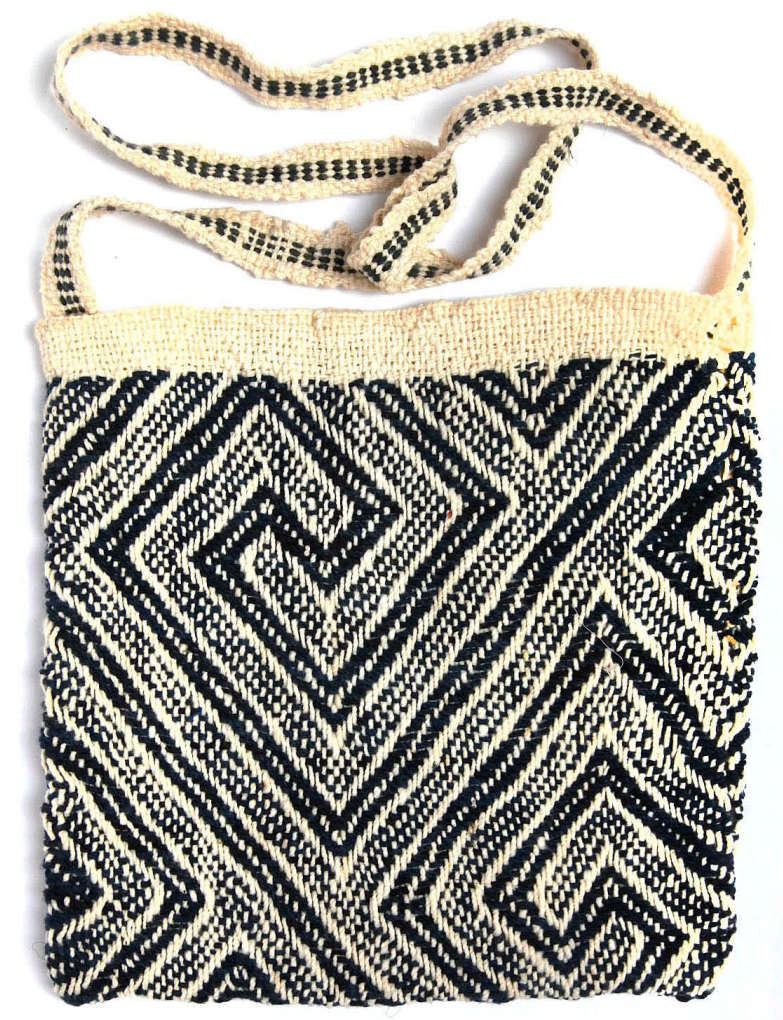

Foto 18 Morral con diseño de ramas de lupuna, xunu kené. Amerika Comapa, CCNN San Martín 2019. Foto: B. Hare

en una primera mirada, las formas aludidas y representadas, además del estilo particular de la decoración de esta cultura. Son las formas de la naturaleza, del medio que las rodea y que hacen parte fundamental de su modo de vida. (Foto 19 y 20)

No hemos encontrado indicios de renovación o de innovación de los diseños, aparentemente todo el repertorio forma parte del lenguaje textil tradicional -con algunas variantes comunes a todo el grupo cashinahuá, incluyendo a los parientes brasileros- heredado de madres y abuelas. Más adelante, se podrá observar en el registro de nombres una diversidad de apelativos diversos para el mismo diseño ${ }^{17}$, o por lo general una pequeña diferencia que poco varía el sentido de la designación. Por ejemplo, tenemos: bashu xaka, pescadito de tawampa o traducido igualmente como escama de shiruy o, para un mismo morral, dunu mapu (cabeza de culebra) y dunu kate (espalda de culebra); también, ojos de lorito u ojos de lorito 'apiñados', para designar al mismo gráfico. Otro diseño fue señalado diferenciadamente como xenpan pei (palmera shapaja) y como xena hexe (semilla de shimbillo), aunque ambos nombres hacen referencia a la flora local. 


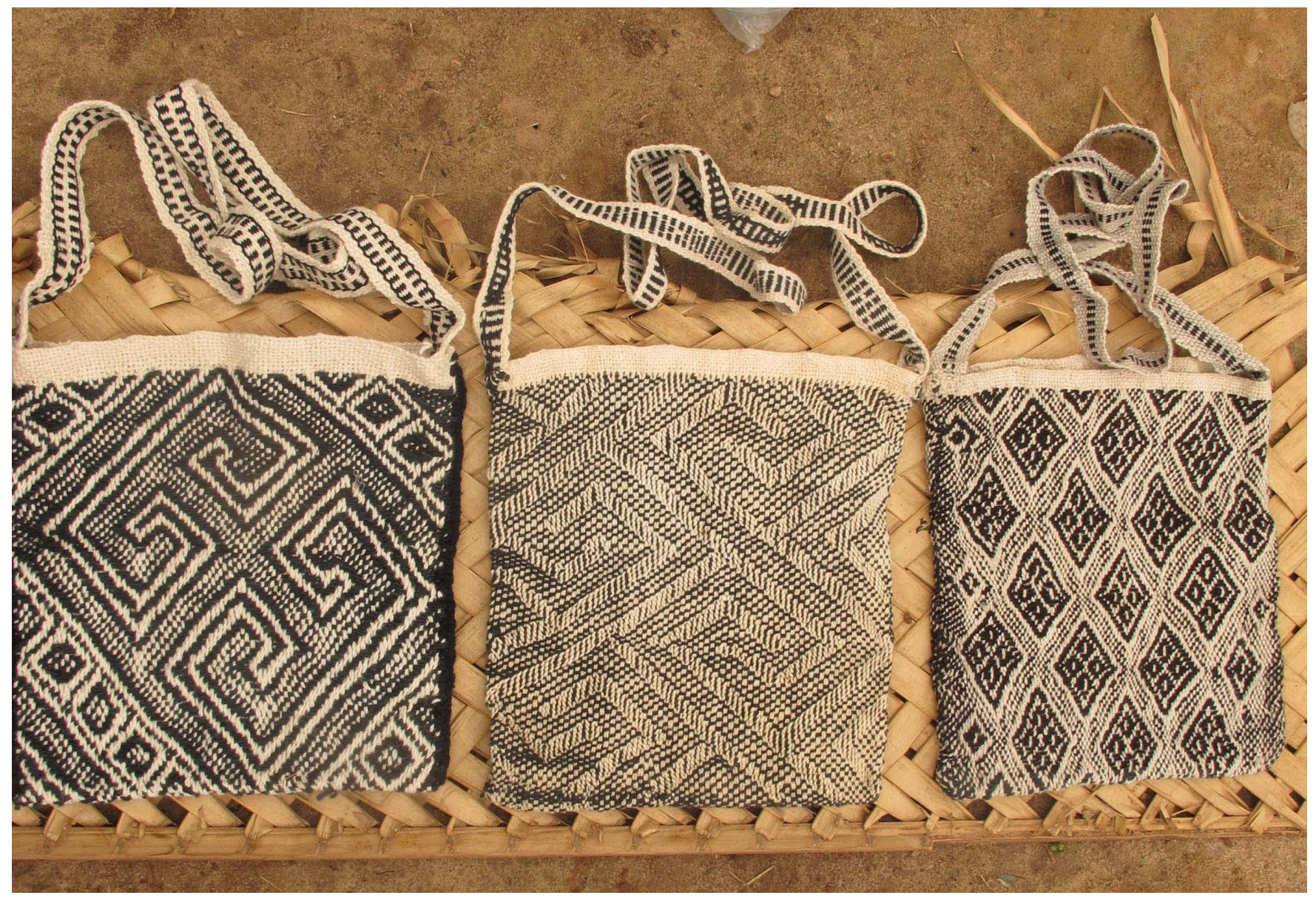

Foto 19 Diseños, de izq. a der.: a) xunu kene, rama de lupuna; b) umin kene, diseño torcido; c) inutai txede bedu, pisada de tigre en ojo de loro. Doris Salomón, Nueva Esperanza 2018. Foto: M.E. del Solar

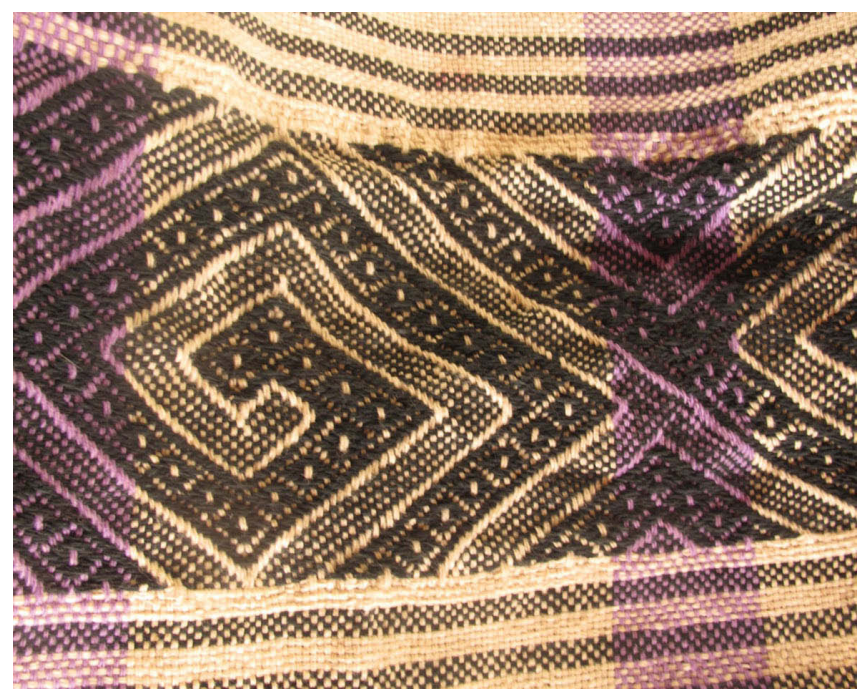

Foto 20 Detalle de hamaca con un diseño nibu hina, rabo de escorpión. María Castillo, CCNN Conta 2018. Foto: M.E. del Solar
Los diseños presentan múltiples variantes que consideran inversiones o transposiciones, redundancias o sobre repetición en las líneas dobles, triples y más, que remarcan el motivo destacado -sobre la base de los mismos diseños básicos-, una geometría en movimiento, vibrante, que, desde nuestra mirada occidental, puede confundir la comprensión del kené. Llama especialmente la atención la composición de los diseños en secciones de la prenda, en donde se muestran porciones ampliadas o parciales del mismo que producen impresiones visuales diversas (Dawson 1975:137), en una aparente asimetría enfatizada por las líneas diagonales del dibujo.

Lagrou (1990:93) observa el cambio de perspectiva entre fondo y figura de los patrones laberínticos de la cestería de otras sociedades amazónicas, que podemos extender igualmente a los tejidos cashinahuá. Al respecto señala Alice Dawson (1975:146), que el empleo de los aspectos positivo y negativo de un diseño (en la textilería) sería otra razón para sugerir que estas formas (en la cerámica) han sido por lo menos influenciadas por prácticas de tejido, si es que no han sido originadas por ellas. ${ }^{18}$ 


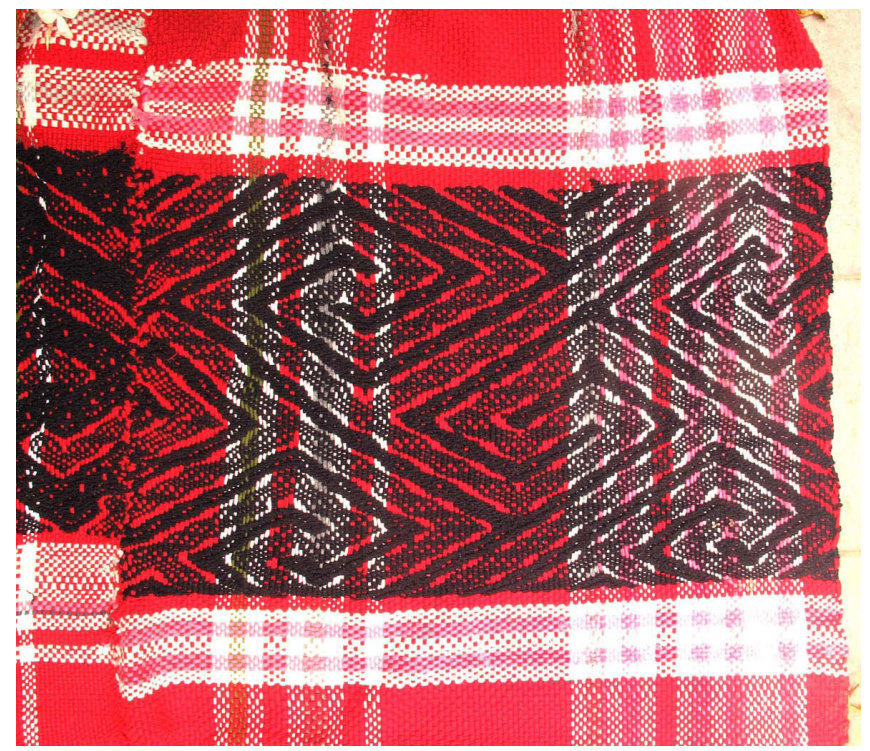

Foto 21 Detalle donde se observa el efecto de asimetría y el diseño incompleto o cortado en la sección decorada de una hamaca del Purús. Es una constante en la decoración cashinahuá. Material sintético. CCNN Conta 2018. Foto: M.E. del Solar

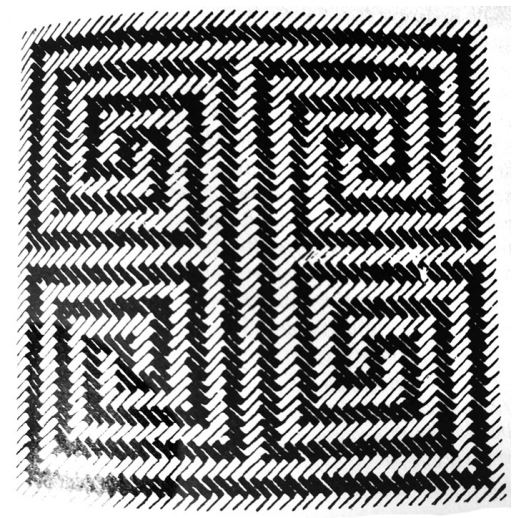

Foto 22 Detalle de diseño awidi, serpiente coralillo, en canasta asargada. Yekuana, Guyanas. En: D. Guss (1989: 107)

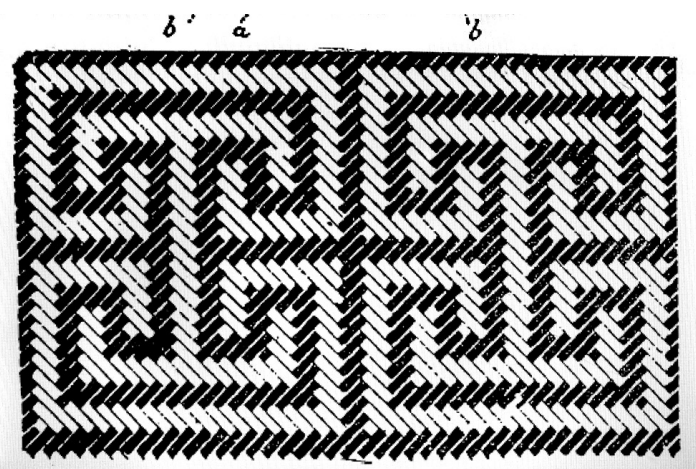

Foto 23 Diseño ‘hueso del diablo’ en canasta asargada (ver Foto17). En: D. Guss (1989:106)

18. Original en inglés, traducción propia.

19. Sophie Desrosiers, comunicación personal, setiembre 2019.
La direccionalidad de las líneas diagonales del kené está determinada por la técnica de sarga aplicada en las secciones con diseño, que limitan el grafismo a un grado de inclinación preciso, con pocas alternativas de juego. (Foto 21) Un argumento que amerita mayor profundización se refiere a la existencia de diseños muy similares provenientes de otras zonas de la Amazonía lo cual nos plantea algunas preguntas que remiten a las condiciones de movilidad de los grupos -y también de los objetos- a la circulación de bienes y de personas, inclusive pertenecientes a diversas familias étnicas.

Vemos la aplicación de la misma técnica de sarga en el tejido de canastas, tradicional a muchos grupos de tierras bajas tropicales, las mismas que presentan entonces similar contrapunto de colores y direccionalidad diagonal en los diseños, determinados por la técnica constructiva. Esta argumentación, podría apoyar el planteamiento de que la confección de tejidos habría posiblemente derivado de la práctica del manejo de fibras vegetales semiduras. ${ }^{19}$ Es muy común el empleo de la sarga en la cestería, en la cual el diseño está involucrado en la misma construcción de la estructura. (Fotos 22, 23, 24 y 25)

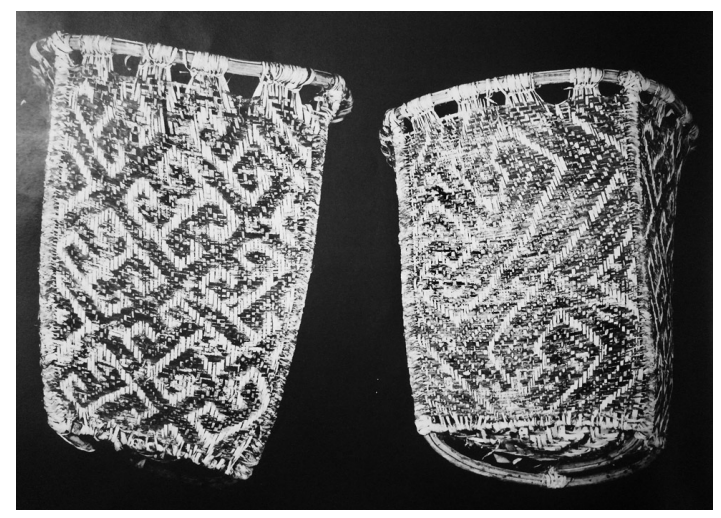

Foto 24 Canasta cashinahuá con técnica asargada en fibra teñida y natural. Izq. Diseño de ganchos en un lado de la canasta, kuki. Der. Diseño en tres lados de la misma canasta. En: Dawson (1975:136)

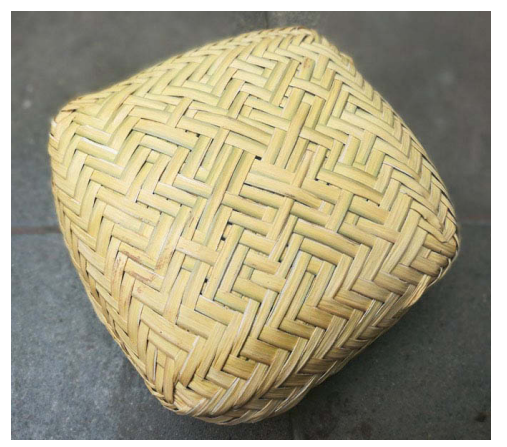

Foto 25 Base de canasta cashinahuá contemporánea tejida con técnica asargada en fibra de palma, shapaja. Doris Salomón, CCNN San Martín 2018. Foto: M.E. del Solar 
Si bien se ha identificado algunas piezas textiles con diseños que cubren toda la superficie de la prenda, como es el caso de algunas hamacas y faldas (Fotos 1 y 26), Dawson (1975:142), señala, específicamente para las hamacas, la elección de un diseño básico, que puede ser agrandado, reducido o cortado arbitrariamente en secciones que adquieren el aspecto de 'ventanas' a través de las cuales se muestra la porción de un diseño que podría ser infinito. (Foto 27) Para Lagrou (1990:59), el patrón de diseño recortado justamente en el punto cuando es posible reconocerlo, requiere de capacidad imaginativa para percibir la continuación del patrón mediante una visión mental y constituye una de las características estilísticas más saltantes del tejido cashinahuá. (Foto 28)
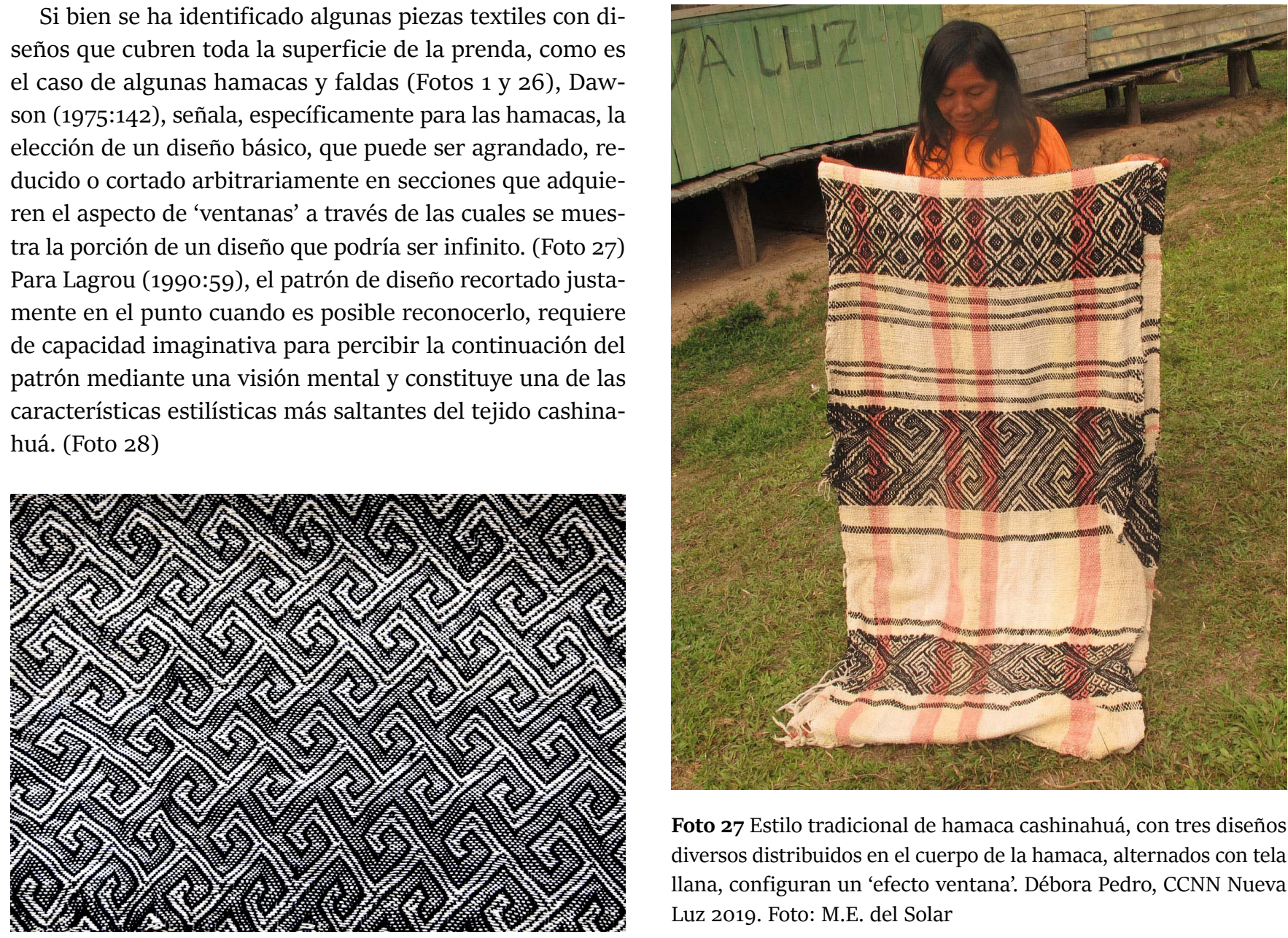

Foto 27 Estilo tradicional de hamaca cashinahuá, con tres diseños diversos distribuidos en el cuerpo de la hamaca, alternados con tela llana, configuran un 'efecto ventana'. Débora Pedro, CCNN Nueva Luz 2019. Foto: M.E. del Solar

Foto 26 Falda tejida en telar de urdimbres contínuas con diseño mae muxa, uña de gato, en toda la superficie de la prenda. Florinda Montes, CCNN Conta 2018. Foto: B. Hare

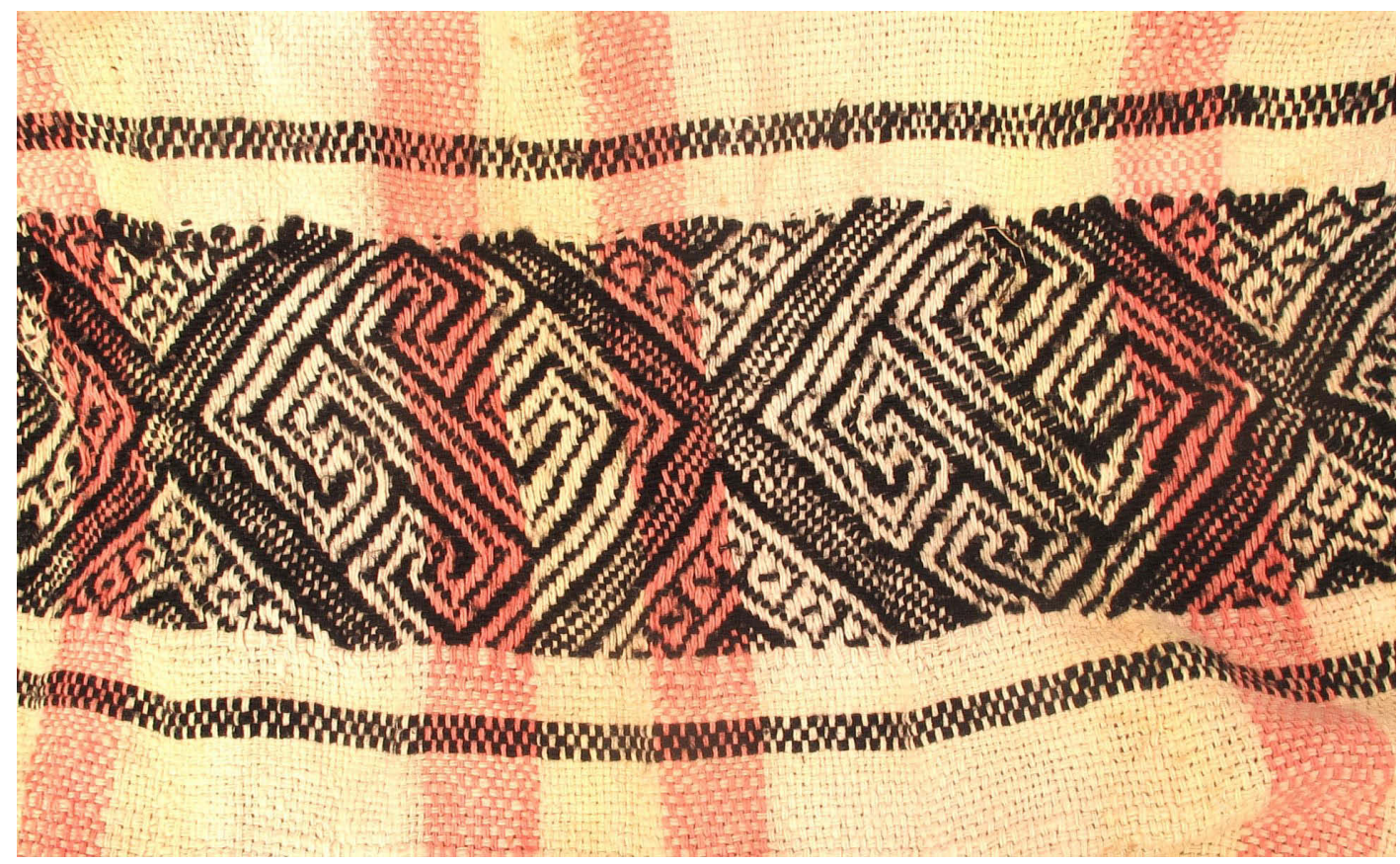

Foto 28 Detalle de anterior, diseño macaco kené. Foto: M.E. del Solar 


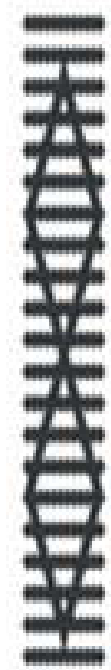

Kaxau jina, cola de guacamayo

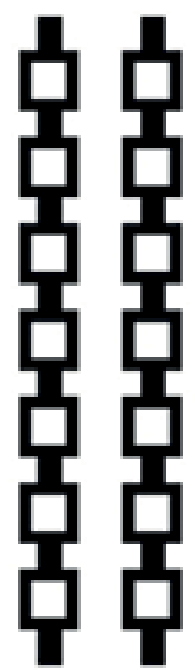

Xena dabe, dos gusanos

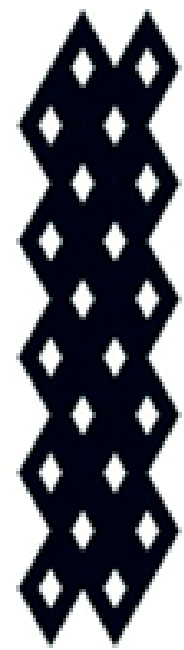

Xapu bexe, pepita de algodón

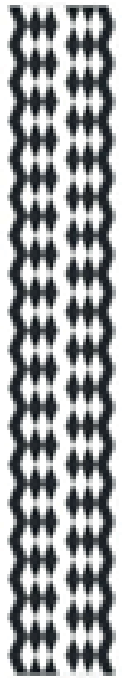

Kaman betu, frente de perro

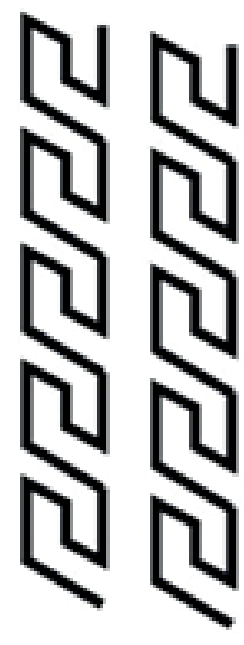

Kape hina, cola de caimán
Las asas de los morrales suelen presentar un patrón de cara de urdimbre que determina en sí mismo un tejido más compacto, resistente y adecuado a su función, lo mismo que una diversidad en los diseños como se observa en algunos ejemplos presentados en la Lámina 3.

Los diseños de la textilería cashinahuá presentan una dirección diagonal debido básicamente al empleo de la técnica sarga en donde el tipo de ligamento determina el alineamiento de los hilos, de trama y de urdimbre, por tanto de la visibilidad equilibrada de ambos elementos a lo largo del tejido. Sin embargo, el patrón de diseño de rombos, continuos o discontinuos, se encuentra organizado, por lo general, en dirección vertical a pesar del alineamiento diagonal del diseño.

En este sentido, podemos señalar dos patrones iconográficos significativos en la decoración aplicada al arte textil:

A. Patrón en rombo, donde se observan los rombos en una serie de combinaciones y secuencias, conectados o libres, rellenos o limpios, en secuencias alternas o continuas, dando forma a una gráfica compleja que vincula al universo natural (aves, felinos, ofidios), donde destaca el diseño ojo de lorito, txede bedu, circundado de caminos, sepi. La secuencia de los diseños más evidentes sigue una orientación vertical por lo general aunque también se observan desarrollos con tendencia diagonal. (Foto 29)

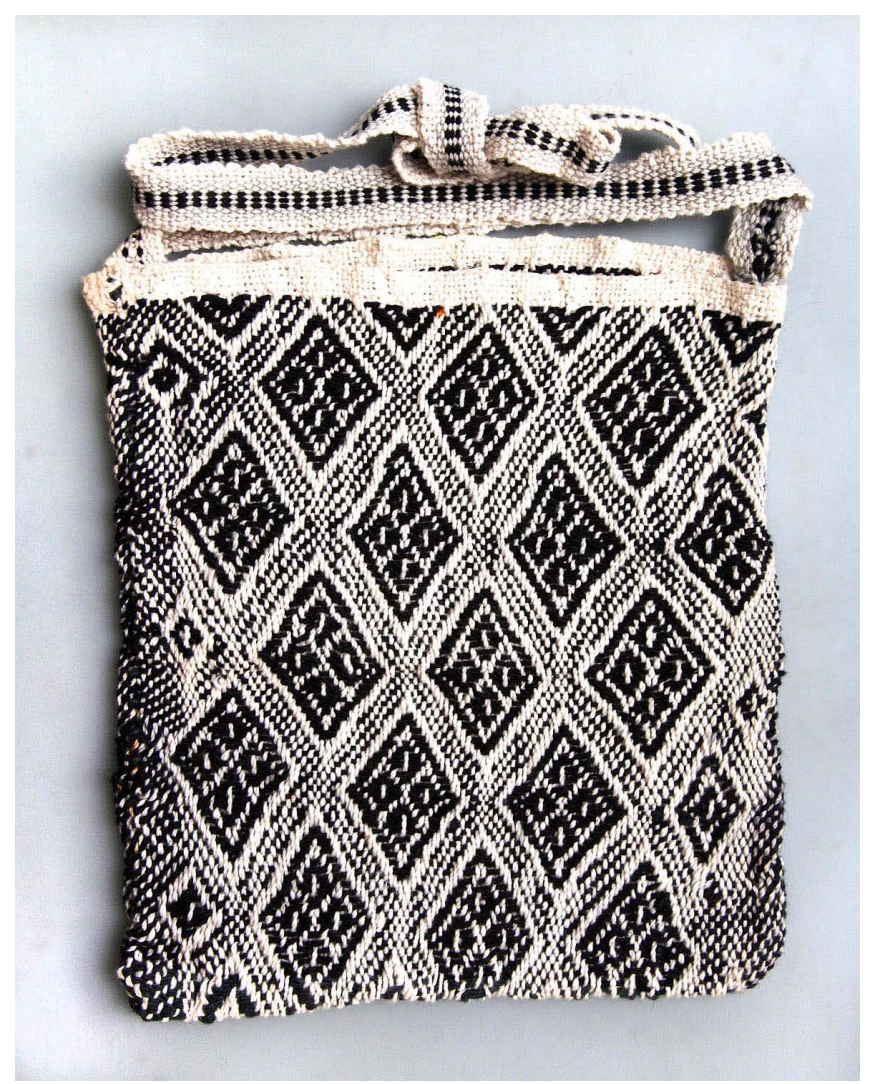

Foto 29 Morral. Patrón en rombo. Diseño inutai txede bedu, pisada de tigre con ojo de lorito. Río Kuranja 2019. Foto: B. Hare 


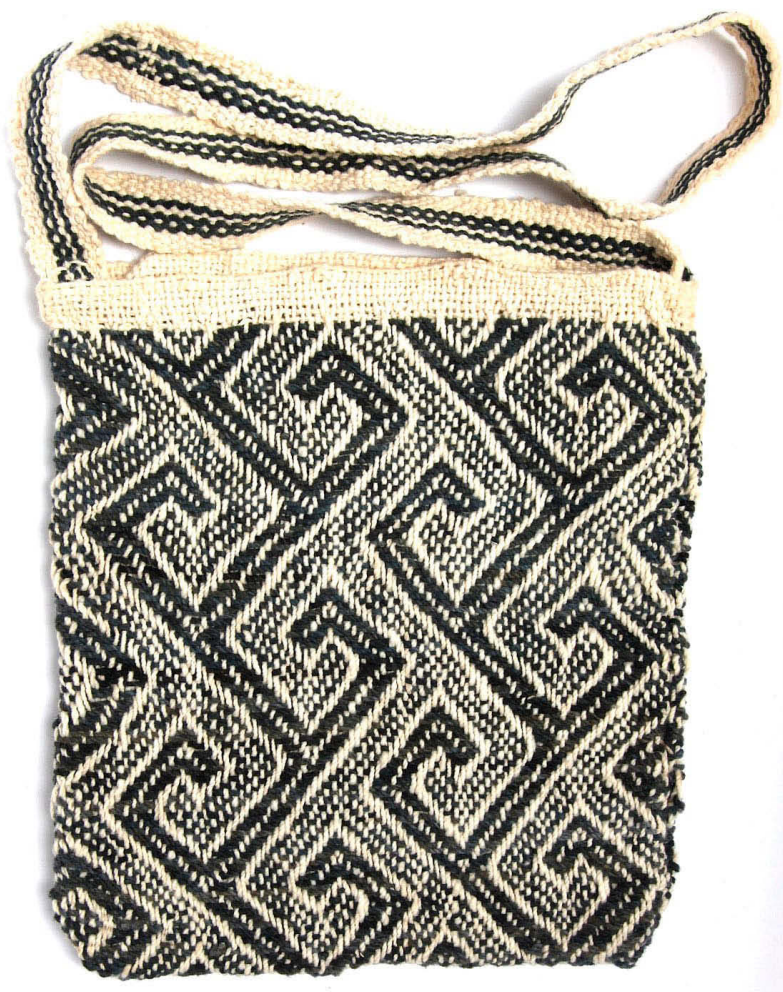

Foto 30 Morral. Patrón diagonal. Diseño mae muxa, uña de gato. Río Kuranja 2019. Foto: B. Hare

B. Patrón diagonal, asociado a un desarrollo diagonal de líneas continuas o quebradas, dobles o simples, que dibujan ganchos, en una suerte de 'interlocking', de rectángulos dobles abiertos en gancho o en la representación de formas vegetales paralelas, que delimitan espacios que igualmente refieren a caminos, sepi. La orientación de los diseños sigue una orientación diagonal. (Foto 30)

La relación de nomenclaturas asignadas a los diseños es vasta en tanto refiere a diversas modalidades de combinación de los elementos iconográficos y varía de acuerdo a la comunidad de origen y a la familia tejedora, pero siempre es posible encontrar el acuerdo entre las tejedoras después de un intercambio de opiniones frente al tejido.

Se puede concluir que el empleo repetido del nombre txede bedu (ojos de lorito) está haciendo referencia, además, a la figura del rombo, base de muchos diseños por lo que, por lo general, forma parte del apelativo compuesto. Entonces, inutai txede bedu podría entenderse como: pisada de tigre en rombo. También se entiende que dunu kate, buisan kate, dunu mapu, dunu mapu istutu o dunu hina dubu -espalda, cabeza y cola de culebra, mantona o boa- designan indistintamente a diseños diversos que aluden al peligroso ofidio que amenaza la vida de los pobladores, especialmente la de los cazadores, en un riesgo constante. Recordemos que los cashinahuá se dedican mayoritariamente a la caza, por lo que es posible que la aplicación de este diseño en los morrales de los cazadores pueda estar asociado a una suerte de conjuro o protección del portador.

El diseño sepi, camino, aparece frecuentemente alinderando o delimitando rombos, con mayor o menor ancho: bai besti (un camino), sepi baijaku (camino grande), sepi huku narunia (allí todos los caminos juntos), o complejidad: sepi natxu daniea (caminos apilados), sepi mepashkara (camino cortado o que se bifurca). Junto con los rombos, son las figuras que más importancia presentan para la conformación de diseños variados, además de ser especialmente significativas para la identidad huni kuin -visibilizadas en el mito de origen señalado antes- en los desplazamientos físicos por las trochas de la selva, o en los viajes del alma durante las sesiones de ayahuasca.

En la esfera ritual, una serie de ceremonias deben de garantizar el aprendizaje, la habilidad y una memoria acuciosa para recordar el variado repertorio de diseños en uso de la familia. Es frecuente que hasta la fecha se pinte a las niñas pequeñas en la cara algunos diseños con tinta de huito o de achiote, como xapu bexe, algodón amarrado, para transmitir de esta manera el conocimiento del arte del lenguaje de los diseños como parte del ritual de iniciación, mientras se cantan canciones alusivas a cada tipo de diseño. La maestra entrega a la niña, que puede o no ser su pariente, su sabiduría a través de los diseños pintados. En el mismo sentido y como parte de los ritos de pasaje que se observan en el ambito de las comunidades nativas, la tejedora maestra suele echar gotas de bawi (planta medicinal) en los ojos de las tejedoras más jóvenes o niñas, para aprender a dominar las técnicas, para no olvidar los diseños, y para saber resolver problemas con inteligencia y llegar a vivir con sabiduría. Esta ceremonia se puede repetir tantas veces como se desee, inclusive hasta la edad adulta, dando cuenta, así, de la importancia del embellecimiento de las personas y de los objetos para lo cual es fundamental su conservación como marcadores étnicos. (Foto 28) ${ }^{20}$

20. Durante mi estadía en las comunidades, mi interés y preguntas sobre técnicas y diseños textiles, propició el ofrecimiento de las gotas de bawi para facilitar mi aprendizaje del tejido. 


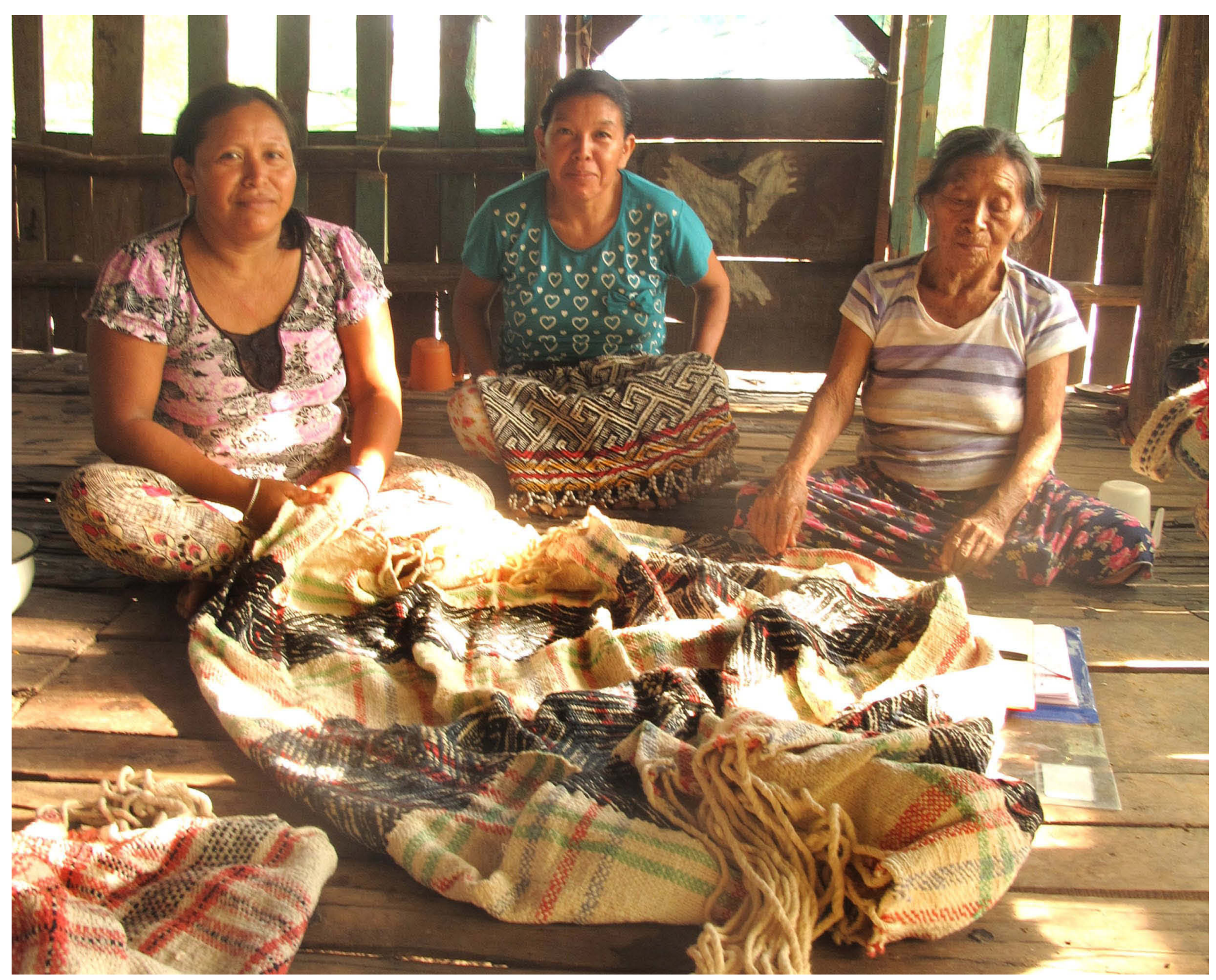

Foto 31 Izq. a der. Girma Bardales, María Nacimiento y Lucía Cumapa. CCNN San Martín 2019. Foto: M.E. del Solar.

El aprecio por un buen tejido considera por sobre todo que este sea parejo, en la tensión y calidad del hilo, nos dice gráficamente la maestra huni kuin Francisca Bardales, todo igualito bien derechito, otro no importa. Al respecto recoge Helen Tanner (1975:123) la admiración de las tejedoras por alguna de ellas mismas que pueda crear diseños complejos y, especialmente, por aquellos tejidos monócromos en donde el diseño es poco visible pero está presente en el objeto. ${ }^{21}$ La falta de simetría en el color y en el diseño, señala la misma fuente, no resta en absoluto a la calidad visual de los tejidos cashinahuá, es necesario rescatar el sentimiento de las propias tejedoras "lo bello no es completamente simétrico nunca”. ${ }^{22}$ (Foto 31)

\section{Agradecimientos}

Quiero agradecer muy especialmente a las maestras tejedoras entrevistadas en las comunidades nativas de Conta y San Martín, en el alto Purús, y de Nueva Luz y Colombiana, en el río Curanja, que compartieron de una manera tan generosa sus conocimientos conmigo, durante las temporadas de campo en los meses de julio y octubre-noviembre 2018 y enero-febrero 2019.

A los integrantes de las instituciones ProPurús, Parque Nacional Alto Purús y EcoPurús, quienes contribuyeron de muchas maneras a resolver mi estadía en la zona. También mi reconocimiento a Maribel Medina por su apoyo de

21. No fue posible conseguir ninguna muestra de este tipo a pesar que varias tejedoras manifestaron conocer ese estilo perfectamente. 22. Traducción personal. 
siempre y a Delia Aponte por su paciencia en la elaboración de los dibujos que acompañan este trabajo. A Isabelle Daillant por el préstamo de la imagen de la tejedora Mosetene.

Mi agradecimiento a Ann H. Peters y Lena Bjerregaard por haber asumido la responsabilidad editorial de este y todos los ensayos presentados en la Conferencia sobre Textiles Precolombinos en Bruselas 2019.

Por último, mi gratitud a Sophie Desrosiers por su inagotable disposición a compartir sus conocimientos y orientar mis interrogantes de la manera más generosa.

Y a Billy por apoyar y compartir mis sueños.

\section{Referencias citadas:}

AGÜERO, Carolina. 2015. Vestuario y sociedad andina. Desarrollo del Complejo Pica-Tarapacá (80o - 140o DC). QILLQA. Universidad Católica del Norte. Santiago: Ocho Libros Editores.

BARCLAY, Frederica. 2009. Análisis de situación de salud de la provincia de Purús, Ucayali. Serie Análisis de Situación de Salud y Tendencias. PERÚ/MINSA/DGE. (Informe versión digital)

BELAUNDE, Luisa E. 2009. Kené. Arte, ciencia y tradición en diseño. Lima: Instituto Nacional de Cultura.

DAWSON, Alice. 1975. Graphic Art and Design of the Cashinahua. En: The Cashinahua of Eastern Peru. (J. P. Dwyer ed.). Studies in Anthropology and Material Culture. Vol One. The Haffenreffer Museum of Anthropology. Brown University.

DESHAYES, P. y B. KEIFENHEIM. 2015. Pensar el otro. Entre los Huni Kuin de la Amazonía peruana. Lima: Instituto Francés de Estudios Andinos.

DESROSIERS, Sophie. 1992. Las técnicas del tejido ¿tienen un sentido? Una propuesta de lectura de los tejidos andinos. En: Revista andina. Año 10, No 1. Cusco: Centro Bartolomé de las Casas.
FERNÁNDEZ, Arabel. 2014. Fajas sara y pata de San Ignacio de Loyola, Patrimonio Cultural del Perú. En: Patrimonio del Perú. Humanidad Andina. C. Galvez y A. Rocchietti (Comp). Córdoba: Editorial Universitaria Villa María - Dirección Regional de Cultura, La Libertad.

2007. El anaku, la lliklla y las fajas sara y pata: supervivencias Inca en la comunidad de San Ignacio de Loyola, Sinsicap - Otuzco. En: La Trama y la Urdimbre. Textiles tradicionales del Perú. Lima: Universidad Ricardo Palma - Instituto Cultural Peruano Norteamericano.

KENSINGER, Kenneth M. 1998. Los cashinahua. En: Guia Etnográfica de la Alta Amazonía. Vol III. Santos Granero y Barclay (edit). Lima: Instituto Francés de Estudios Andinos.

1975. Studying the Cashinahua. En: The Cashinahua of Eastern Peru. (J. P. Dwyer ed.). Studies in Anthropology and Material Culture. Vol One. The Haffenreffer Museum of Anthropology. Brown University.

LAGROU, Els. 2009. Arte indígena no Brasil. Agencia, alteridade e relacao. Belo Horizonte: Editora C/ Arte.

MEISCH, Lynn A. 2007. Fajas sara: Supervivencia de una tradición textil inca en el norte del Perú. En: La Trama y la Urdimbre. Textiles tradicionales del Perú. Lima: Universidad Ricardo Palma - Instituto Cultural Peruano Norteamericano. 2006. Messages from the Past: An Unbroken Inca Weaving Tradition in Northern Peru. Textile Society of America Symposium Proceedings. Http://digitalcommons. unl.edu/tsaconf/345

RENARD-CASEVITZ, F.M. et al. 1988. Al Este de los Andes. Tomo I. Lima: Instituto Francés de Estudios Andinos.

TANNER, Helen. 1975. Cashinahua Weaving. En: The Cashinahua of Eastern Peru. (J.P. Dwyer ed.). Studies in Anthropology and Material Culture. Vol One. The Haffenreffer Museum of Anthropology. Brown University. 
Contents: Introduction - Lena Bjerregaard and Ann Peters - Mexico - 1. Mesoamerican Archaeological Textiles: An Overview of Materials, Techniques, and Contexts - Laura Filloy Nadal - 2. Urdimbres enlazadas de Mesoamérica. Textil de la Cueva del Gallo, Morelos, México - Patricia Ochoa Castillo \& Rosa Lorena Román Torres • 3. Los textiles procedentes del actual estado de Guerrero, México: una revisión a su estudio desde la perspectiva arqueológica y etnohistórica - Elizabeth Jiménez García - 4. Classic Textiles from Cueva del Lazo (Chiapas, Mexico). Archaeological context and conservation issues - Davide Domenici \& Gloria Martha Sánchez Valenzuela • 5. Textiles y otros materiales arqueológicos del valle de Tehuacán, México, en los Museos reales de Arte e Historia (MRAH), Bruselas - Julia Montoya $\cdot 6$. The World on a Whorl: Considerations on Aztec Spindle Whorl Iconography - Jesper Nielsen • 7. Mexica Textiles: Archaeological Remains from the Sacred Precincts of Tenochtitlan and Tlatelolco - Leonardo López Luján \& Salvador Guilliem Arroyo • Peru • 8. Andean Textile Traditions: Material Knowledge and Culture, Part 1 - Elena Phipps - 9. Introduction into the history of the textile collection at the Ethnological Museum Berlin Beatrix Hoffmann • 10. Archaeological Textiles of Sechín Bajo - a formative Site of the North Coast of Peru: Preliminarily Results - Katalin Nagy - 11. Headdress forms in the Paracas Necrópolis Mortuary Tradition - Ann H. Peters - 12. Nasca Textiles of south Peru, Los Molinos, Sector B. Analysis and Insights - Dr.

Daniela Biermann - 13. Pre-Columbian Textile Structures at Castillo de Huarmey, Peru - Aleksandra Laszczka, Jeffrey C. Splitstoser, \& Miłosz Giersz - 14. The curious case of Sir Henry Wellcome's wooden statuette clad in tie-dyed Wari cloth - Penelope Dransart 15 . Tocados del Horizonte Medio al Intermedio Tardío en la costa central: Una visión desde el valle de Asia, Perú (Siglos VII-XII d.C.) - Rommel Angeles Falcón • 16. Hallazgo de una Ofrenda Textil con material Horizonte Tardío e Inca Local en el valle medio de Pisco - Luis Peña Callirgos • 17. Trajes de poder. Los conjuntos Chimú con borlas - Victòria Solanilla • 18. Structure, Design, and Gender in Inka Textiles - Blenda Femenías • 19. Lambayeque Textile Iconography and its Continuity in Chimu and Inca Cultures, and its link to modern Ecuadorian Pujilí Corpus Christi Celebrations - Yvonne Fleitman \& Alisa Baginski • 20. La imagen divina y el simbolismo religioso en textiles del Antiguo Perú - Uwe Carlson • Conservation, reconstruction, analyses • 21. Provenance investigations of raw materials in pre-Columbian textiles from Pachacamac; strontium isotope analyses - Karin Margarita Frei \& Lena Bjerregaard • 22. Analysis of Paracas fibre material from the Gothenburg Collection - Anna Javér • 23. La conservación de dos fardos funerarios provenientes de contextos arqueológicos: El caso de la cueva del Lazo, Ocozocoautla, Chiapas y la cueva de la Candelaria, Torreón, Coahuila, México - Gloria Martha Sánchez Valenzuela • 24. The Arizona Openwork (Tonto) Shirt Project - Carol James

\section{Zea Books}

Lincoln, Nebraska, 2017 ISBN 978-1-6og62-115-5 doi: $10.13014 / \mathrm{K} 2 \mathrm{X} 63 \mathrm{~K} 31$

Complete pdf edition online at https://digitalcommons.unl.edu/zeabook/59

Essays online at https://digitalcommons.unl.edu/pct7/

Print edition at Lulu.com https://bit.ly/2LjmJ8s 
